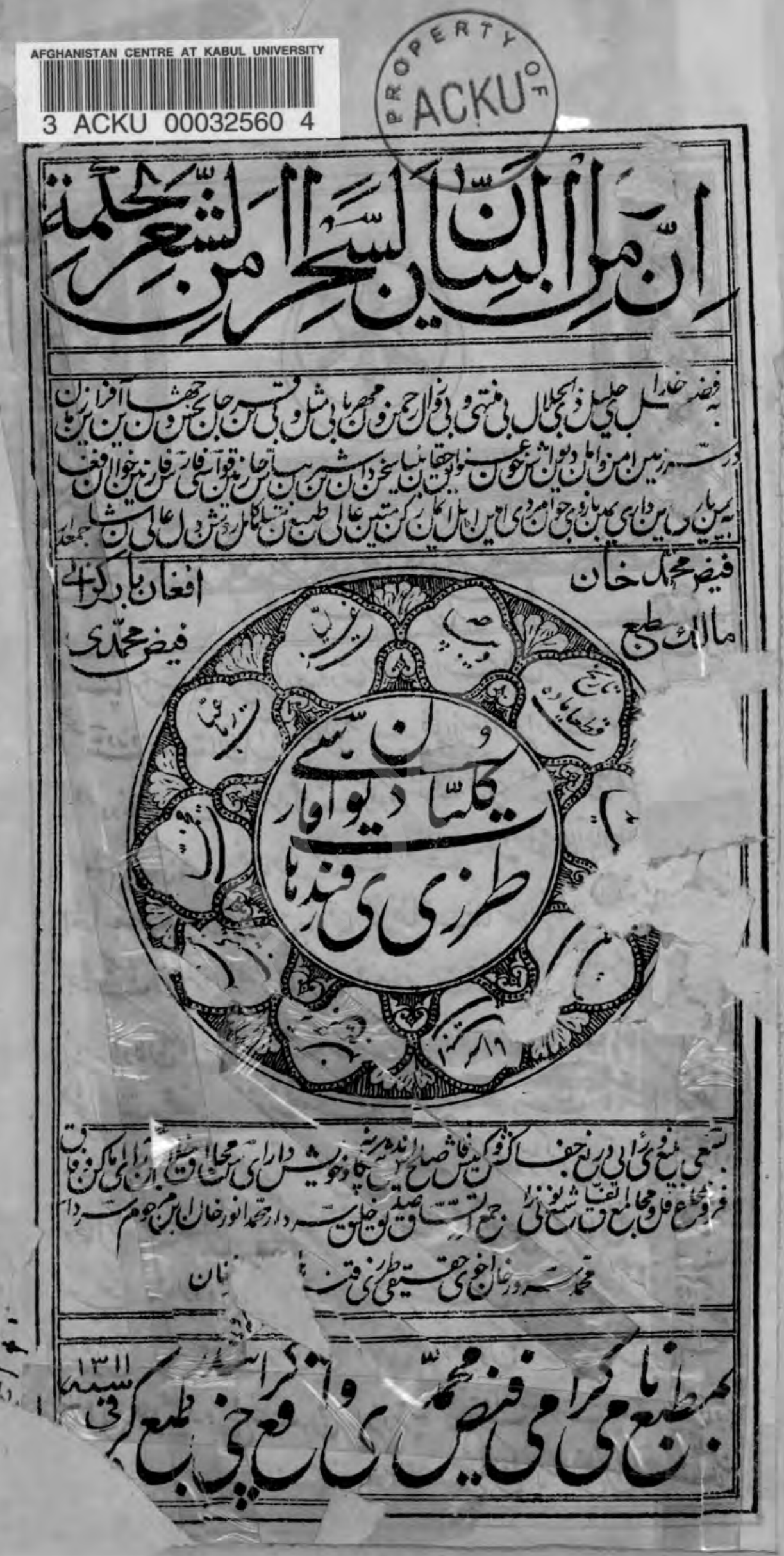




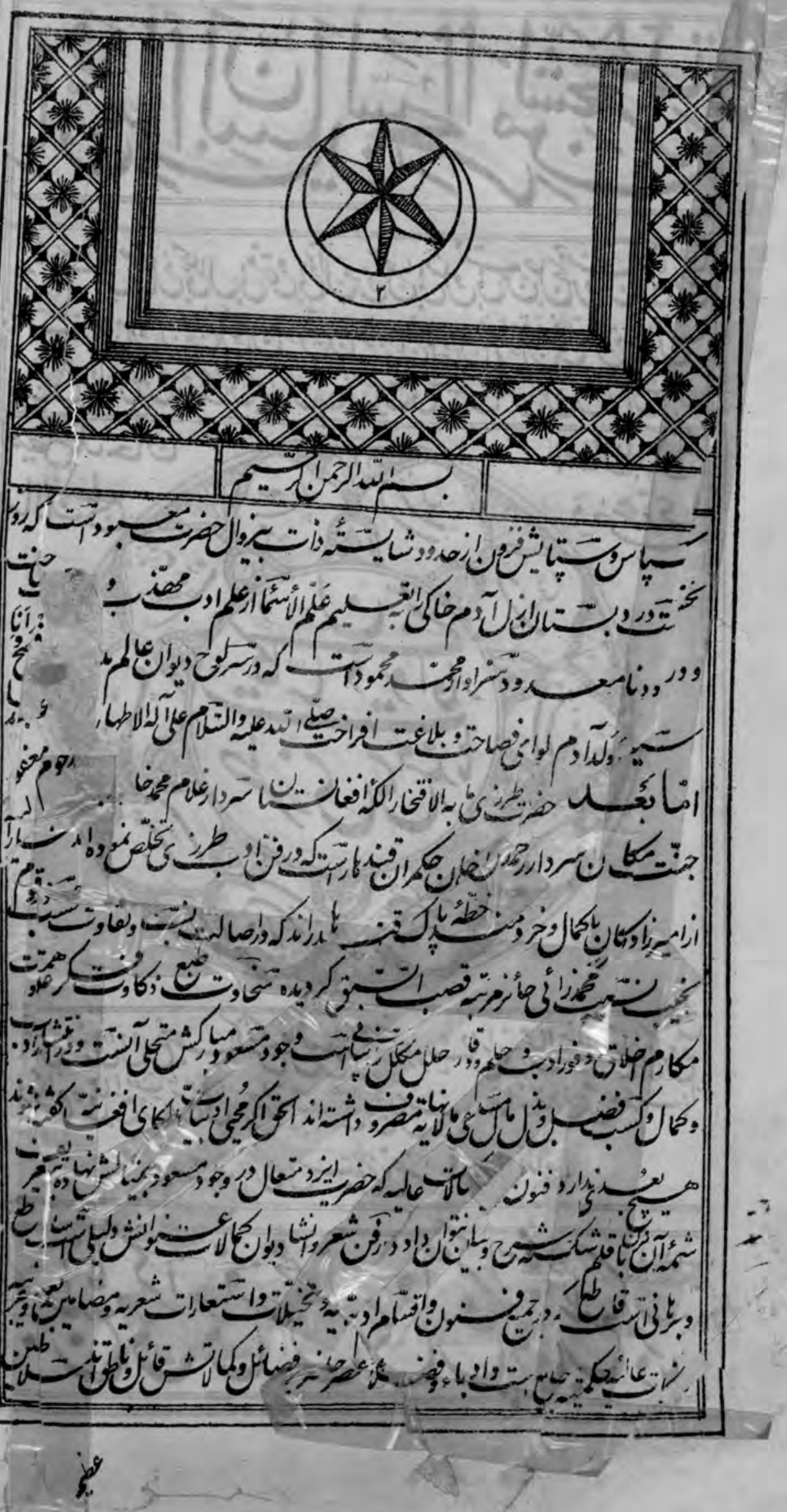




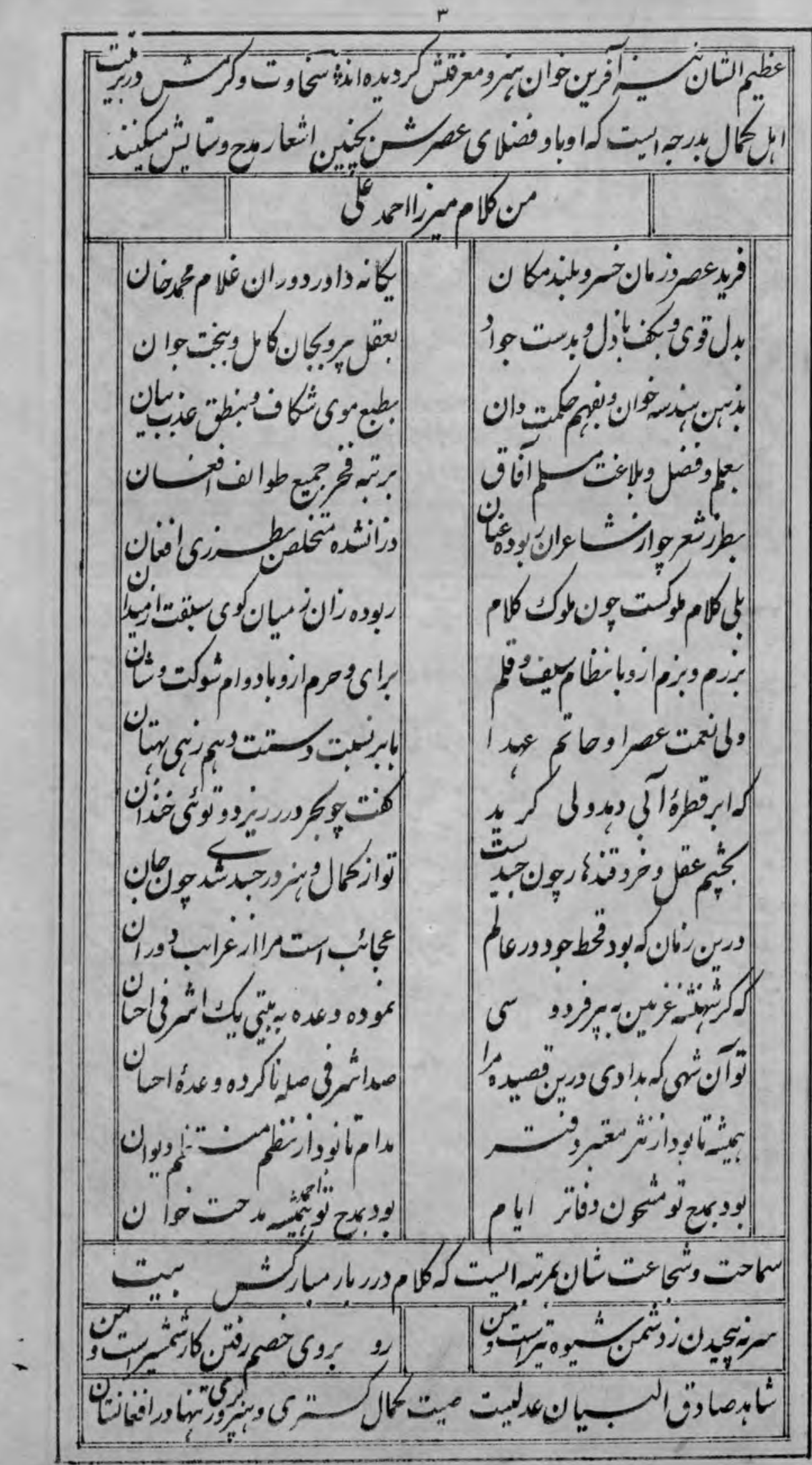




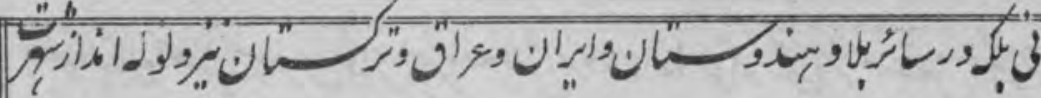

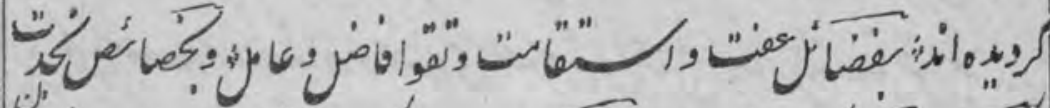

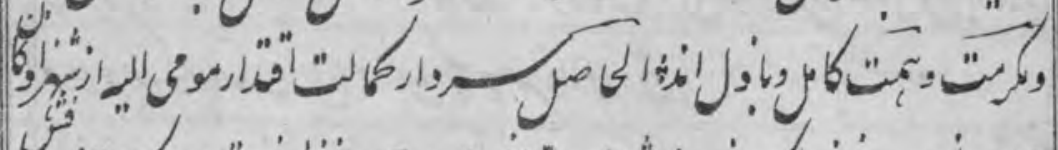
حen

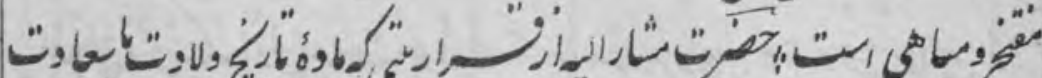
إم

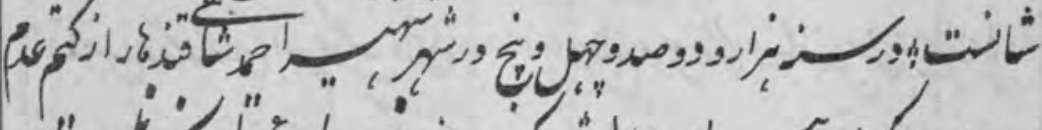

(1)

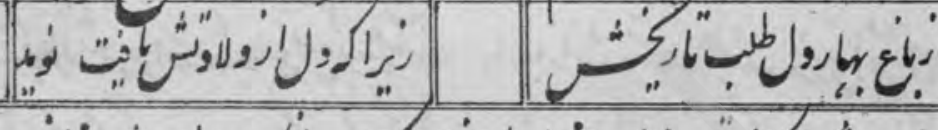

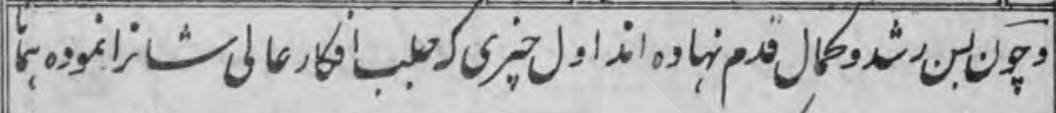

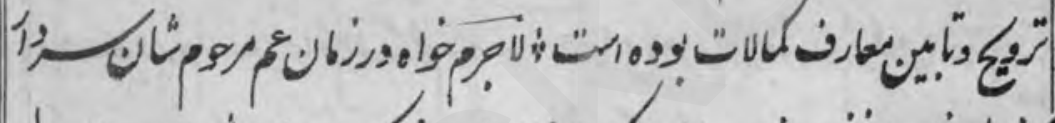

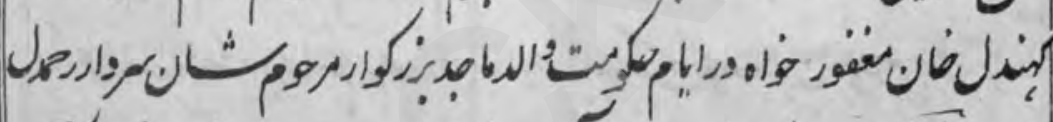

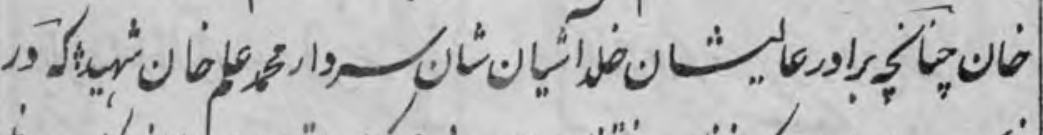

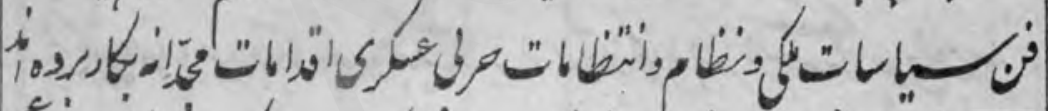

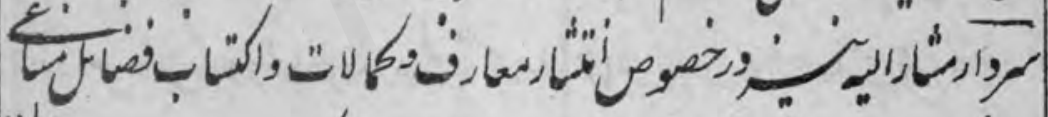

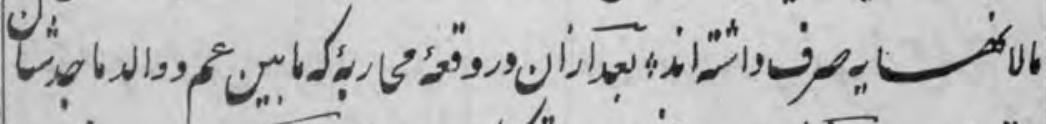

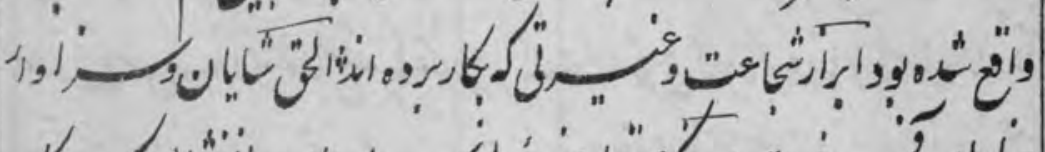

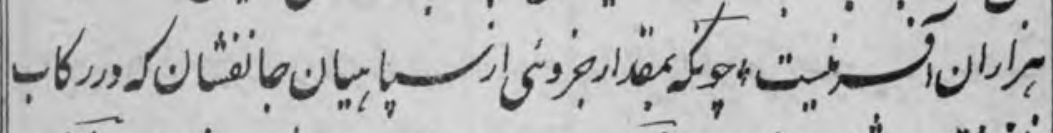

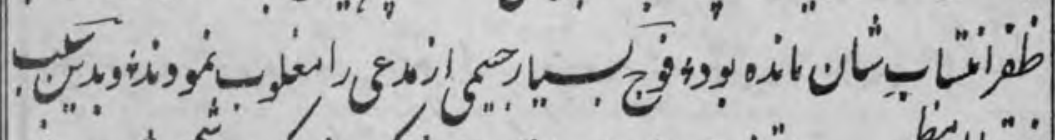

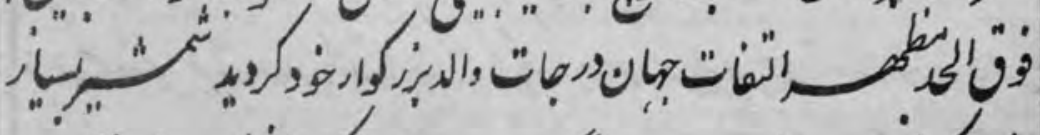

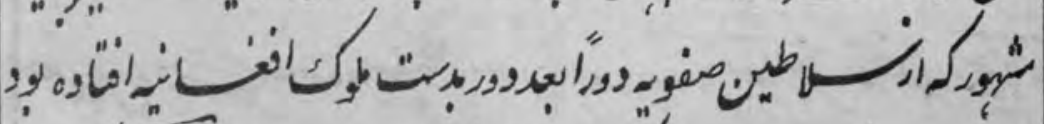

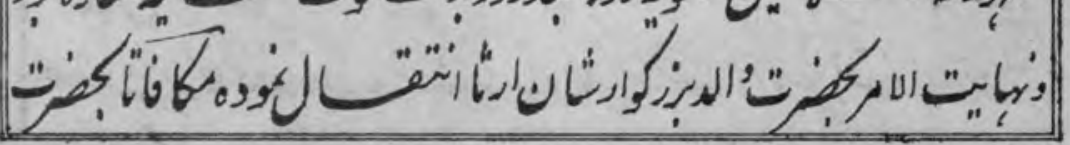




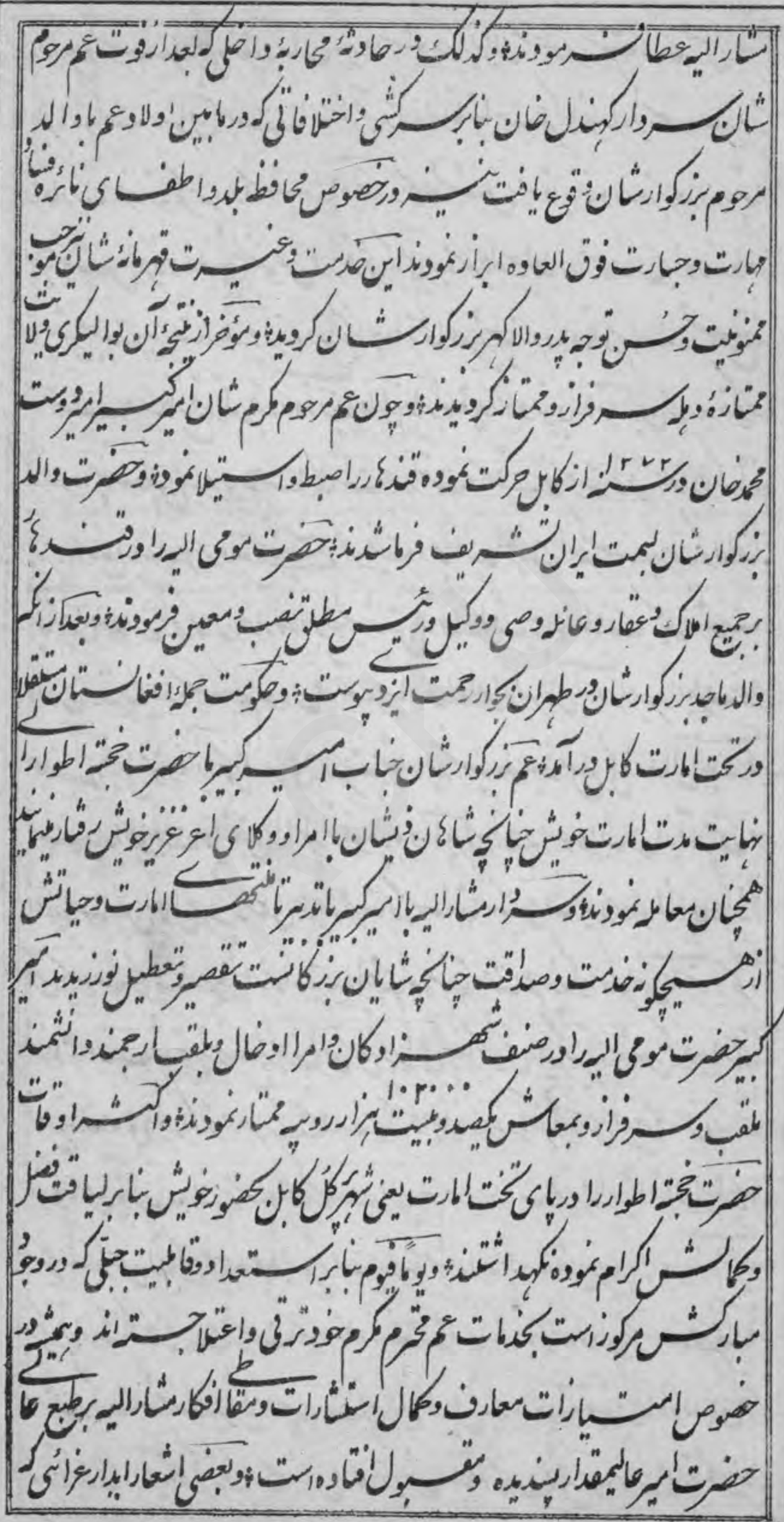




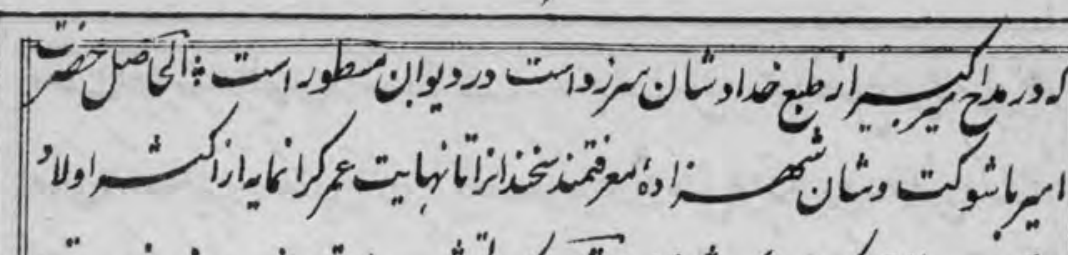

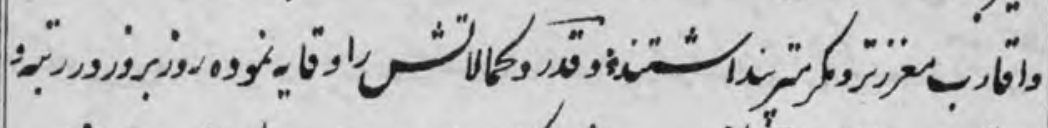

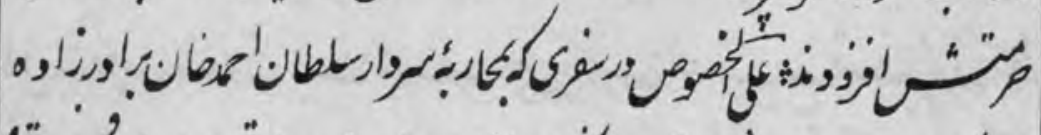

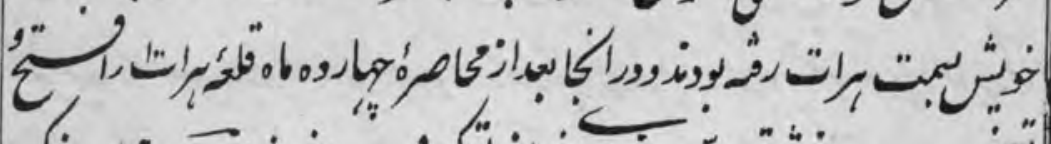
"شى":

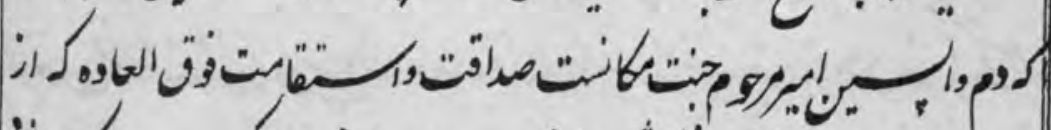

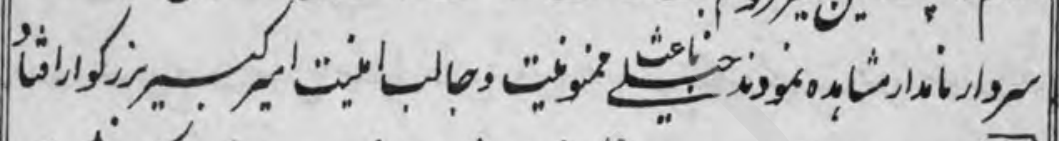

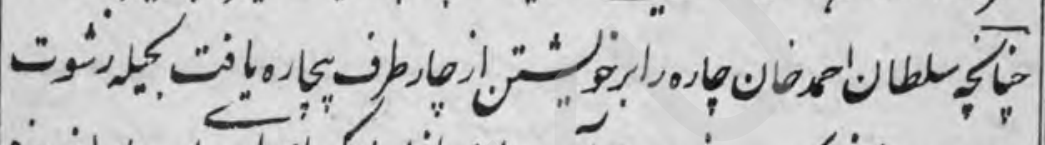

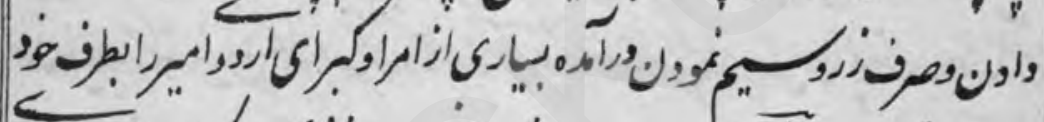
مل

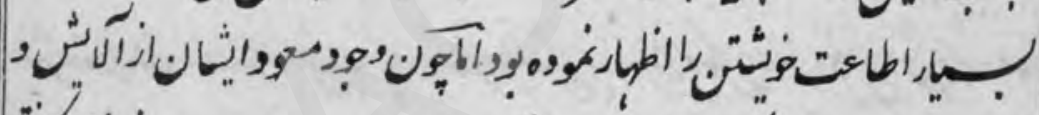

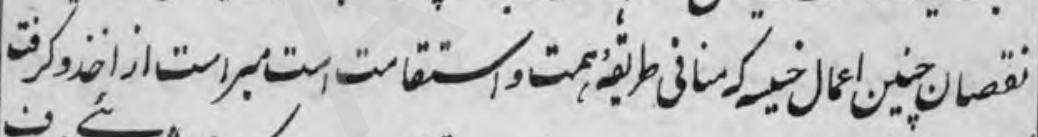

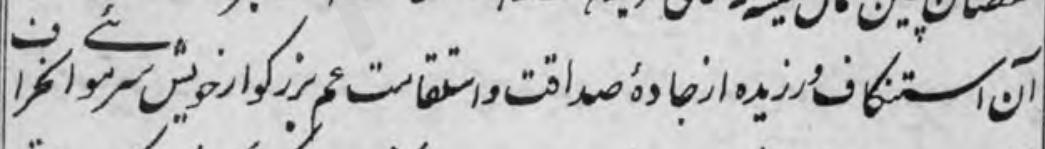

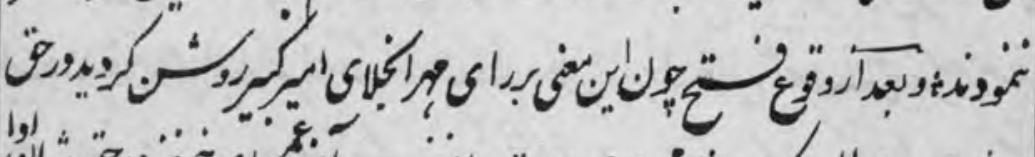

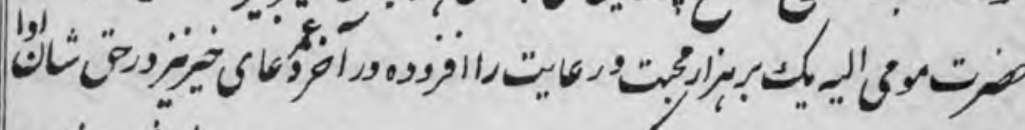

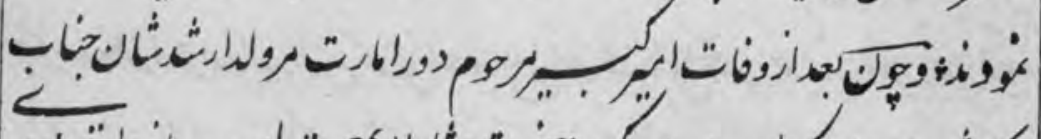
اري ".

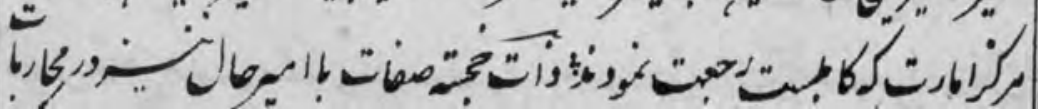
(2) 


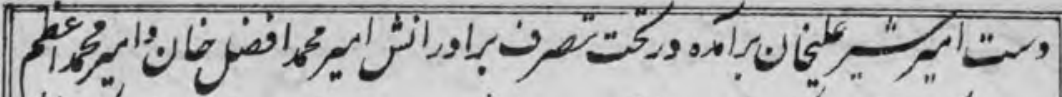
is (b)

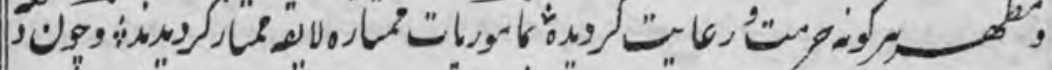

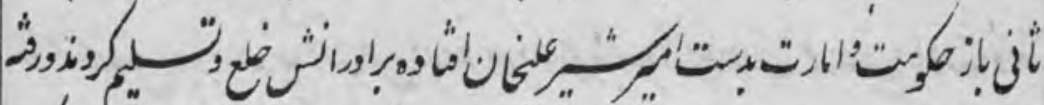

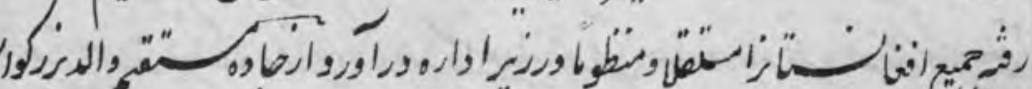

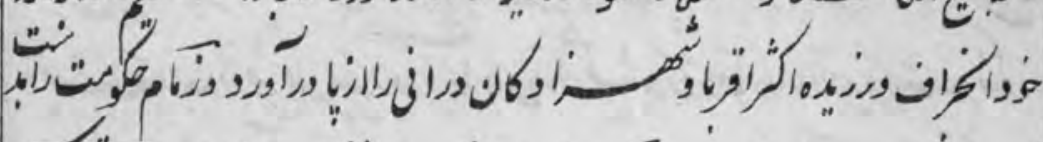

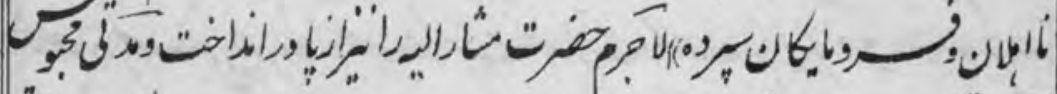

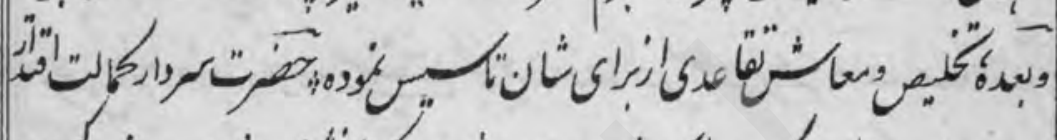

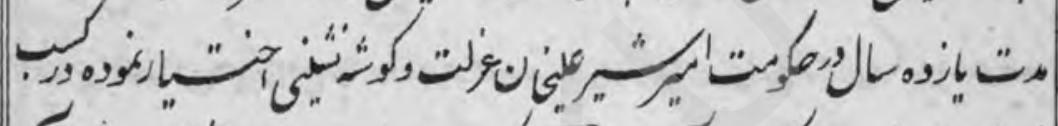

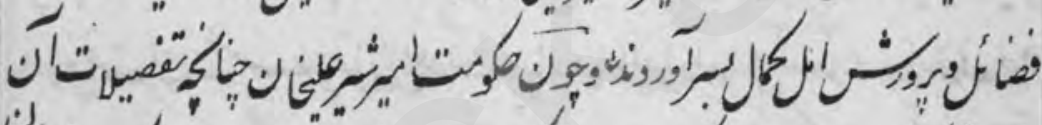

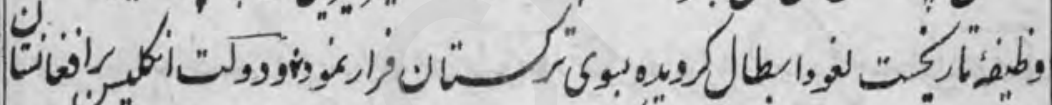

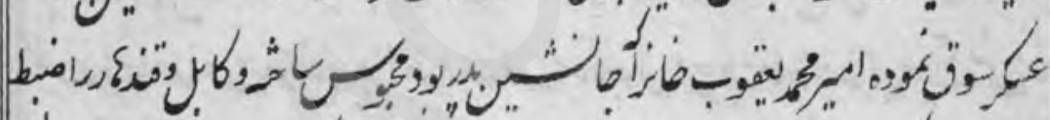
ن.

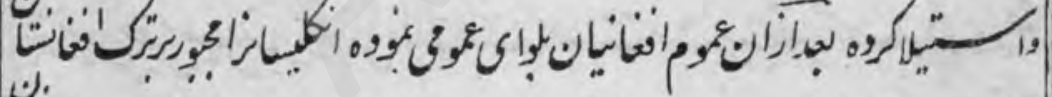

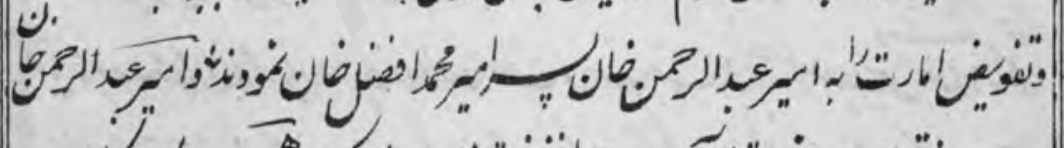

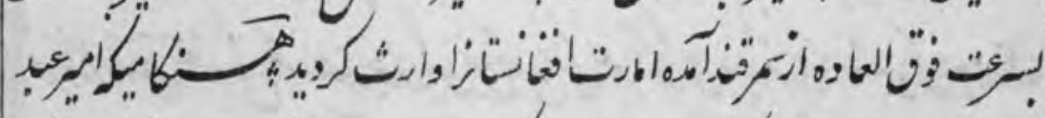

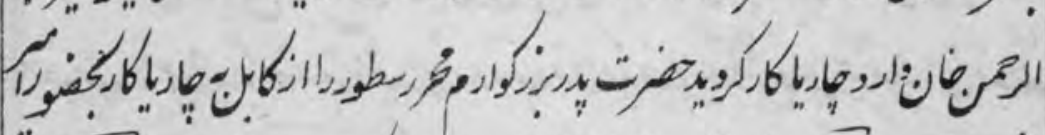

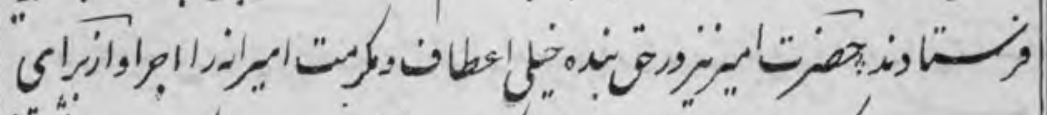

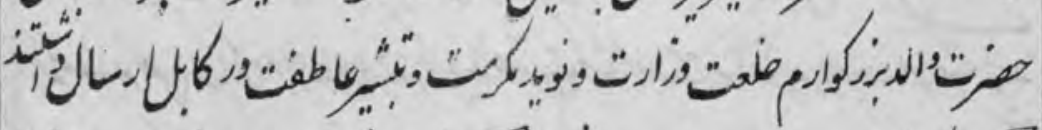

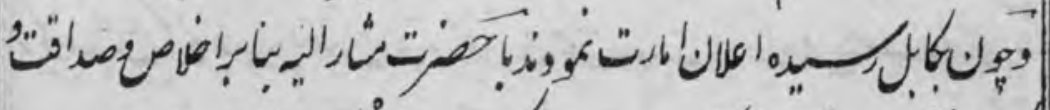

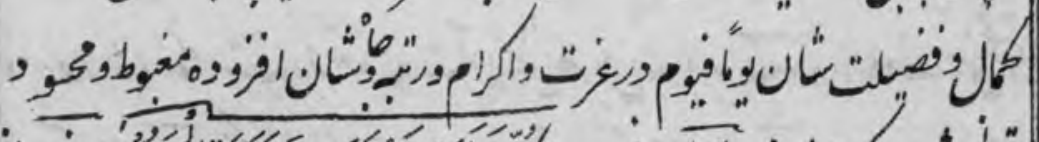

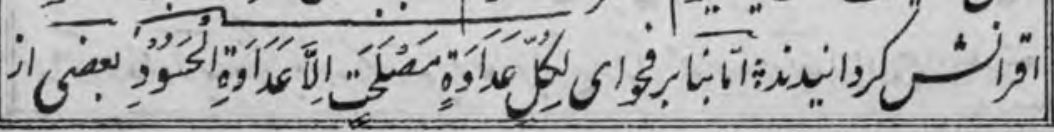



(5) $\sigma_{0}{ }^{2}$

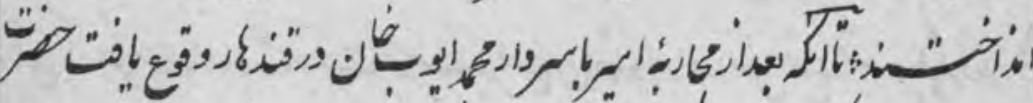
24

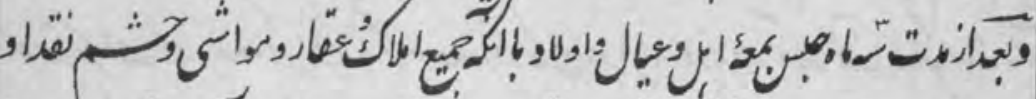

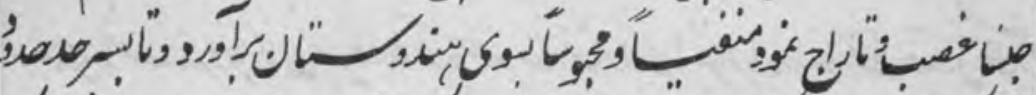

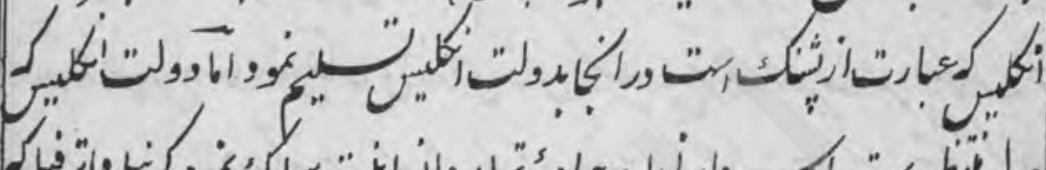

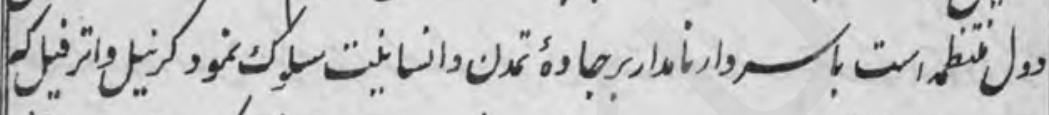

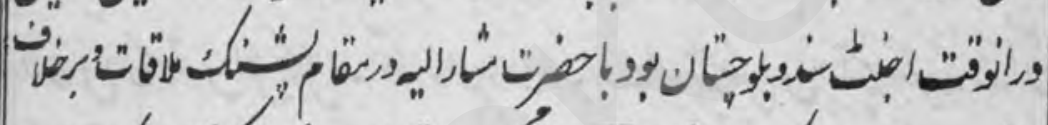

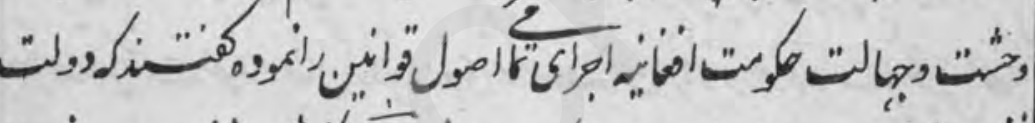

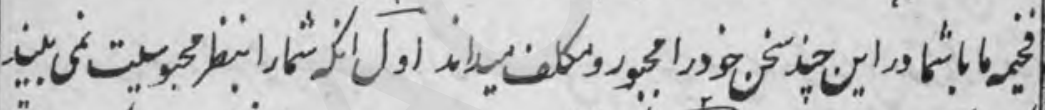

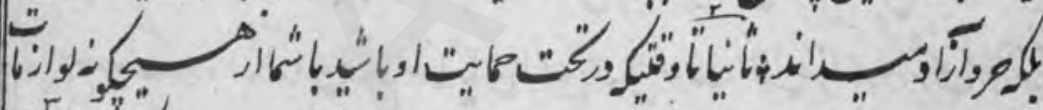

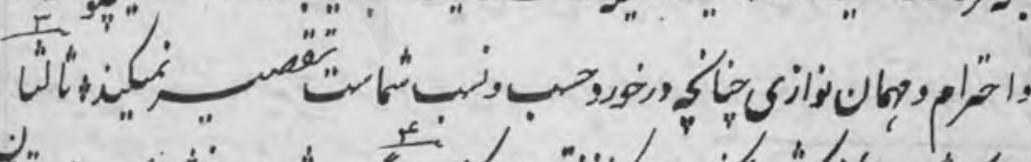

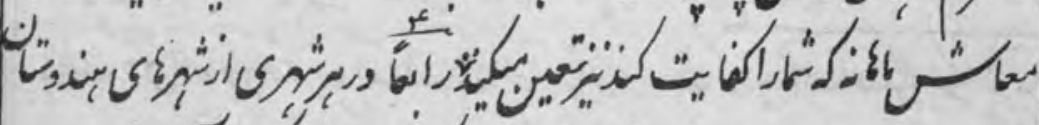

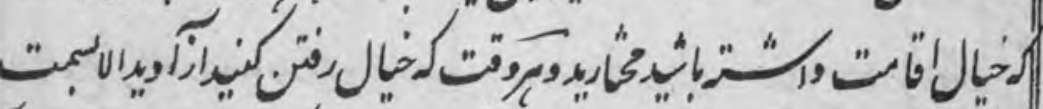

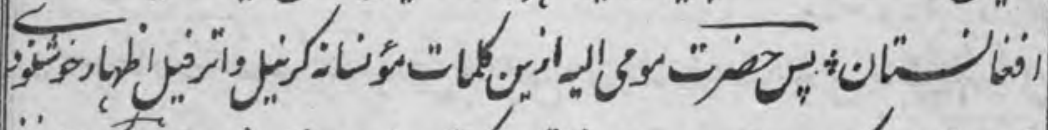

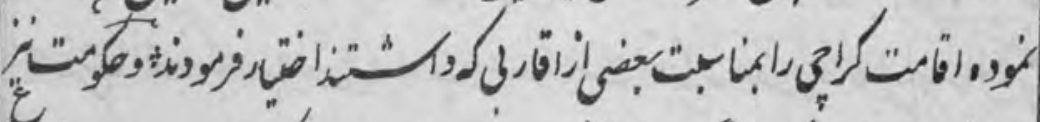

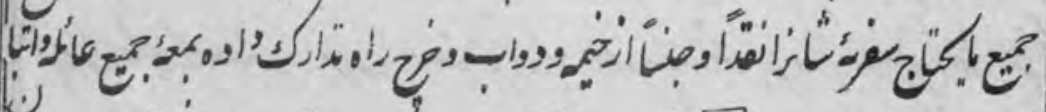

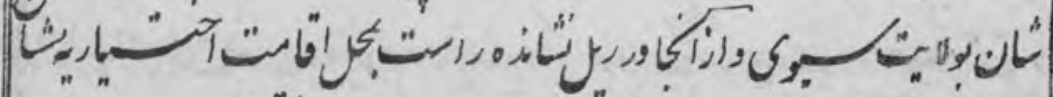

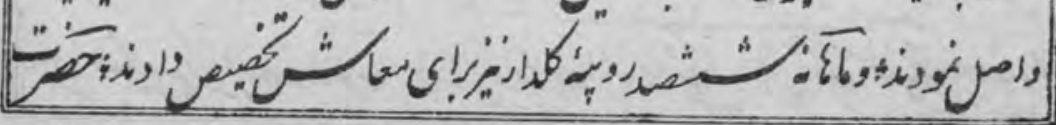


|

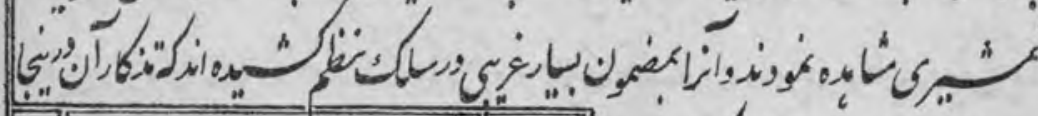
|

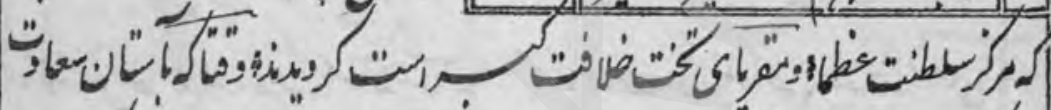

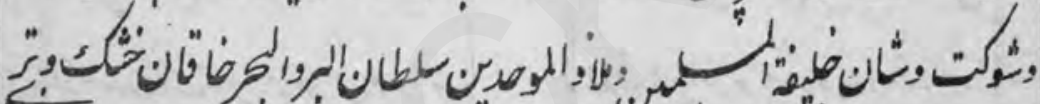

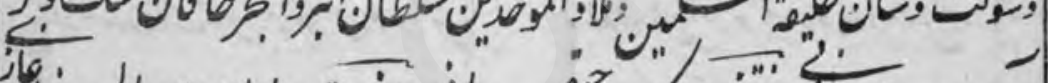

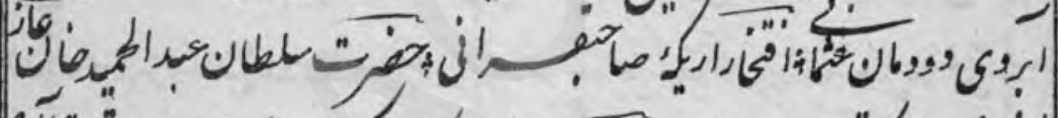

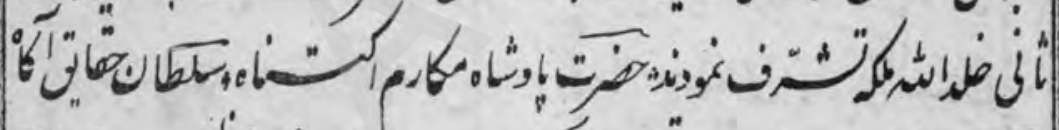

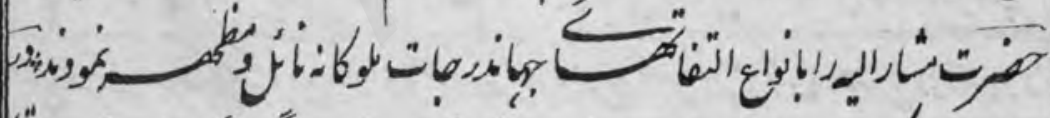

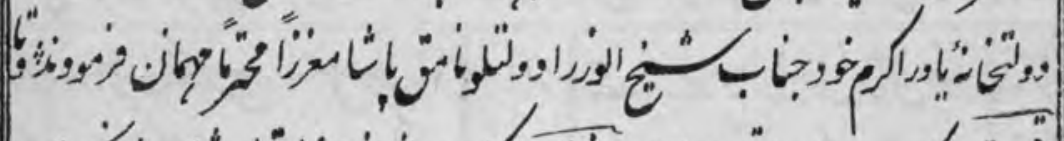
ب.

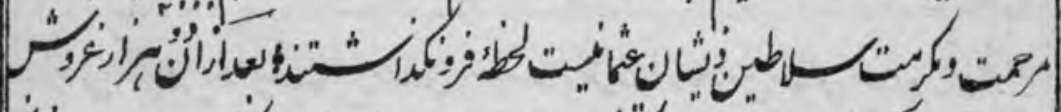

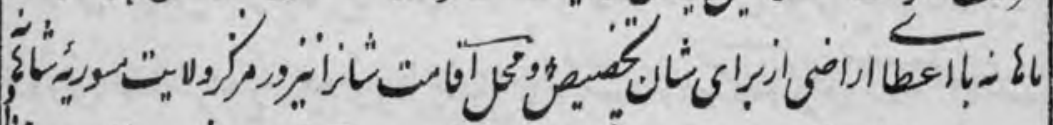

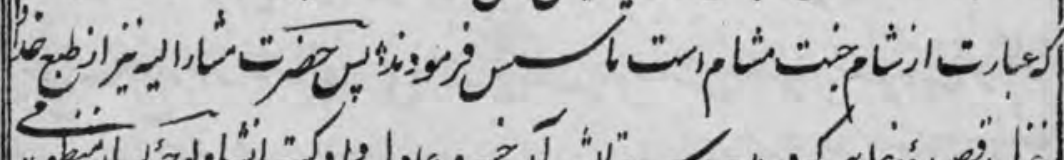

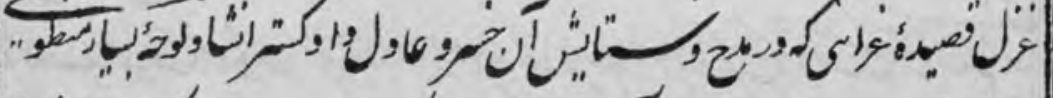
[ون 


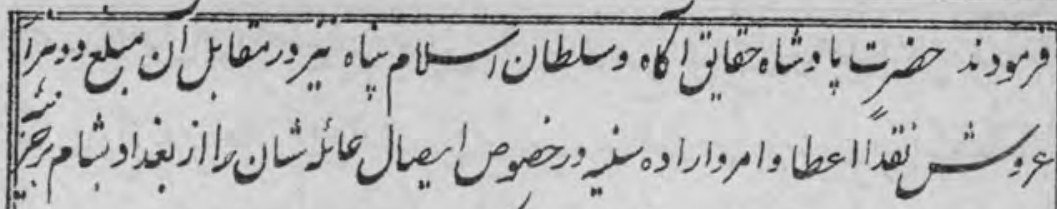

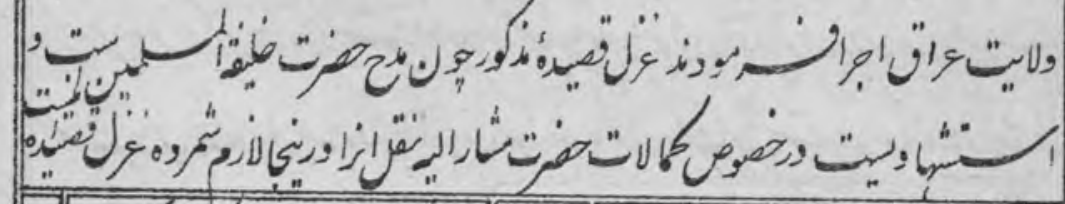
| 


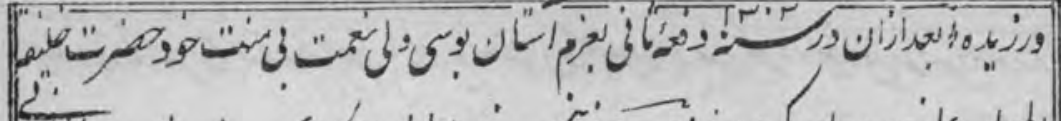

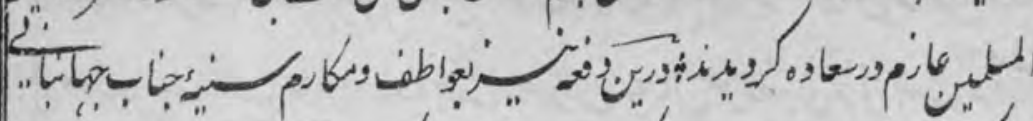

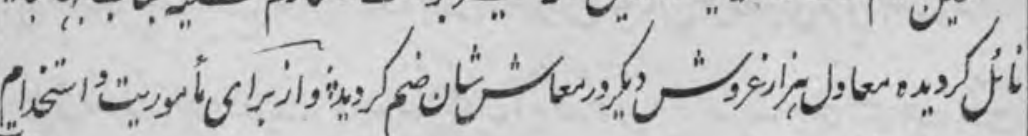

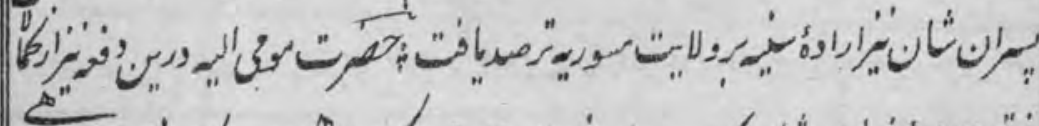

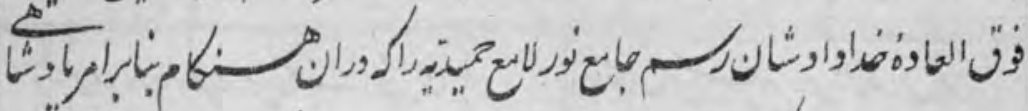

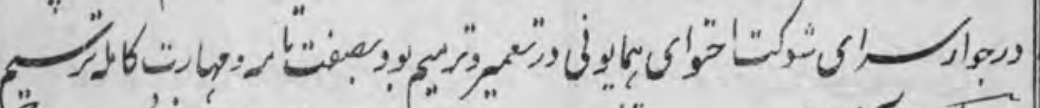

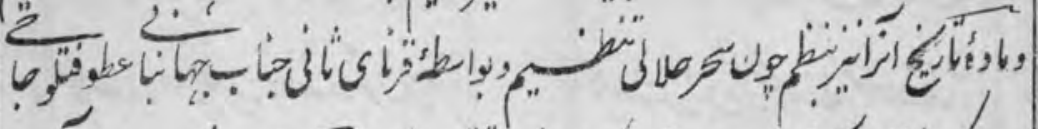

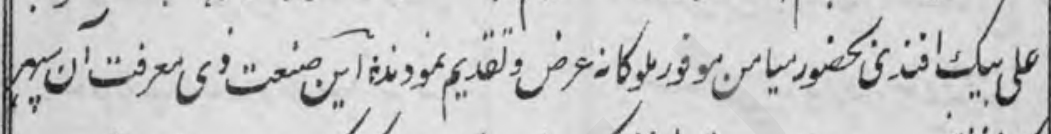

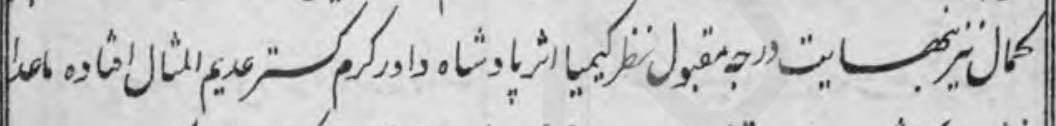

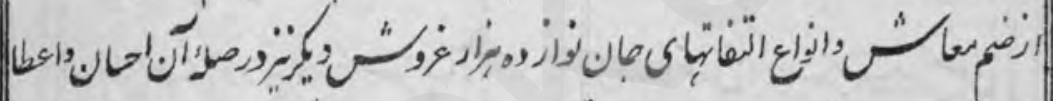

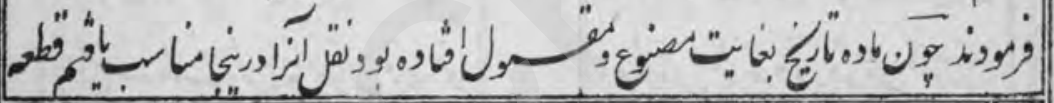

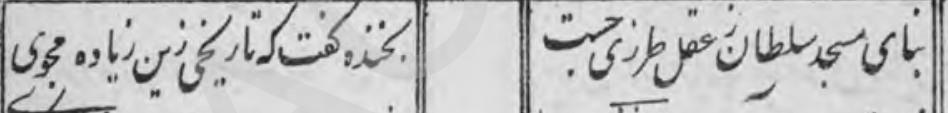

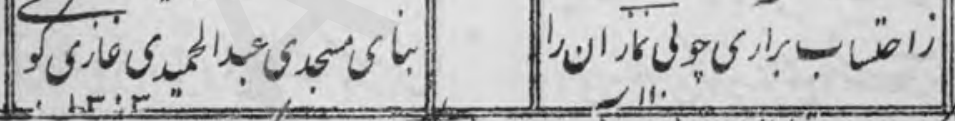

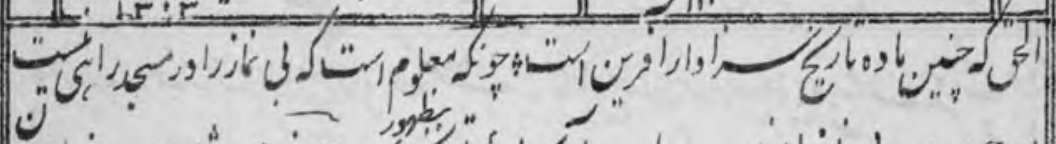

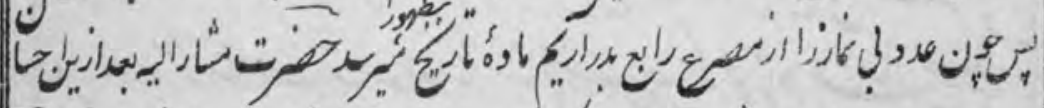

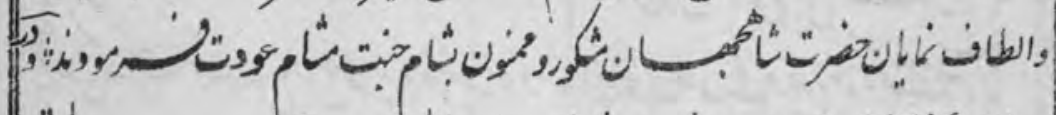

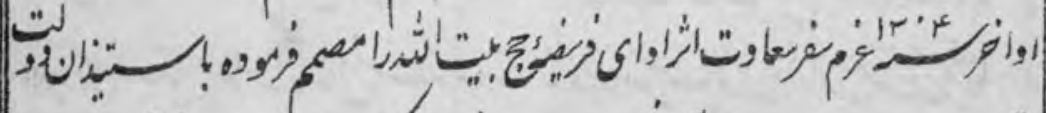

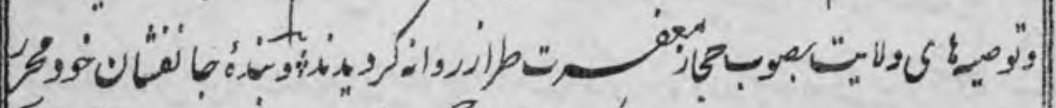

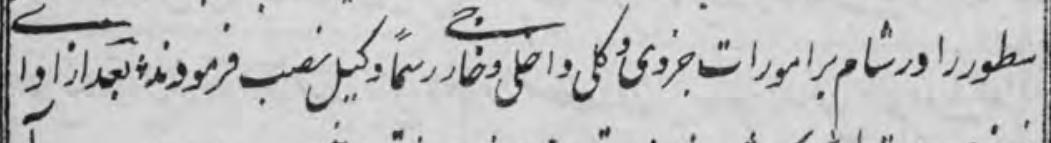

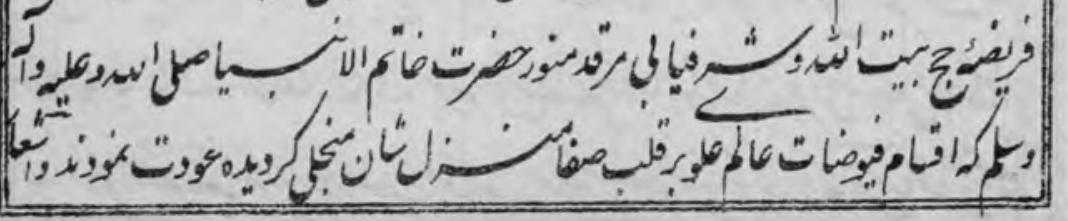




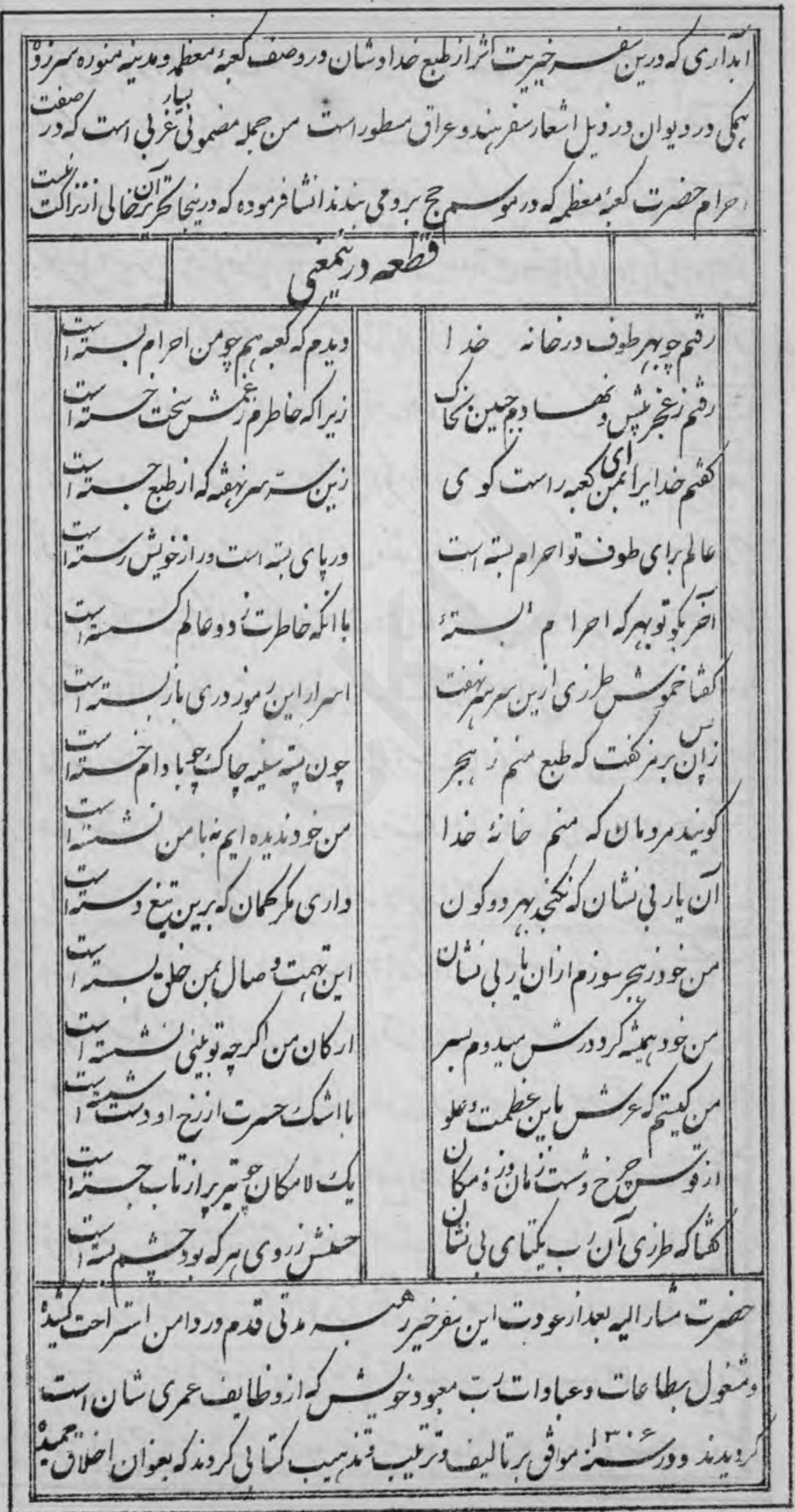




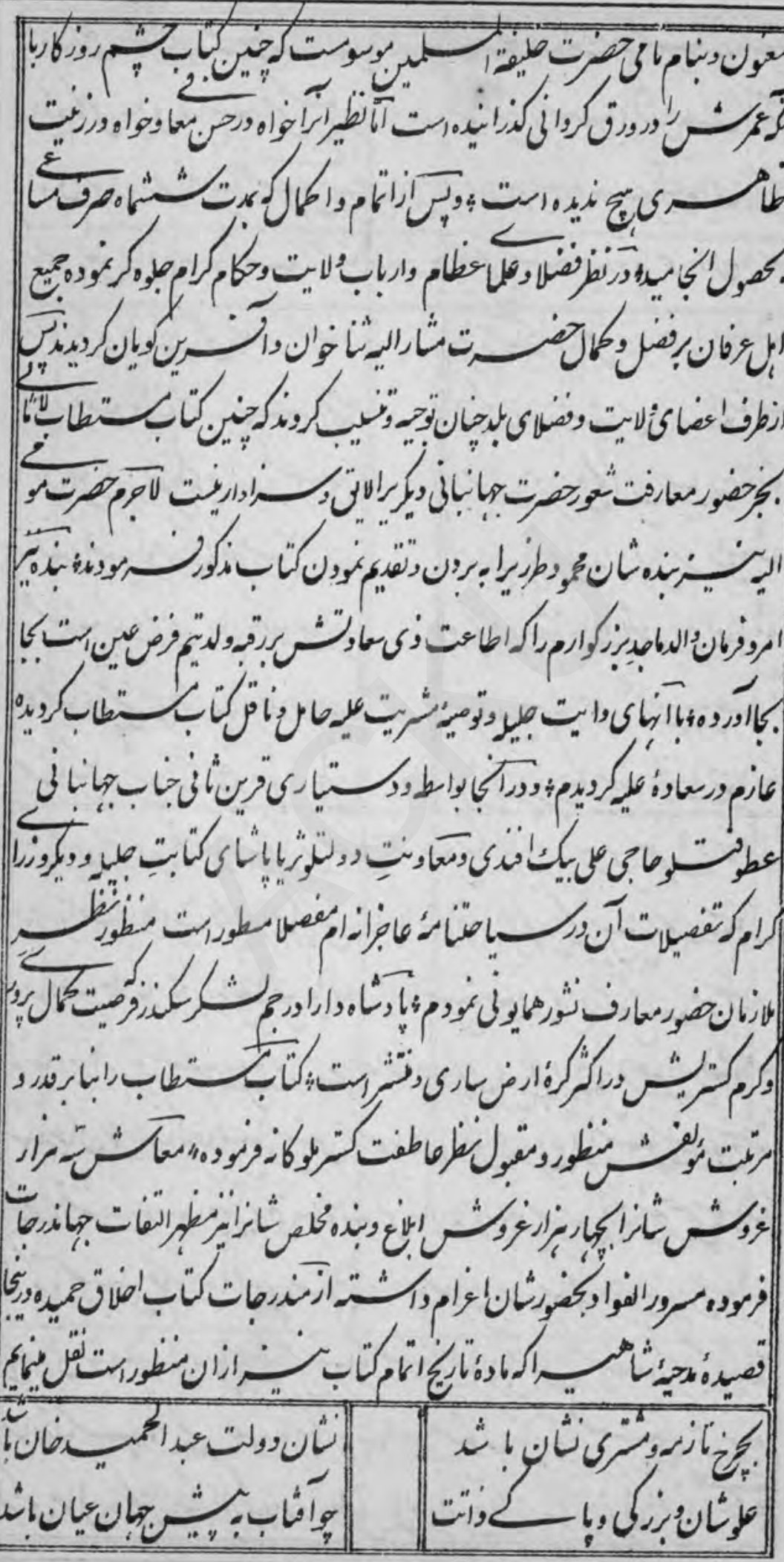


10

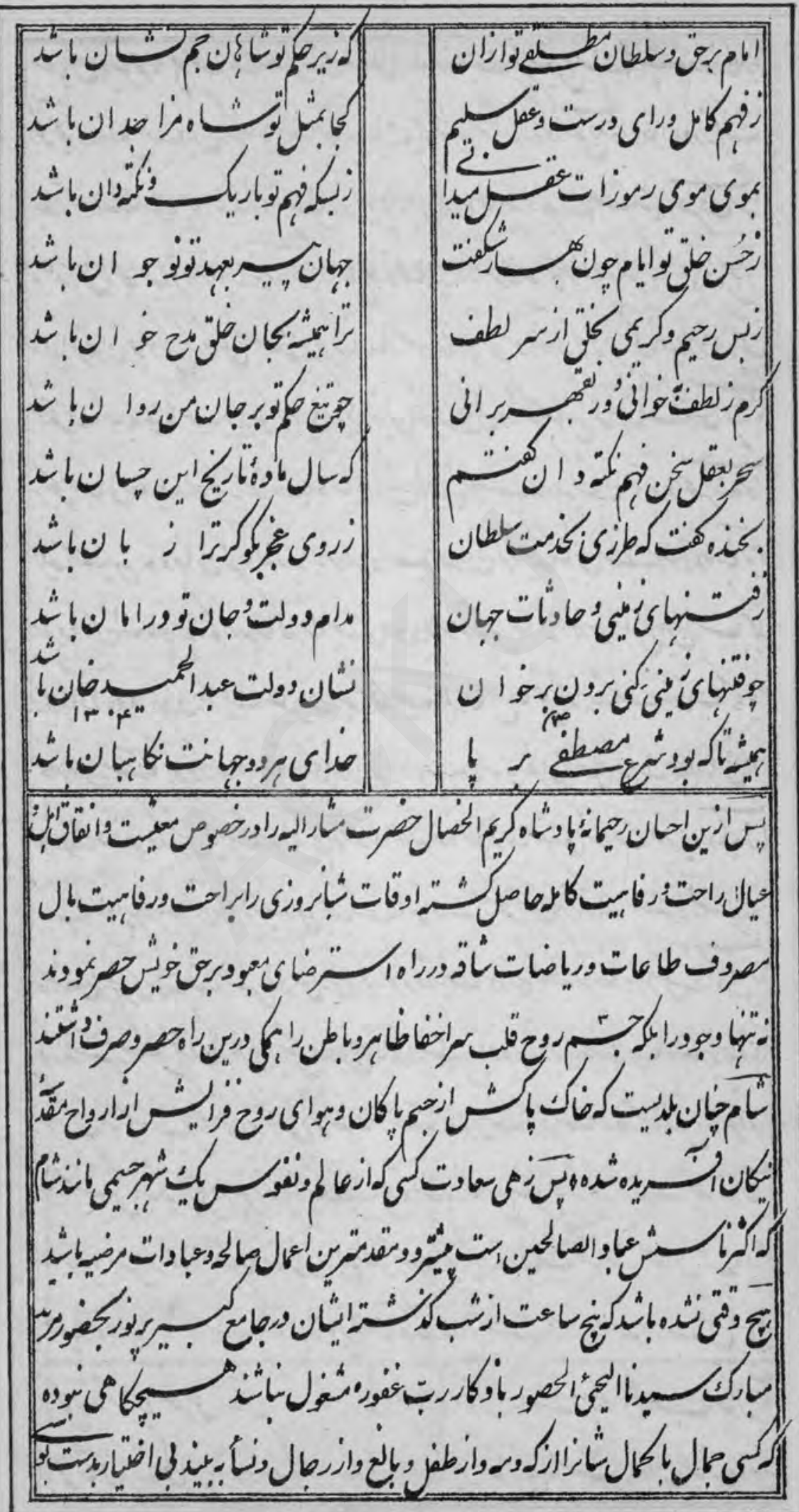




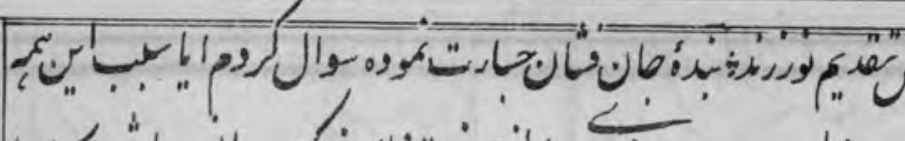

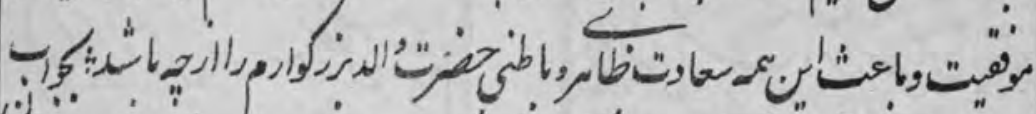

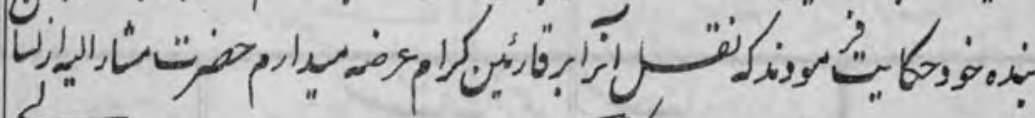

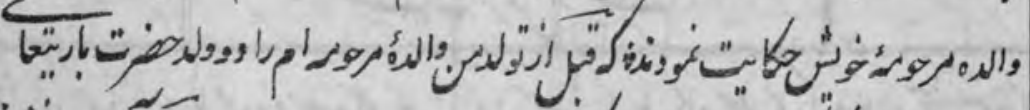

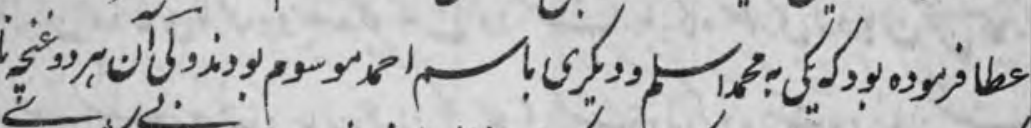

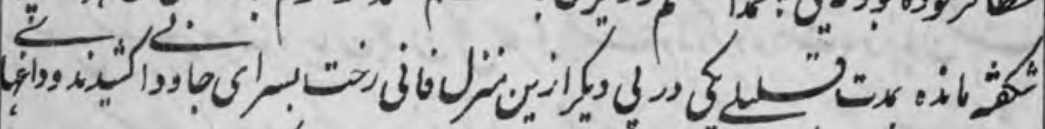

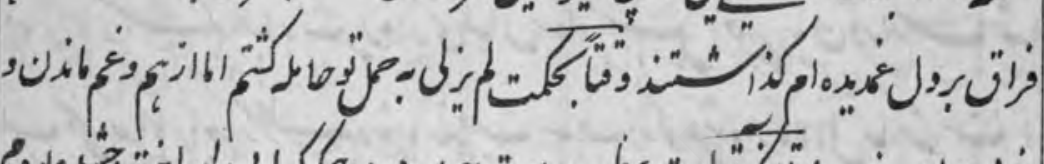

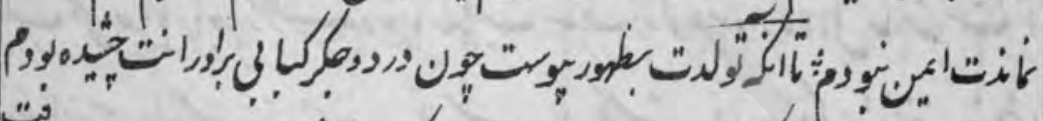

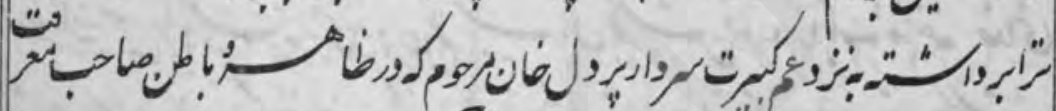

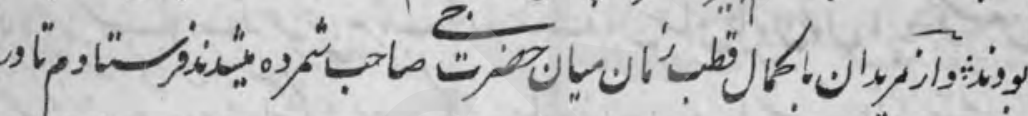

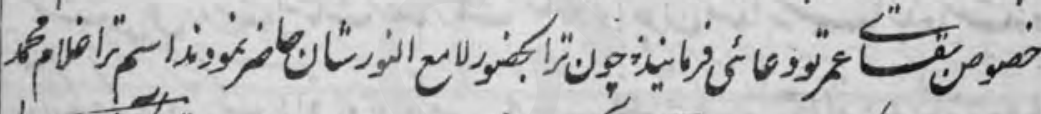

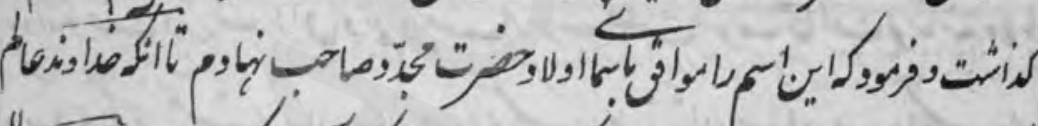

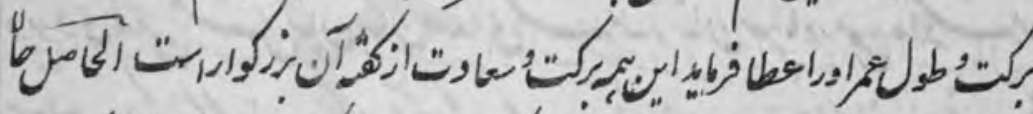

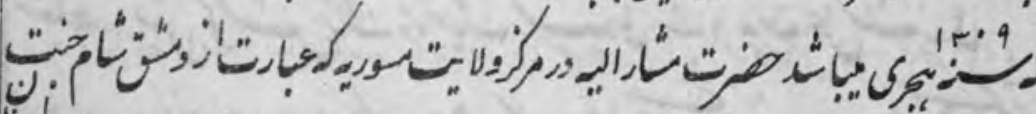

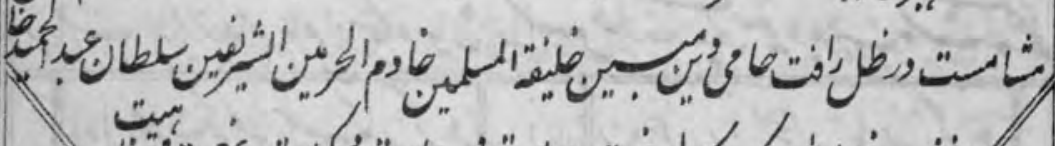
演

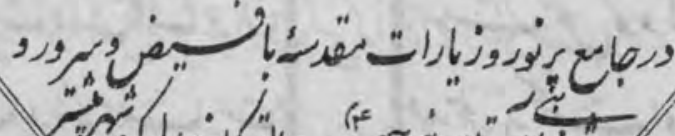

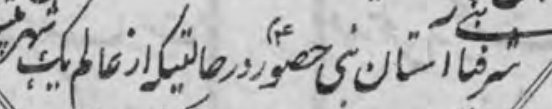
"

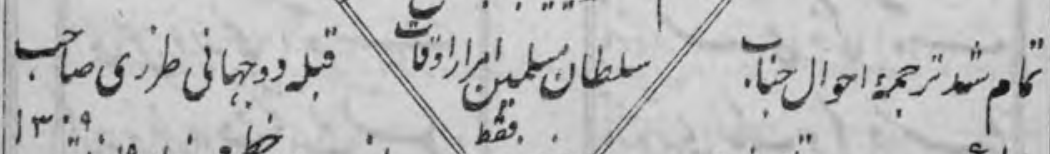

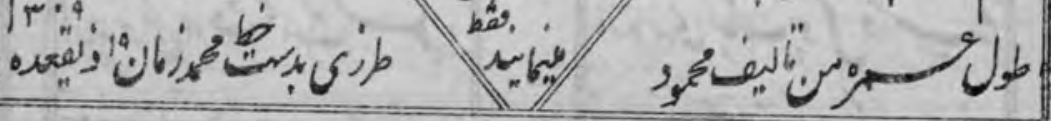




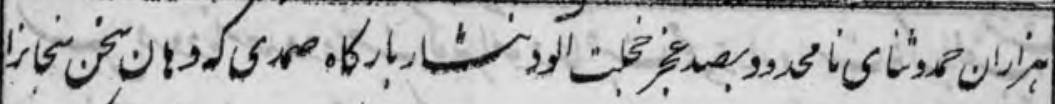
: $\Rightarrow 3-1$ -

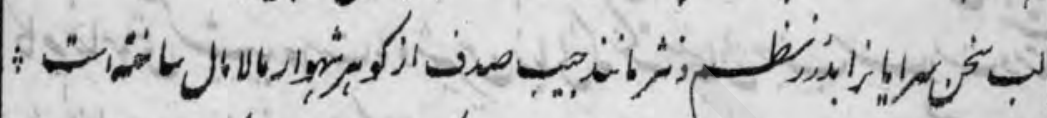

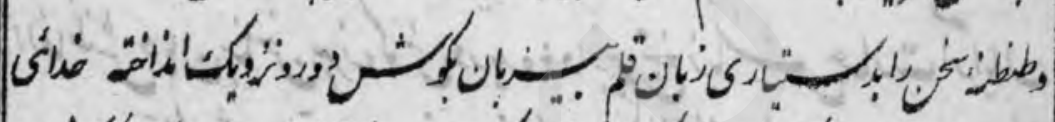
U

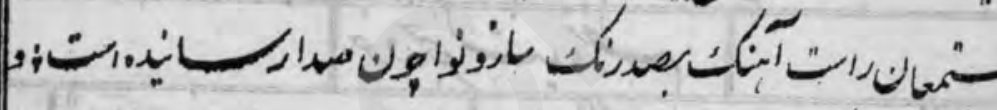

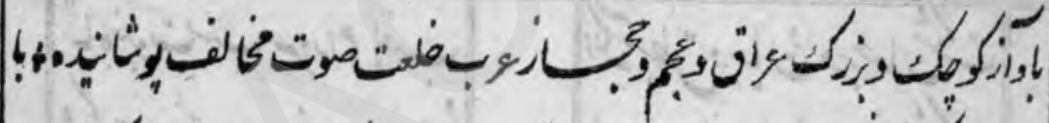
-

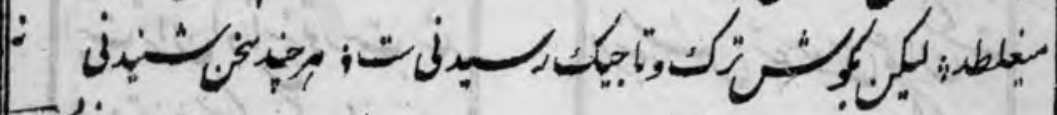

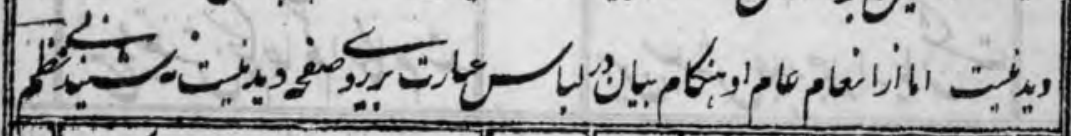

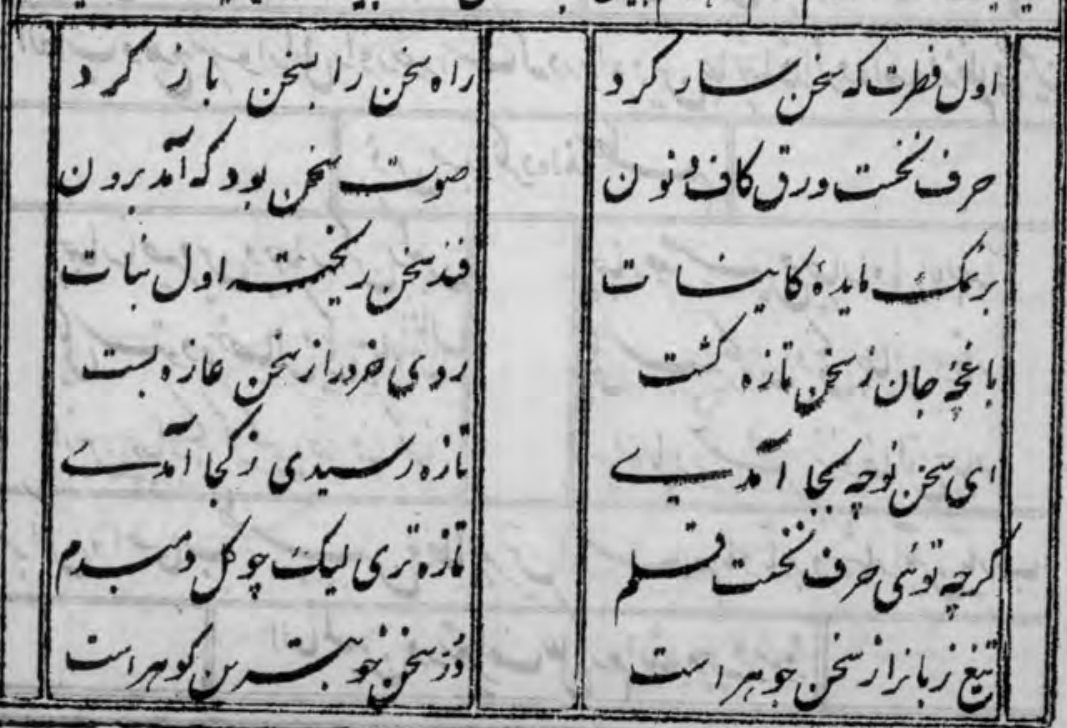




\section{$1 A$}

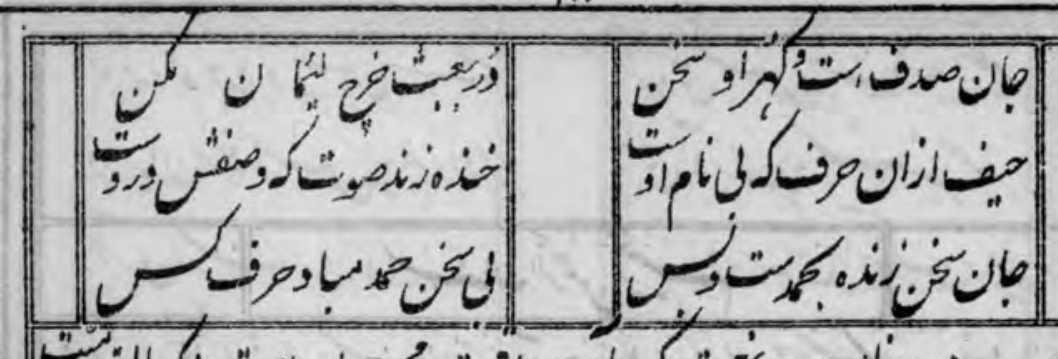

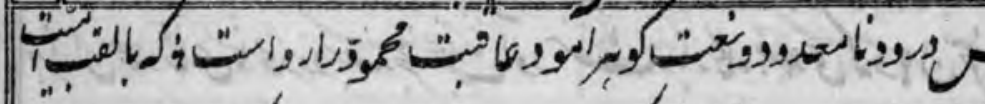

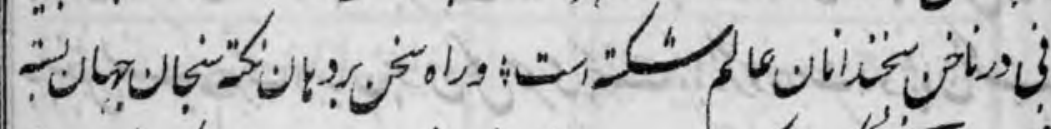

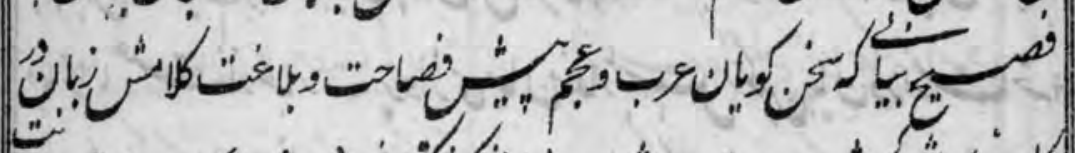
莙

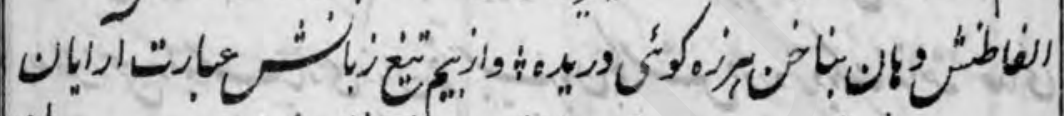

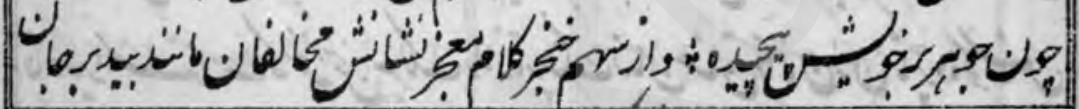

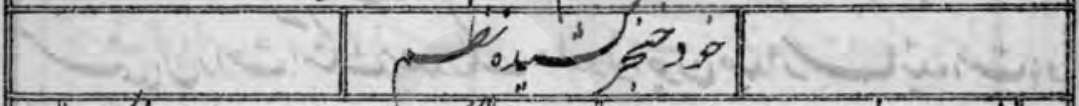

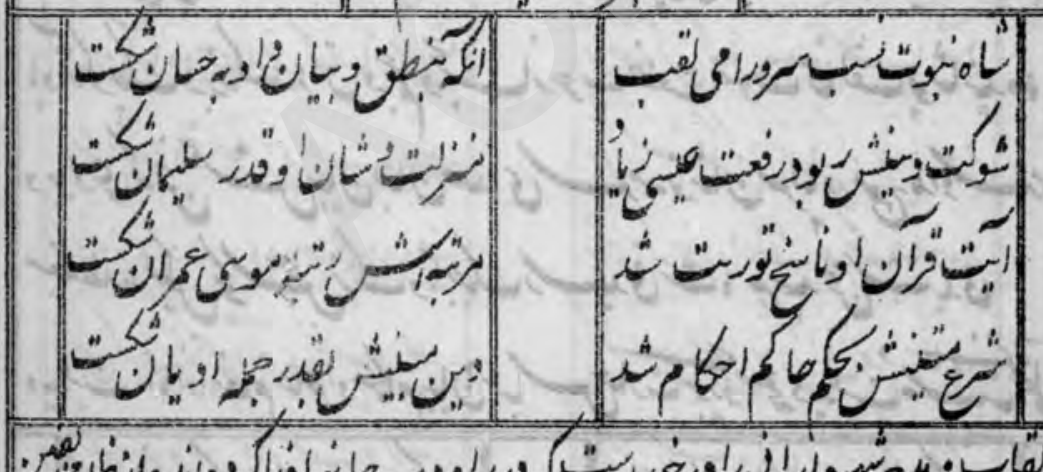

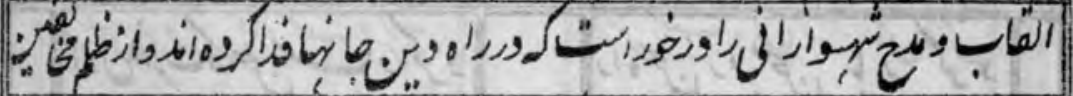

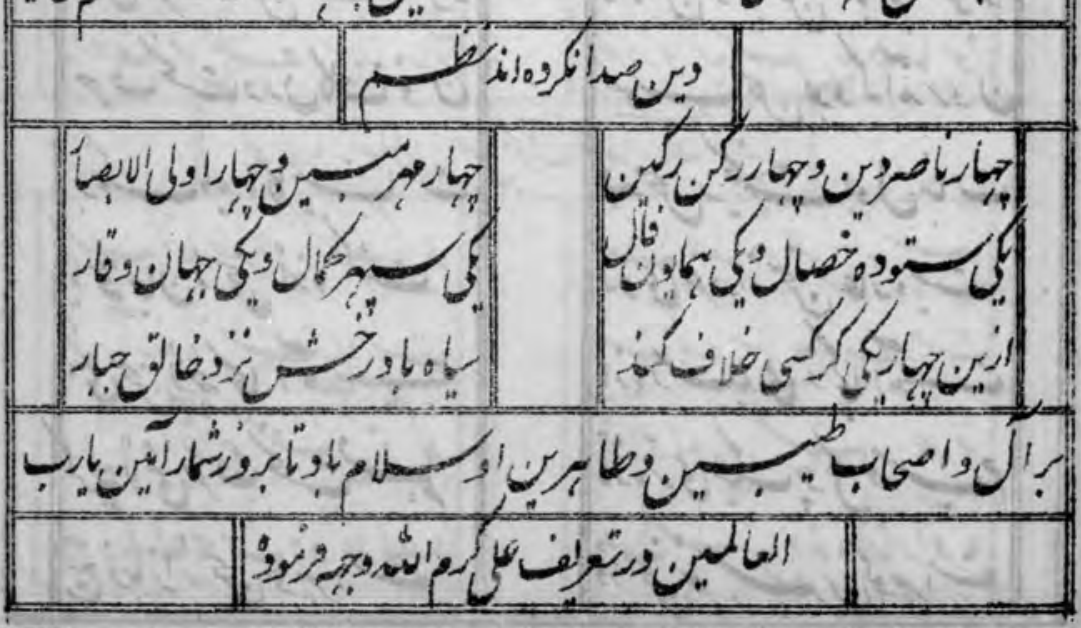


19

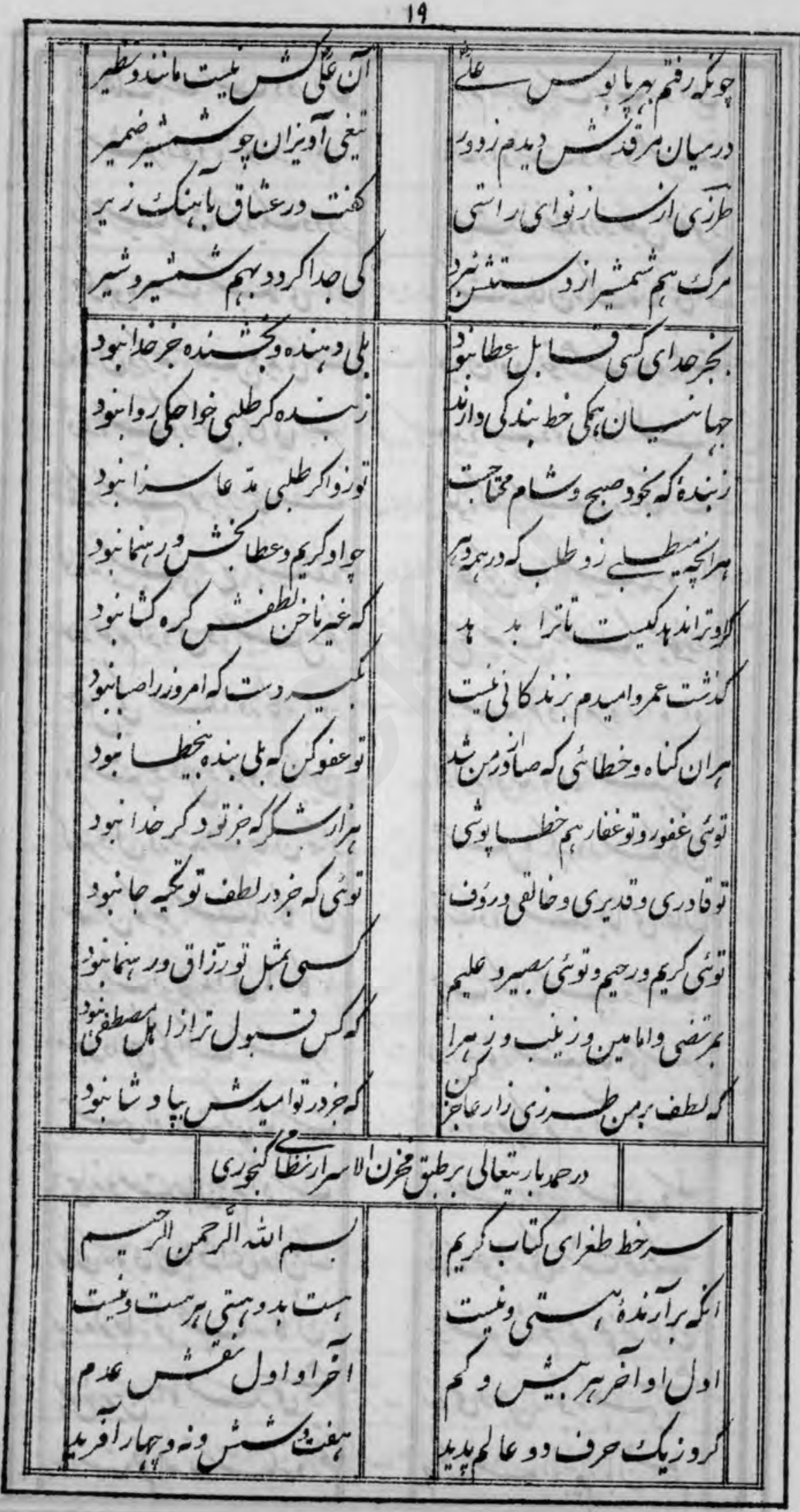


r.

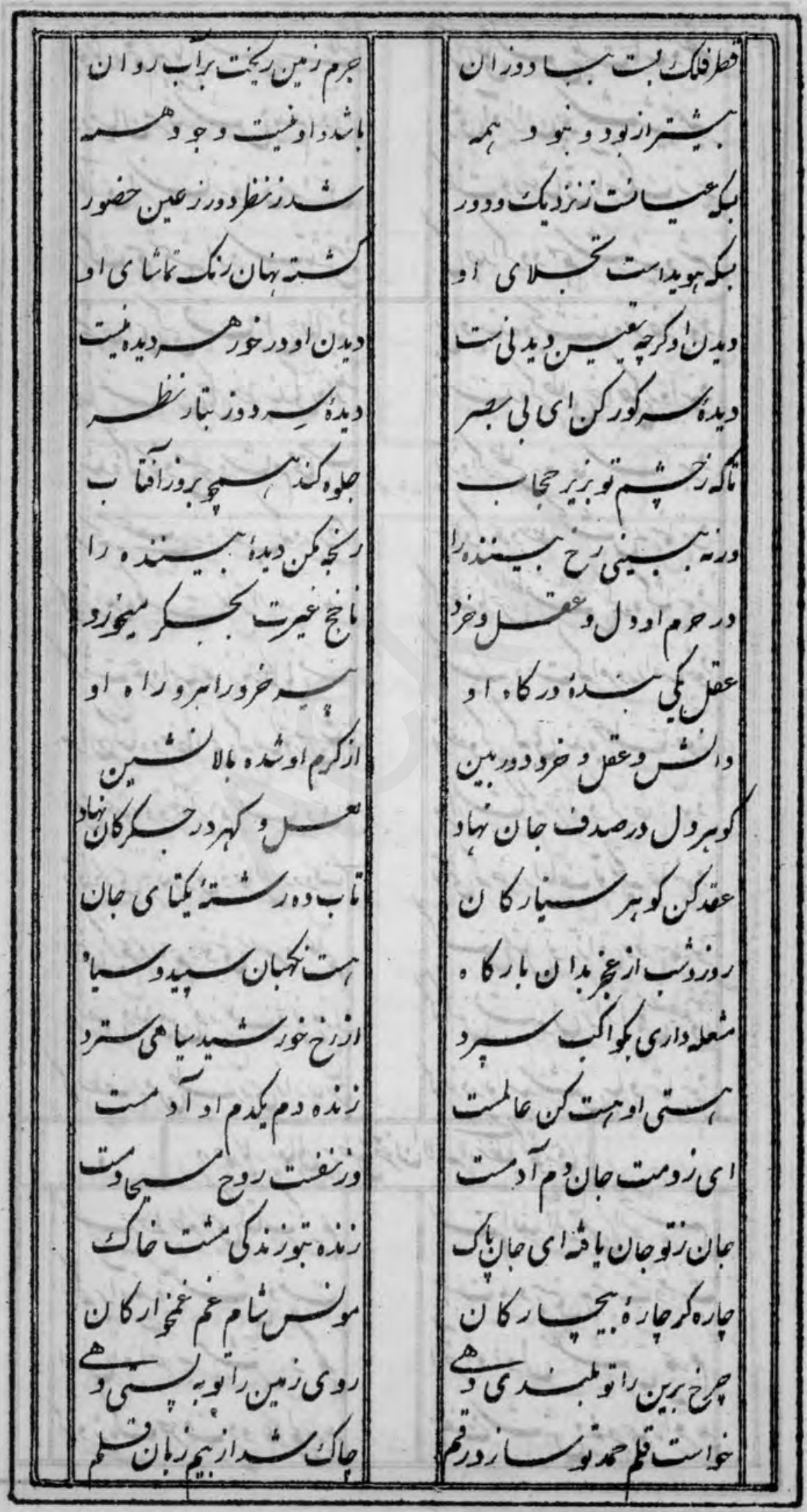


ri

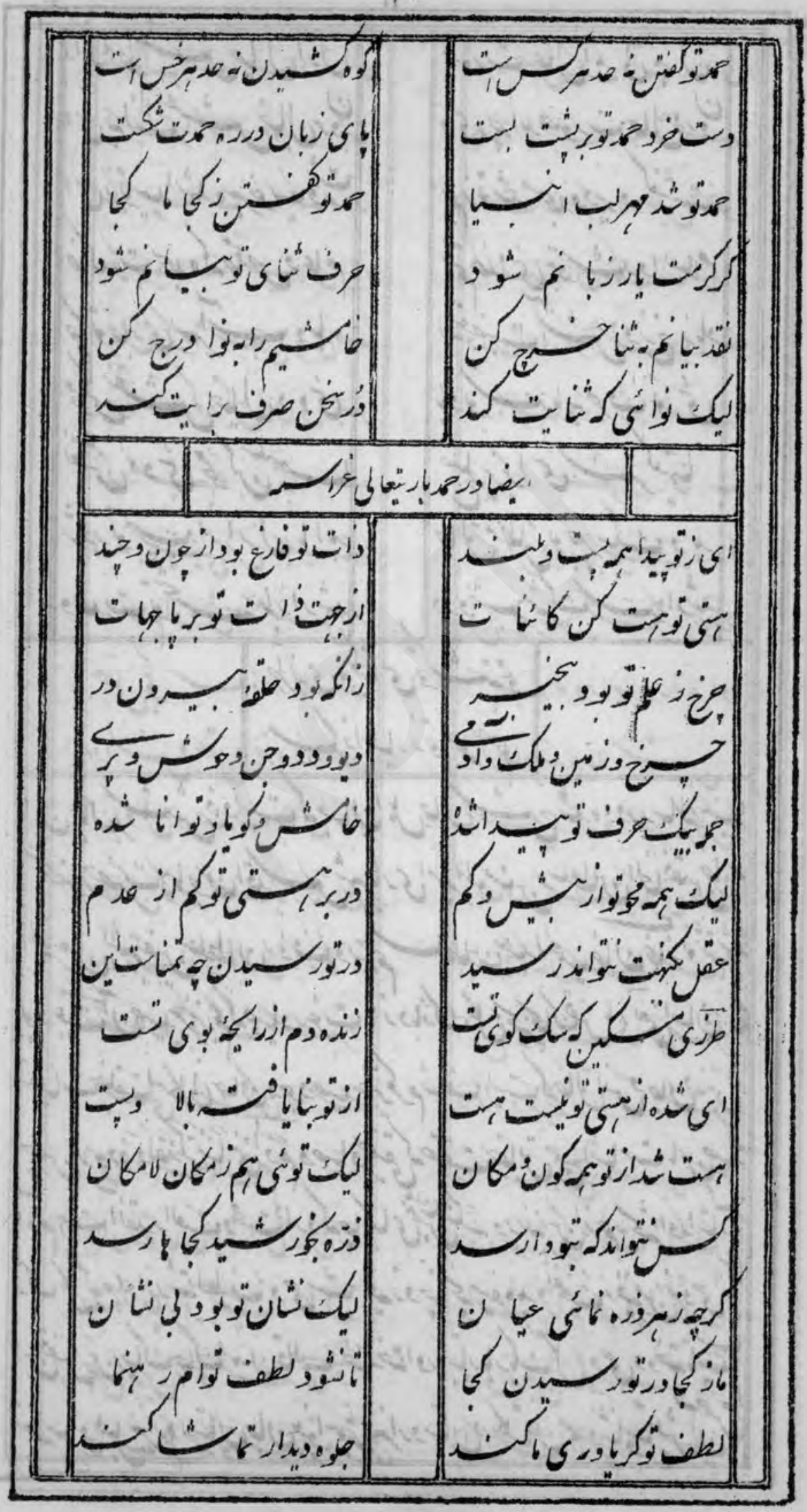




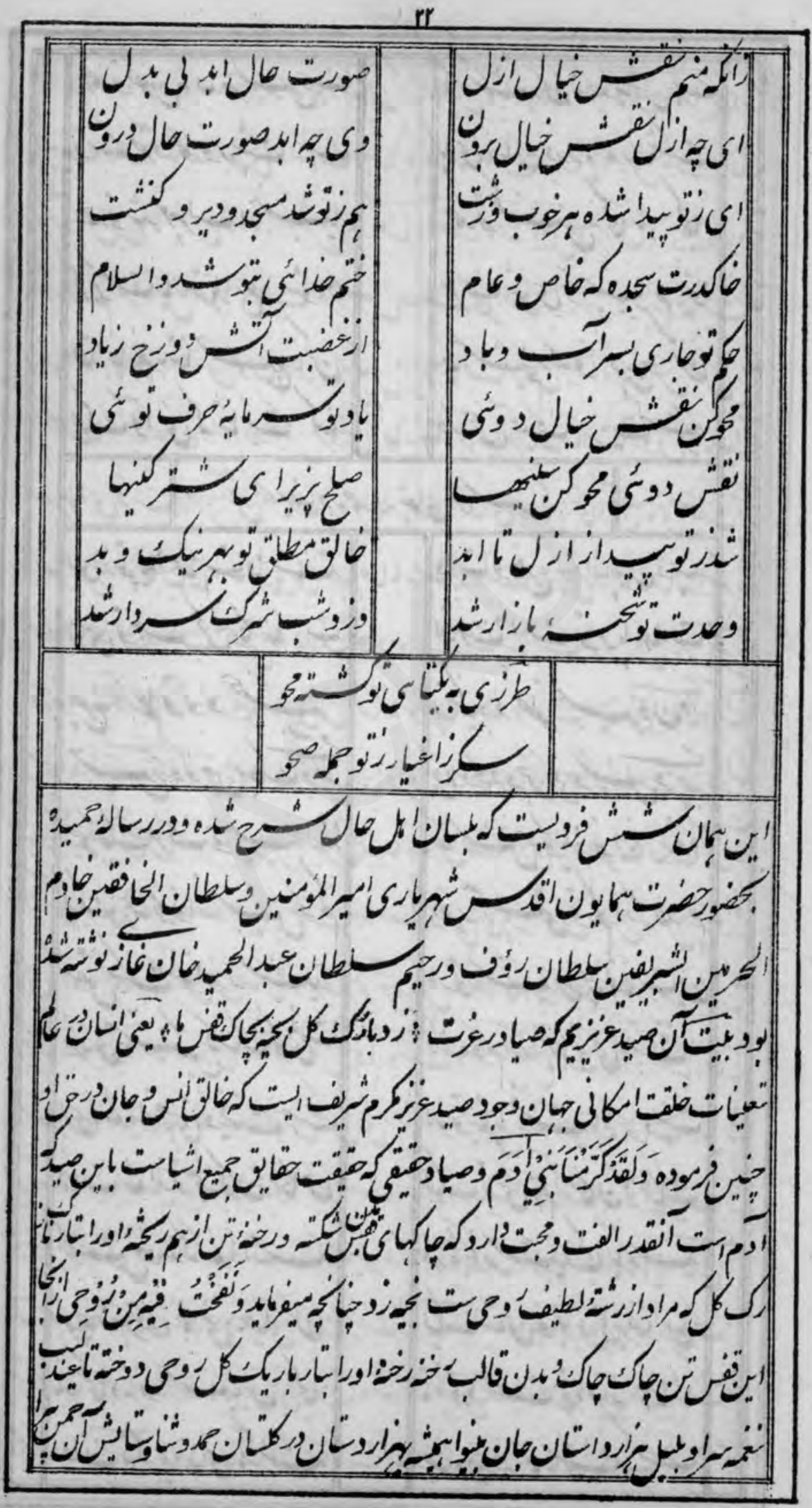




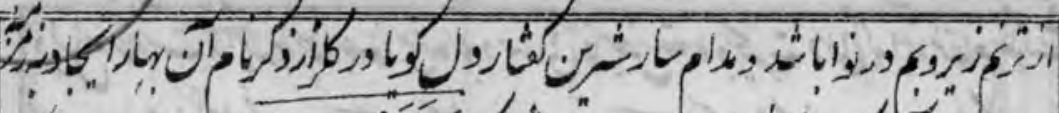

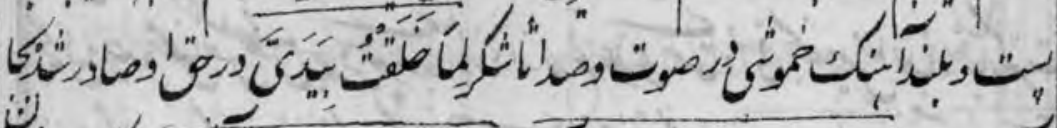
ن己.

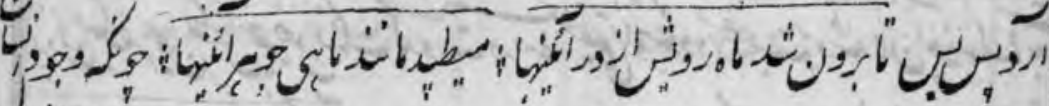

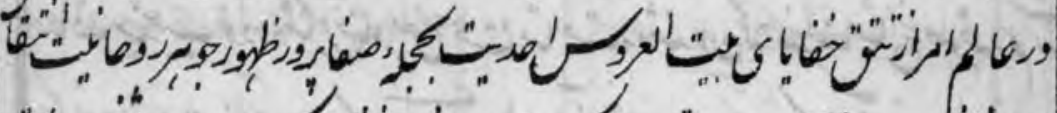

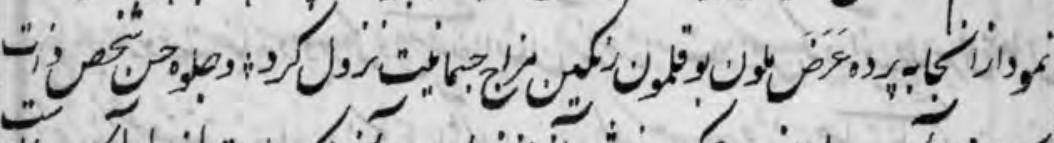

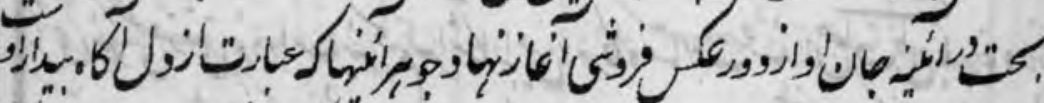

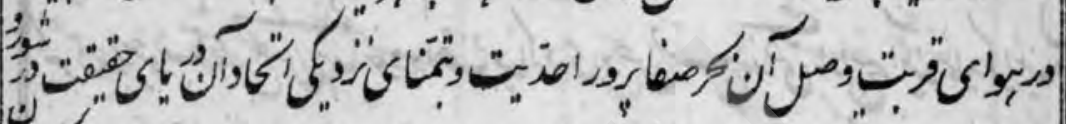

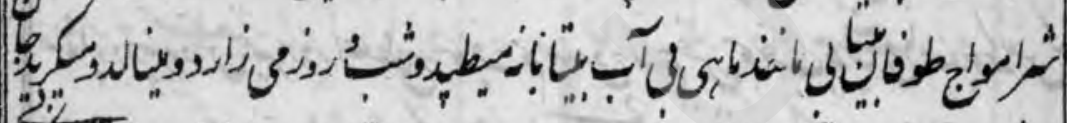

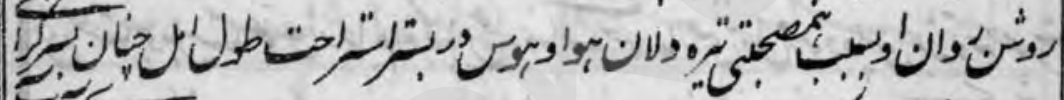

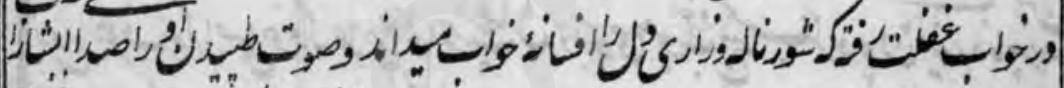

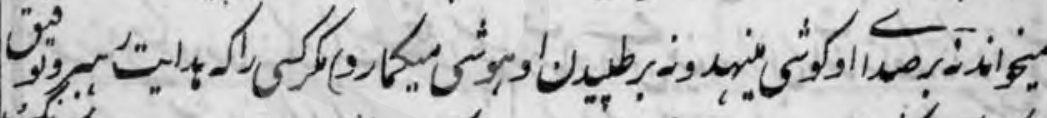
تورك"

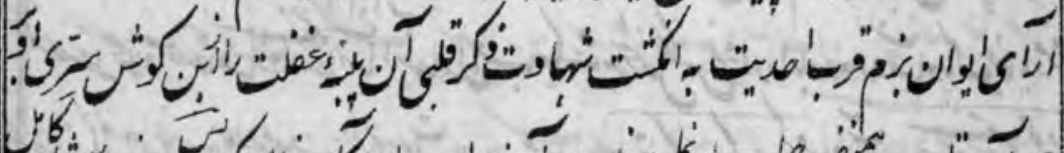

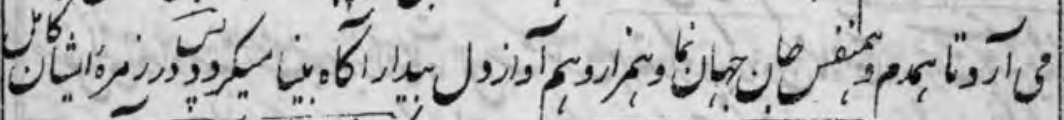

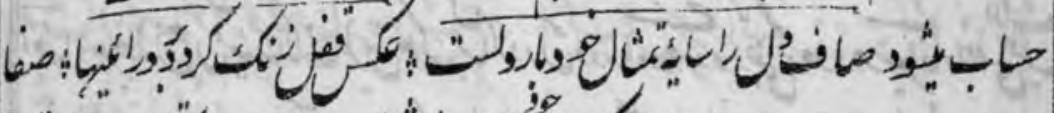

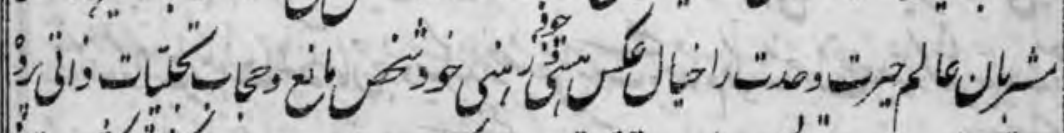
, of

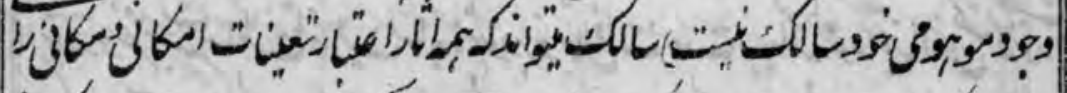

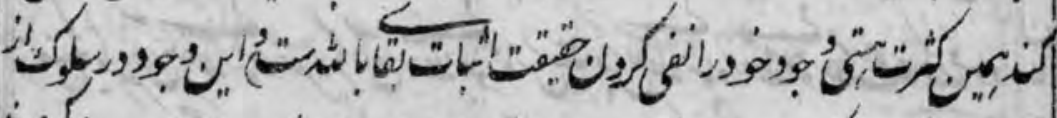

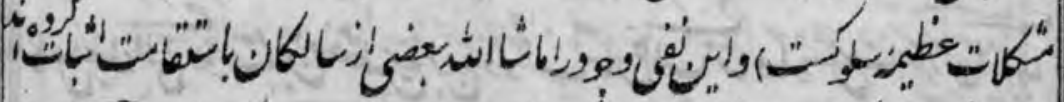

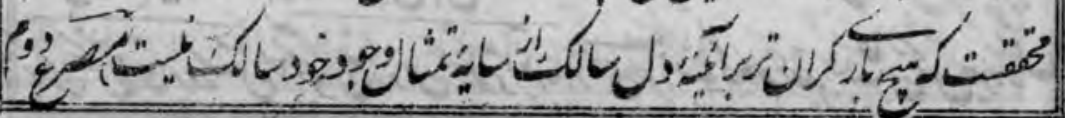




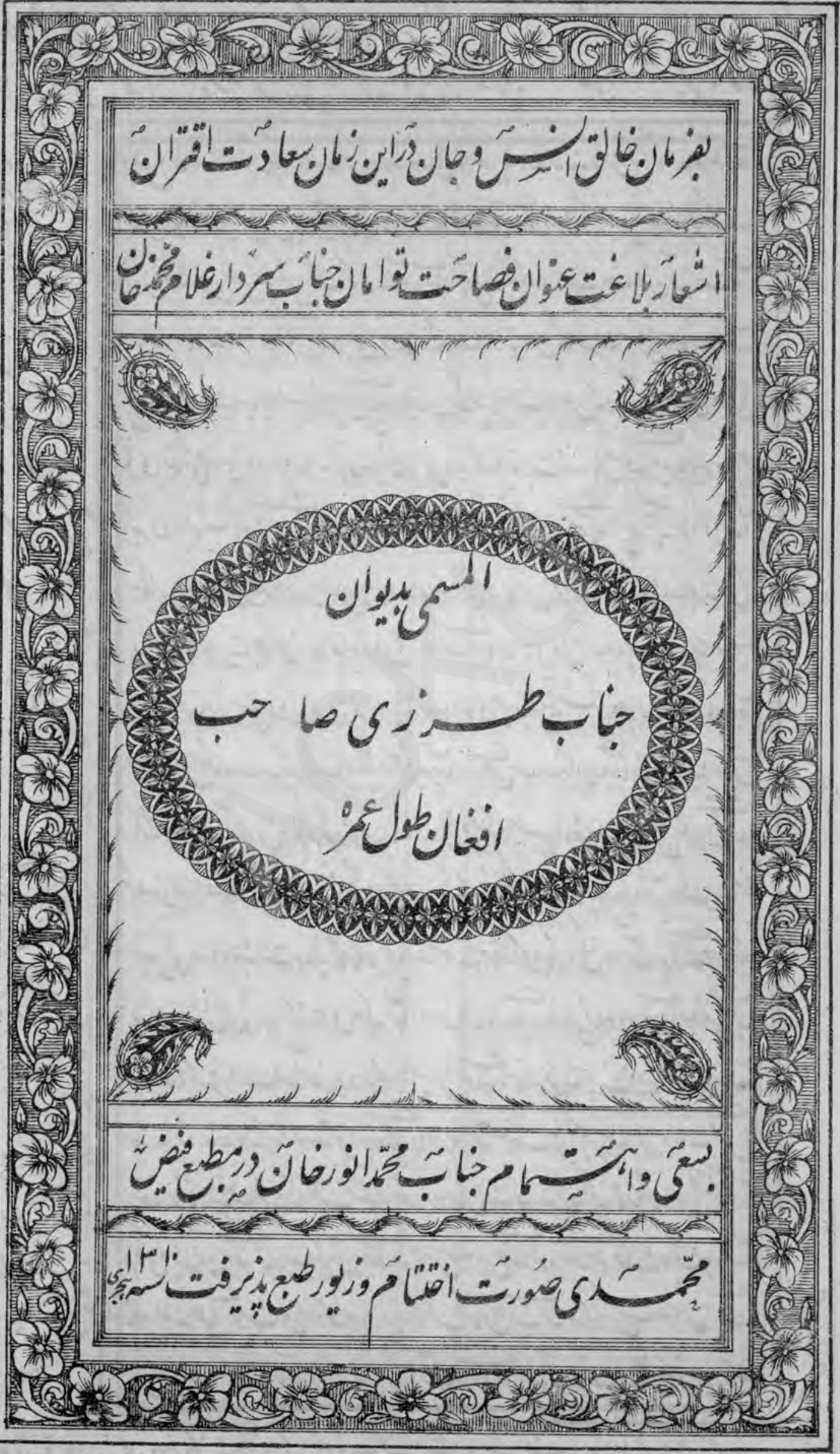


M

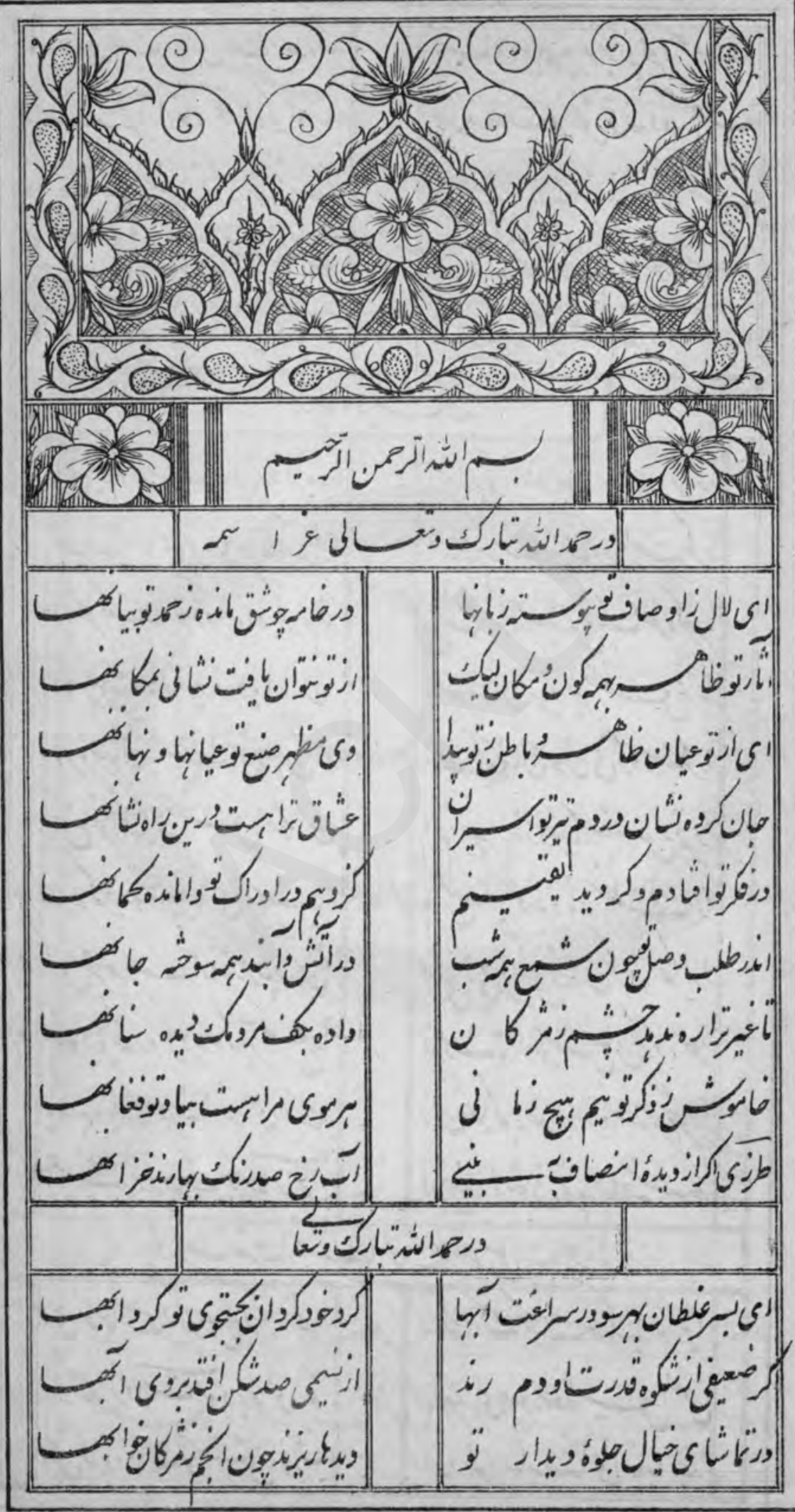




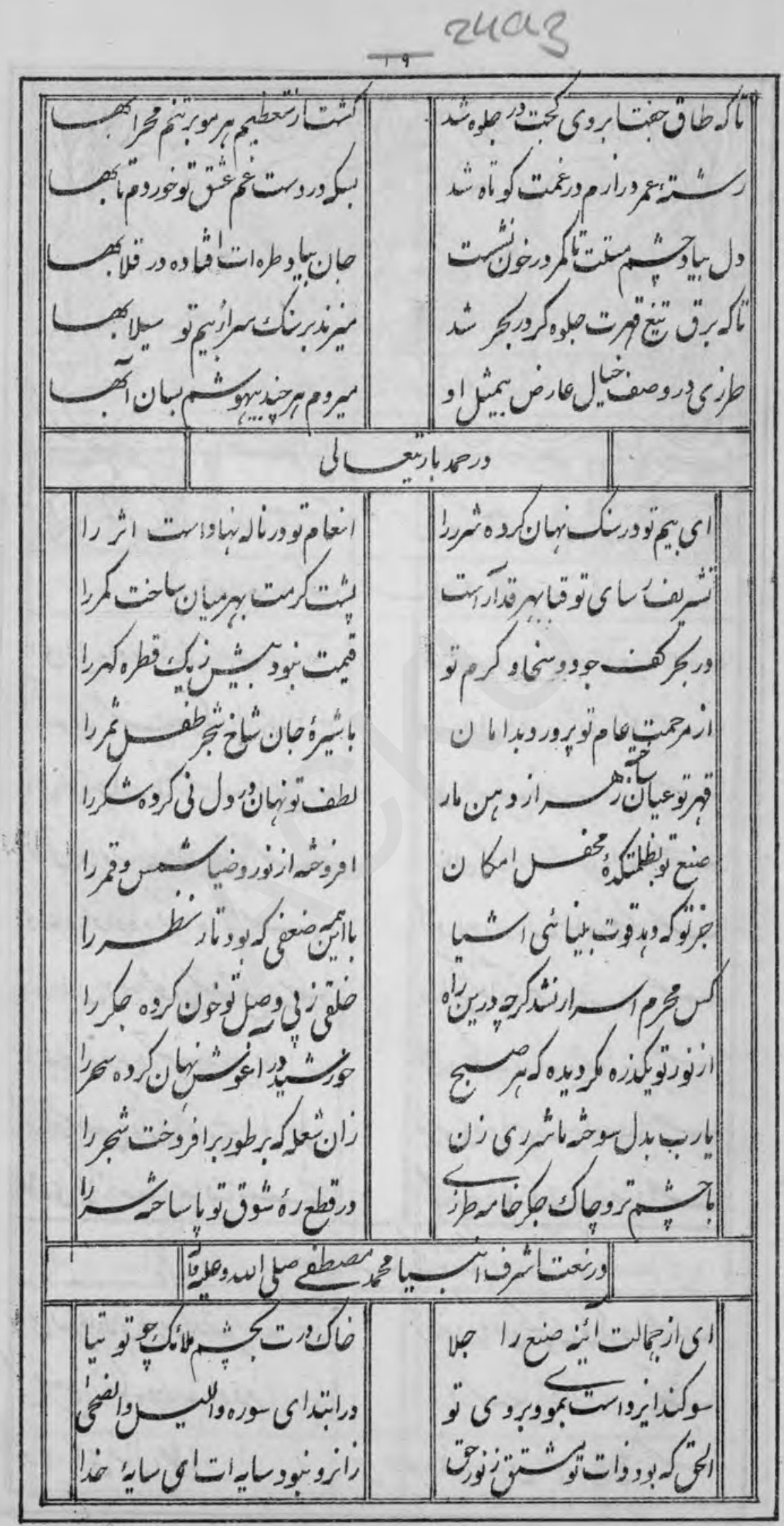




\section{$24 \mathrm{Or}_{4}$}

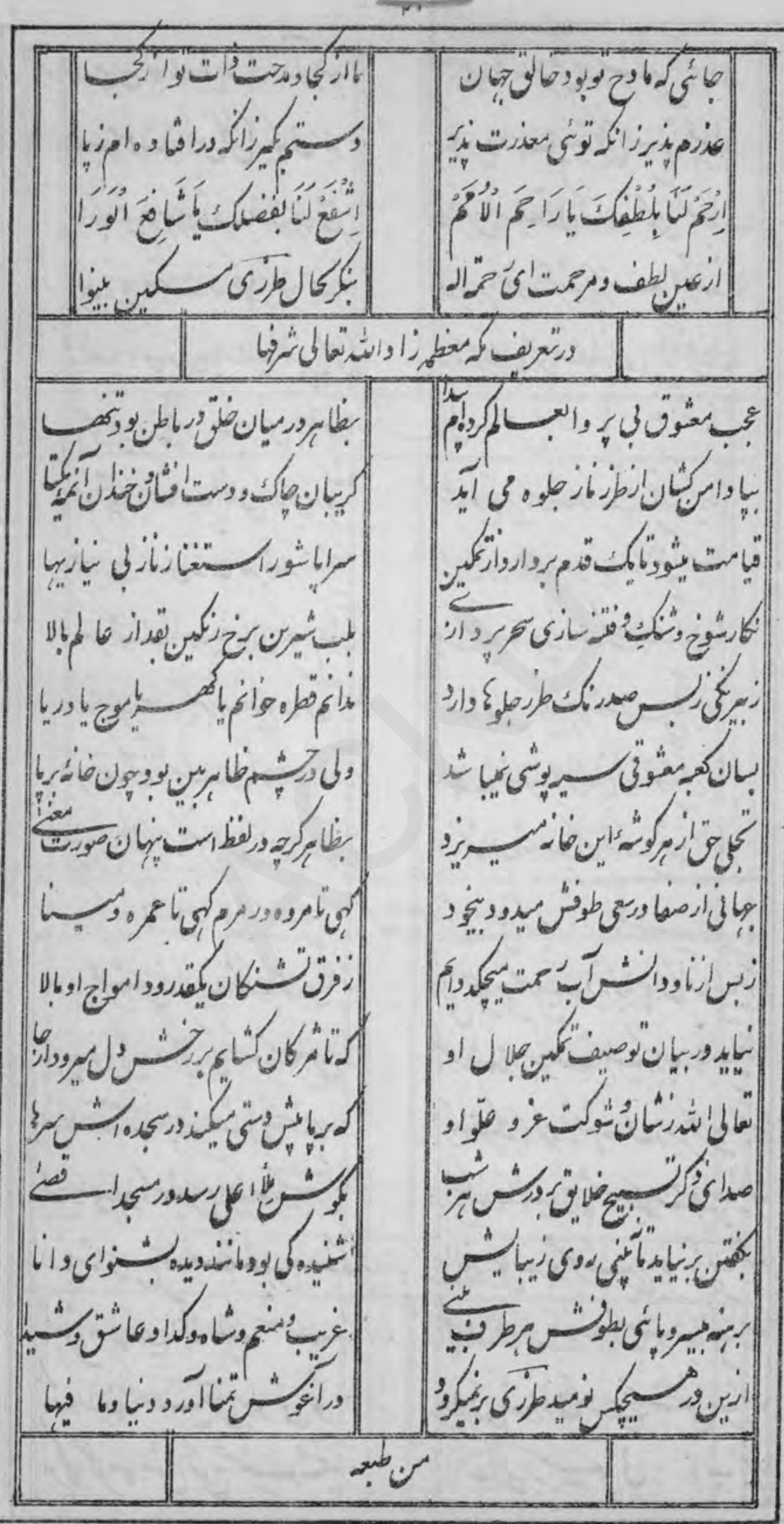


$-1$

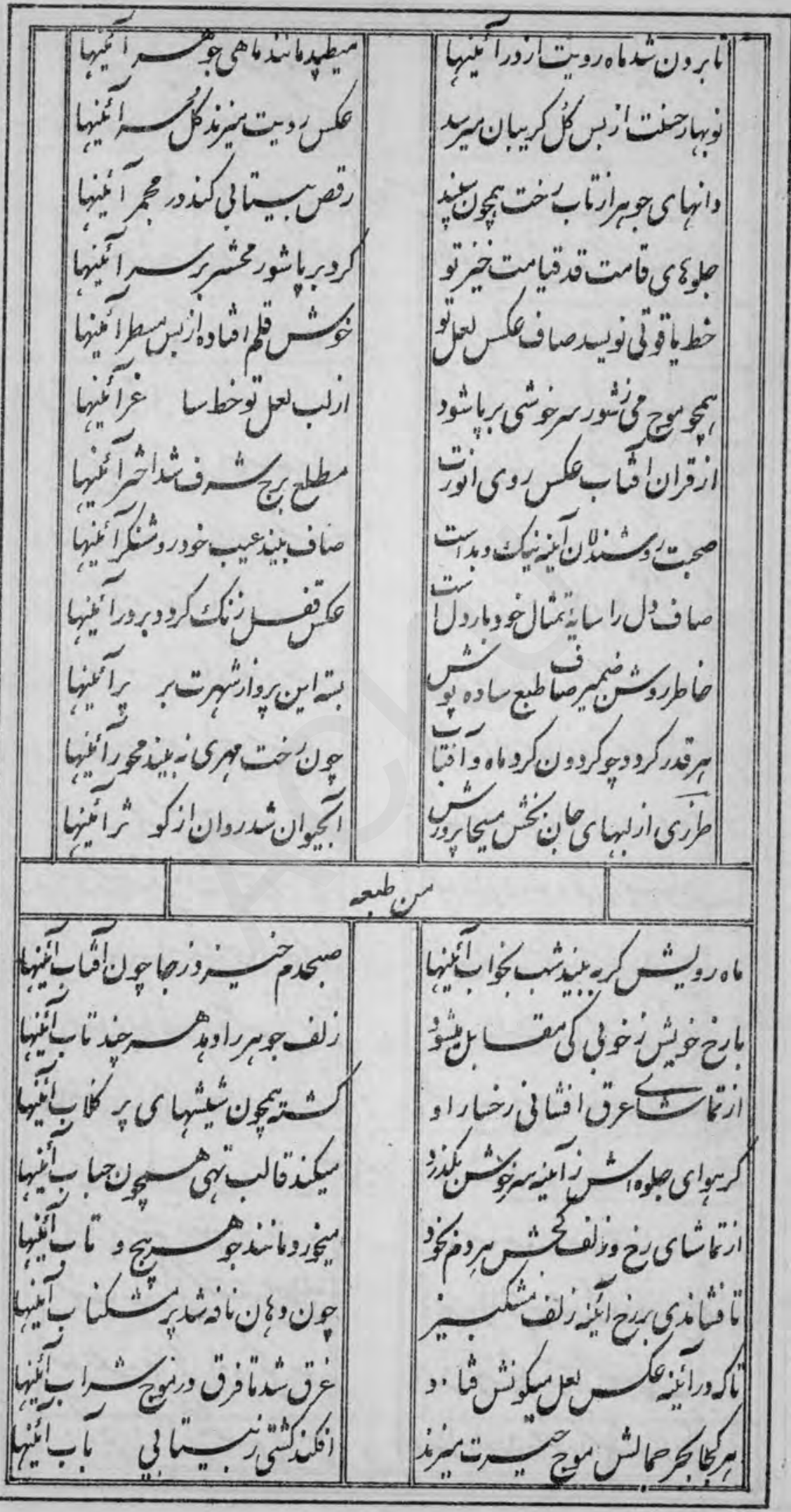




\section{$24 a_{6}$}

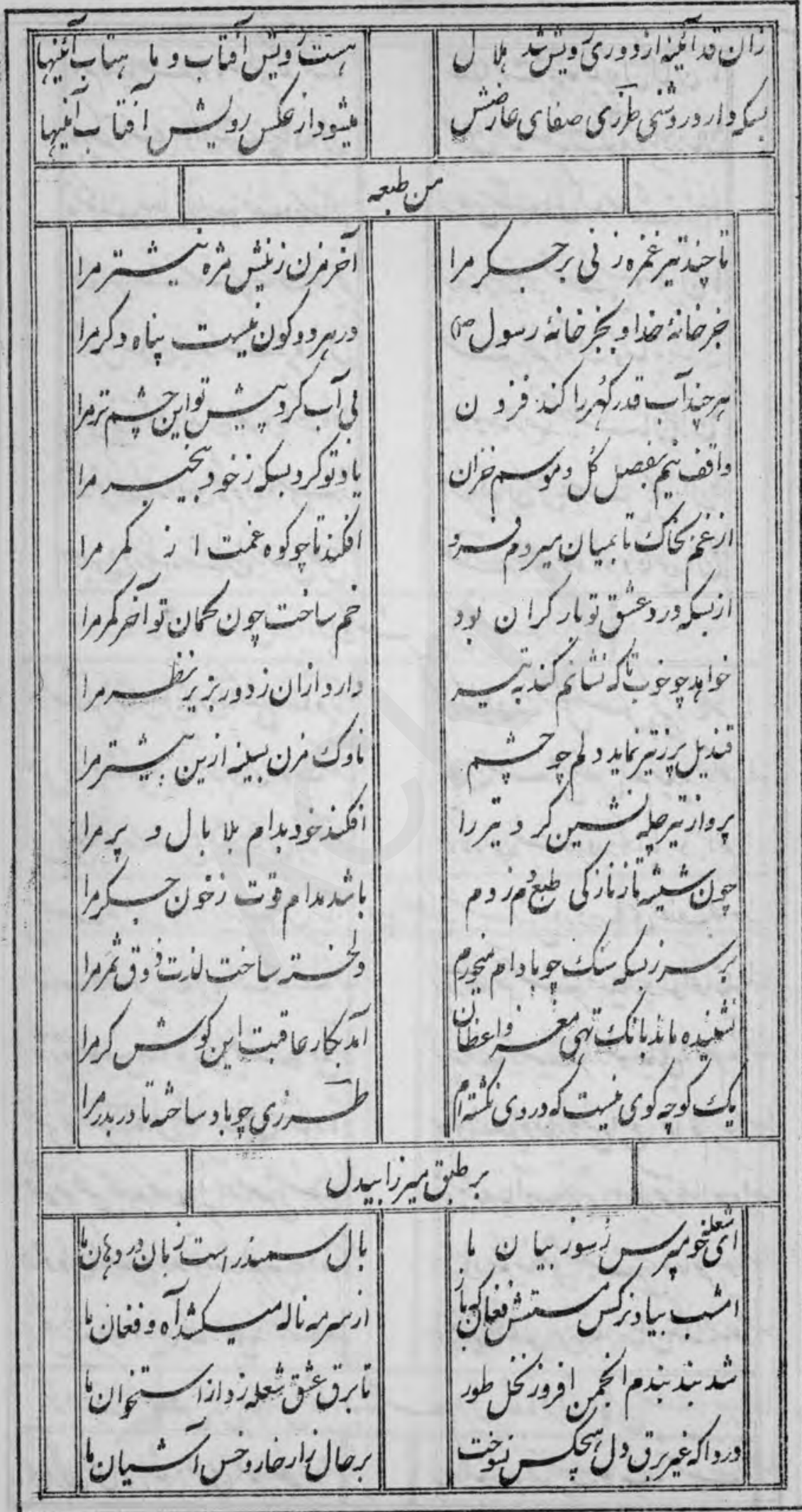




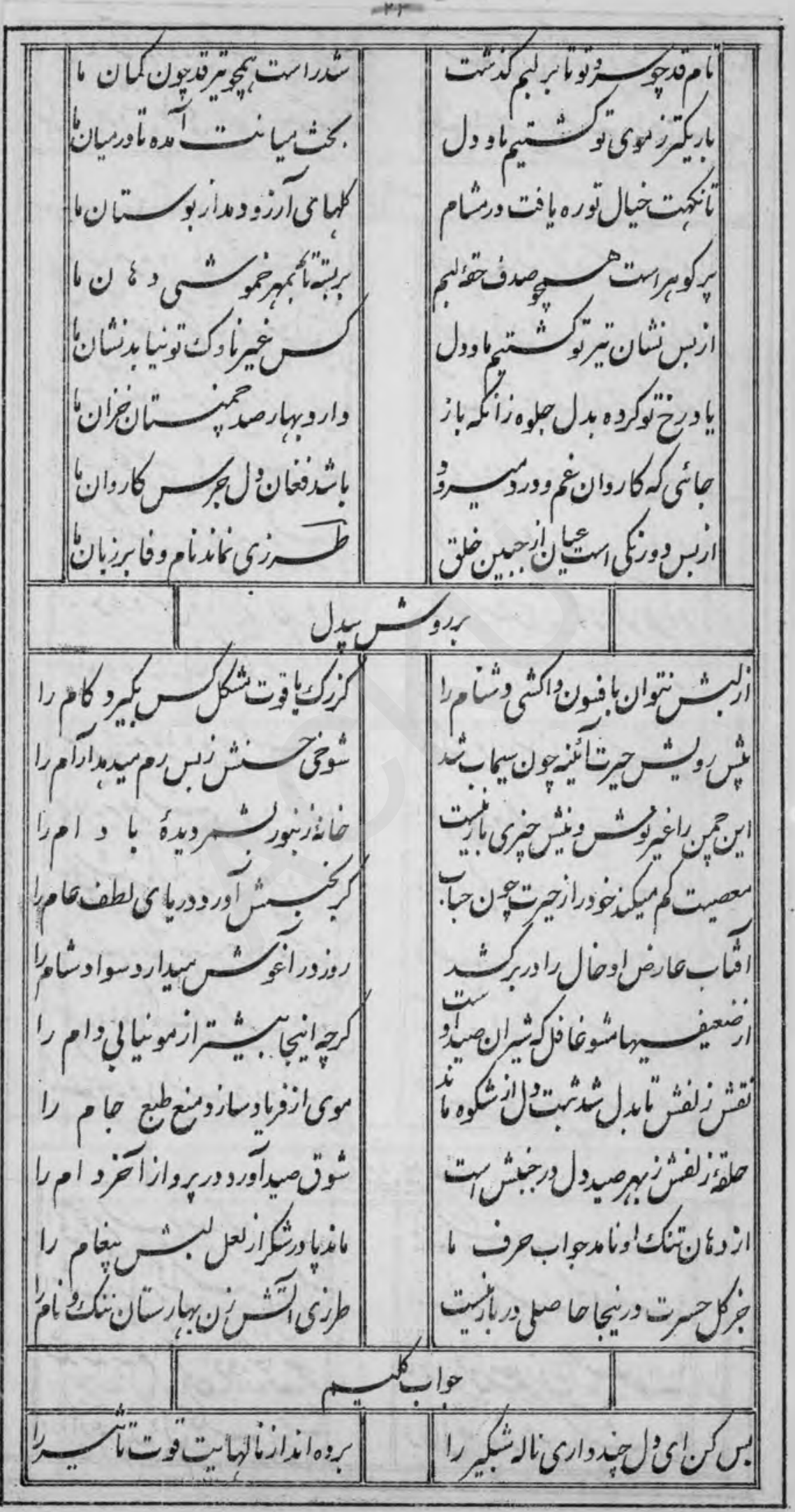




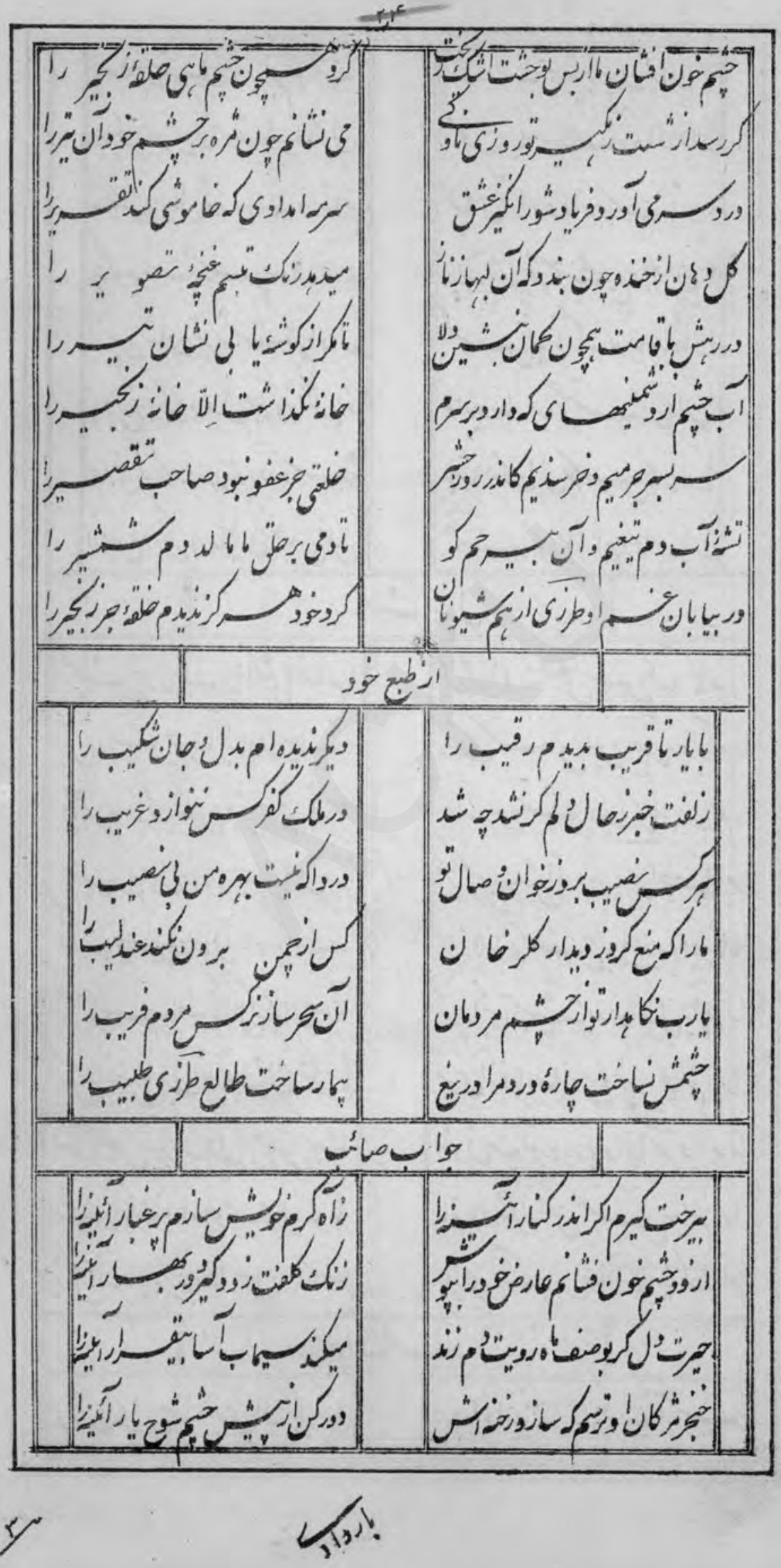


ro

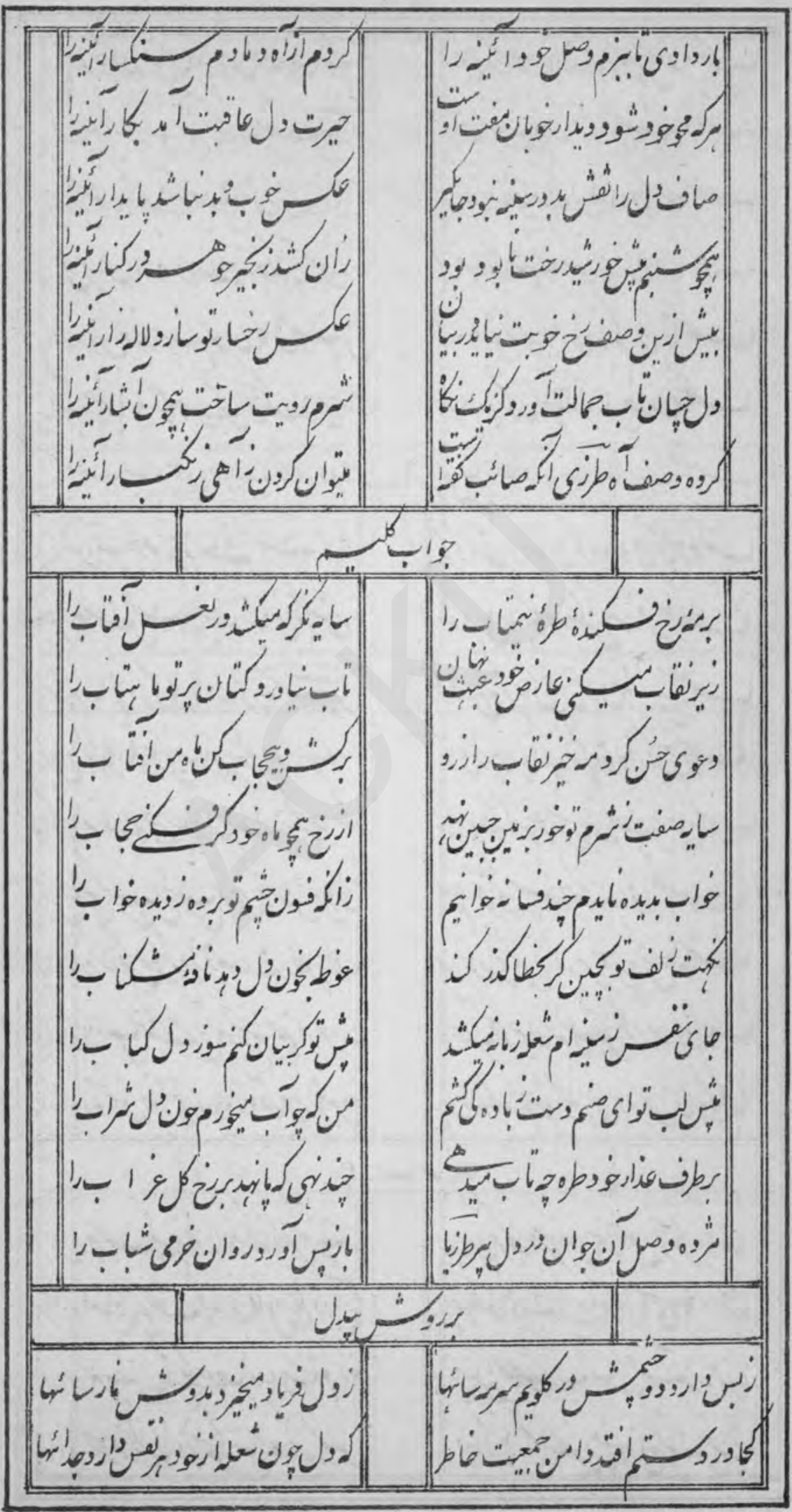




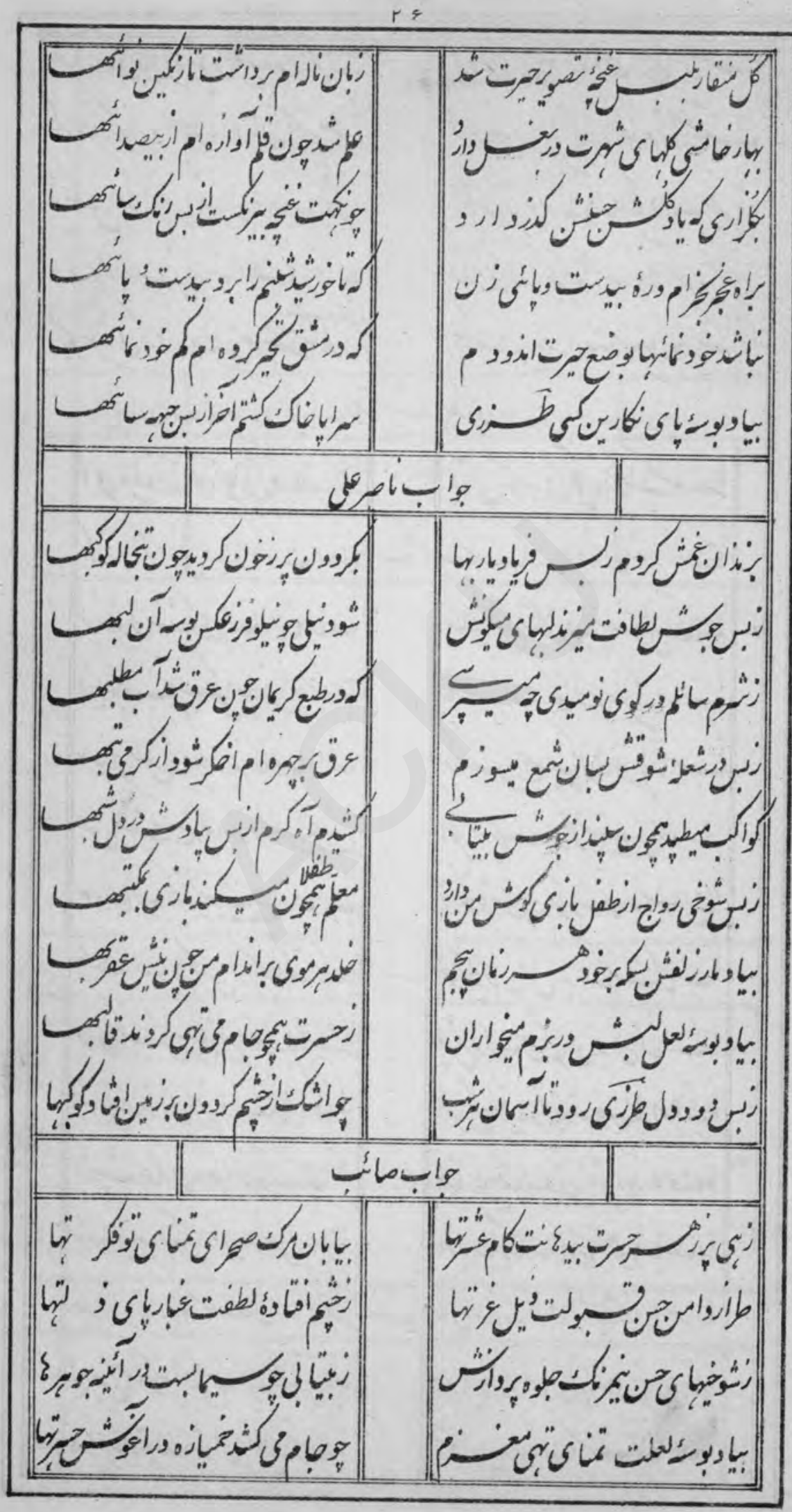


rv

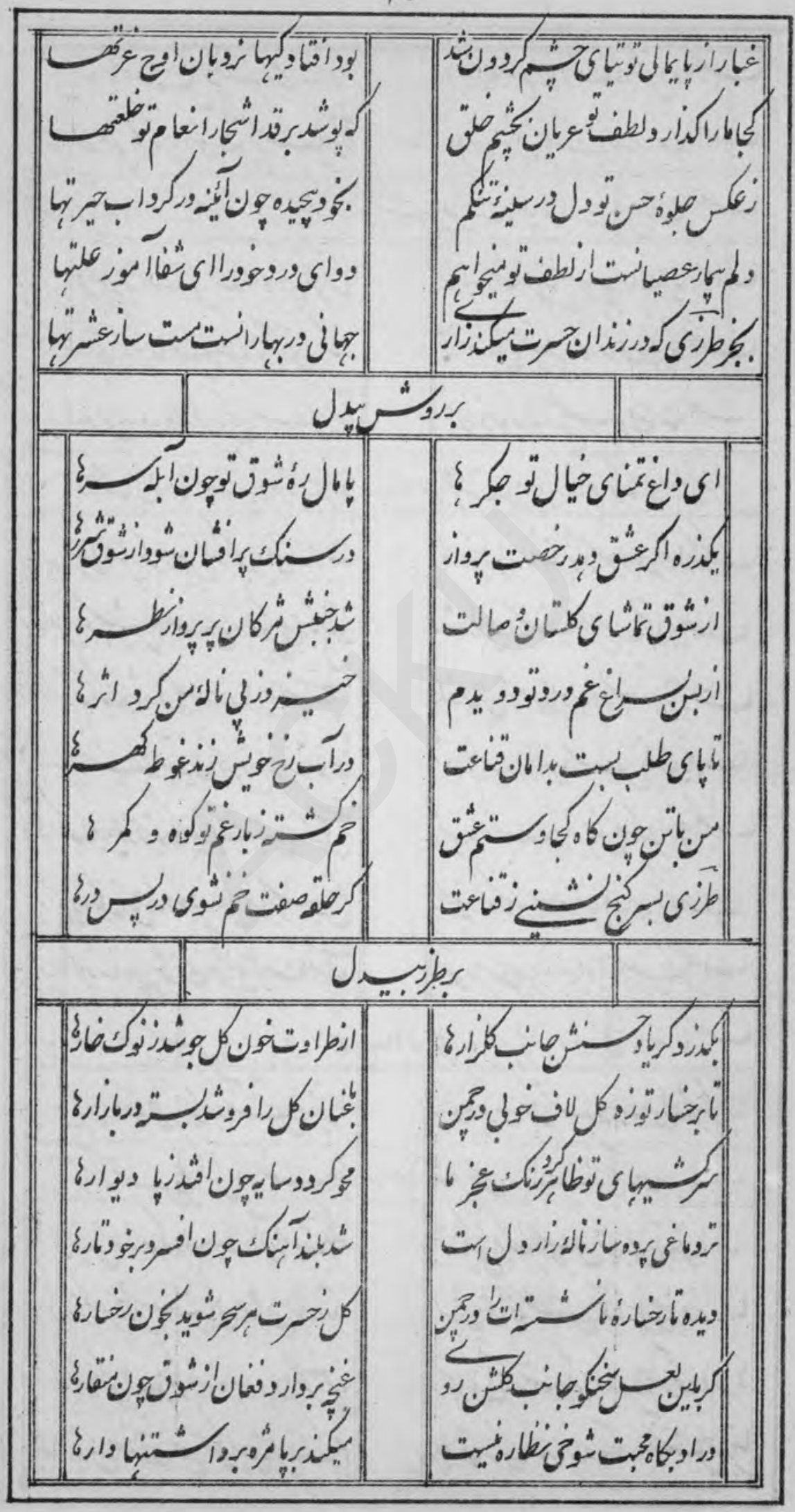


r

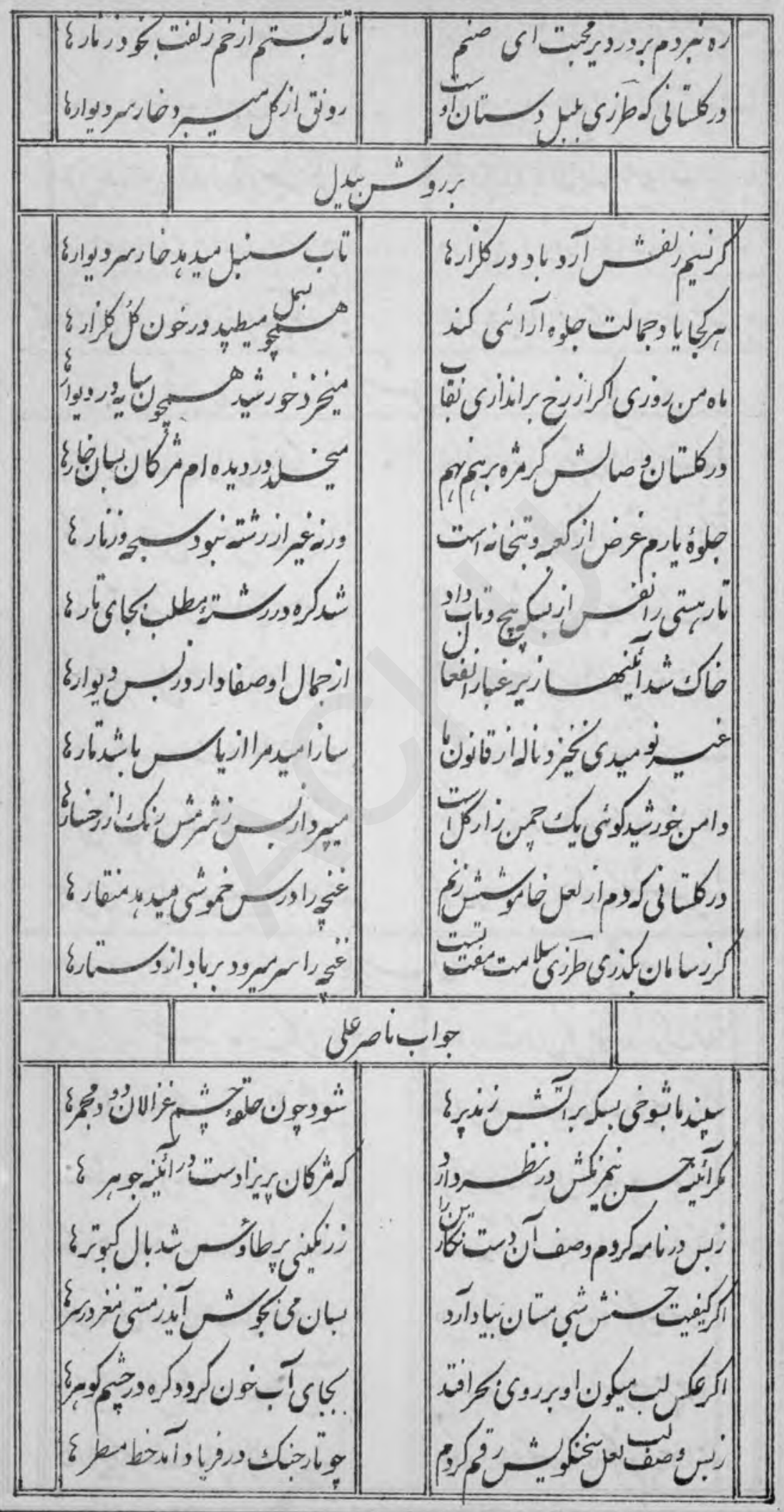




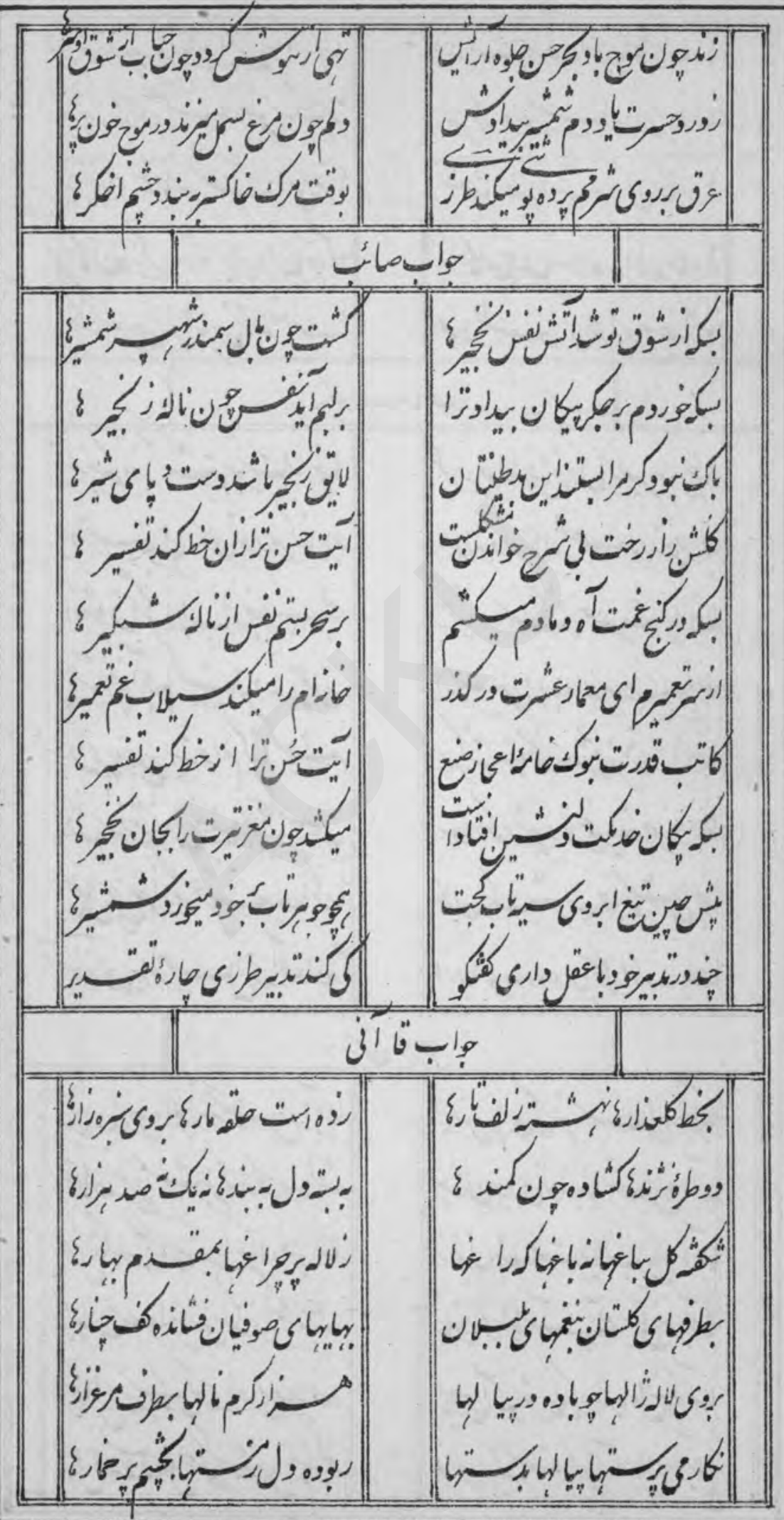


r.

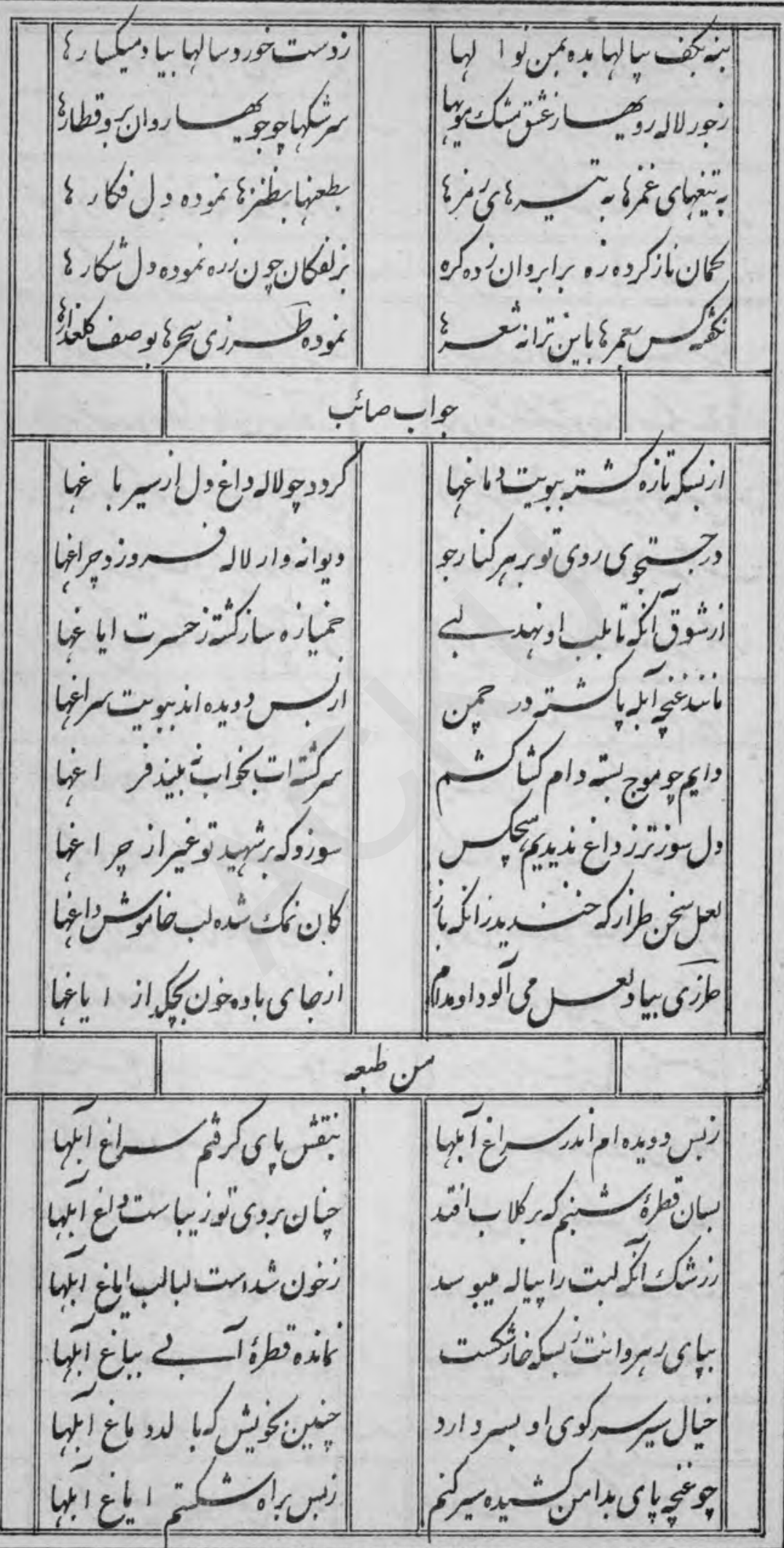




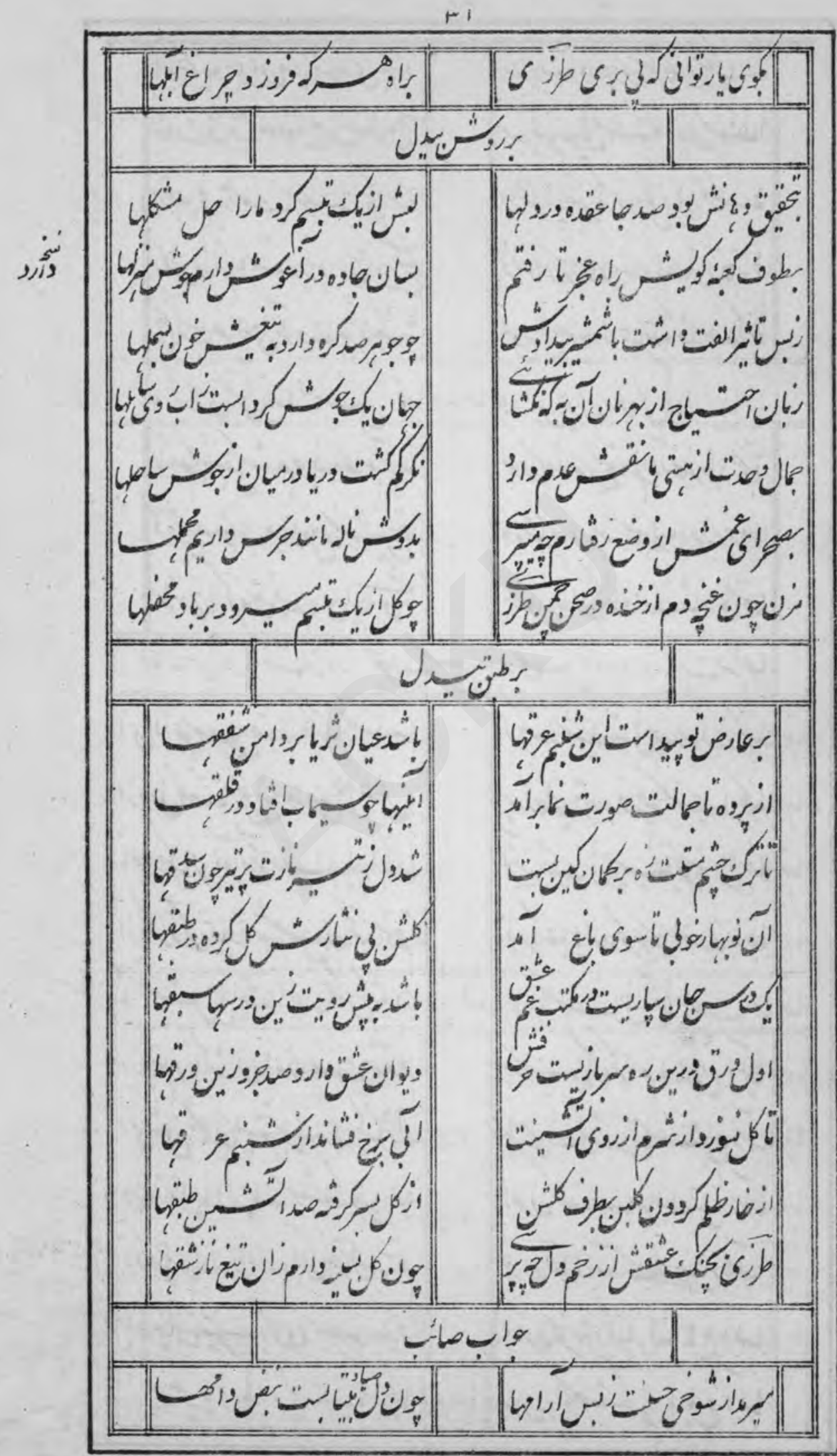




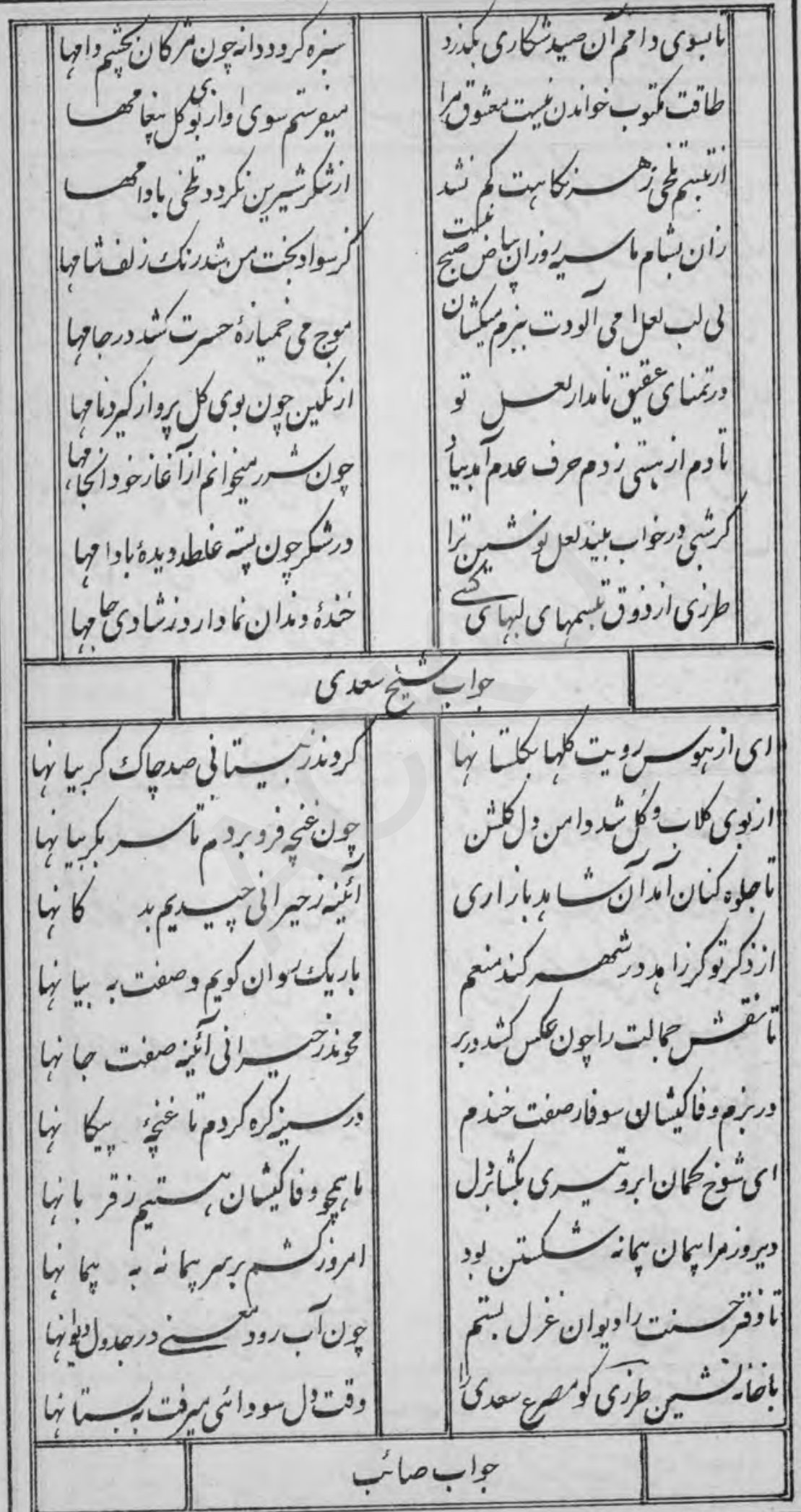




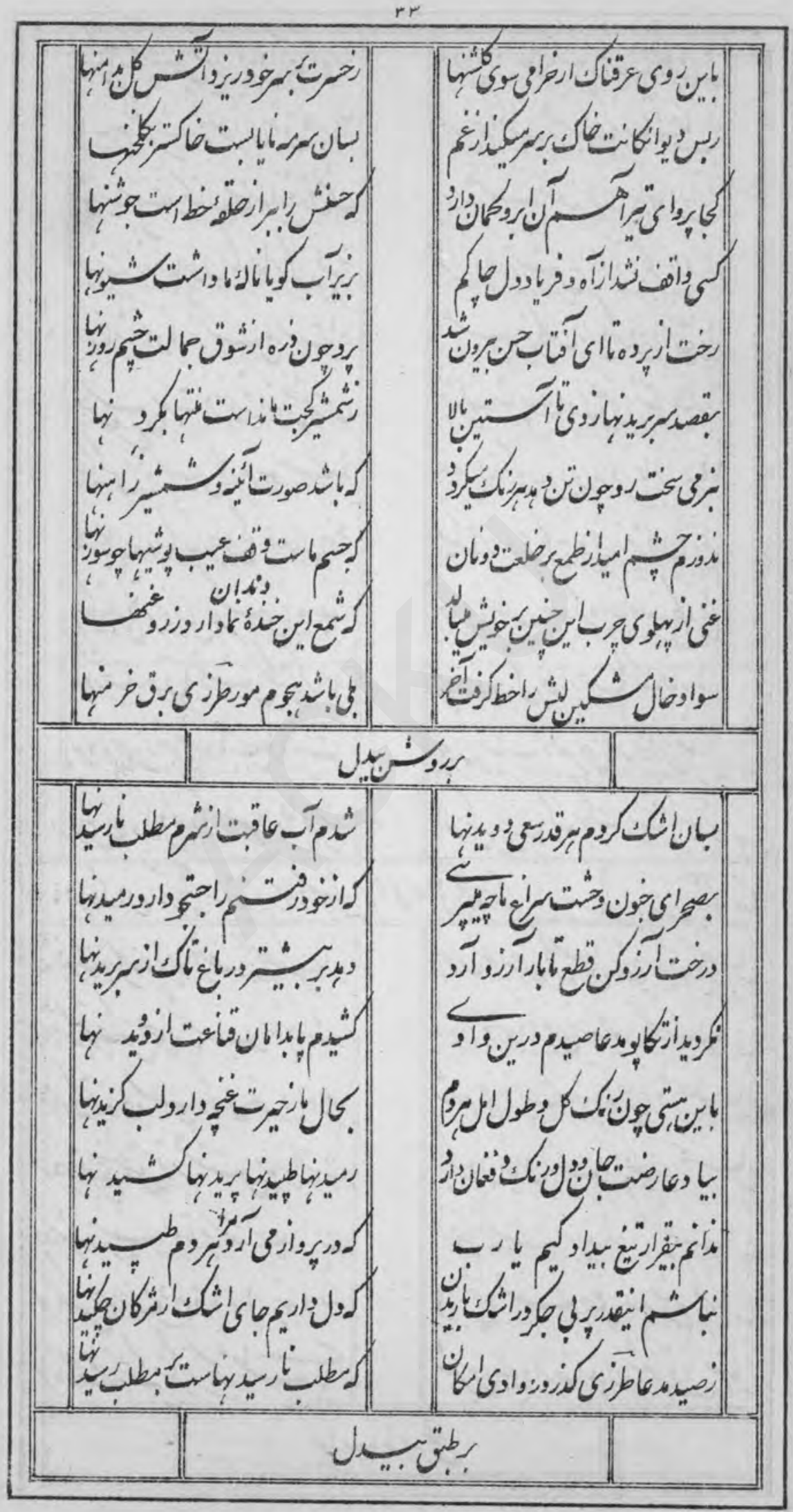


$r r$

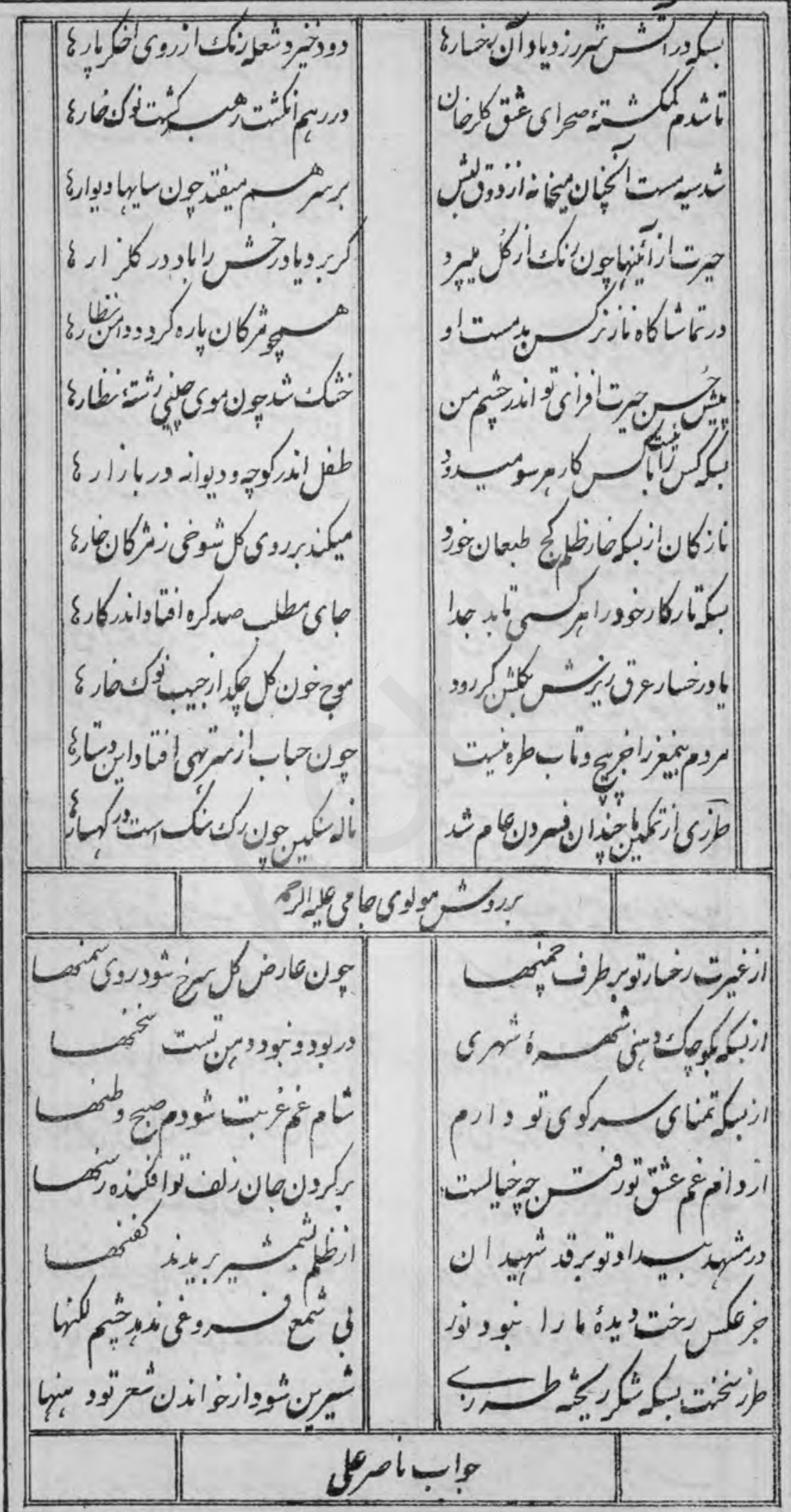




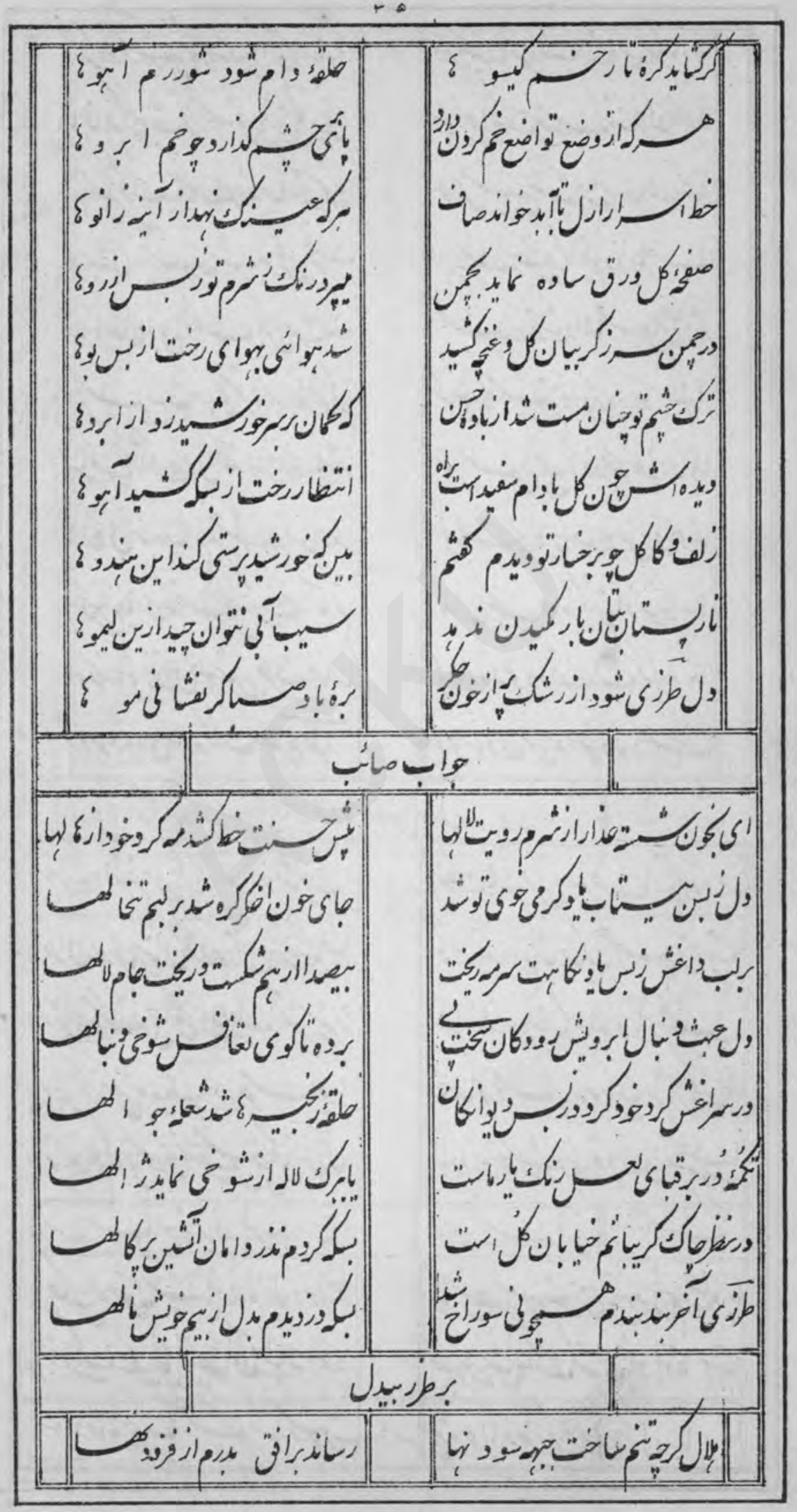




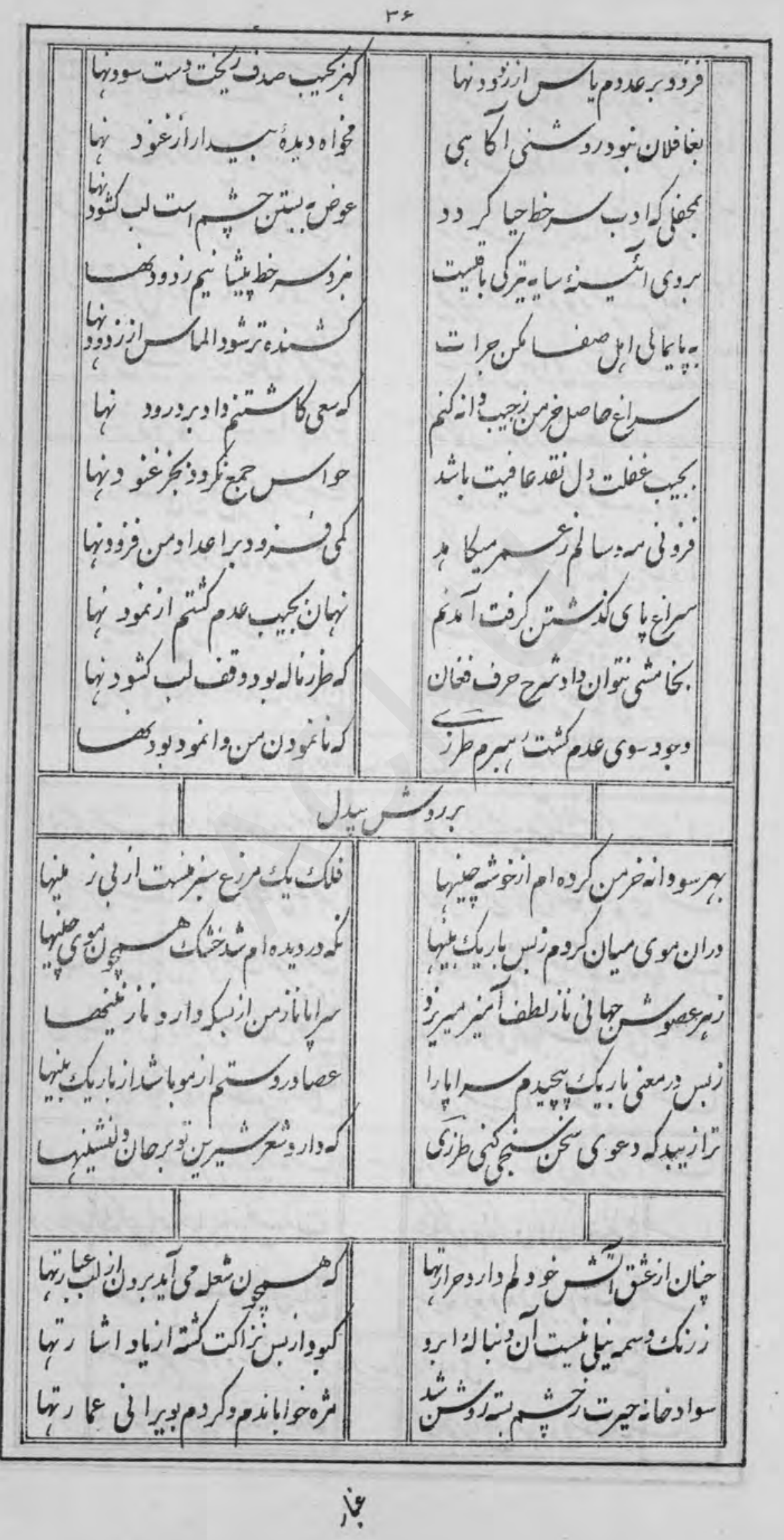




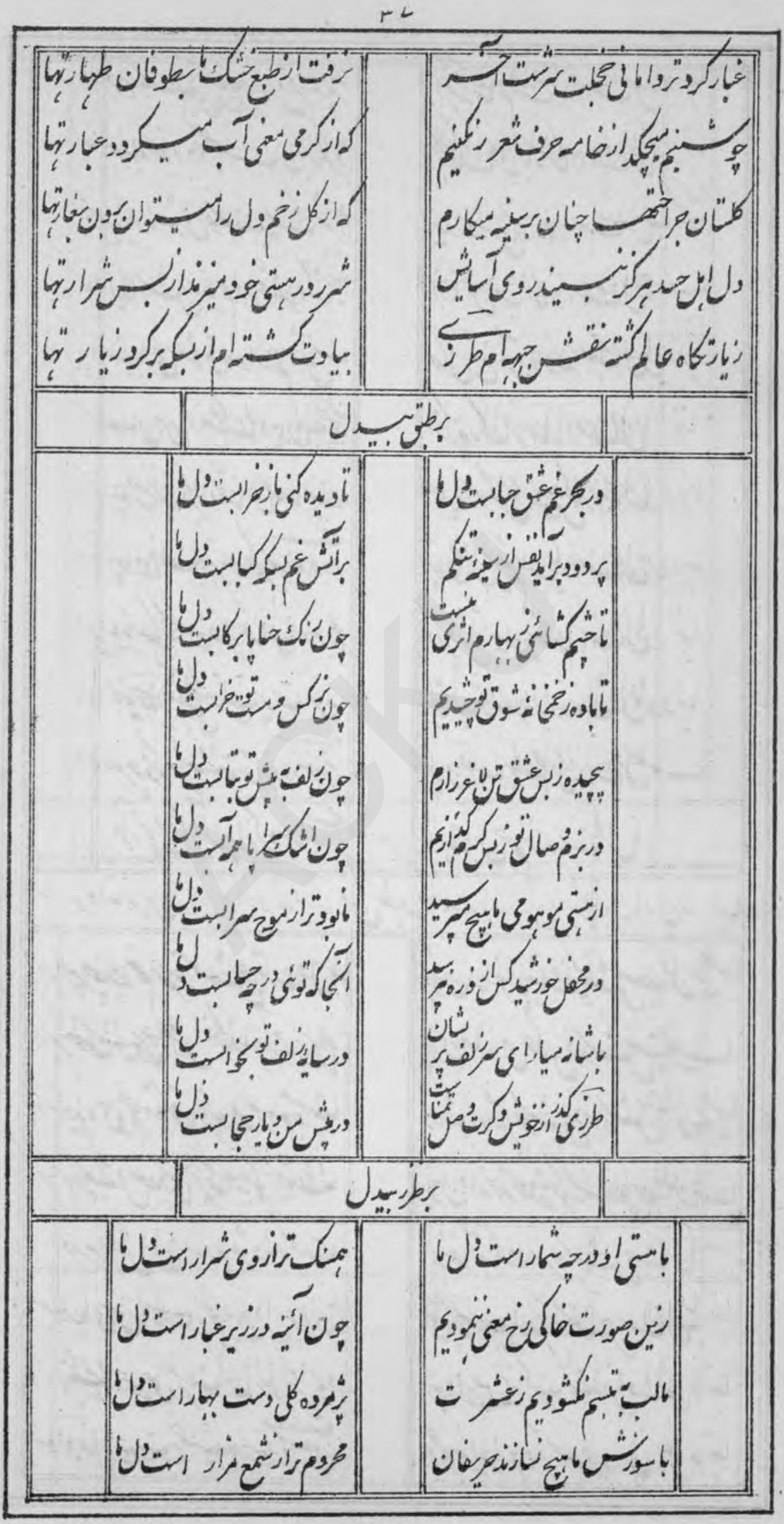


rト

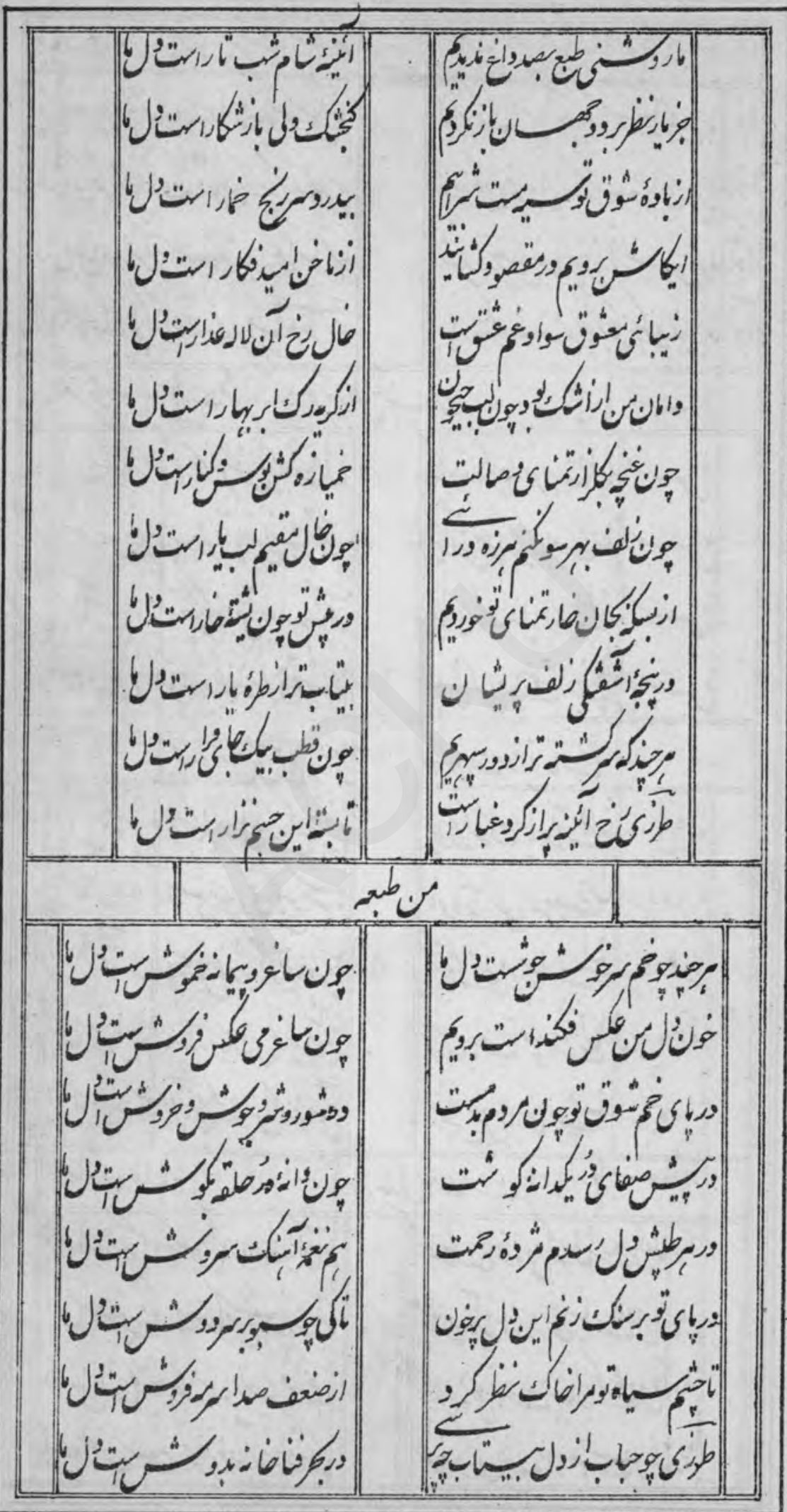

3.?. 
r 9

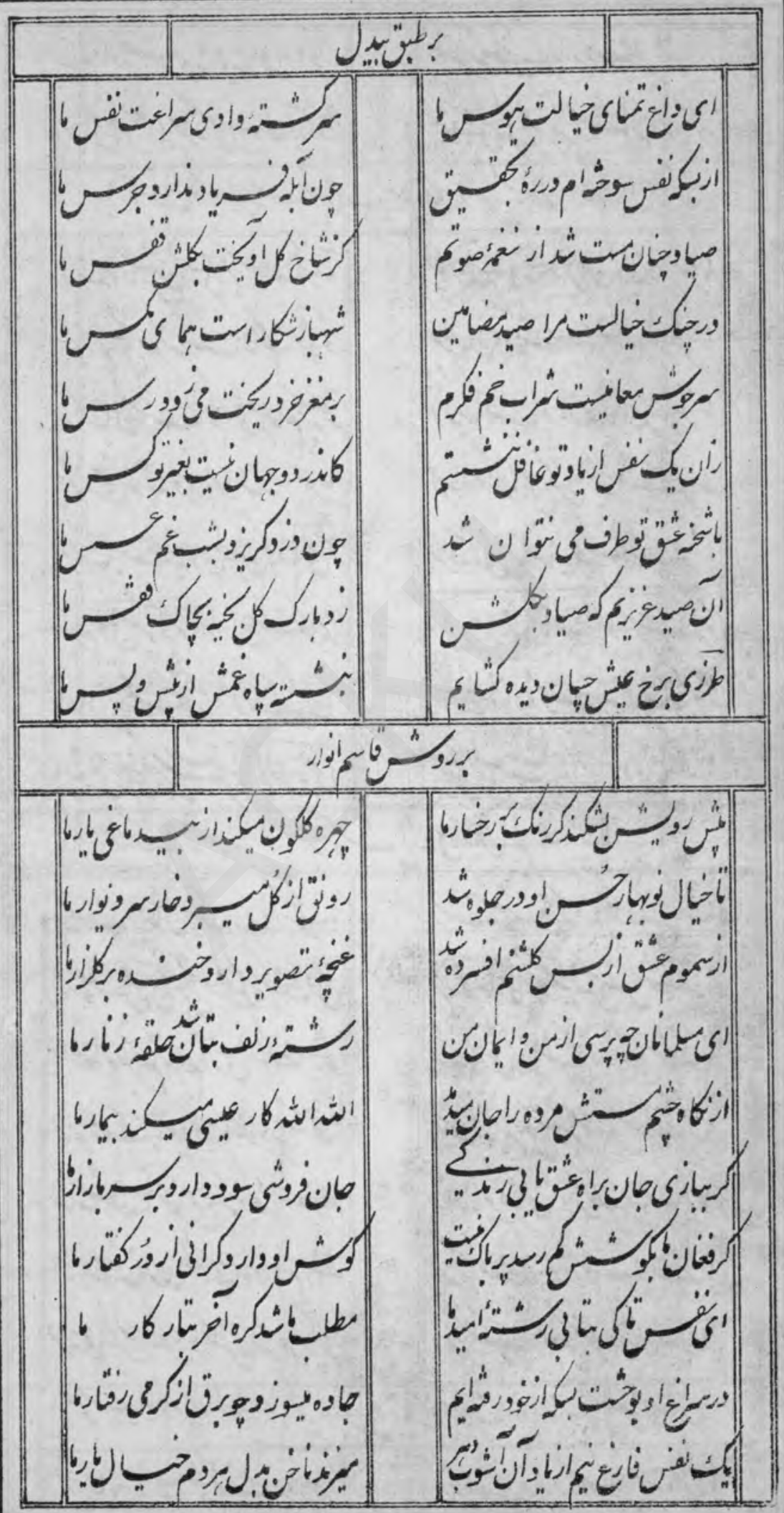




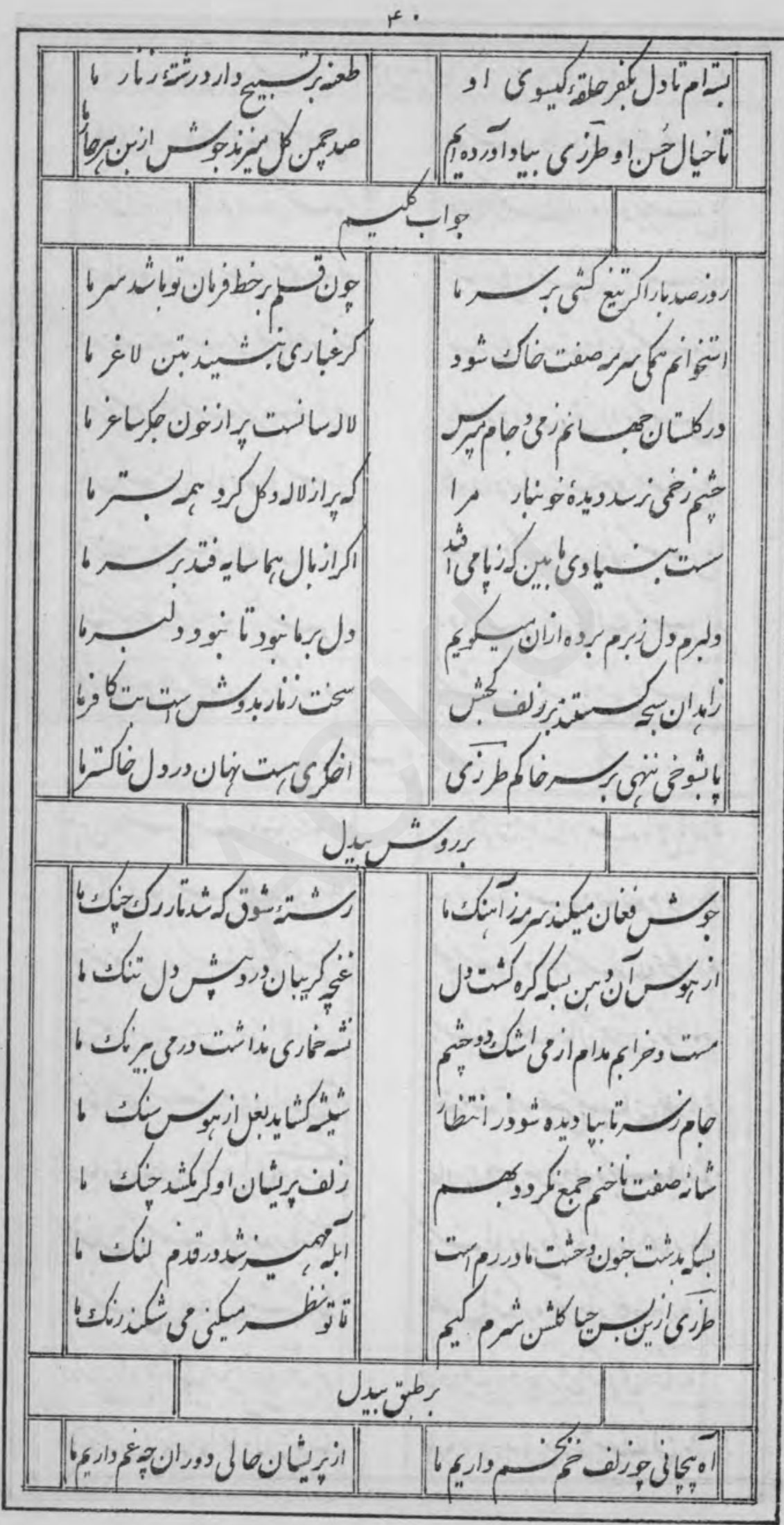


$+1$

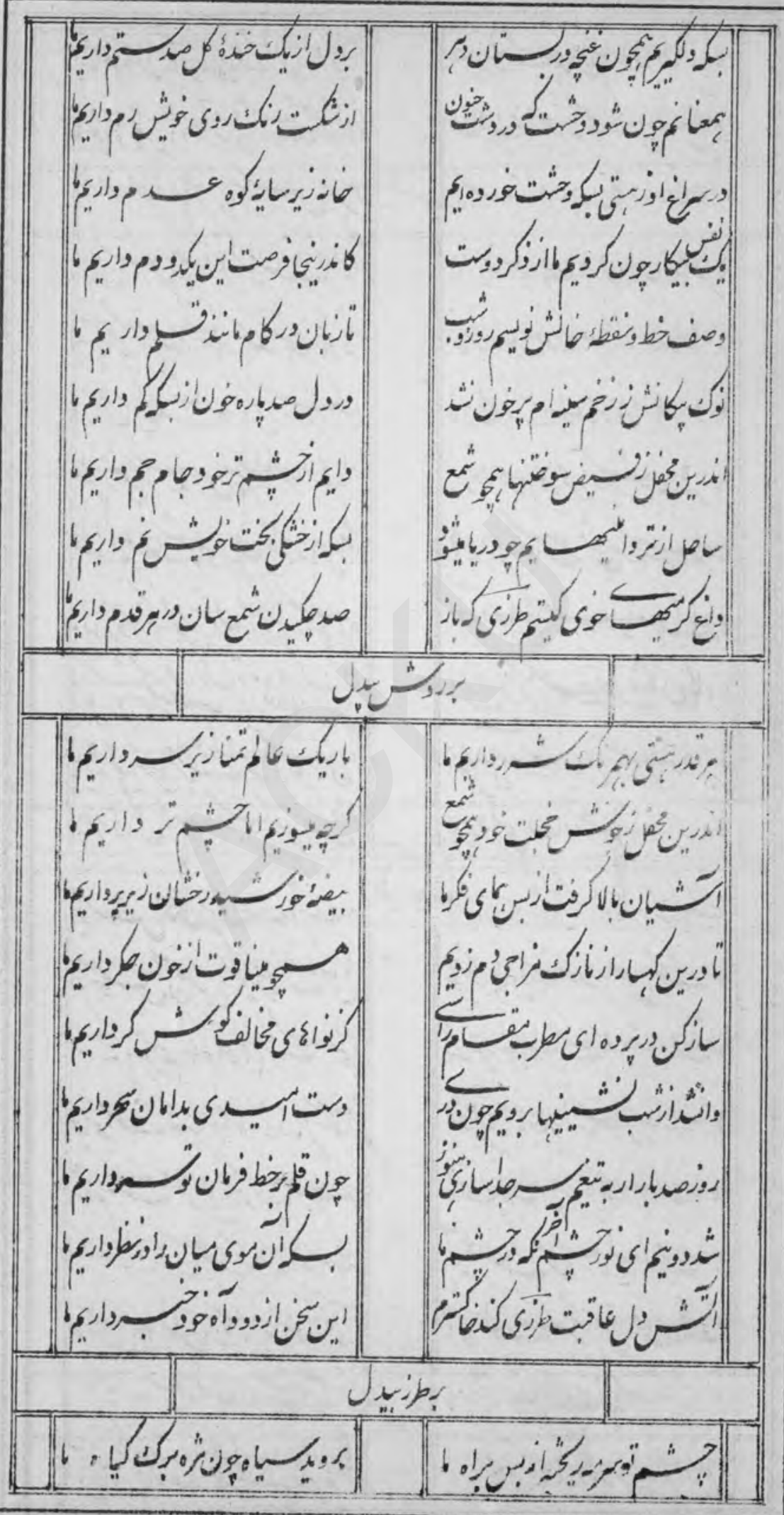


$r$

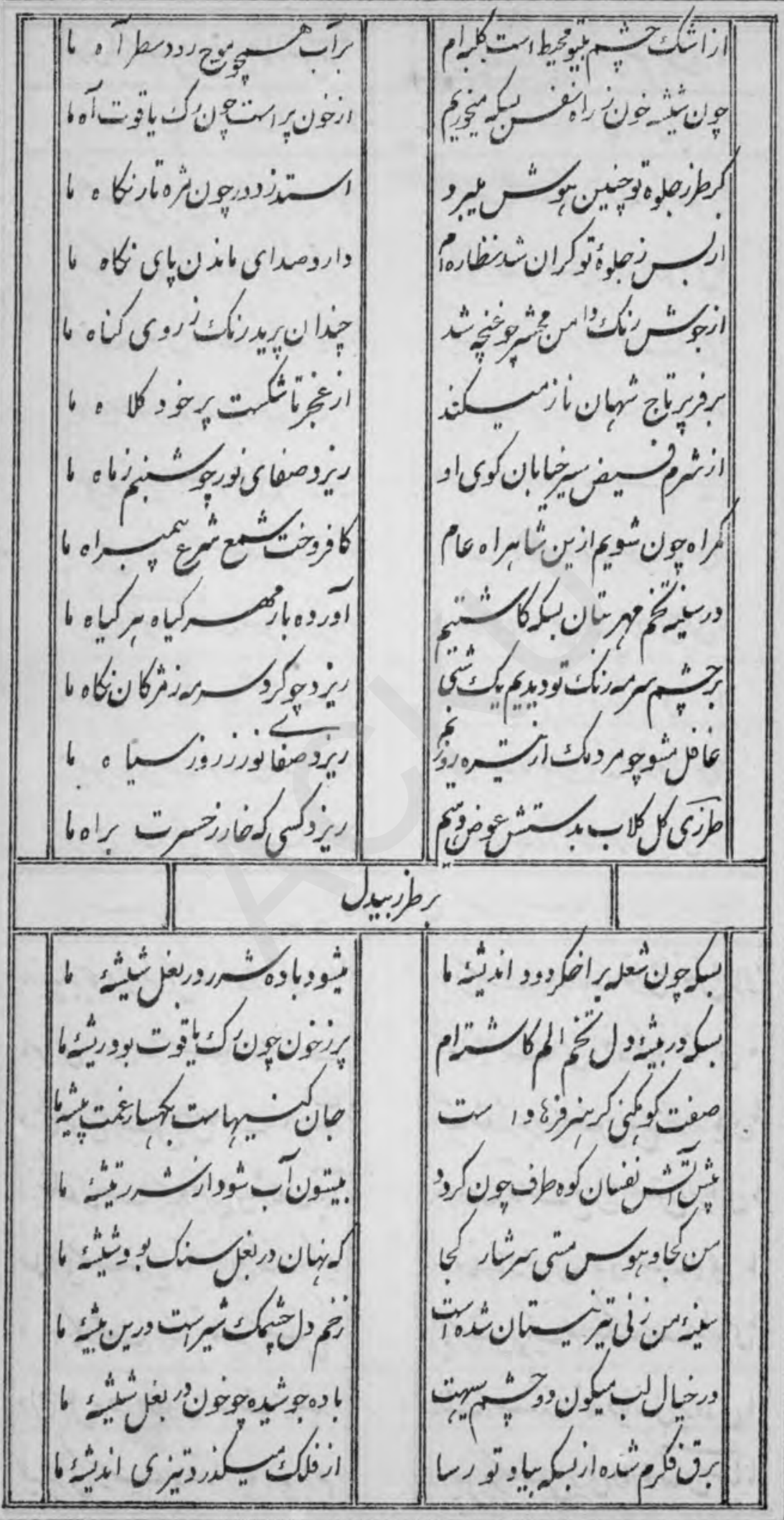




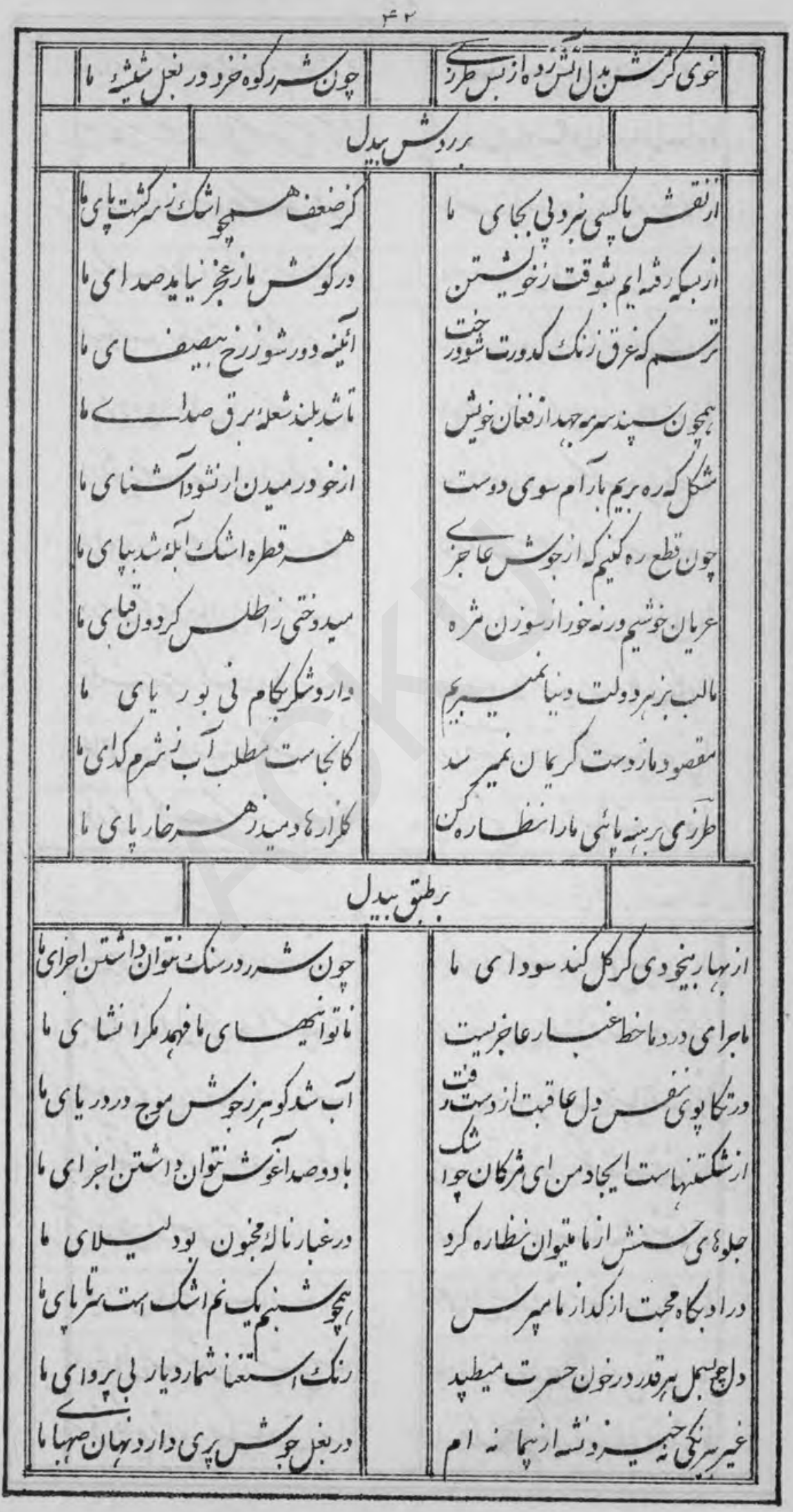


$r f$

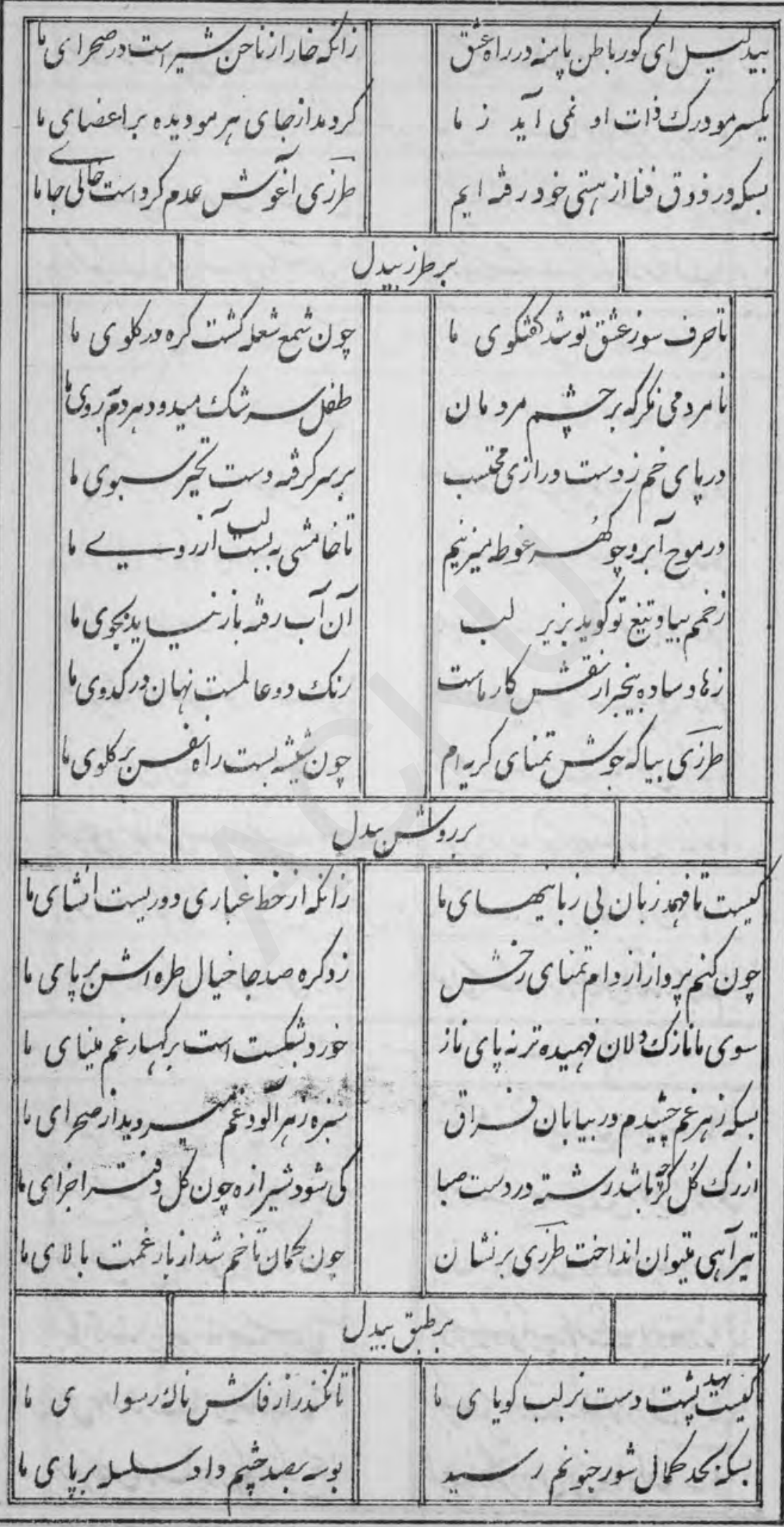




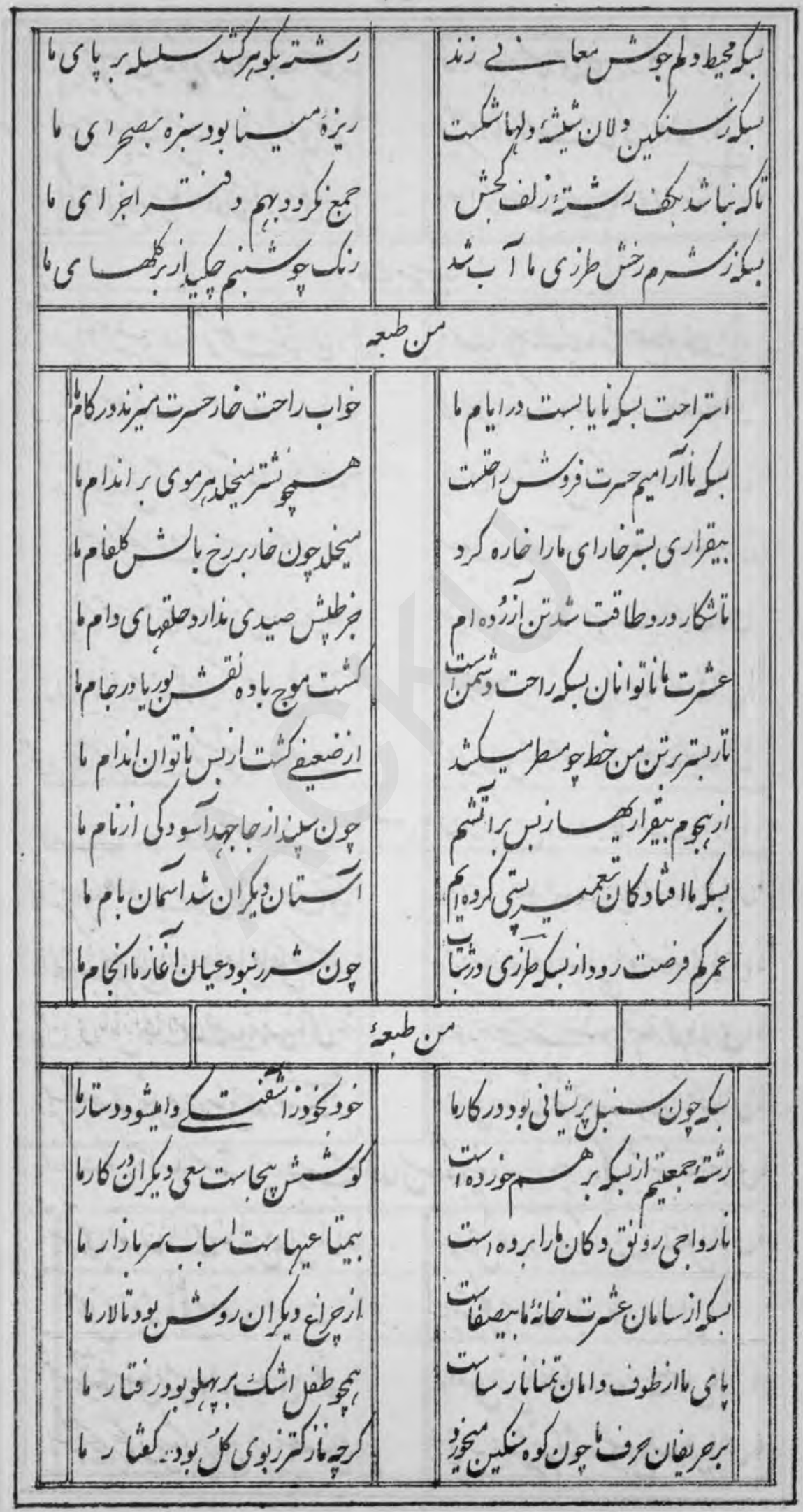




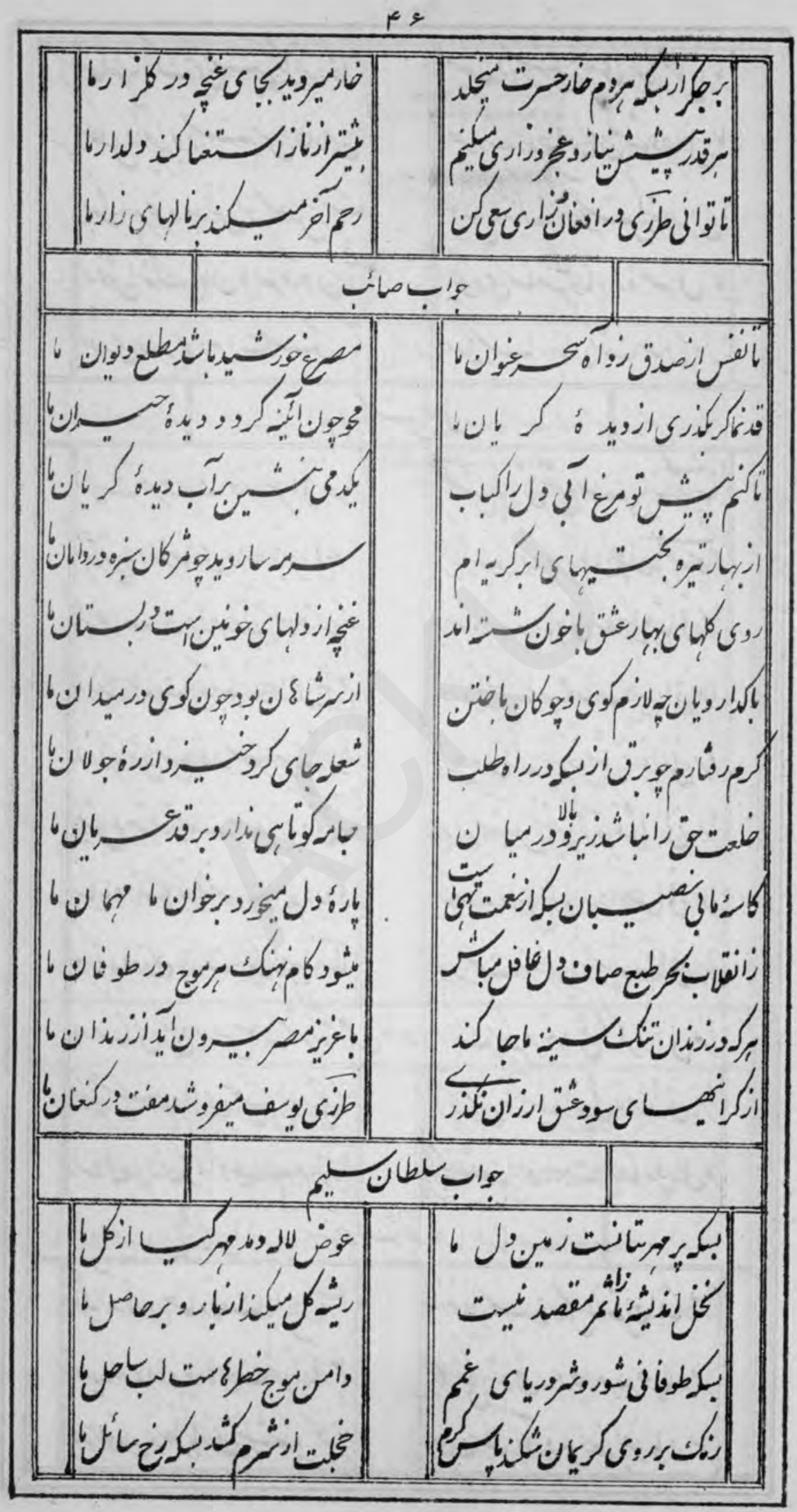


r v

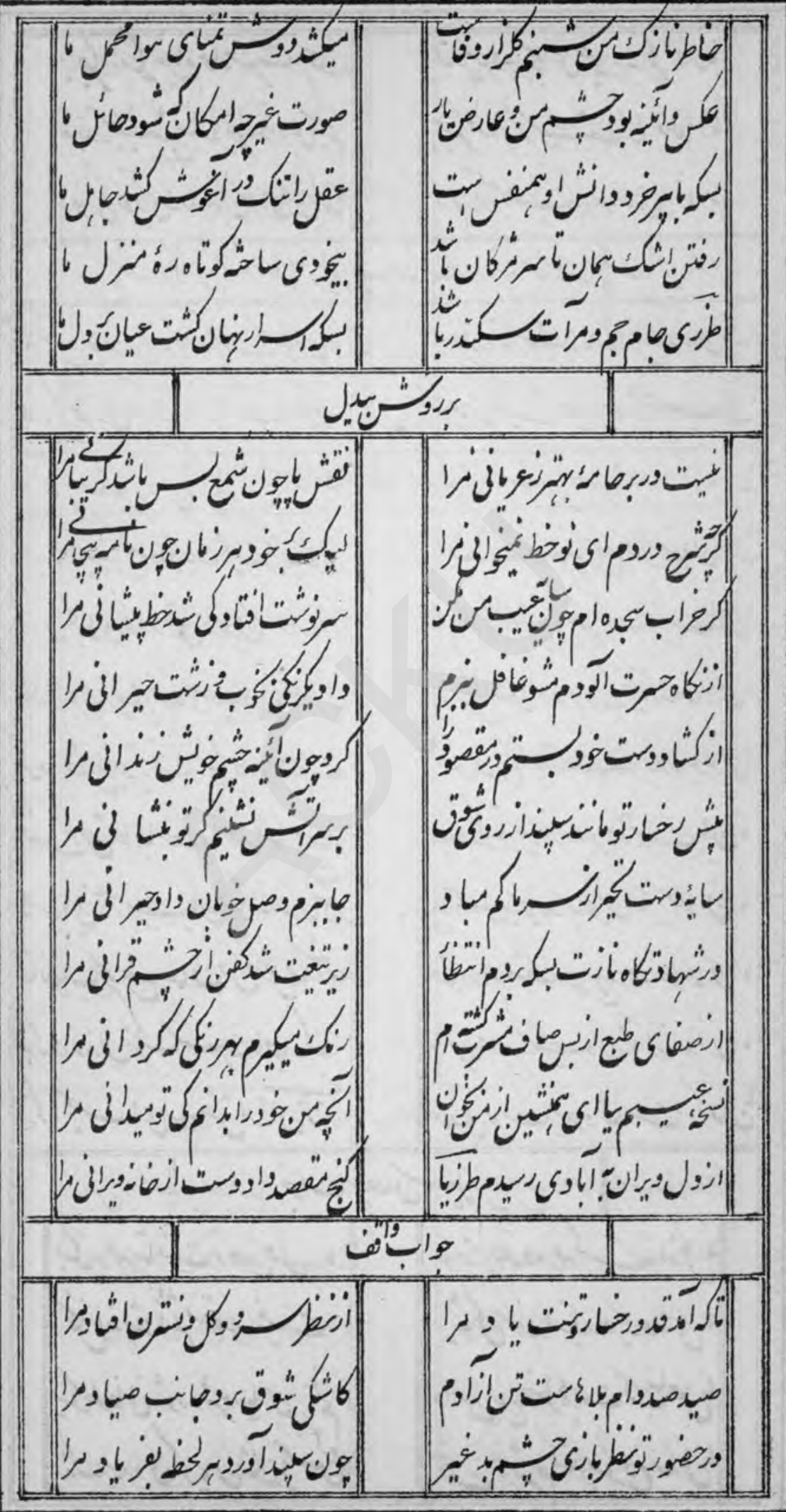


$F \wedge$

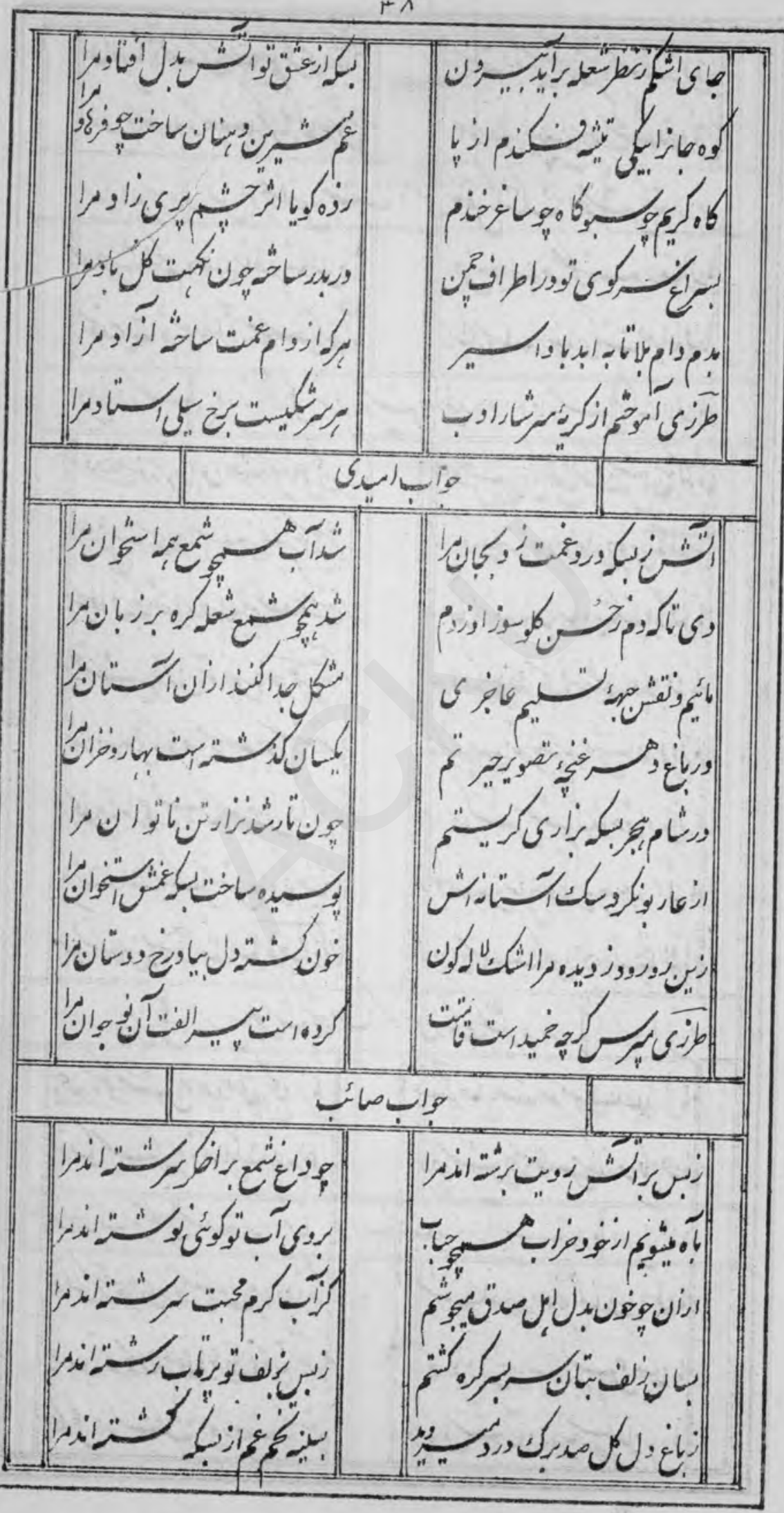


r. 4

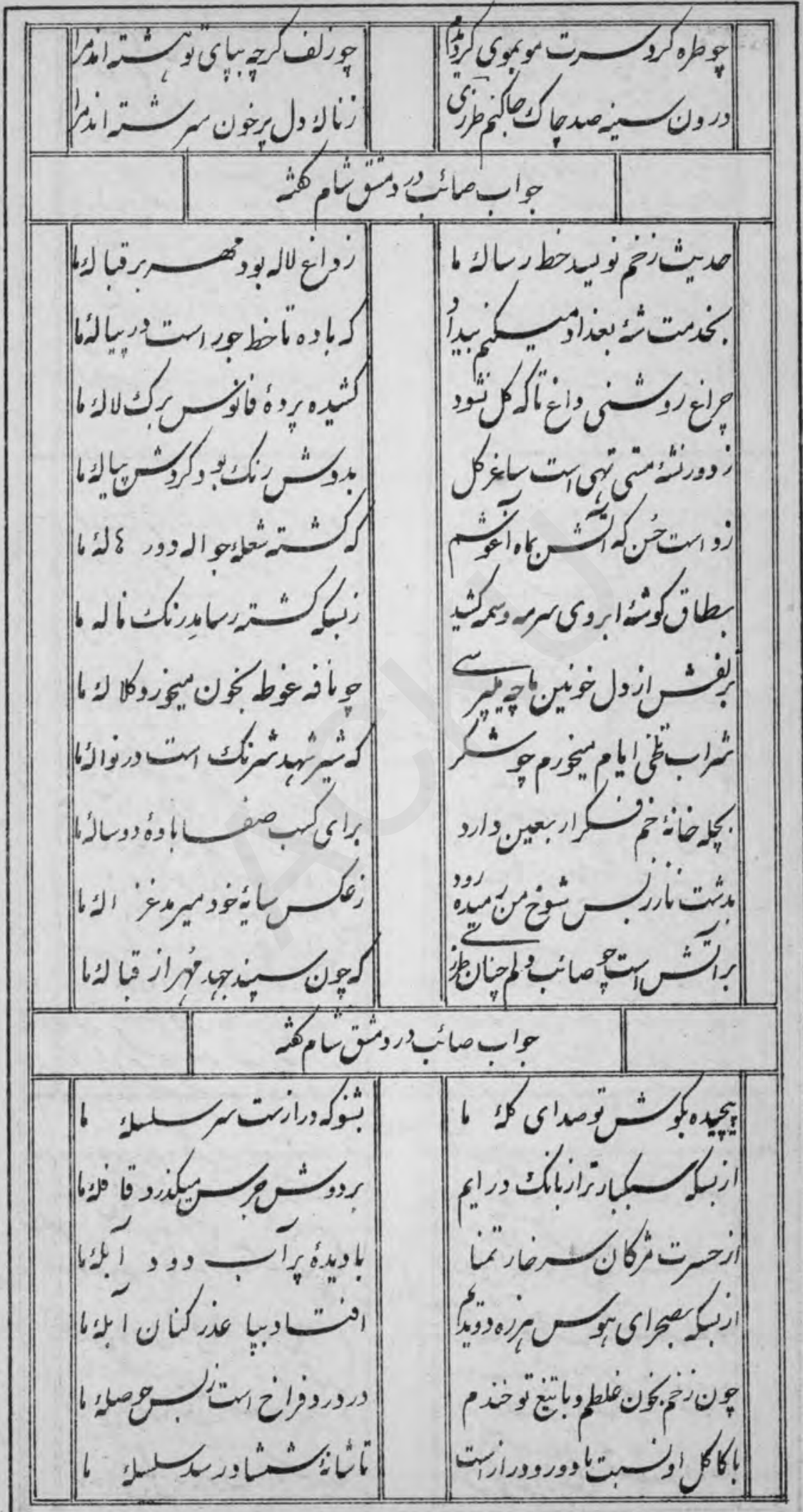


$\Delta$

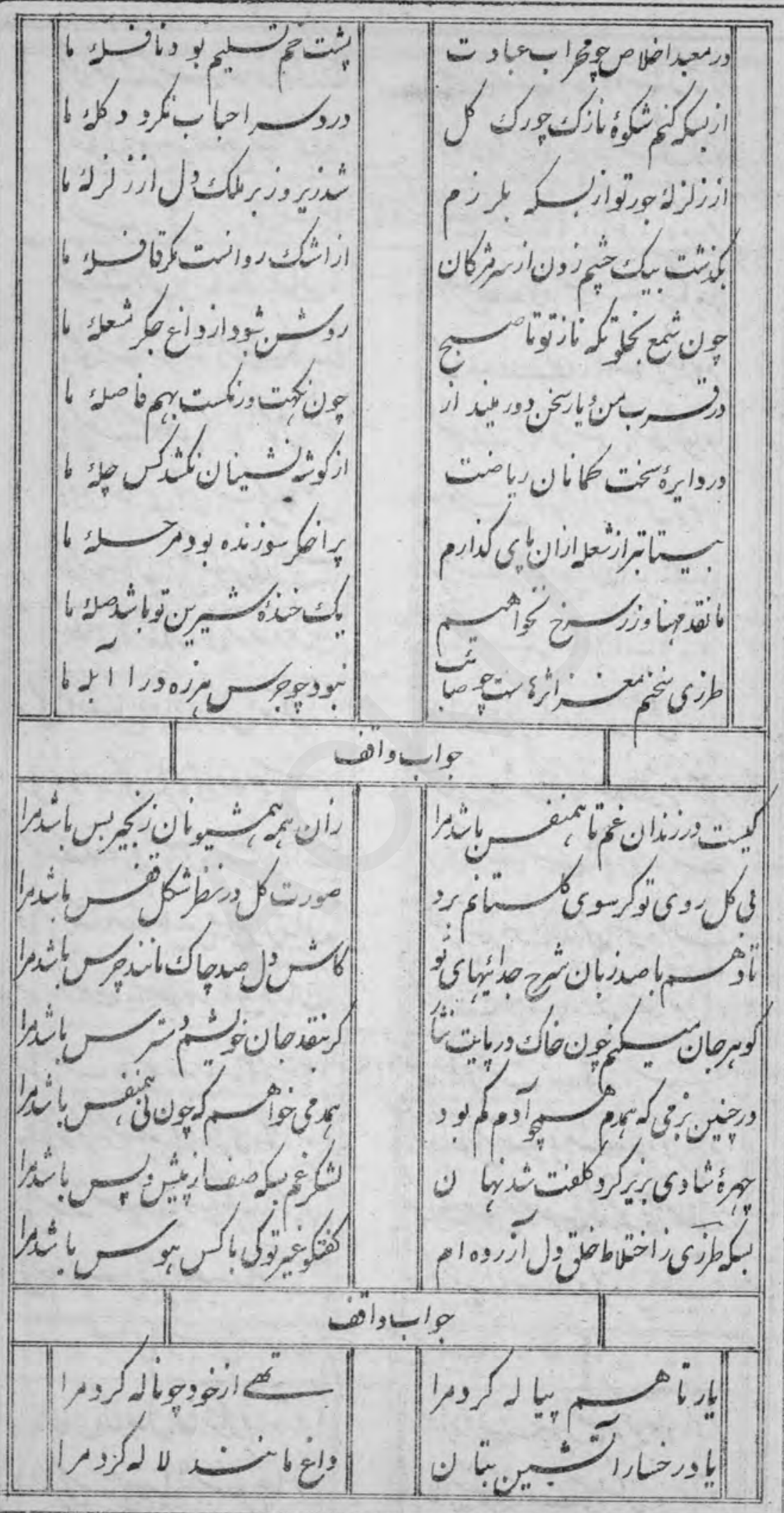


- 1

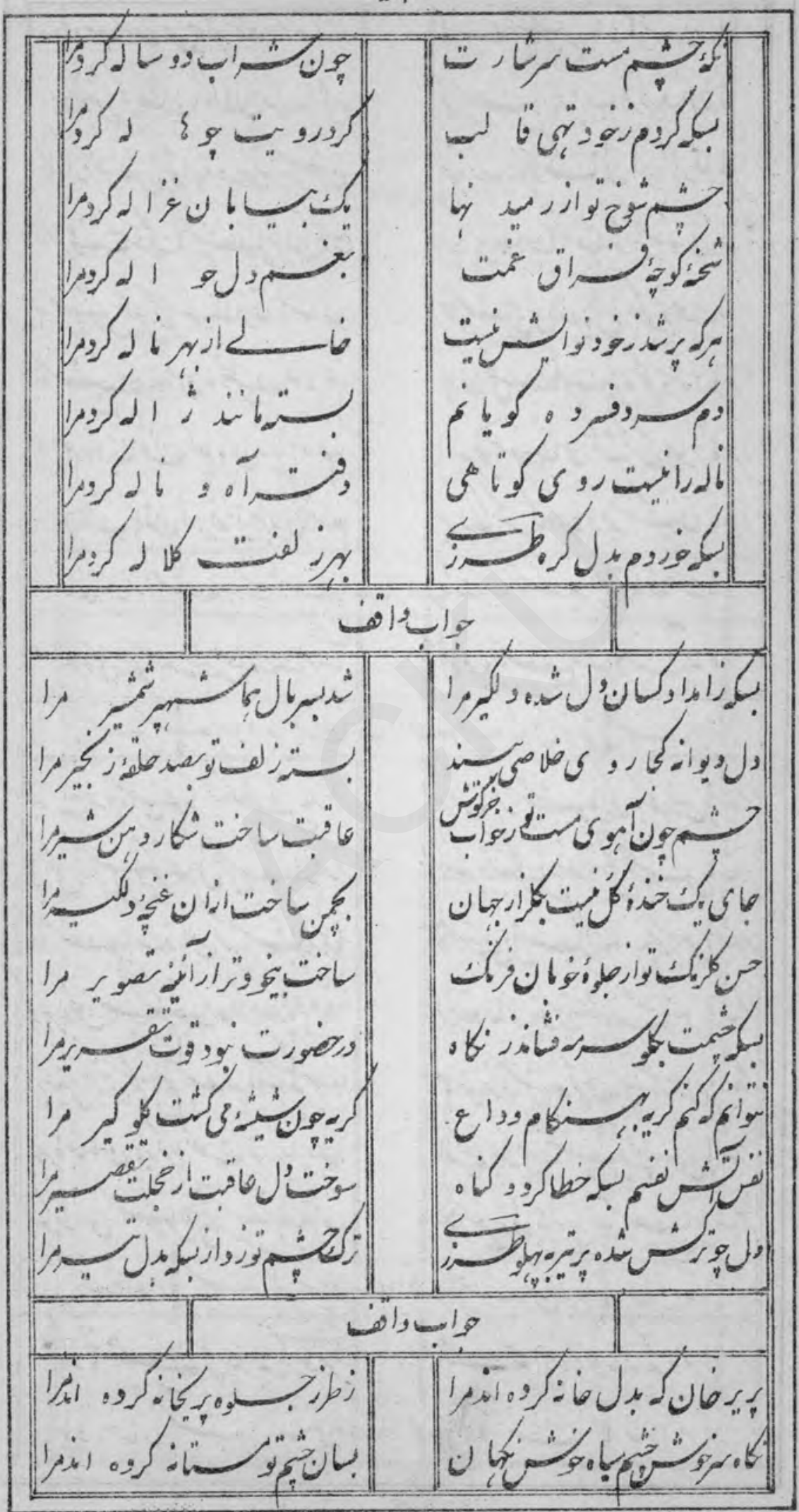


a $r$

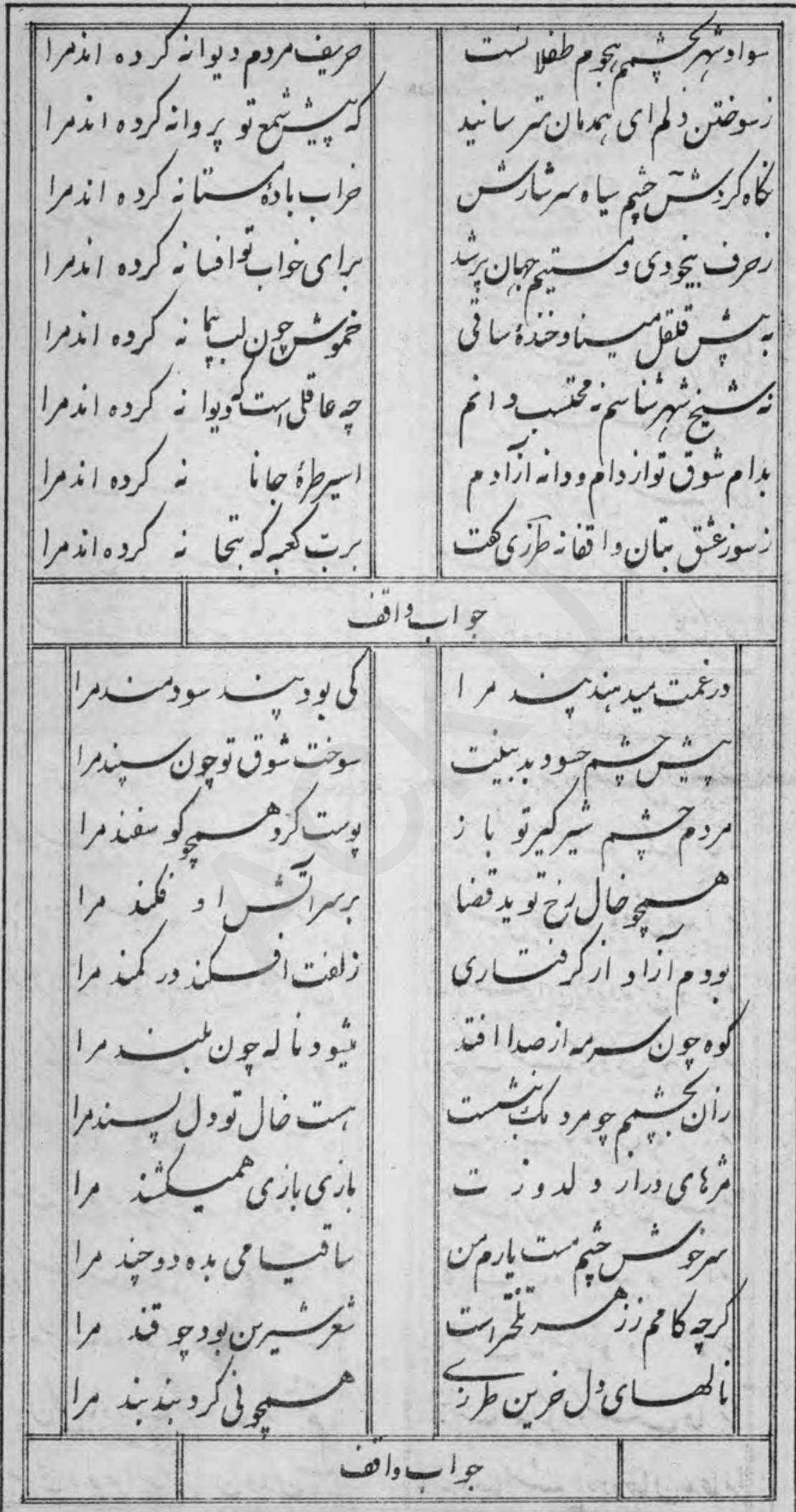


$0 r$

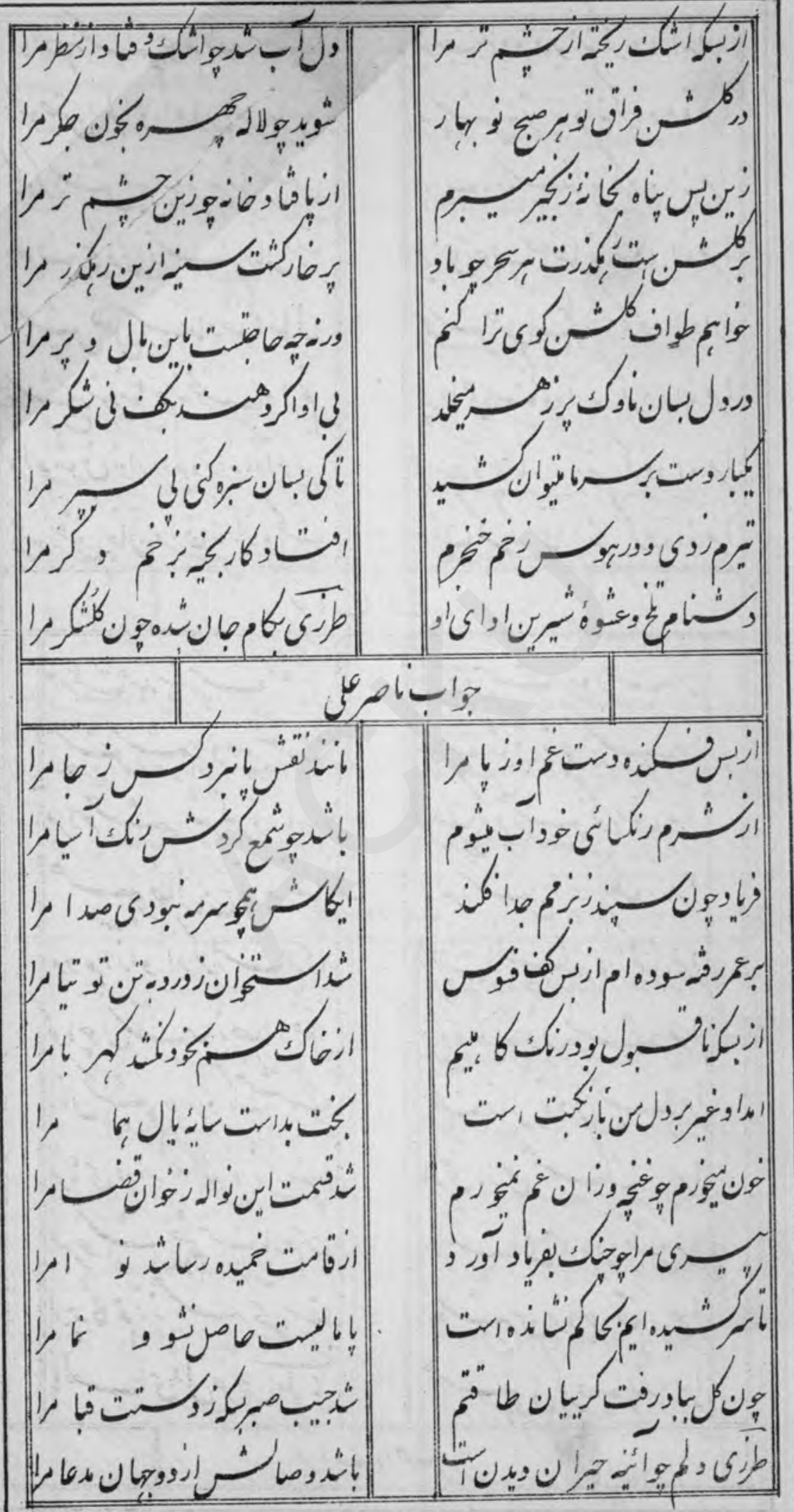


a k

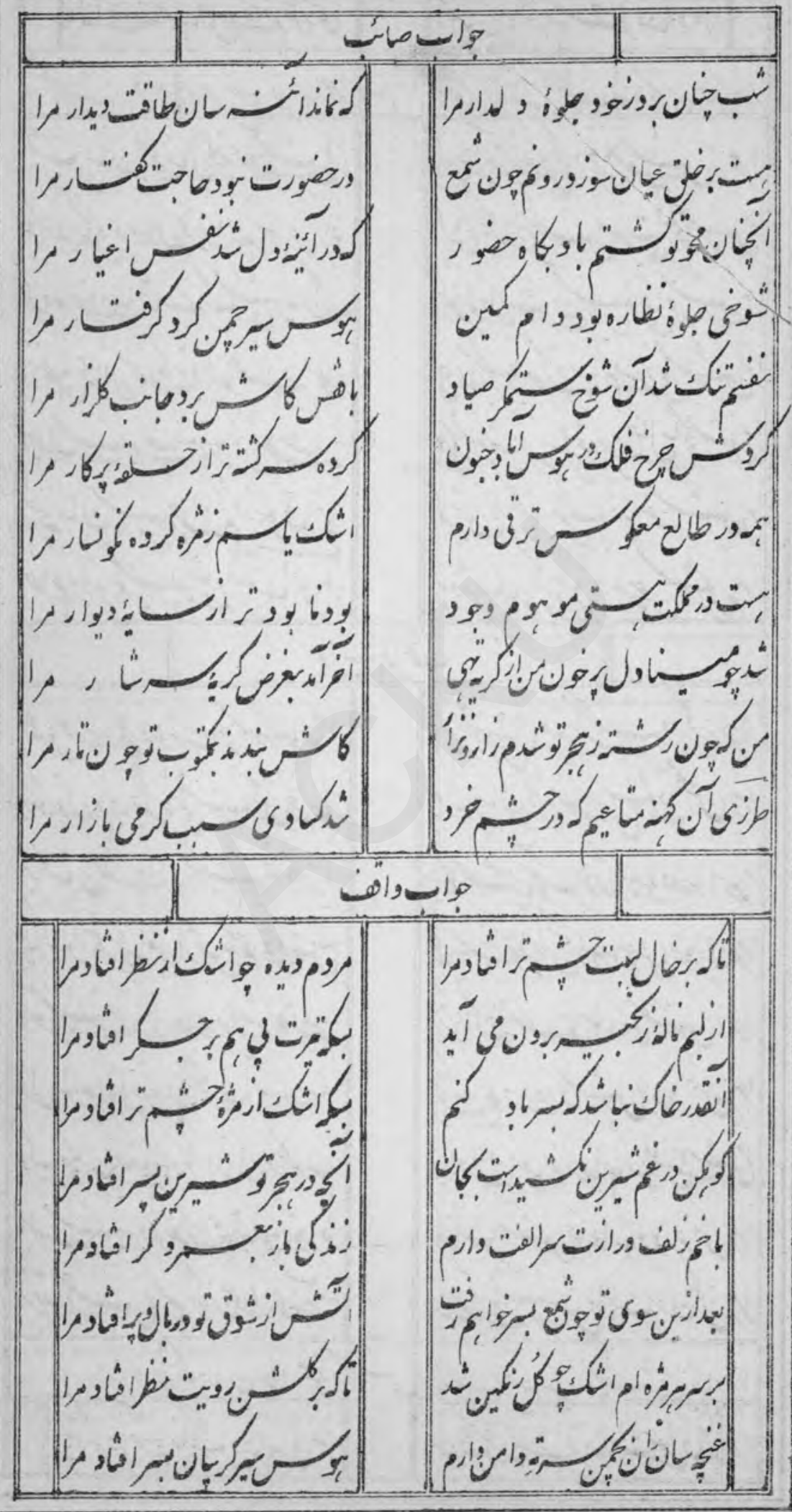




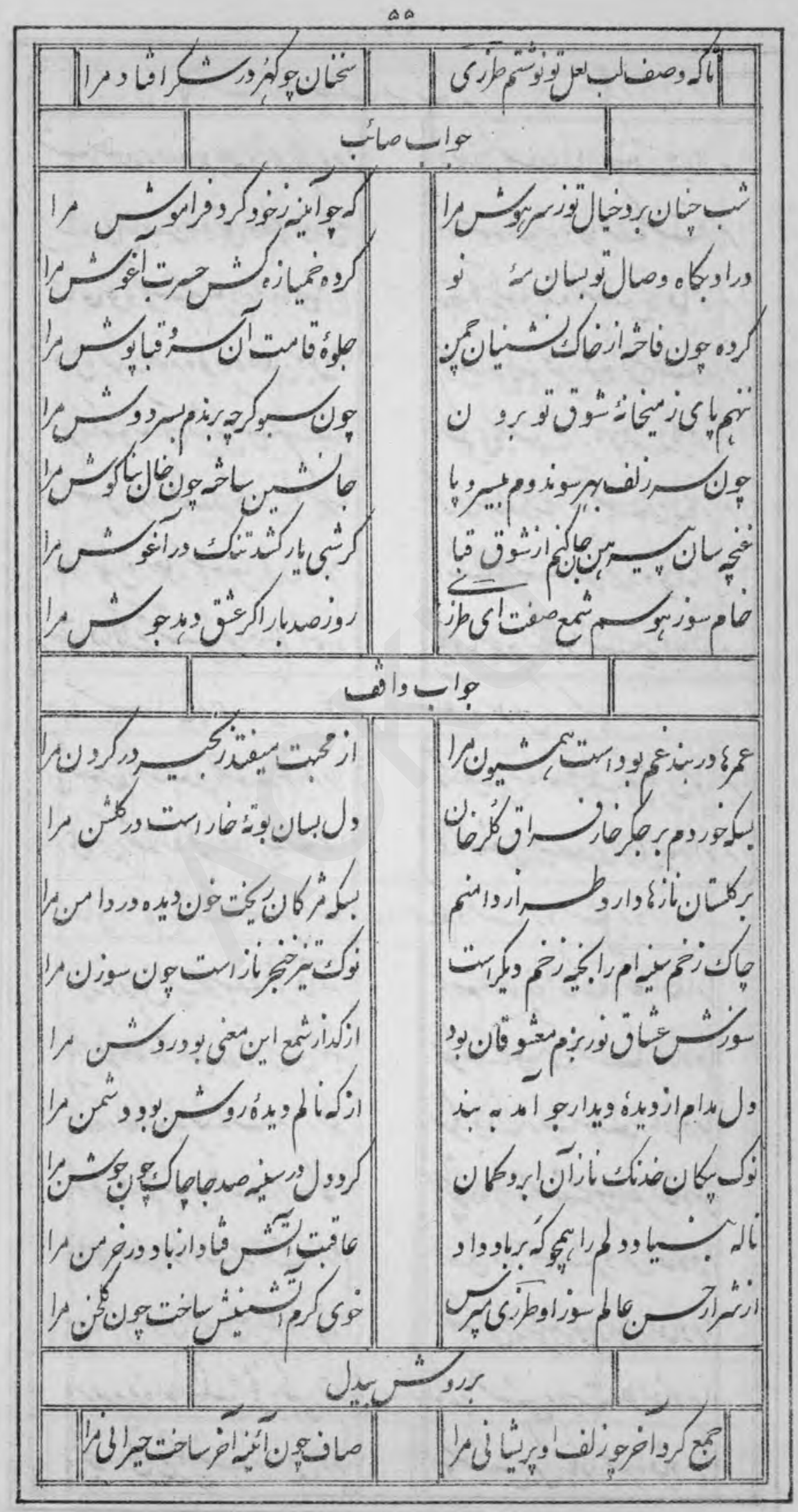


05

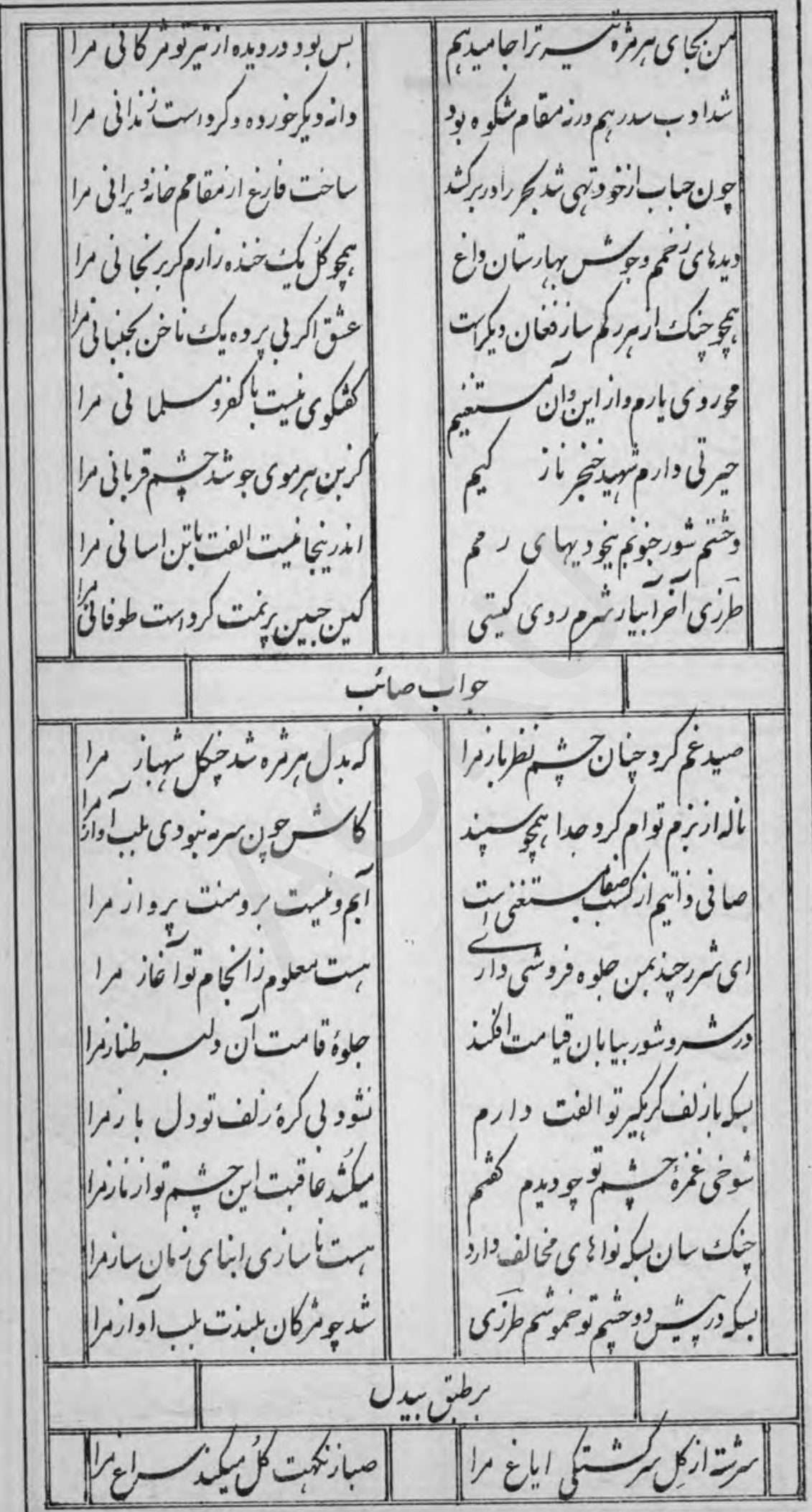


$\Delta \quad$ r

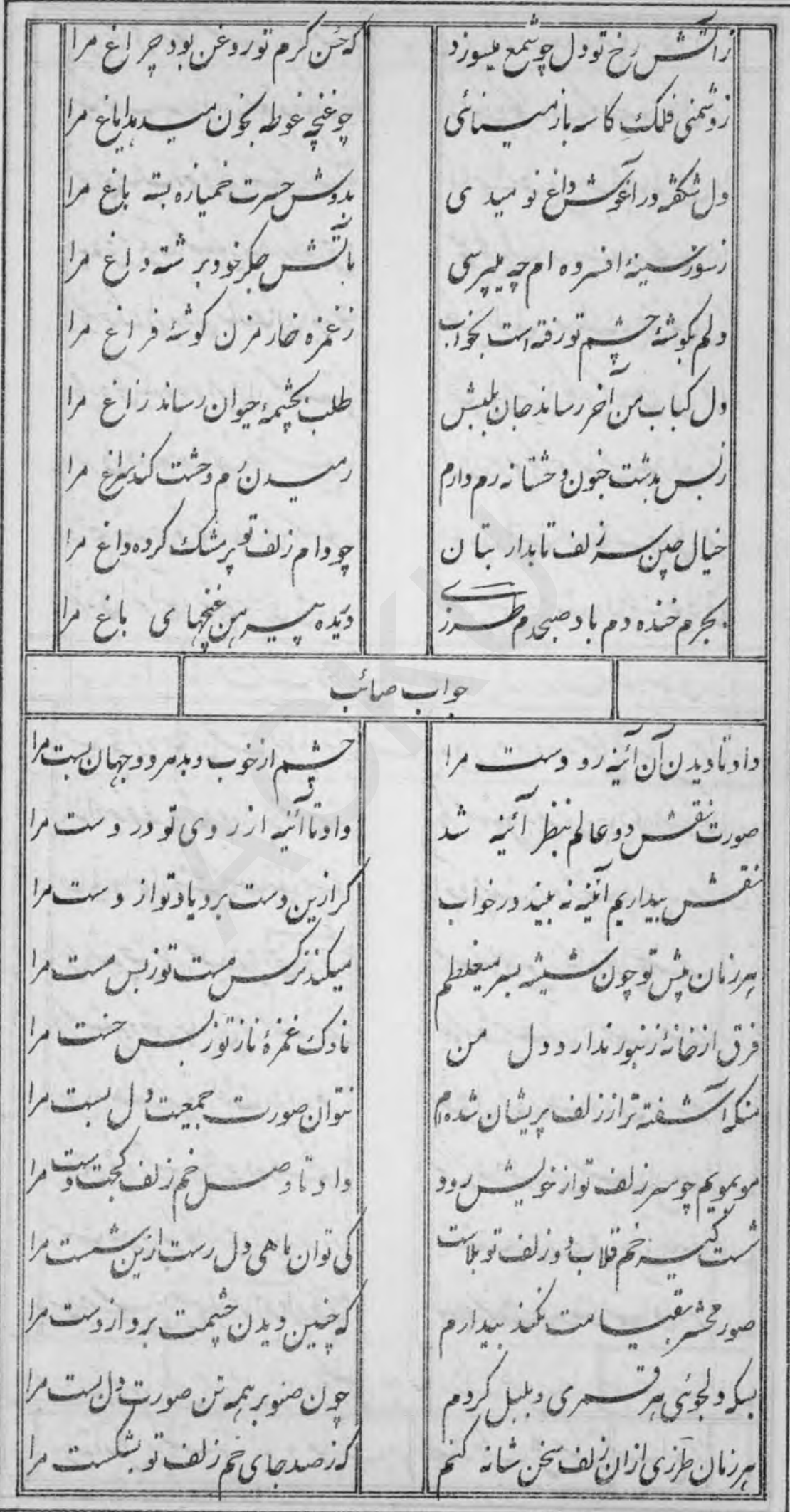




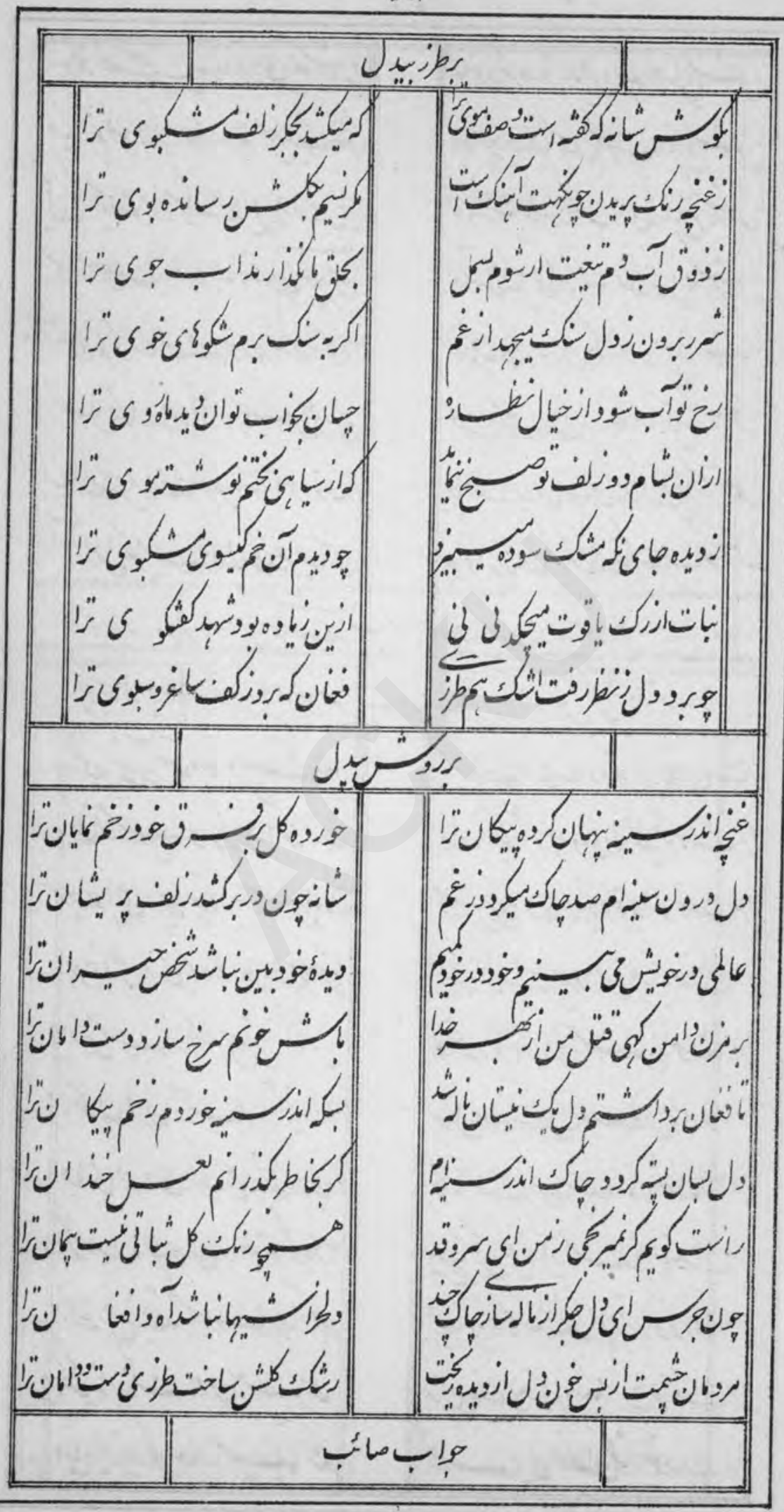


64

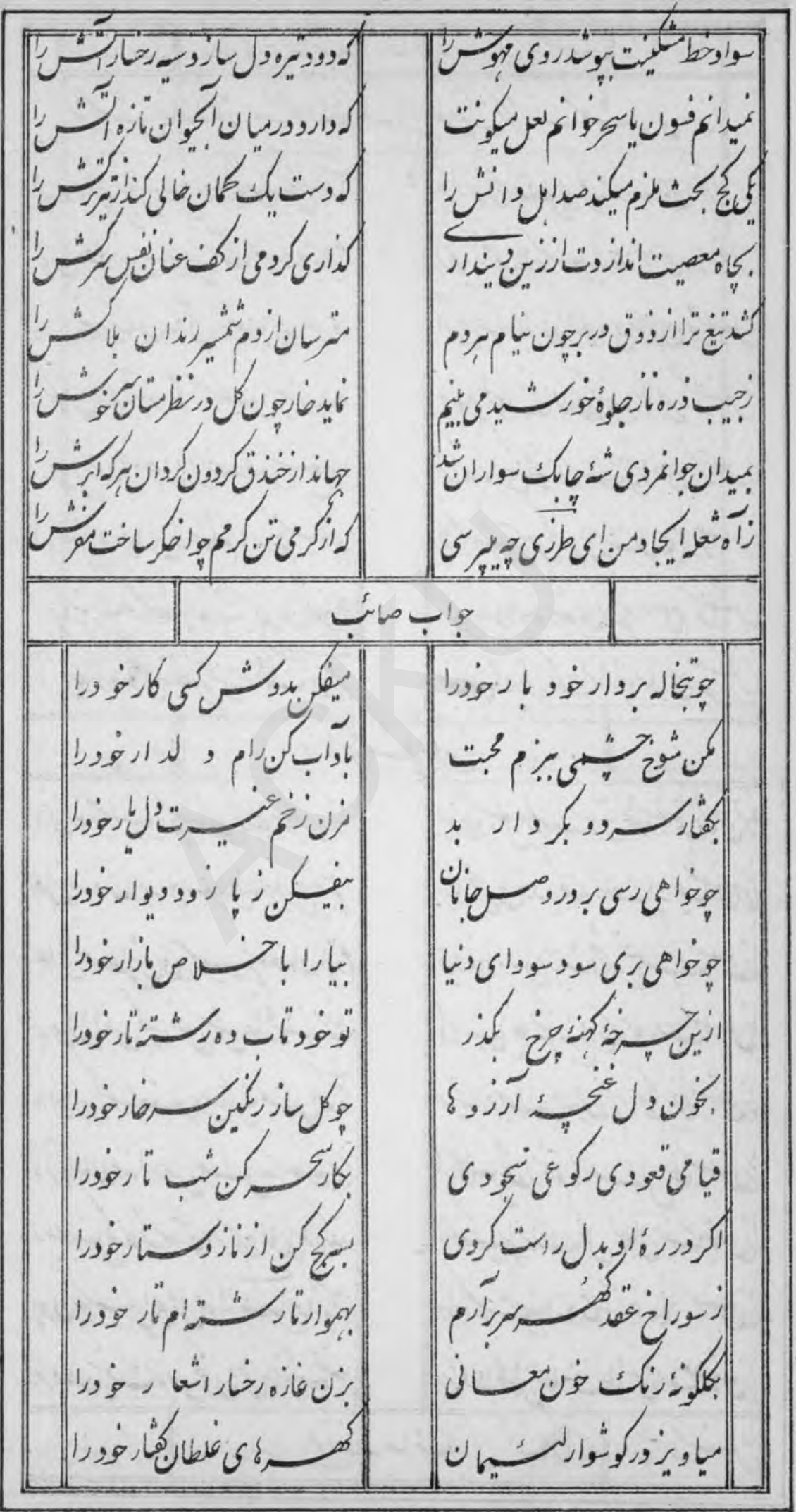


s,

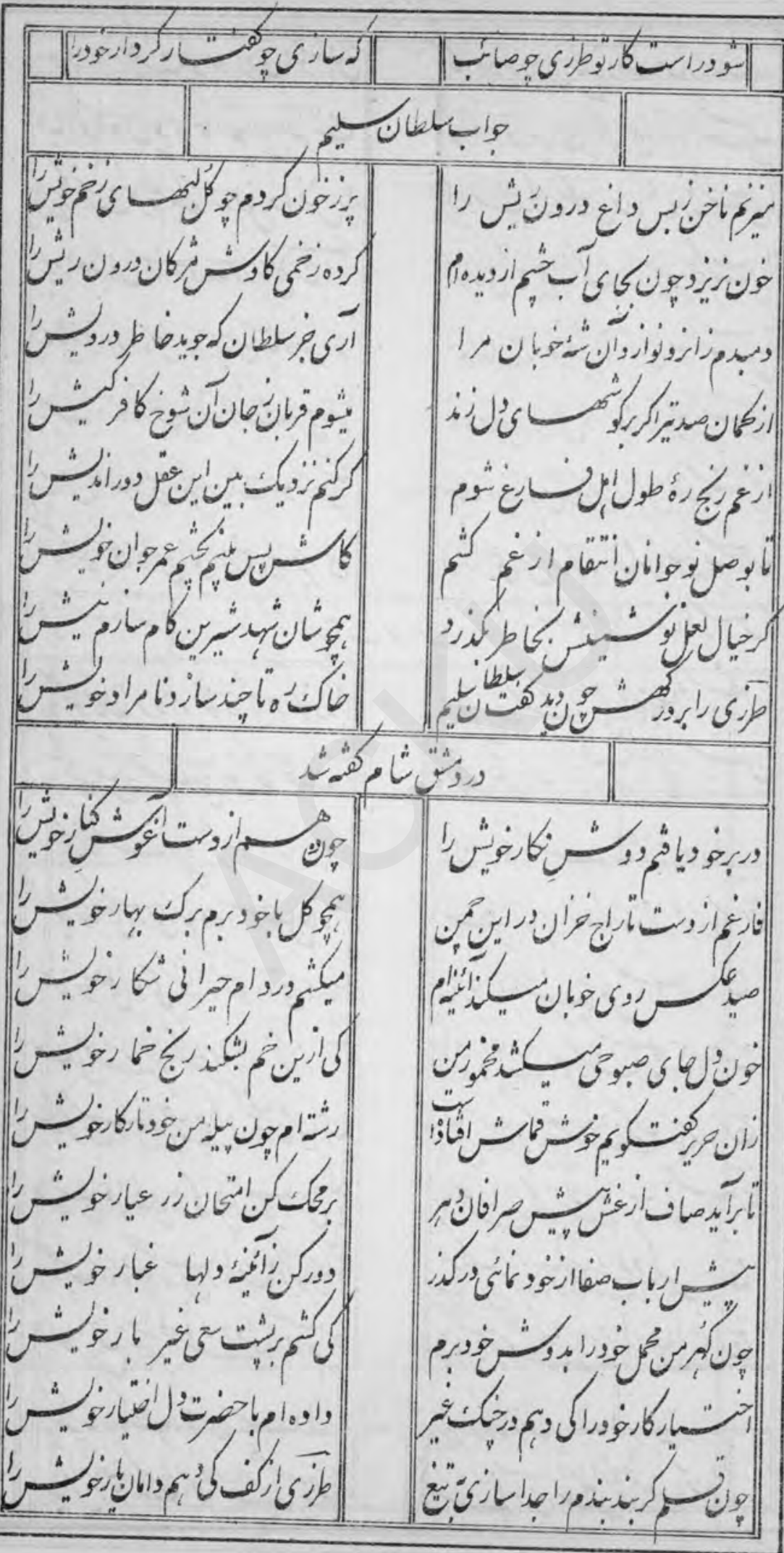


s 1

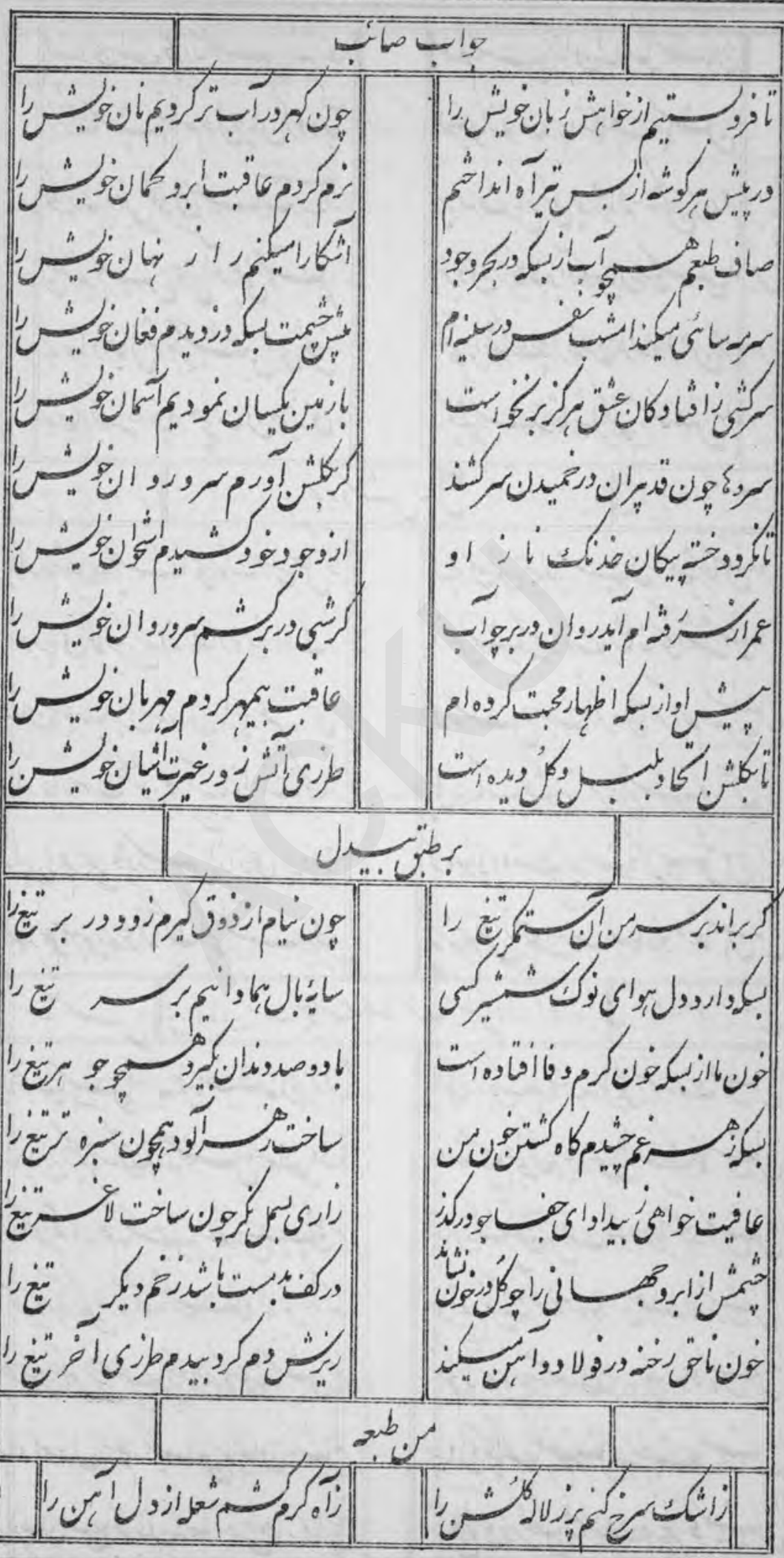


s r

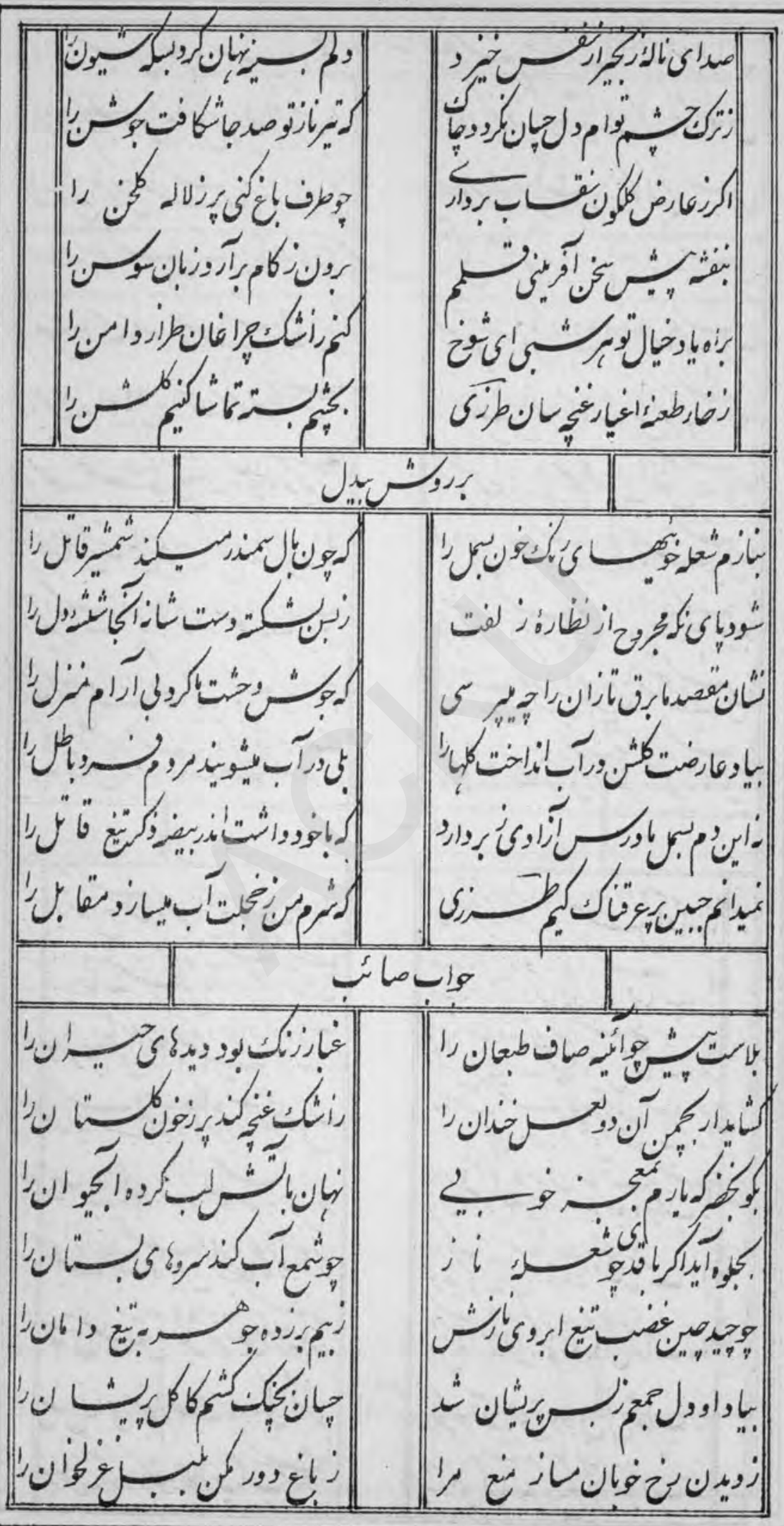




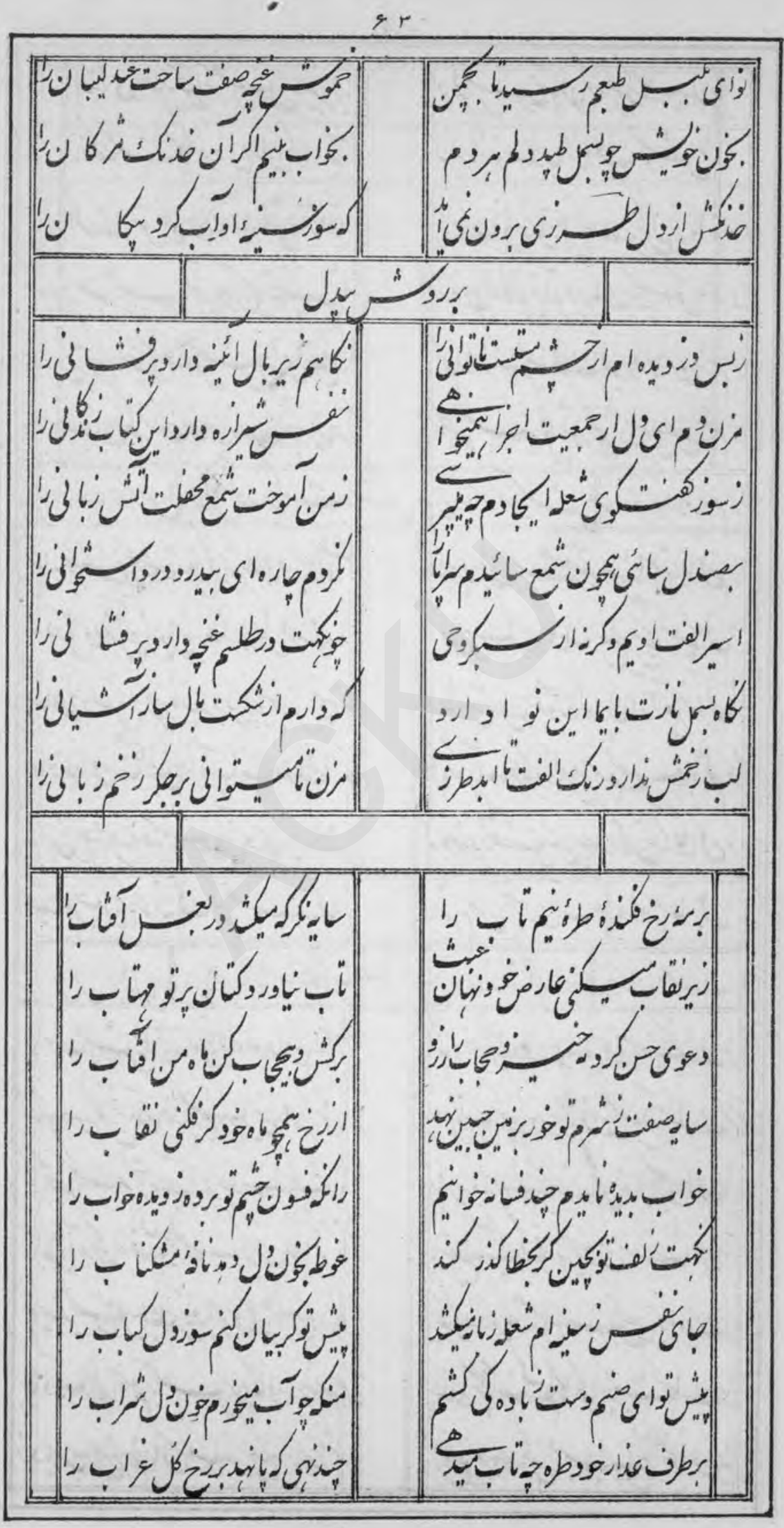


$5 t^{5}$

$\mid$ |




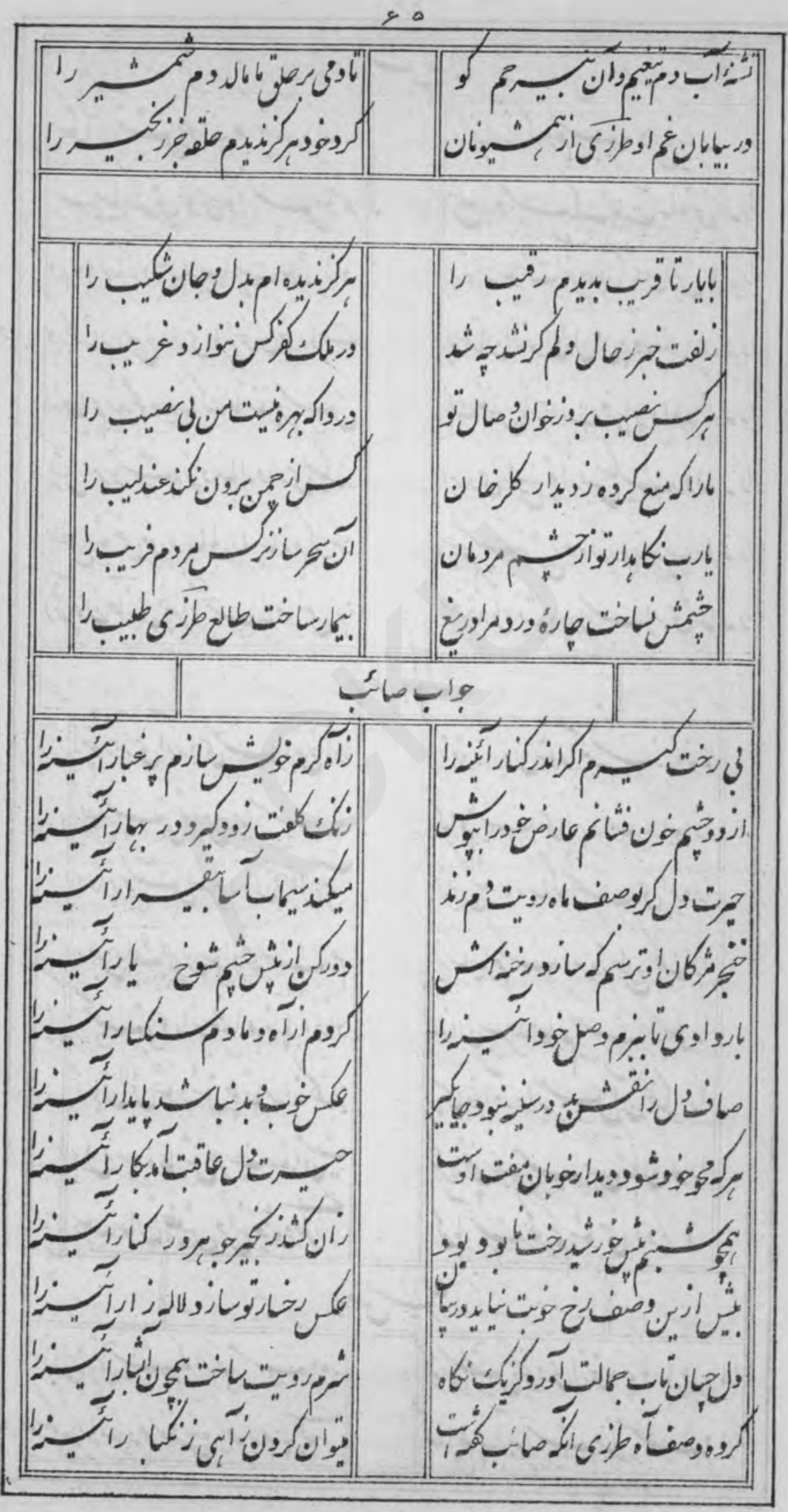


\&5

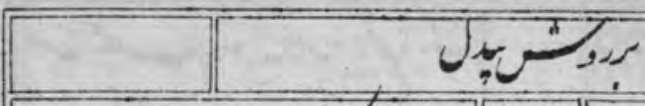

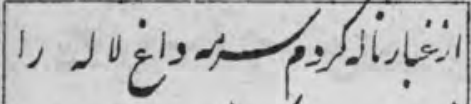

ثै

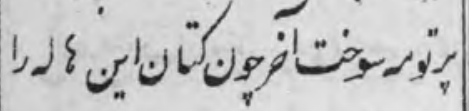

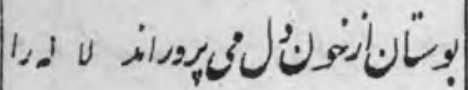

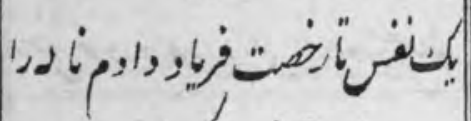

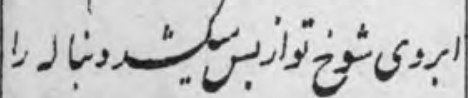

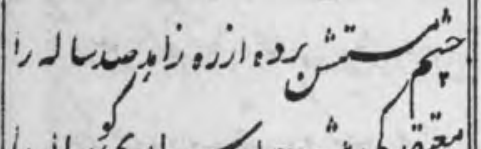

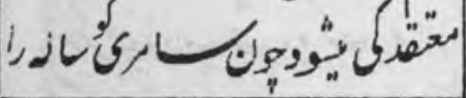

|

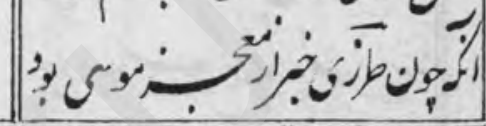

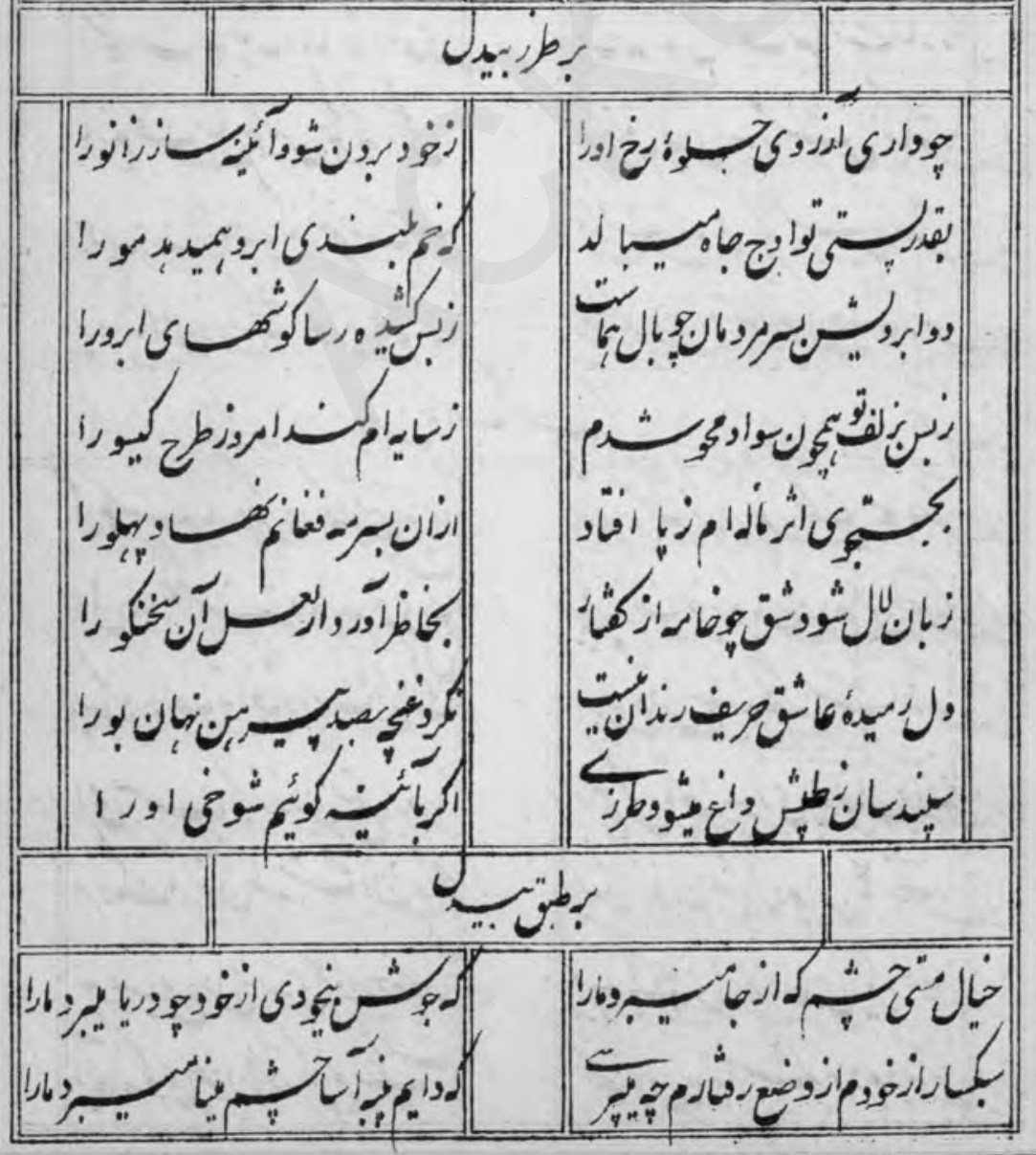


\& 6

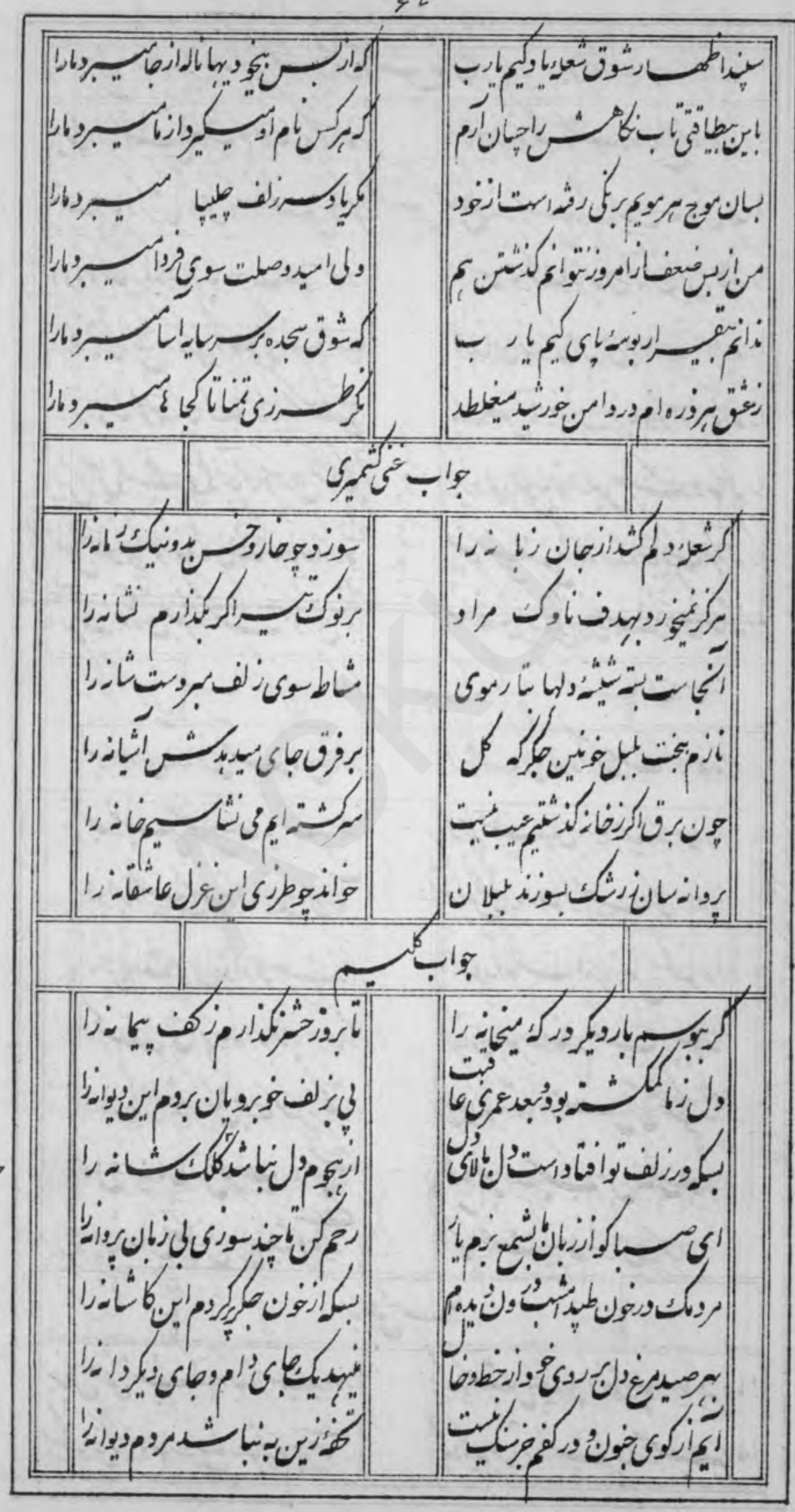


Gn

||




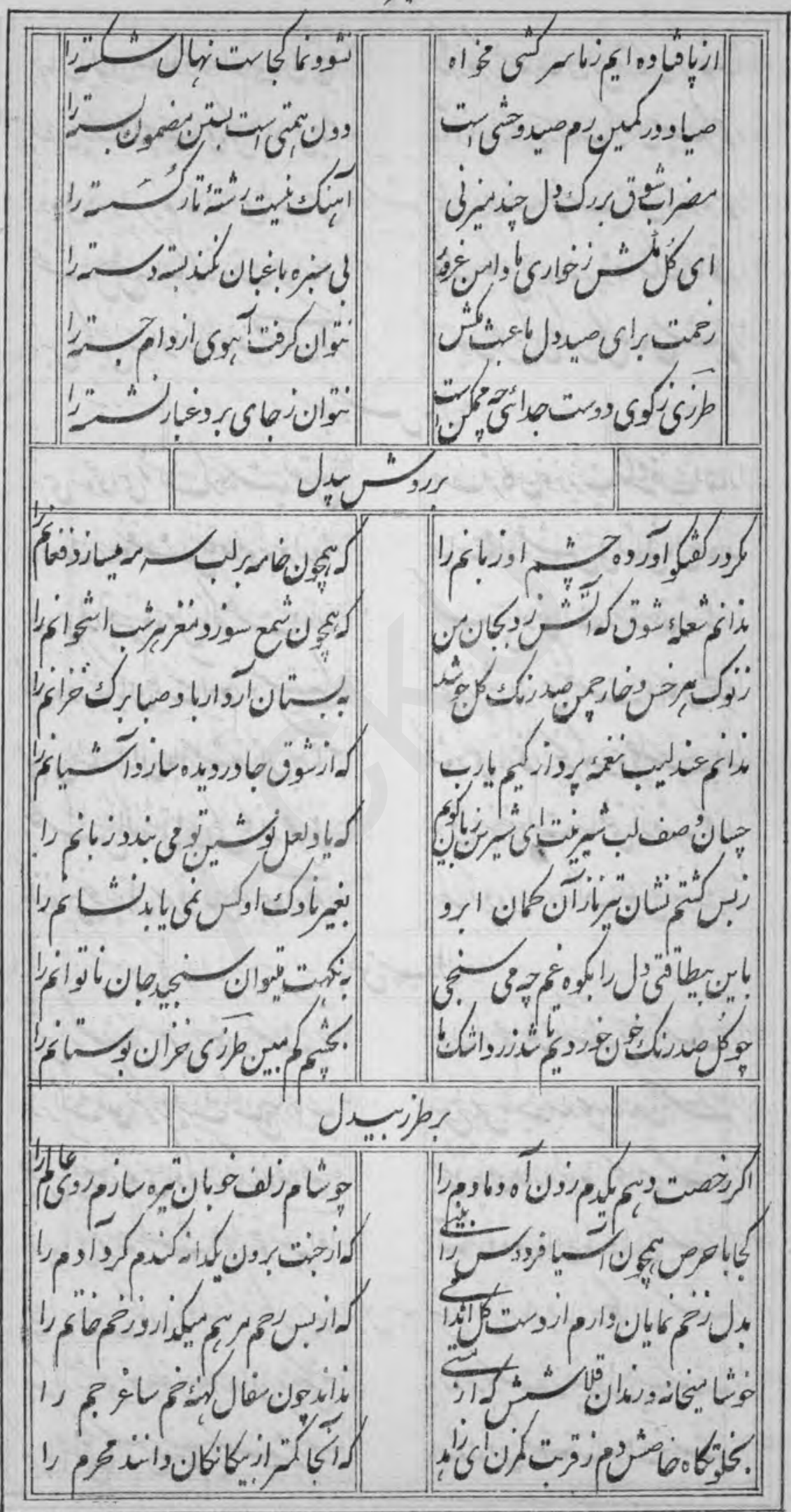


L.

$\mid$


41

|




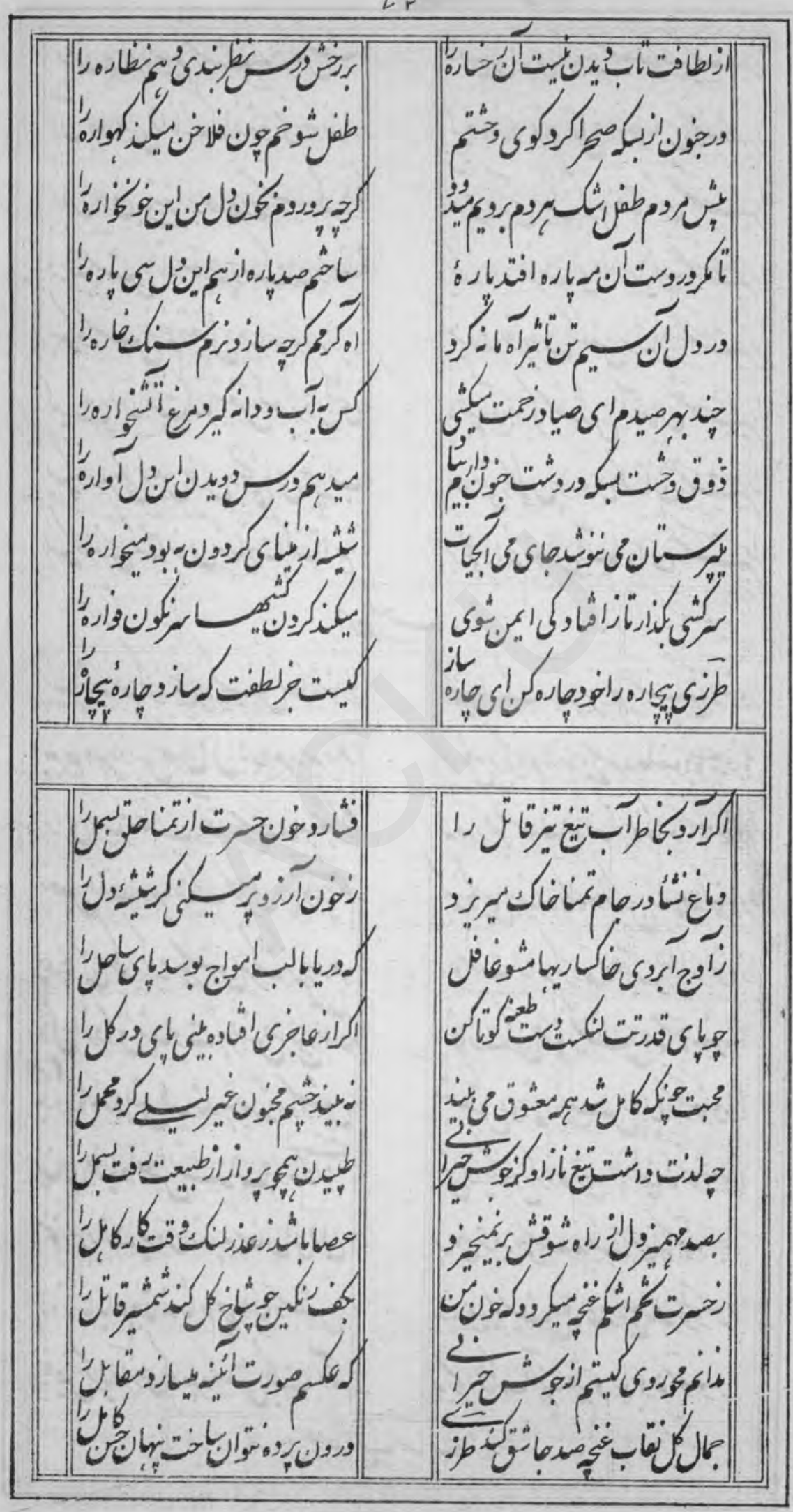


$\checkmark r$

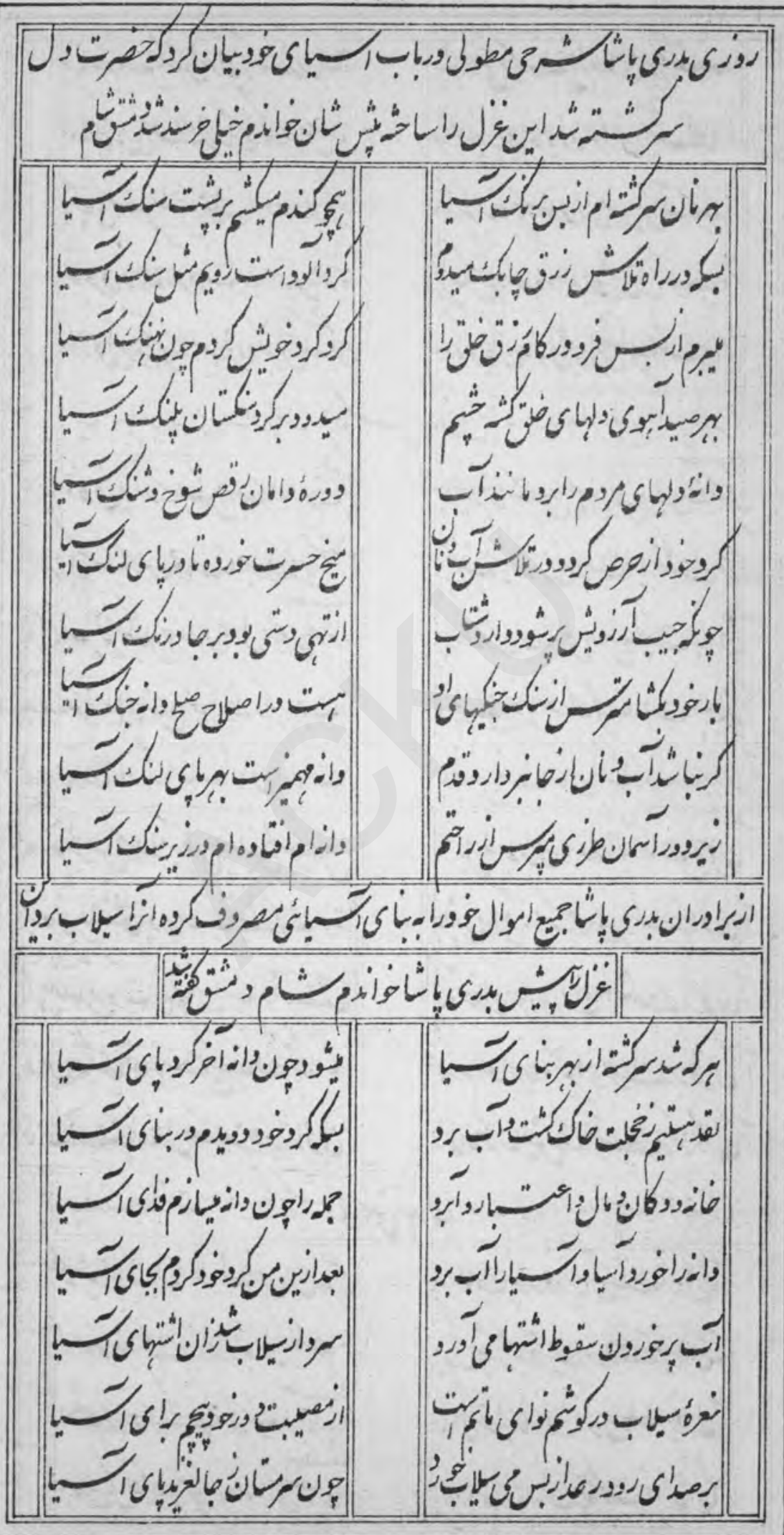


LF

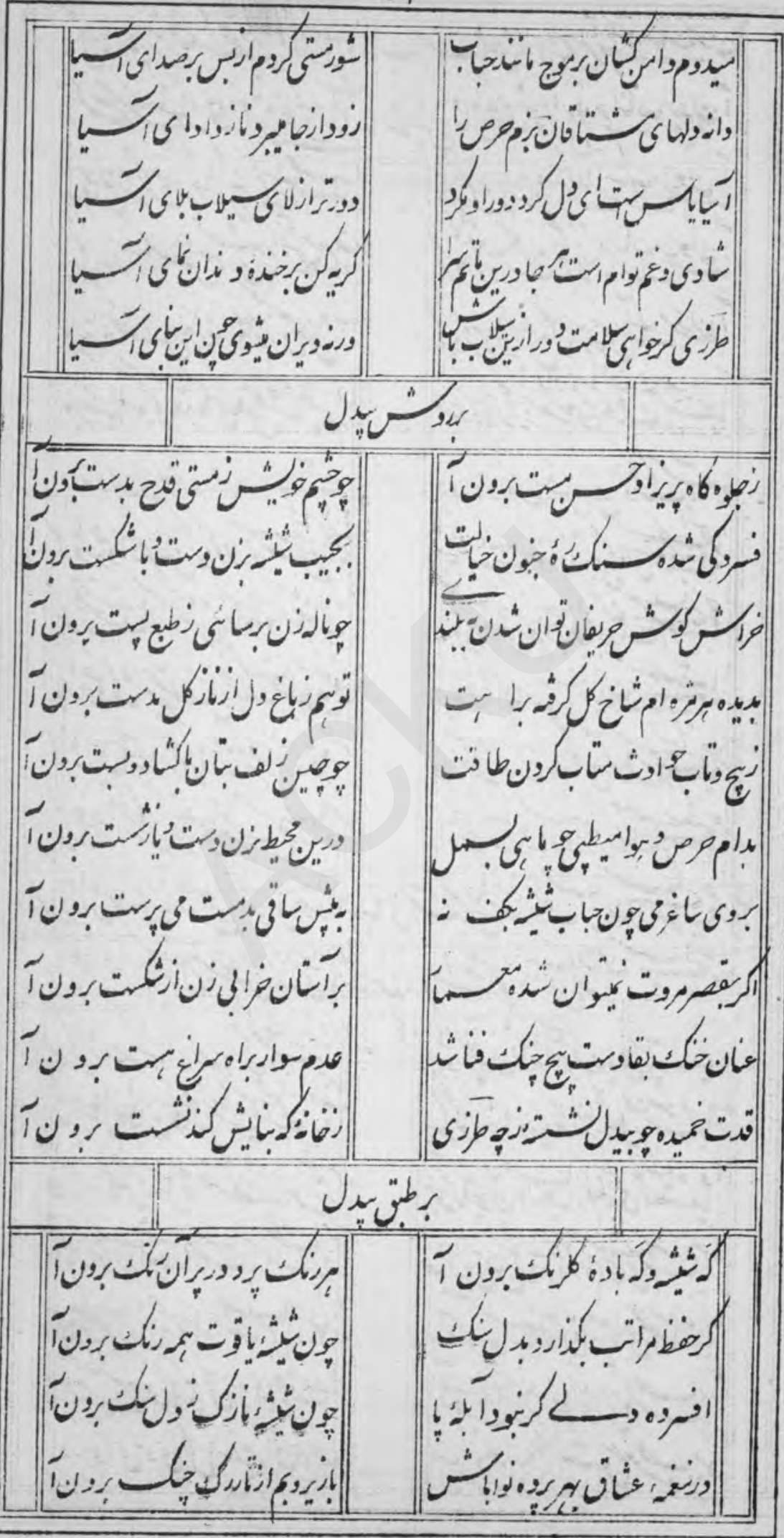


$\angle A$

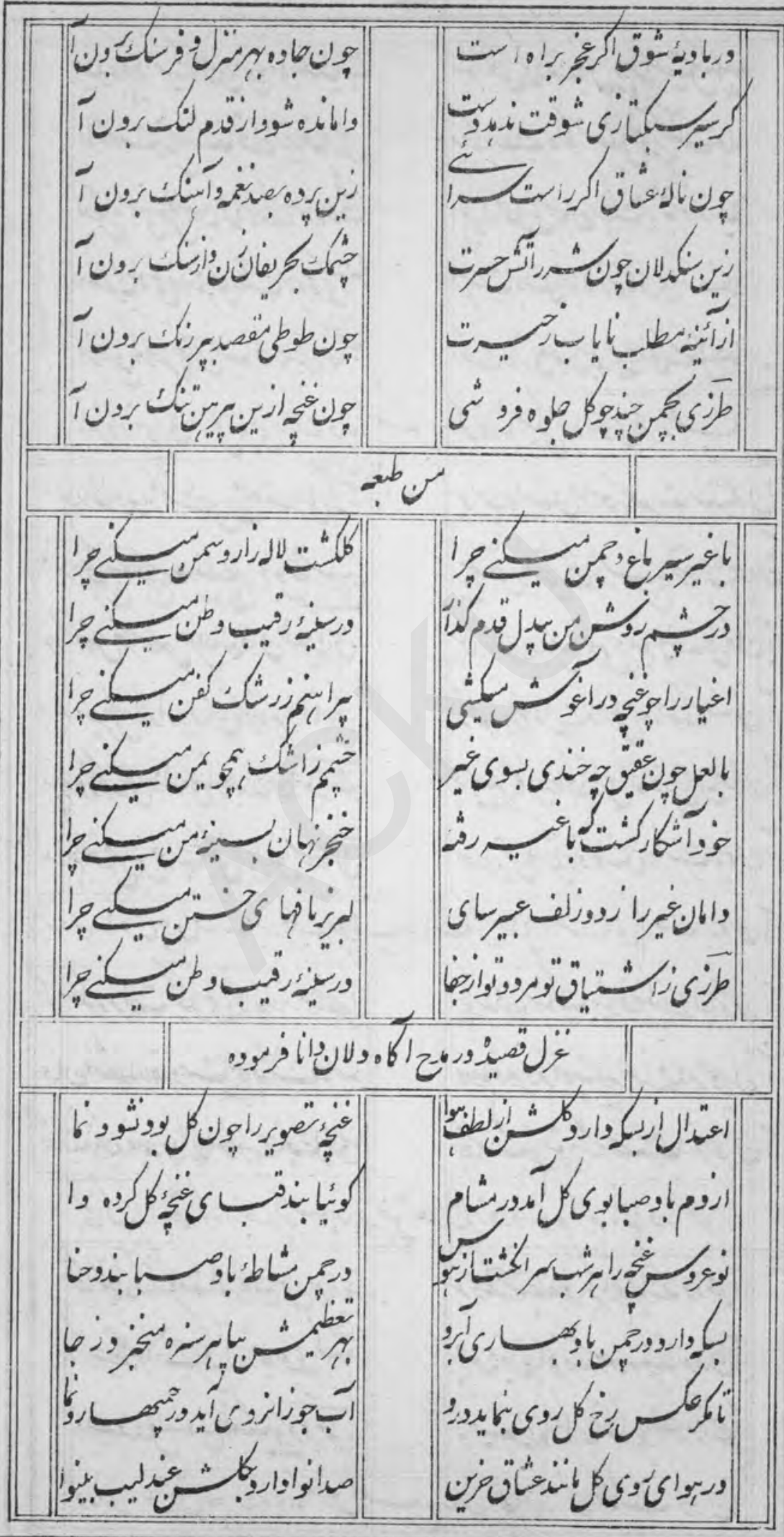


Ve

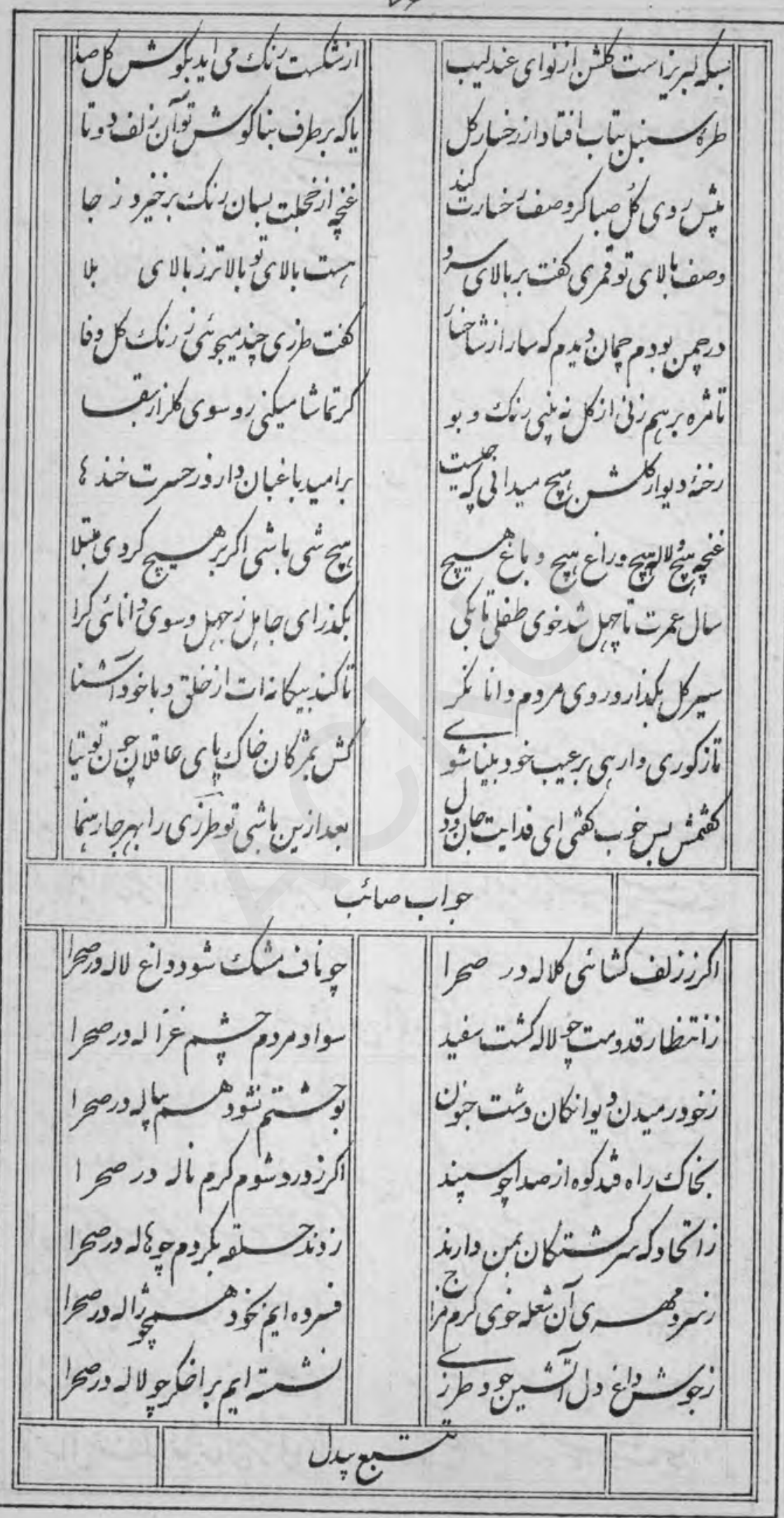




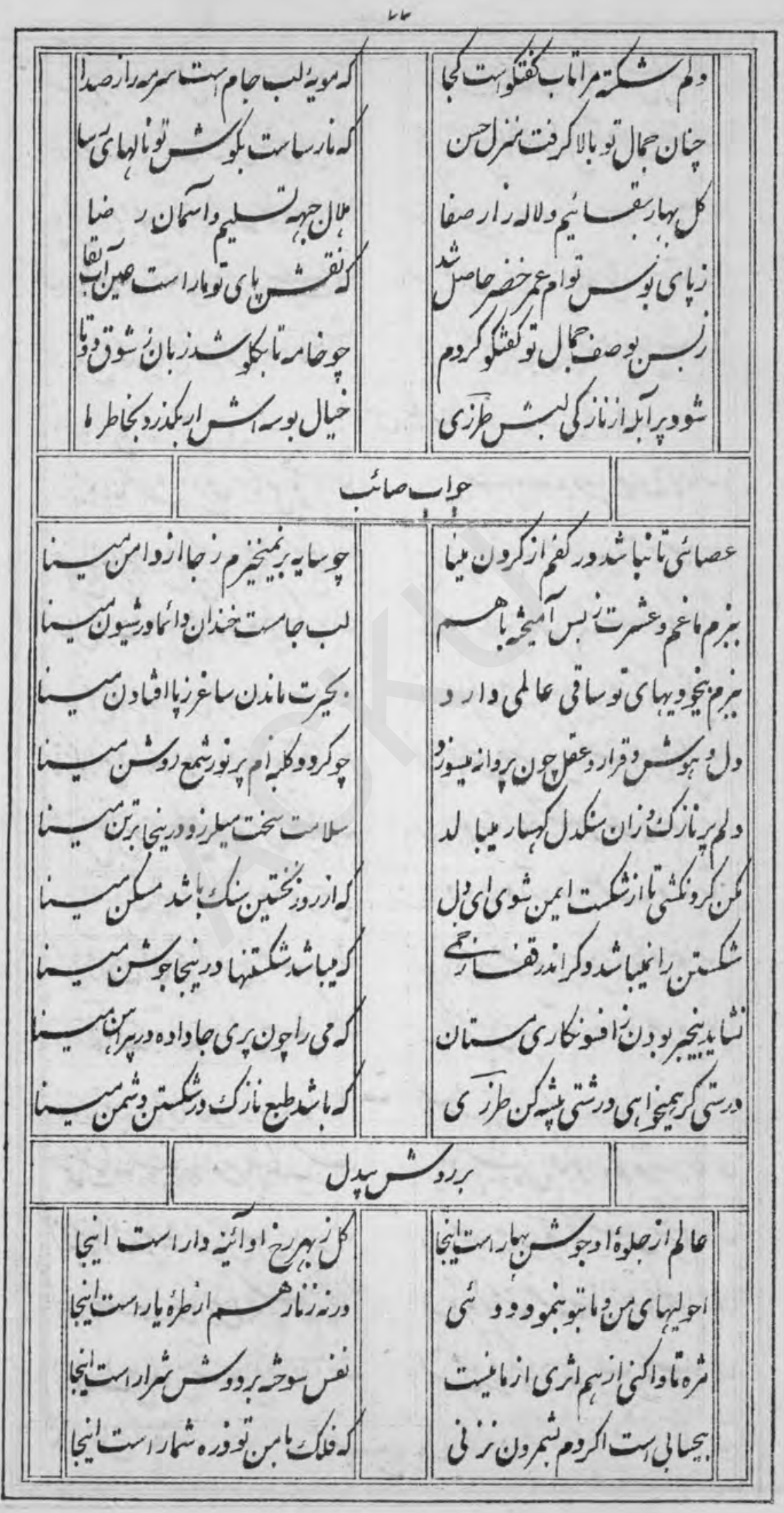


VA

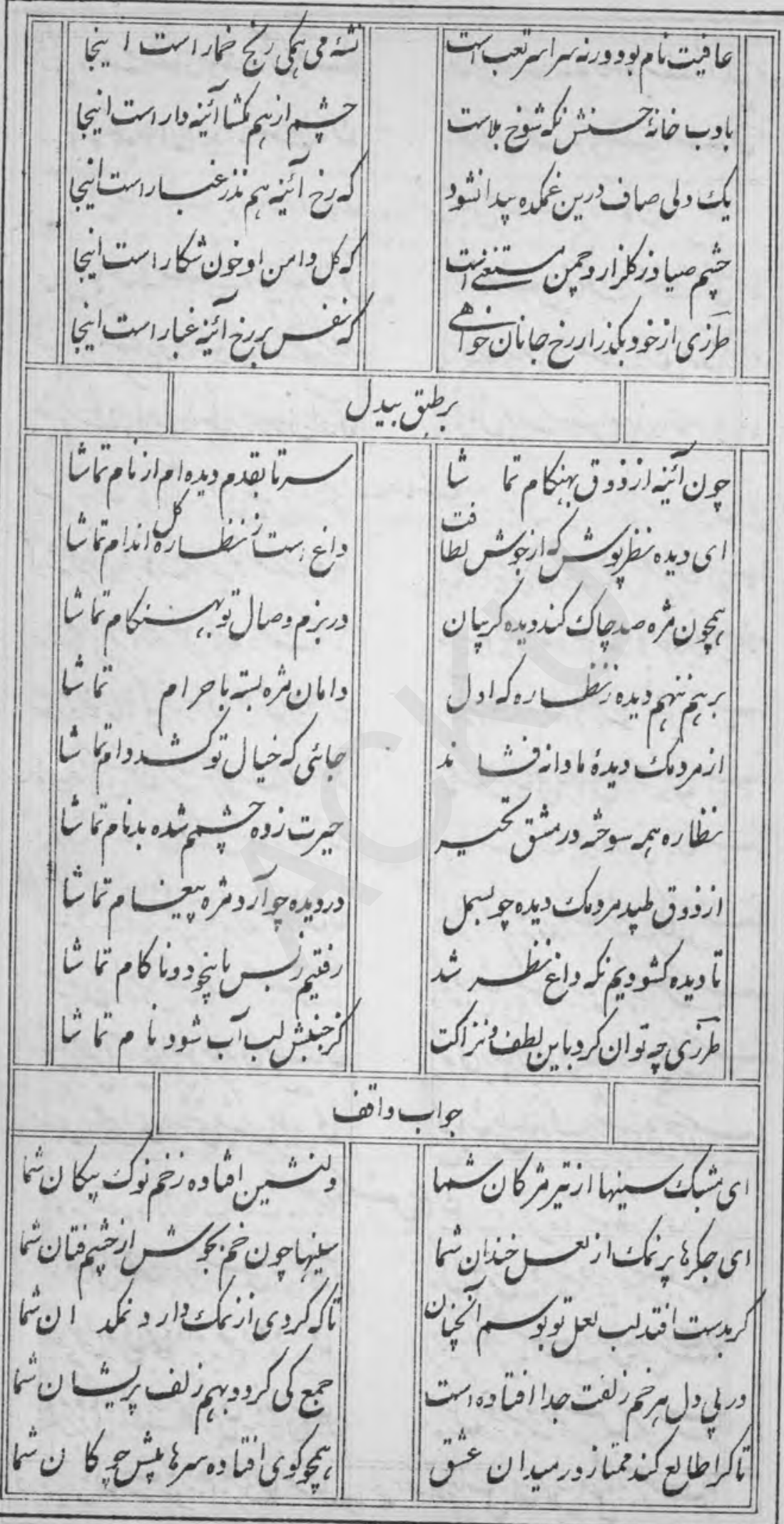


เง

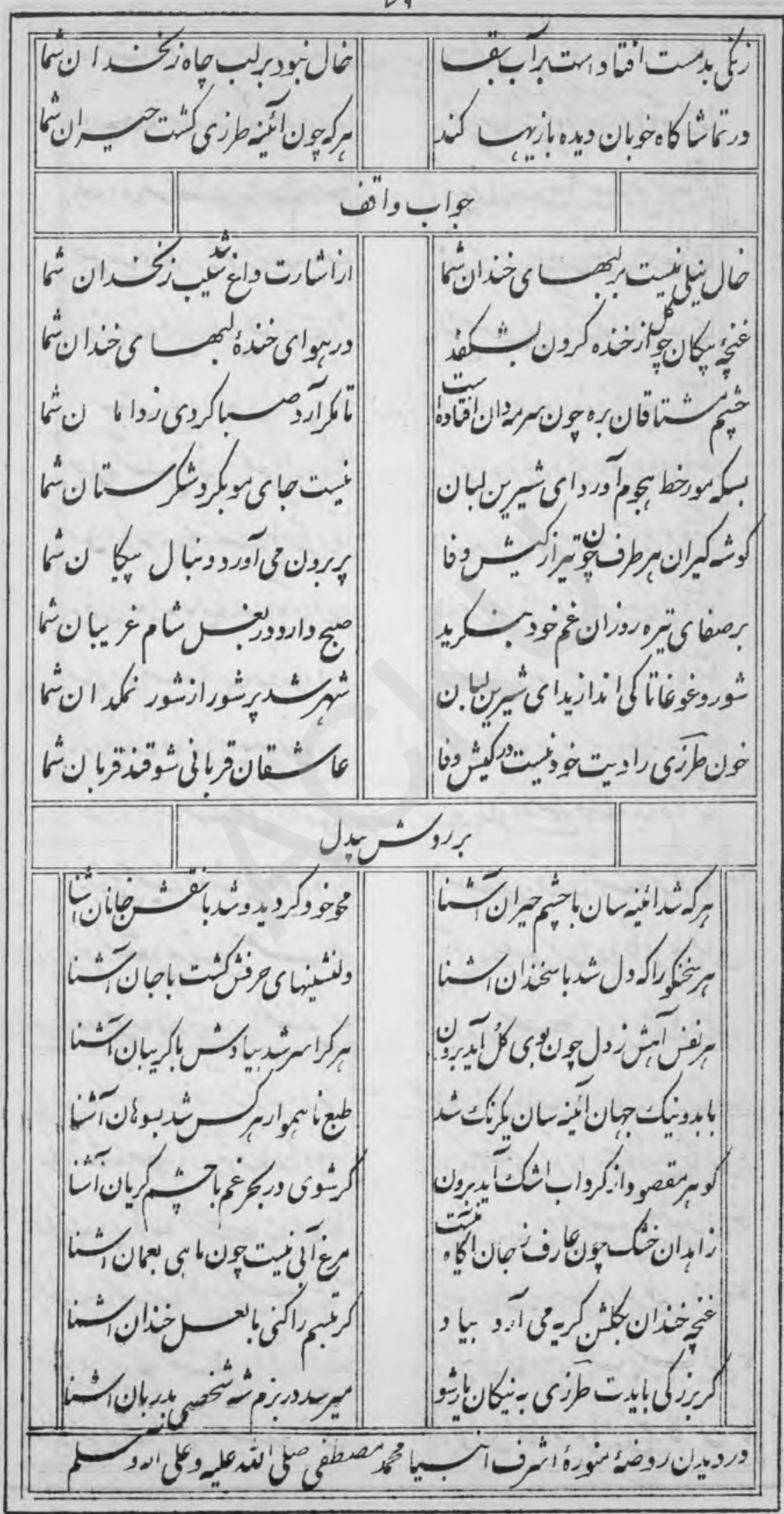


1.

| 1.




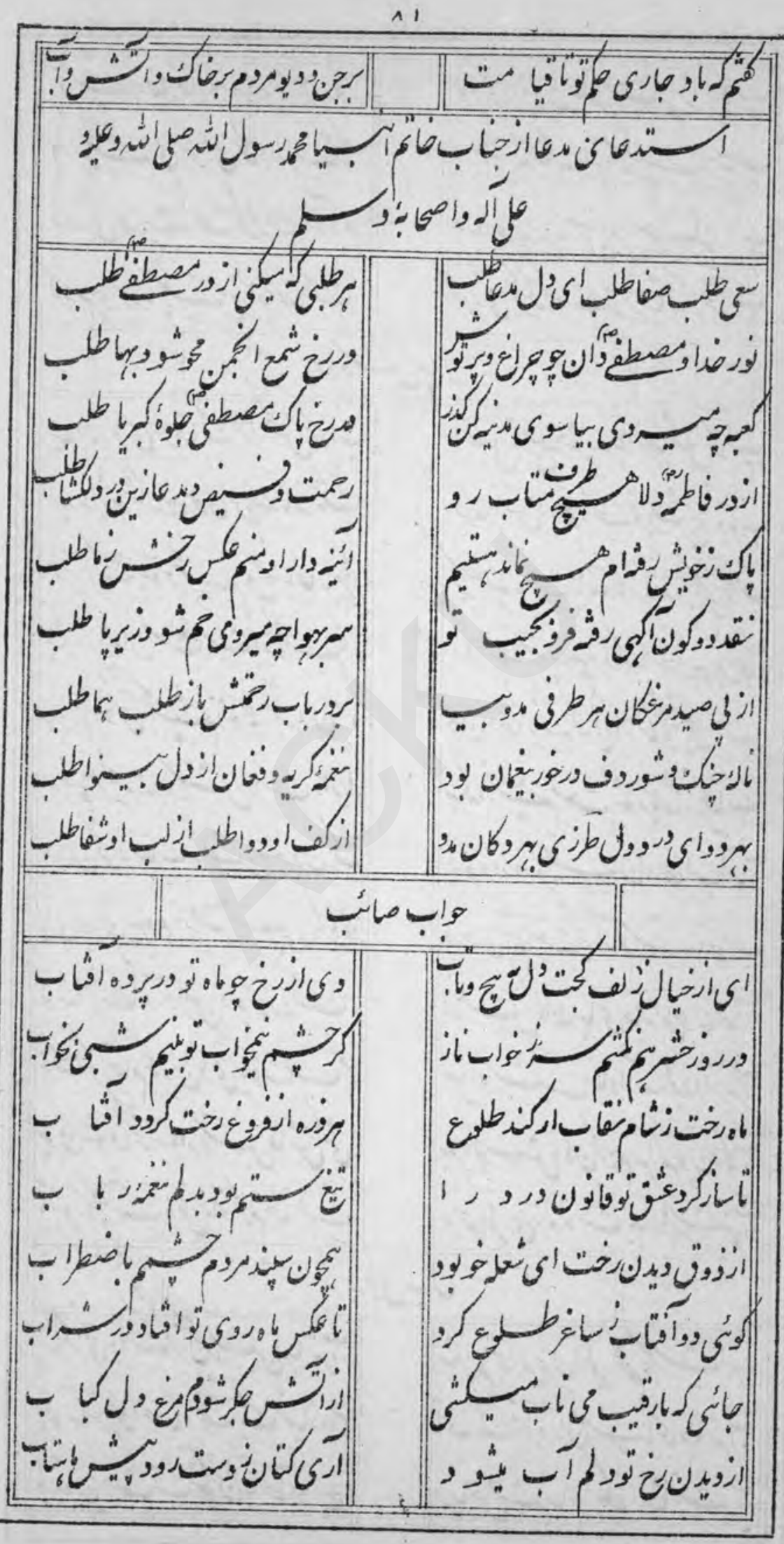




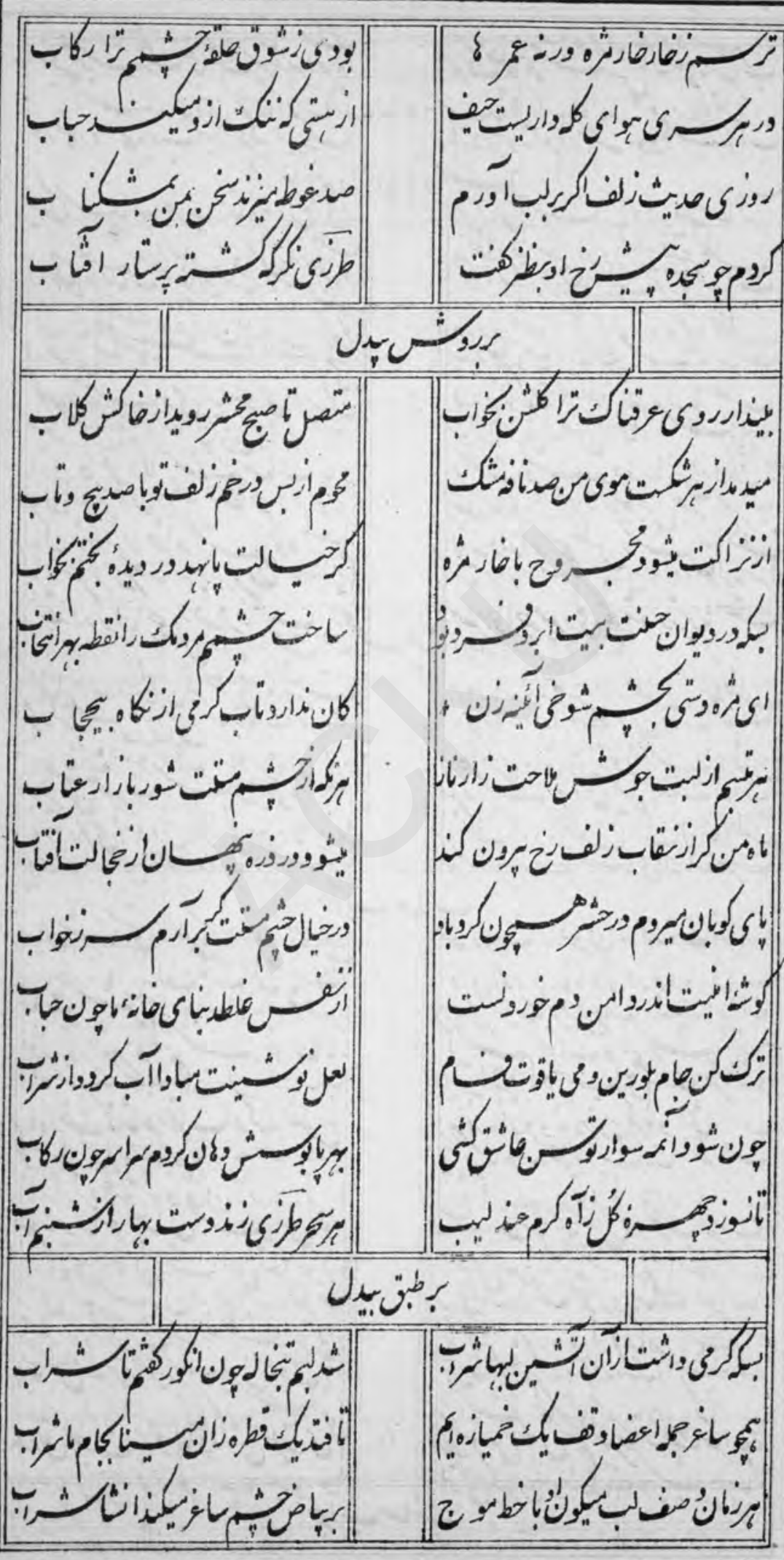




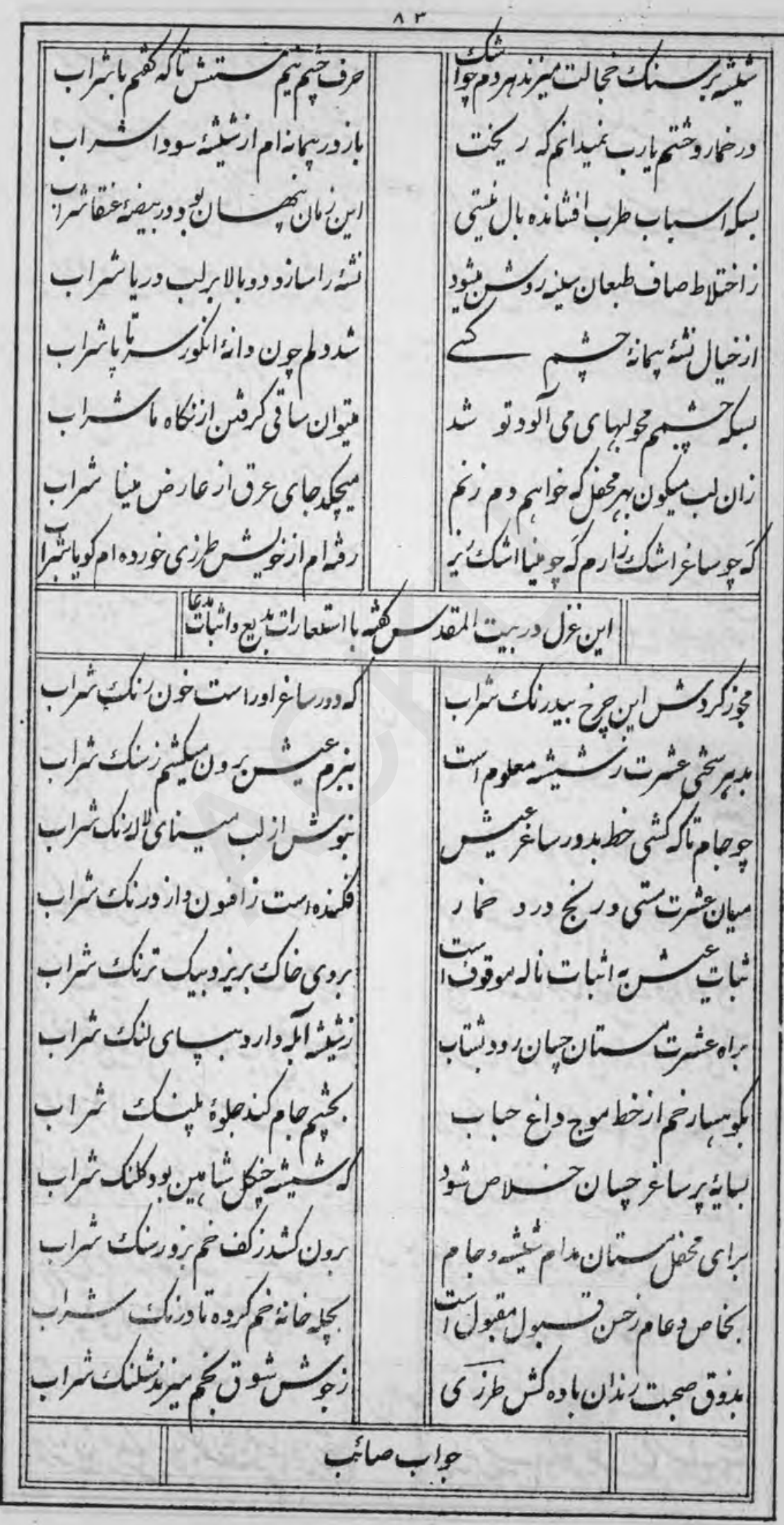


$A \varepsilon$

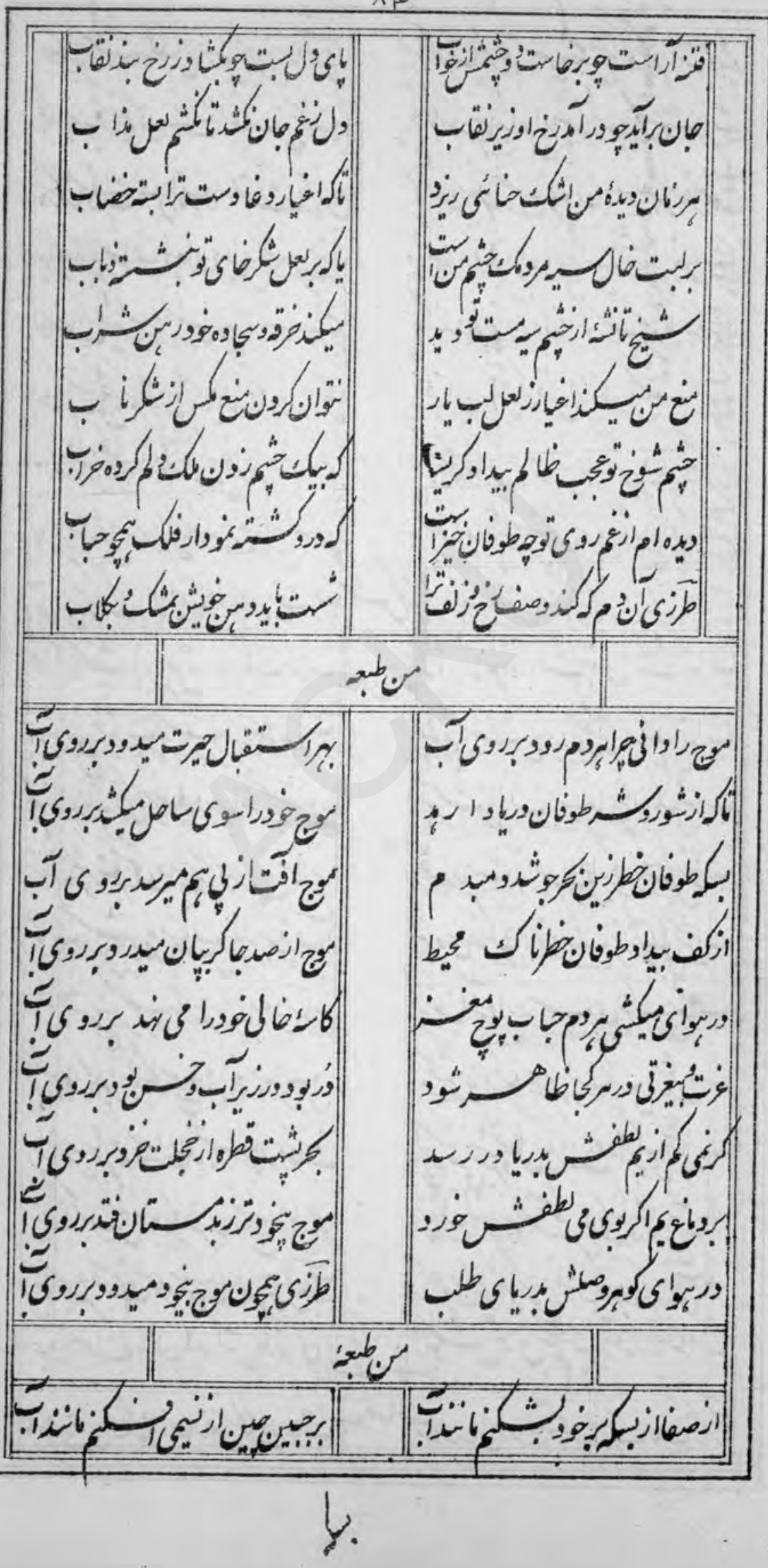


$A D$

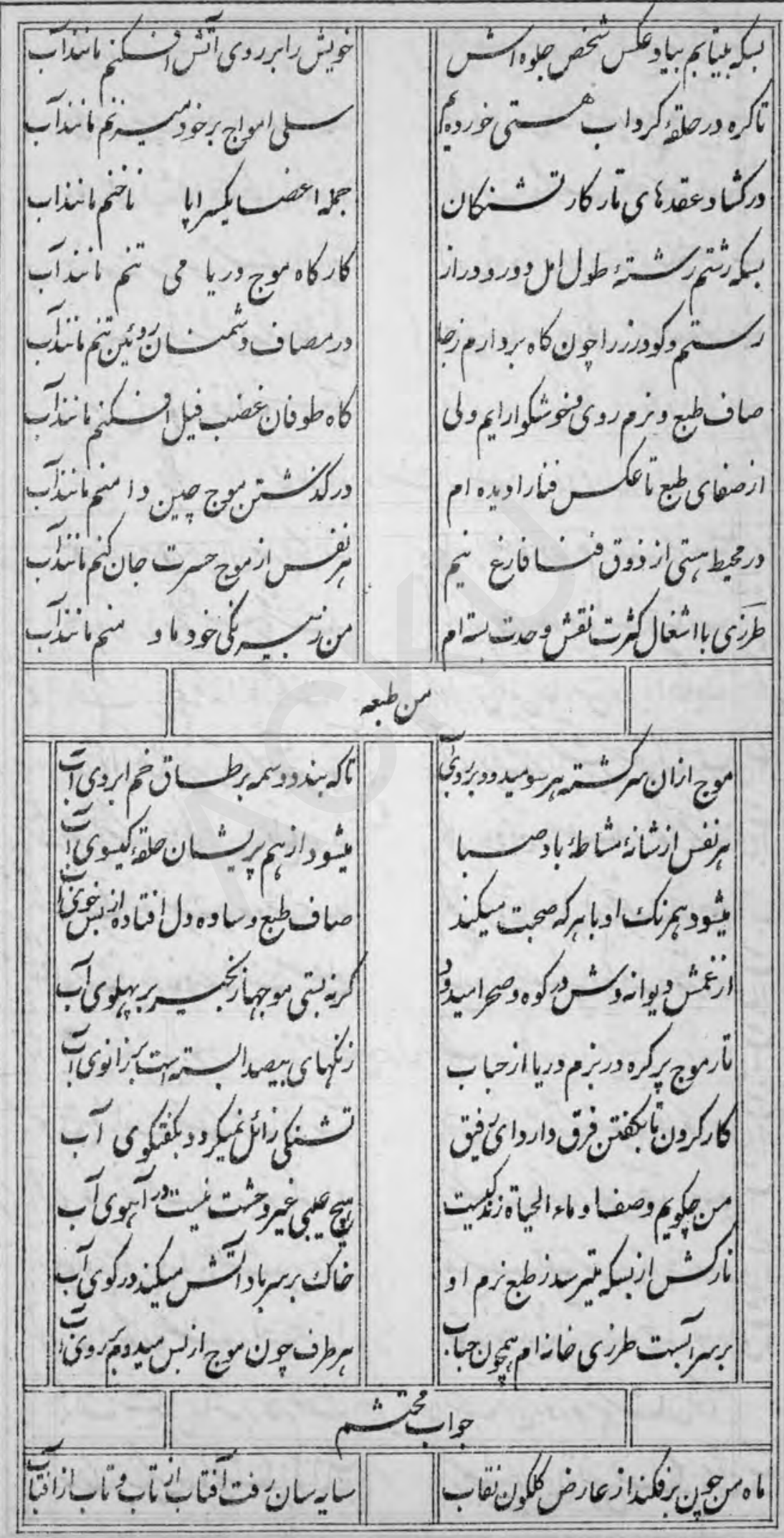


A

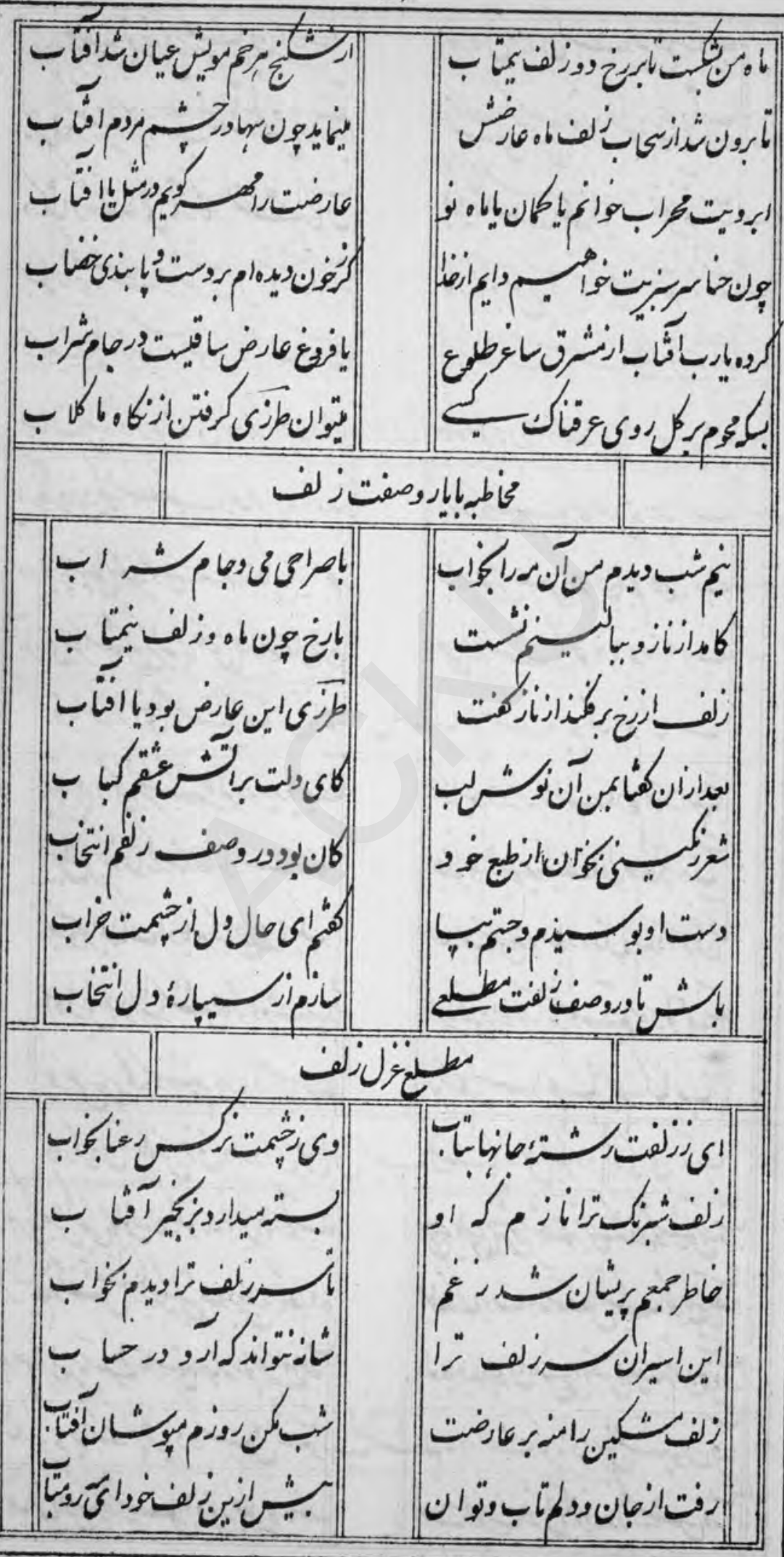


12

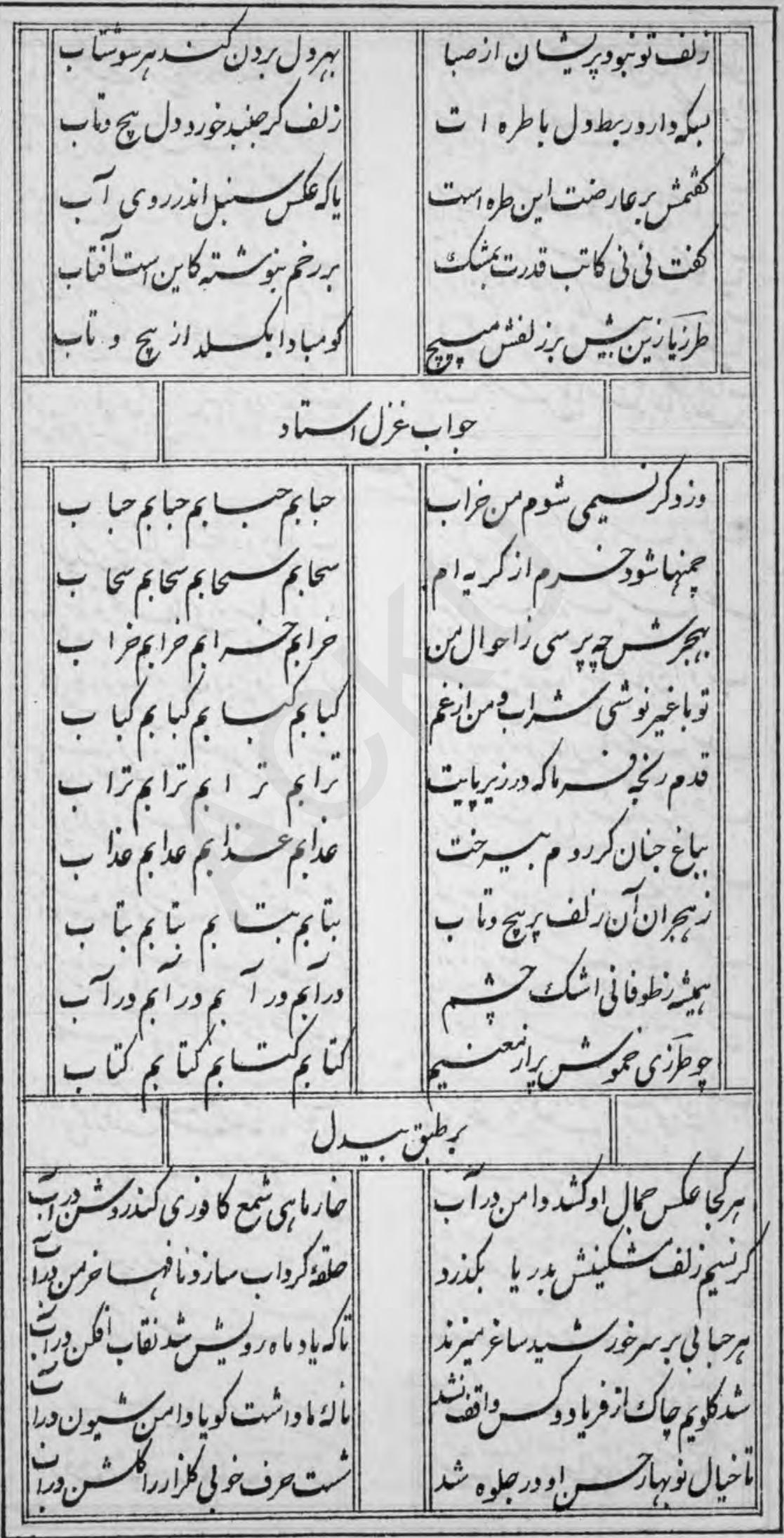


$A \wedge$

|


$\wedge 4$

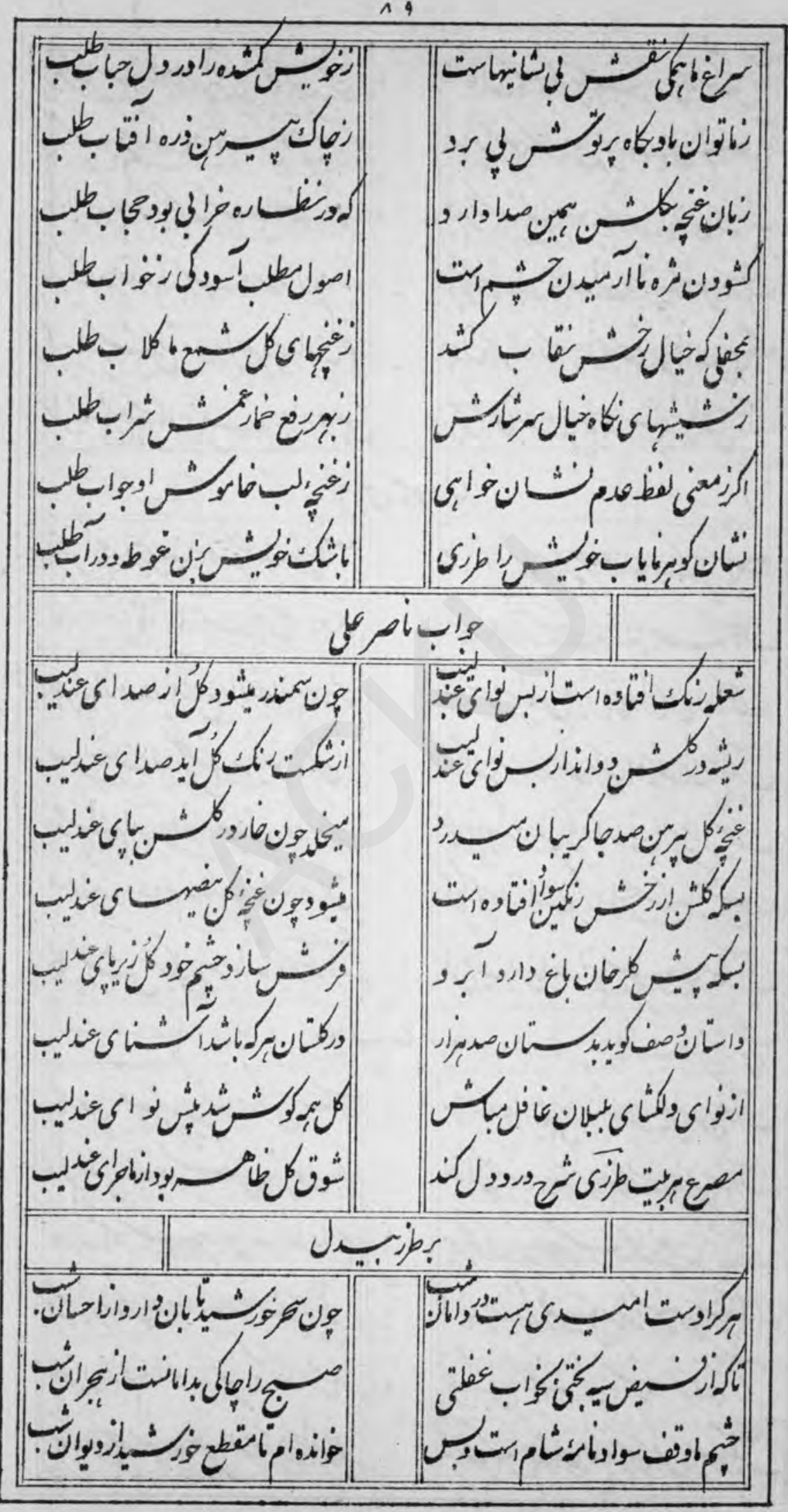


q.

|

$\int_{n \cdot 0,0}$

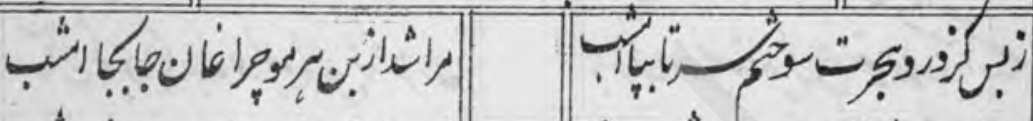

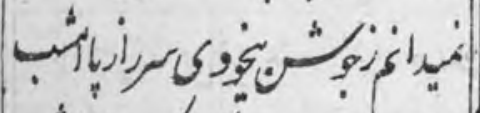

|

-

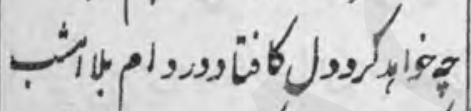

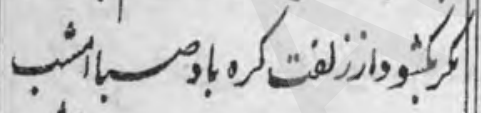

.

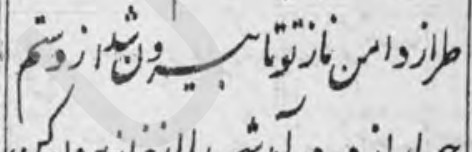

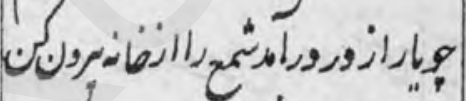

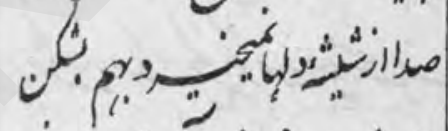

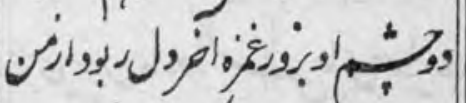

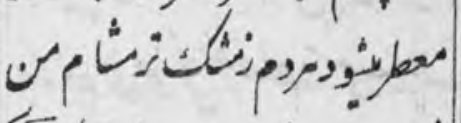

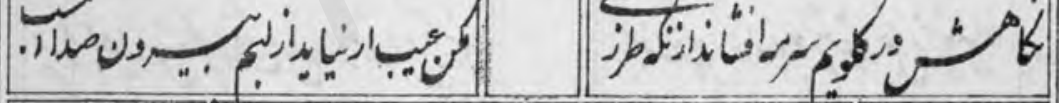

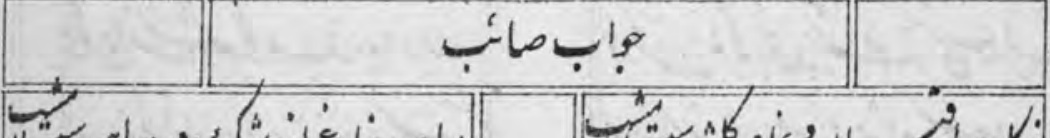

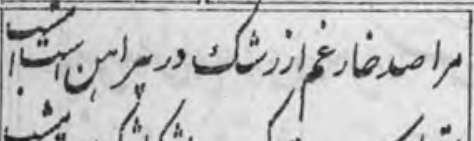
1. T.

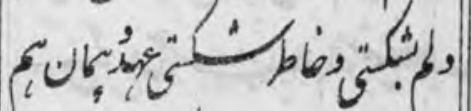

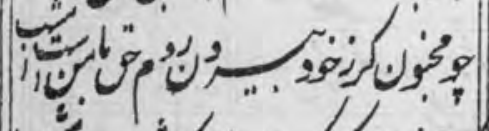

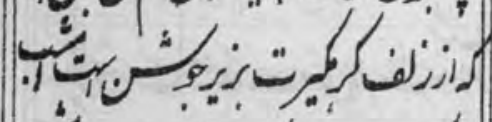
ن

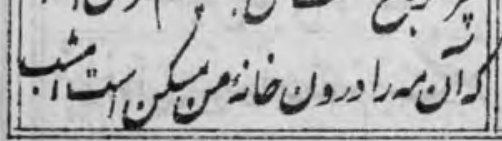

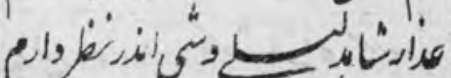
هاري"

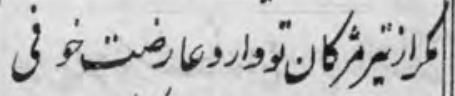

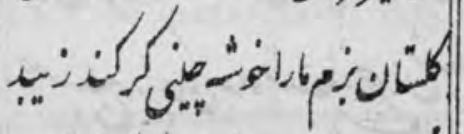
2 


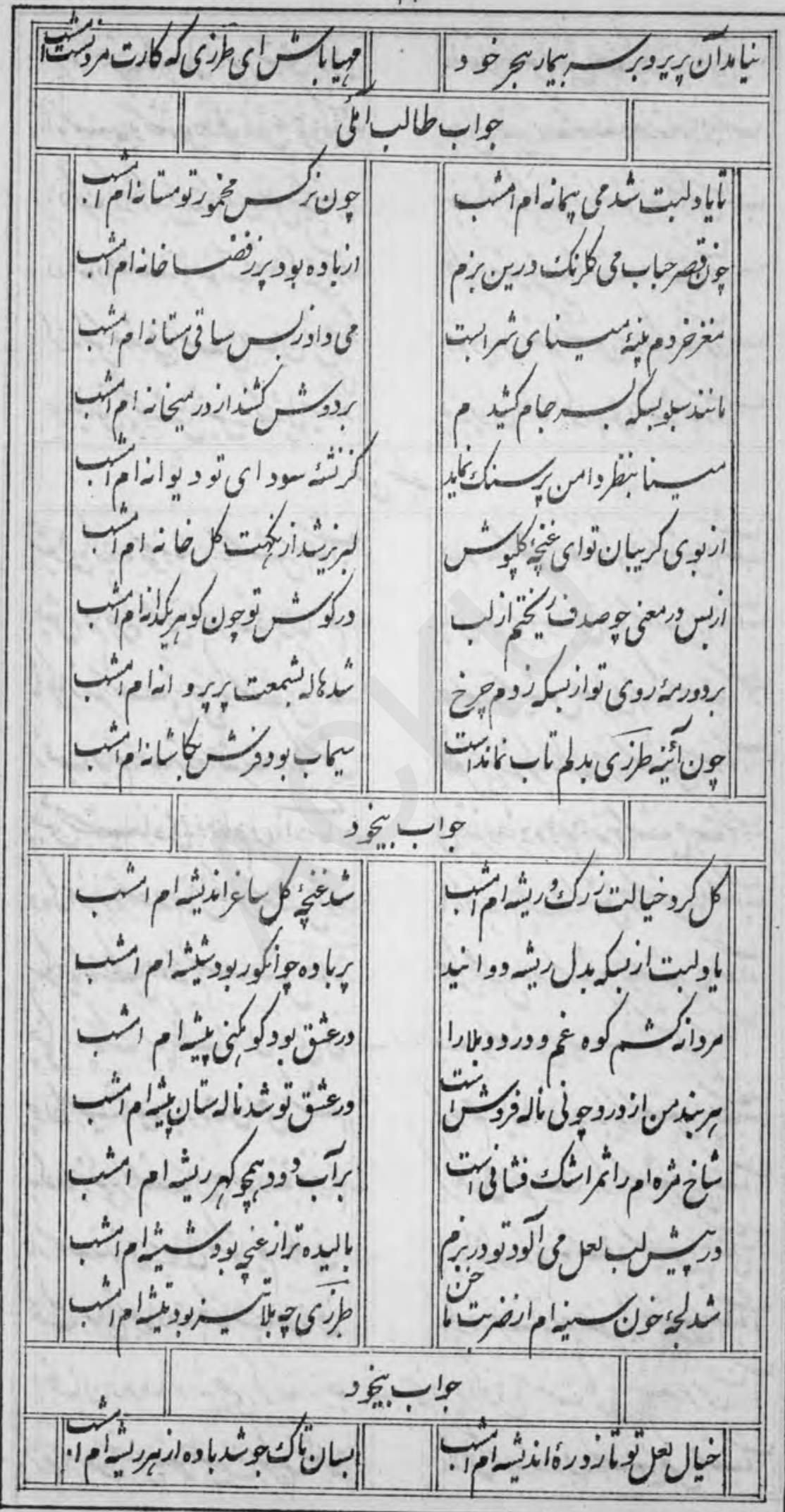




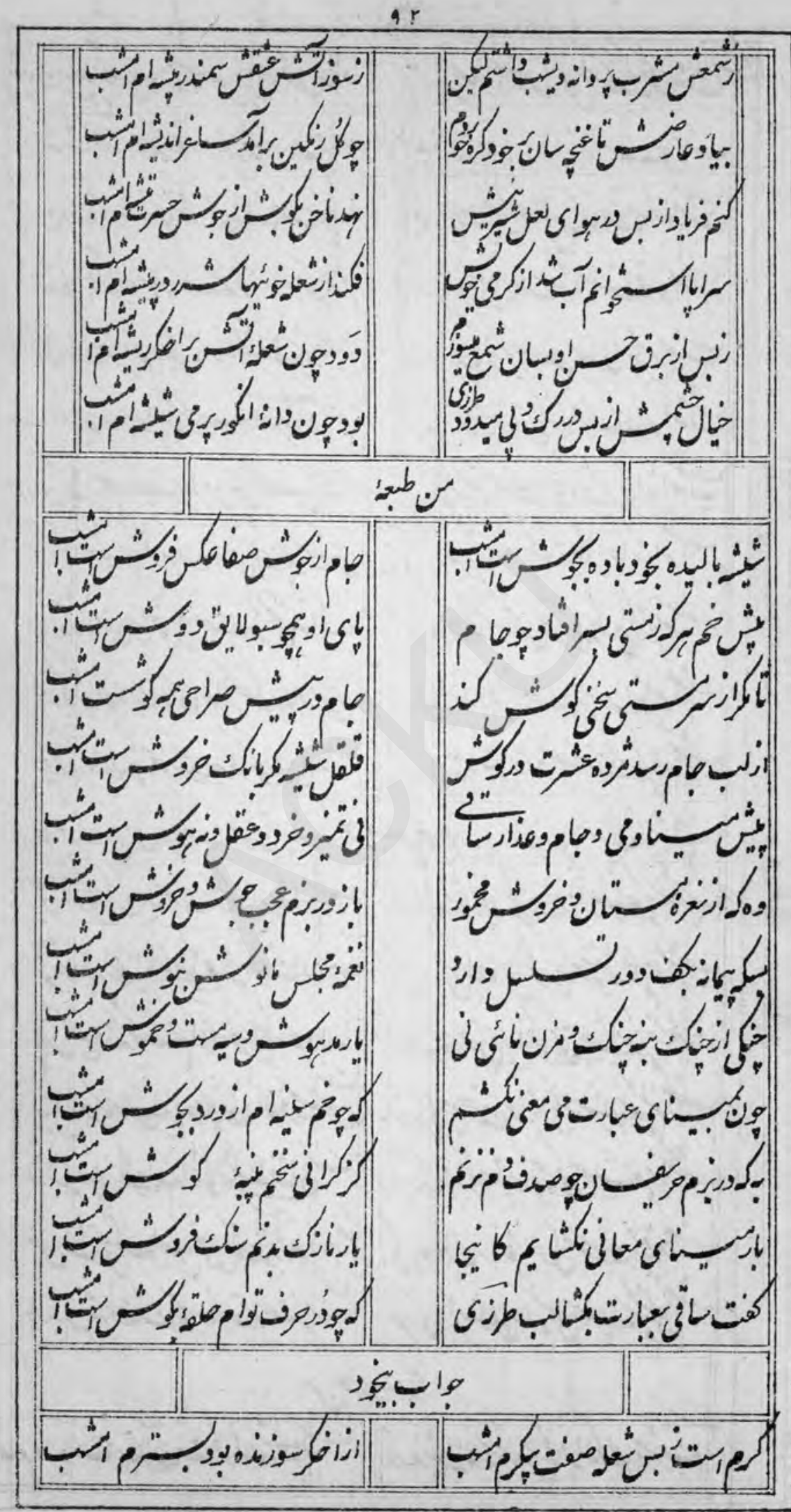

$0 \%$ 
$9 r$

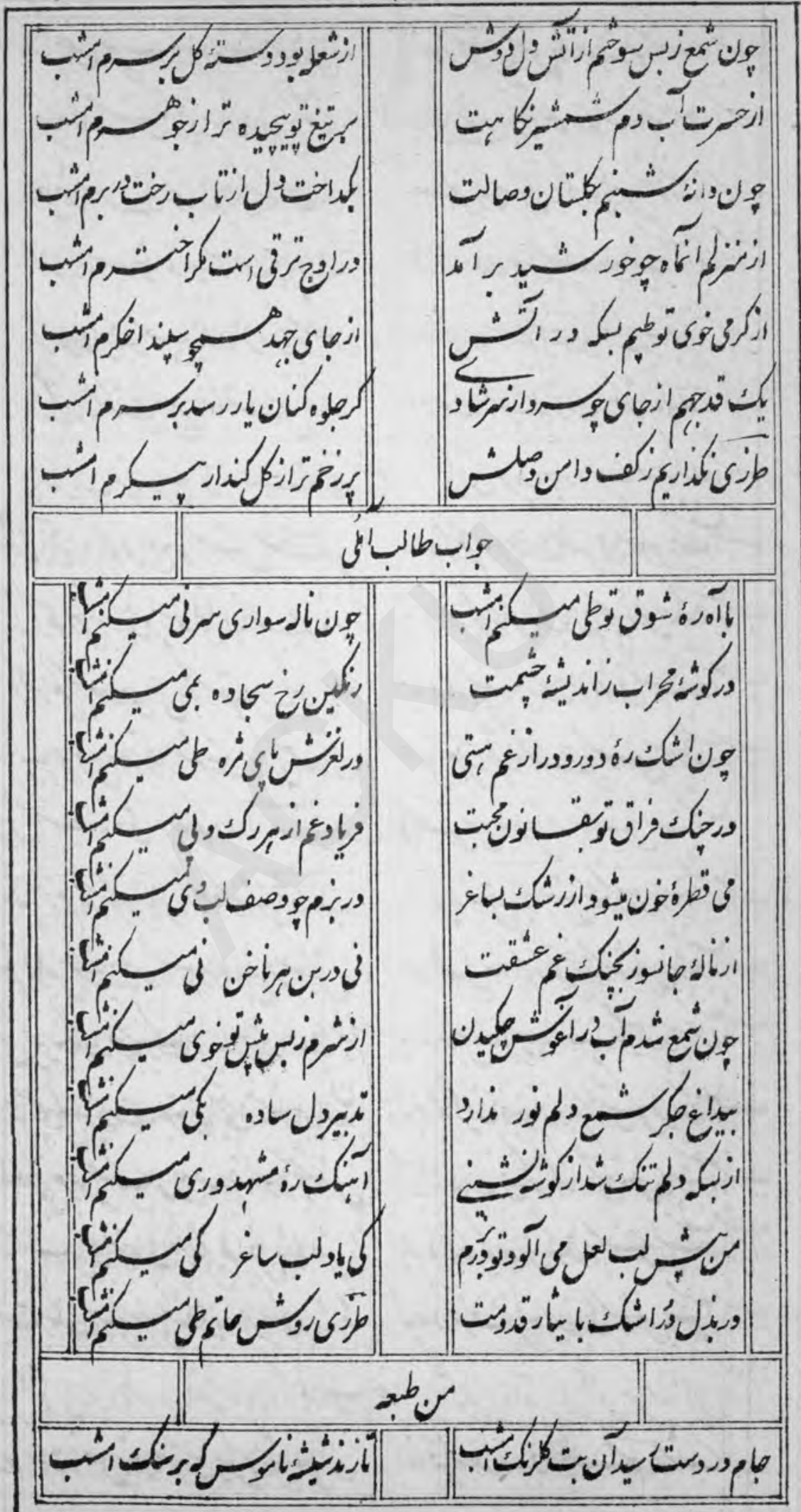


4

(1)

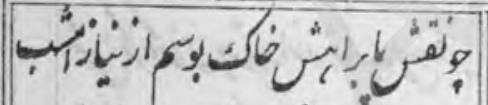

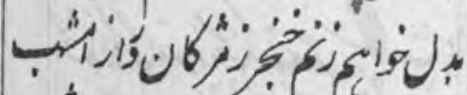

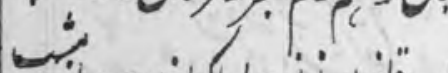

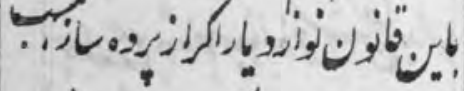

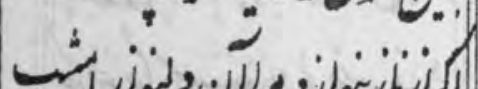

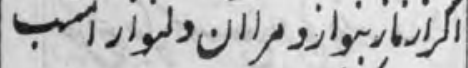
"ر.

- 1, . ilis

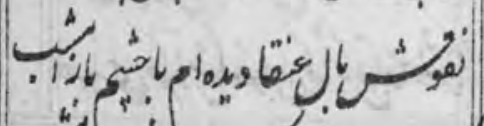

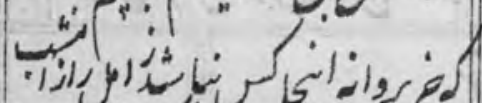
(1)

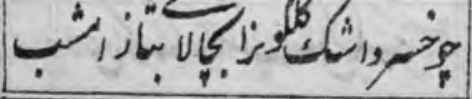

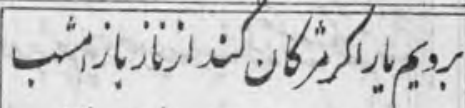
ק : نار " .

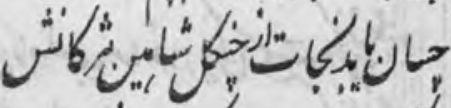
(

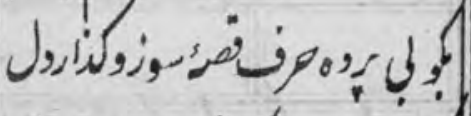
? 


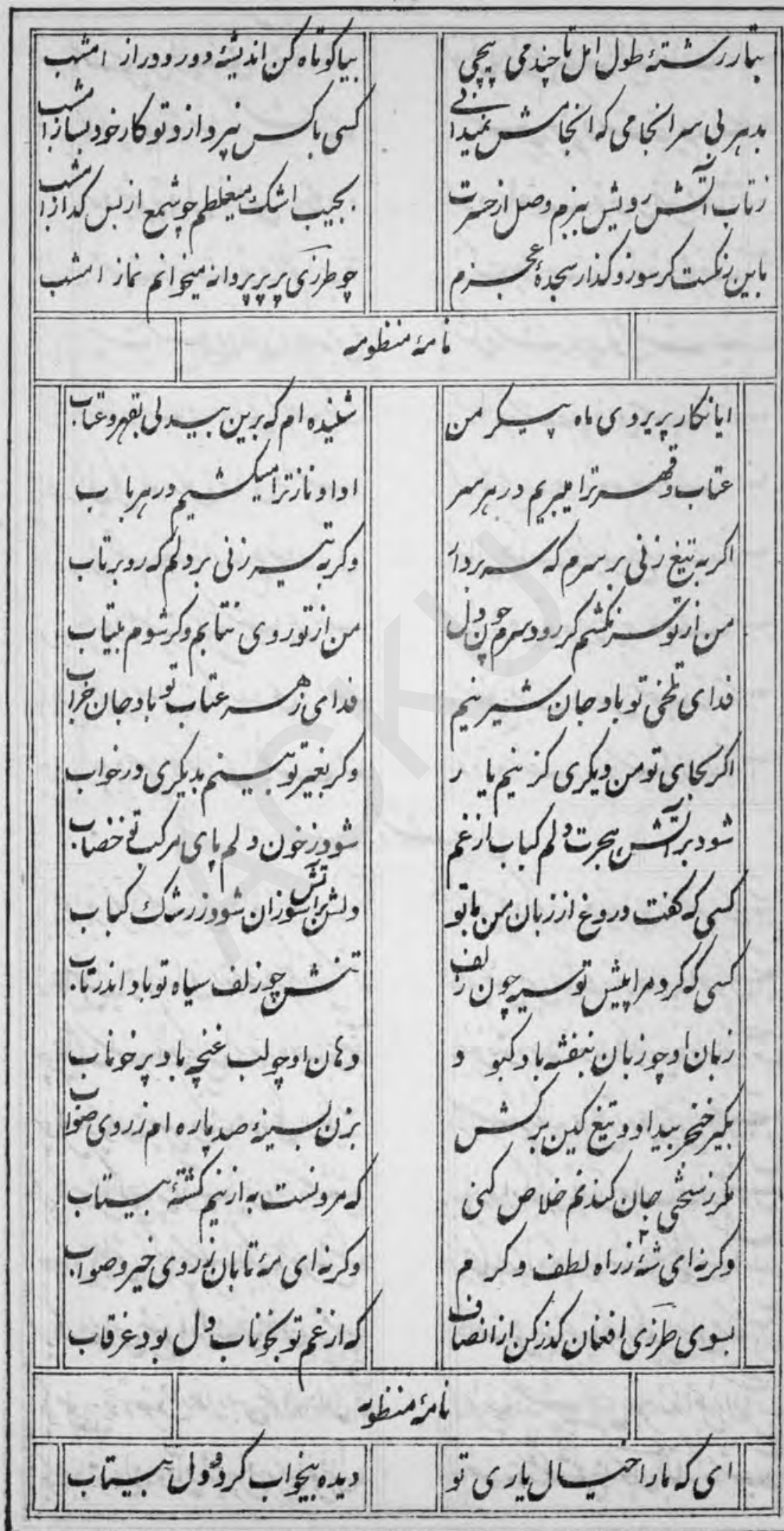


44

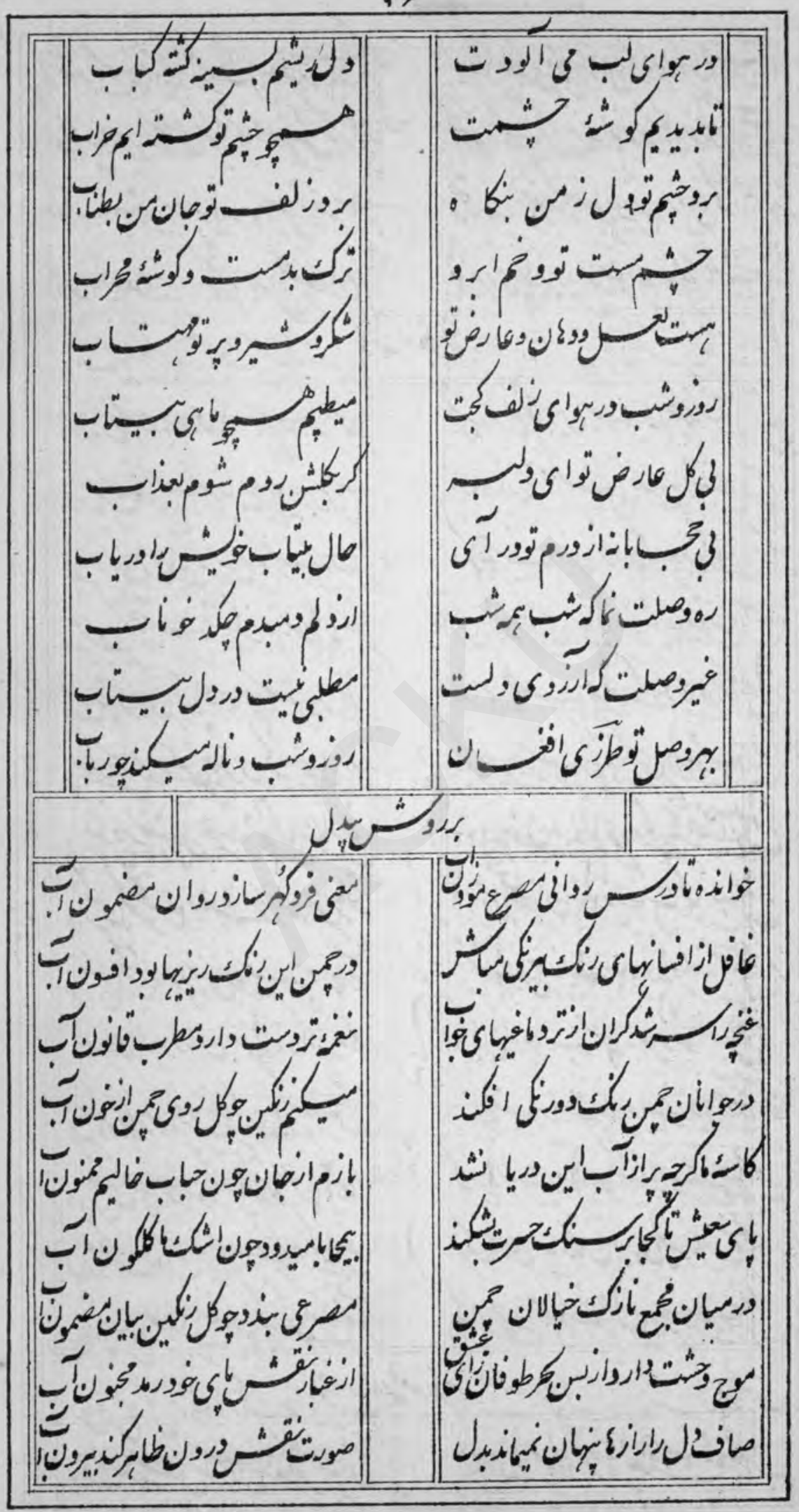




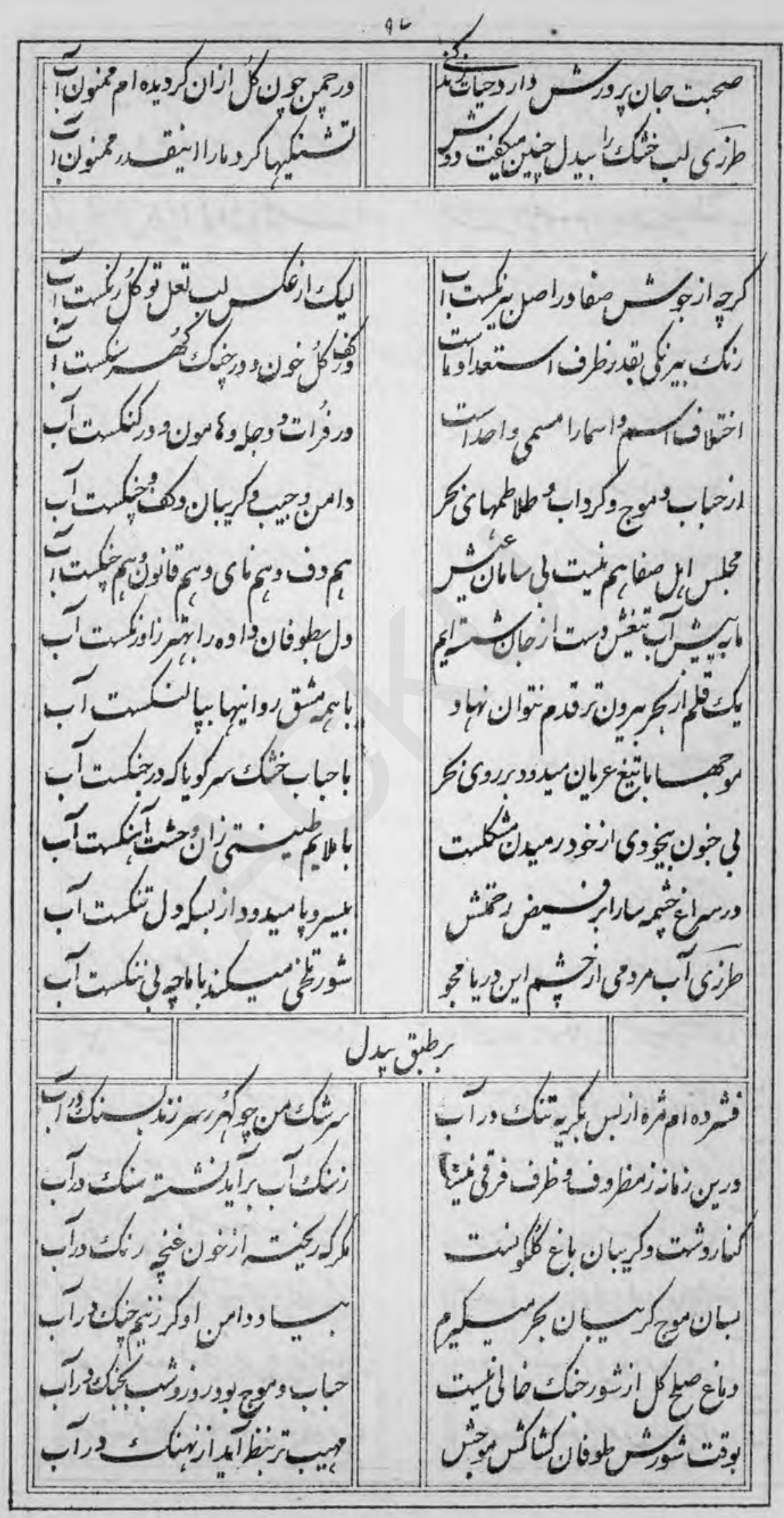




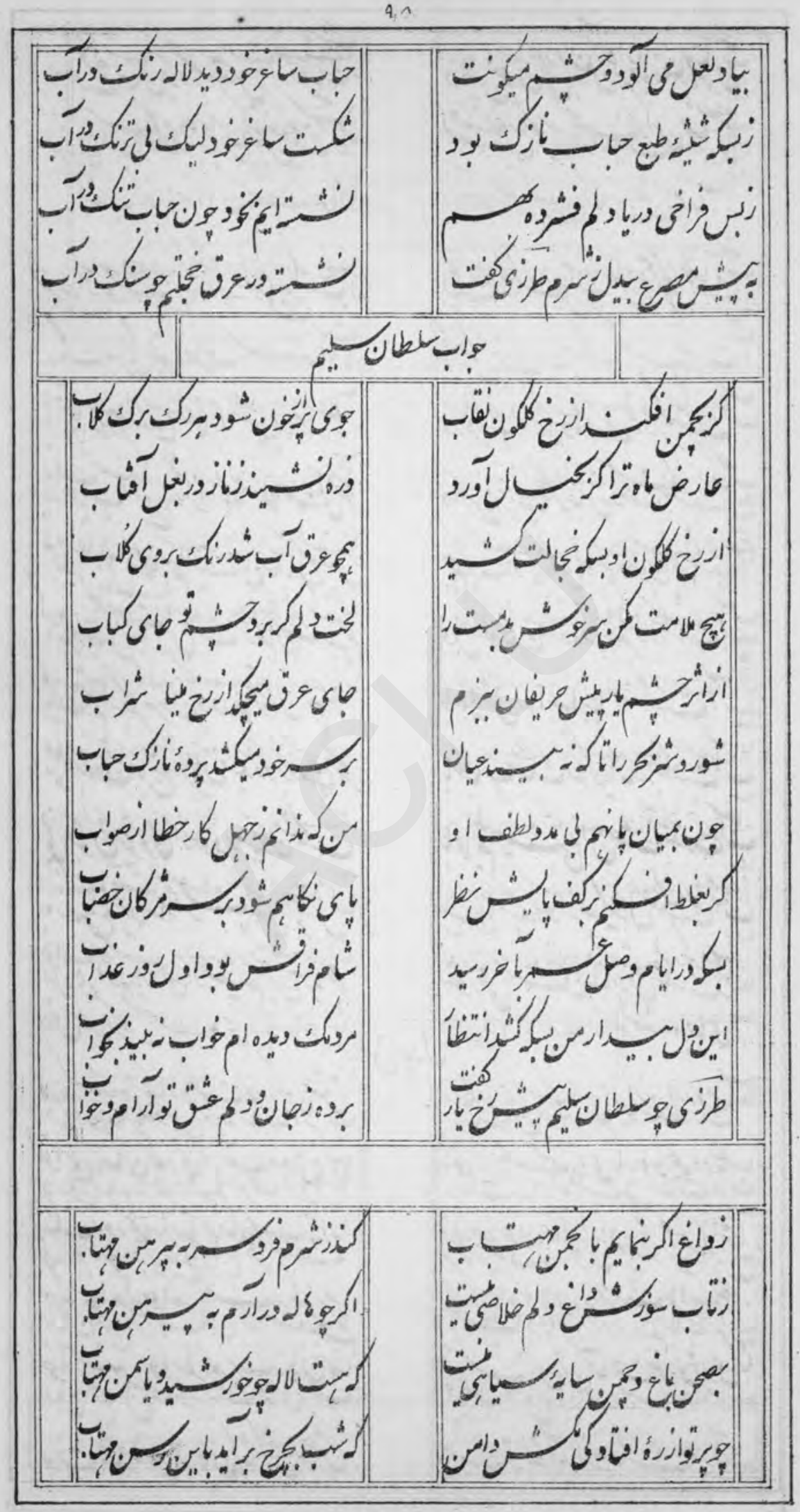

j) 
94

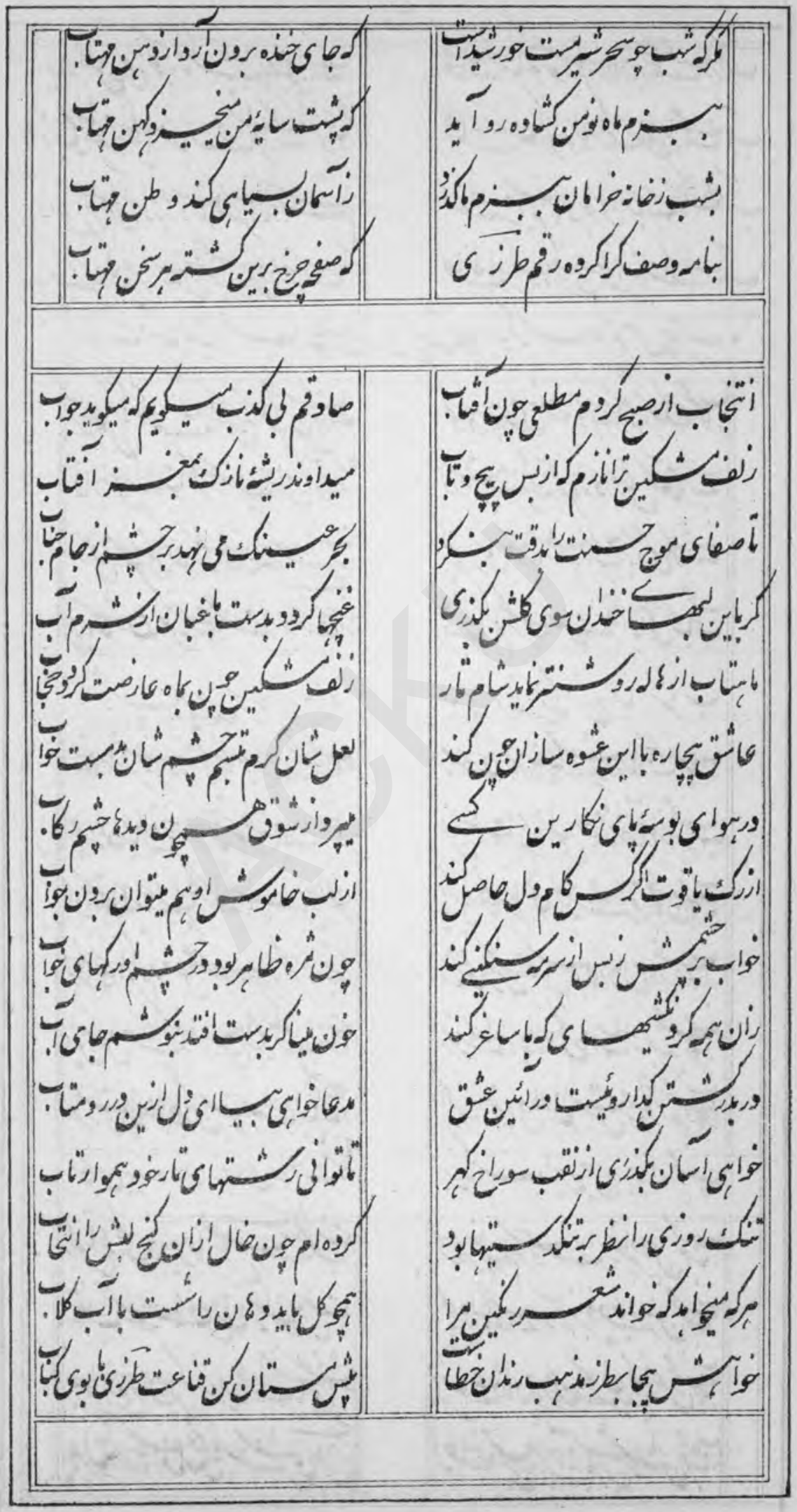


10

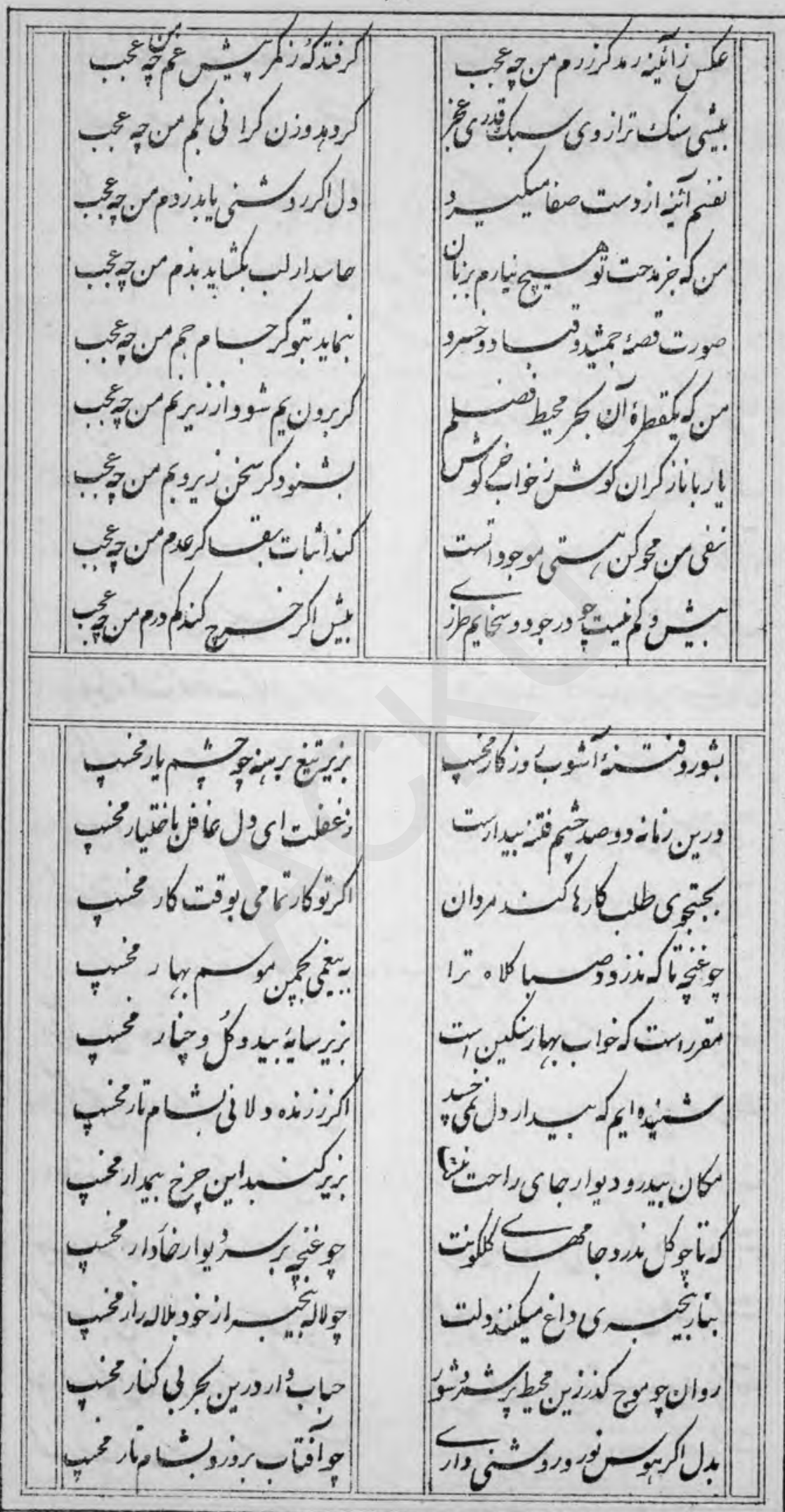


$1 \cdot 1$

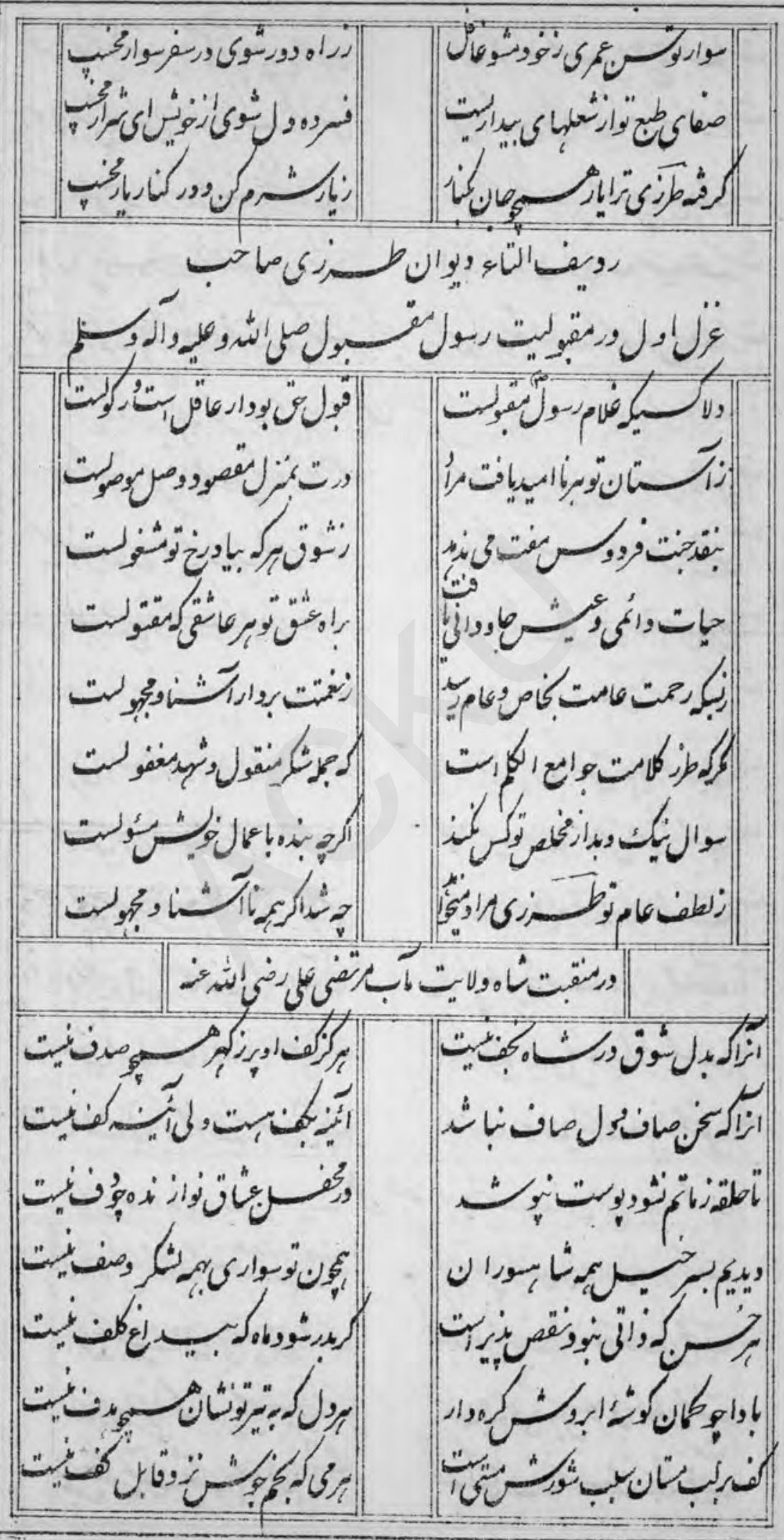


$1 \cdot r$

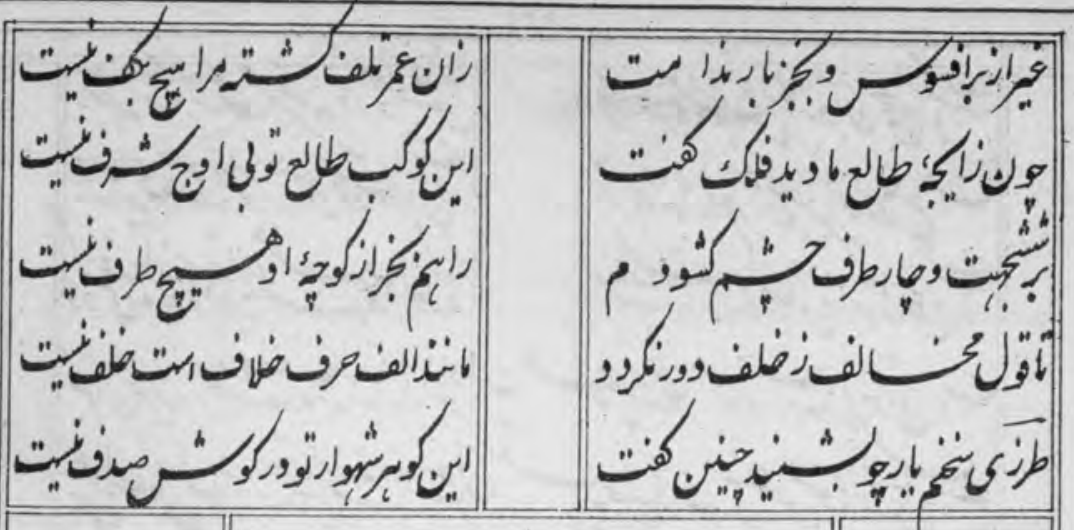

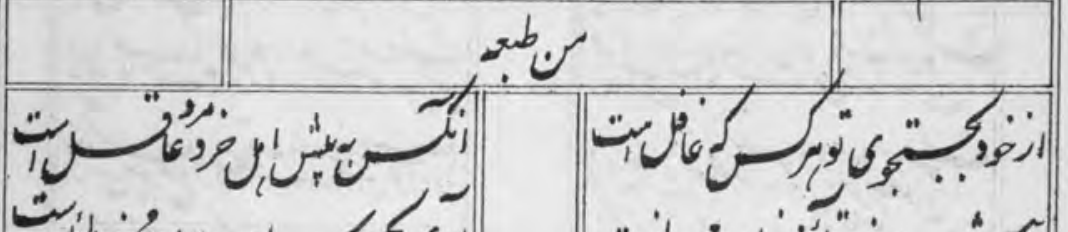

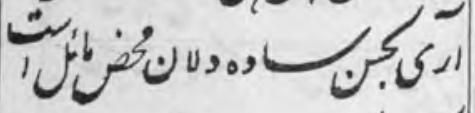

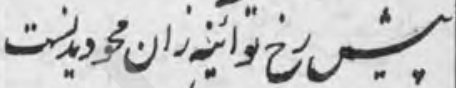

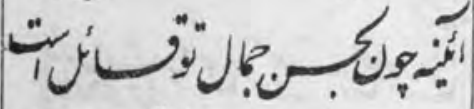

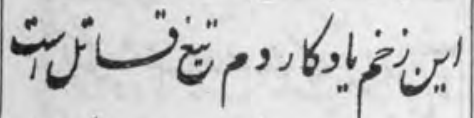

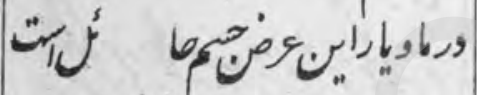

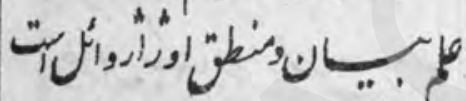

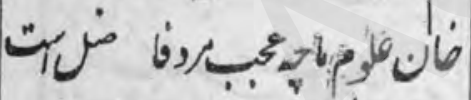

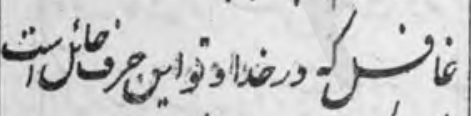

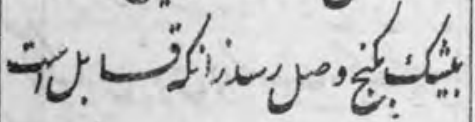

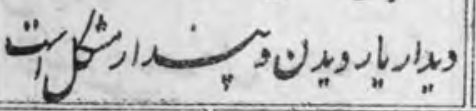

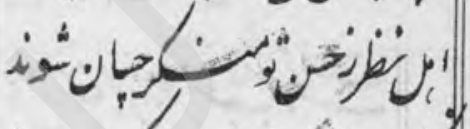

$9+\int_{n}$

"

, رئنق

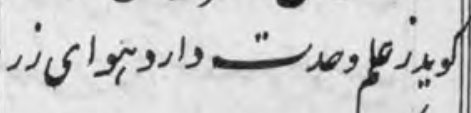

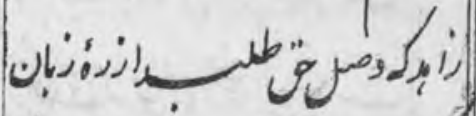

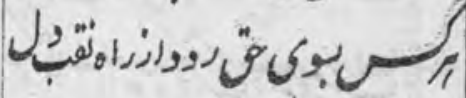

P.

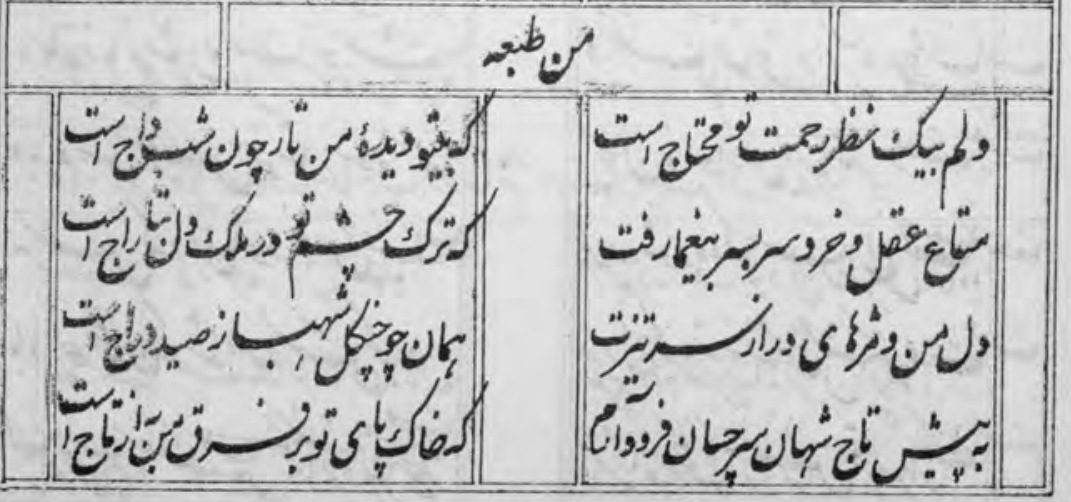




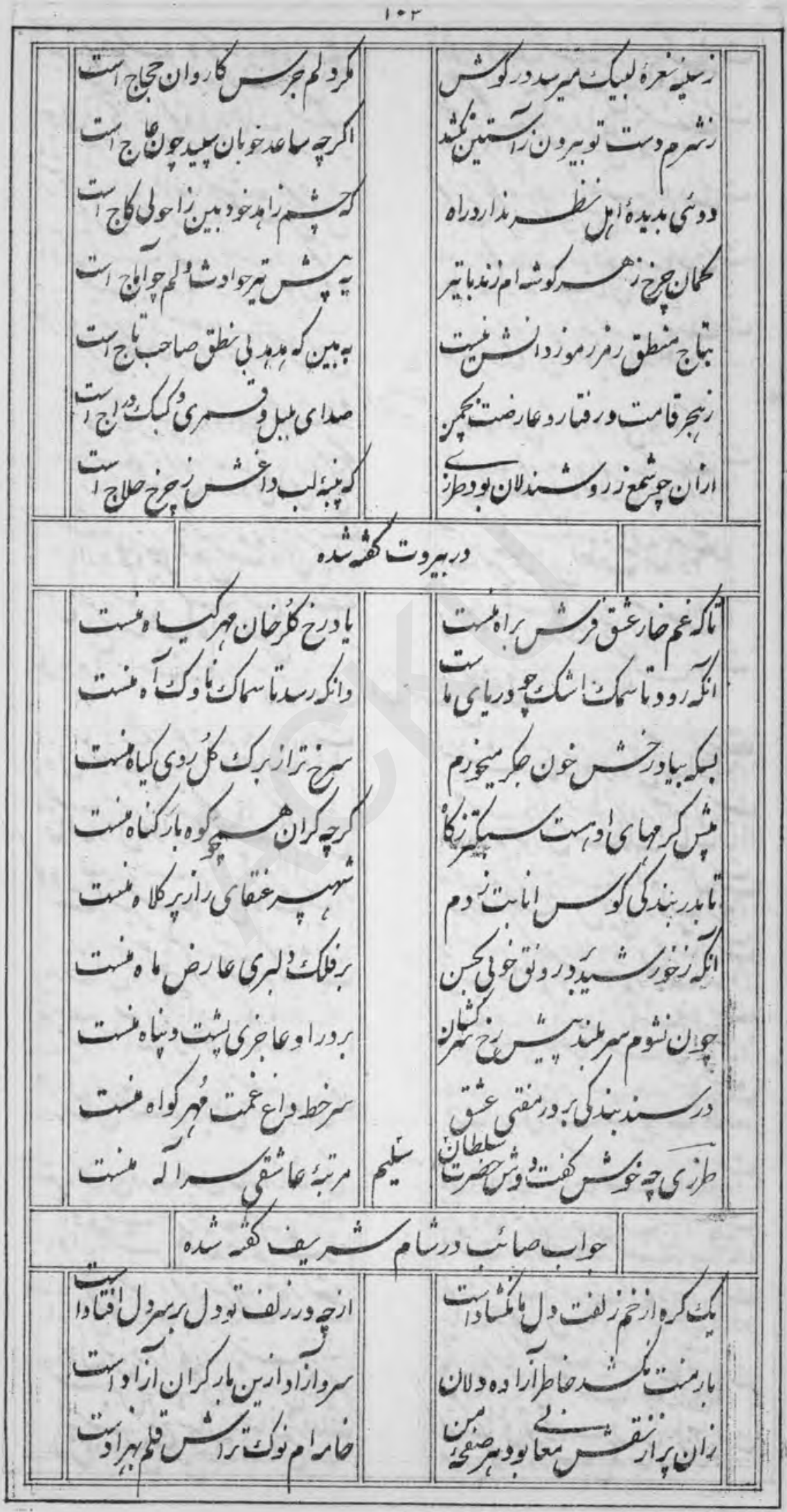


I P

|

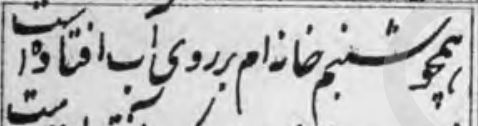

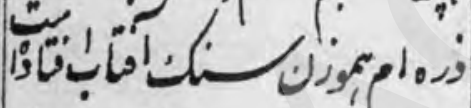

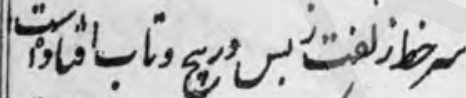
يـ 年

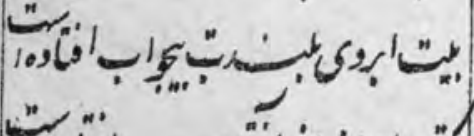

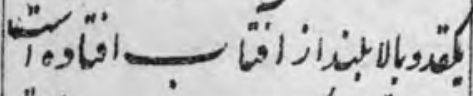

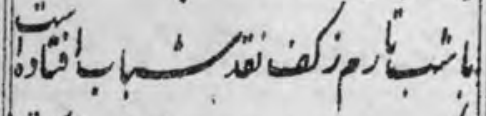

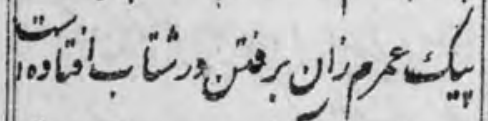
تان

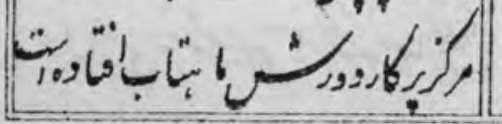

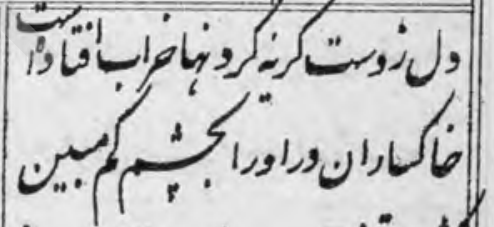

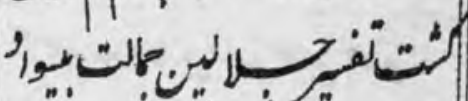

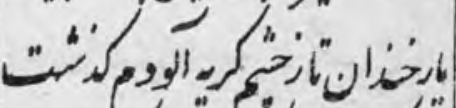
1. "r"

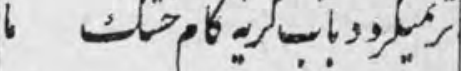

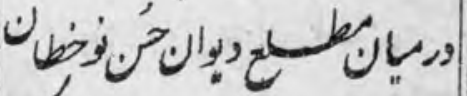

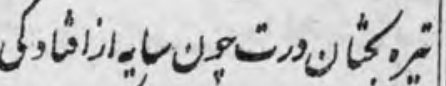

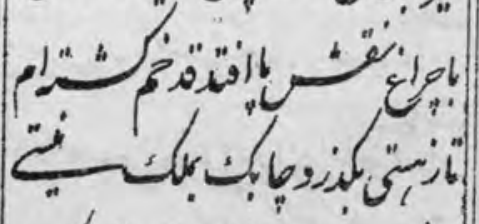

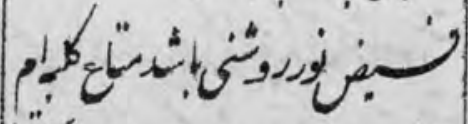

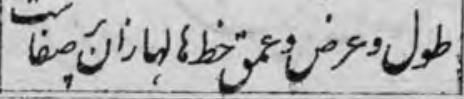


100

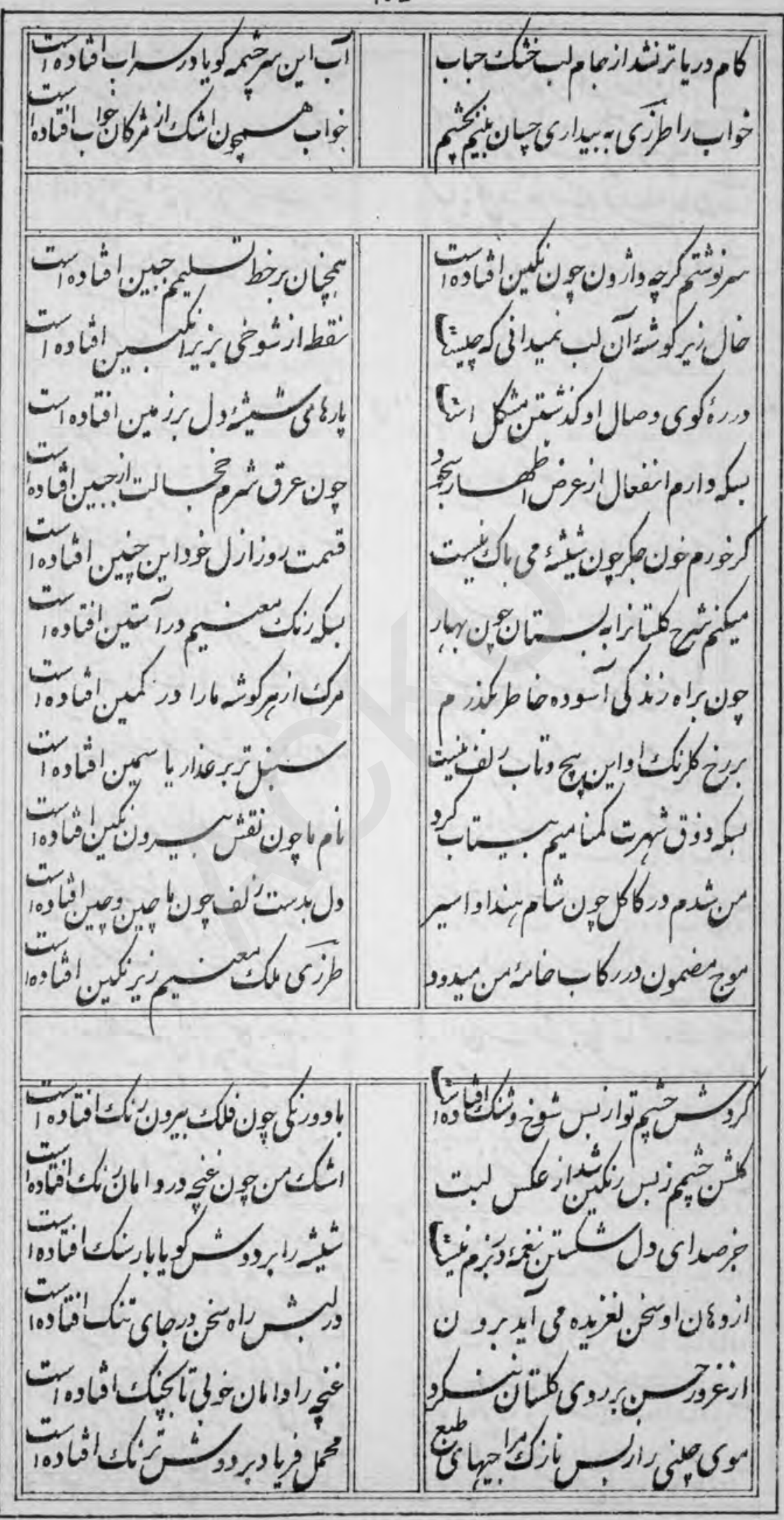




\section{I.9}

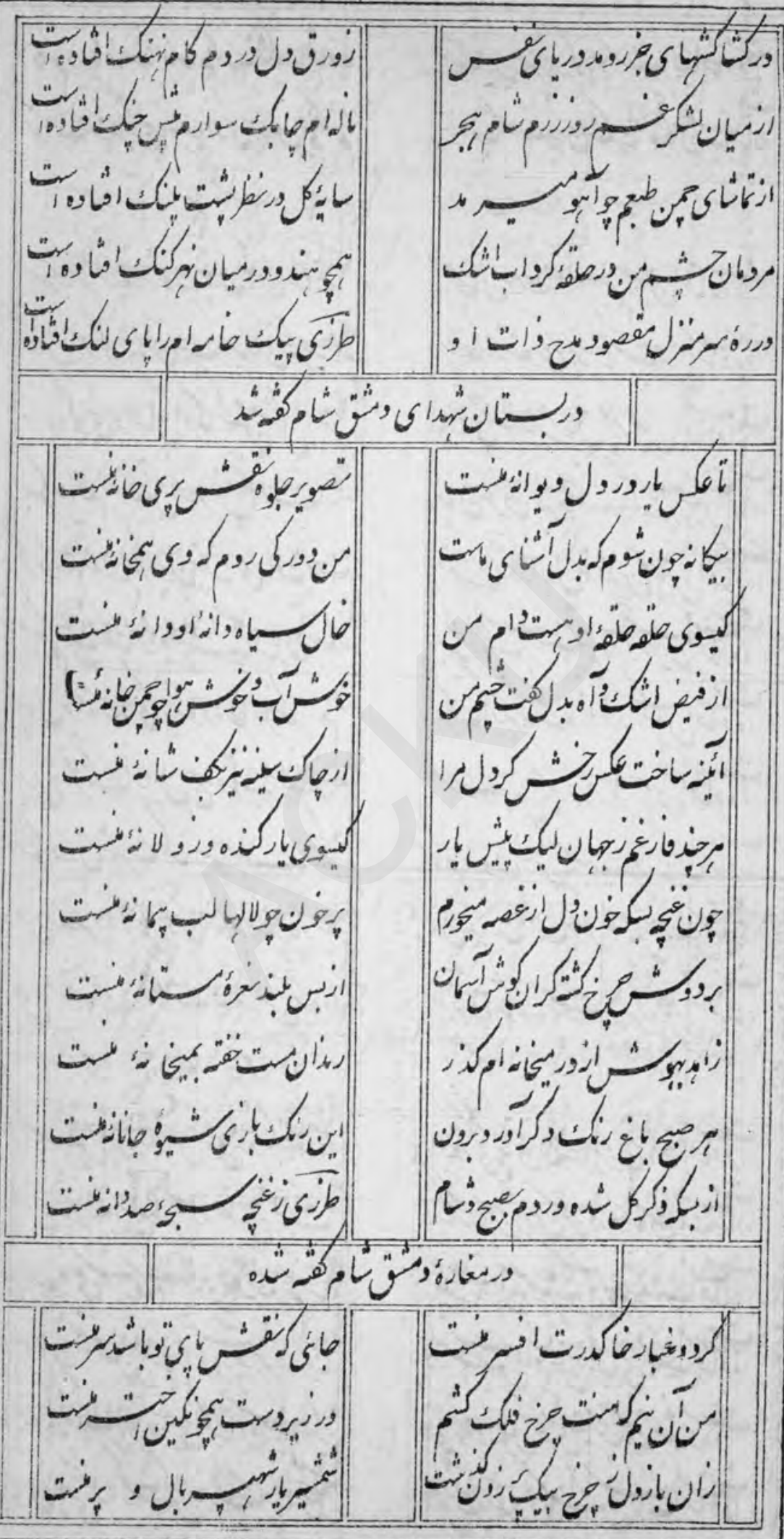


$1 \cdot v$

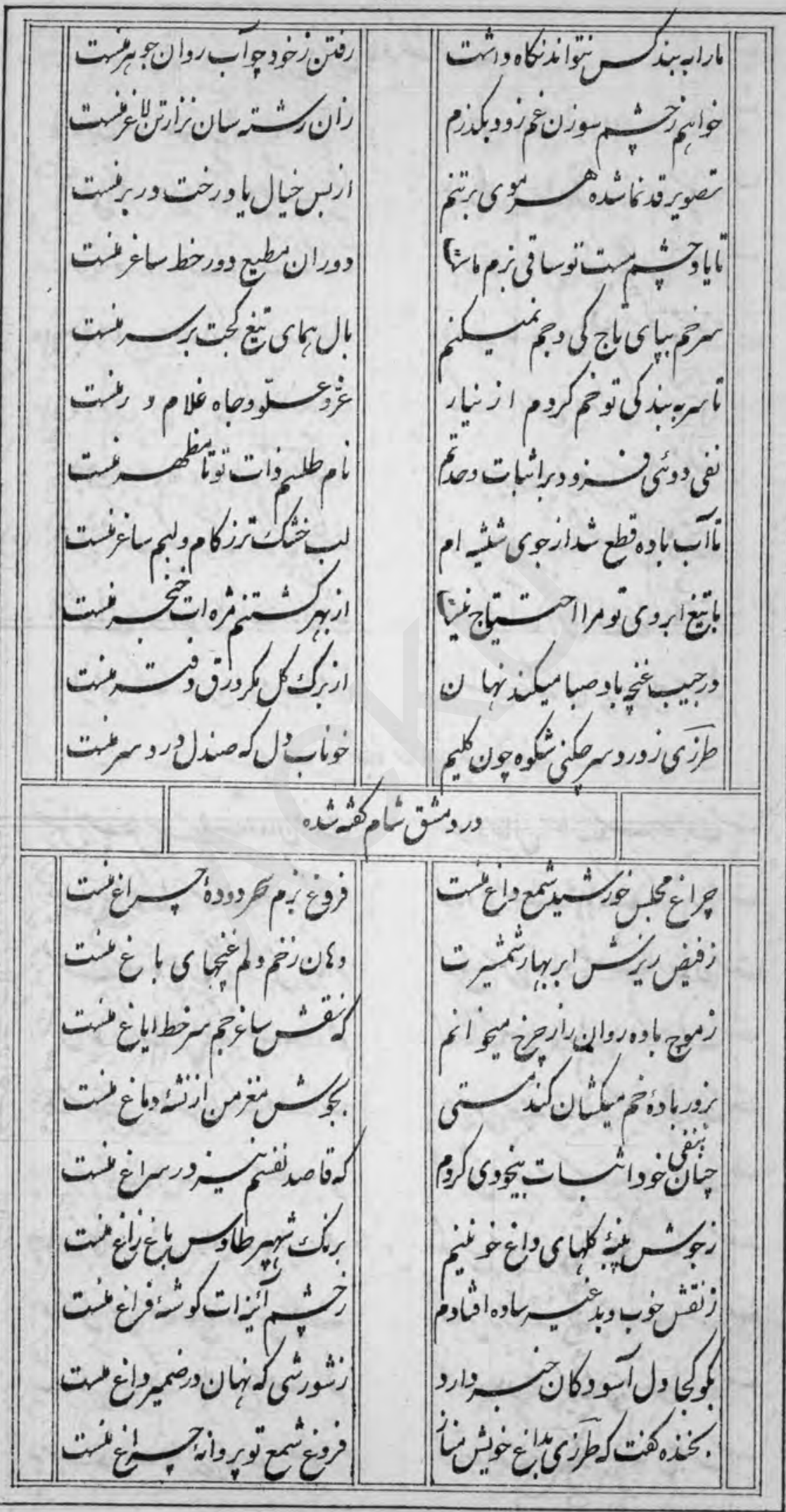




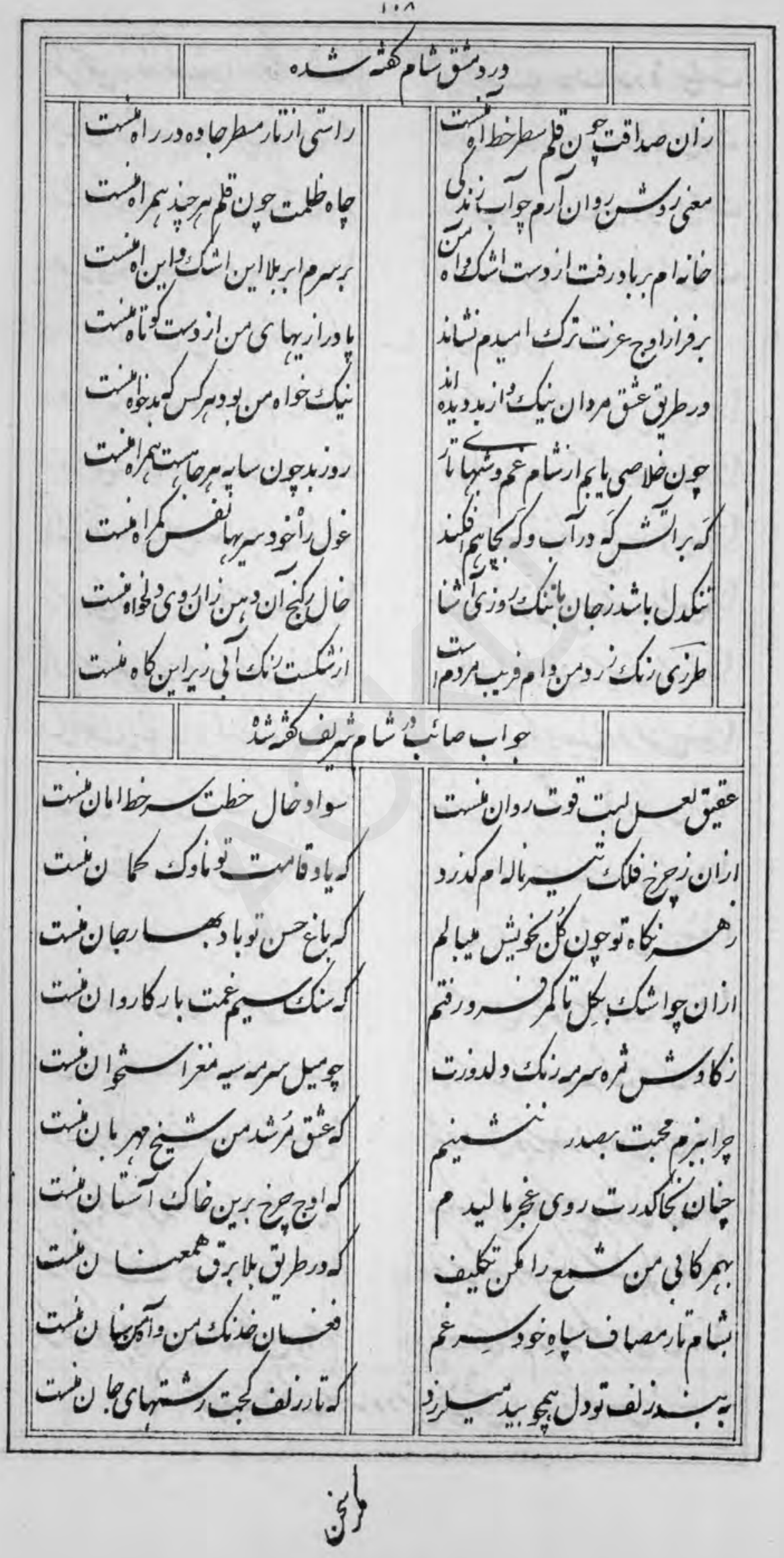




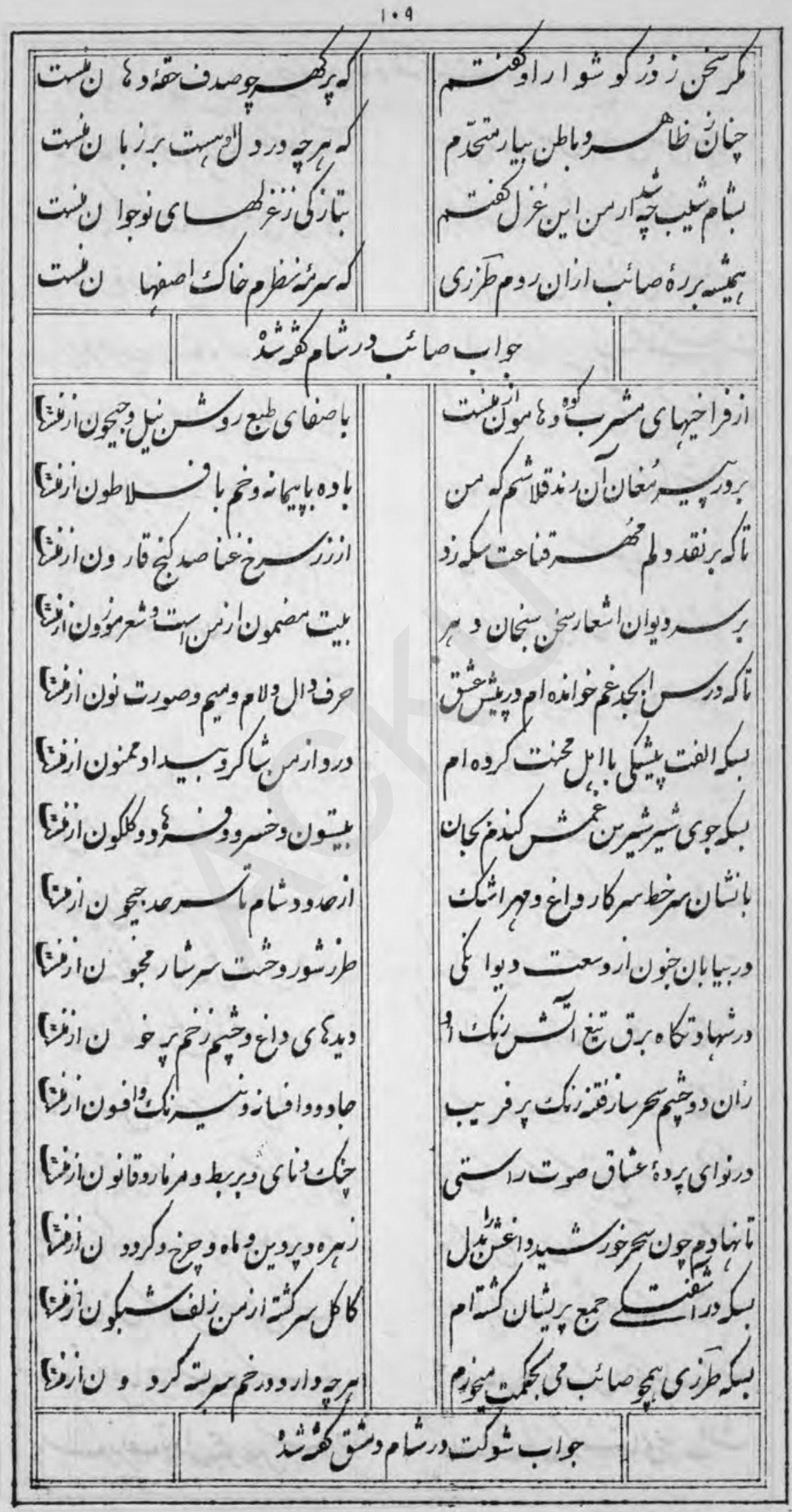


11.

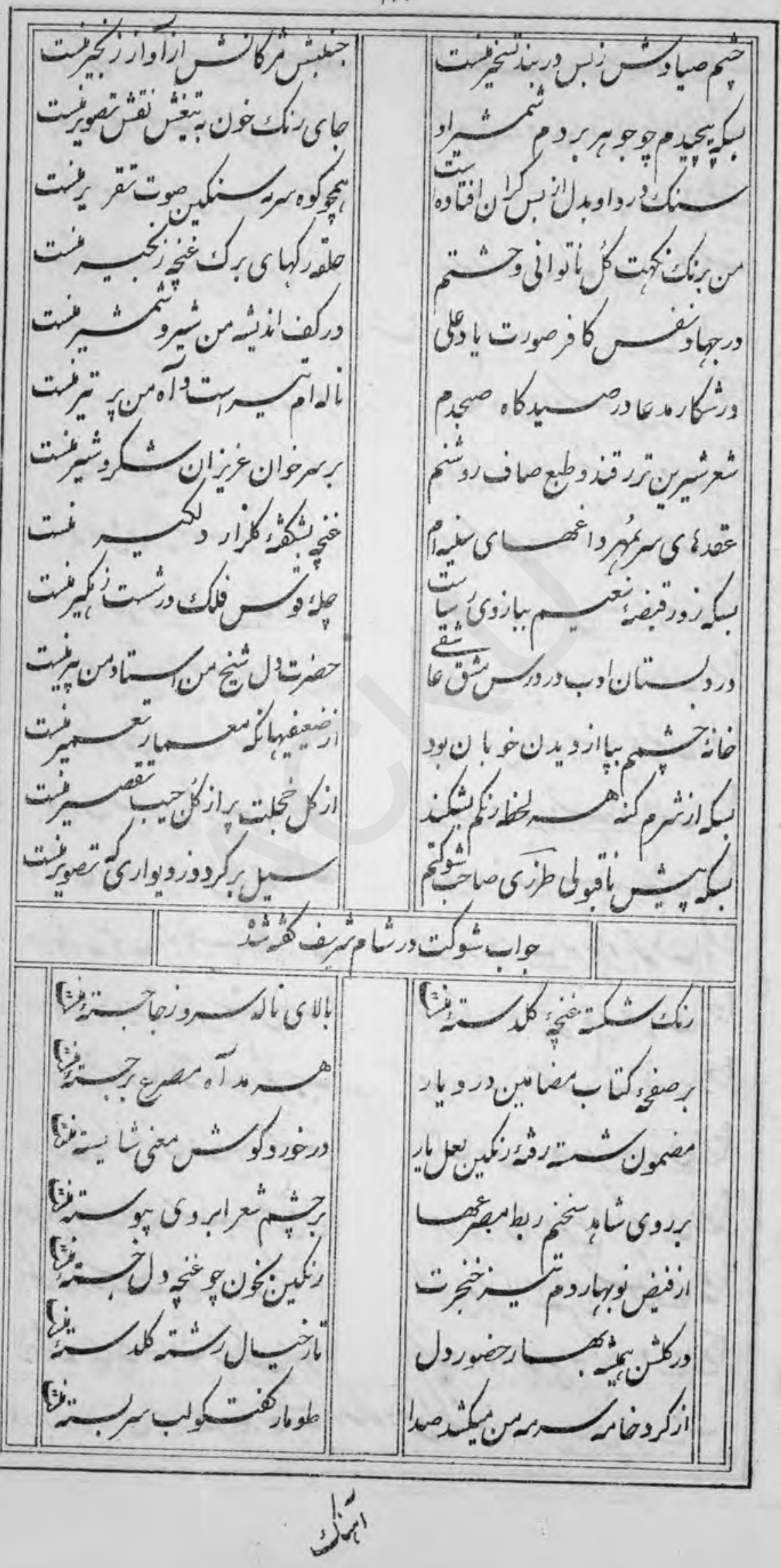


HI

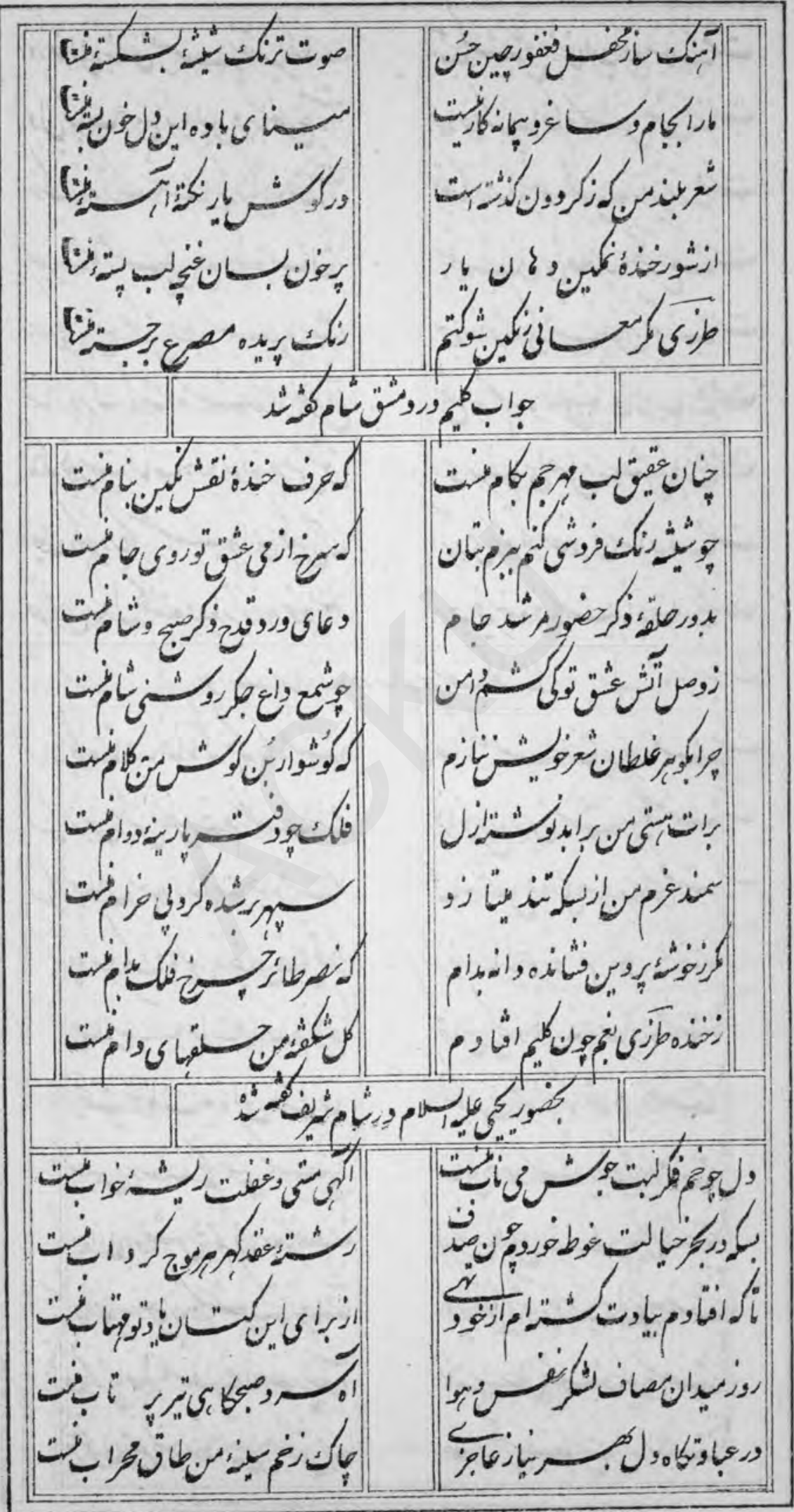




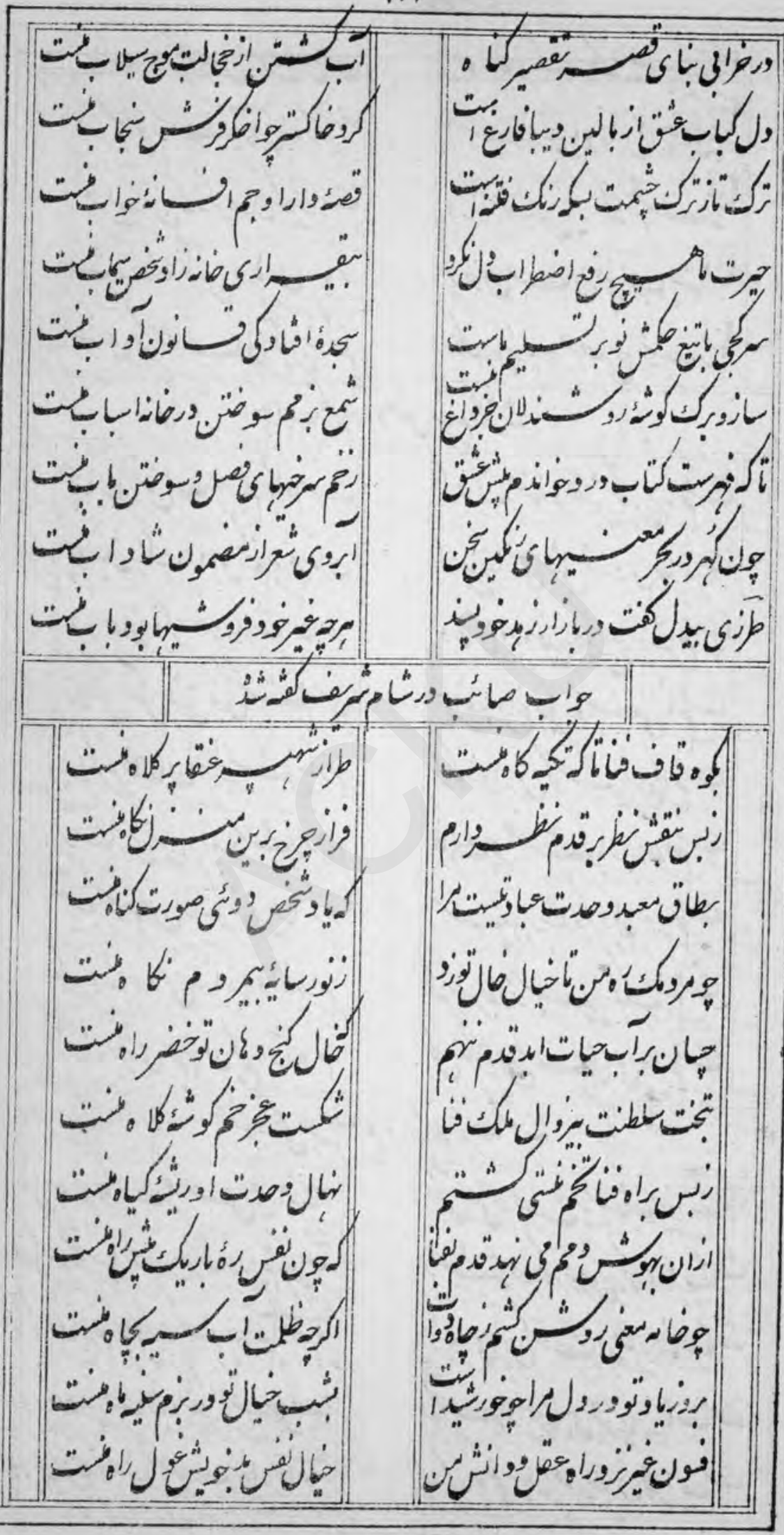


ir

||




\section{$1 / 0$}

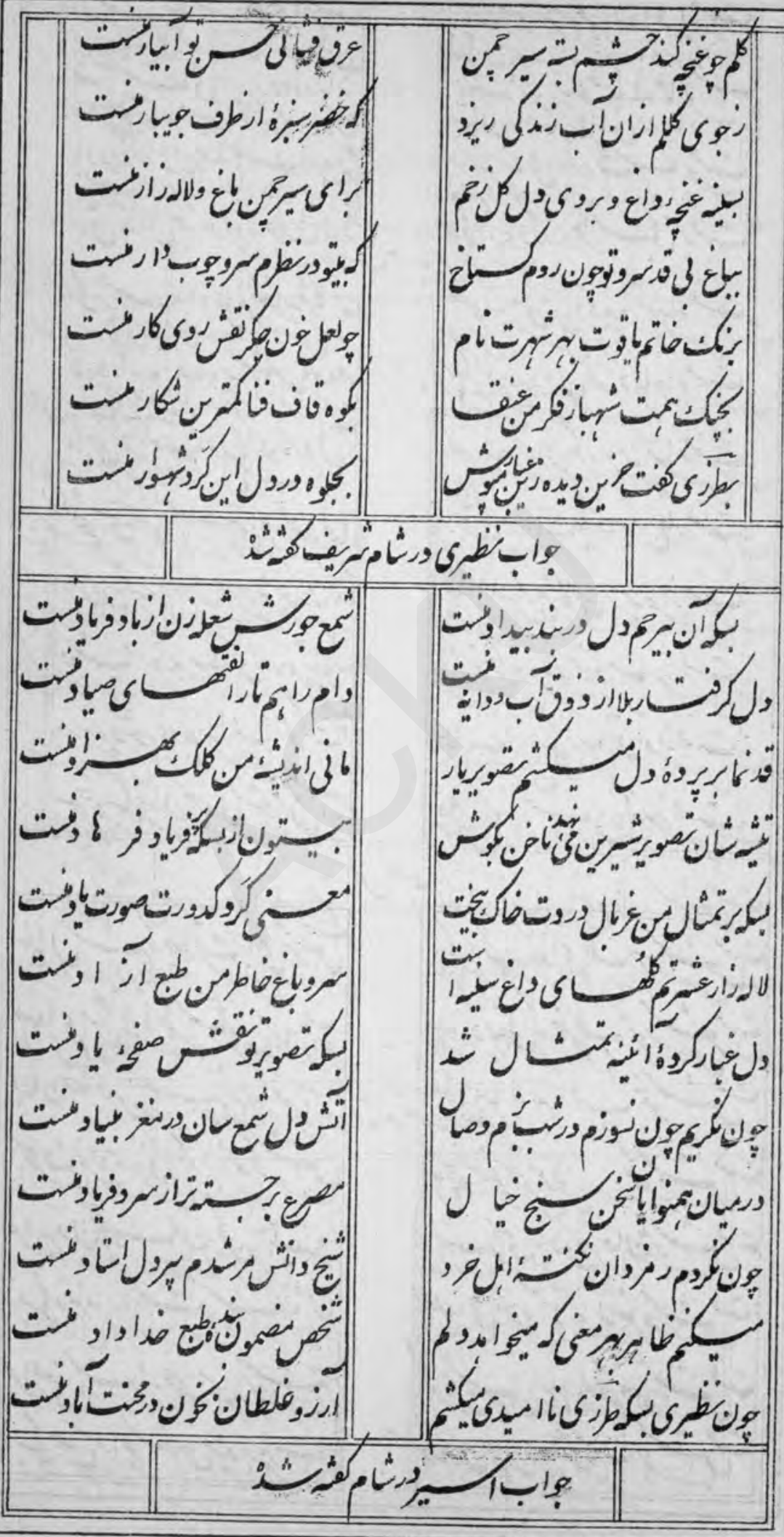


110

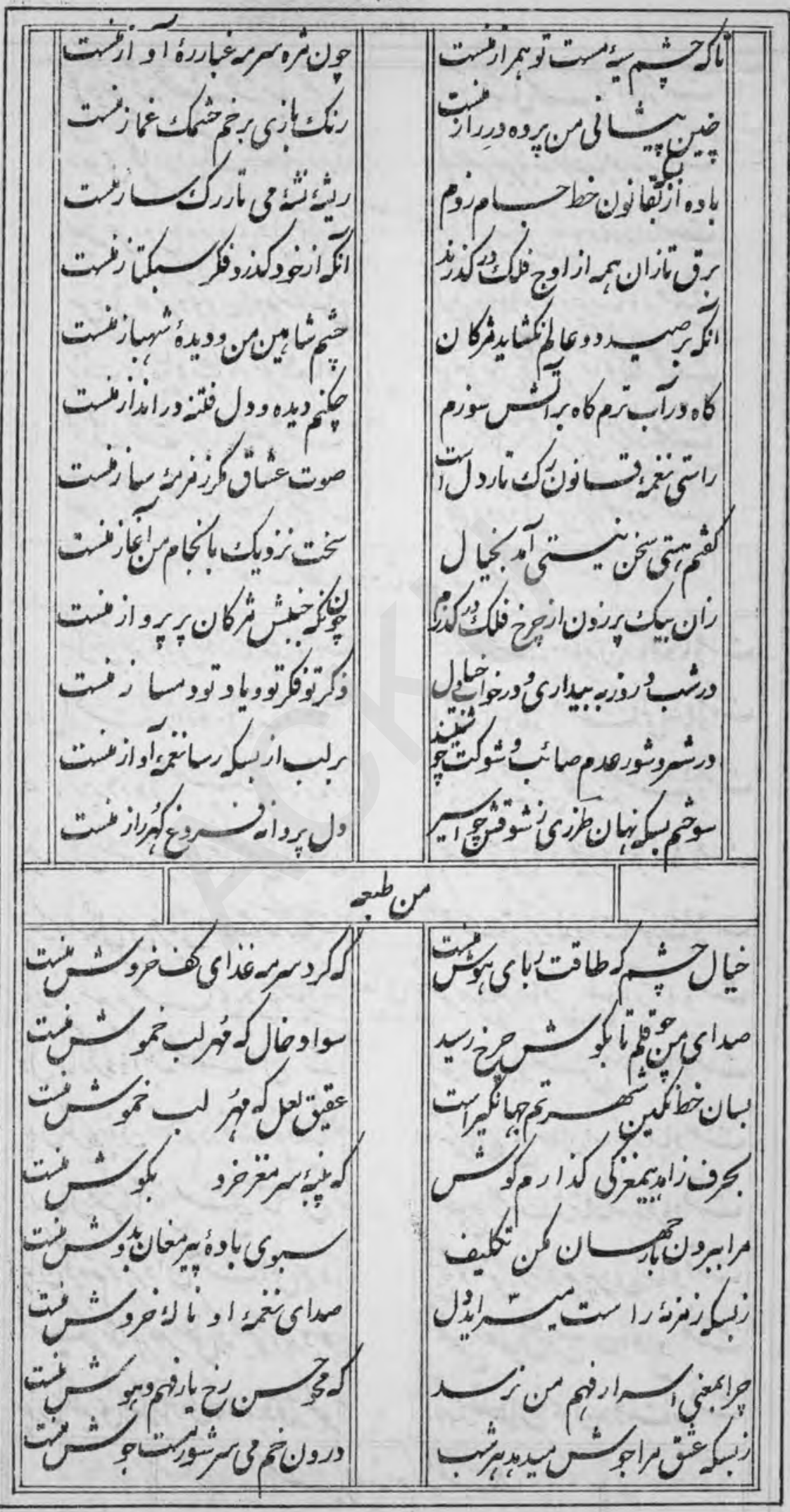


118

|

"'bا' 
116

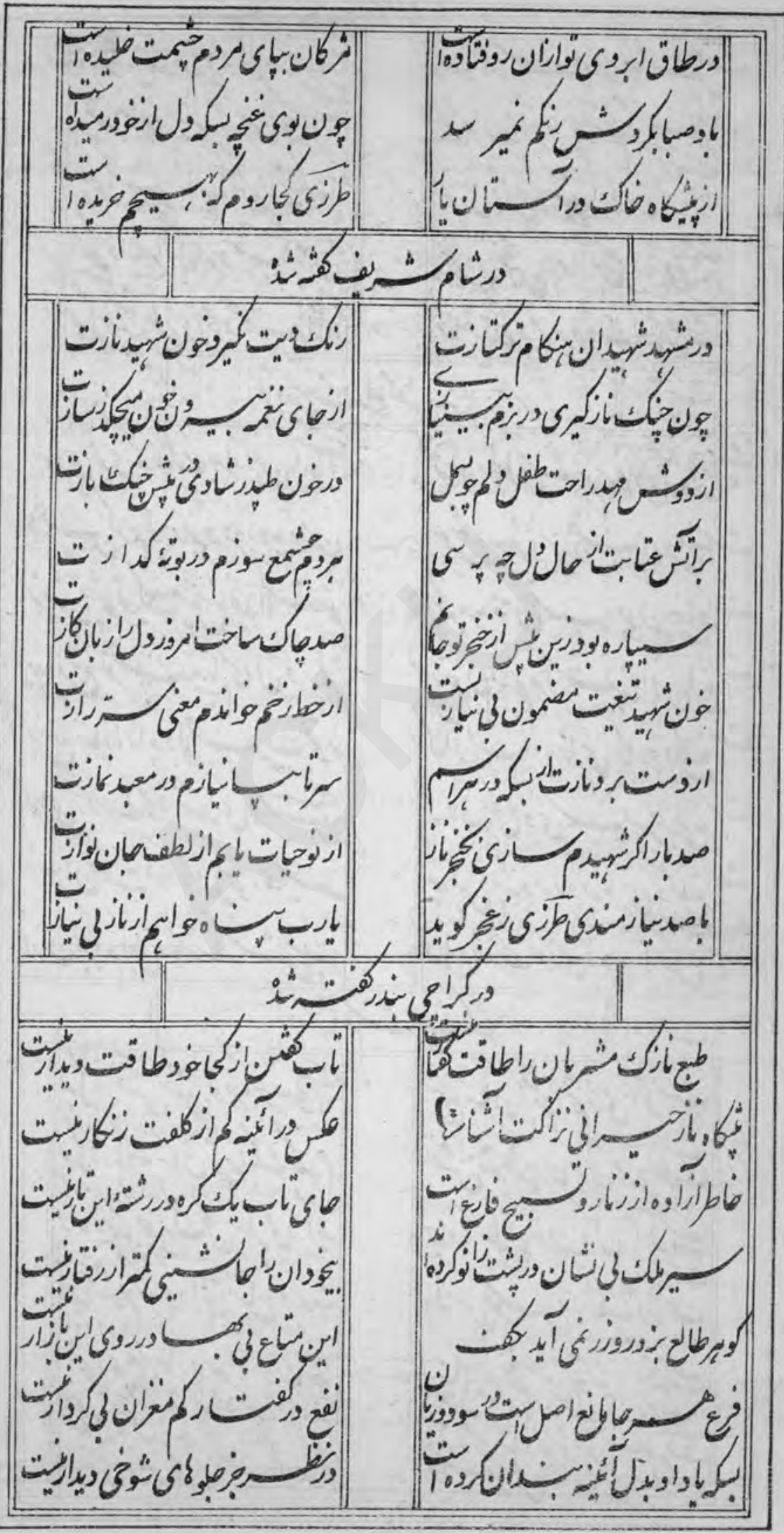


IIA

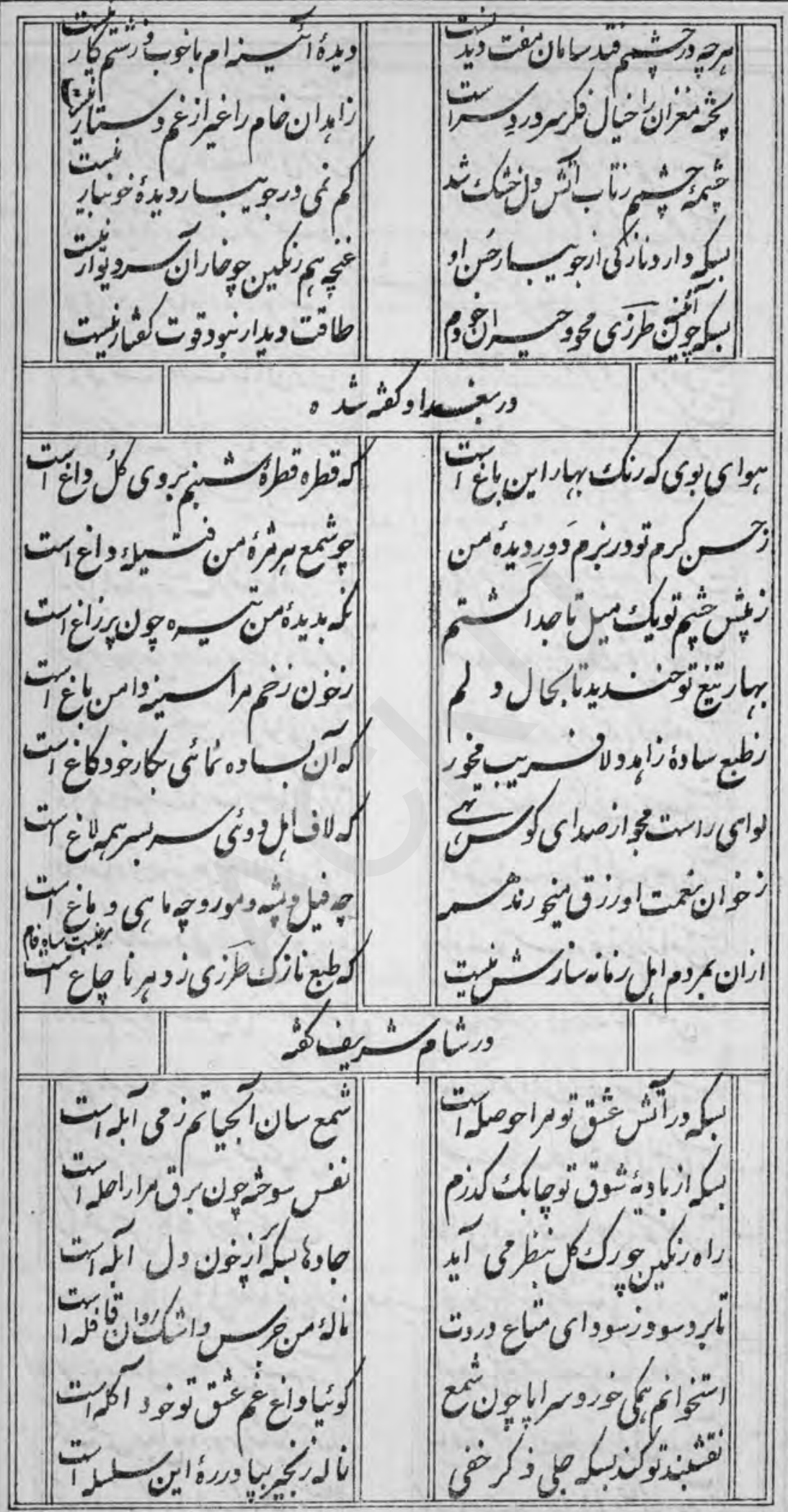

ow 
119

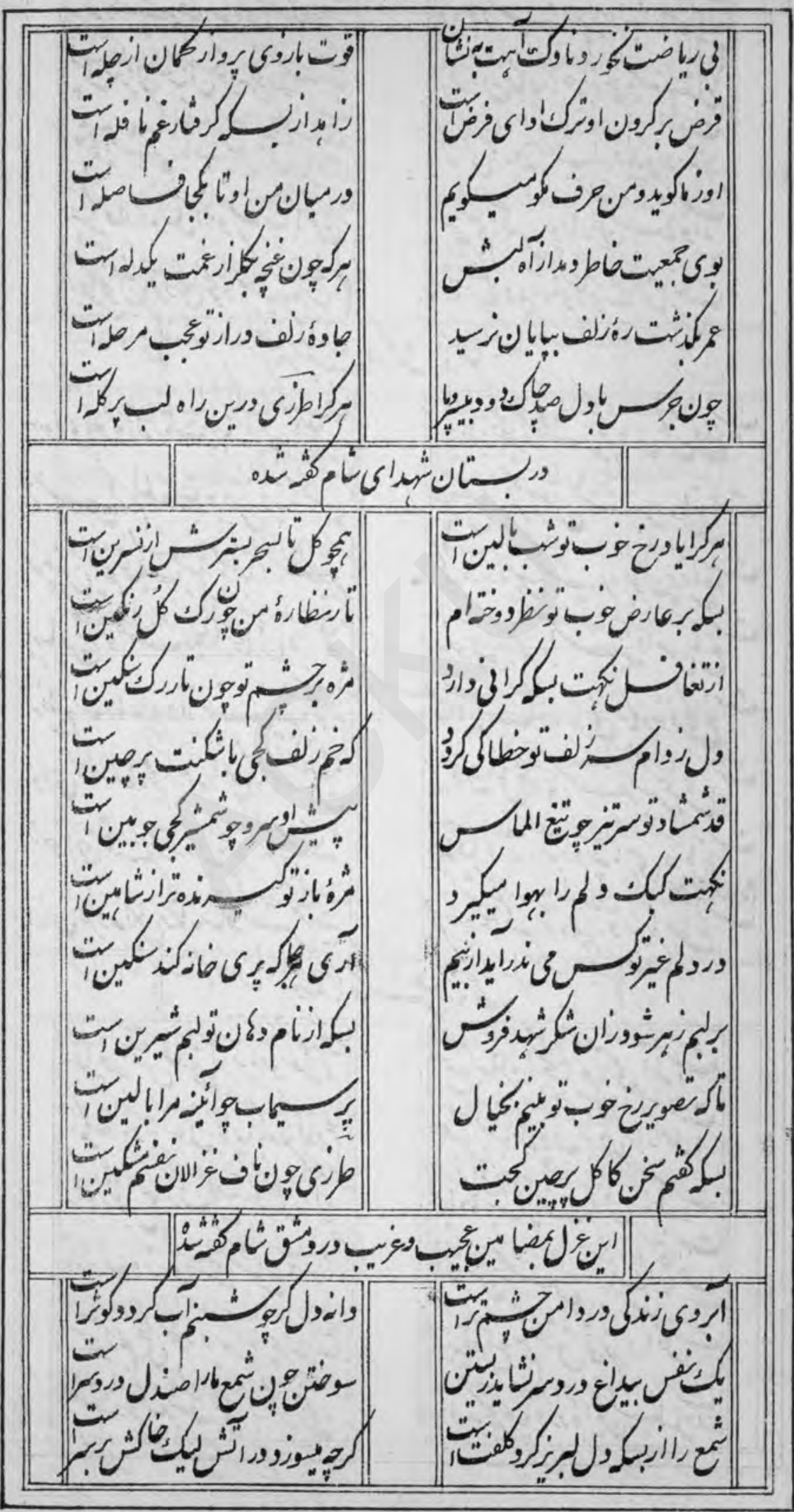


Ir

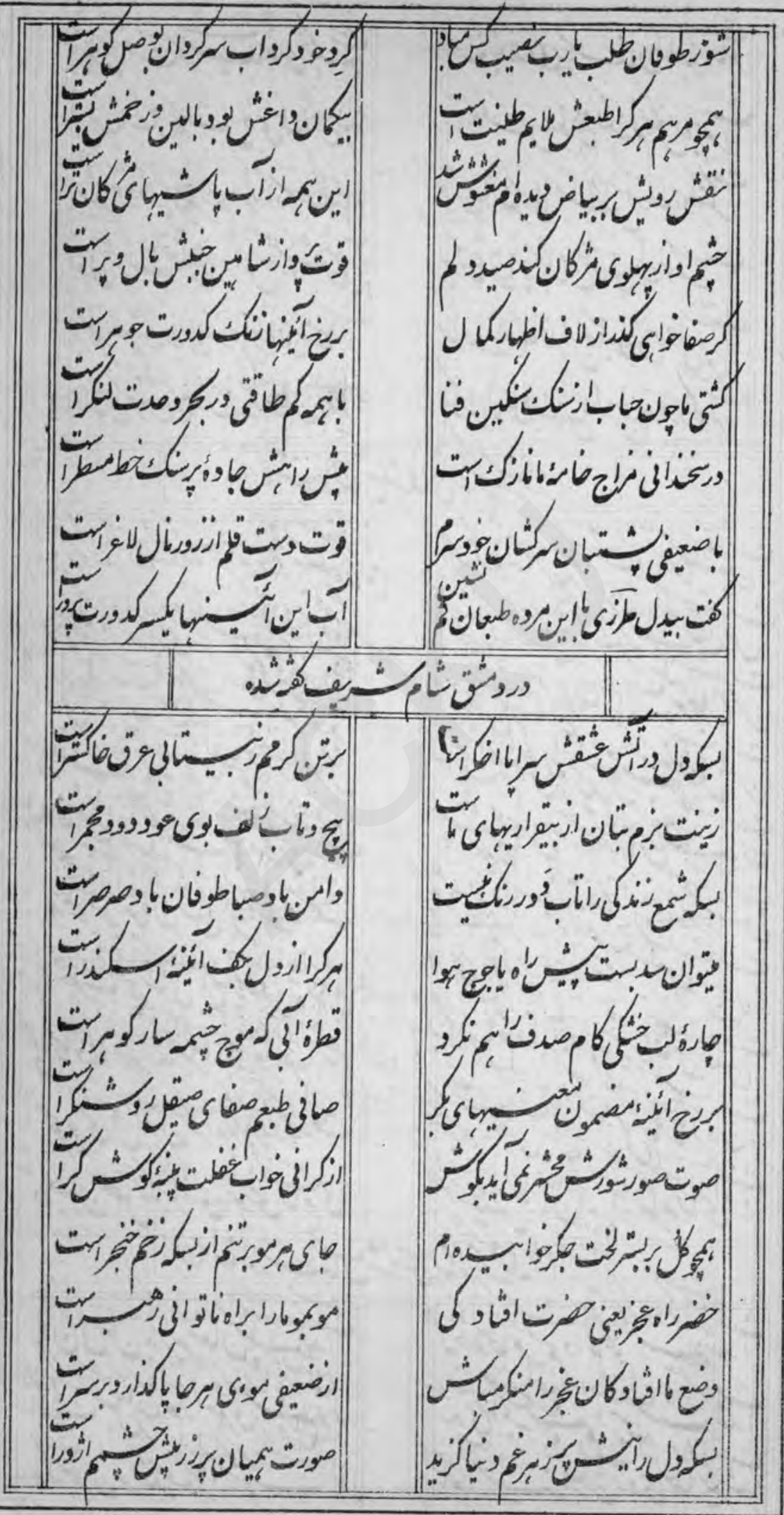




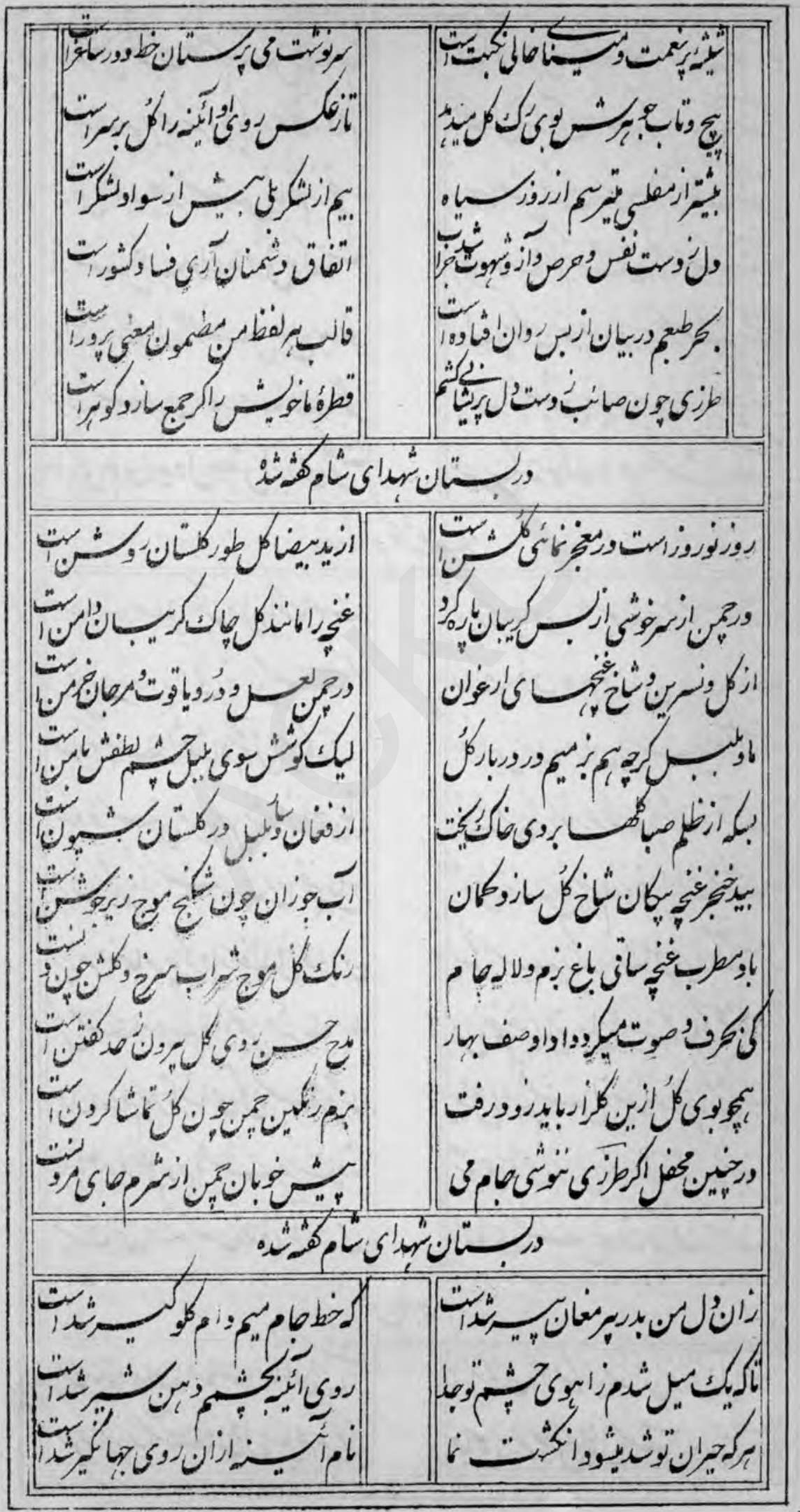


Irr

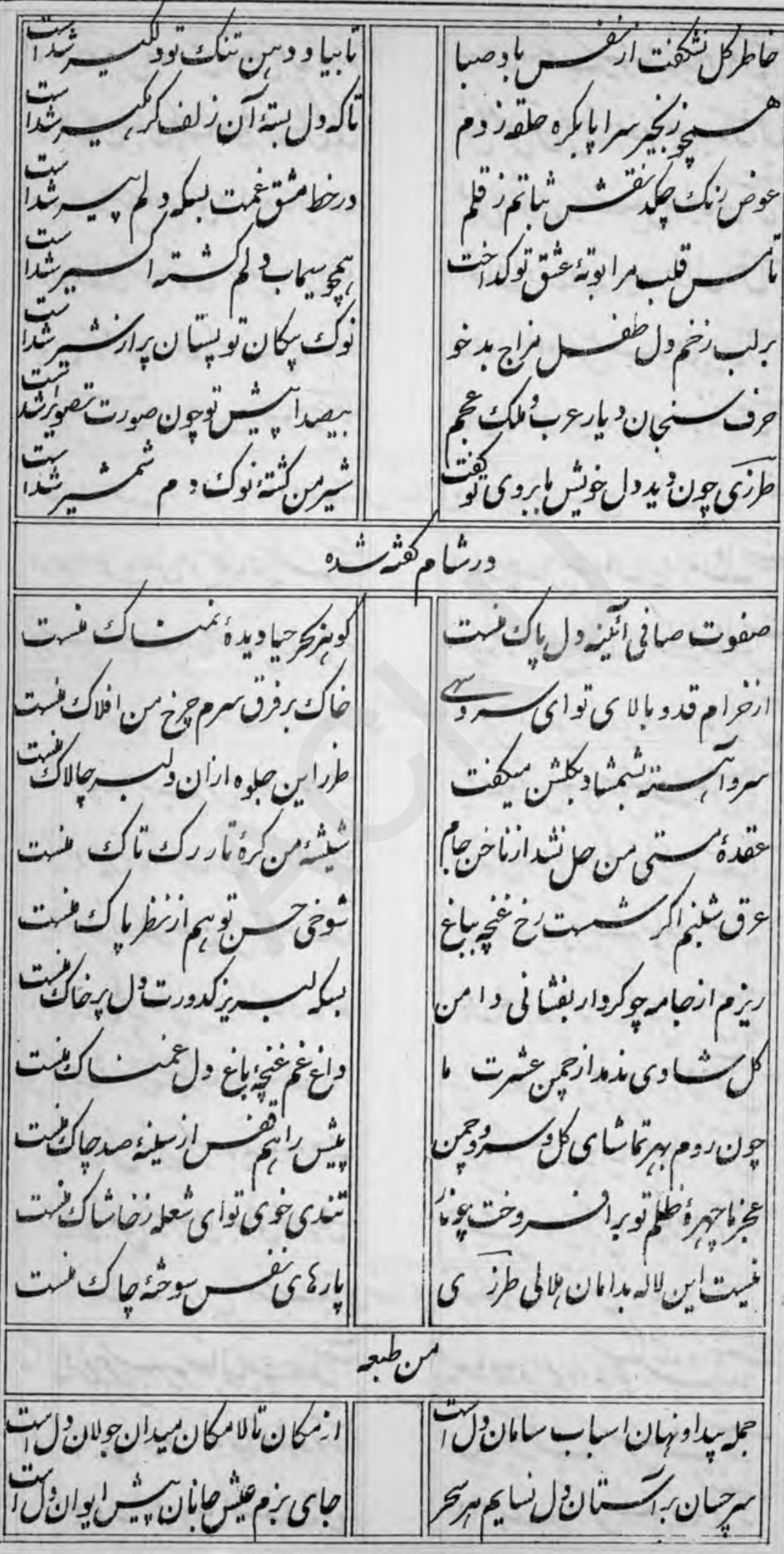

$\left(90^{\circ 6}\right.$ 
Irr

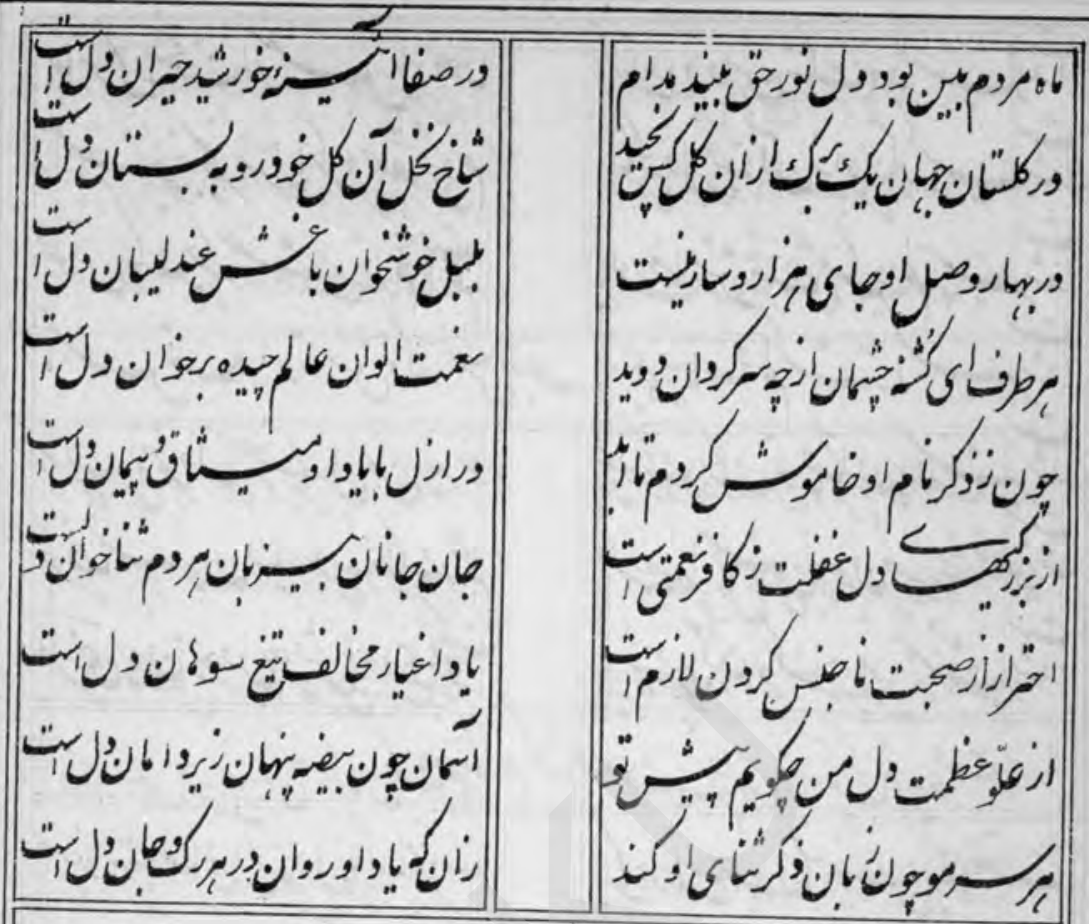

|




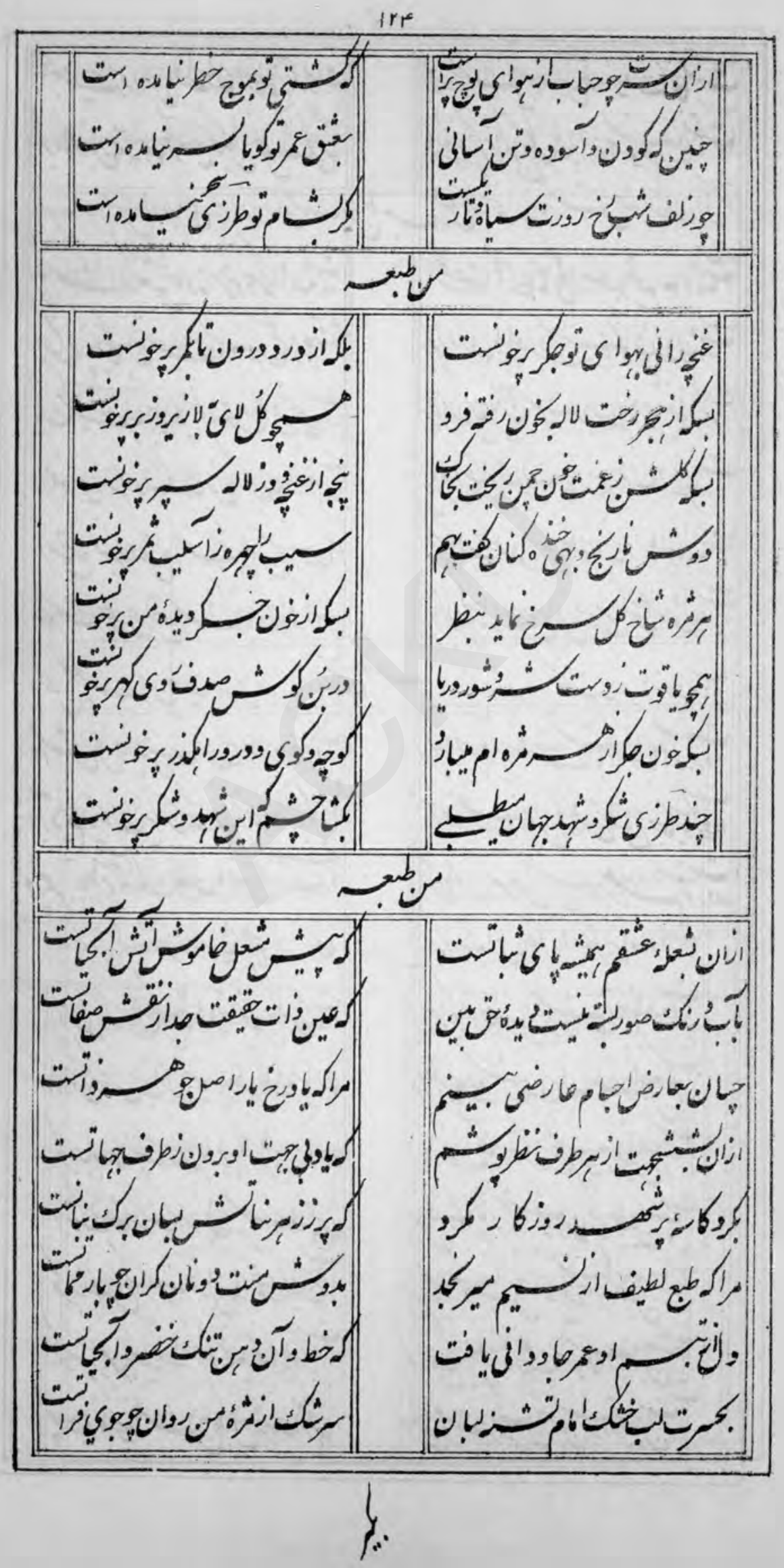


100

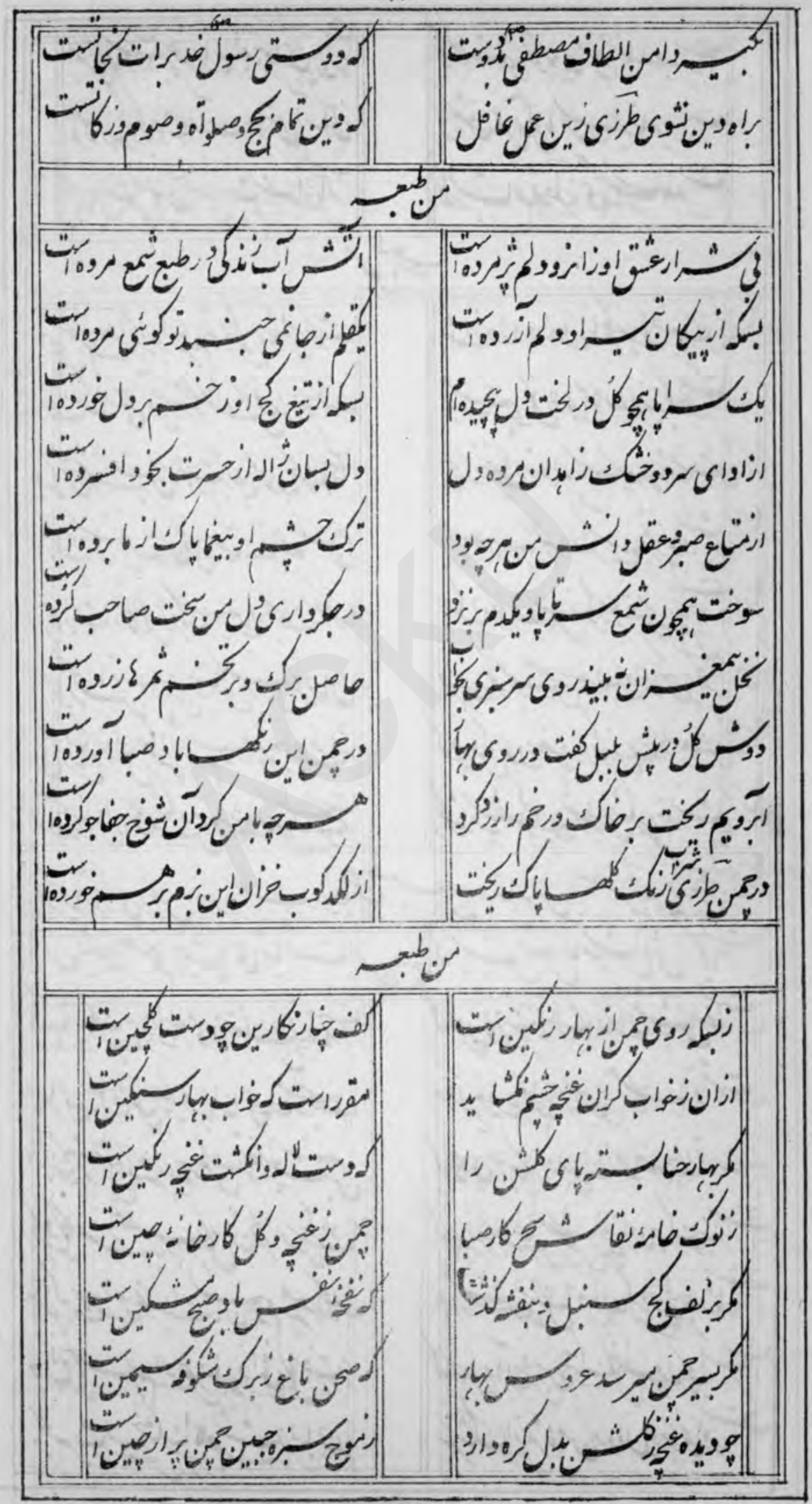




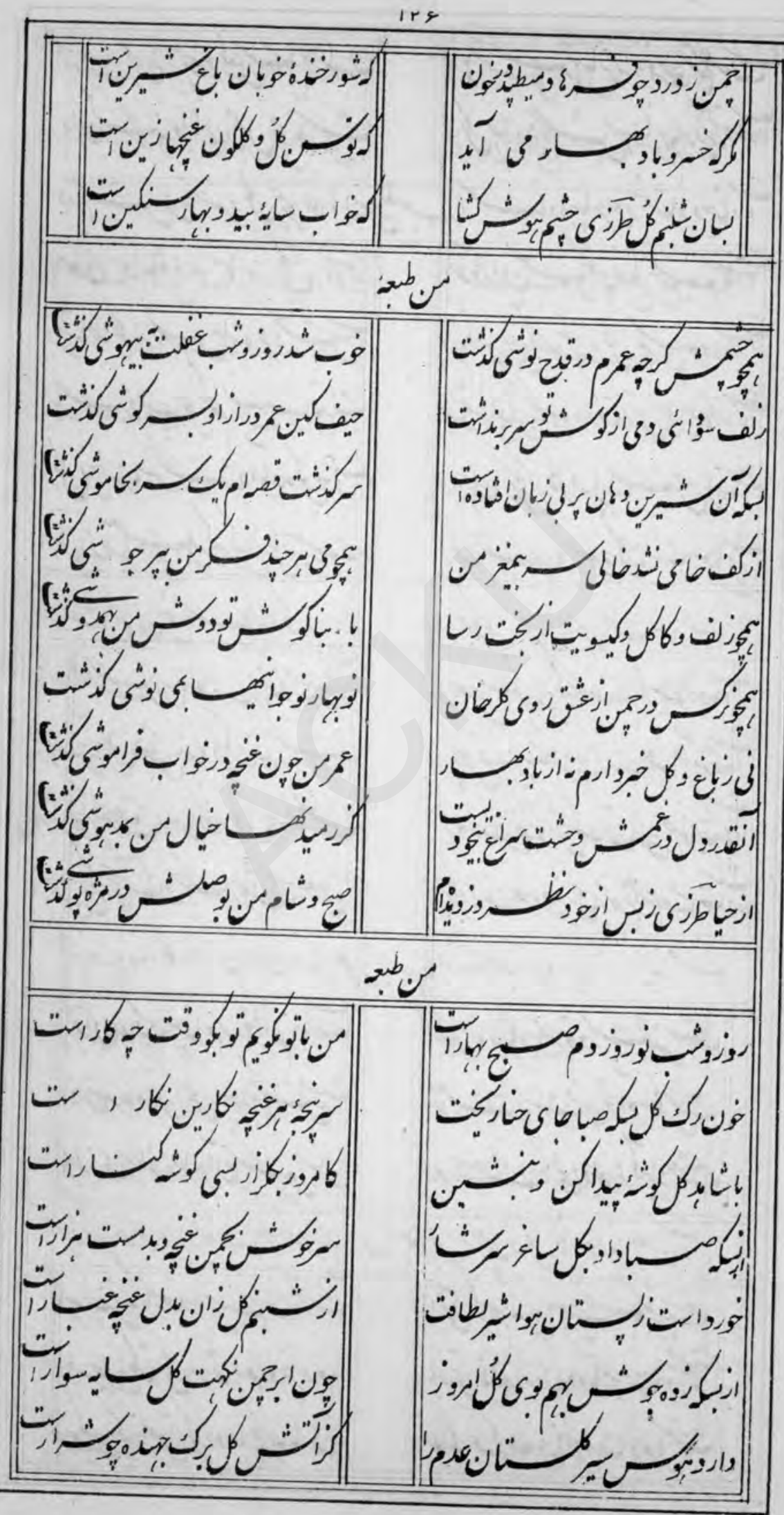


Ire

|| $\mid$


$15 \pi$

(1)

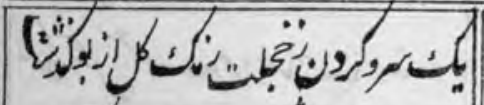

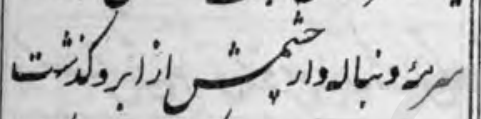

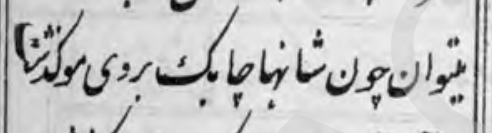

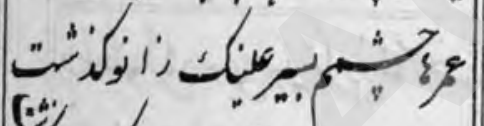
(4).

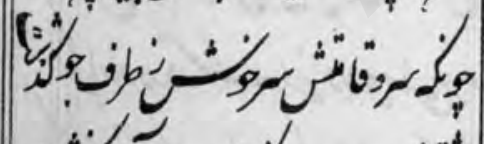

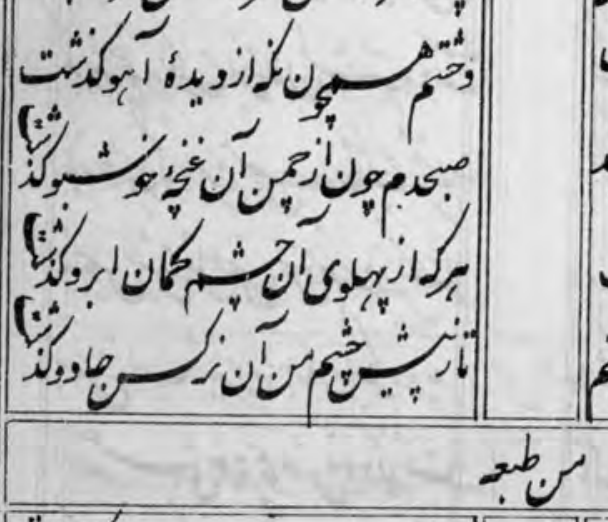

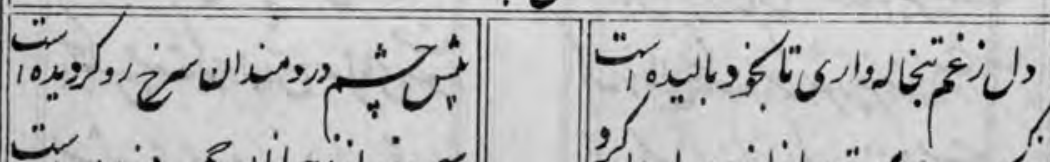

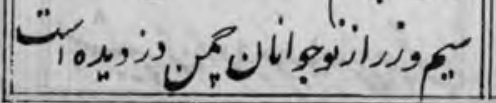
و

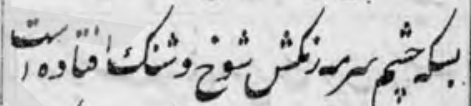
كbrovitists "

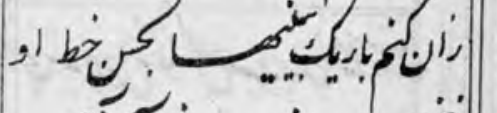

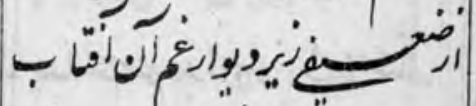

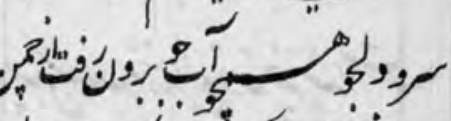

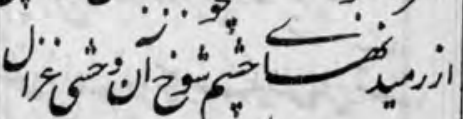

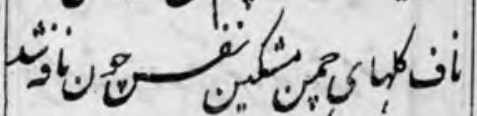

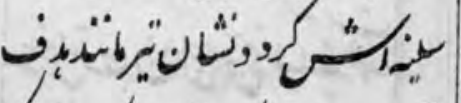

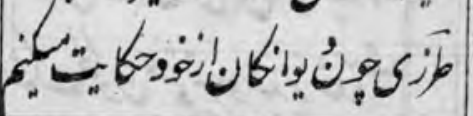

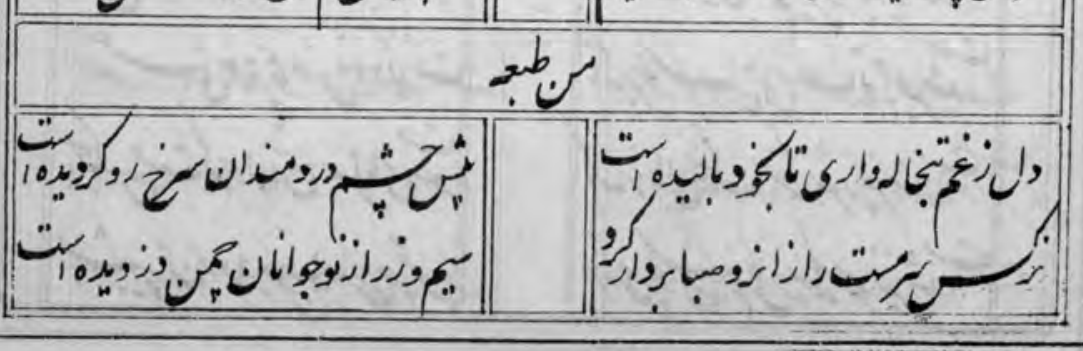


109

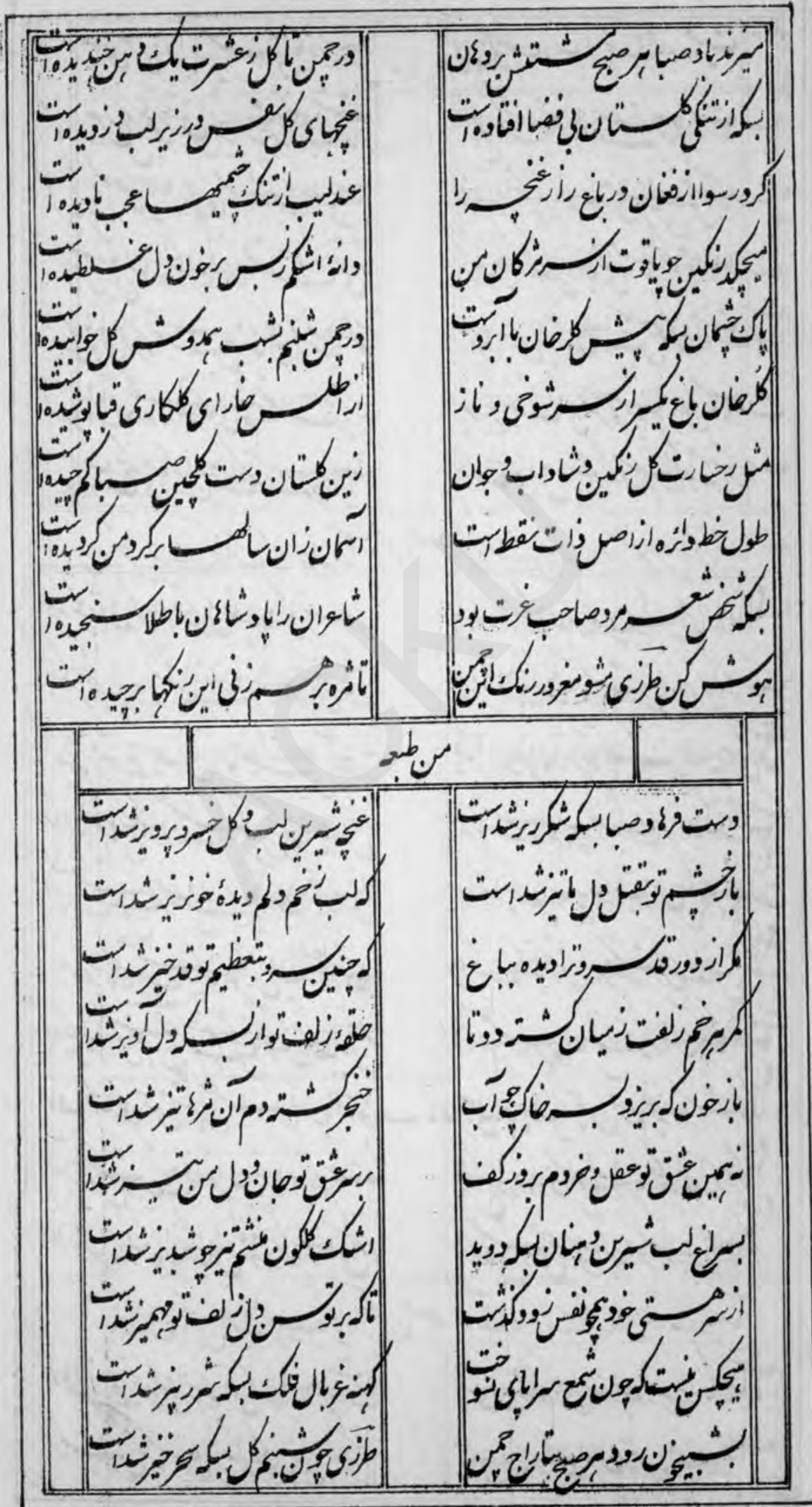




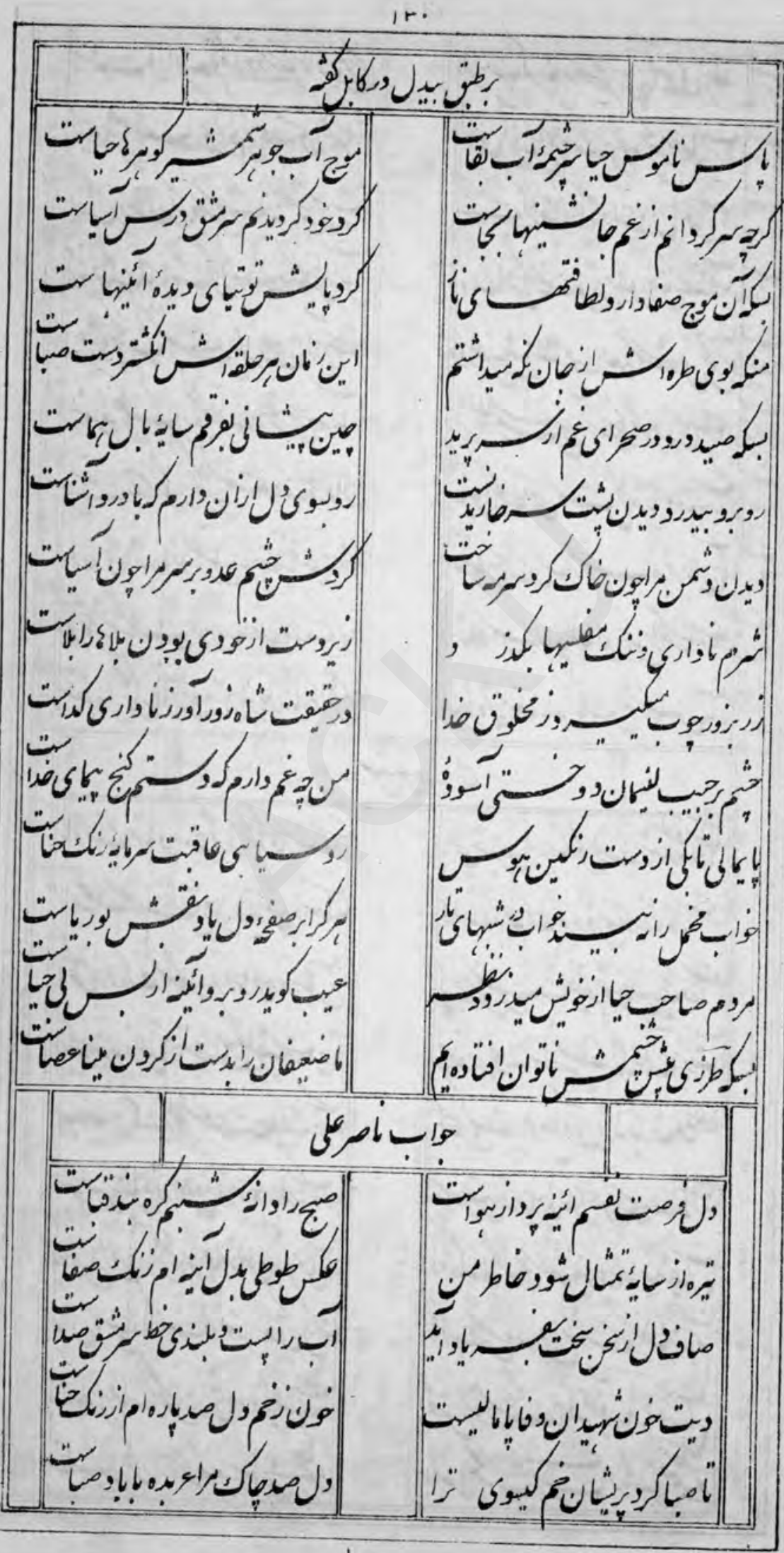




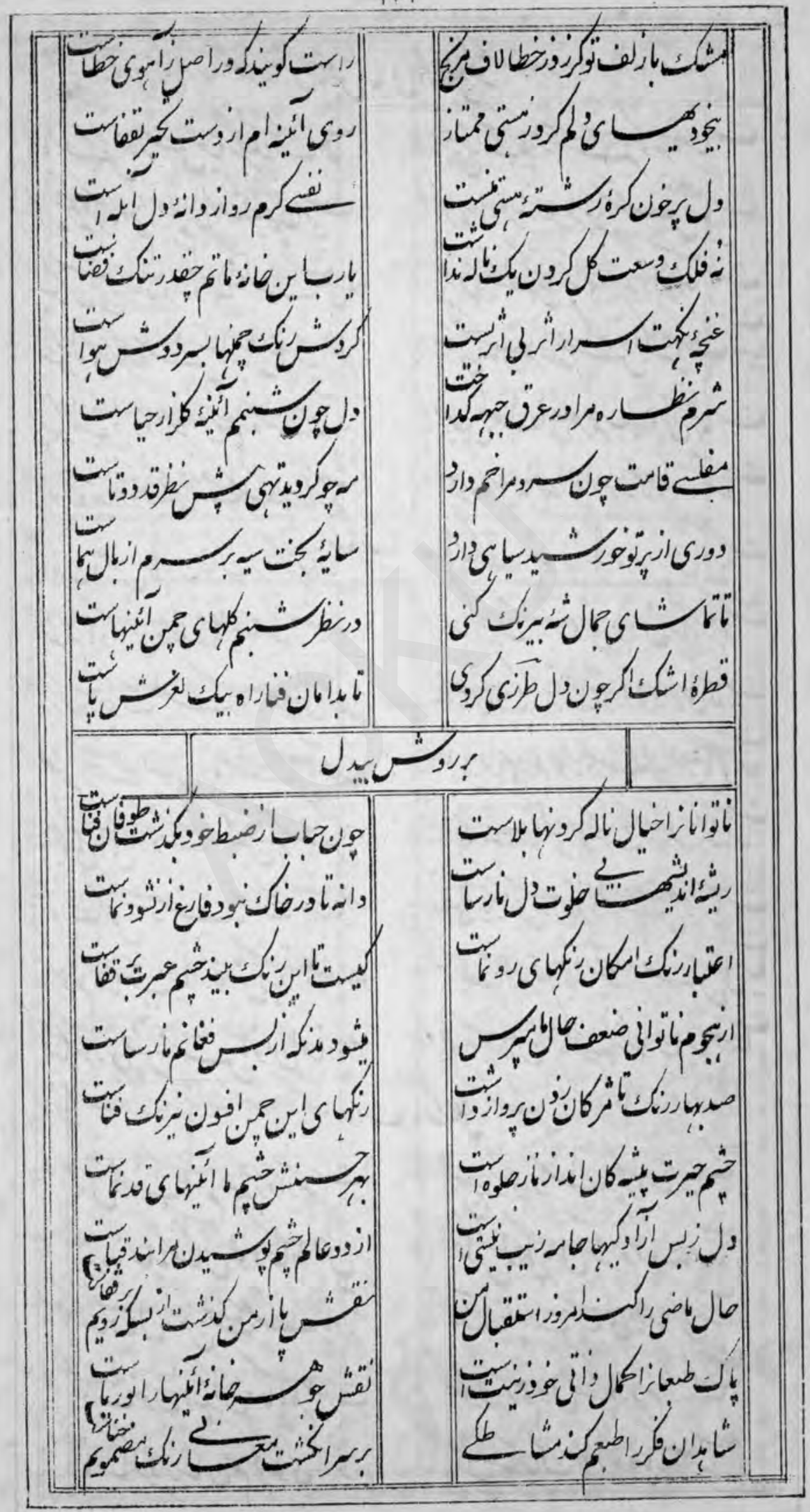


Irr

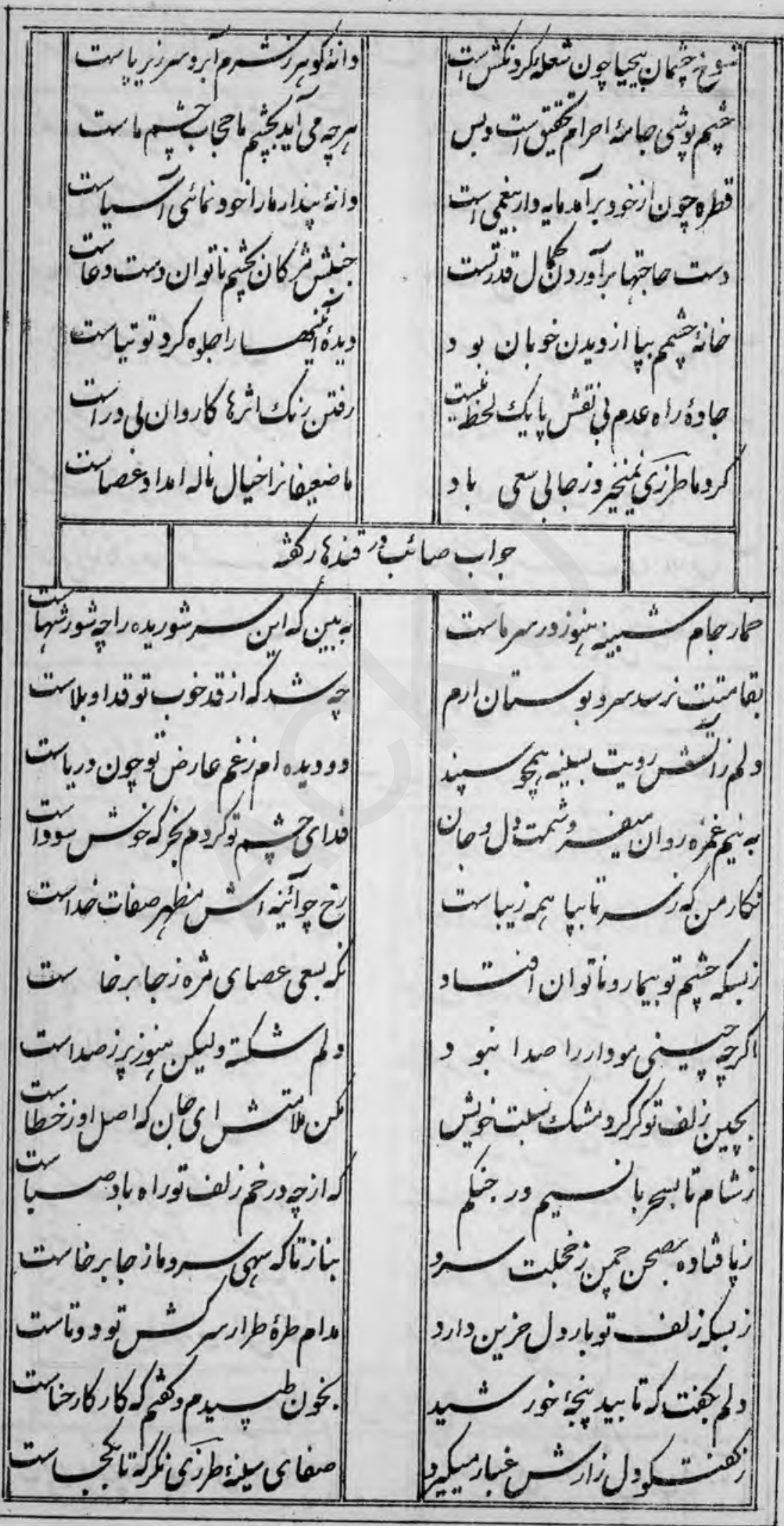


irr

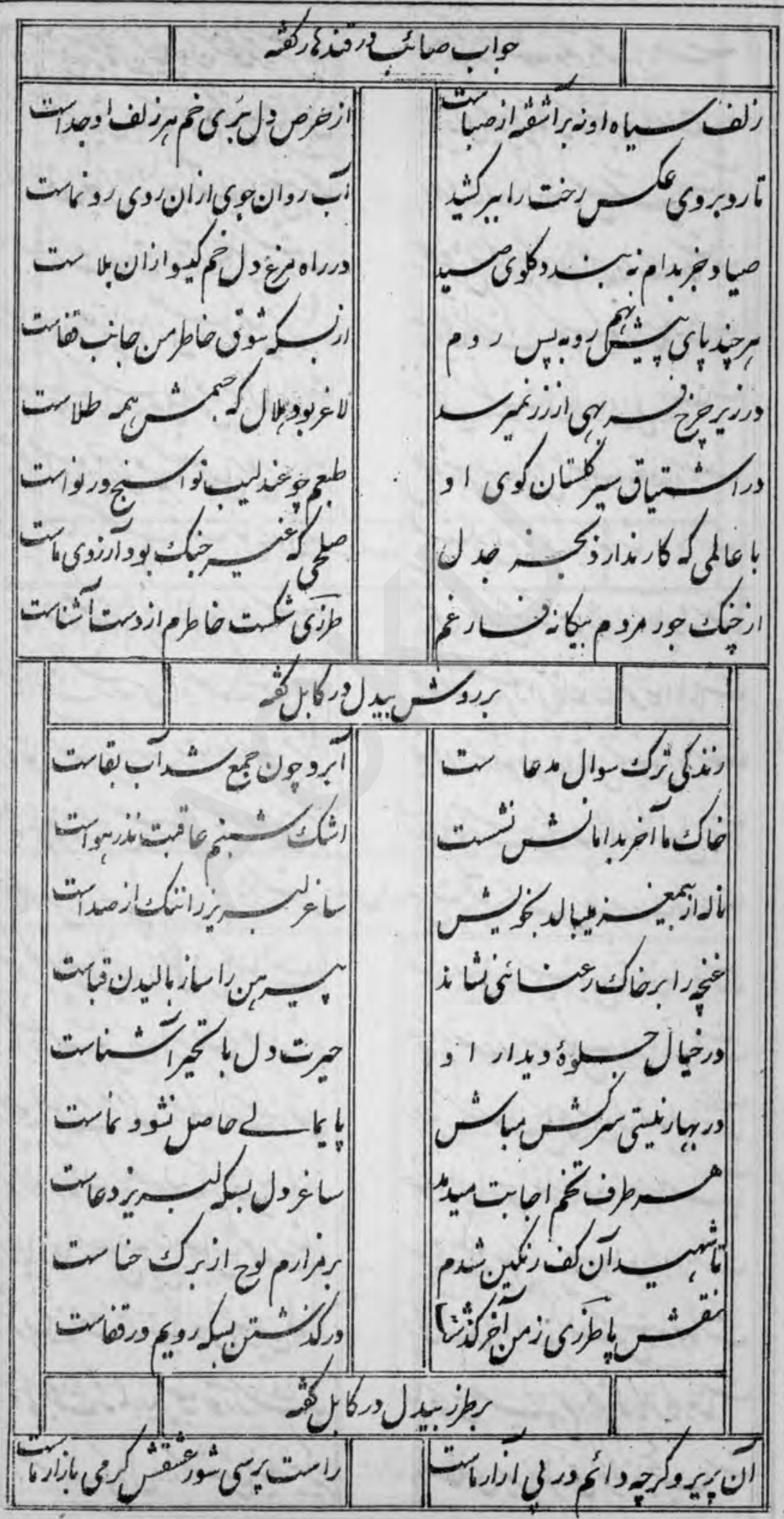


Irt

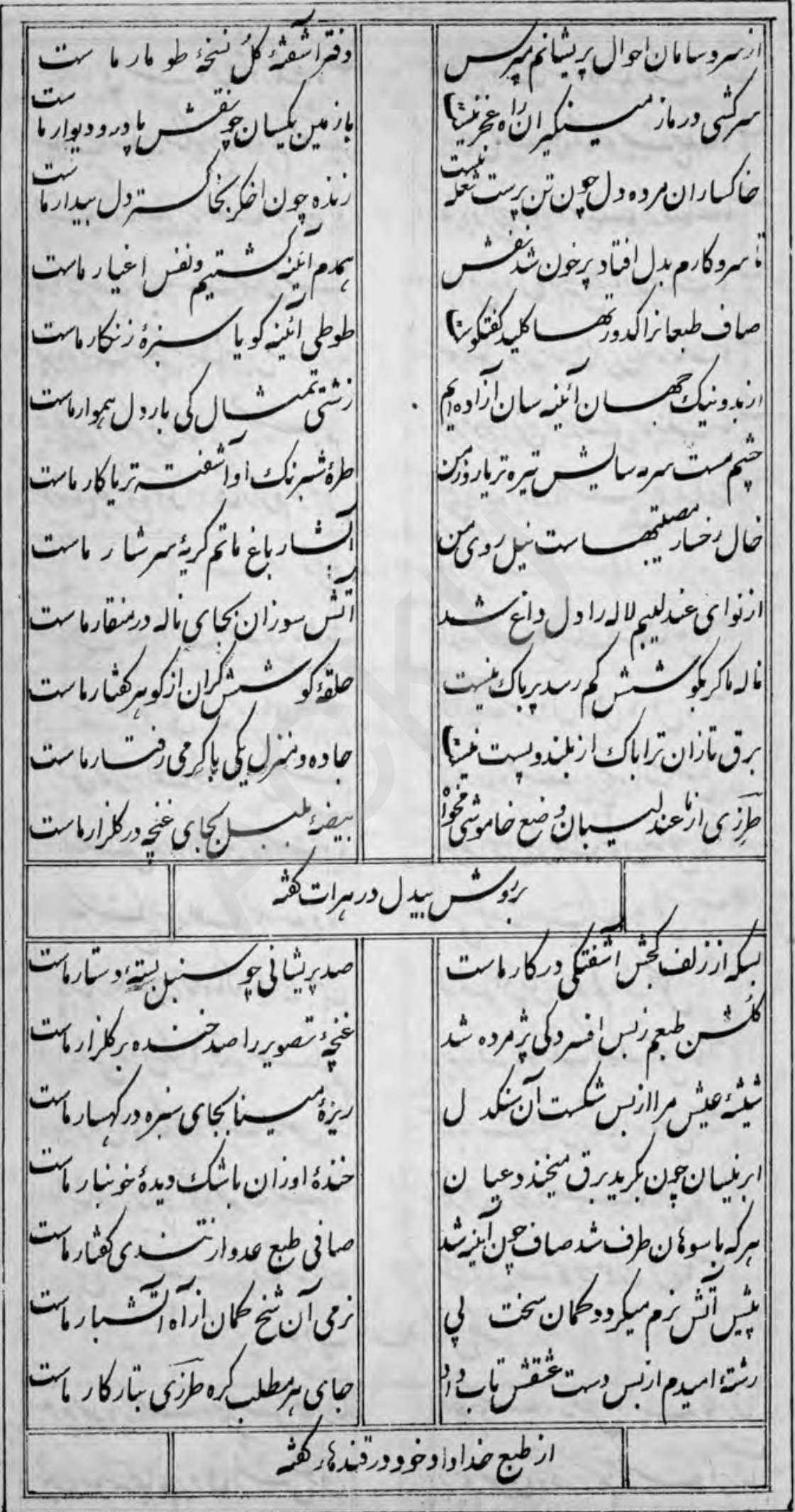


100

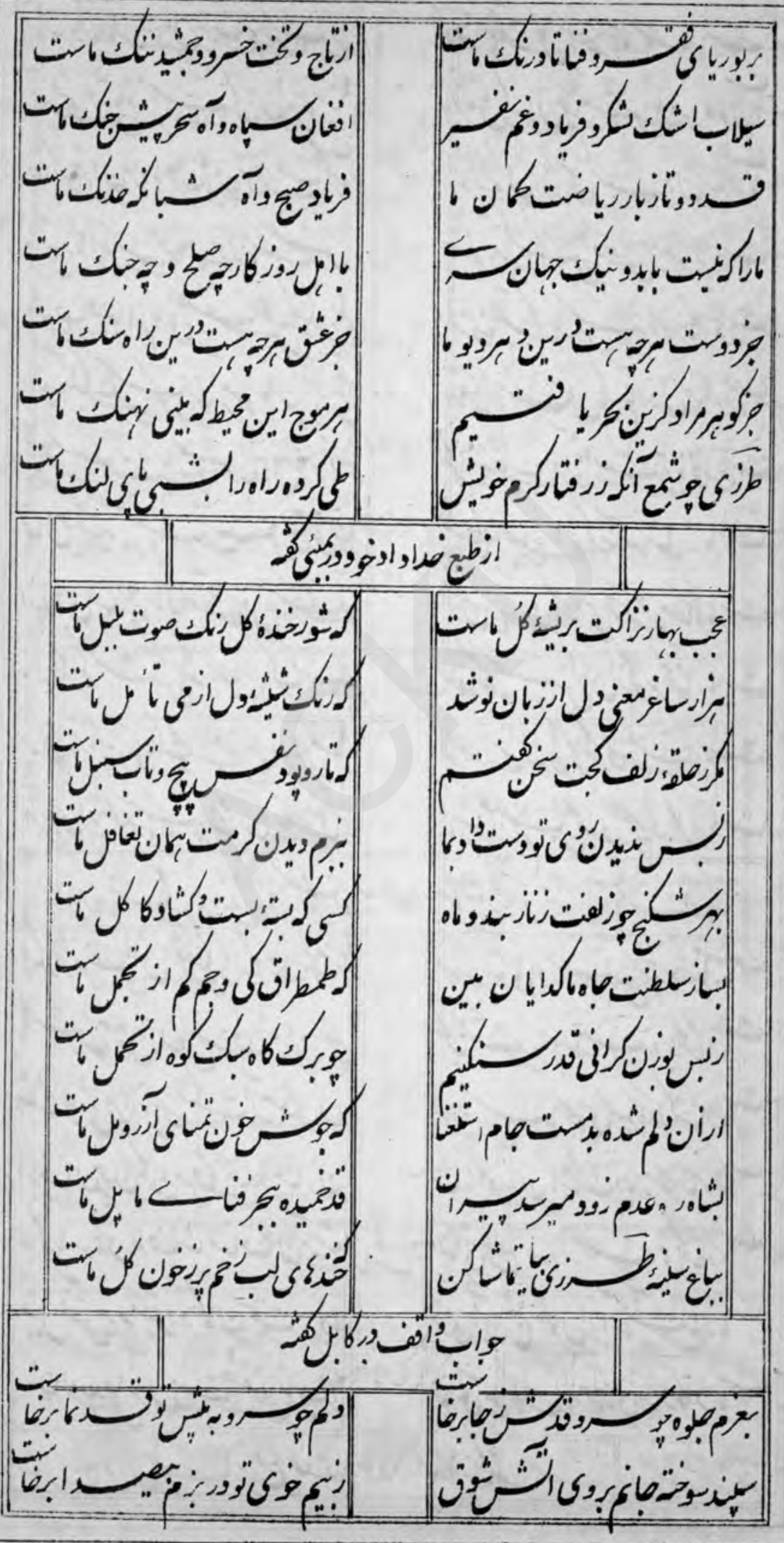


Irs

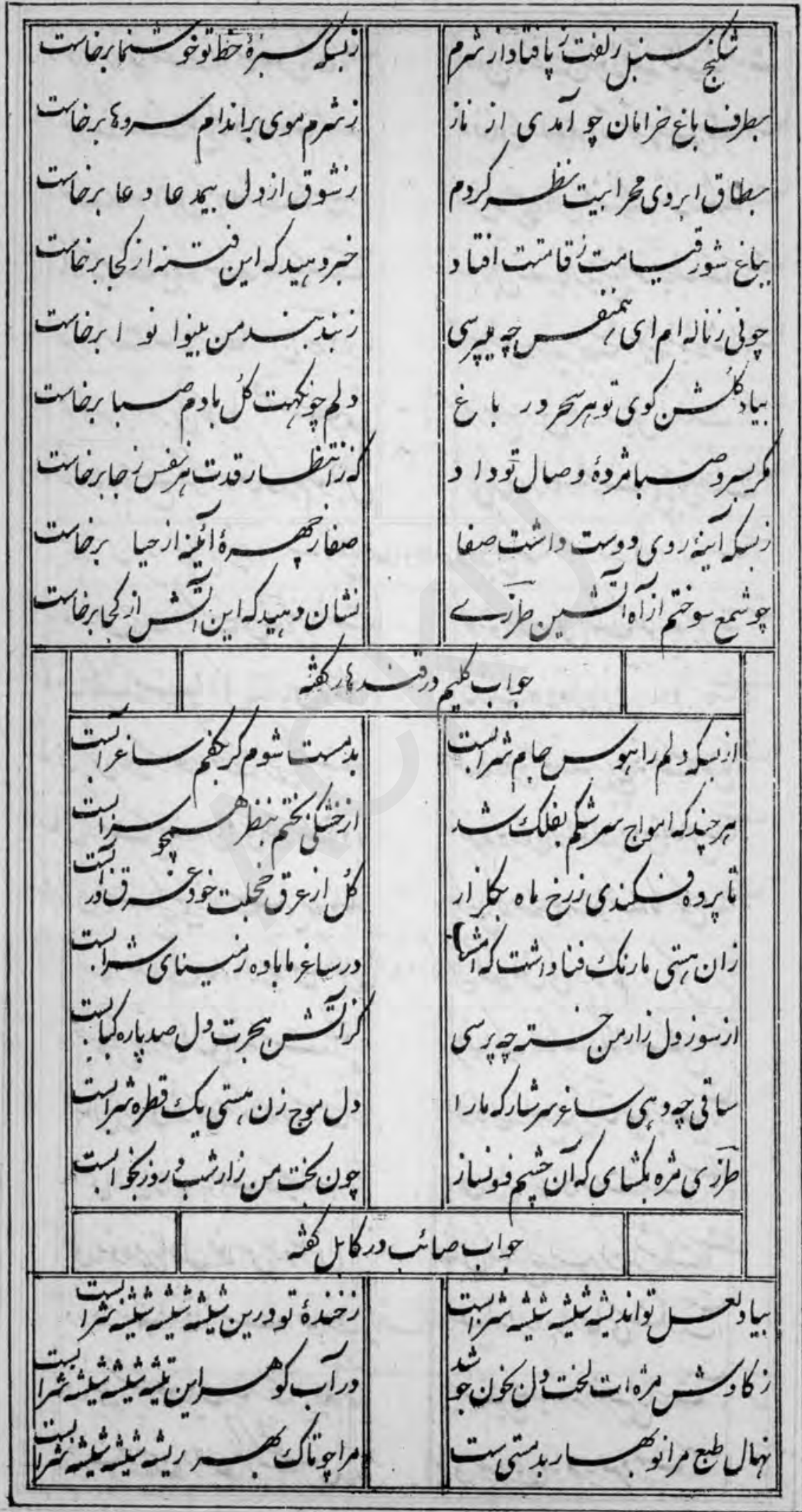


Iルレ

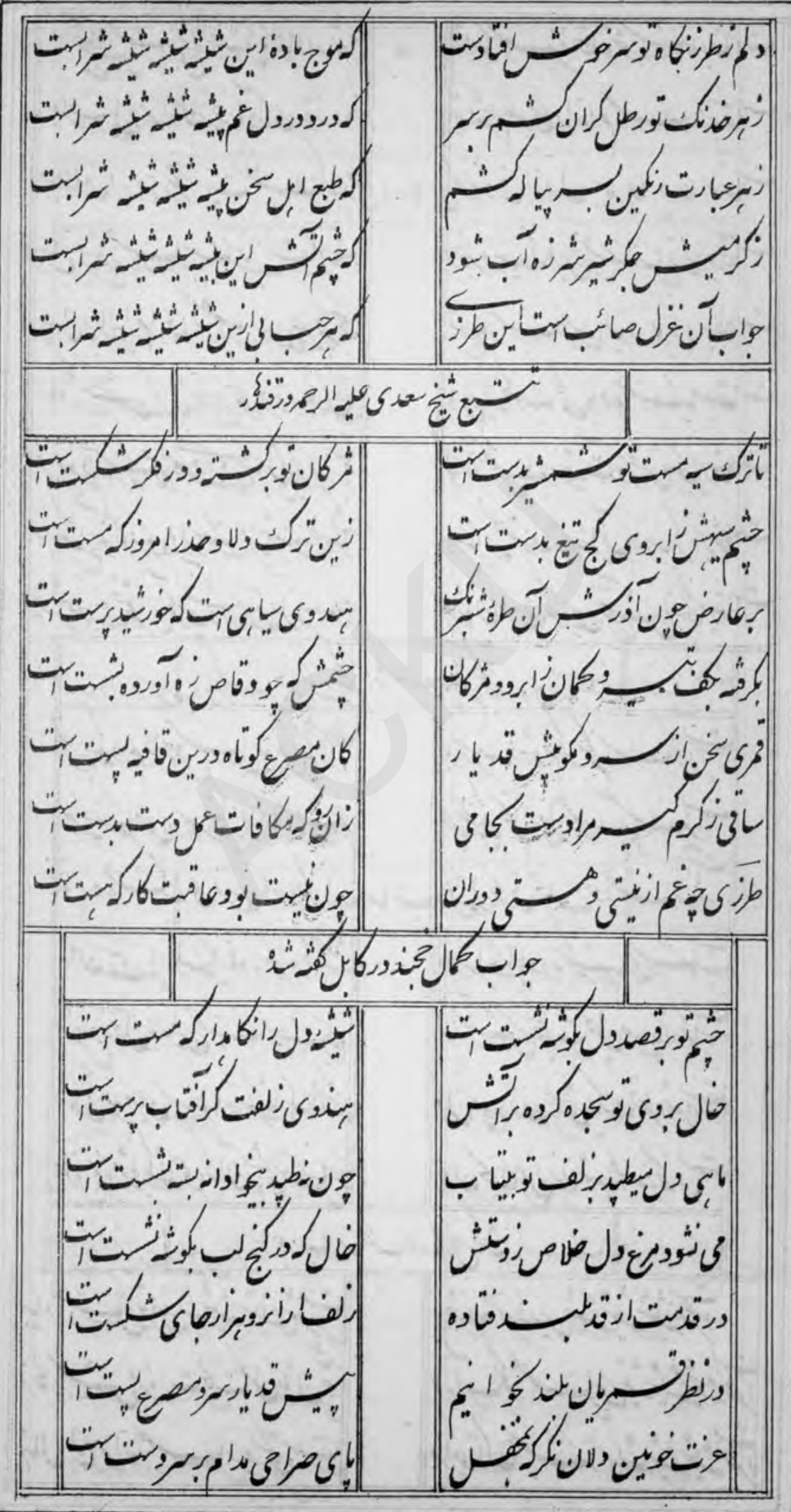




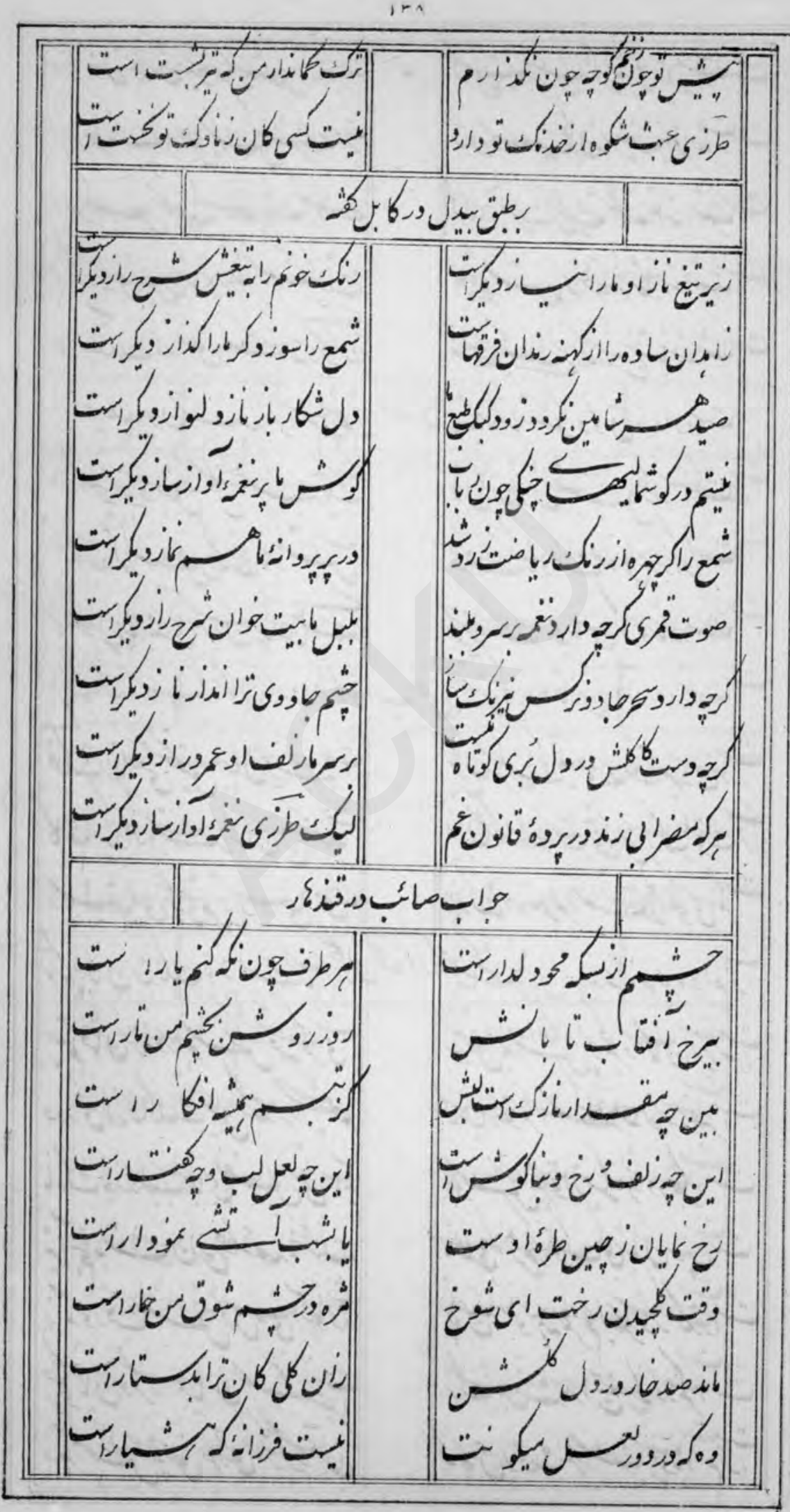


irs

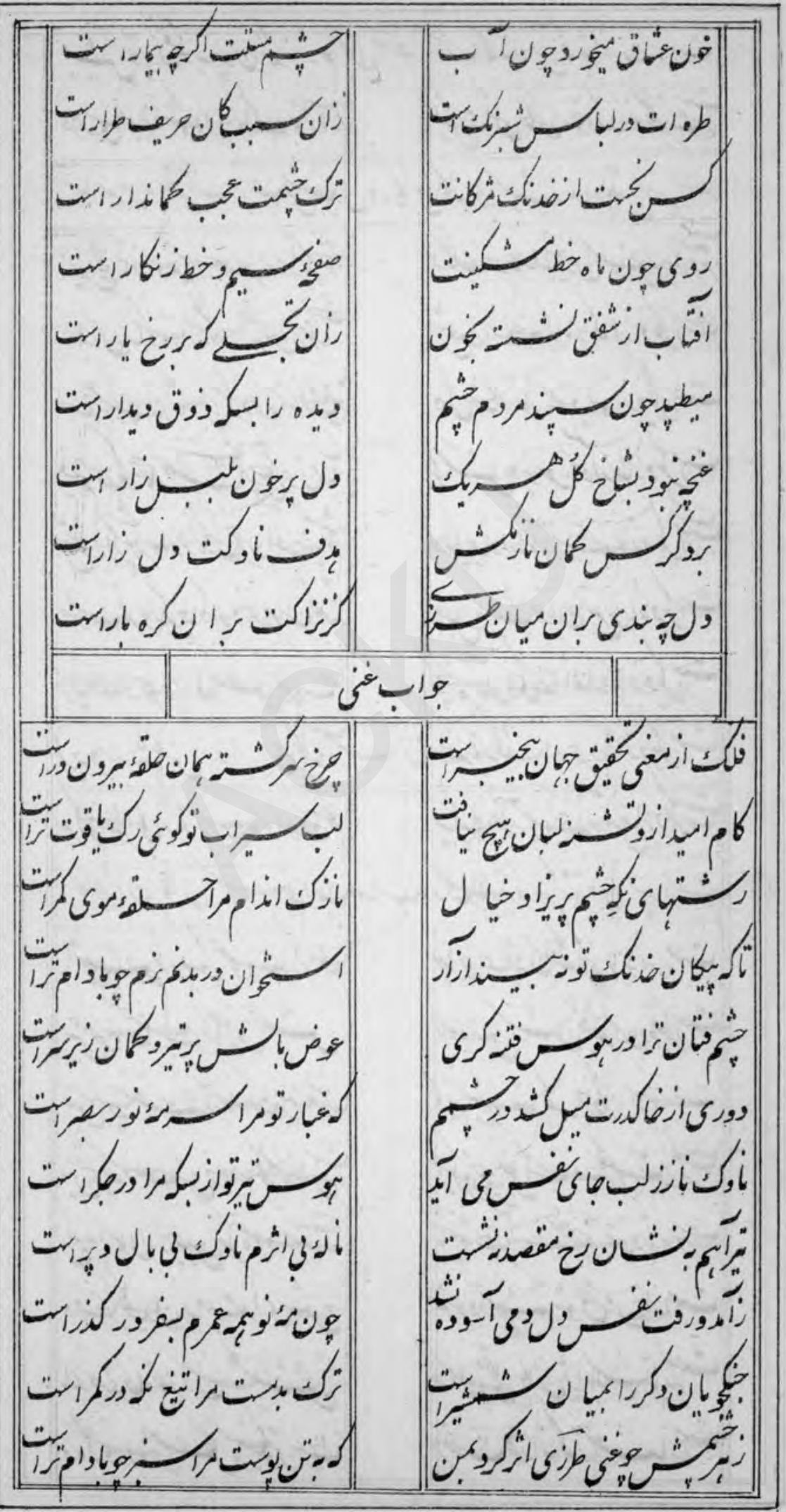


If

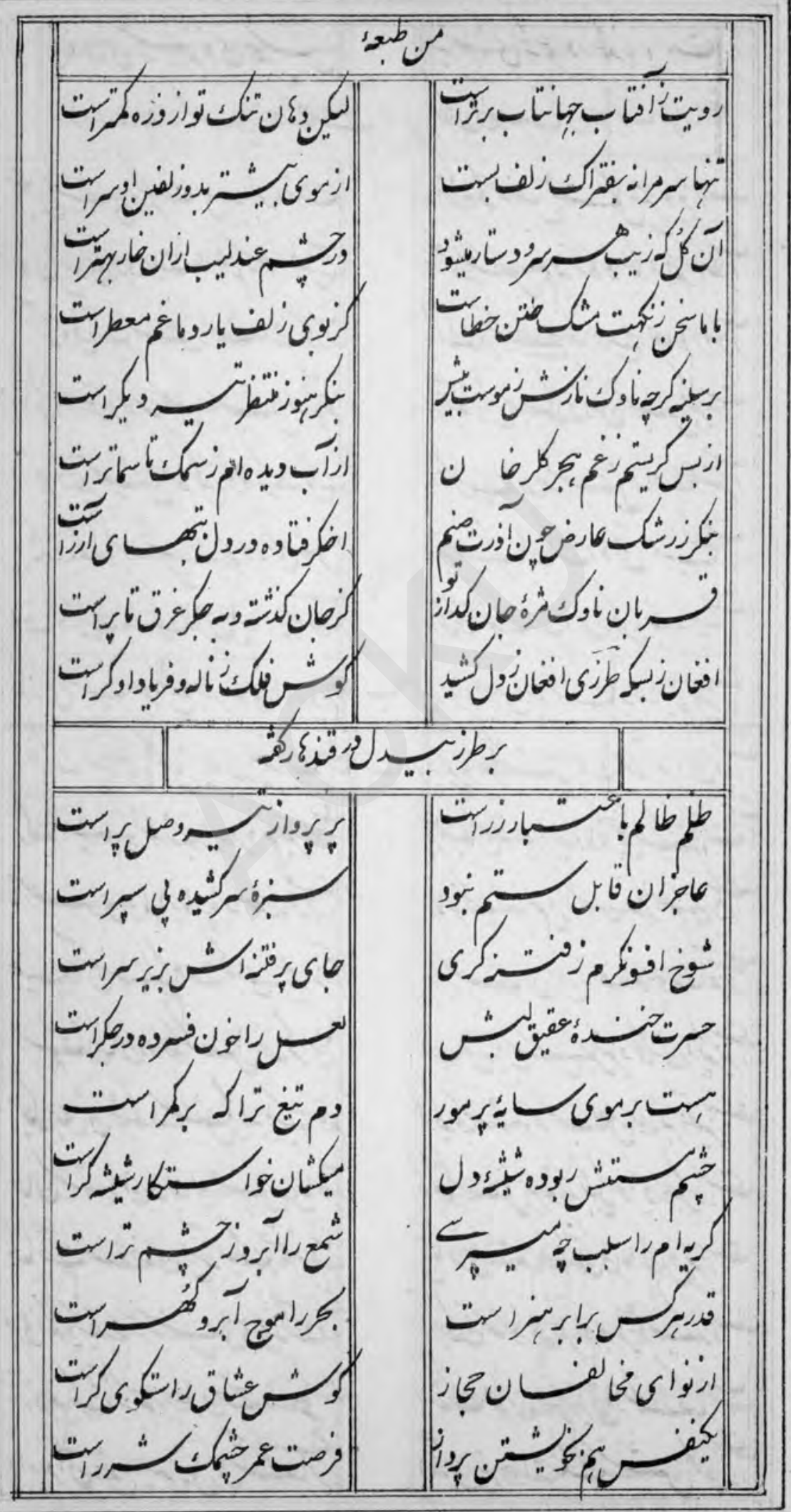


$|F|$

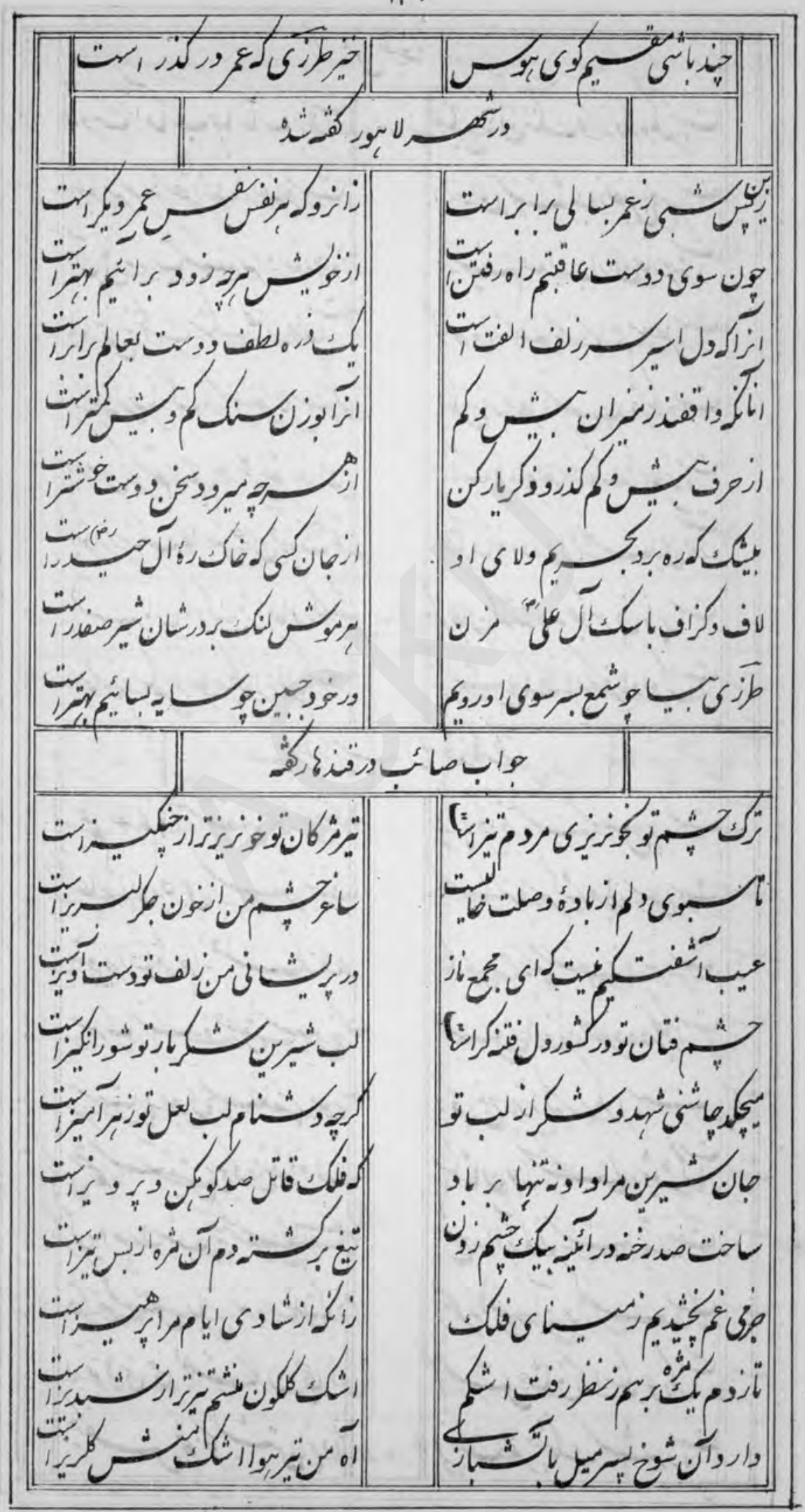


If

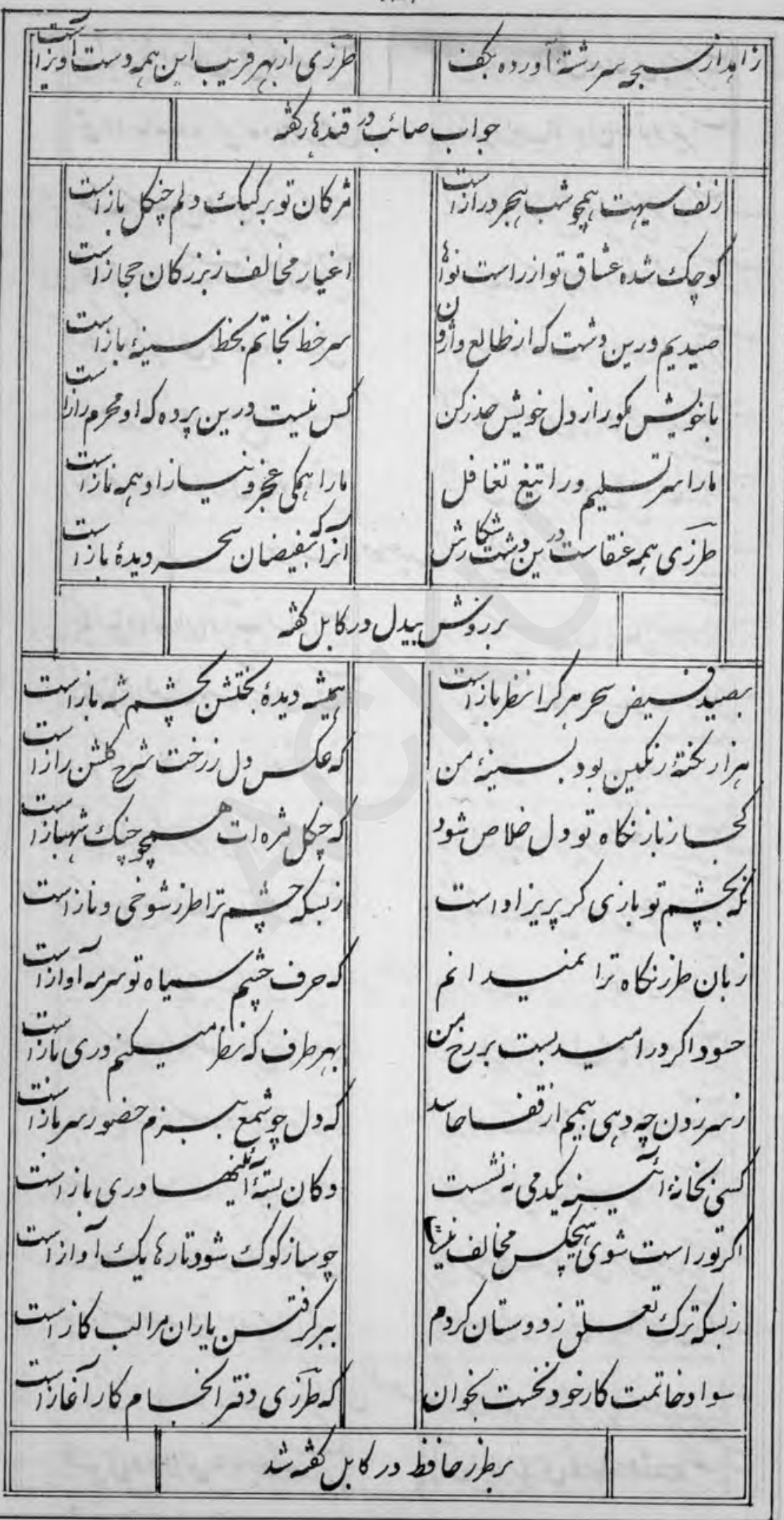

Jv. 
Ifr

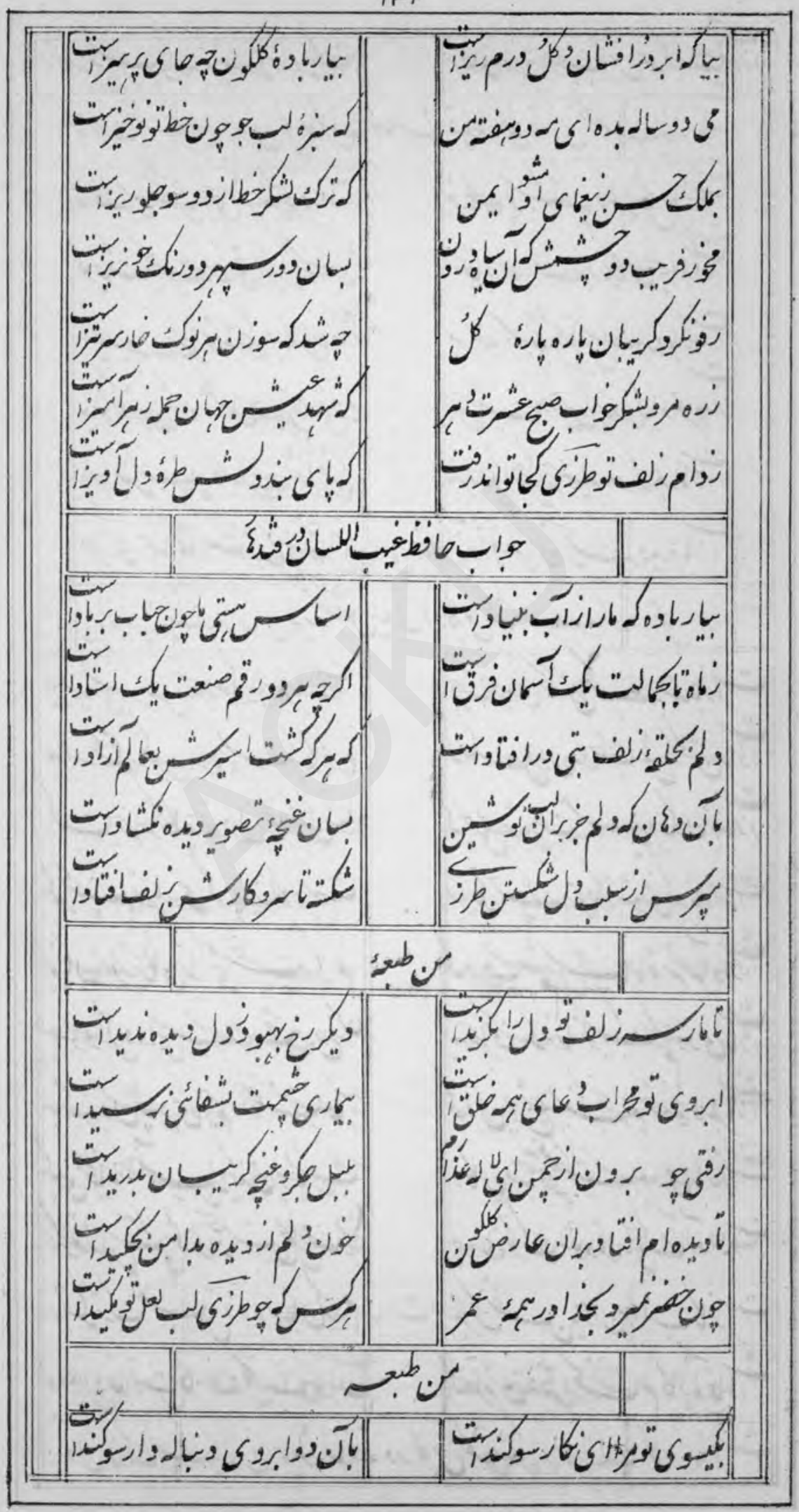


ifere

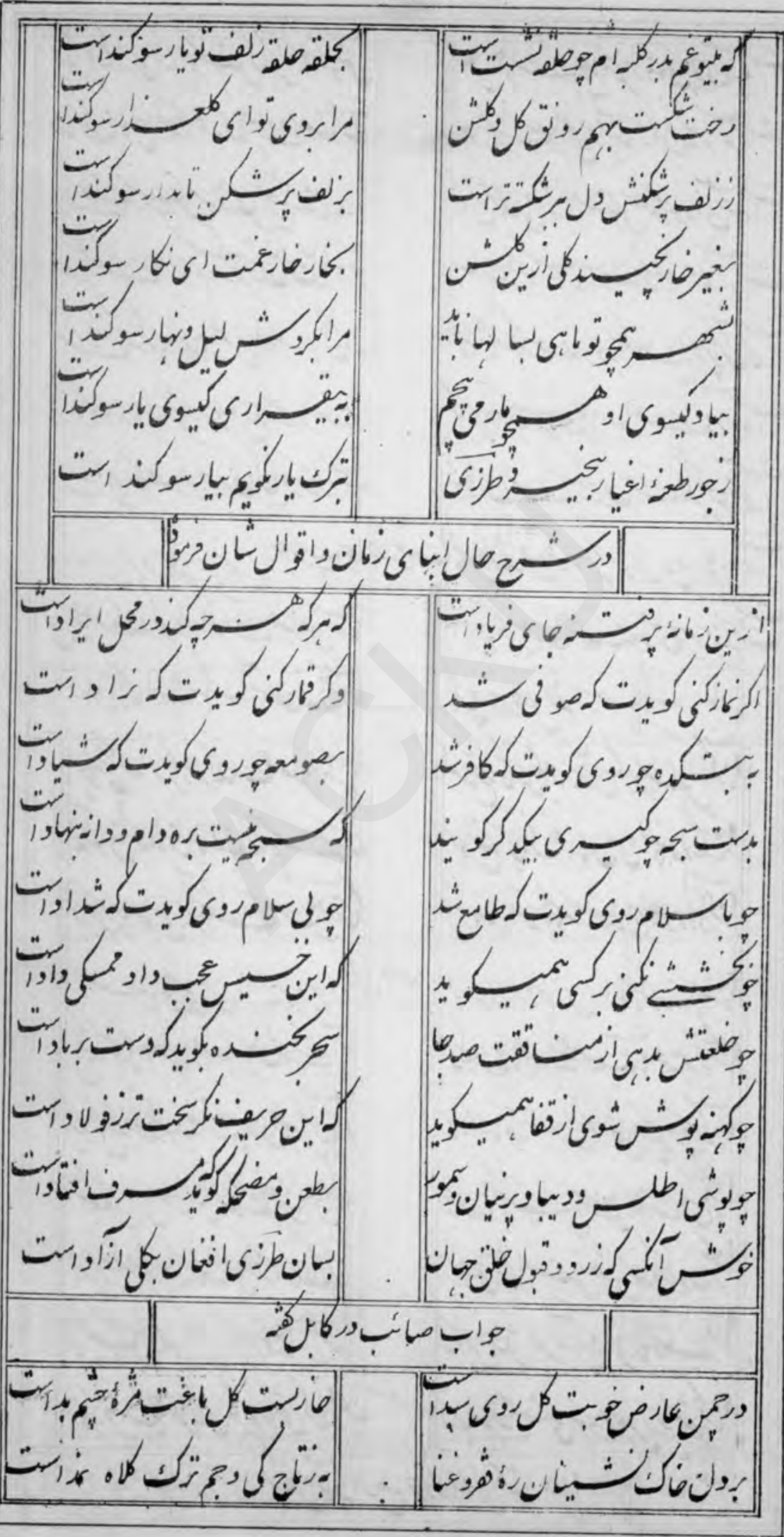


$1 x^{\circ}$

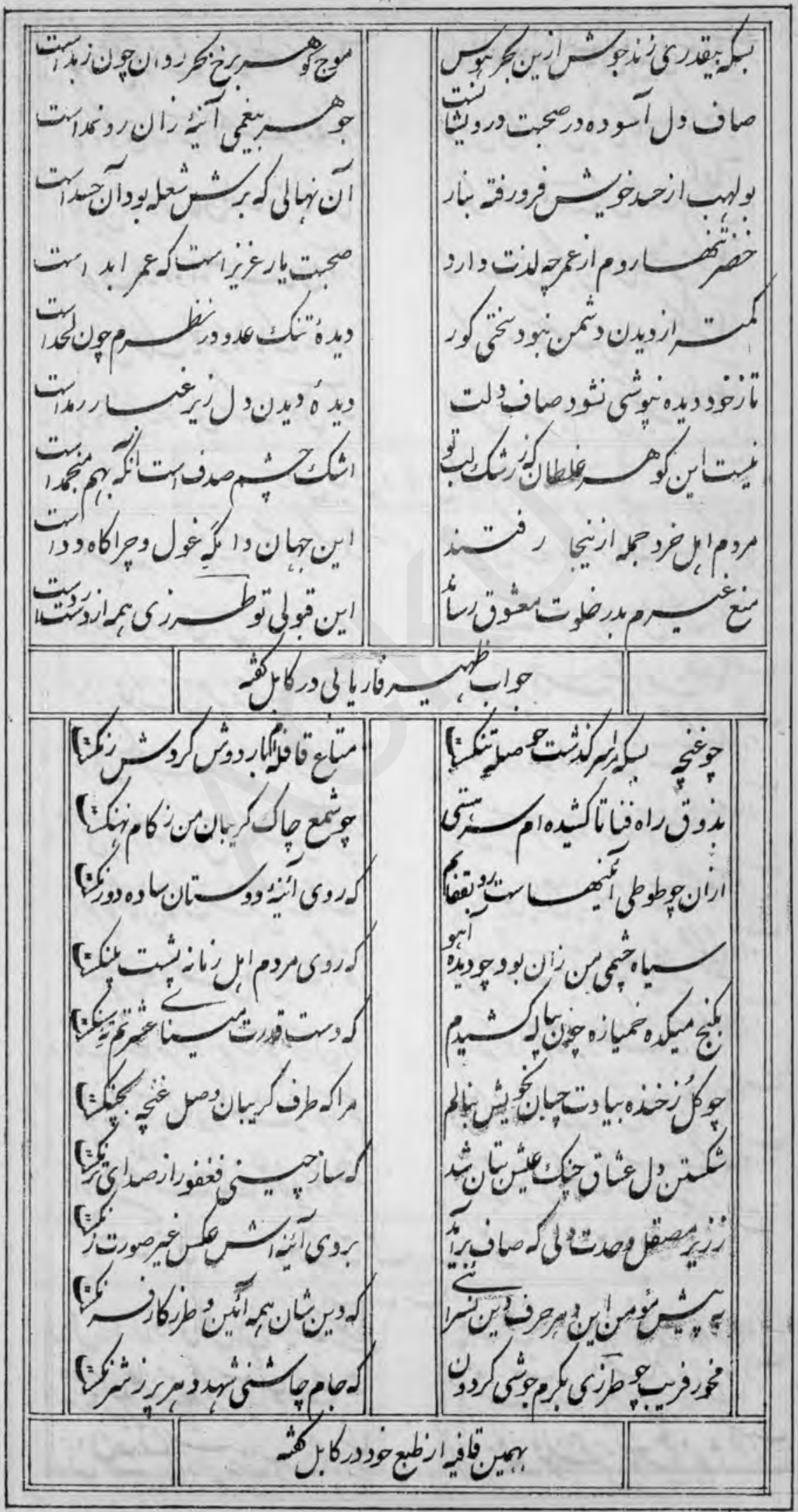


If

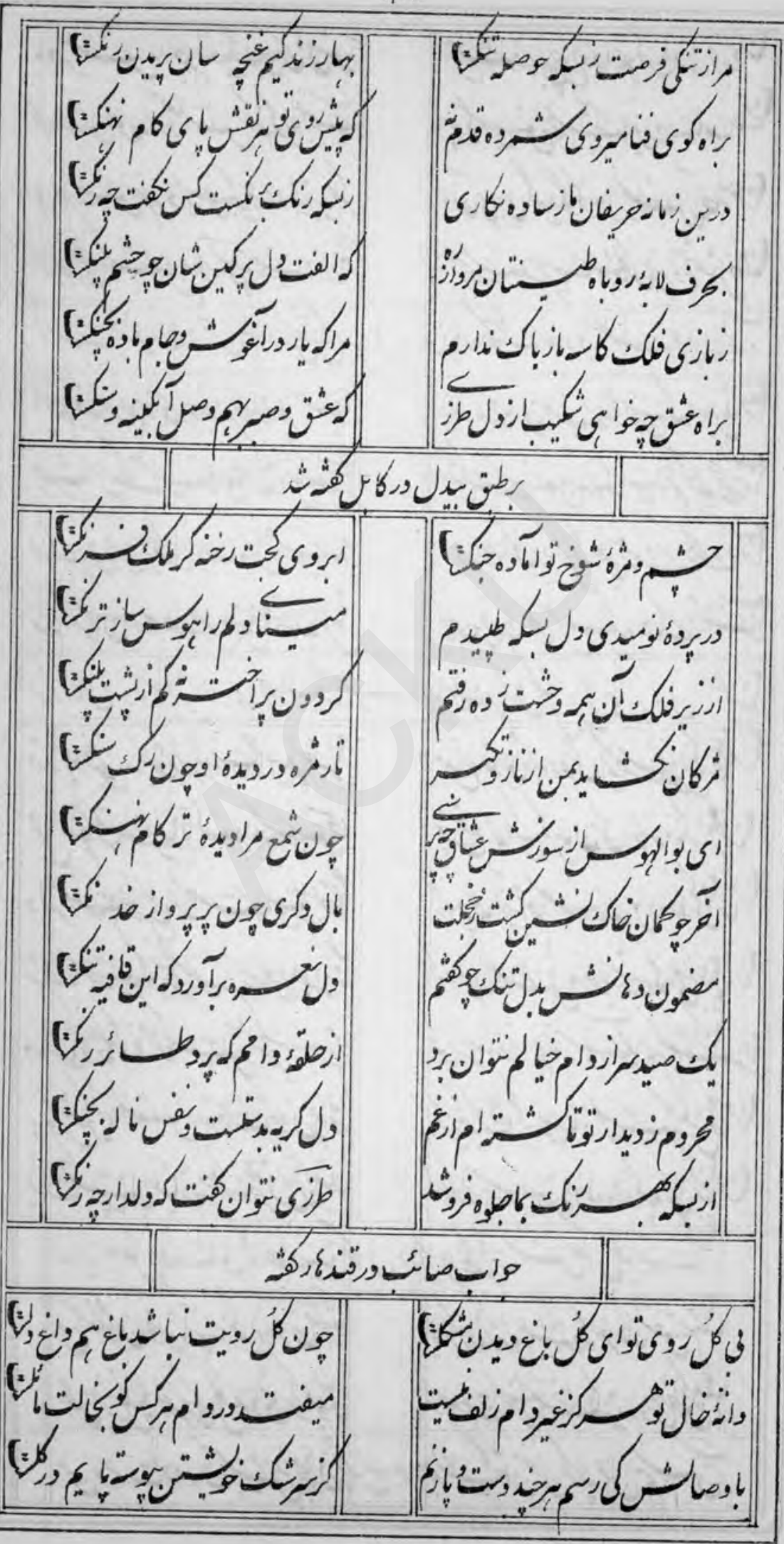

igin. 
ir

$\mid$


if

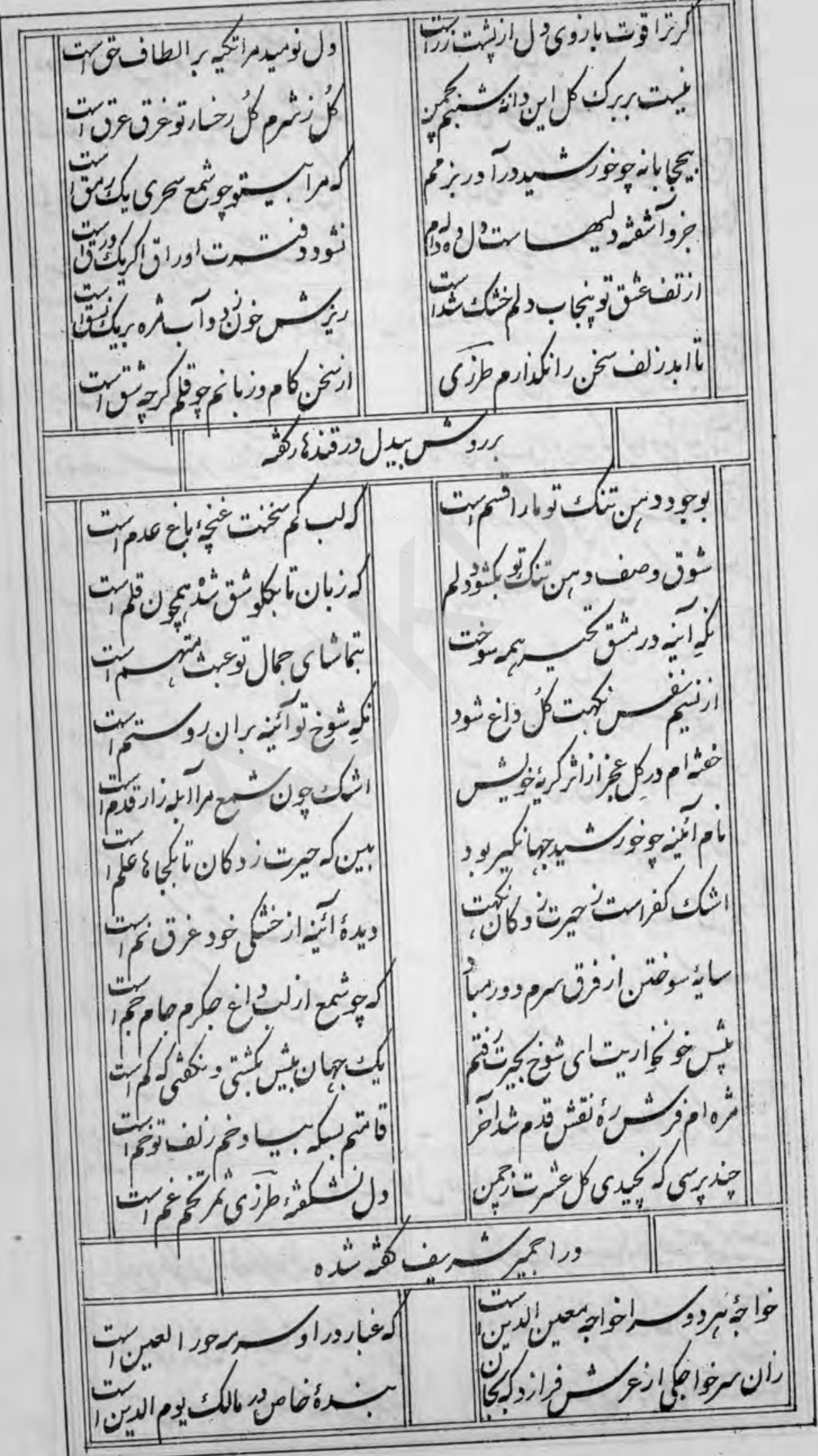


Ir 19

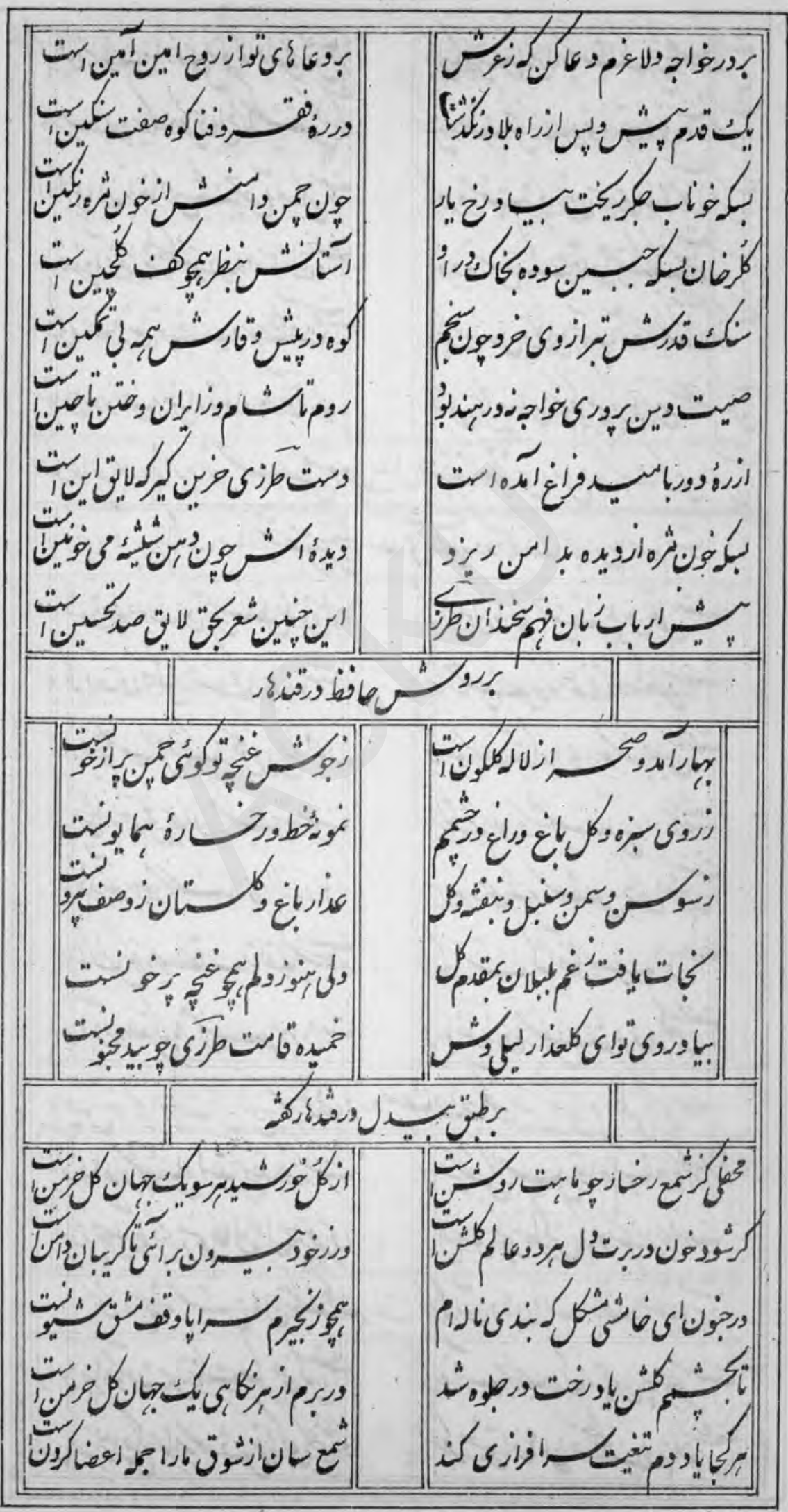


10

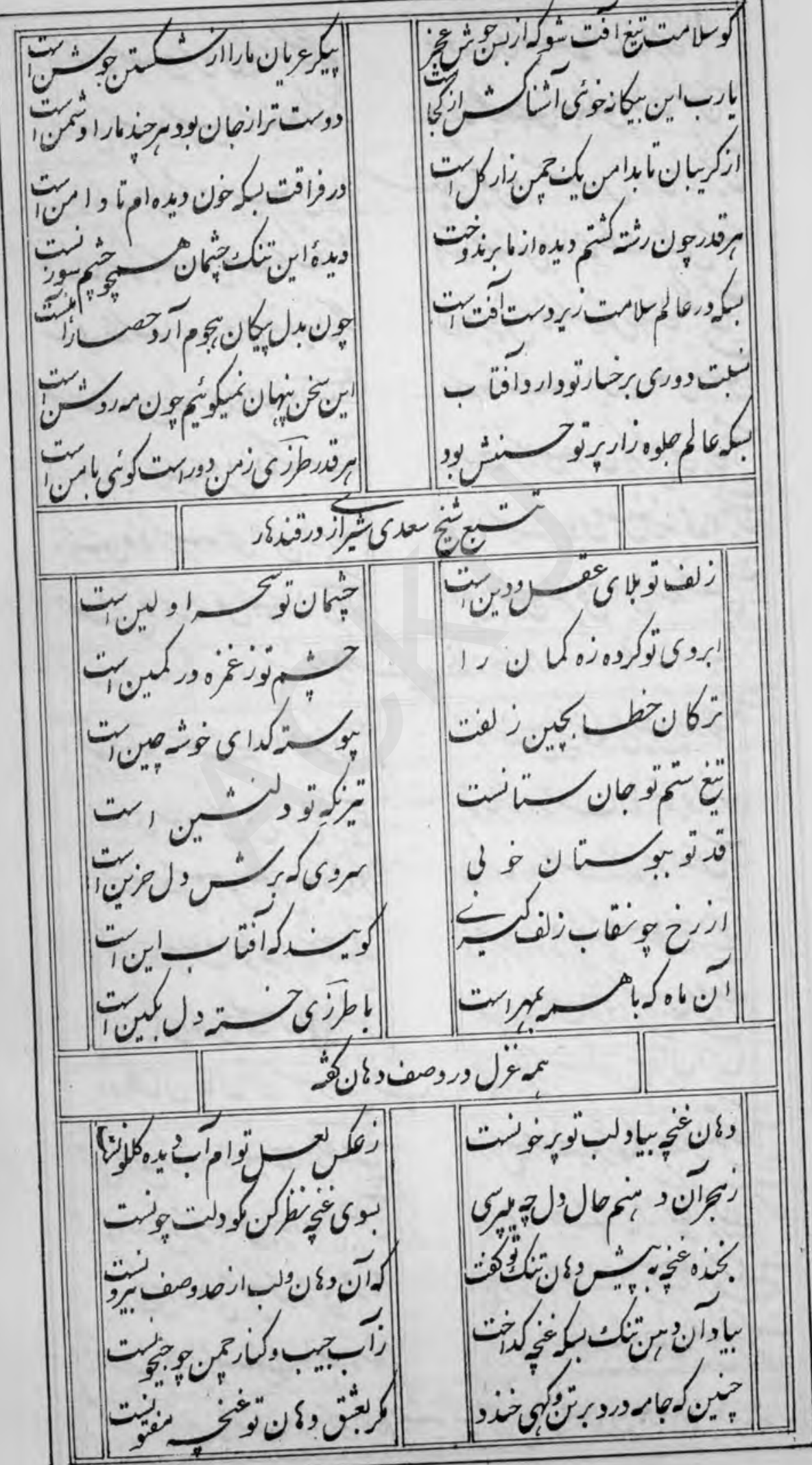


ID

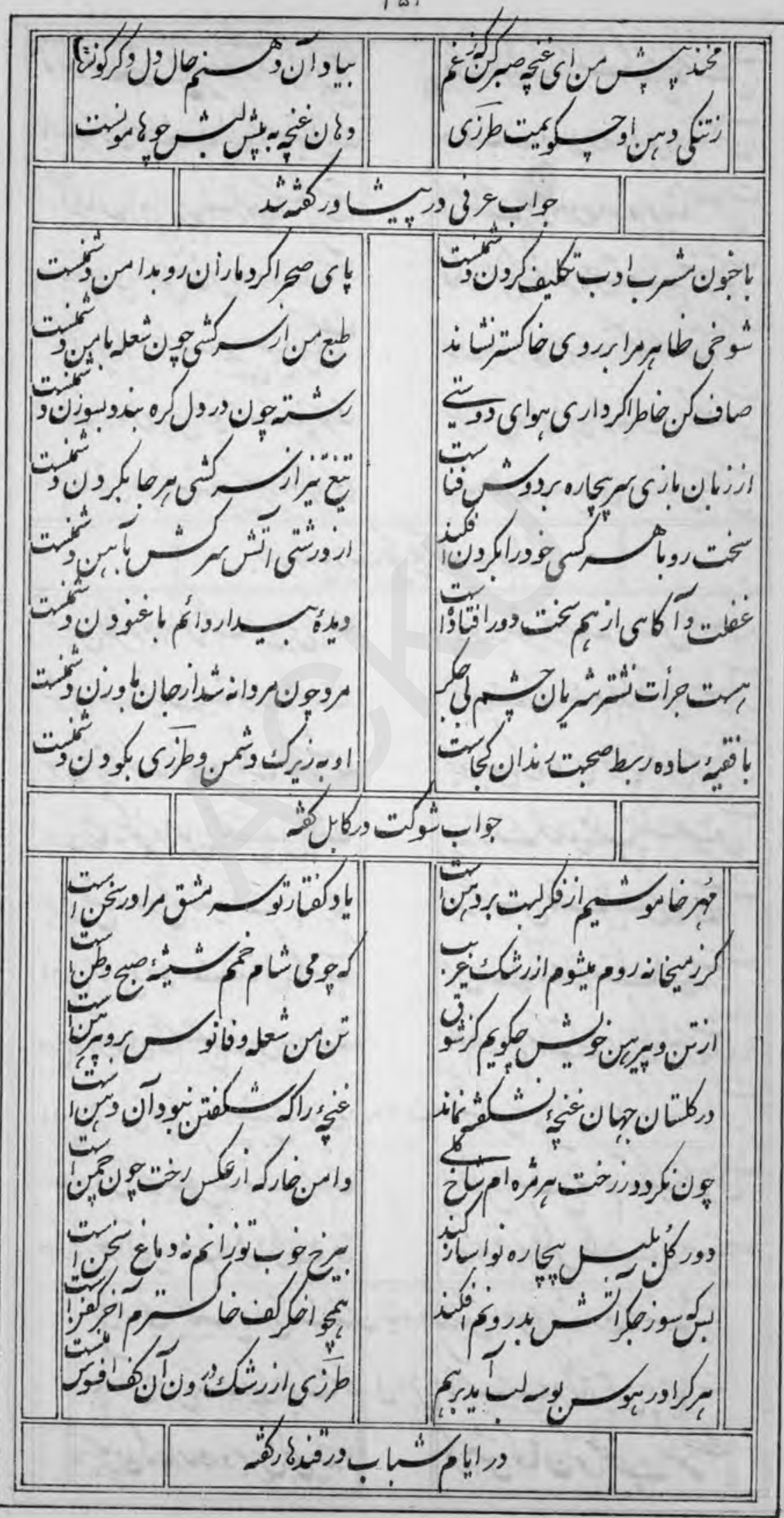


tor $r$

|


lor

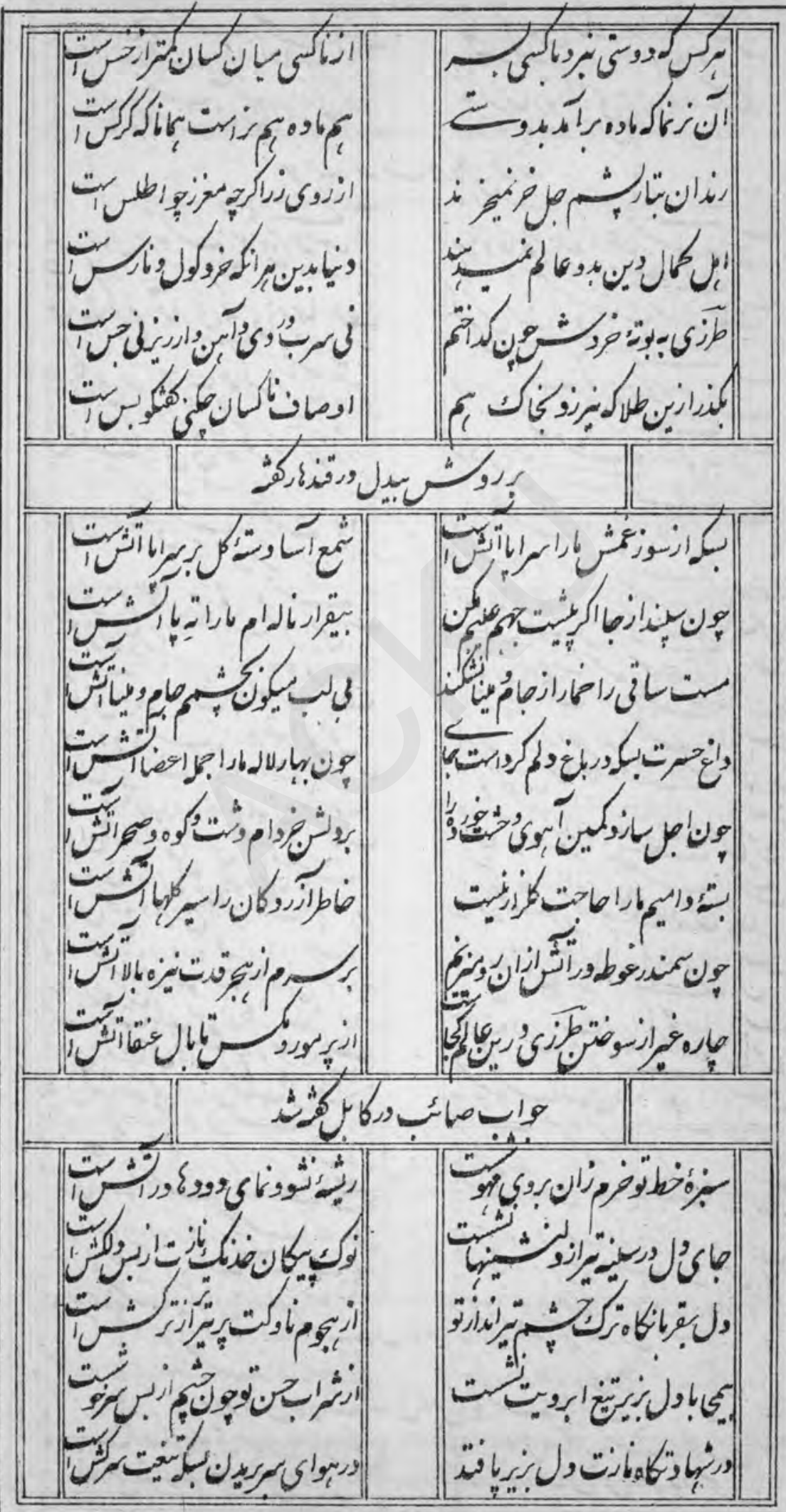


$10 \%$

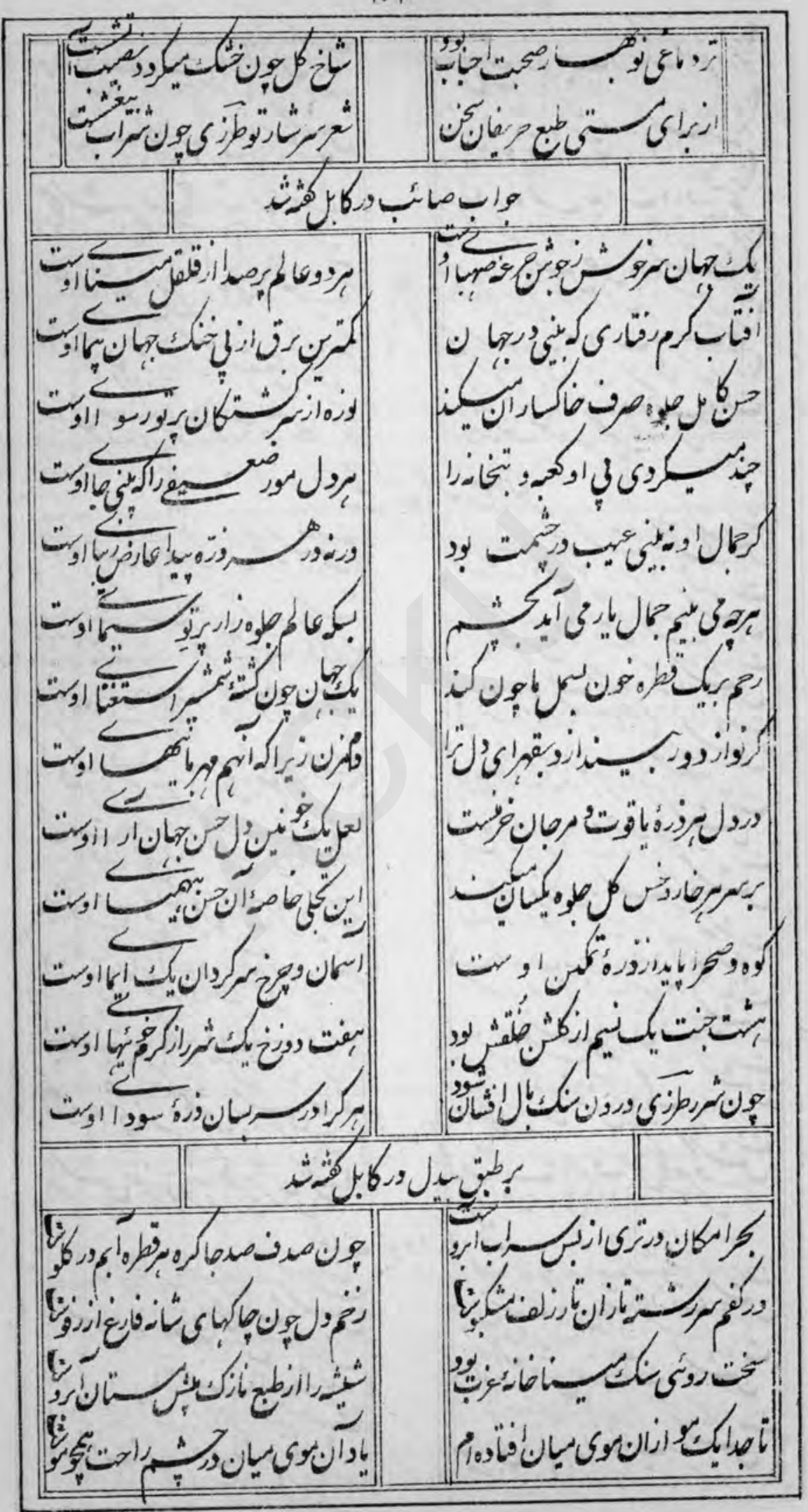


100

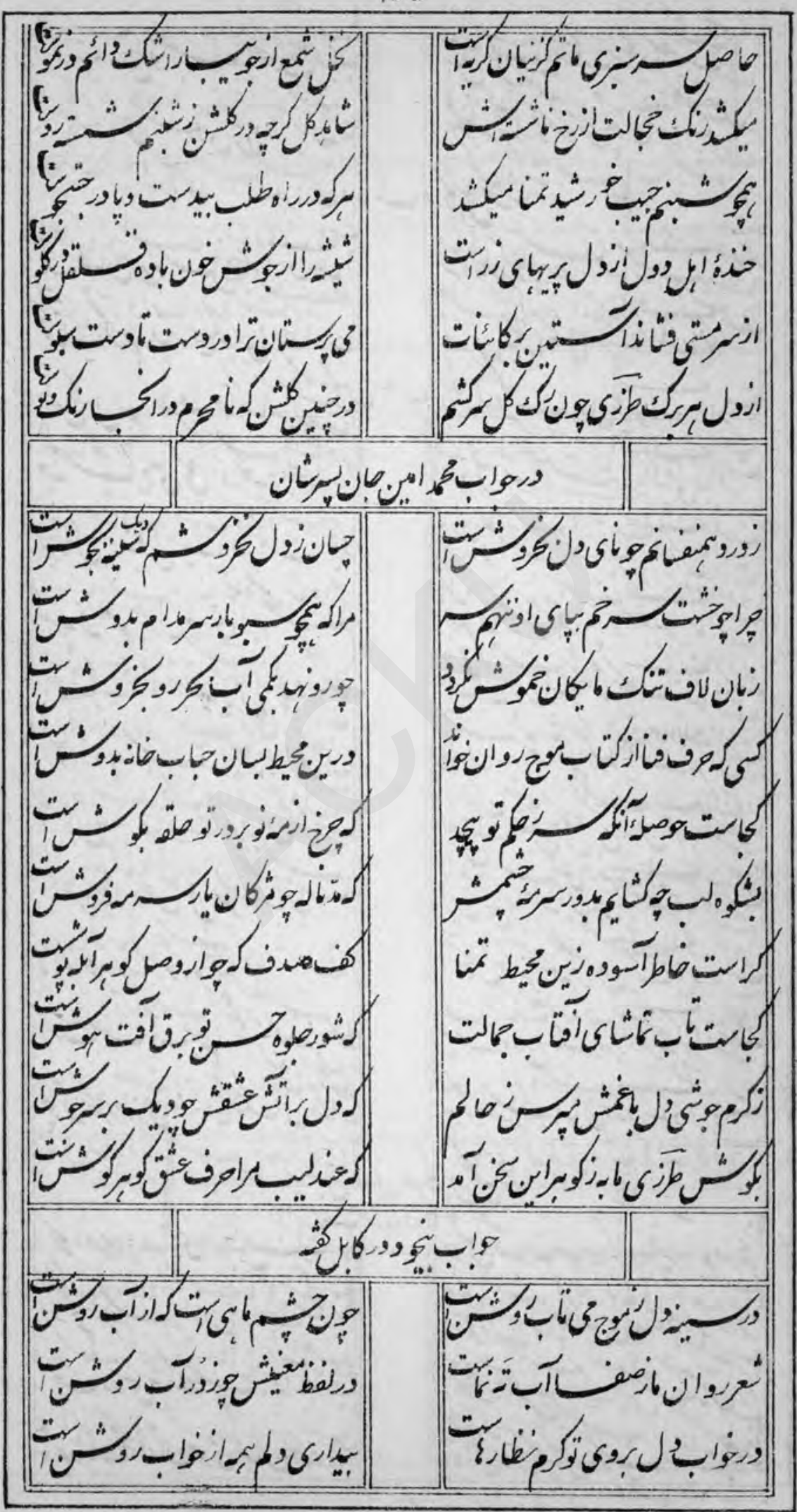


$10 \%$

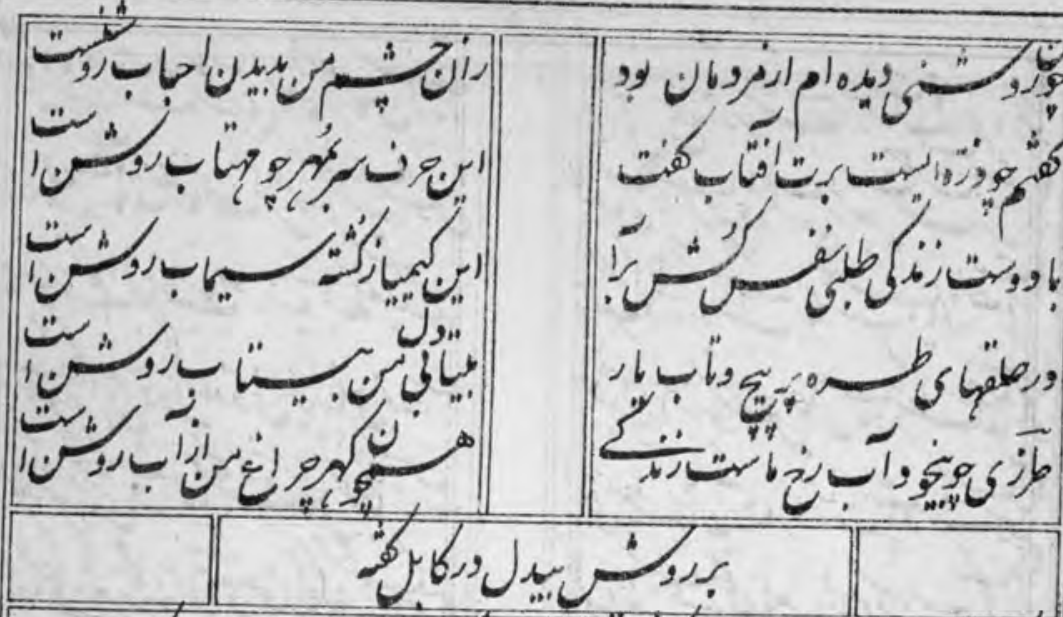

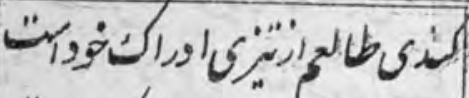
تون

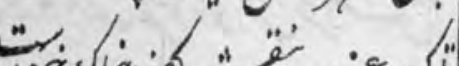
نو " i. " " 1989

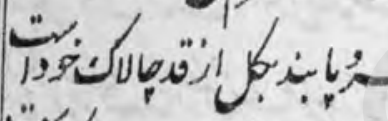
و ت رإماز "

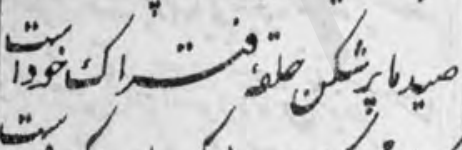
هن

נים

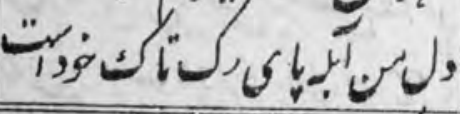

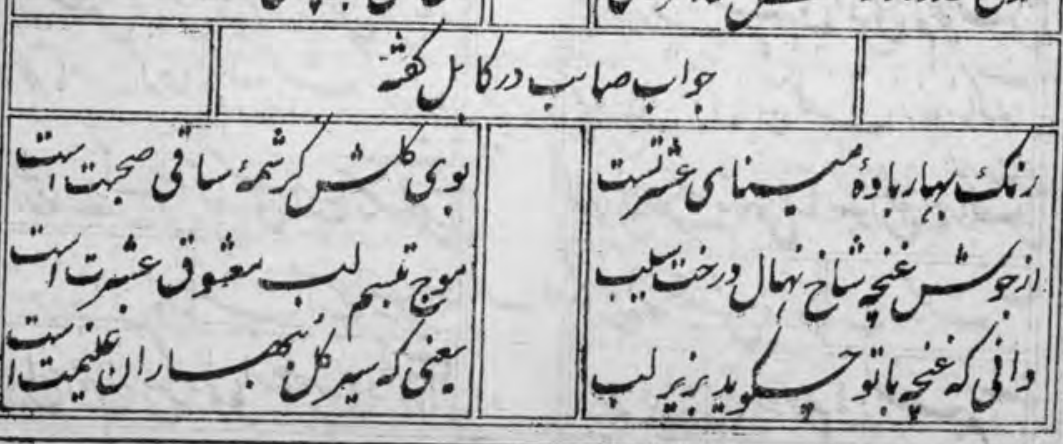


102

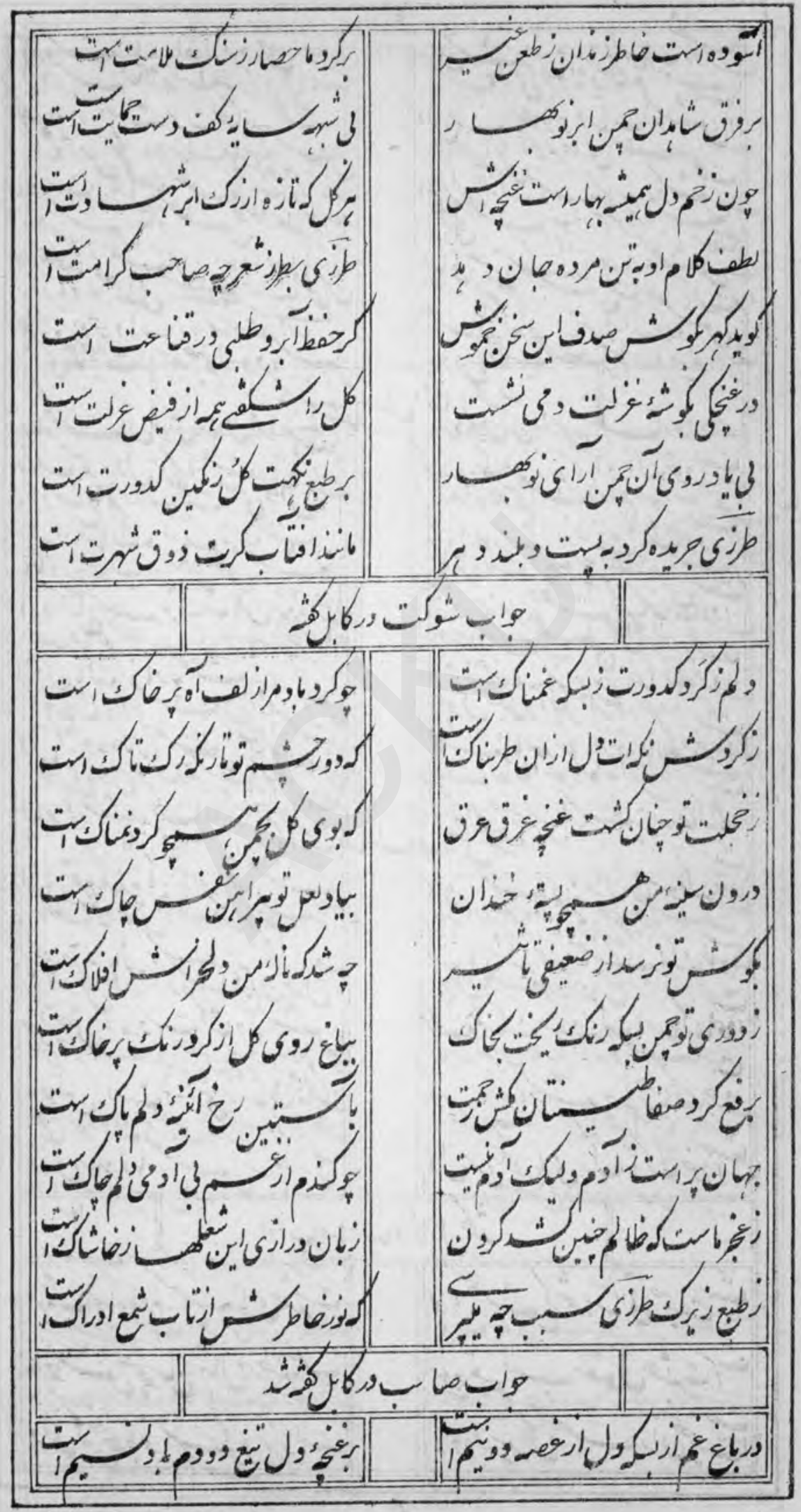


101

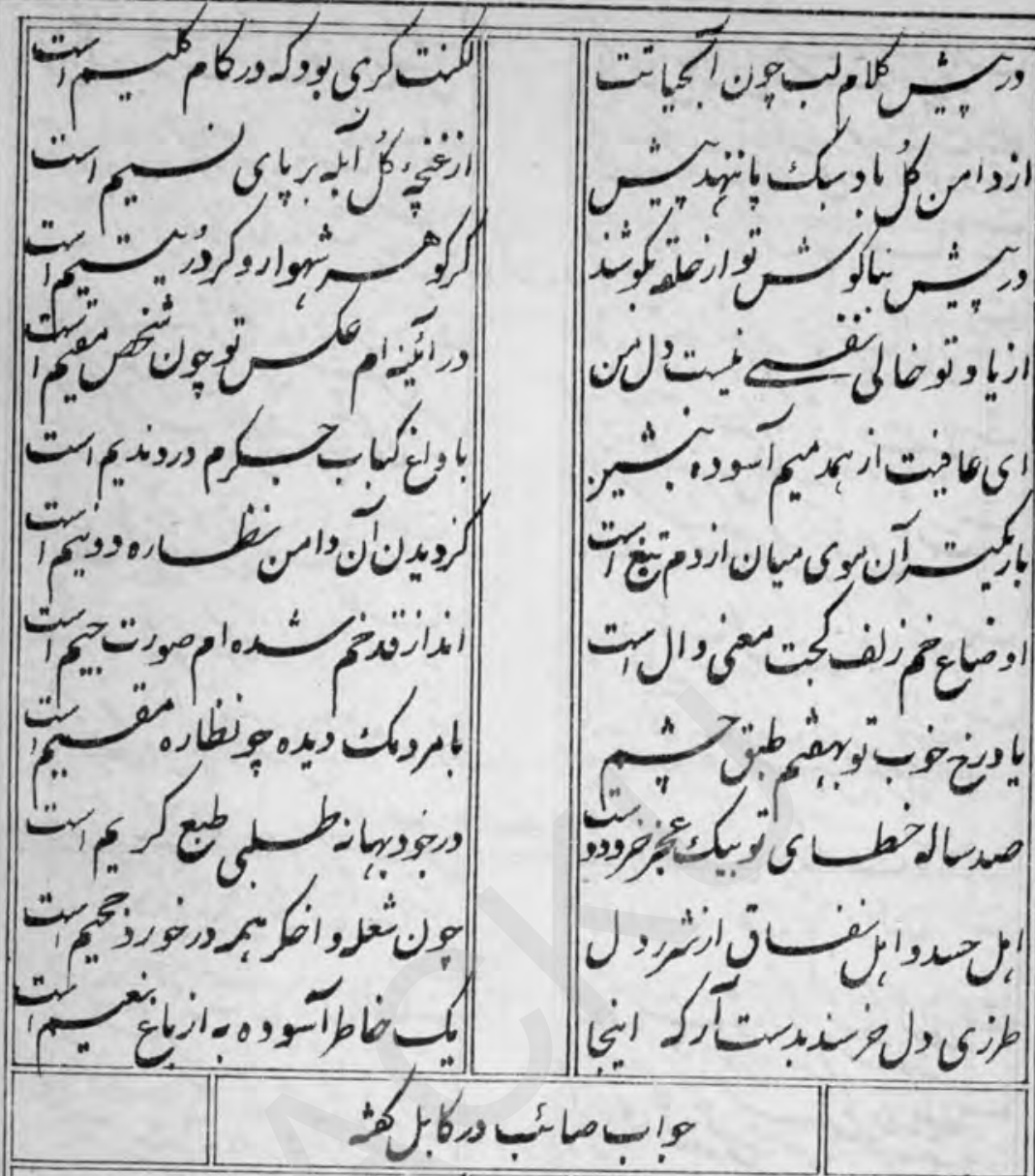

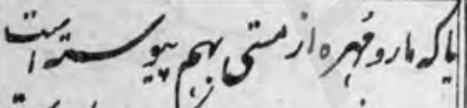
“

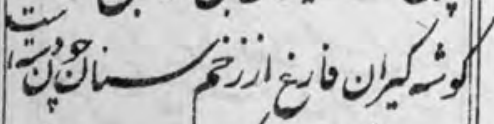

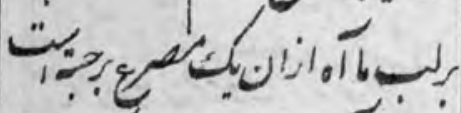
9ر: 1" (4) إنه

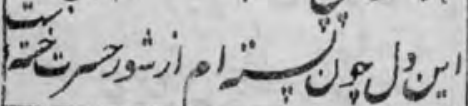

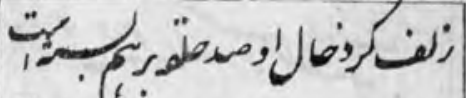

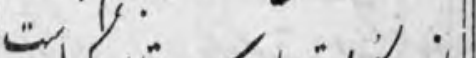

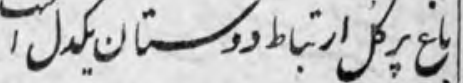
: ج

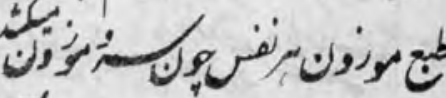

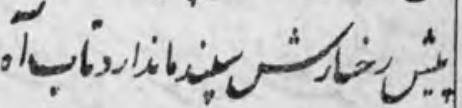

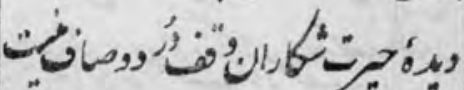

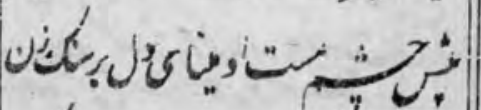
, | 
109

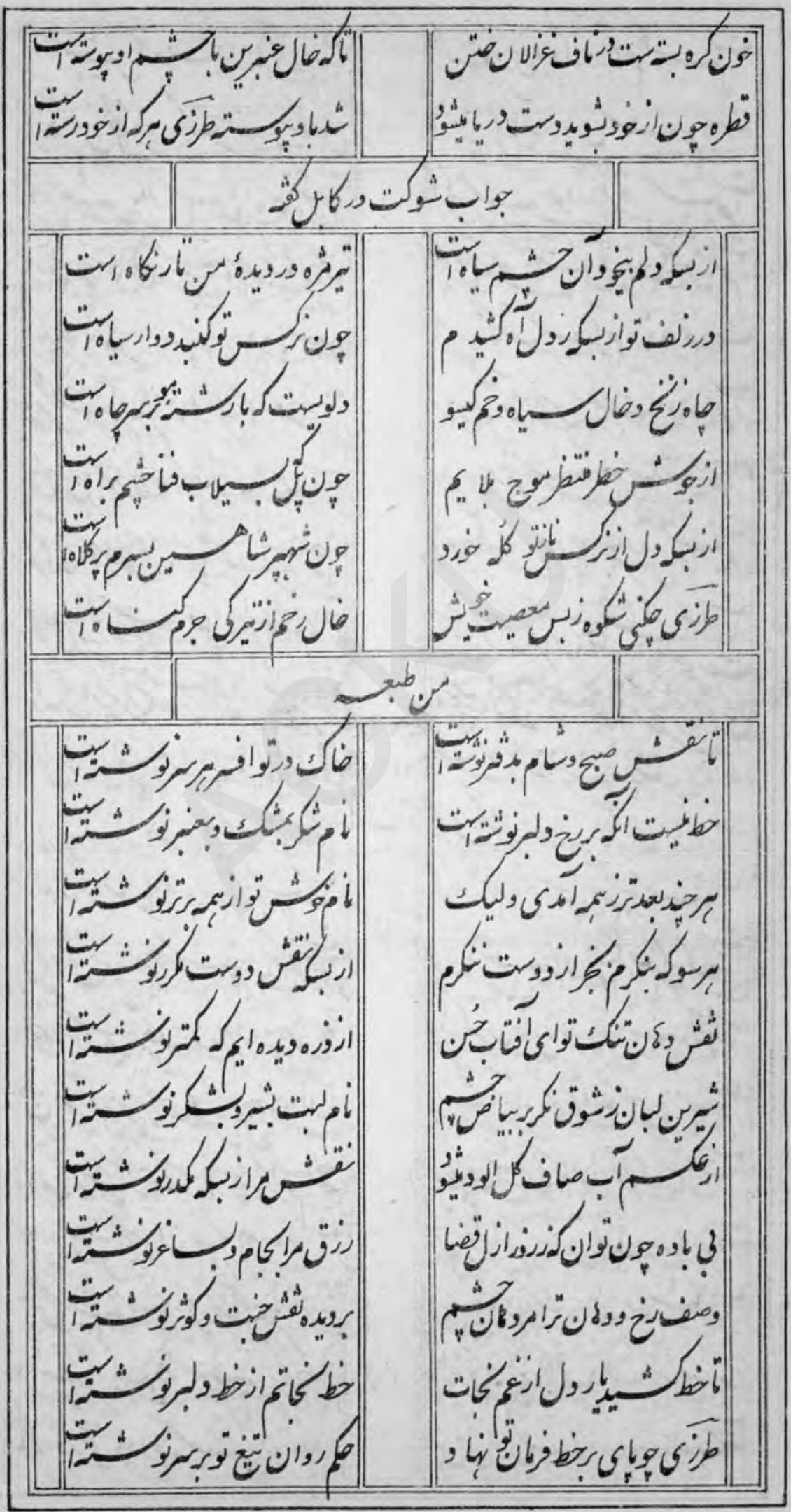




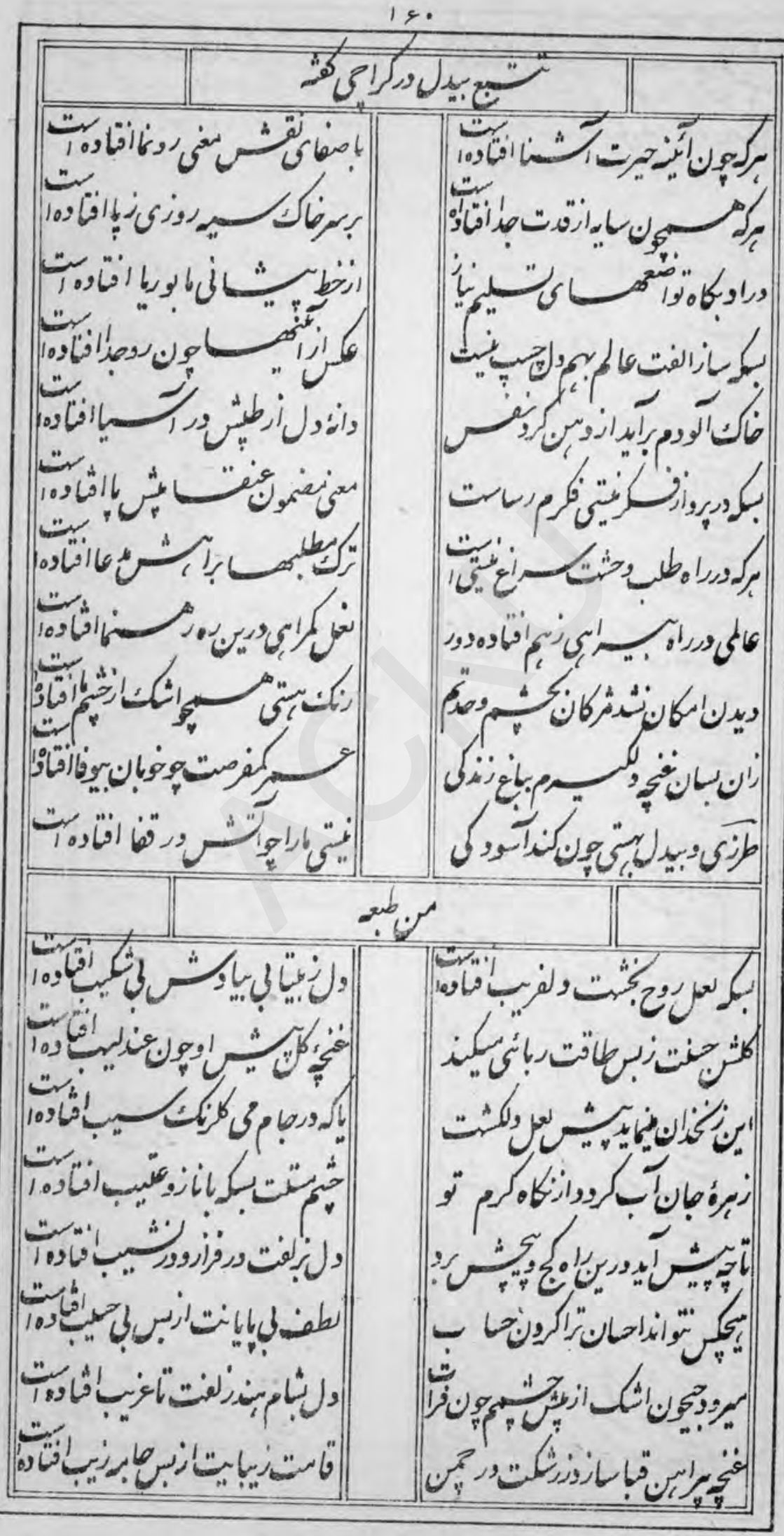


$1 \% 1$

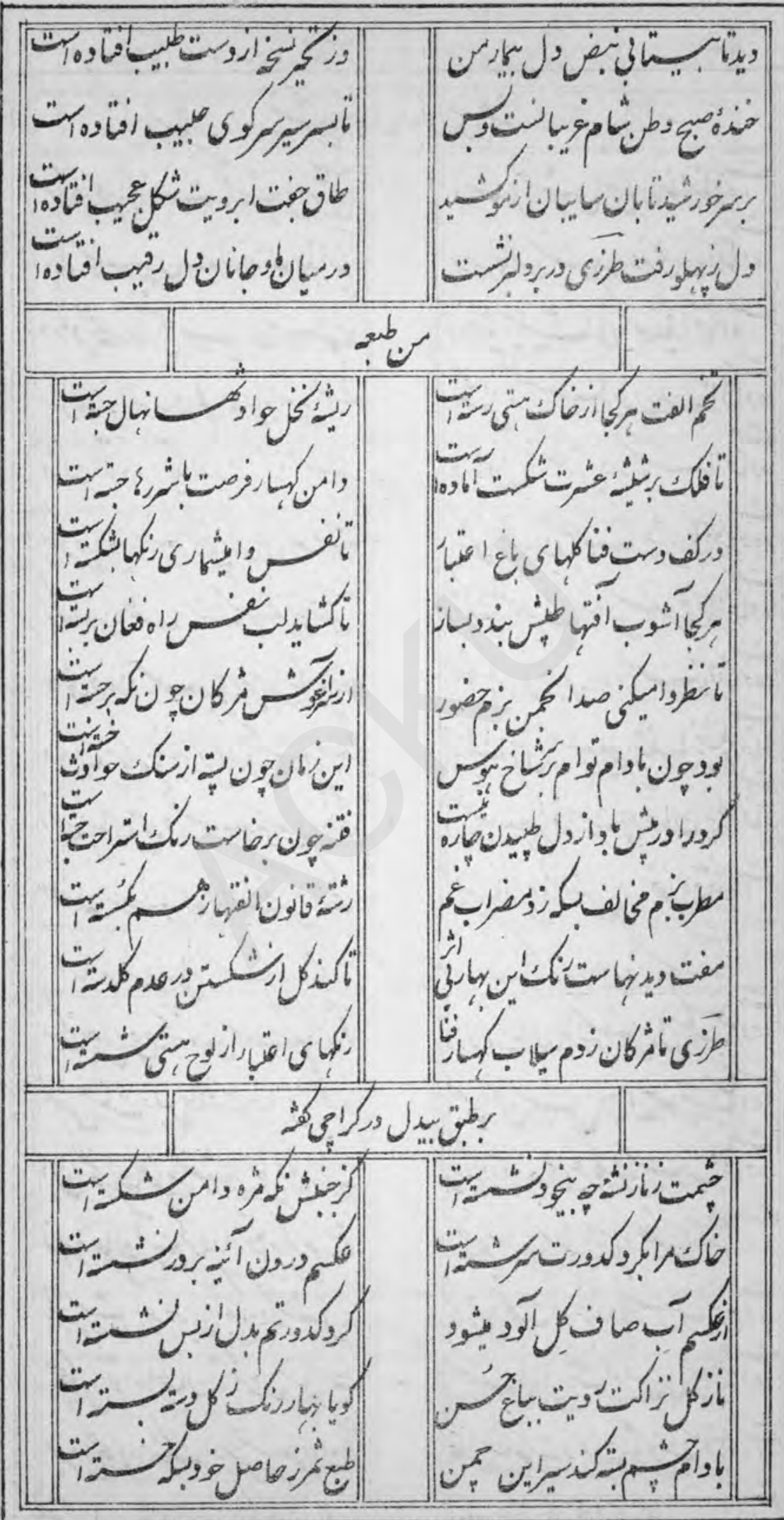


125

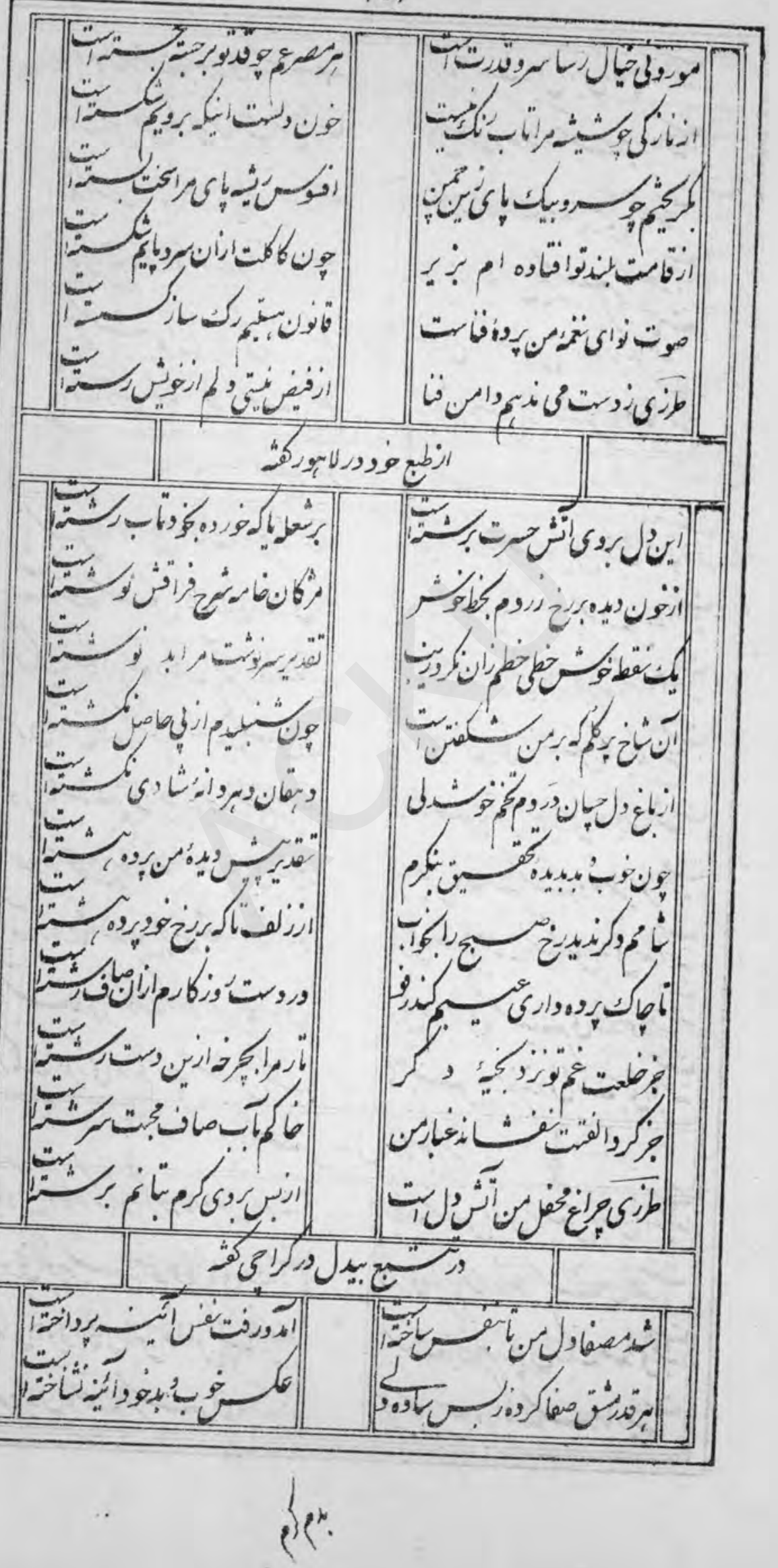




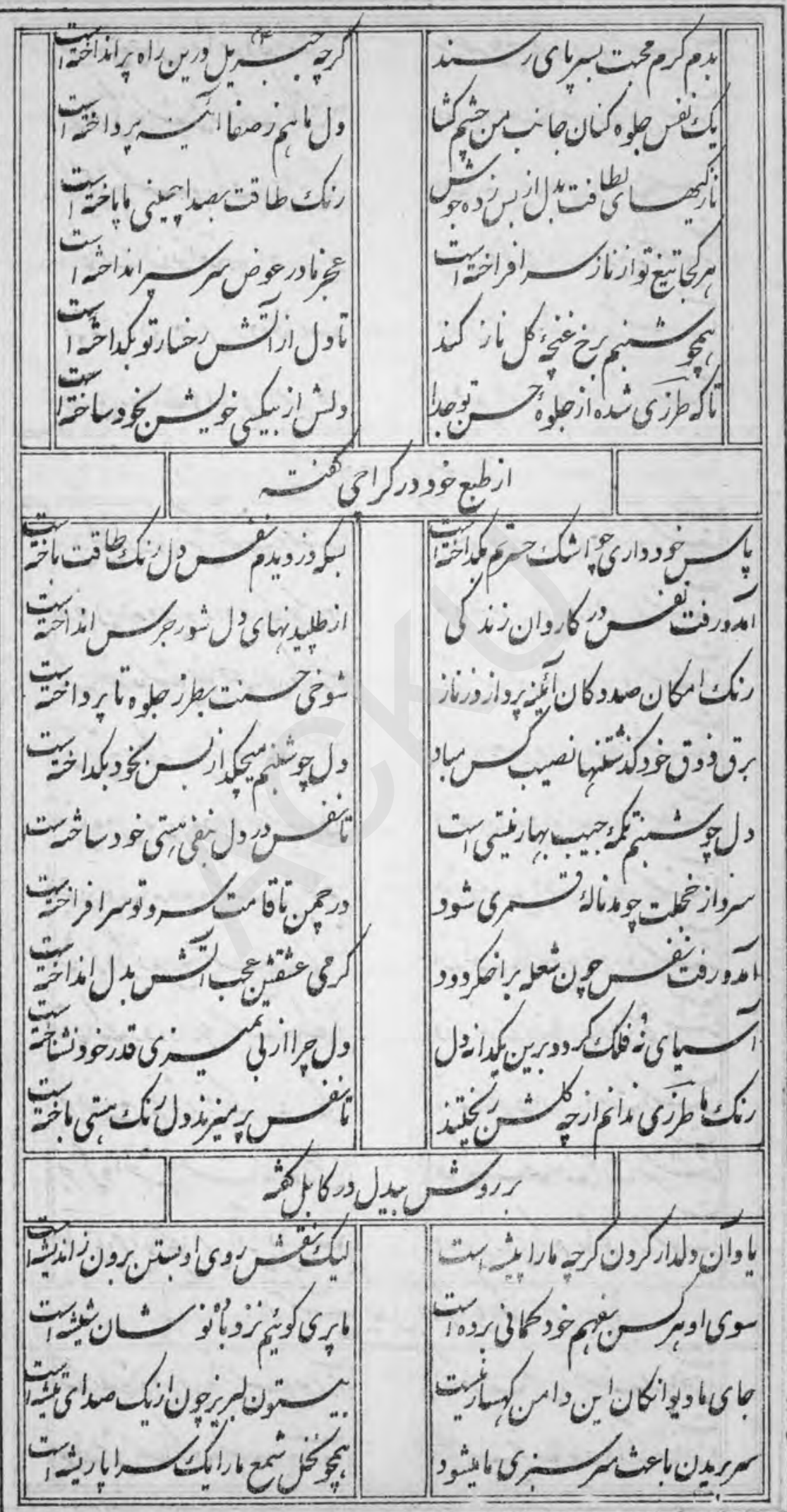


ists

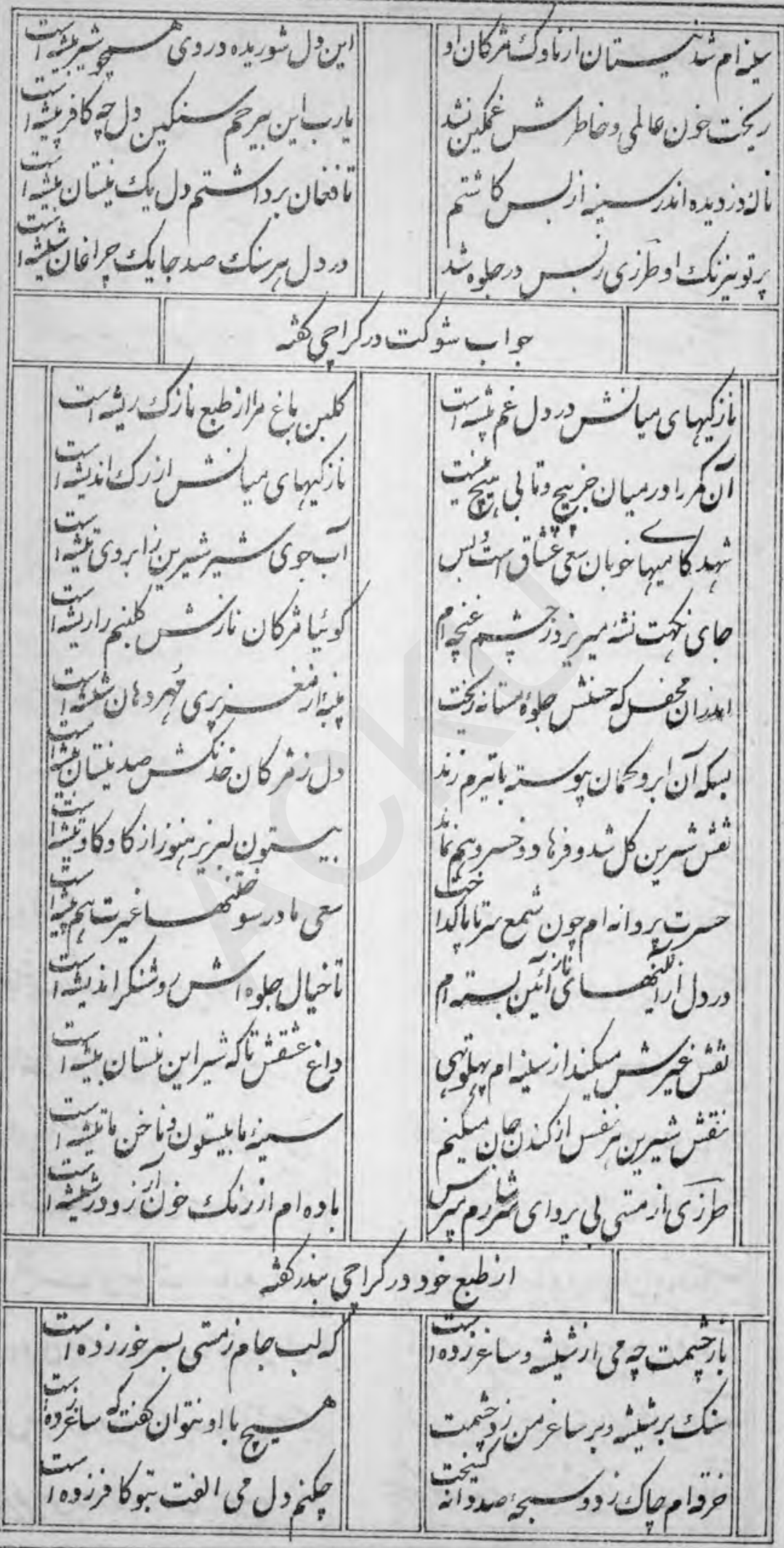


130

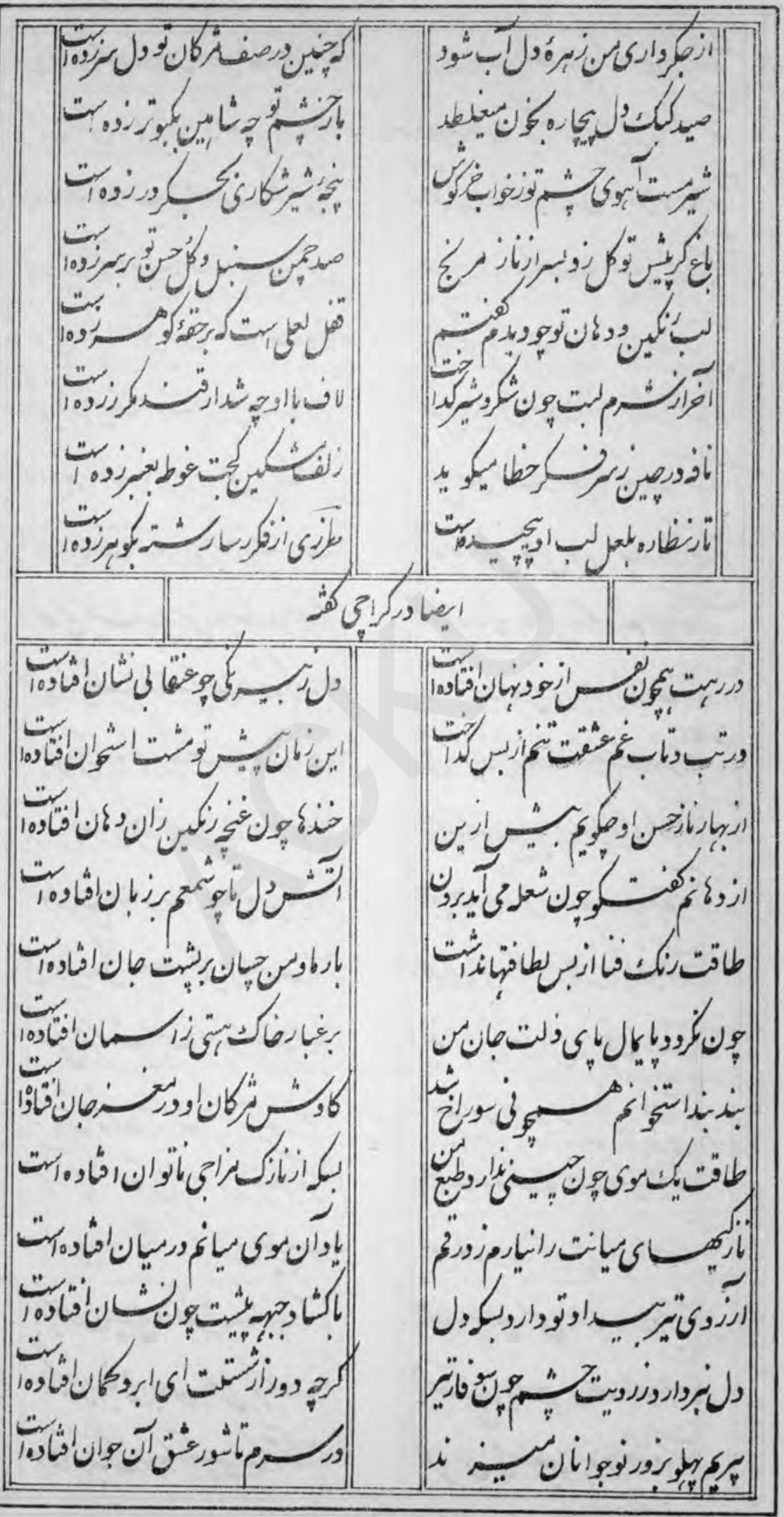




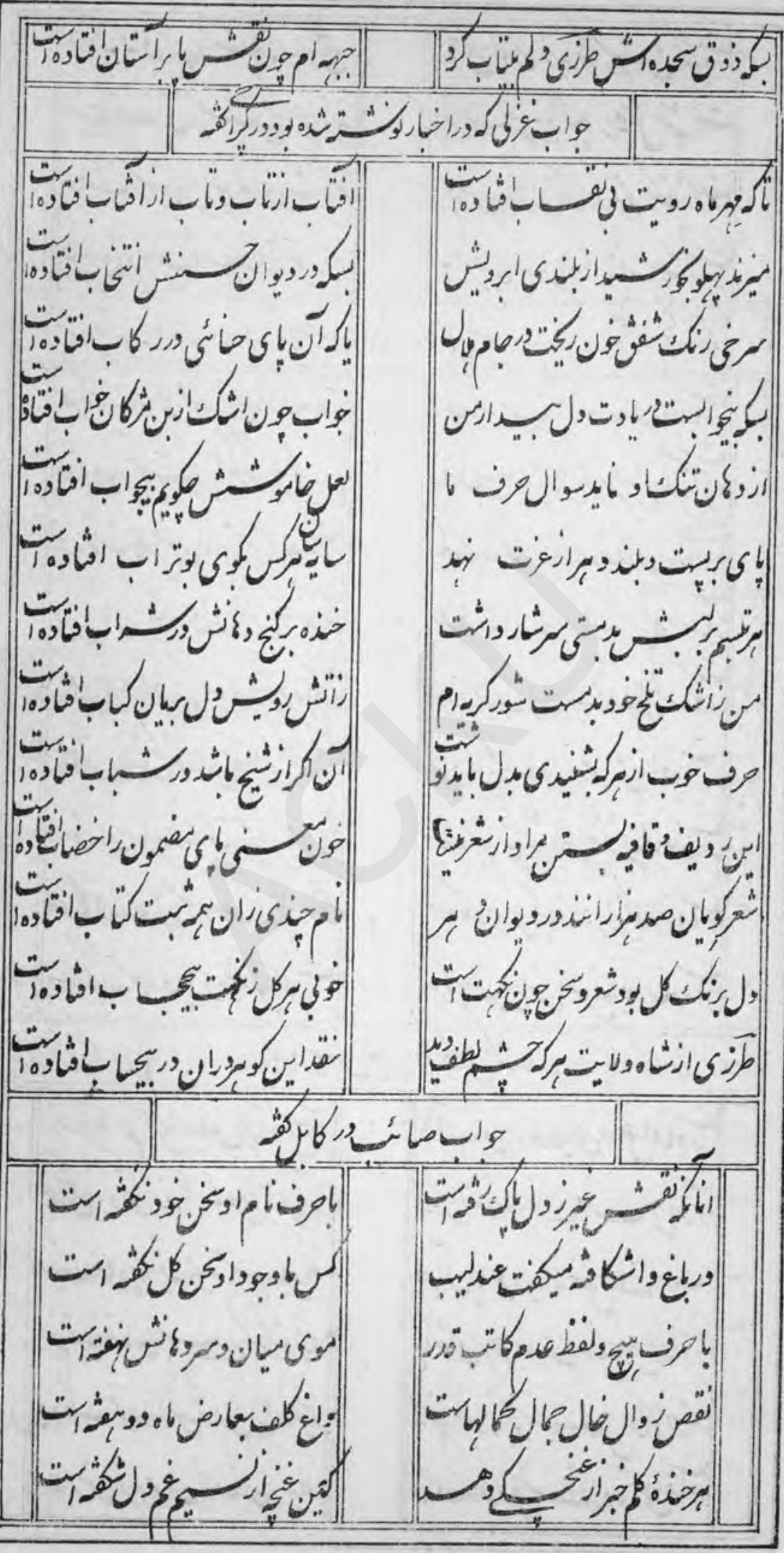

; 
196

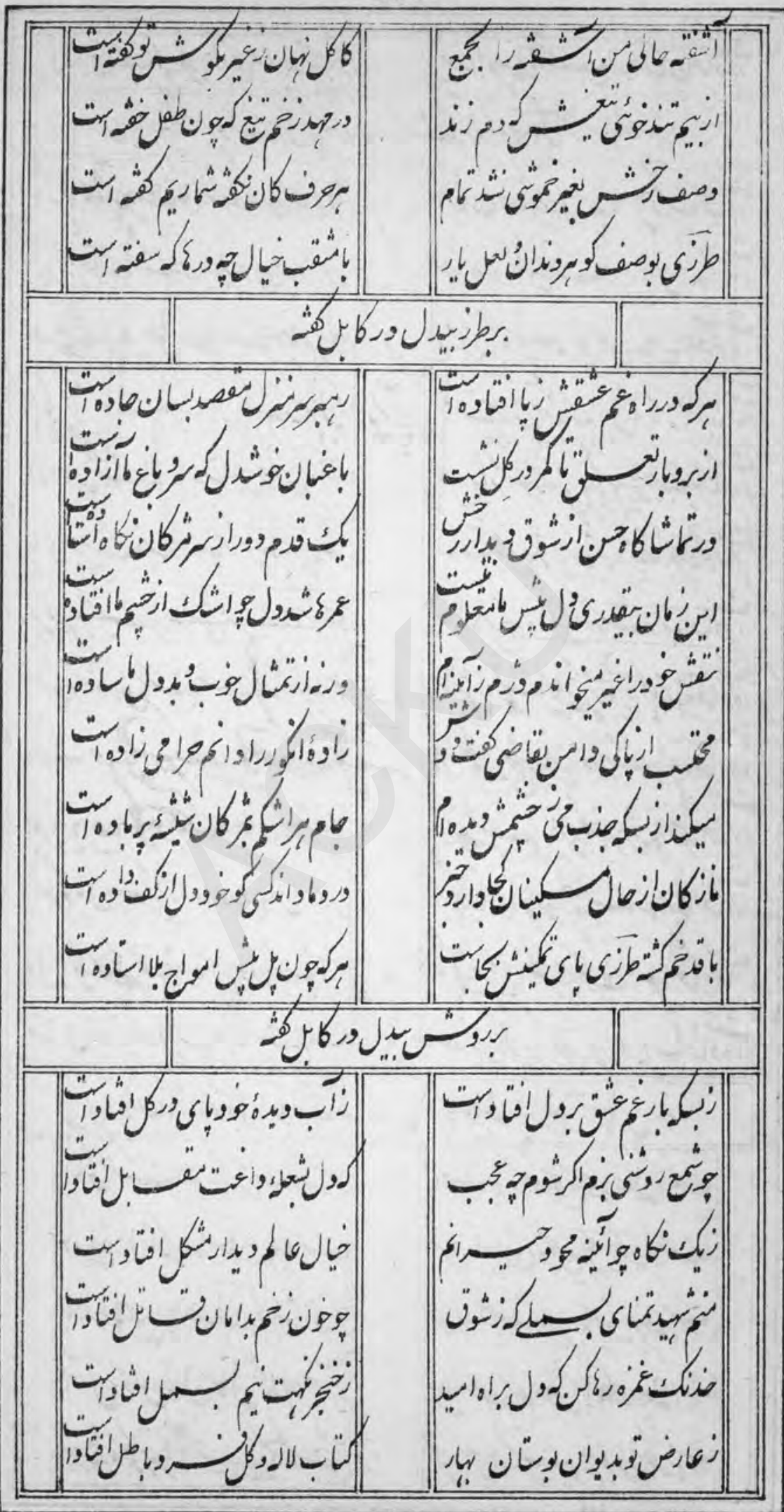


I 4

|


$1=9$

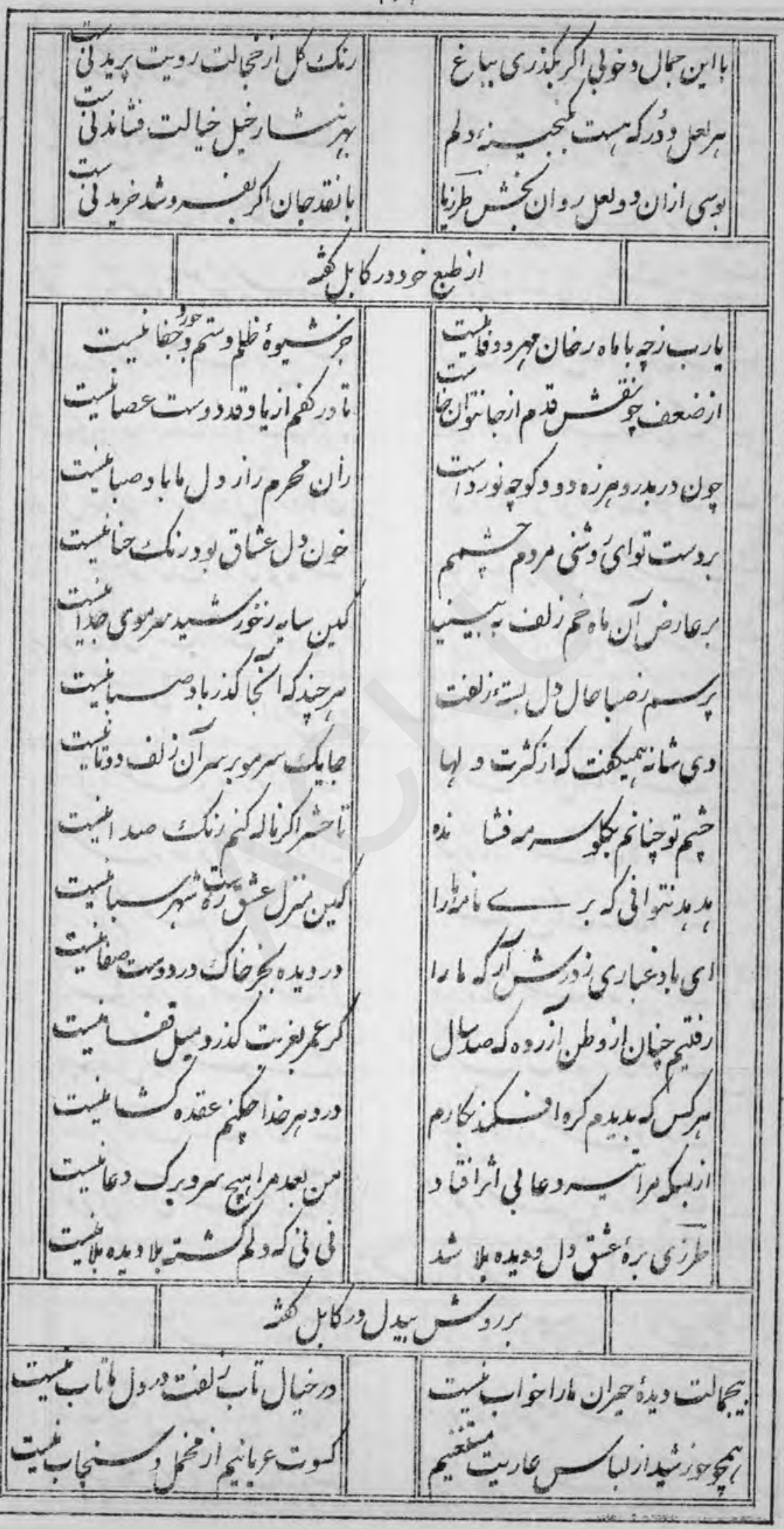


IV

||

35 


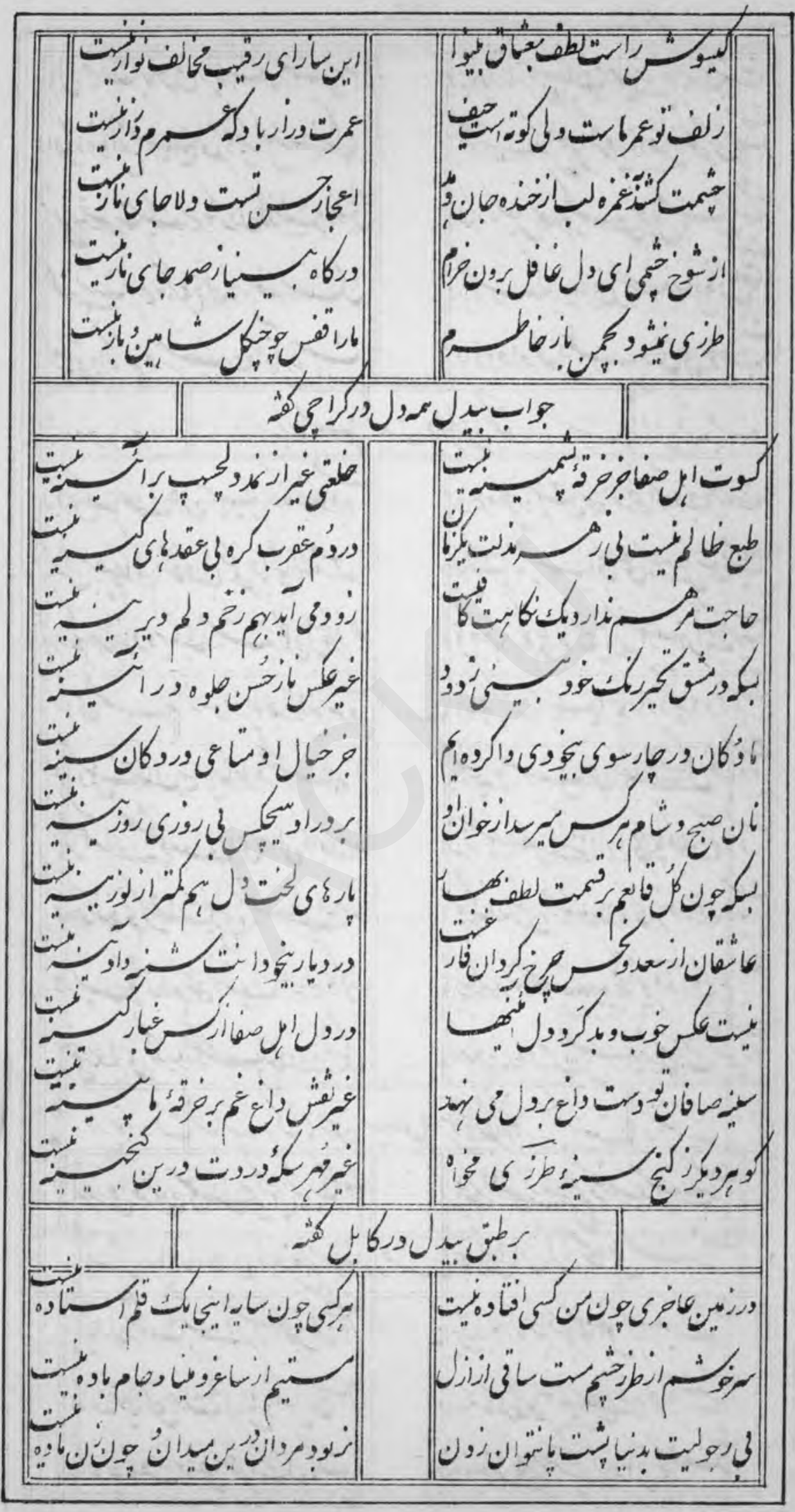


Ir

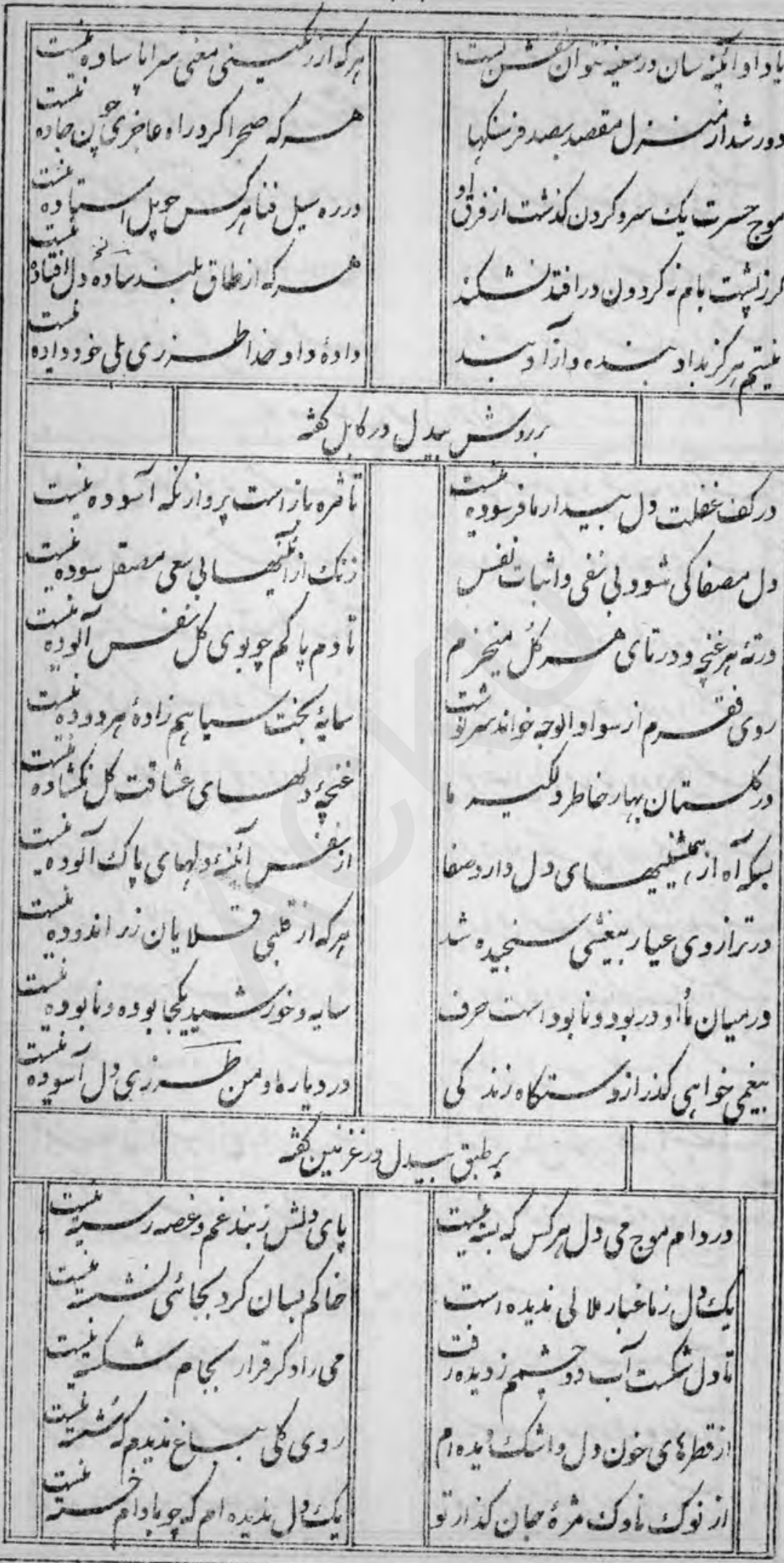




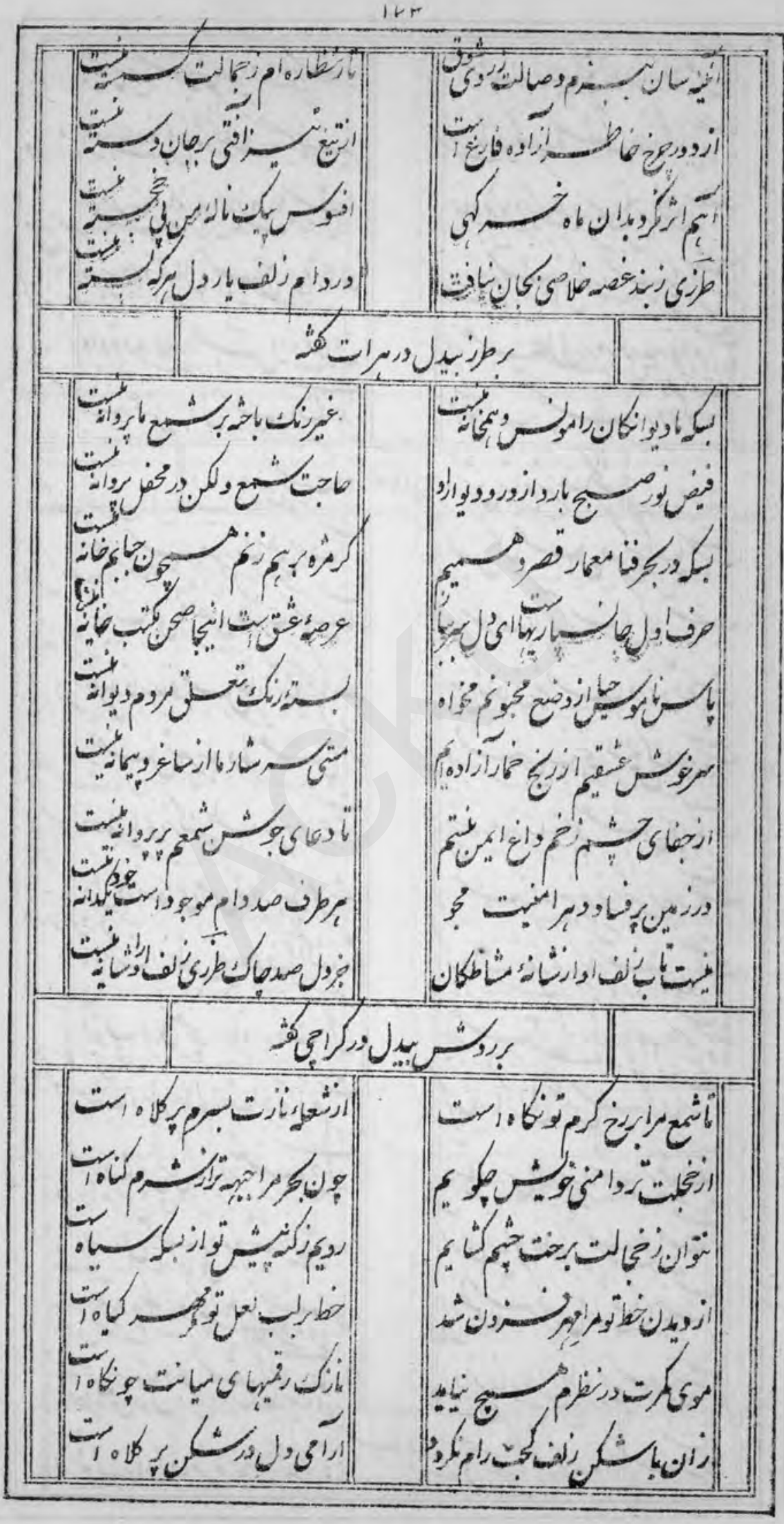


$1 \vee F$

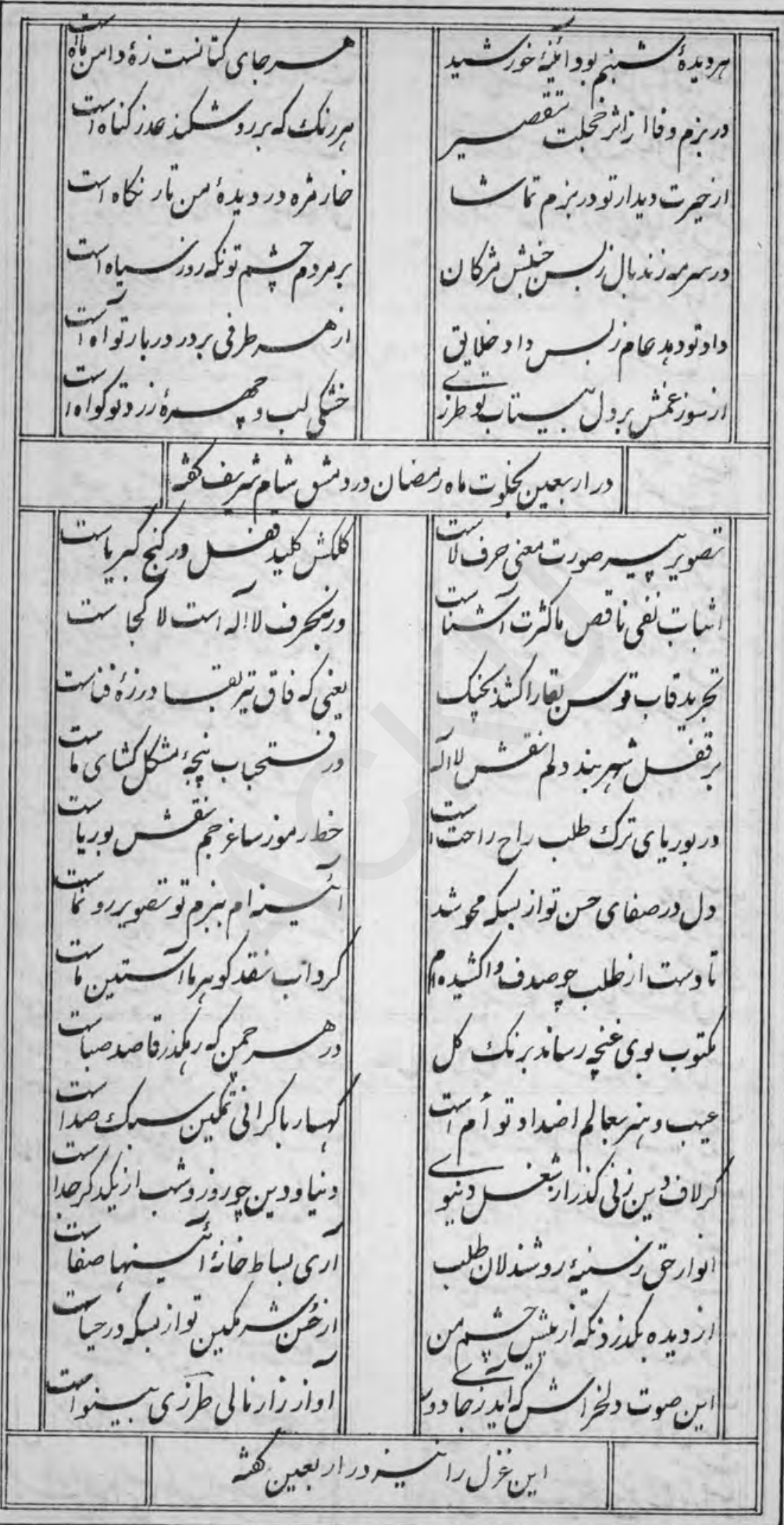


IVo

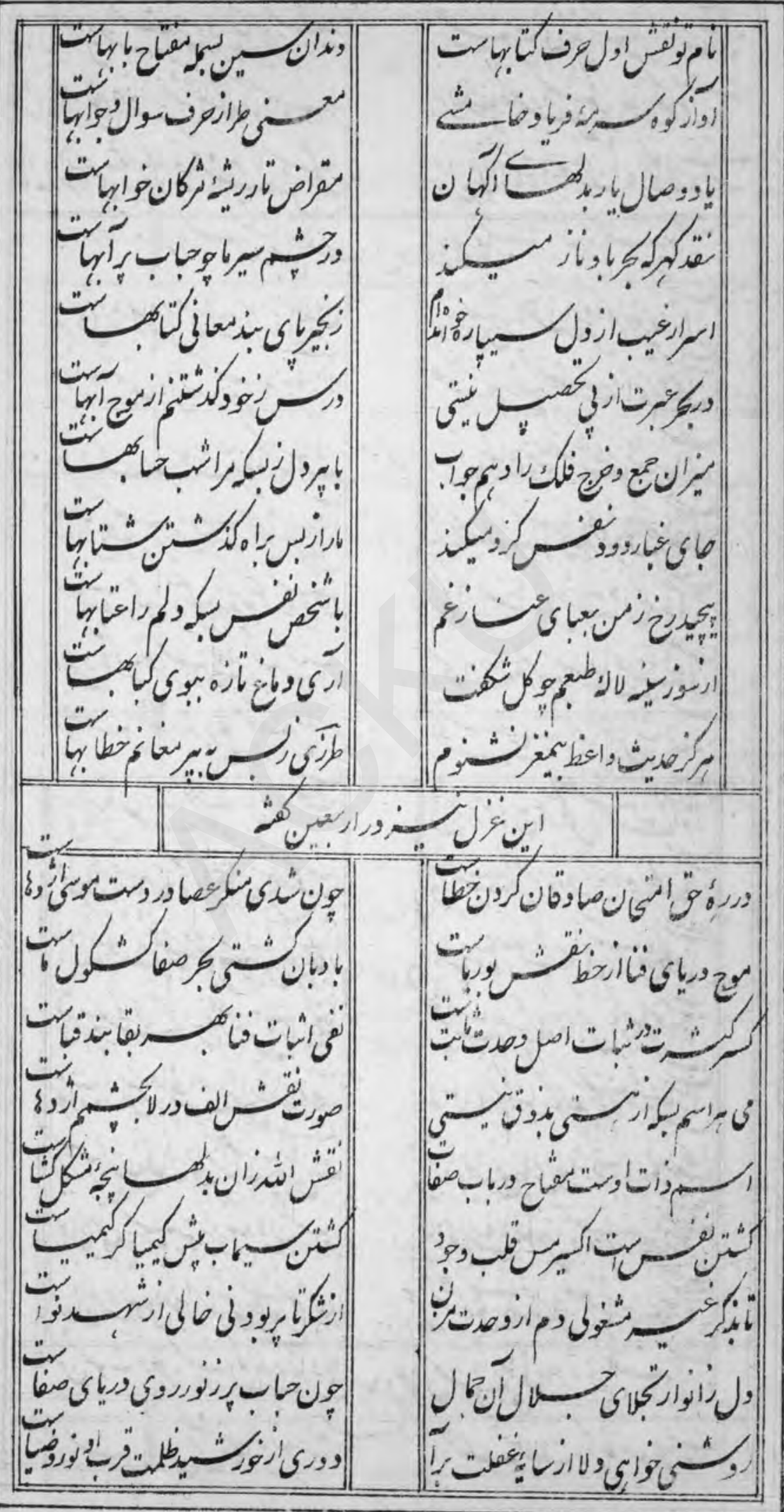


15s

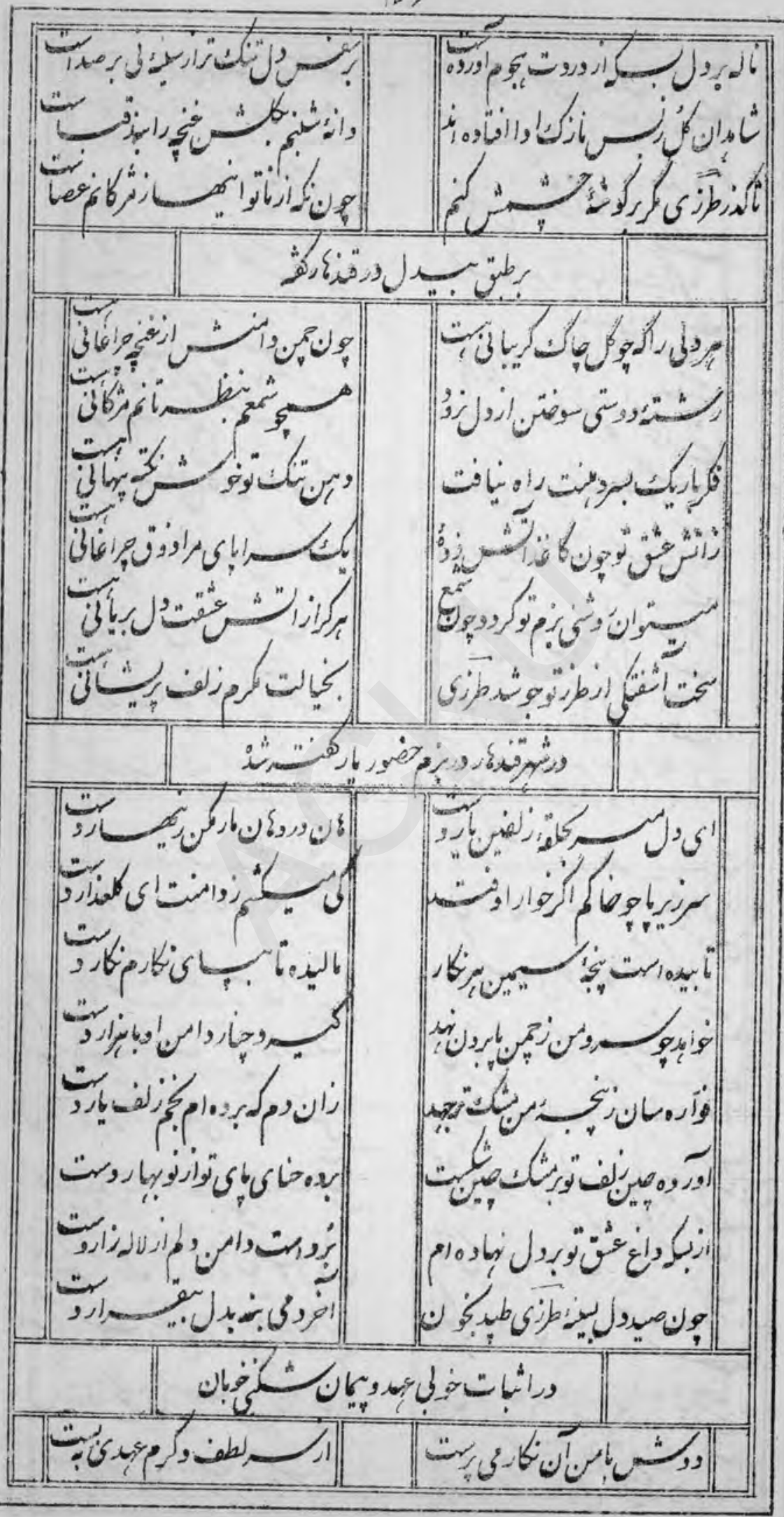


$12 v$

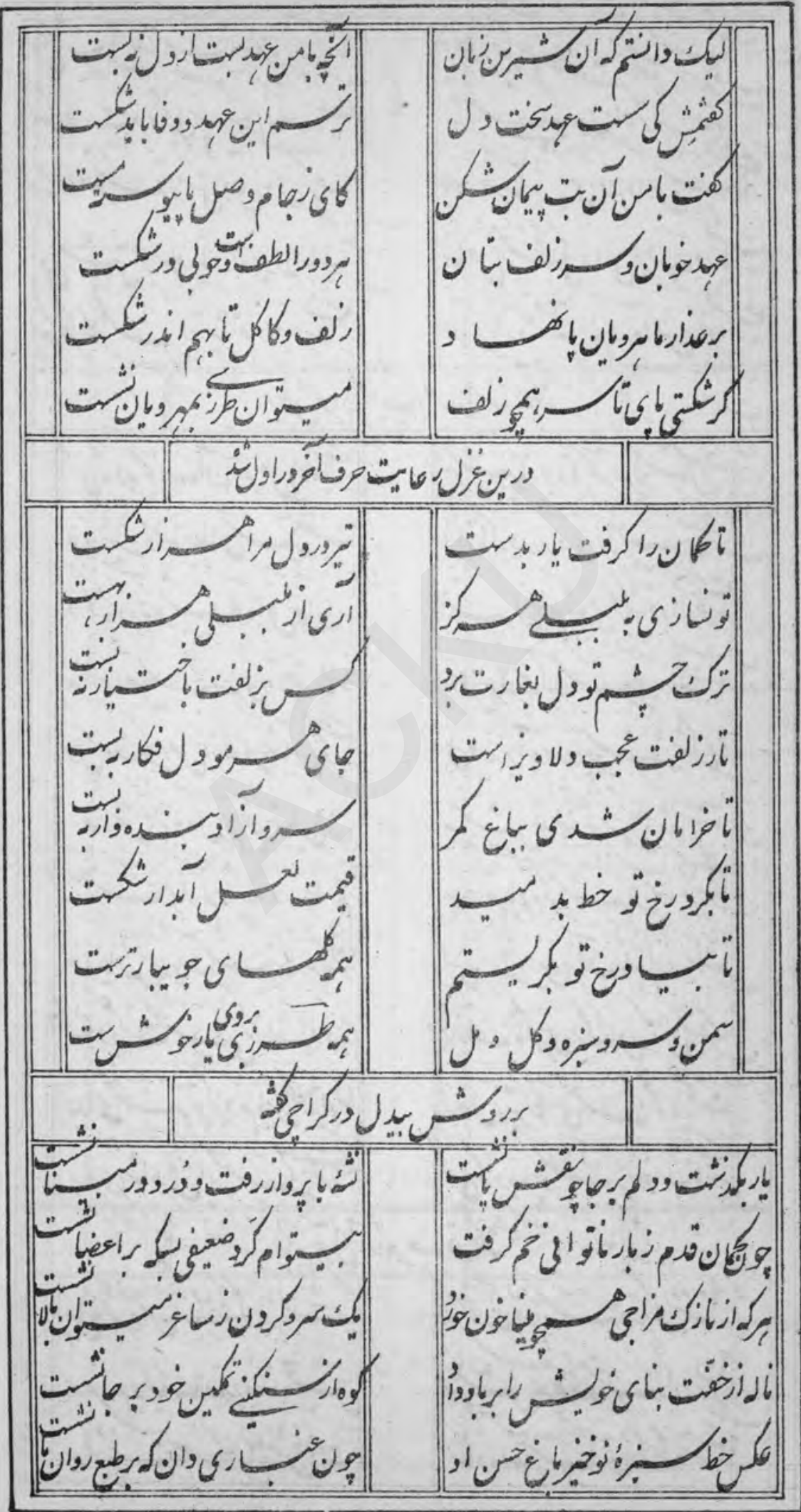


ルN

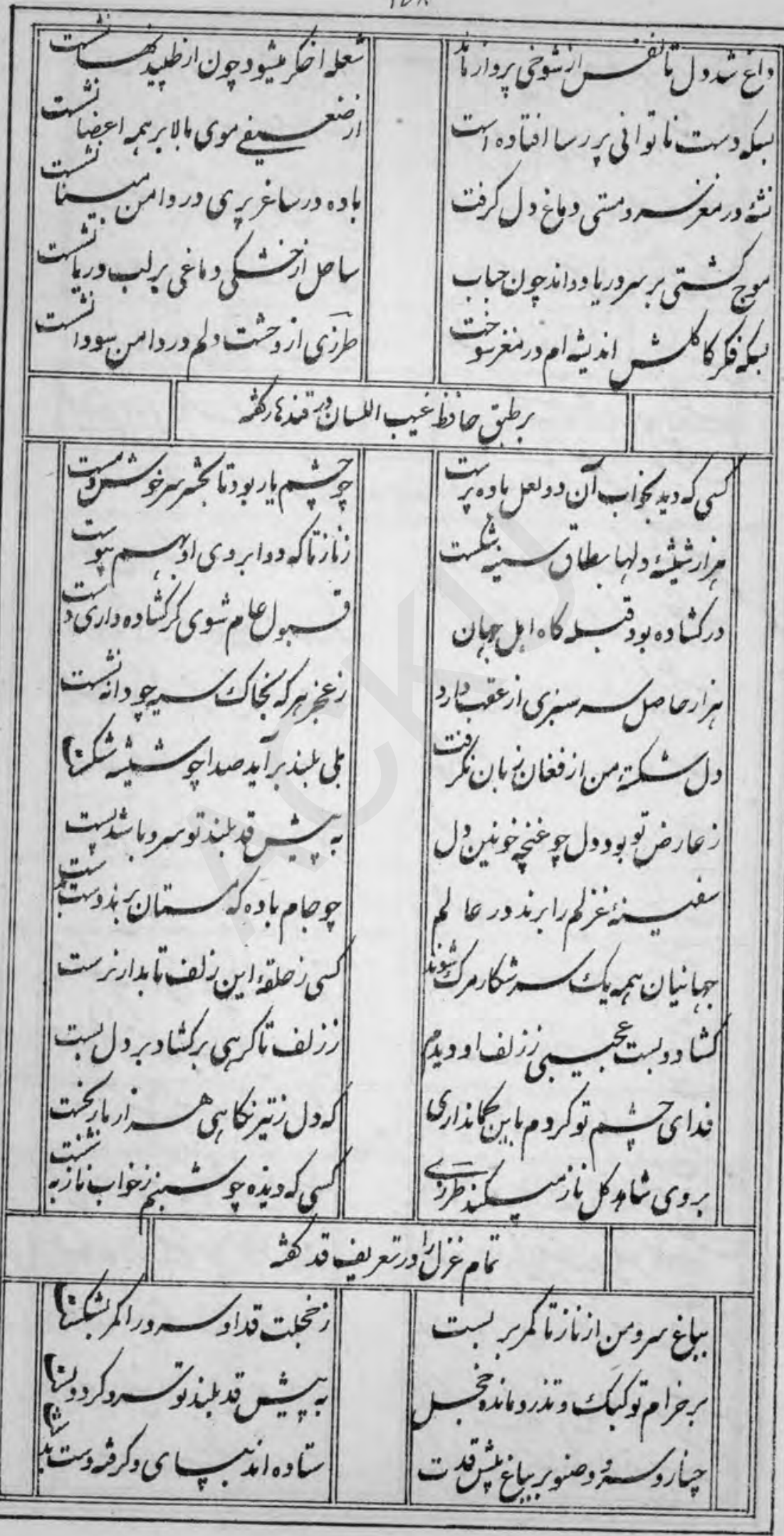


iv 9

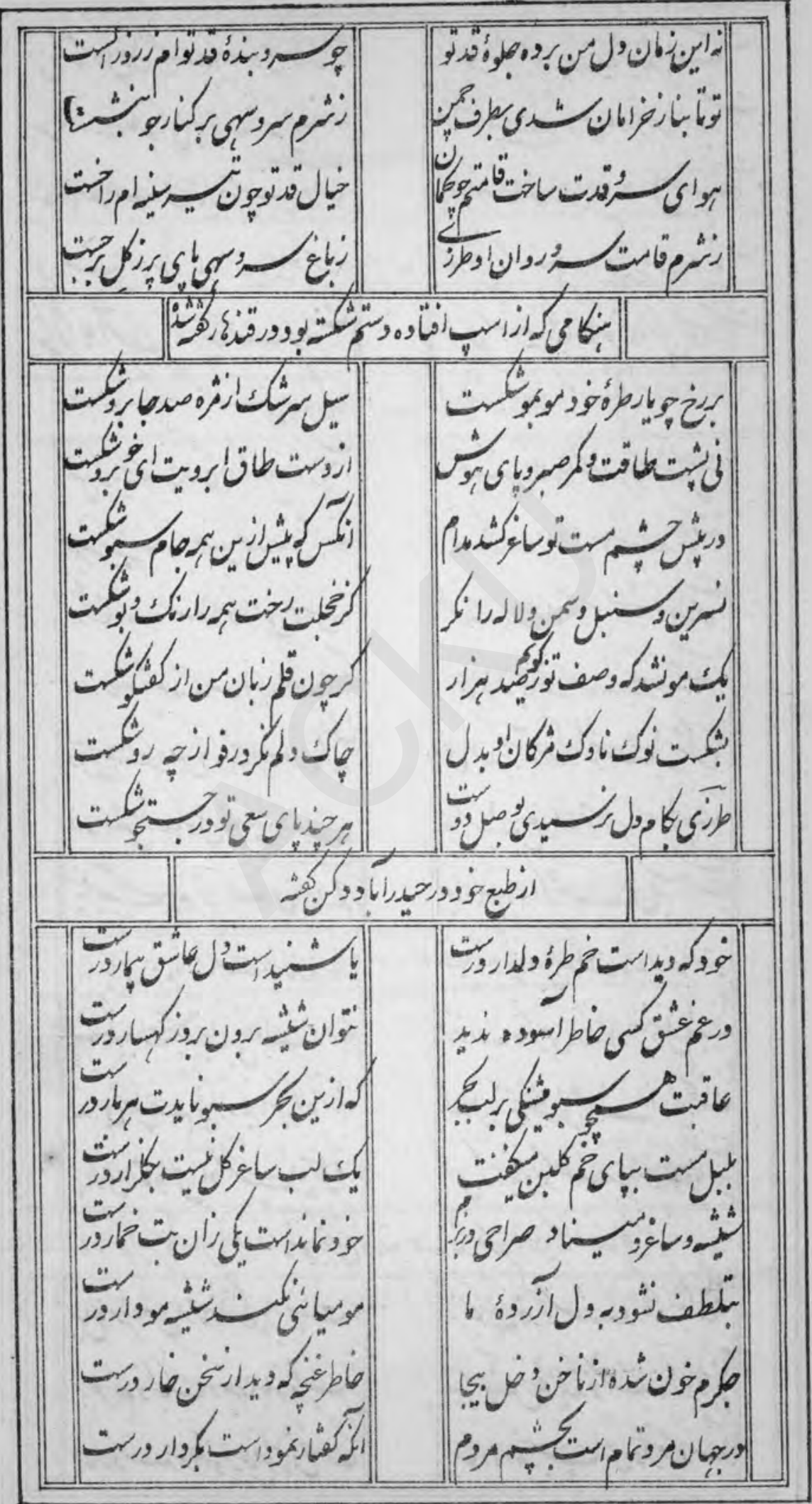


IA.

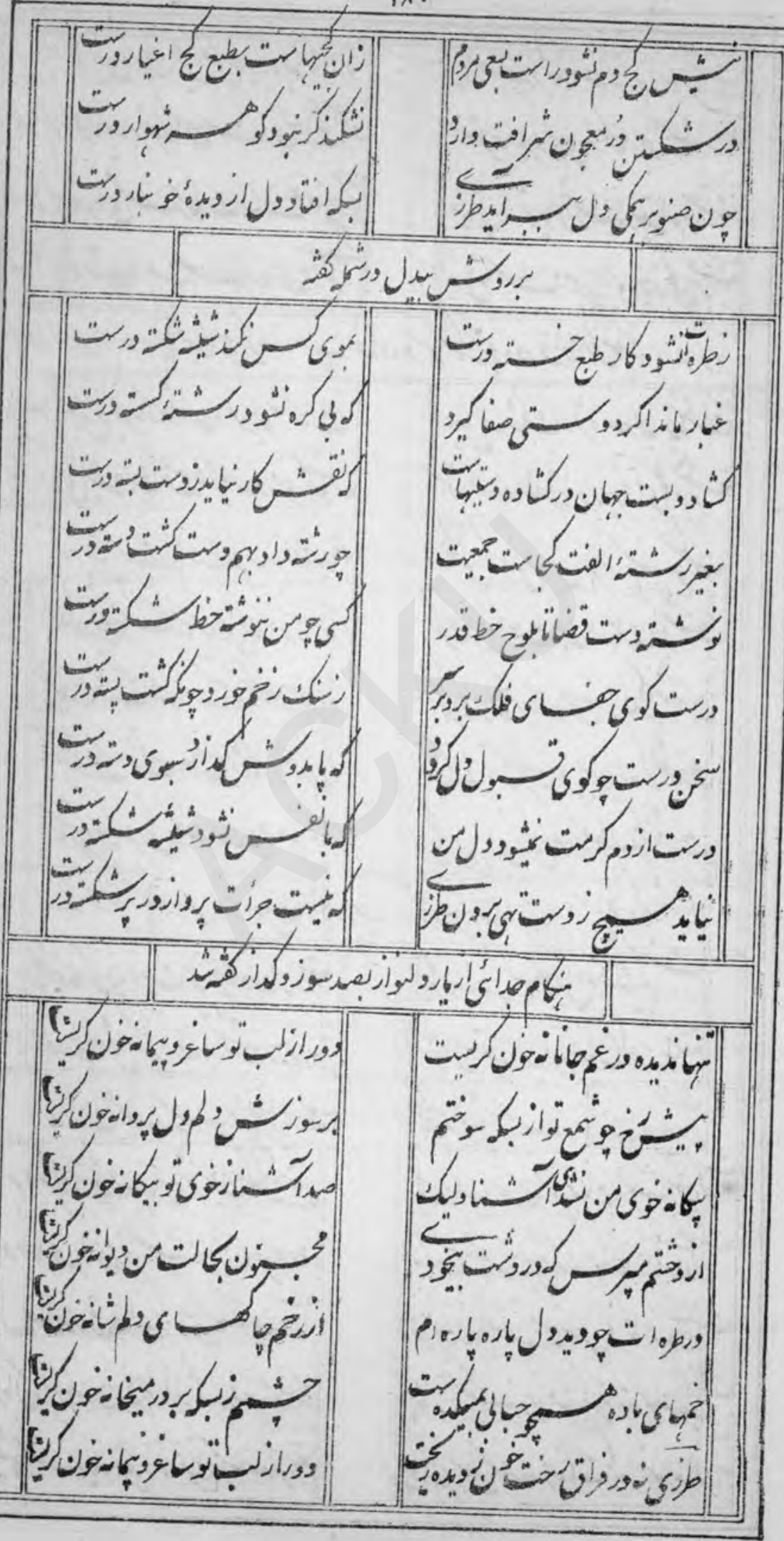

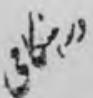




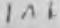

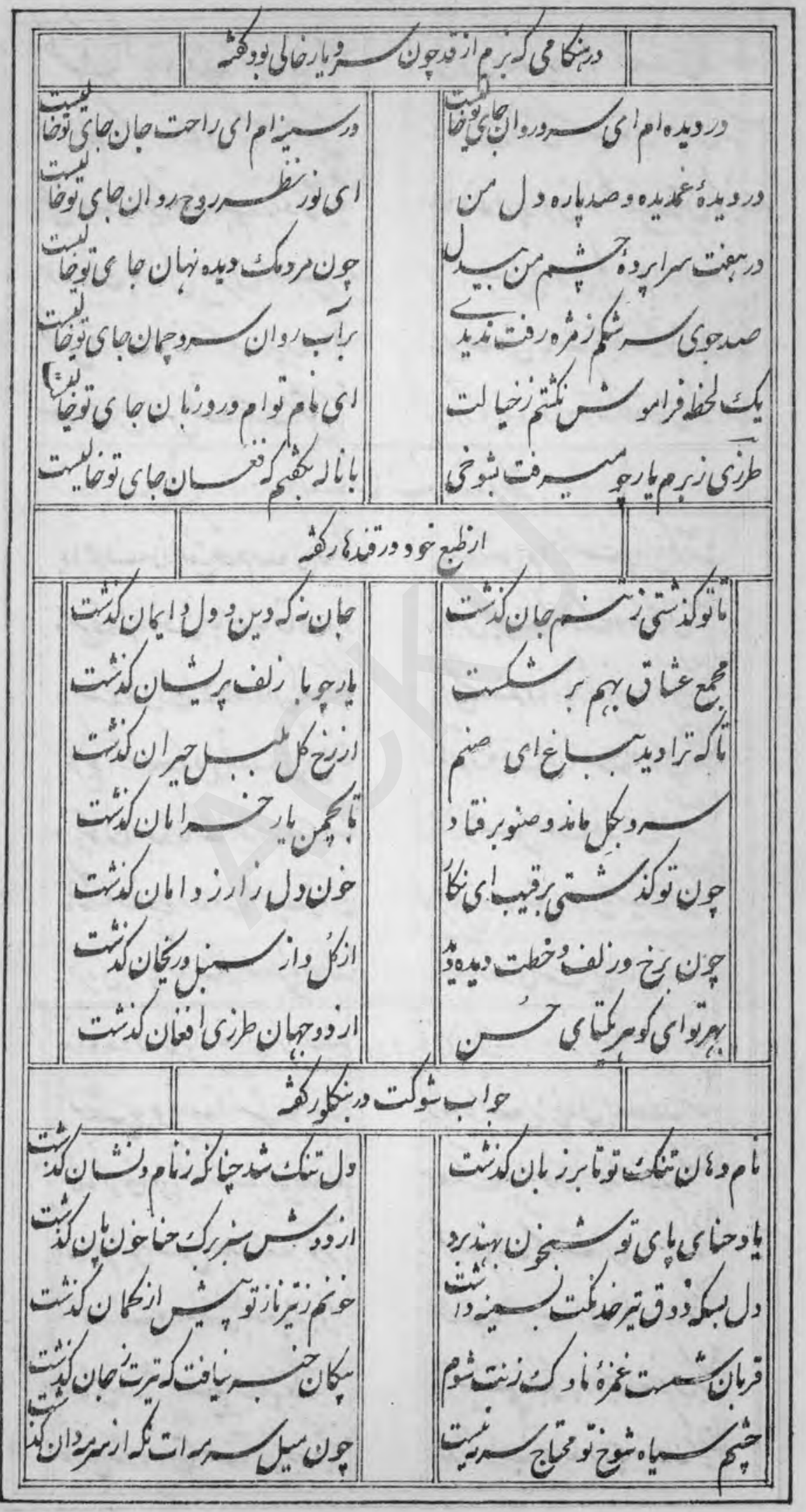


A r

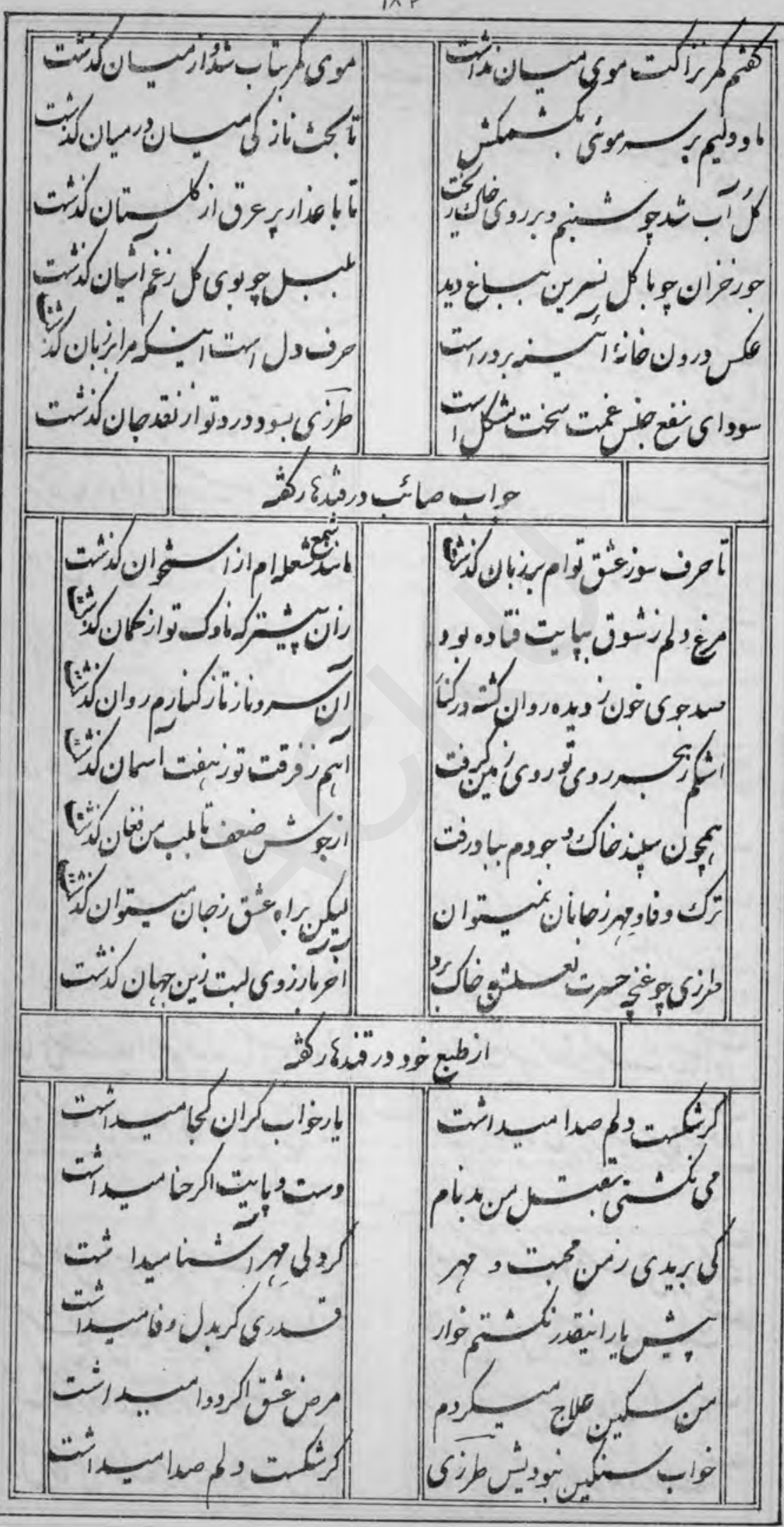


In

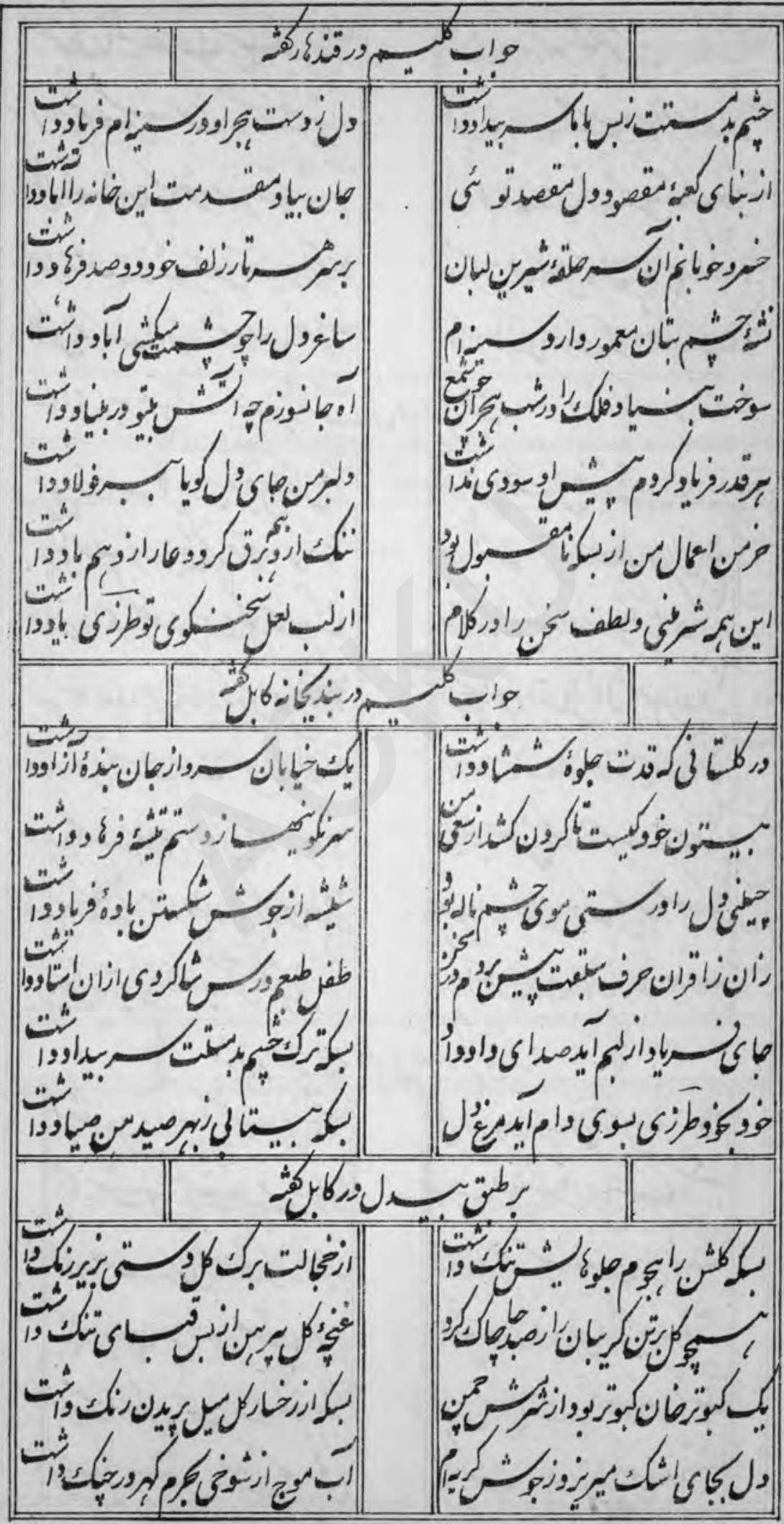


IAf

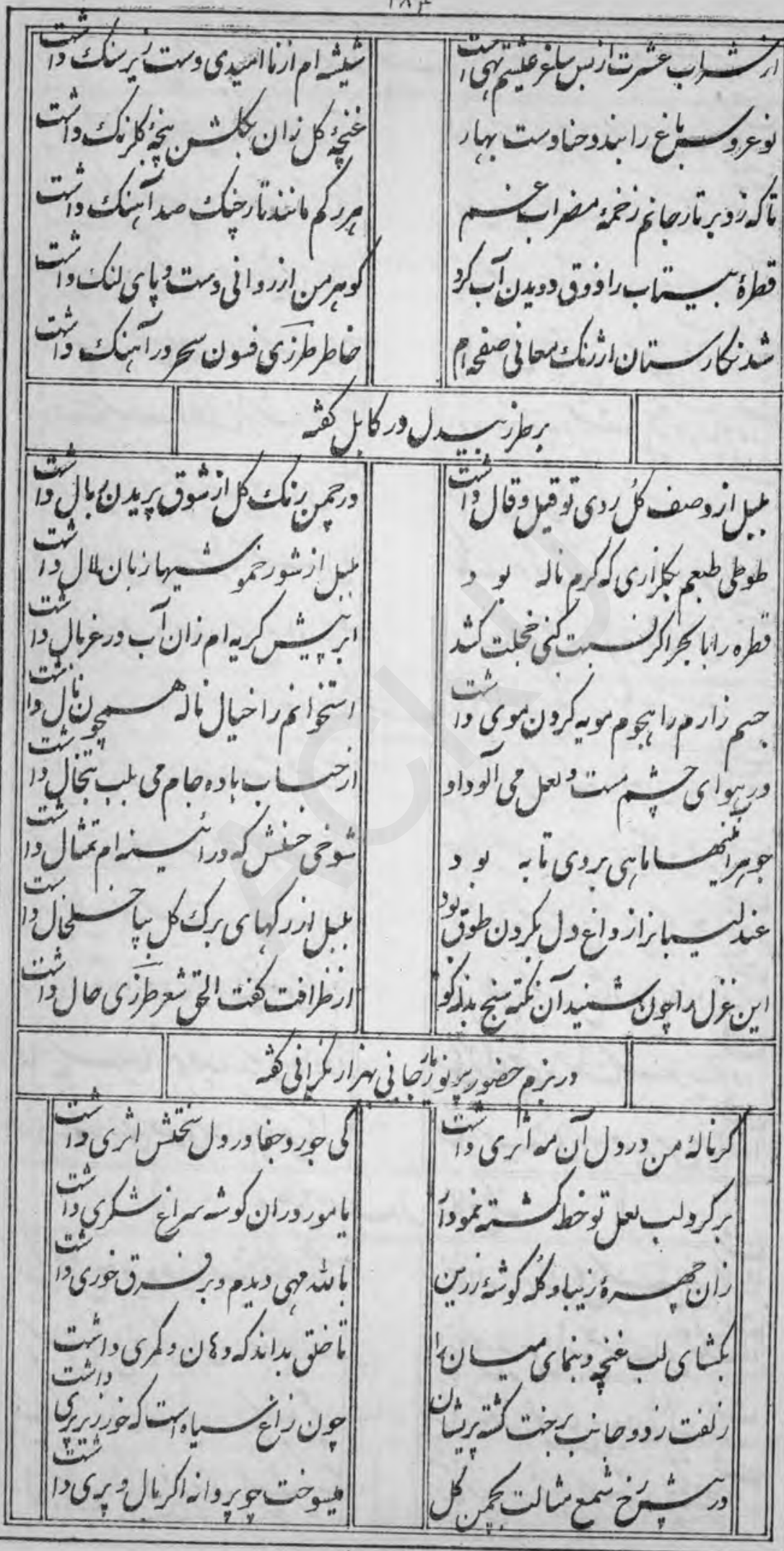


$1 \wedge \Delta$

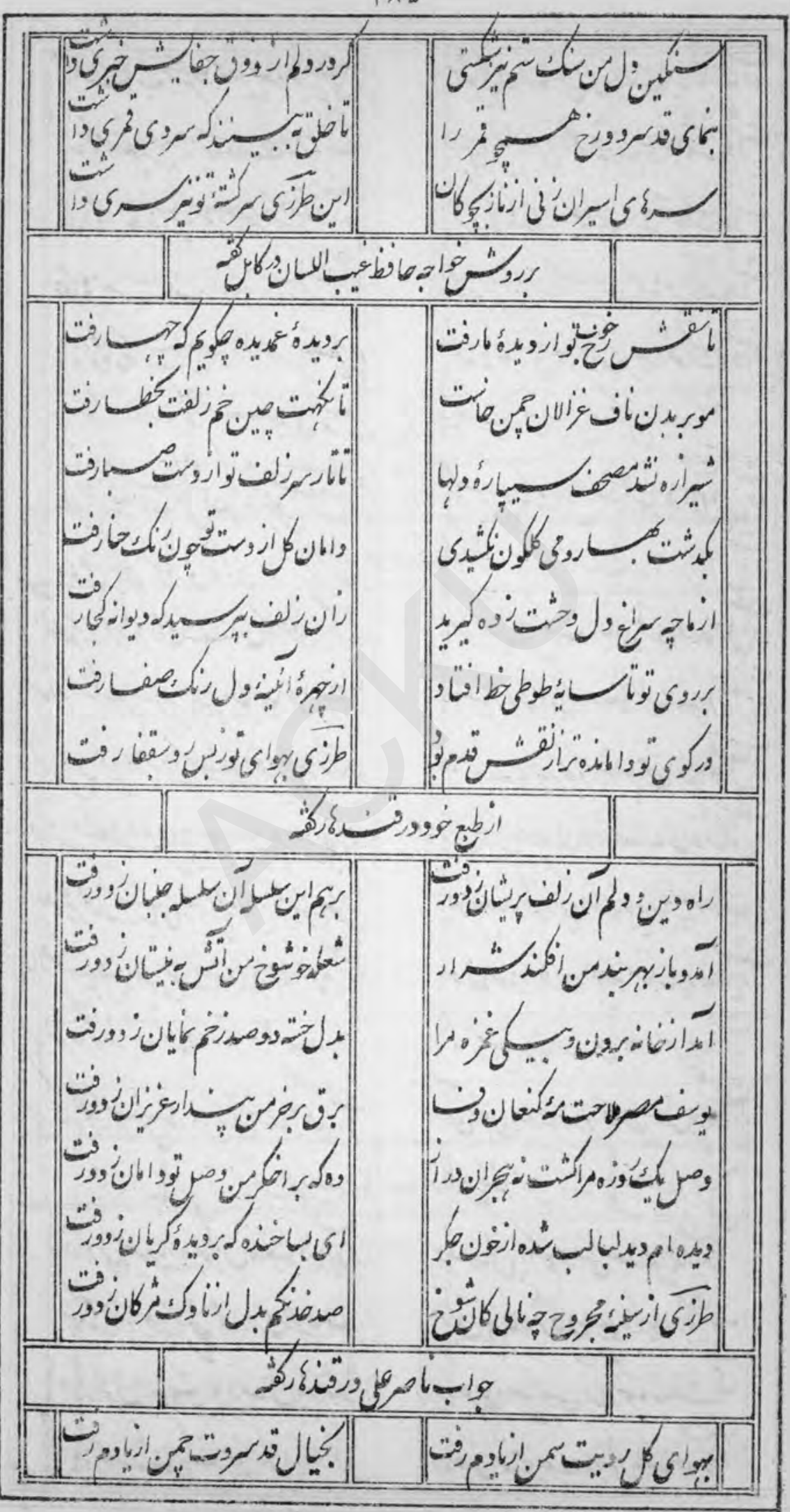


IAs

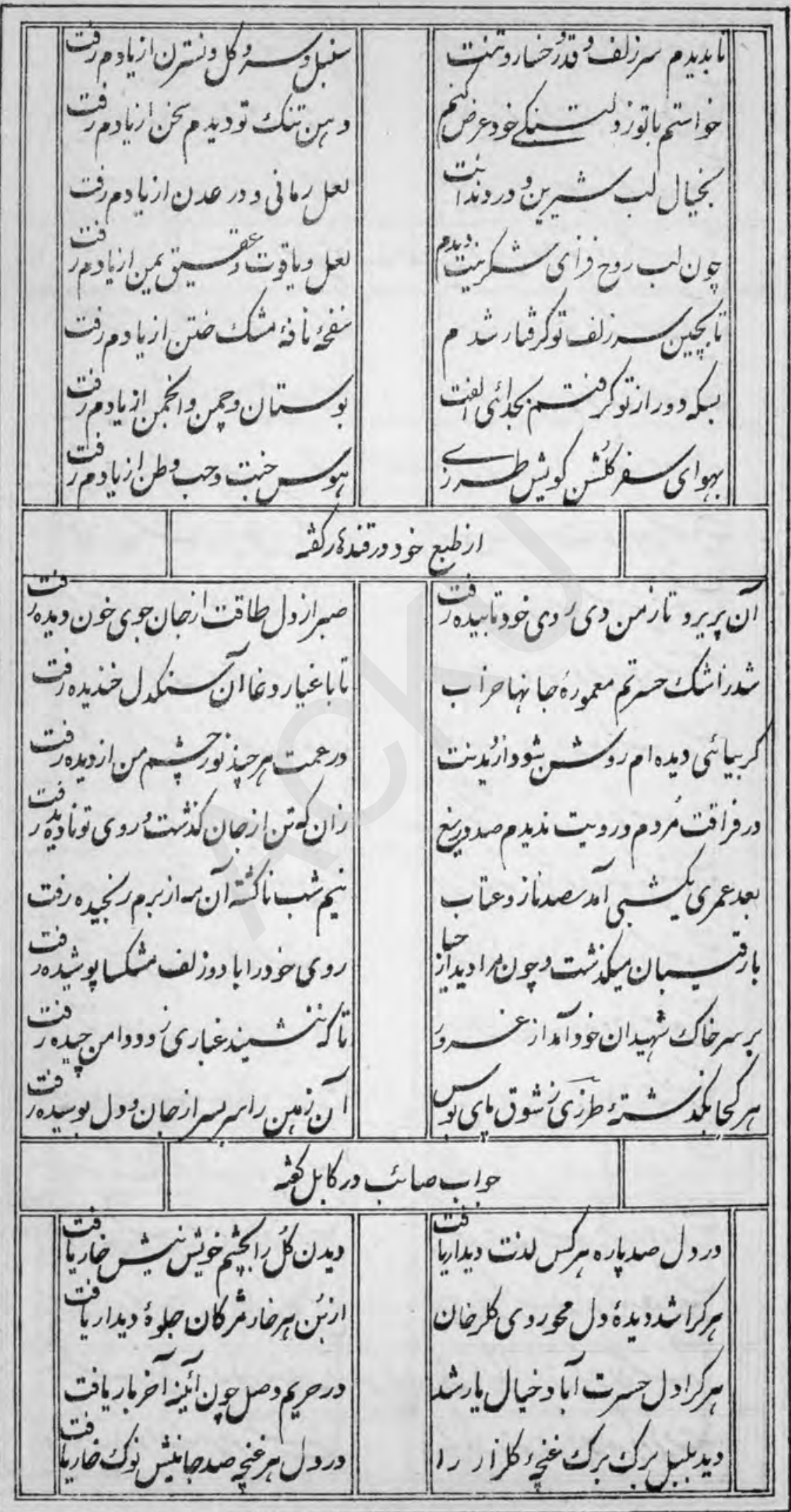


IA

|| $\mid$


$\operatorname{lA} A$

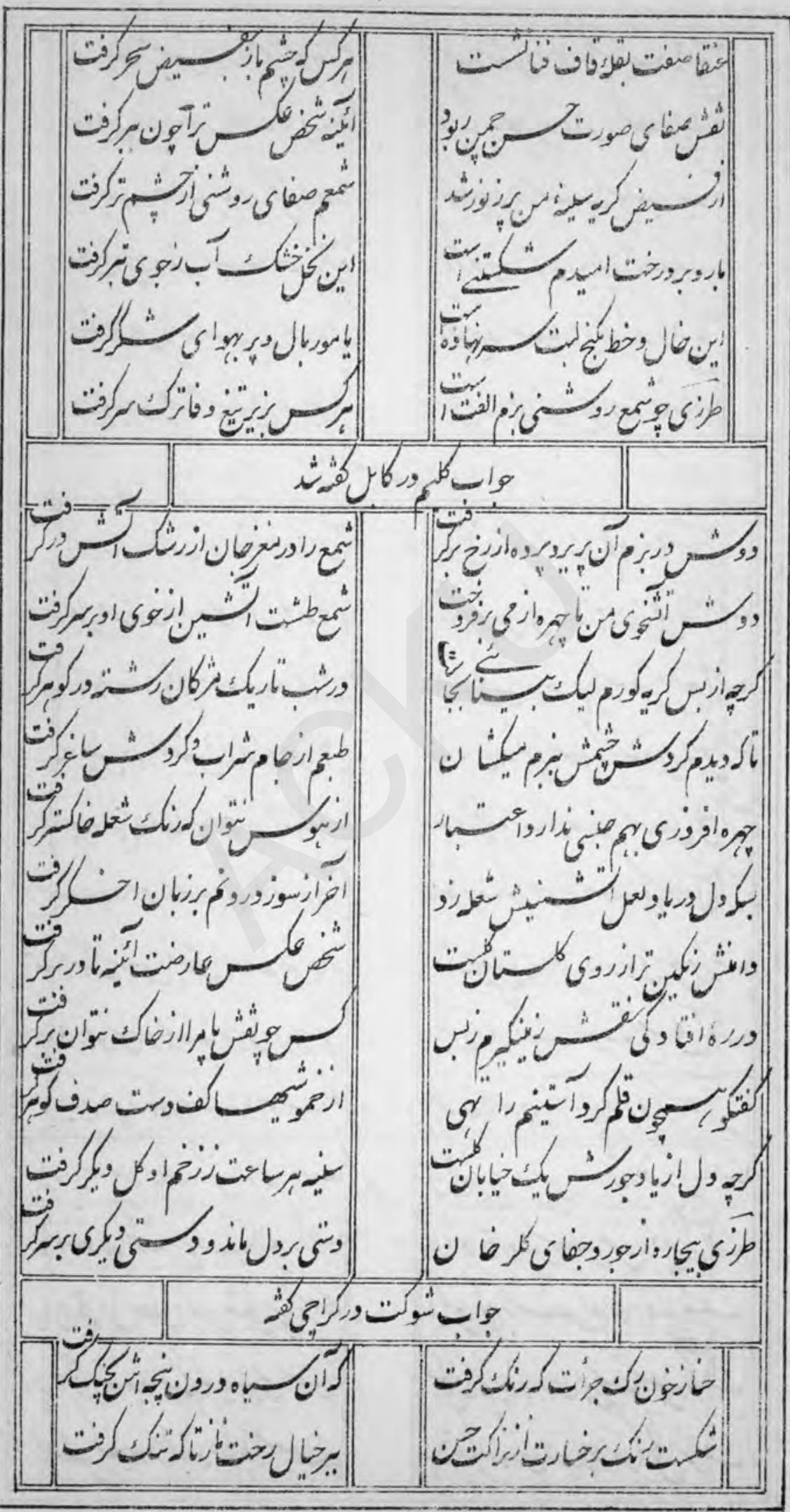

W. 


\section{9}

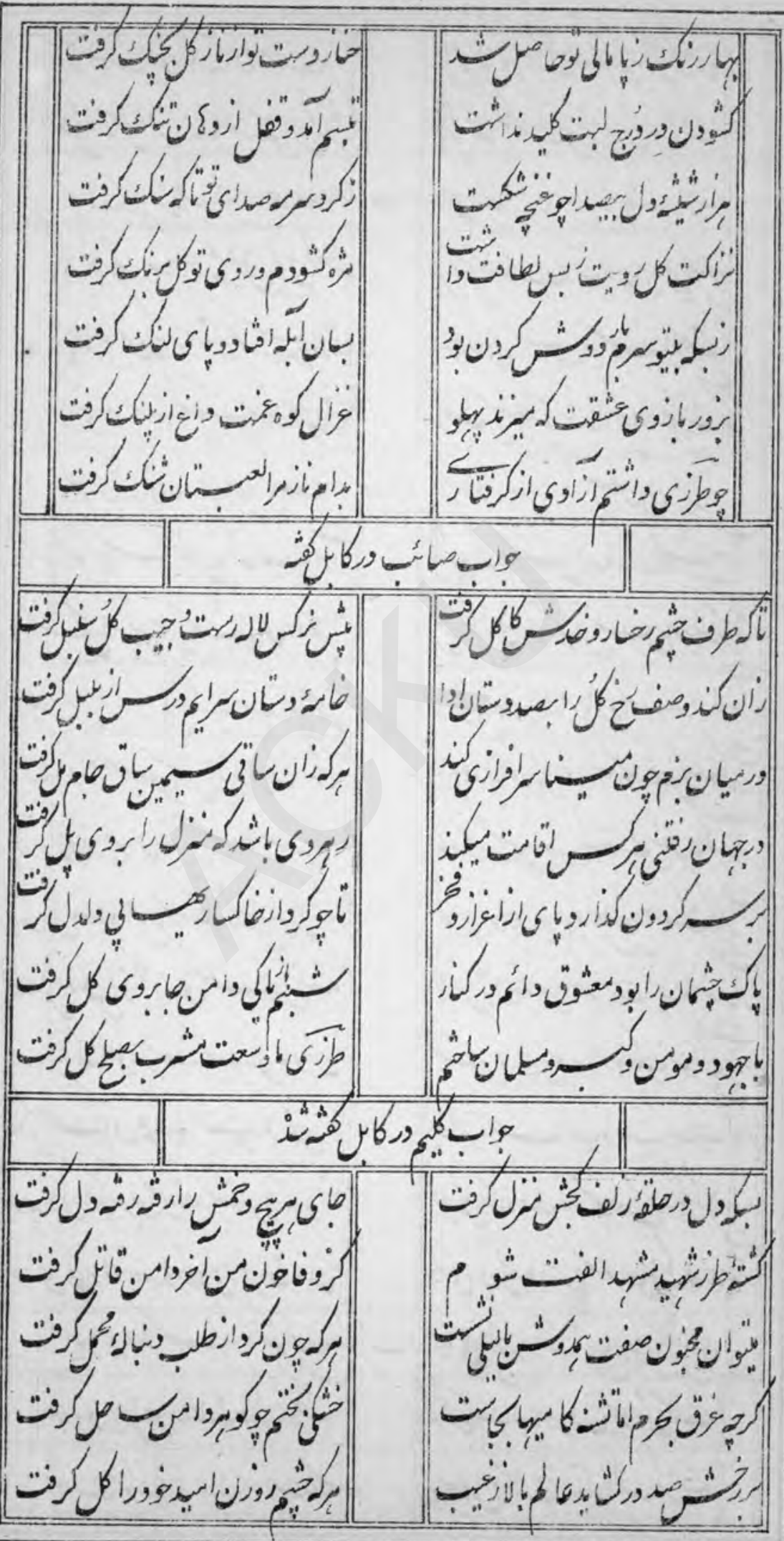


191

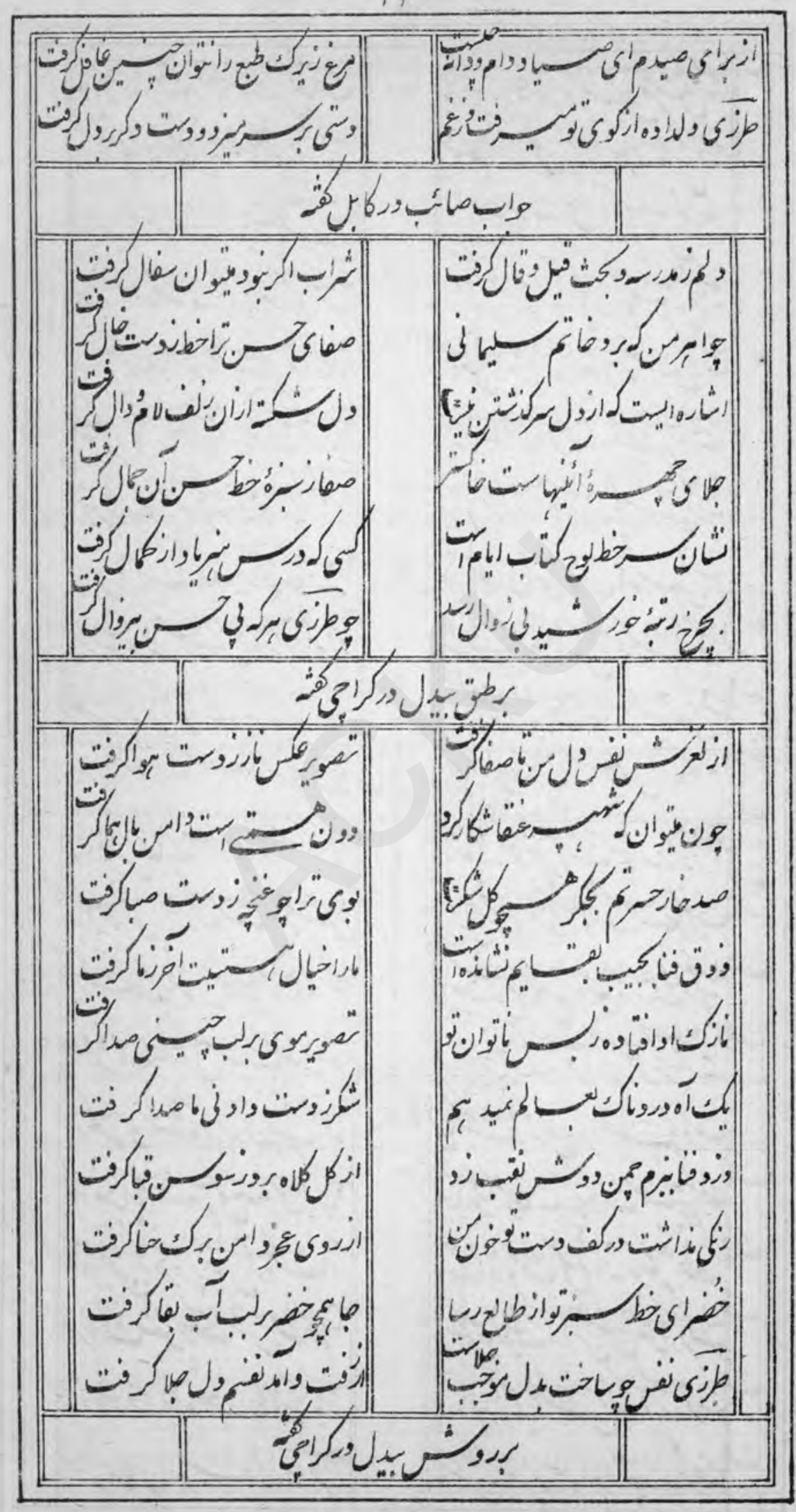


141

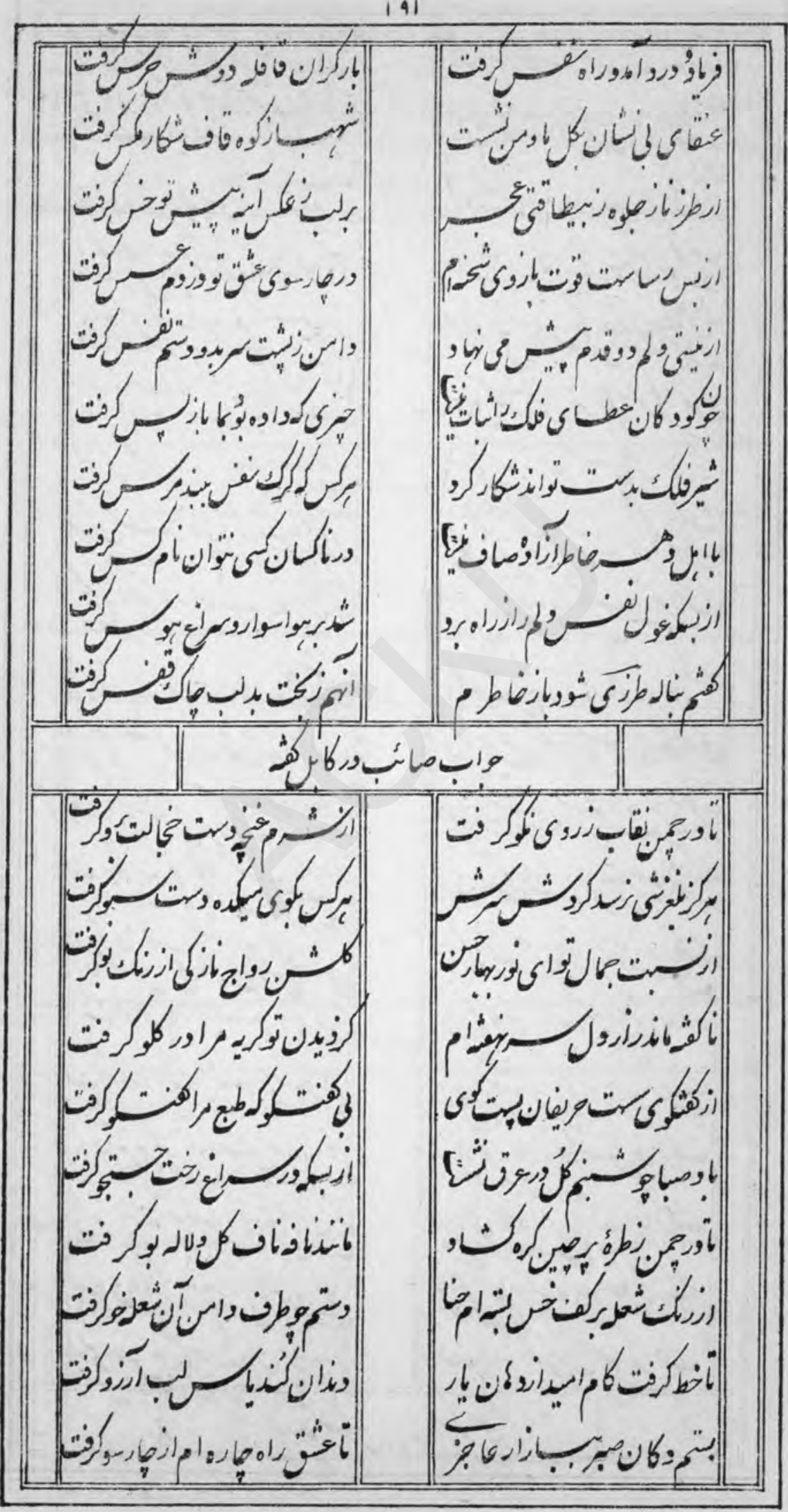


$14 r$

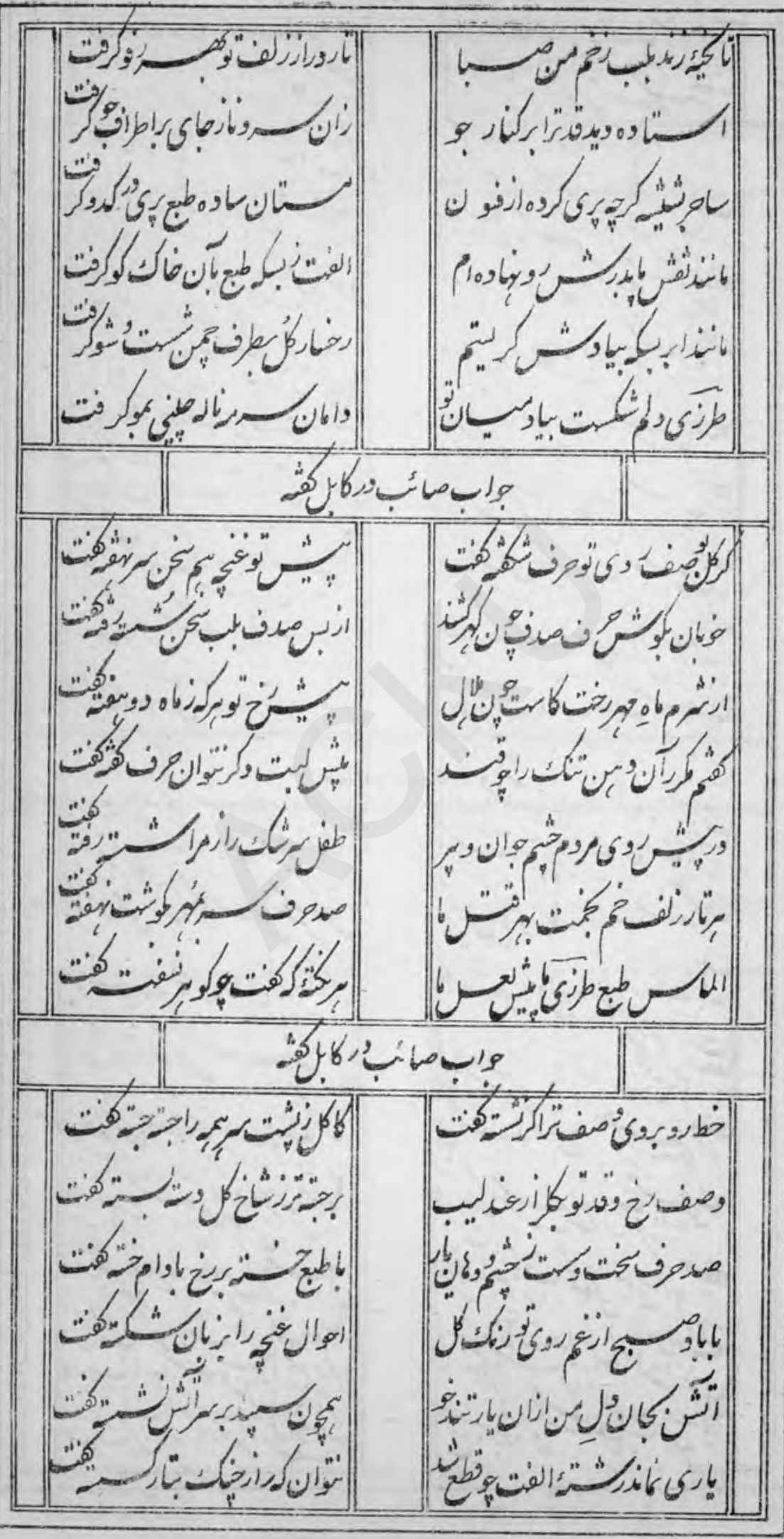


194

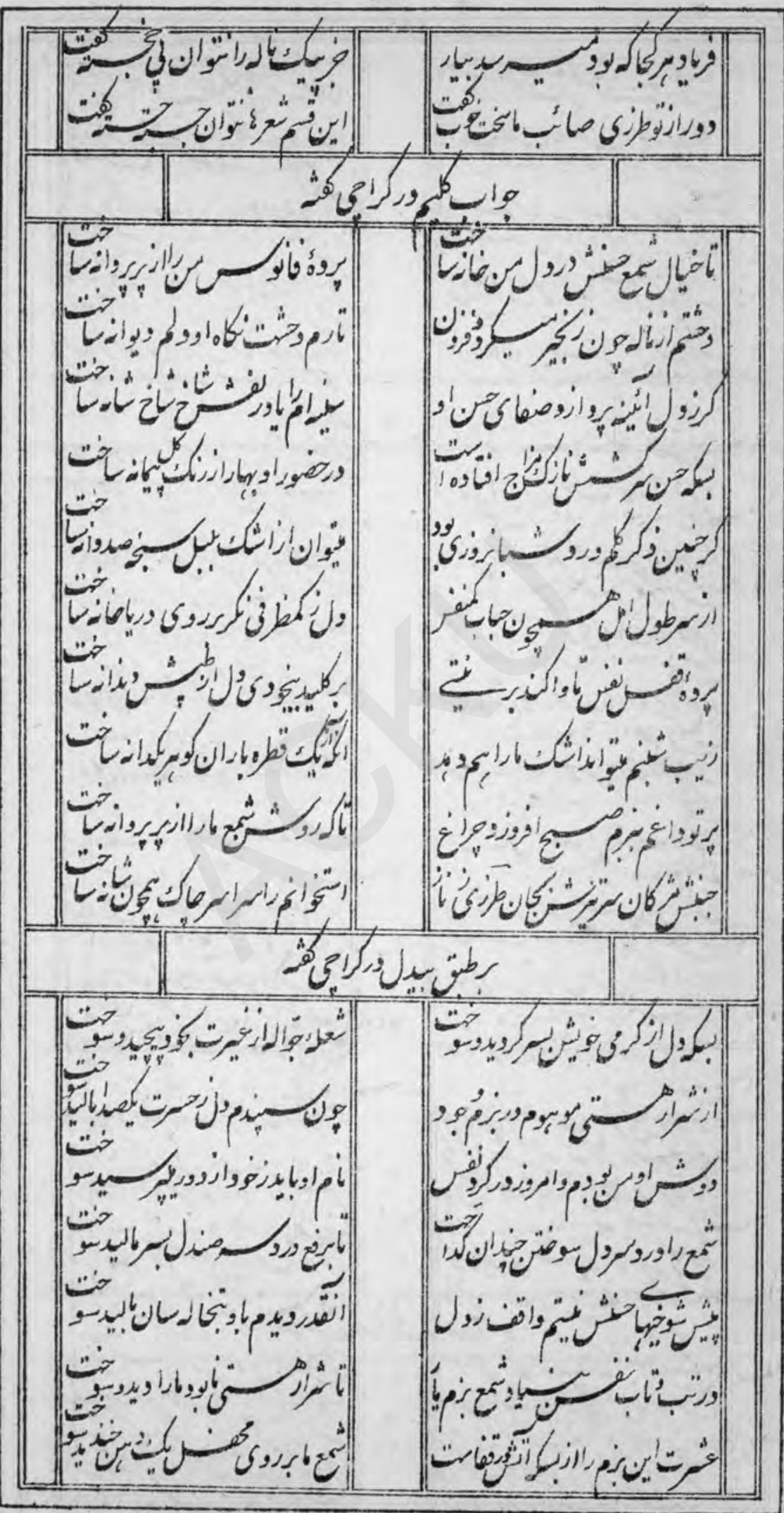




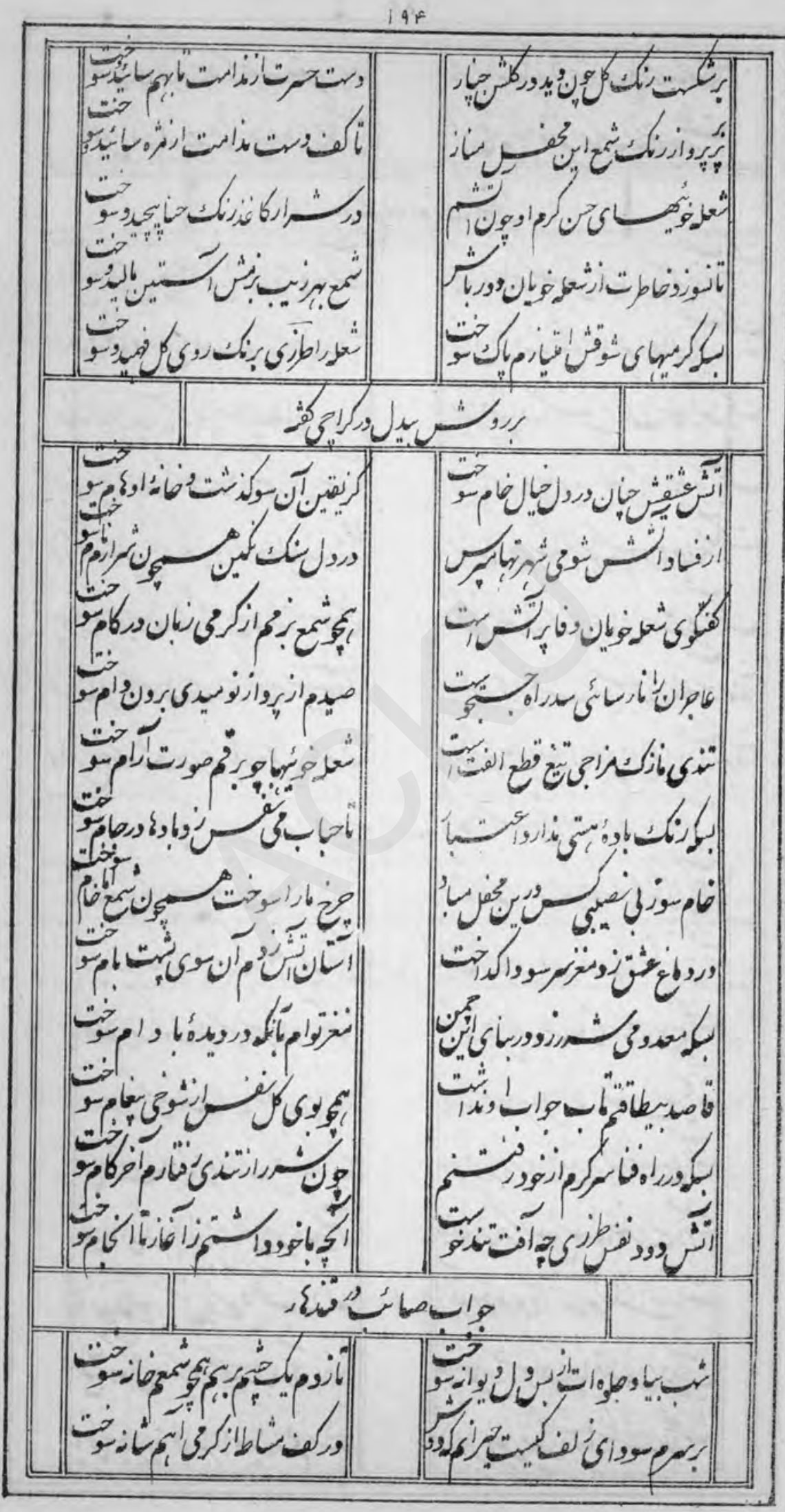


190

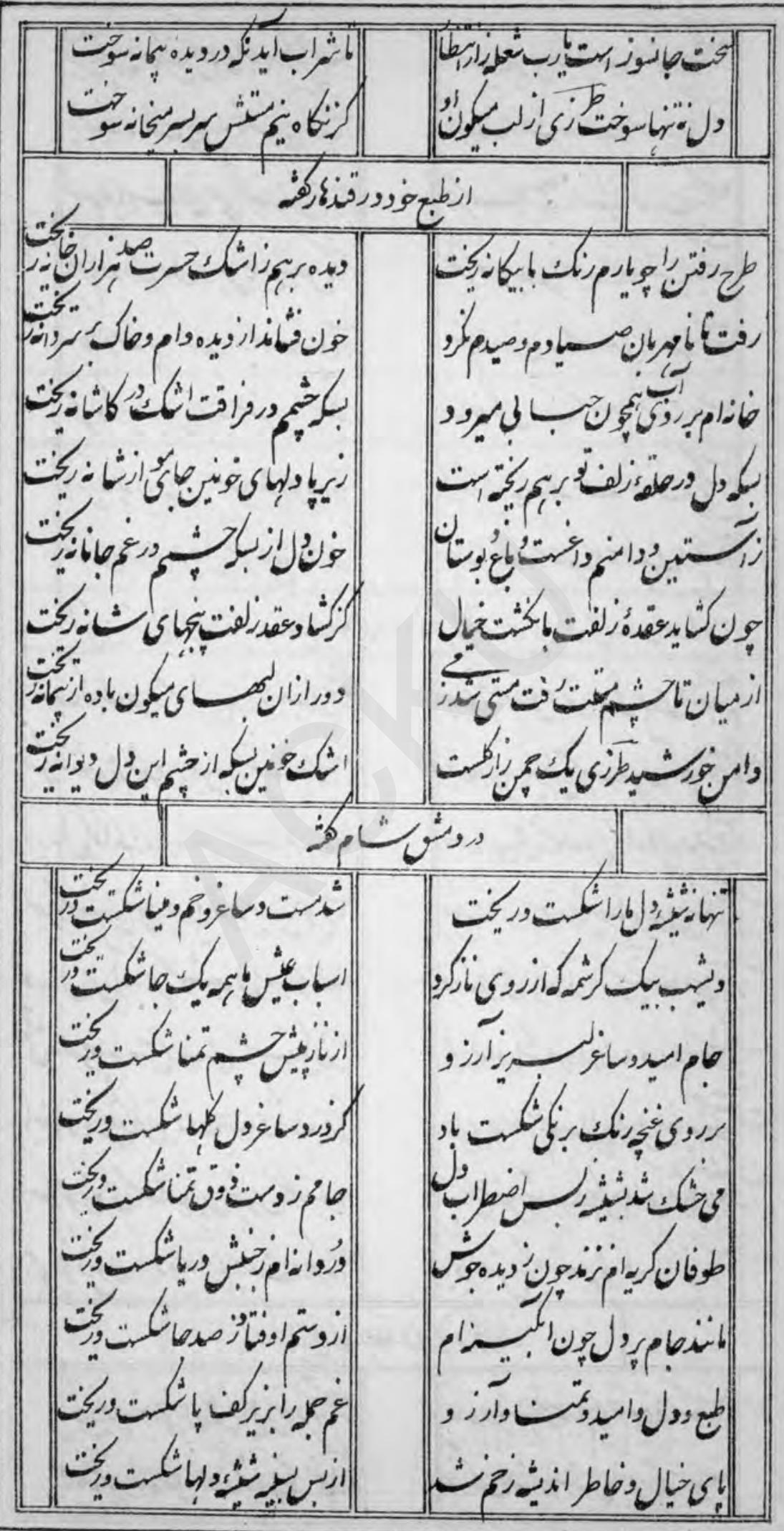


194

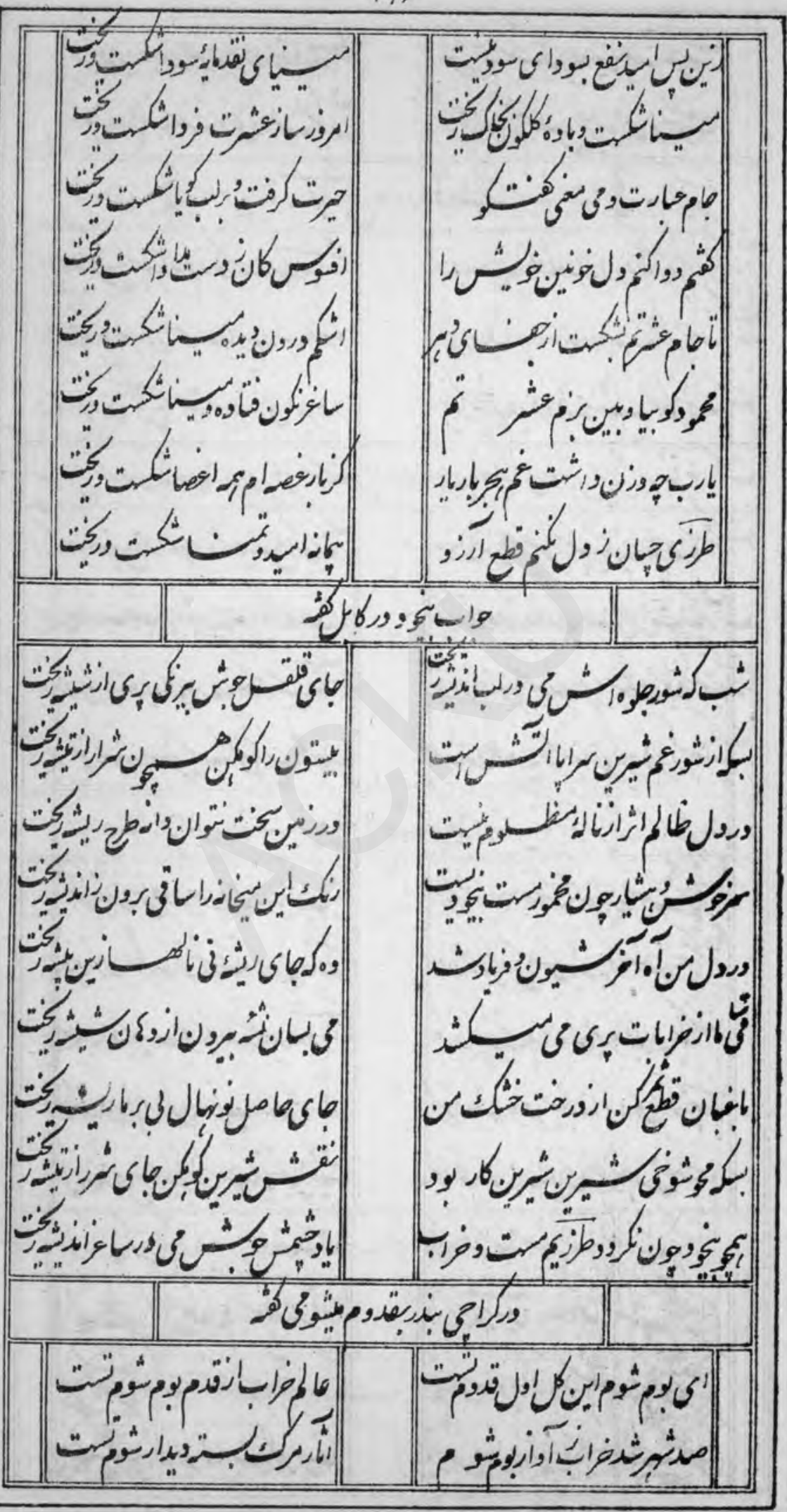


142

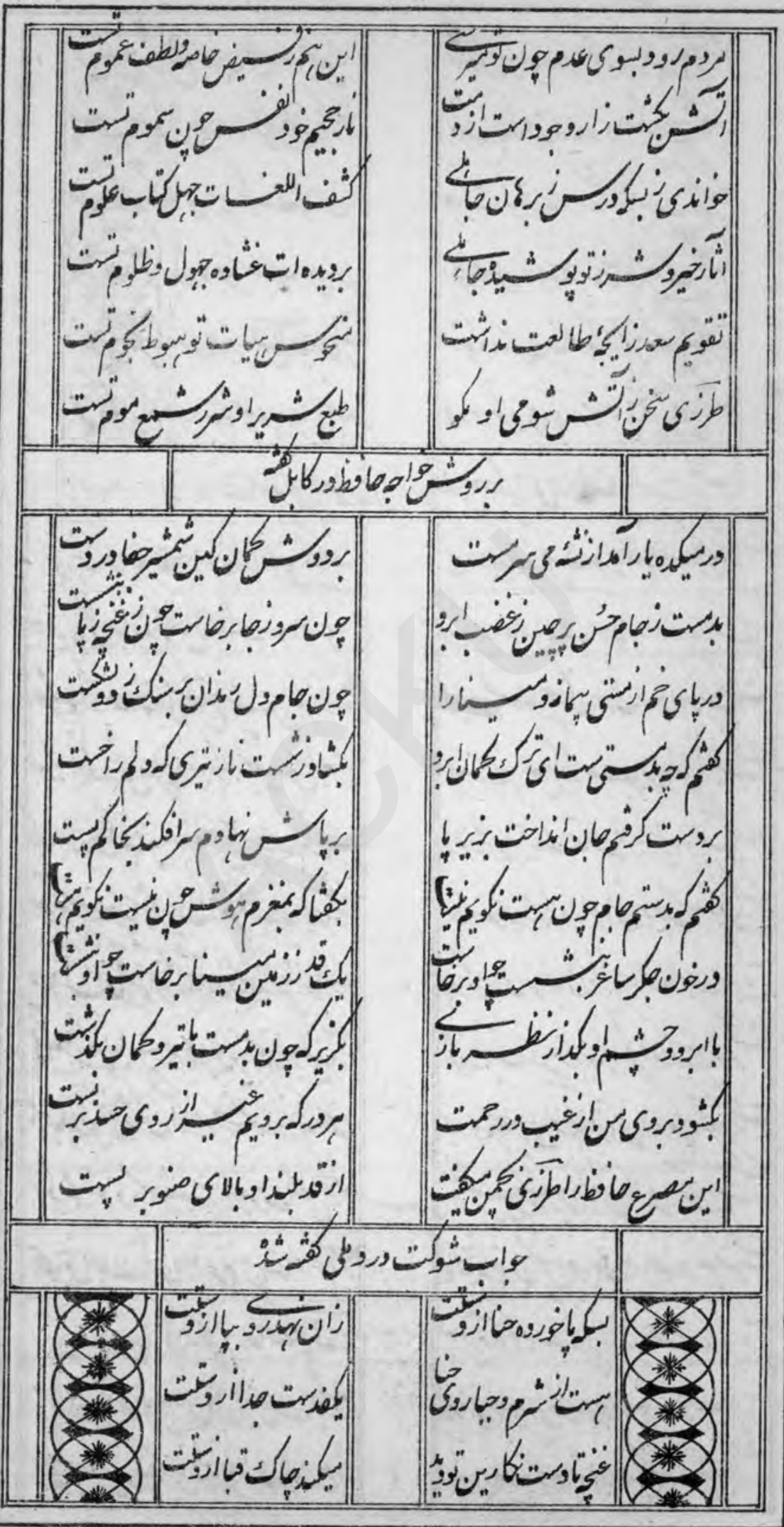


141

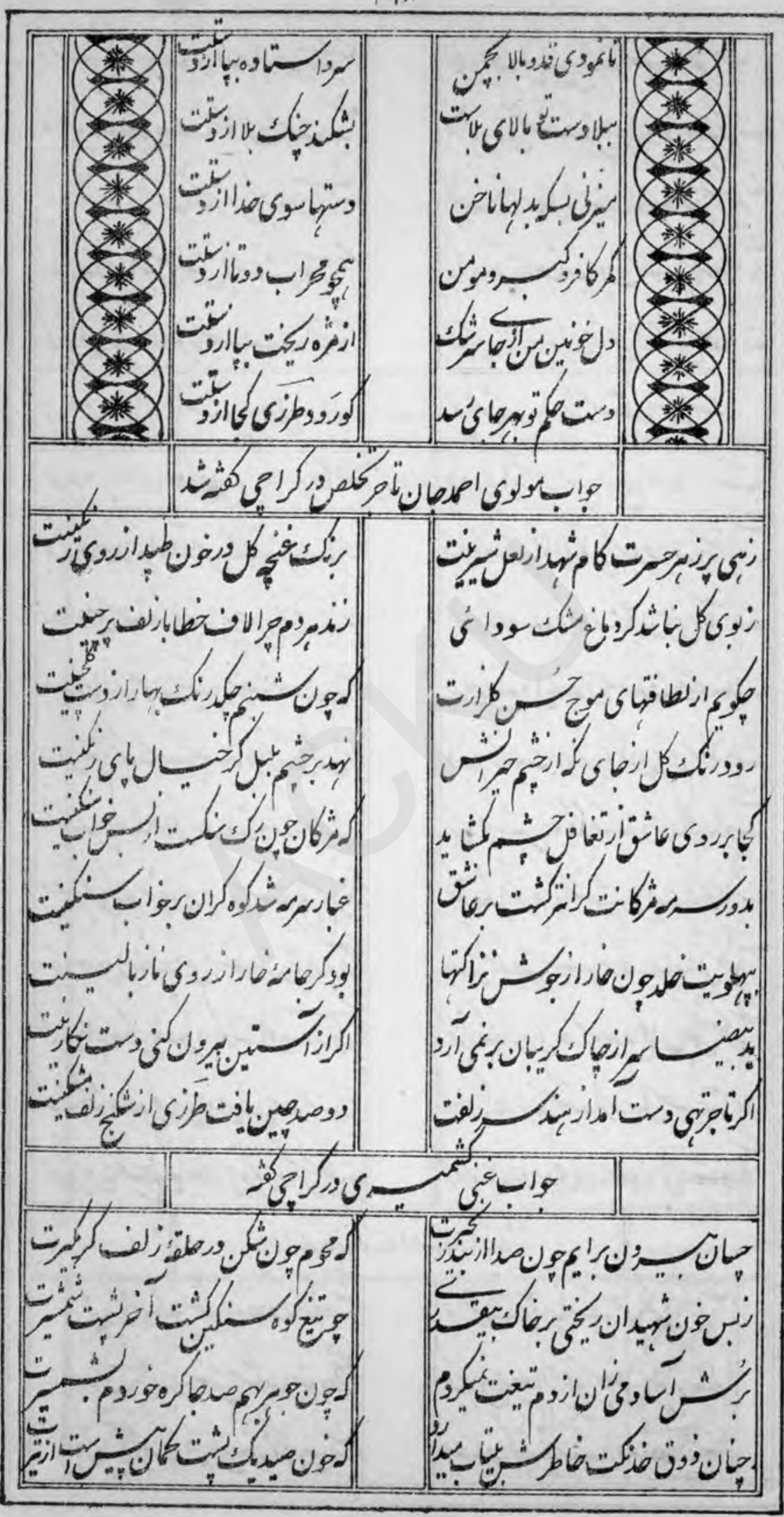




\section{9}

|




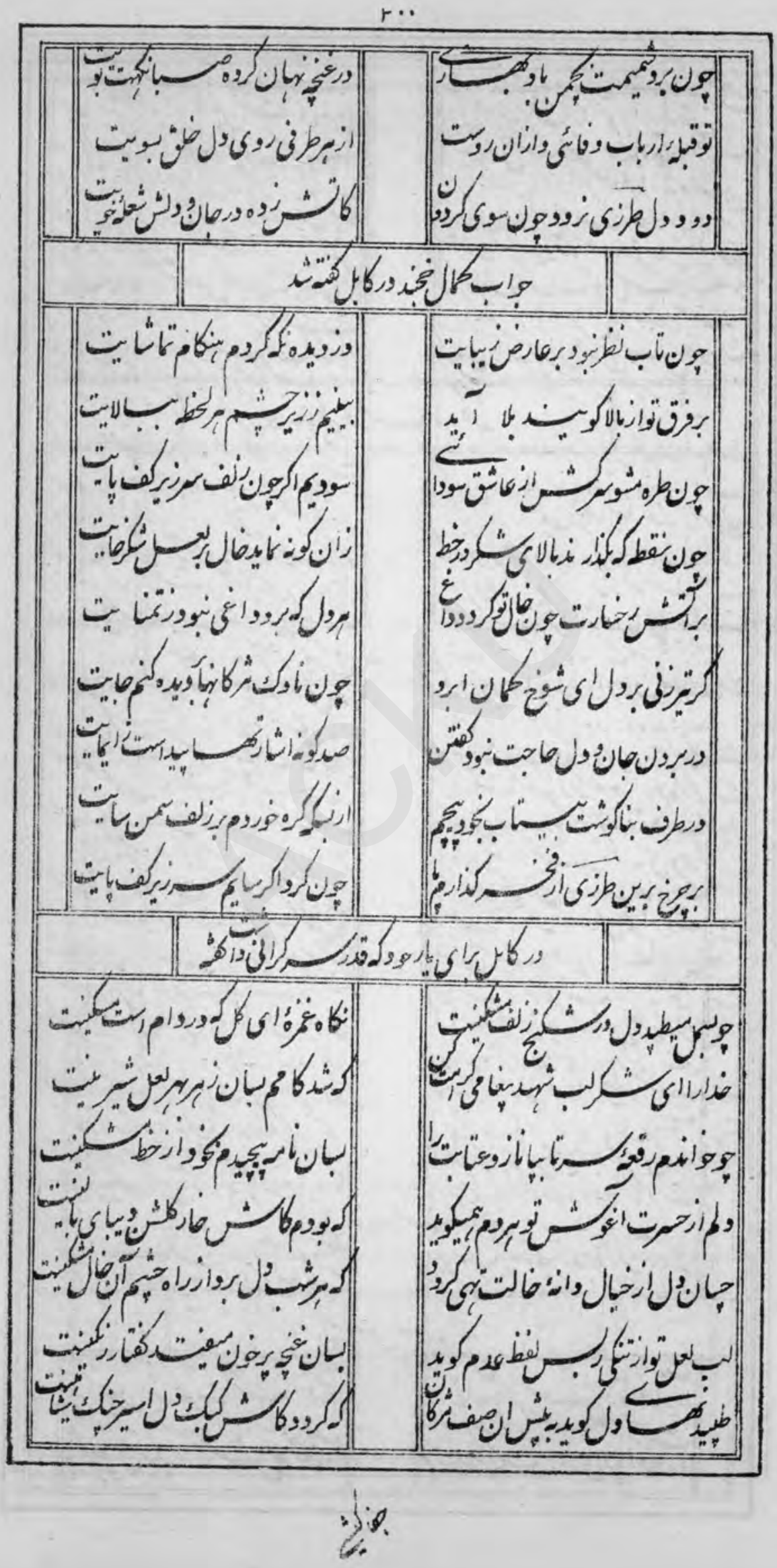




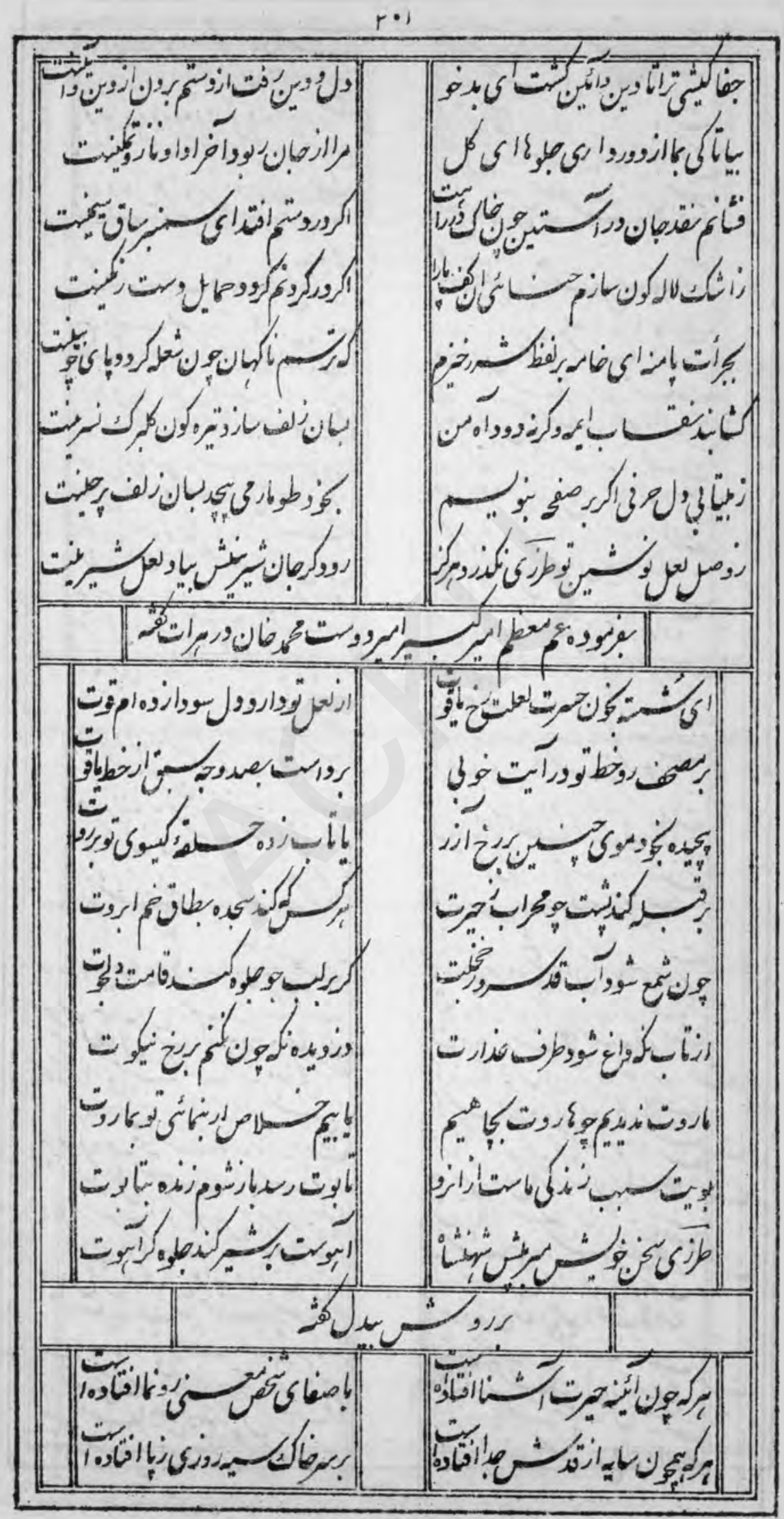




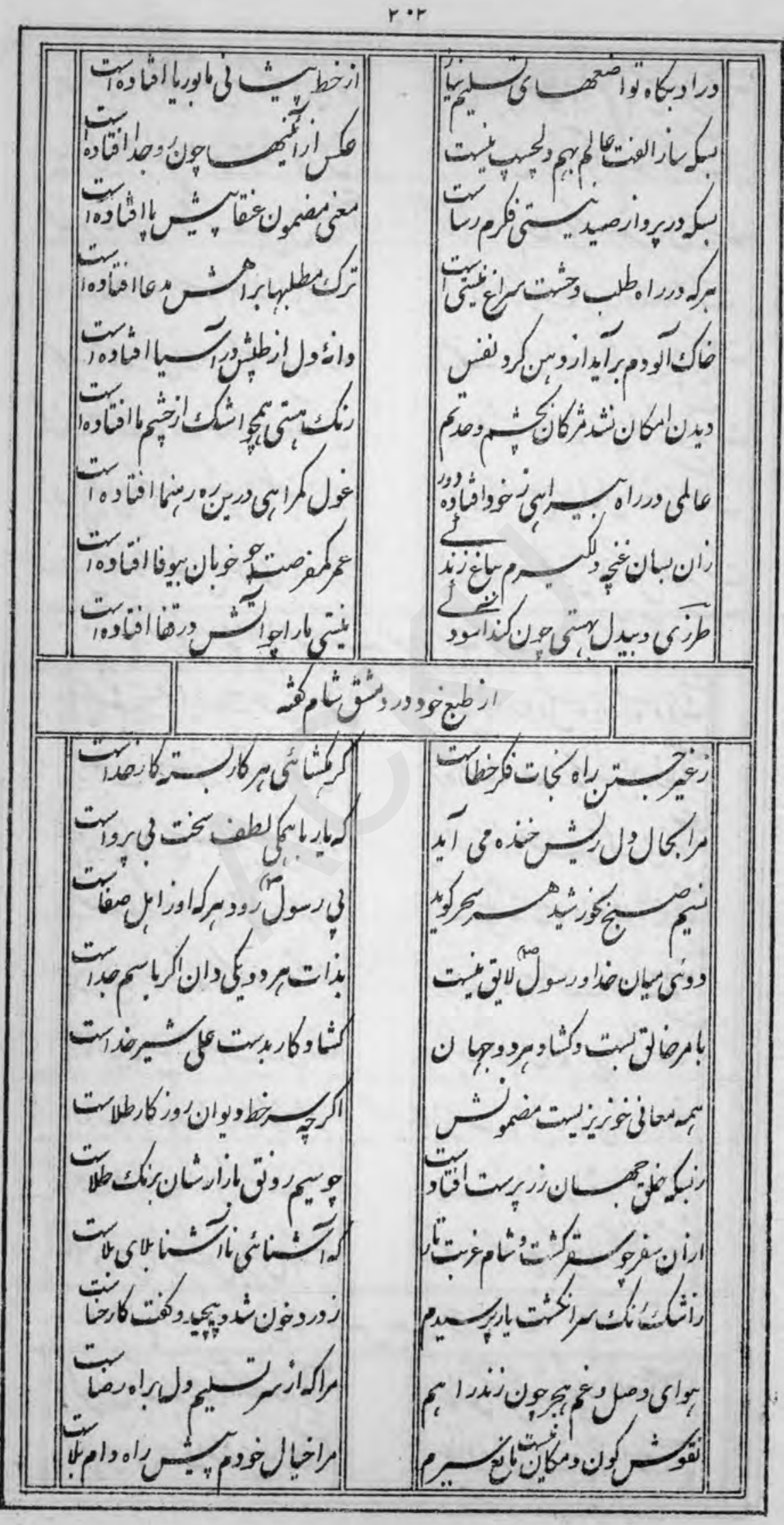




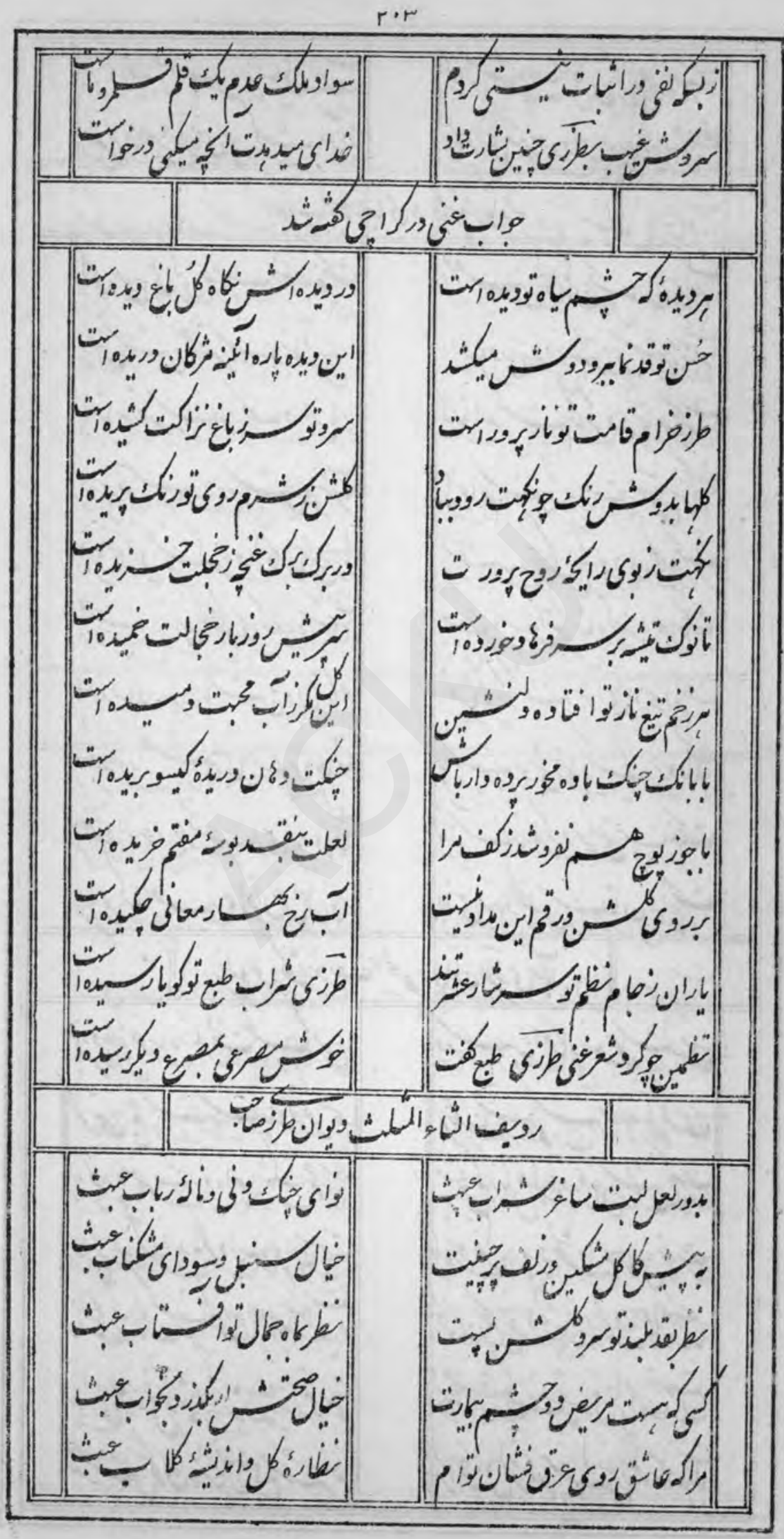


$r \cdot F^{2}$

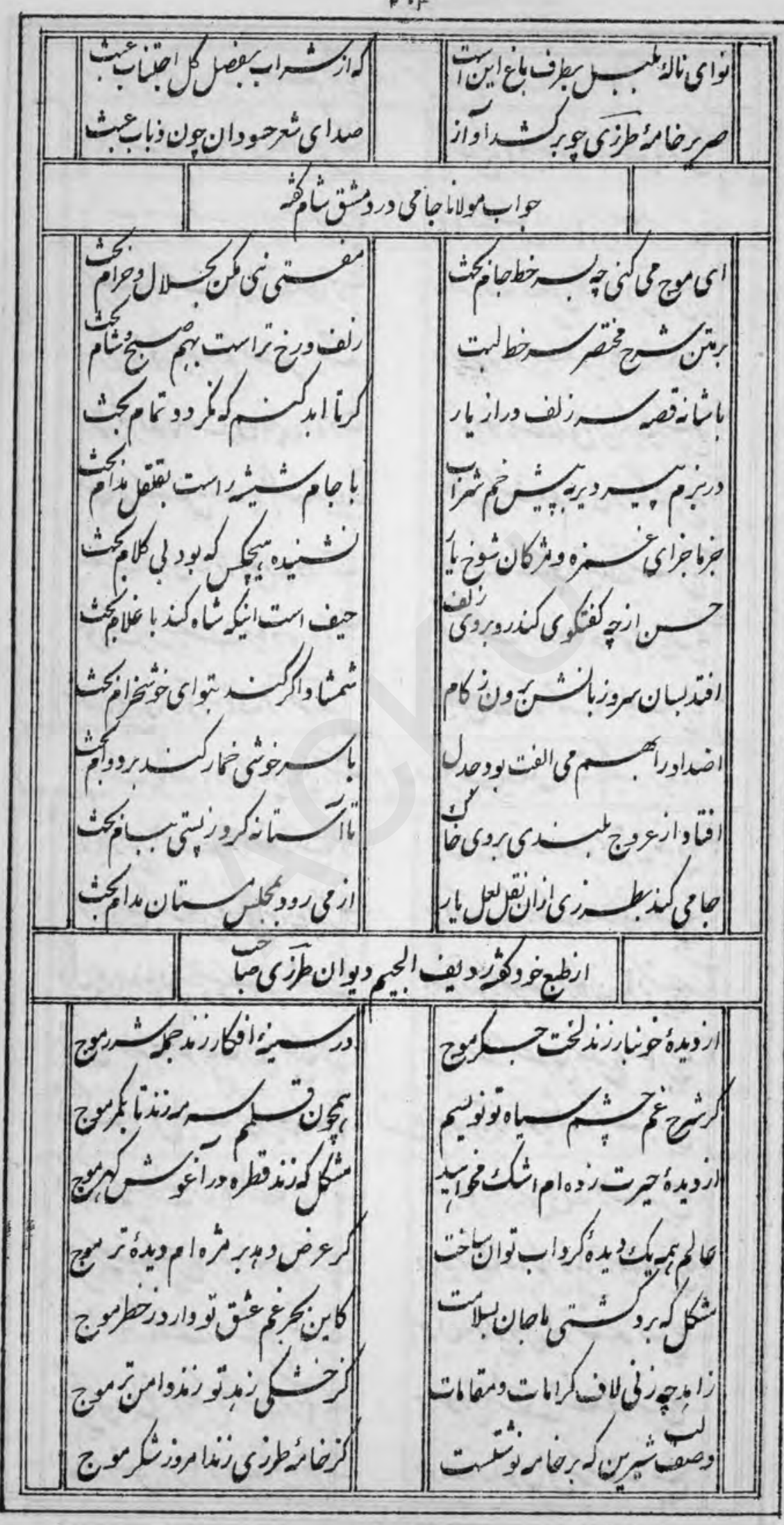




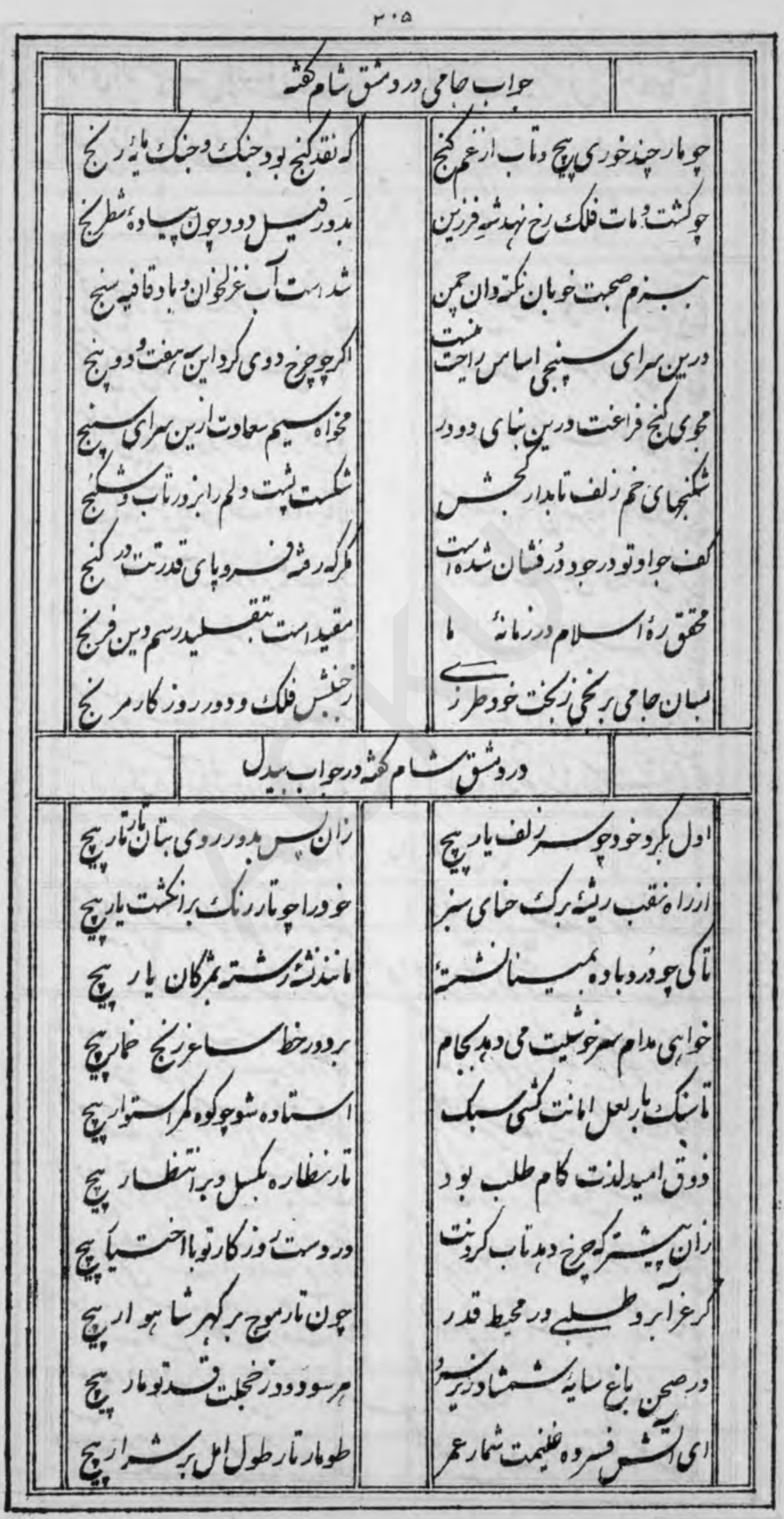




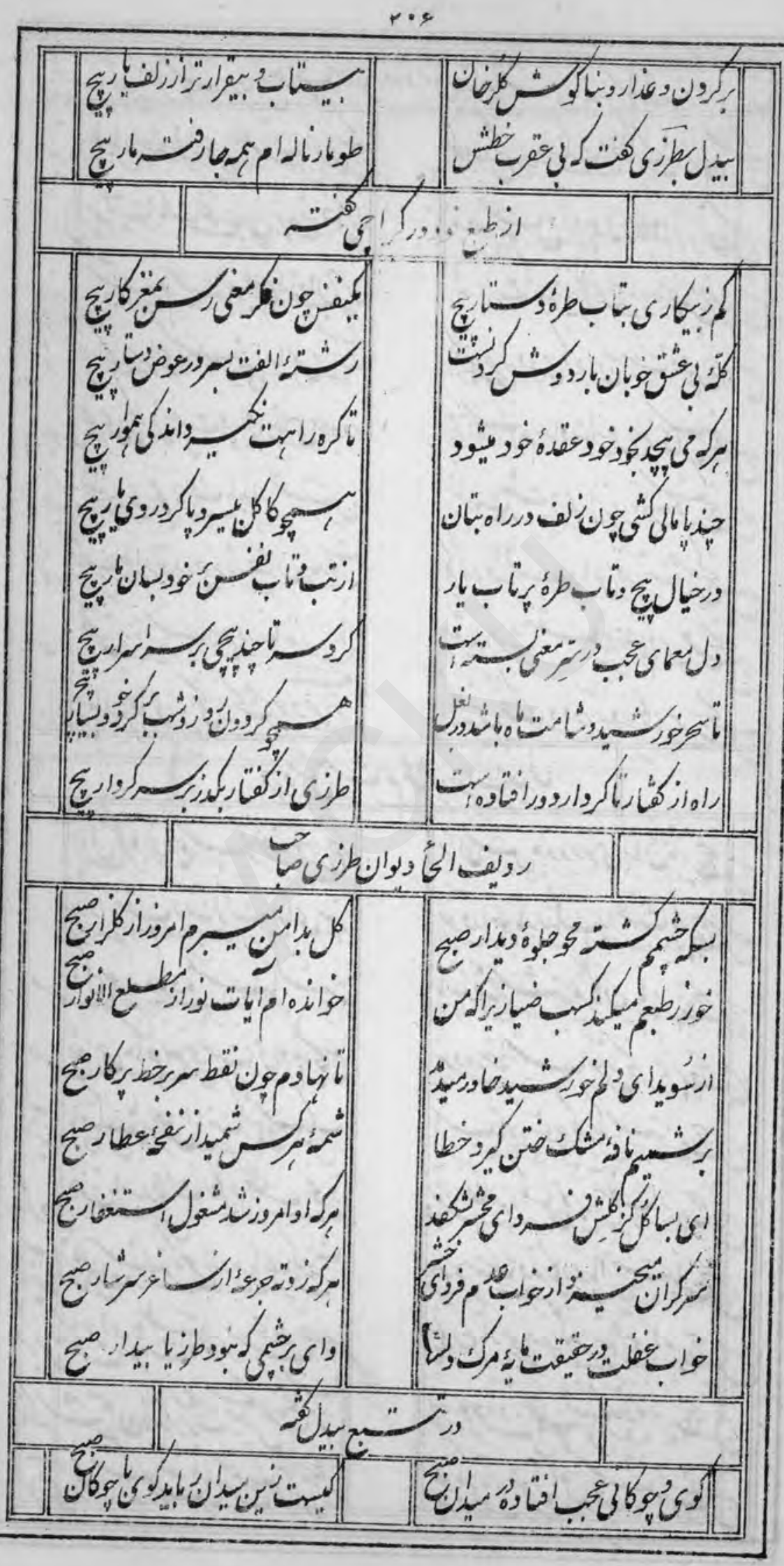


$r \cdot r$

$\mid$




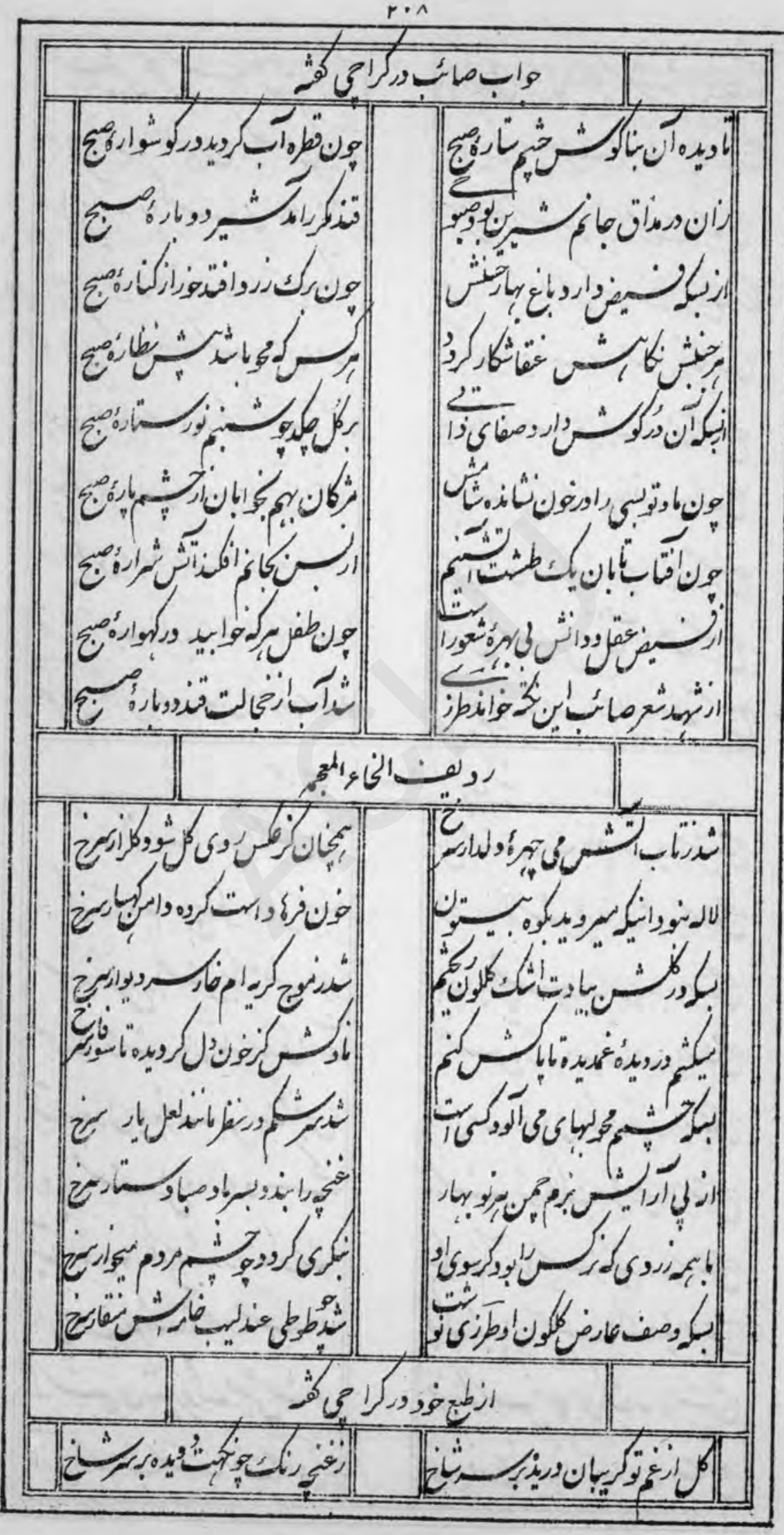


$+\cdot 4$

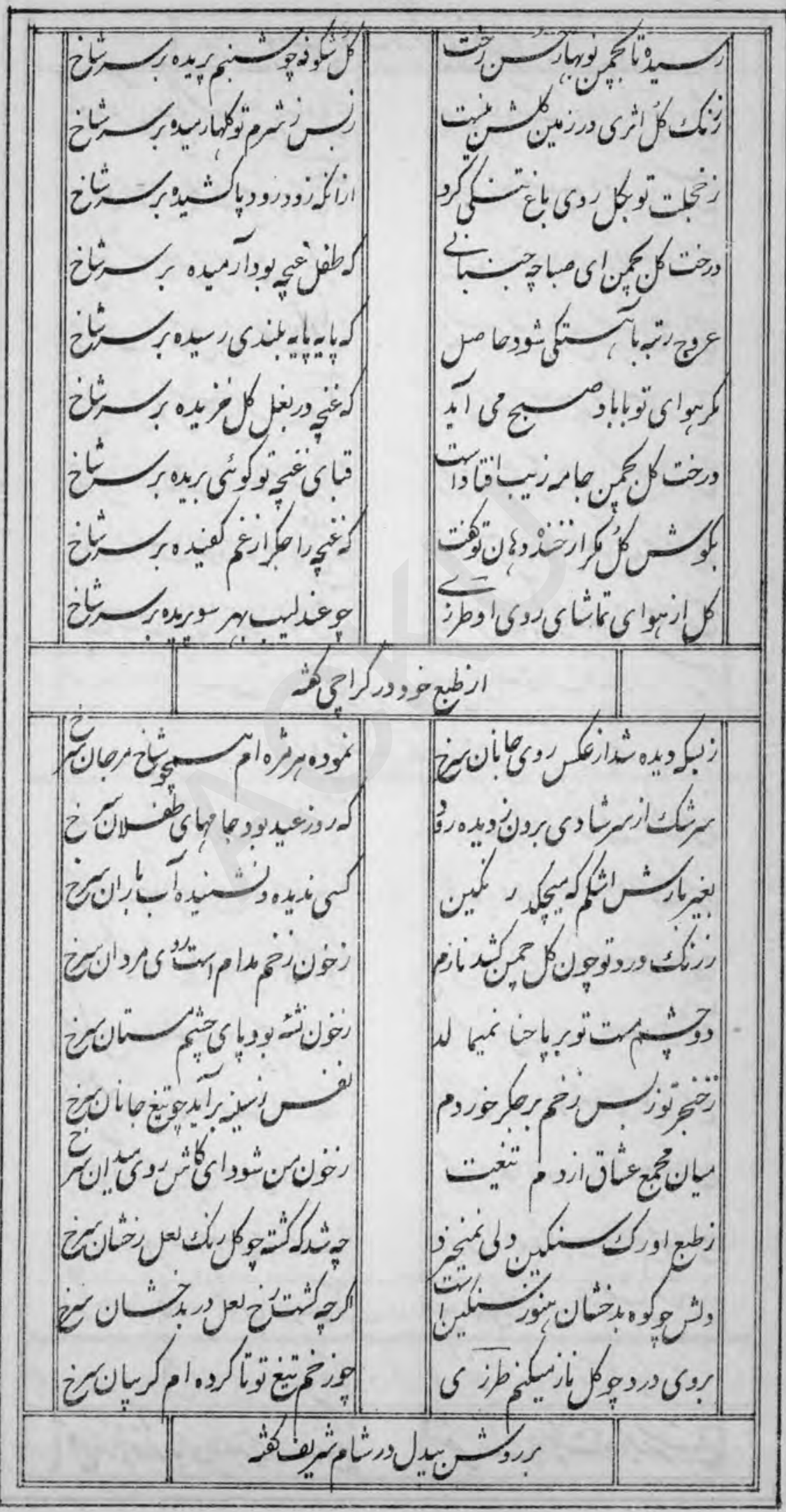




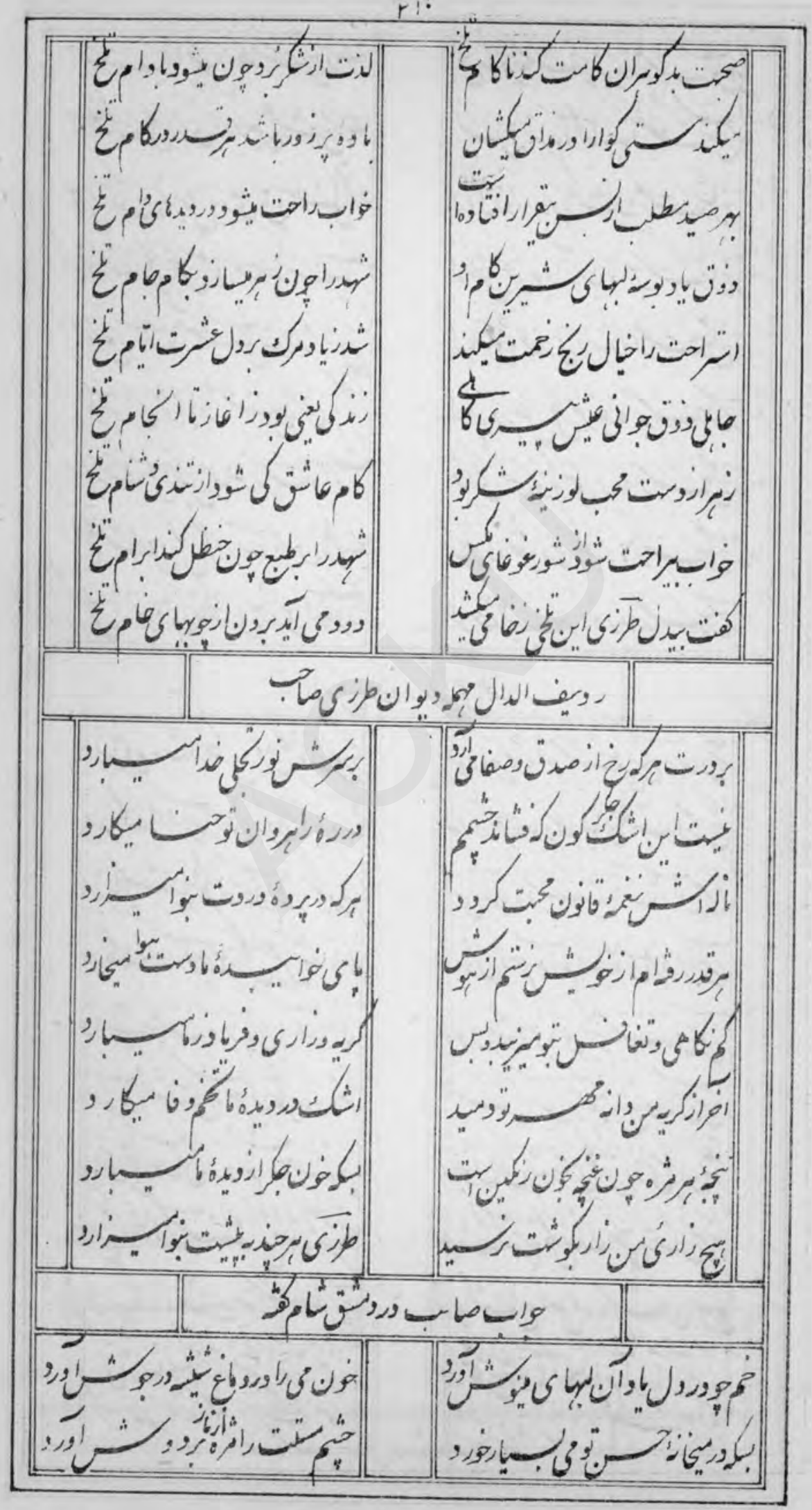




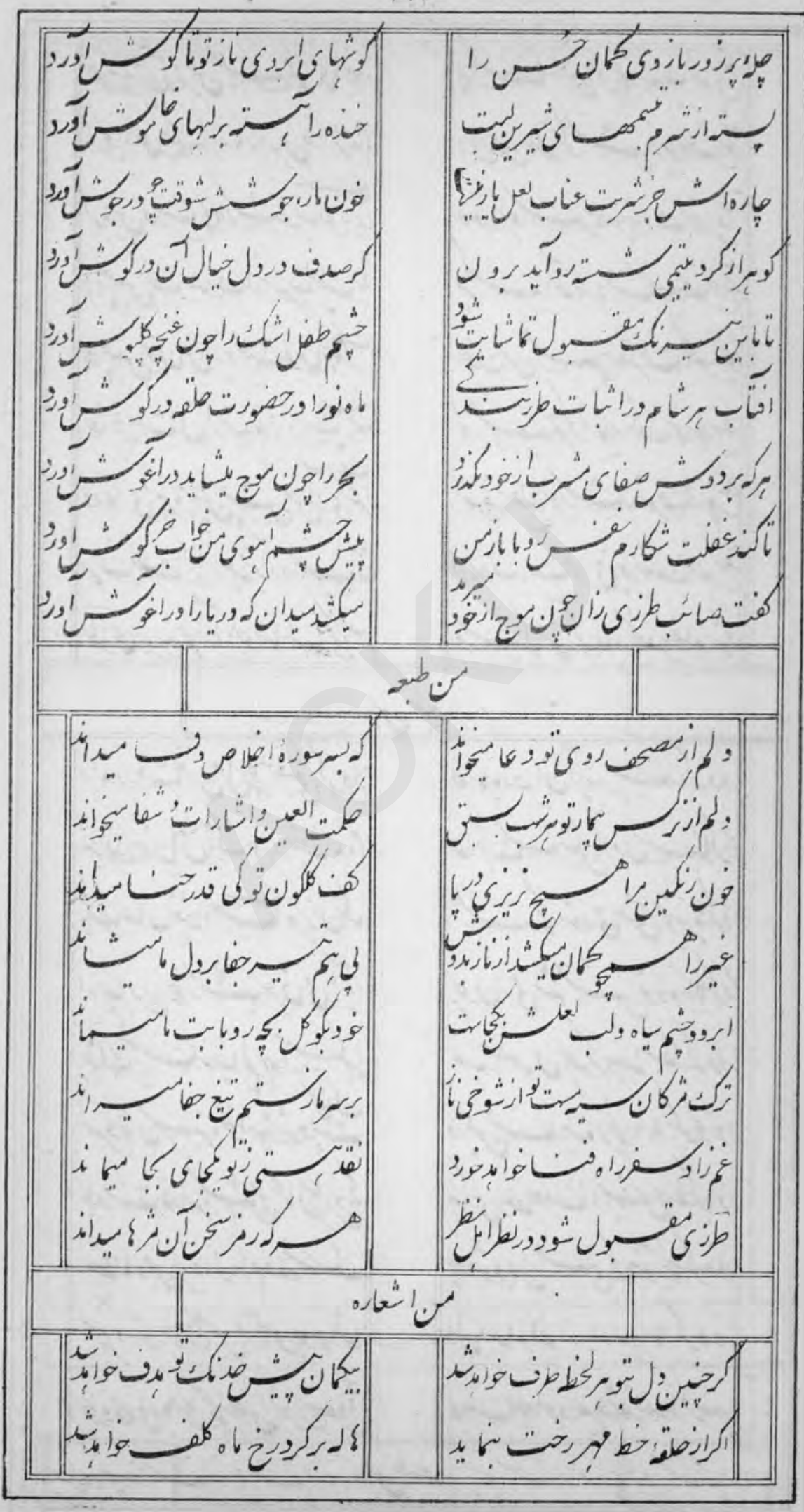


$r i r$

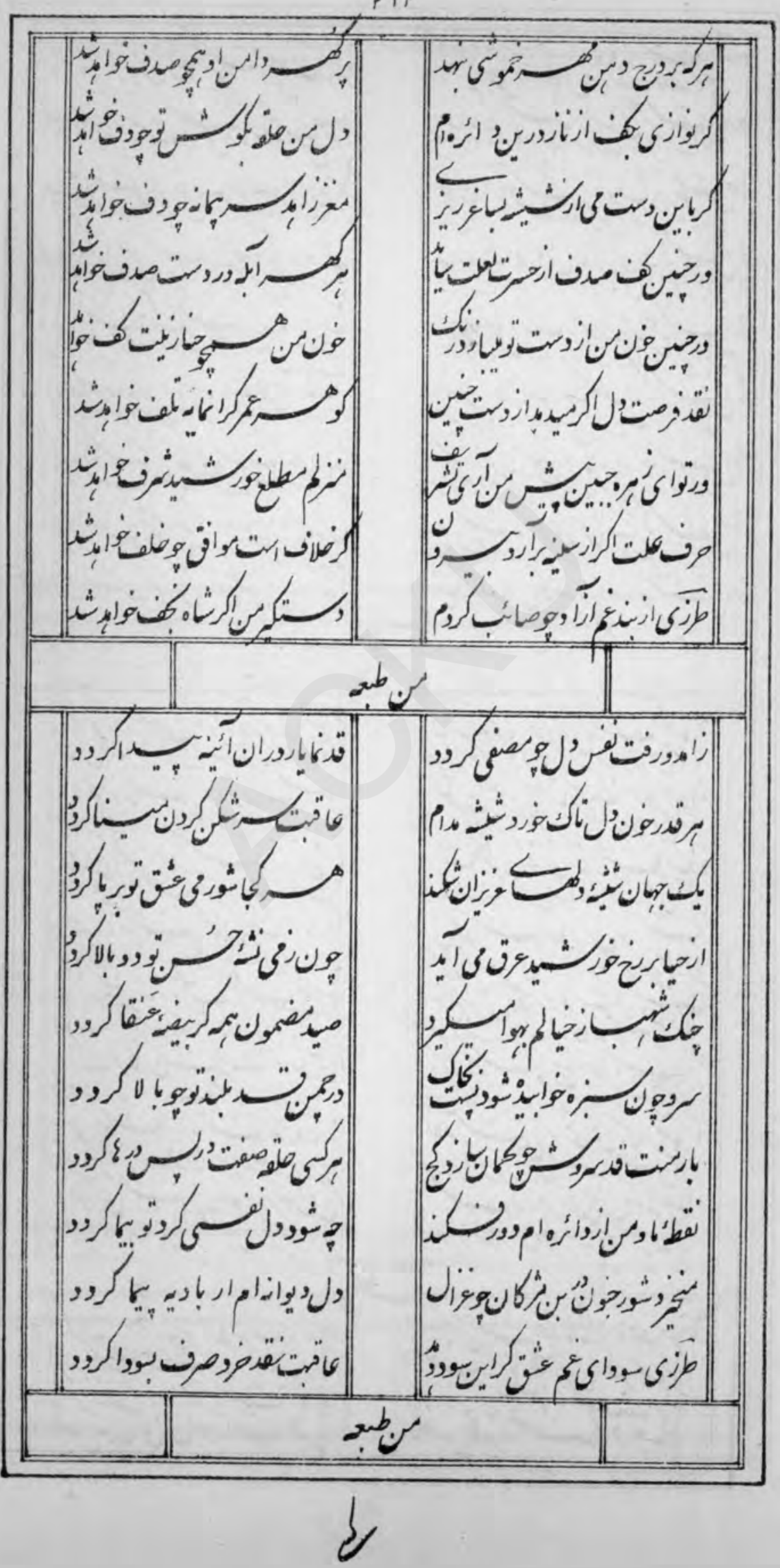


rit

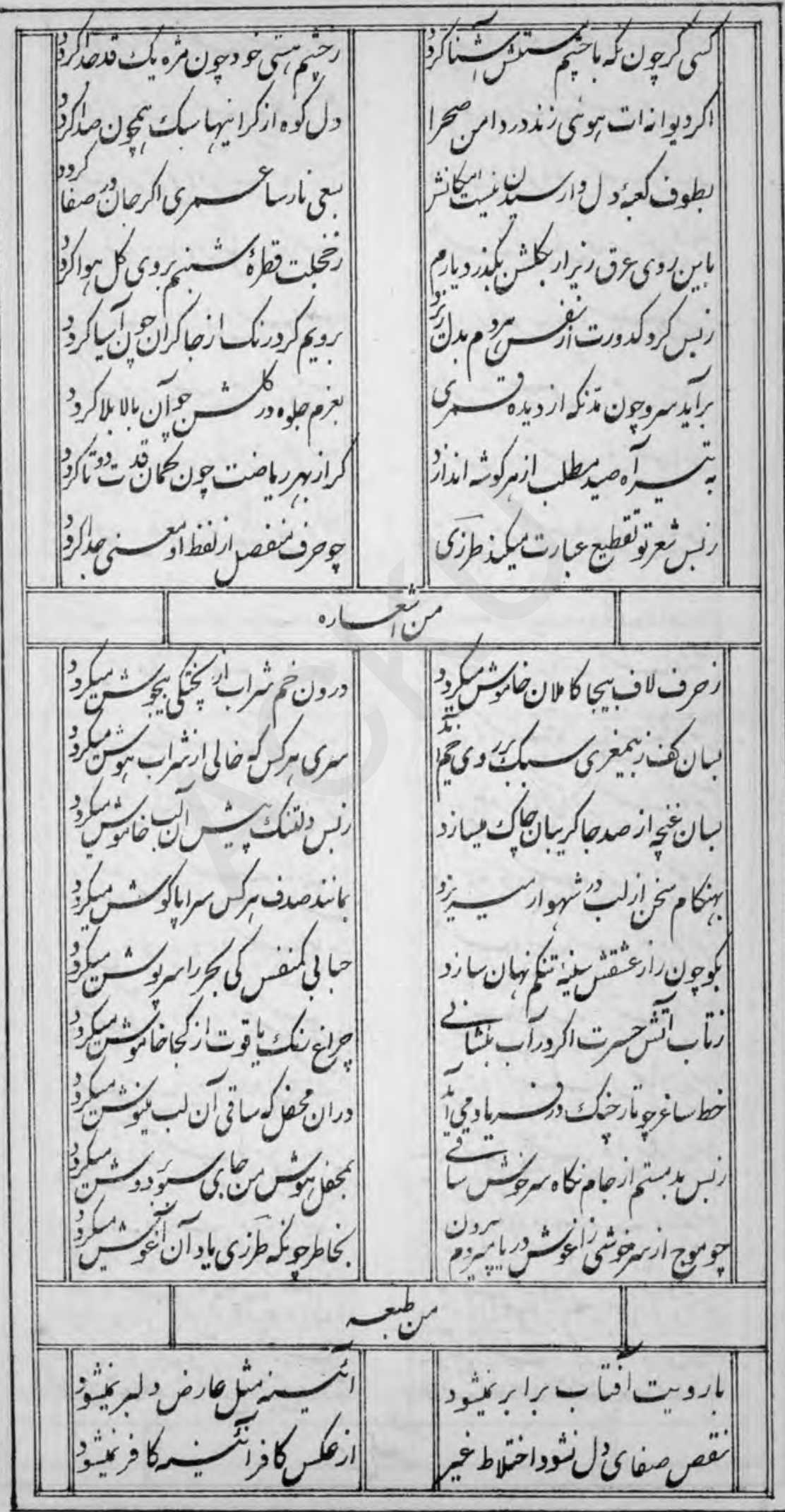




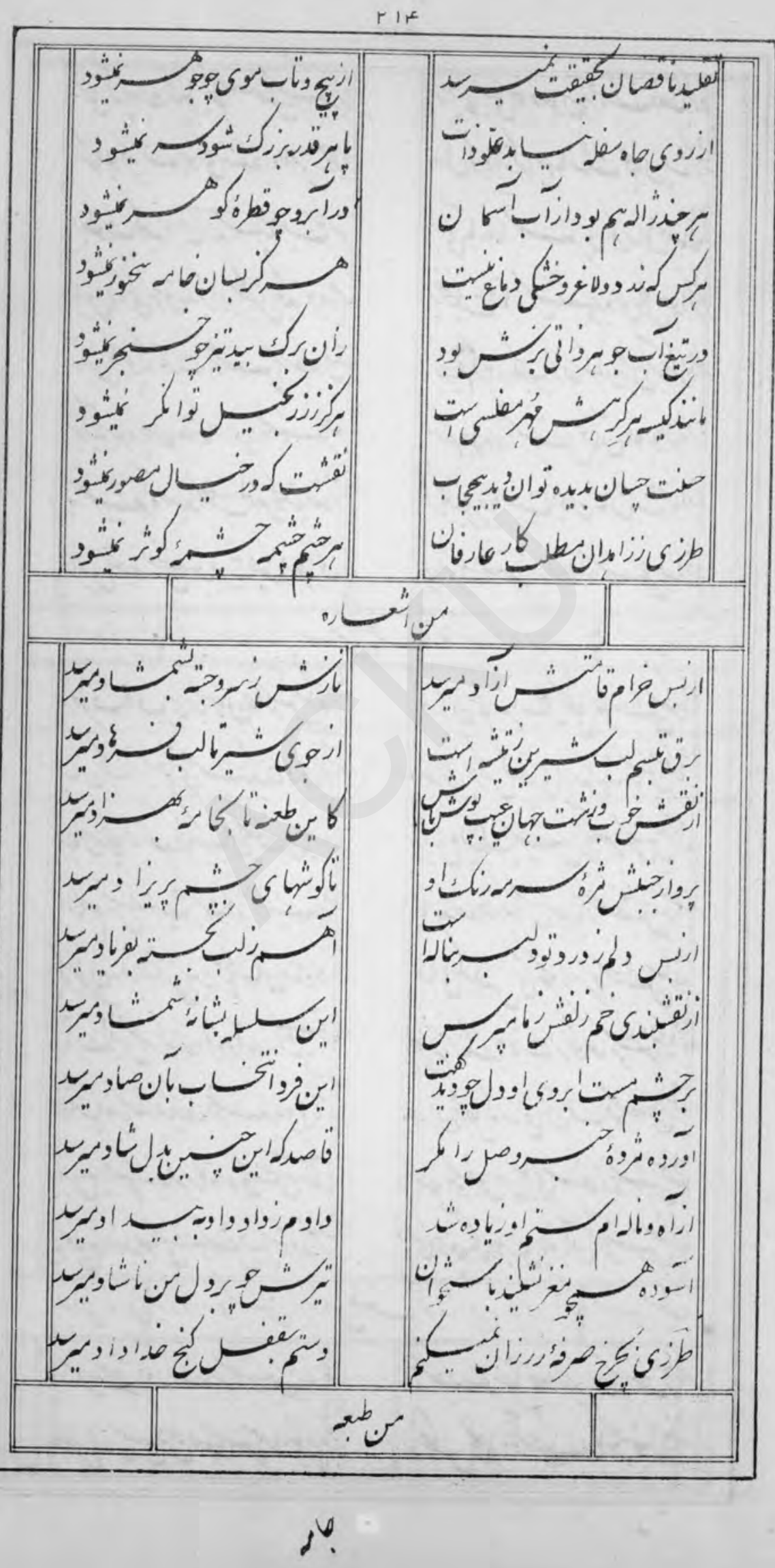


r io

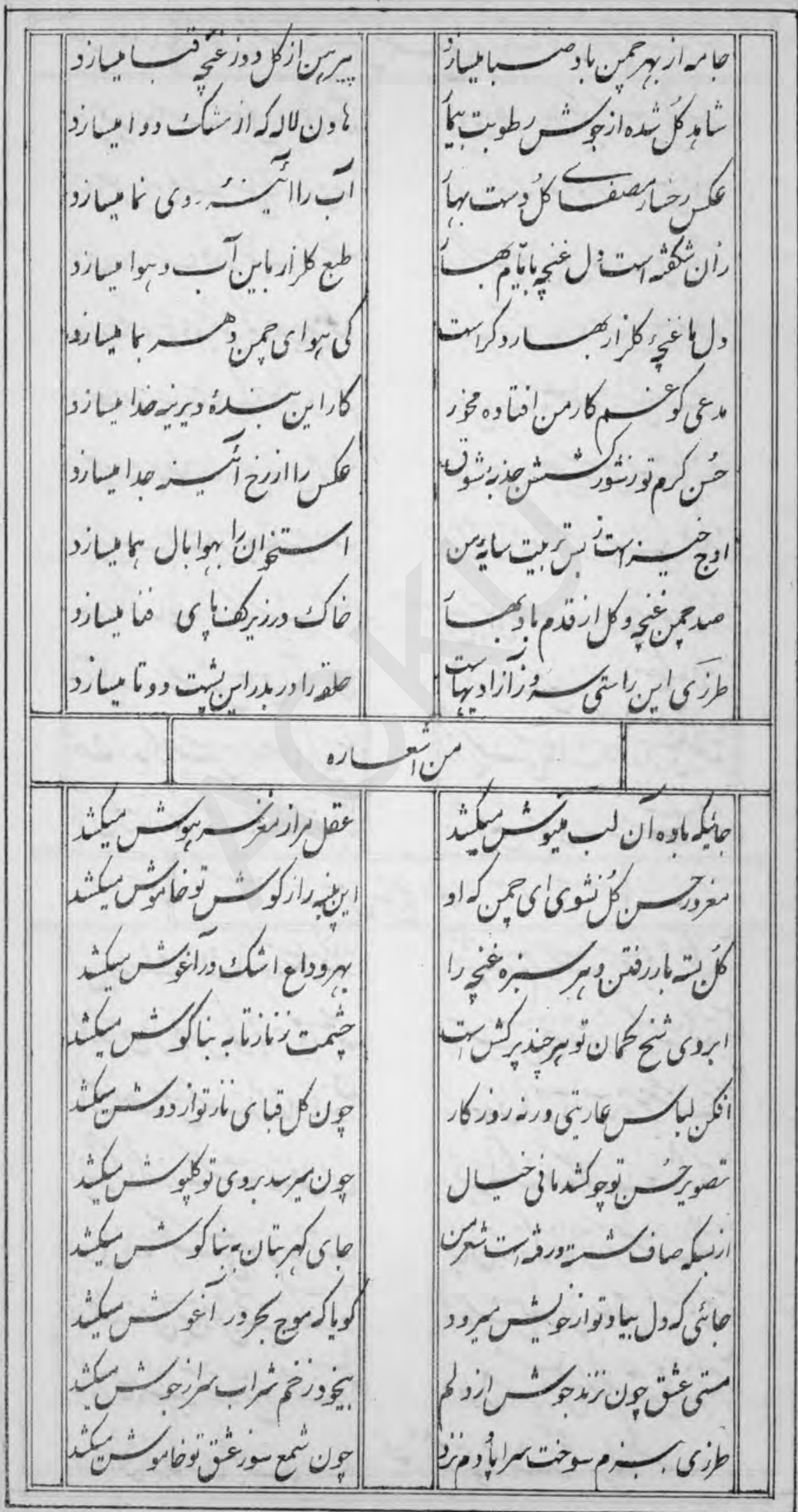




\section{r.}

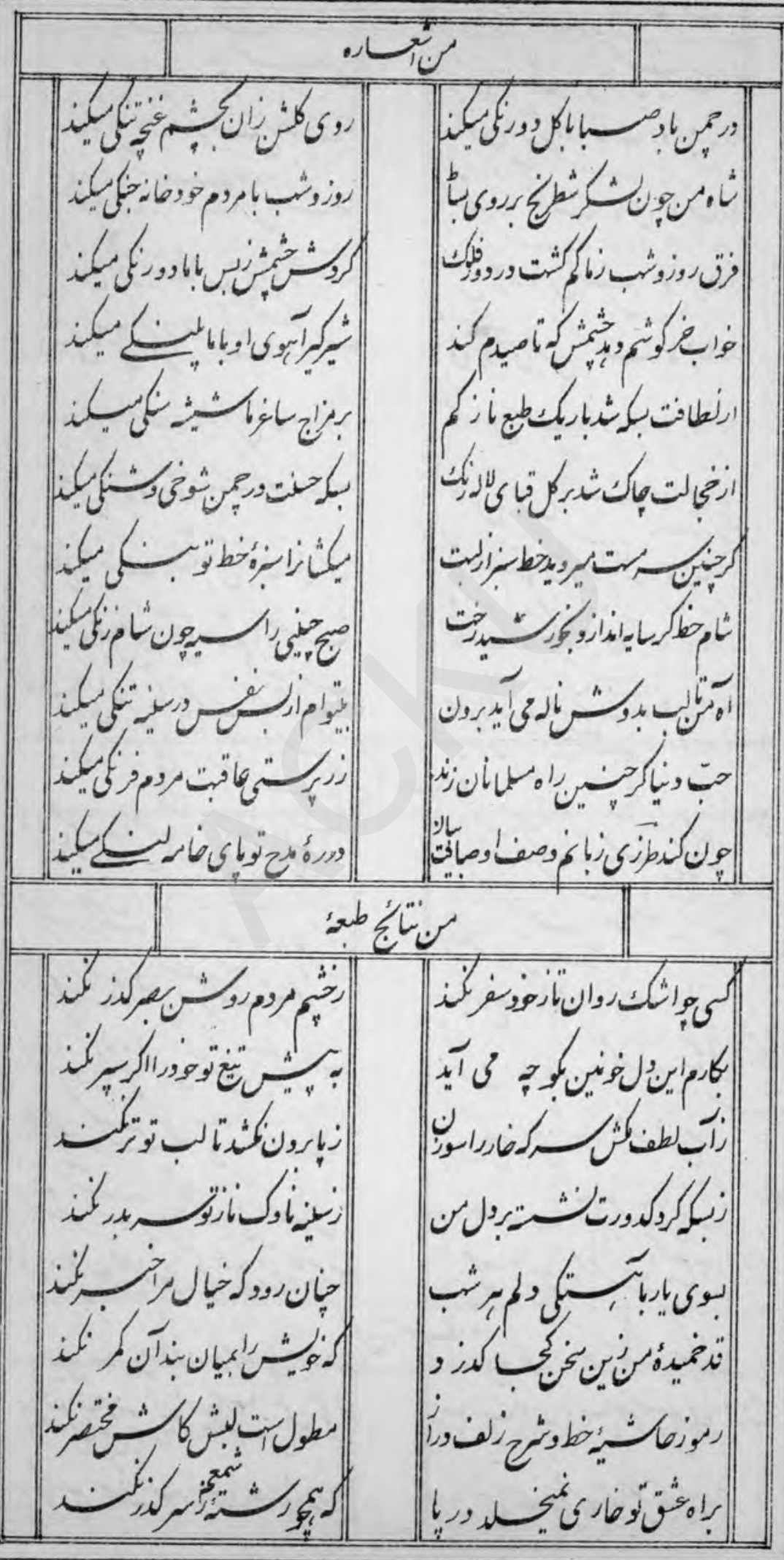


CIL

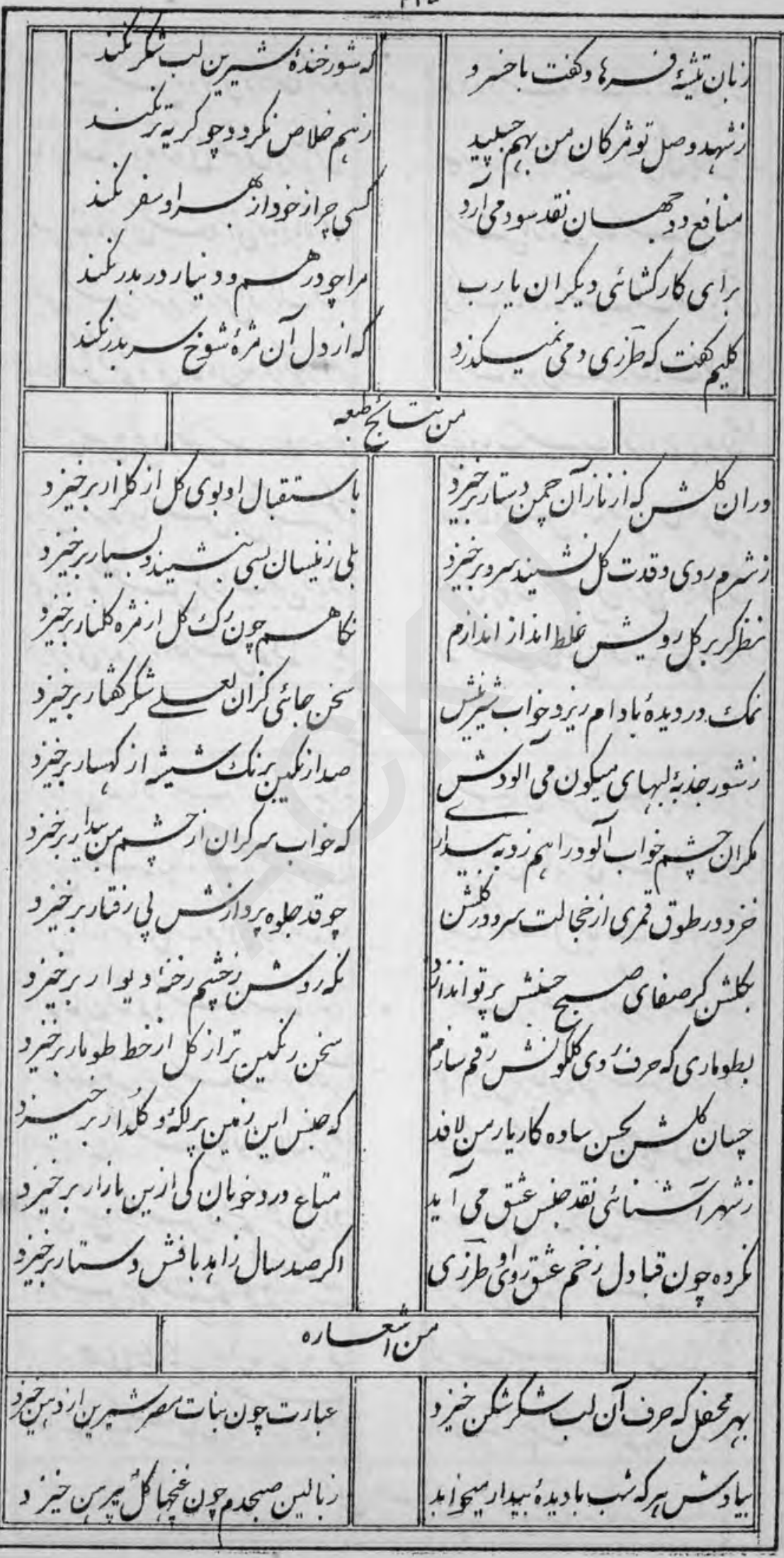




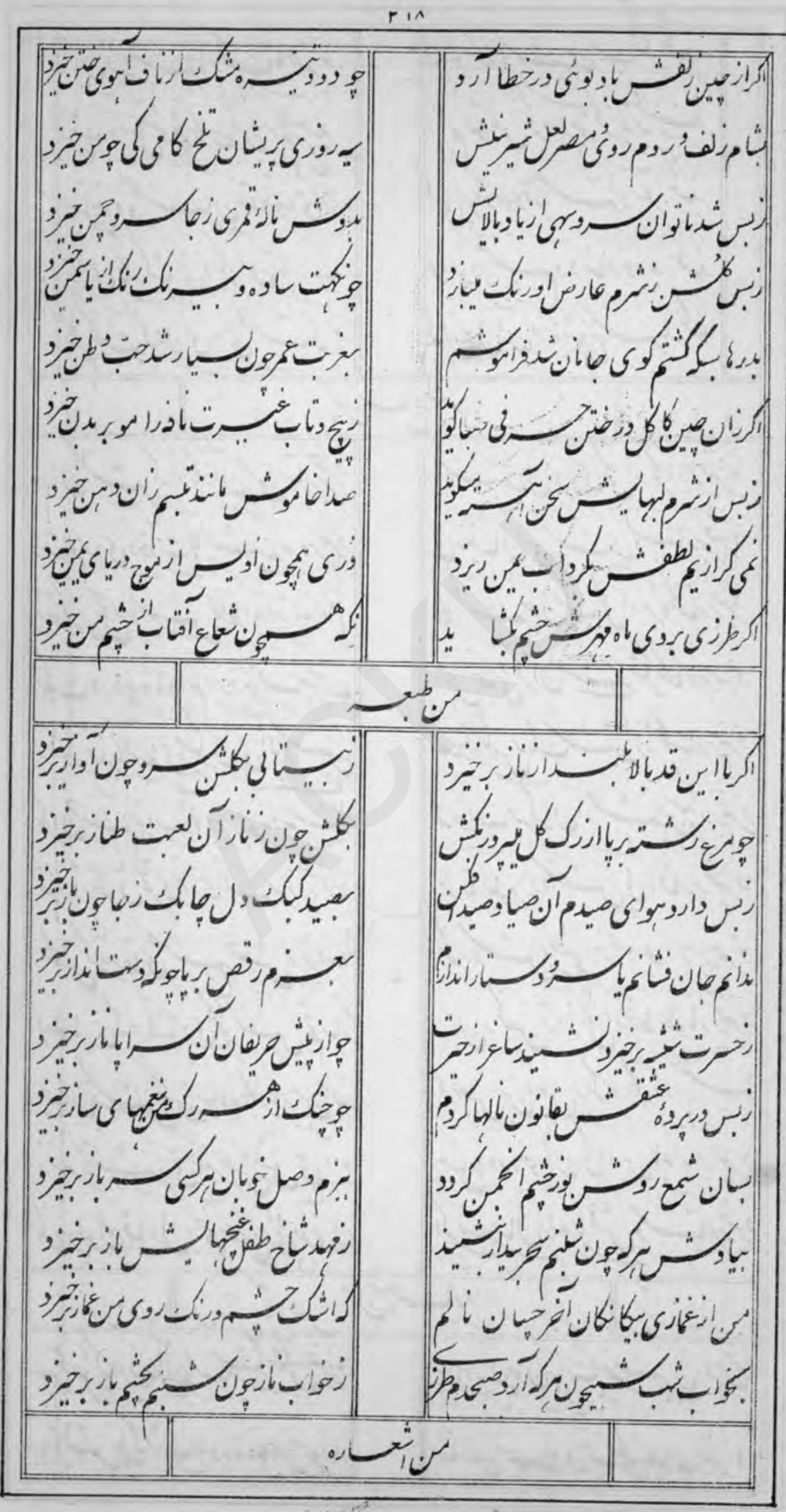




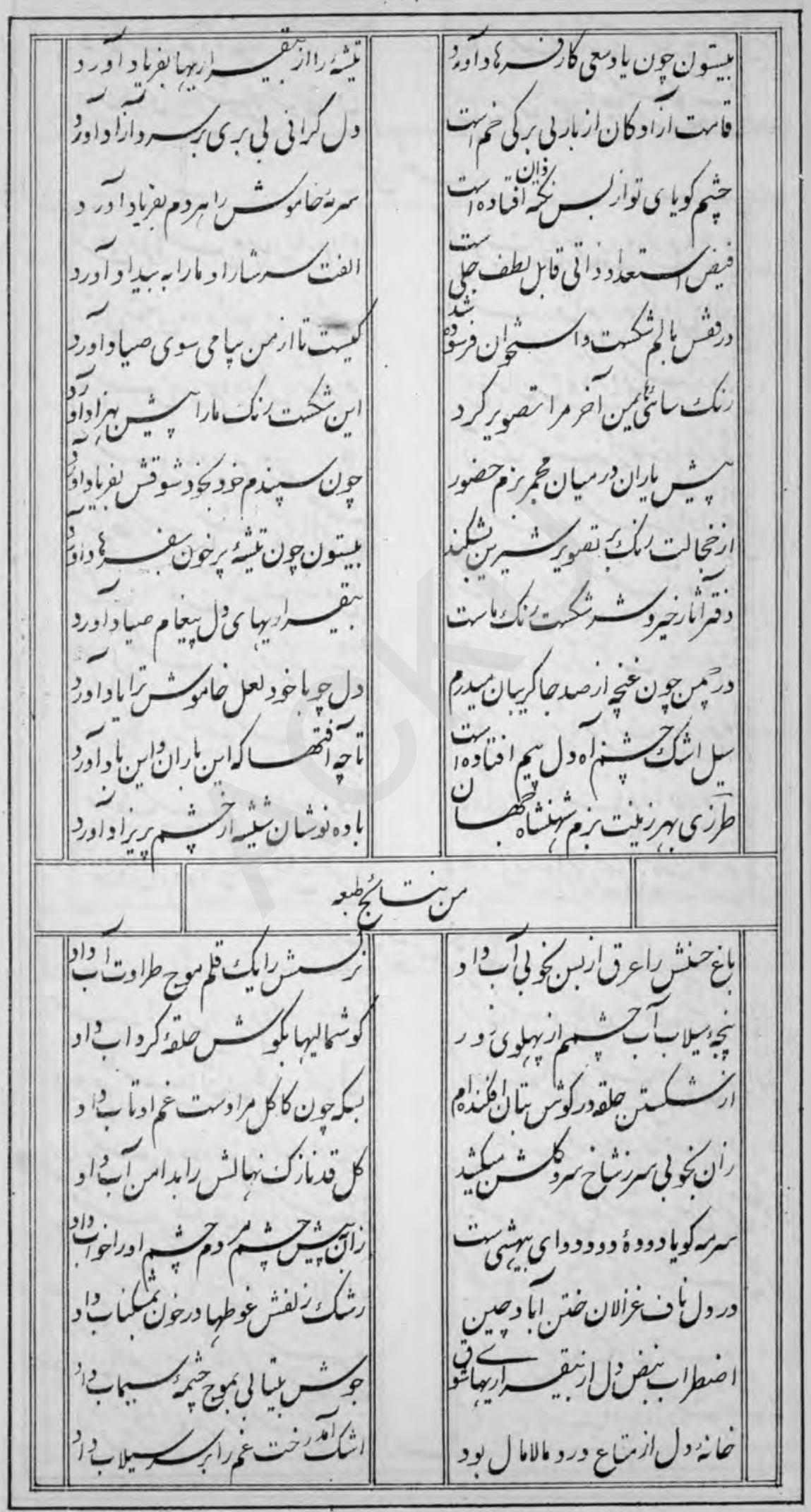




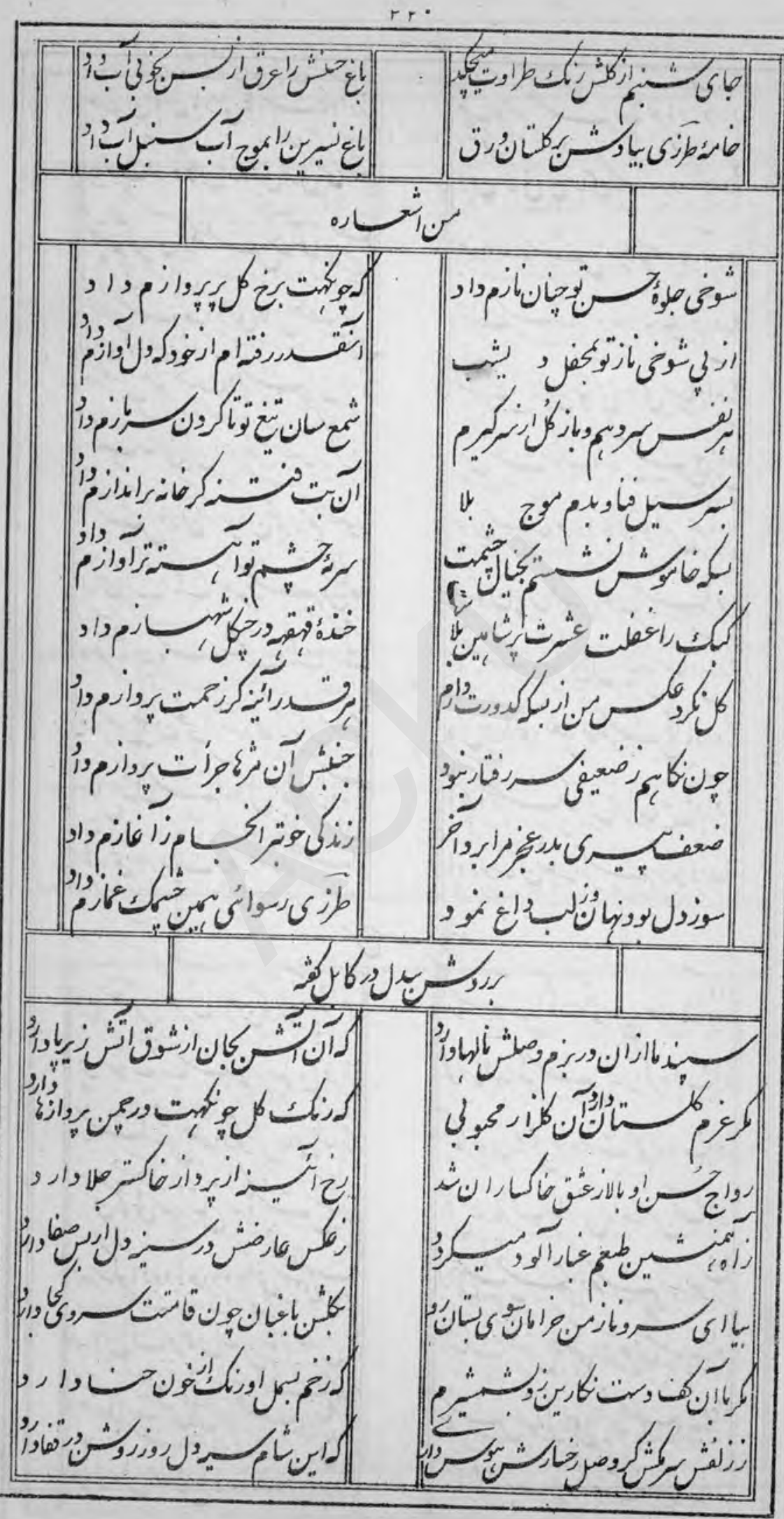

…… 
$r r$

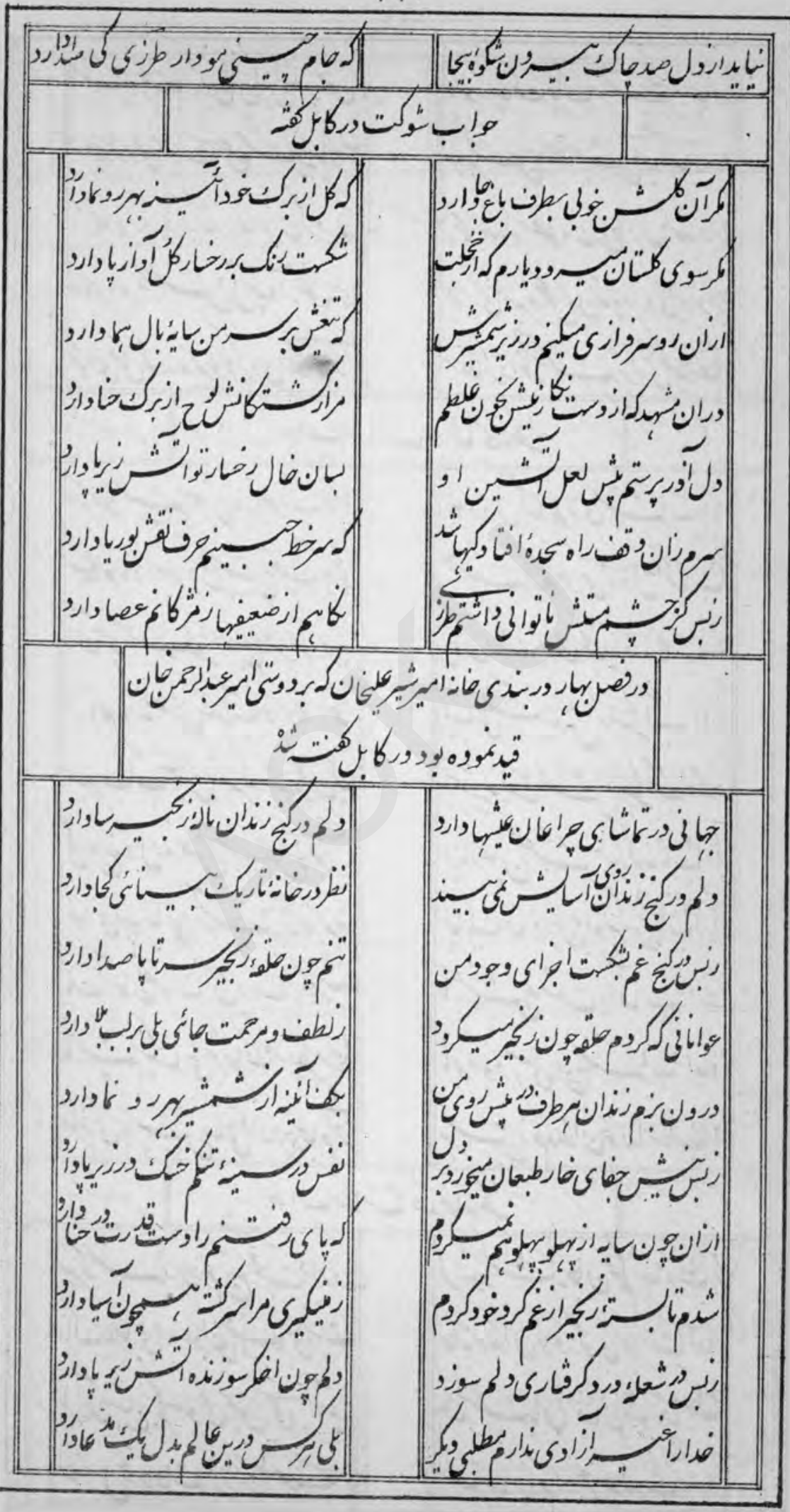




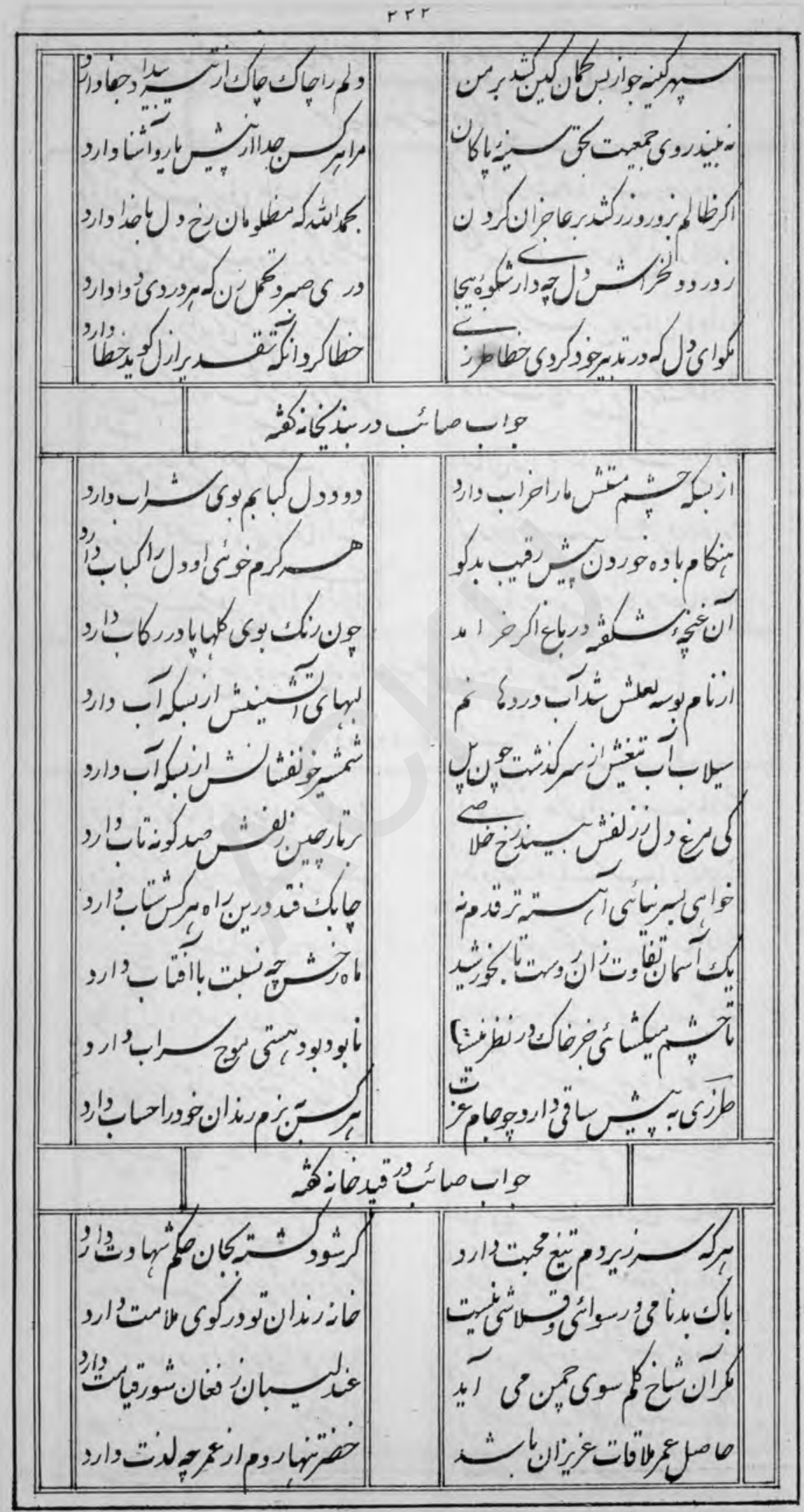




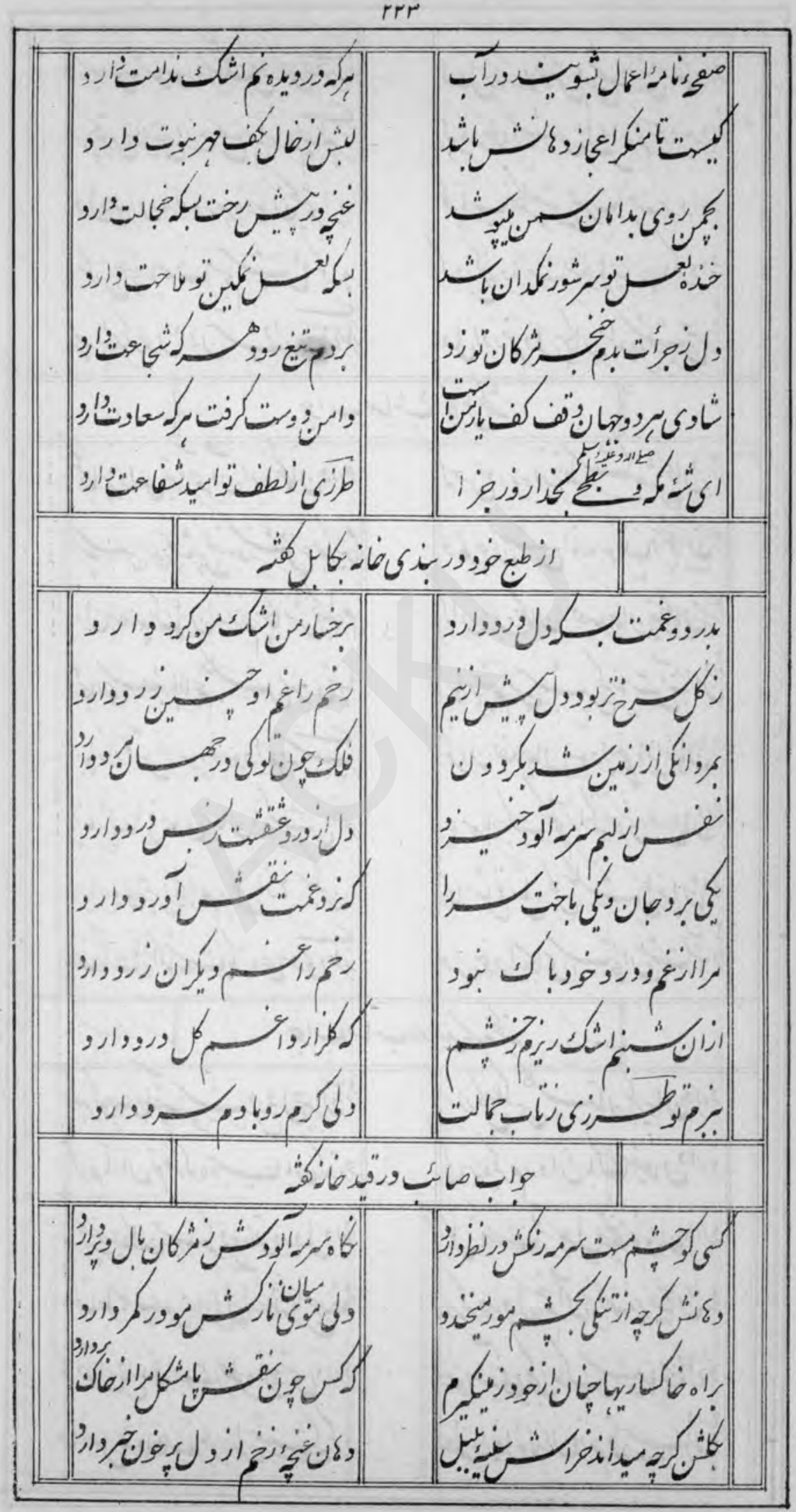




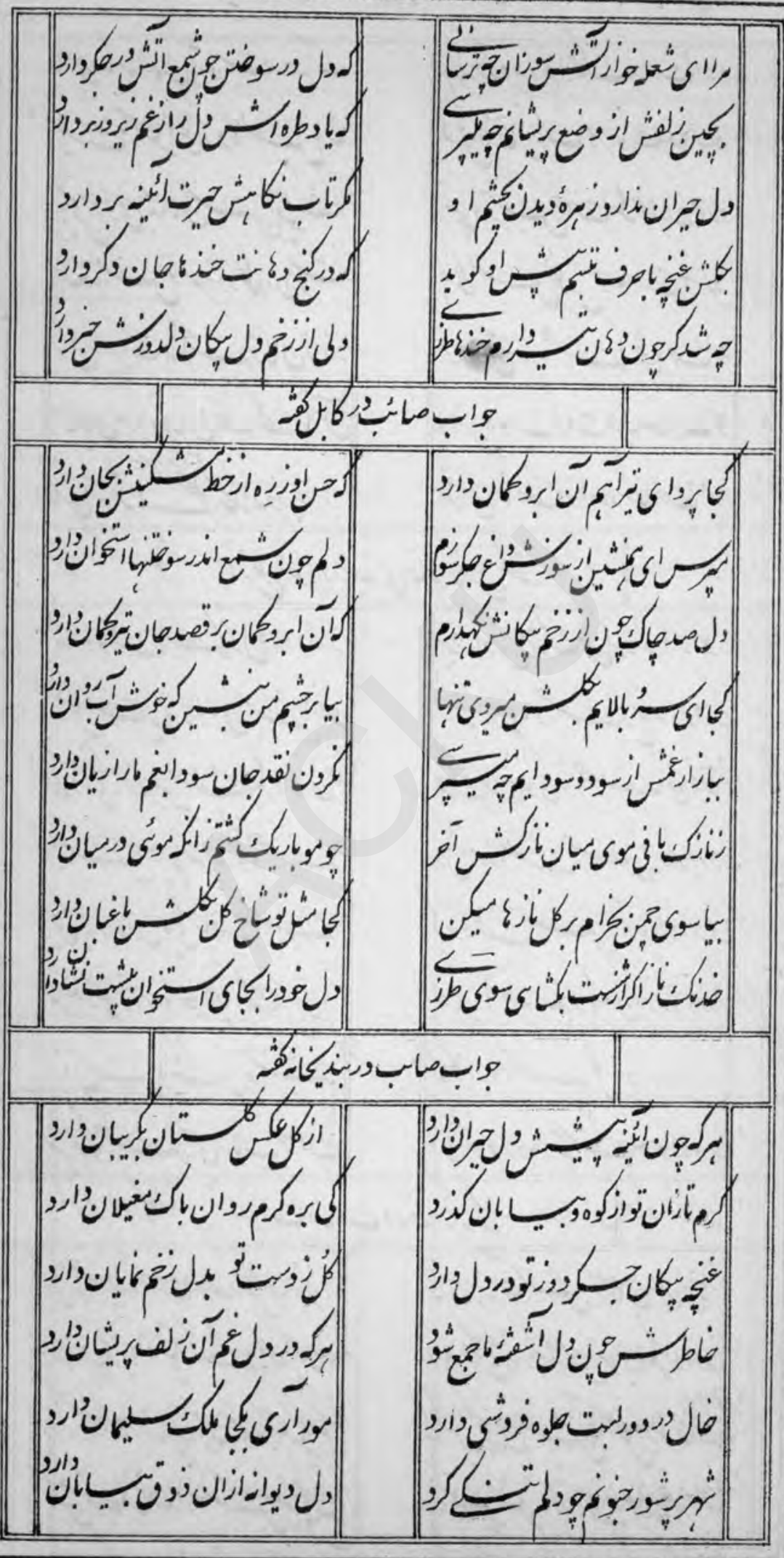


rro

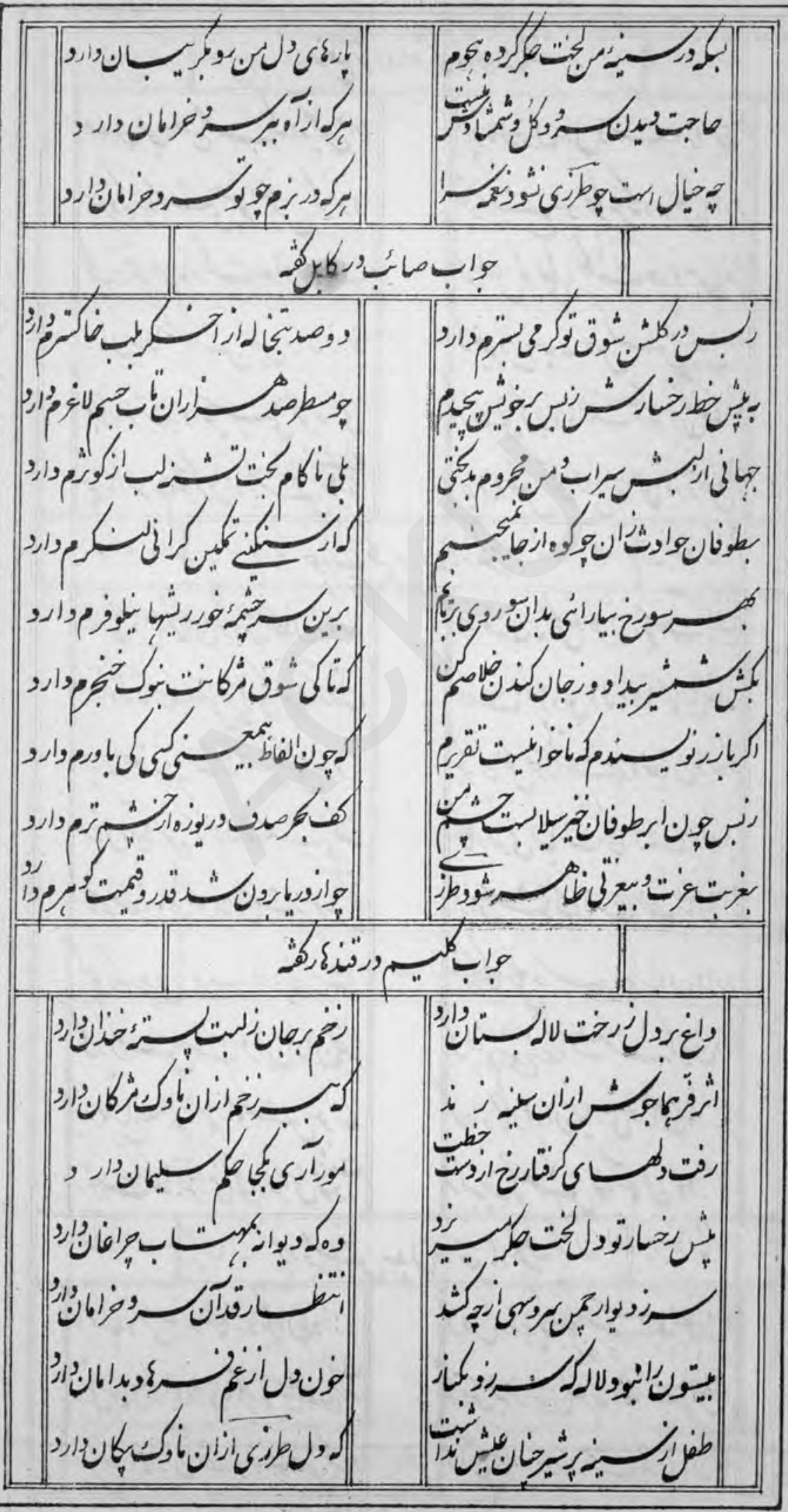


rre

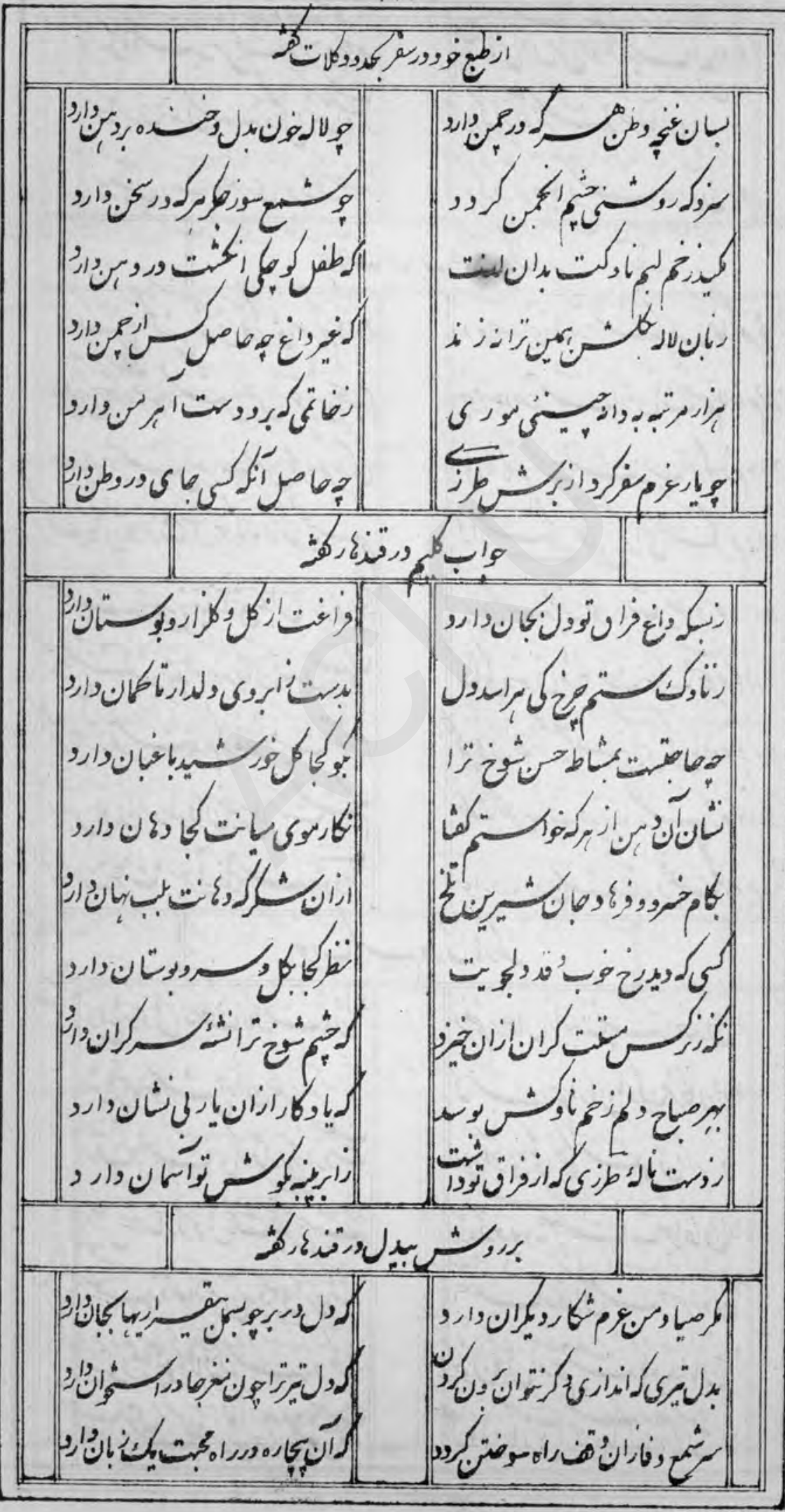


rru

|| $\mid$


rrA

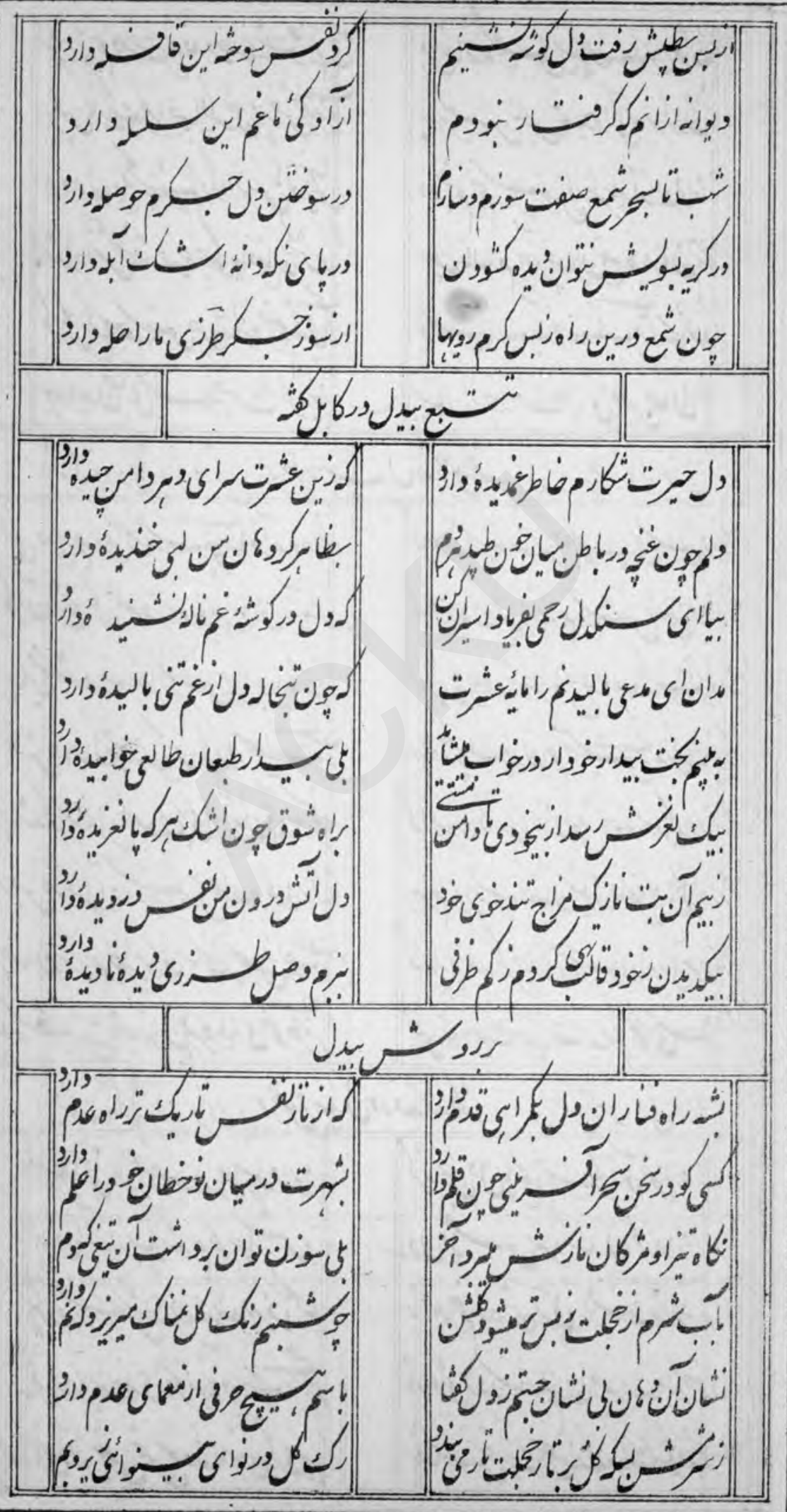


rrq

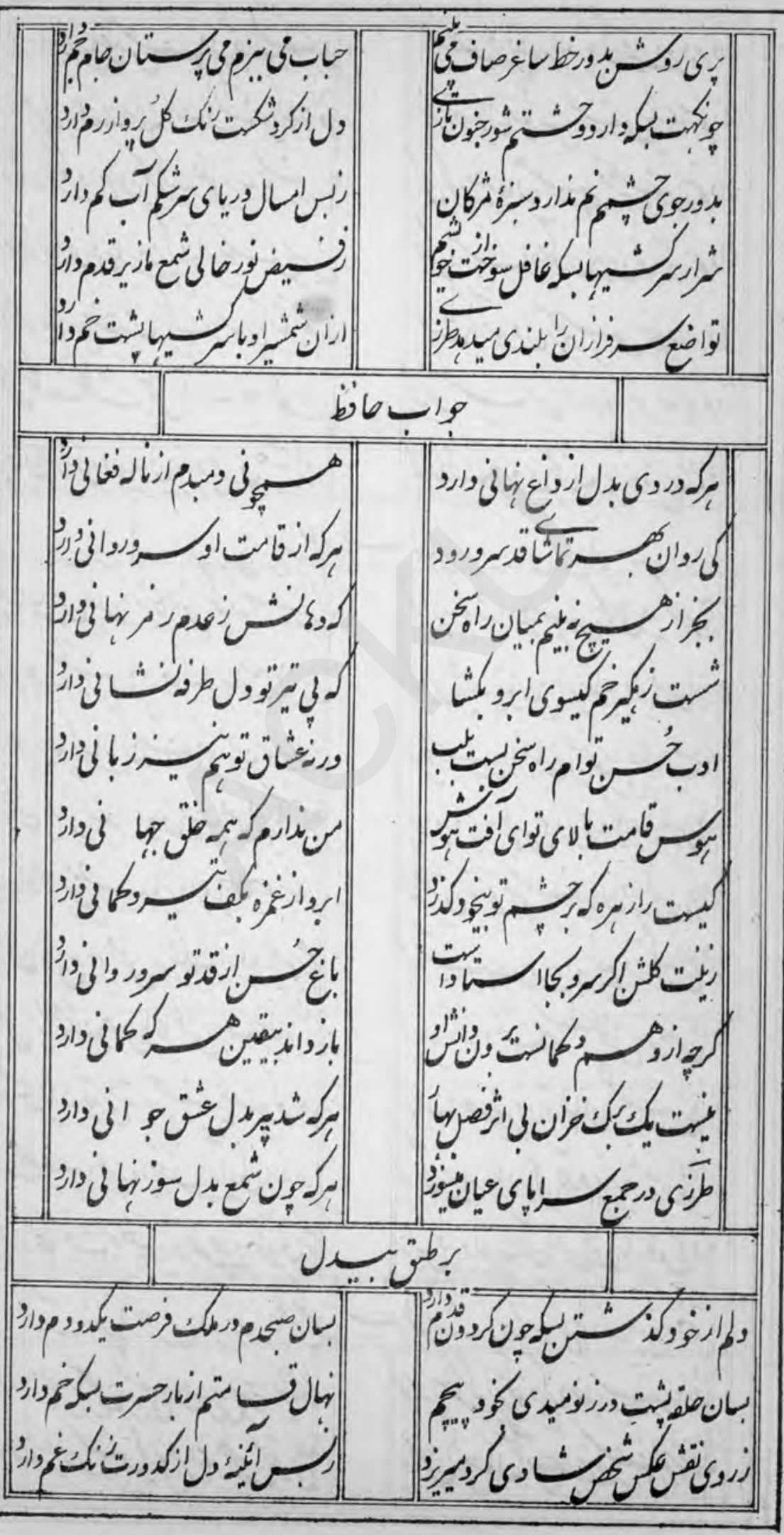


rr.

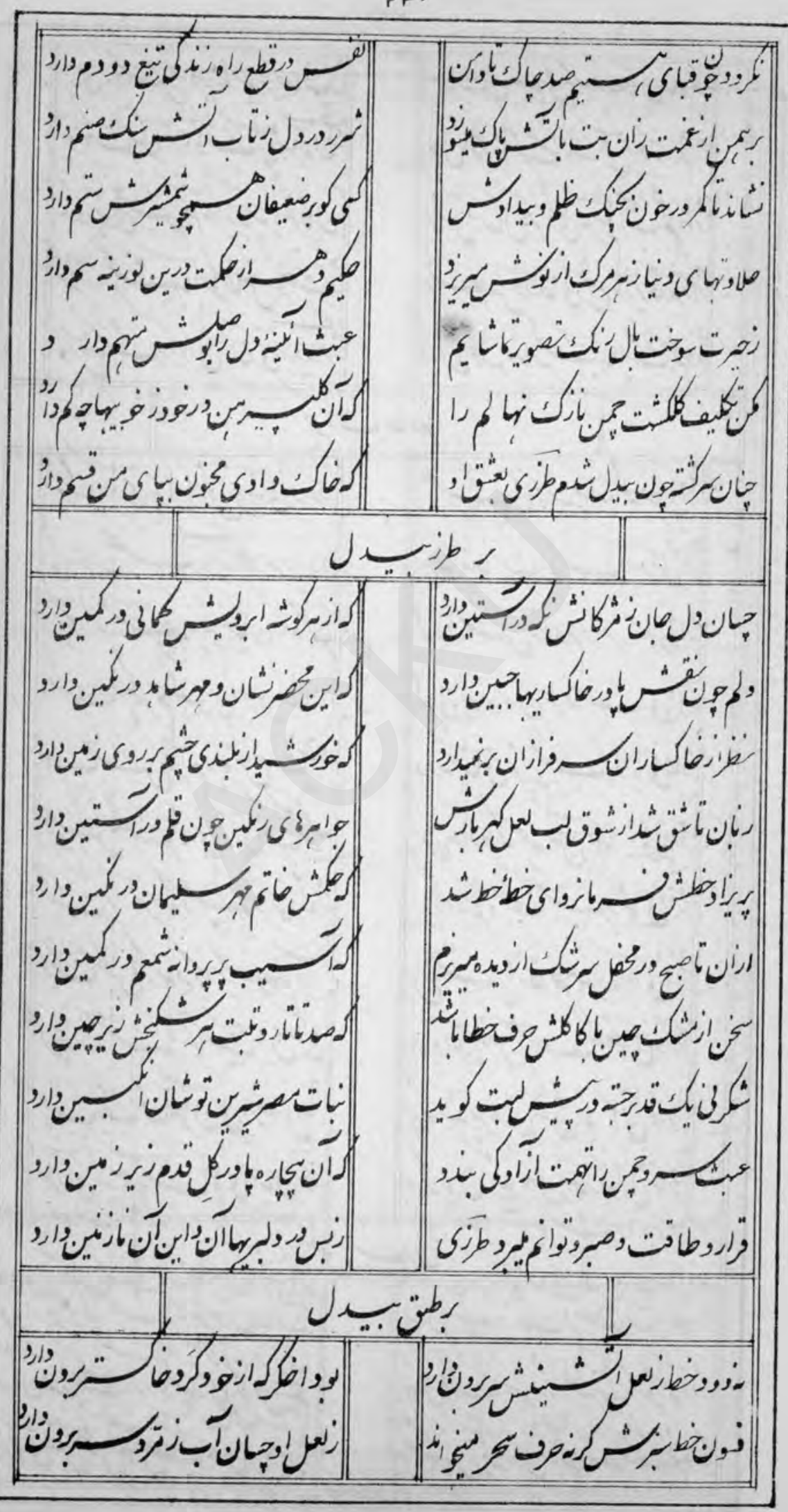


rr

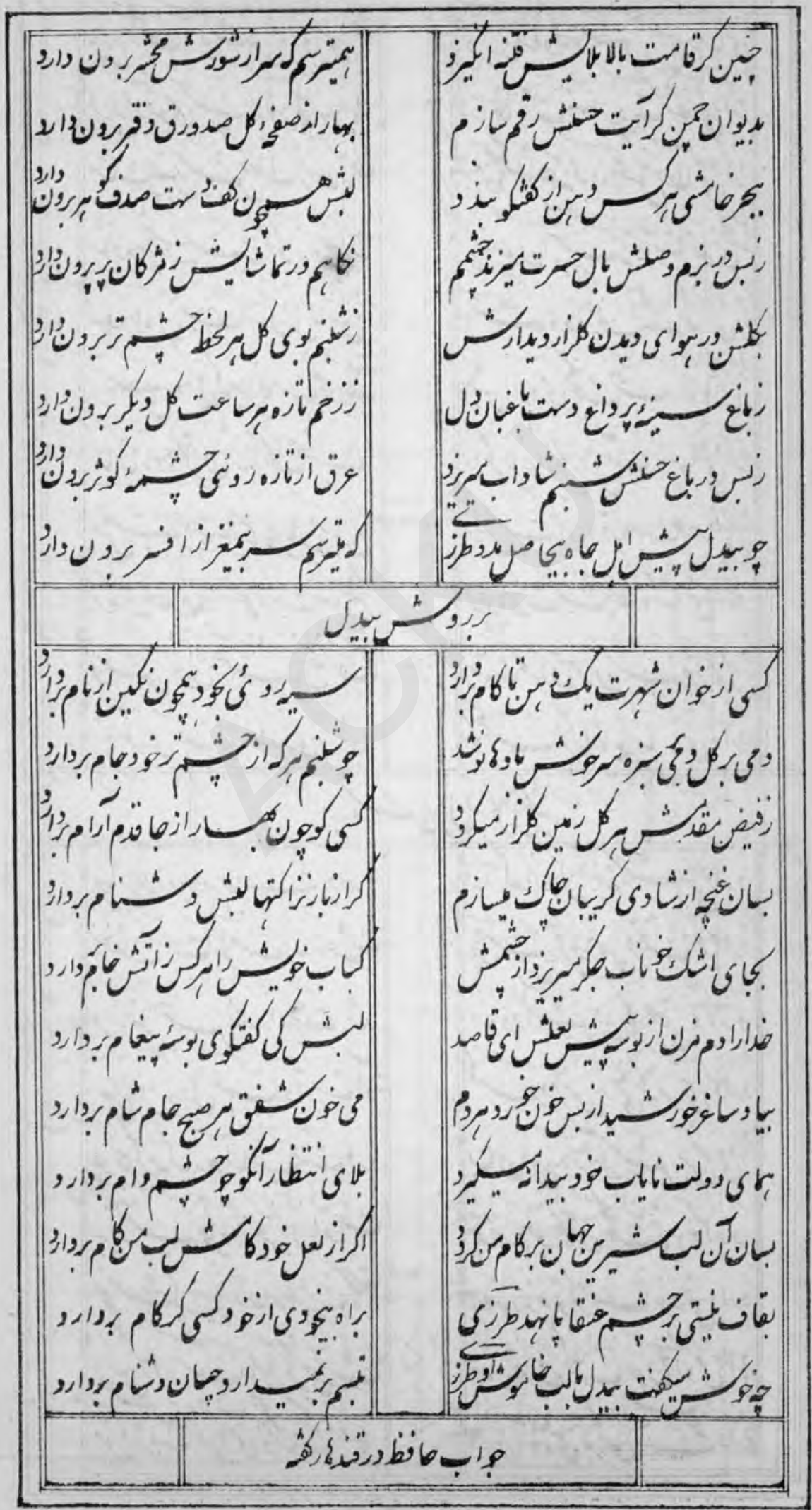


rrr

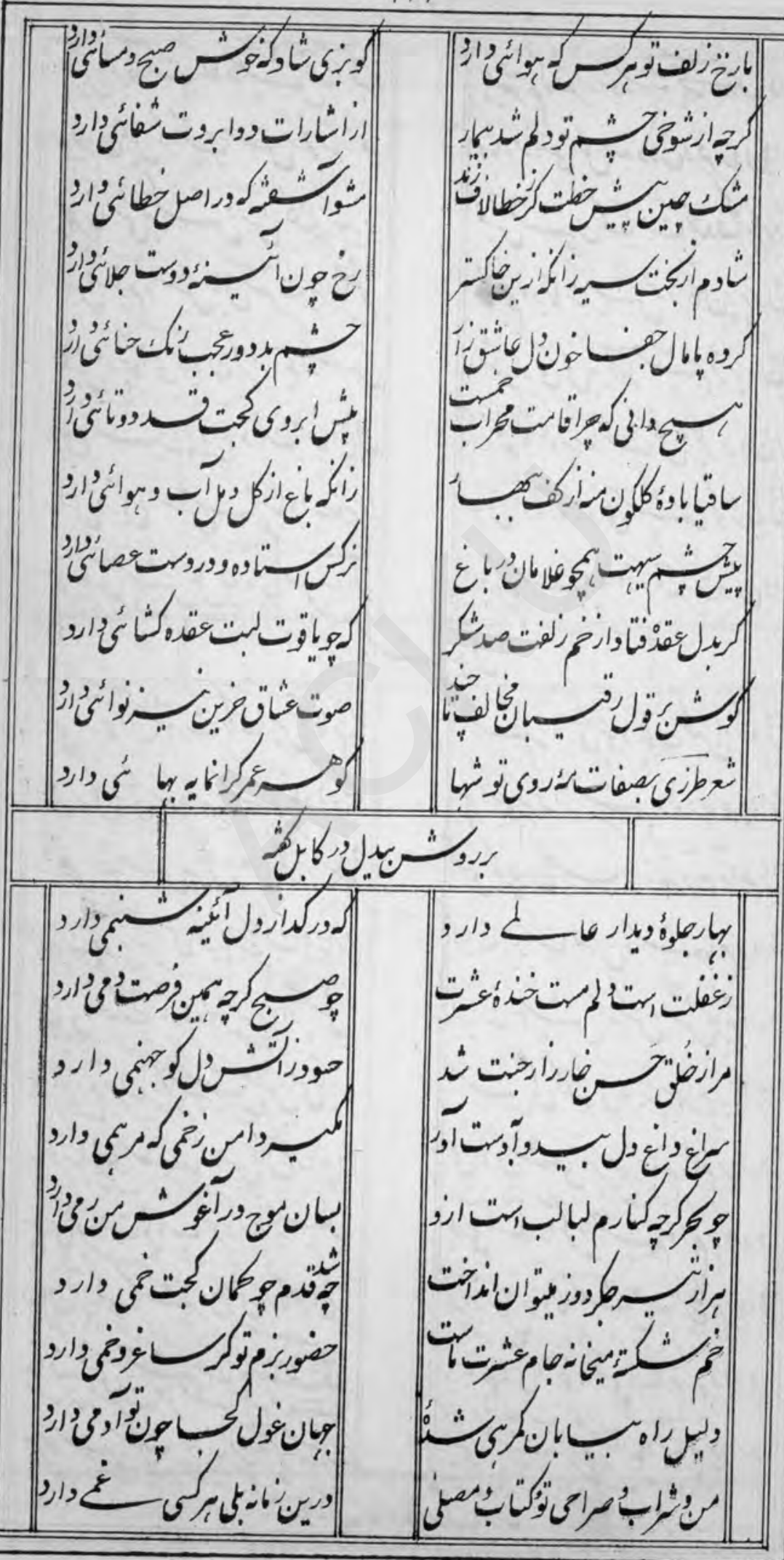




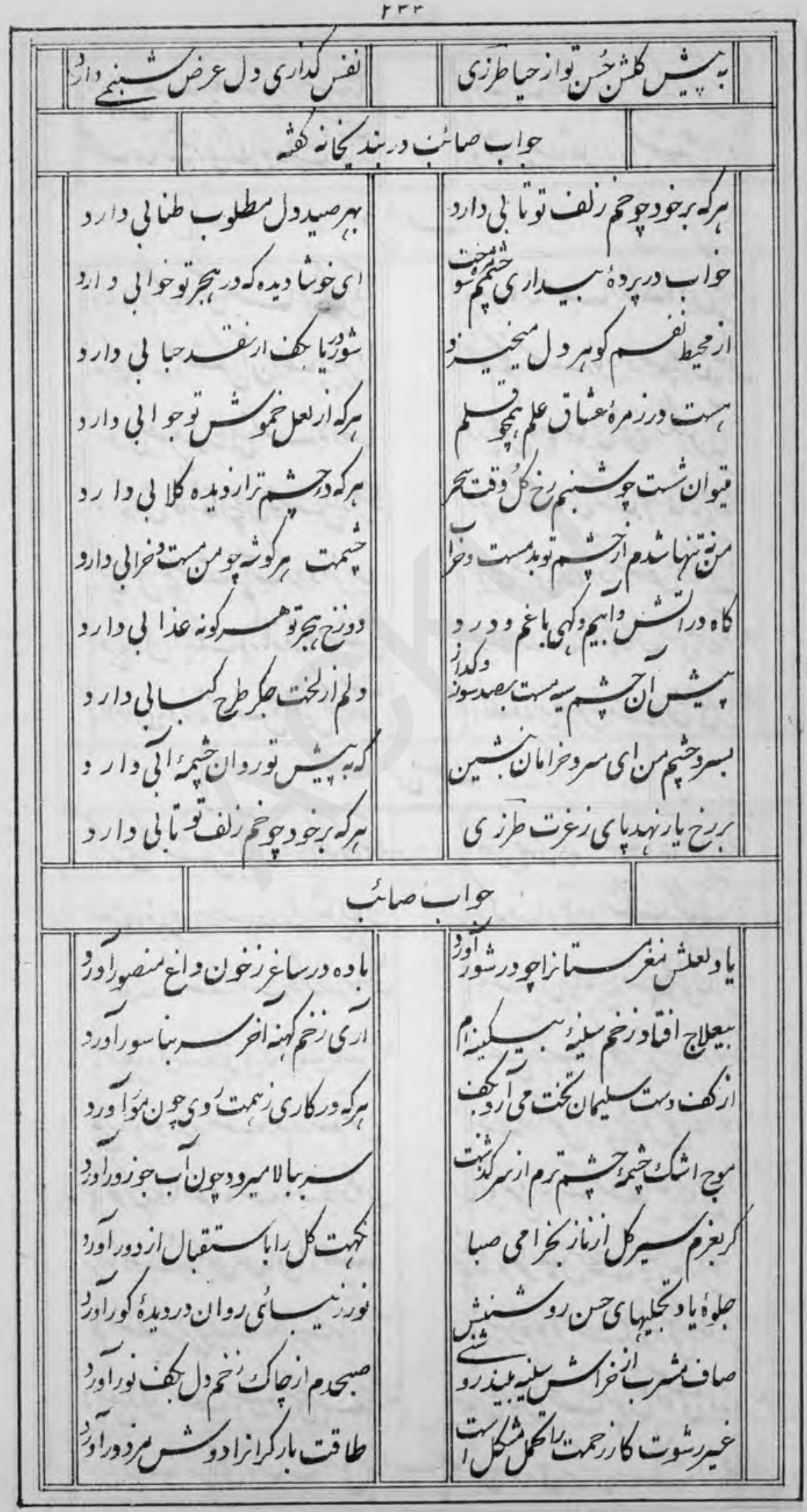


rre

||


ros

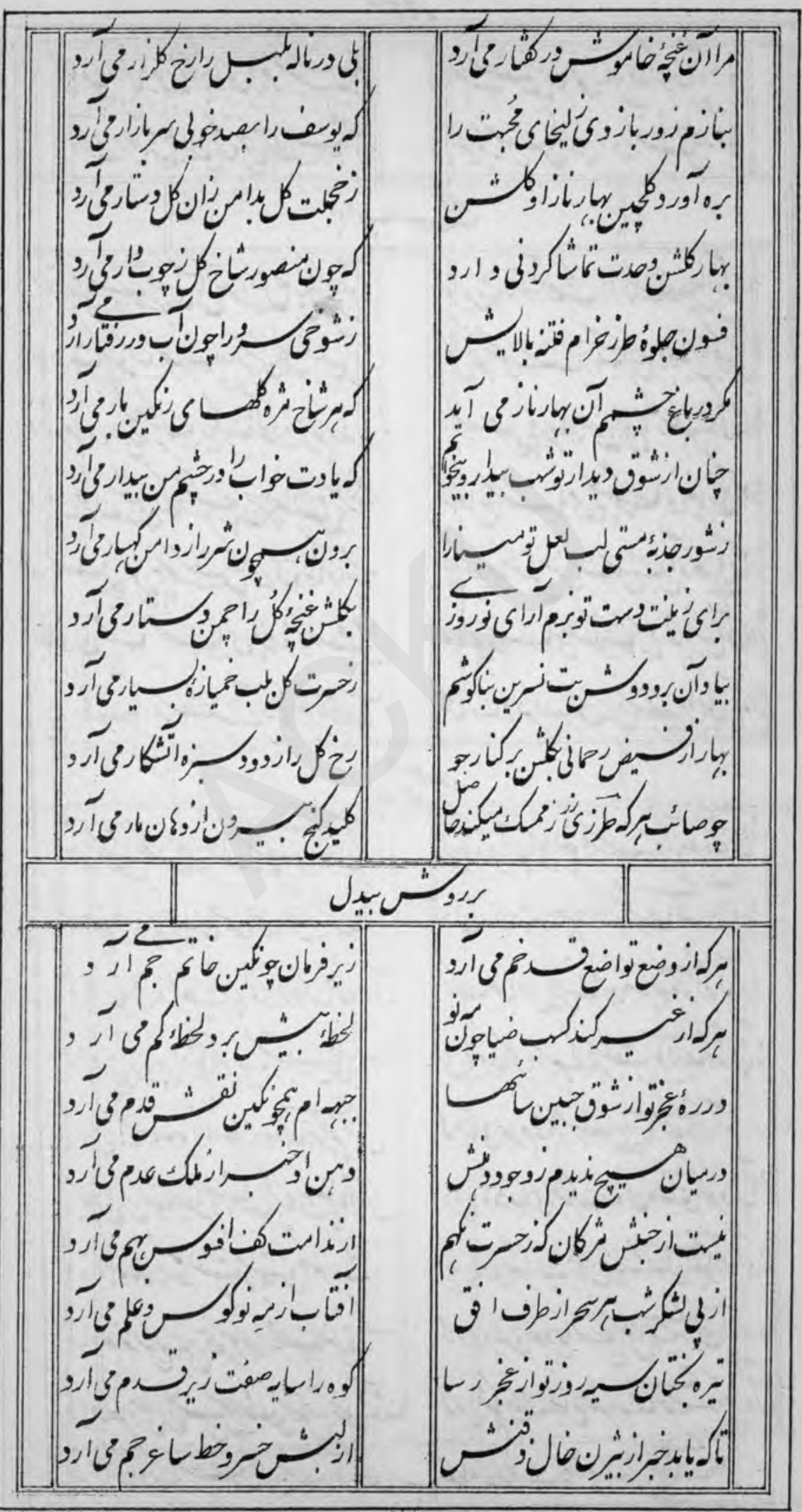




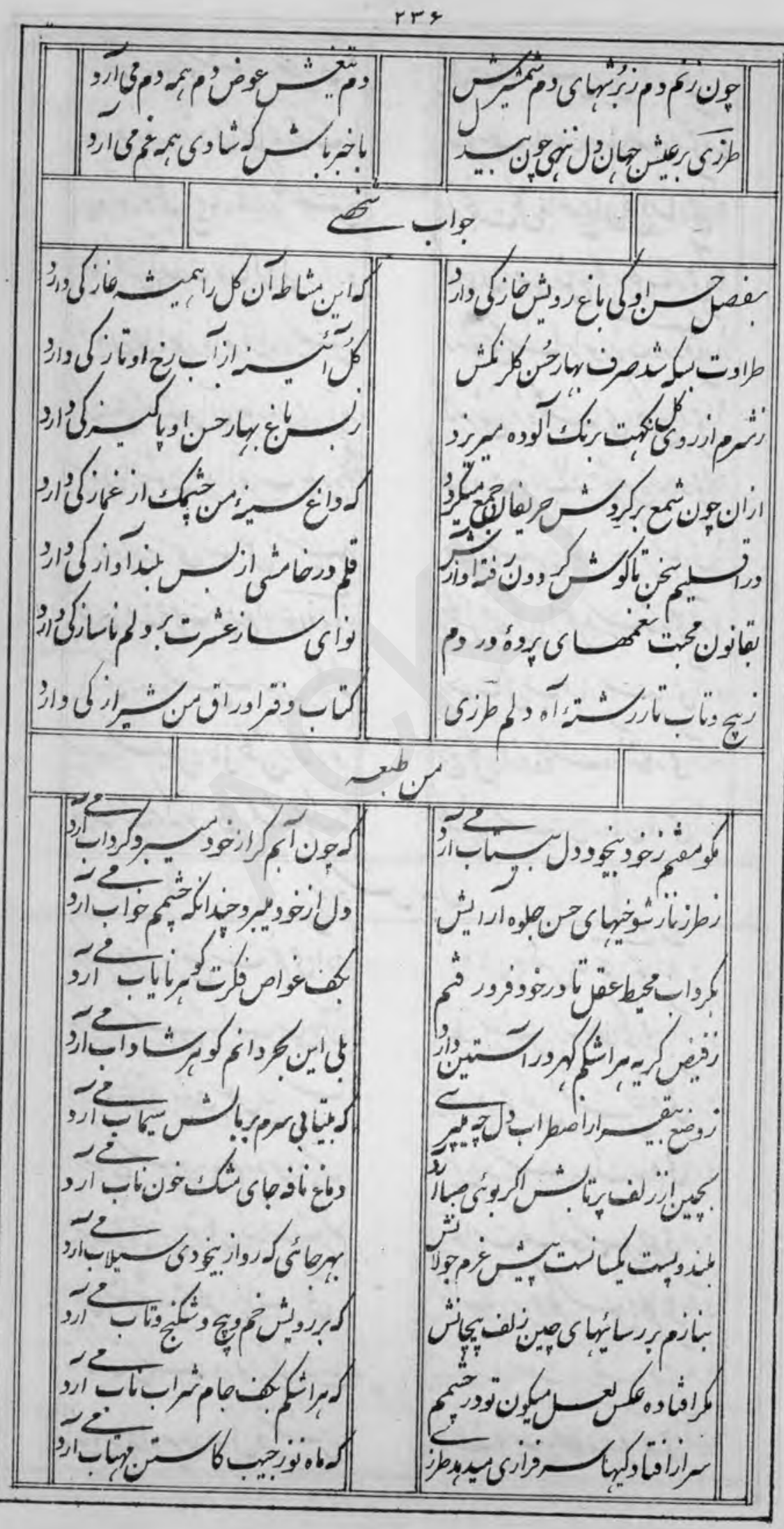




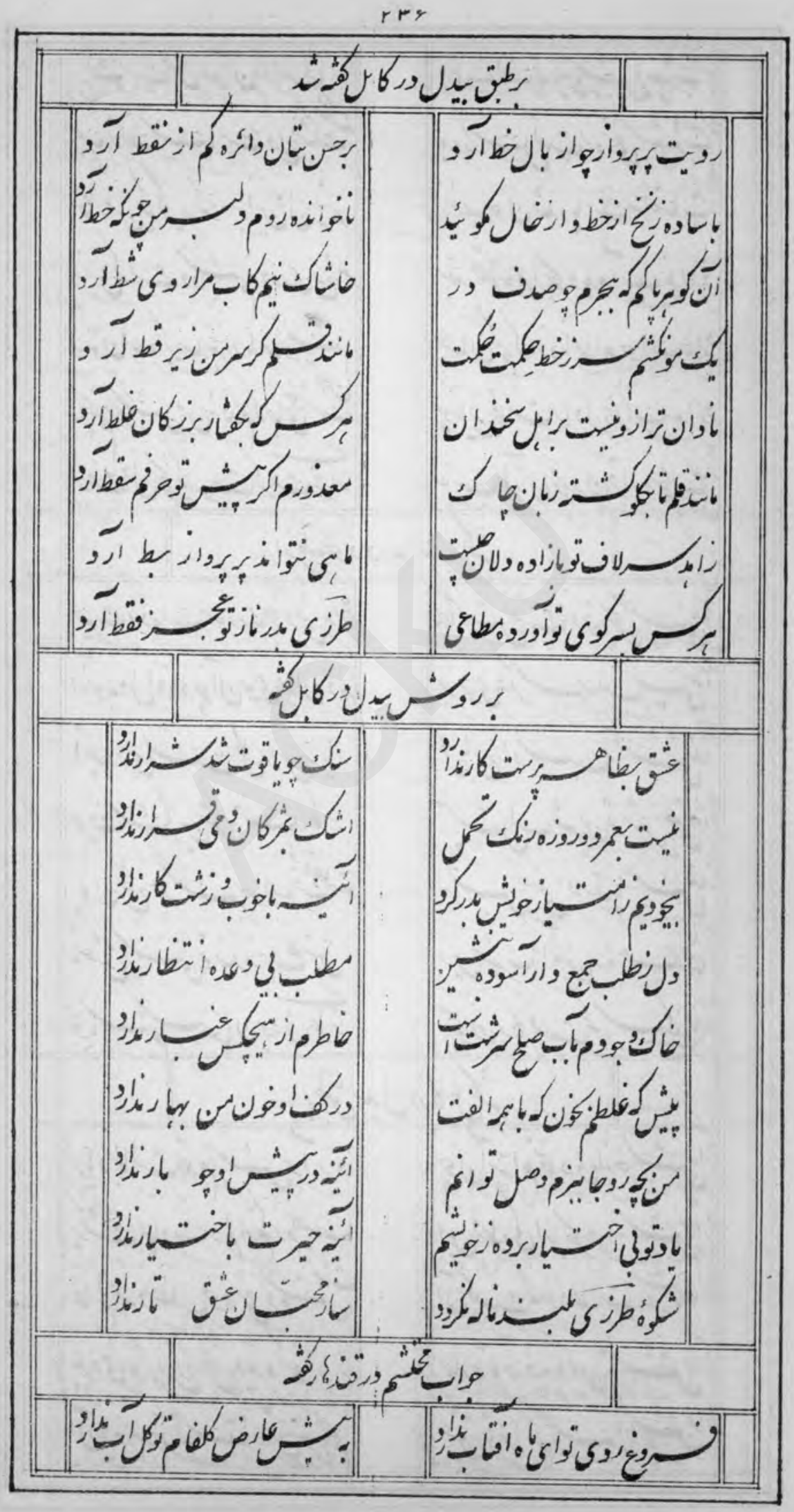


rra

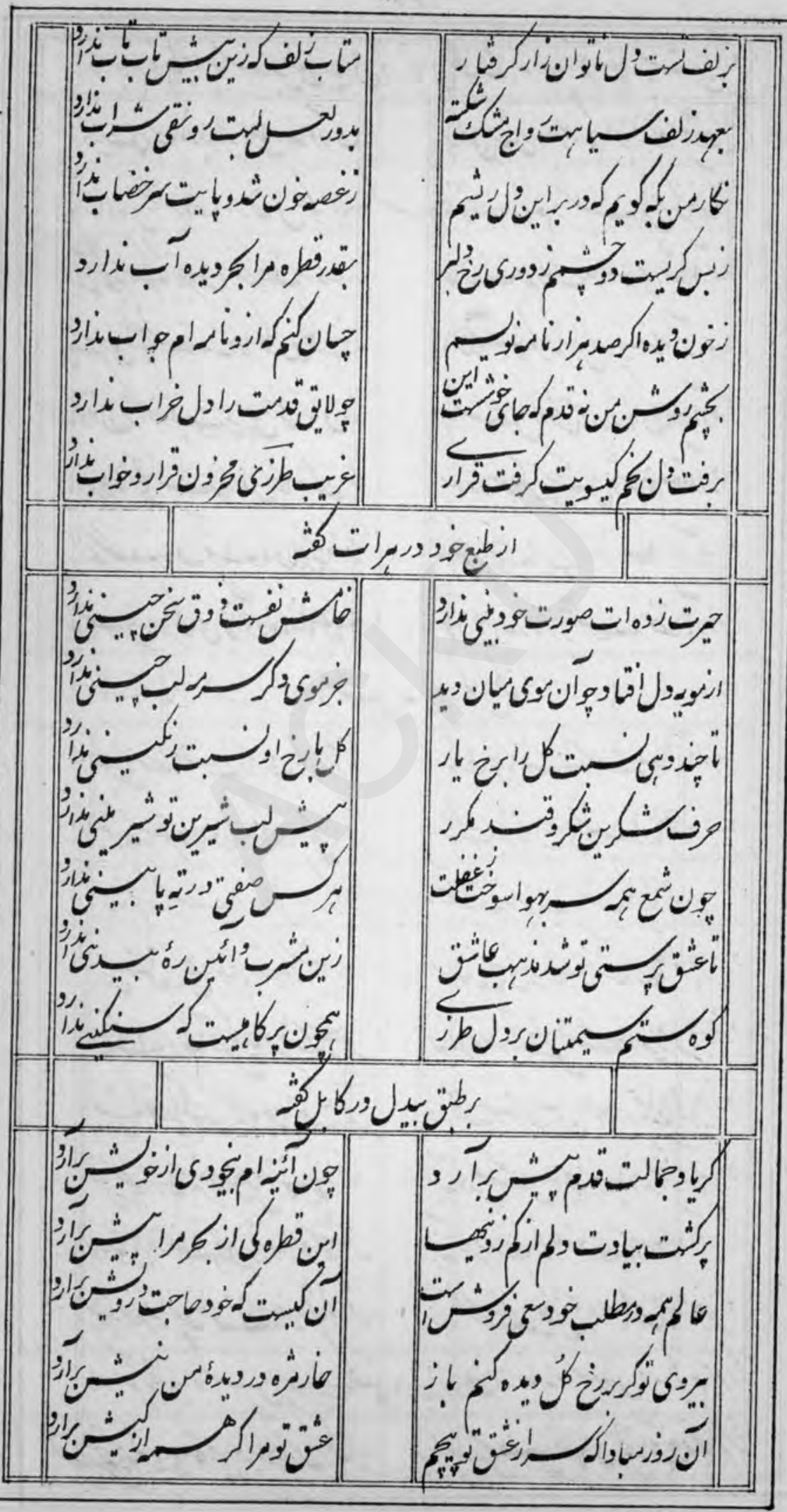


rra

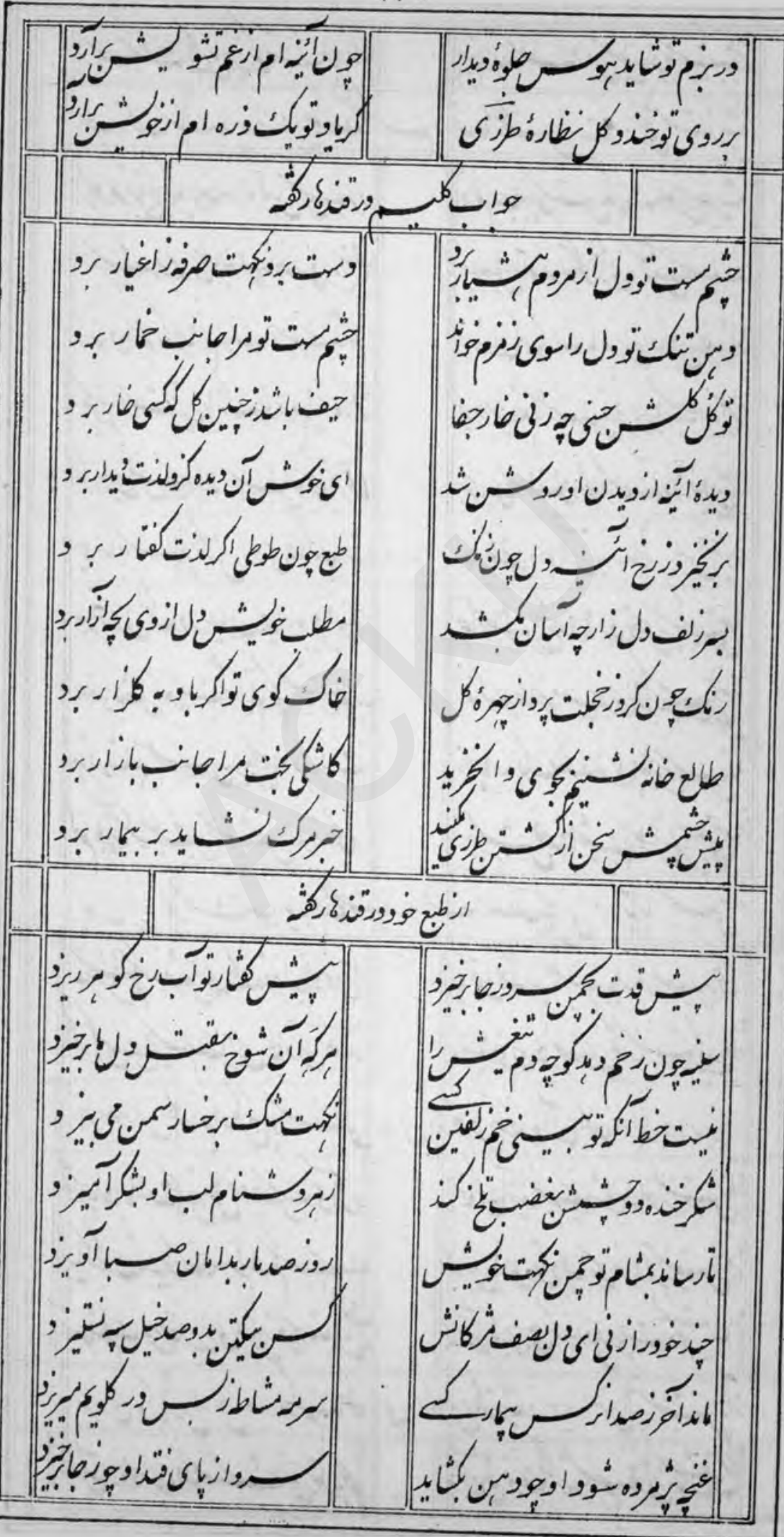


r

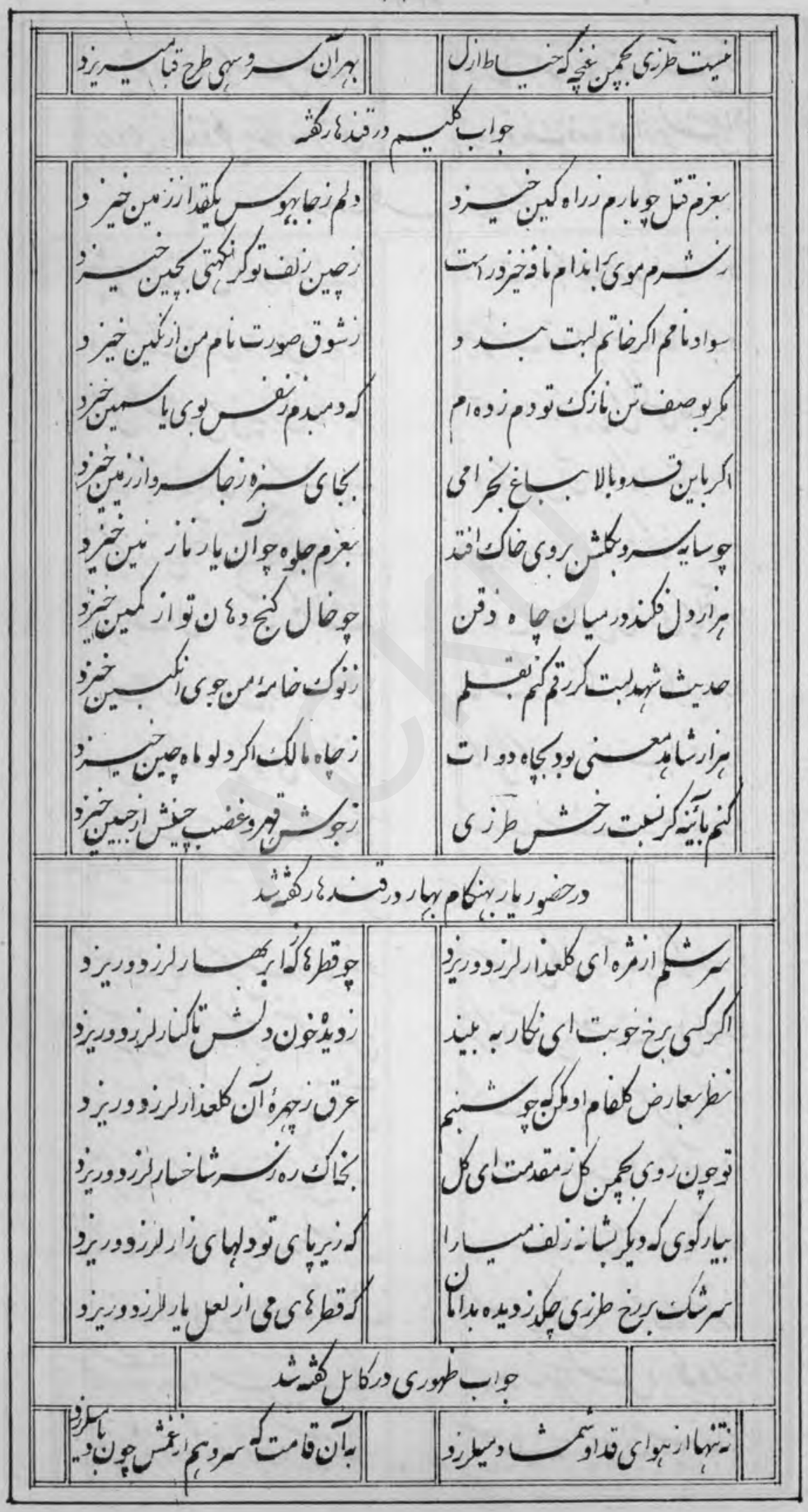


$p+i$

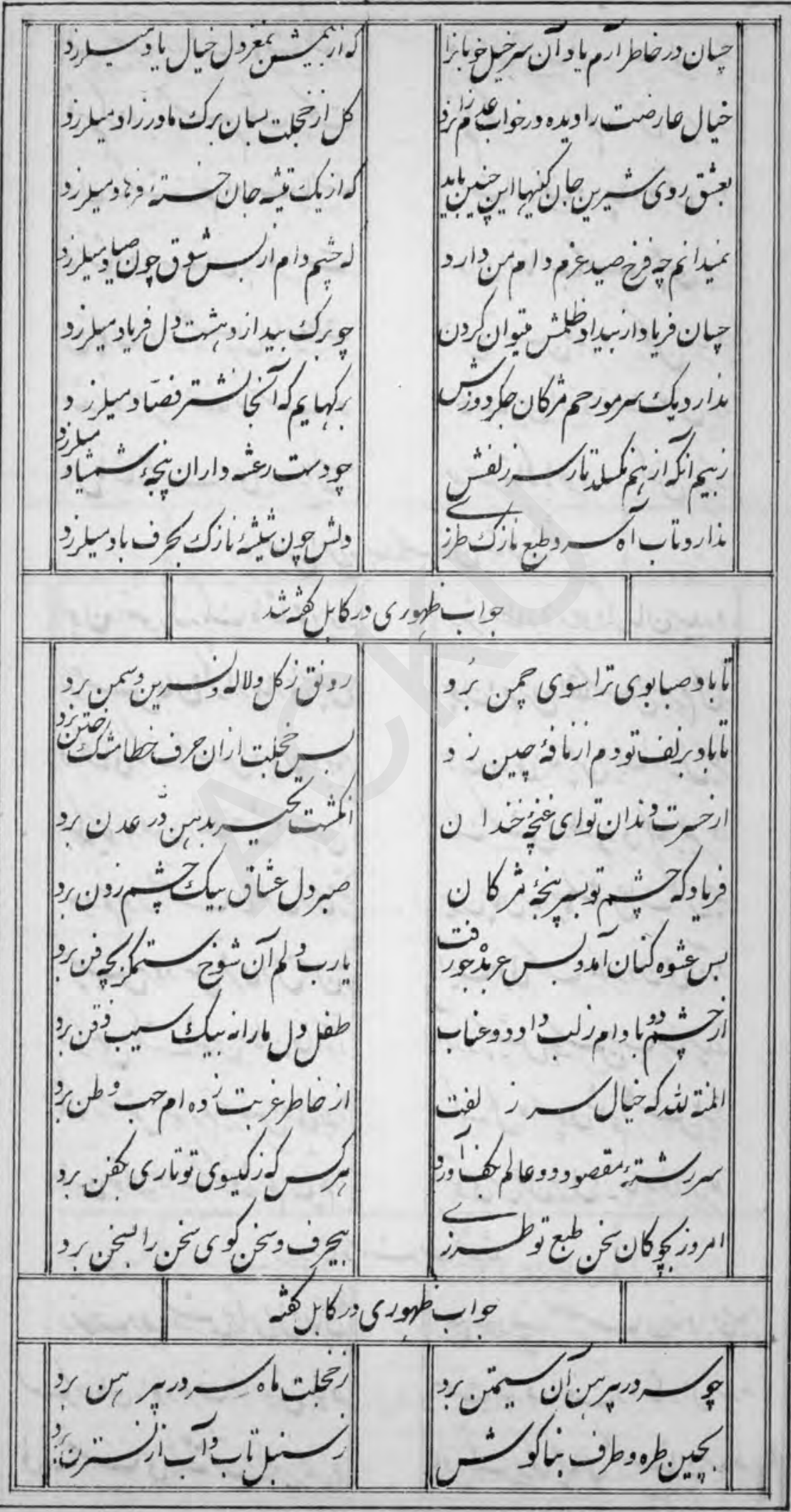


$r r$

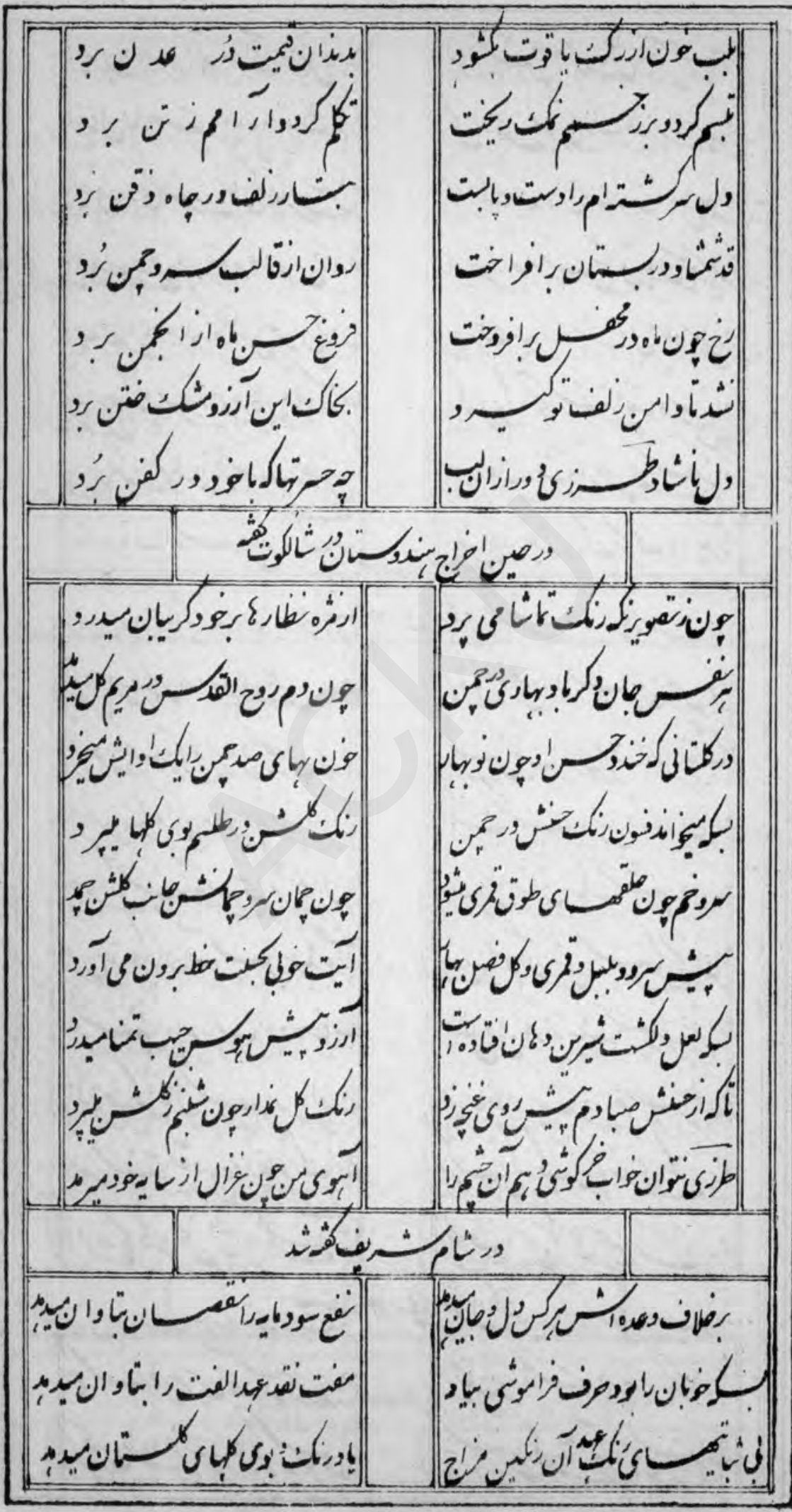


$r v$

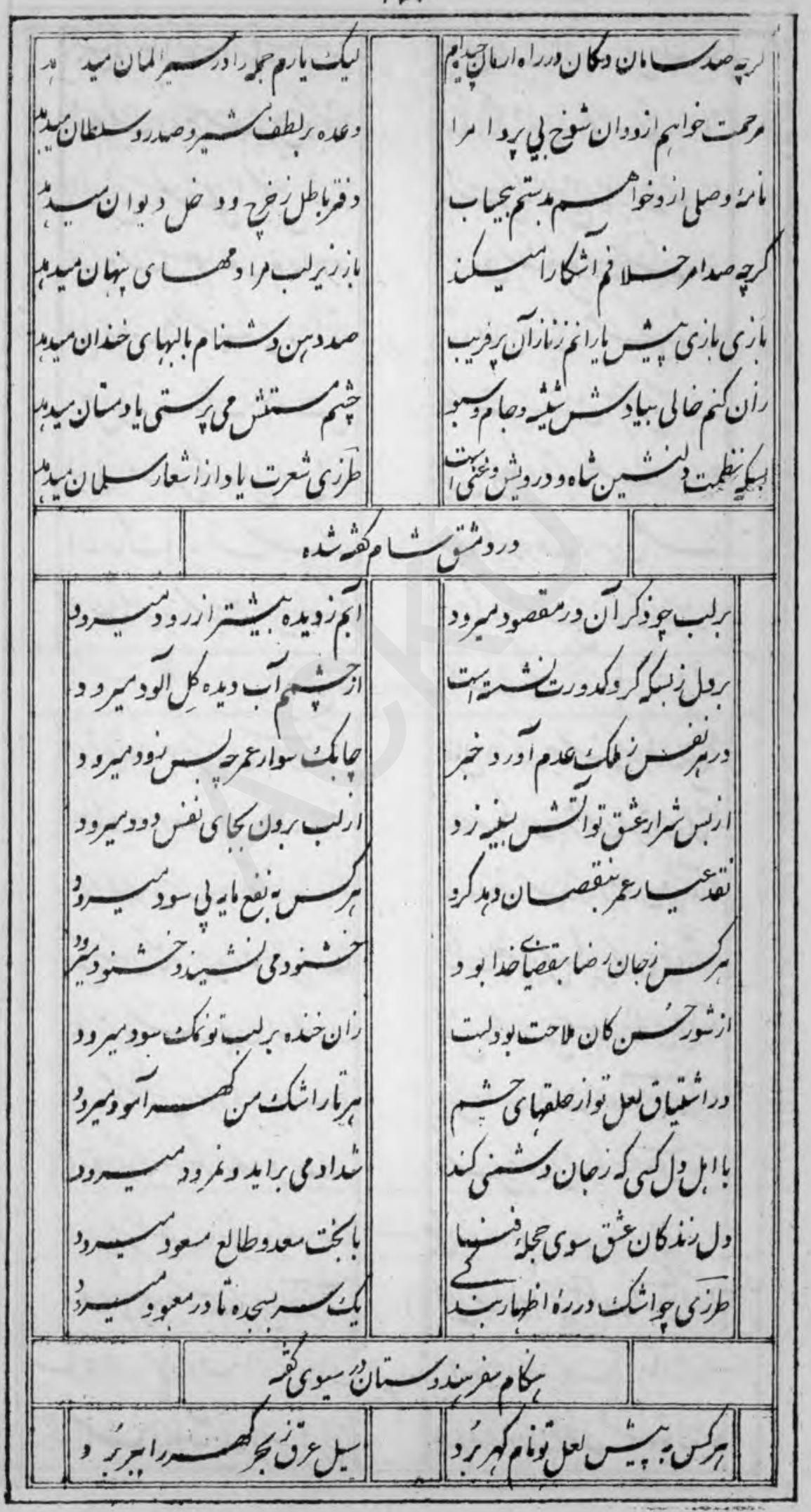


$r r$

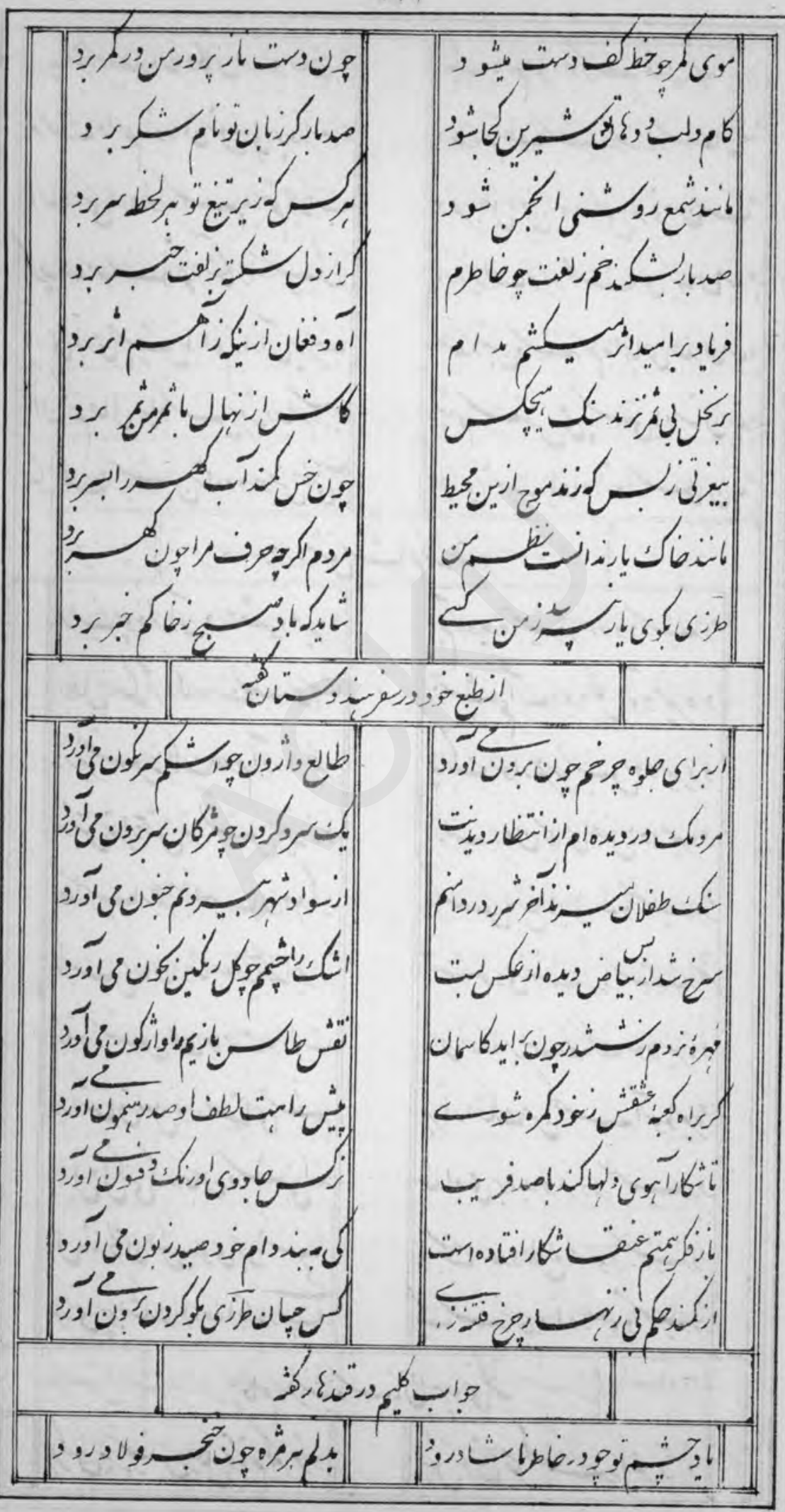


reo

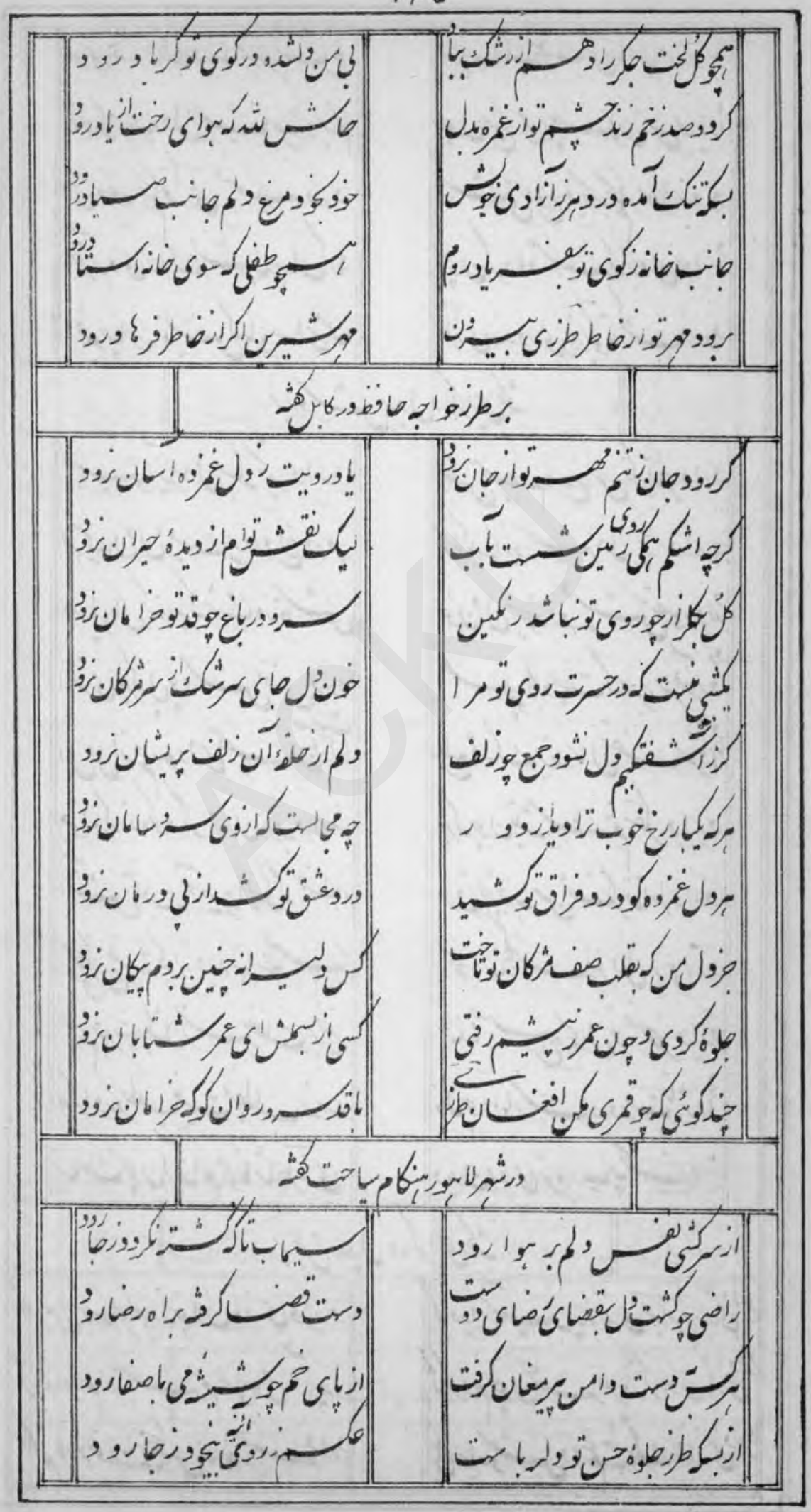


rof

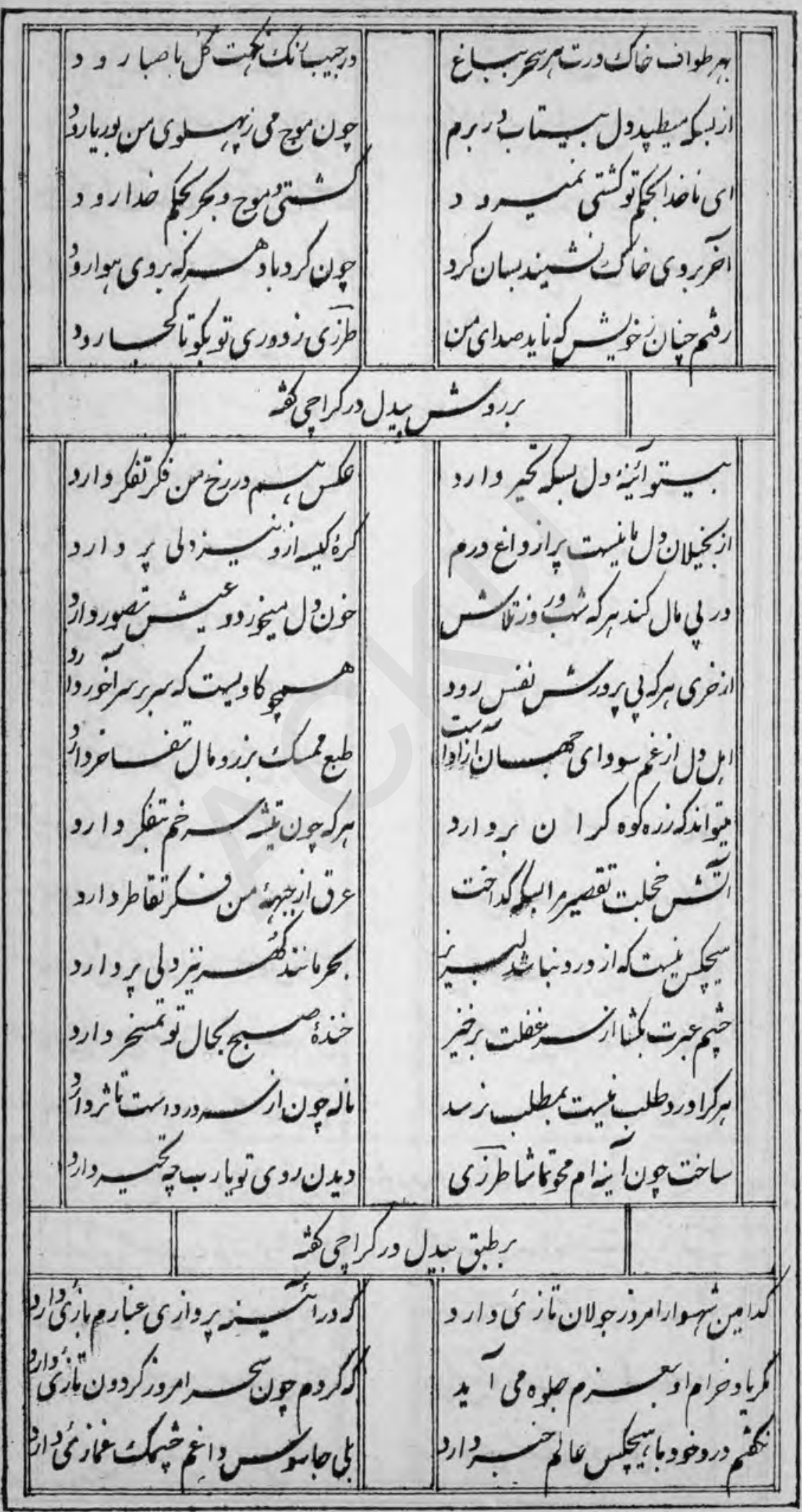

j. 
rro

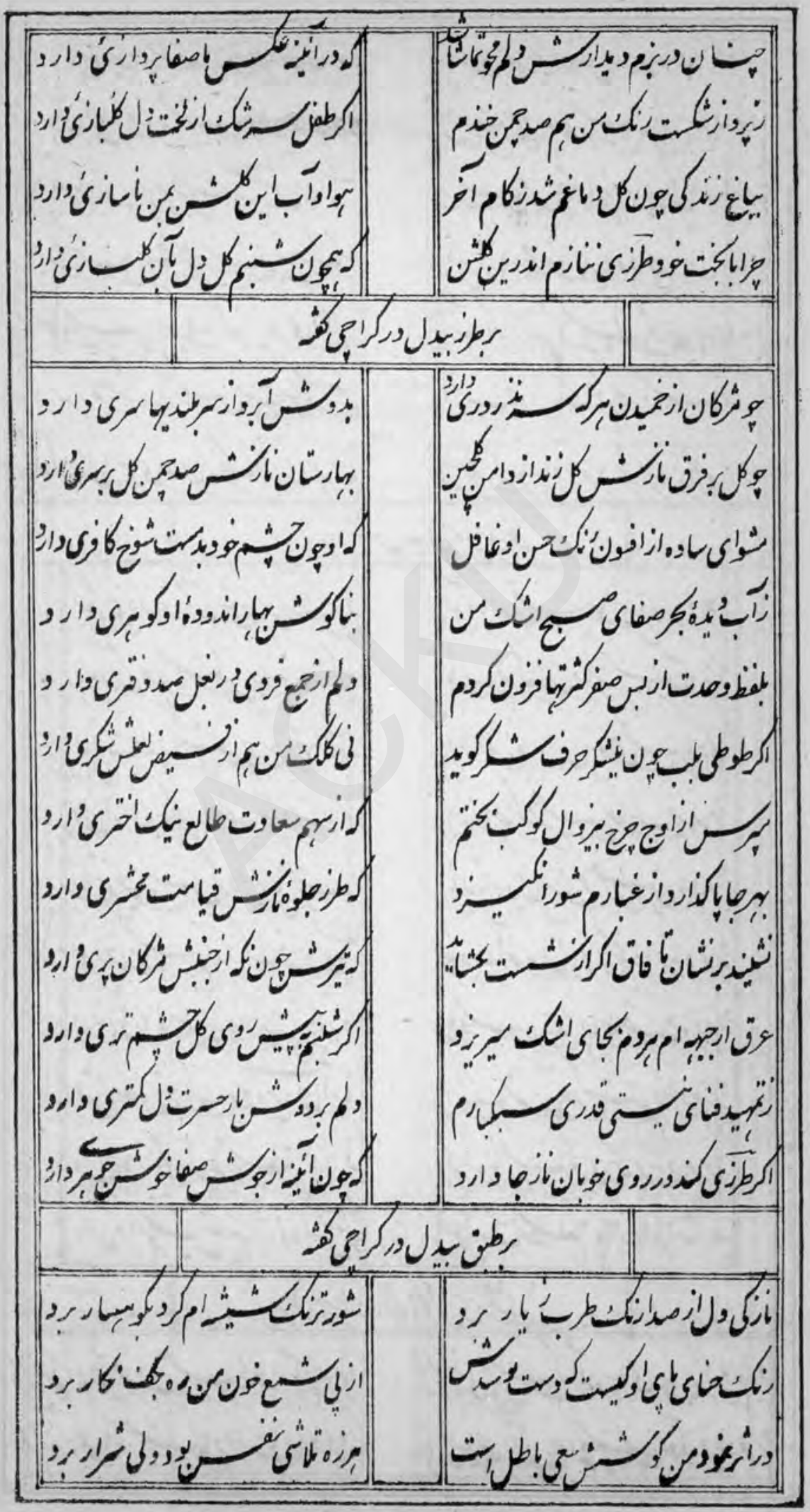


$r+1$

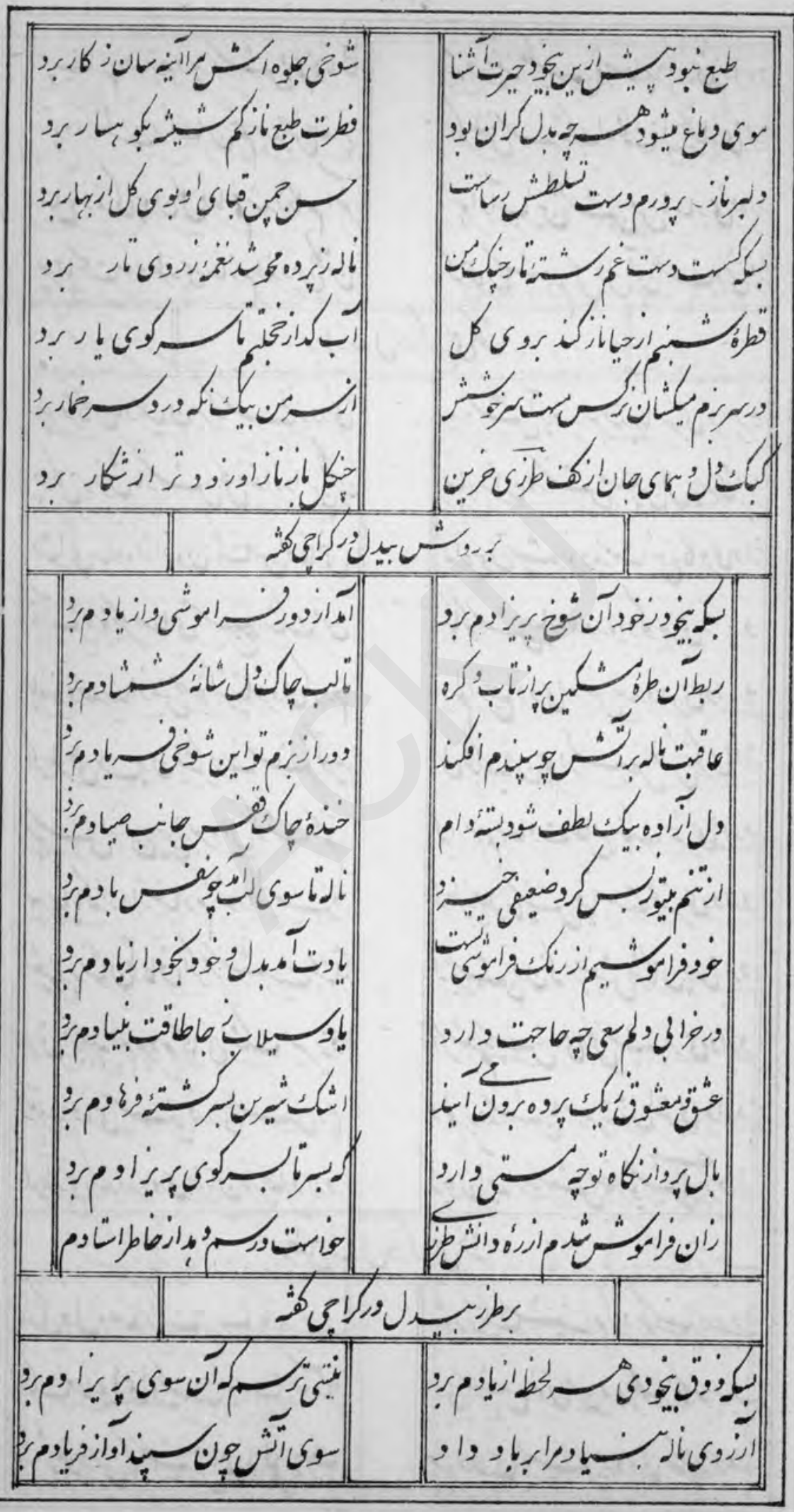


rra

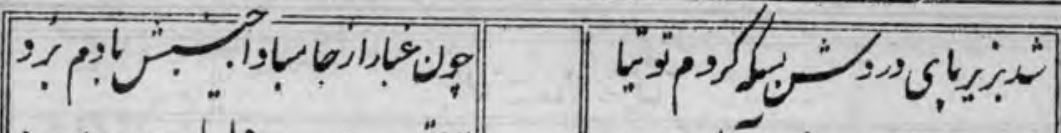

:

,

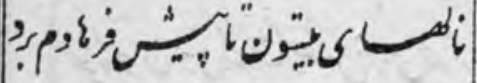

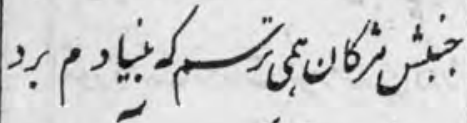

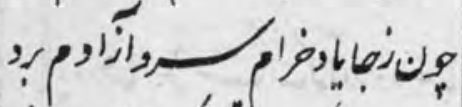
:

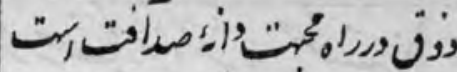
9 "Nis, .

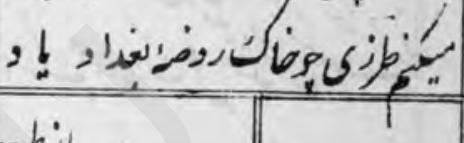

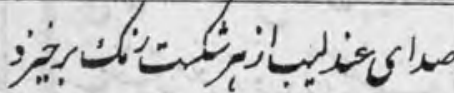

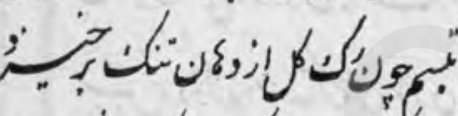
. :

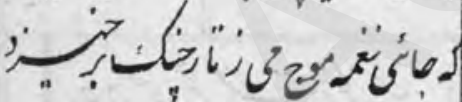
P.

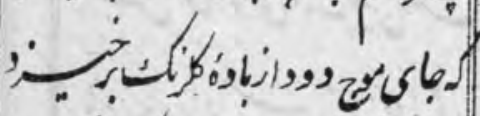

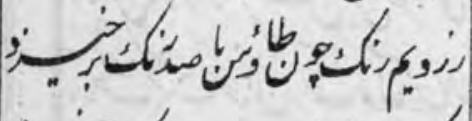
"

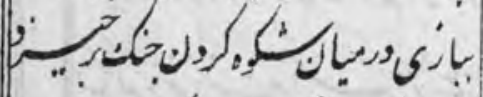

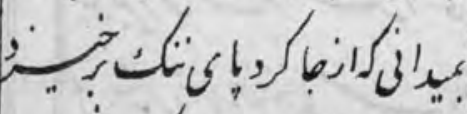
is بو

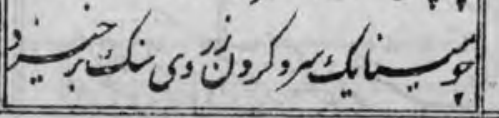

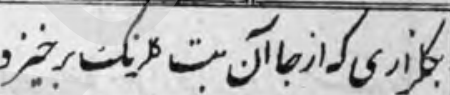

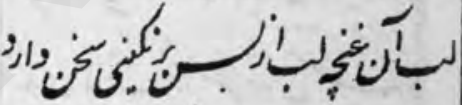

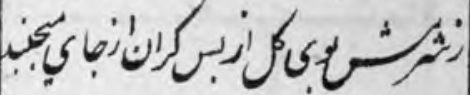

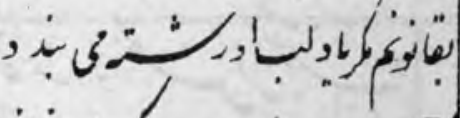

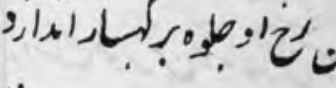

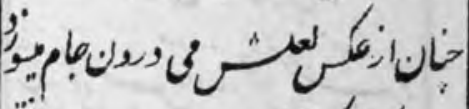

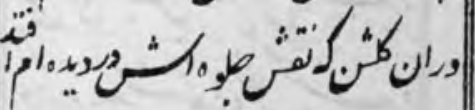

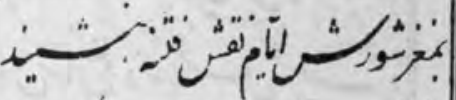

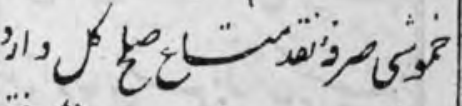

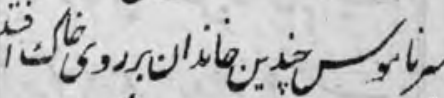

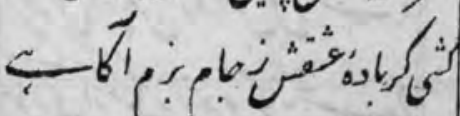

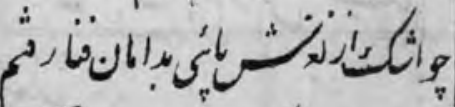

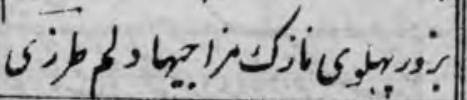




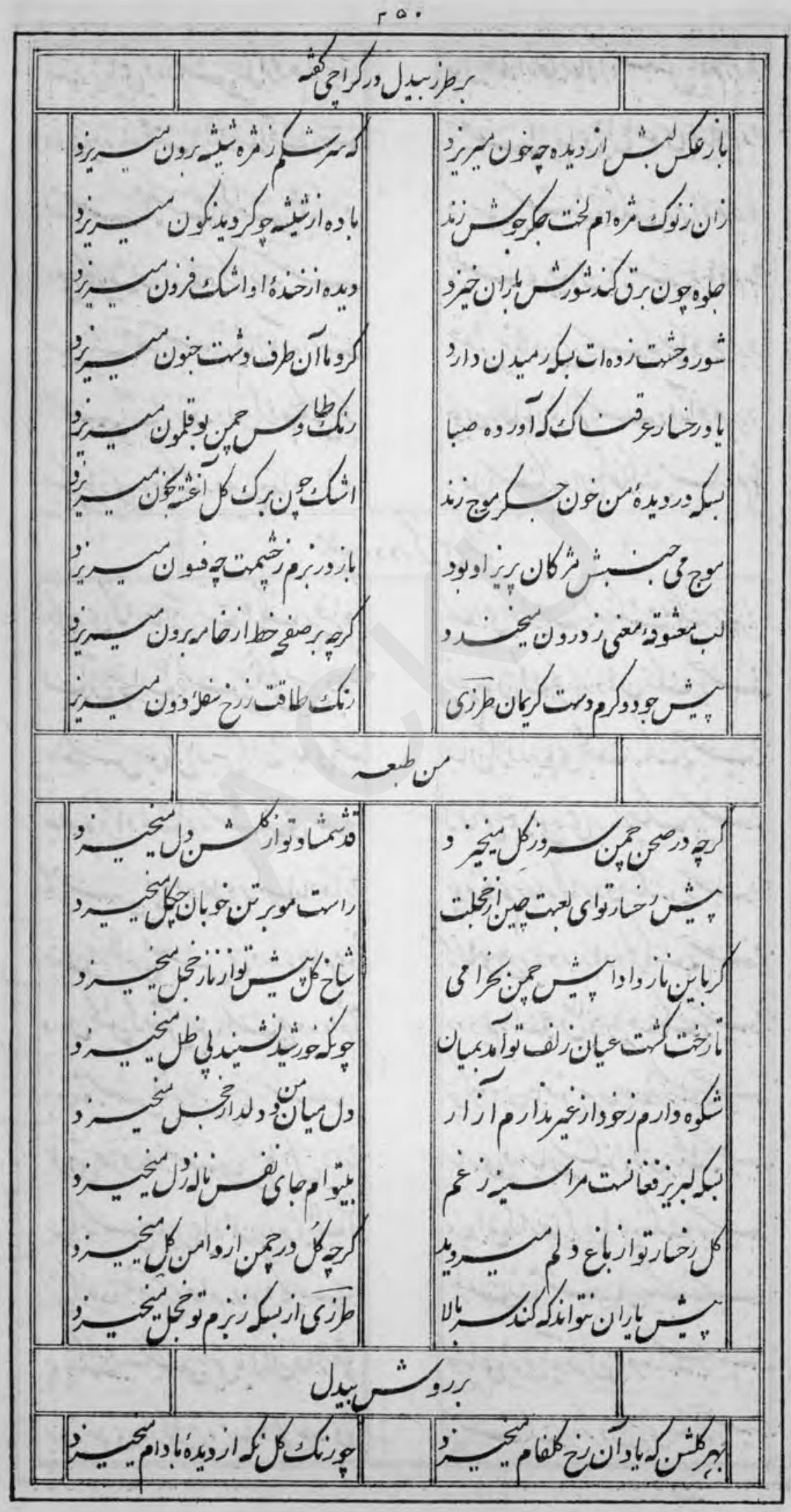


rol

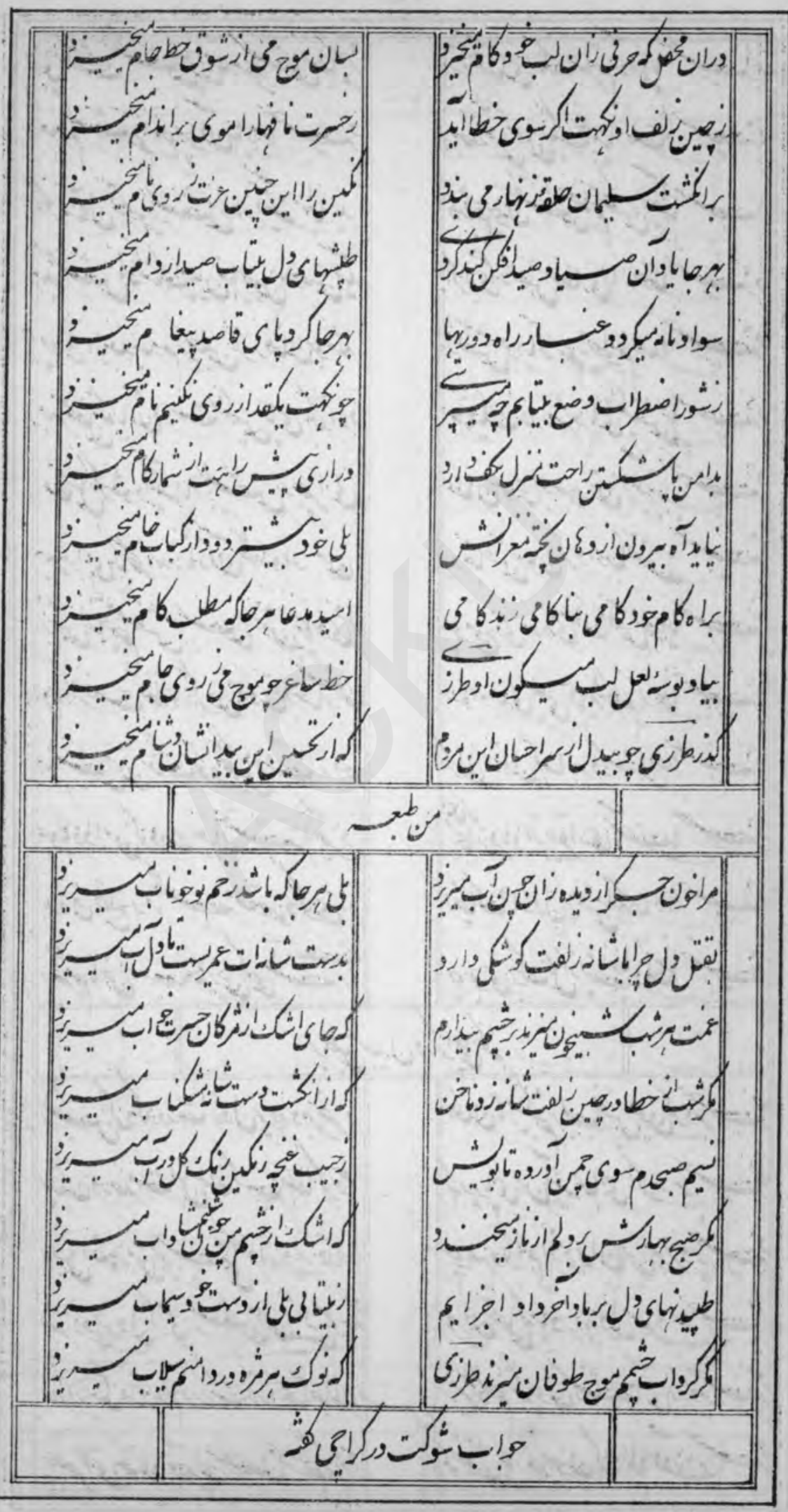


rat

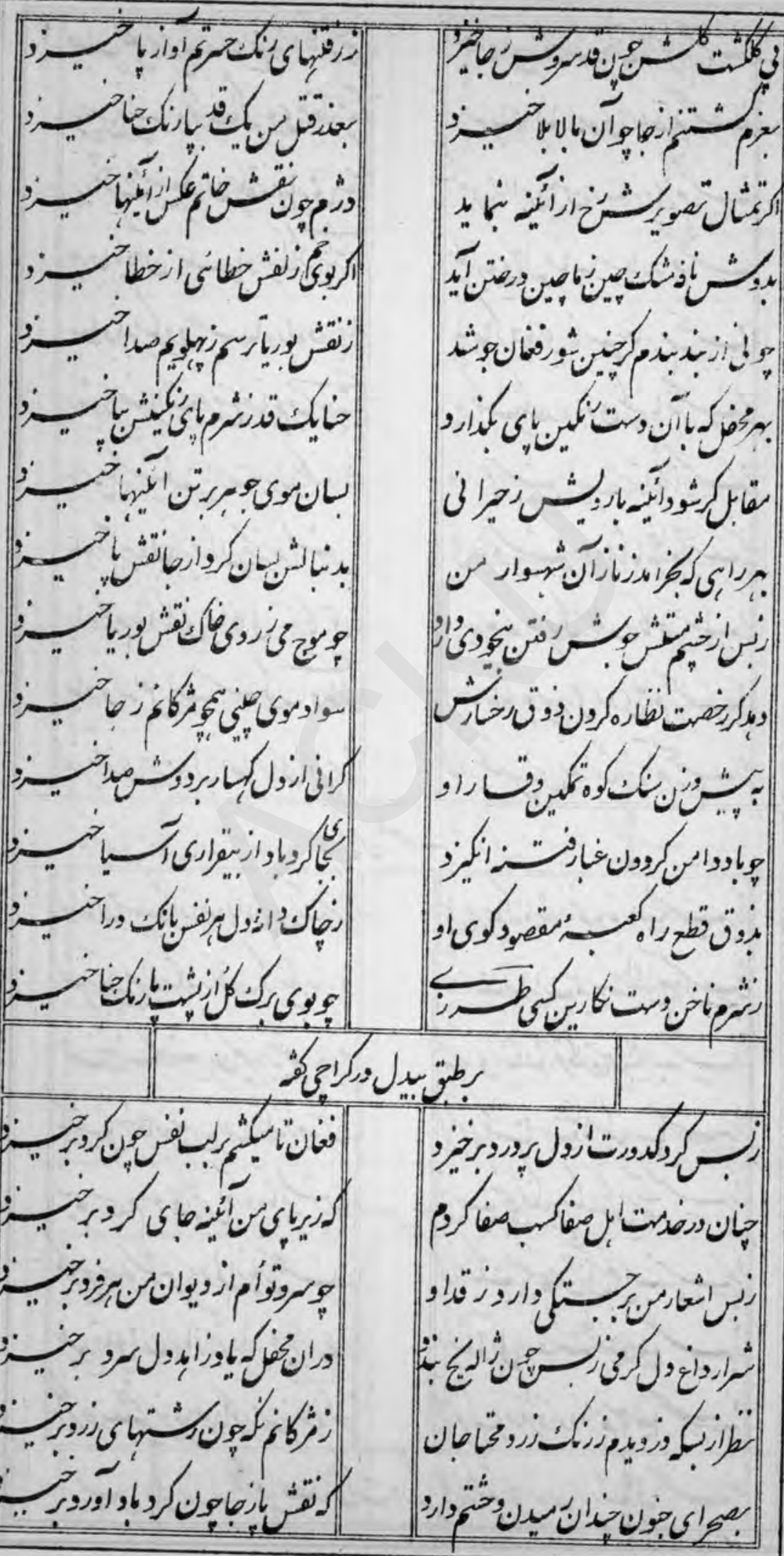


$r \Delta r$

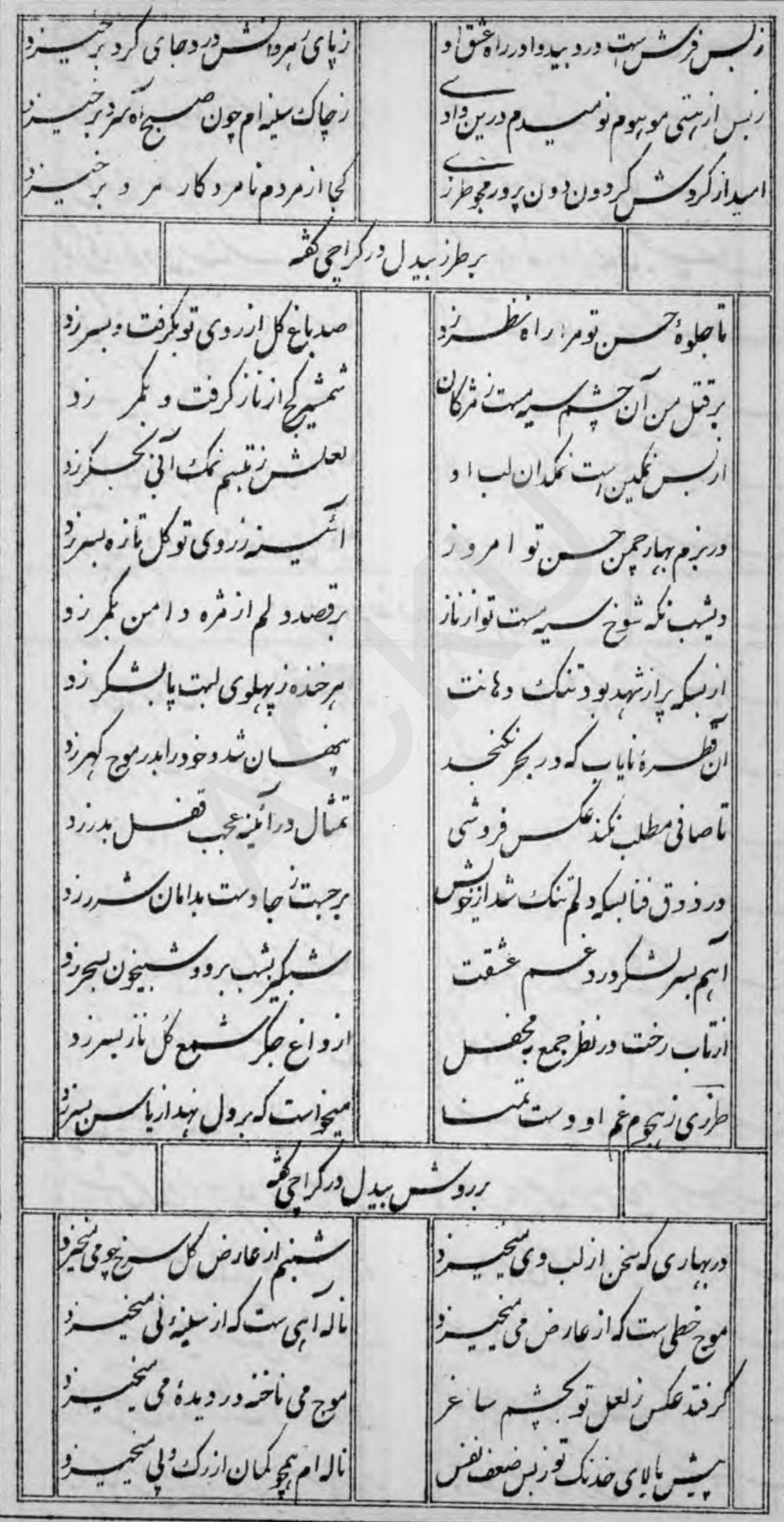




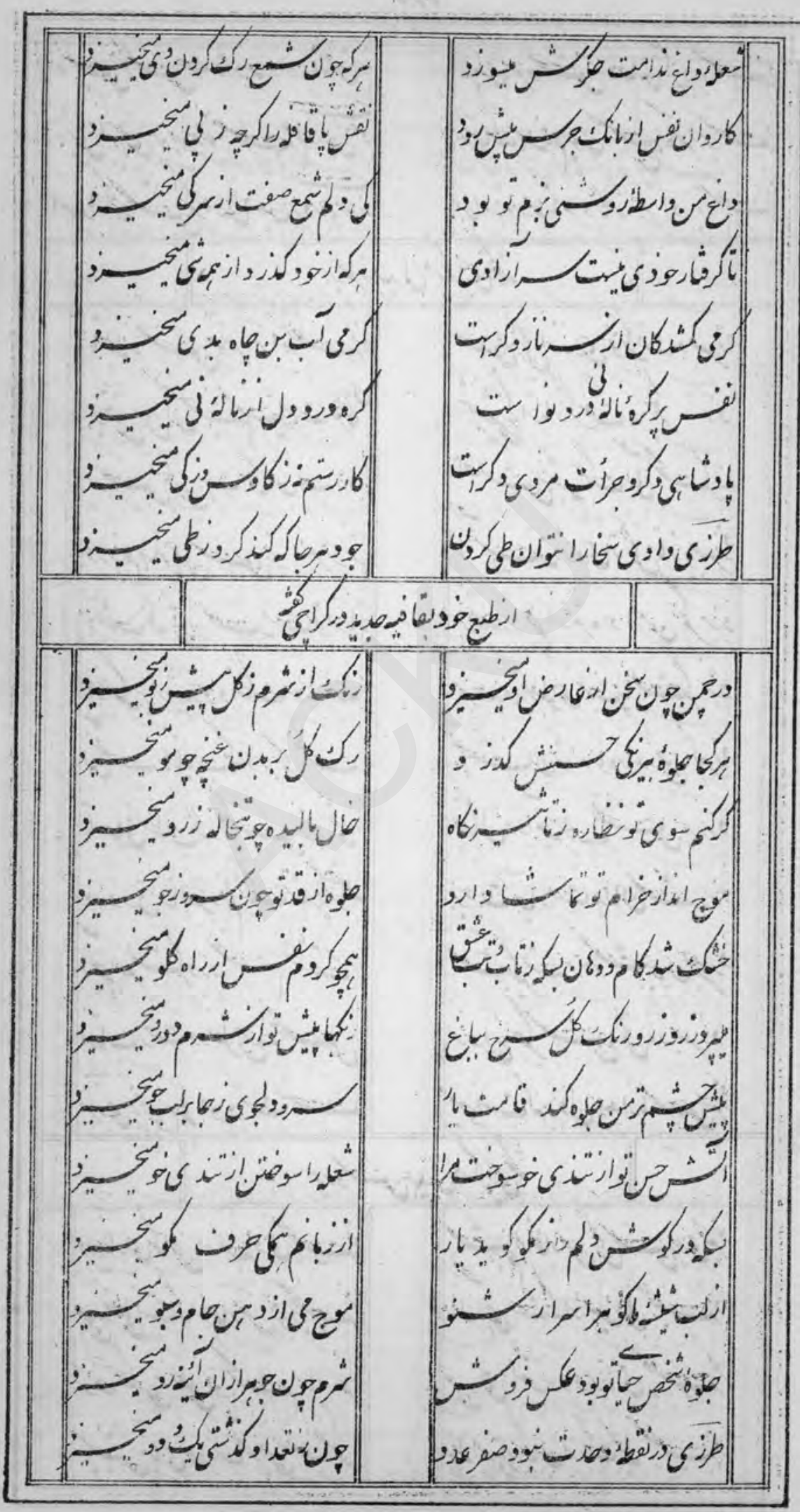


$r \Delta \omega$

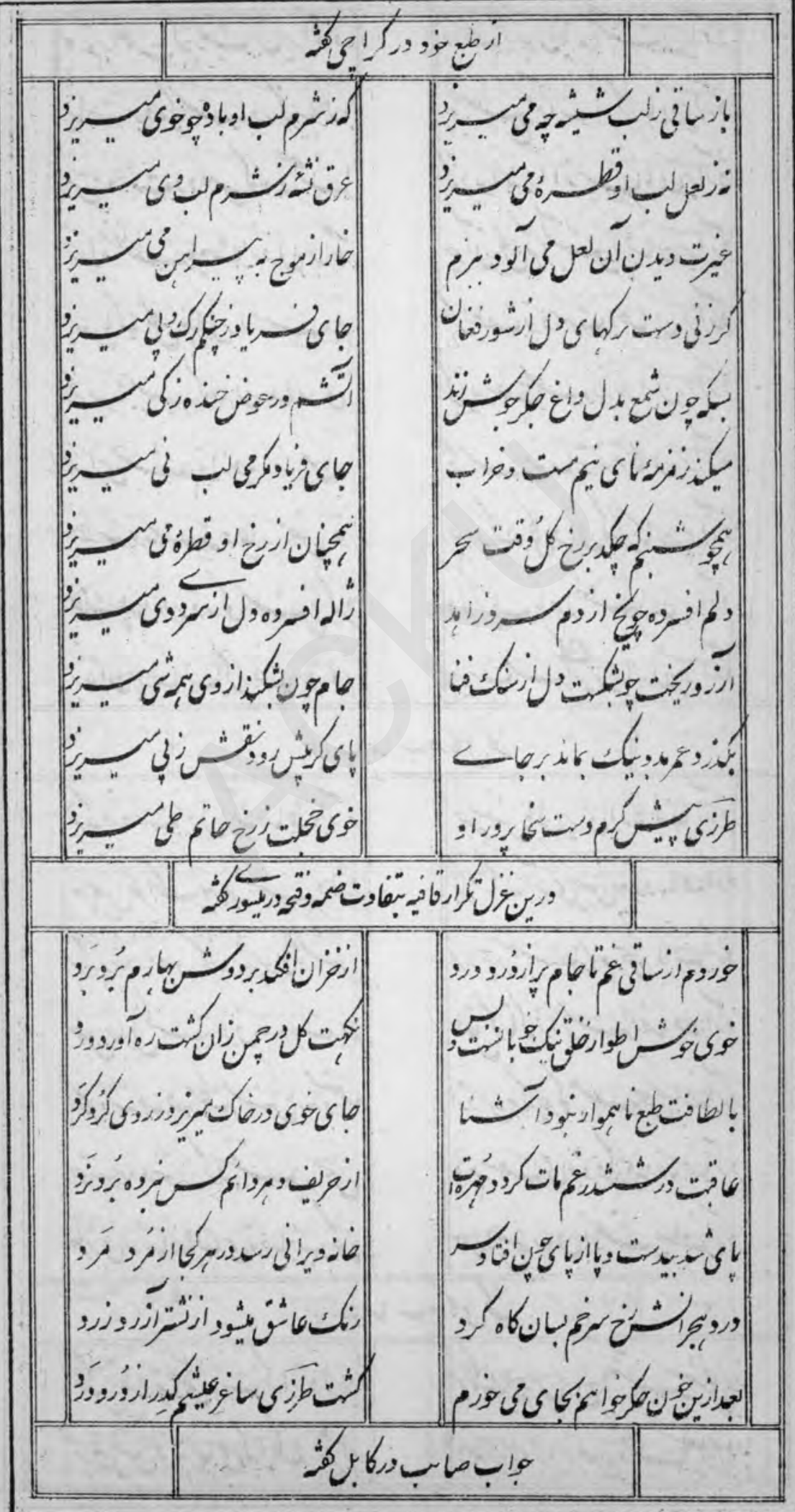


$r a p$

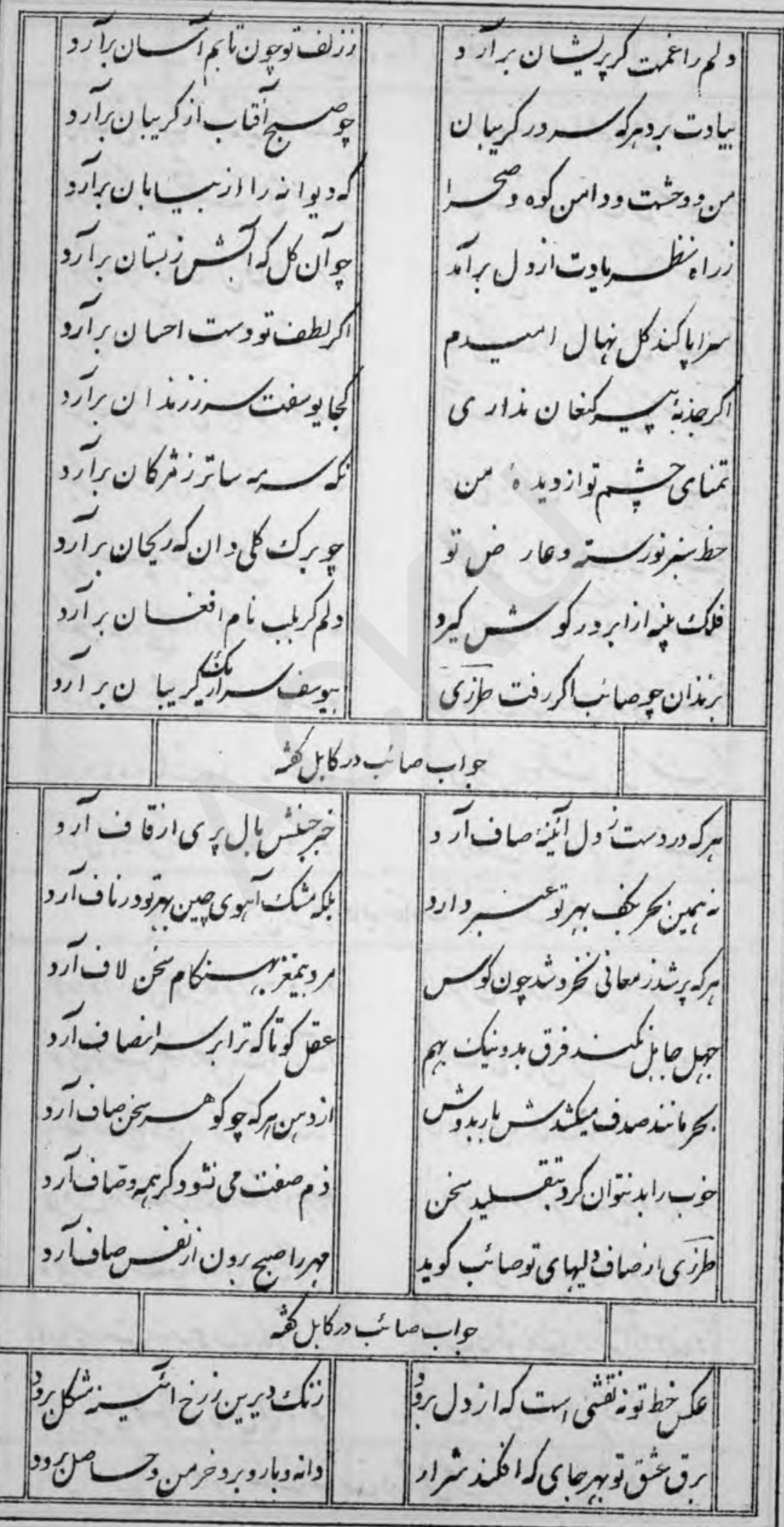


166

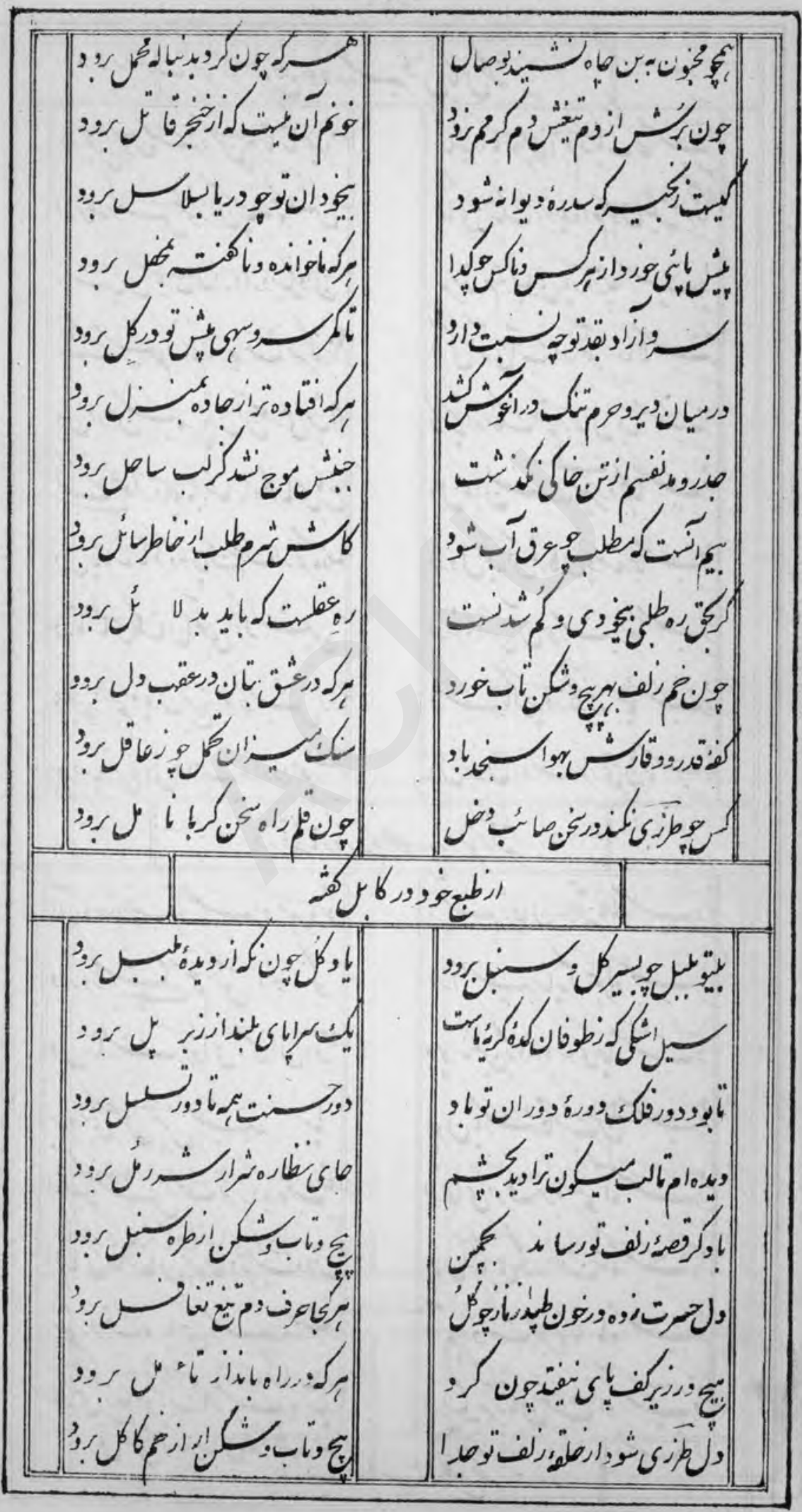




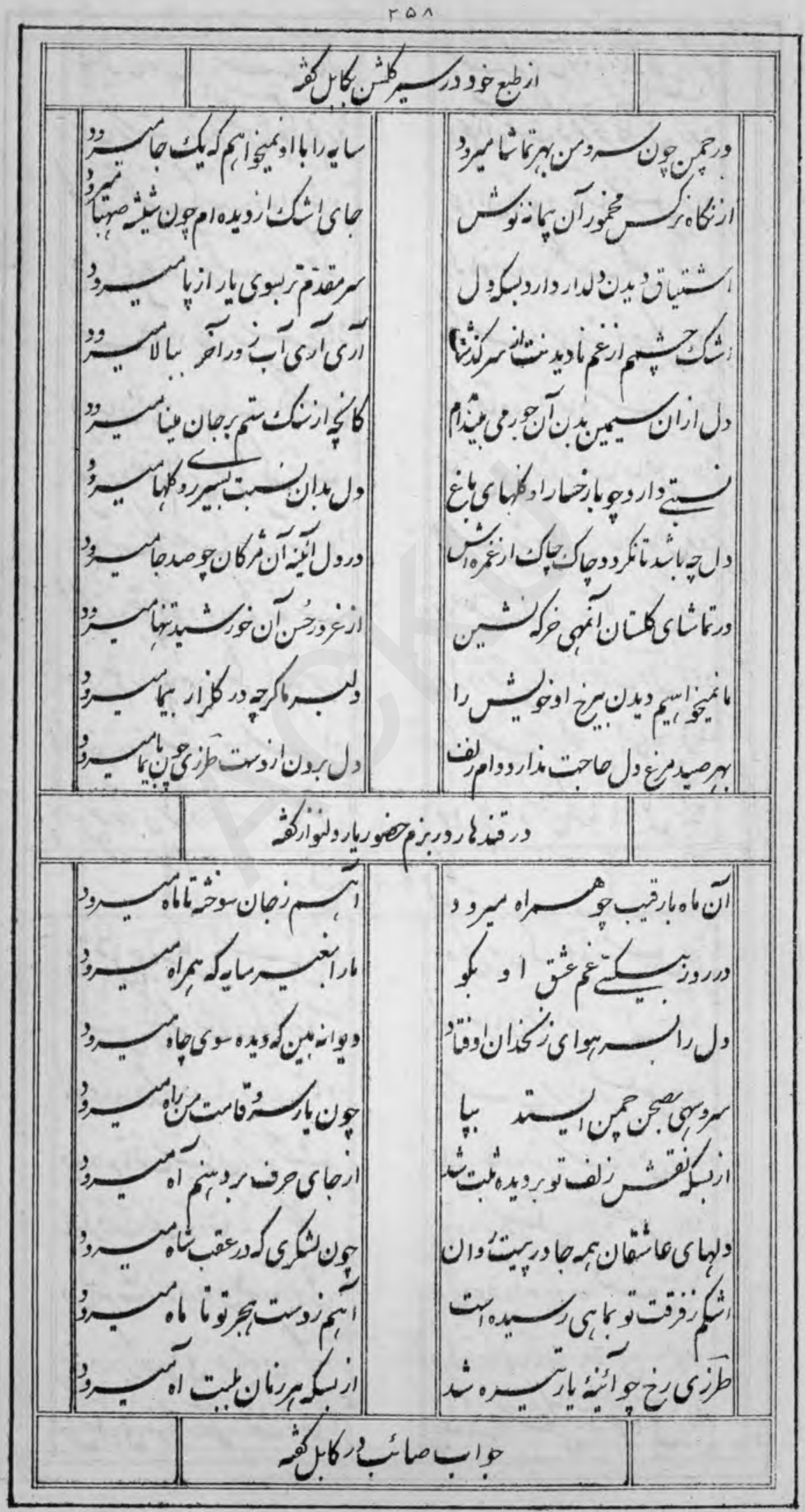


$r \circ q$

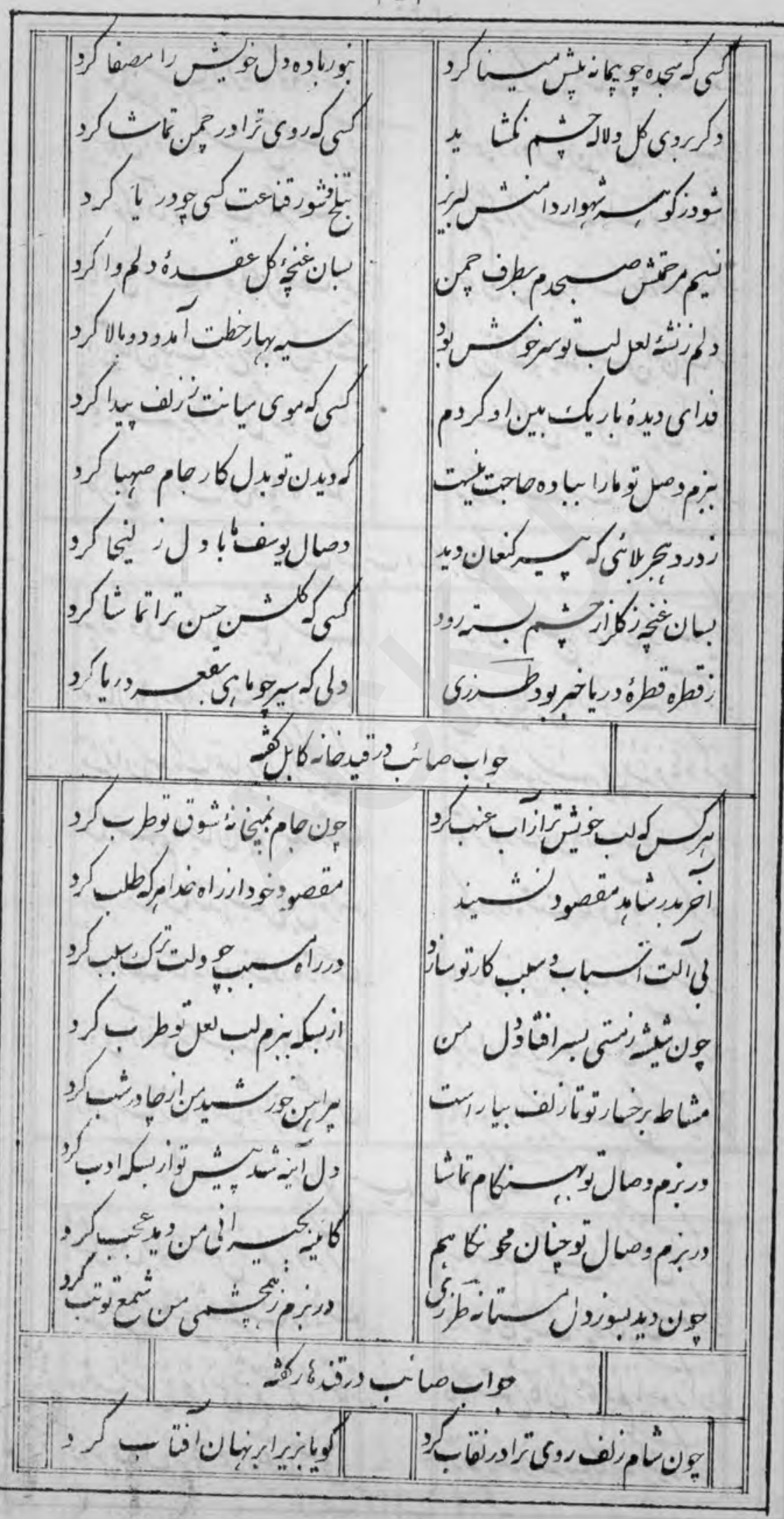




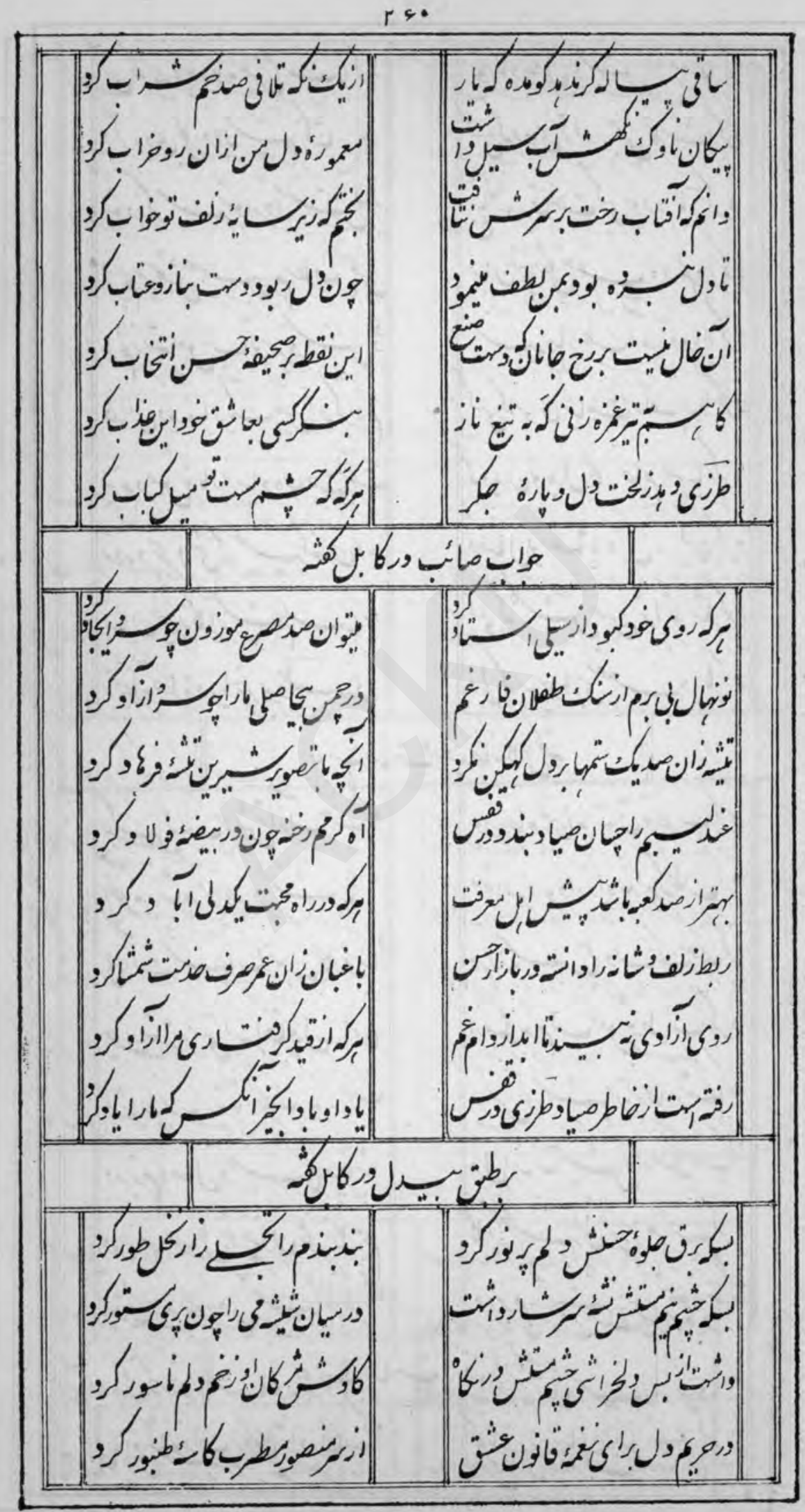


$r|l|$

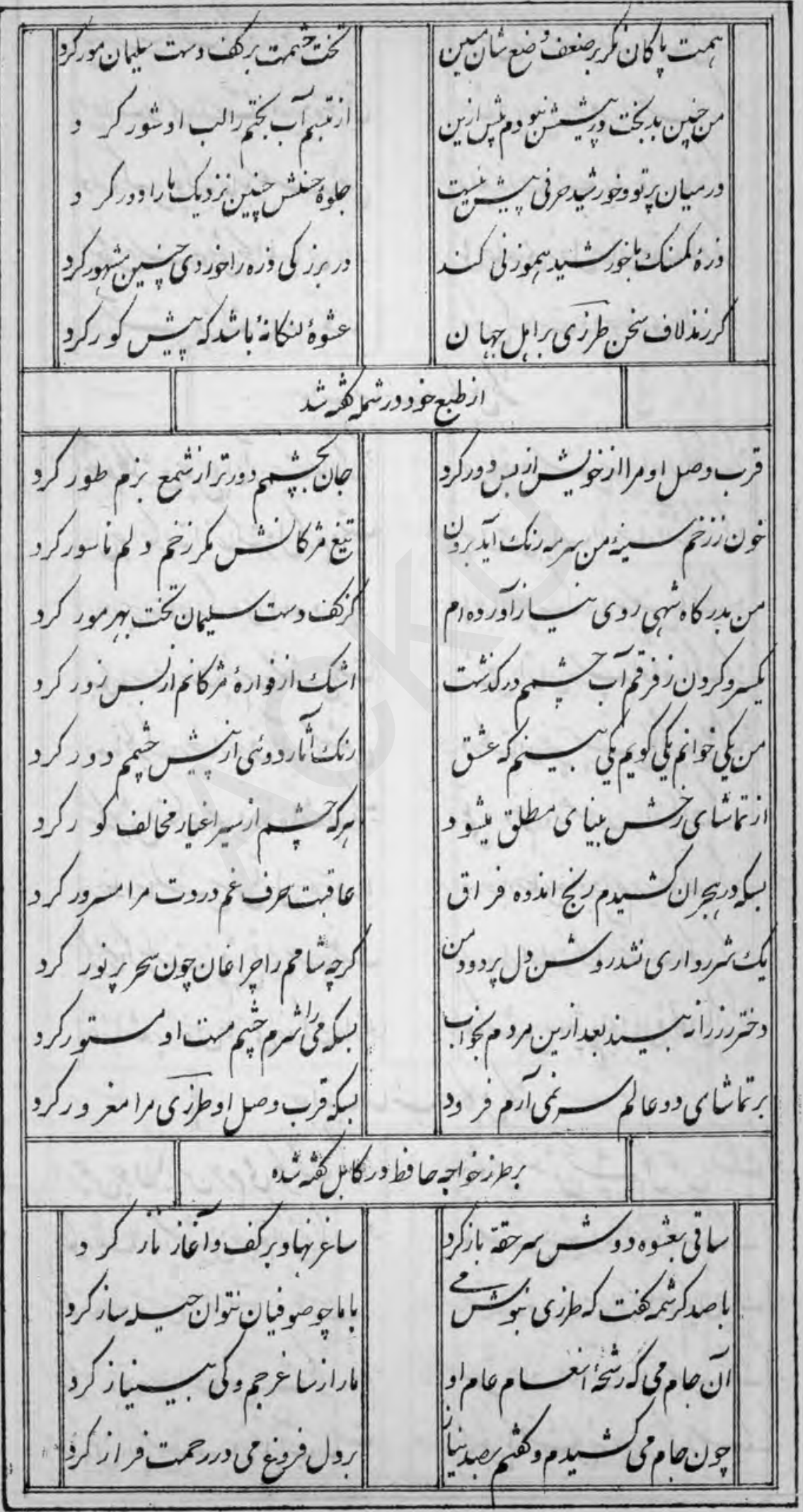


$r y r$

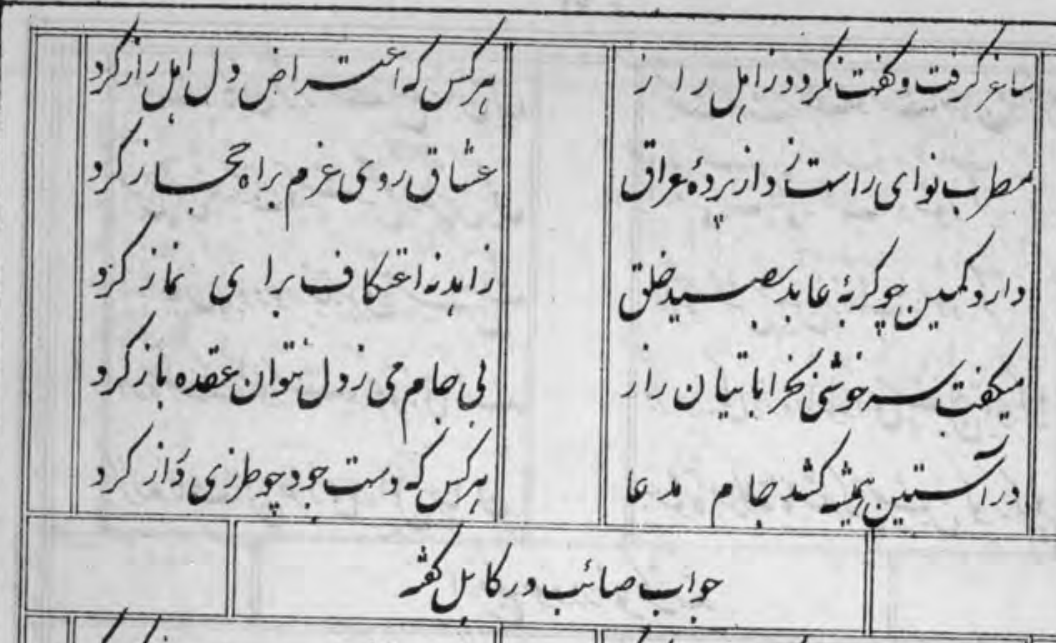

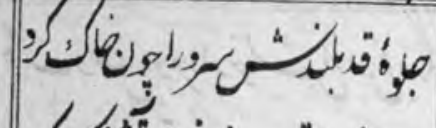

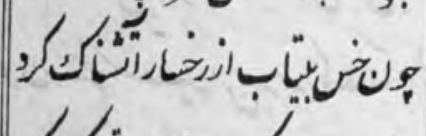

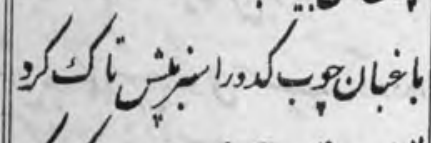

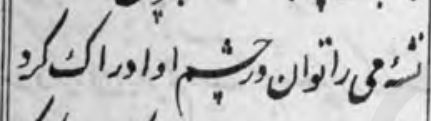

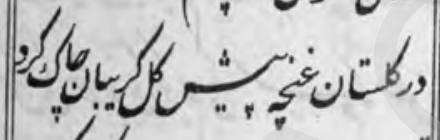

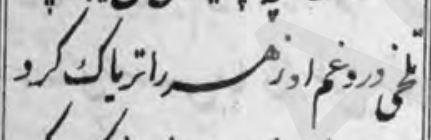
2. .

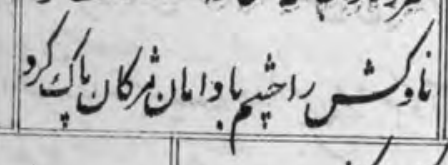

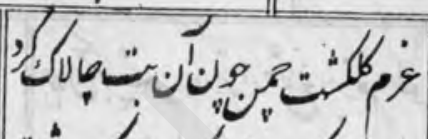

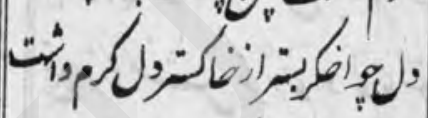

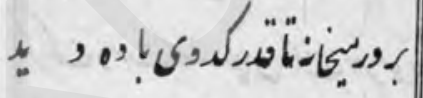

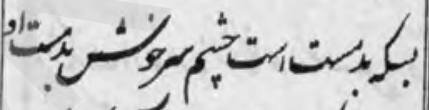

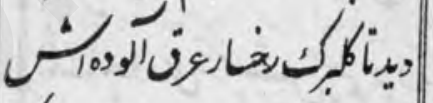
$\checkmark$ _...

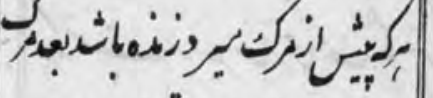

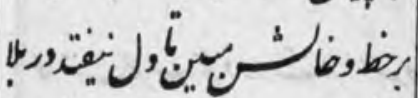

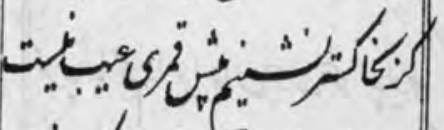
| (i)

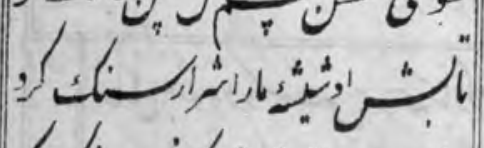

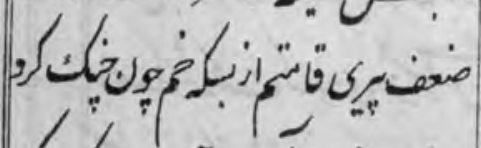
كان

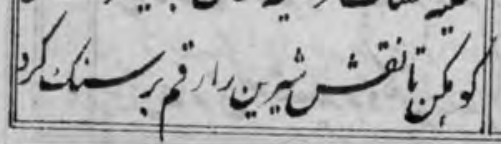
2, بك.

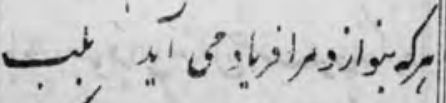

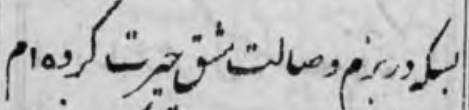

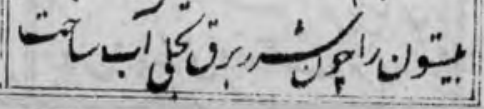




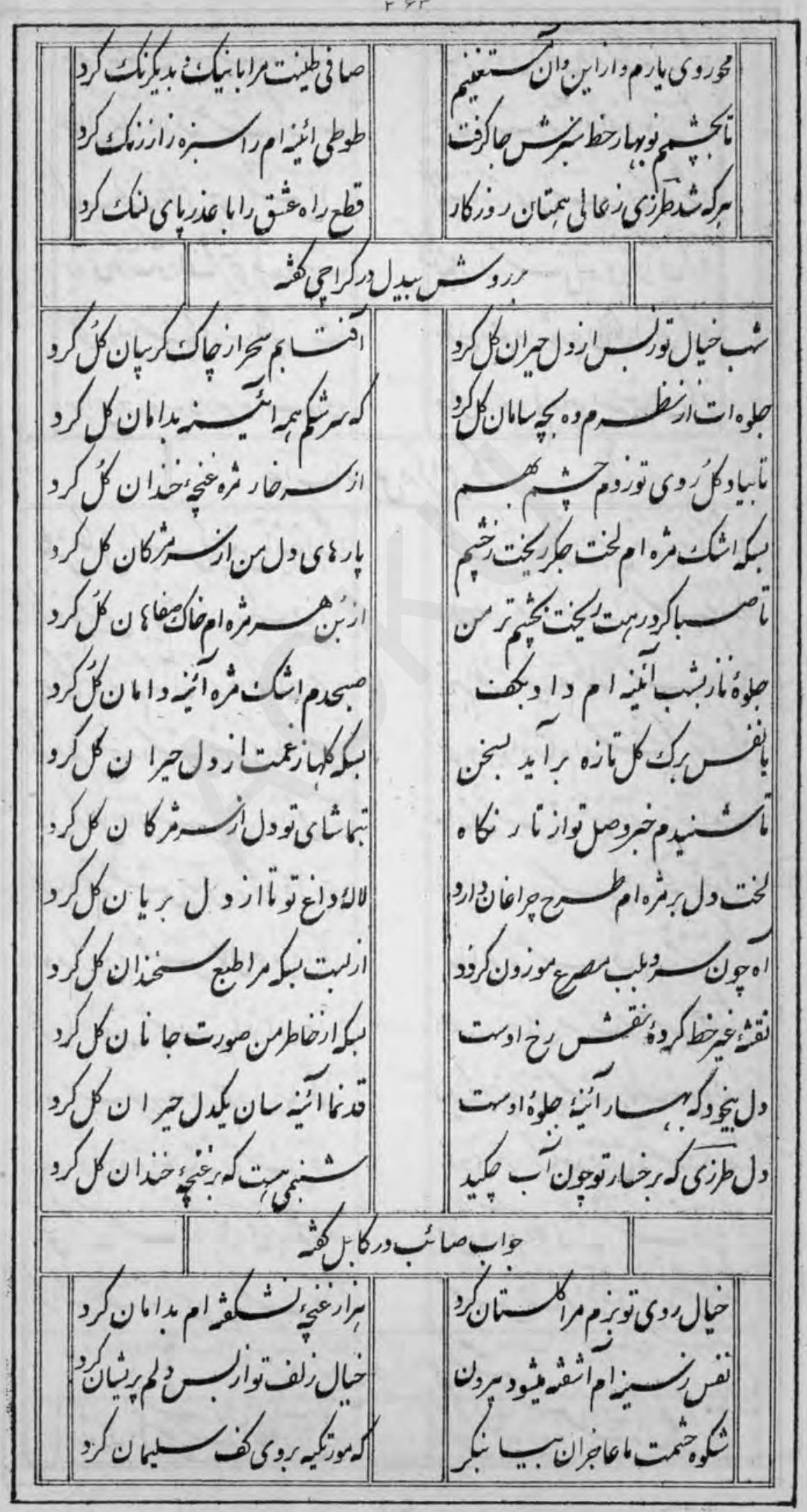




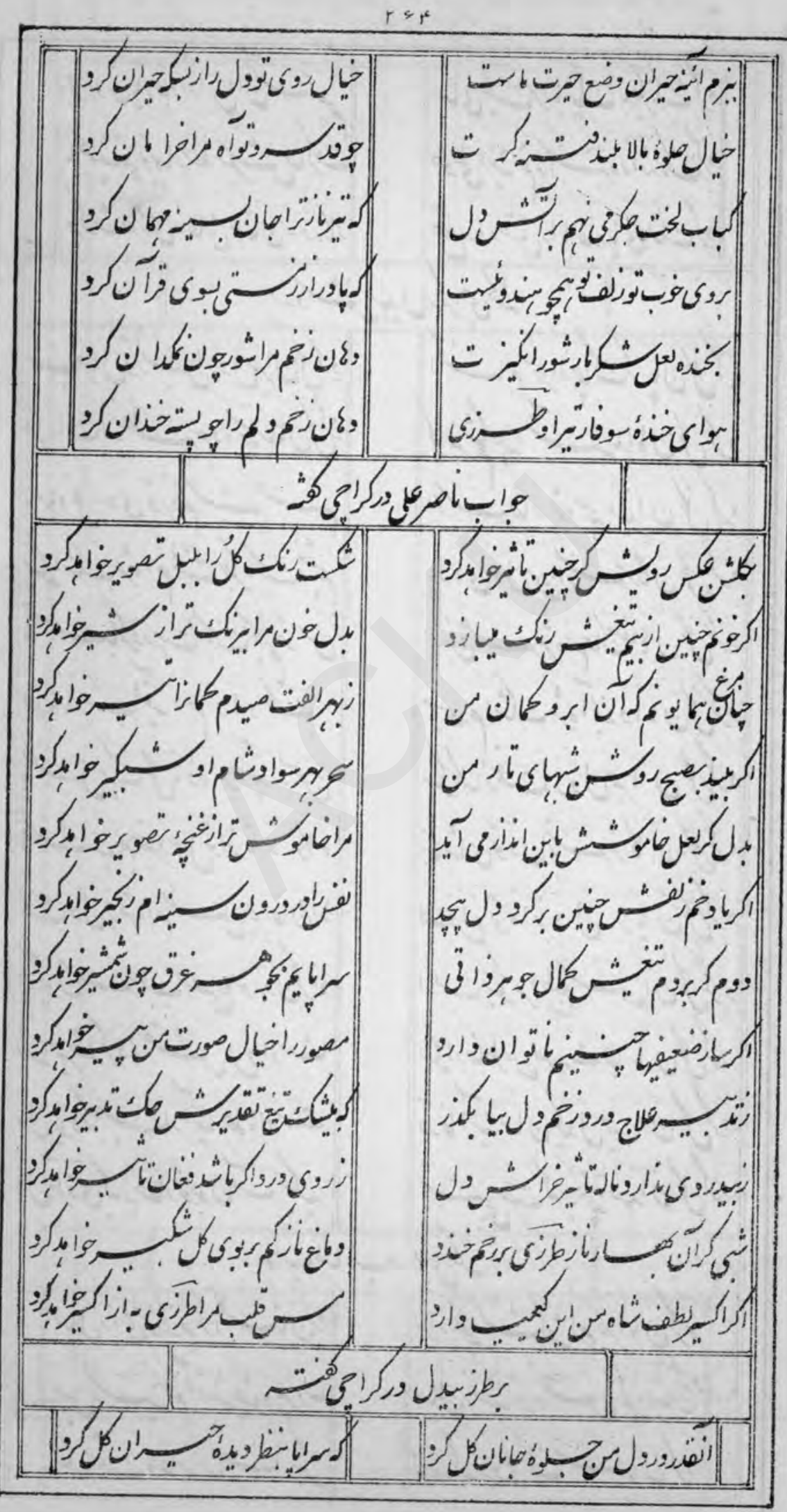


150

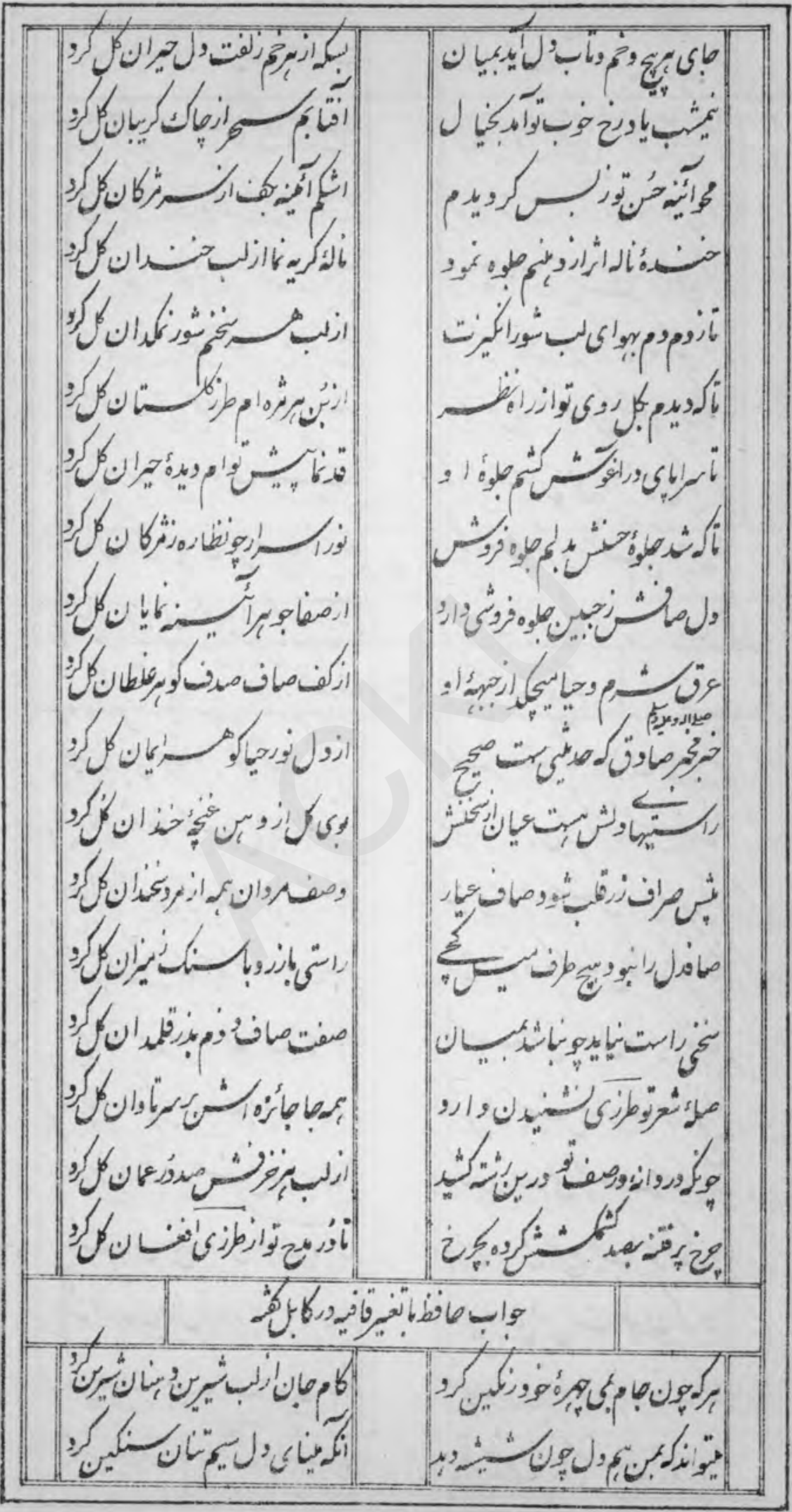


ris

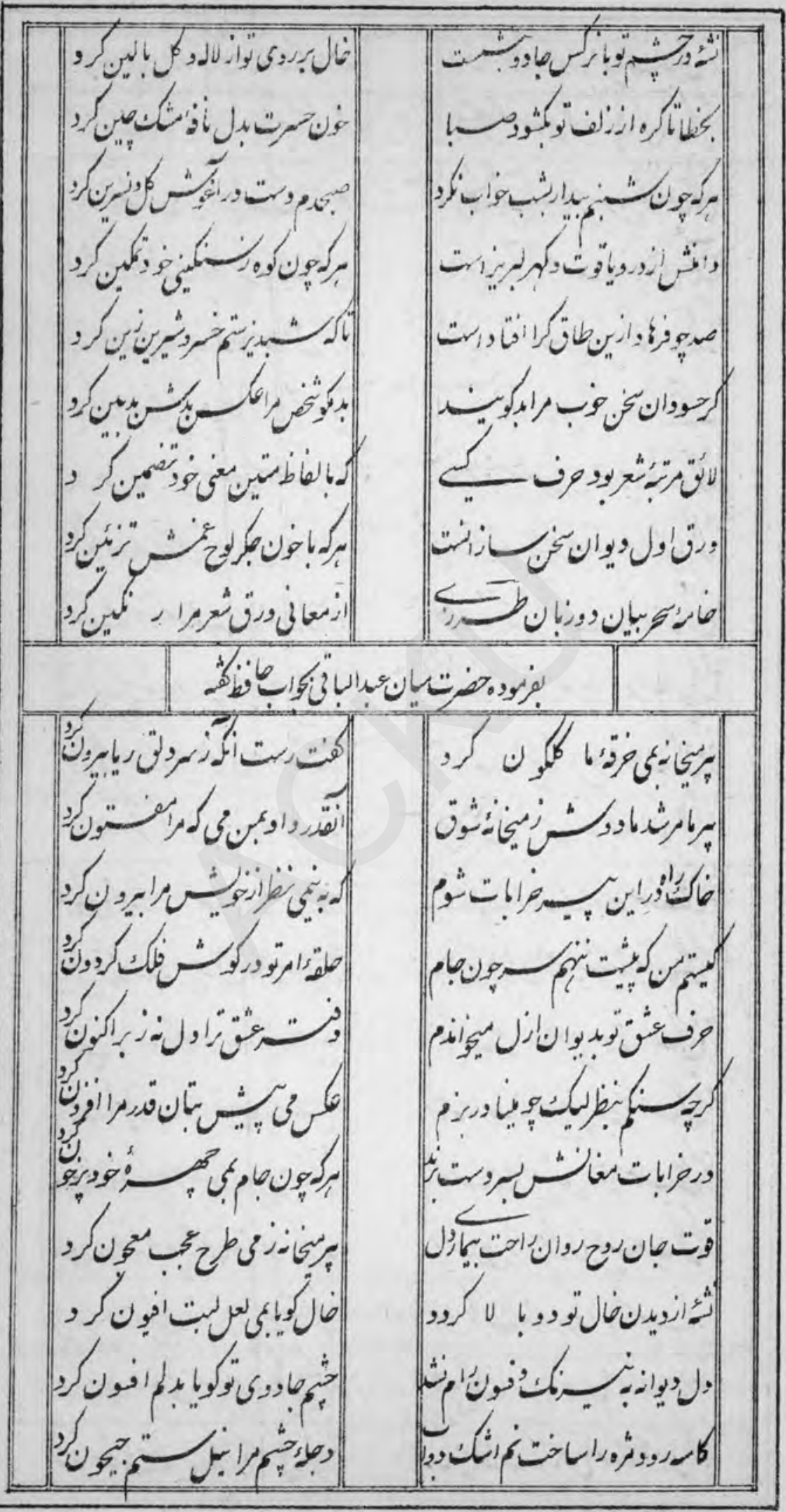




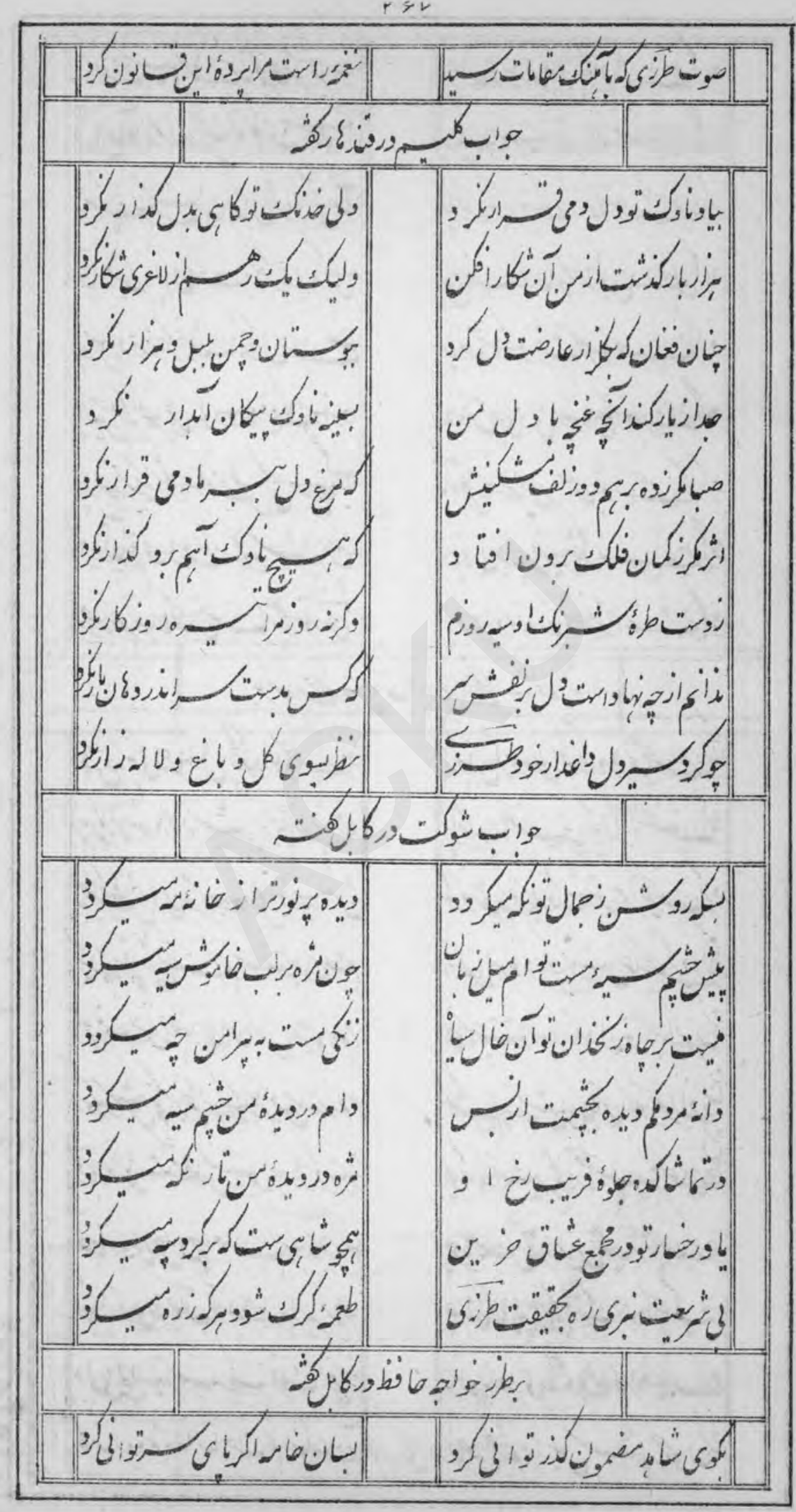


r $4 A$

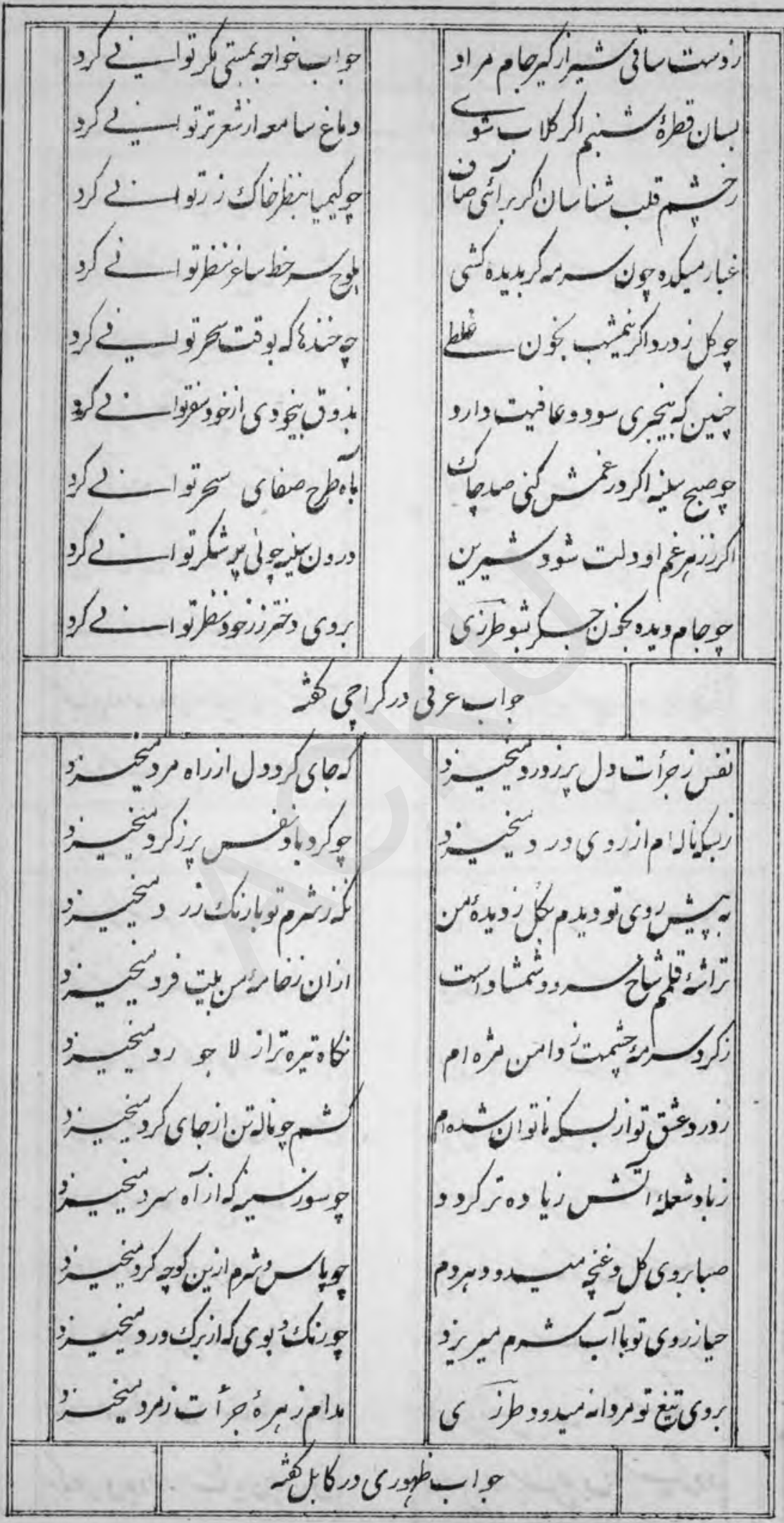

th 


[|


ro.

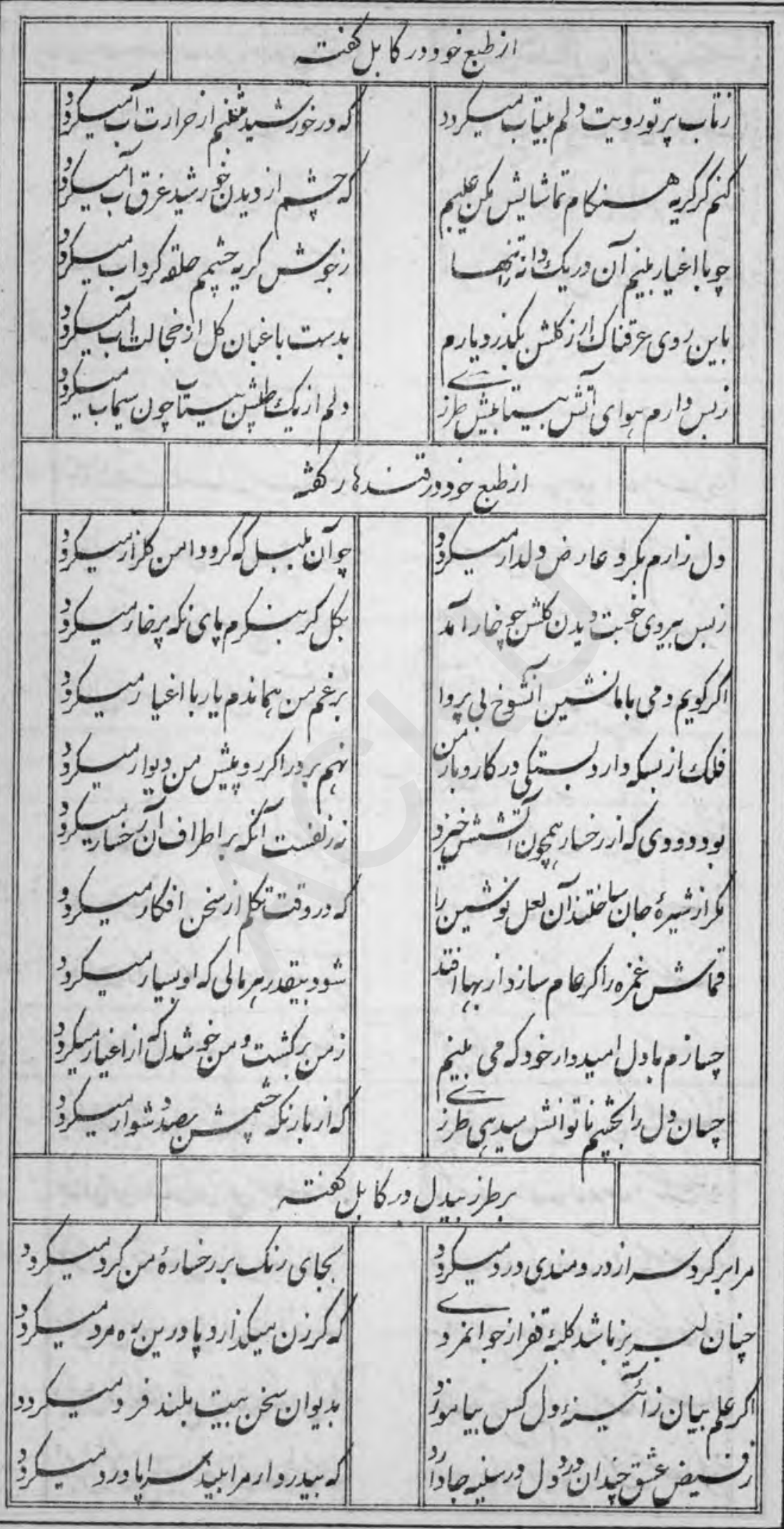

jo. 
roi

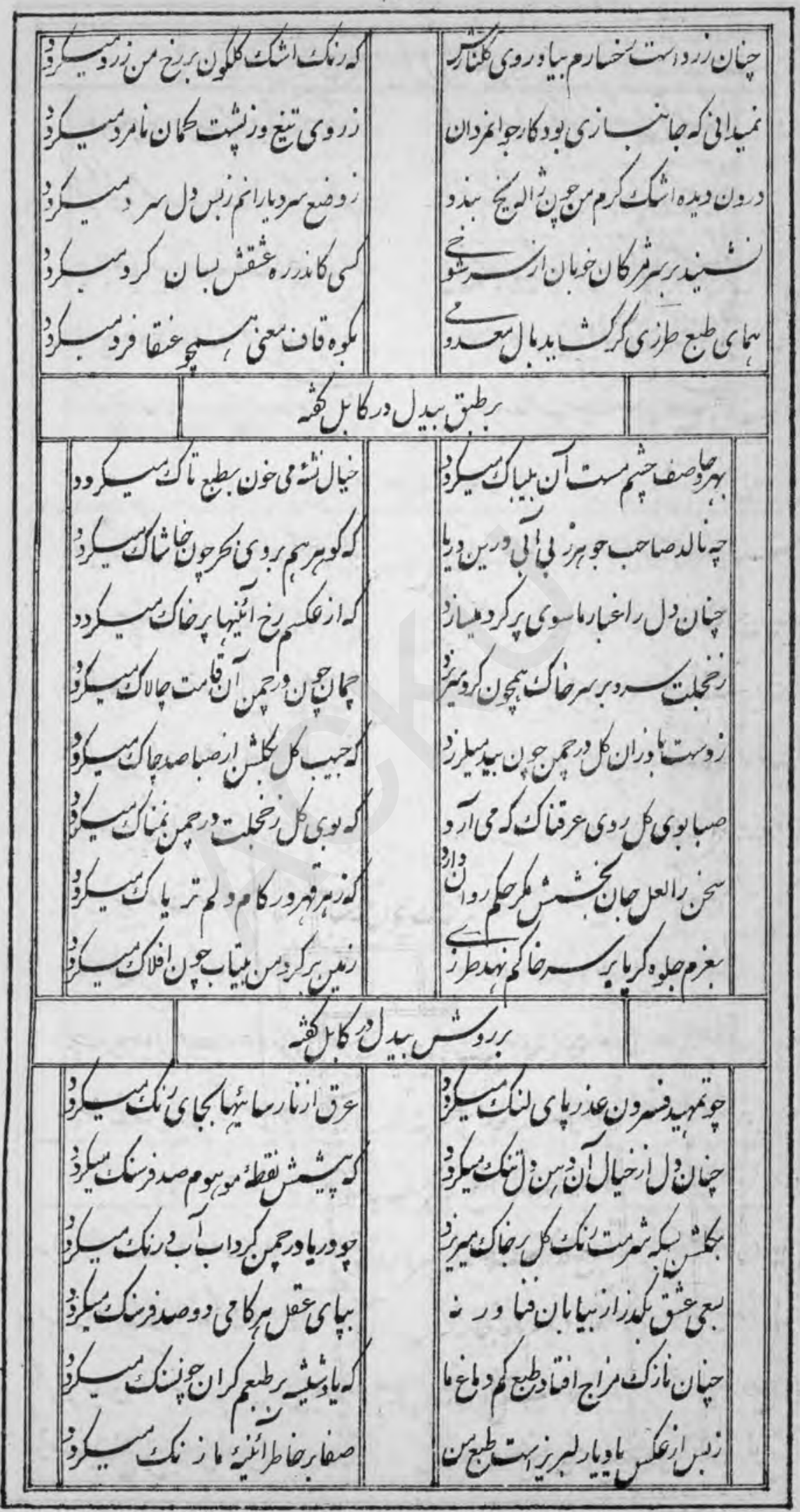


$r レ r$

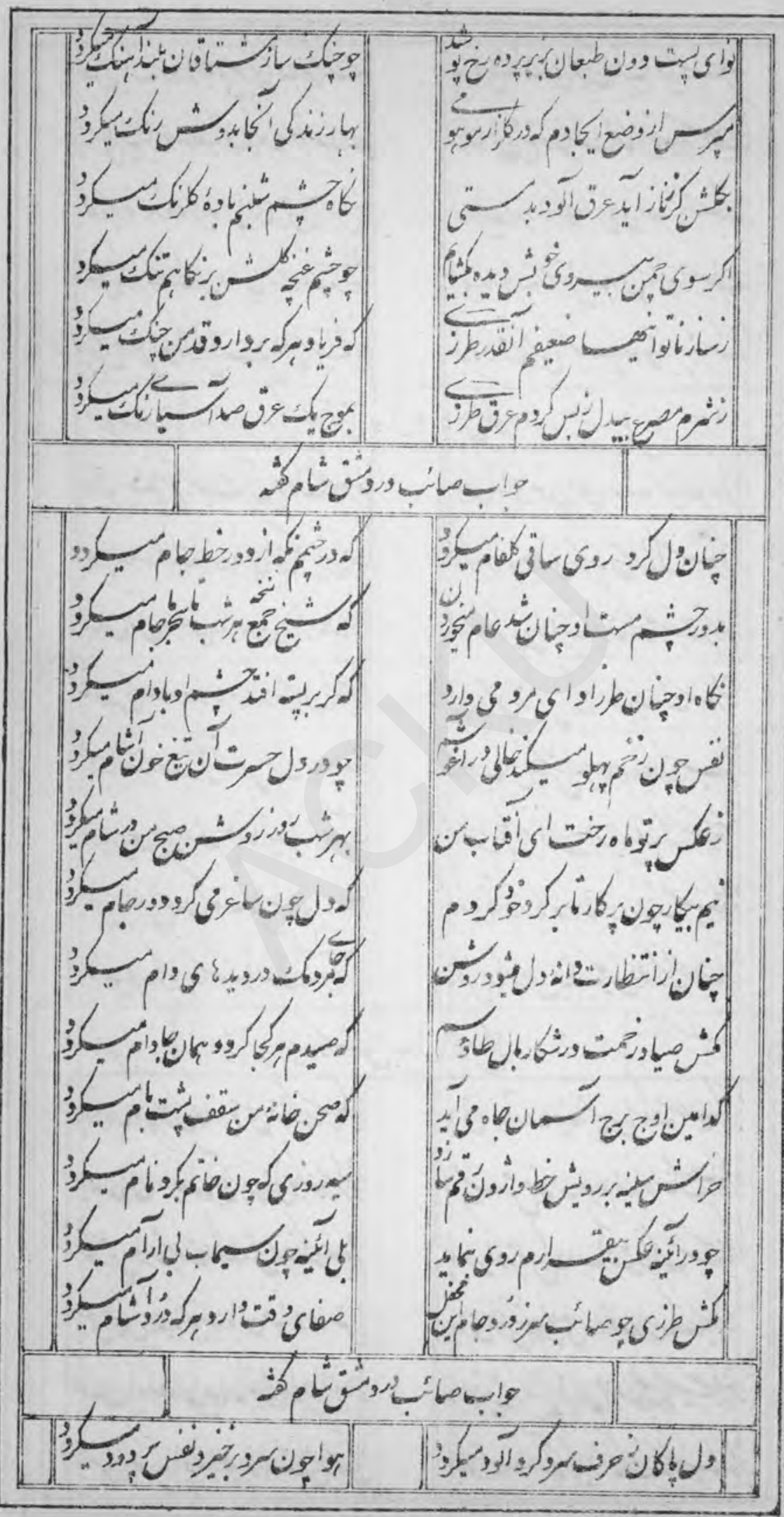

3.36 
$r r r$

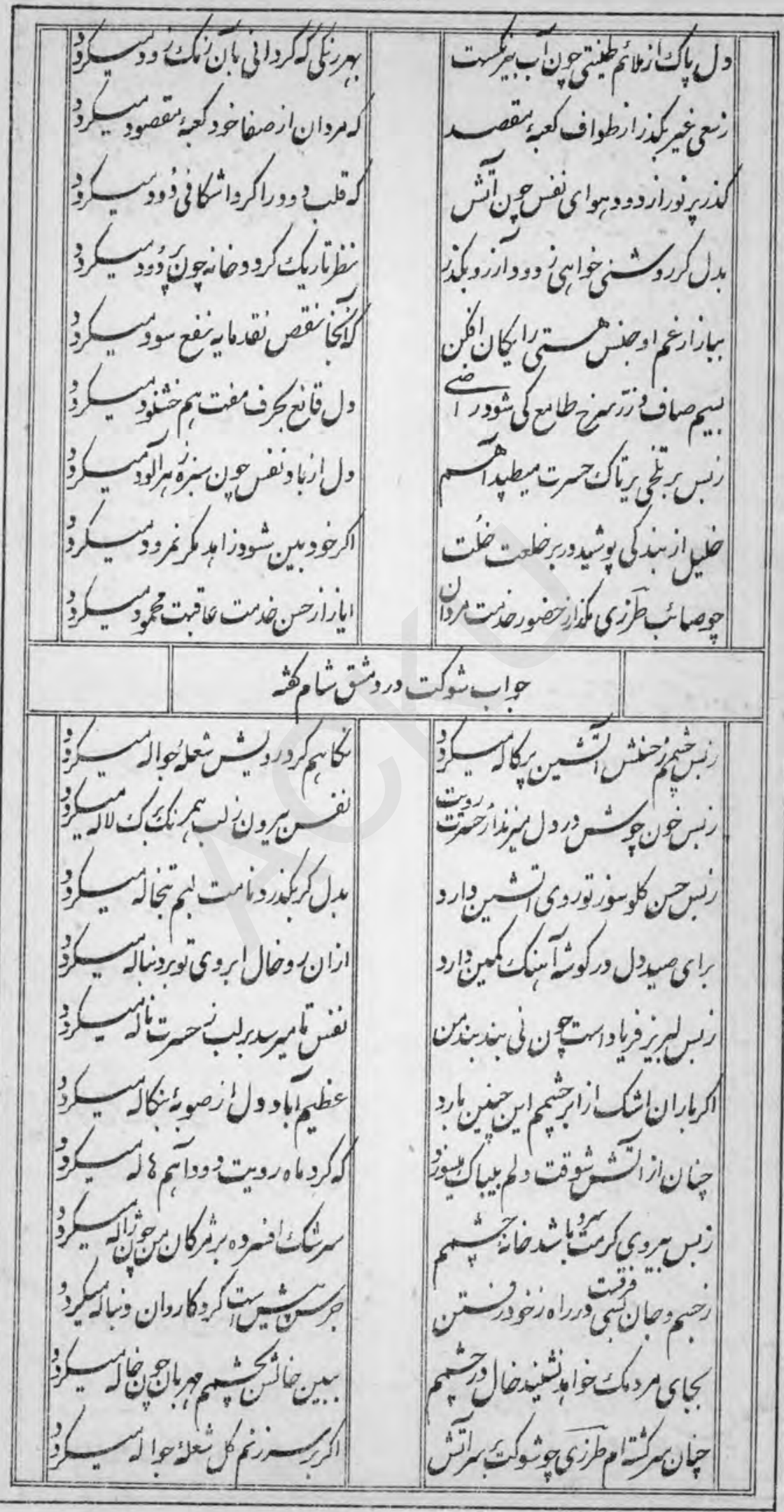


$r<r$

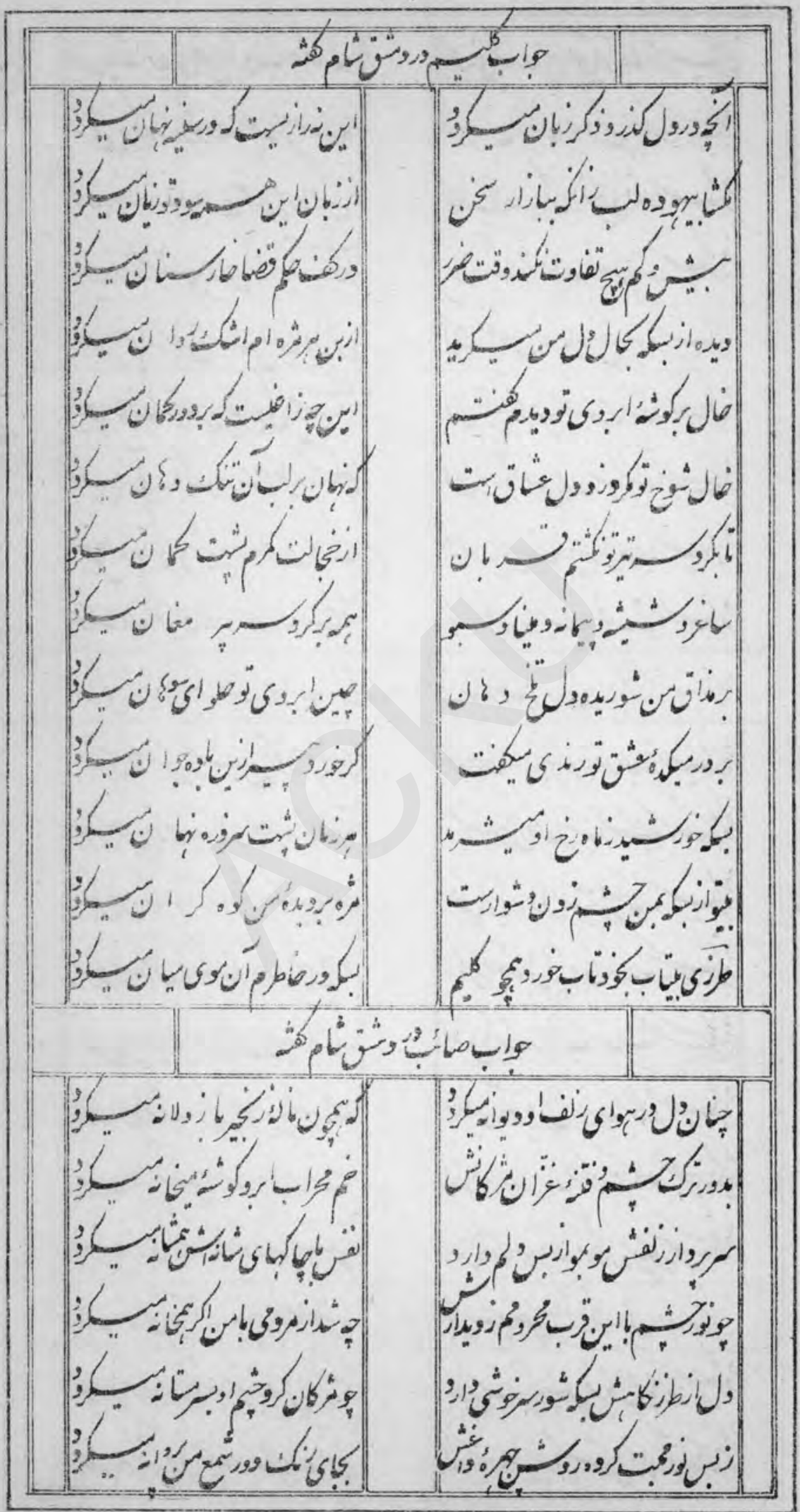


TVA

|


r 5

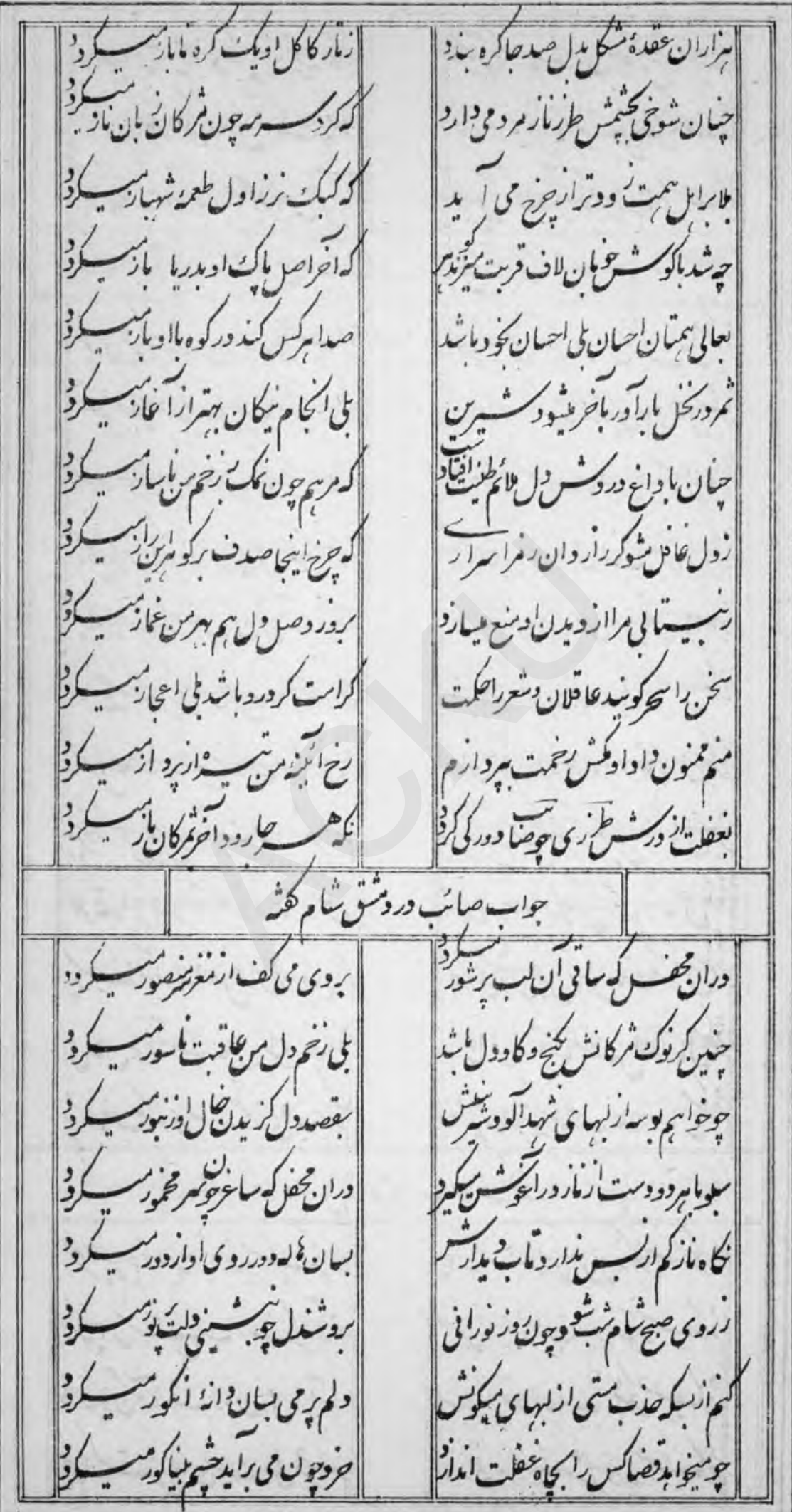




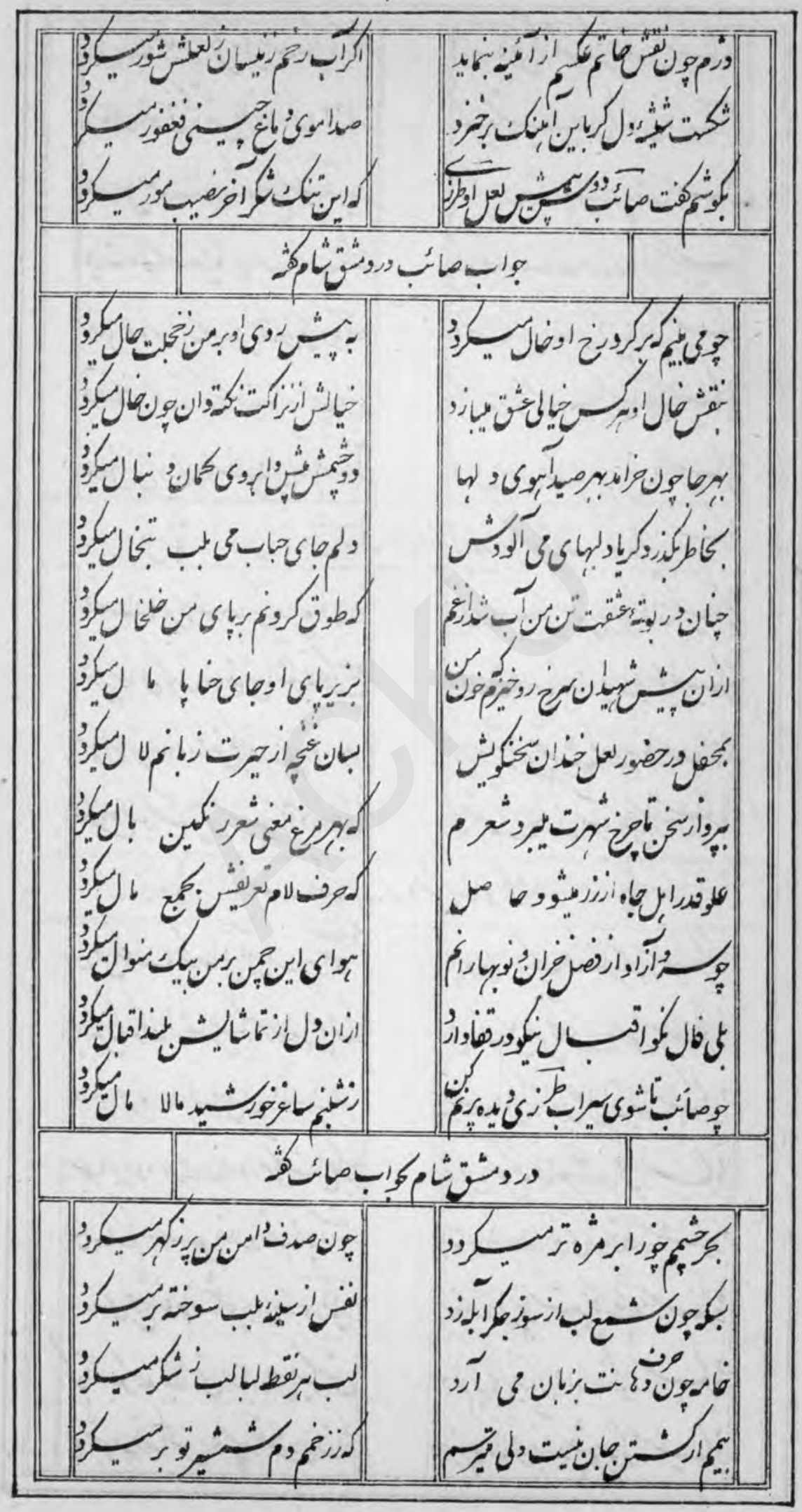


FN

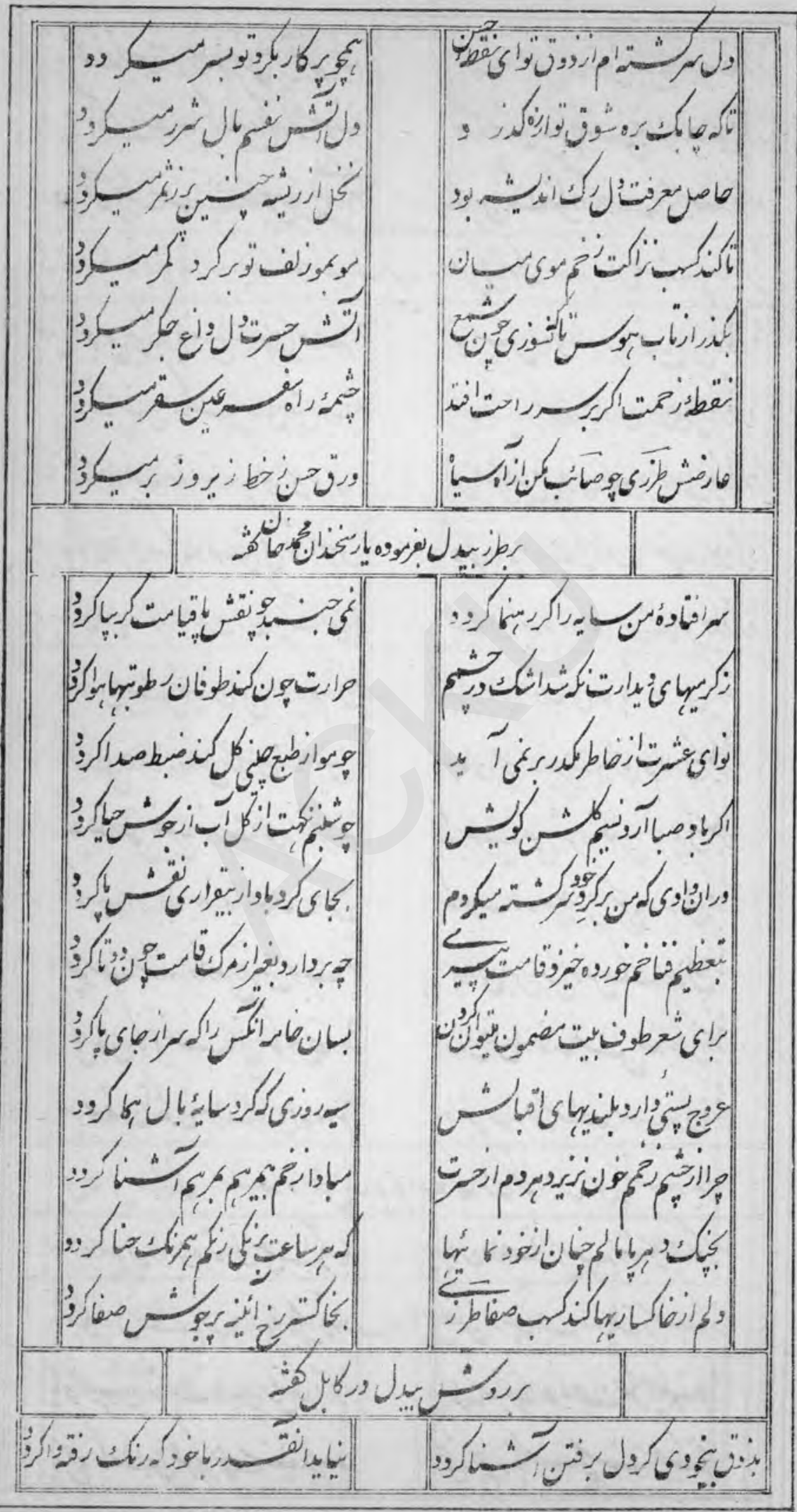


$r \times q$

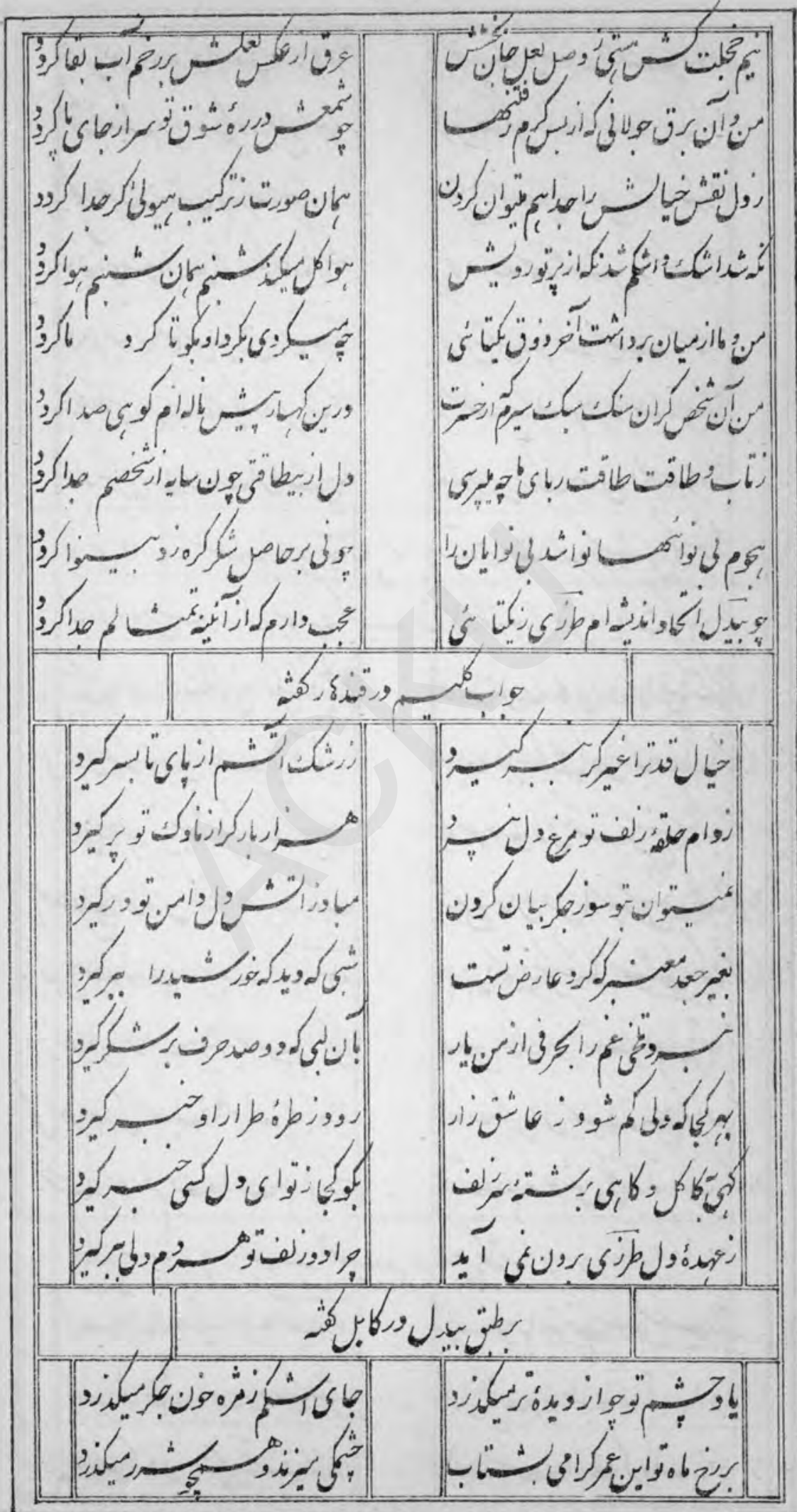


$r \wedge$.

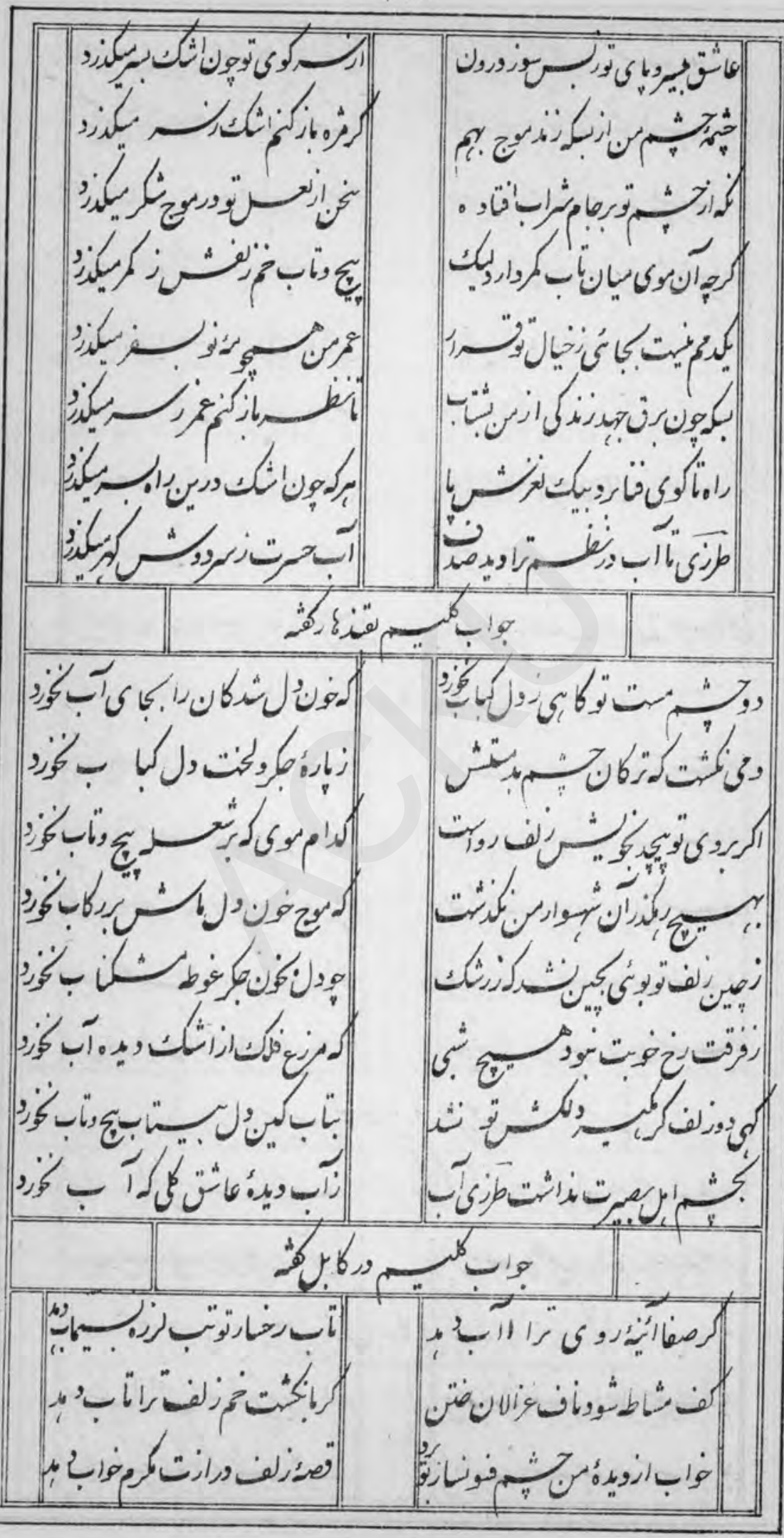


$r \wedge i$

|


$P \wedge r$

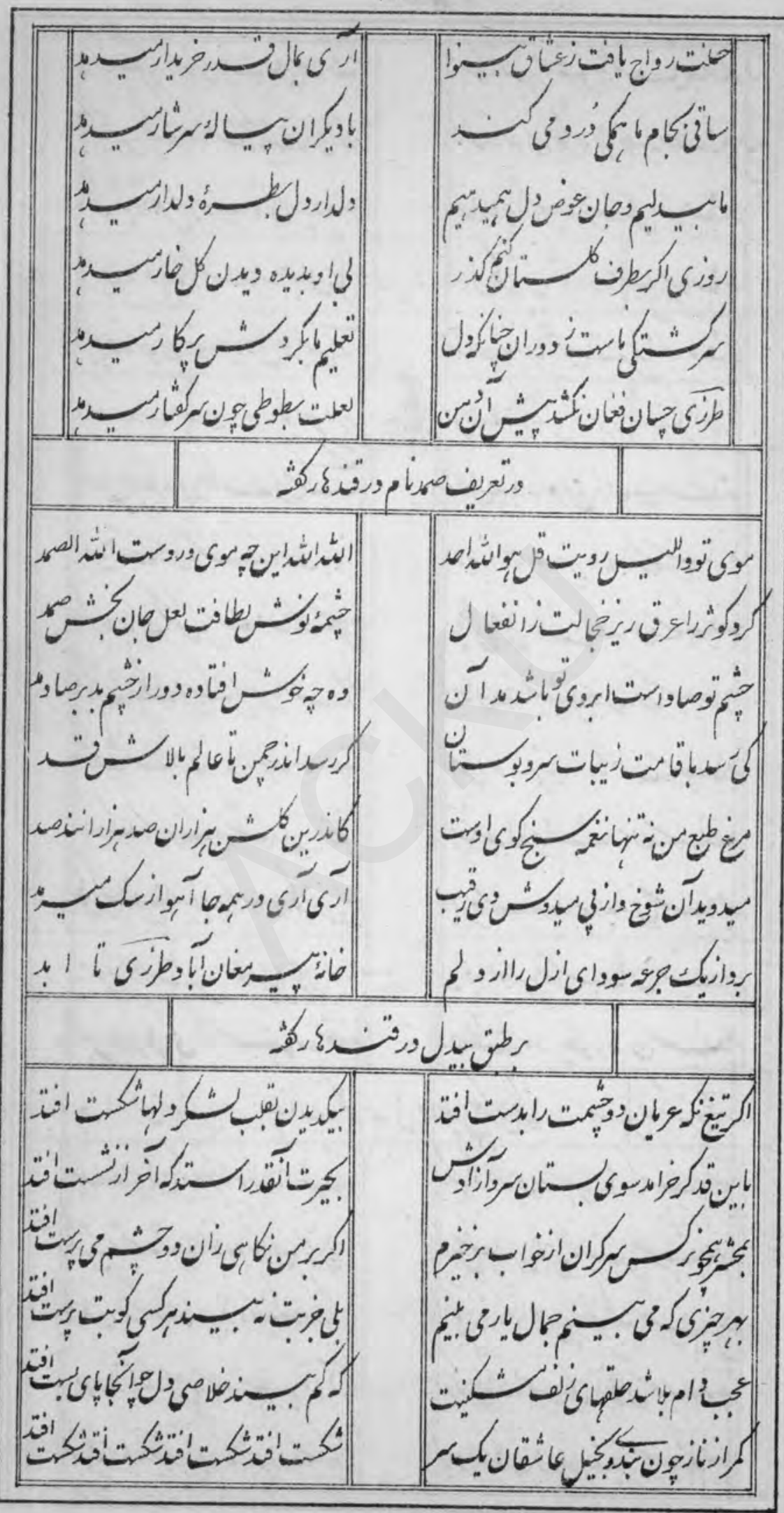

u. 
$r \wedge r$

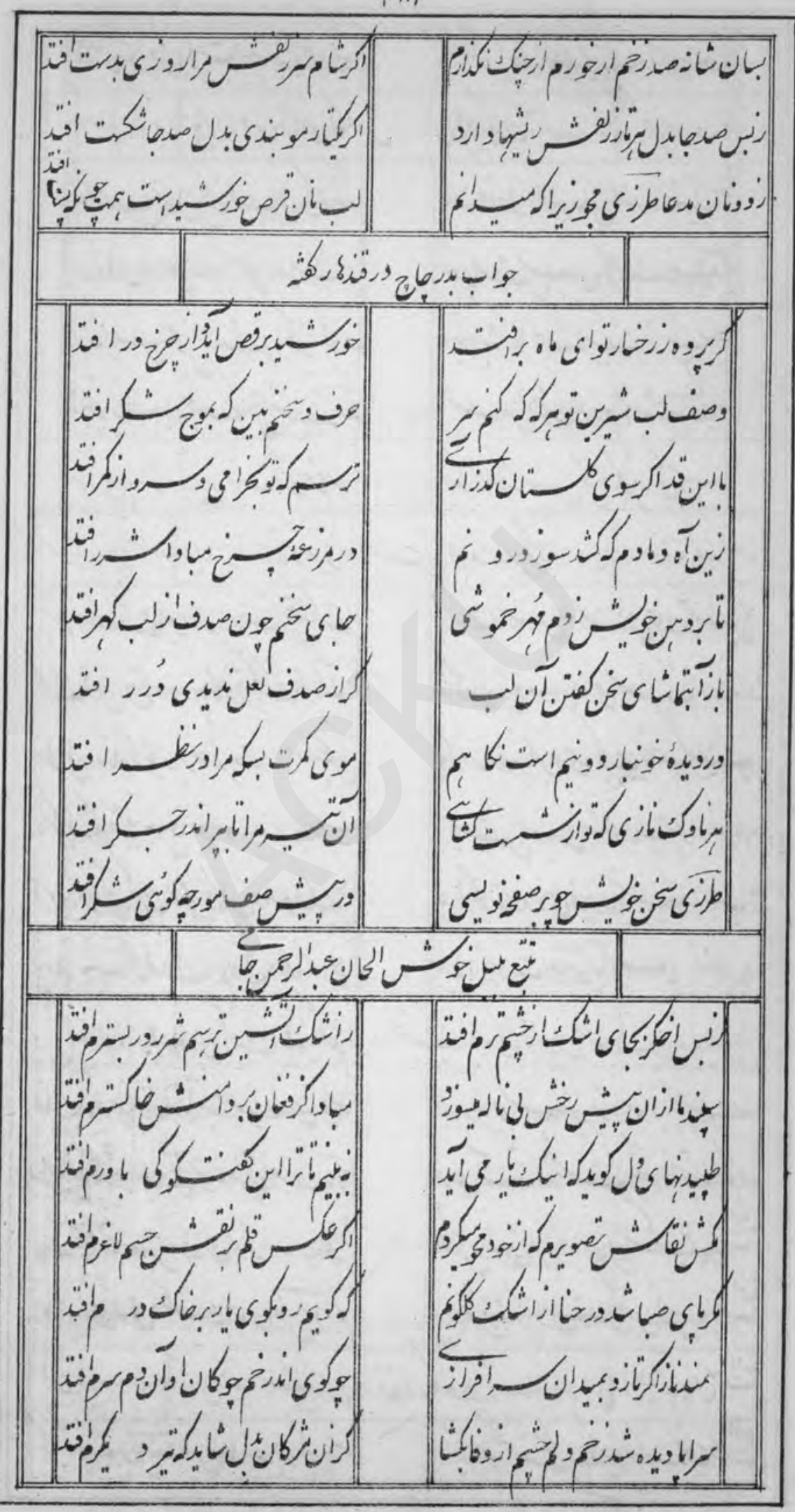


$r \wedge r$

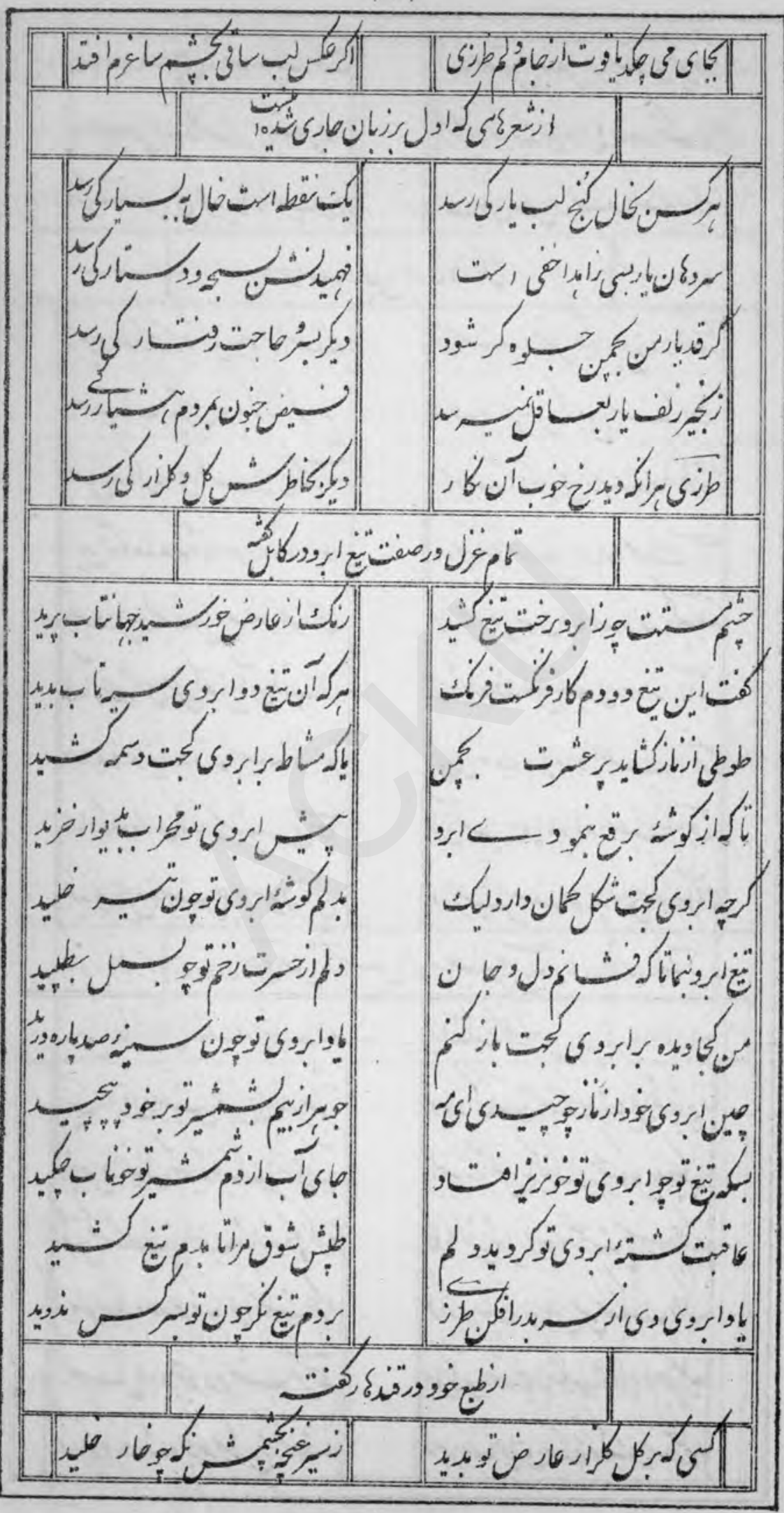

;y 


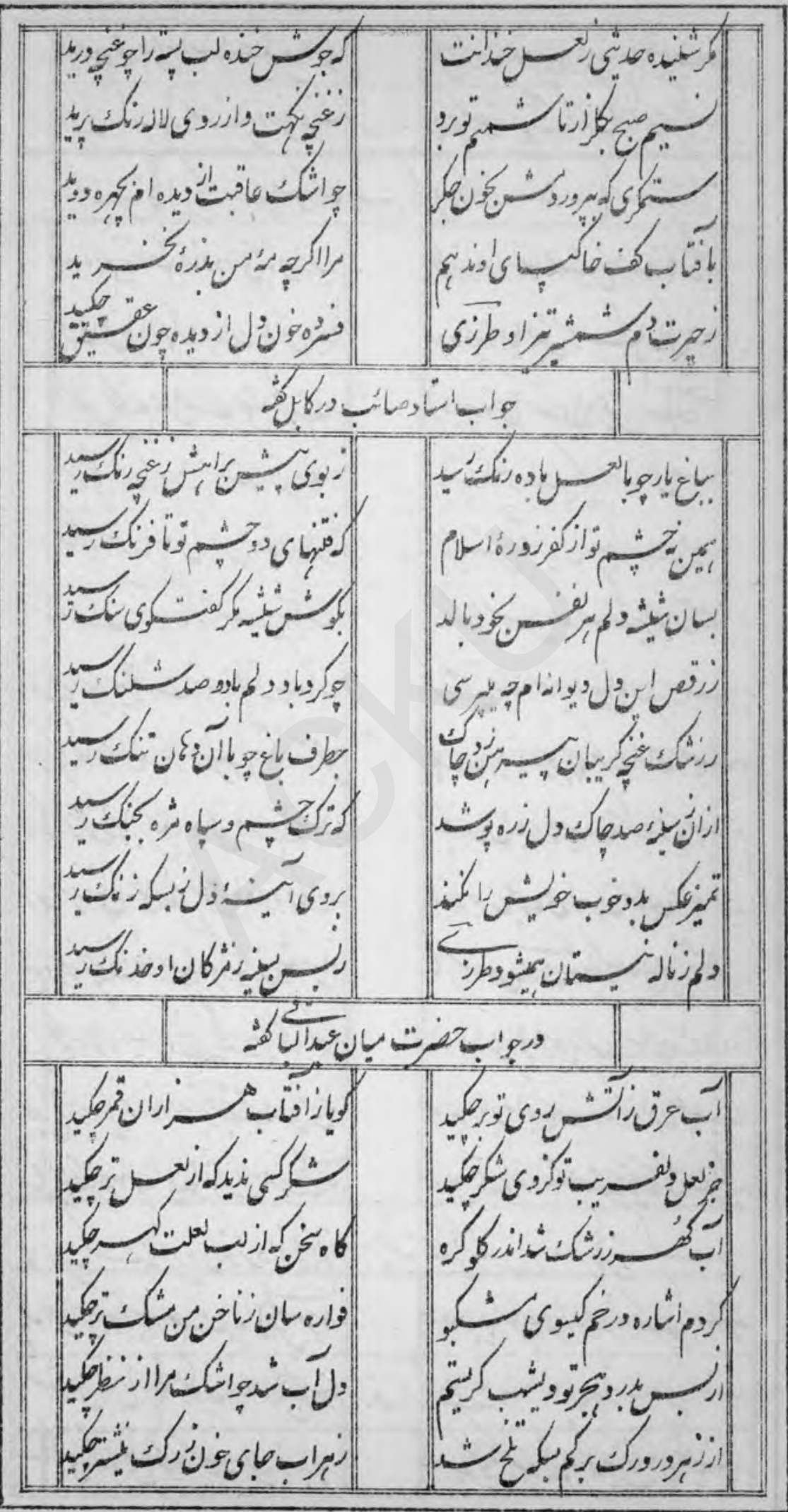


$r A G$

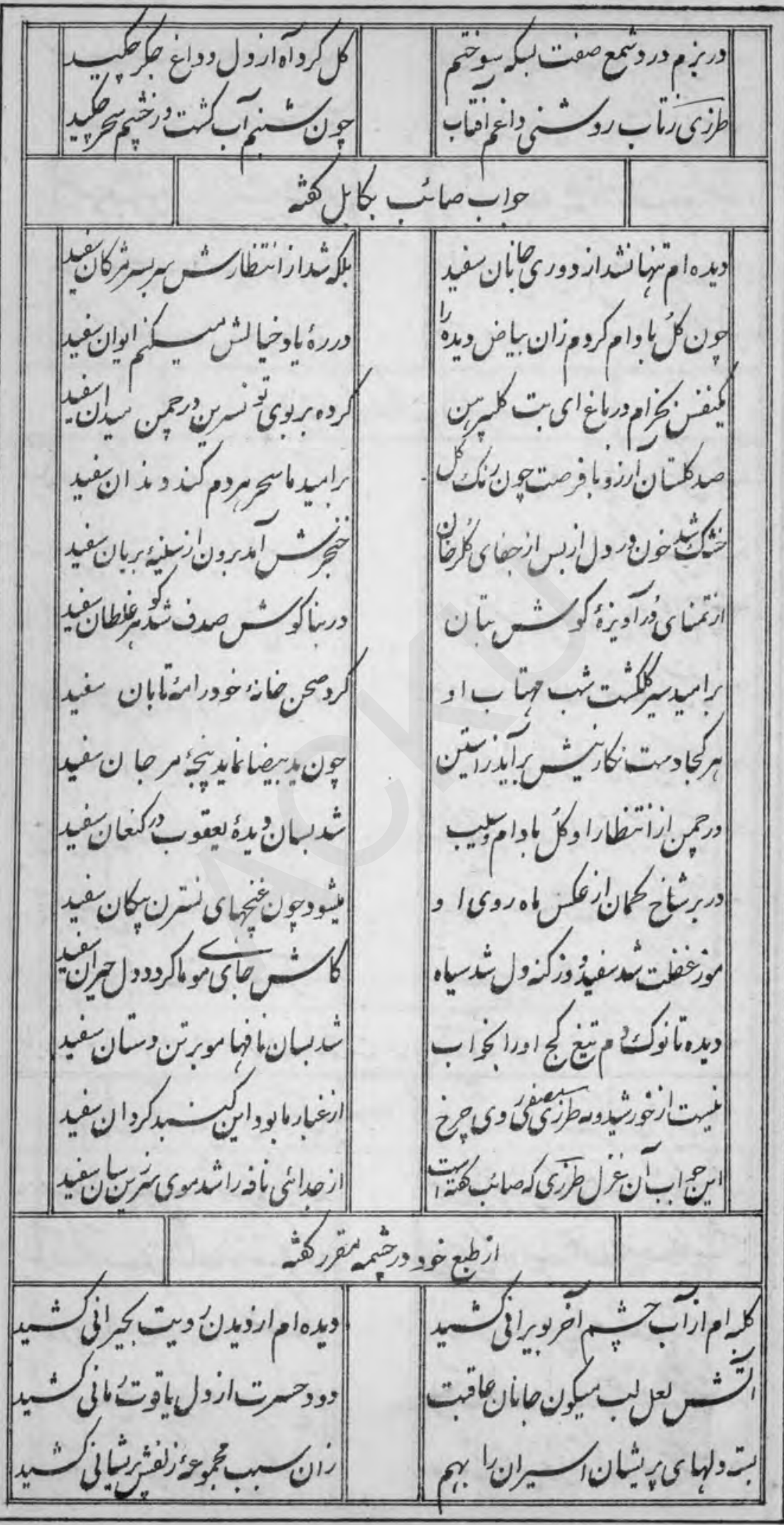


rAr

|


YA

|


$r \wedge 4$

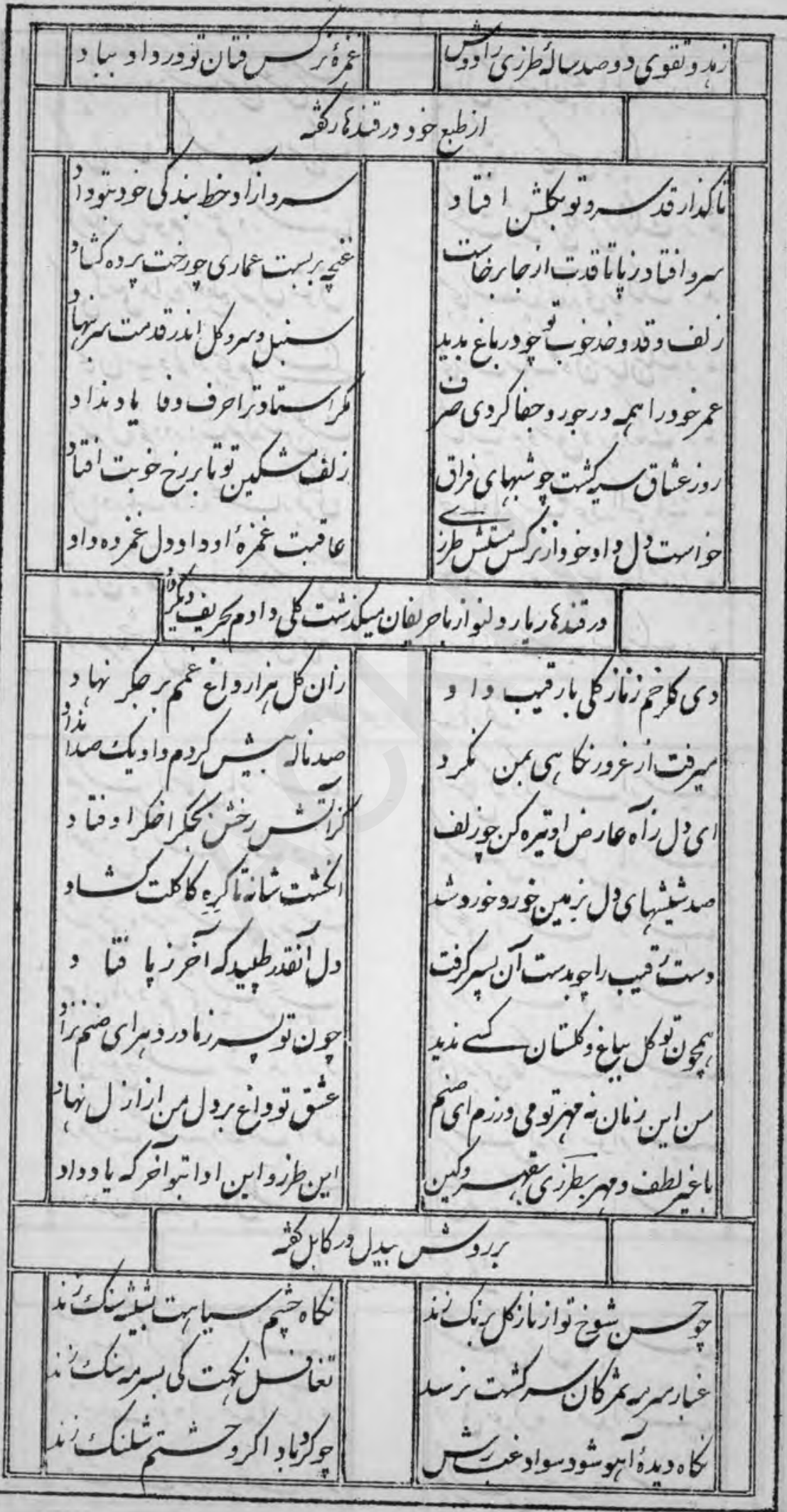


r.

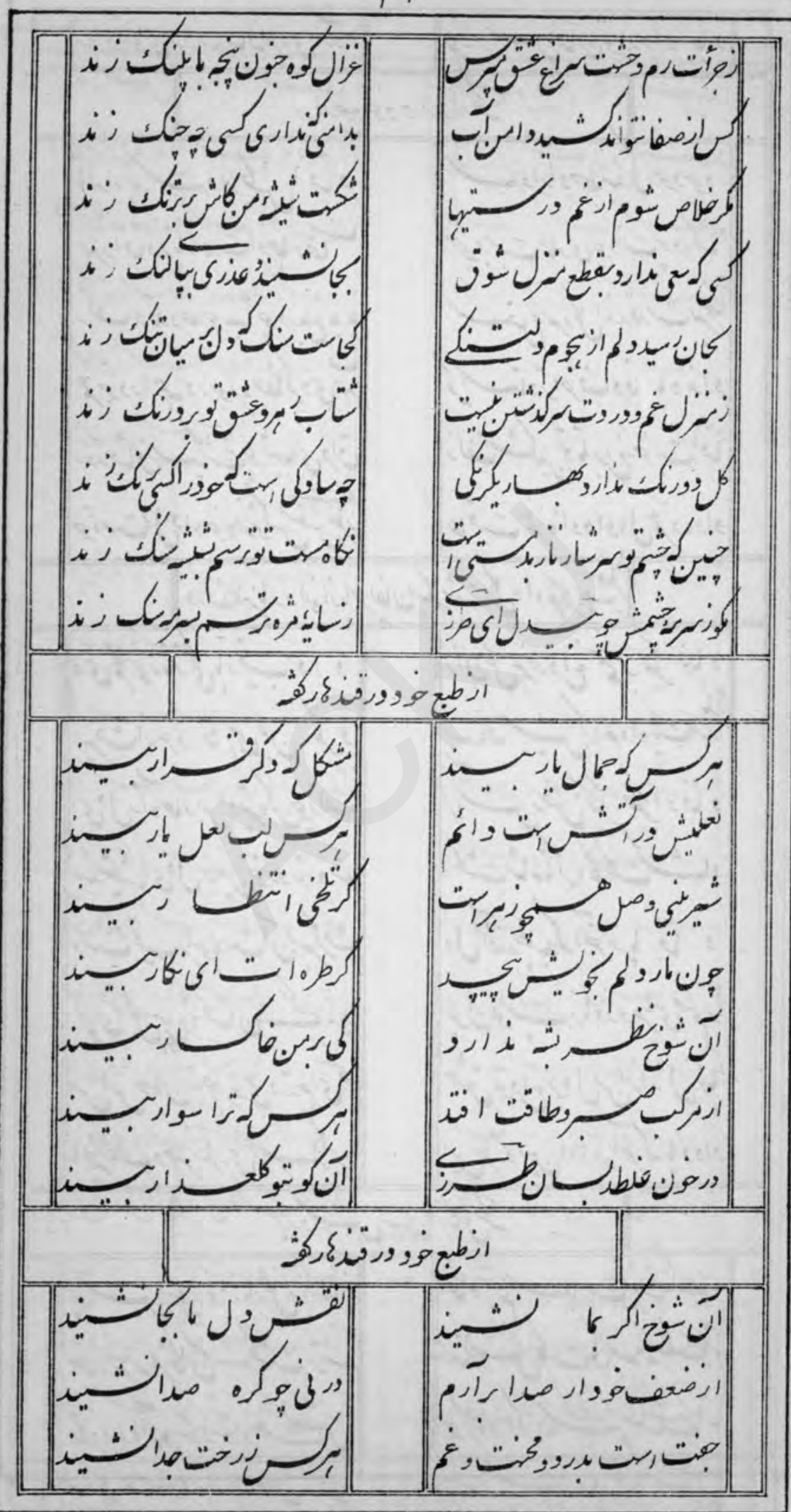


F 91

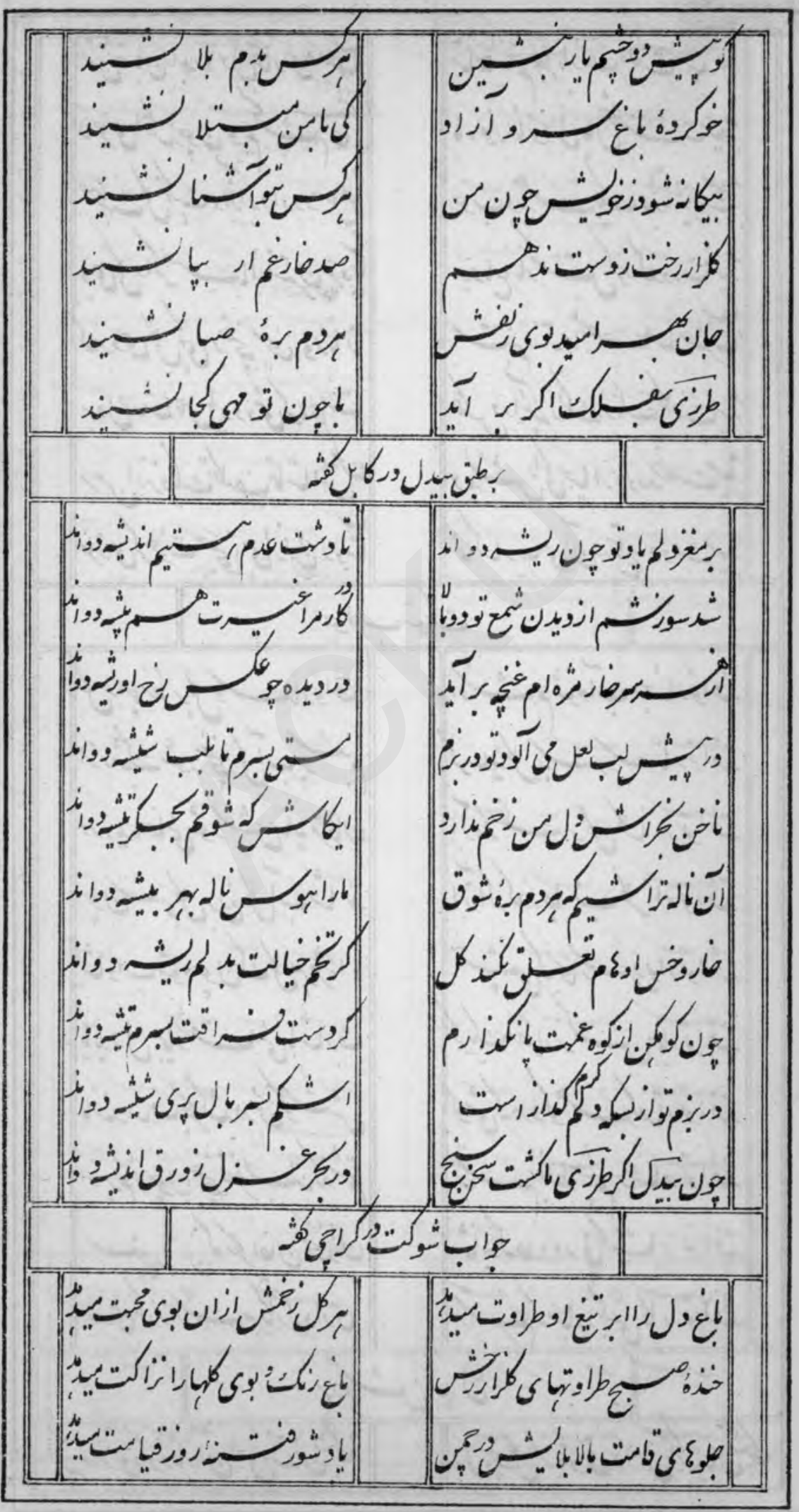


rar

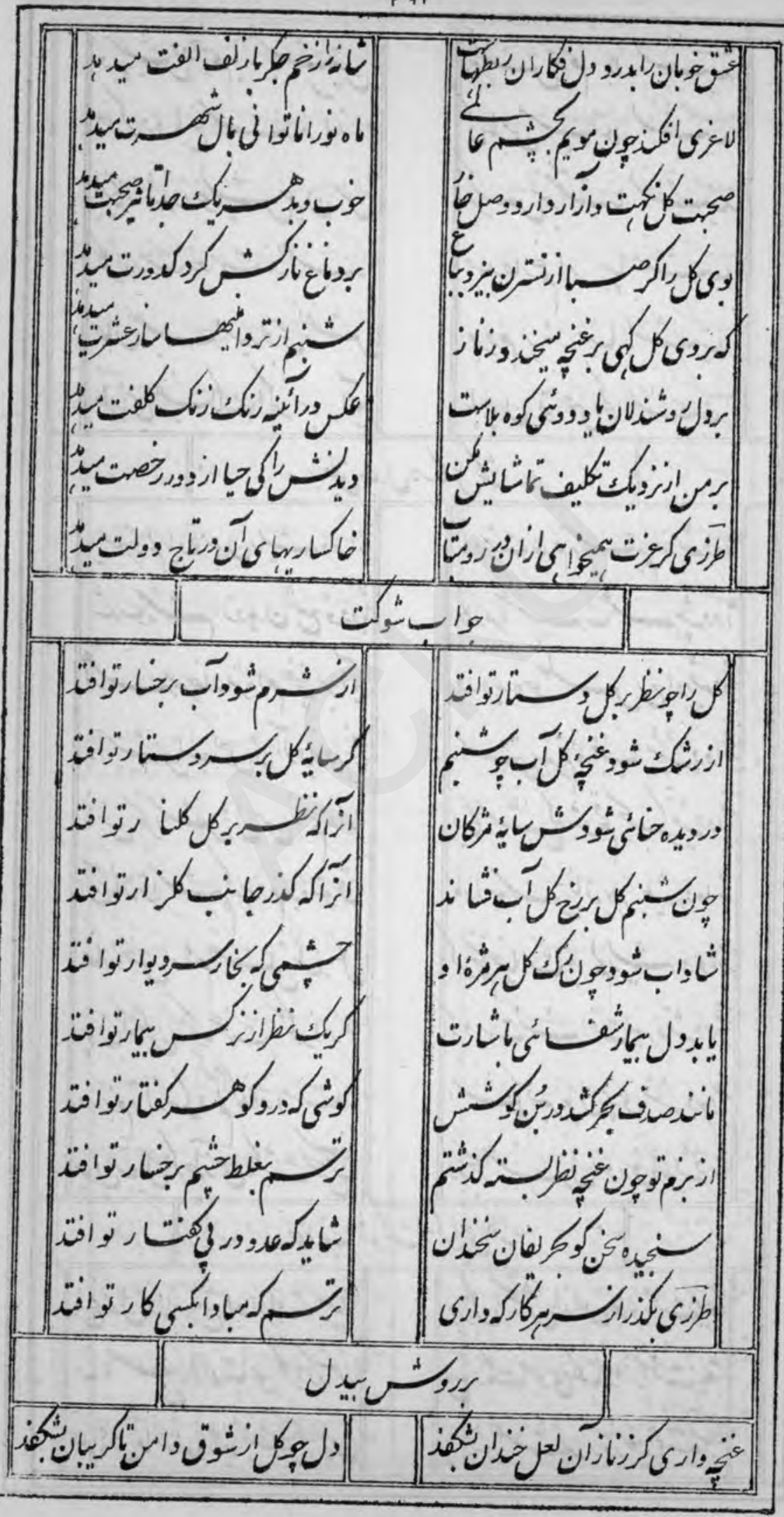


$r 4 r$

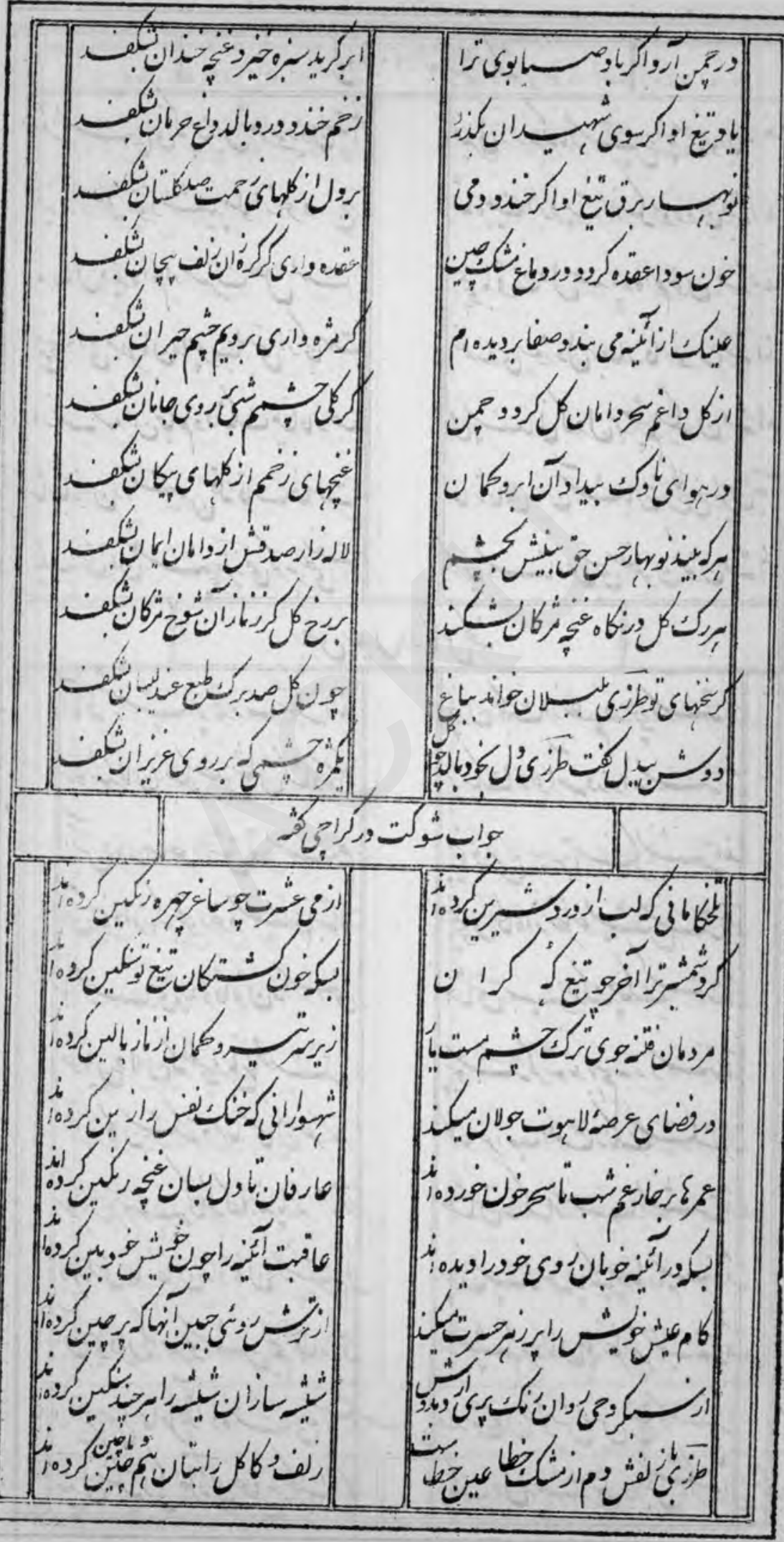


r 95

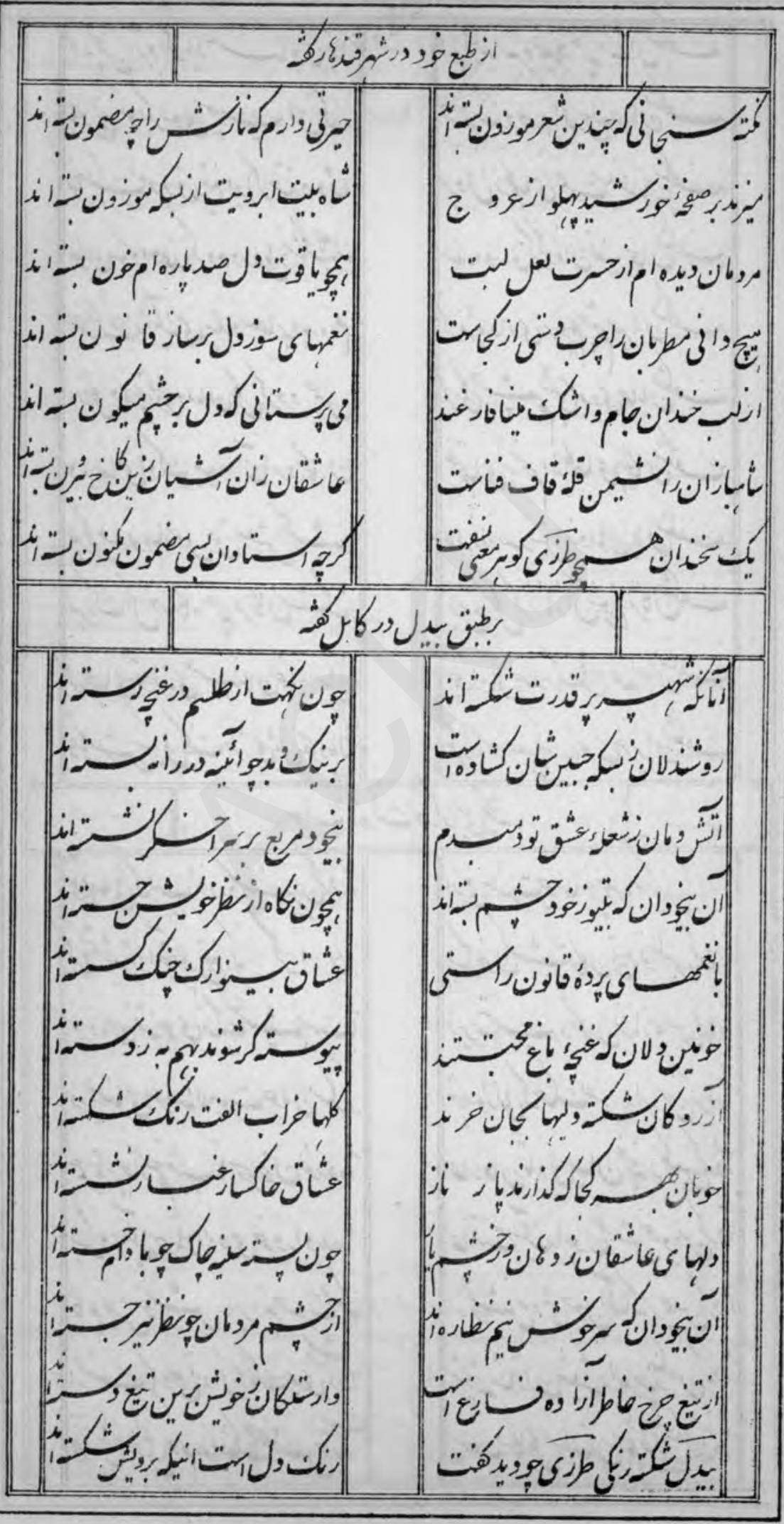


40

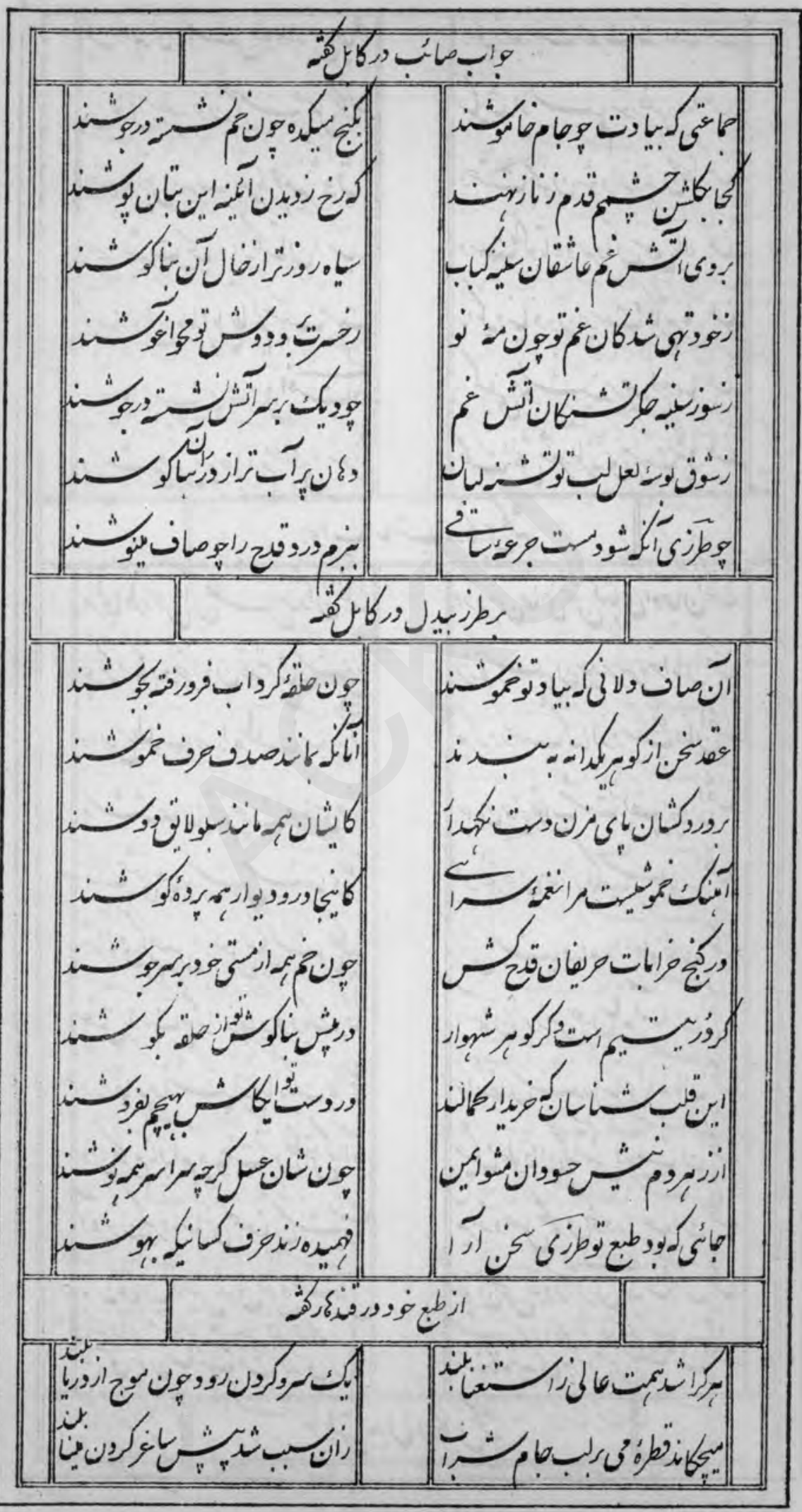


$r^{9}=$

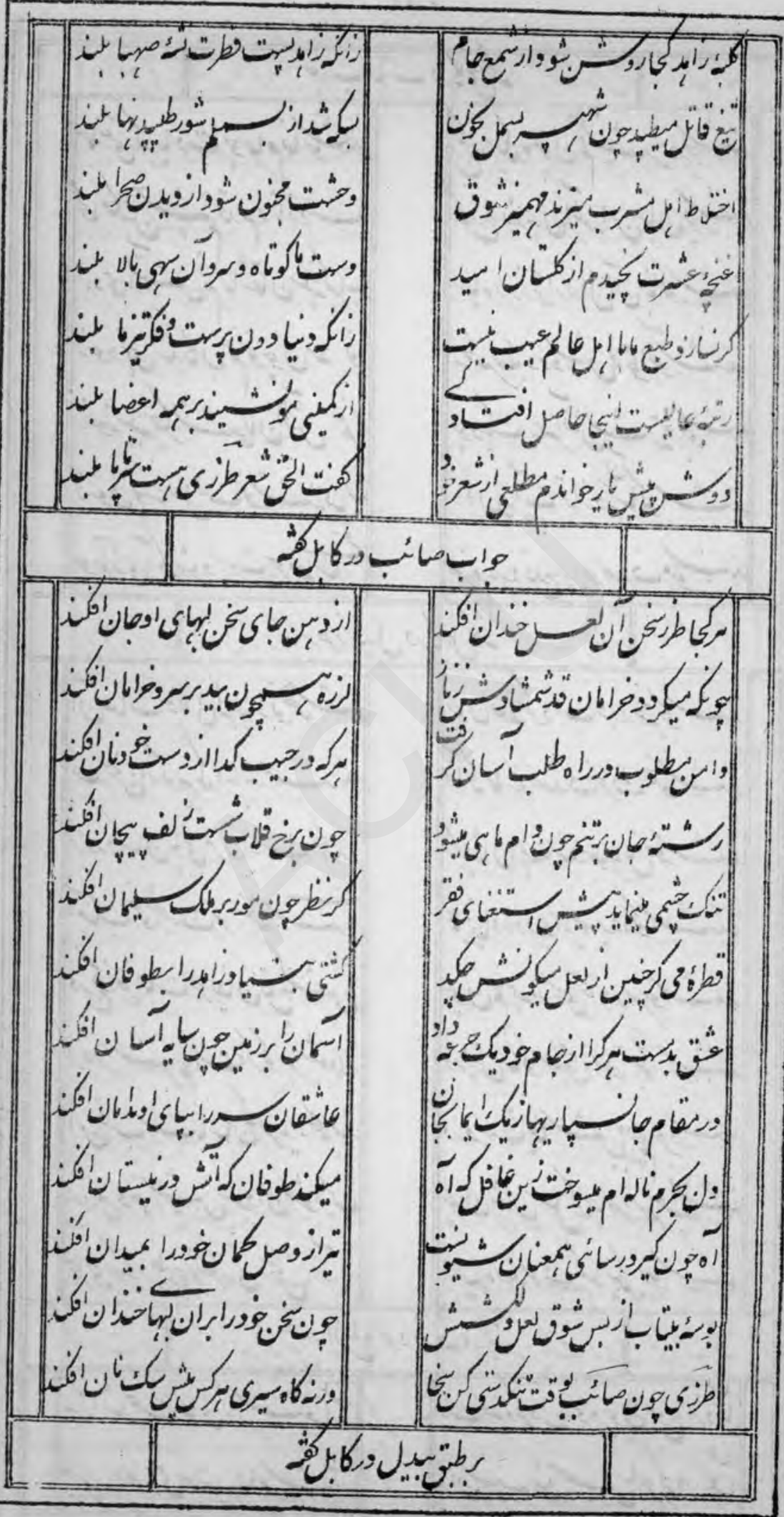


r $4 r$

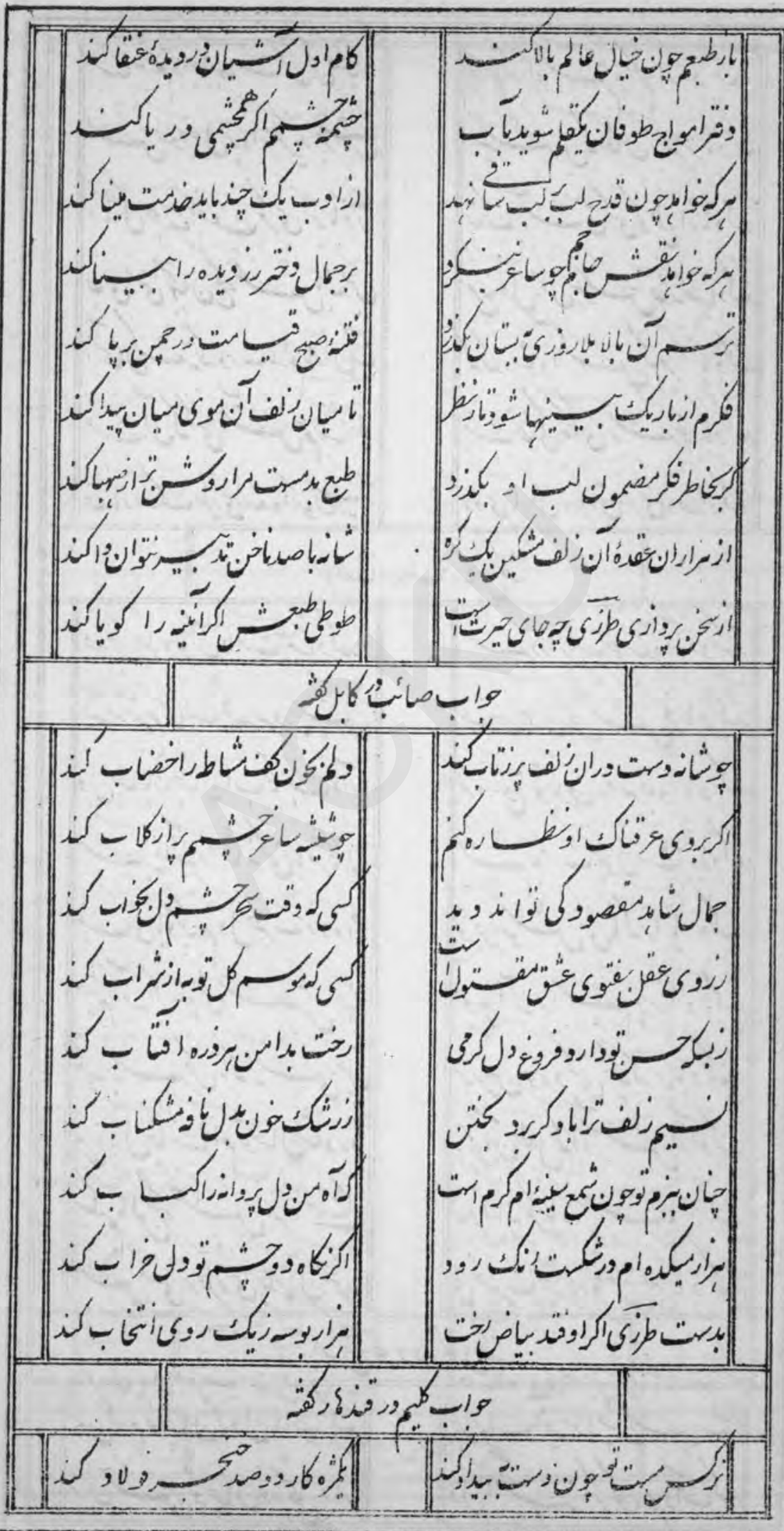




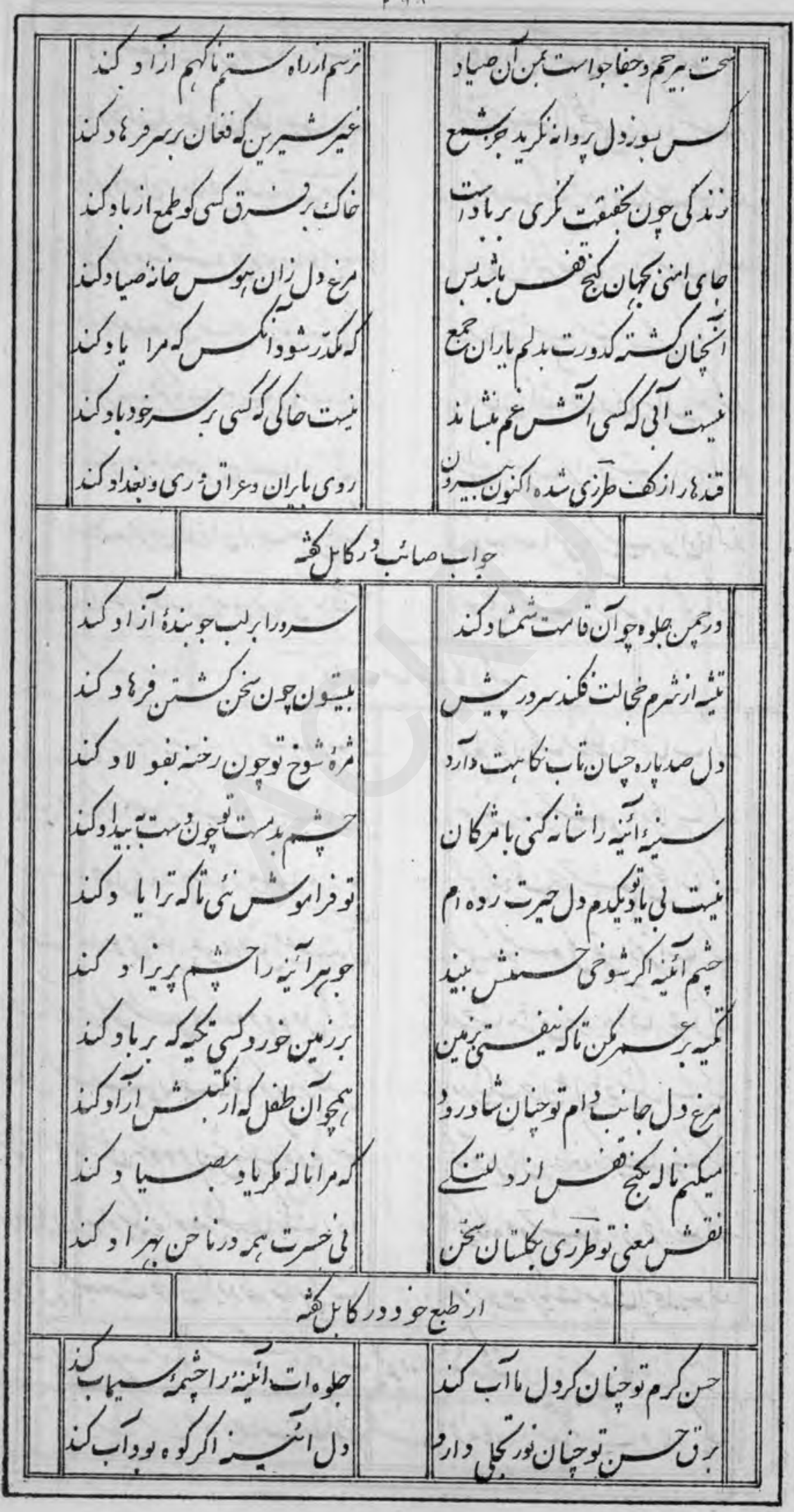


$\begin{array}{r}+49 \\ \hline\end{array}$

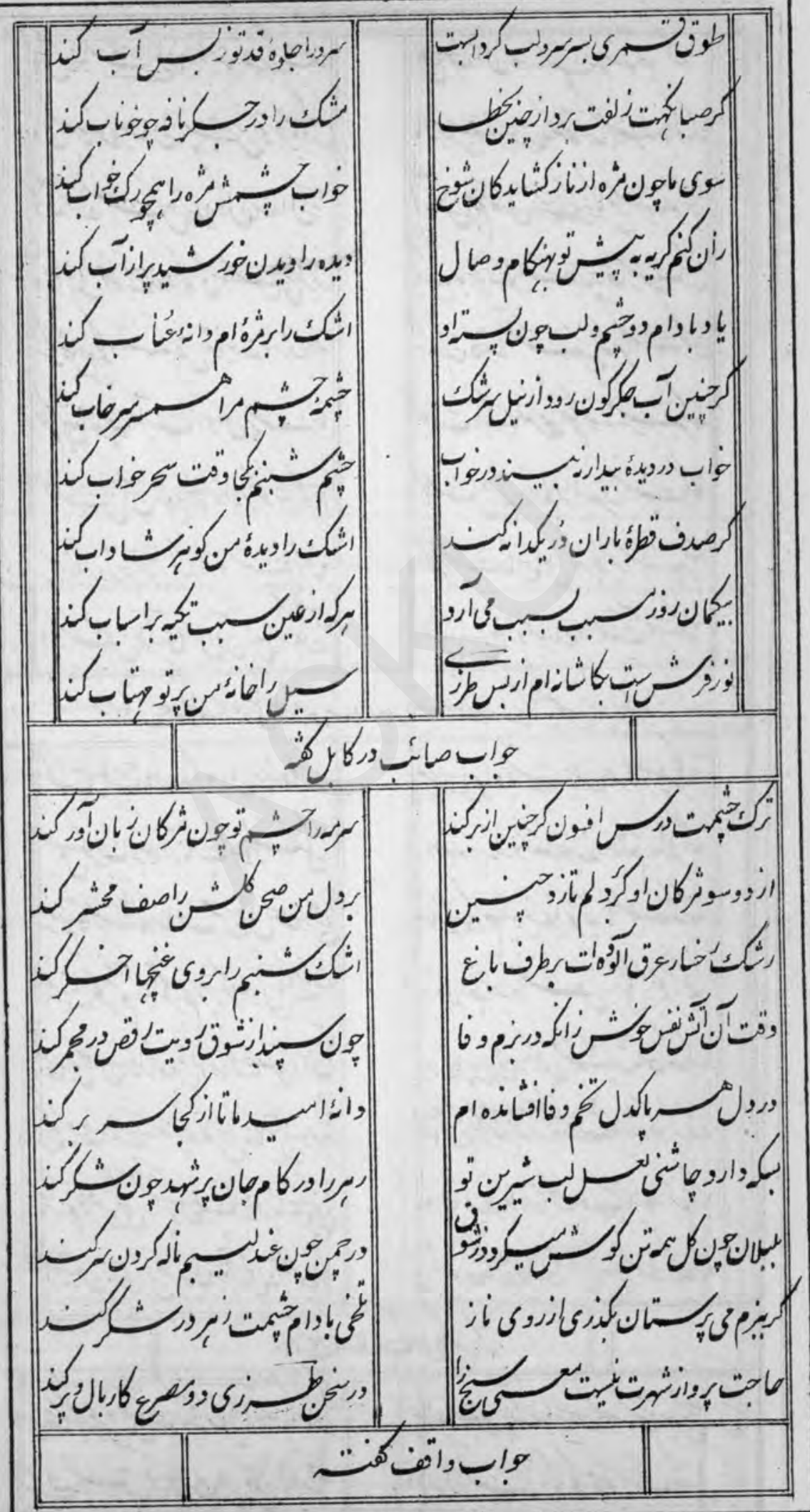




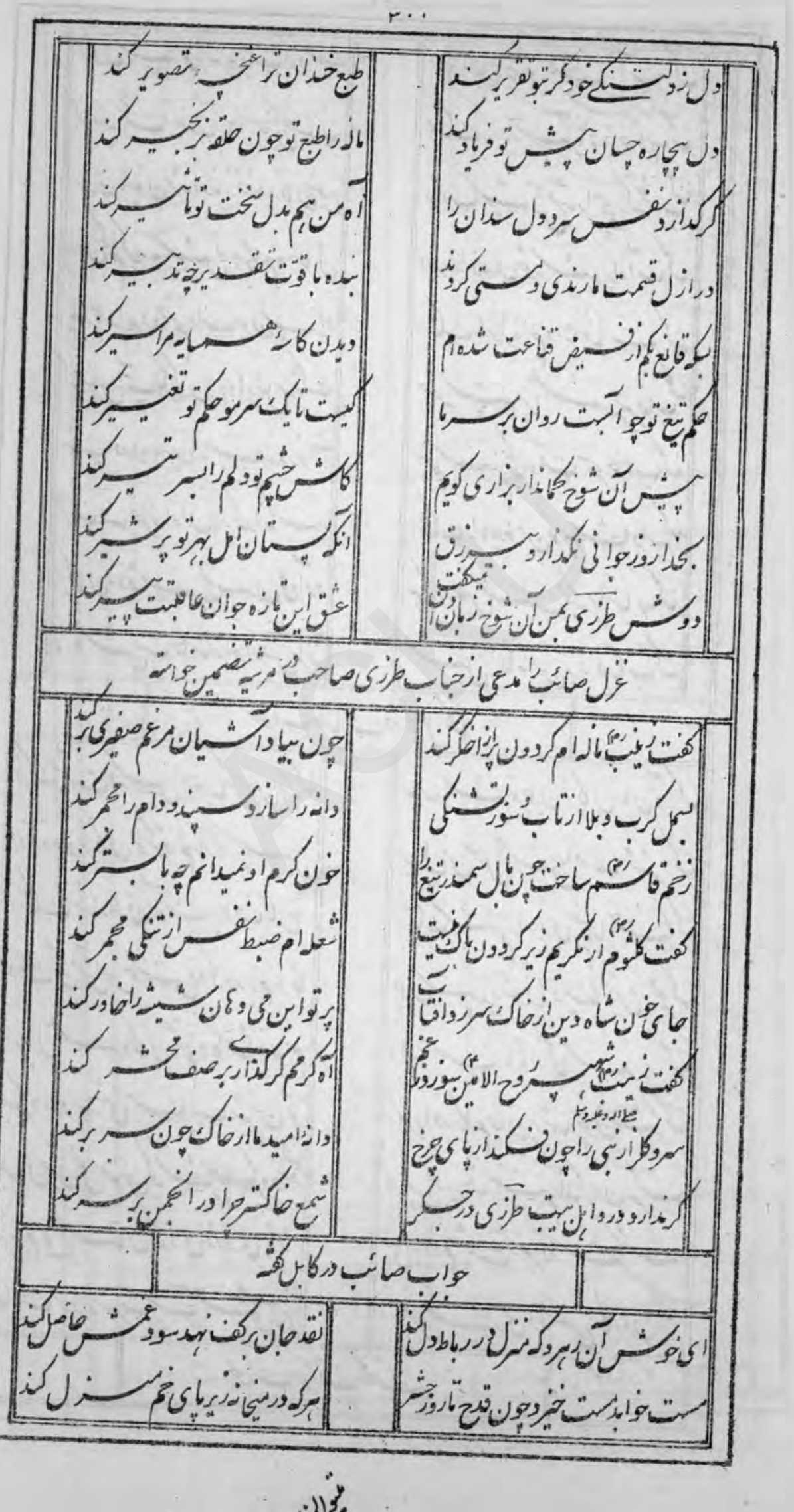




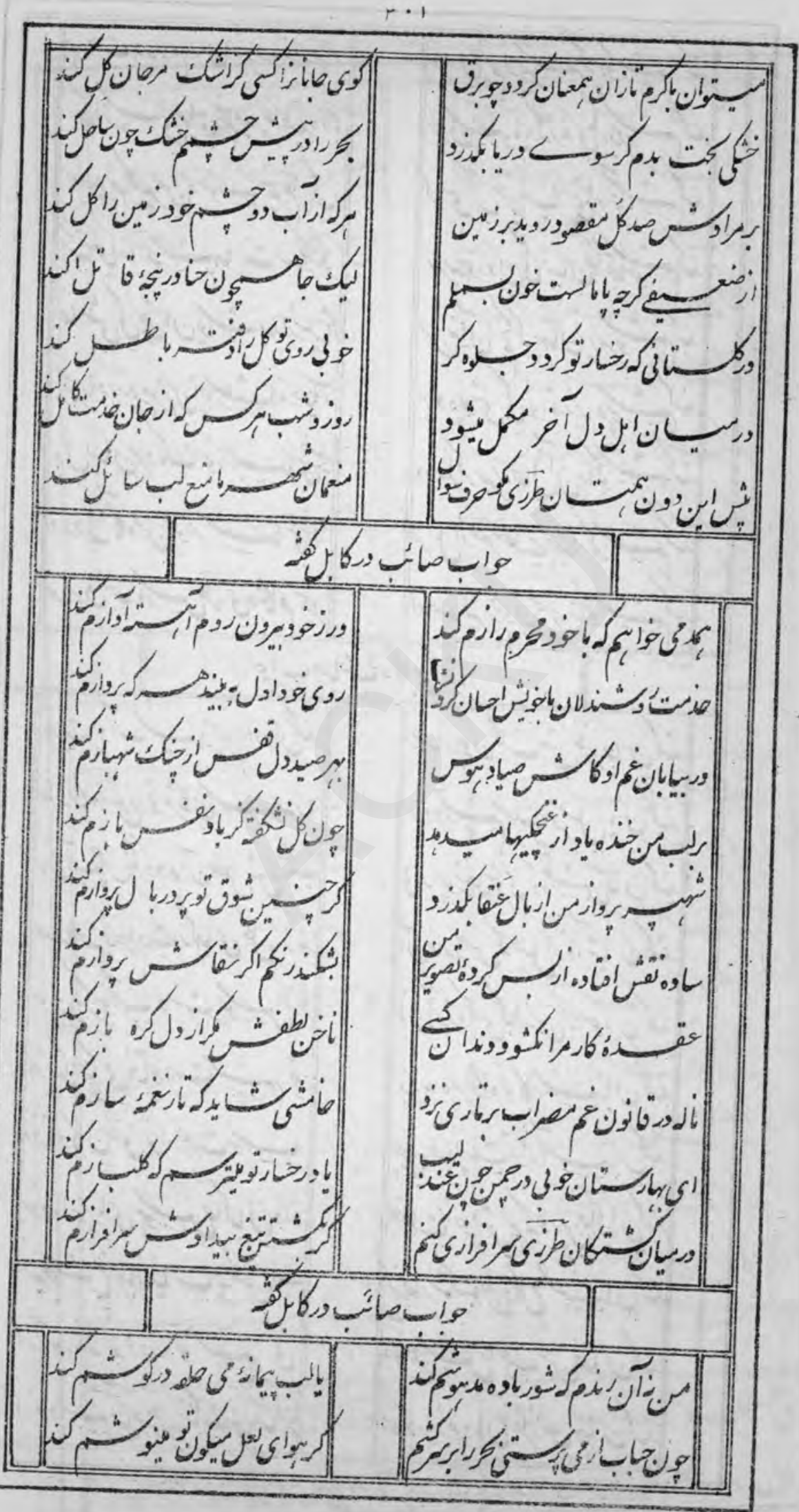


$r \cdot r$

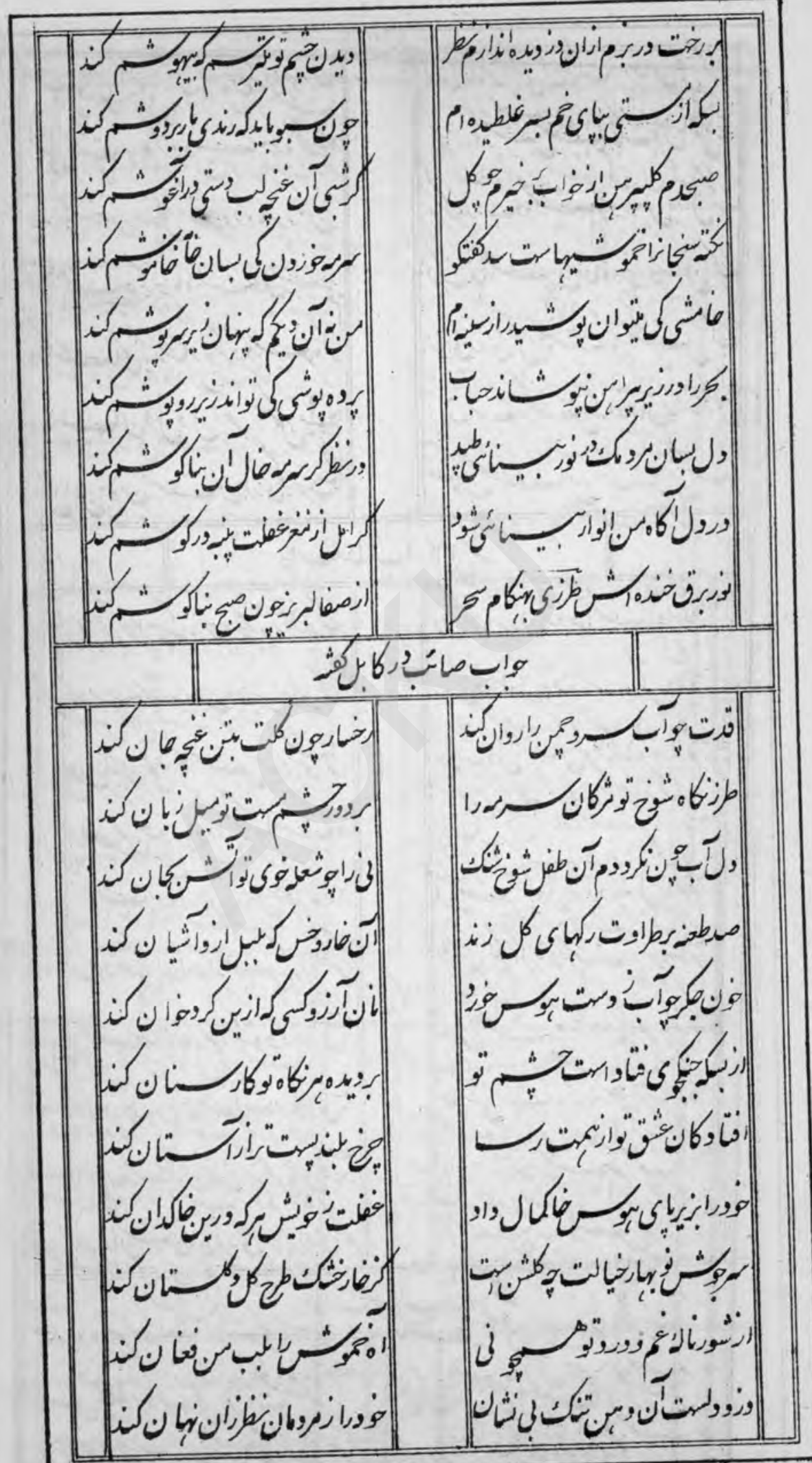


$\mu \cdot r$

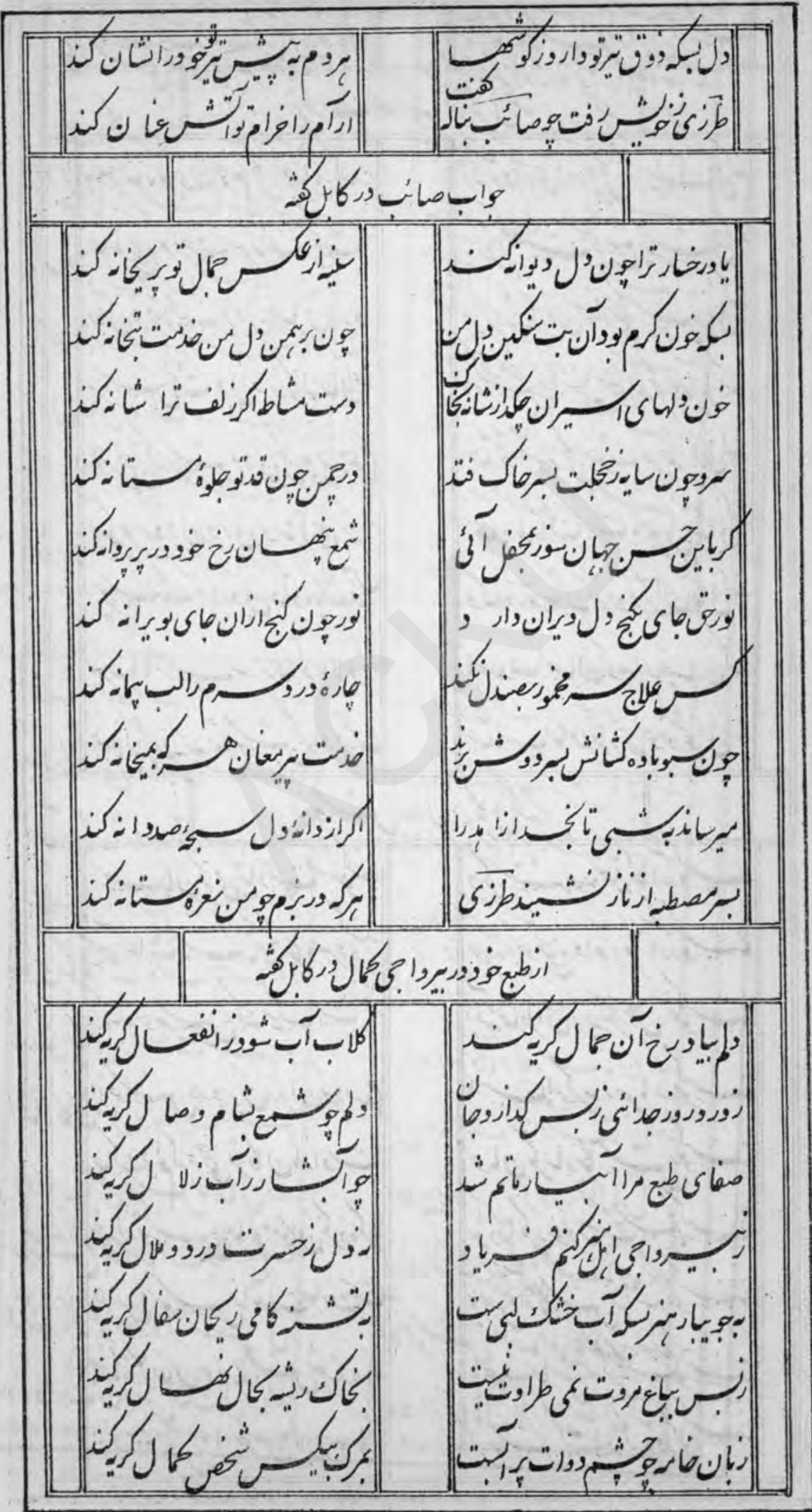


r.p.

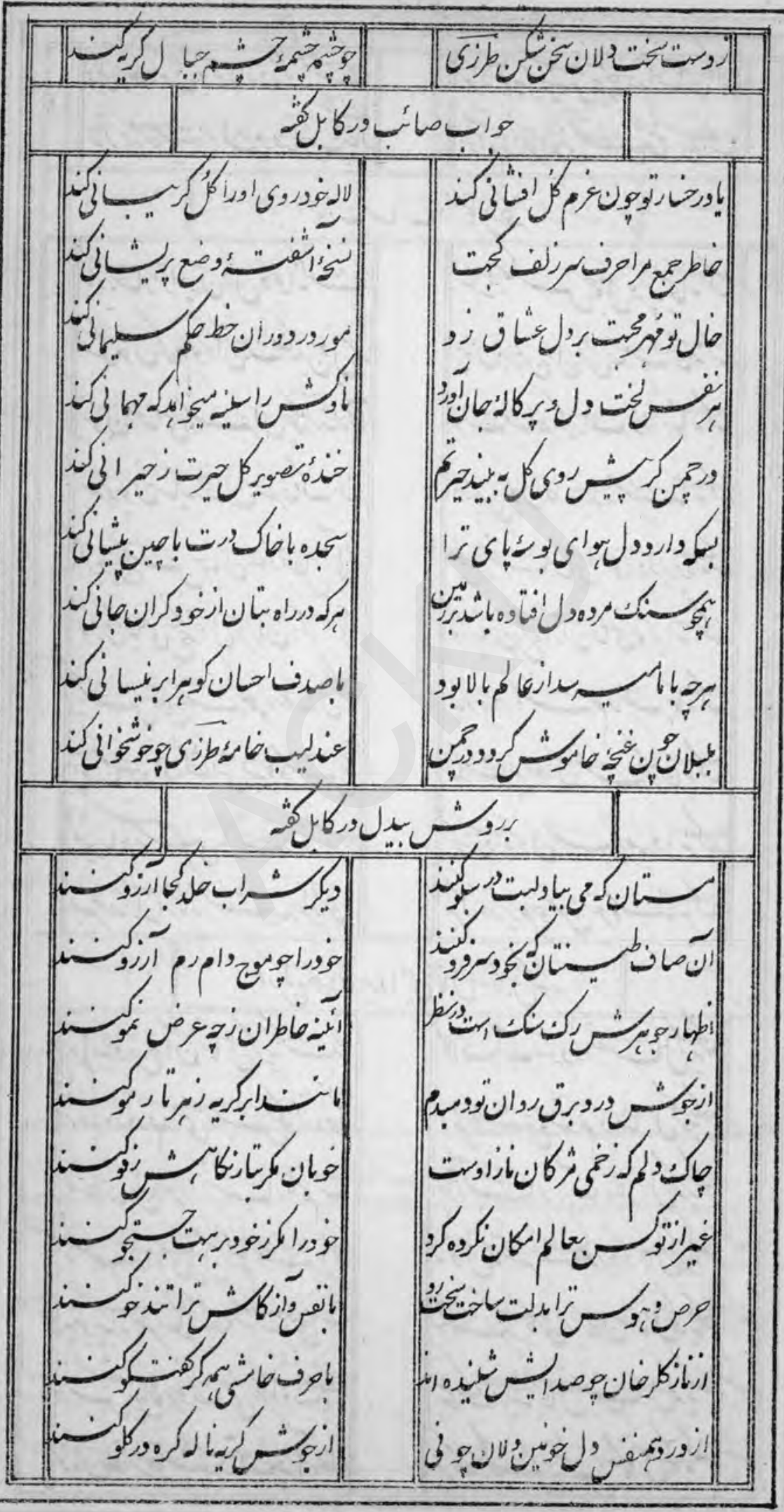


$\because \Delta$

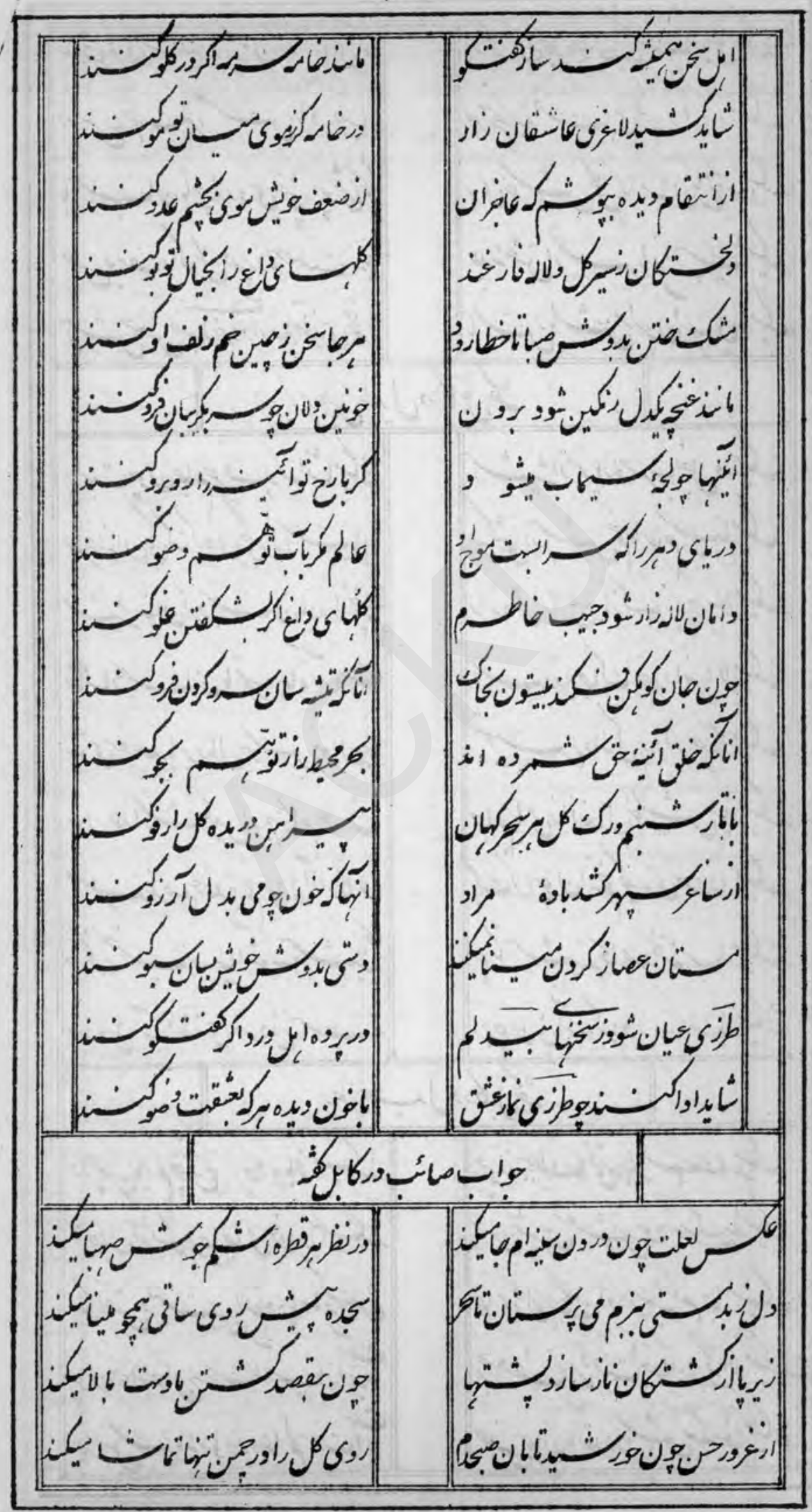




\section{9}

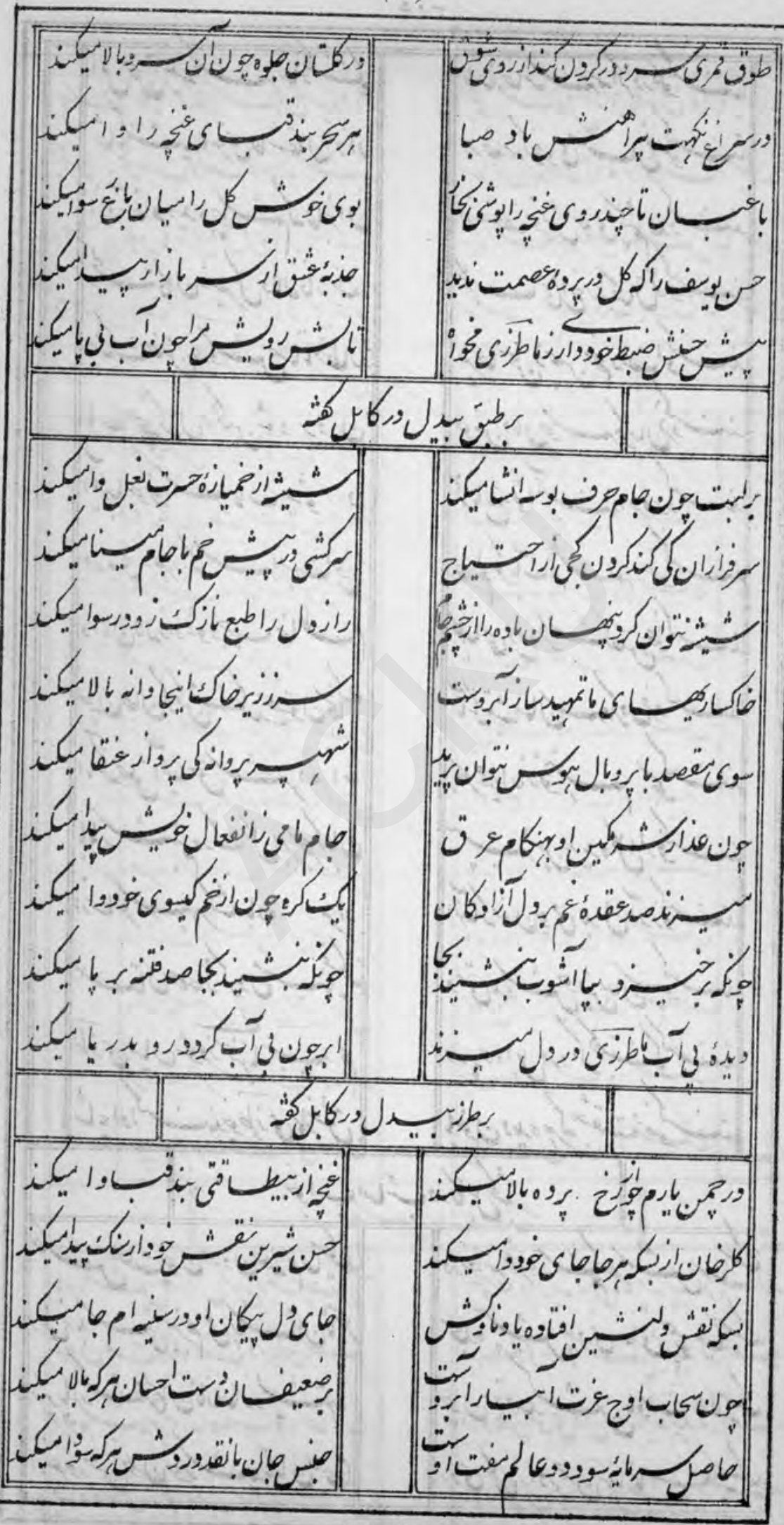

$$
\int
$$




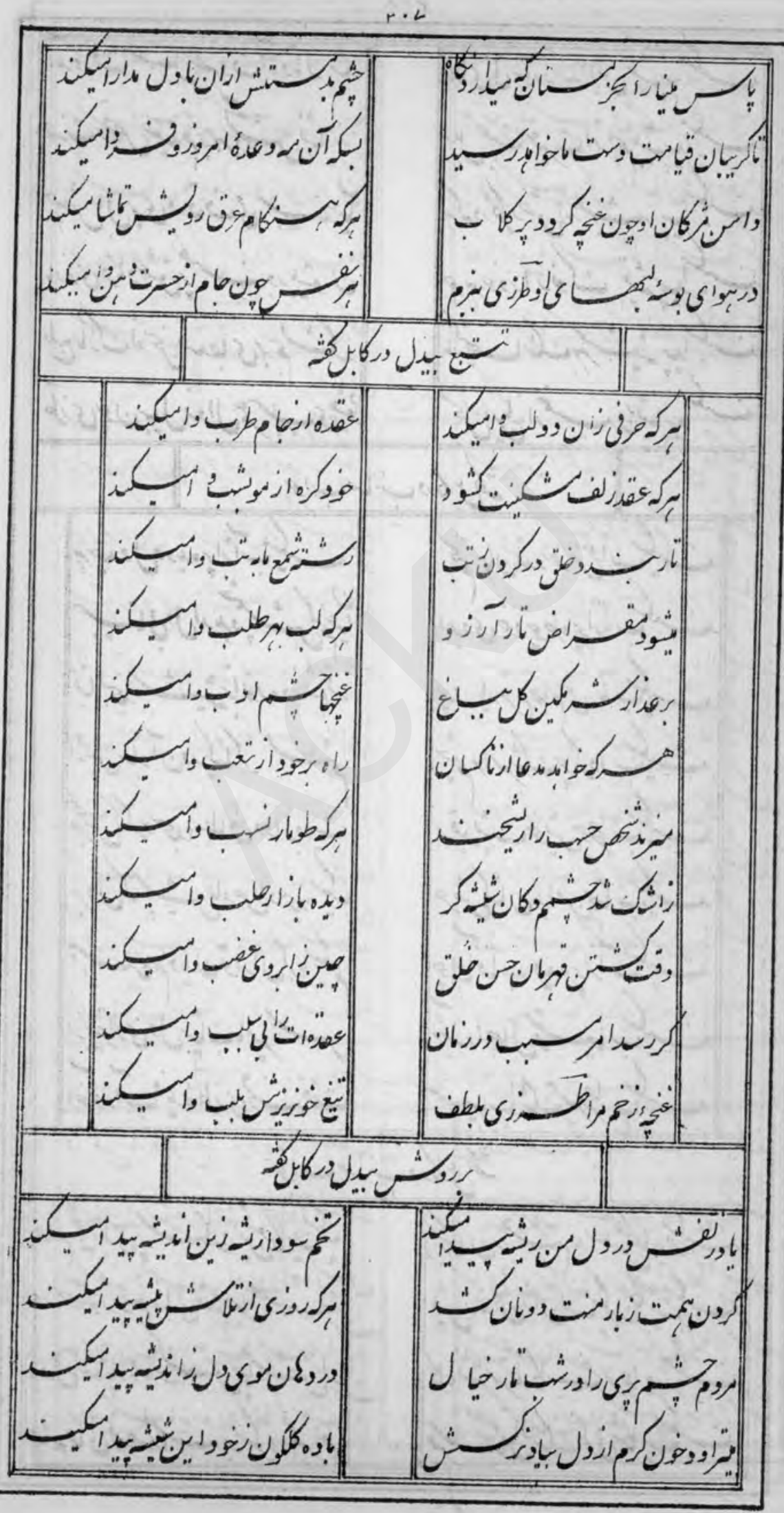


$r \cdot \wedge$

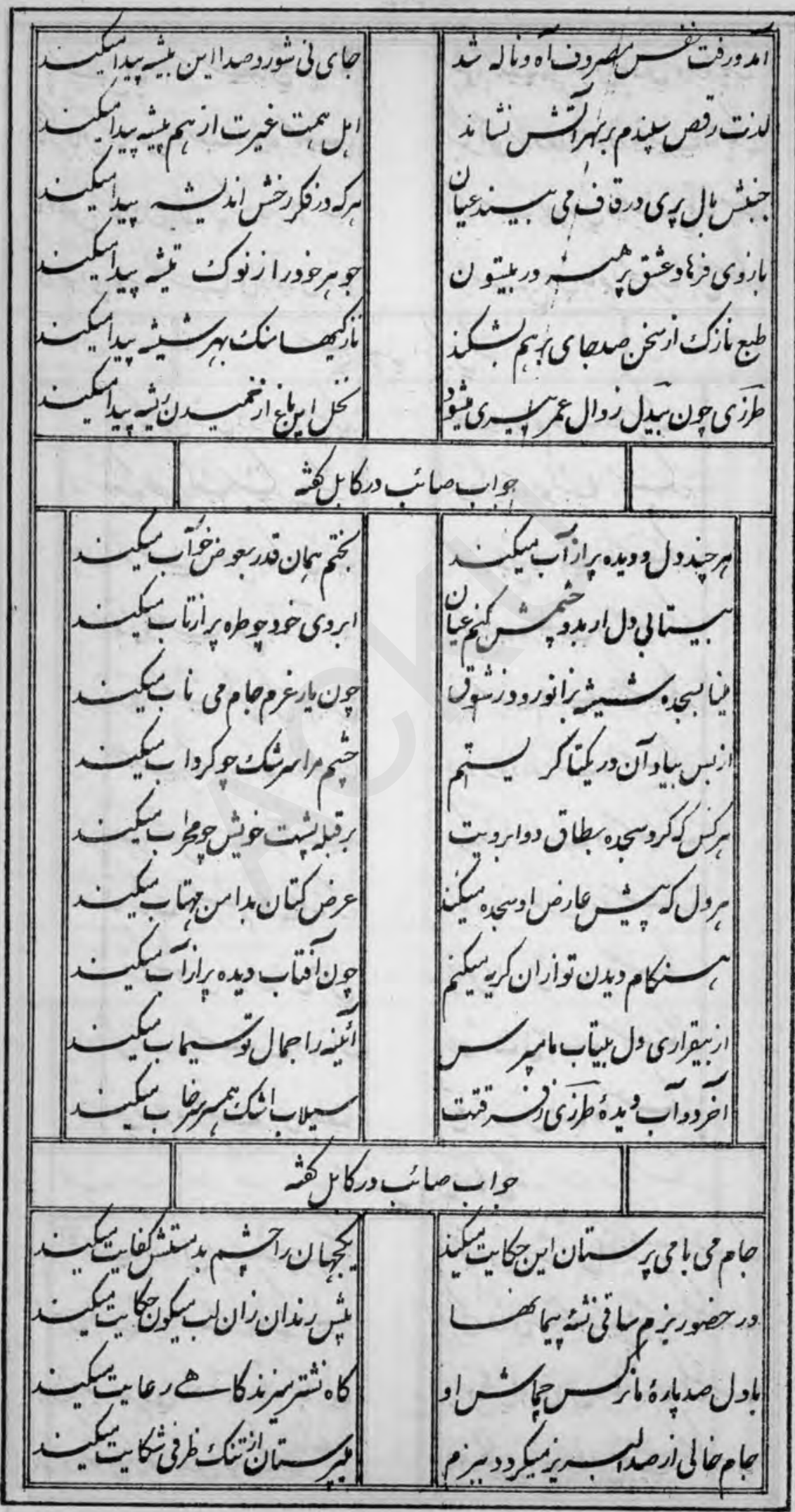

iv. 
r.q

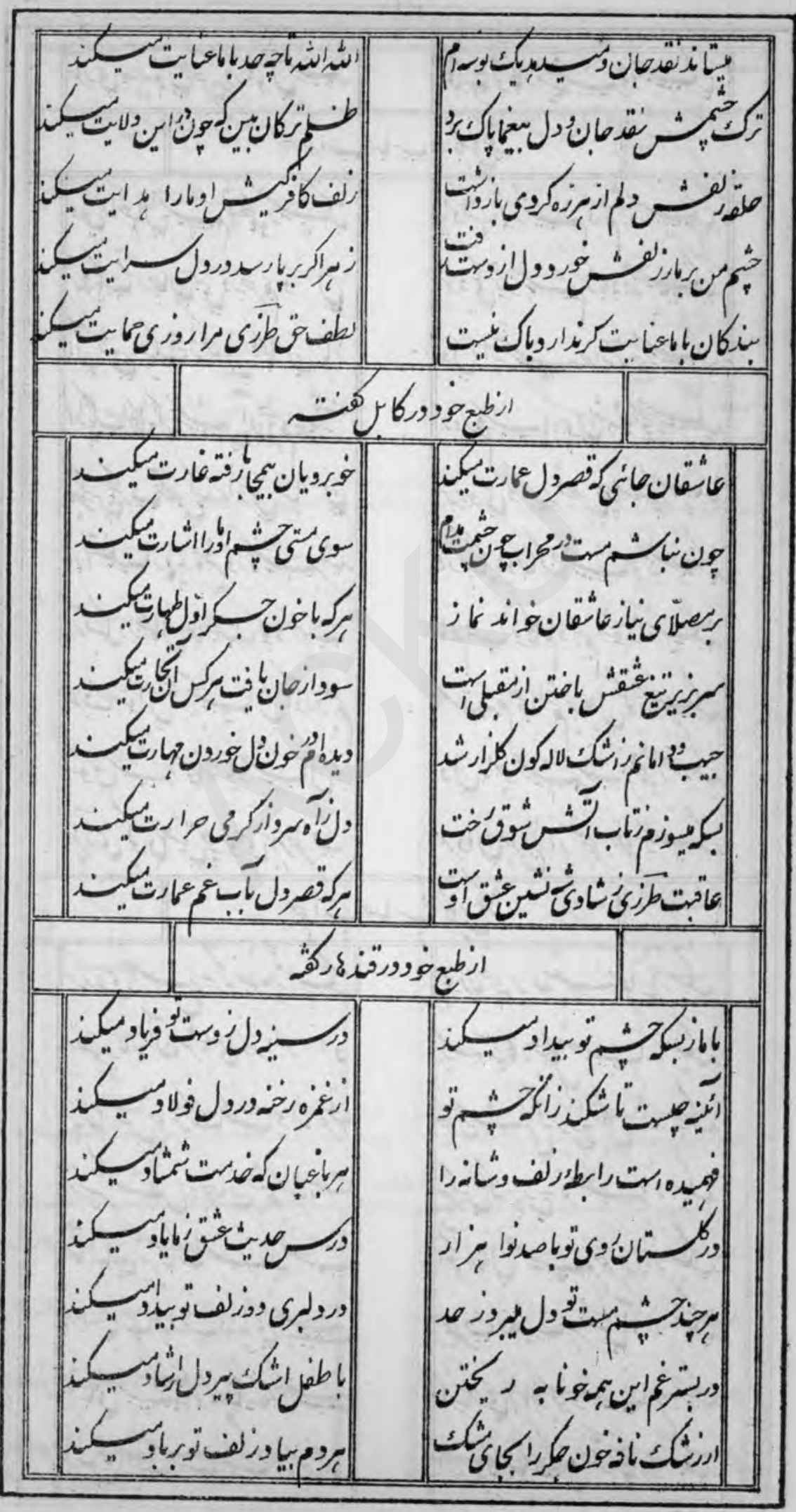


ri.

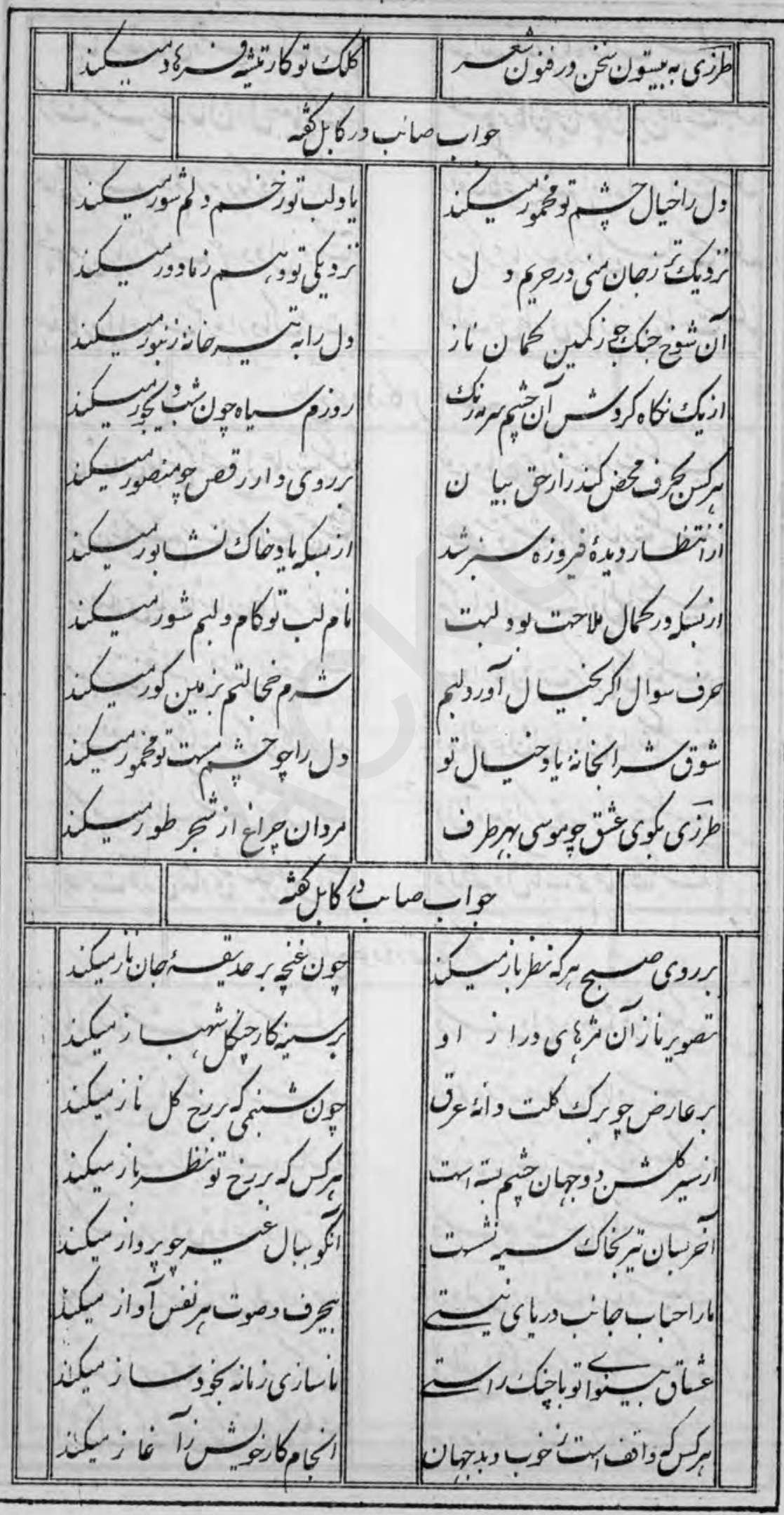


ri

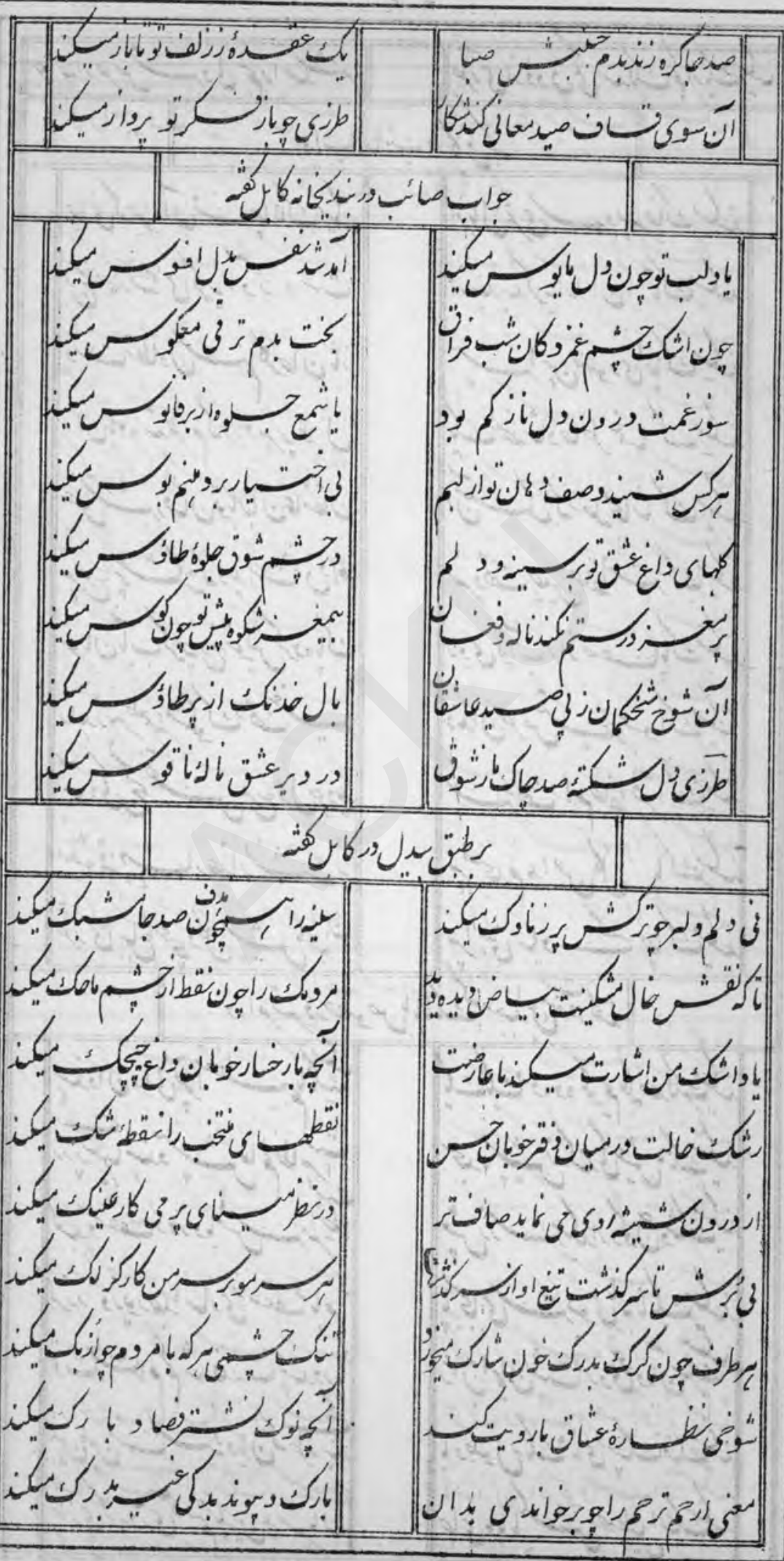




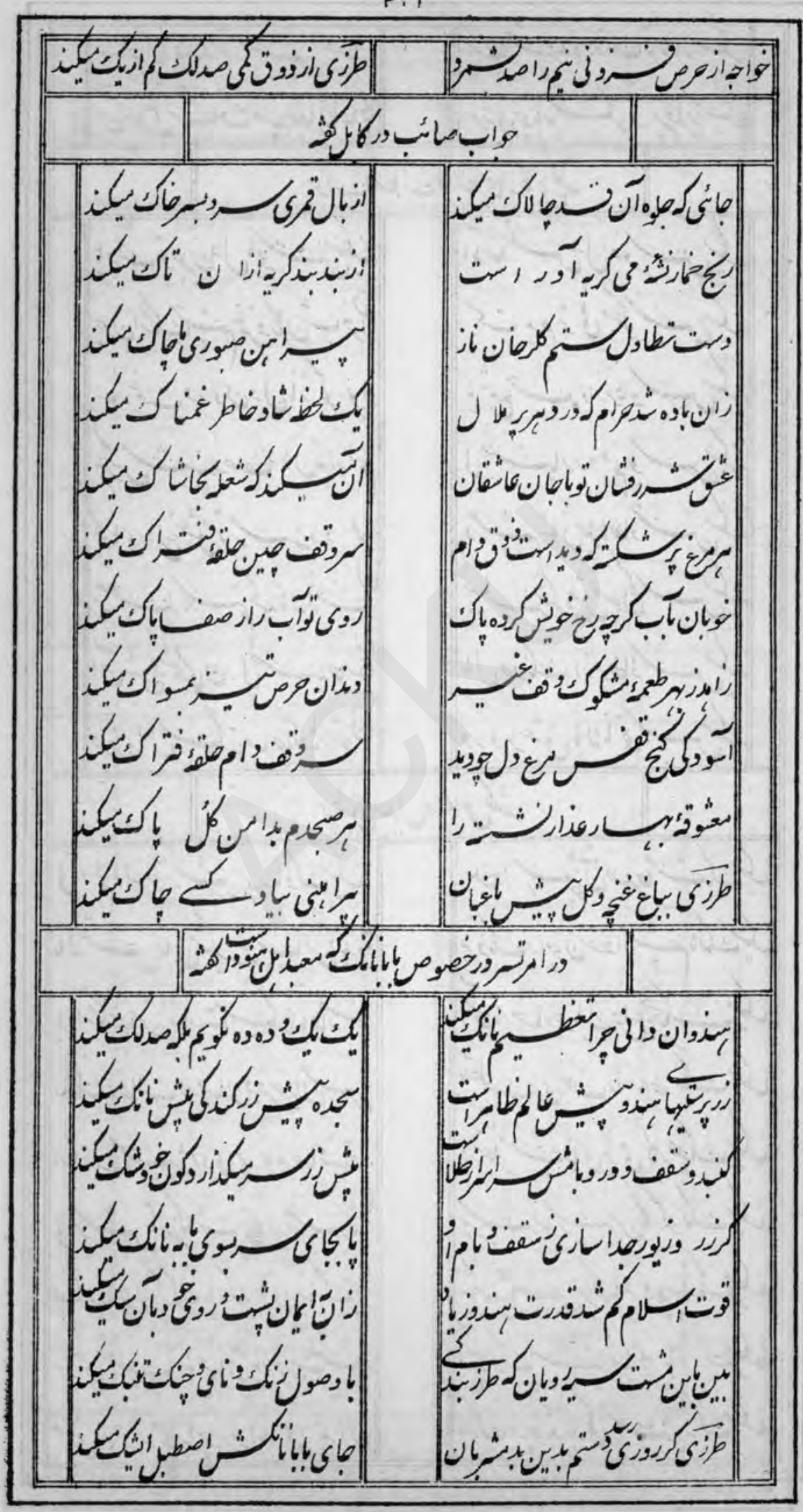


r

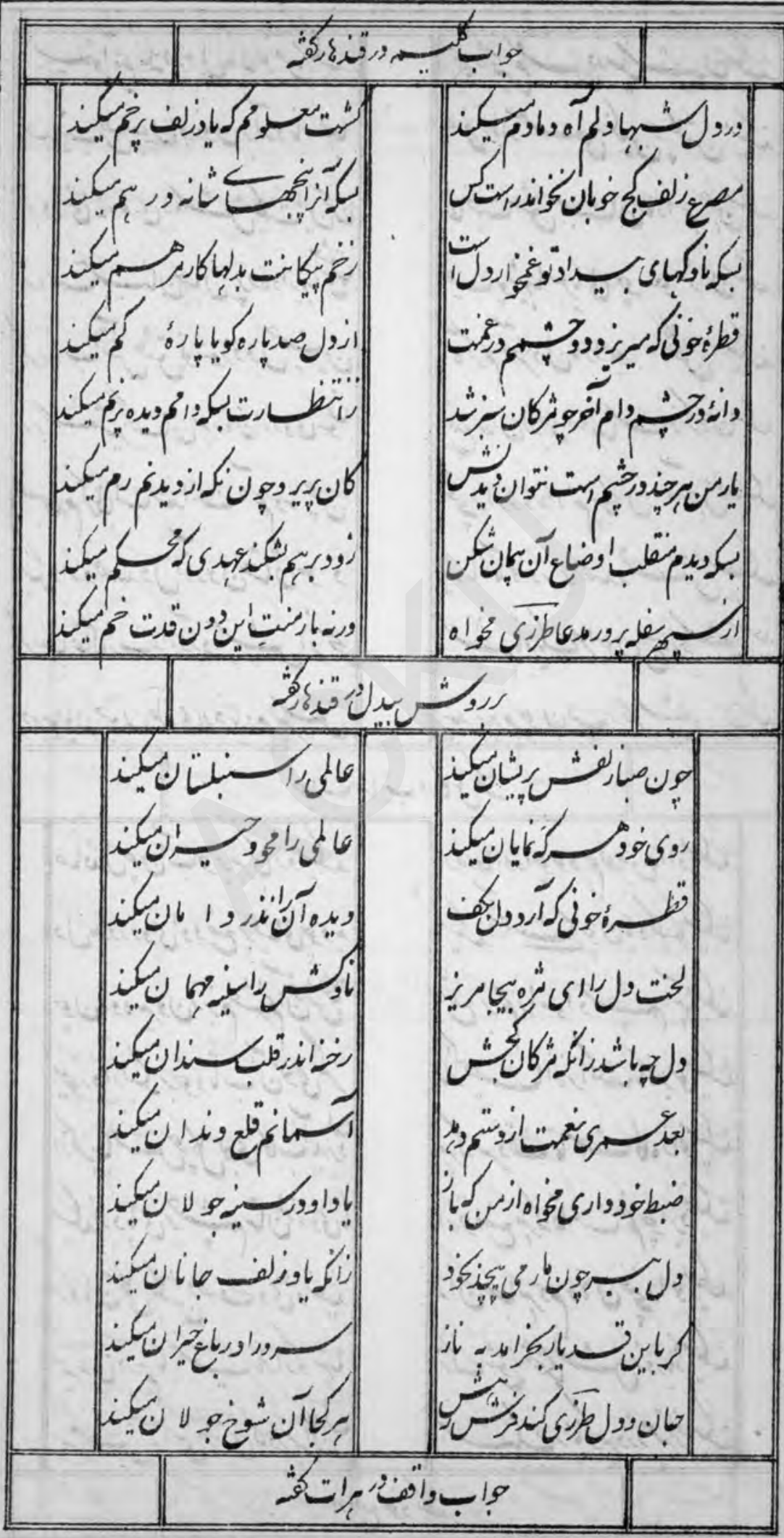




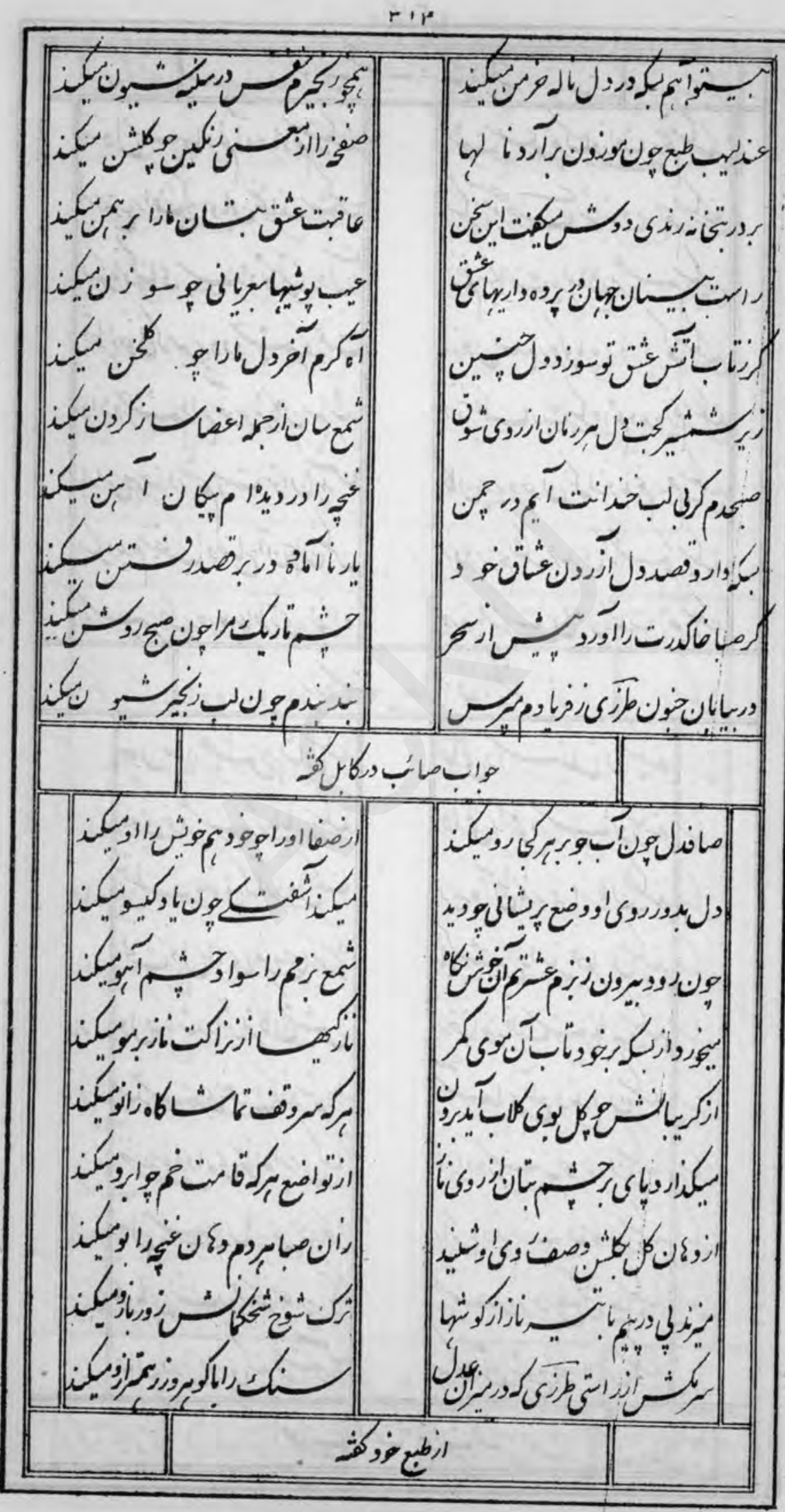


$r \mid s$

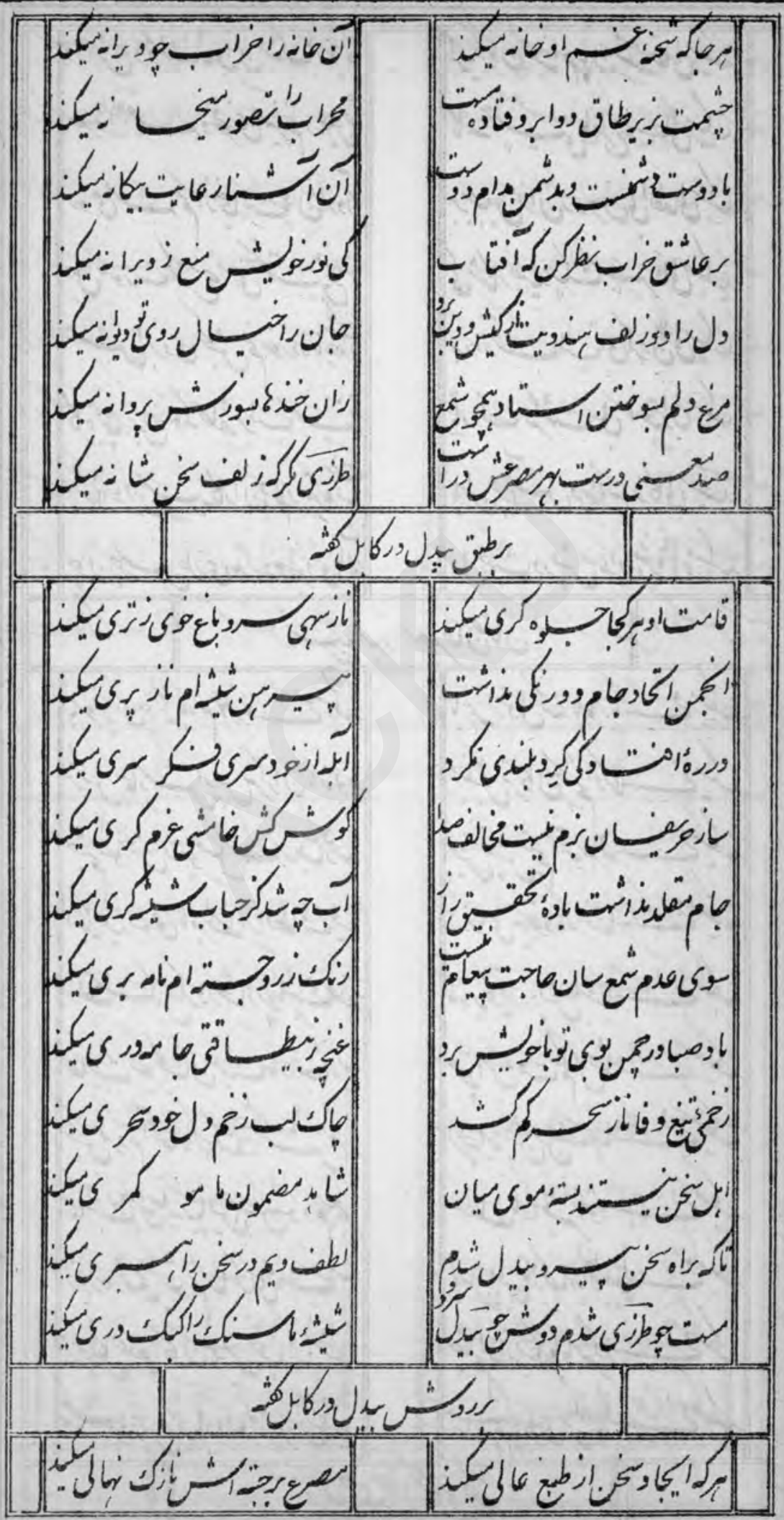


ris

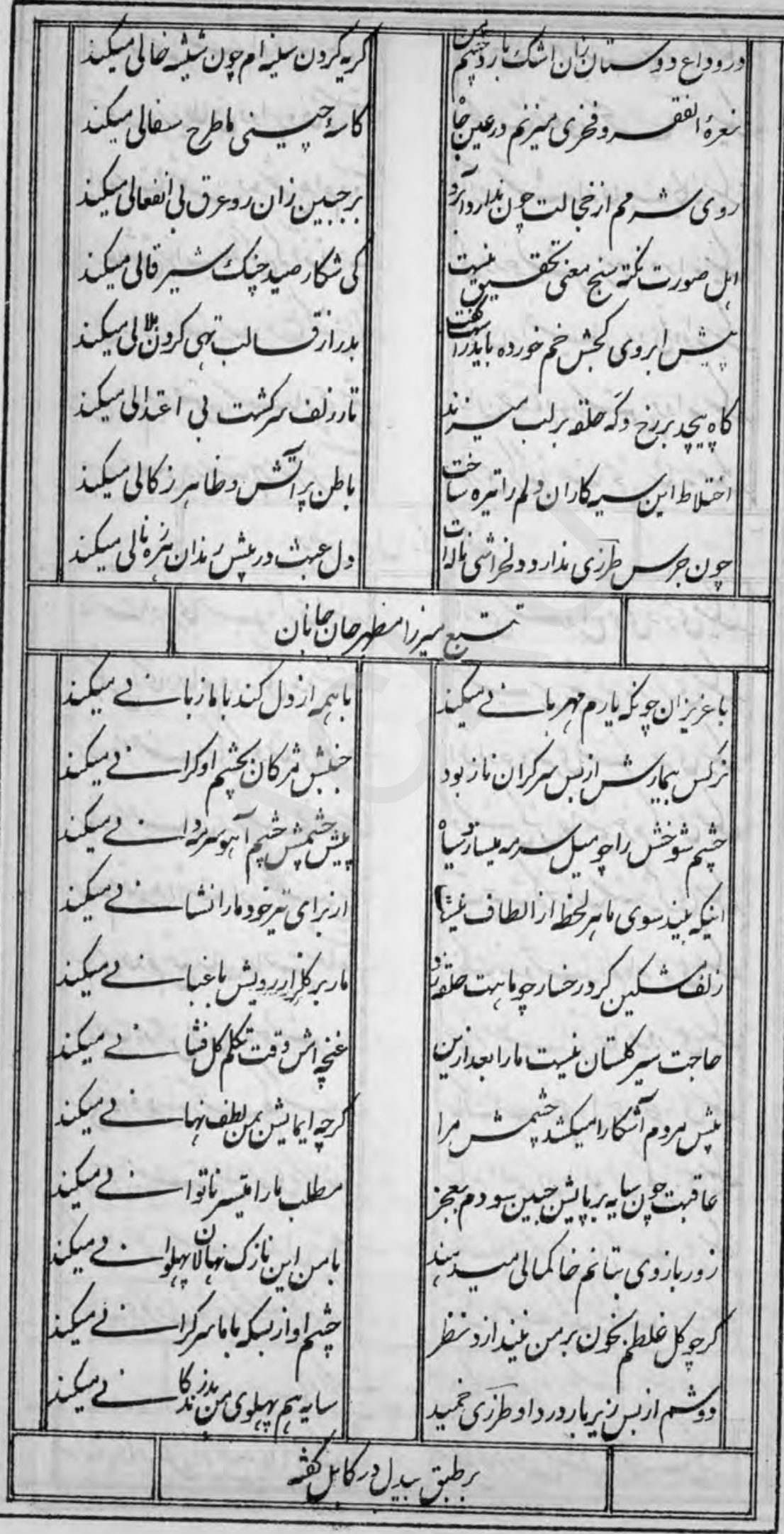


FIL

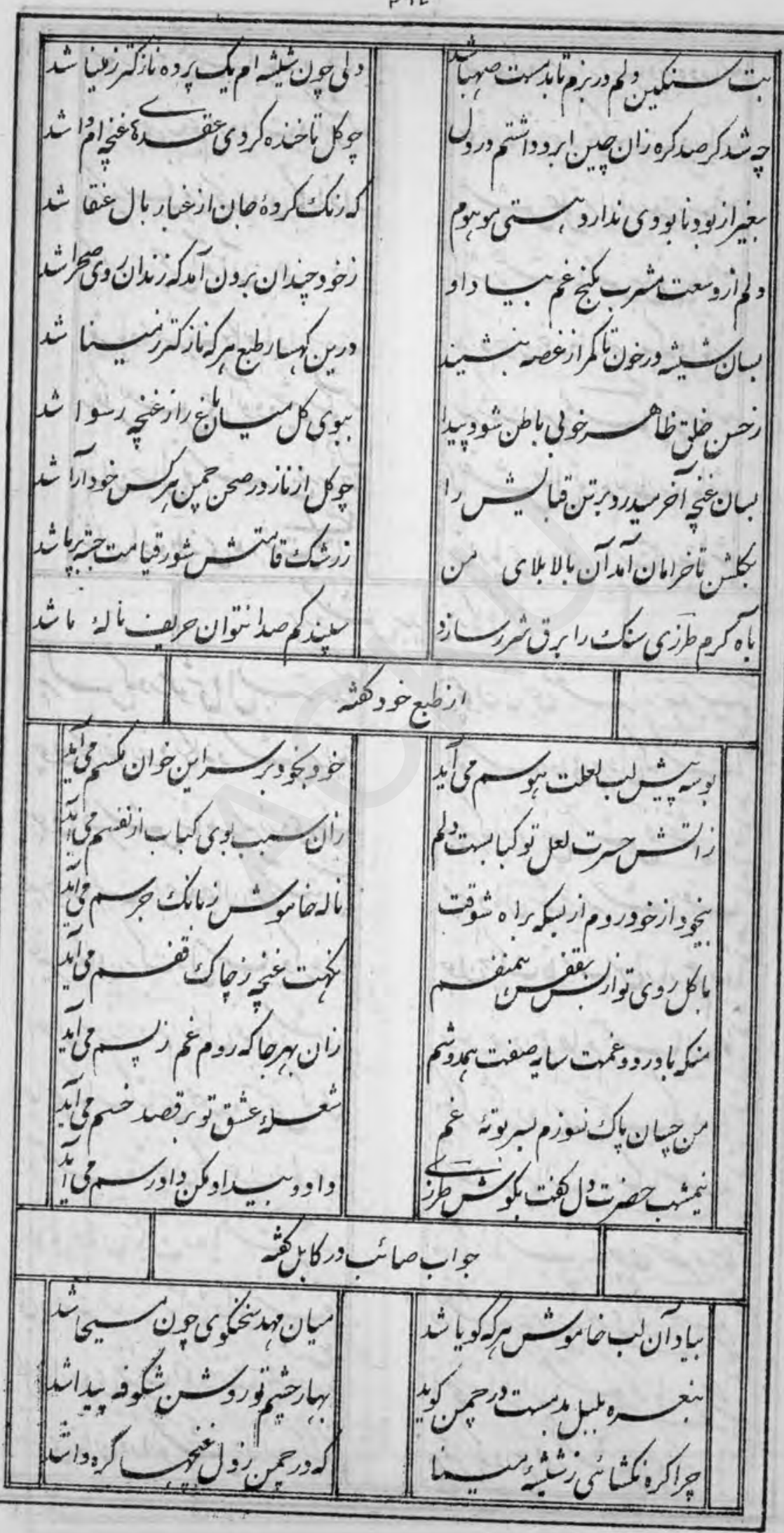


$r \mid A$

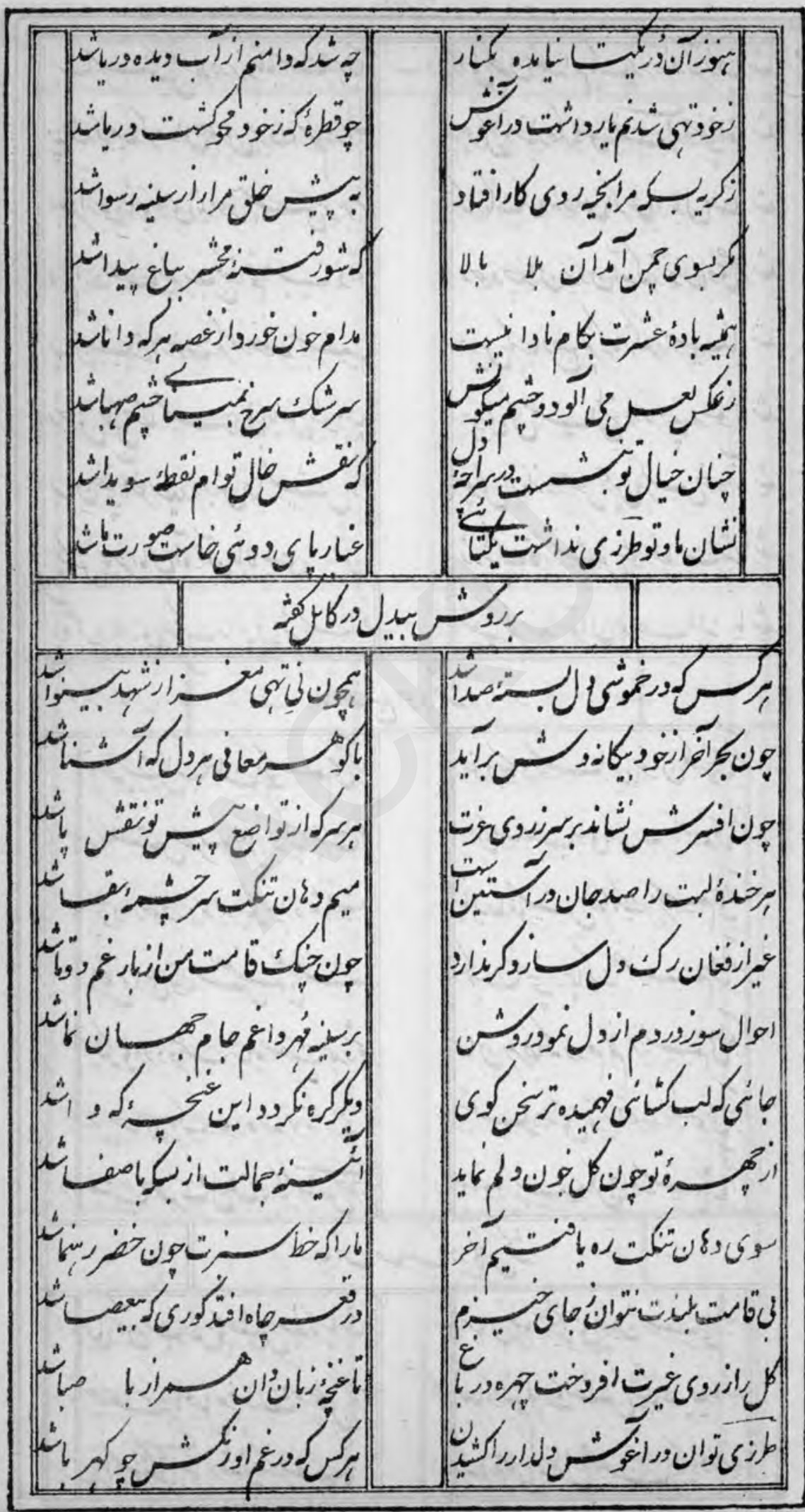


ris

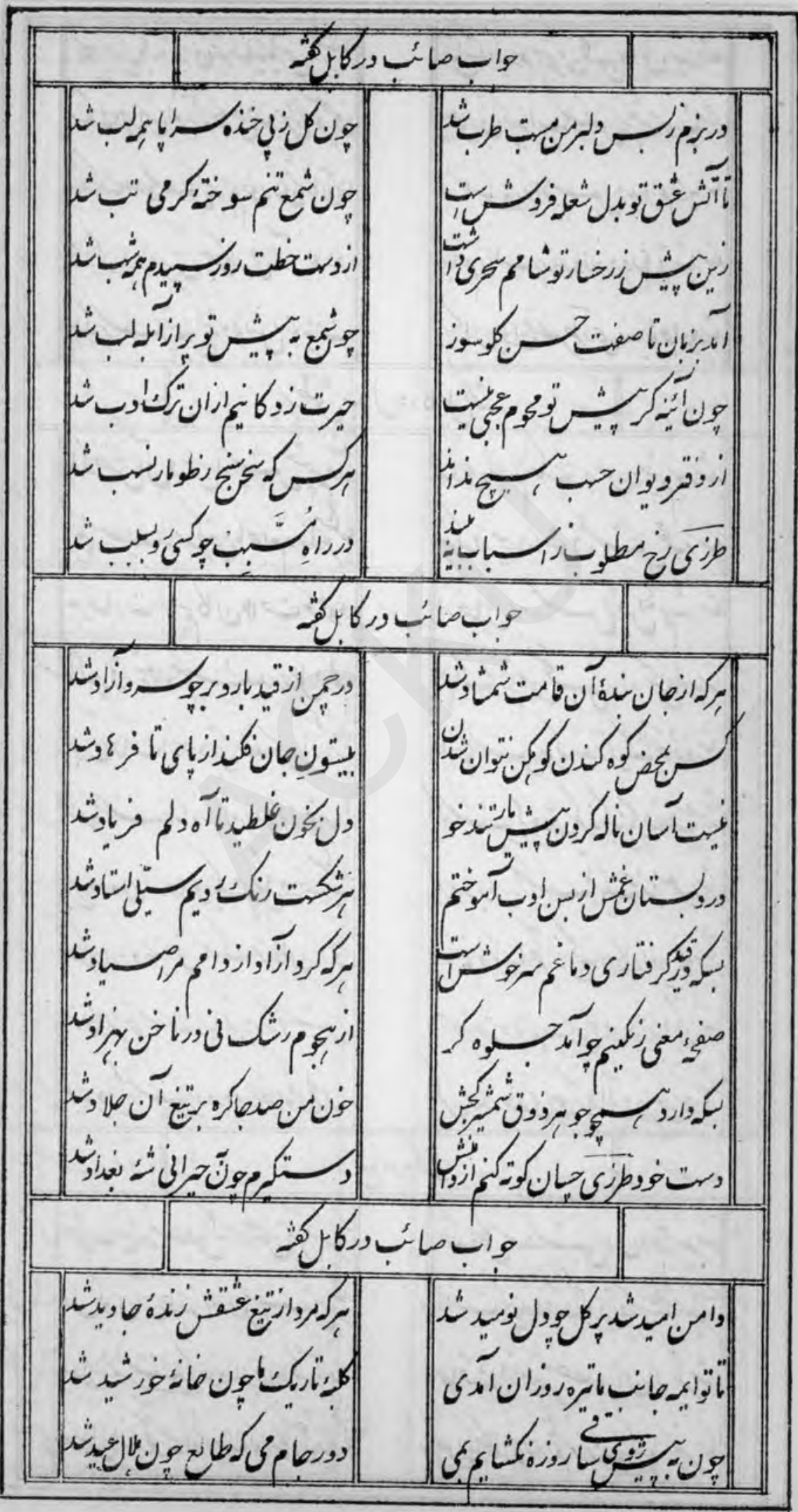


r

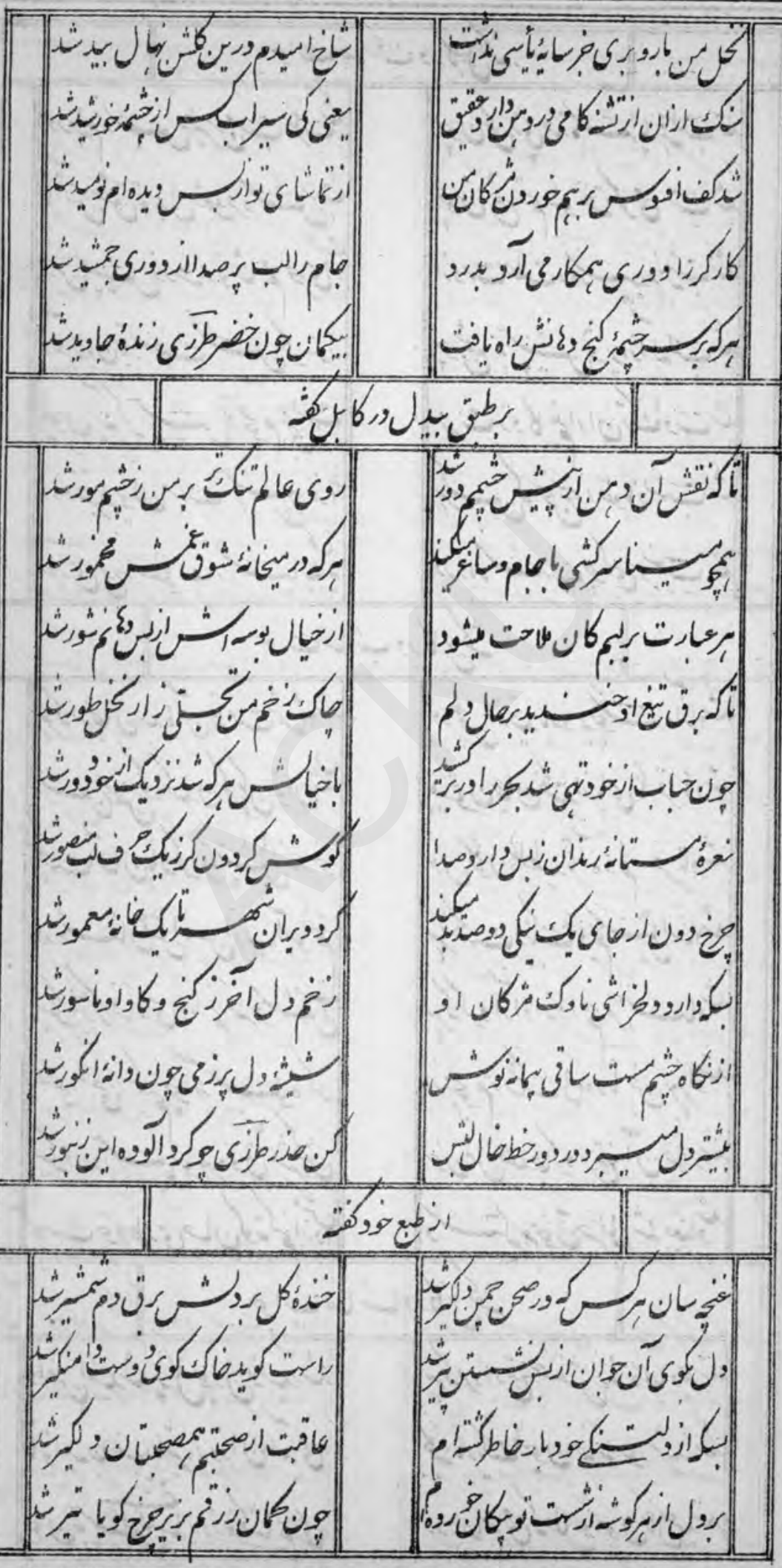




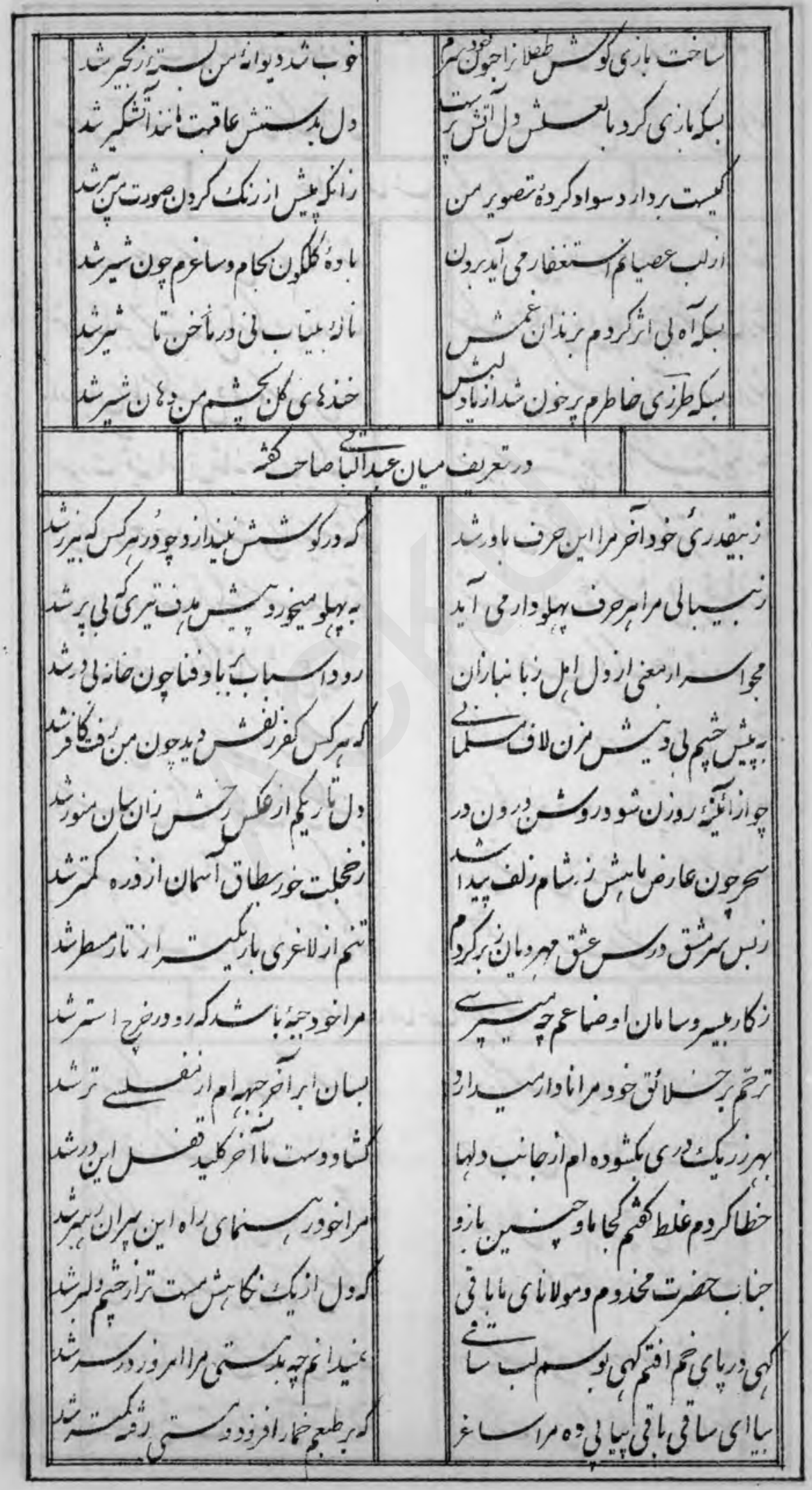




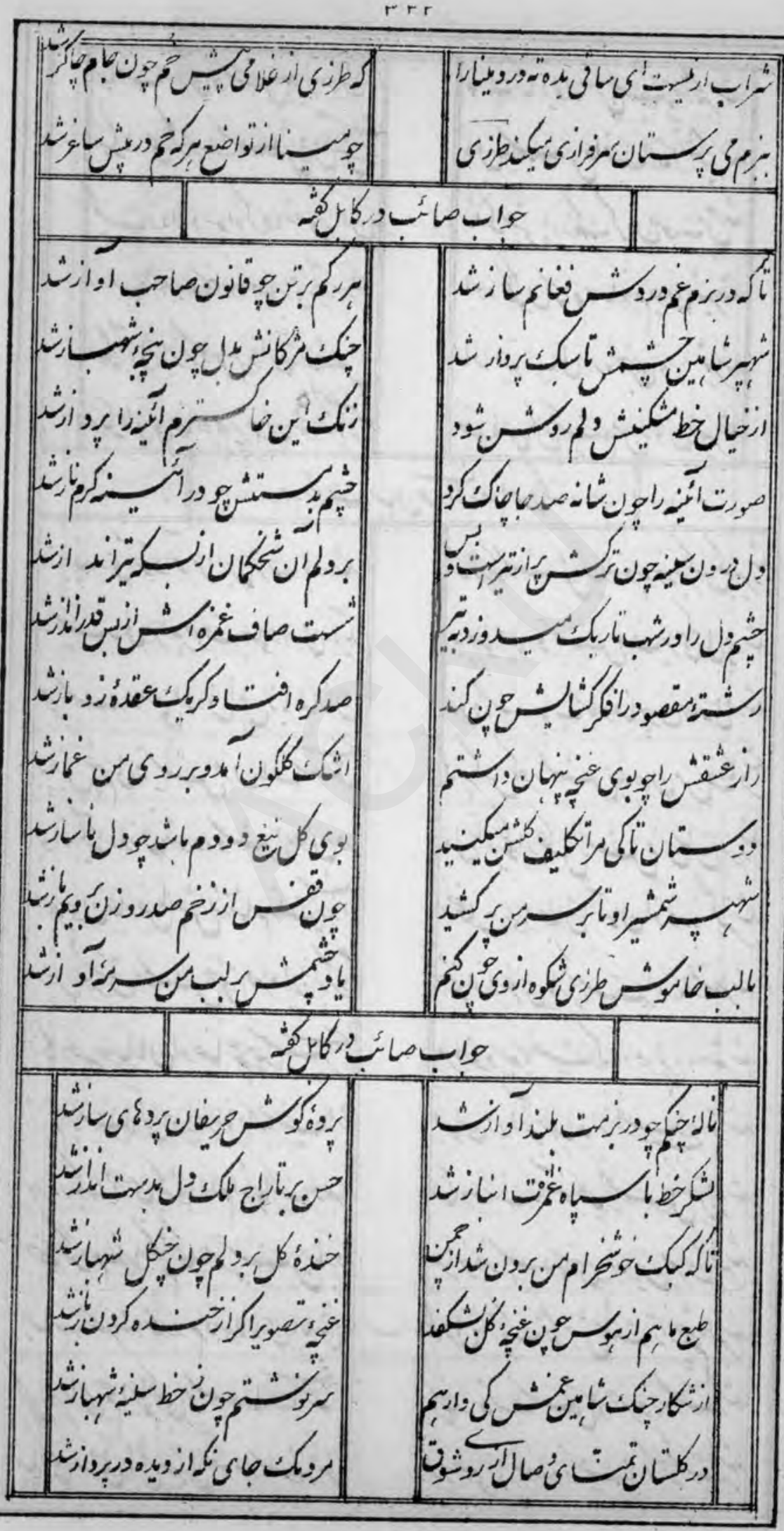


rr

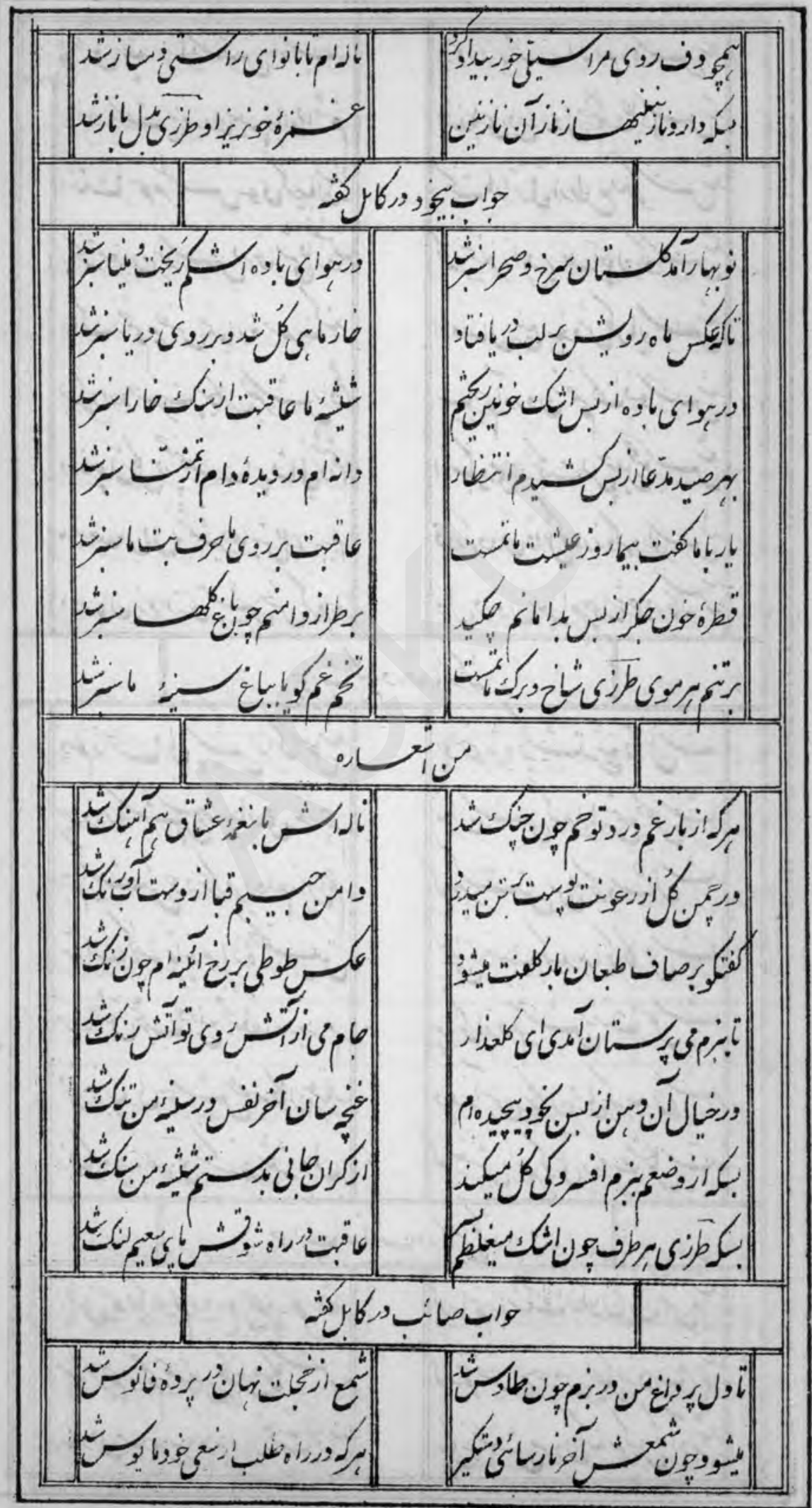


r

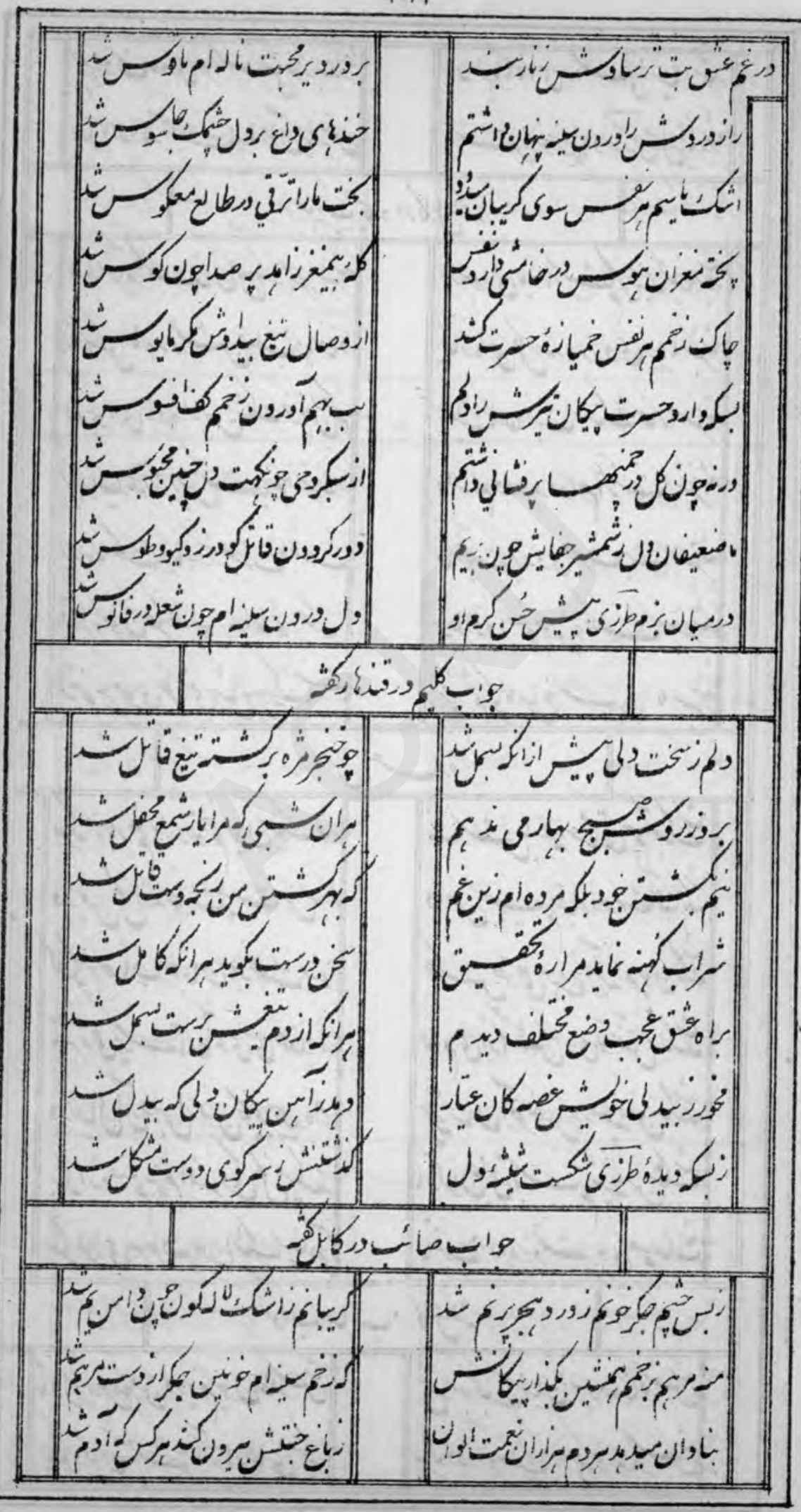


r 50

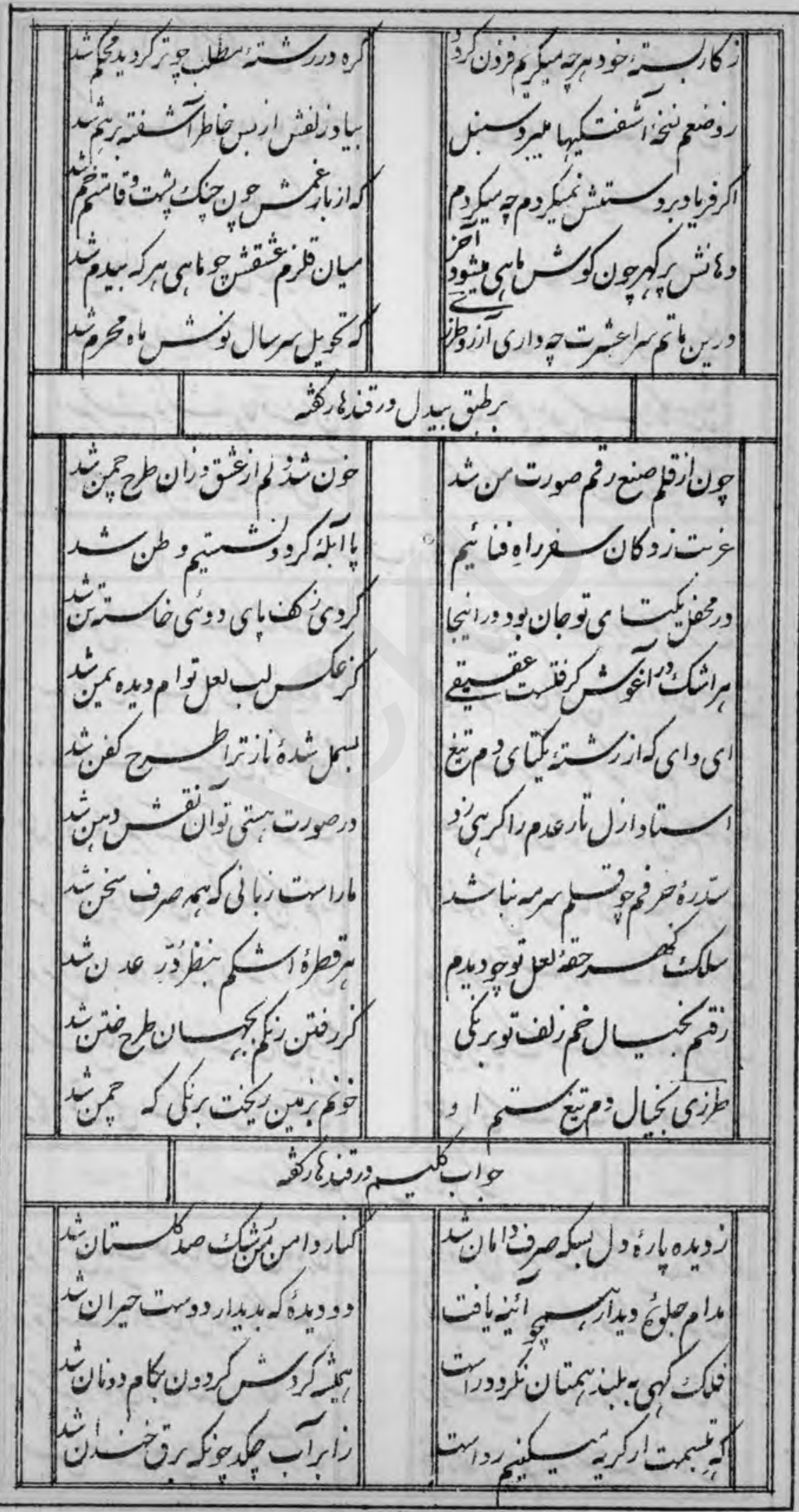


prs

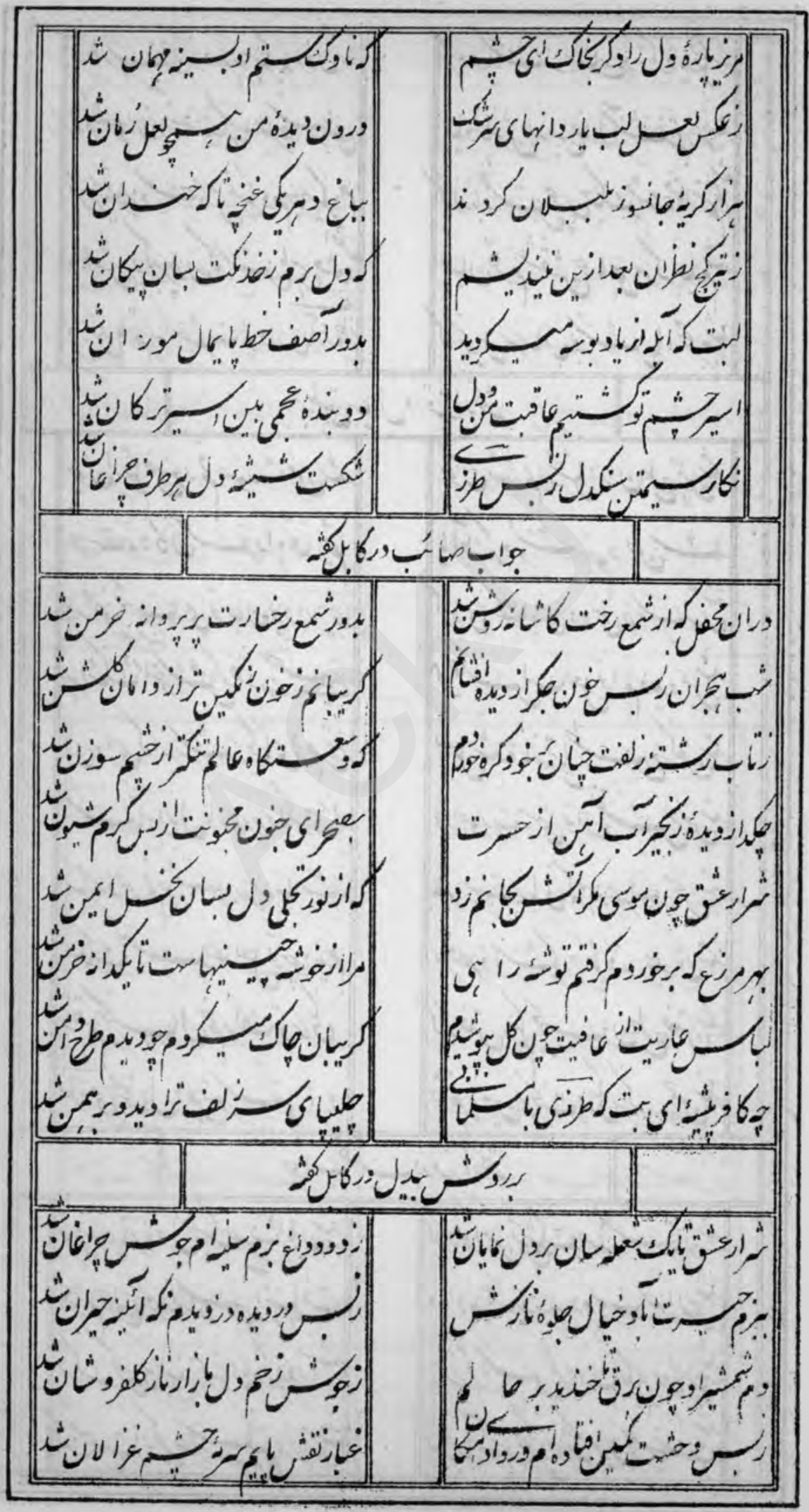


$r r$

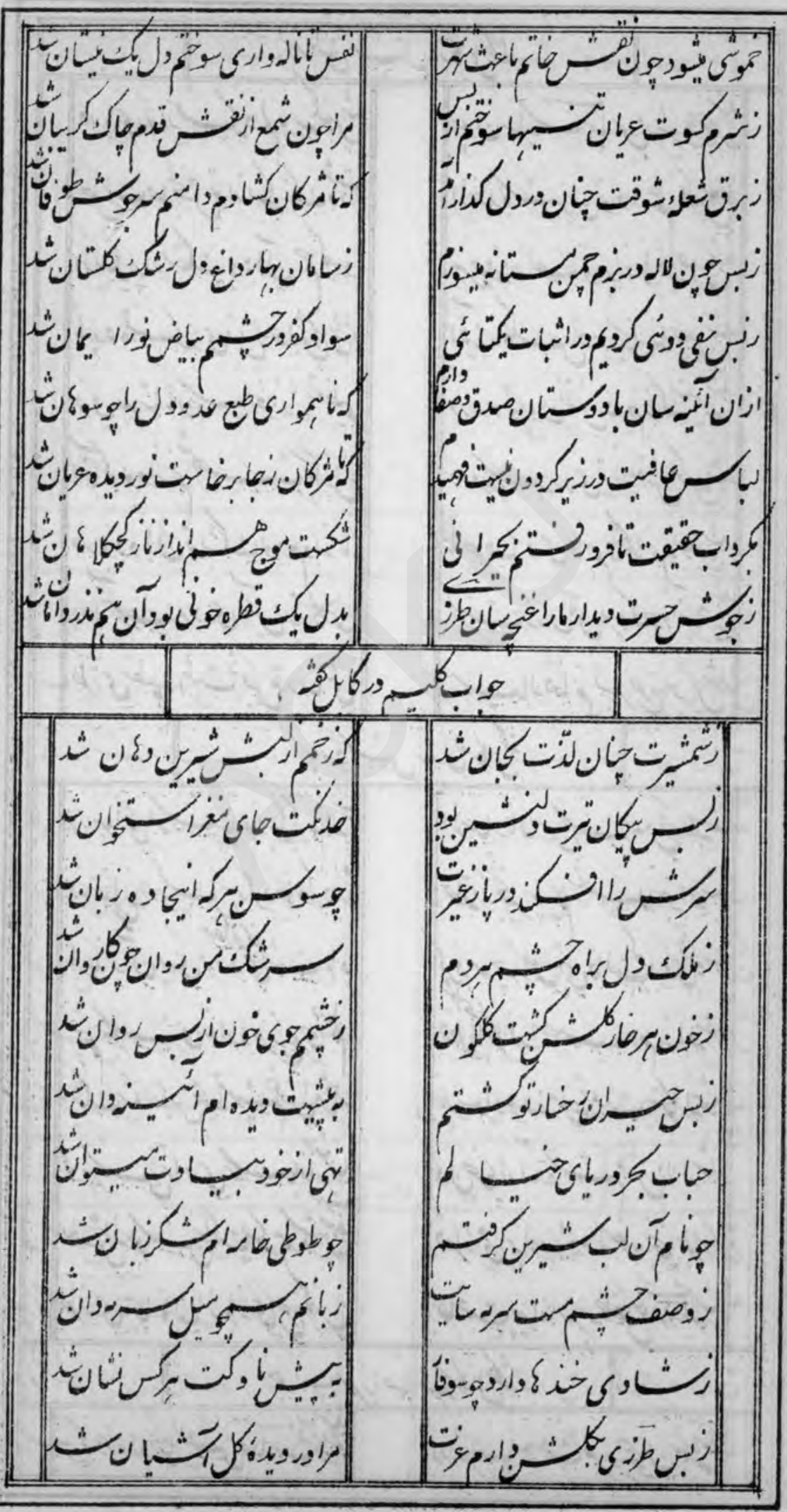


rrA

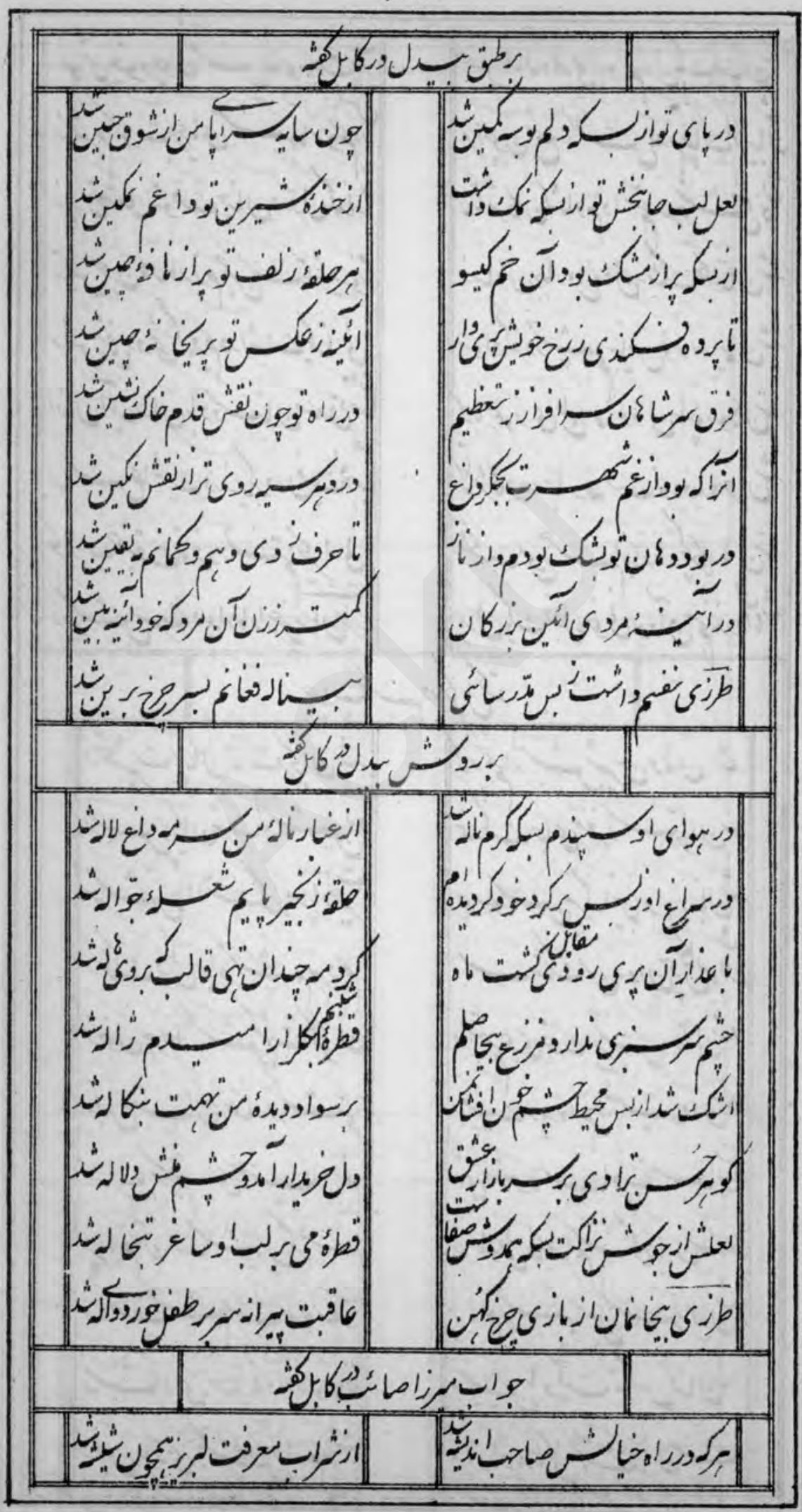


rra

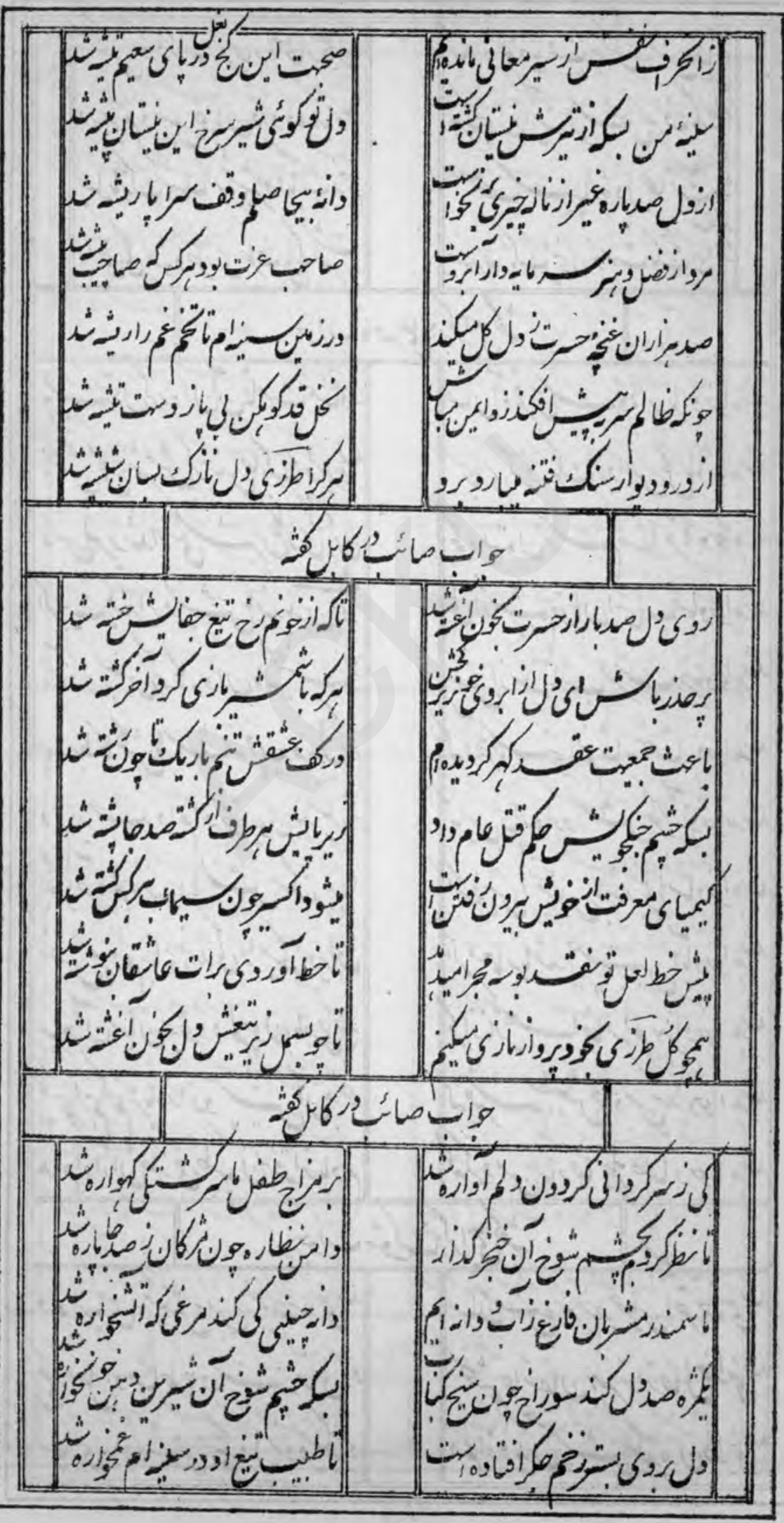


r

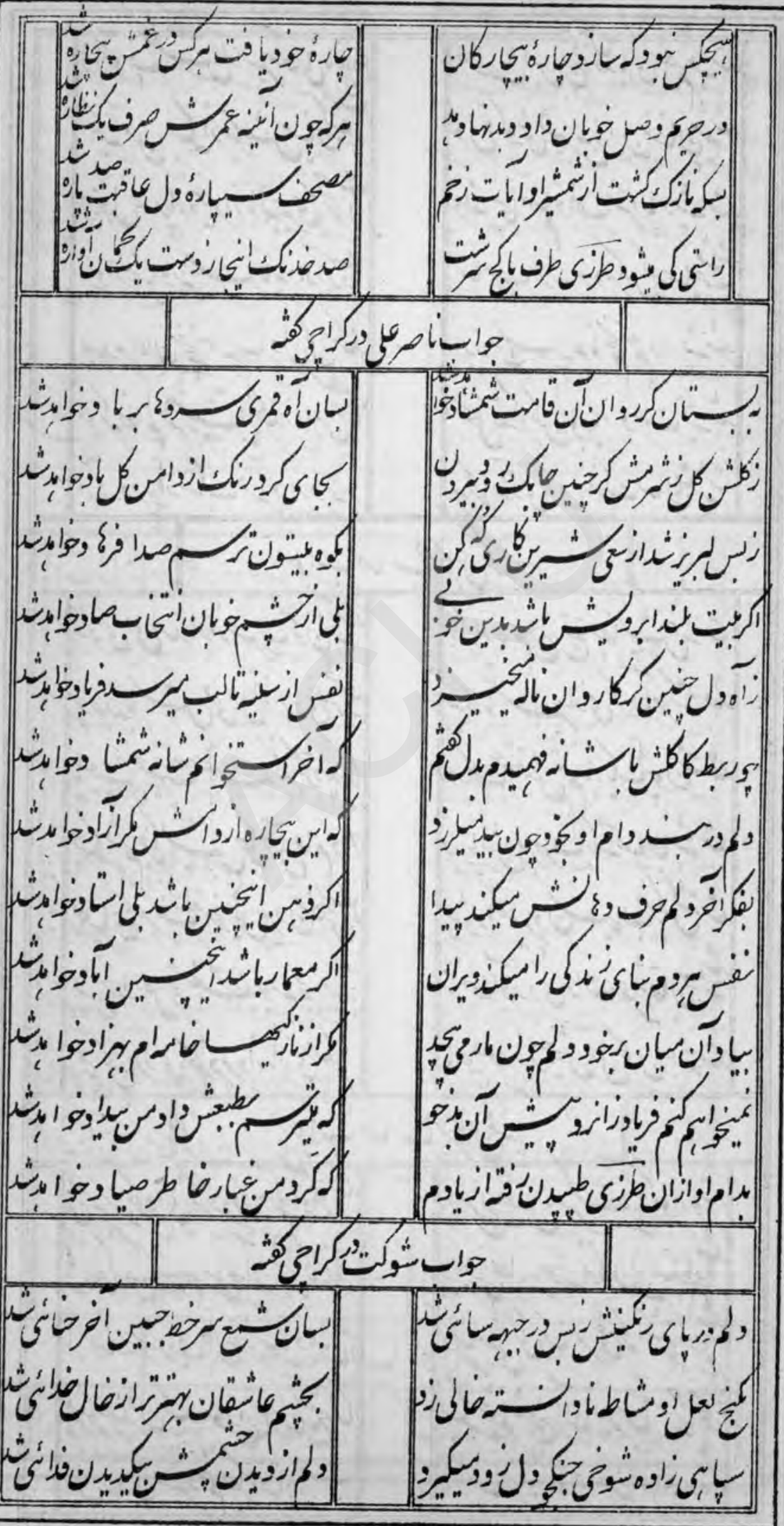




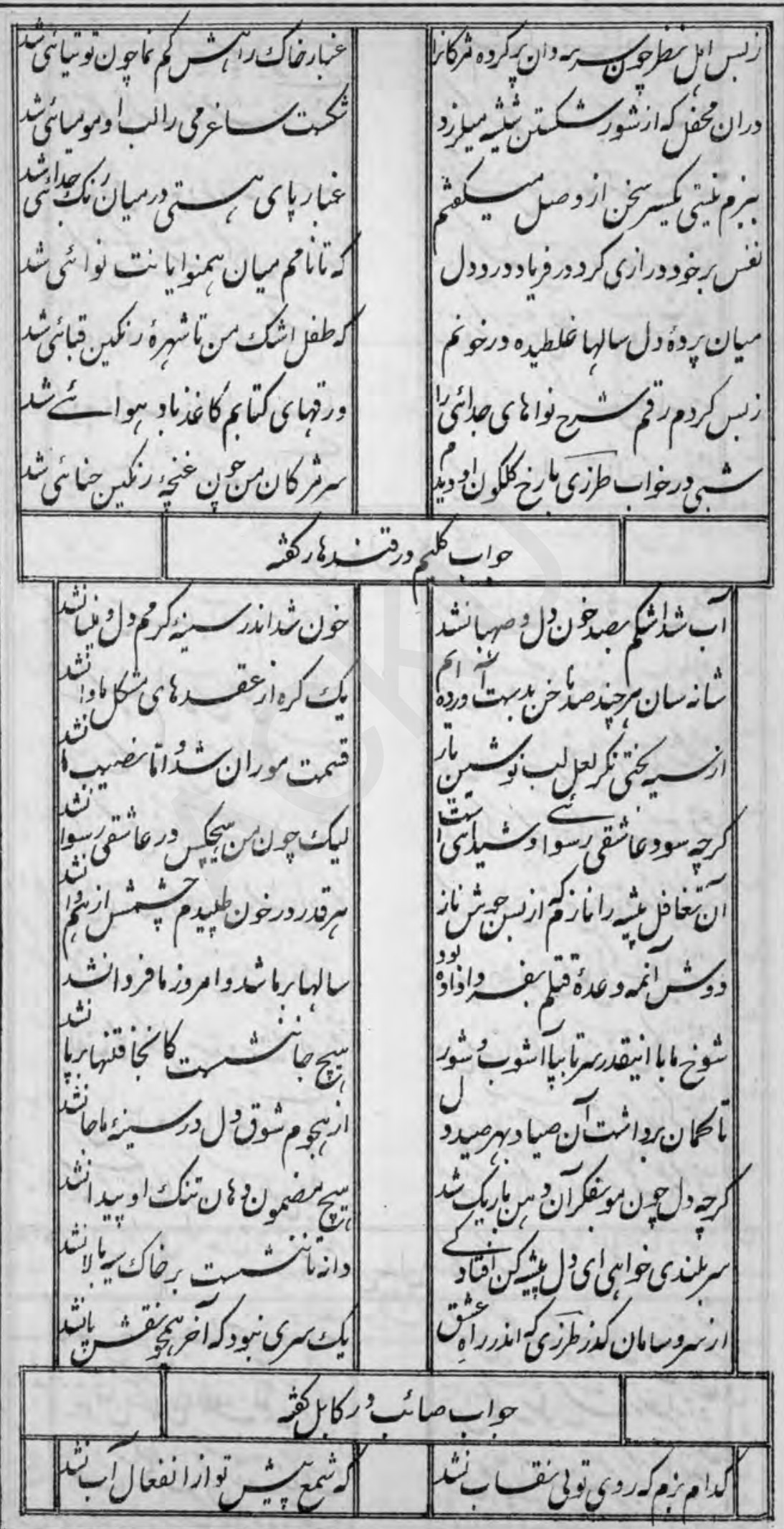




\section{$r r r$}

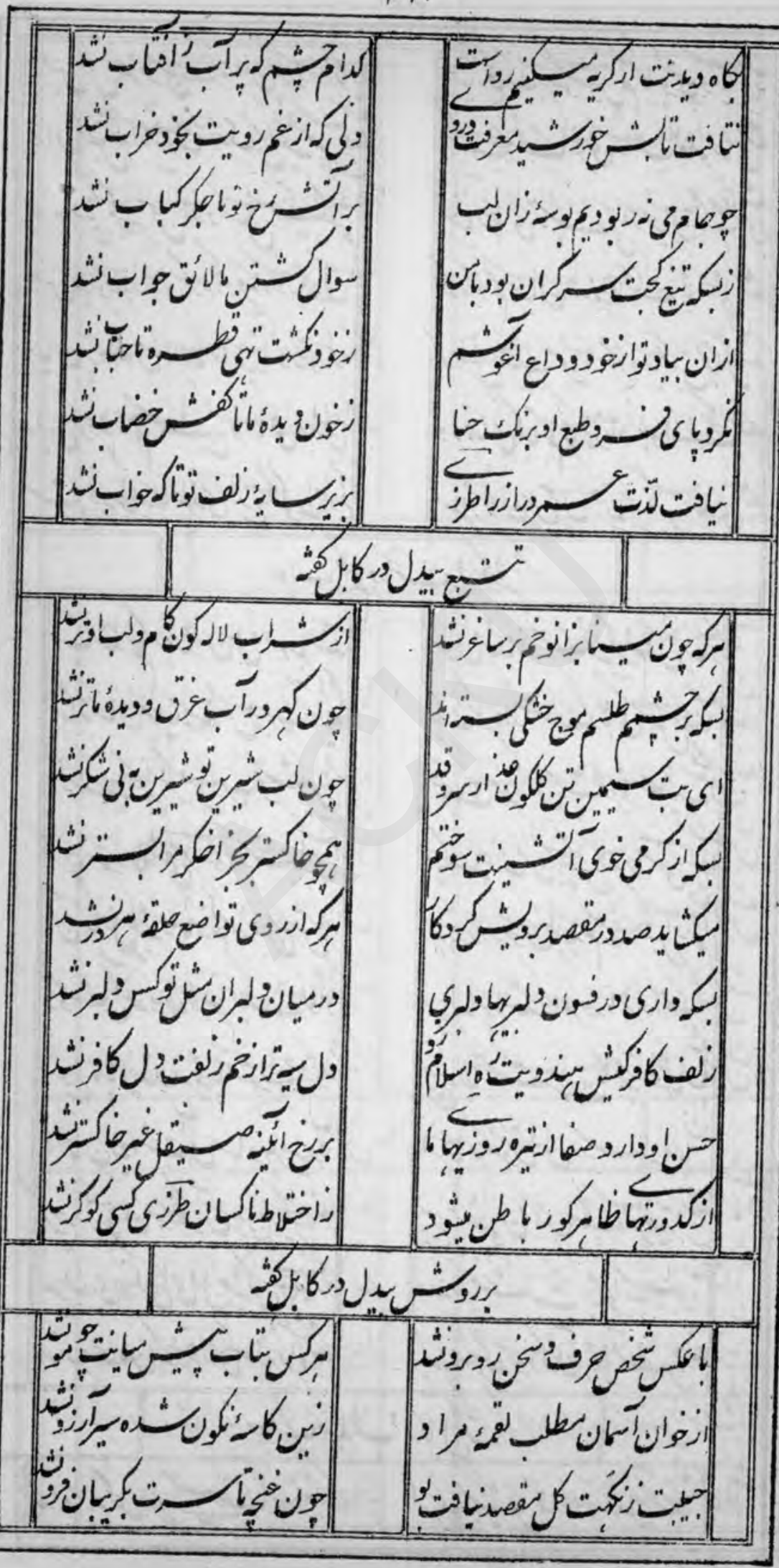


rrr

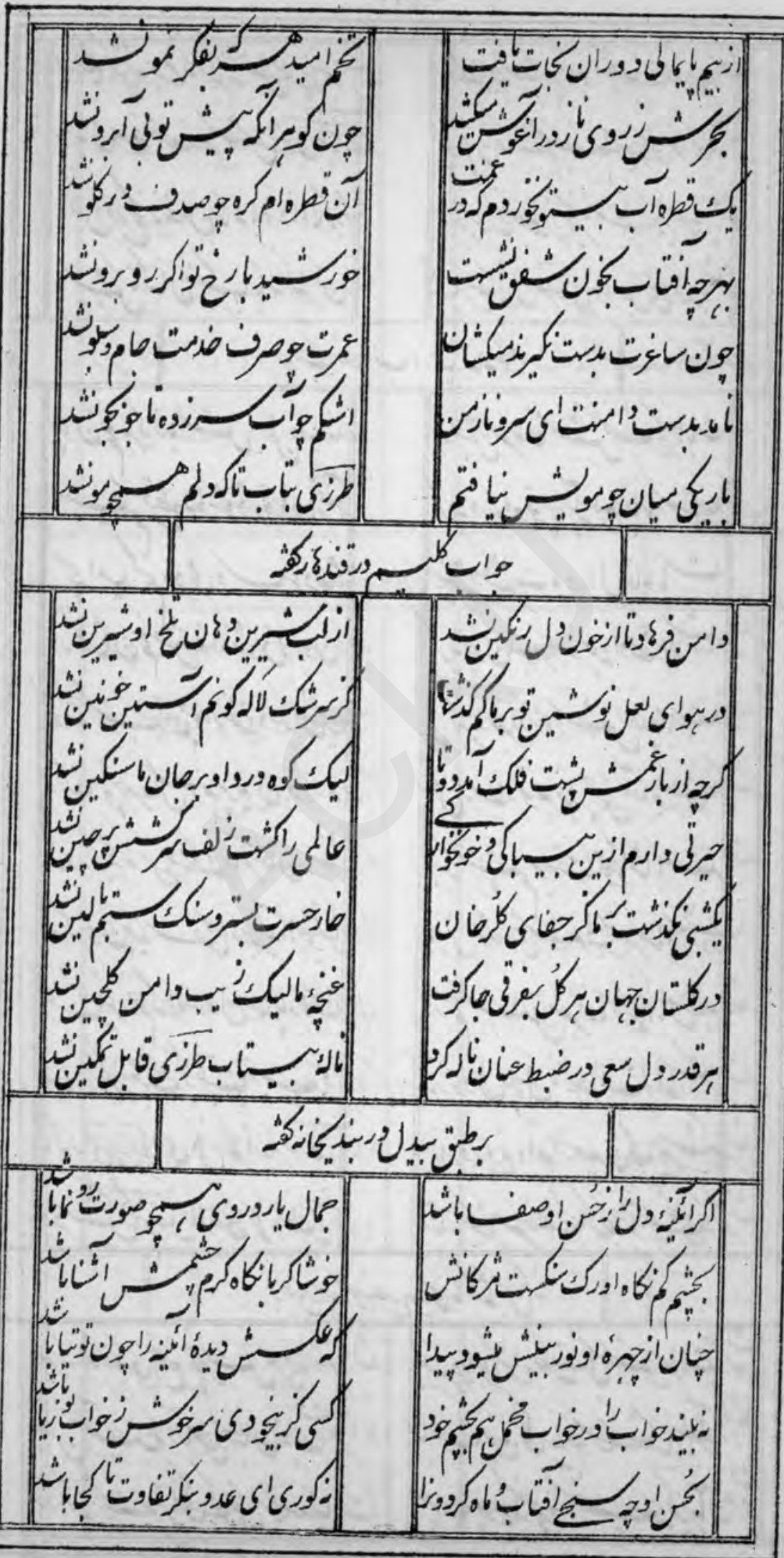


r re

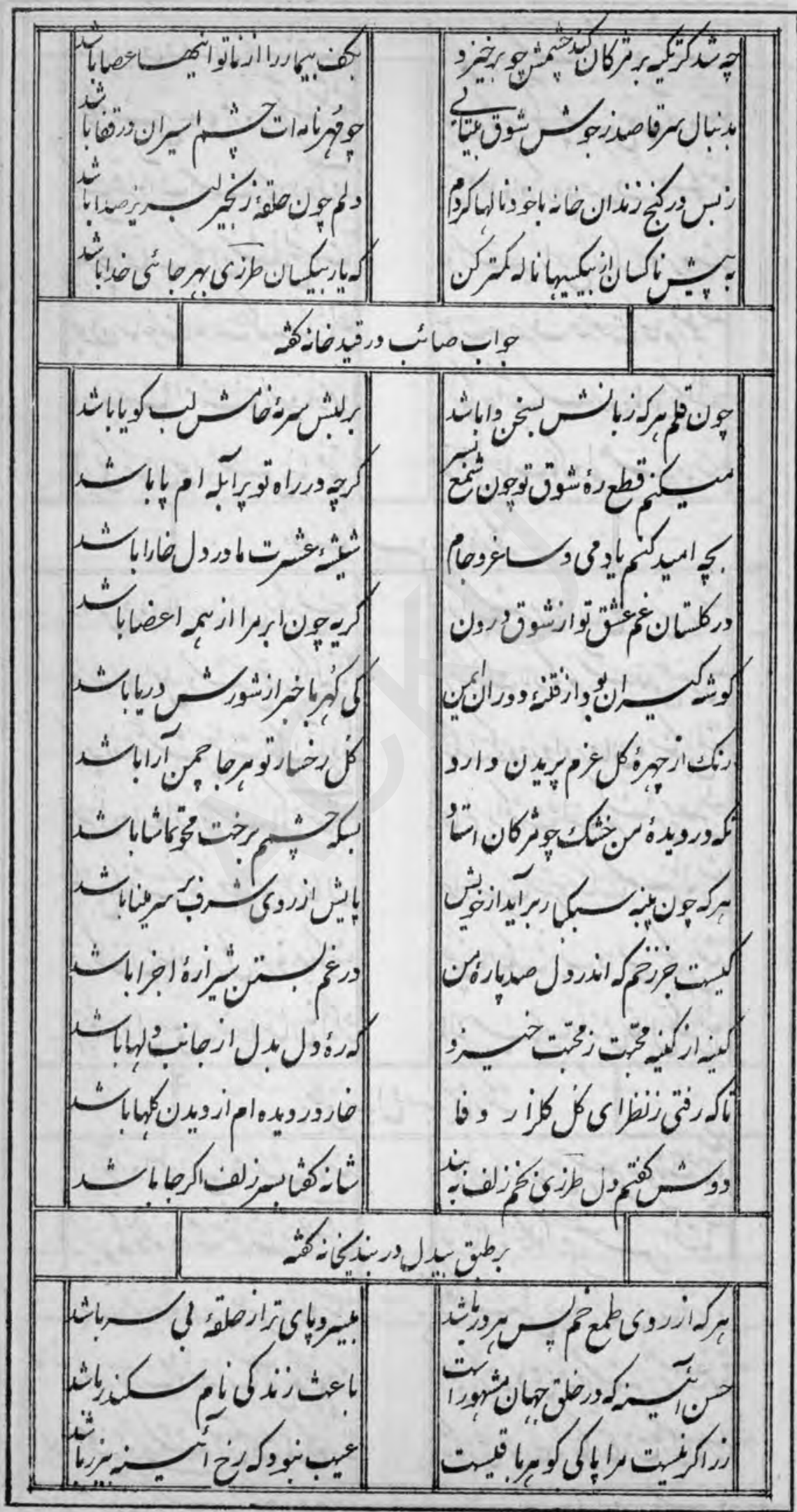


ro

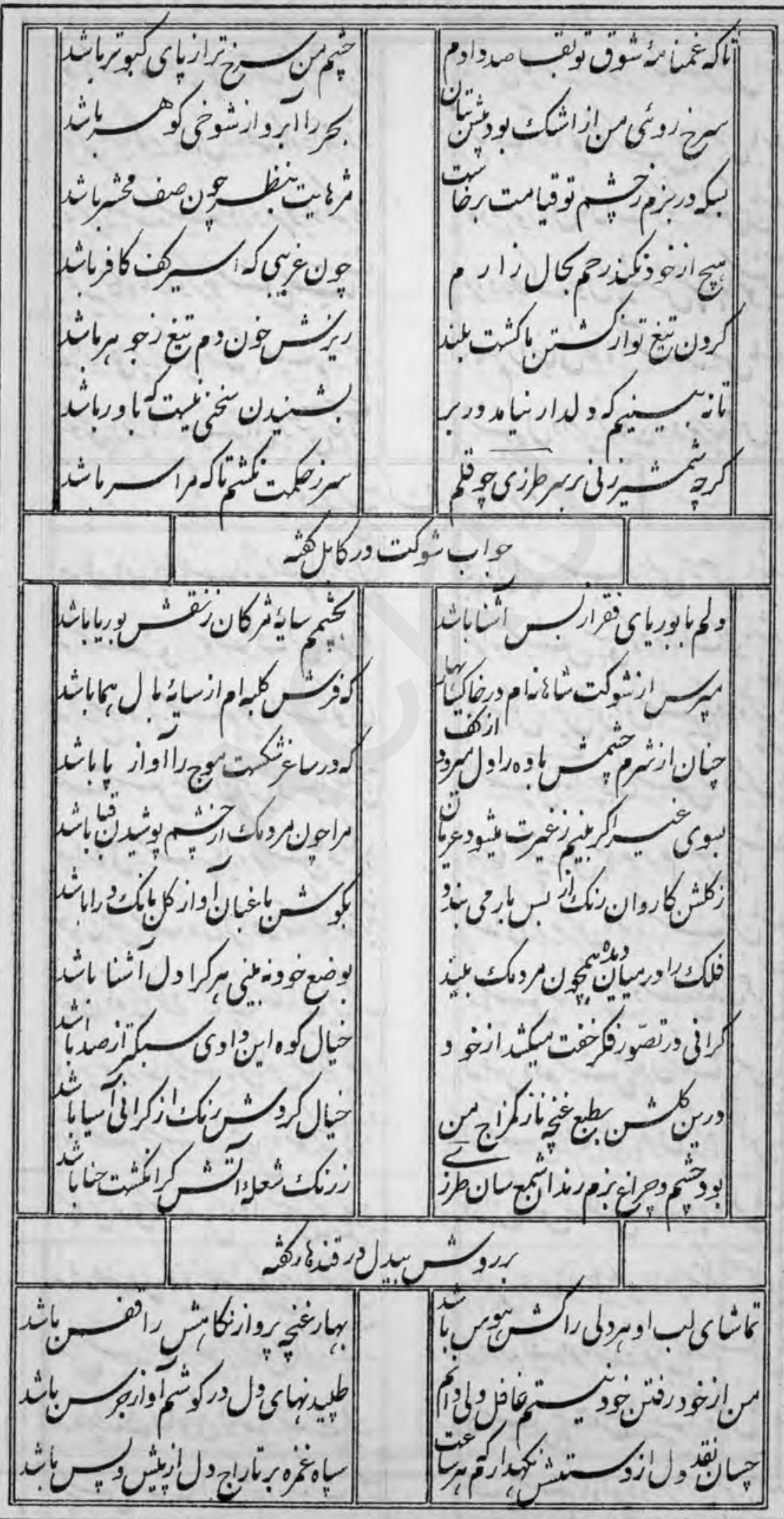


rry

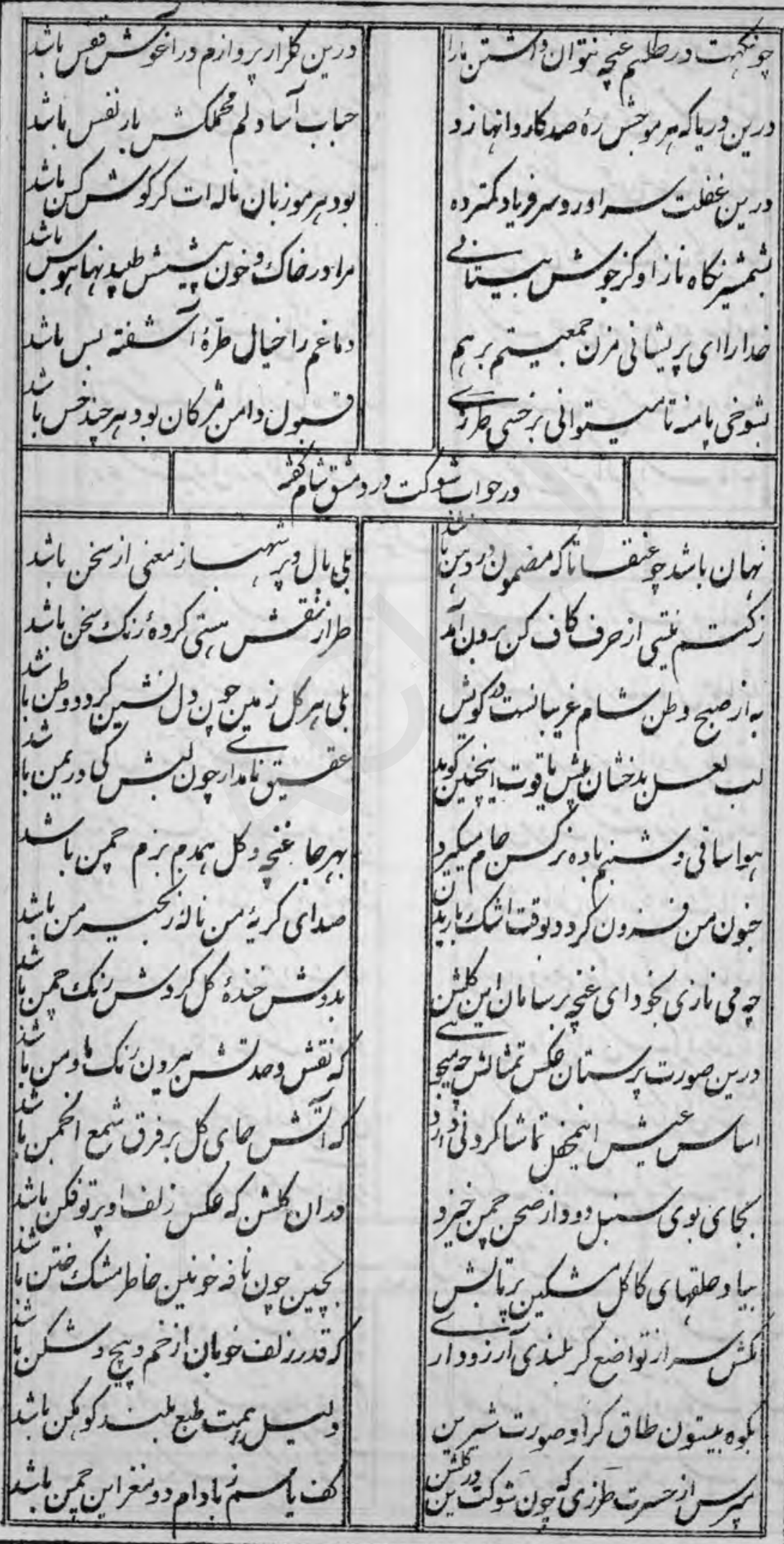


$r r$

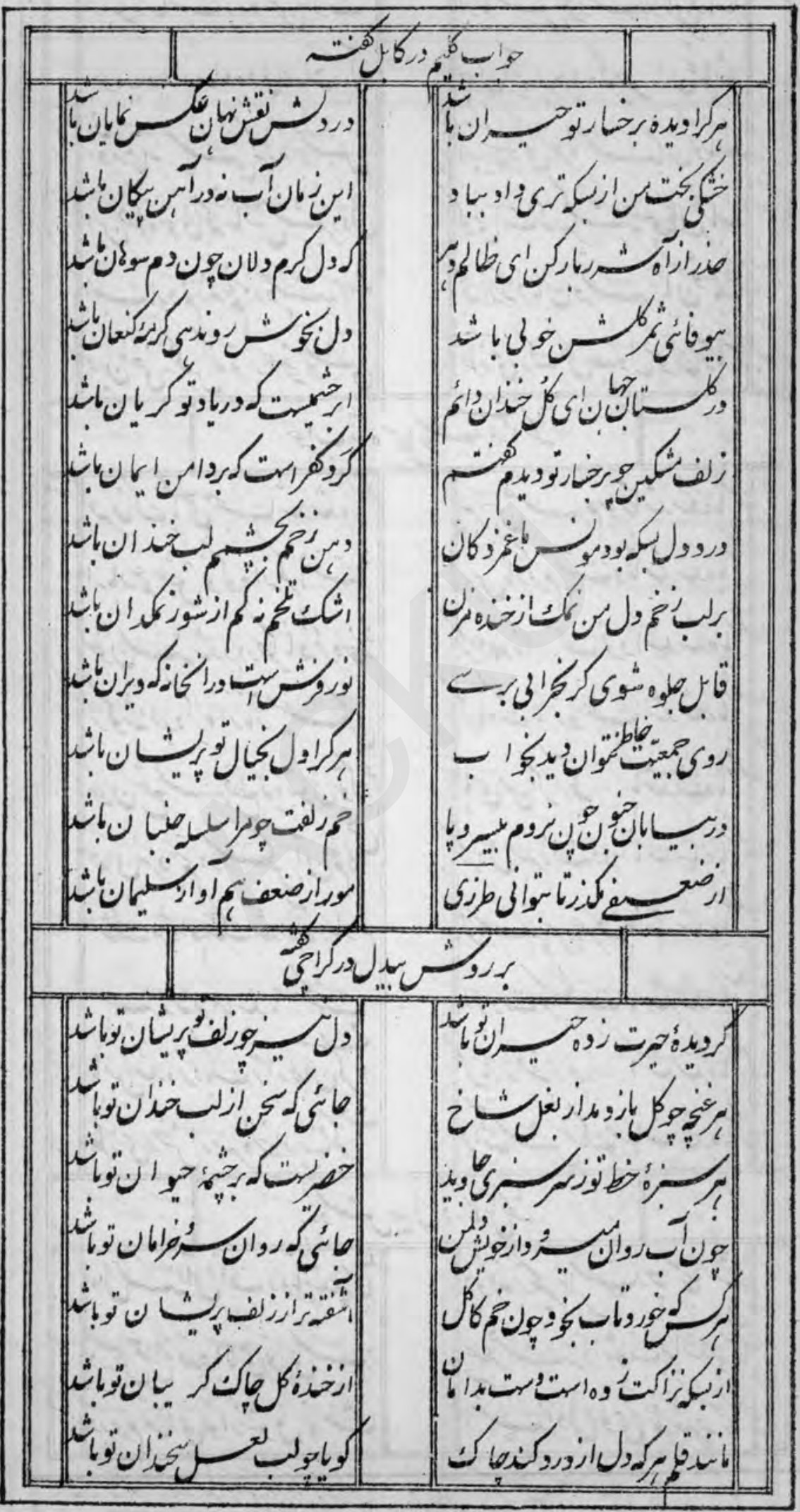


$r$ YA

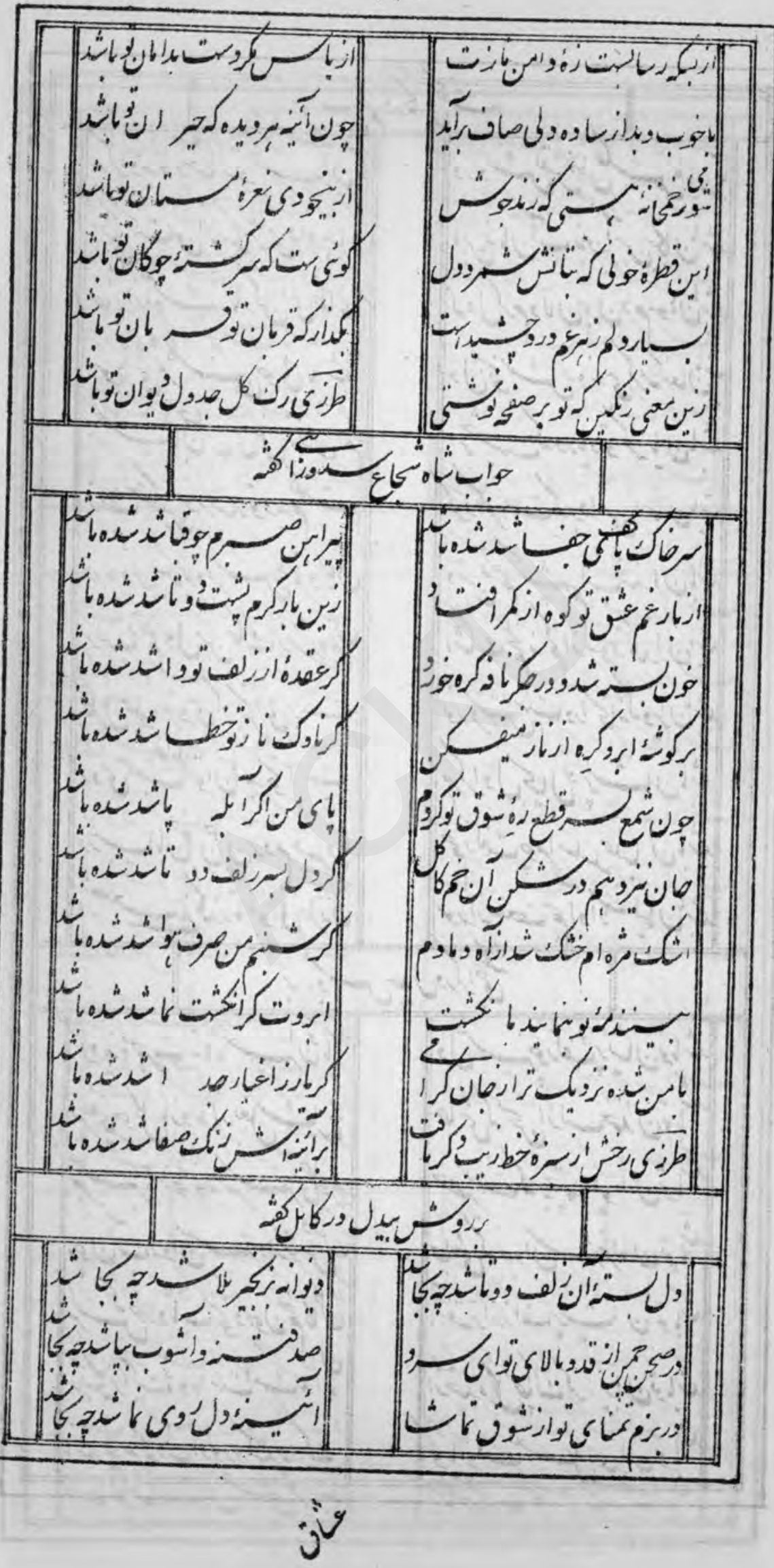


ror 9

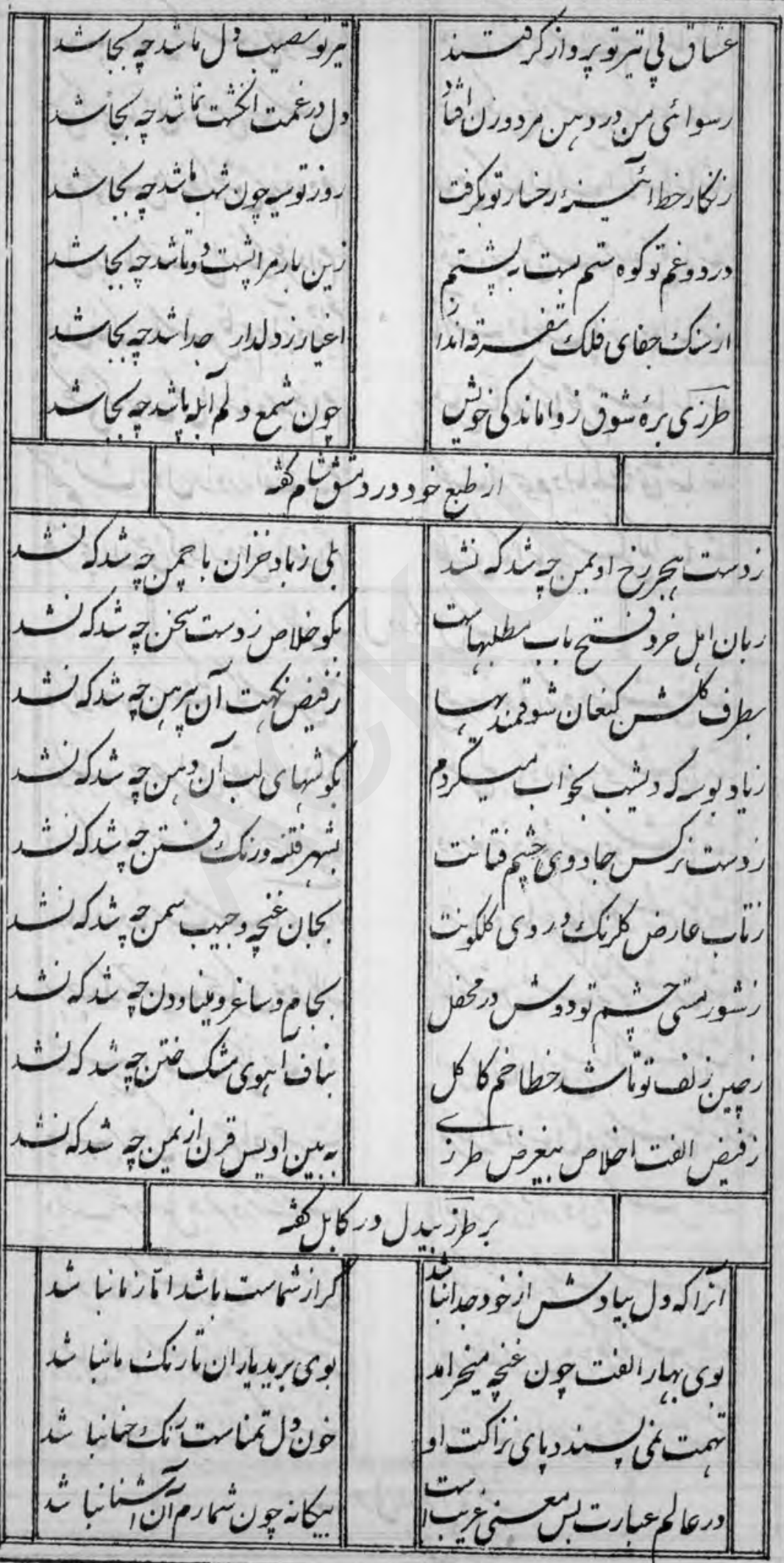


re.

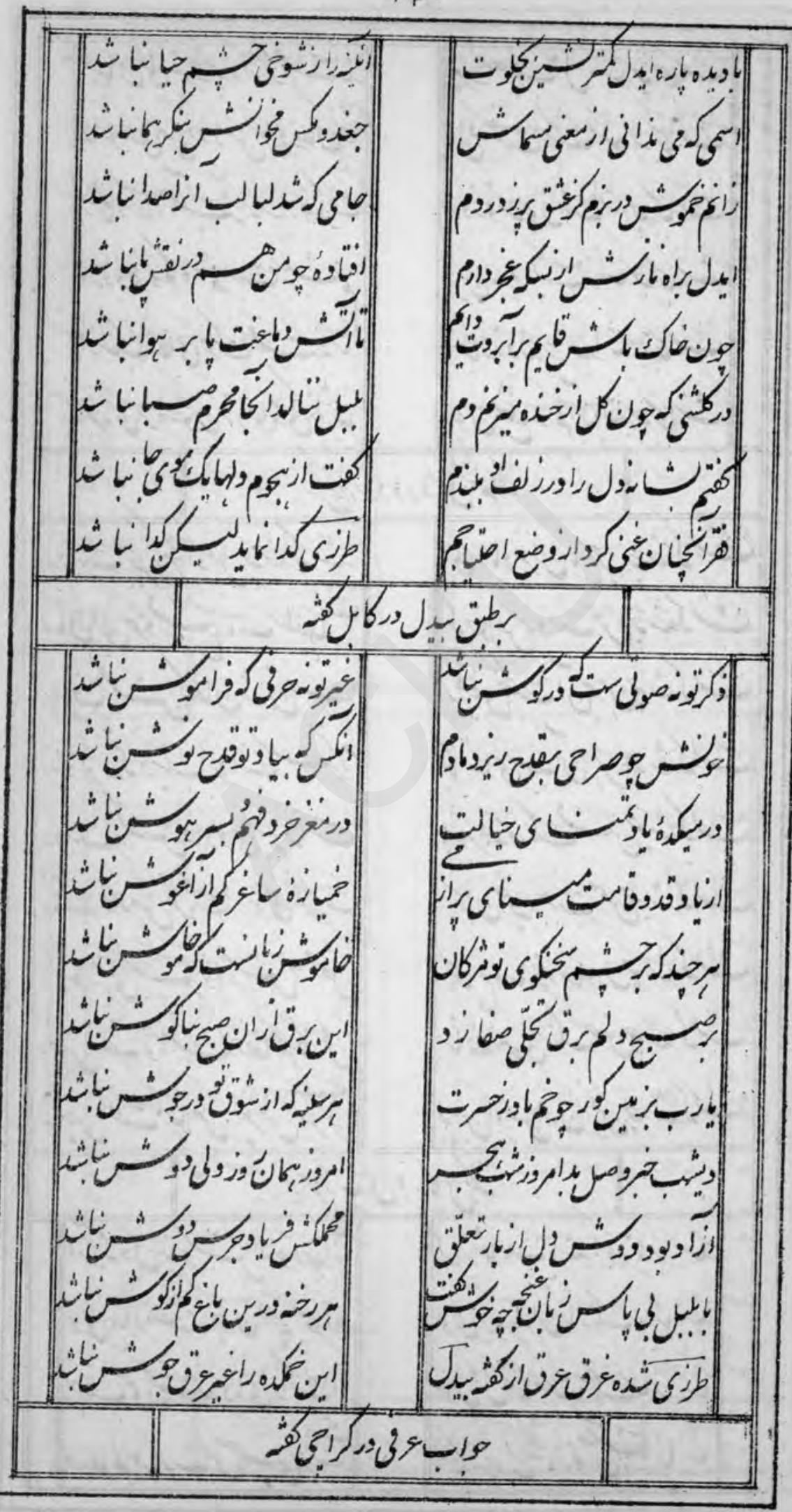

3 
ref

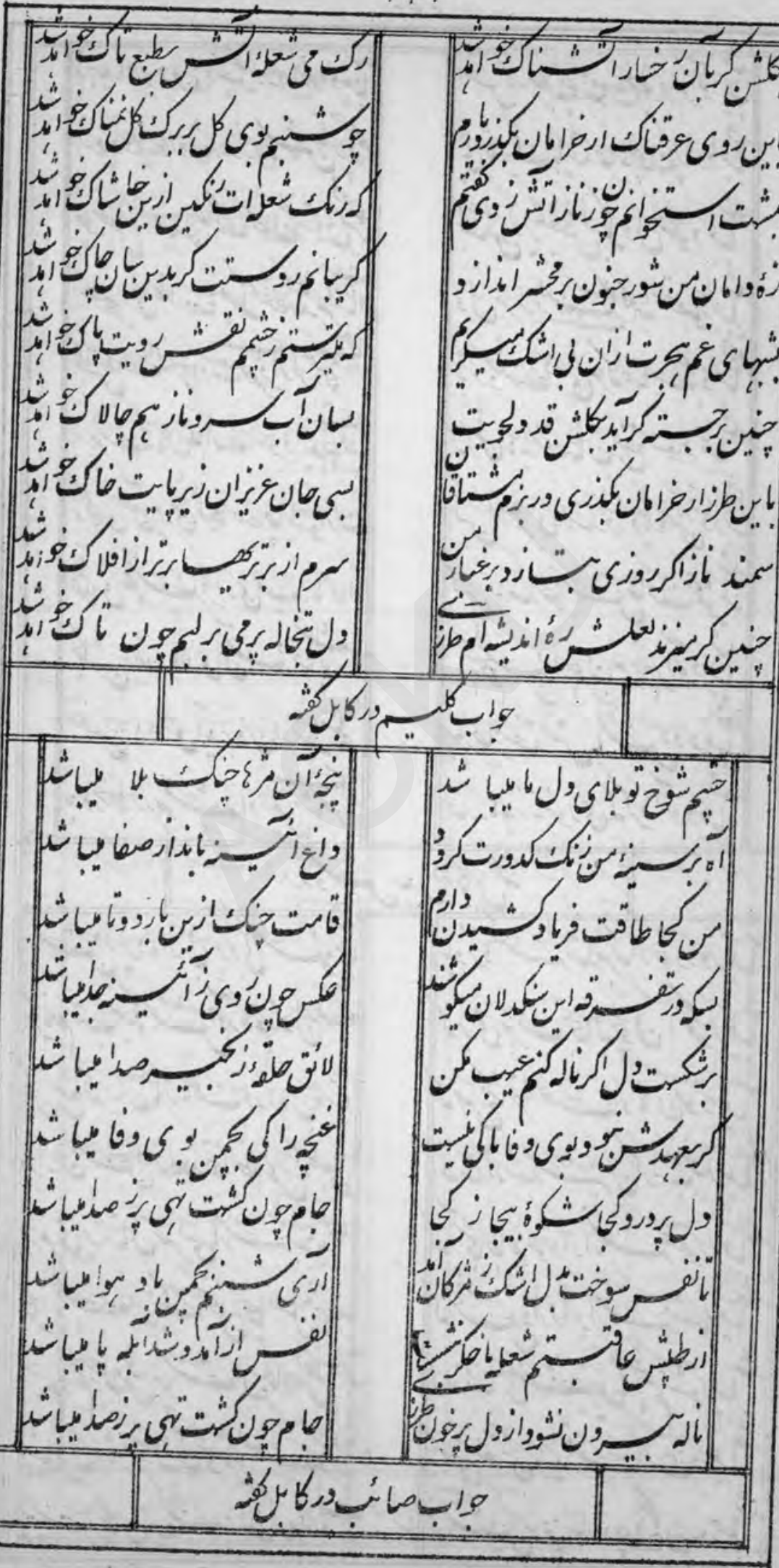


rer

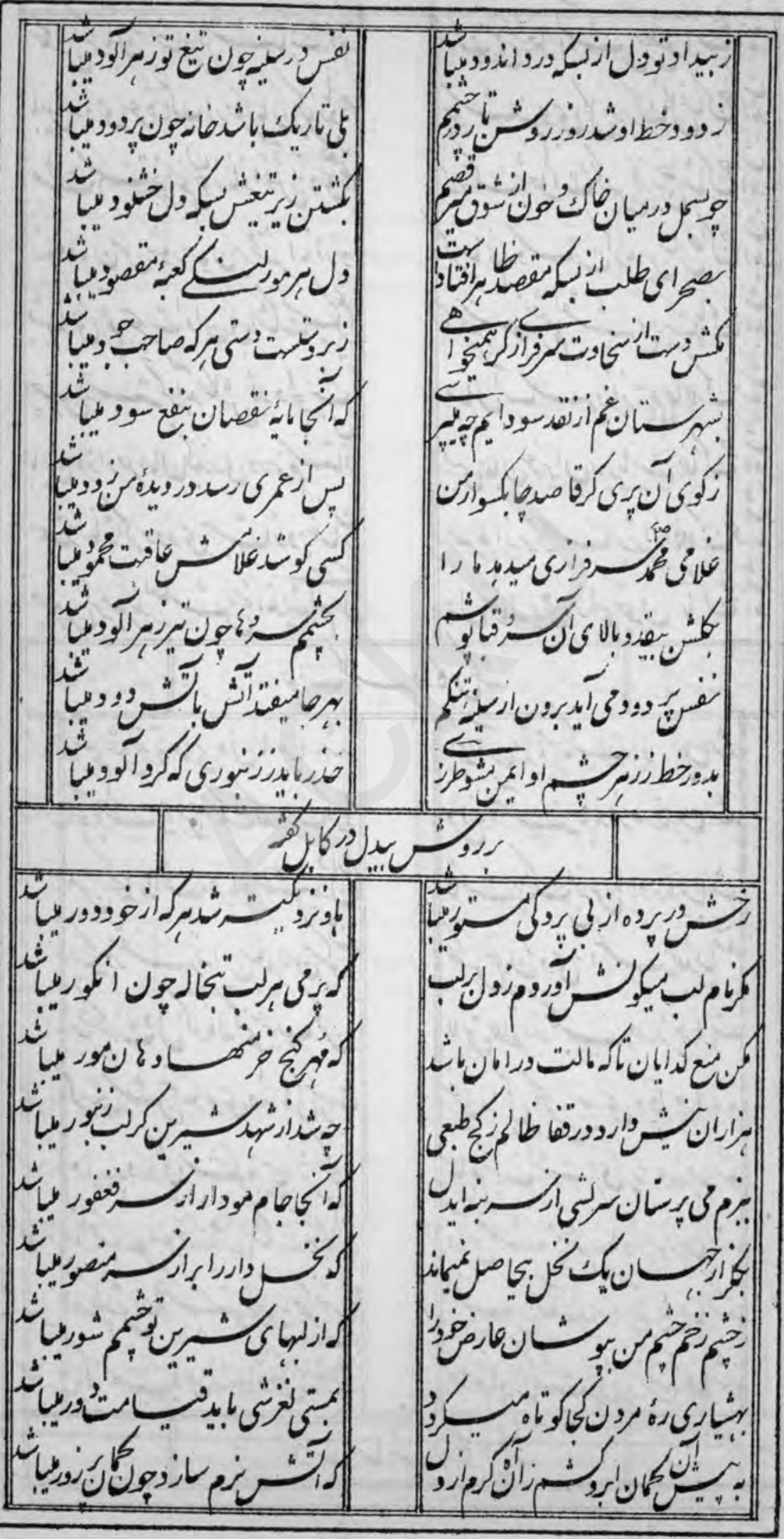

s. 
rrer

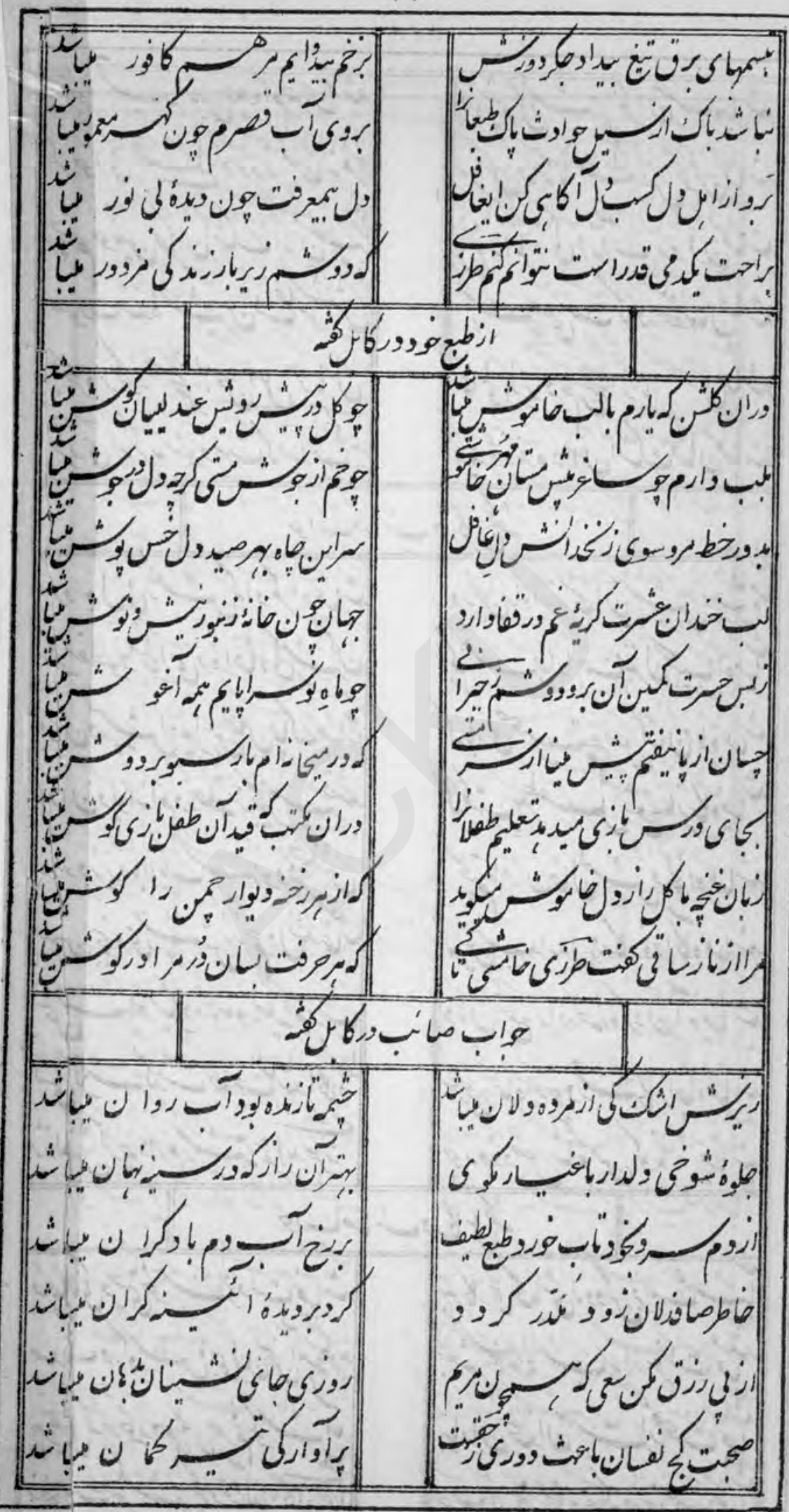


FFF

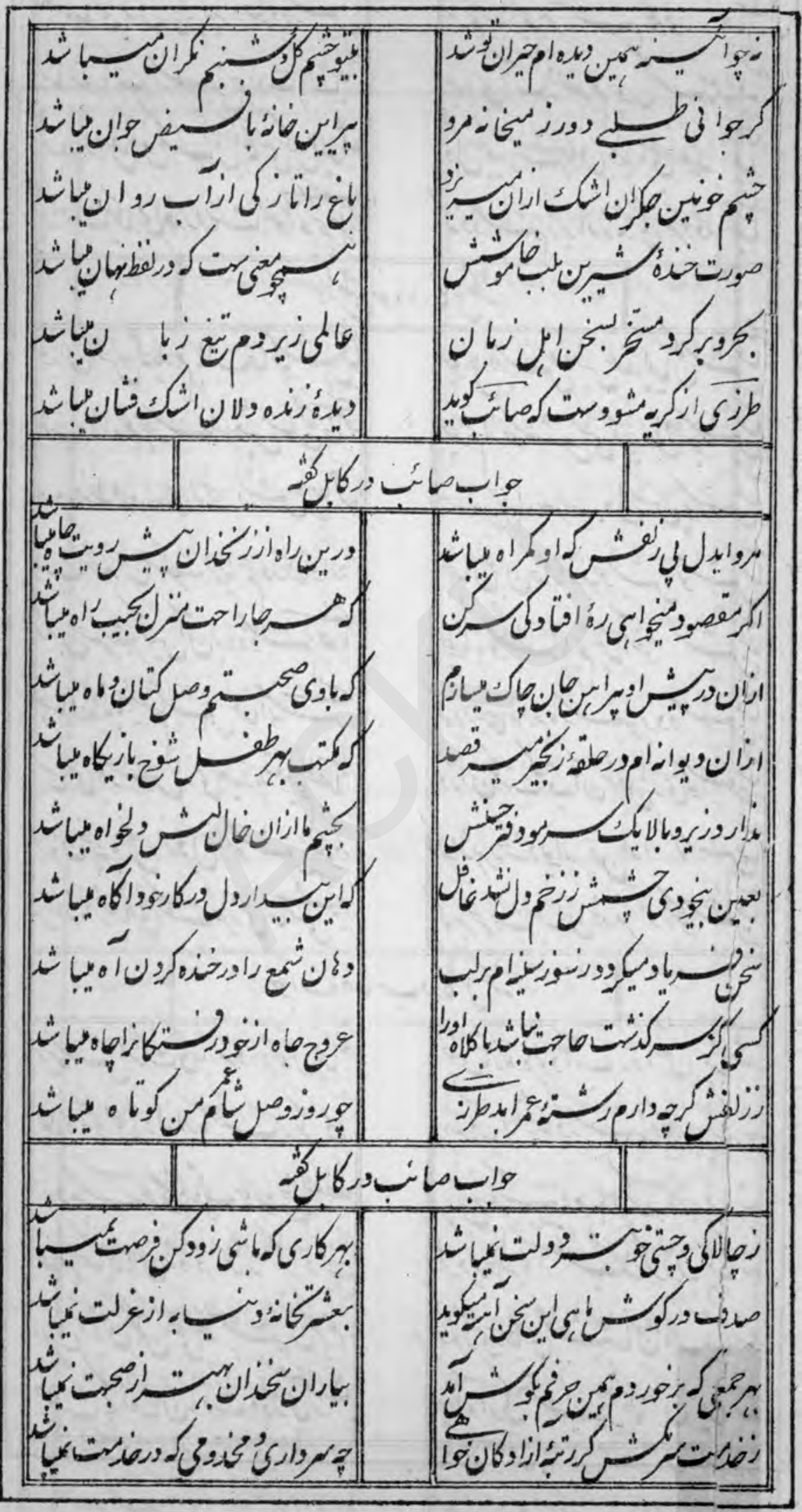

s)." 


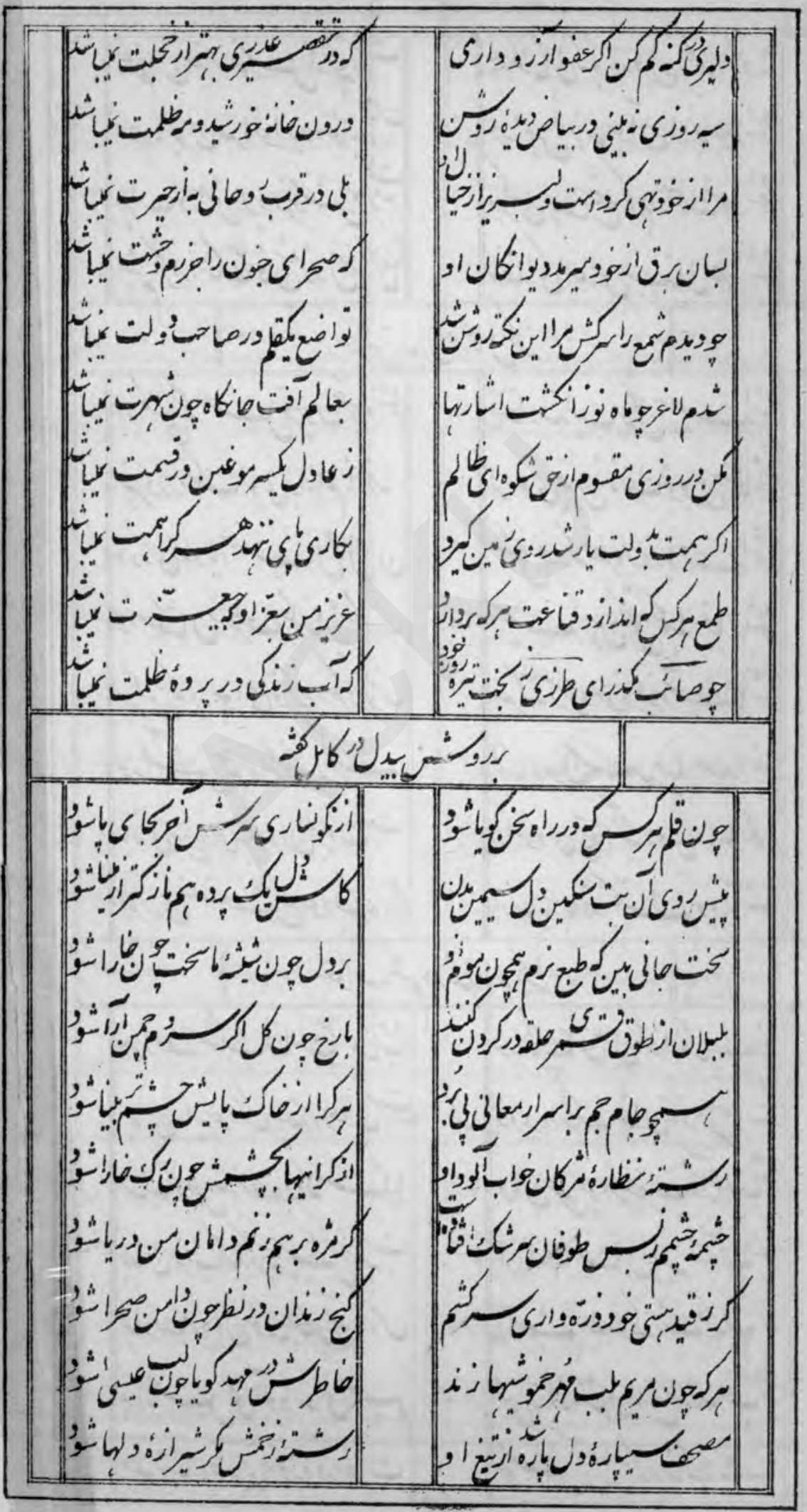


res

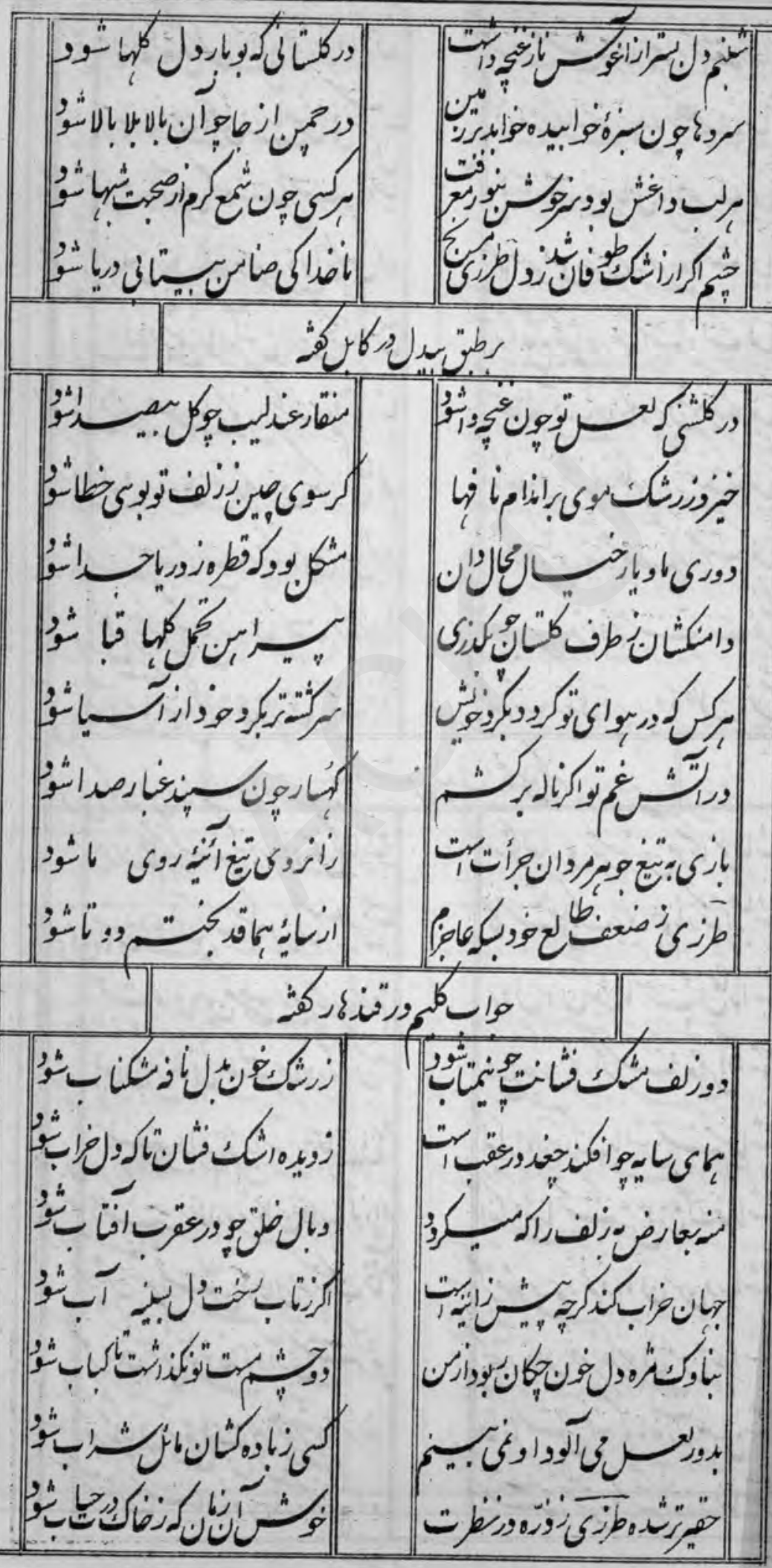


rト

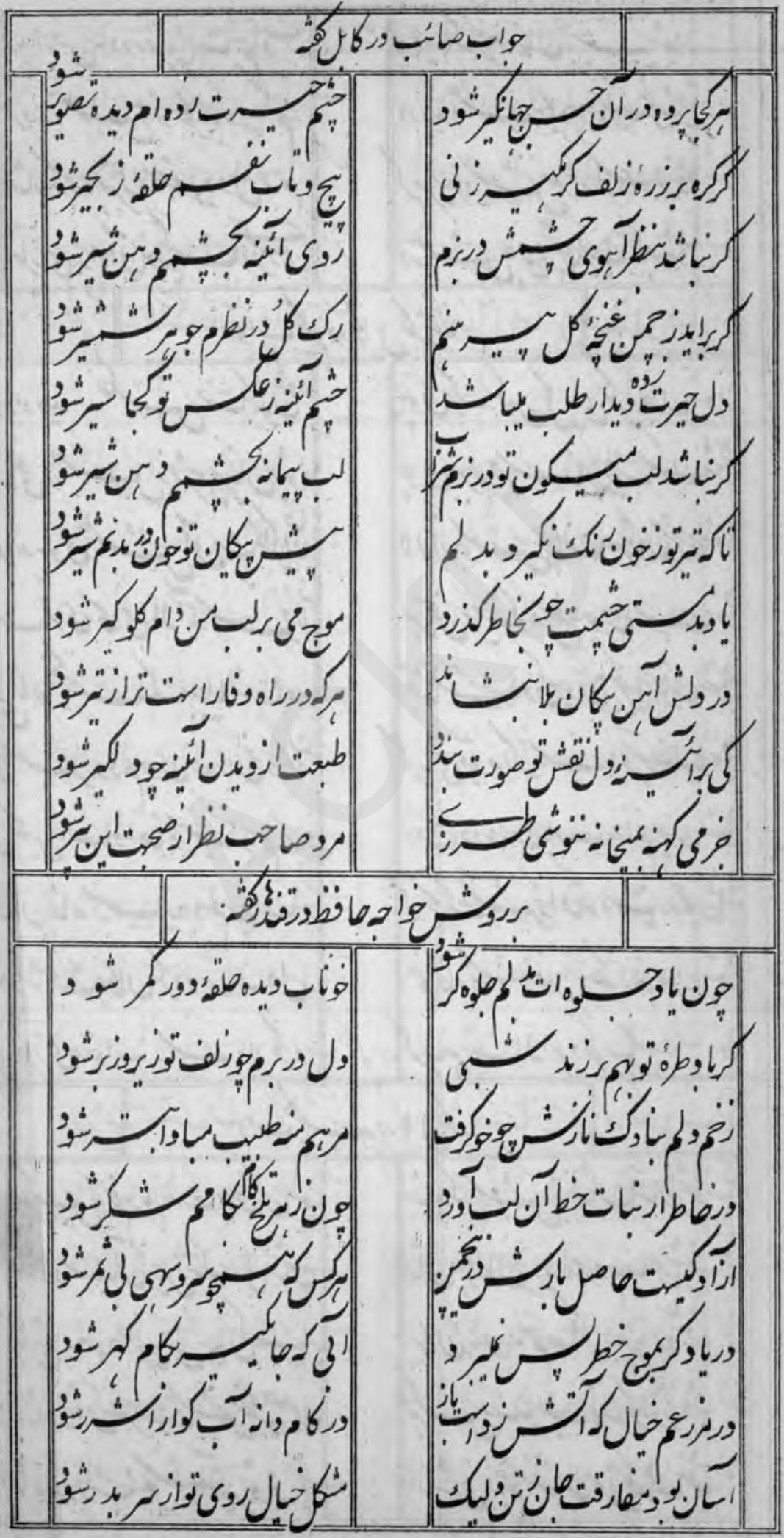


$r \wedge$

||


req

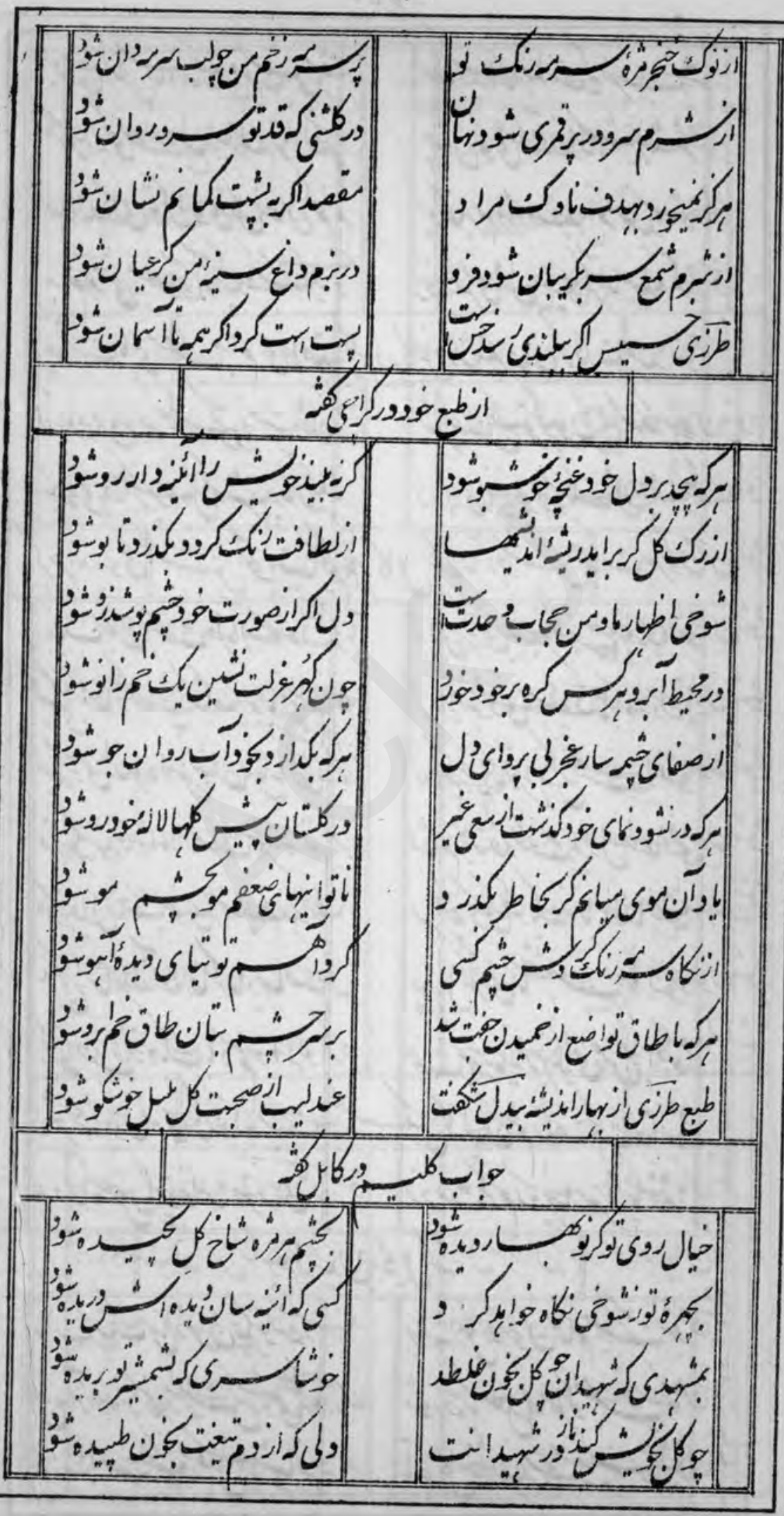


$r \omega$.

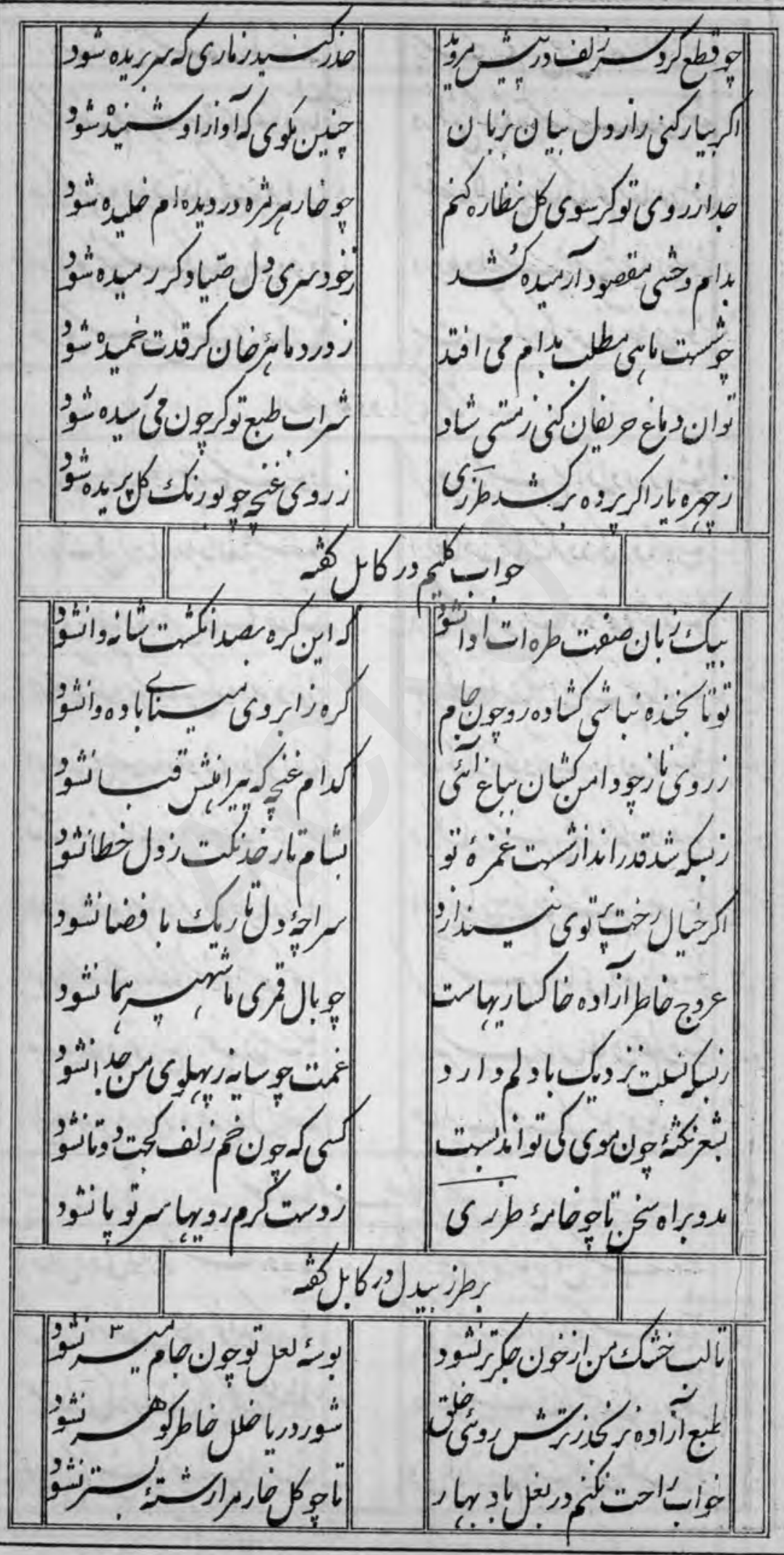

: 
rol

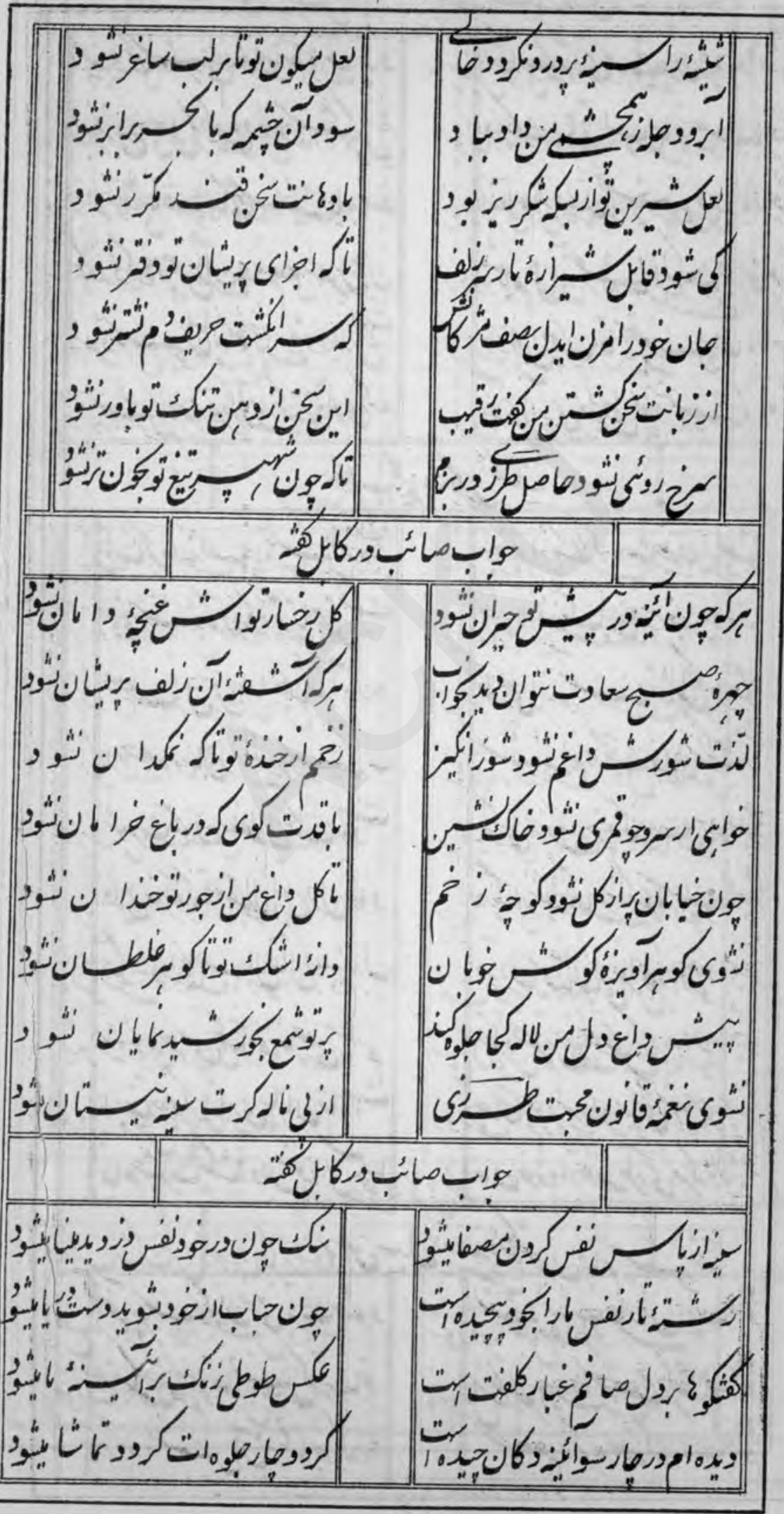


rar

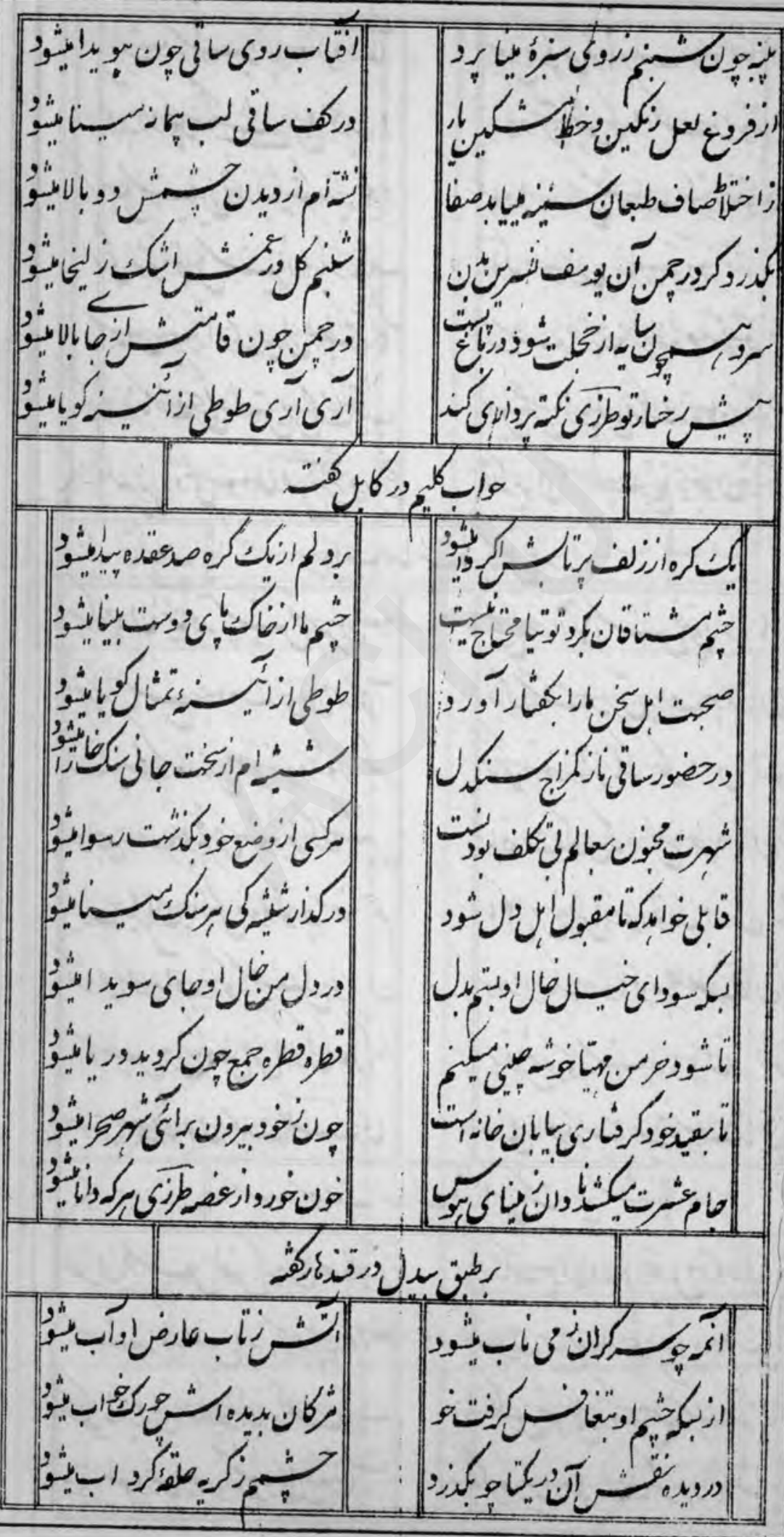


$r a r$

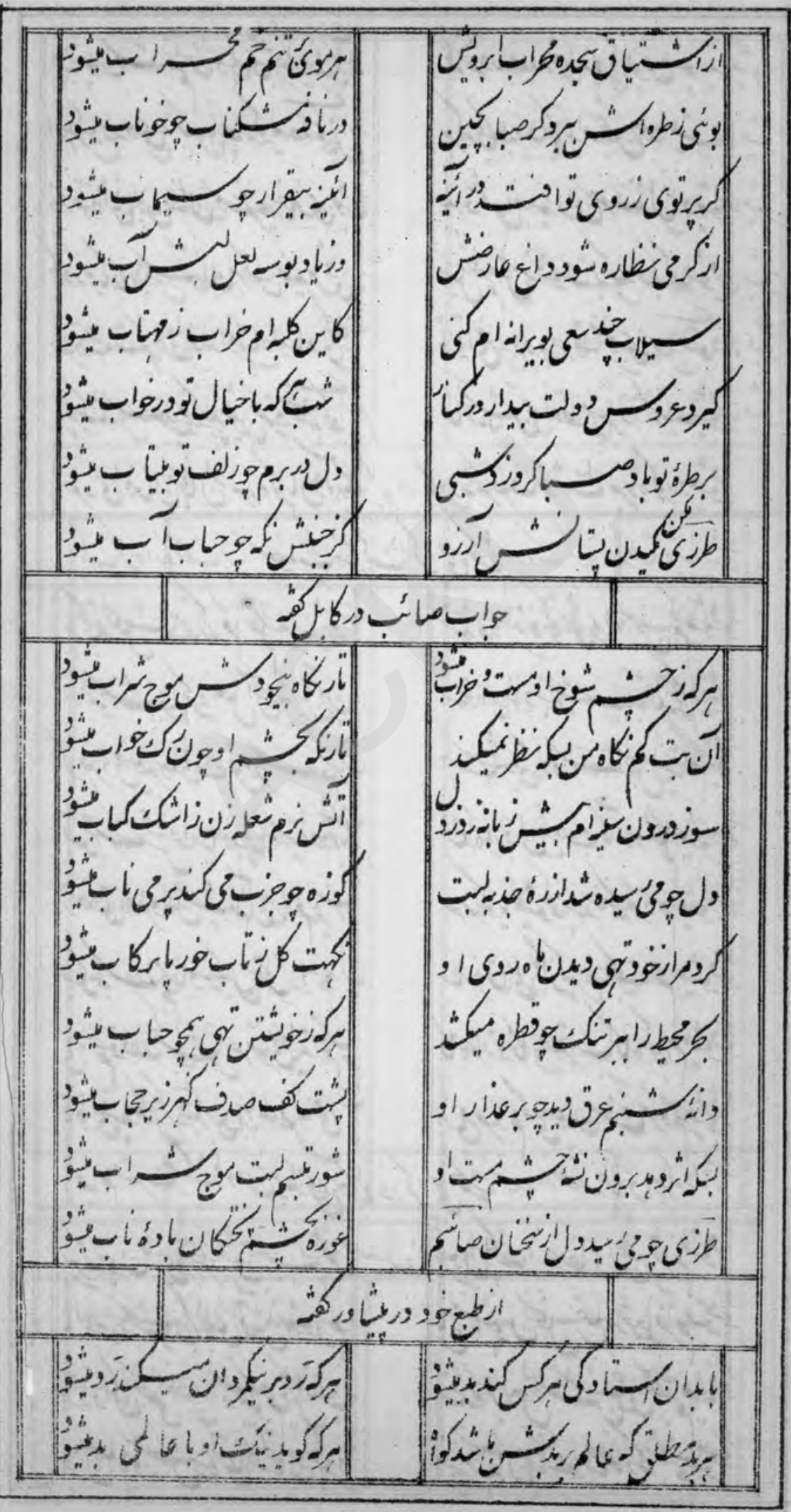


$r a r$

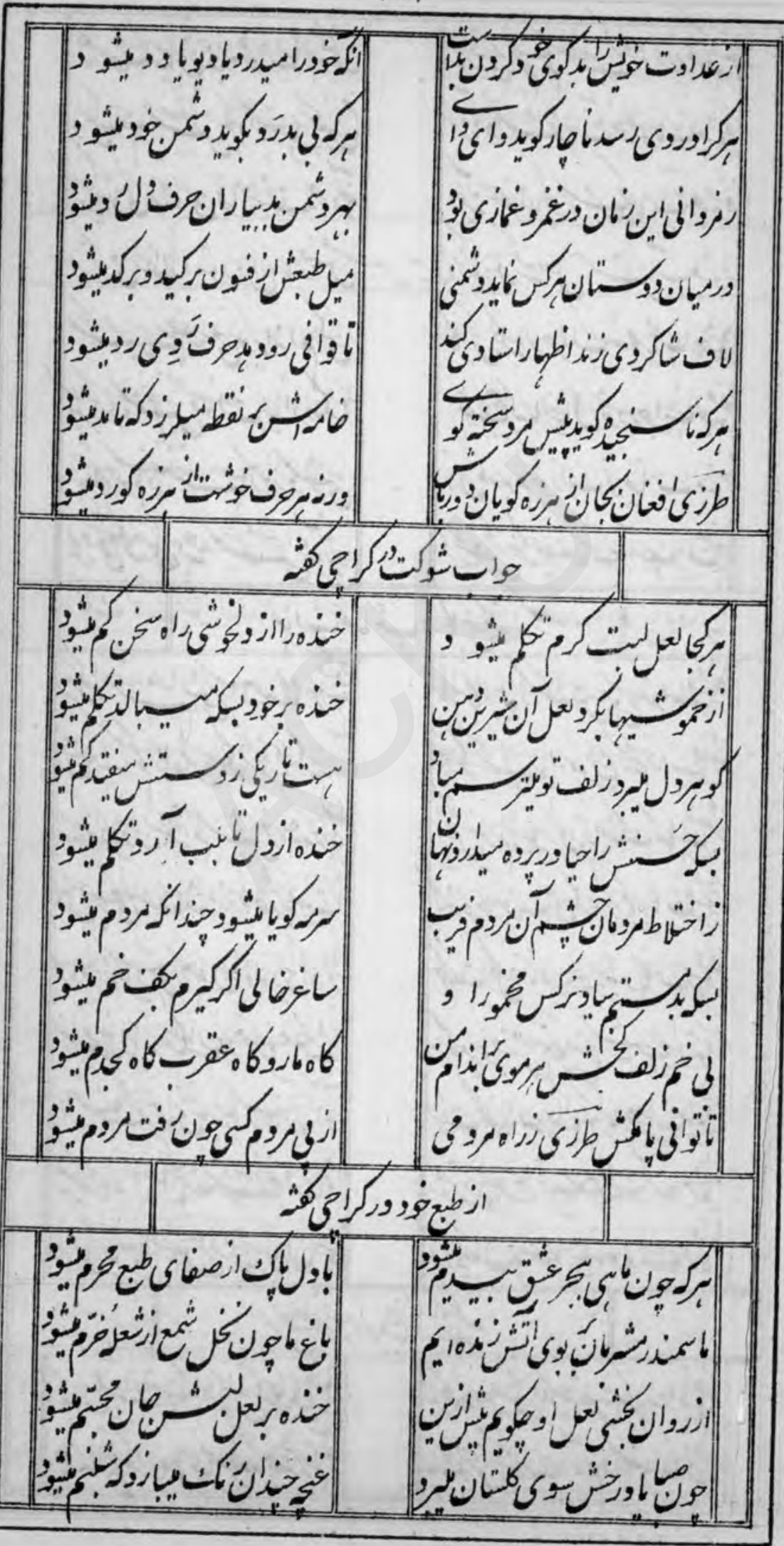


$\sim \Delta \Delta$

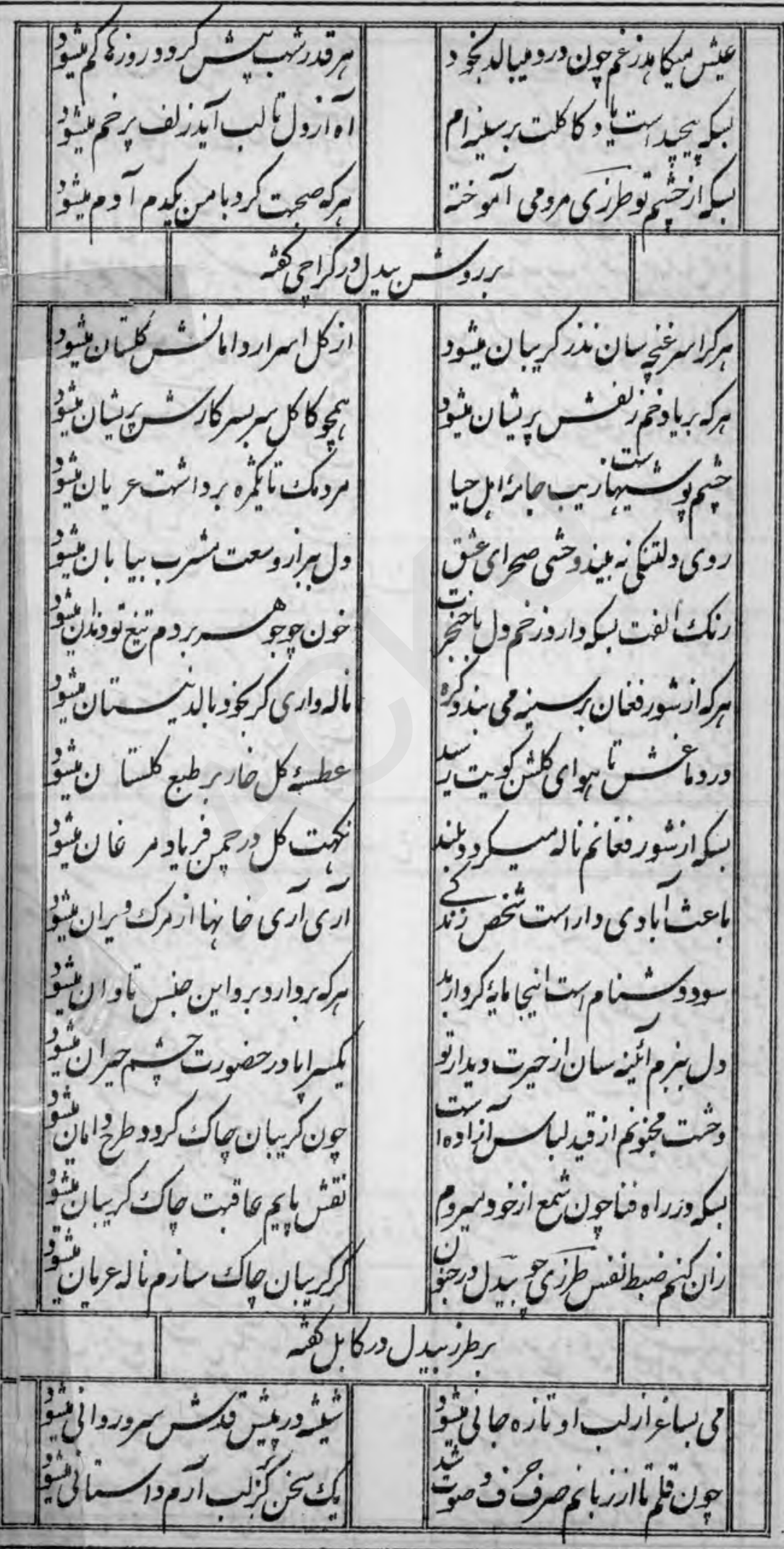


$r i s$

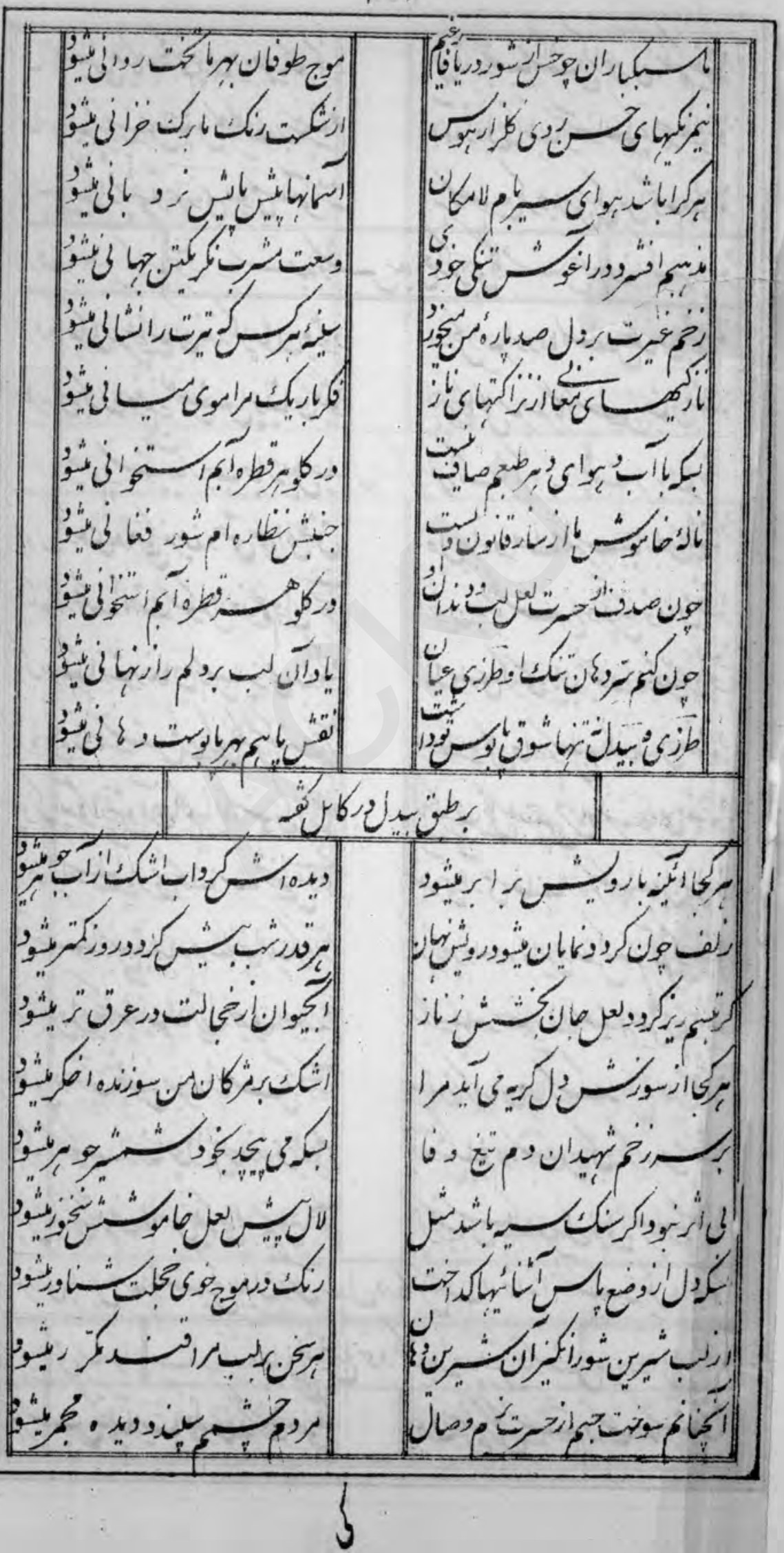


$-\omega<$

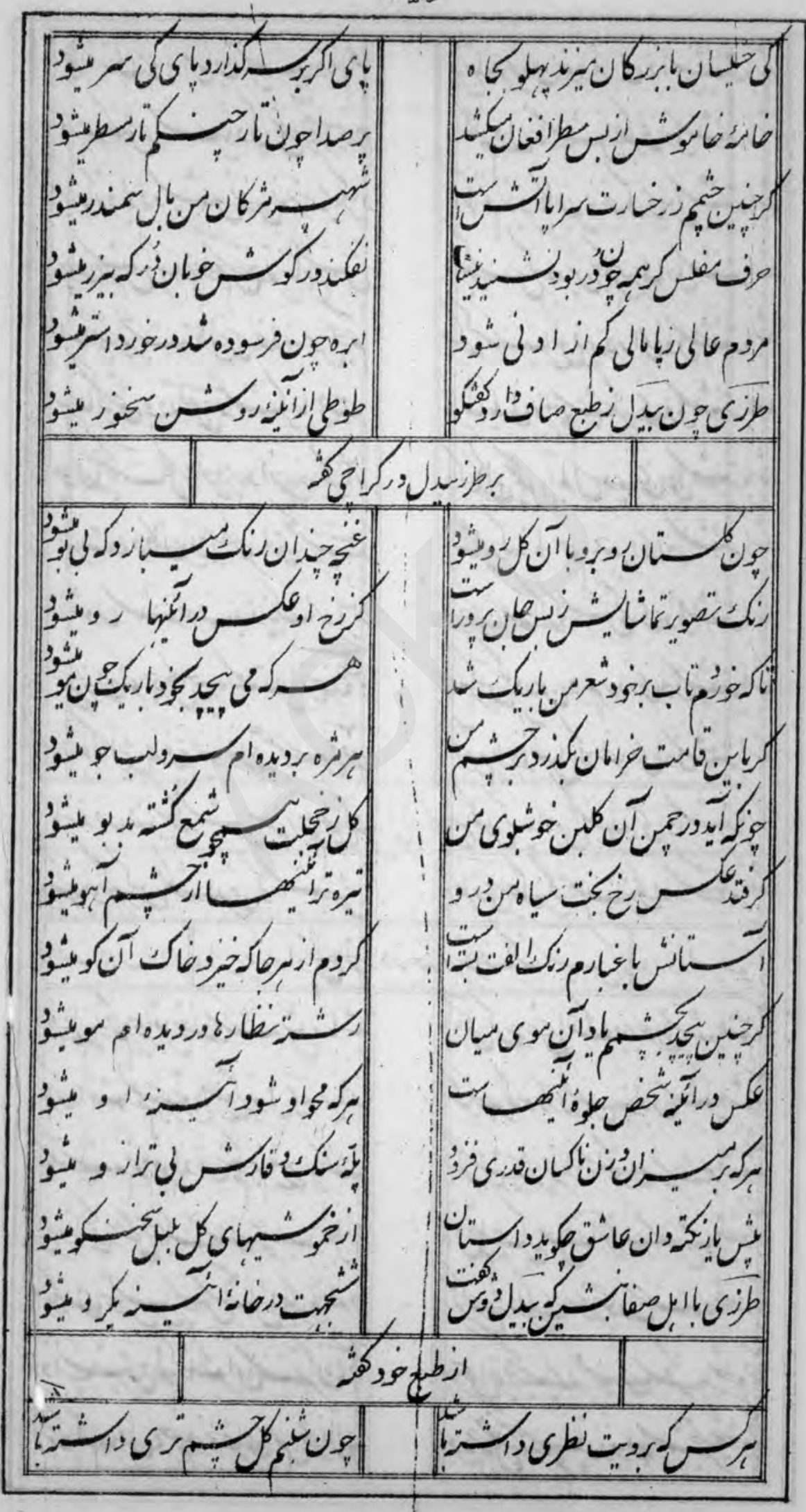


$\operatorname{ran}$

|


$r \Delta 4$

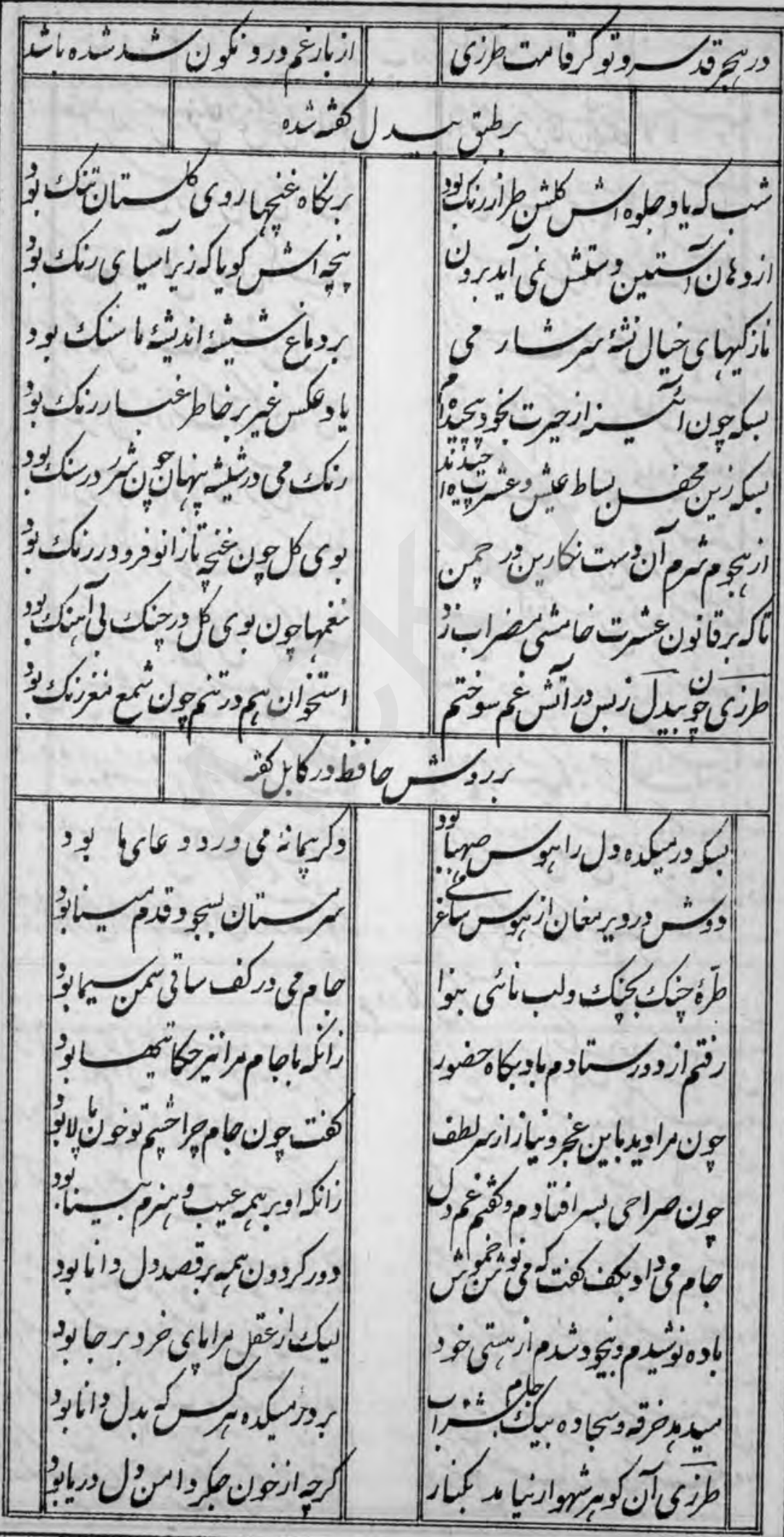


ry

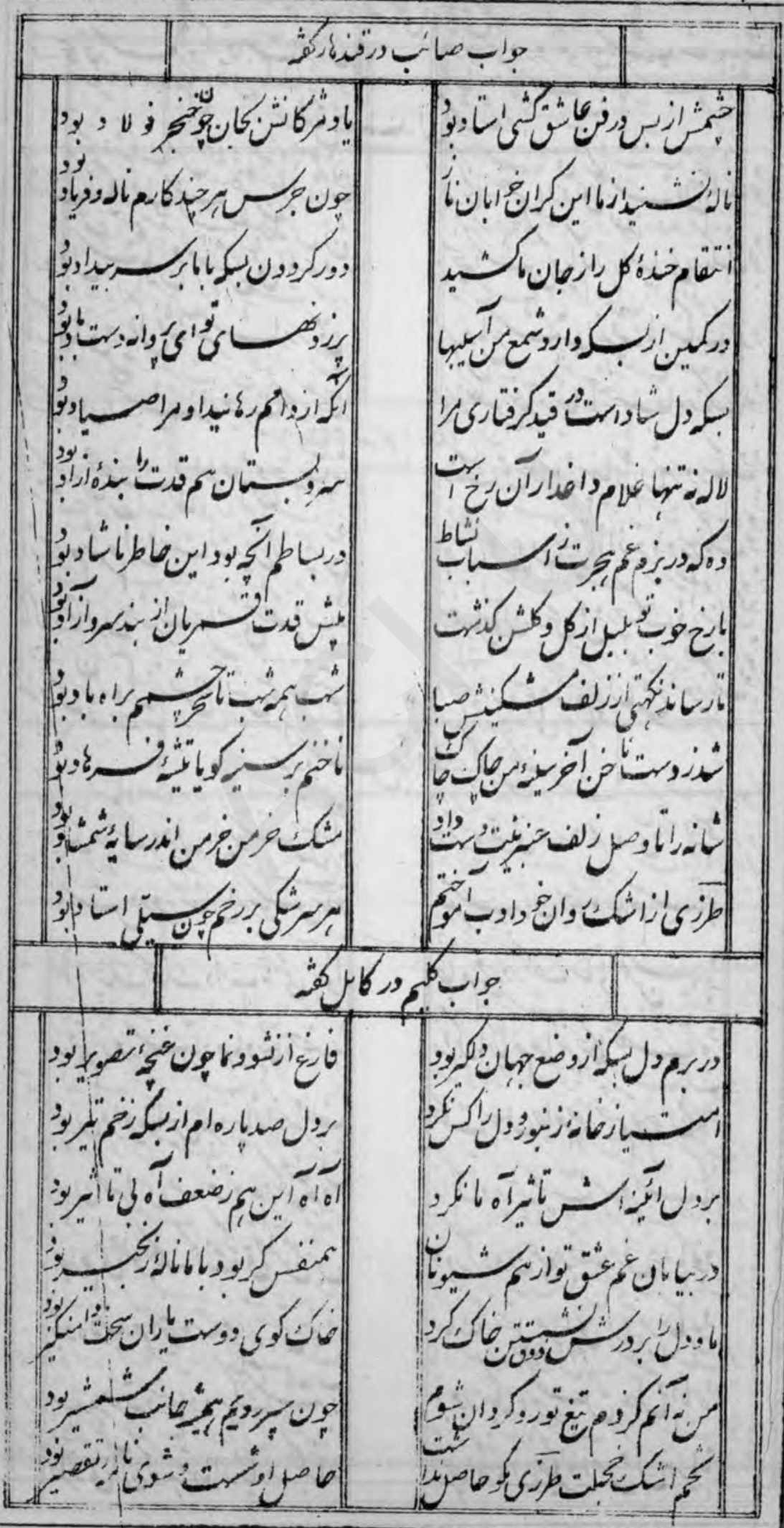


$r \& 1$

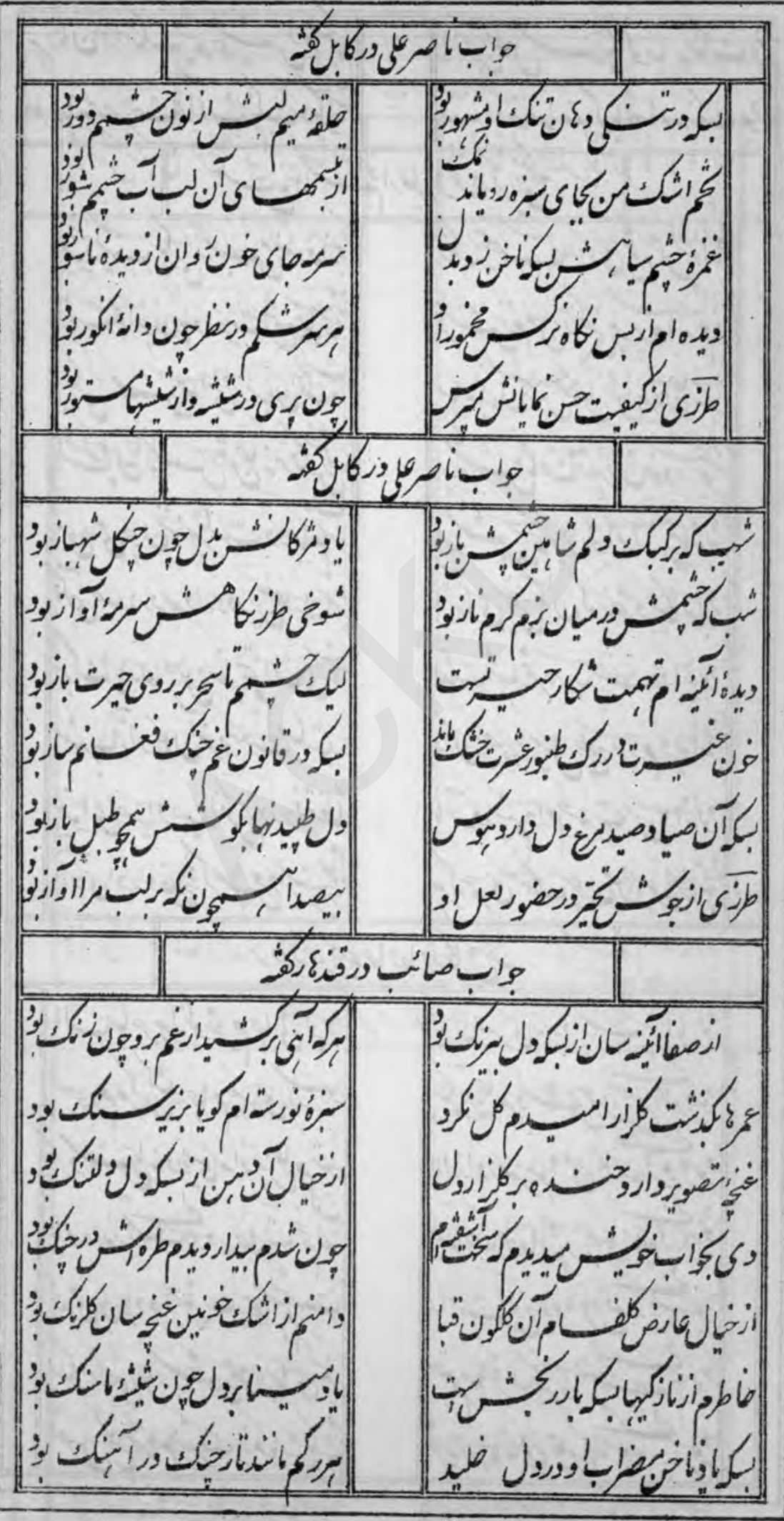




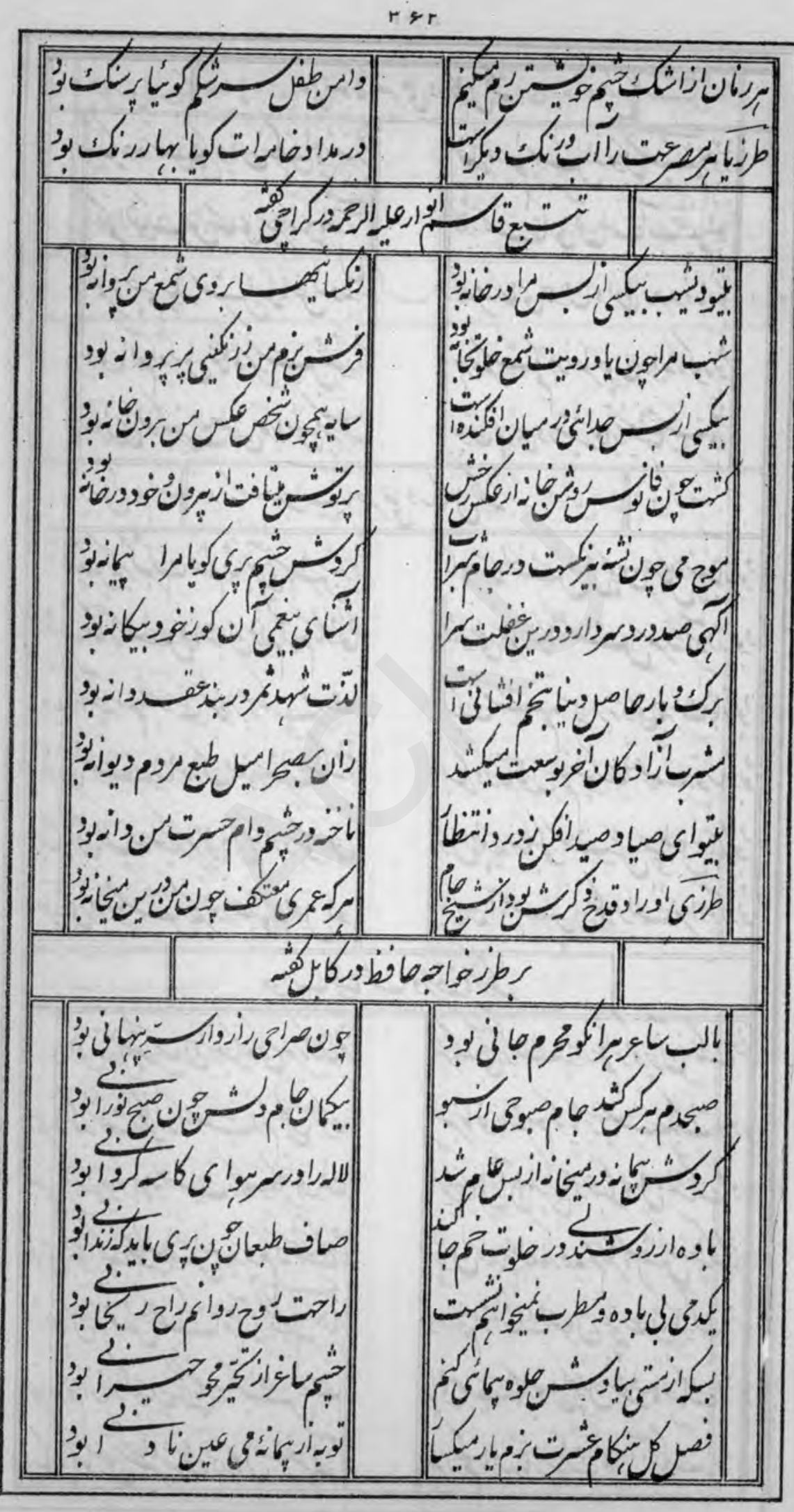




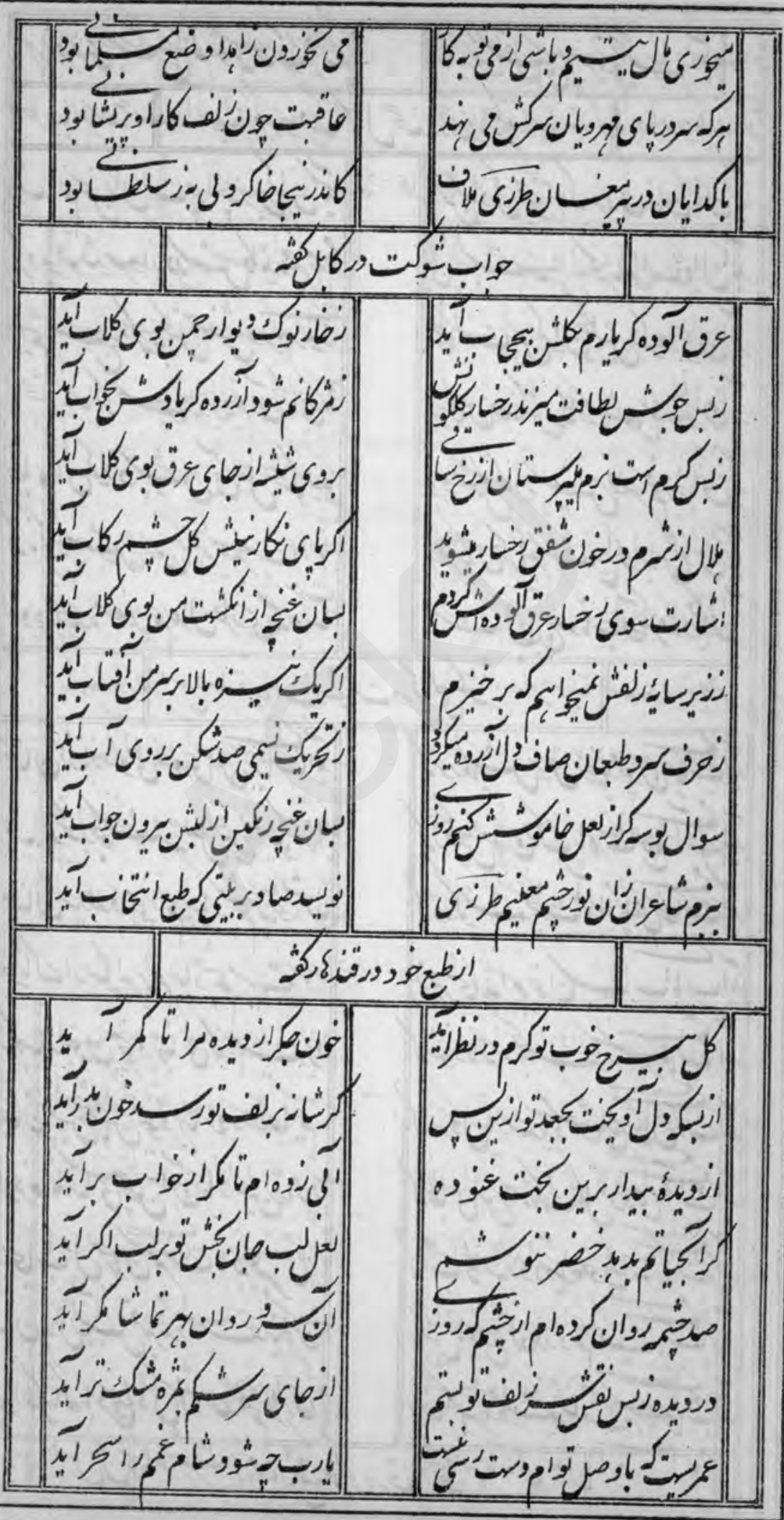


rs

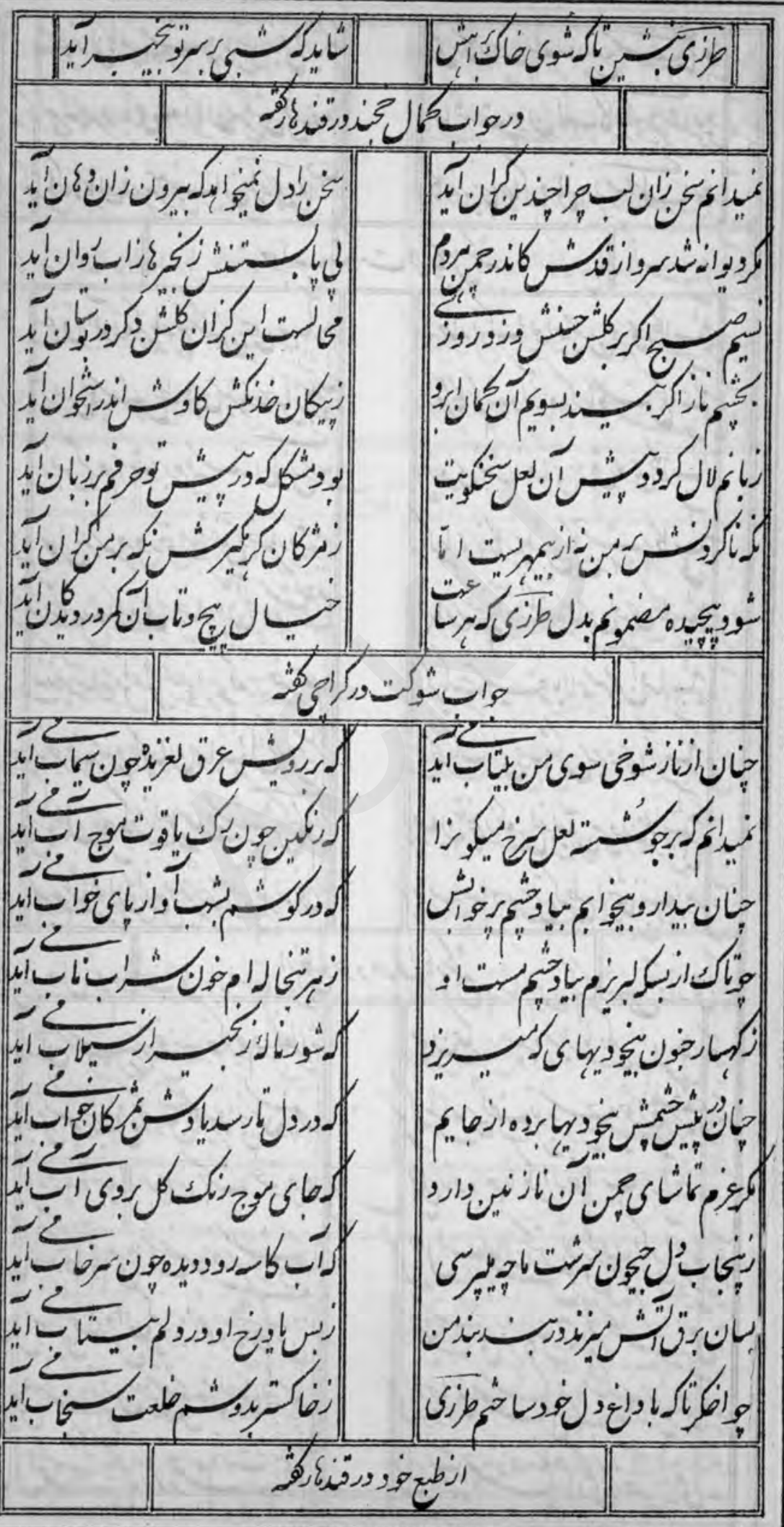


ryo

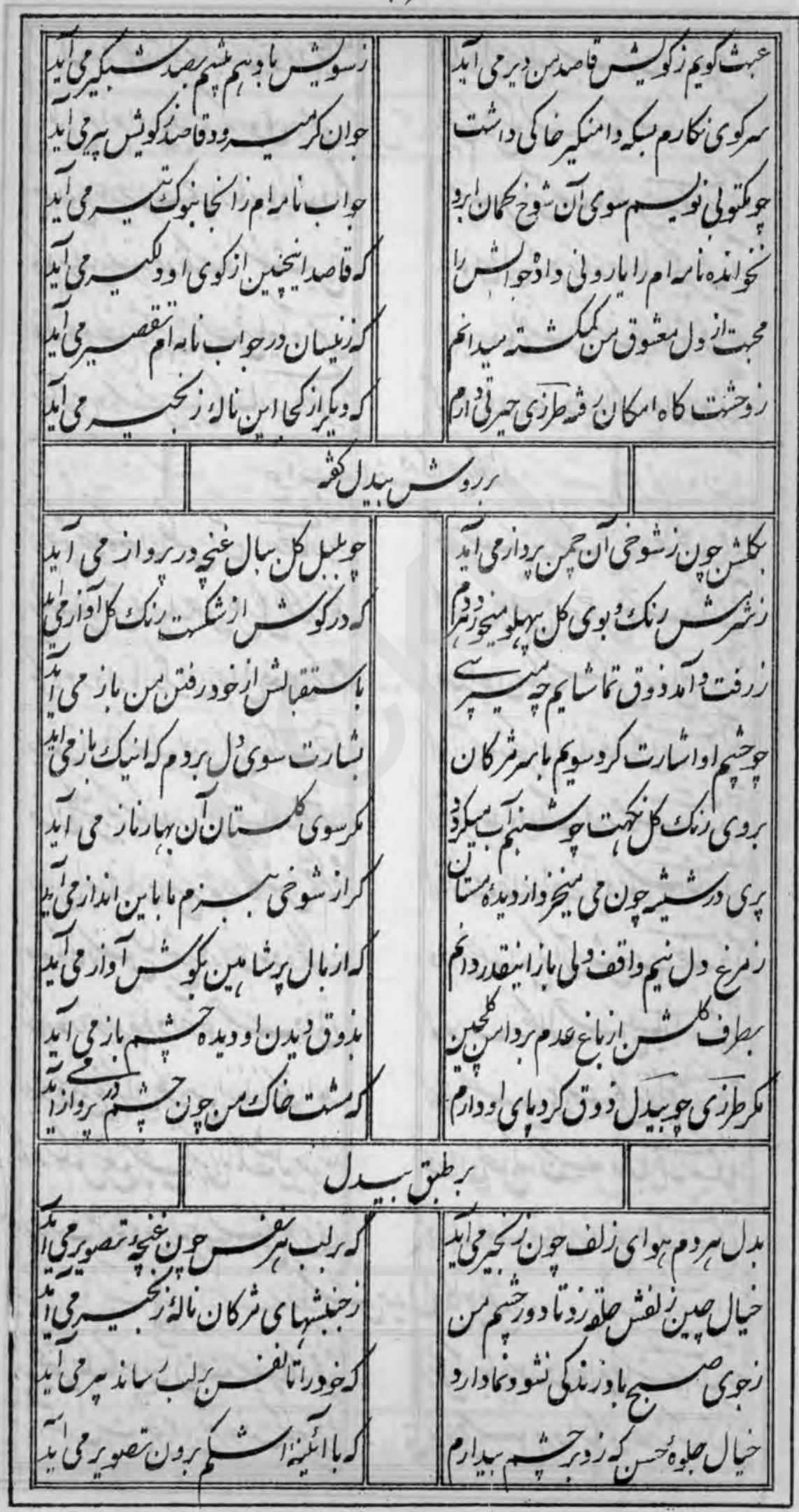


158

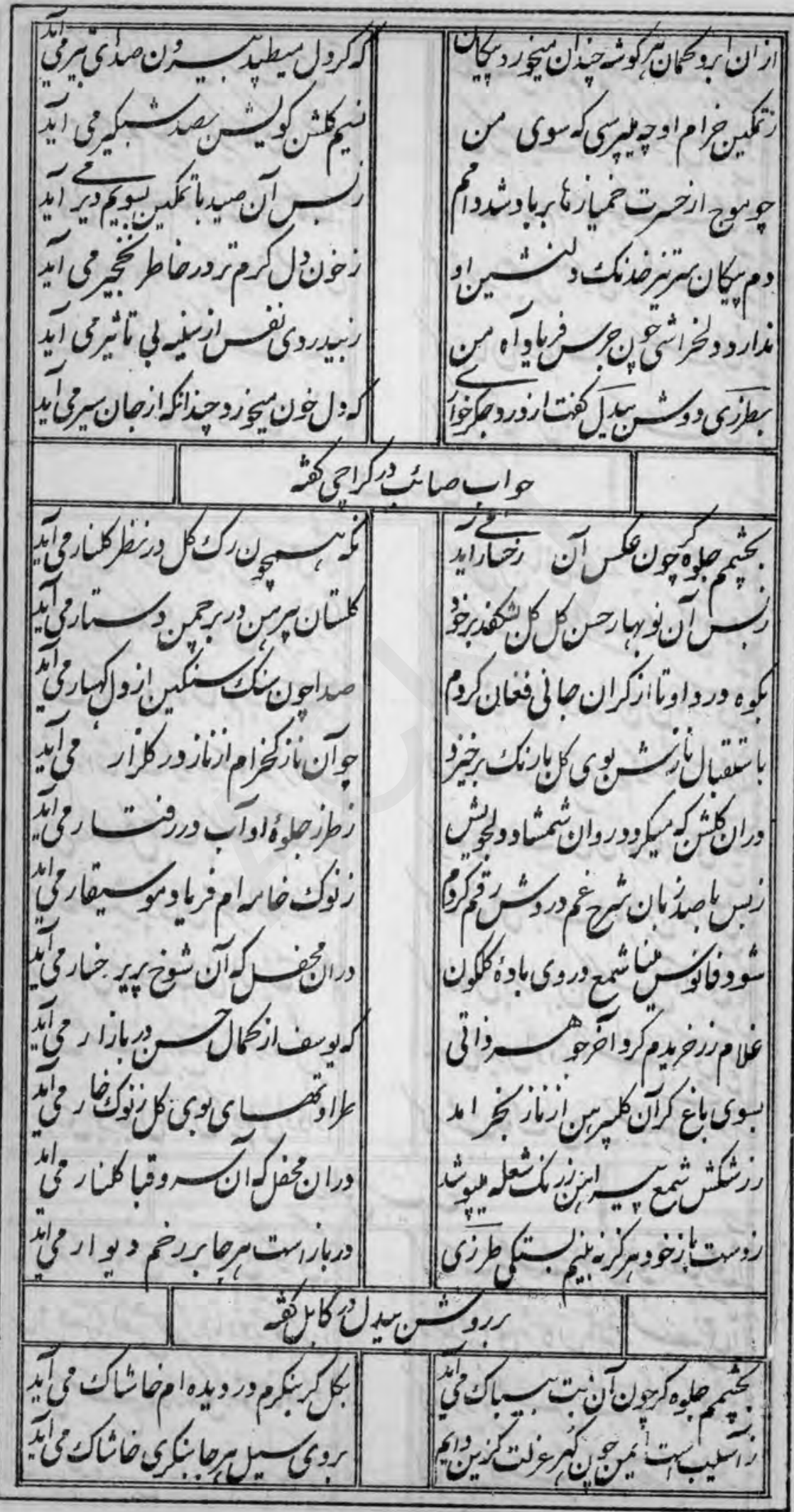

jis. 
rs

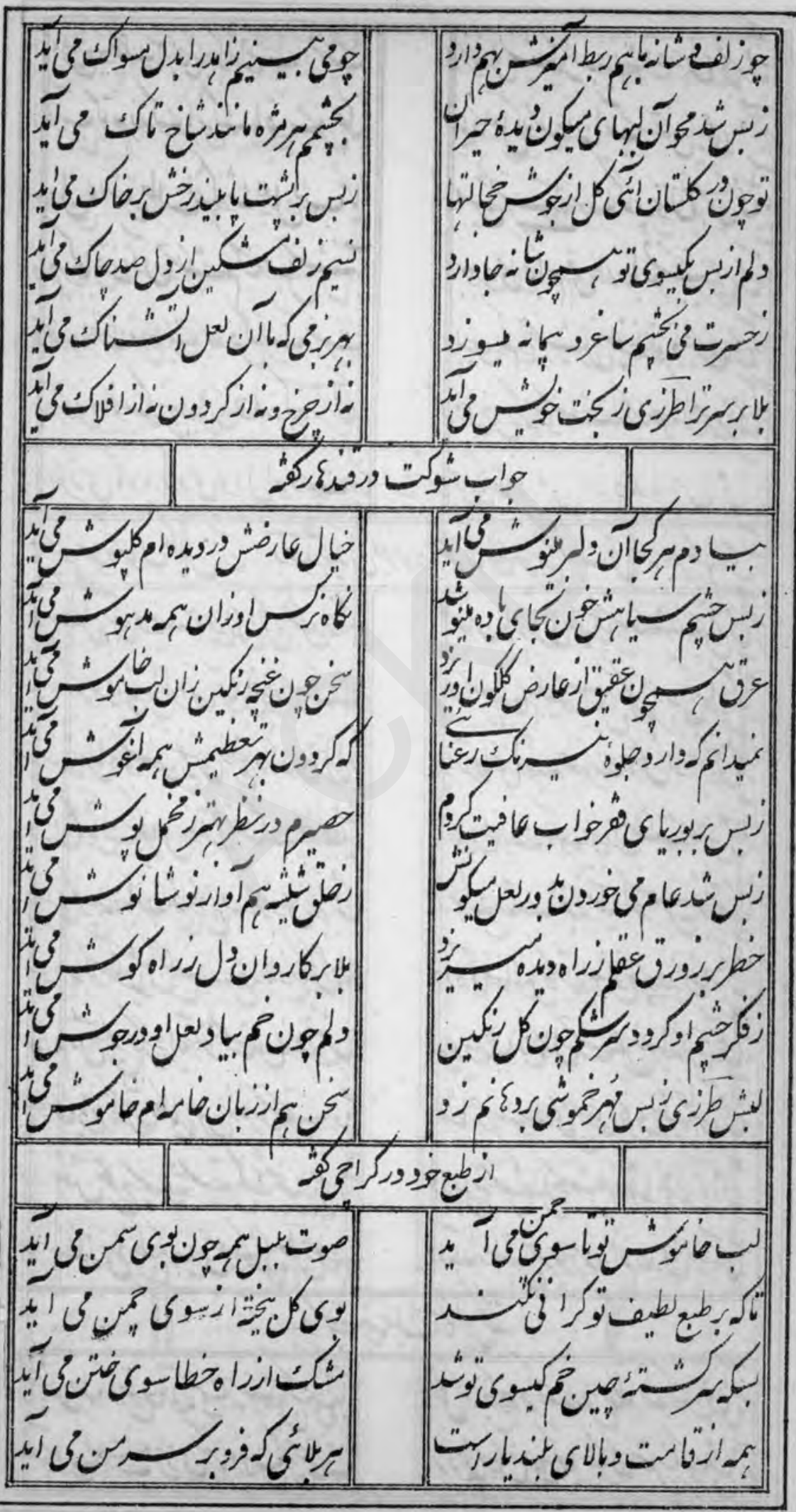


$r>1$

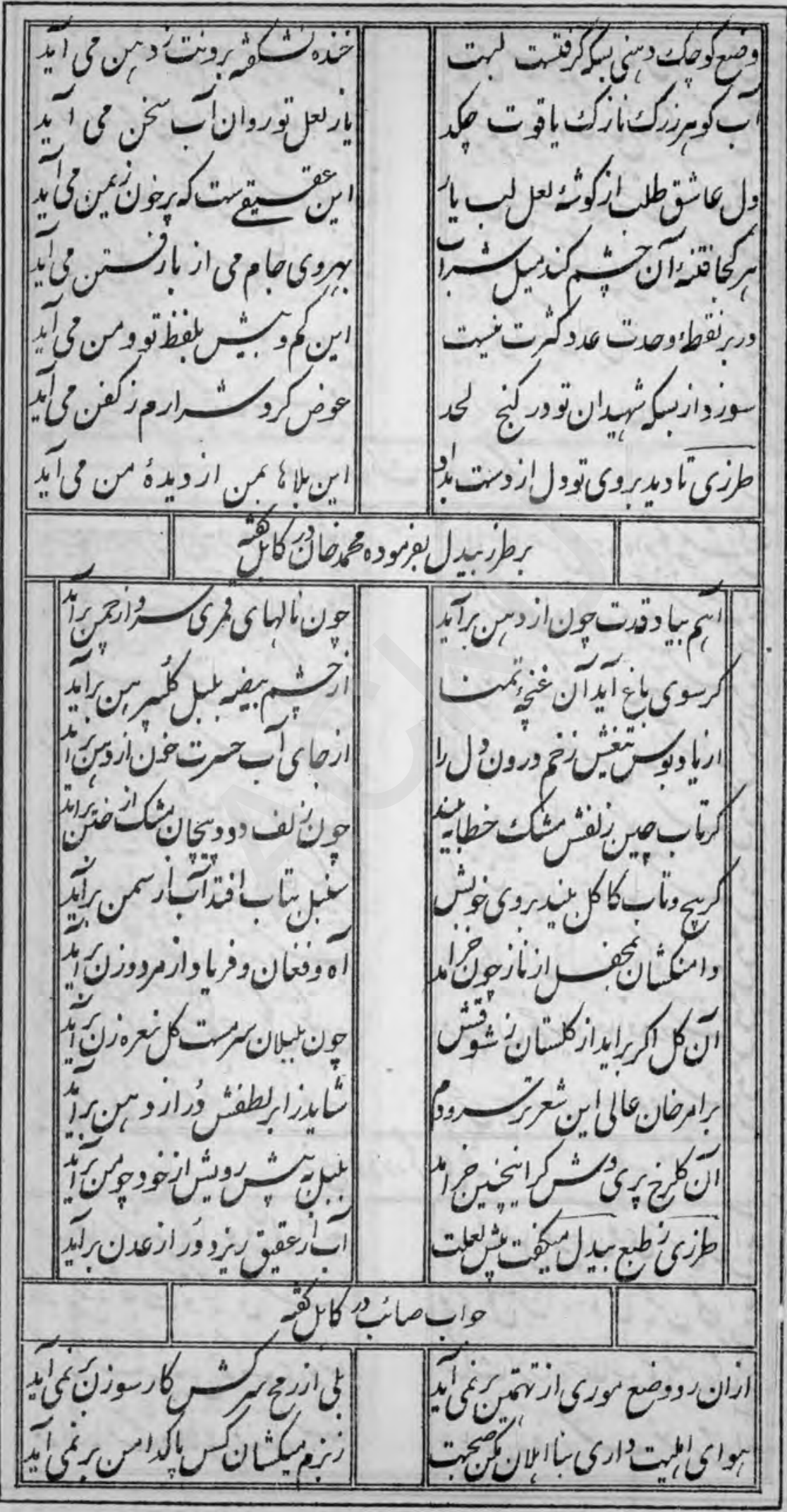




\section{r 4}

$\mid$


rro,

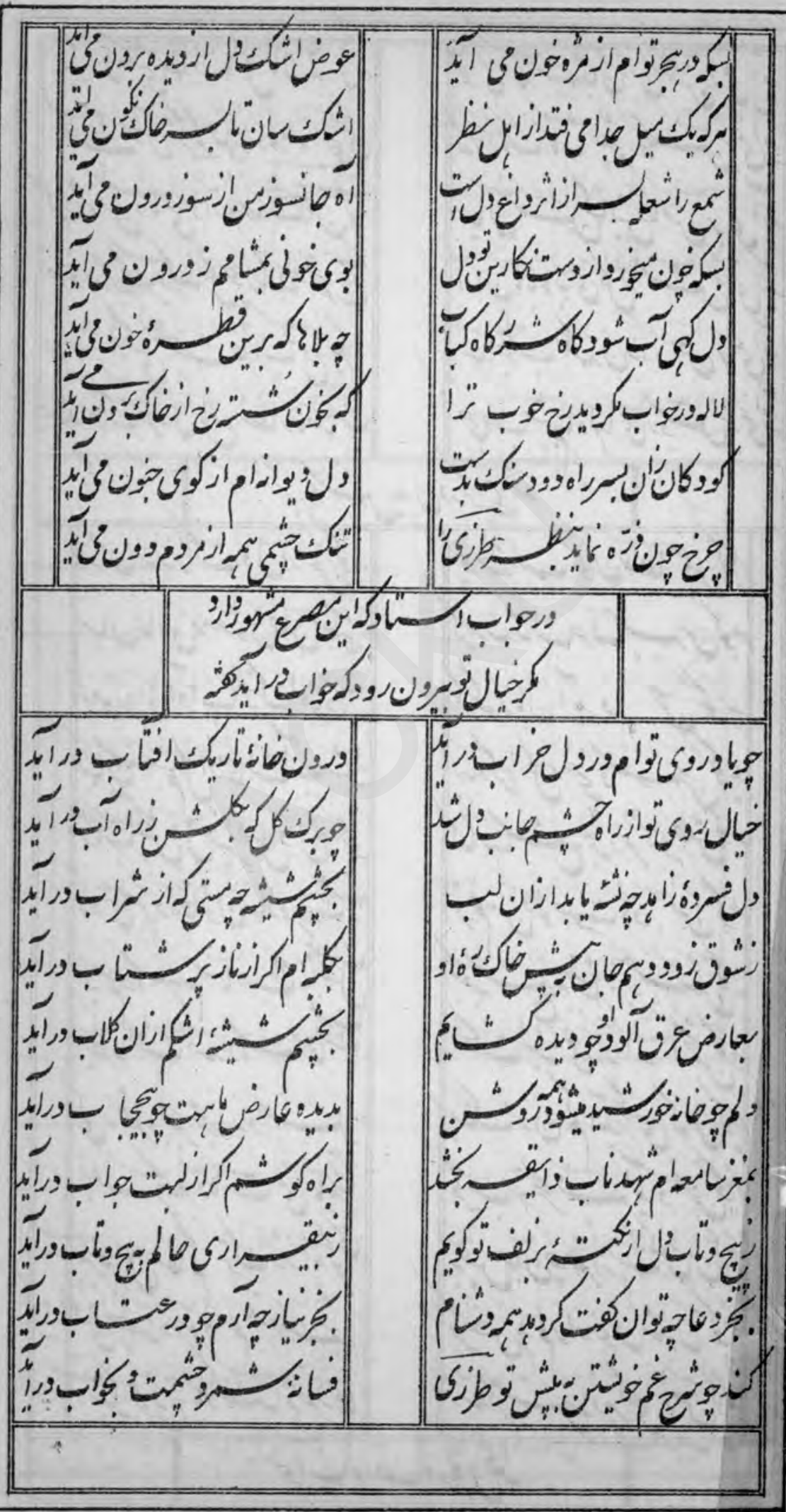




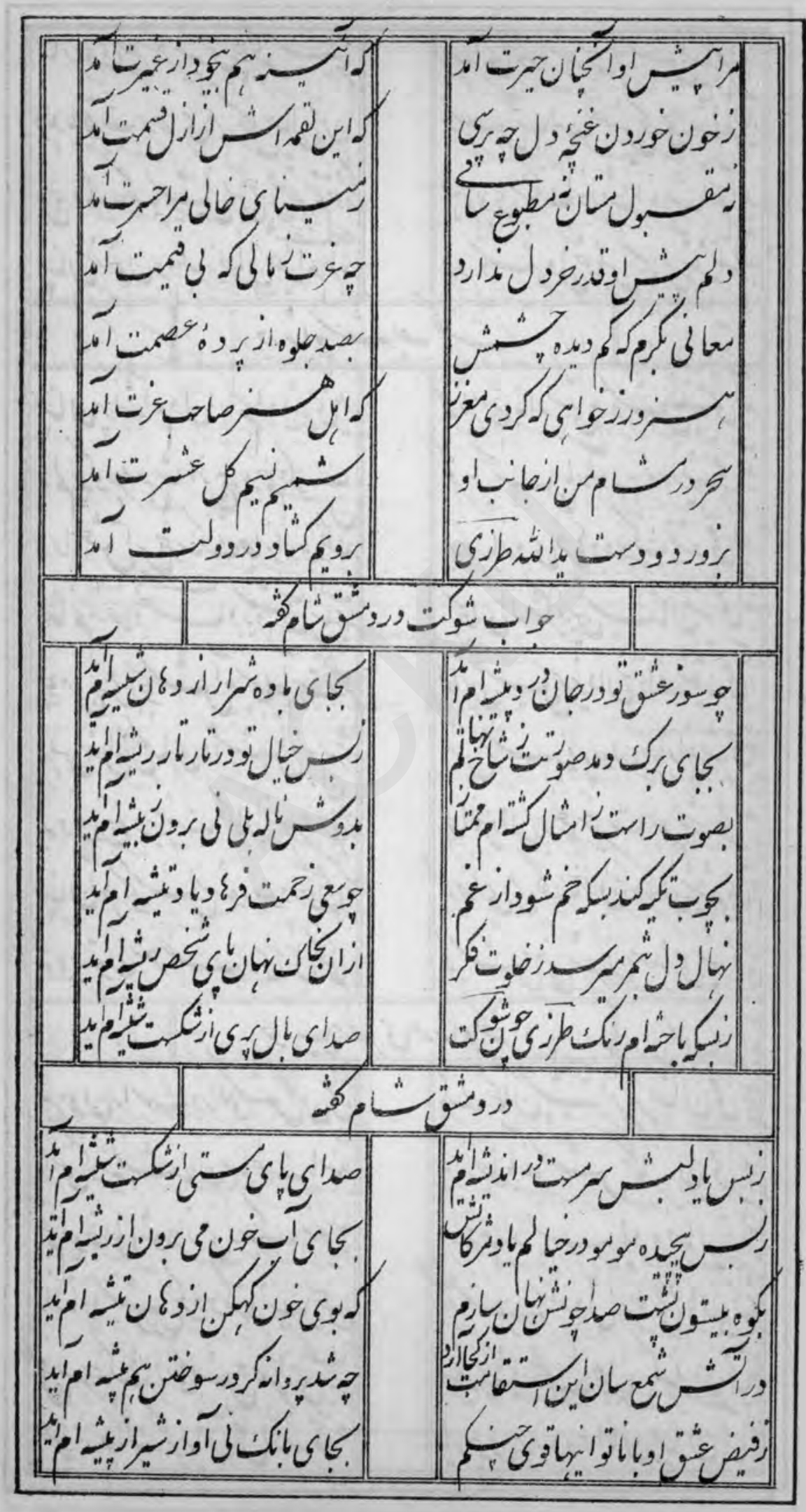


rvr

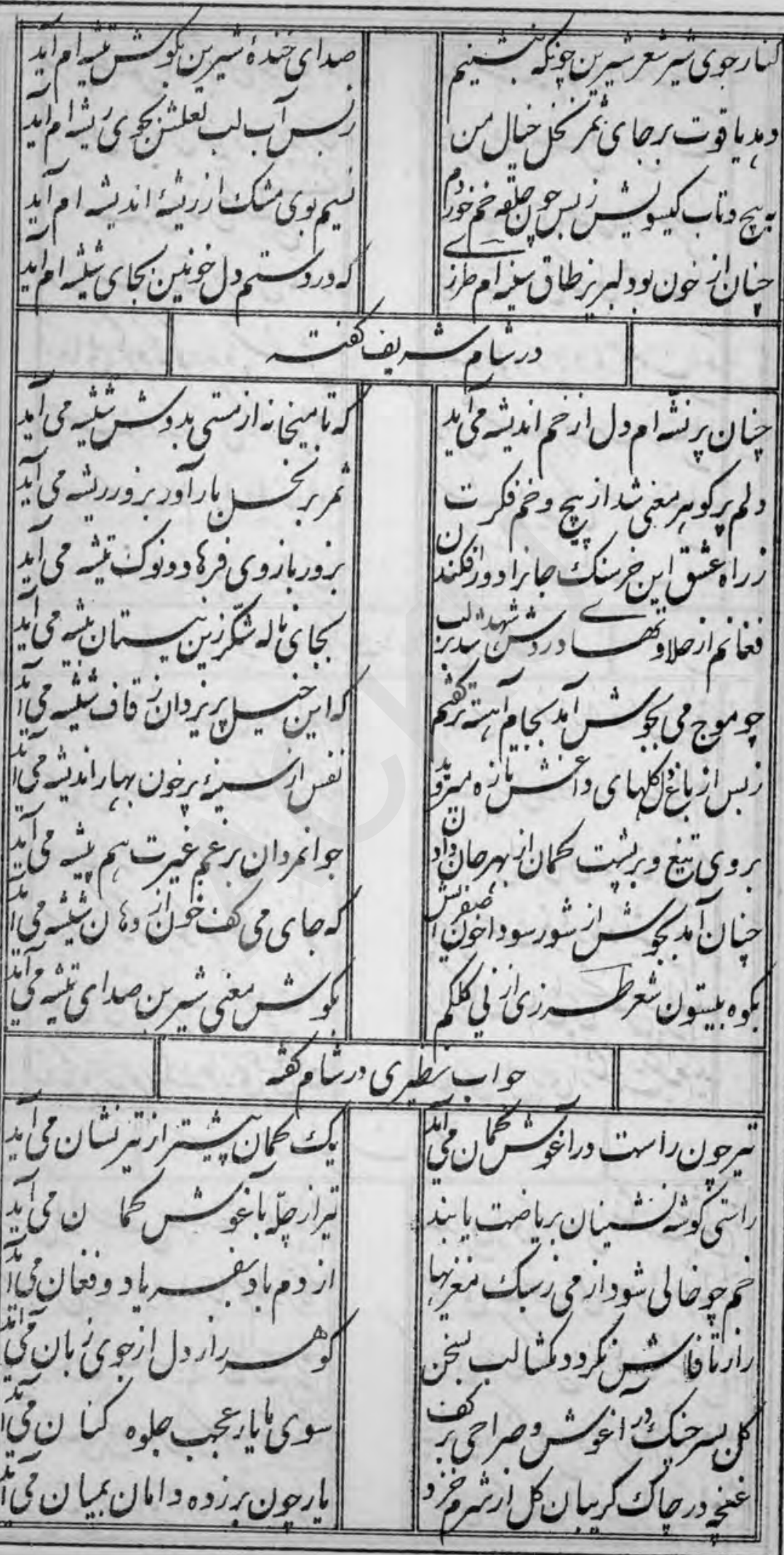


rrr

|


rre

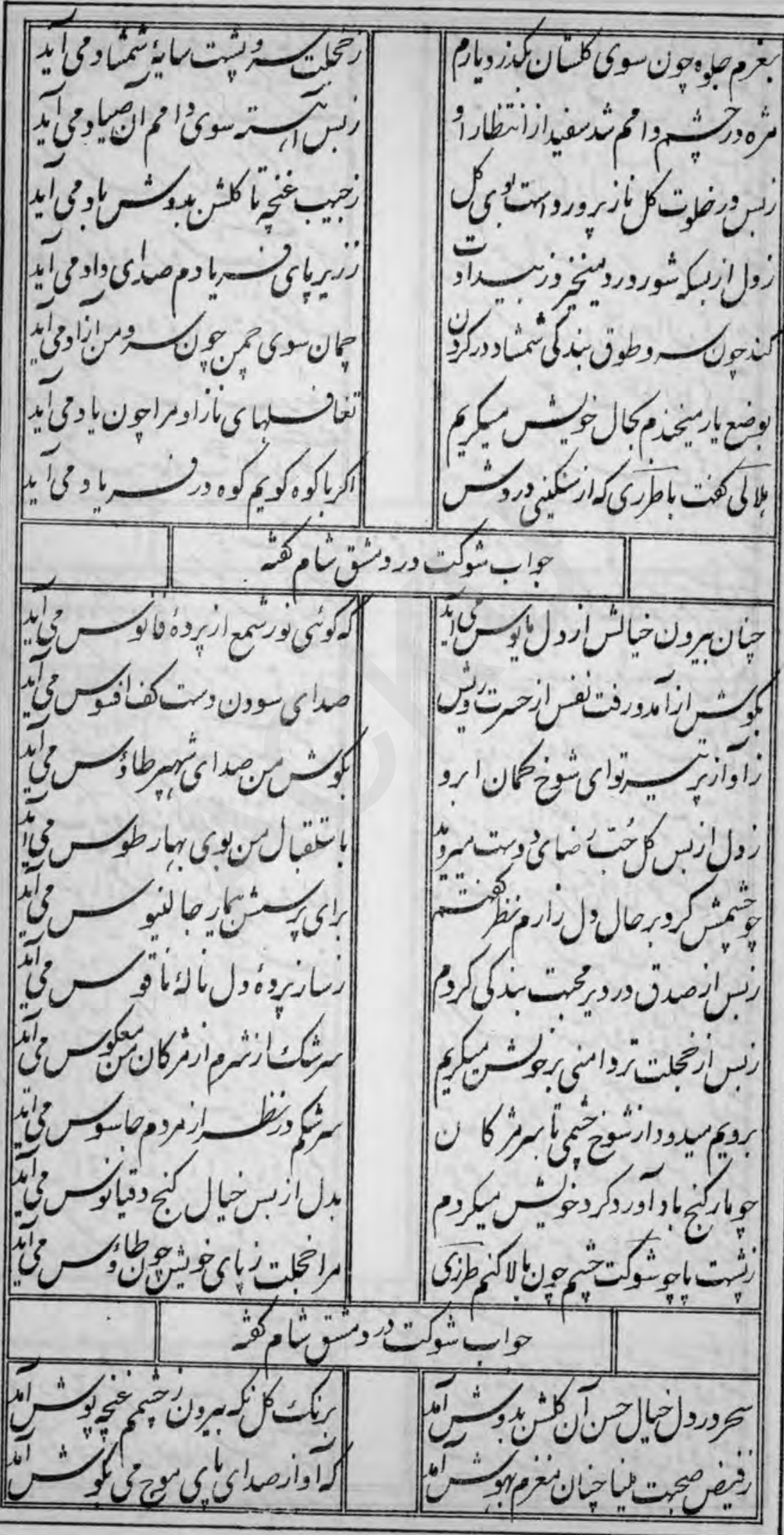

3! 
rVA

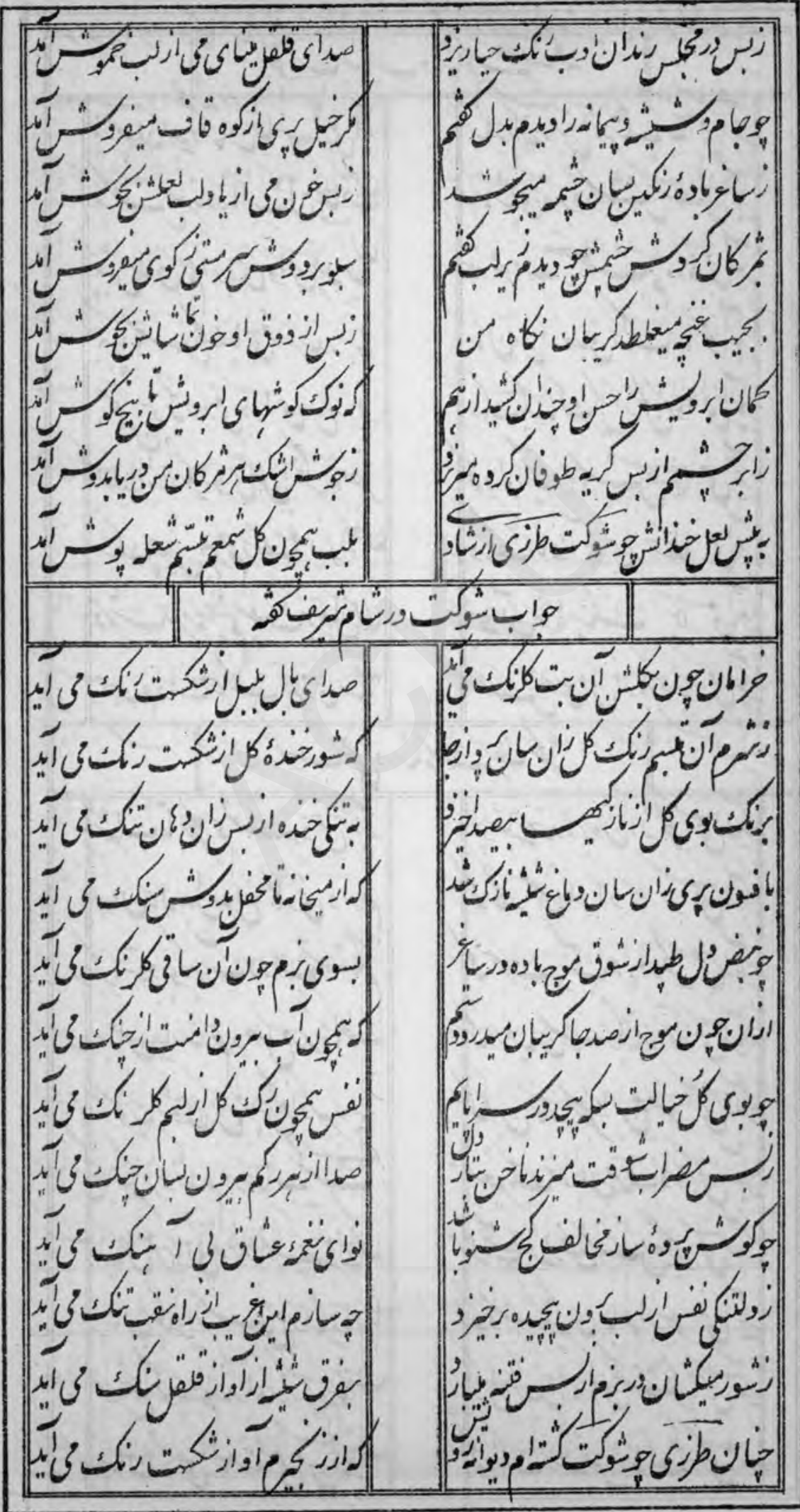




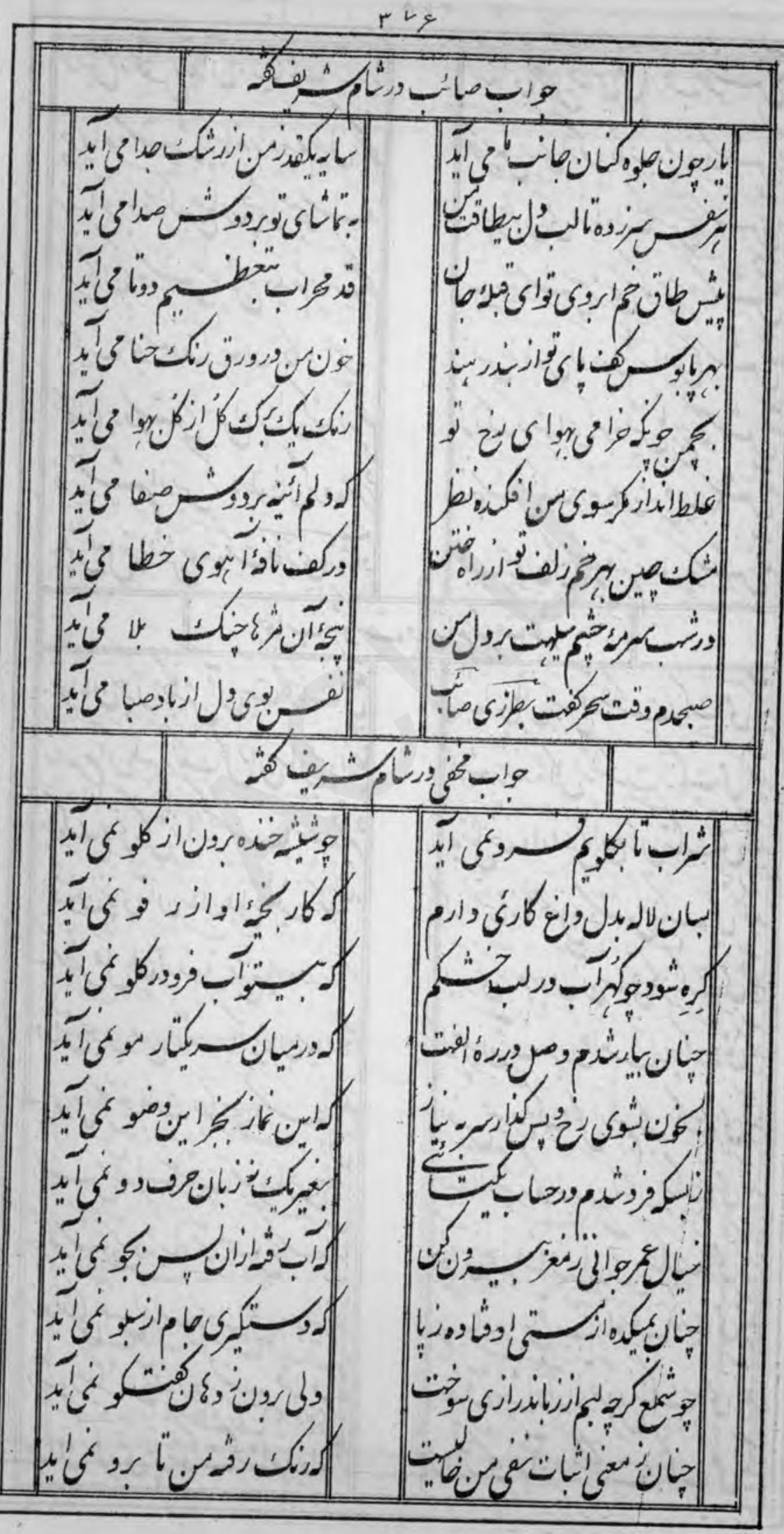

$\therefore 9$ 
rv

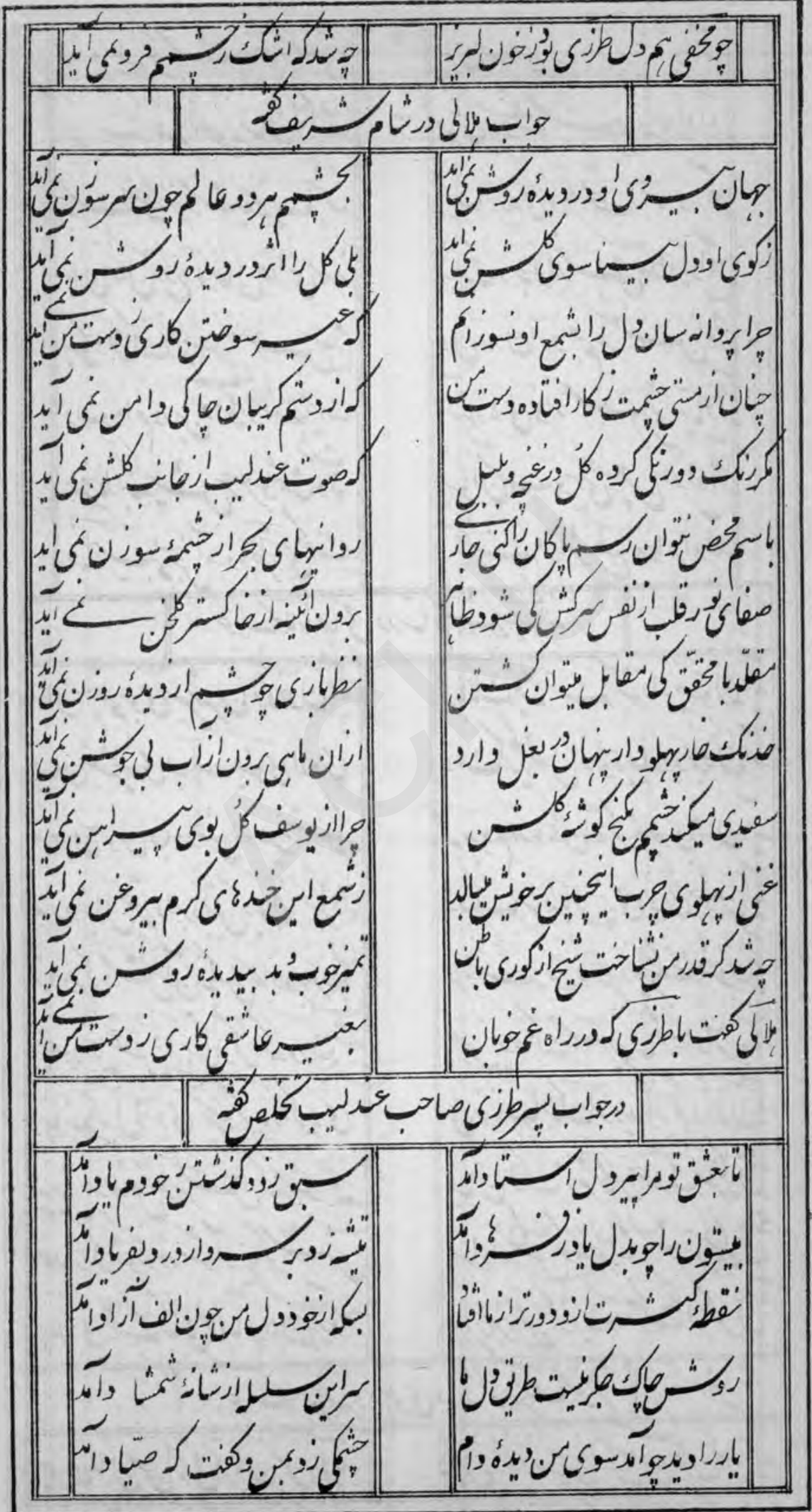


rVA

|| $\mid$




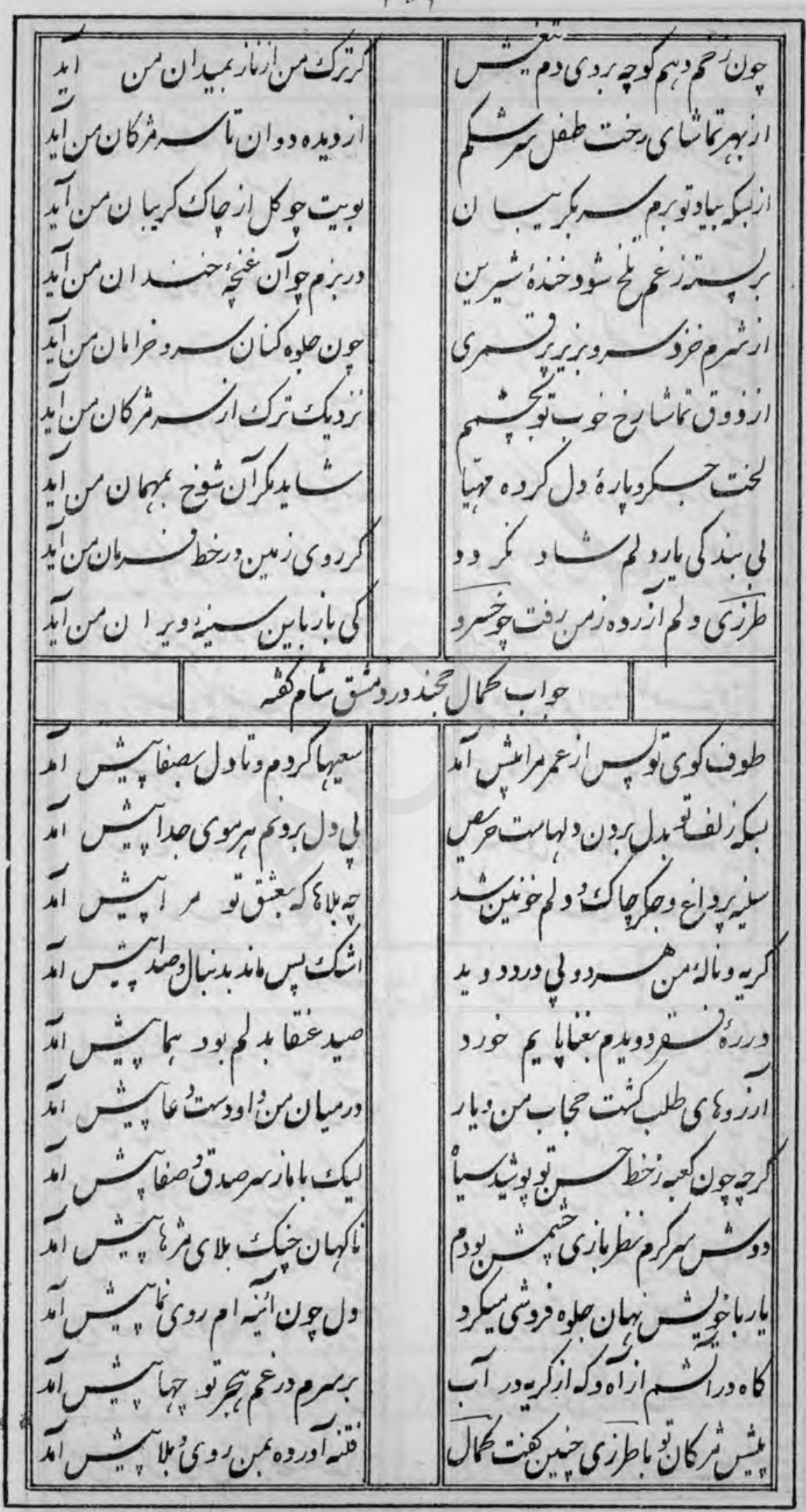


$r 4$.

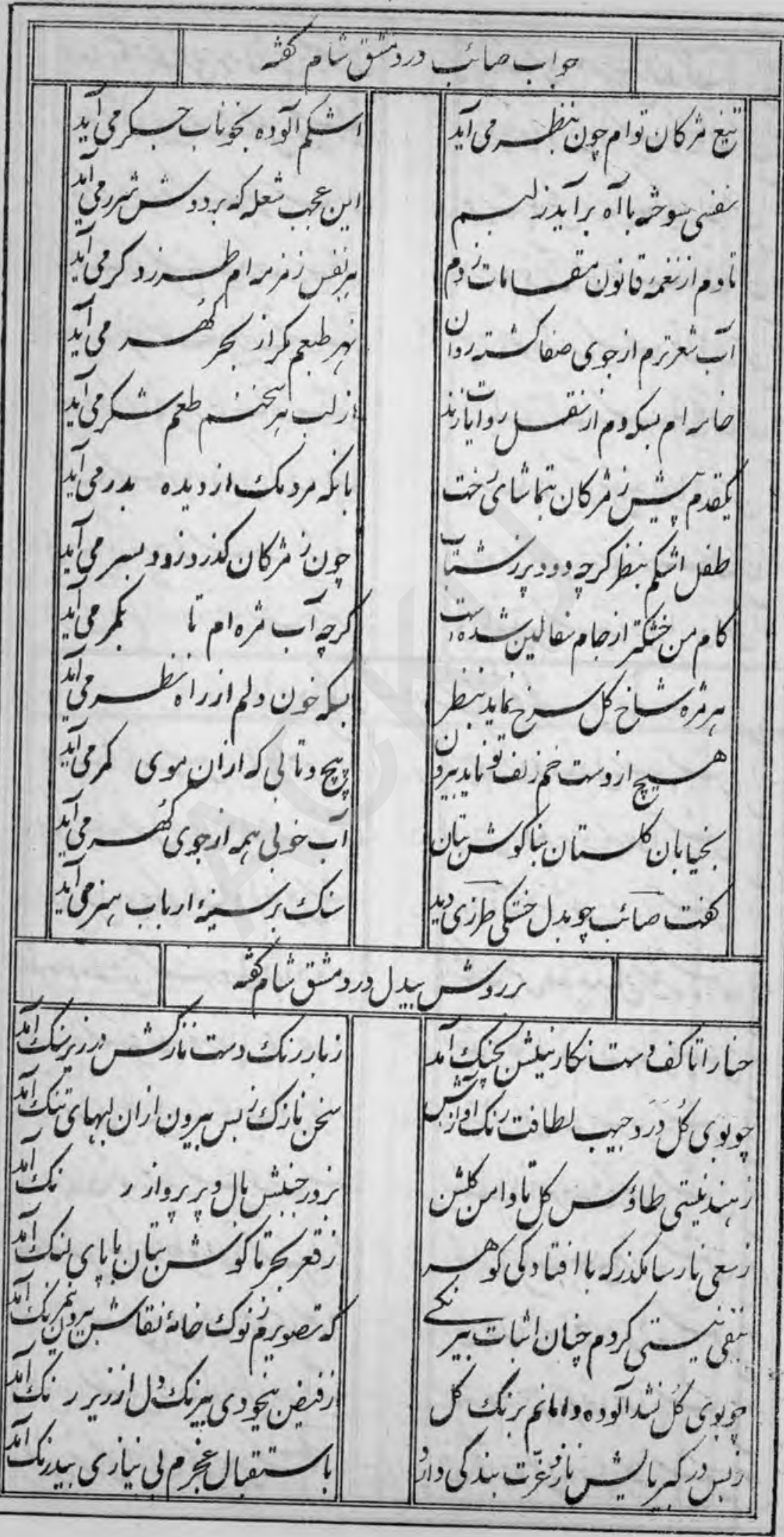

is. 
$r \wedge i$

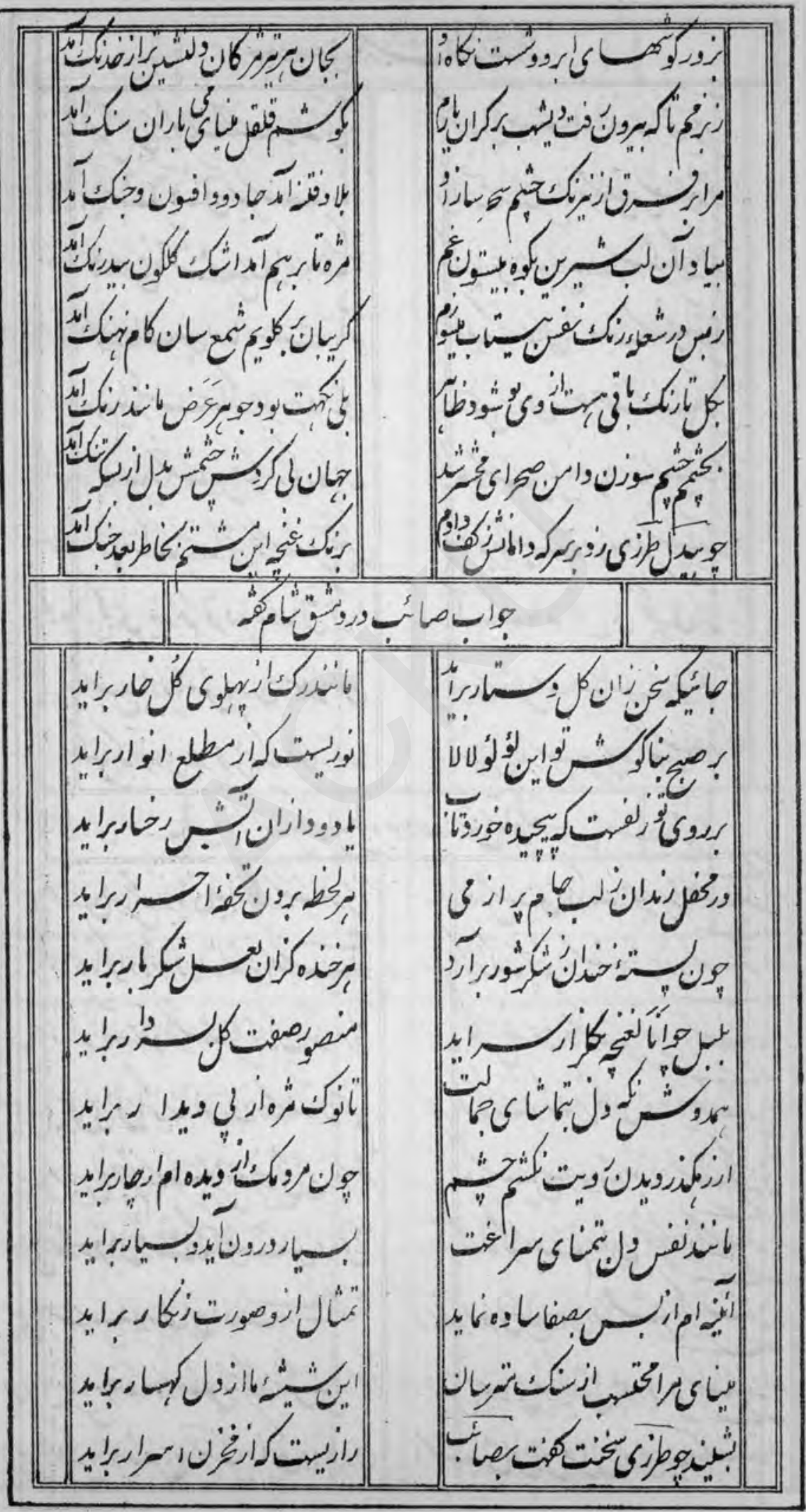




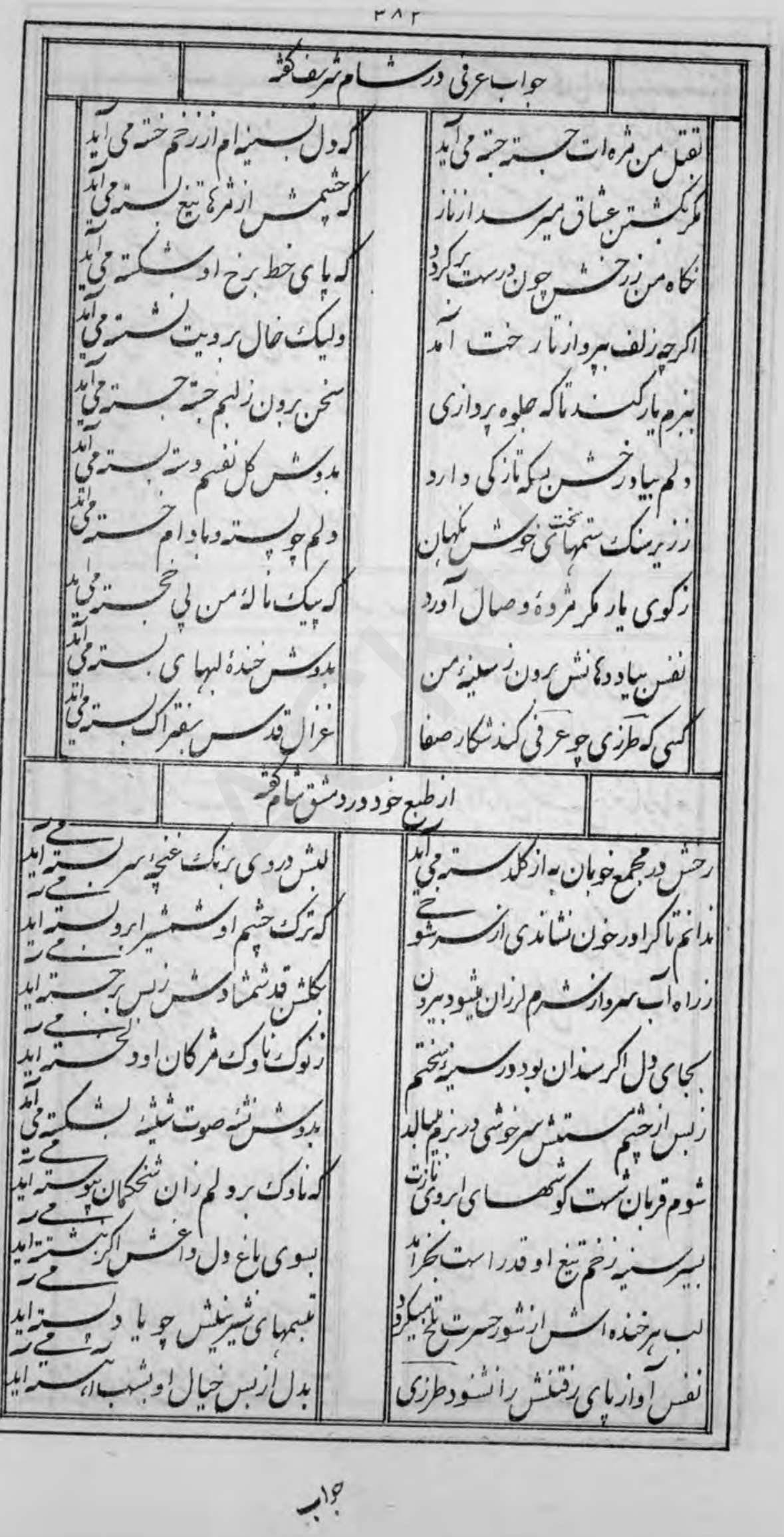


rAr

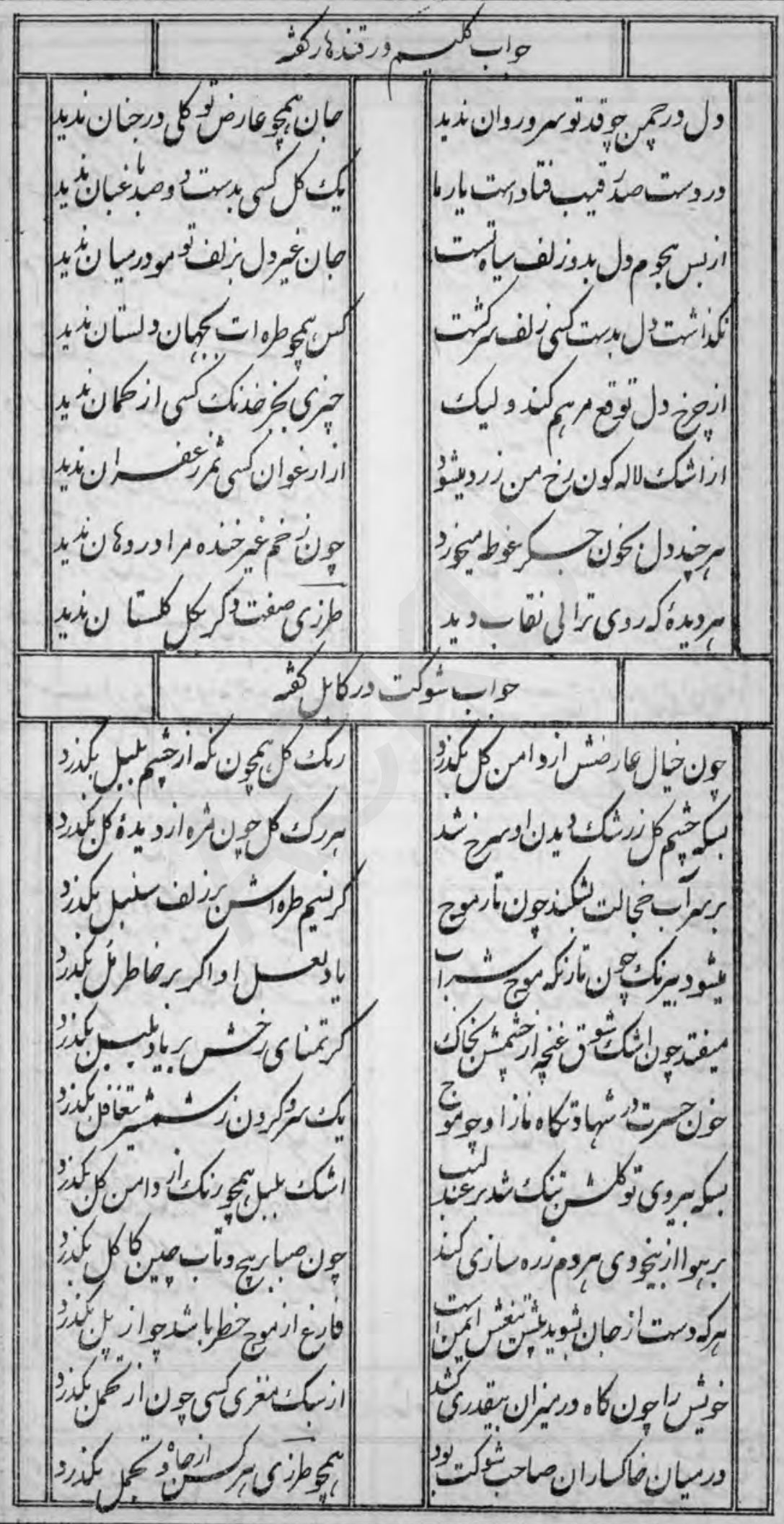


$r \wedge r$

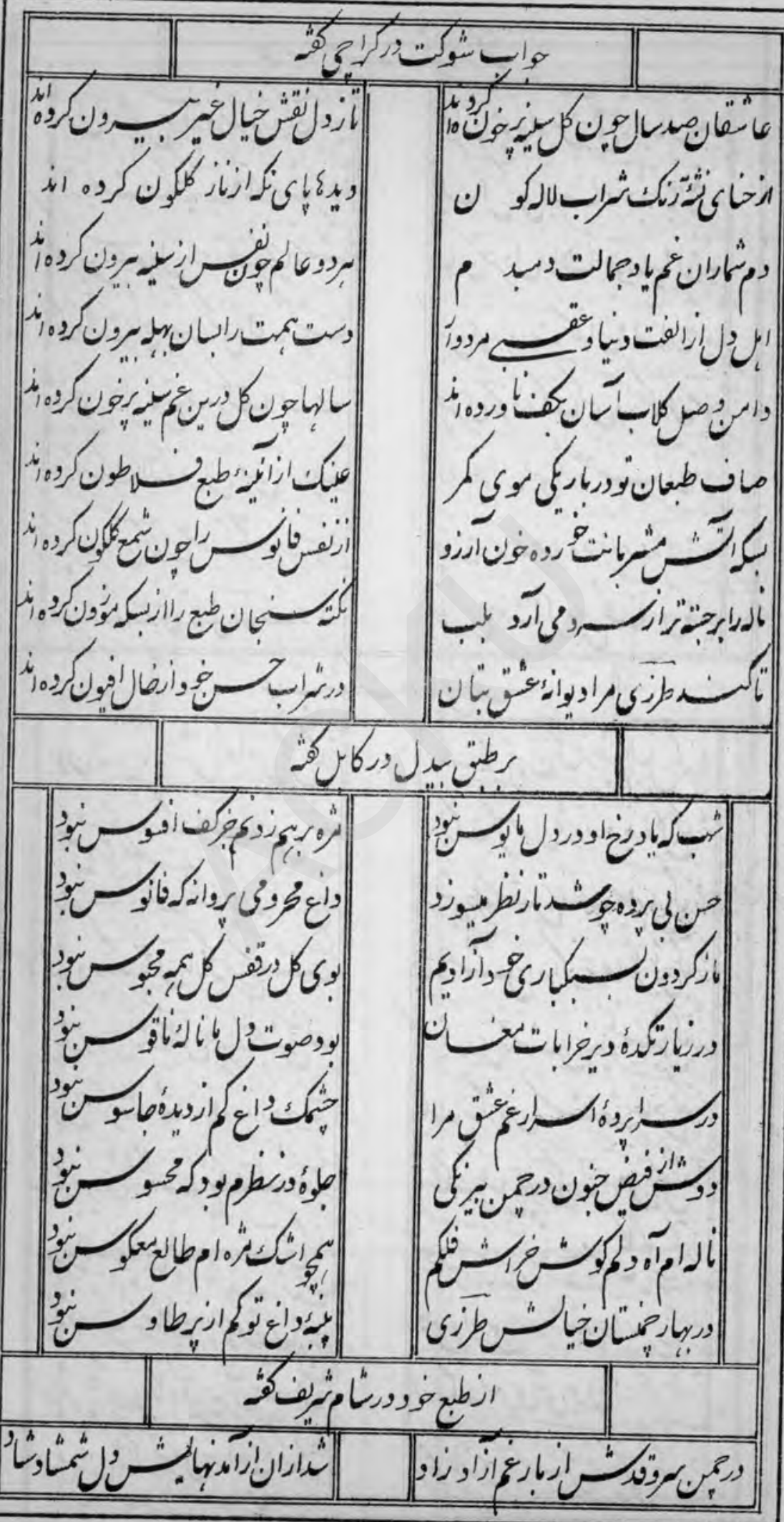




\section{$+10$}

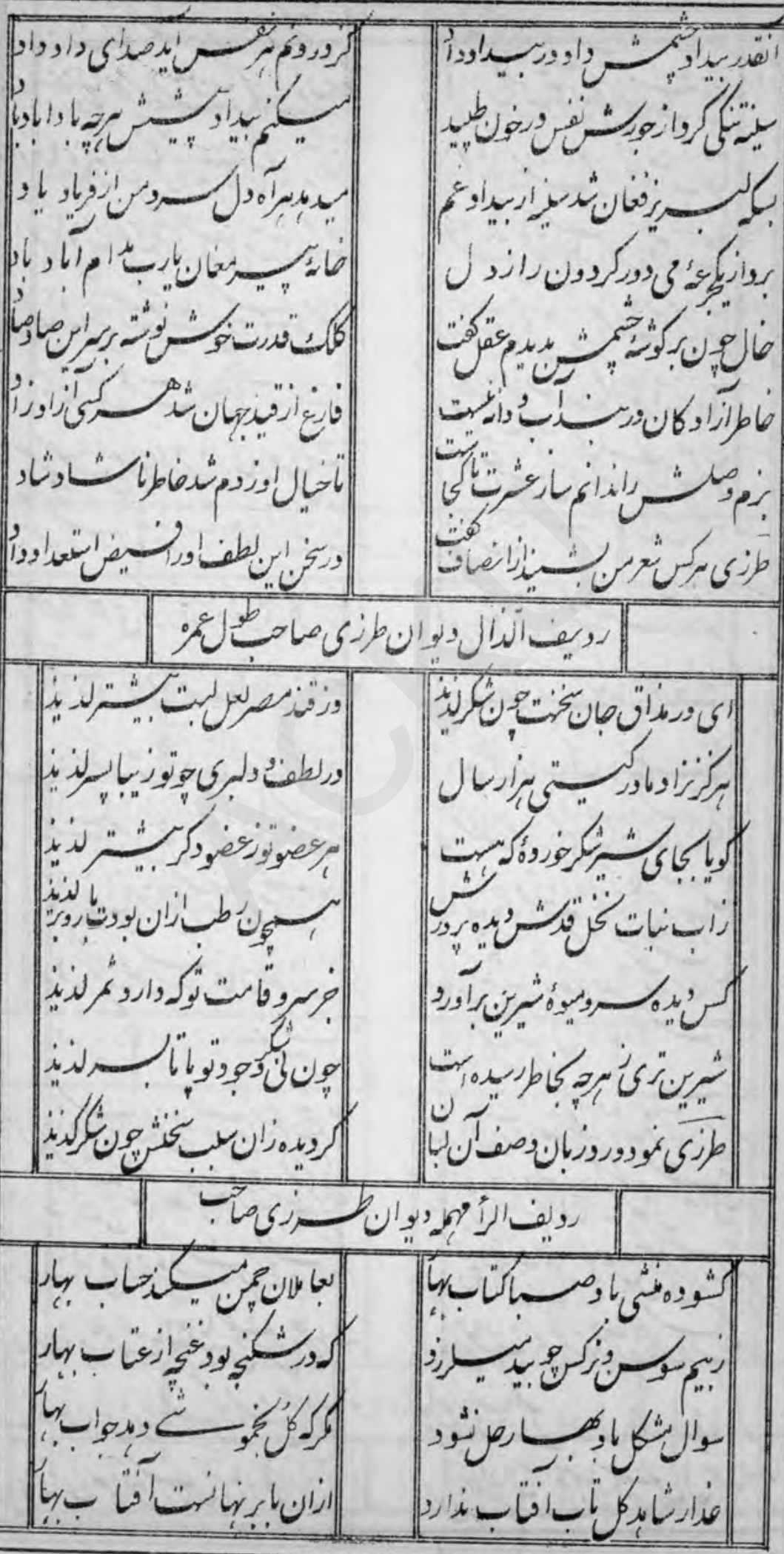


rA

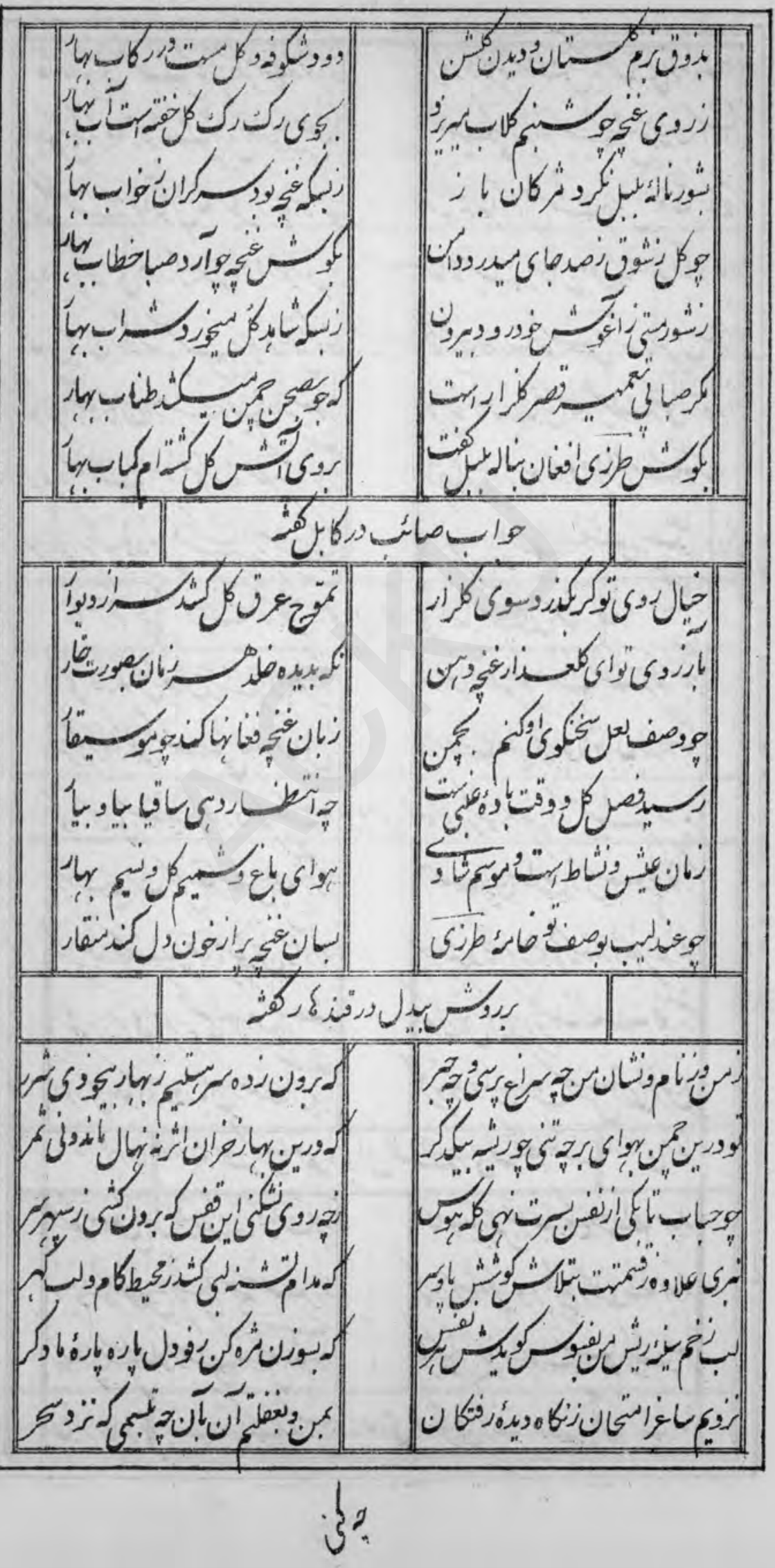


|人⿱二

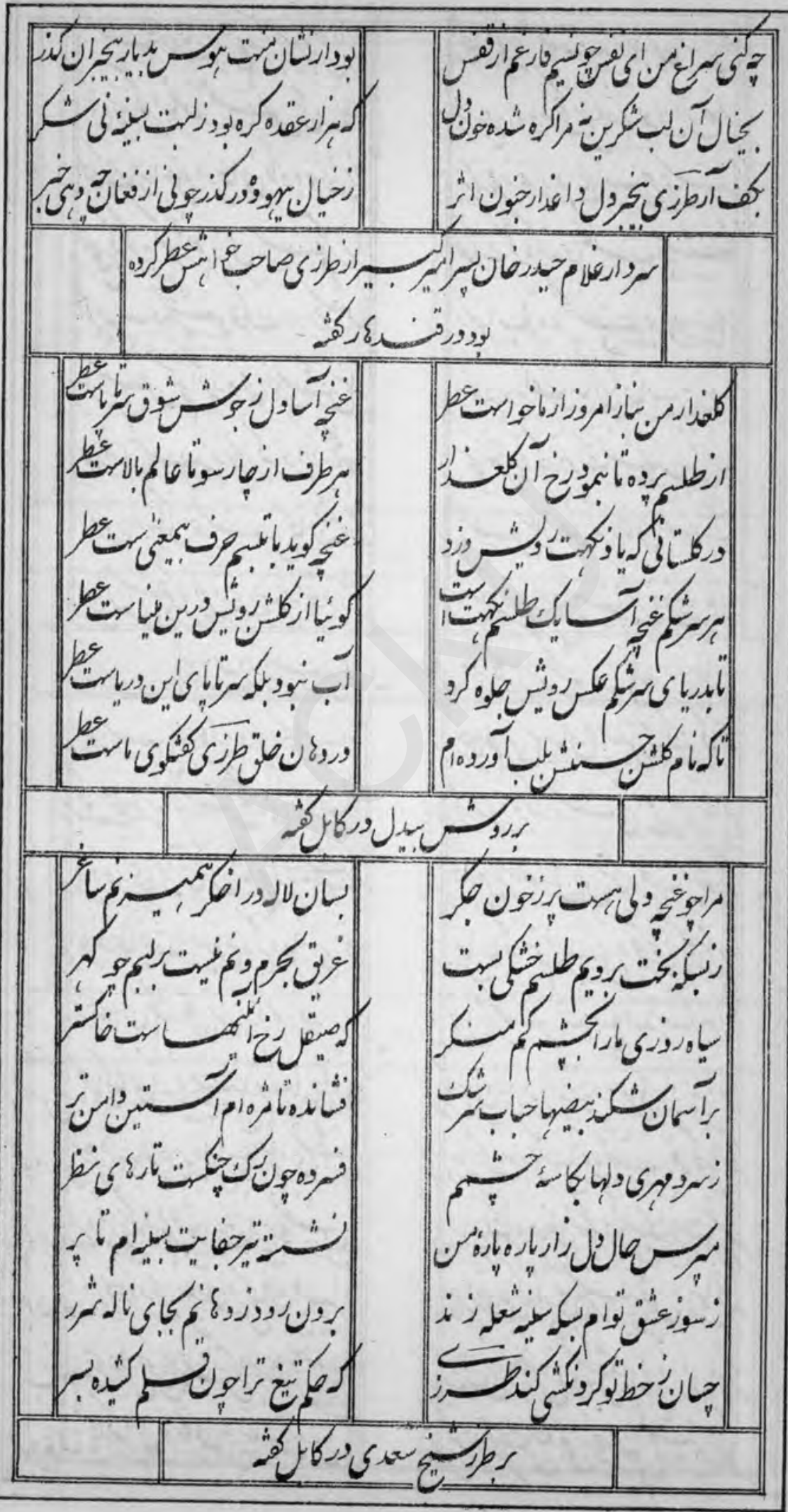


$r A 1$

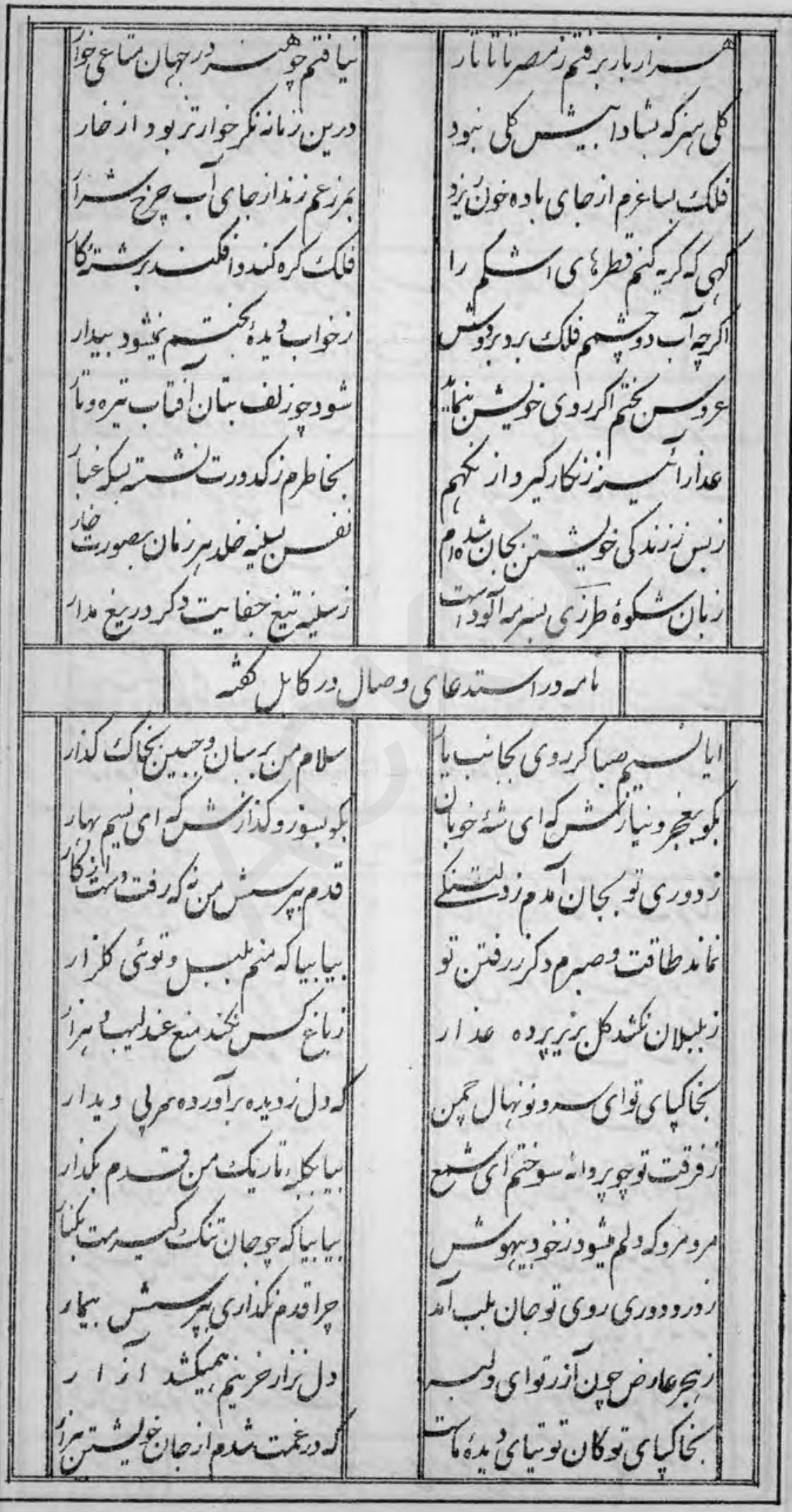


rA $q$

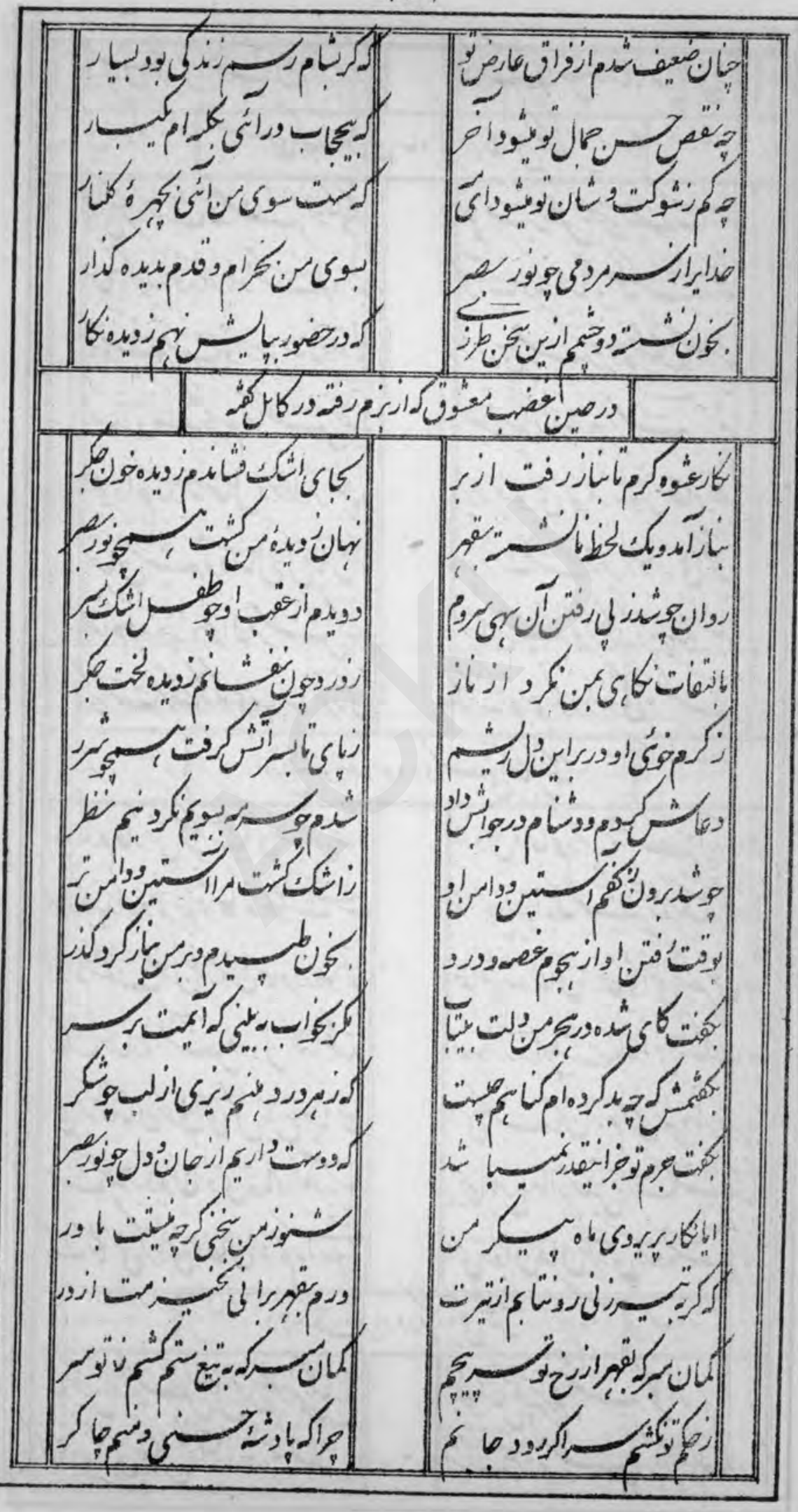


r

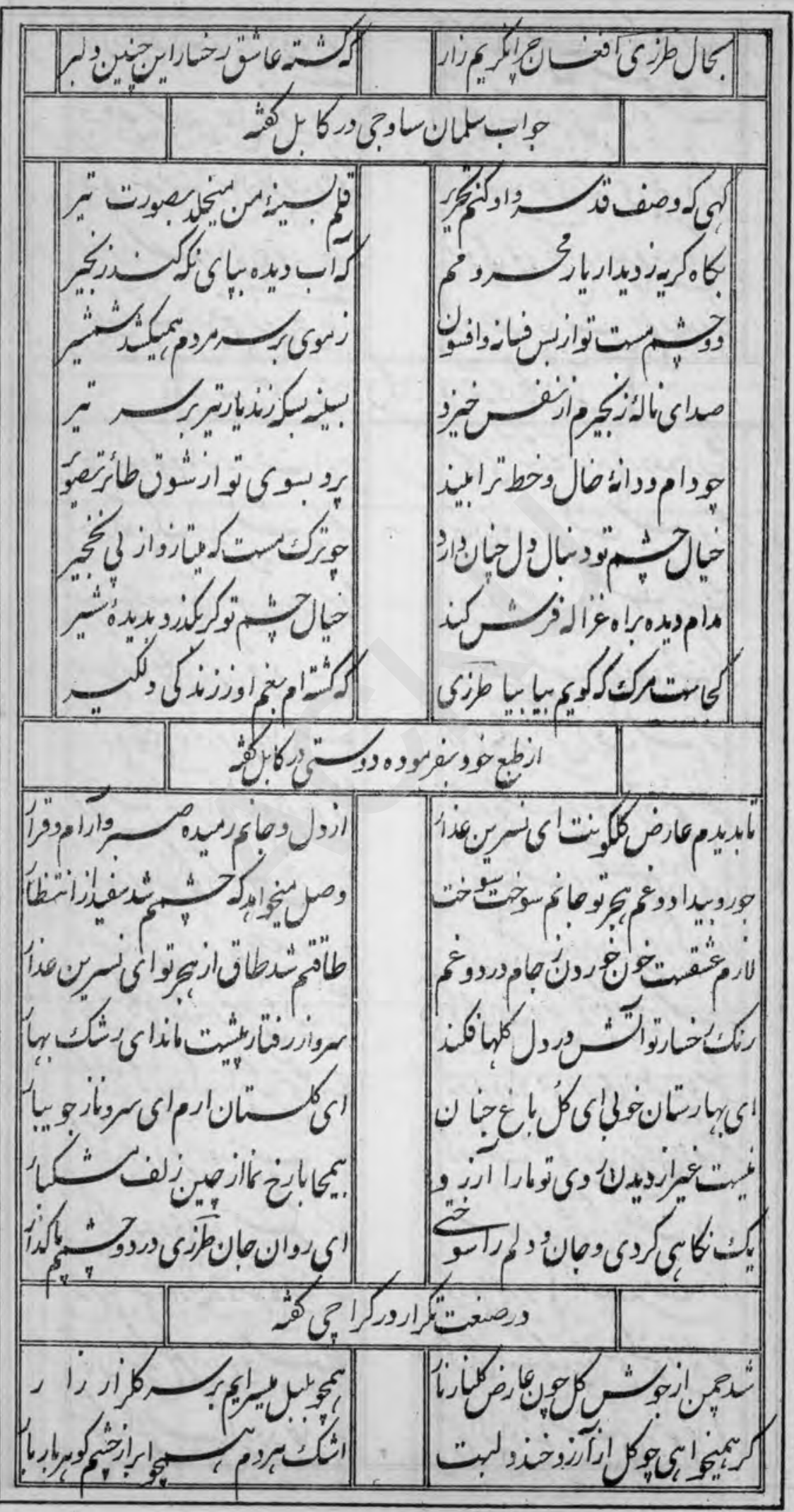


$+41$

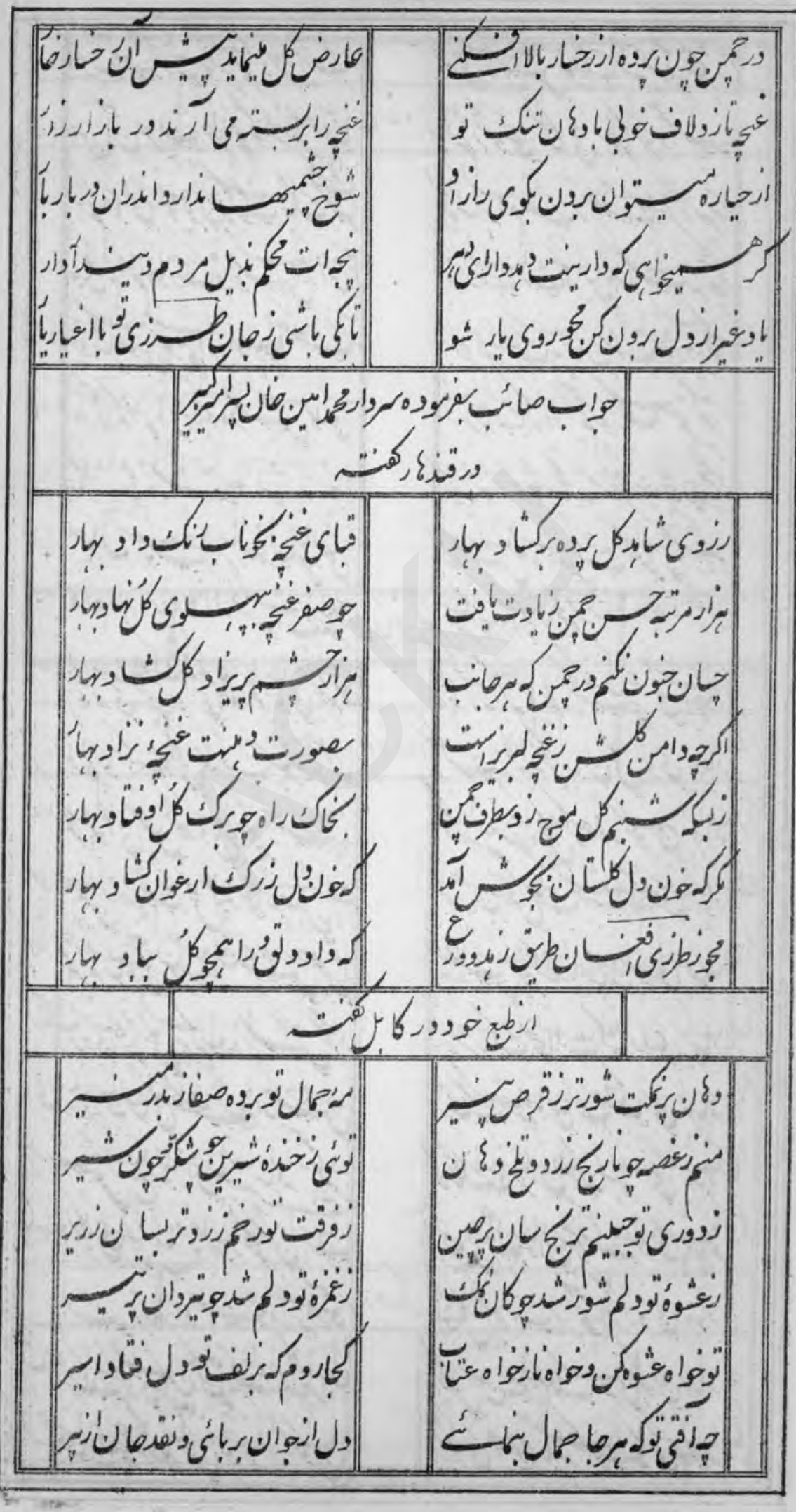




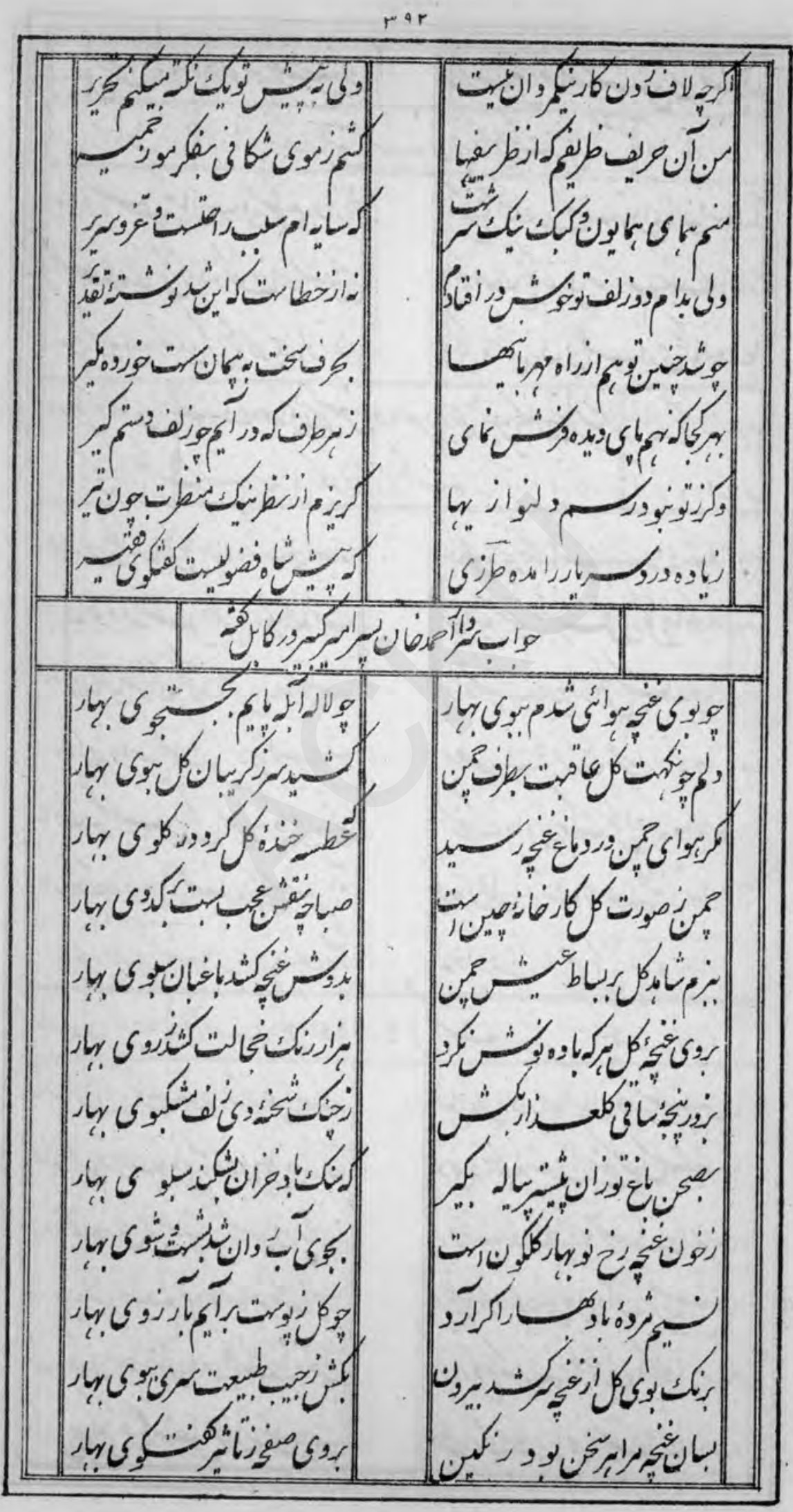


rar

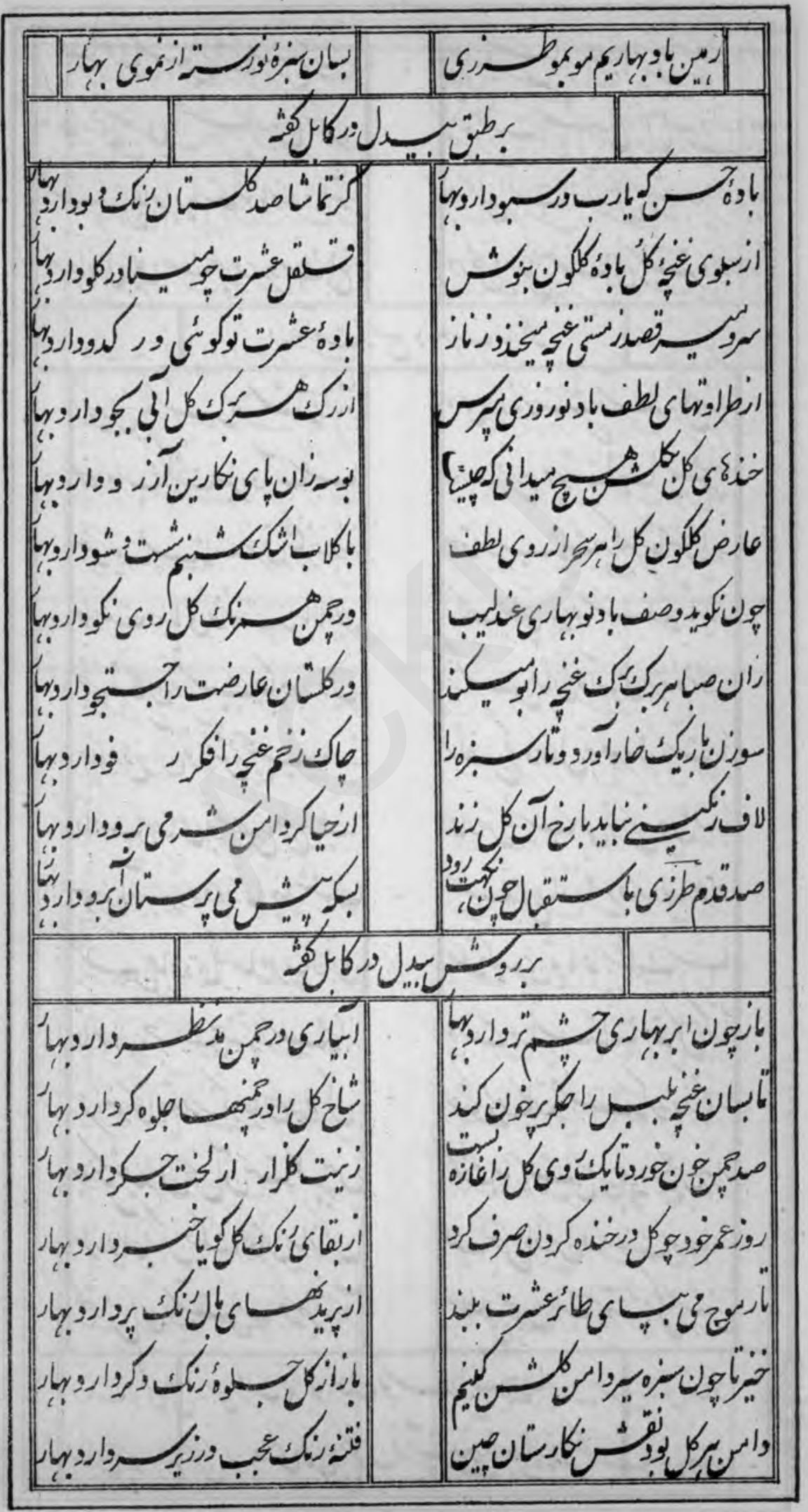




\section{rat}

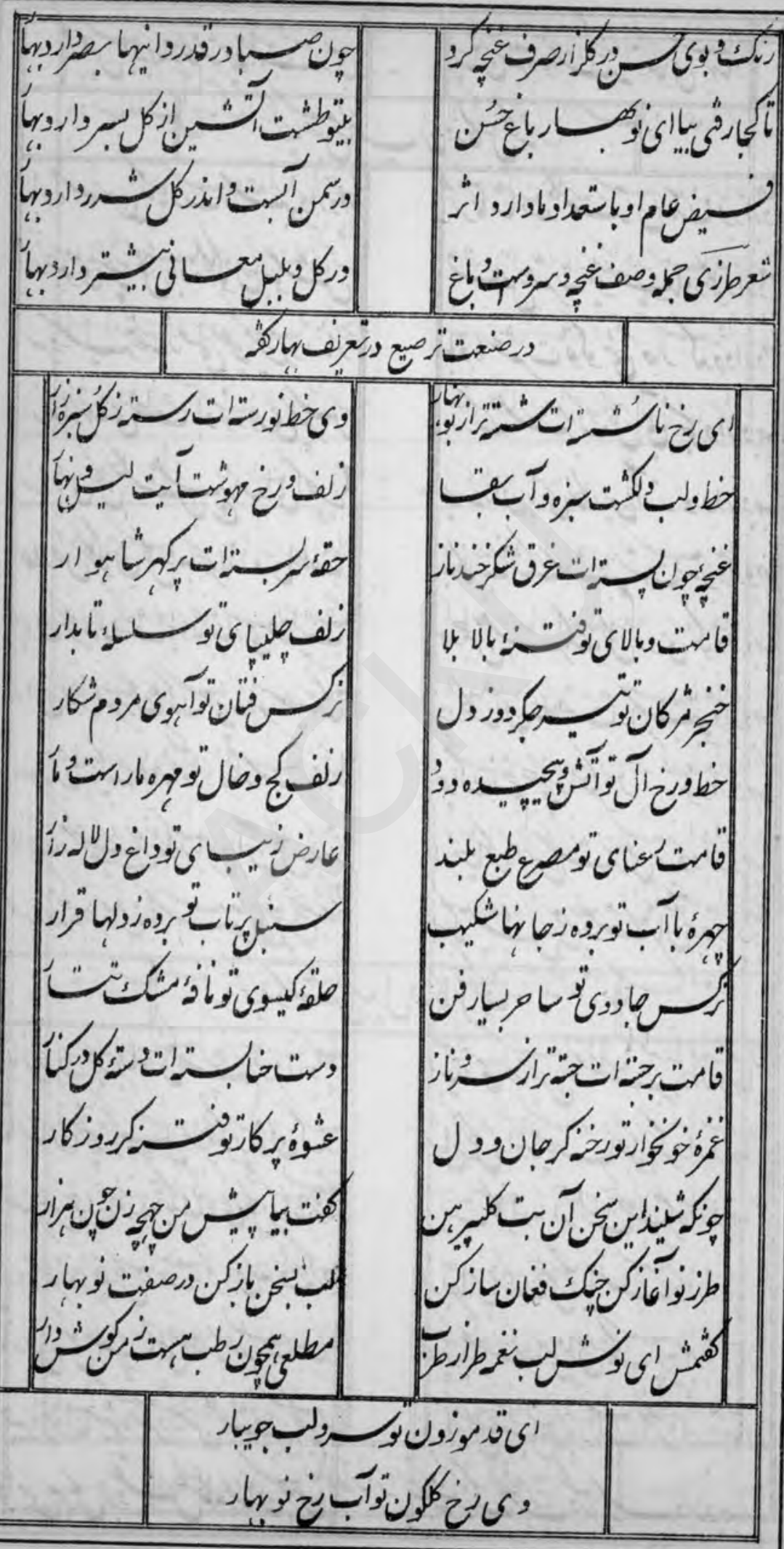


$\Gamma 90$

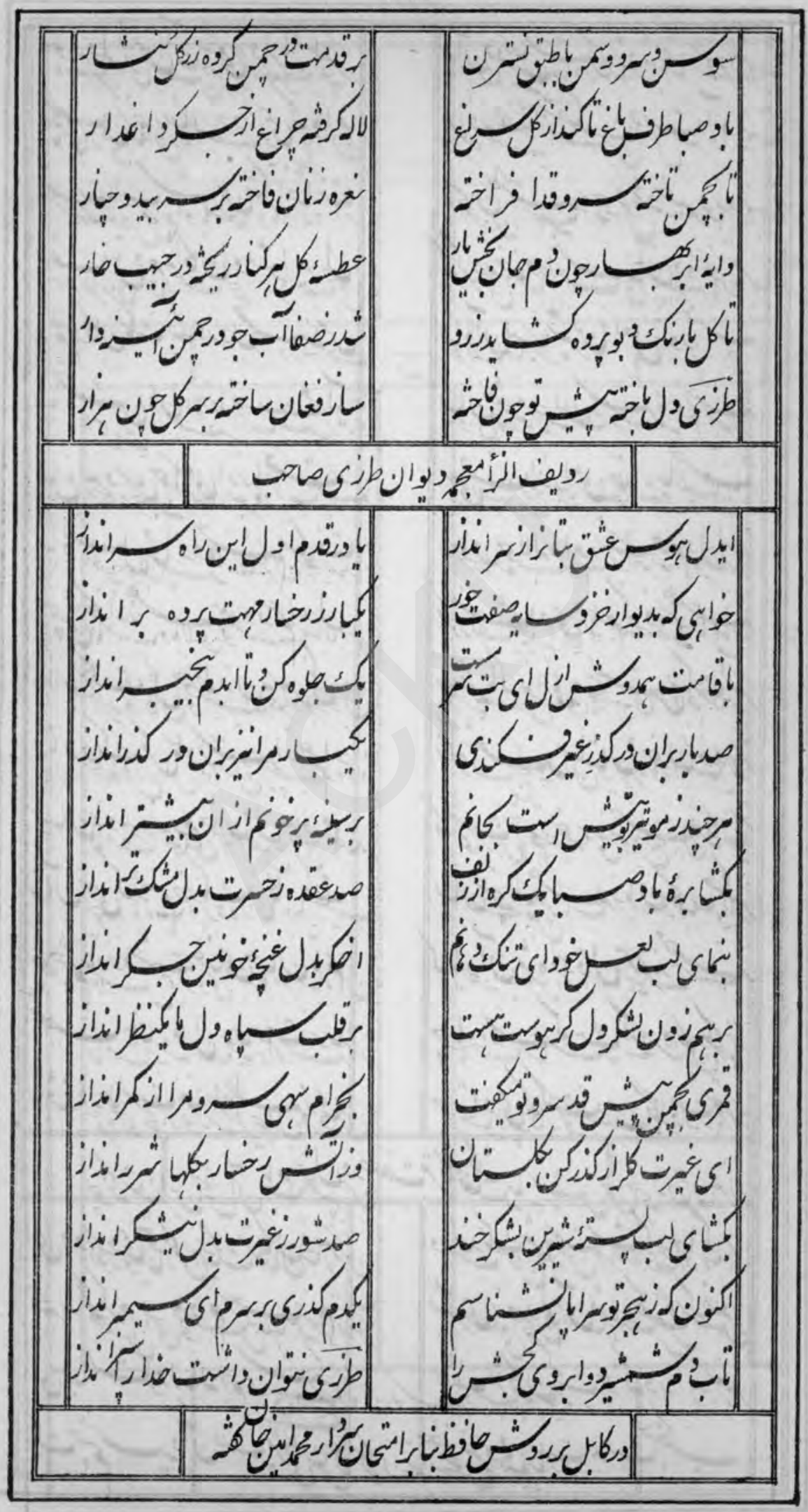


r 4

|


rab

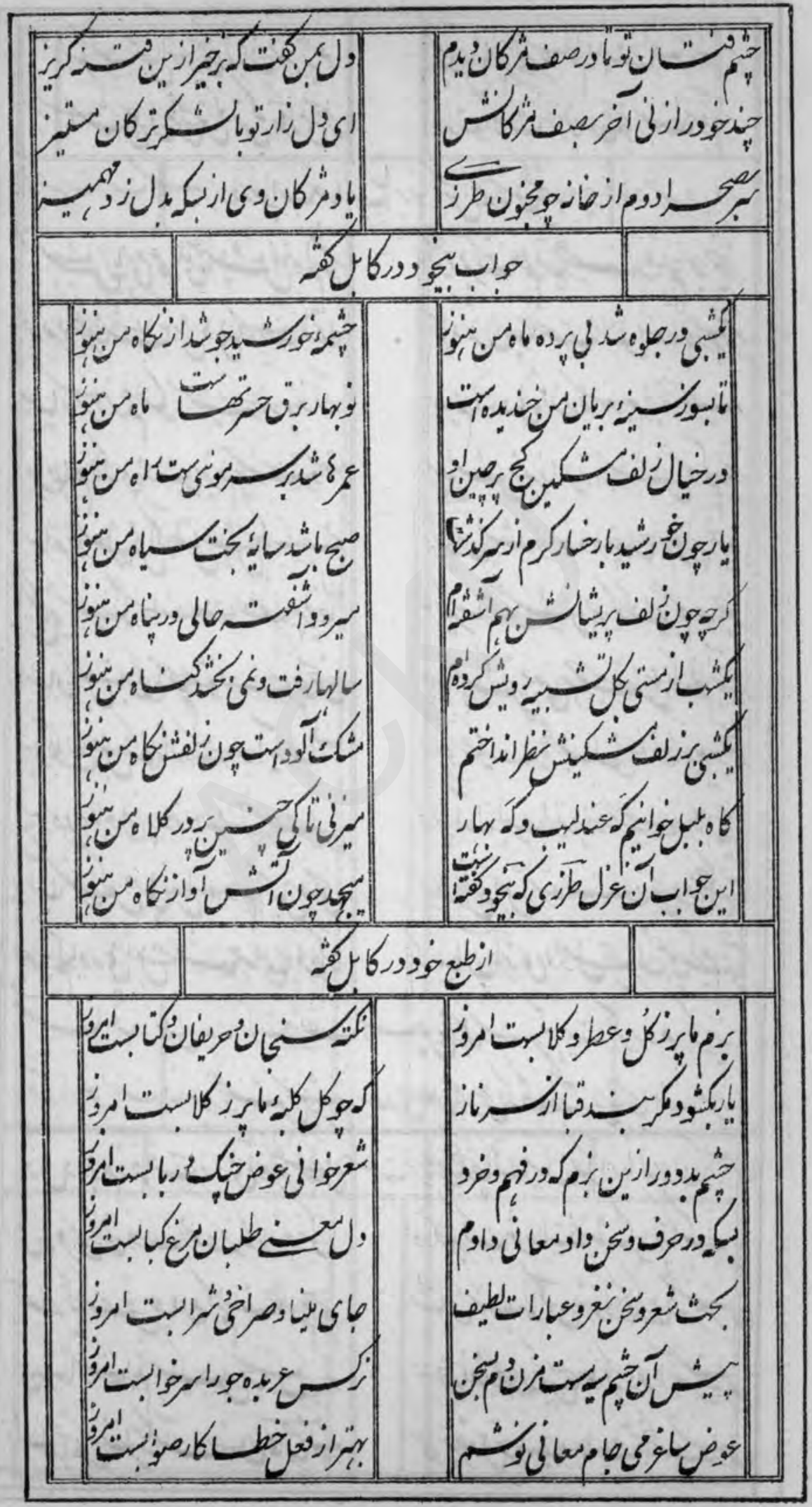




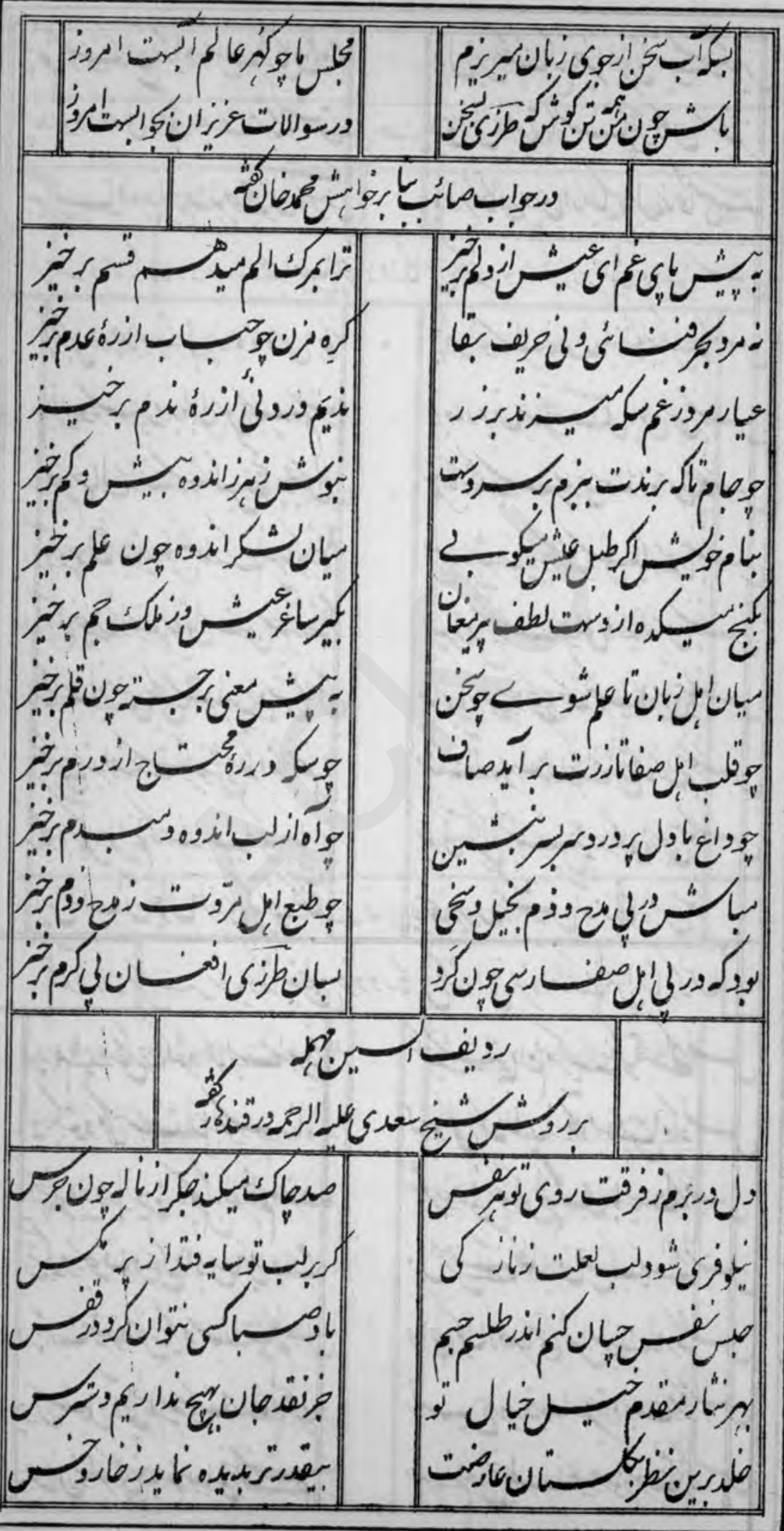




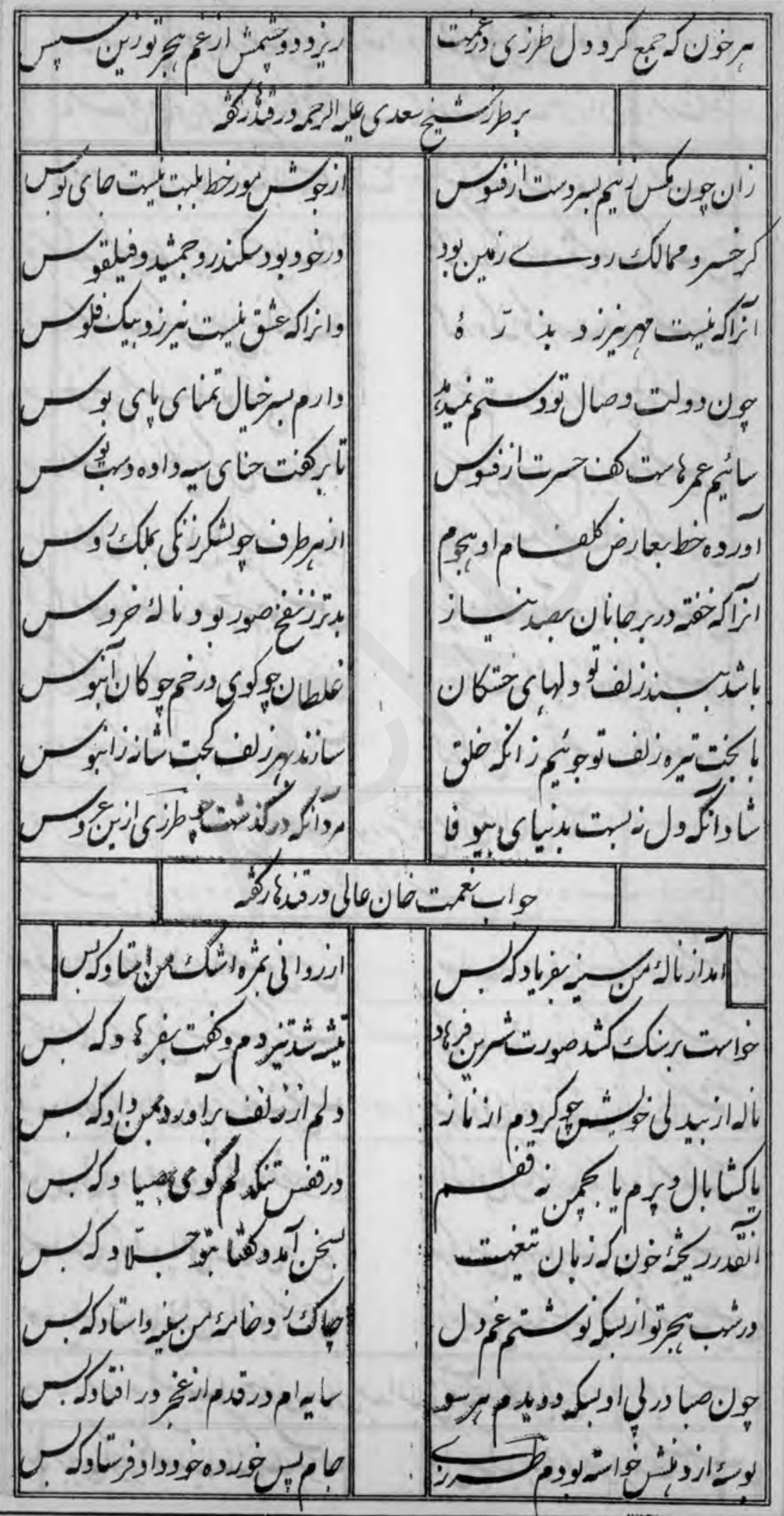


F..

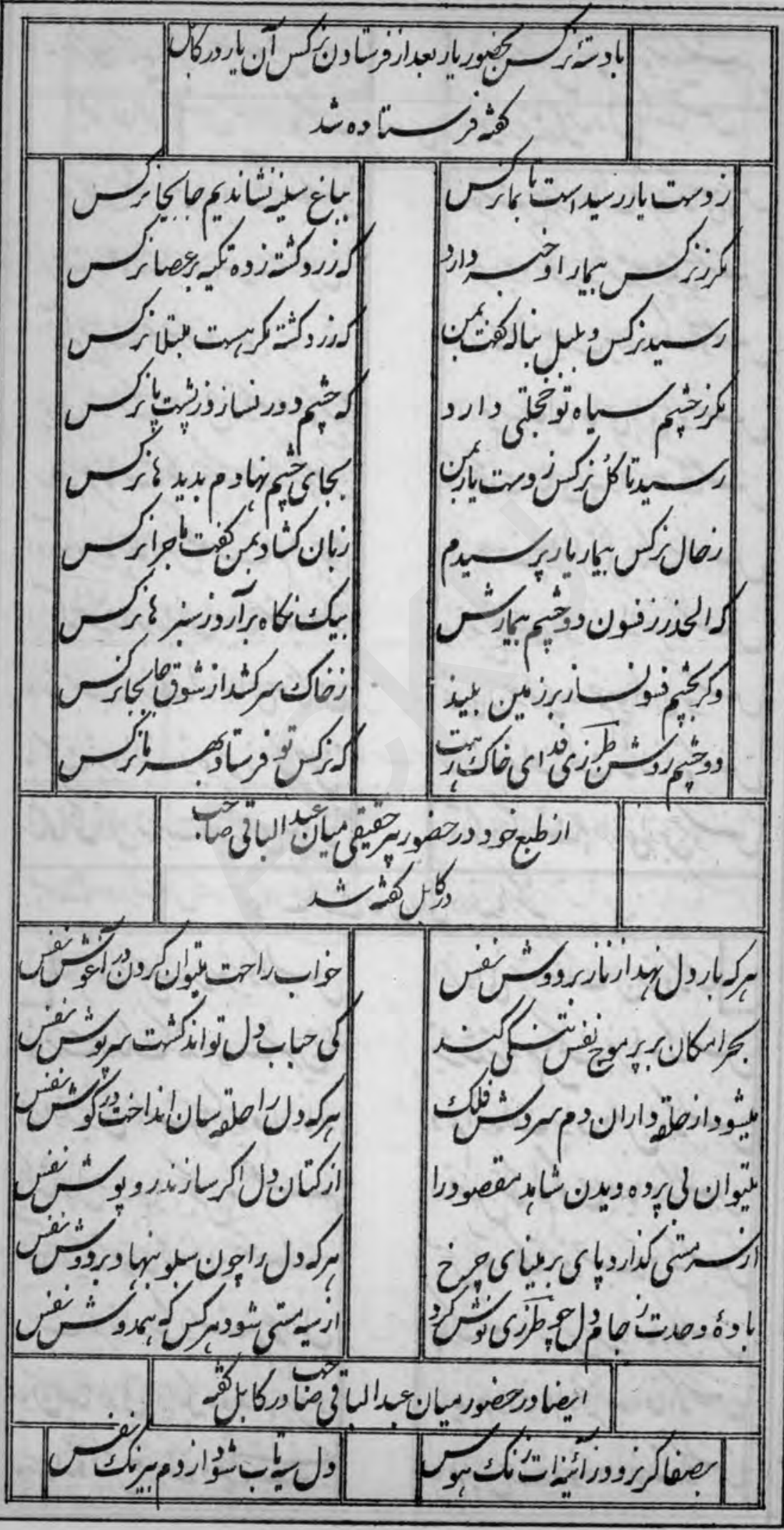


c. 1

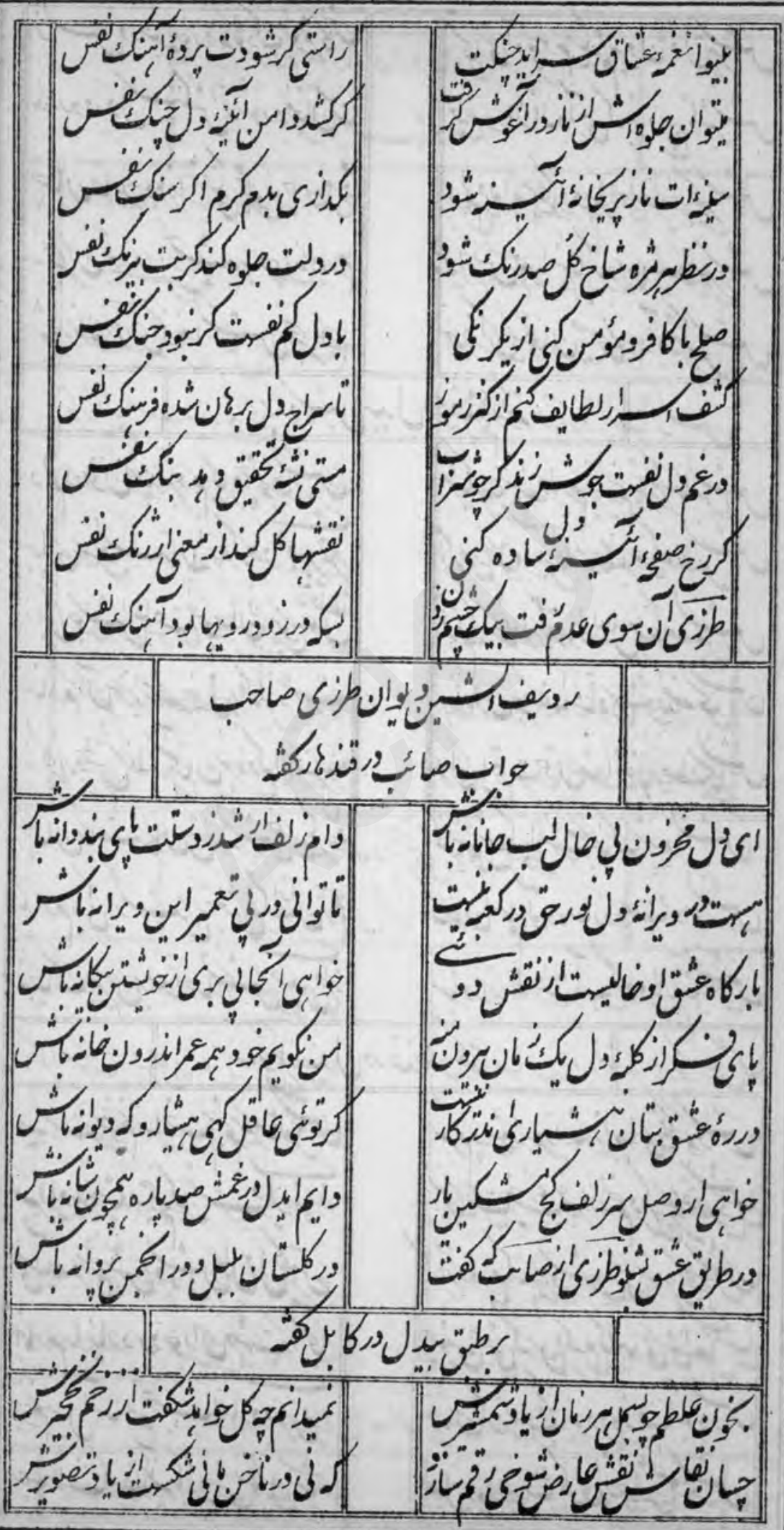




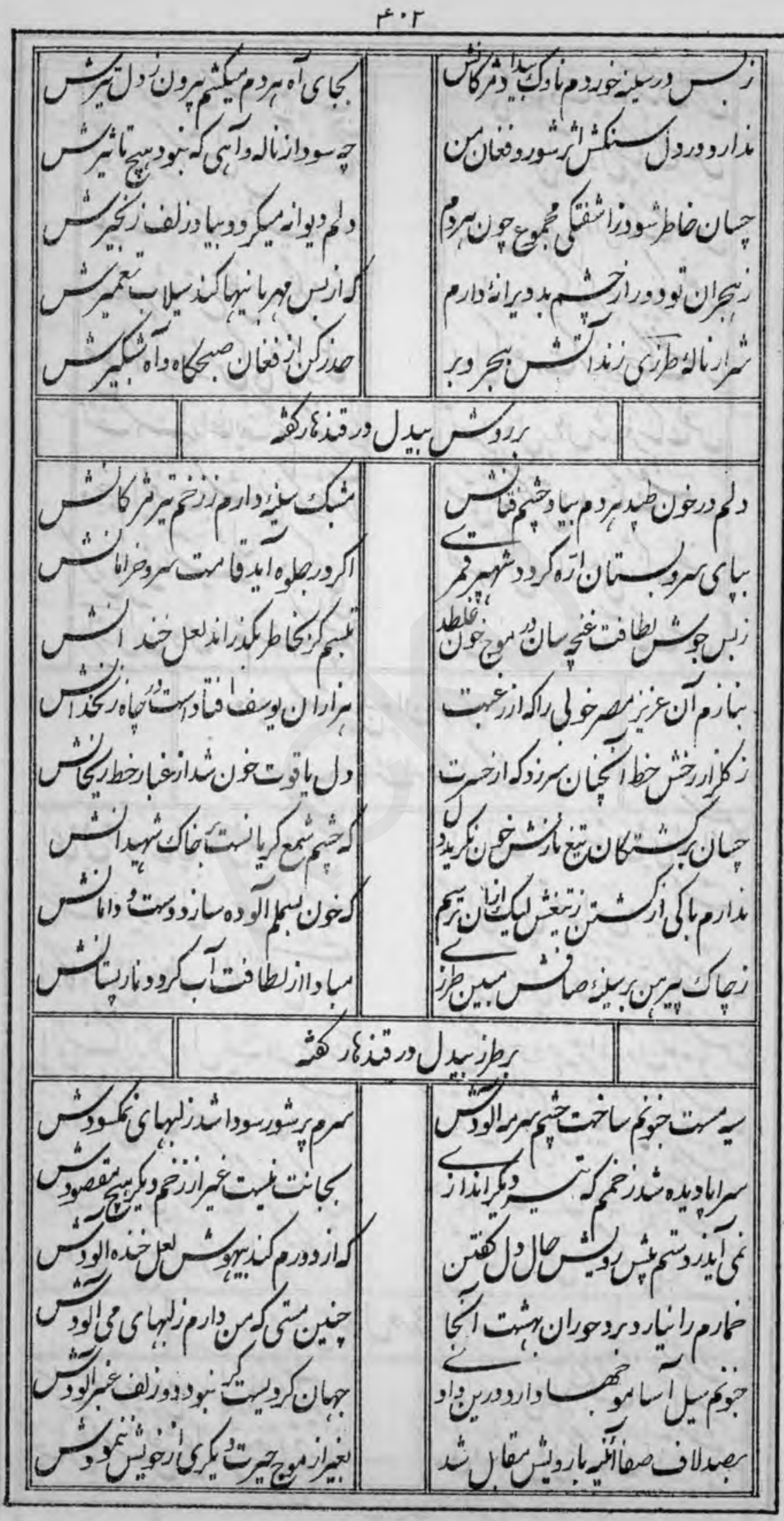


$r \cdot r$

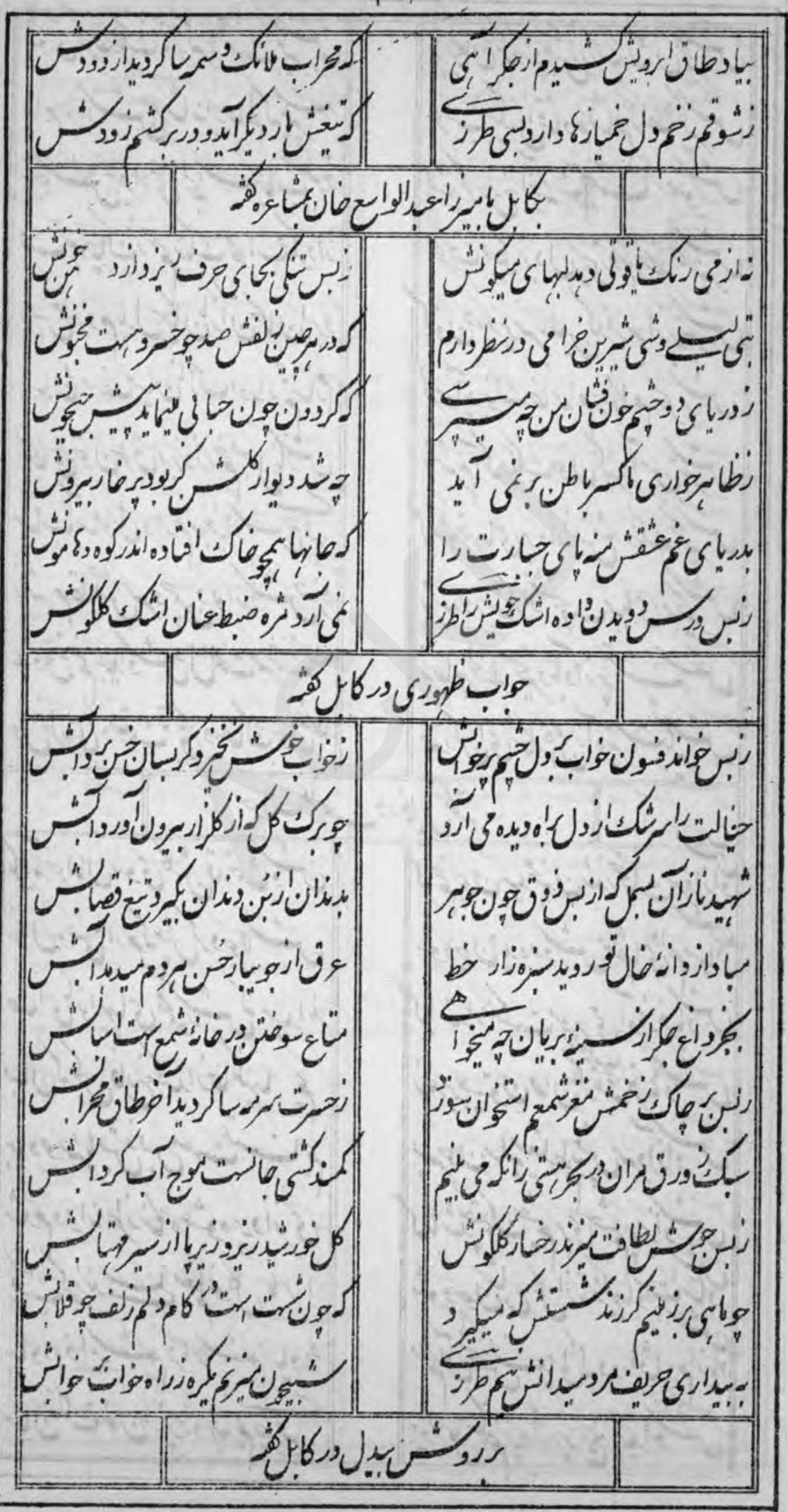


ع

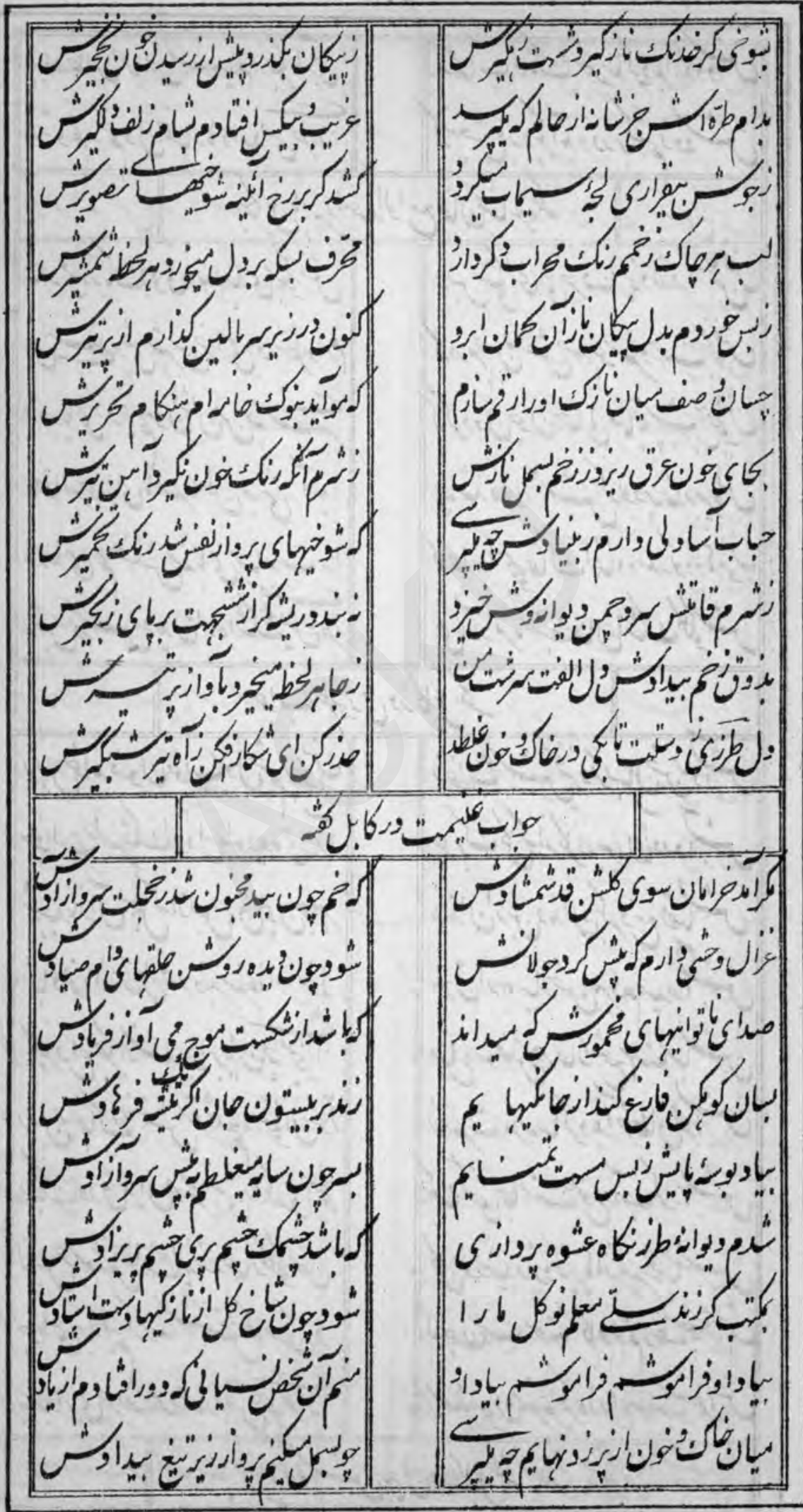


E.Q

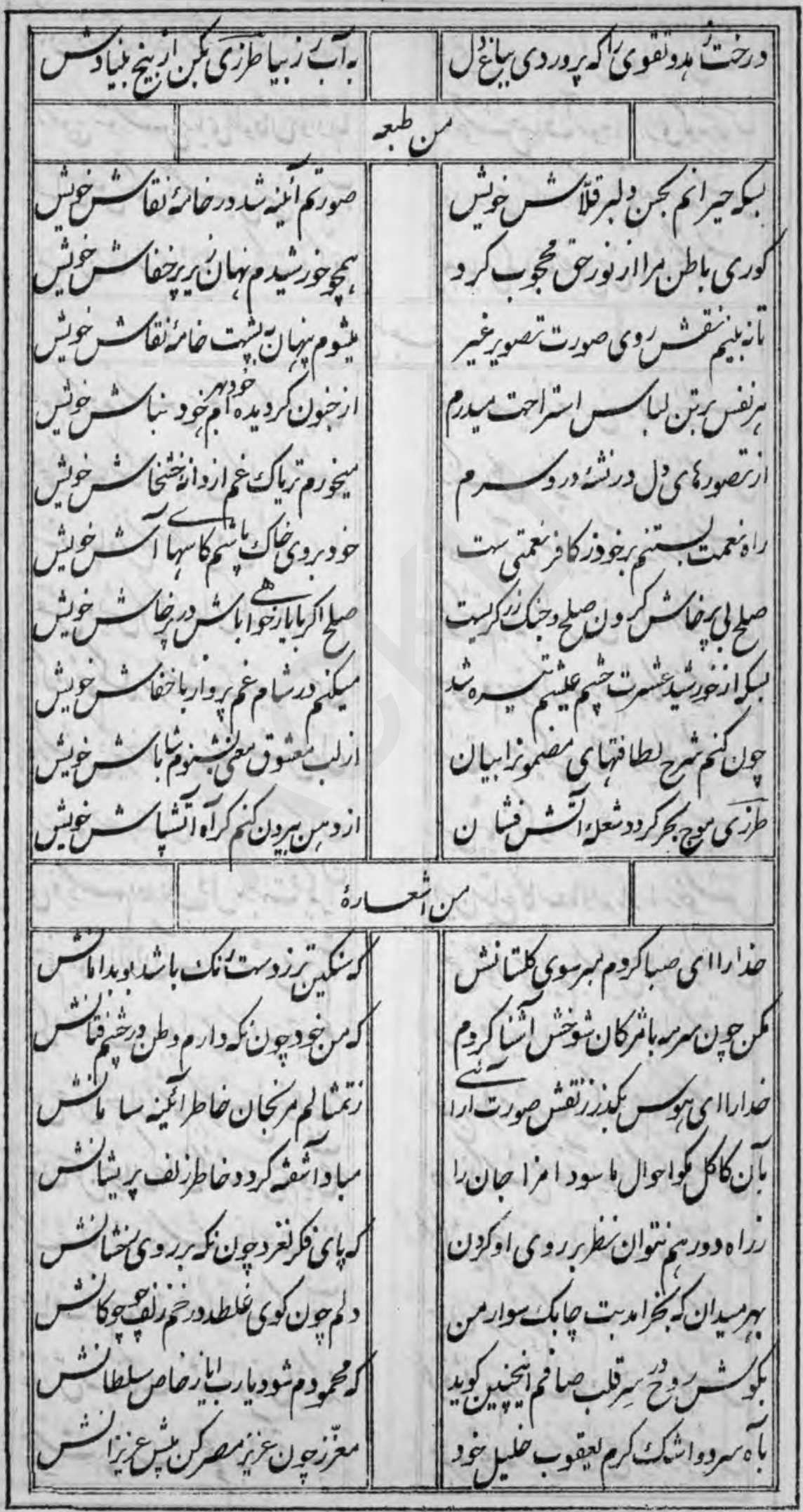


s.

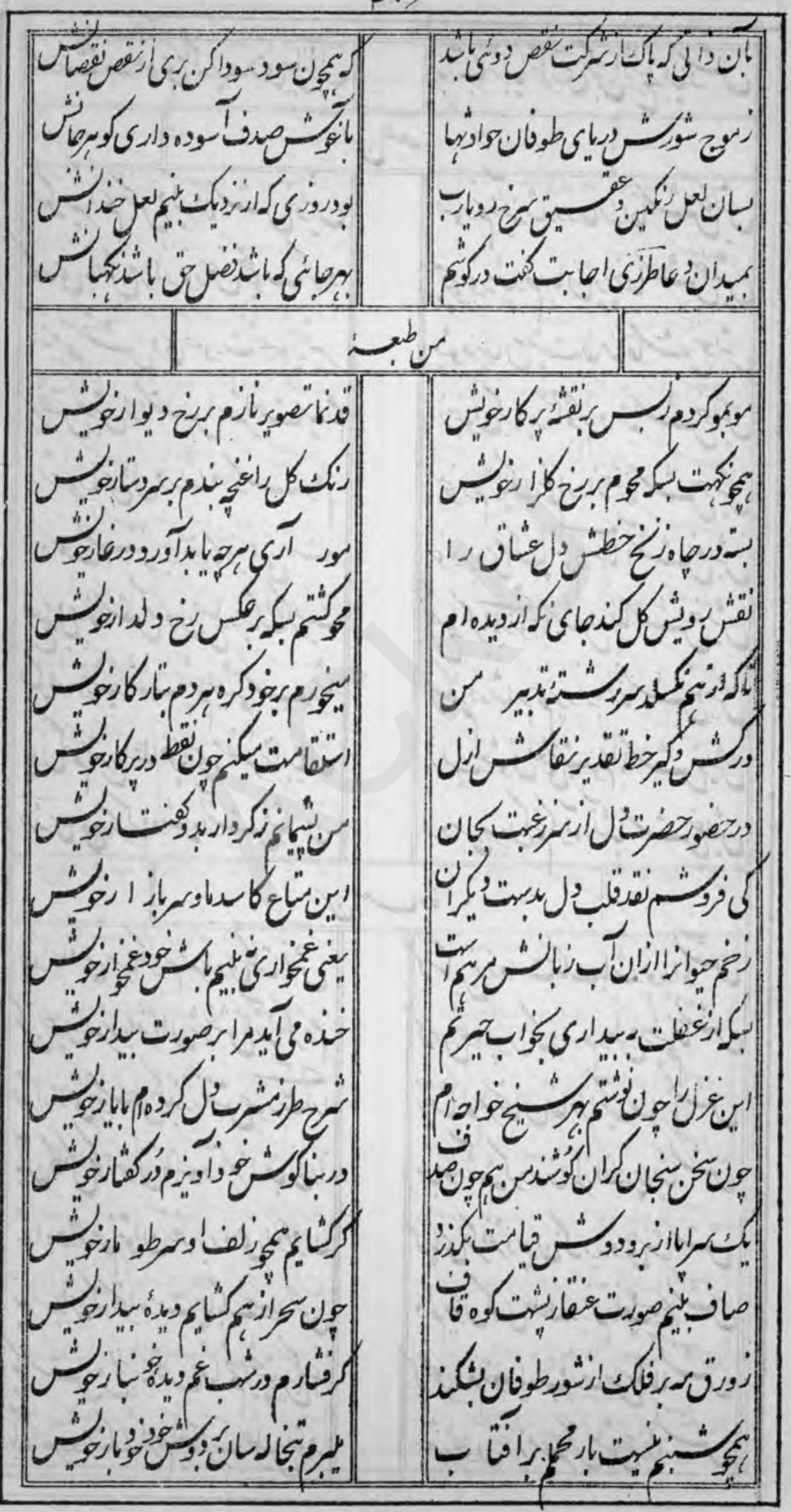


F. $r$

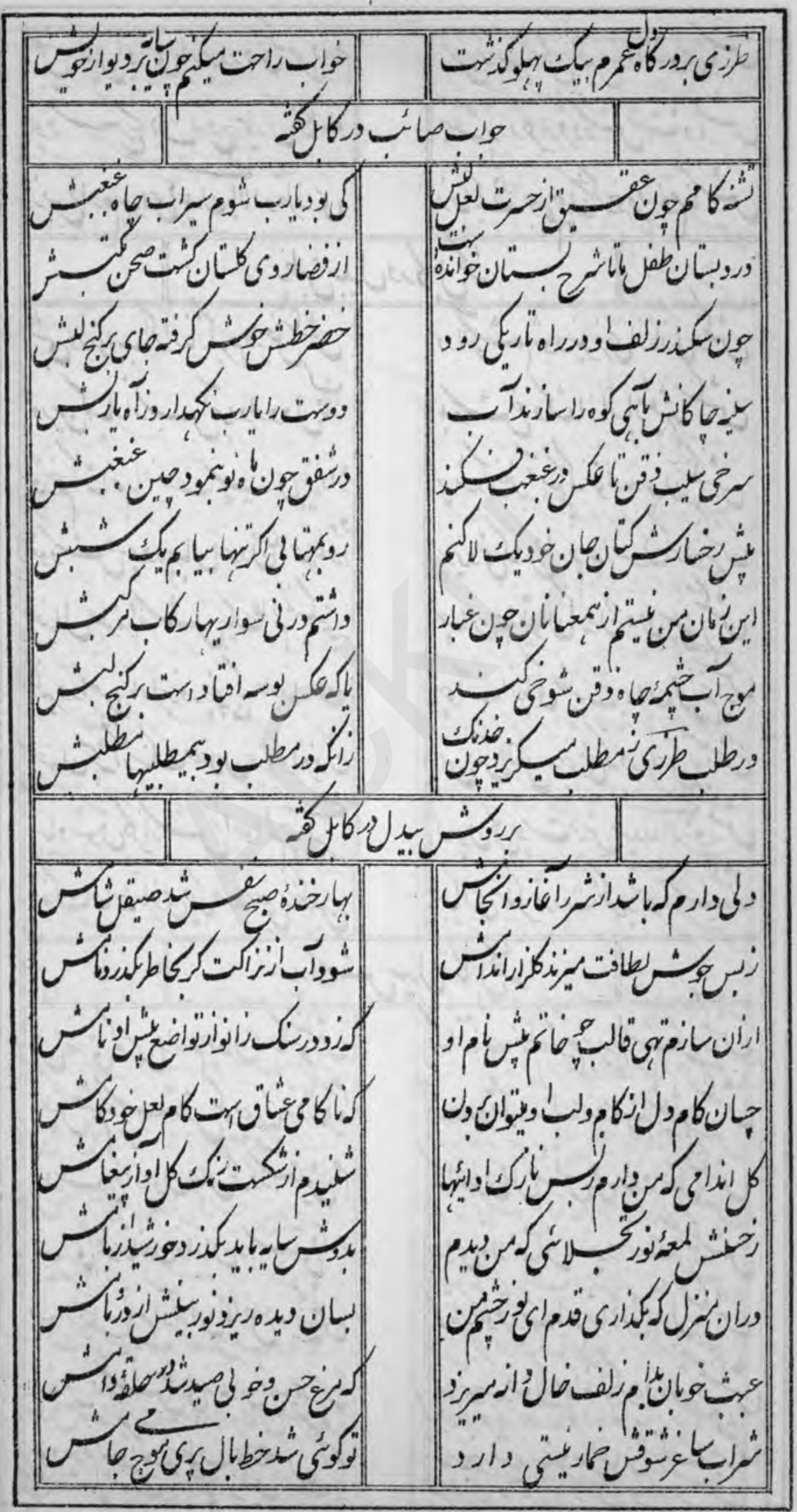


F. 1

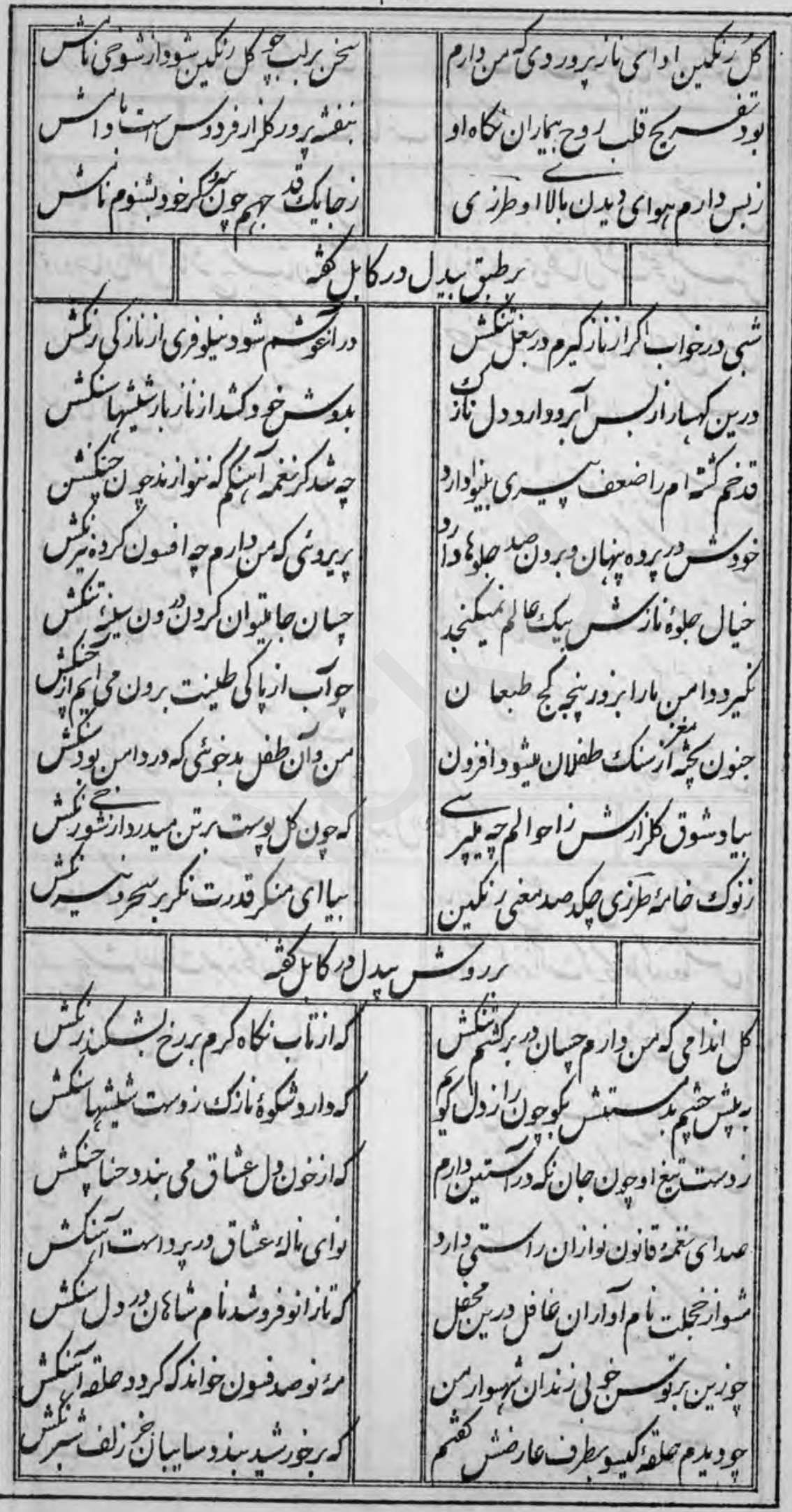


r. 4

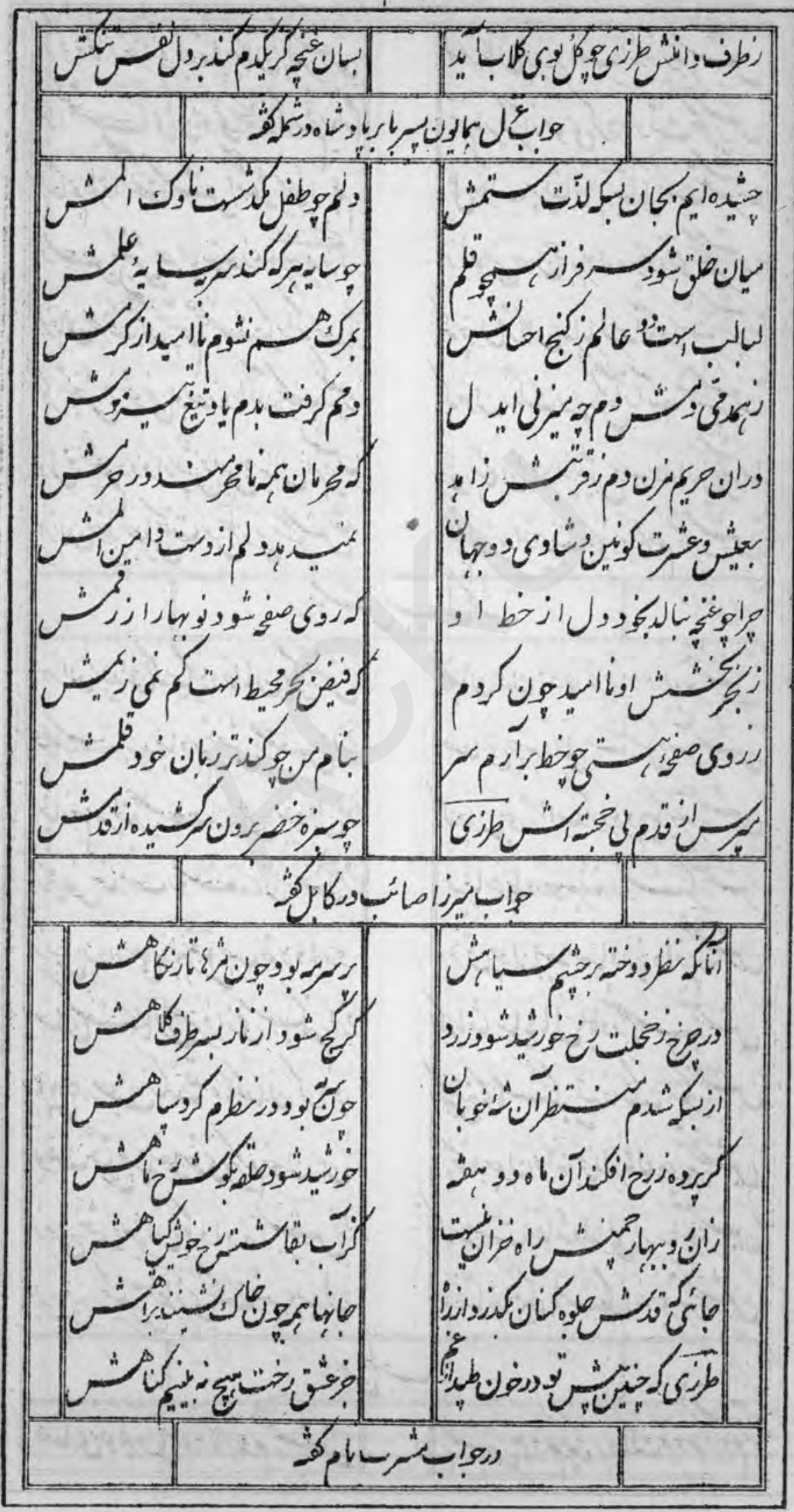


ri.

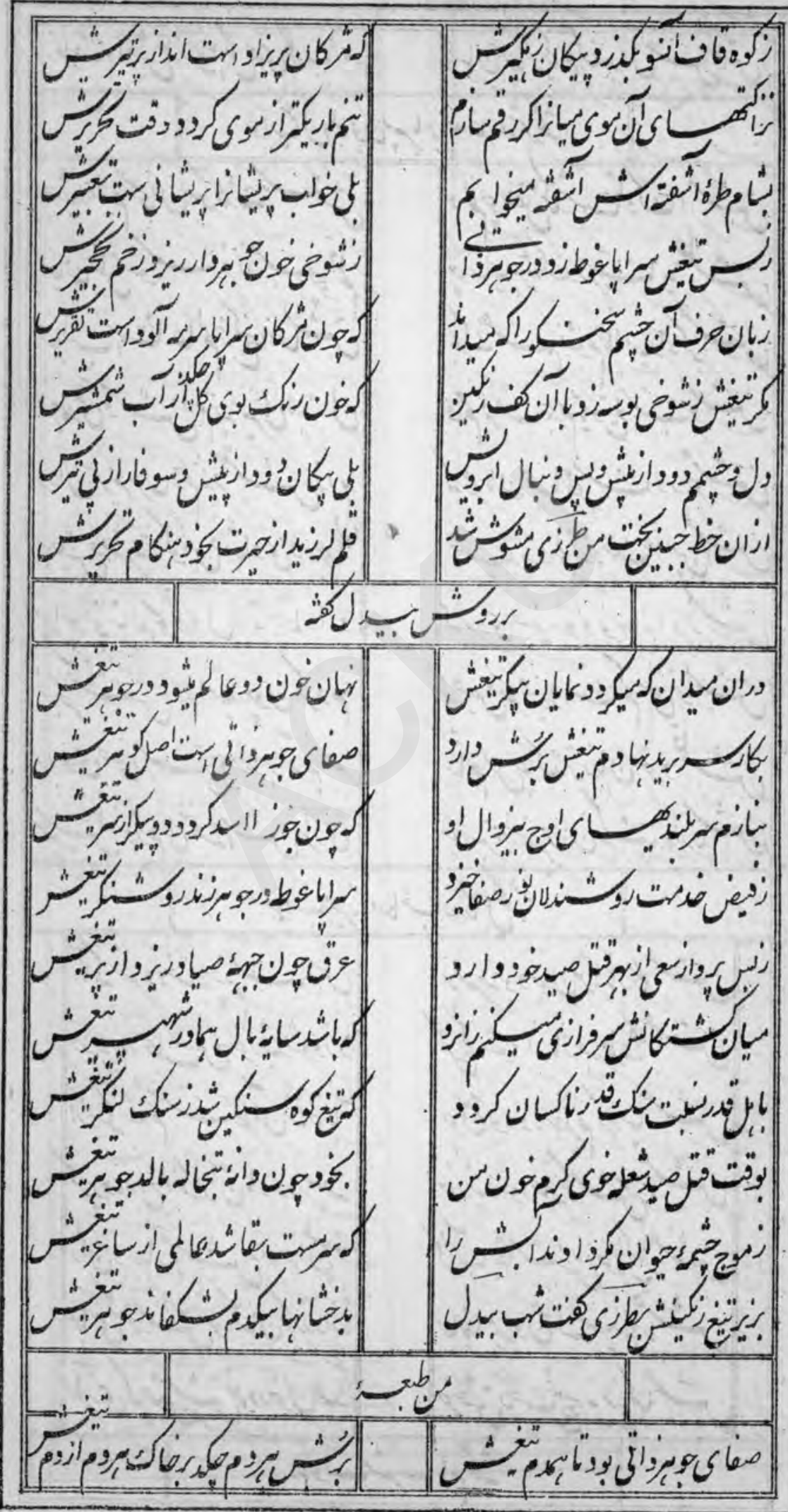


F 1

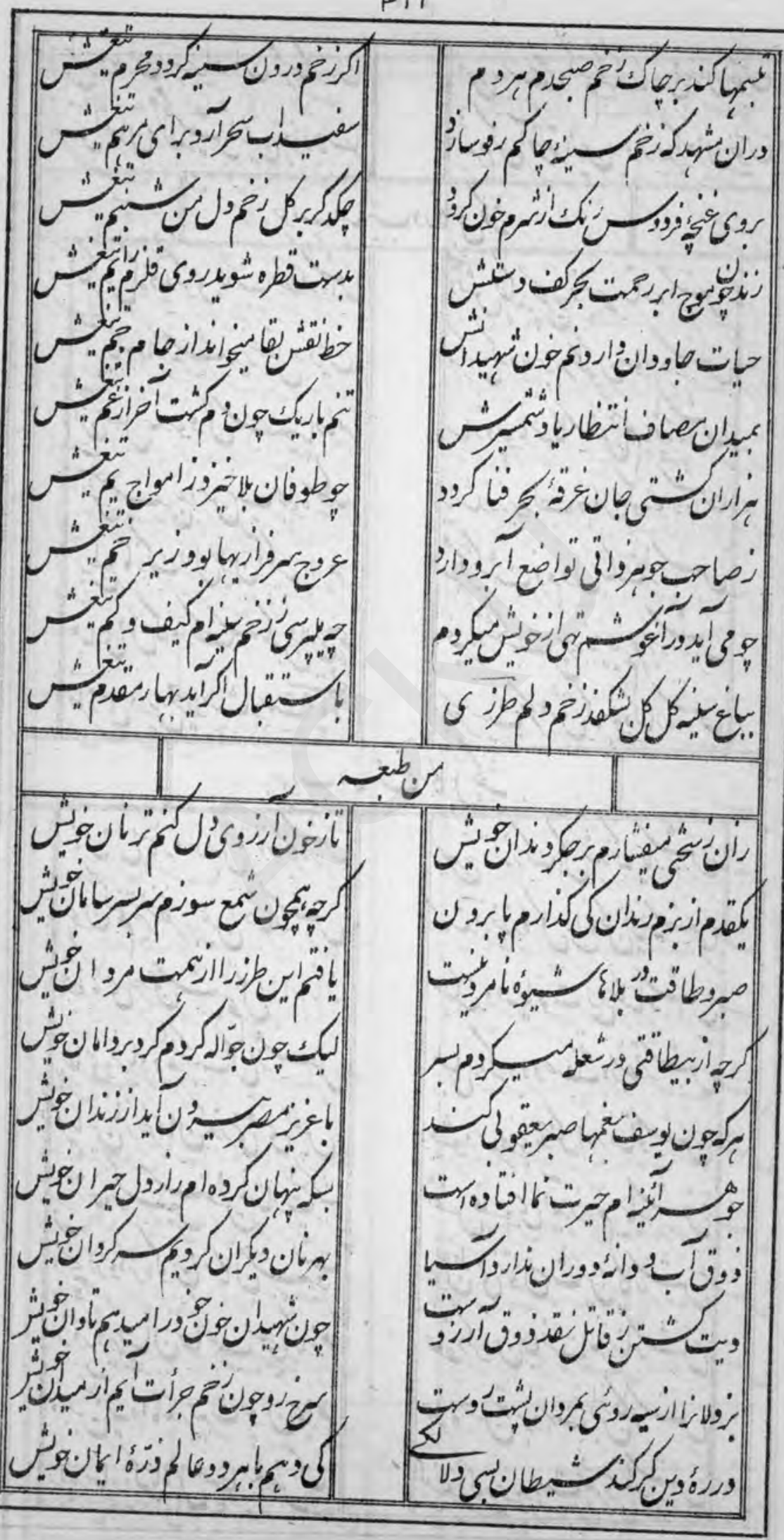


$r \mid r$

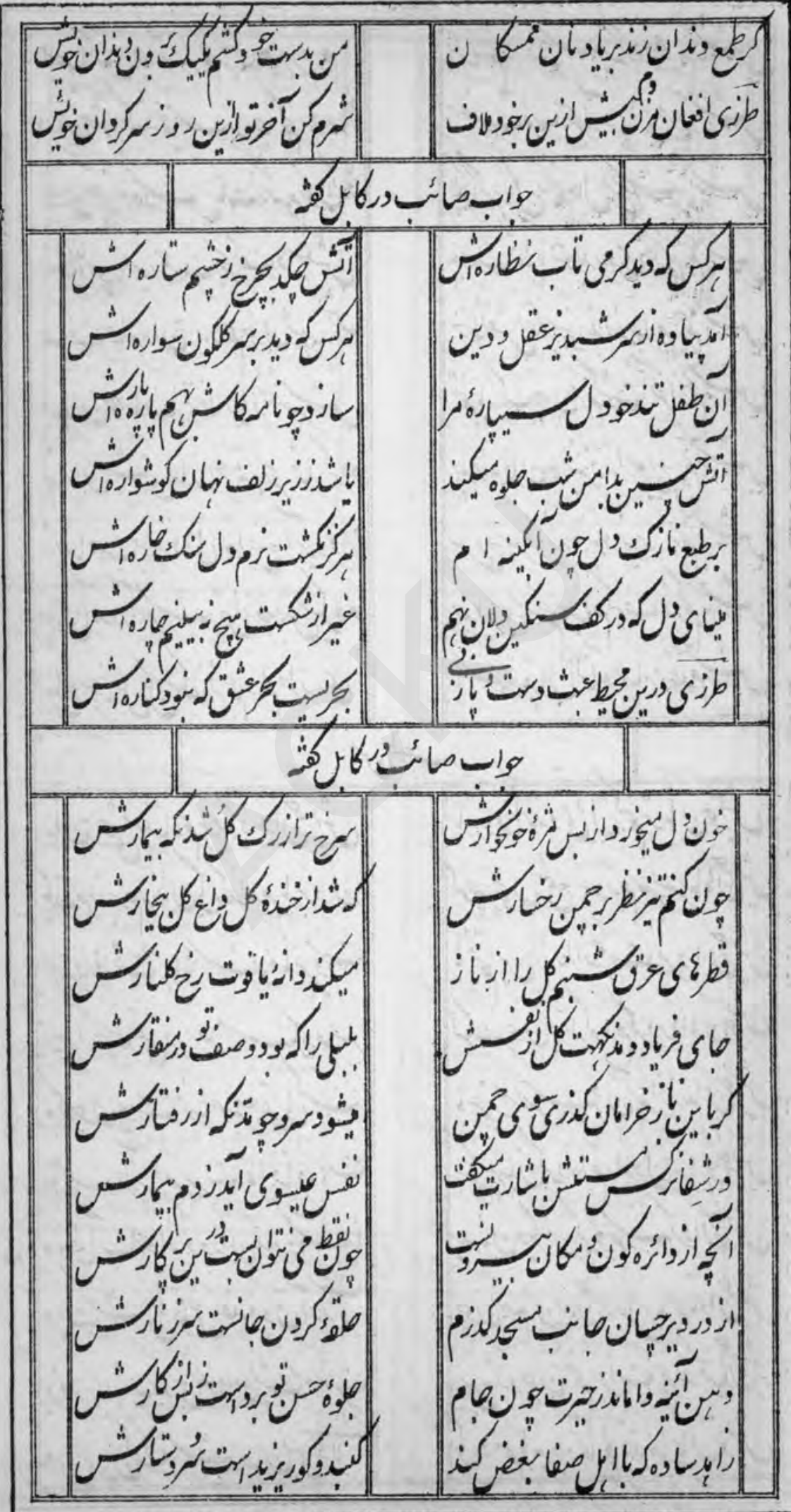

Y. 
Fir

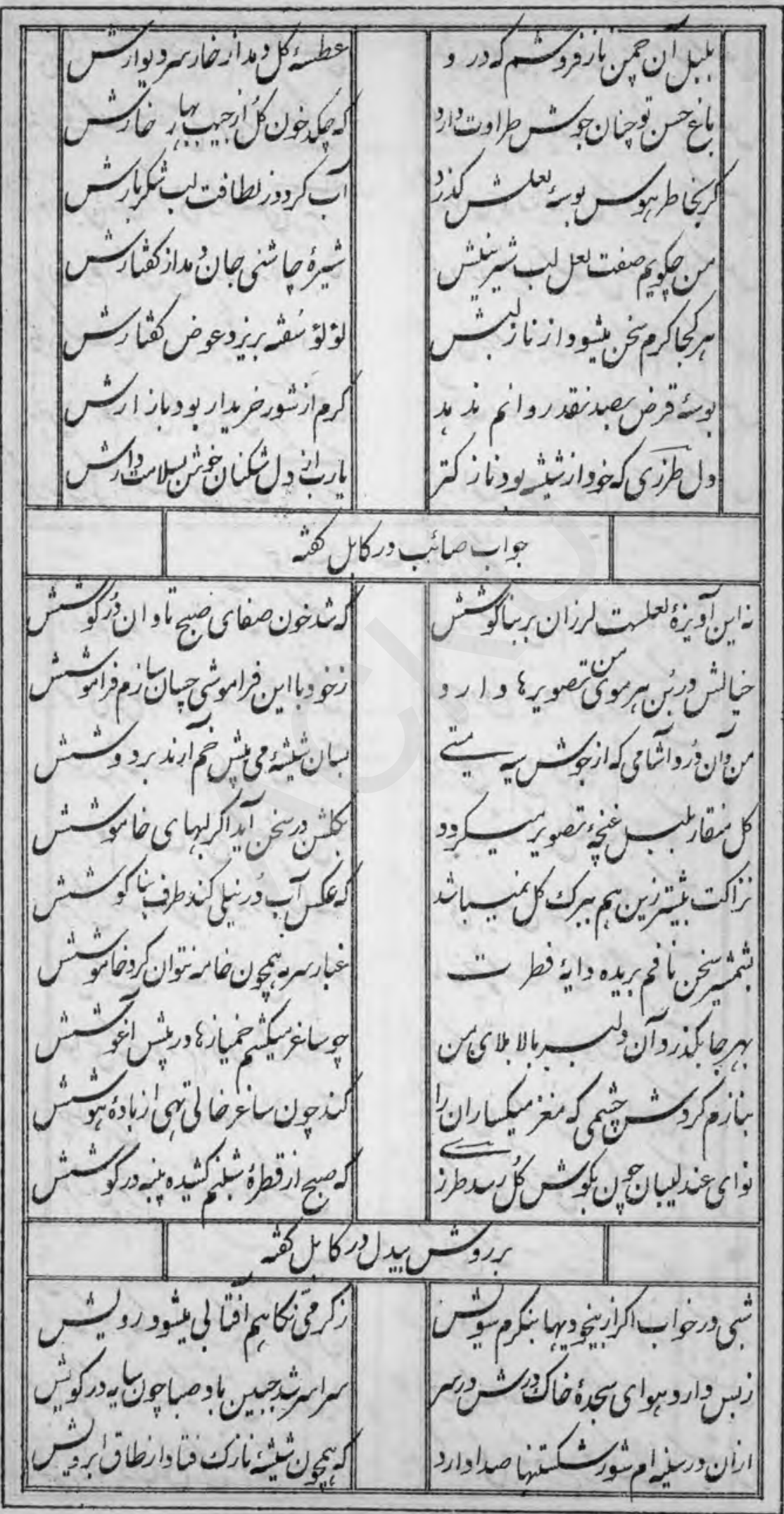




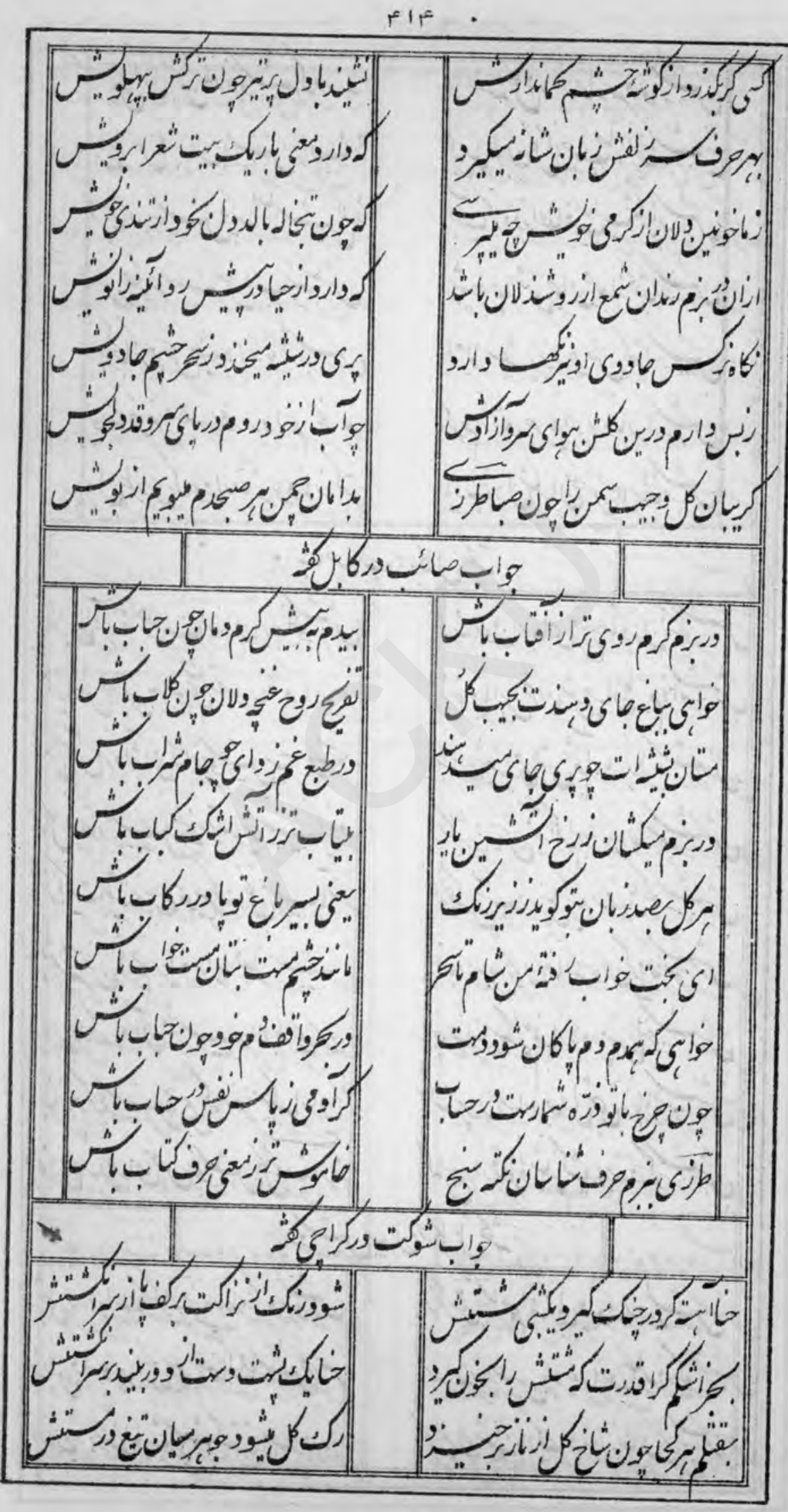

¿ip! 


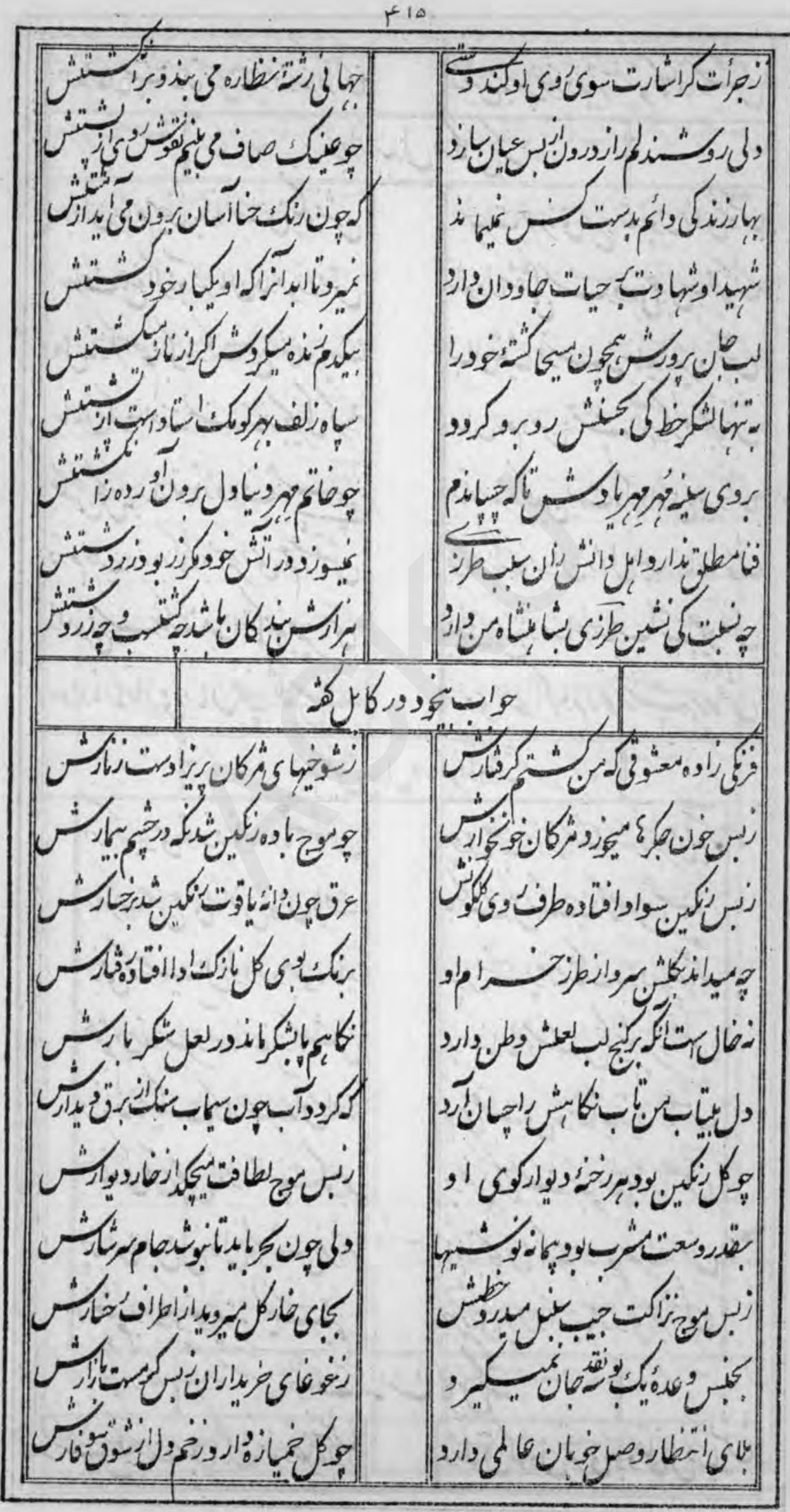


ris

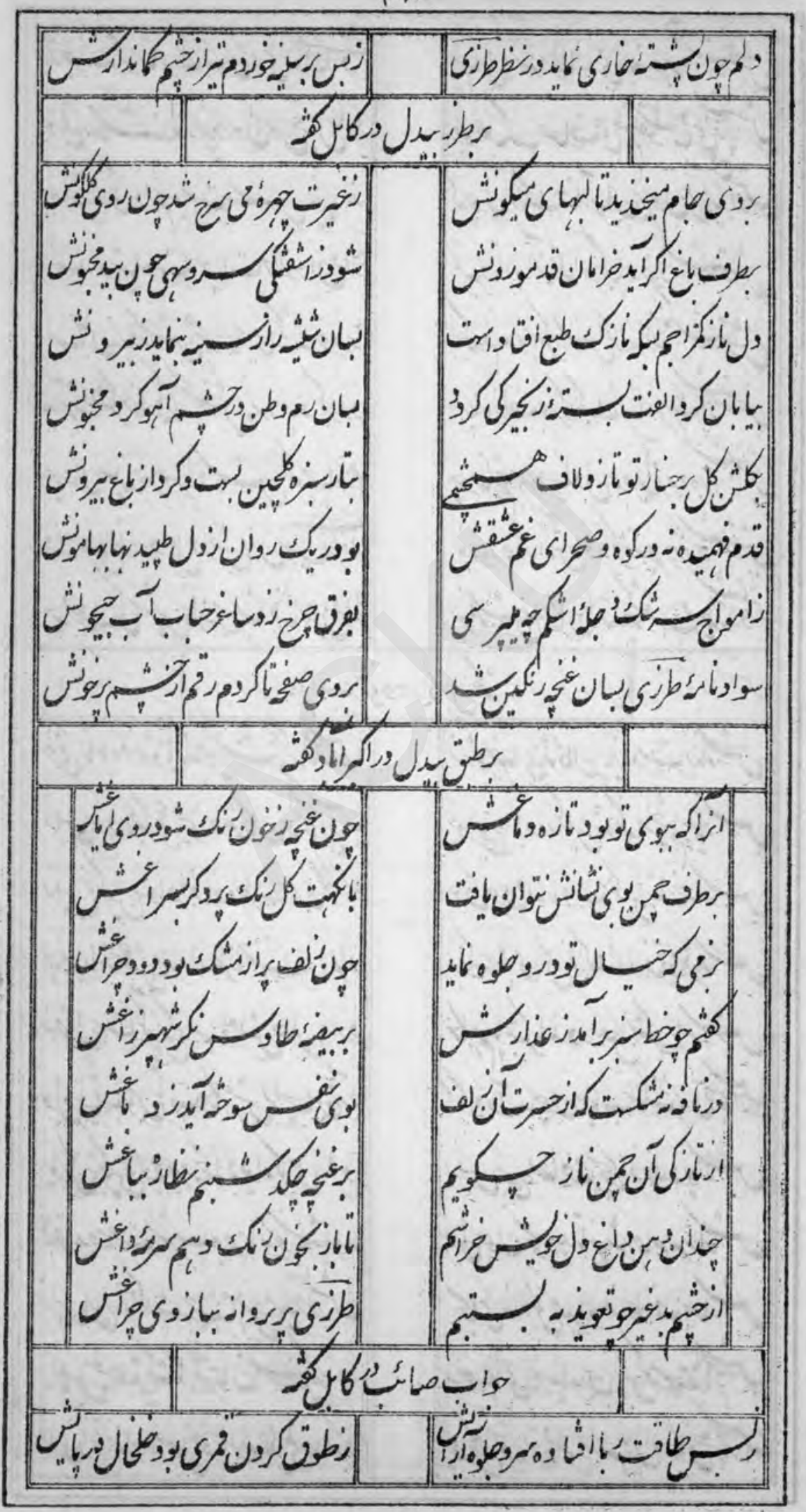


FIL

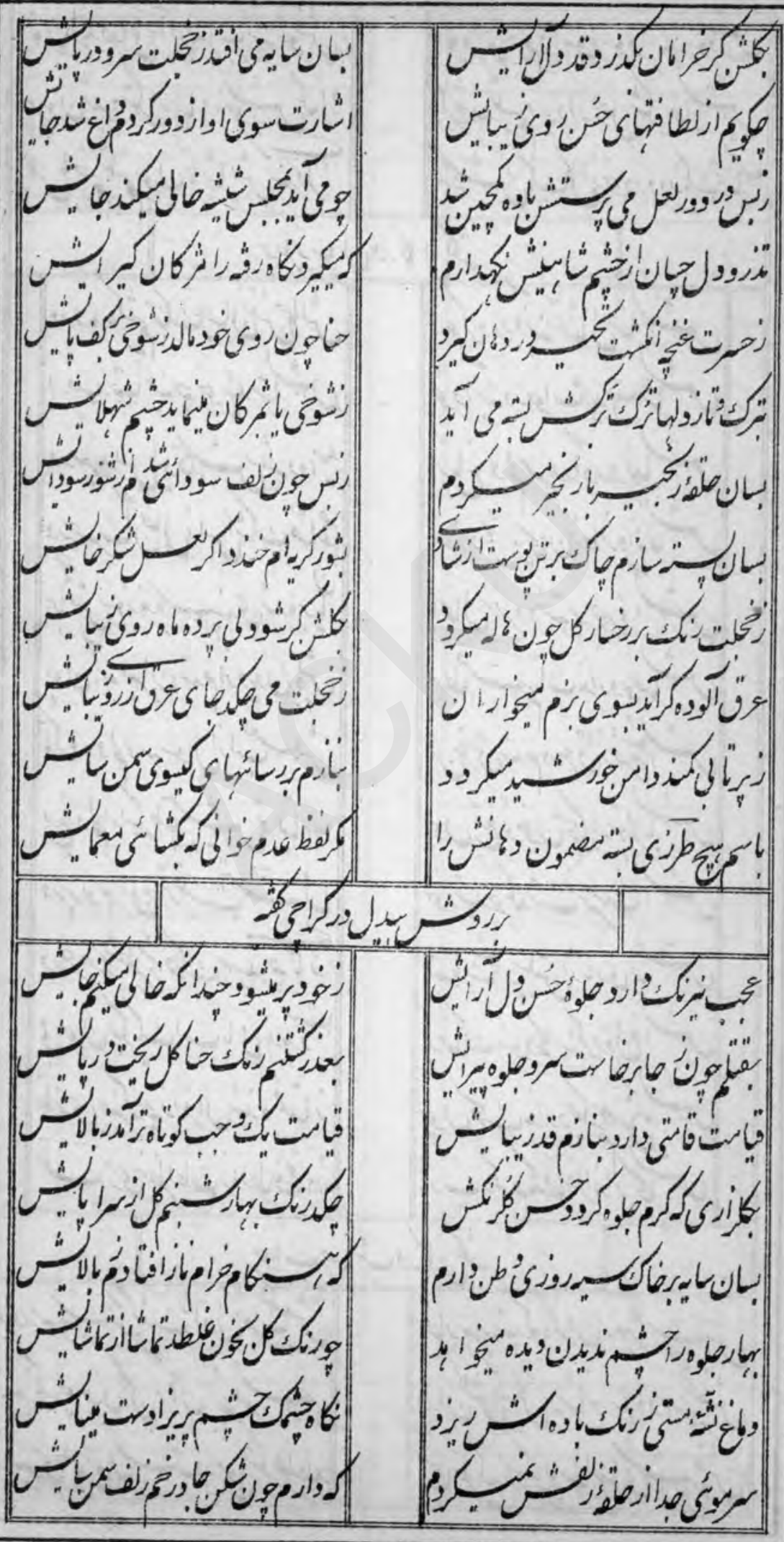


f I

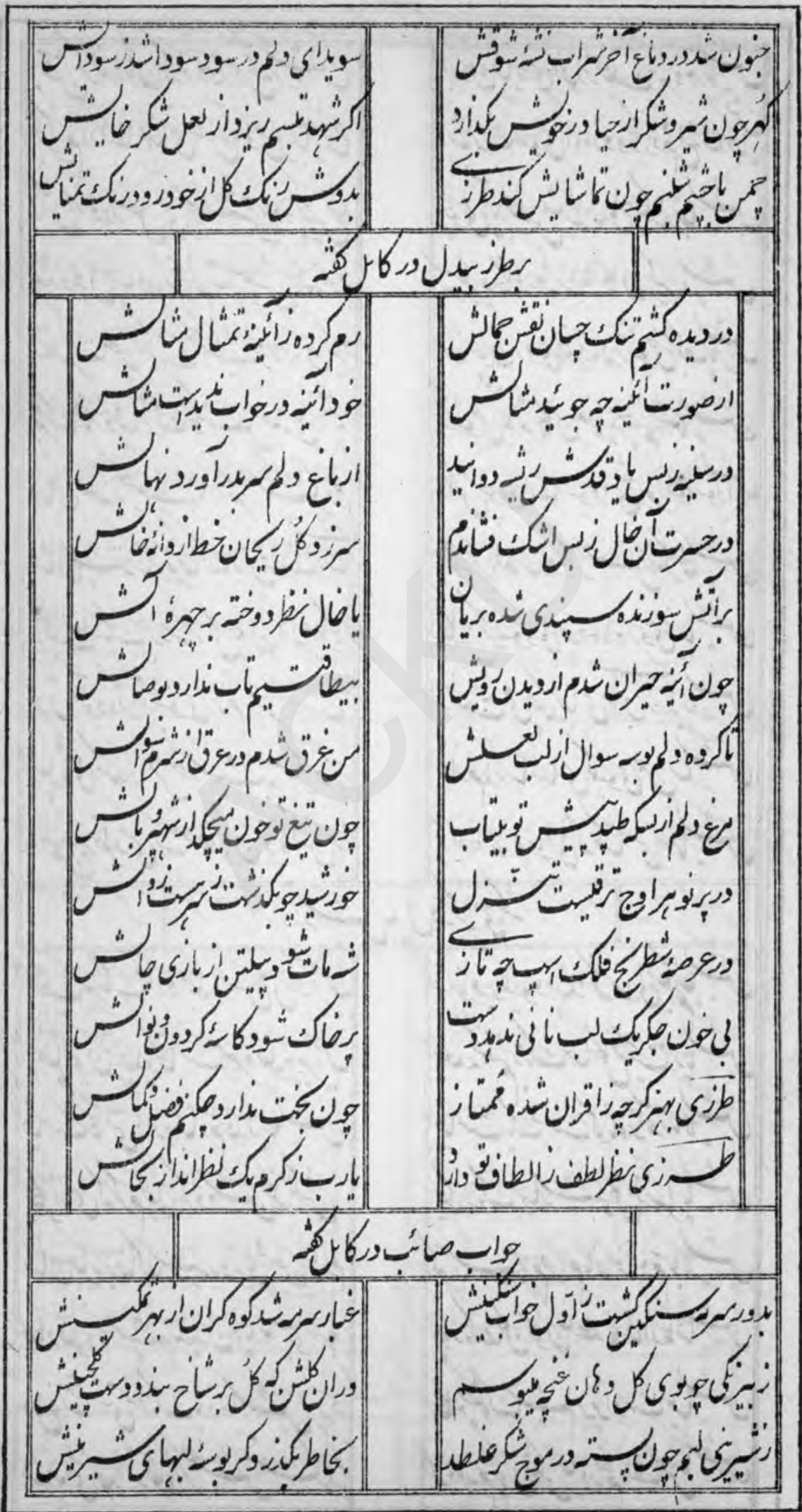


$* 11$

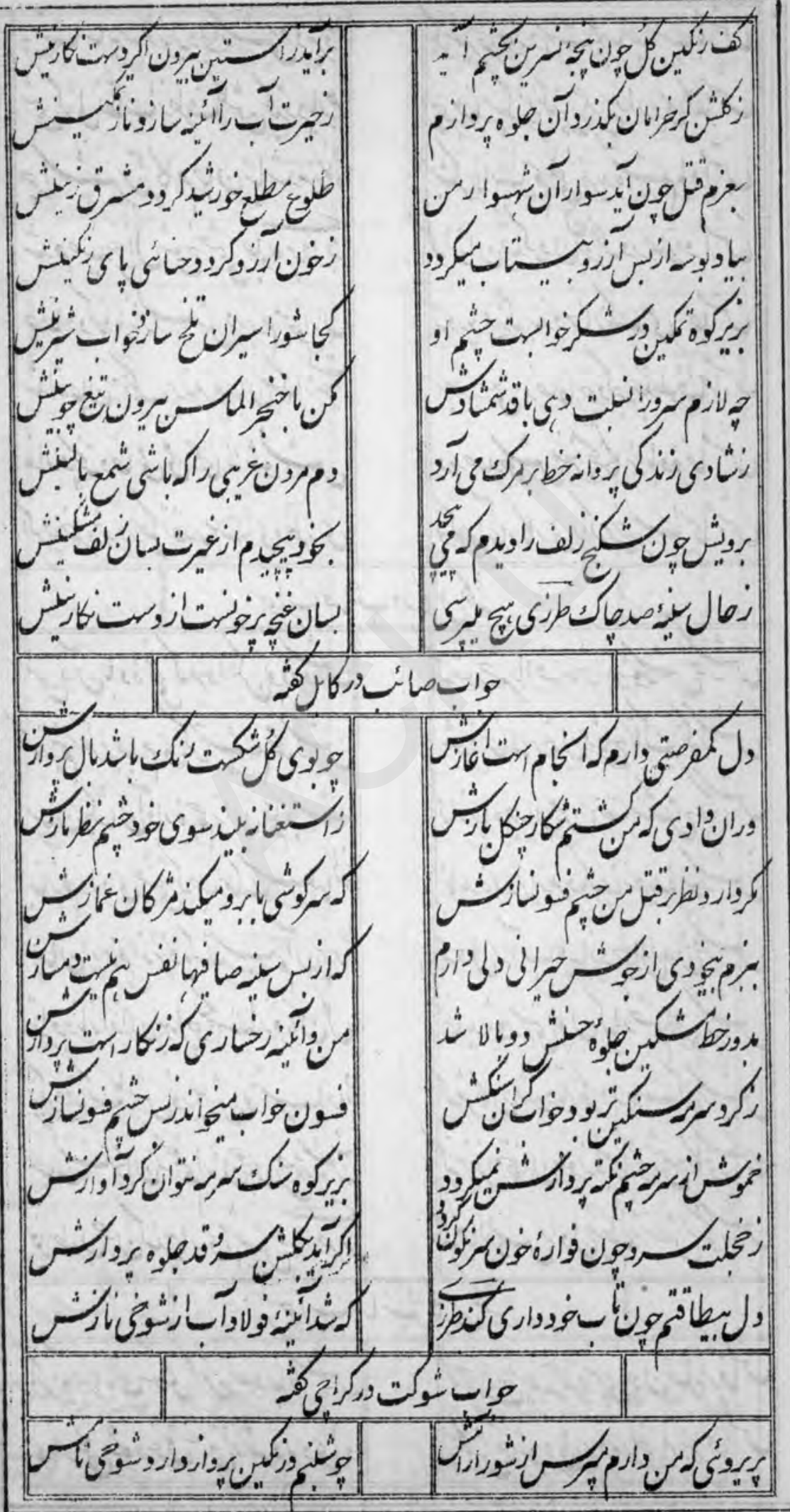


re

|


$r^{6}+1$

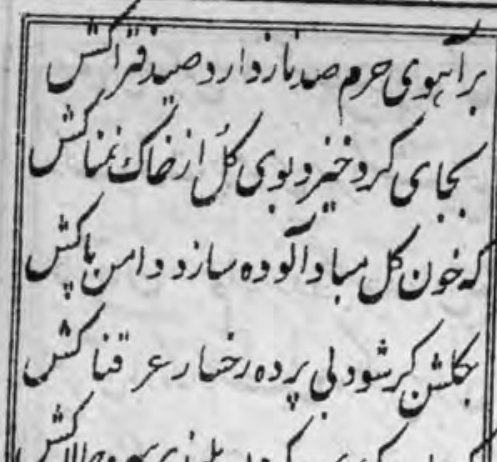
ه ه نَ"

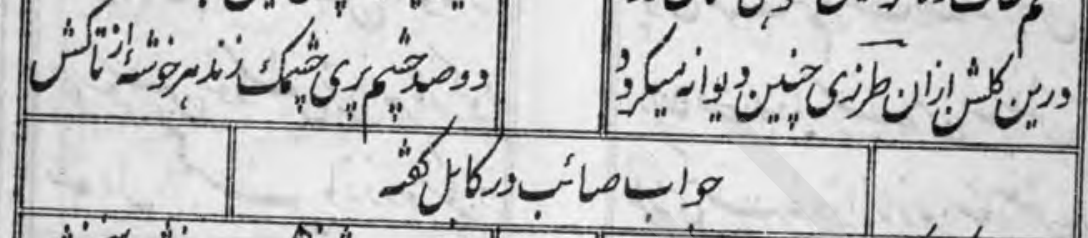

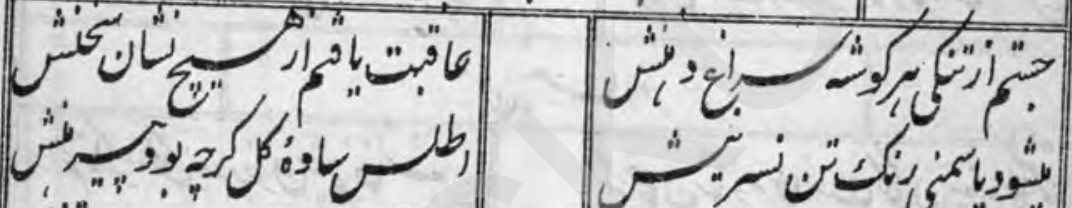

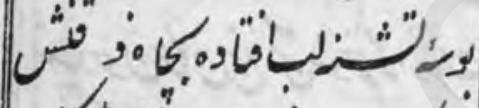

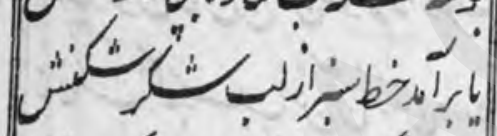

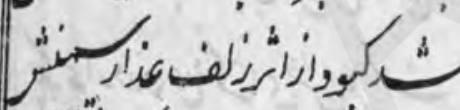

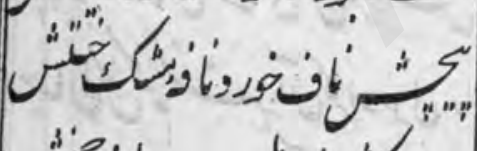

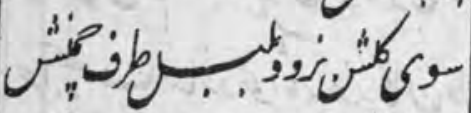

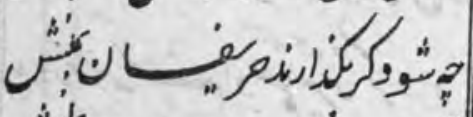
ن"

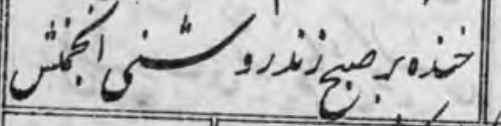
|cos [ "

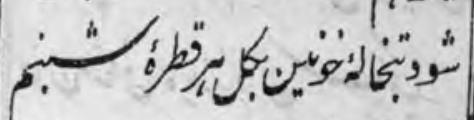
(2)

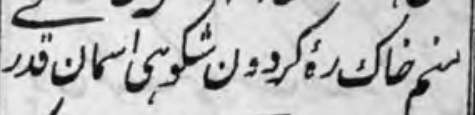
, C "s يون ت

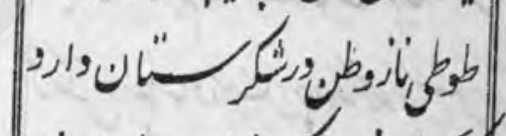
كرونة

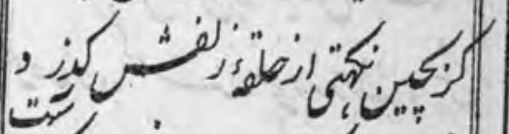
)

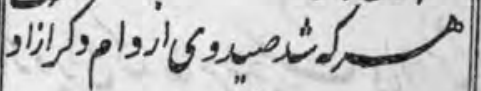
Ulisis

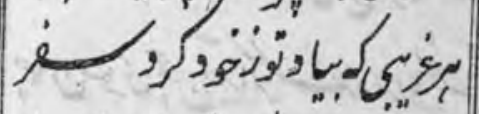

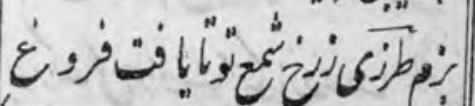


rrr

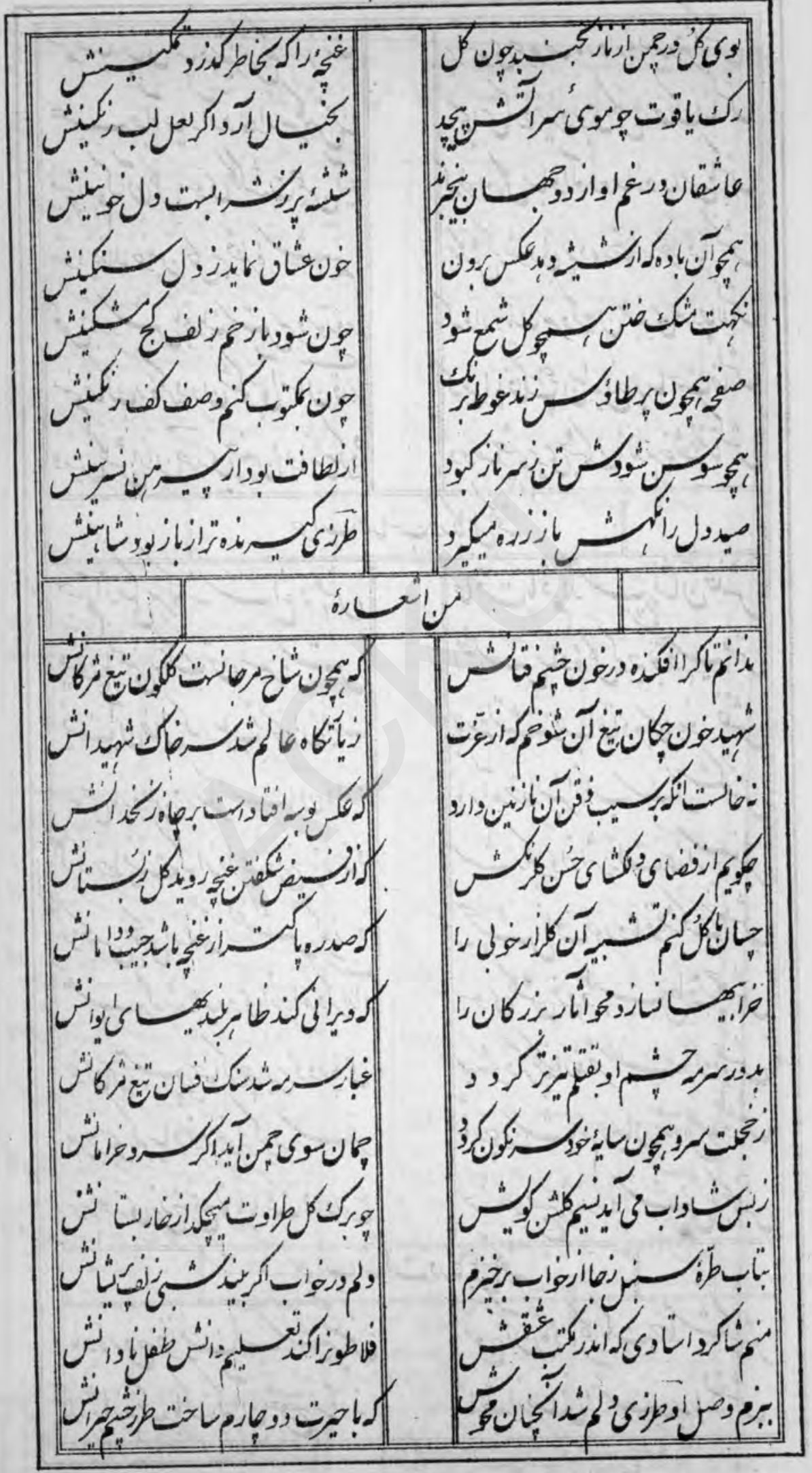




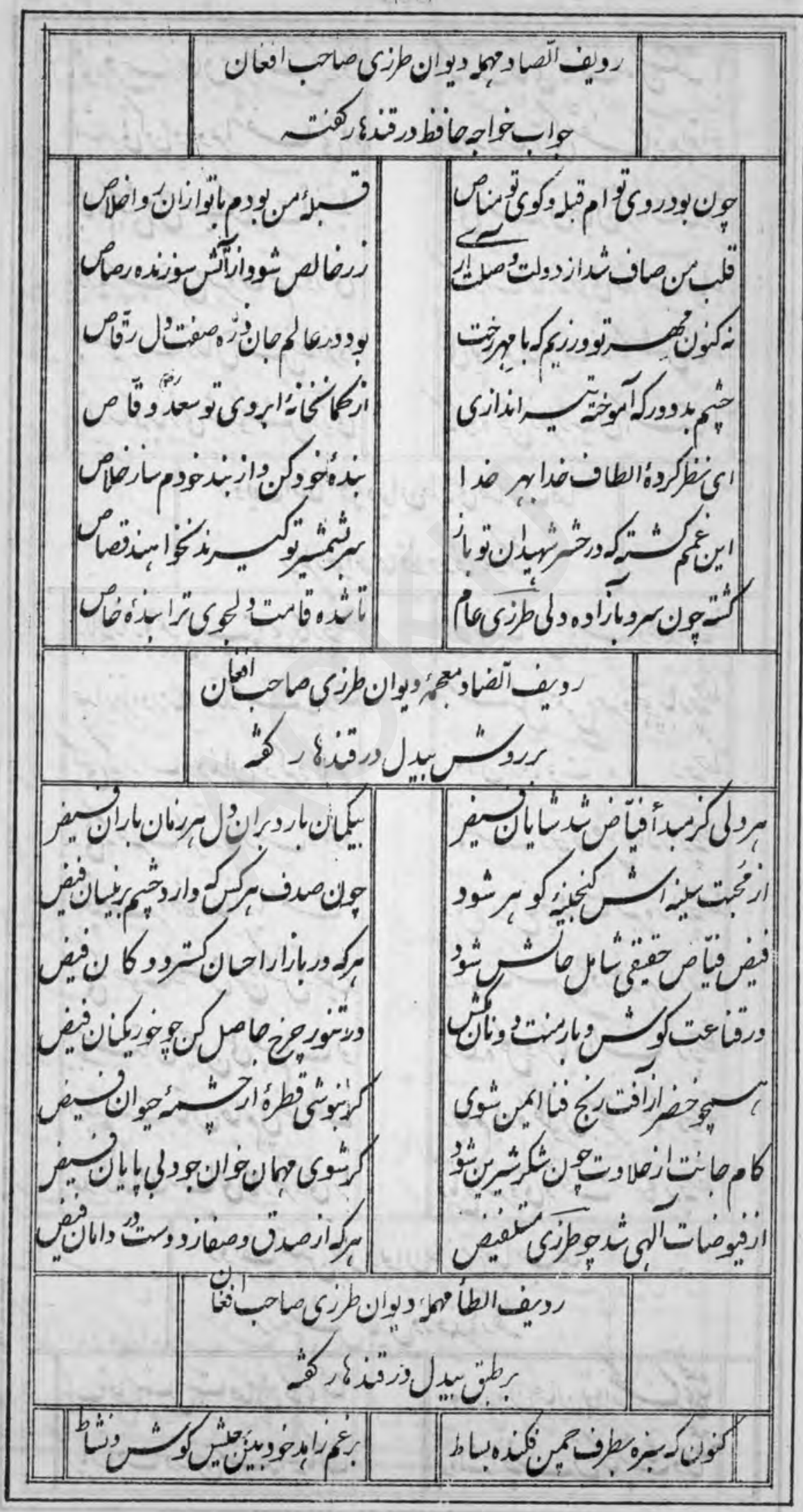




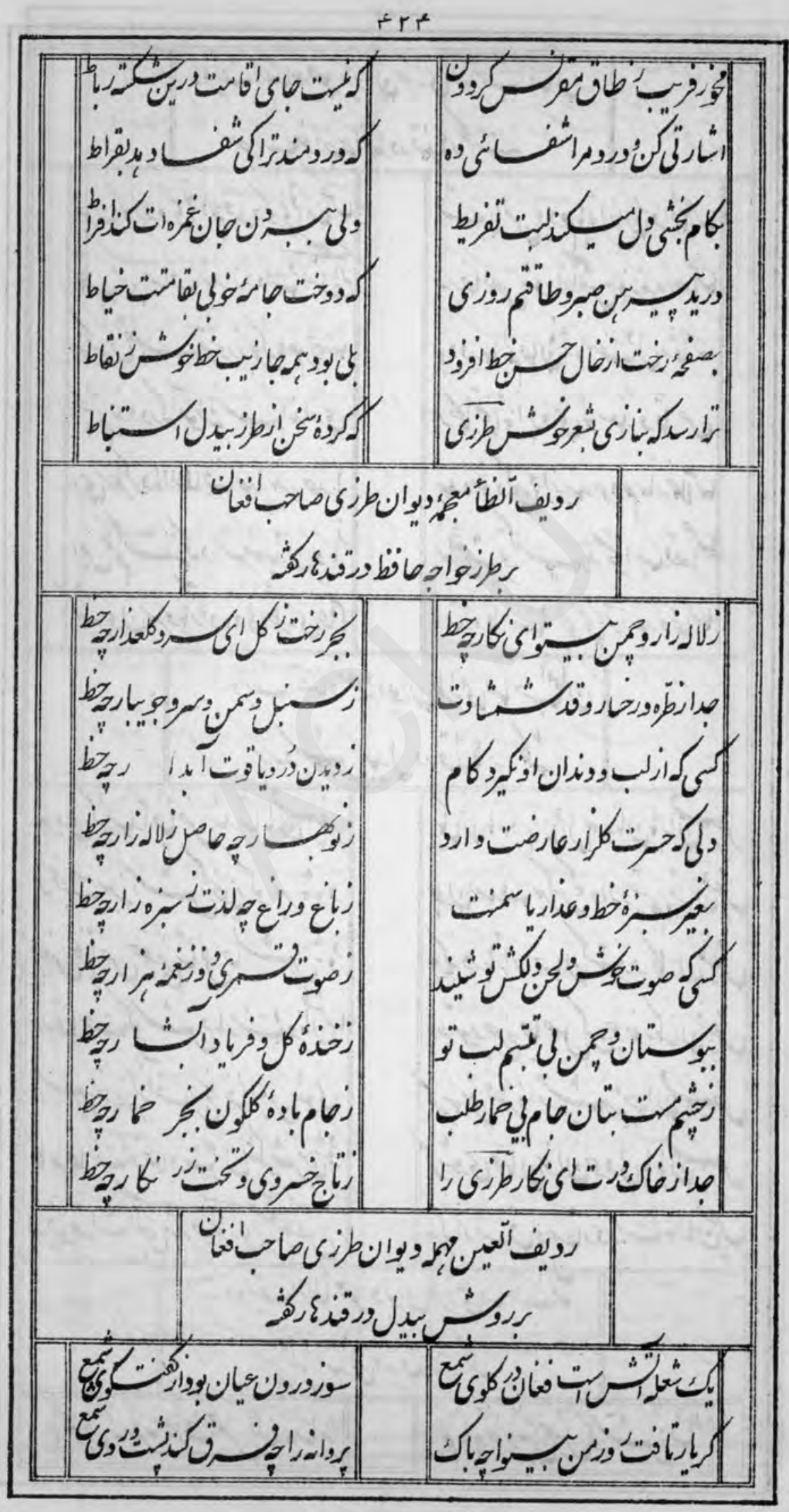


C r a

\begin{tabular}{|c|c|}
\hline 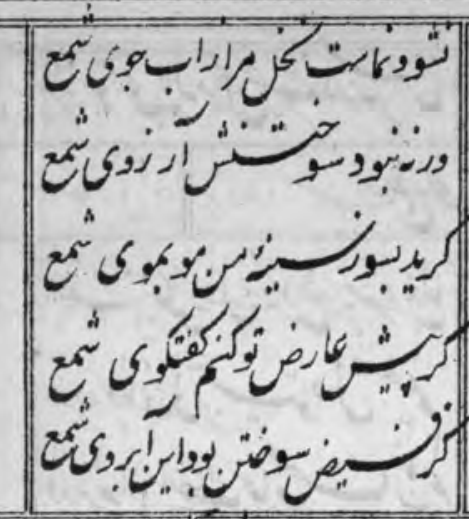 & 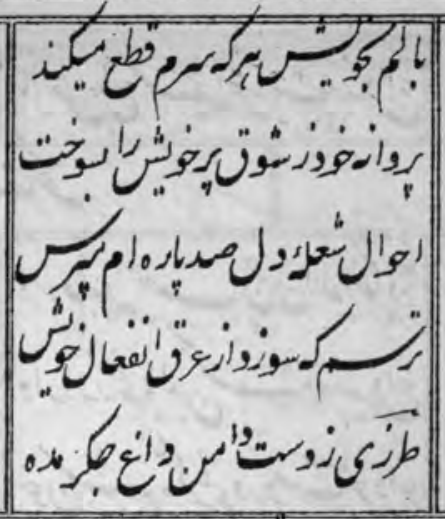 \\
\hline 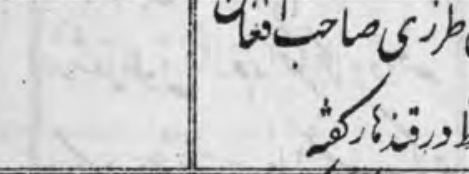 & 190 \\
\hline $\mid$ & $\mid$ \\
\hline 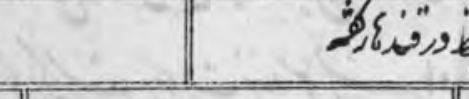 & 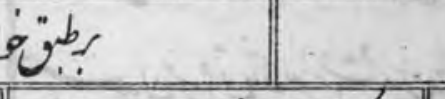 \\
\hline 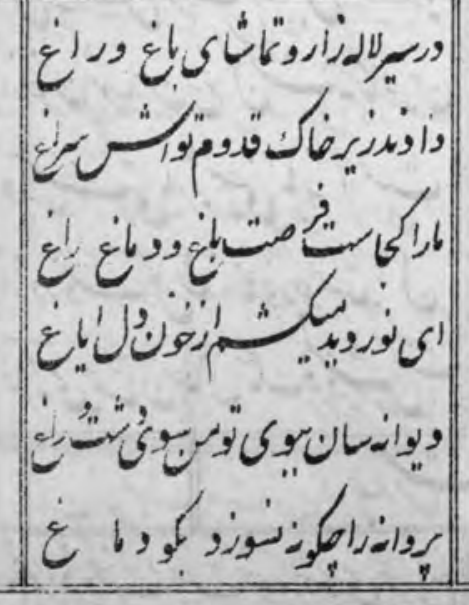 & $\mid$ \\
\hline
\end{tabular}




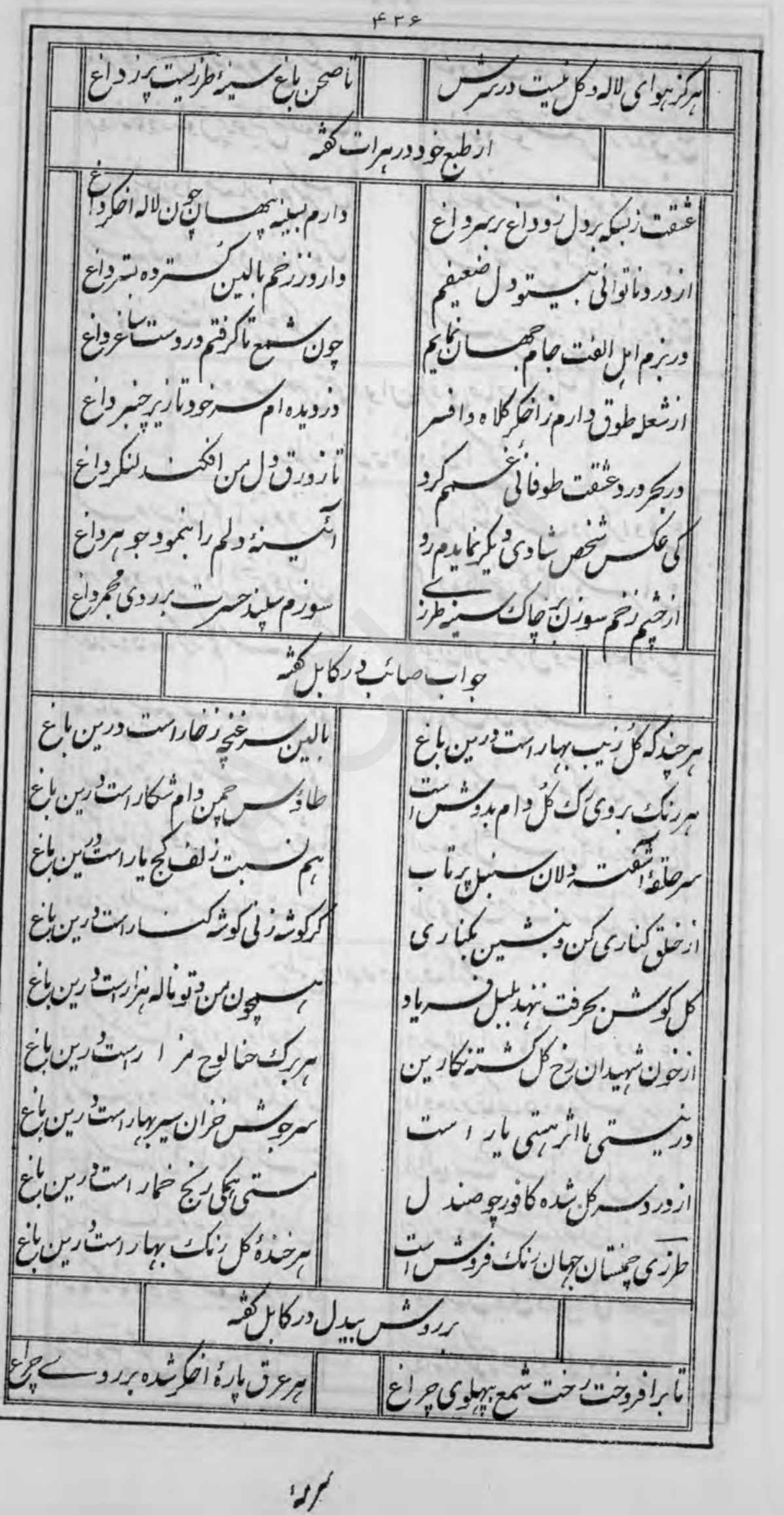


ErL

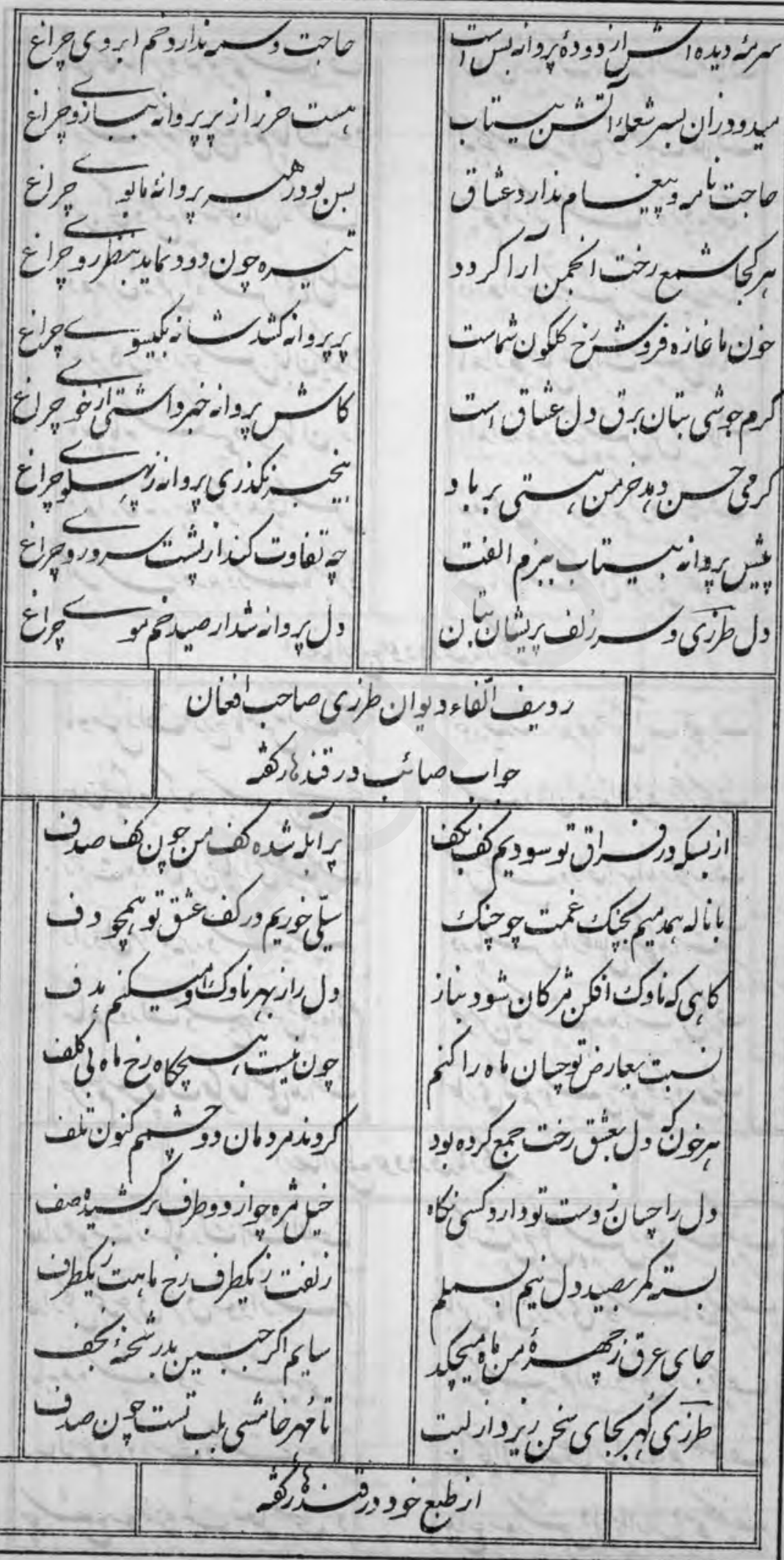




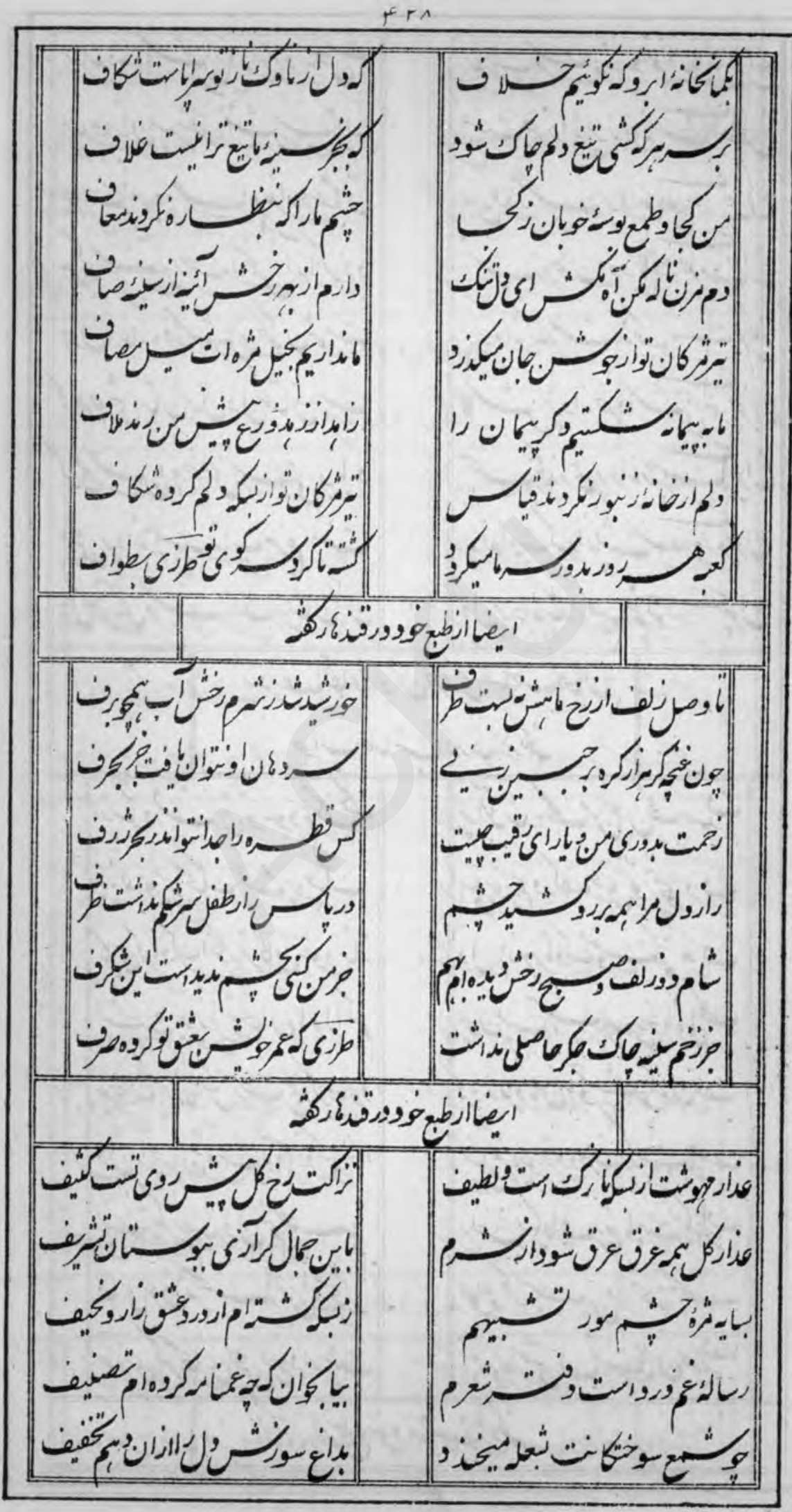


rra

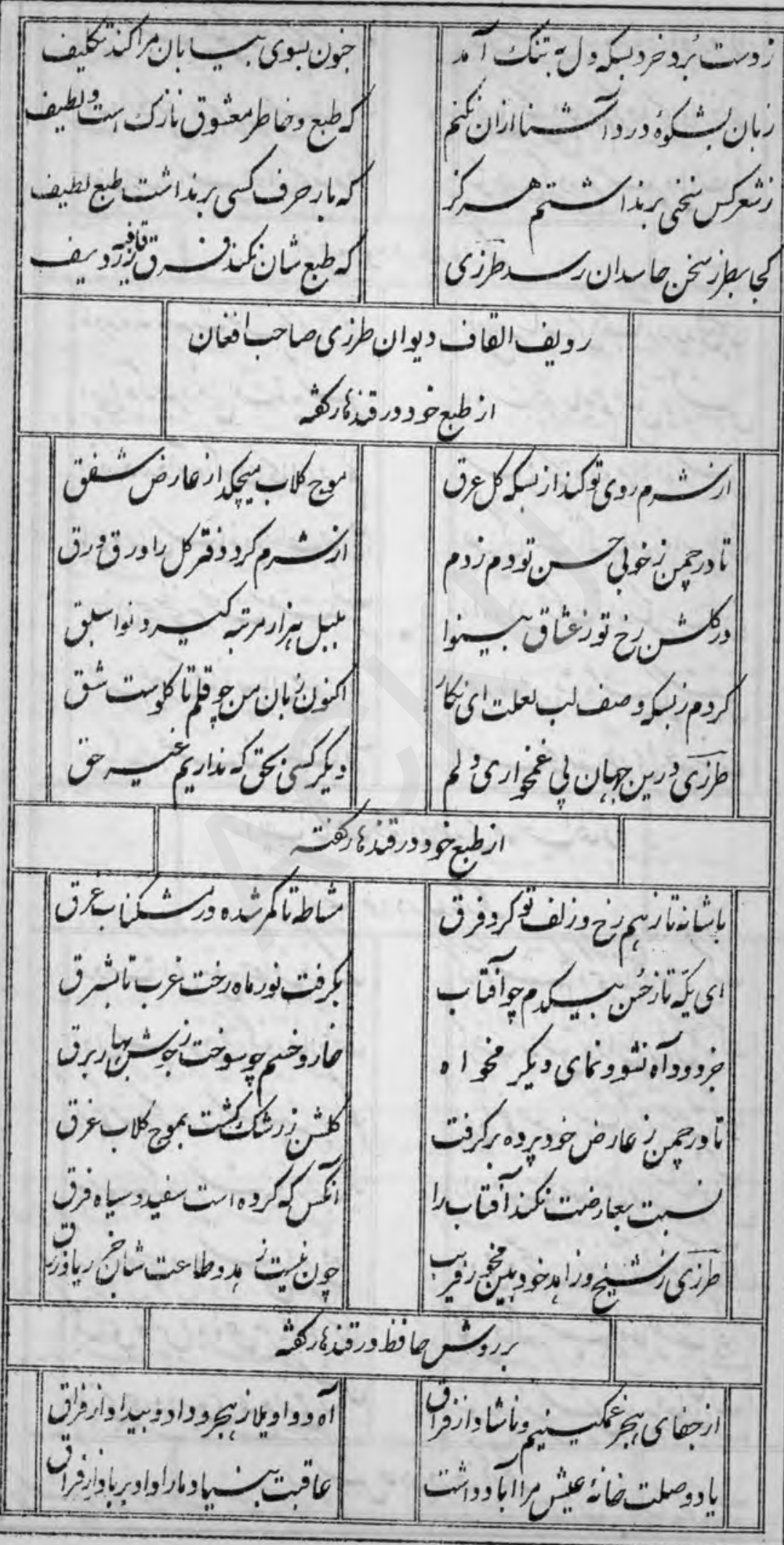


r

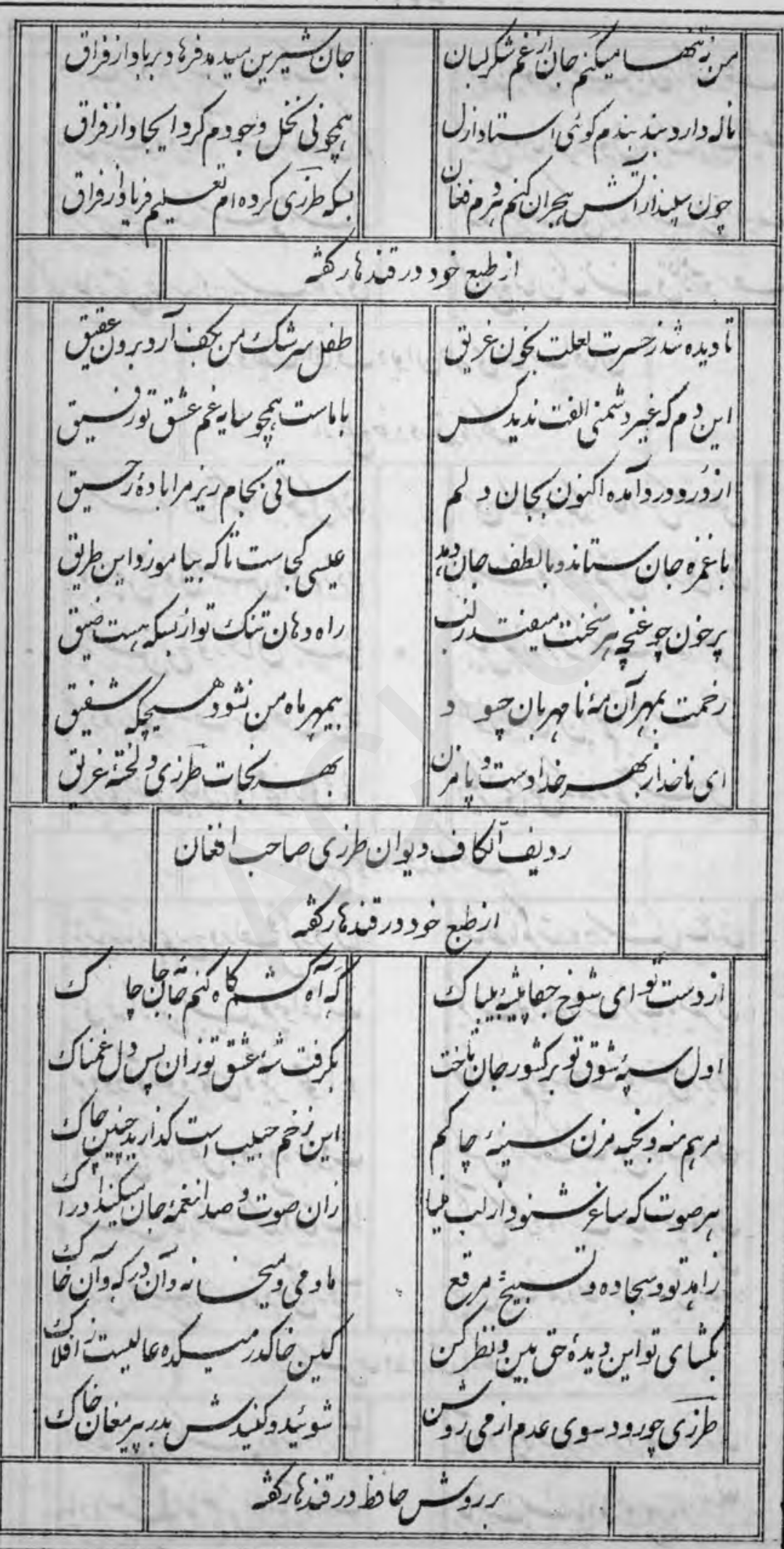


Fr

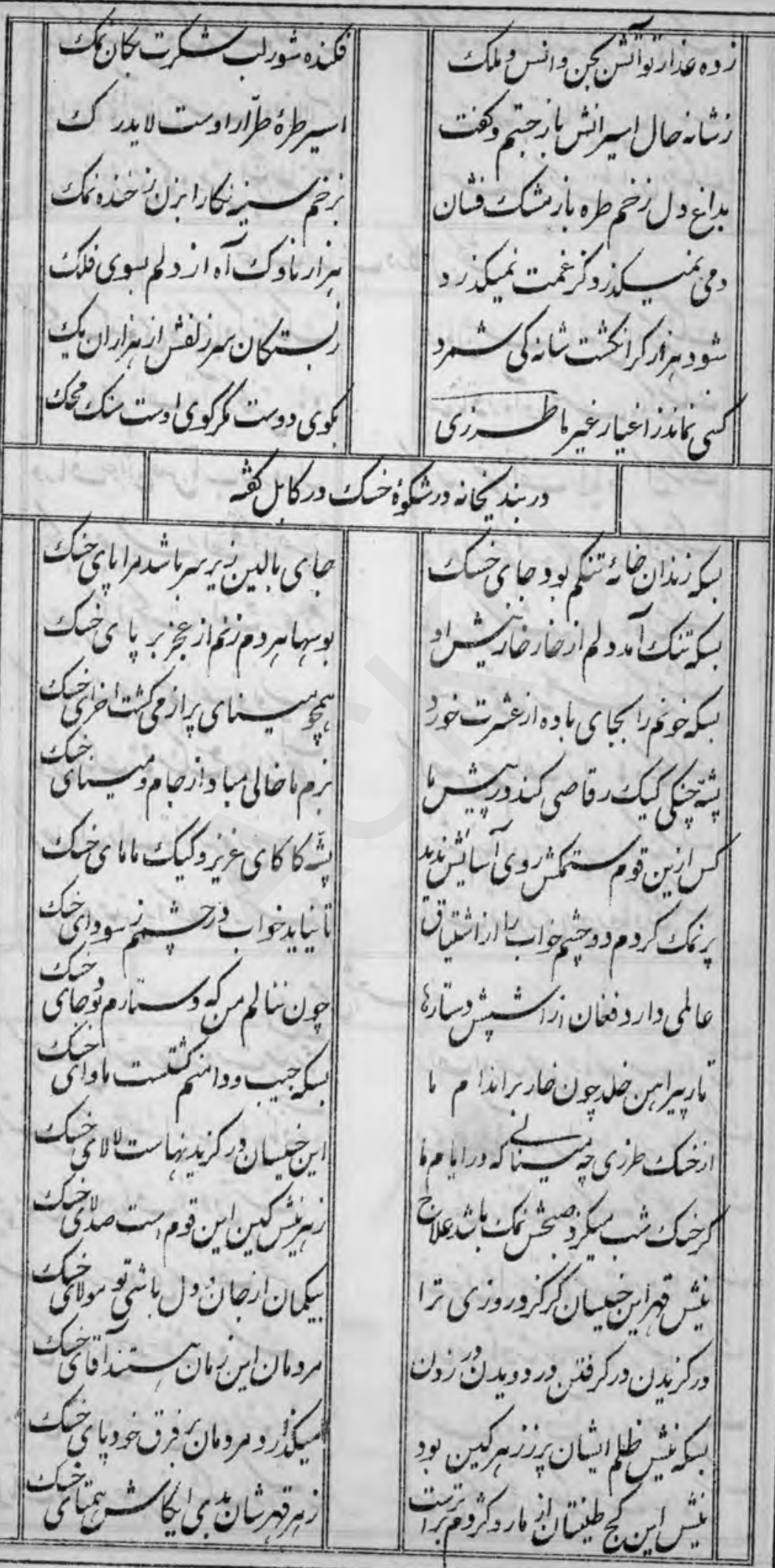


err

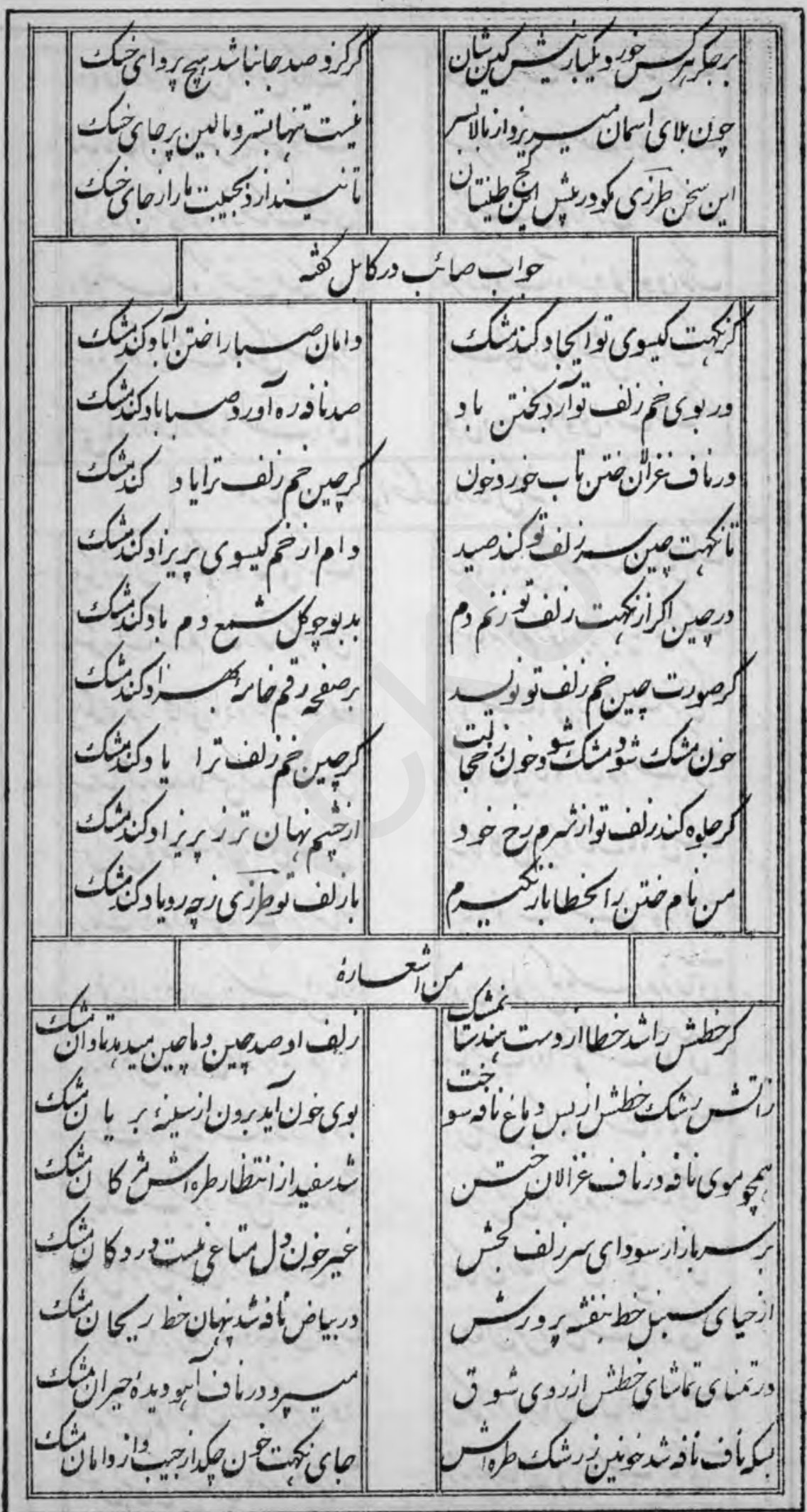




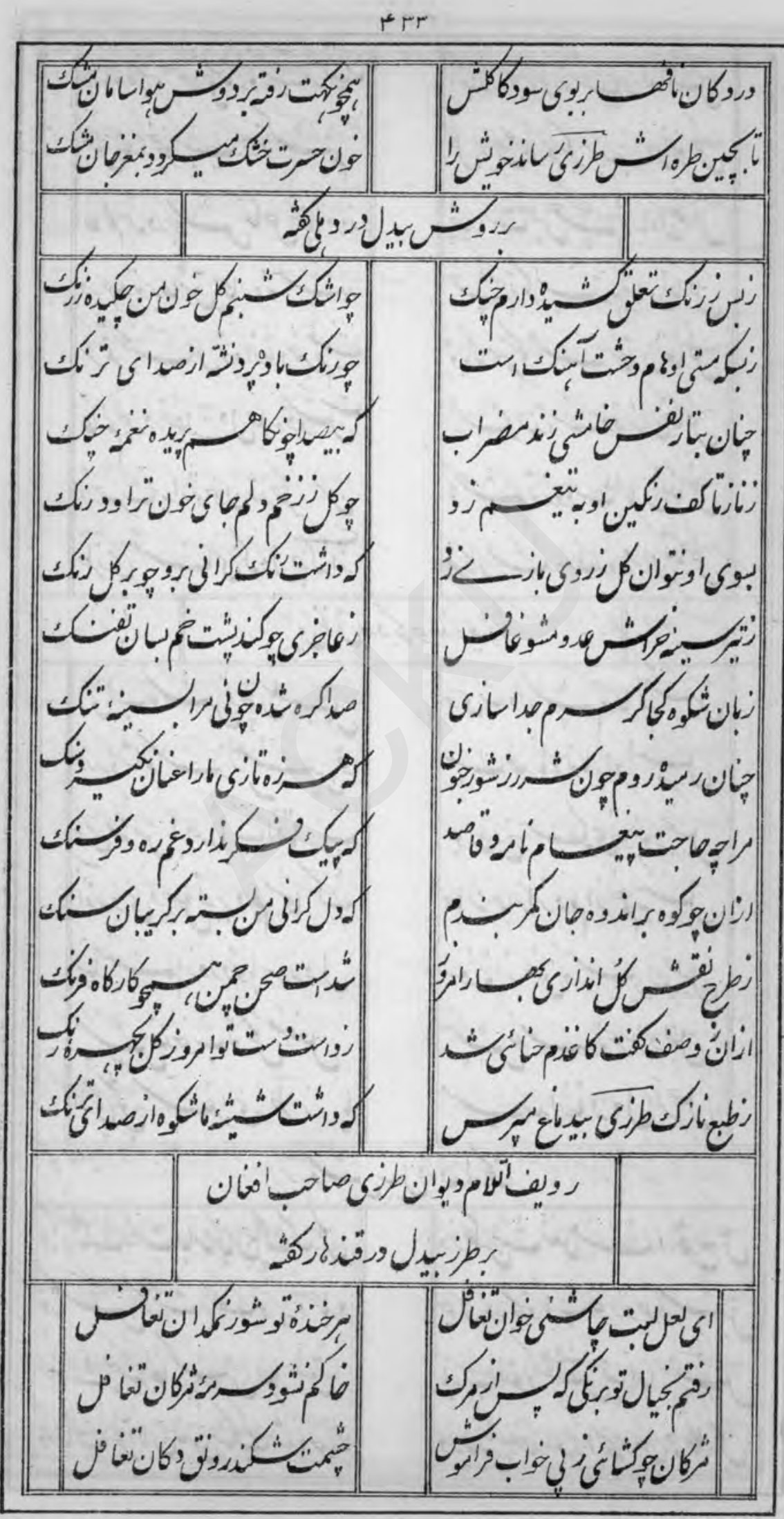


Fre

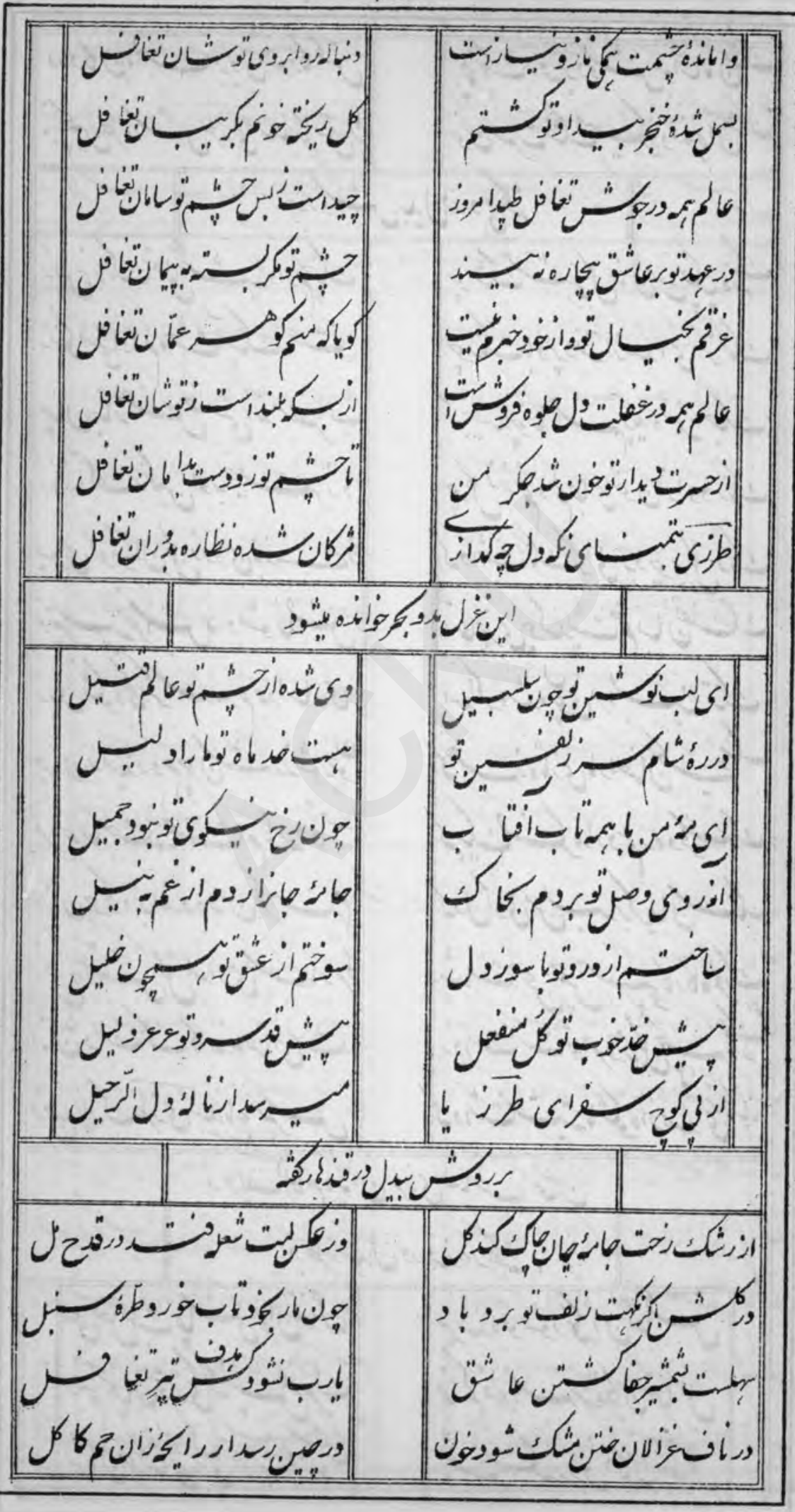


F Ha

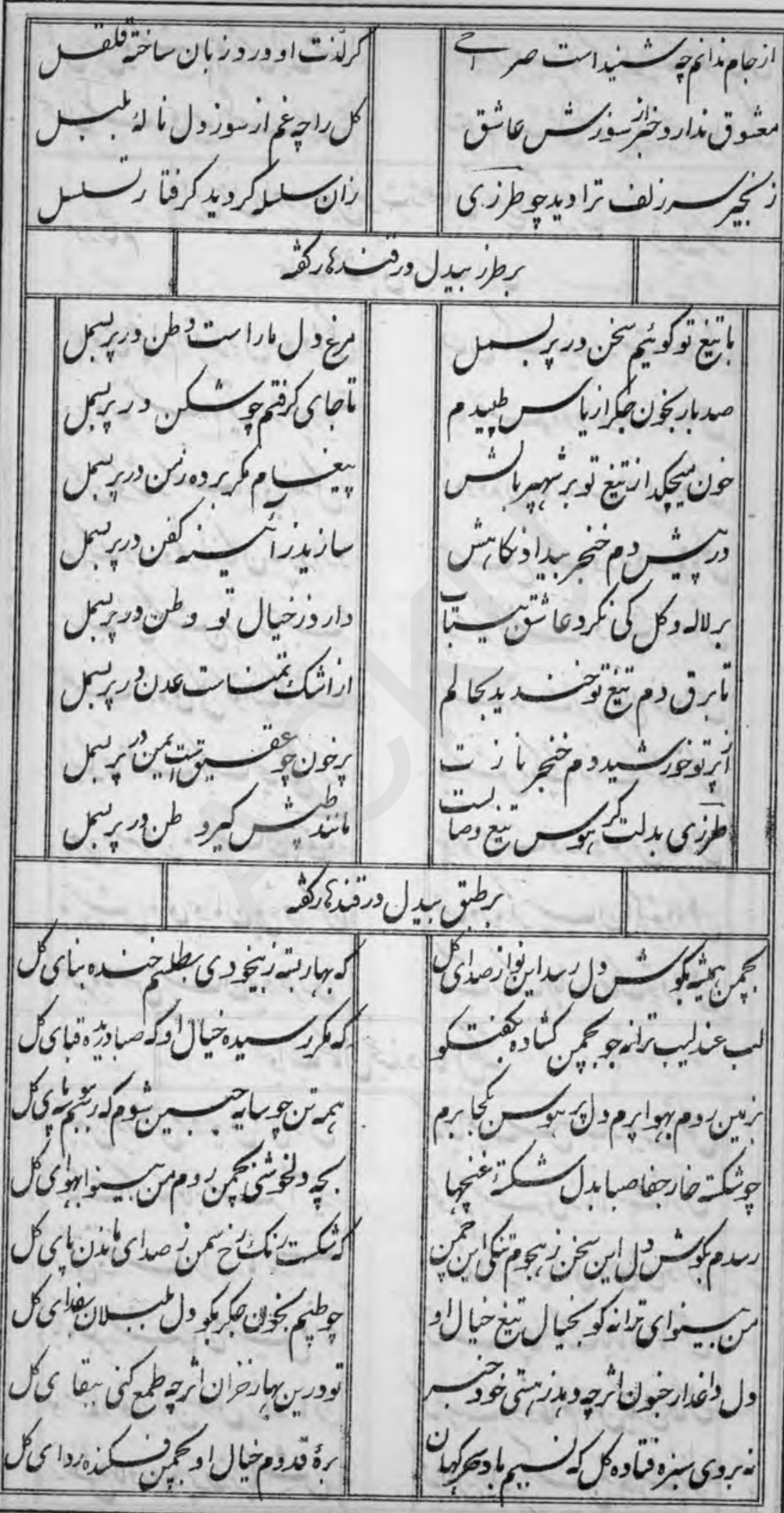


rrs

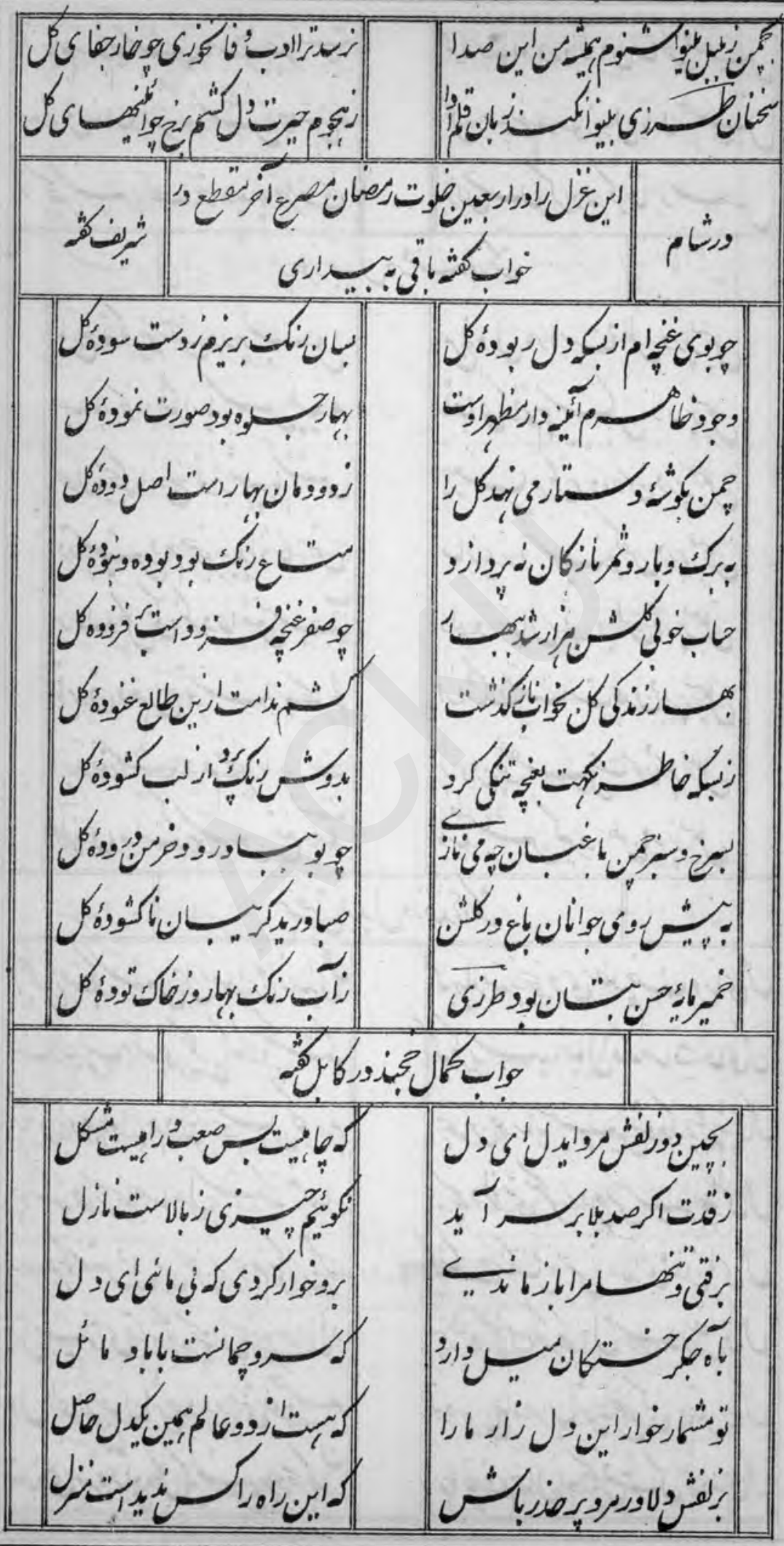


Fr

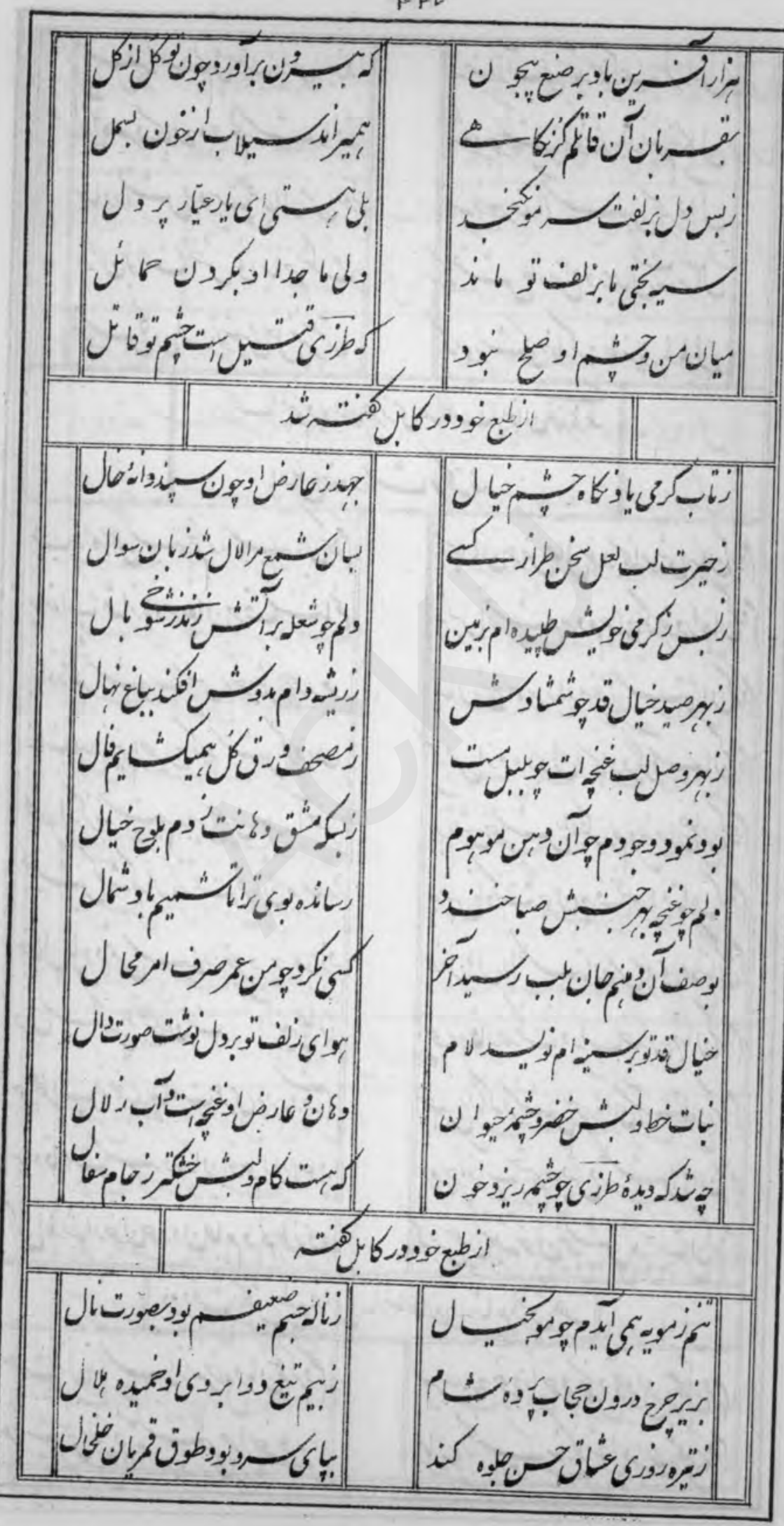


r r

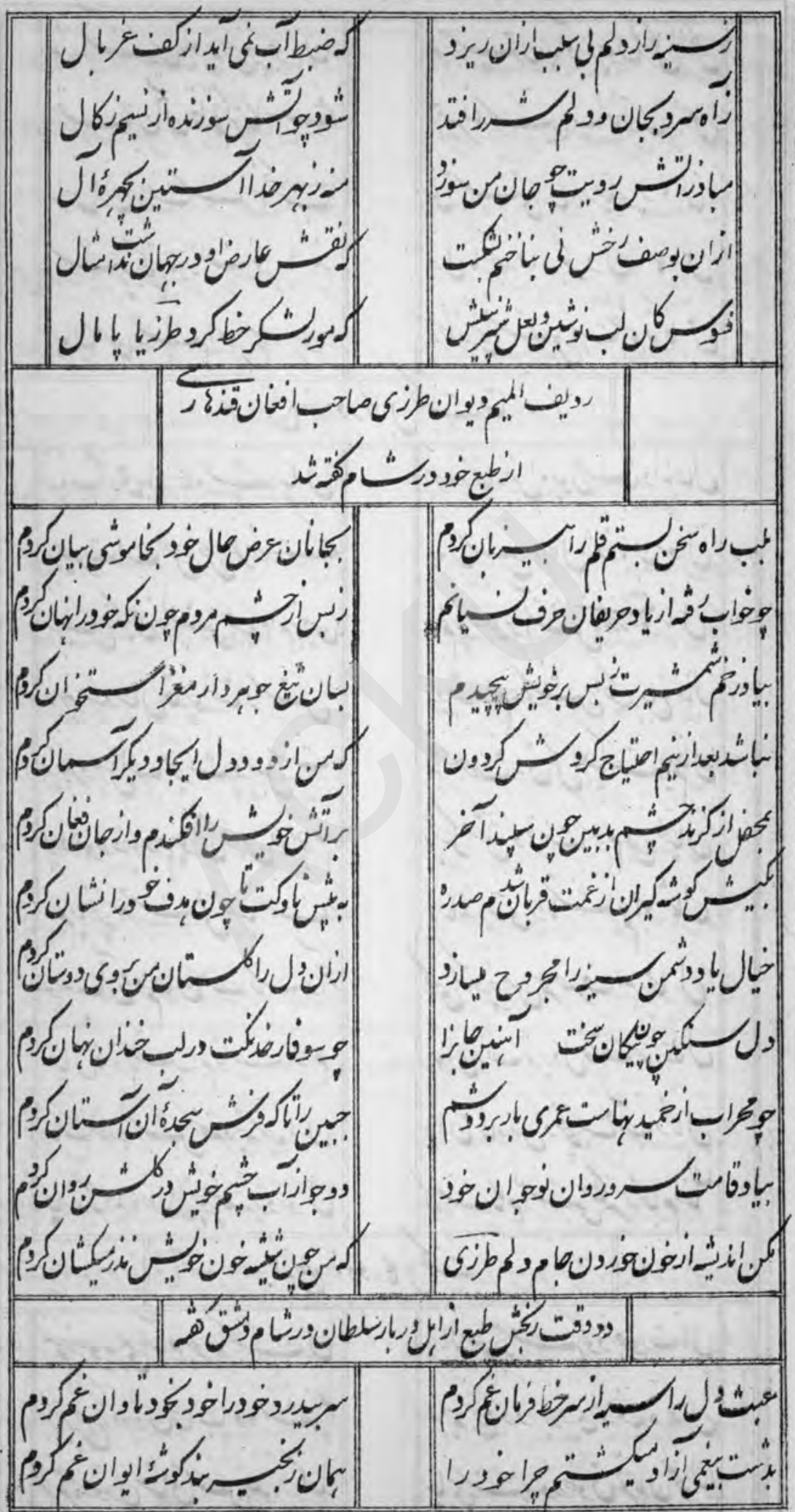


rer

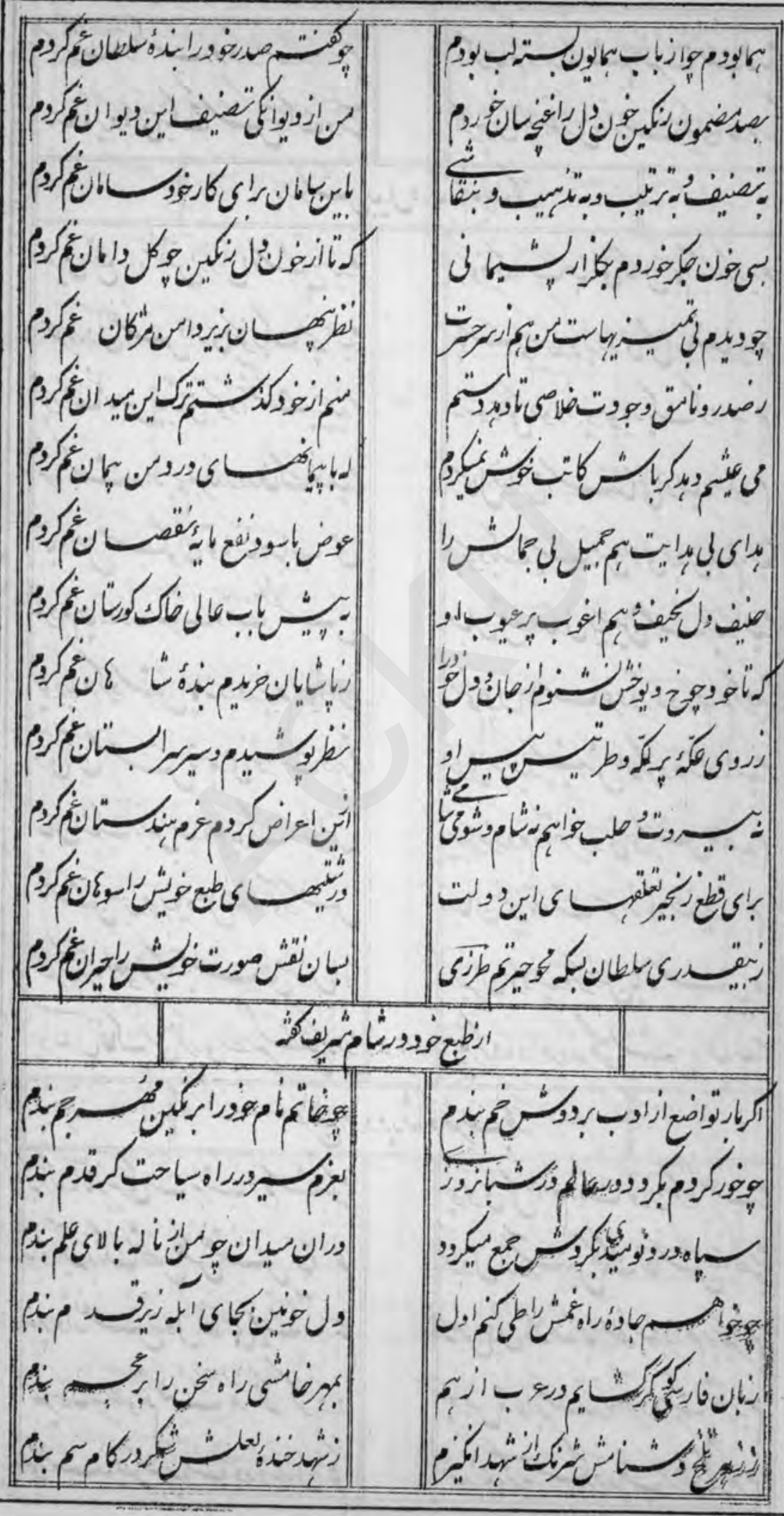


r p

|


F

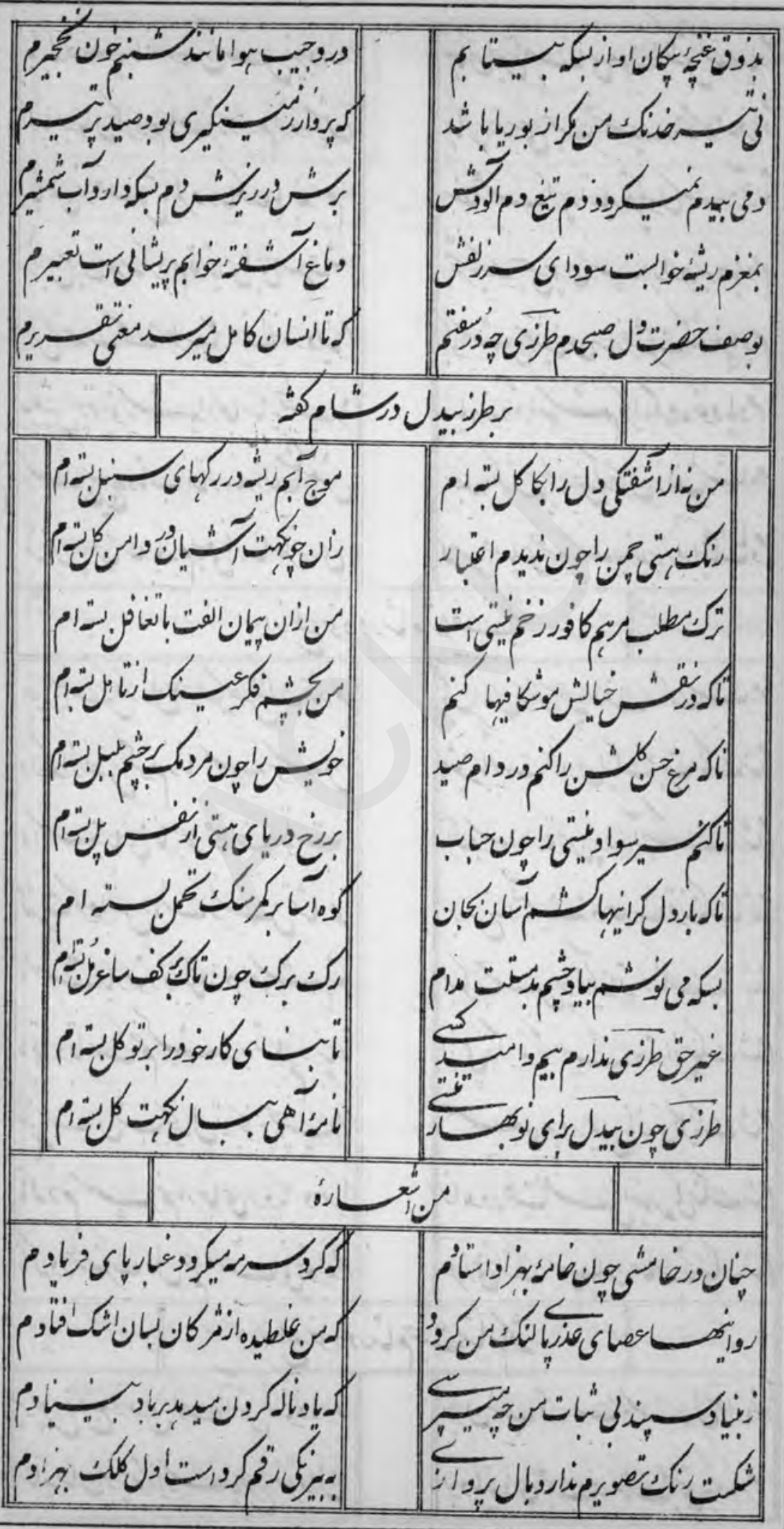




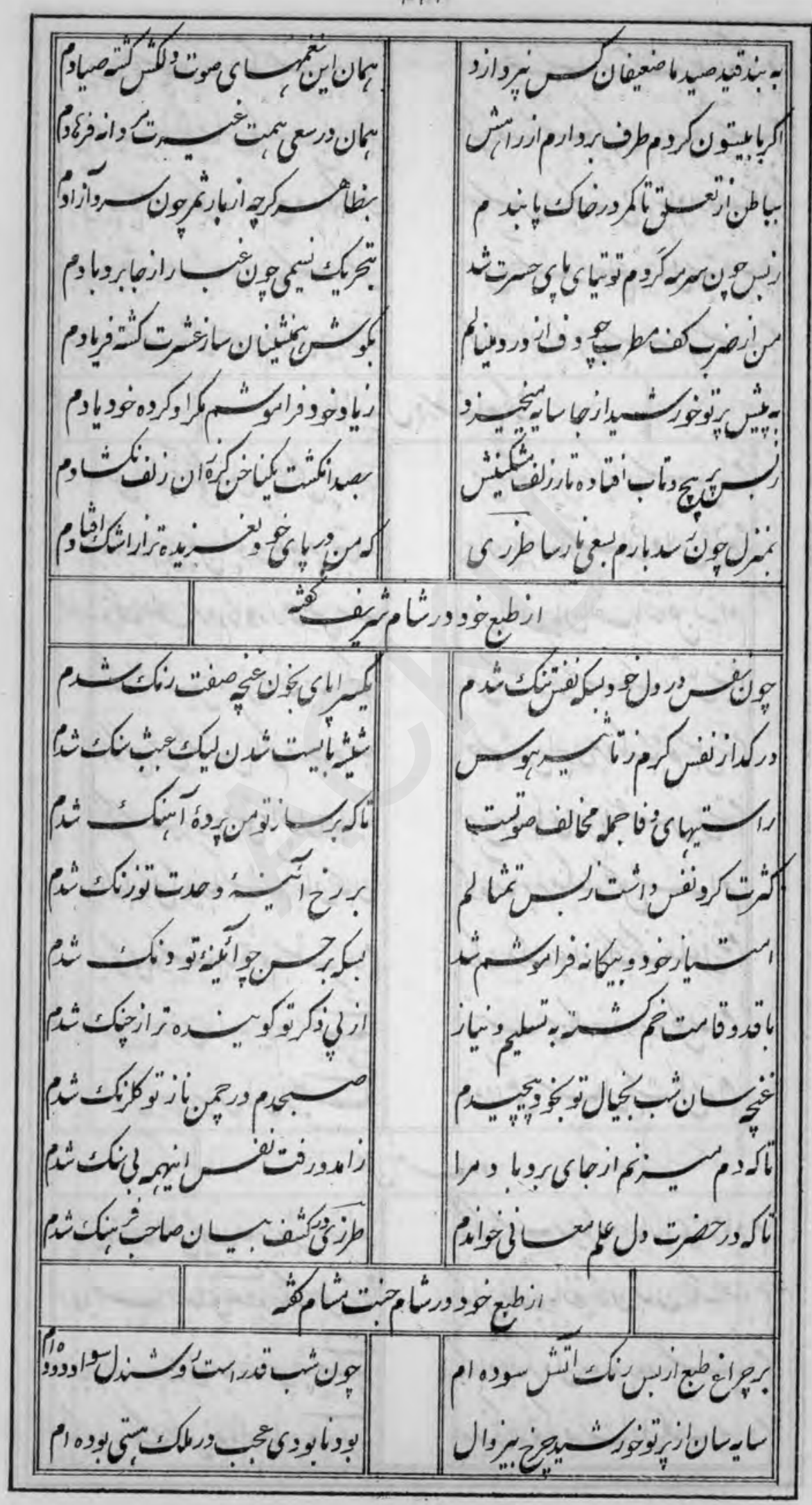

s 
pr

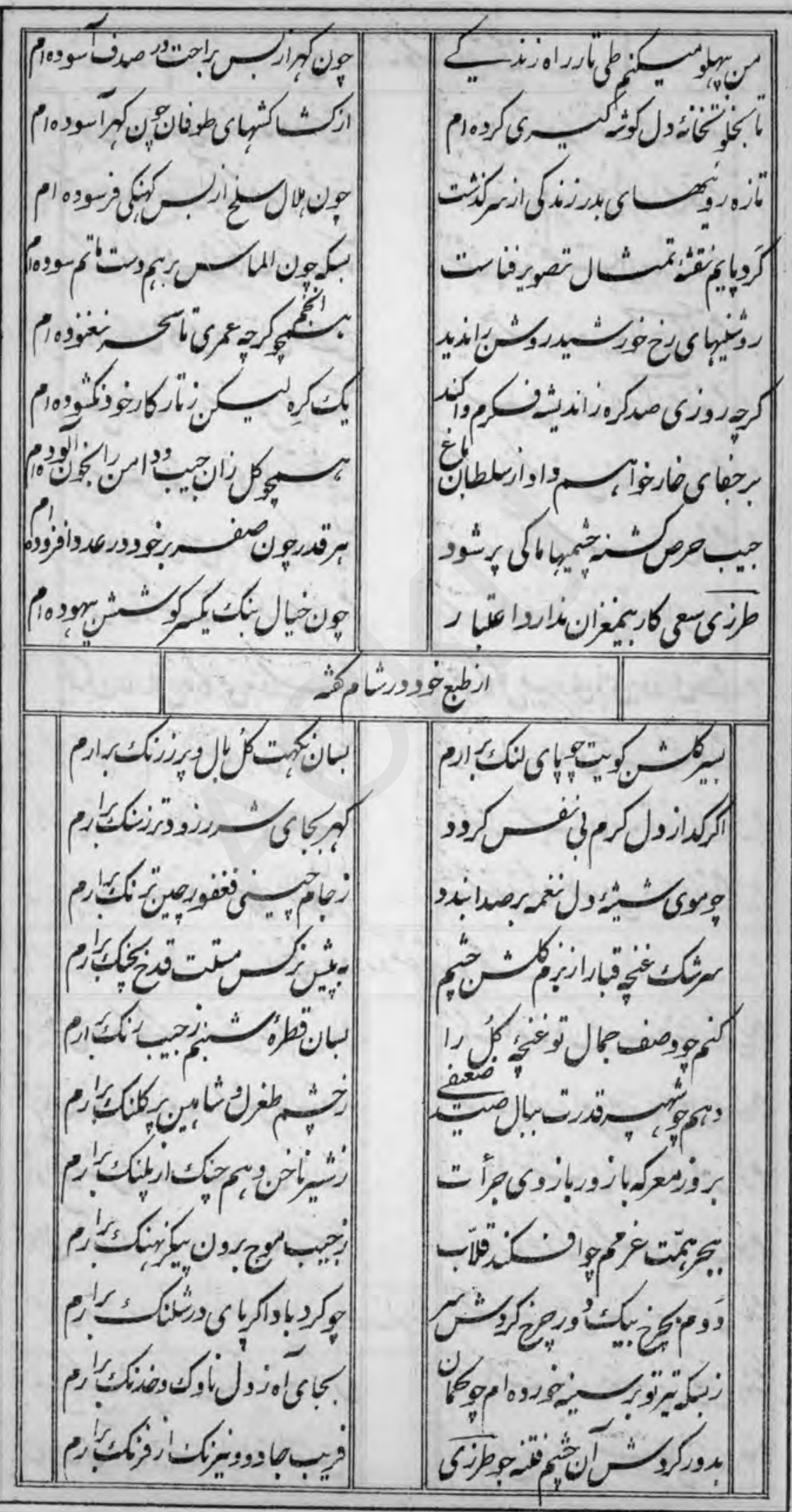




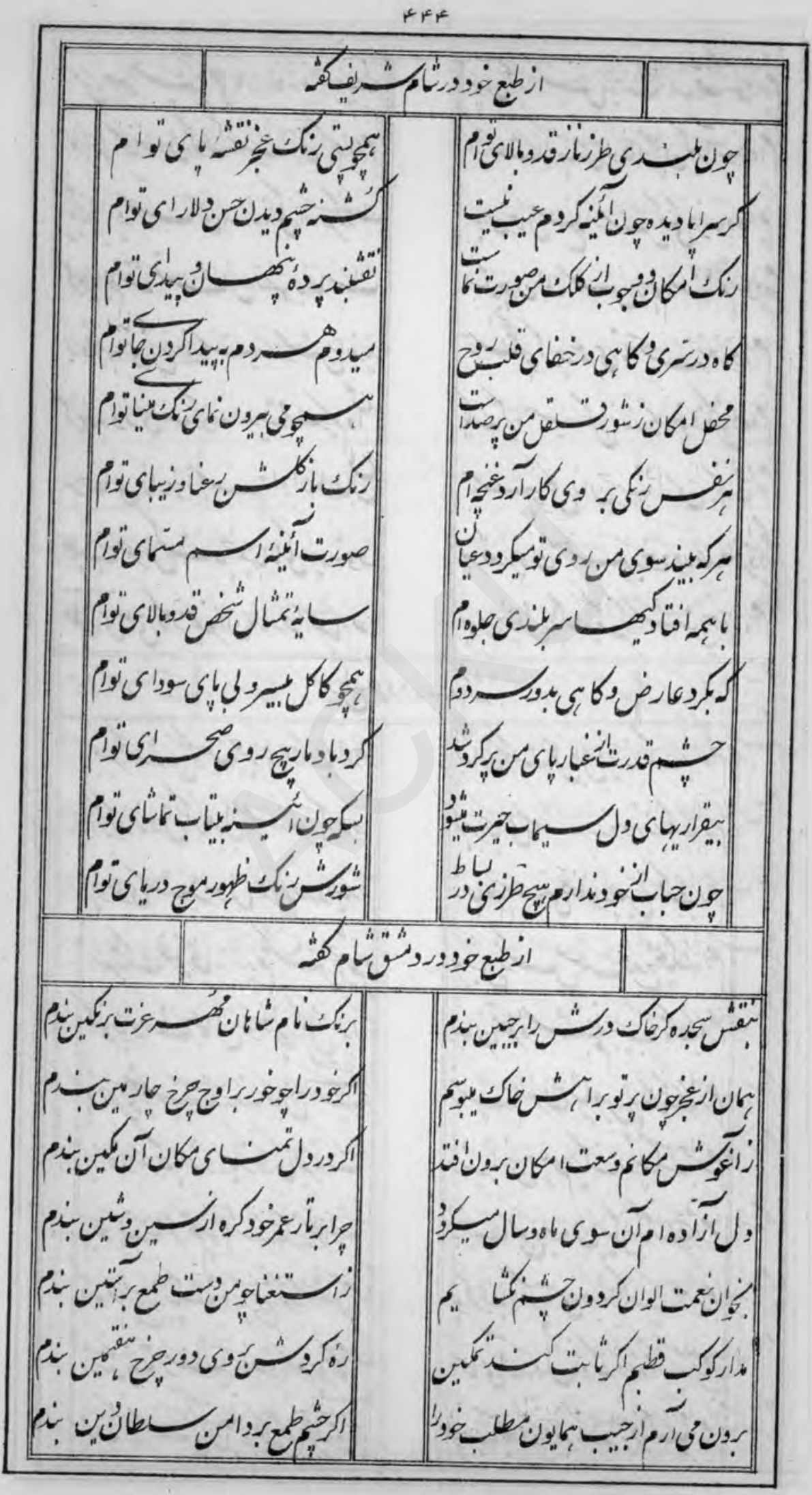




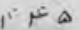

(

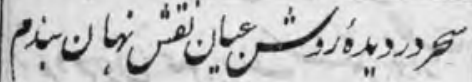
الروان

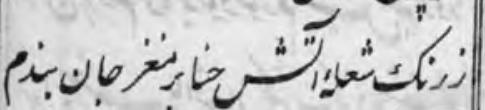

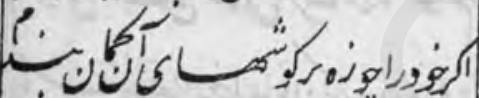

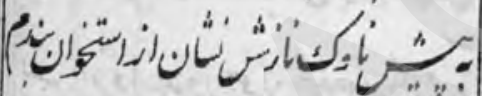

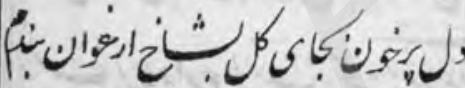

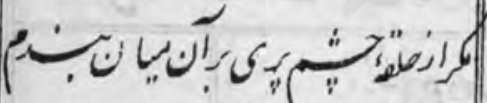
(i.

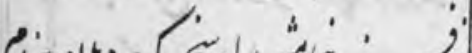
(ن) من

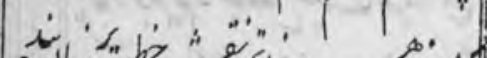
(5)

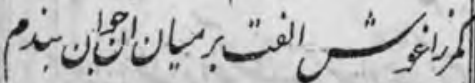
ن.

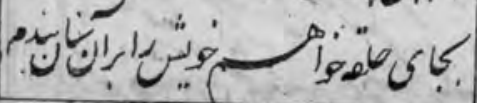

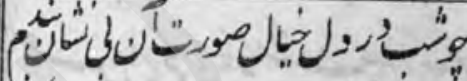
\% (6)" 14 2ar?

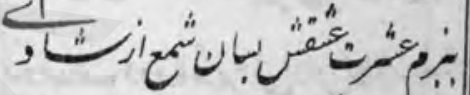

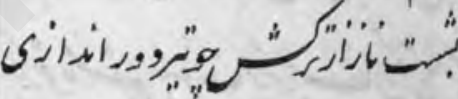
"2: "

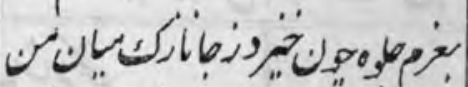
" 2)

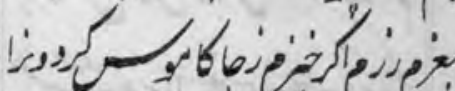

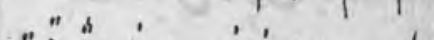

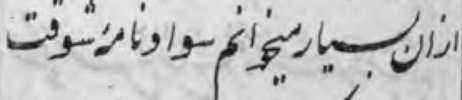
")

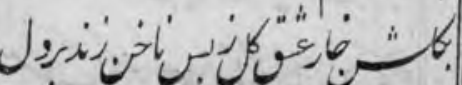
C. -

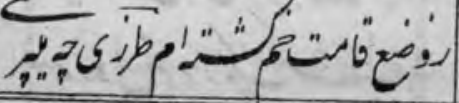




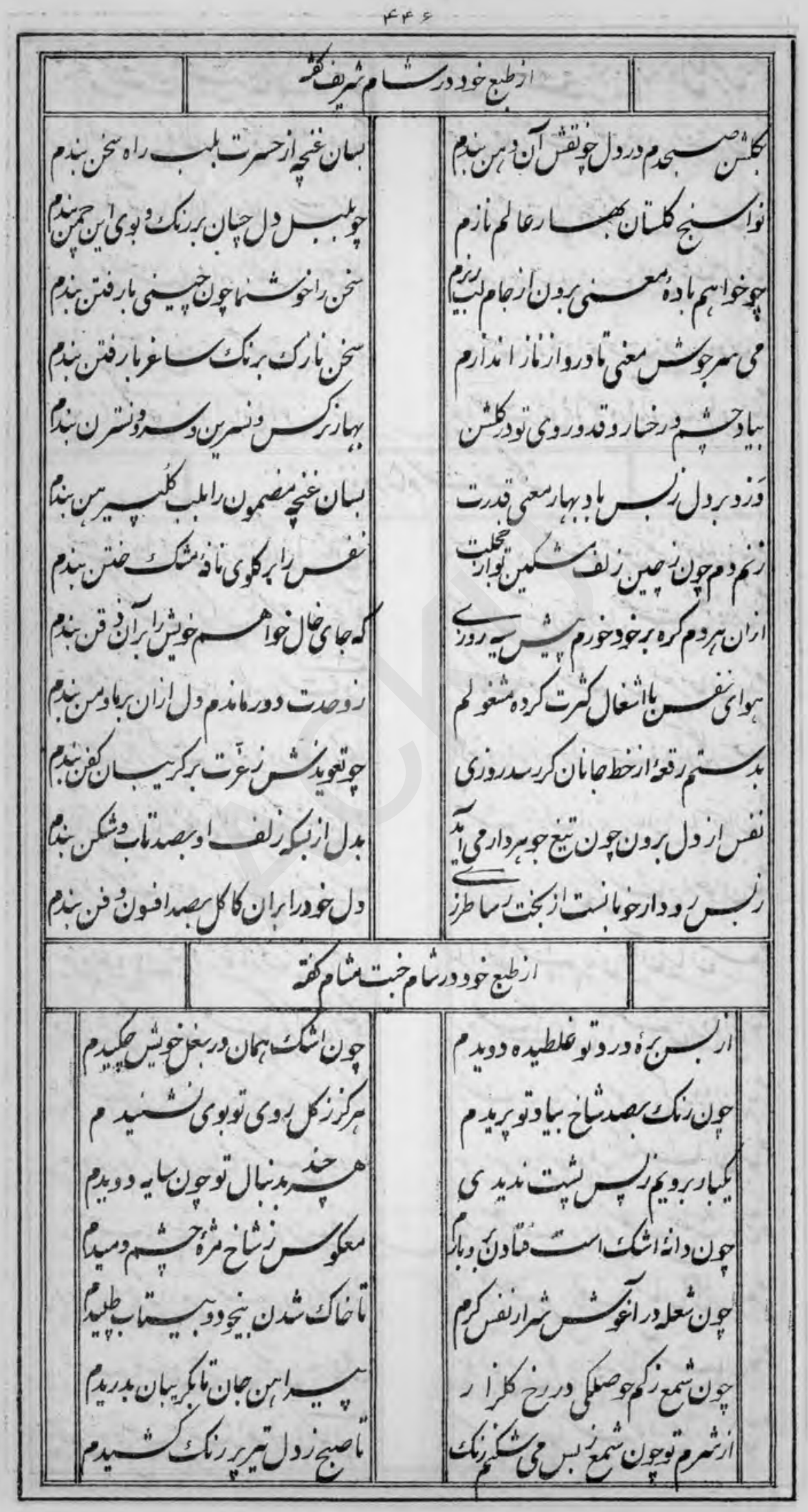

(2): 
Fit

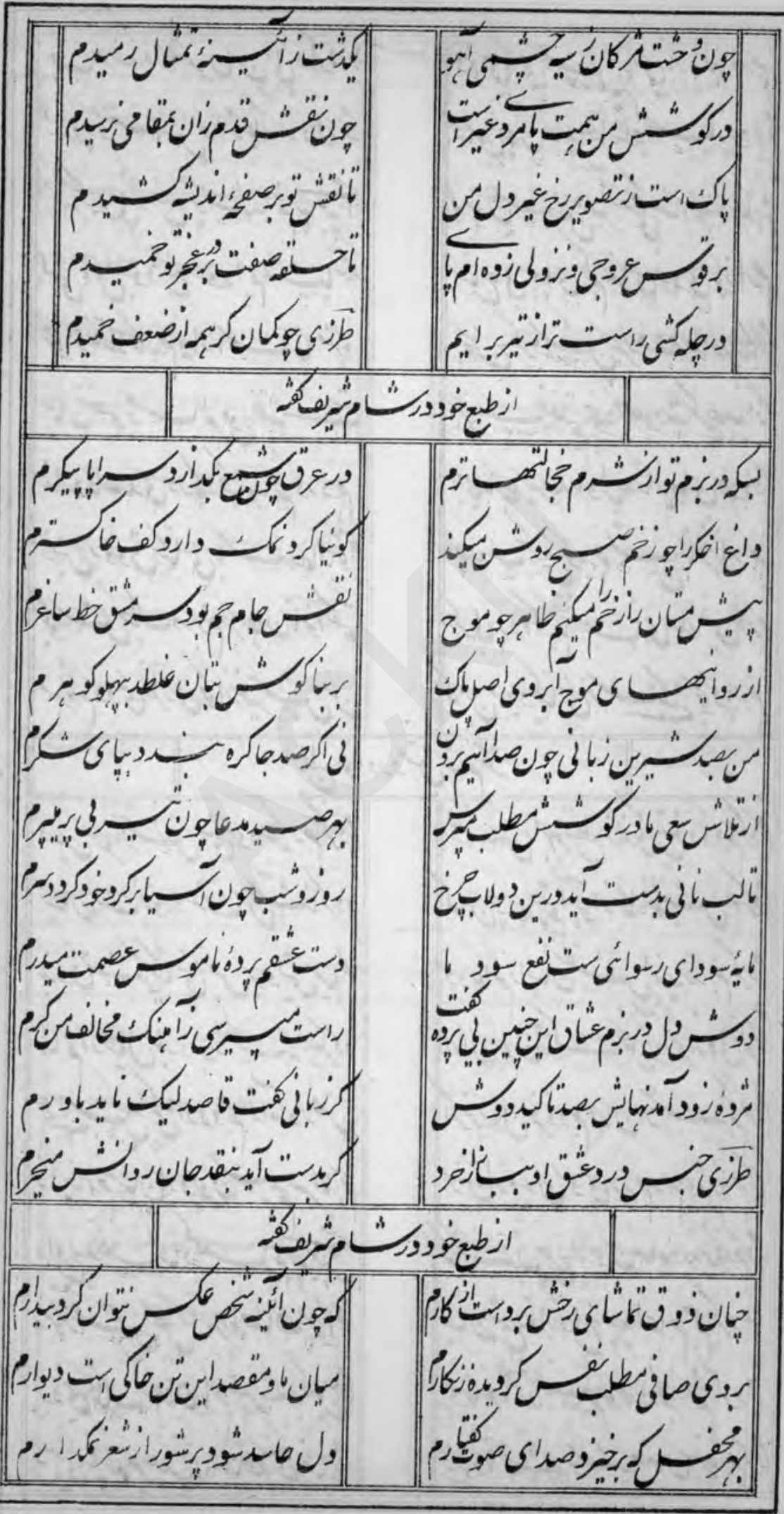


HeA

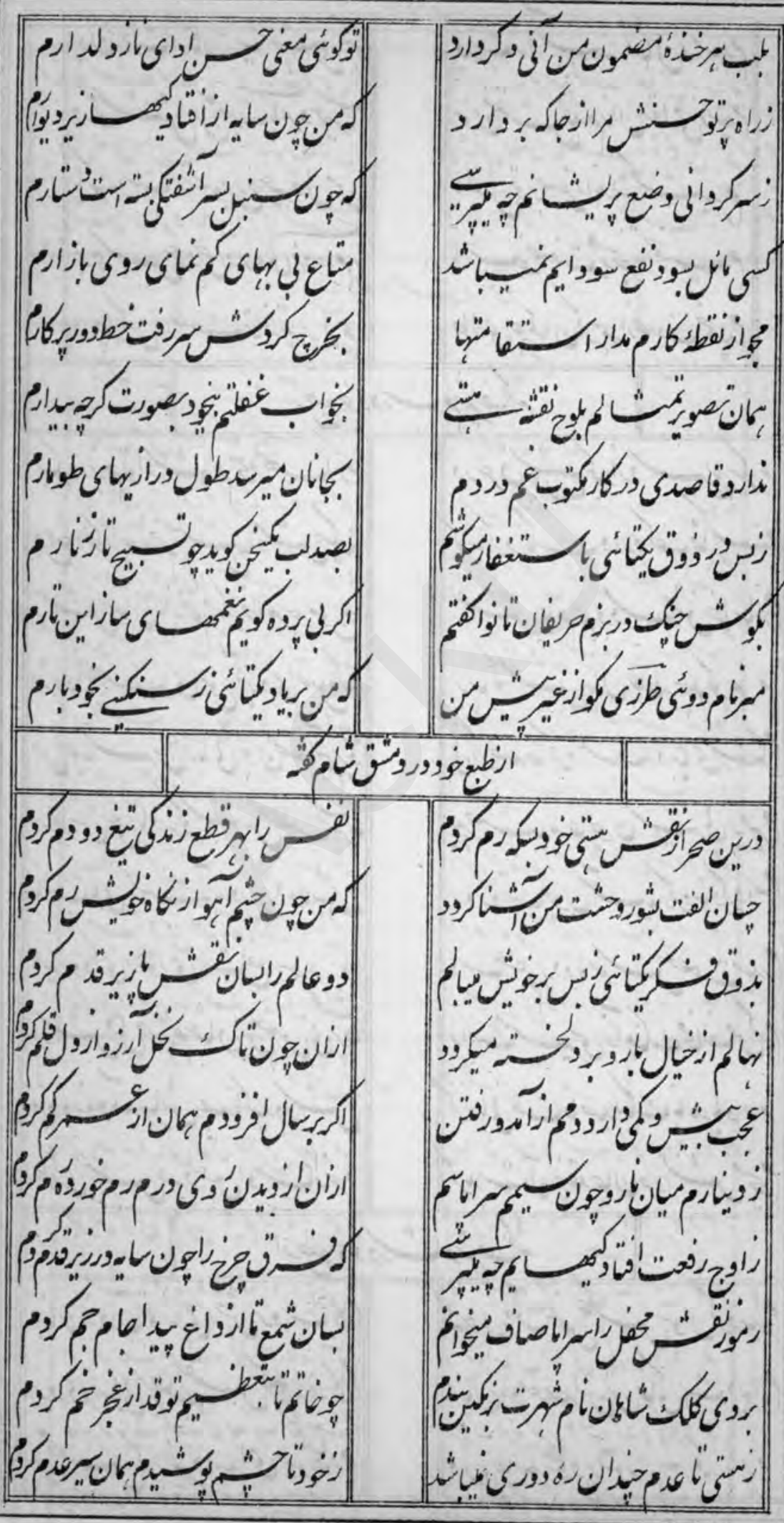


Fq

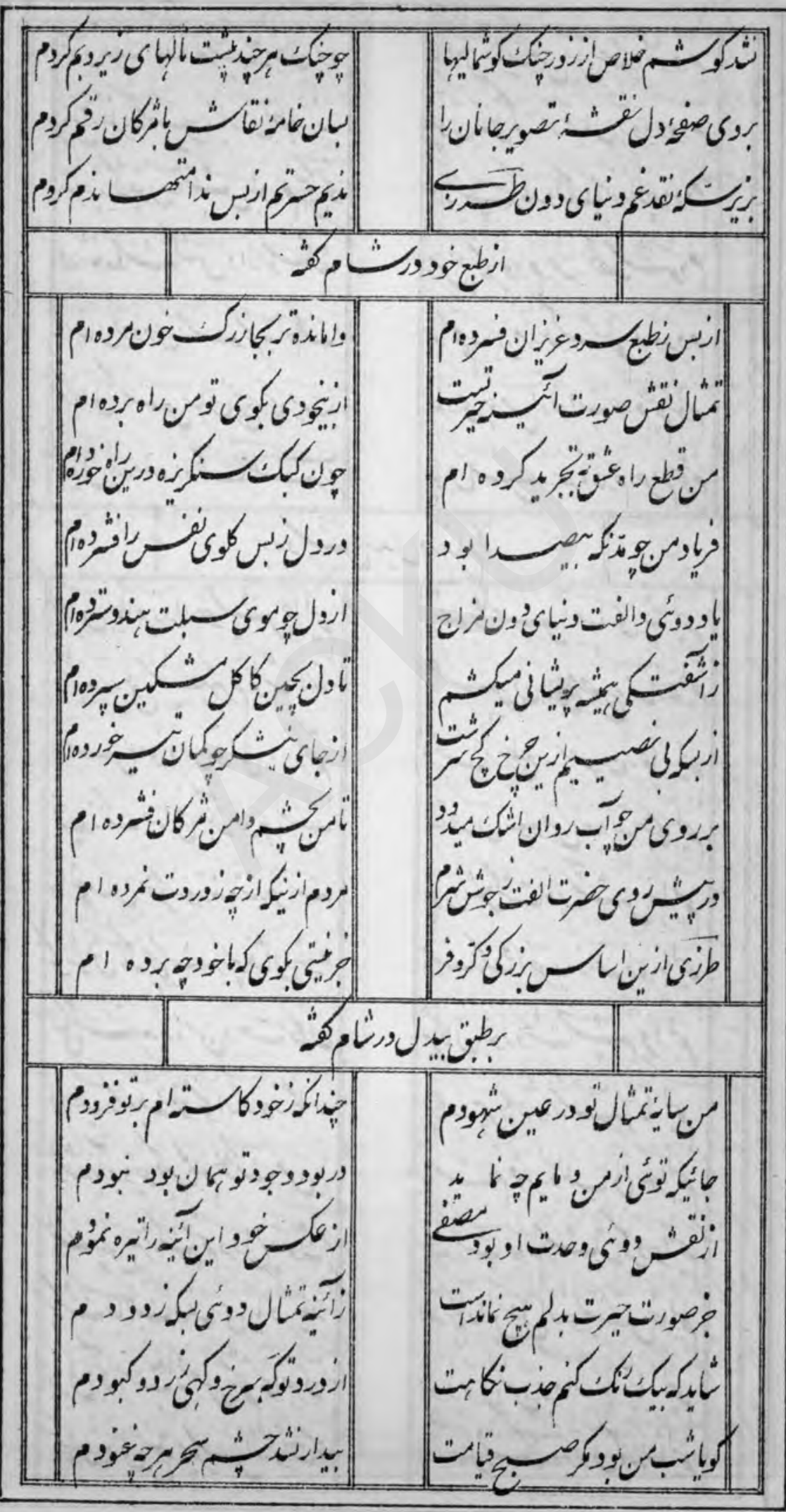


$+\infty$

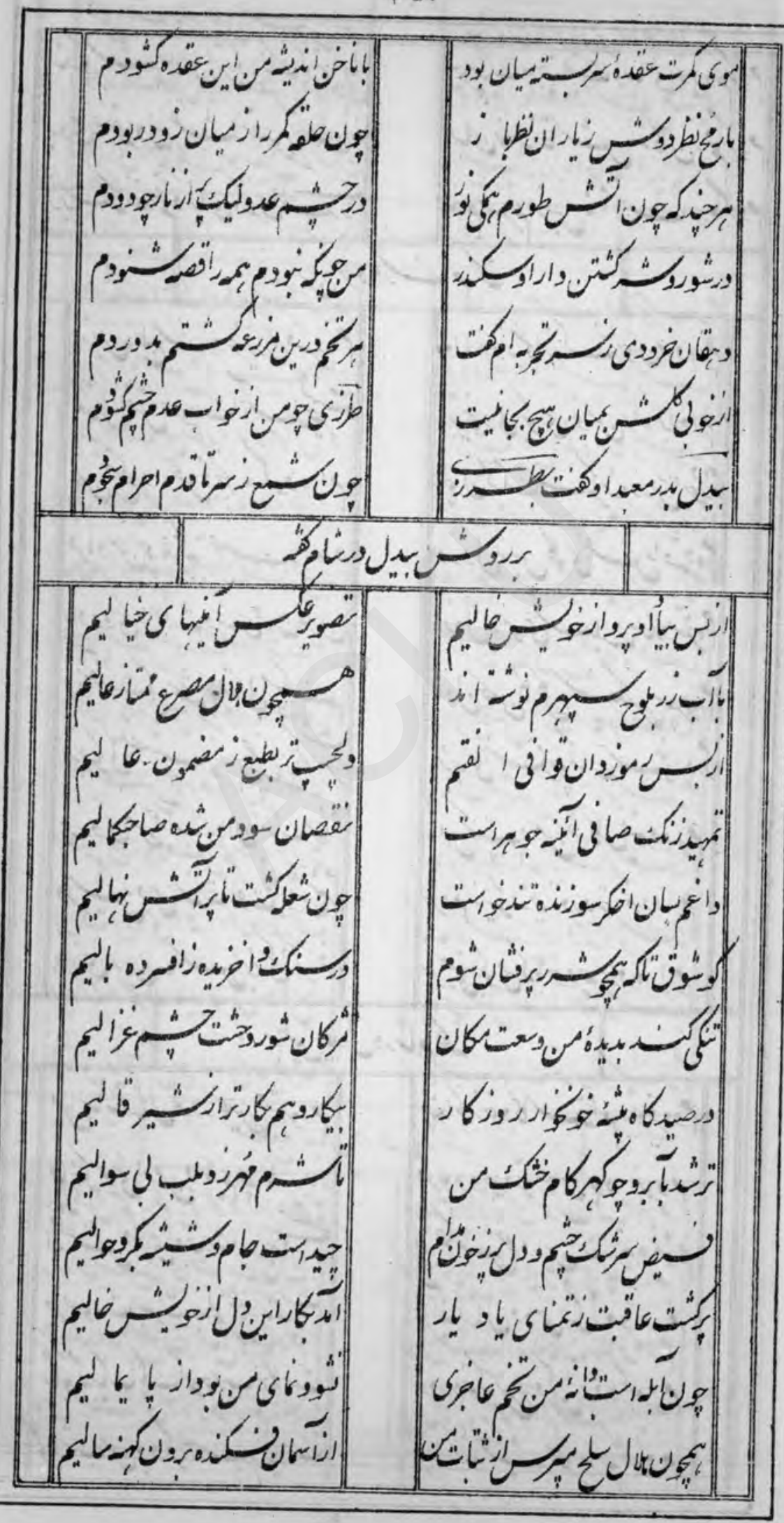


$p \Delta 1$

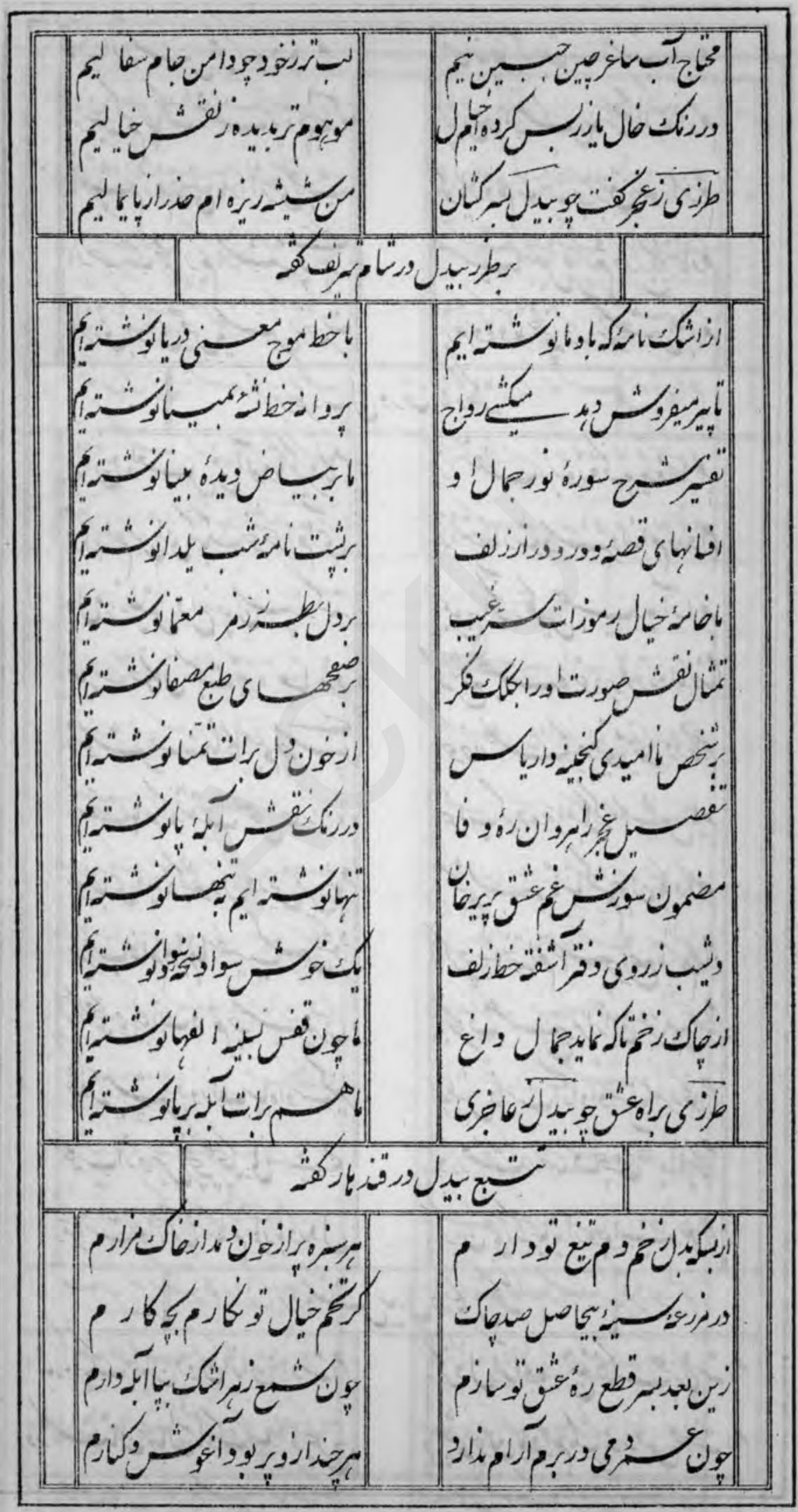




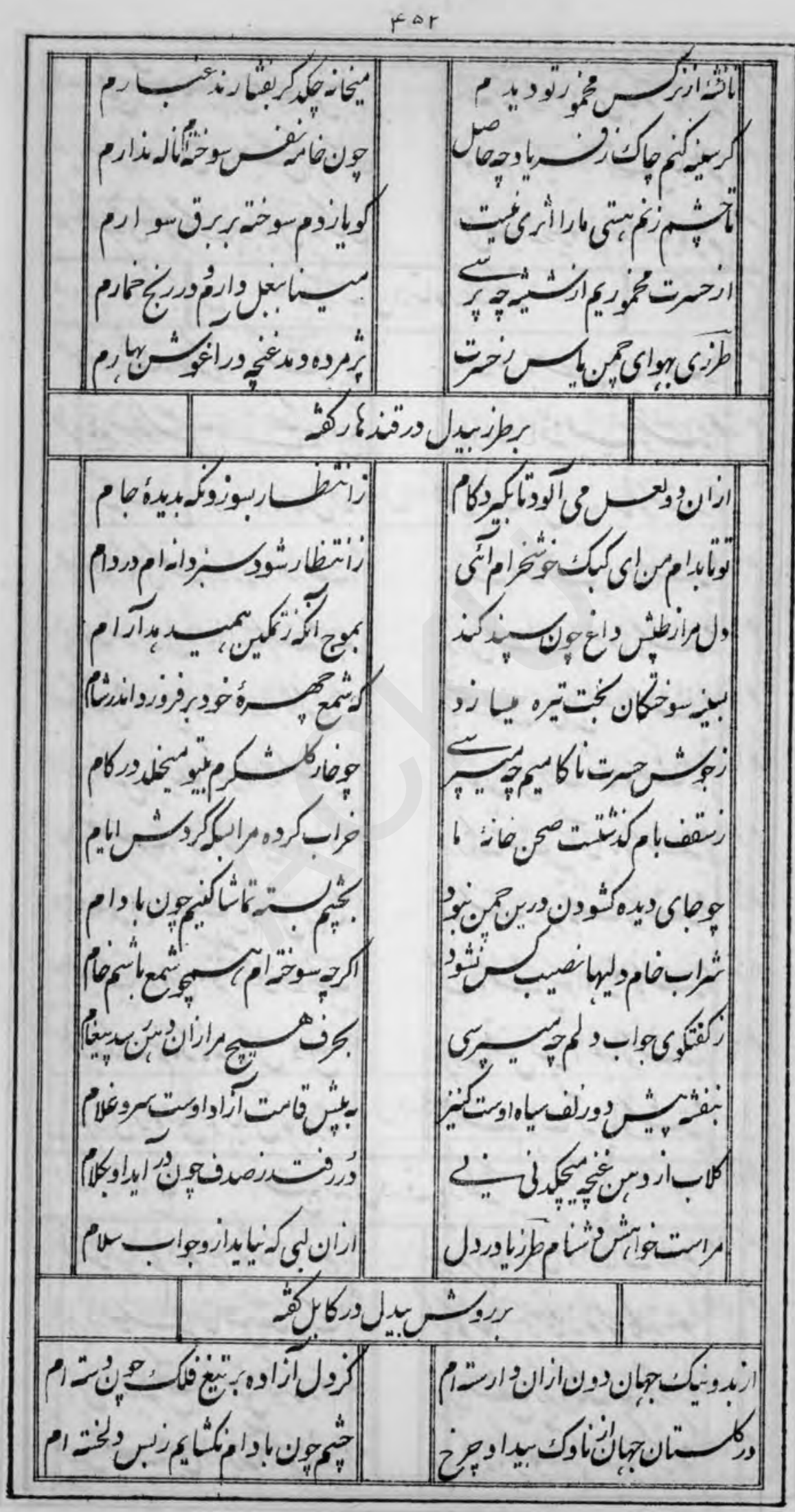


$r \Delta r$

||


$p \omega p$

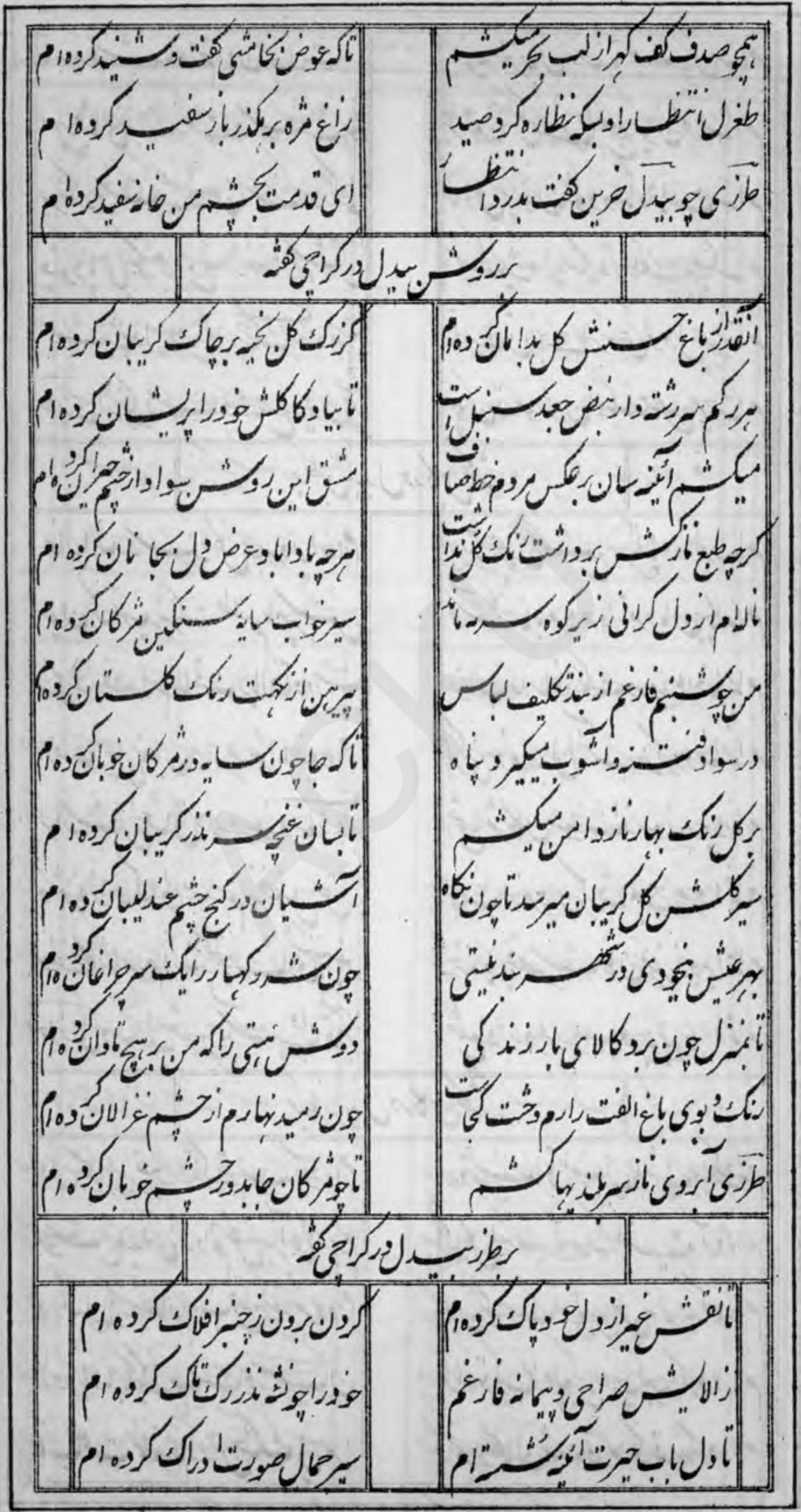


$r^{\circ} \Delta$

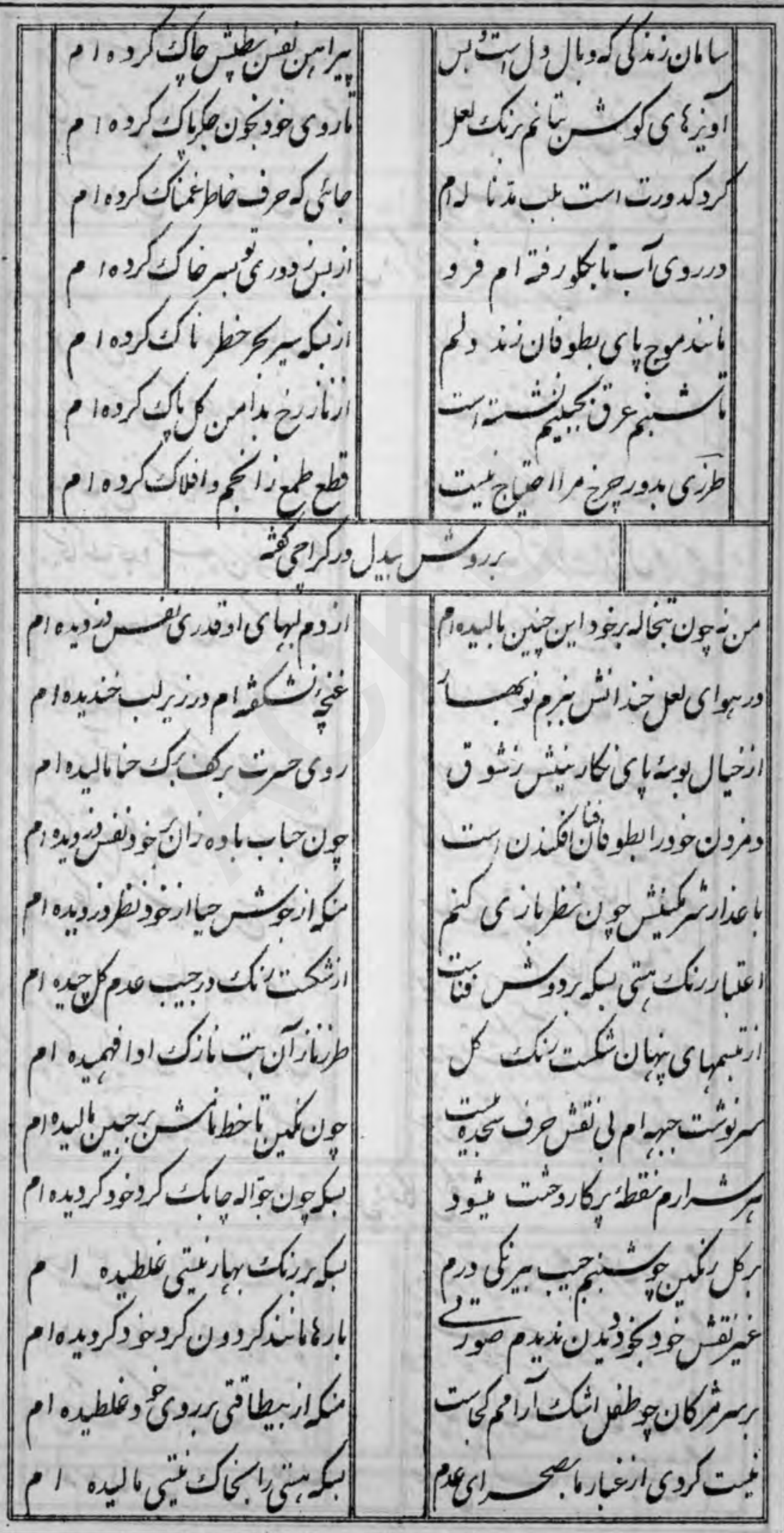




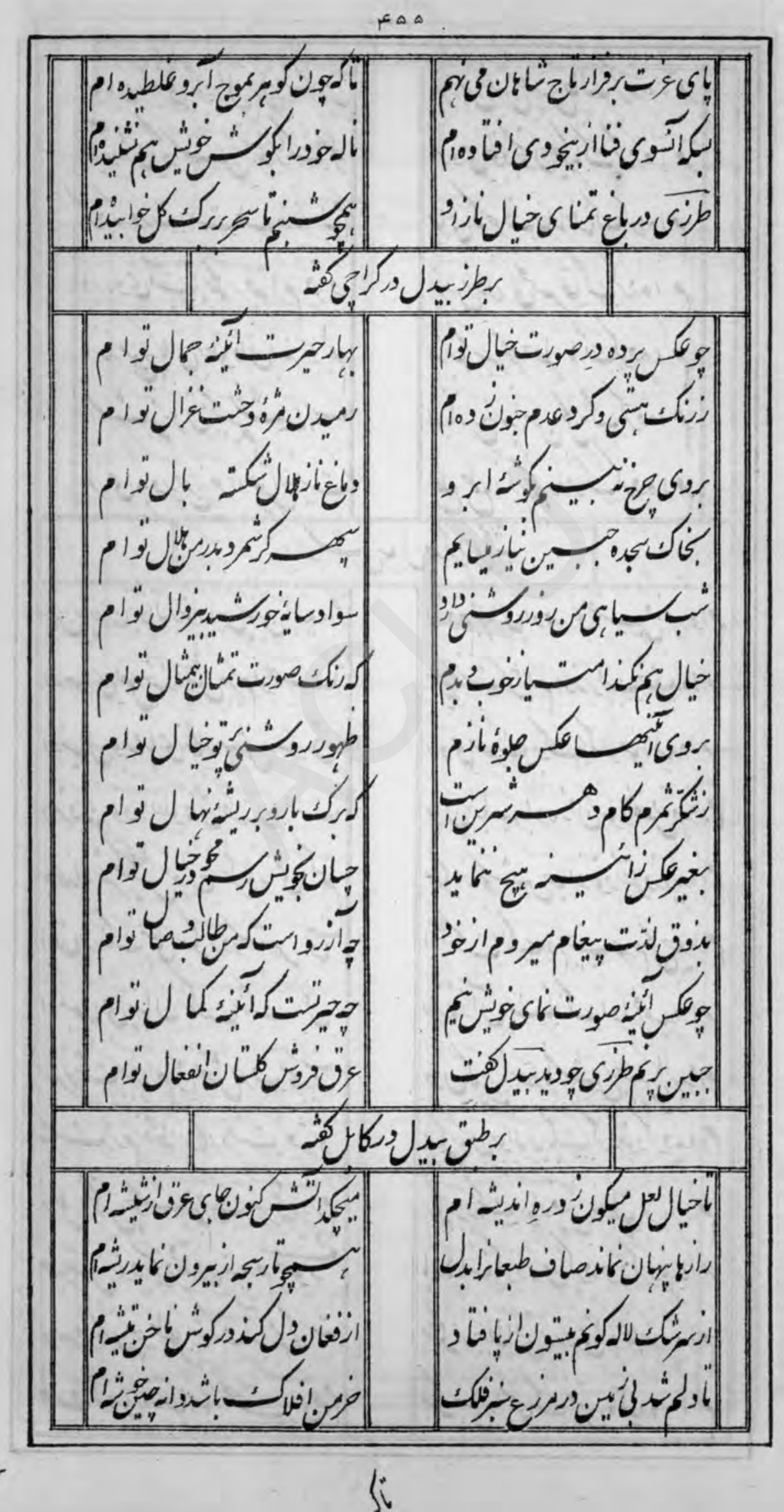


NOL

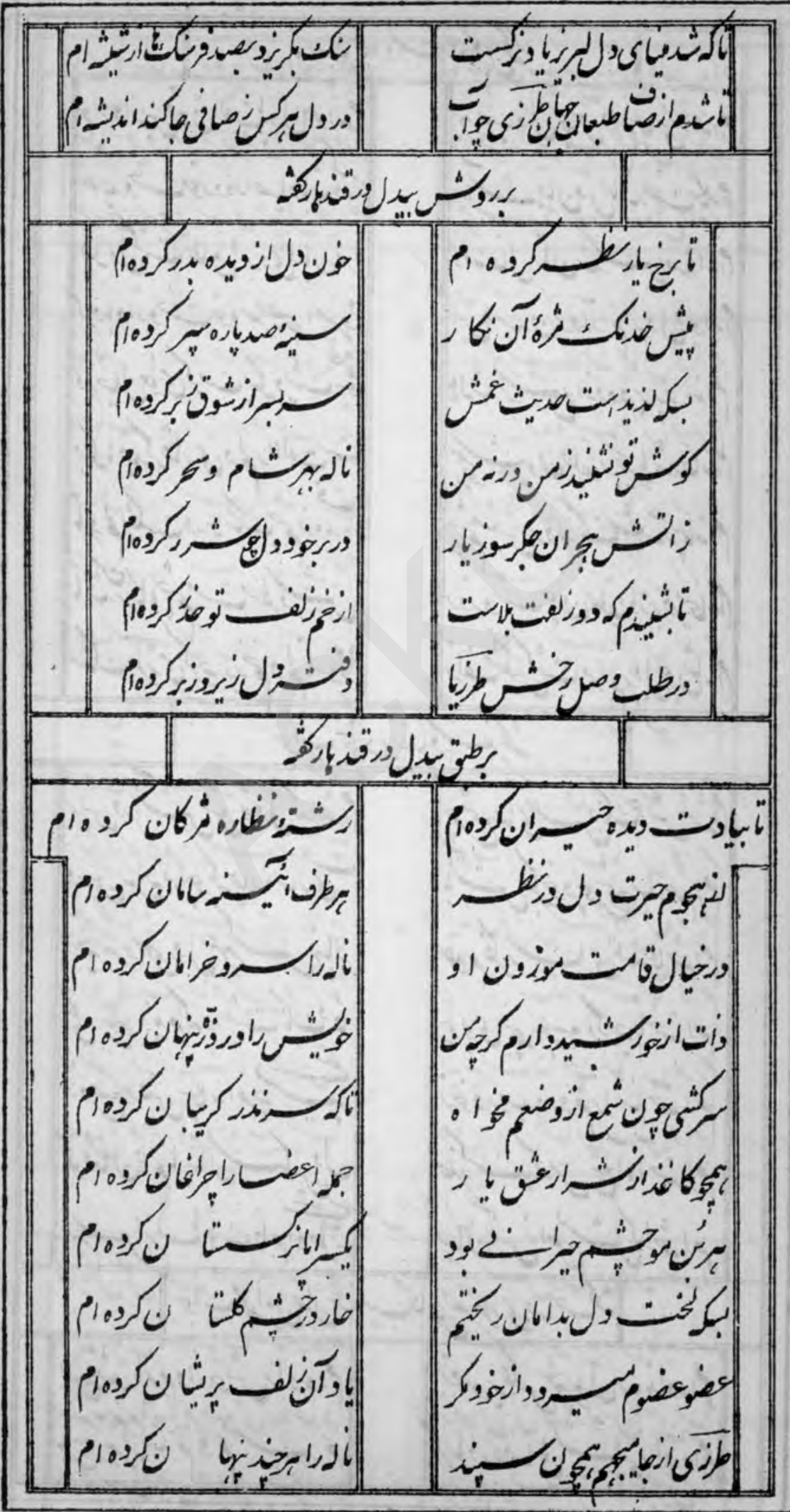




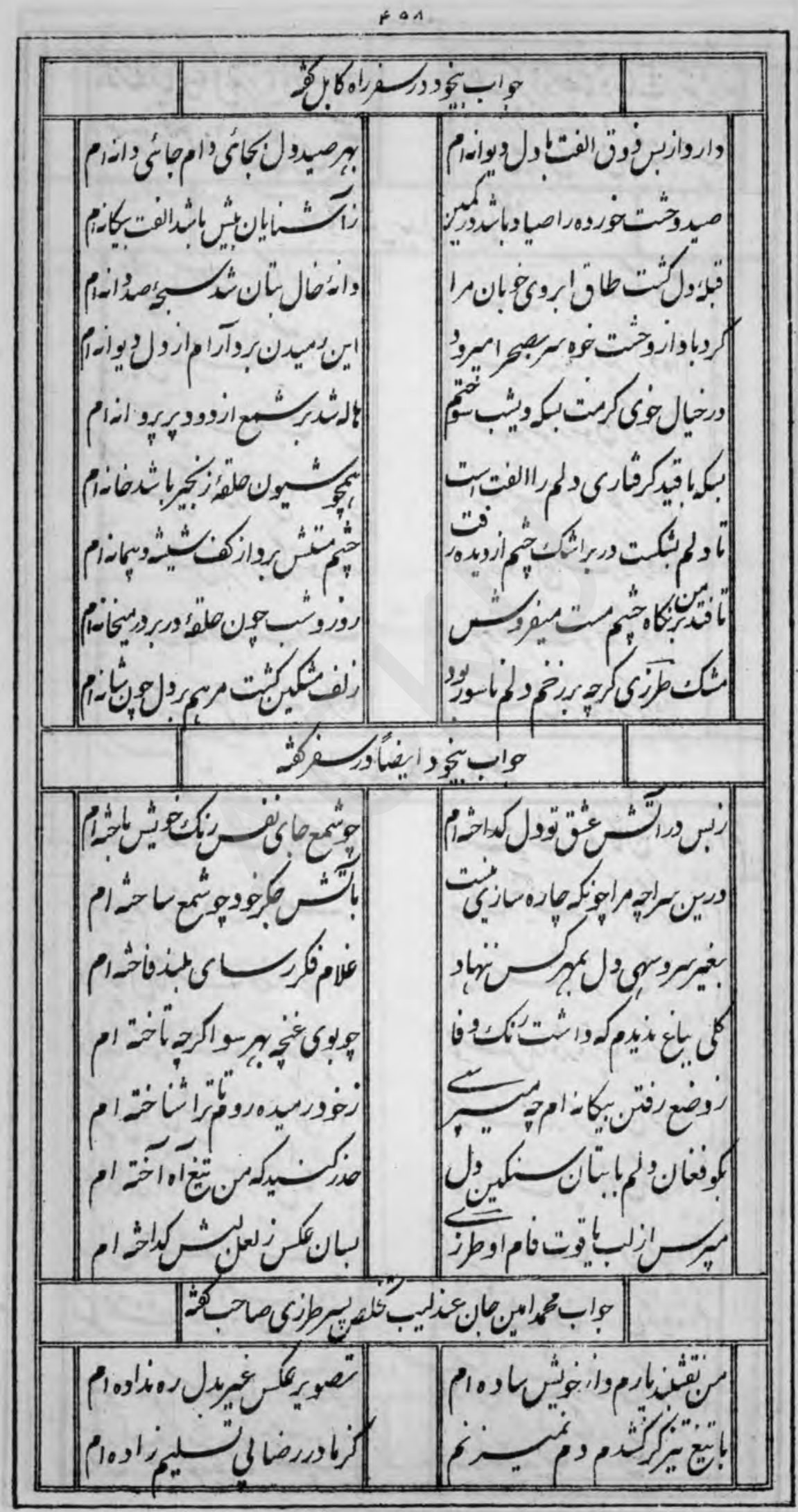


ro 4

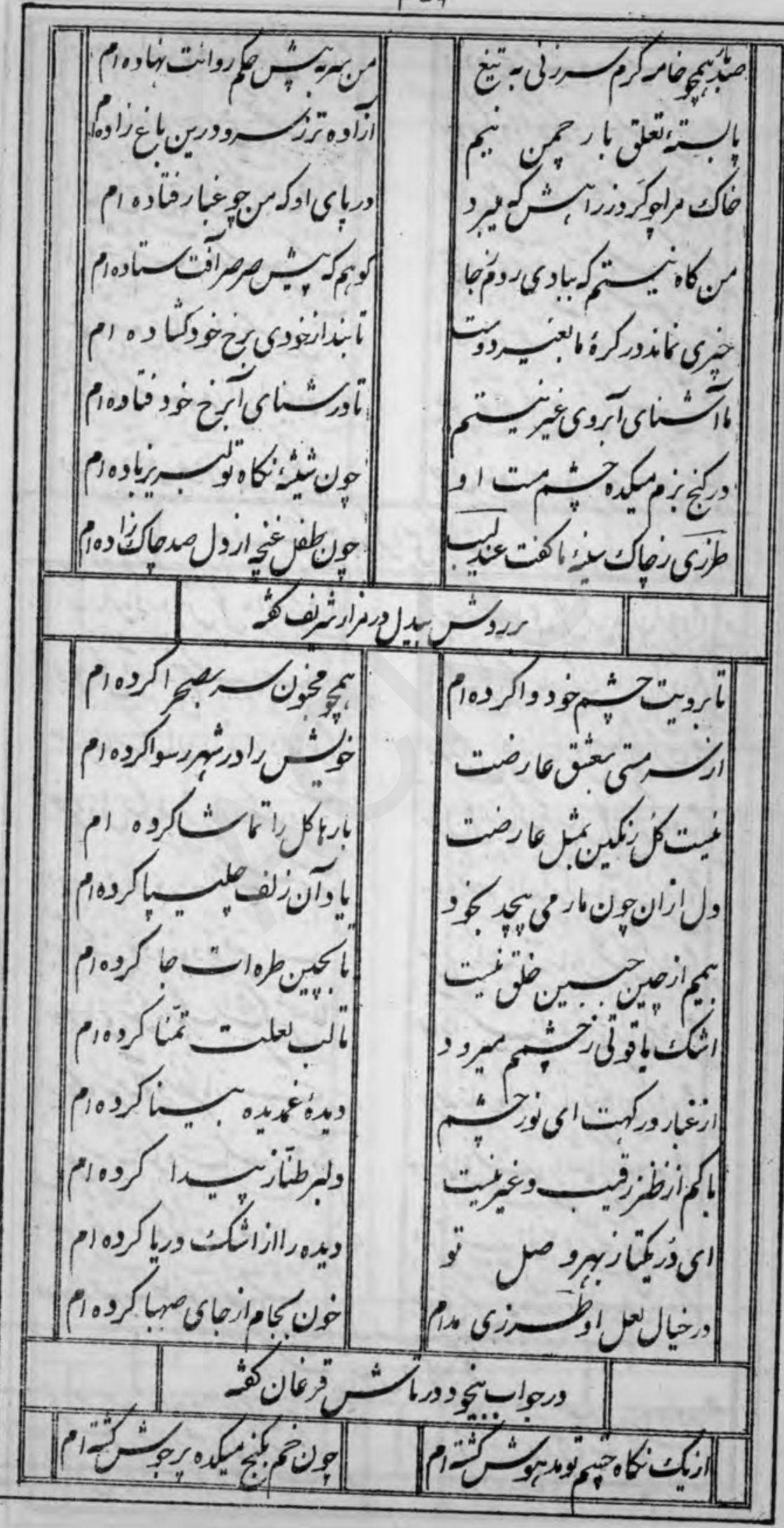


\& 5

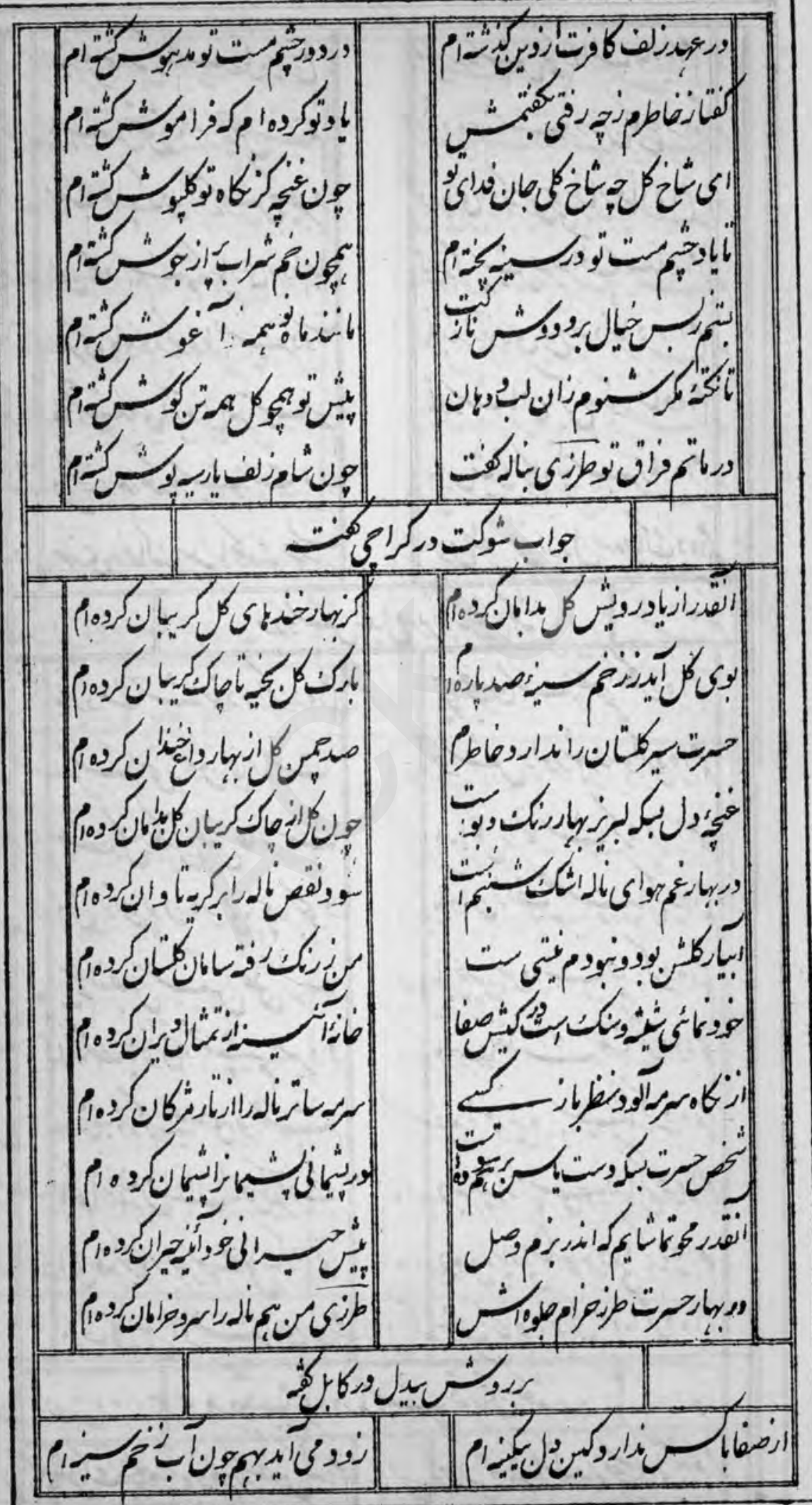


rs

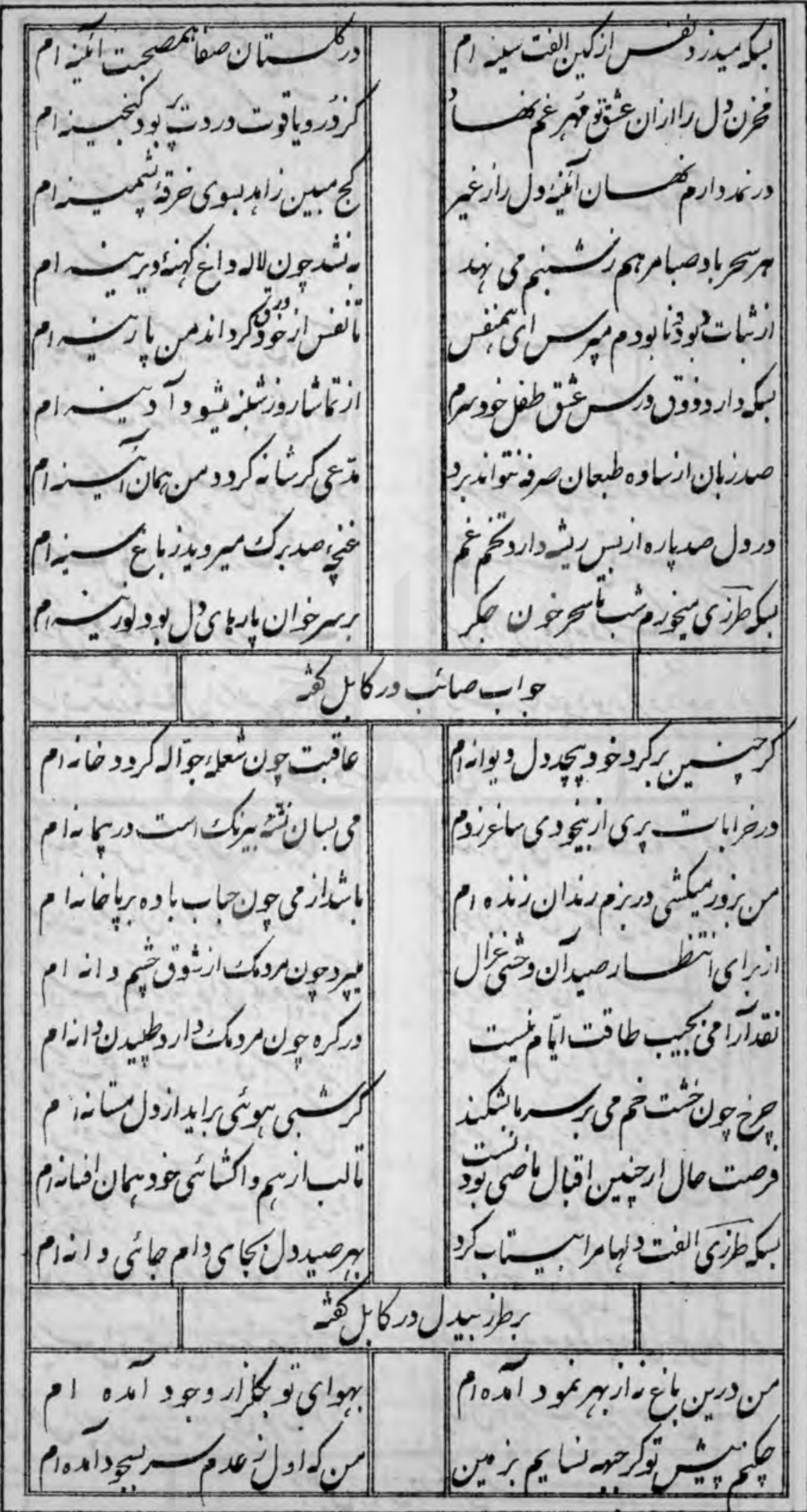


rs

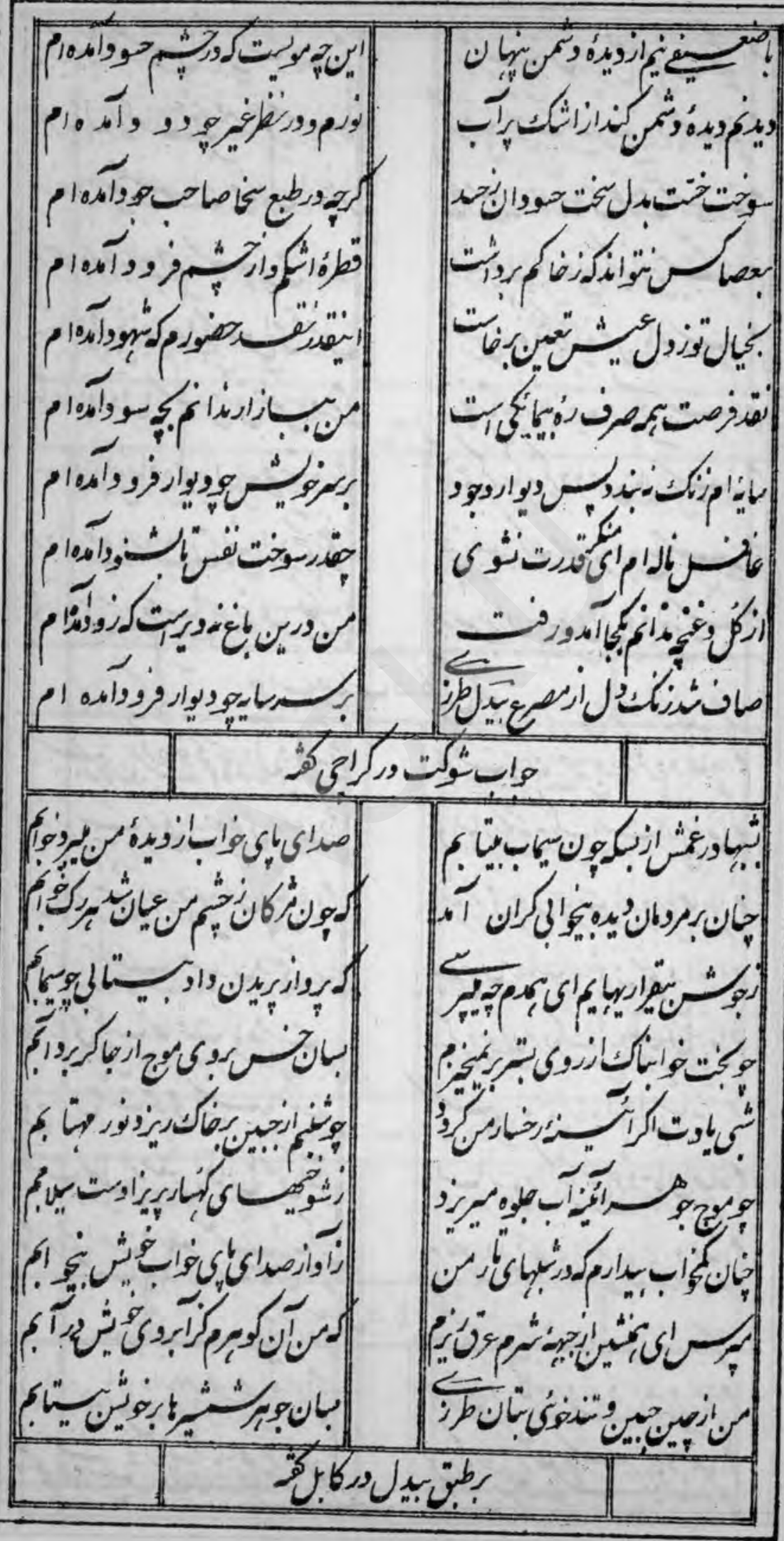


r $\$ r$

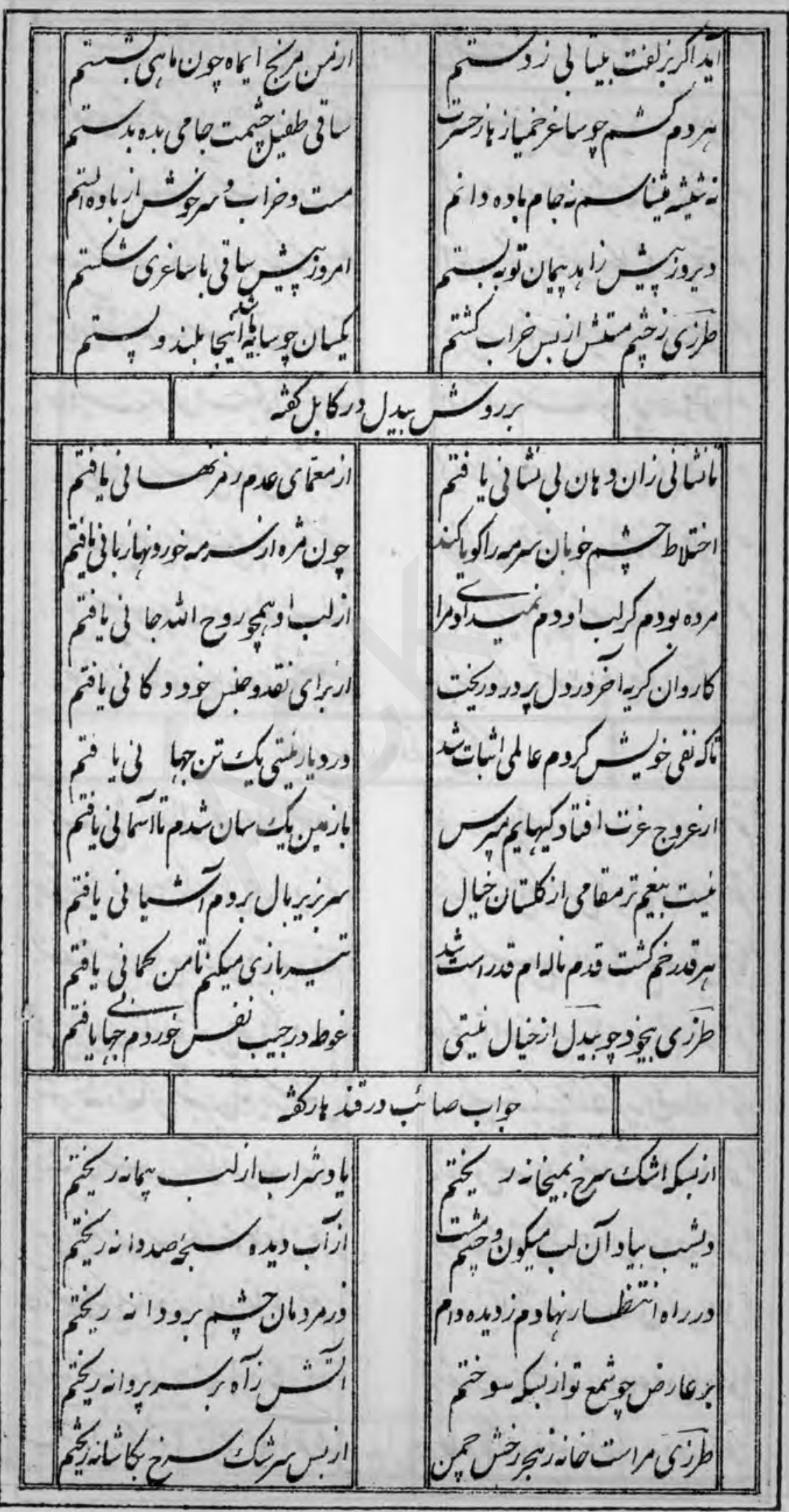




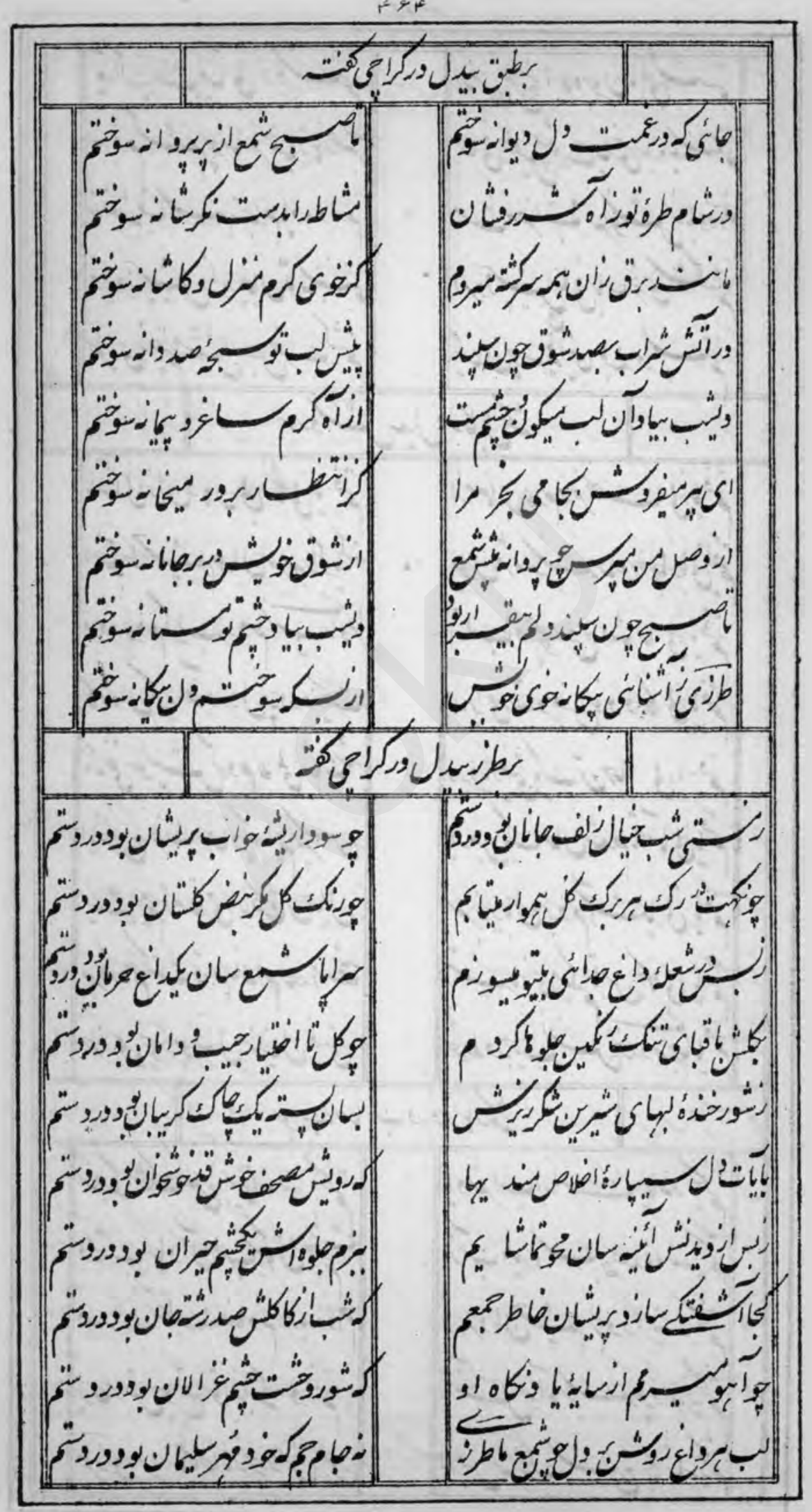




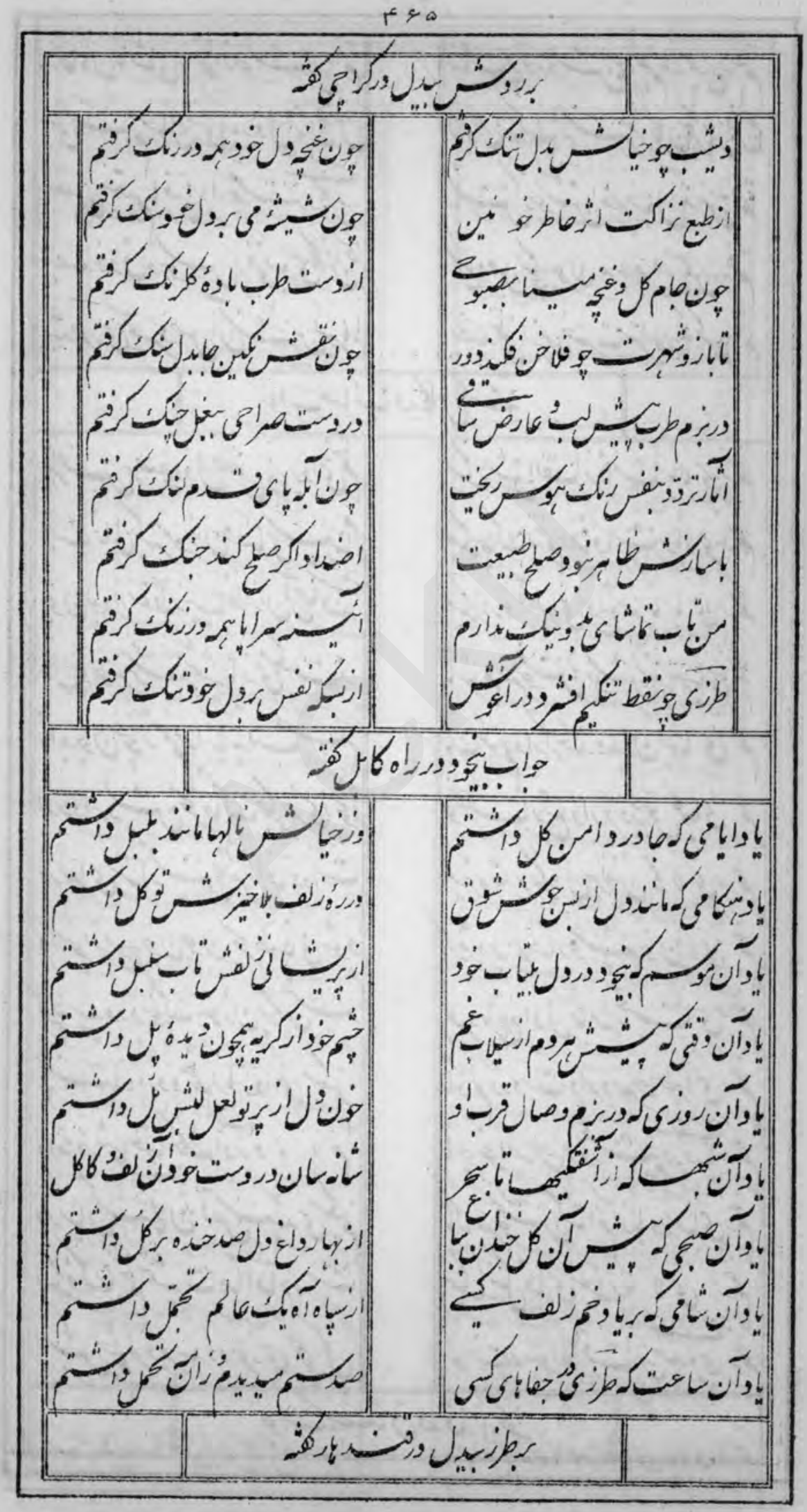


$4<5$

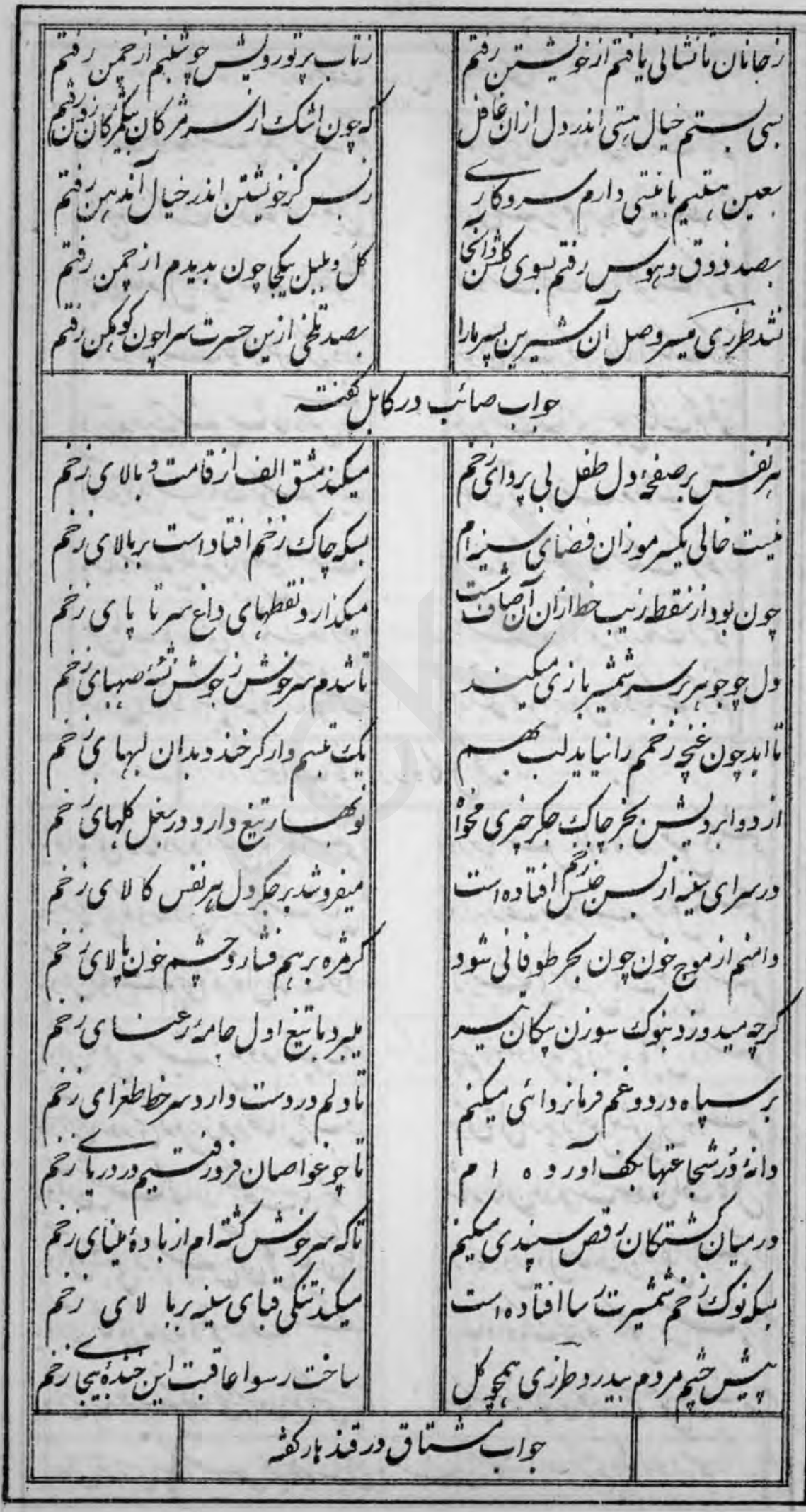




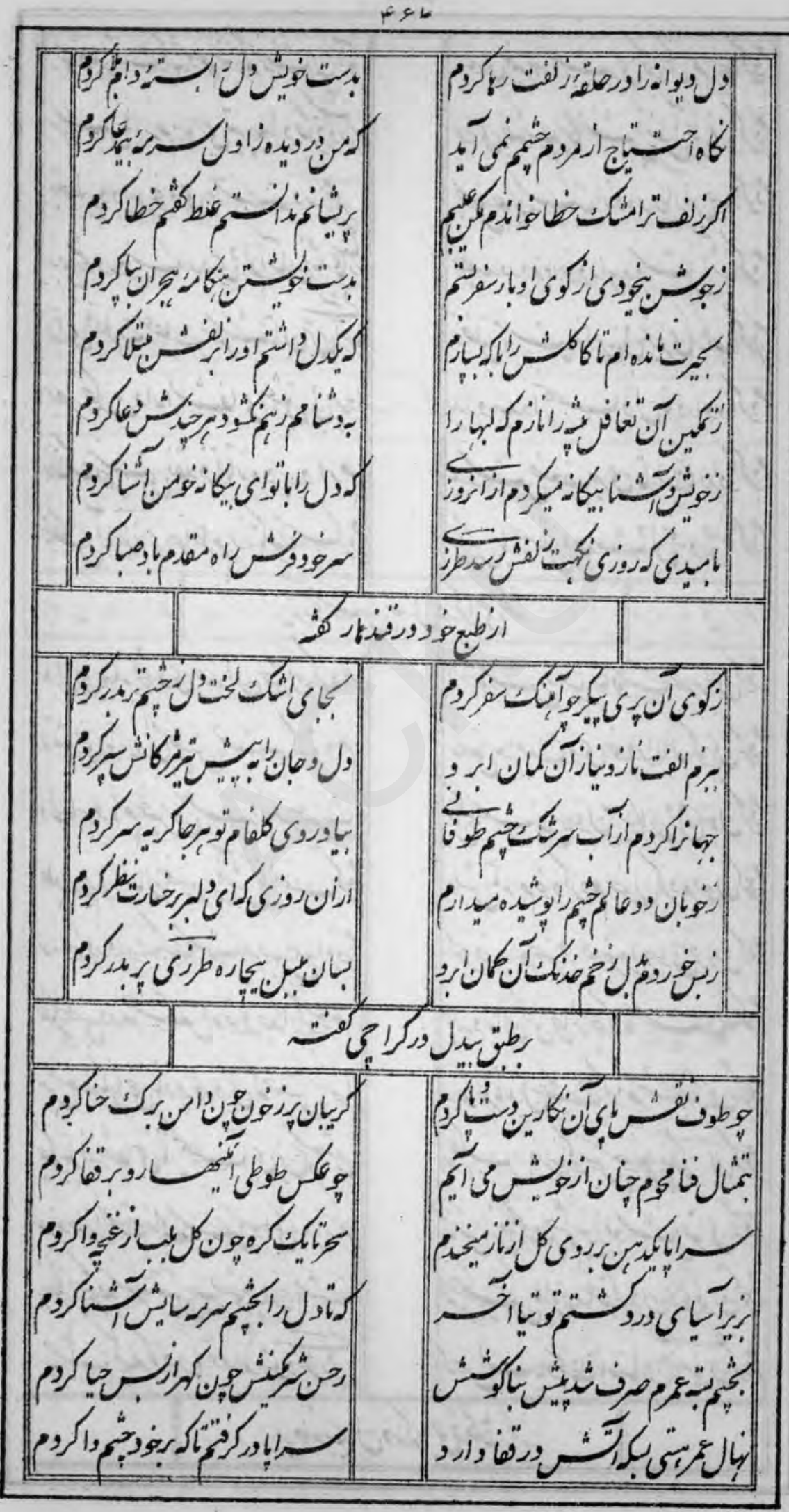


$r \leqslant n$

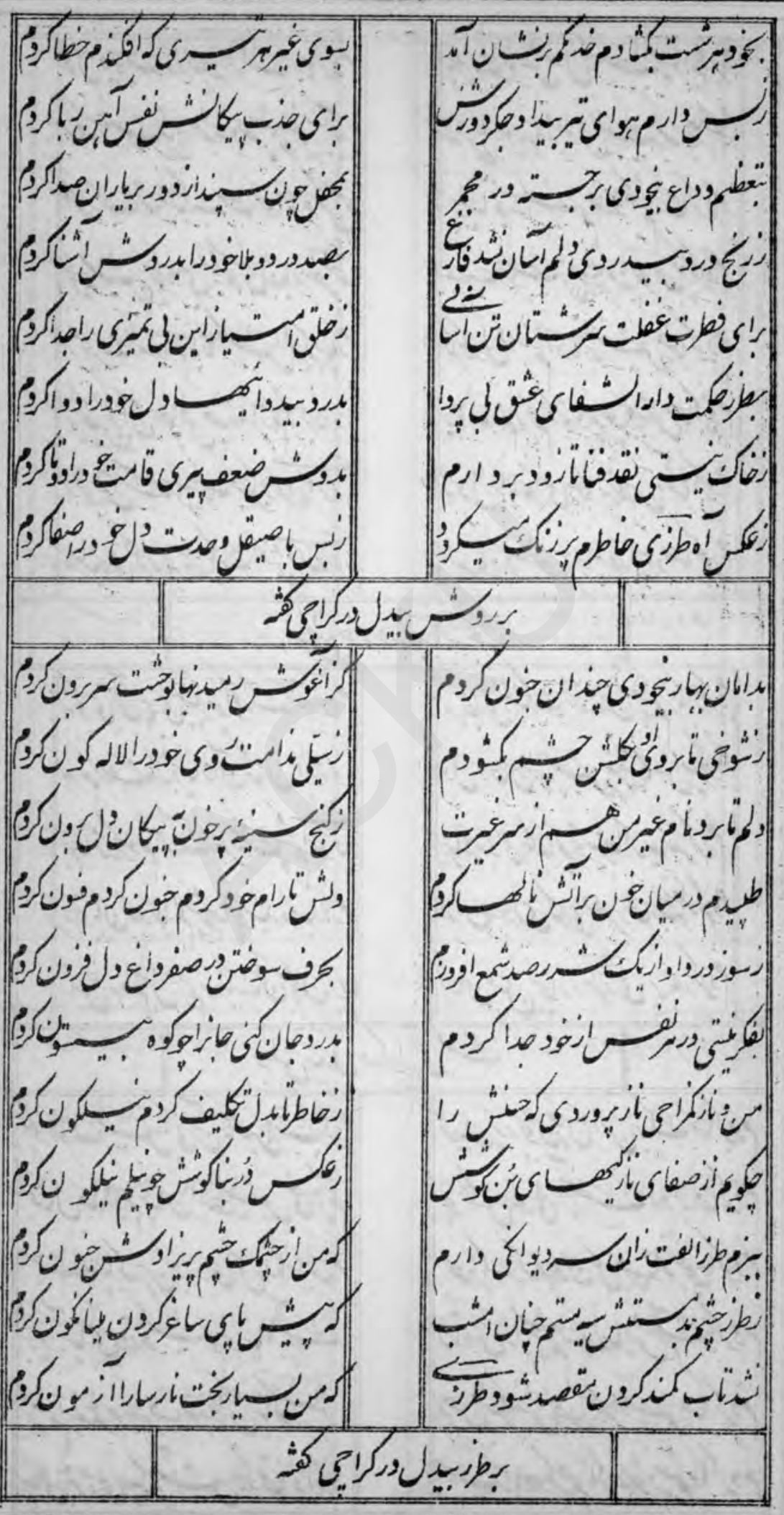


$1^{5}>4$

\begin{tabular}{|c|c|}
\hline $\mid$ & 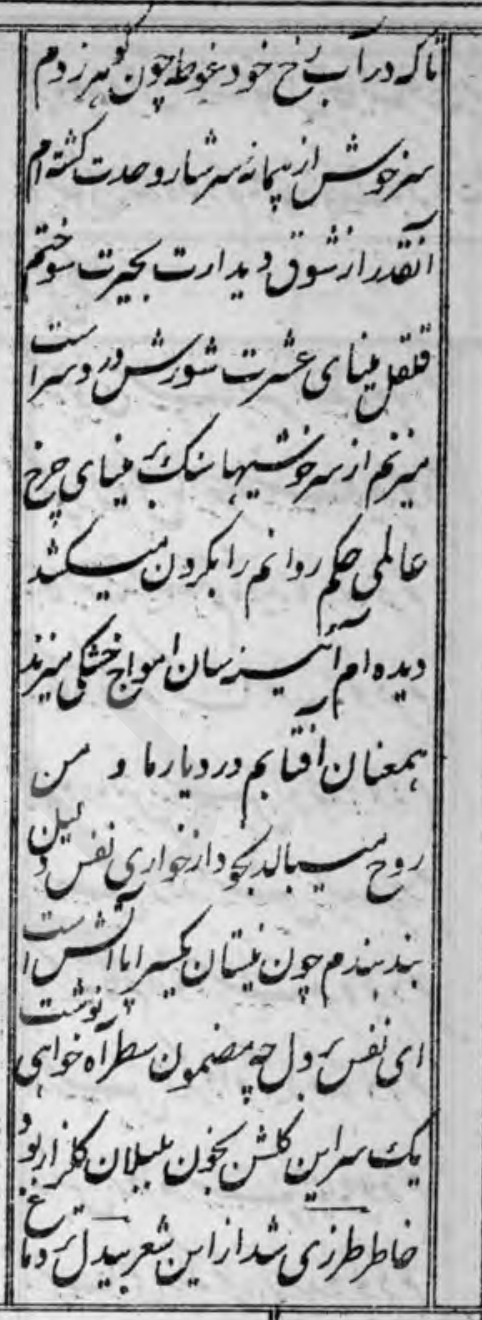 \\
\hline | & 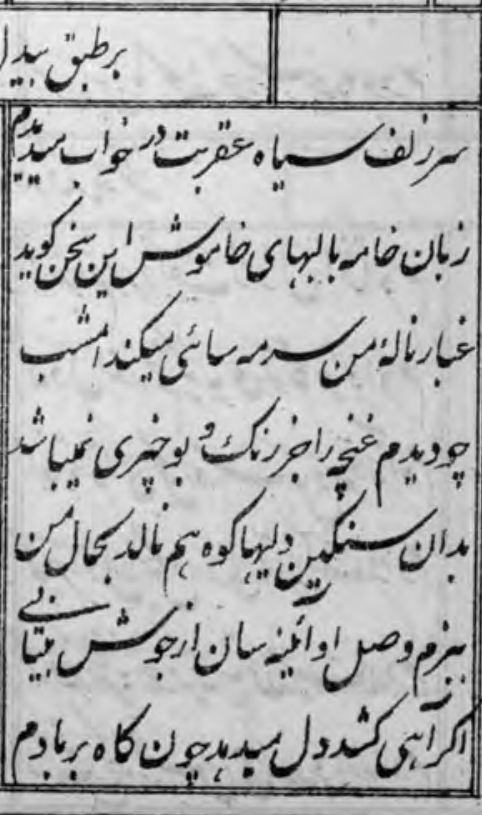 \\
\hline
\end{tabular}




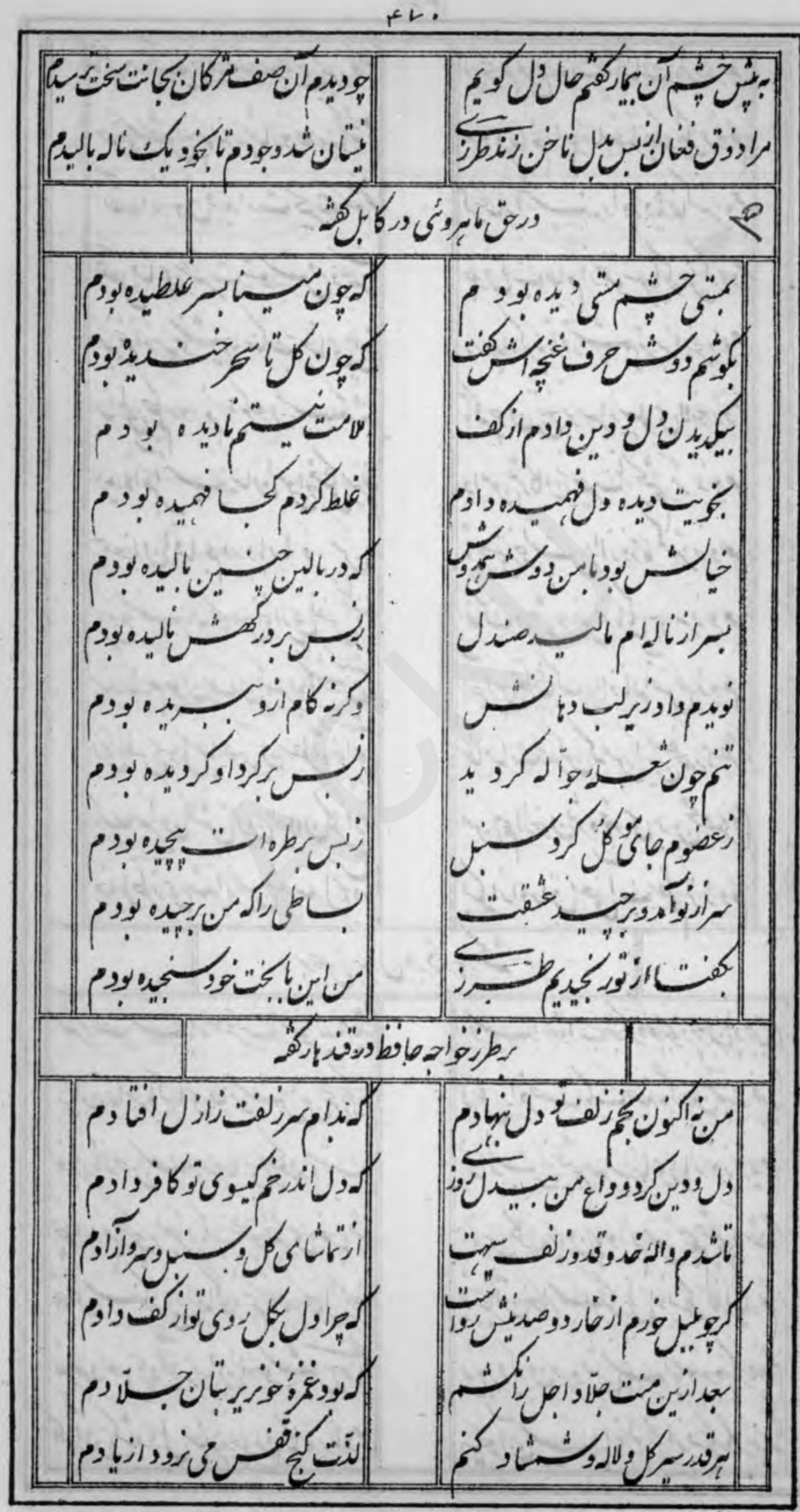

s: 
F

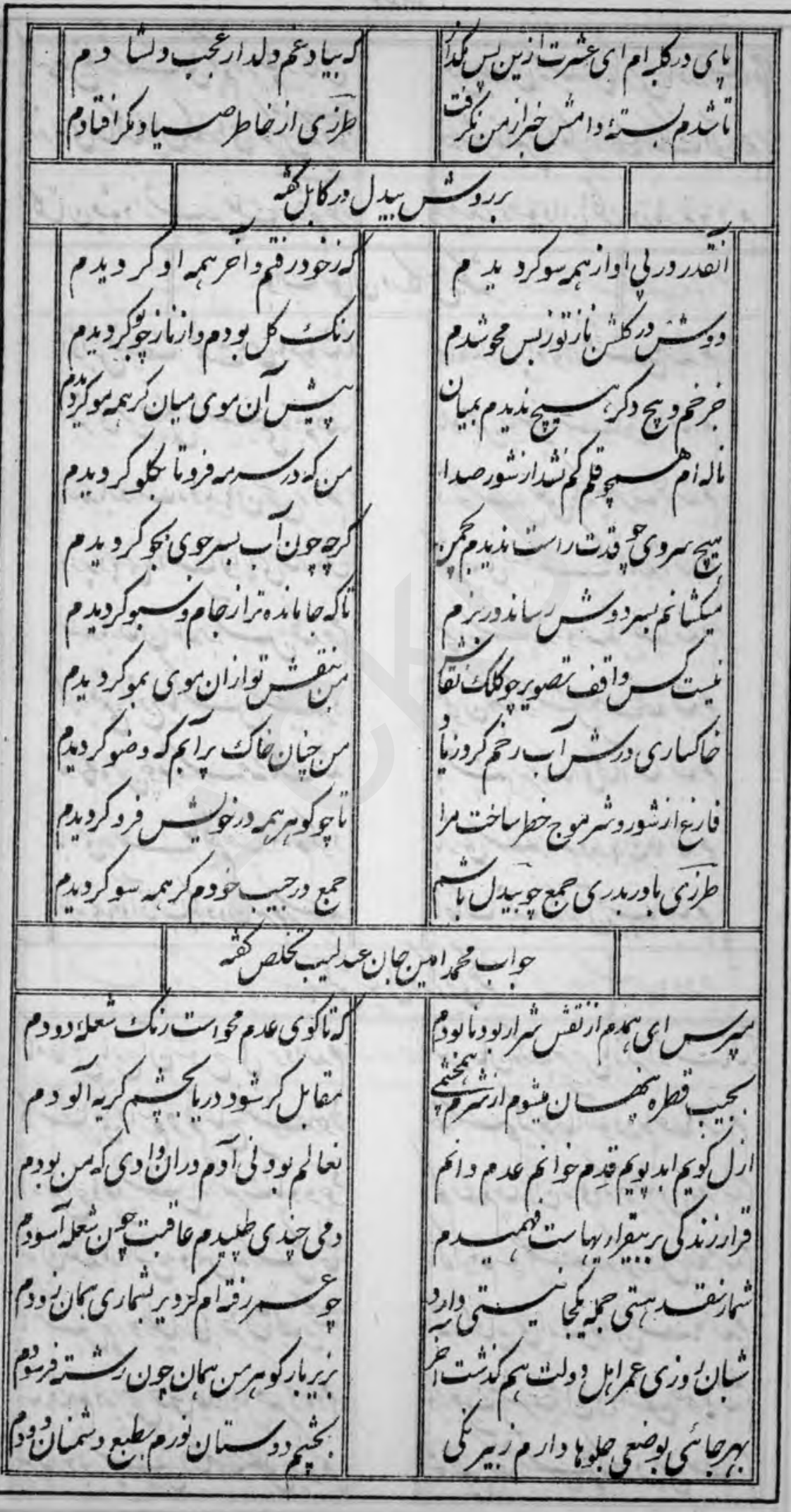




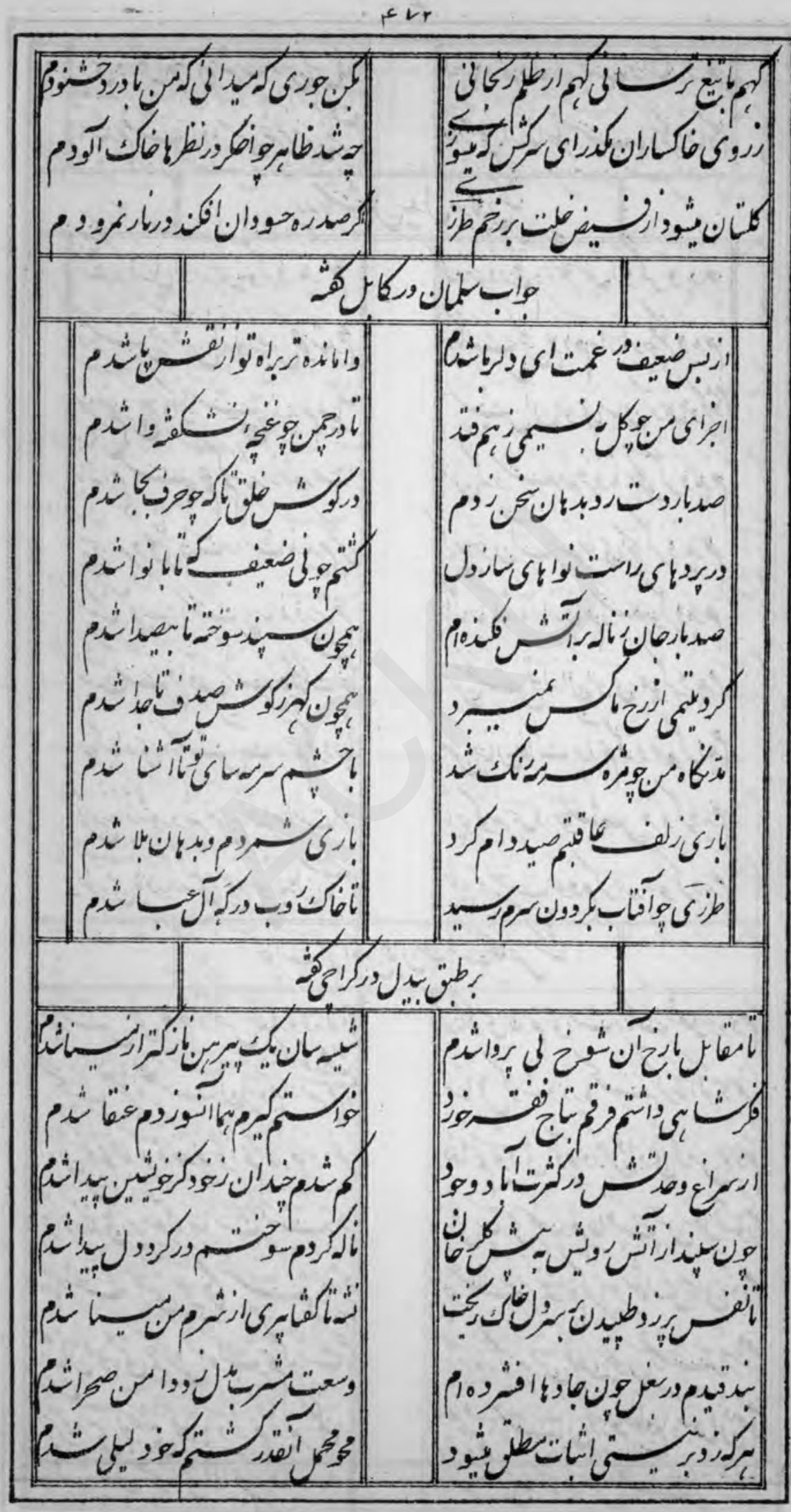


Frr

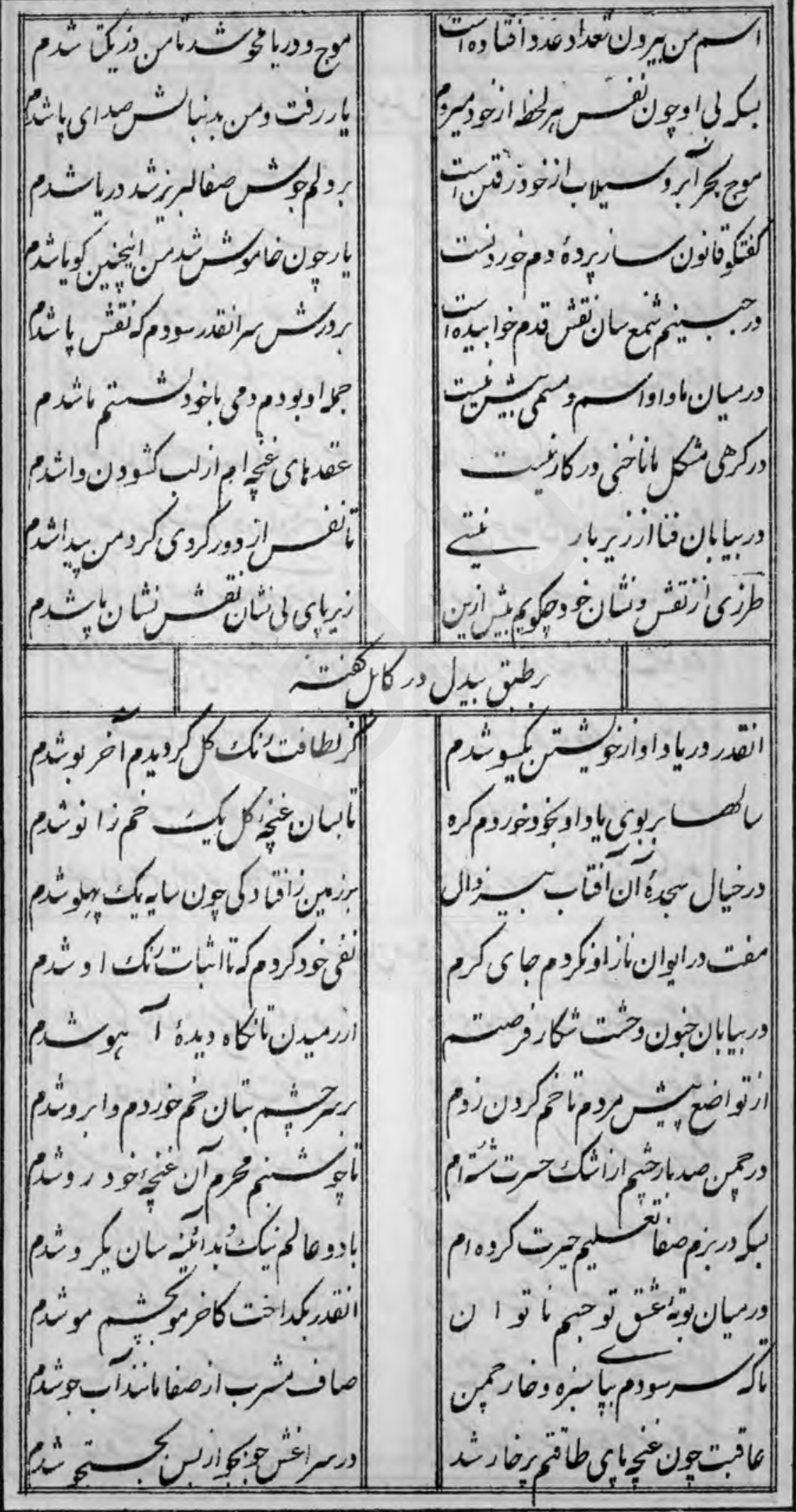




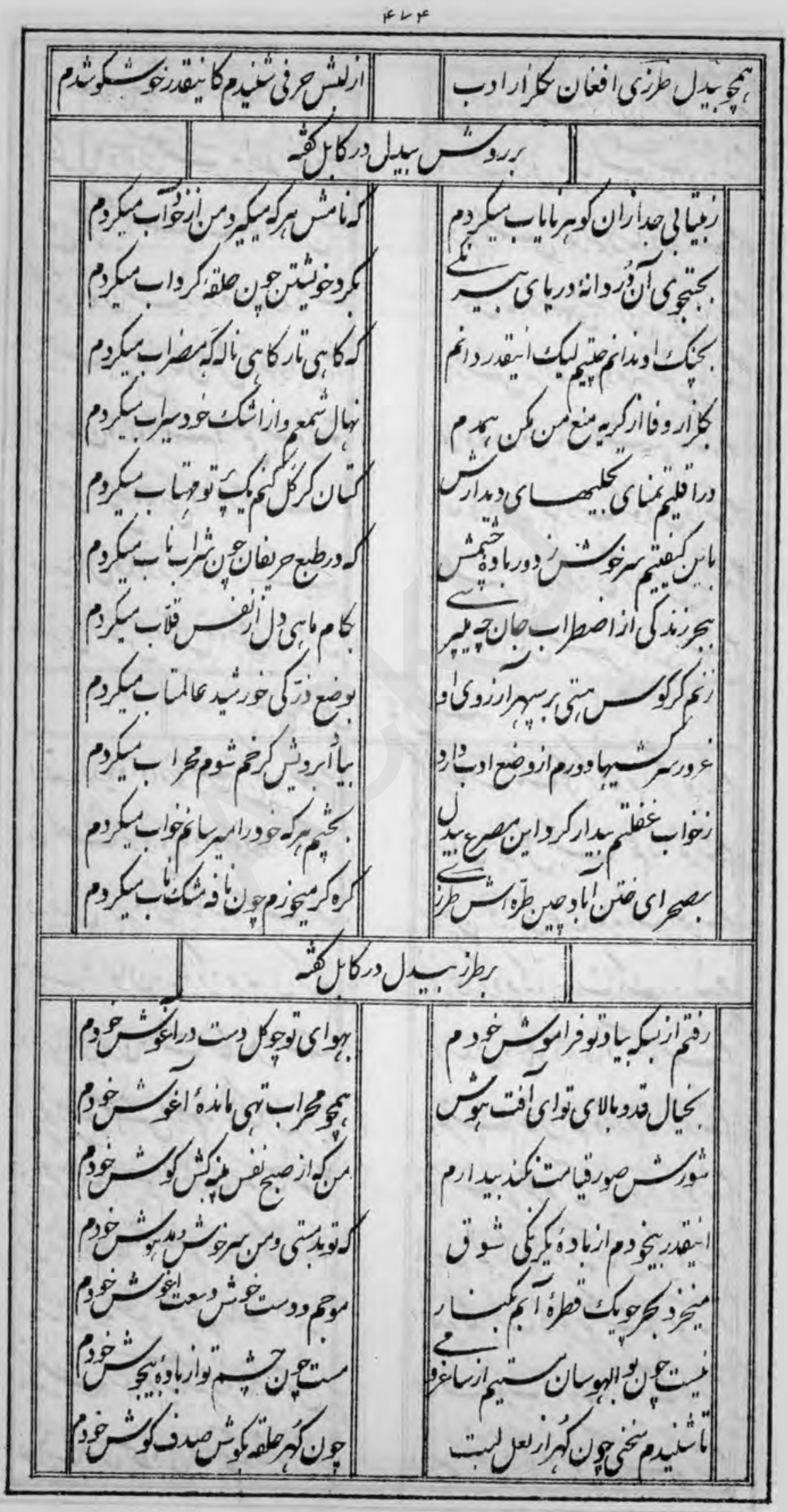


ica

|| $\mid$


Fr

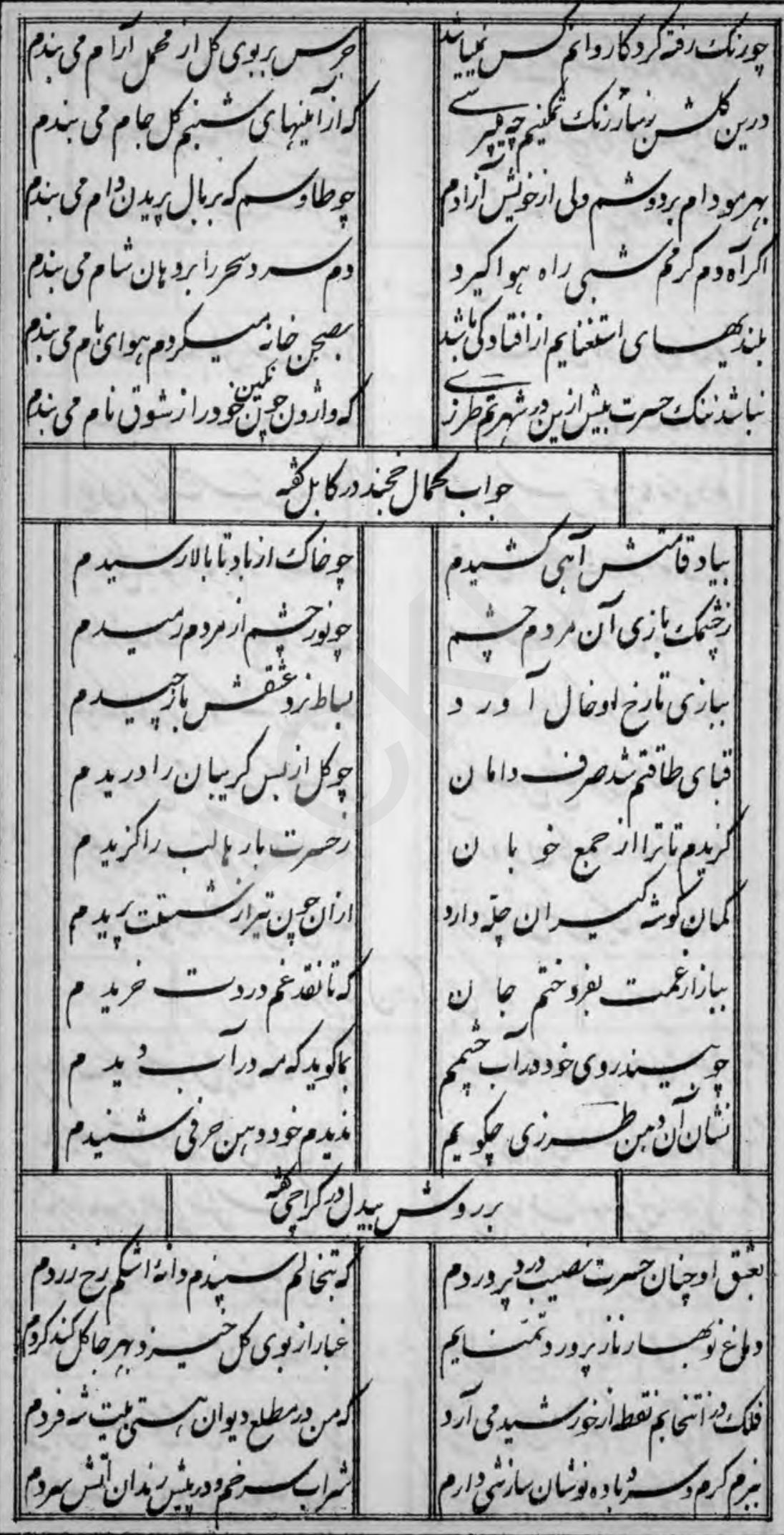


rok

|| $\mid$


$+21$

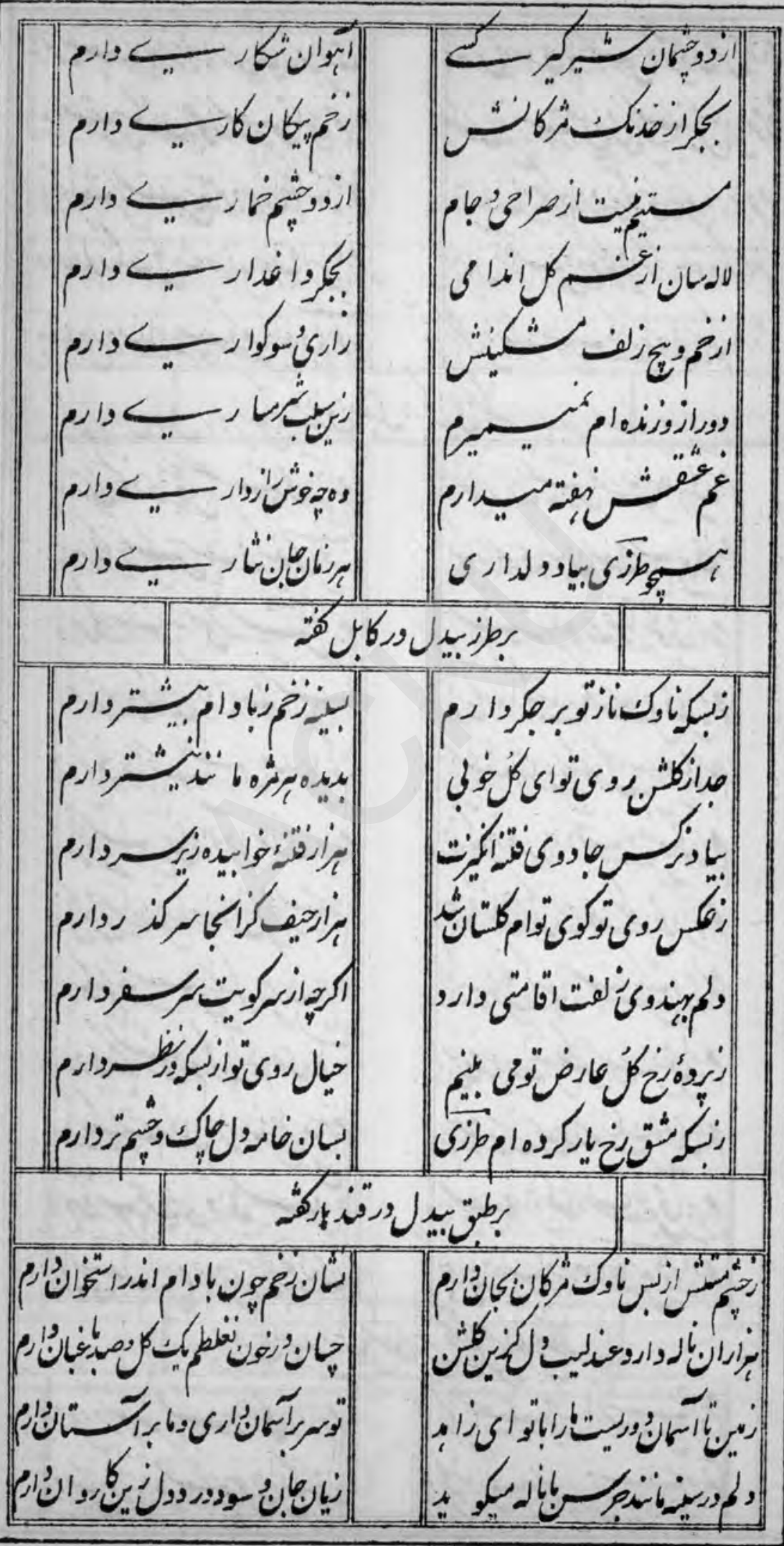


rvq

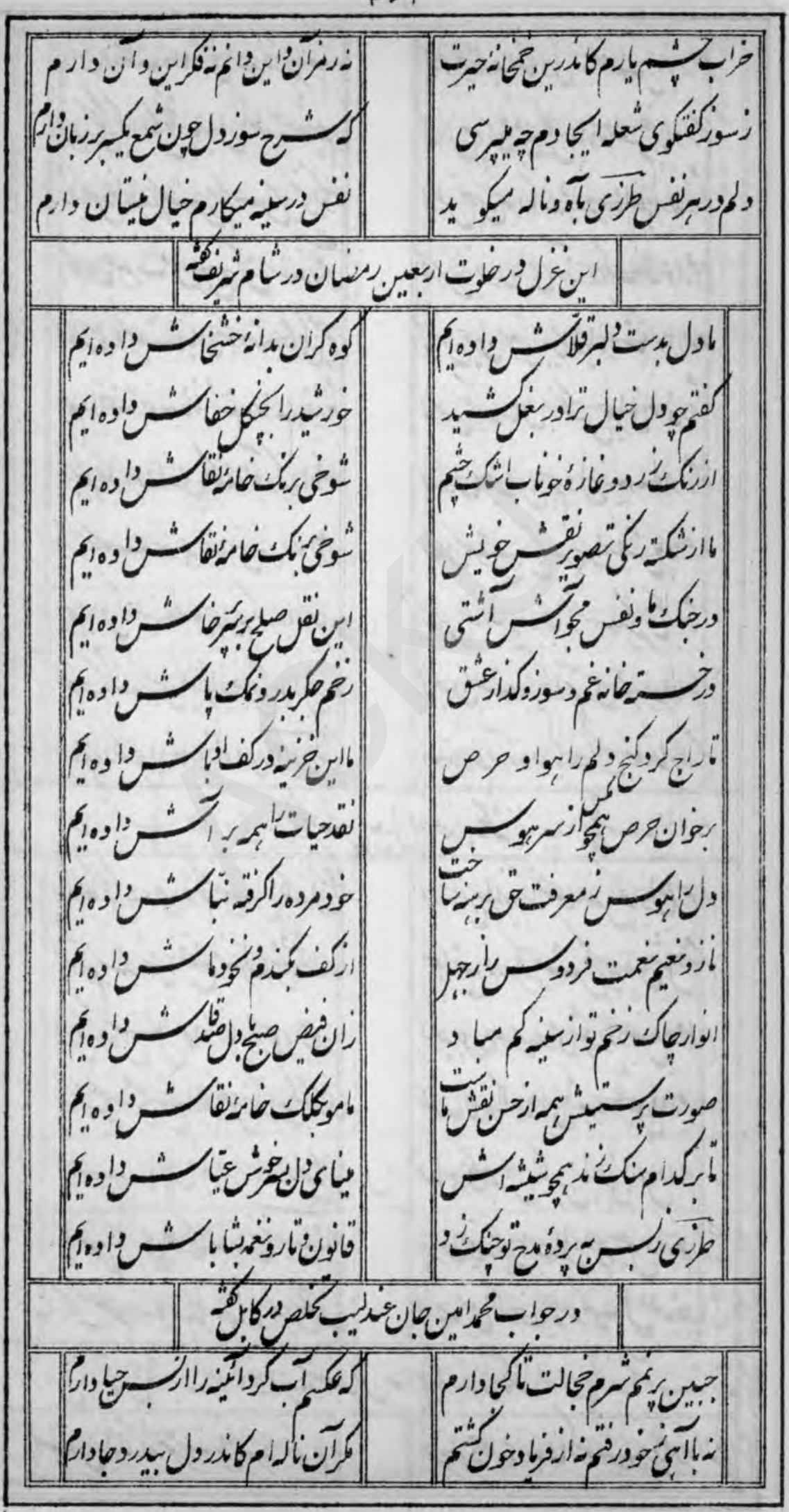


*

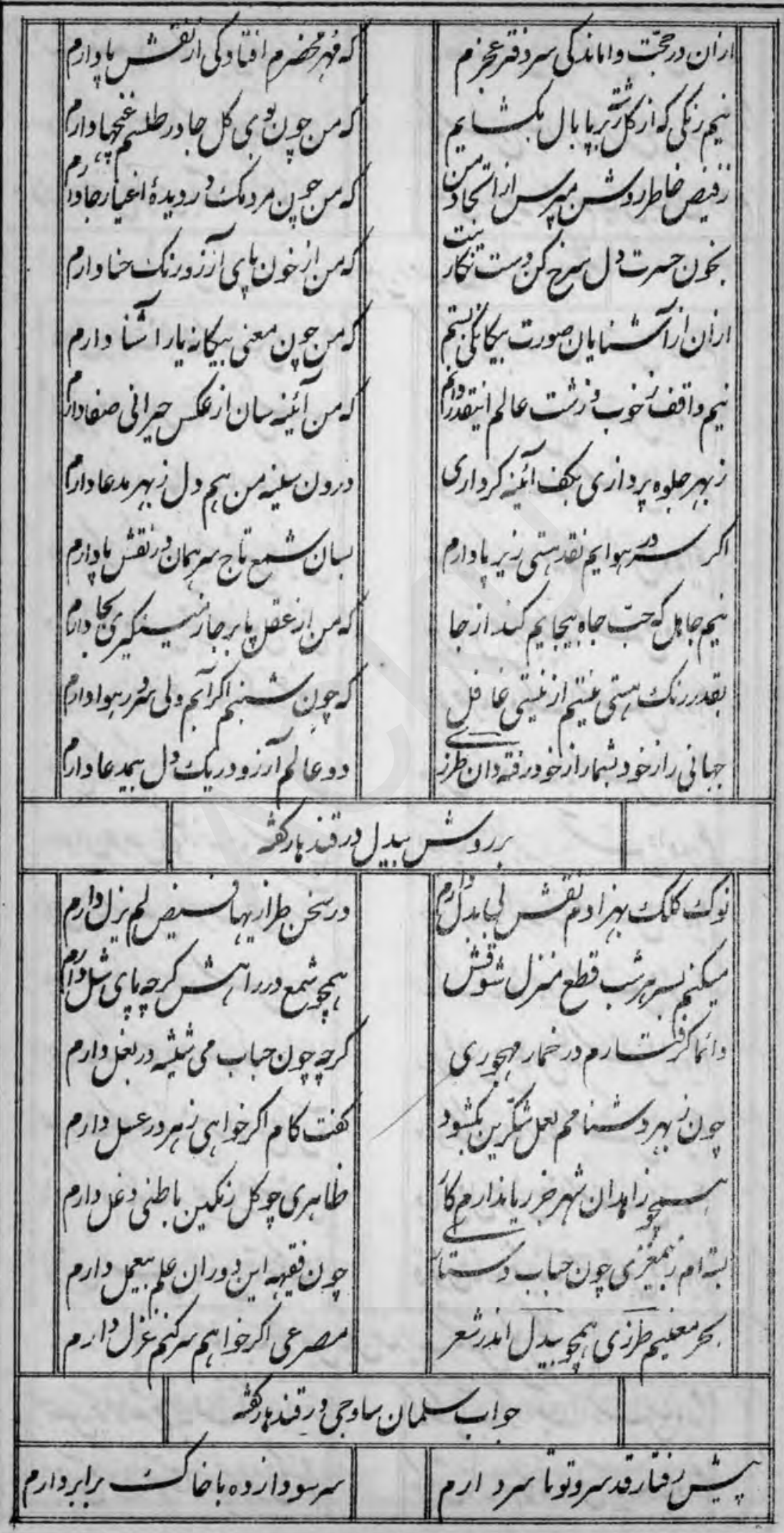


FAI

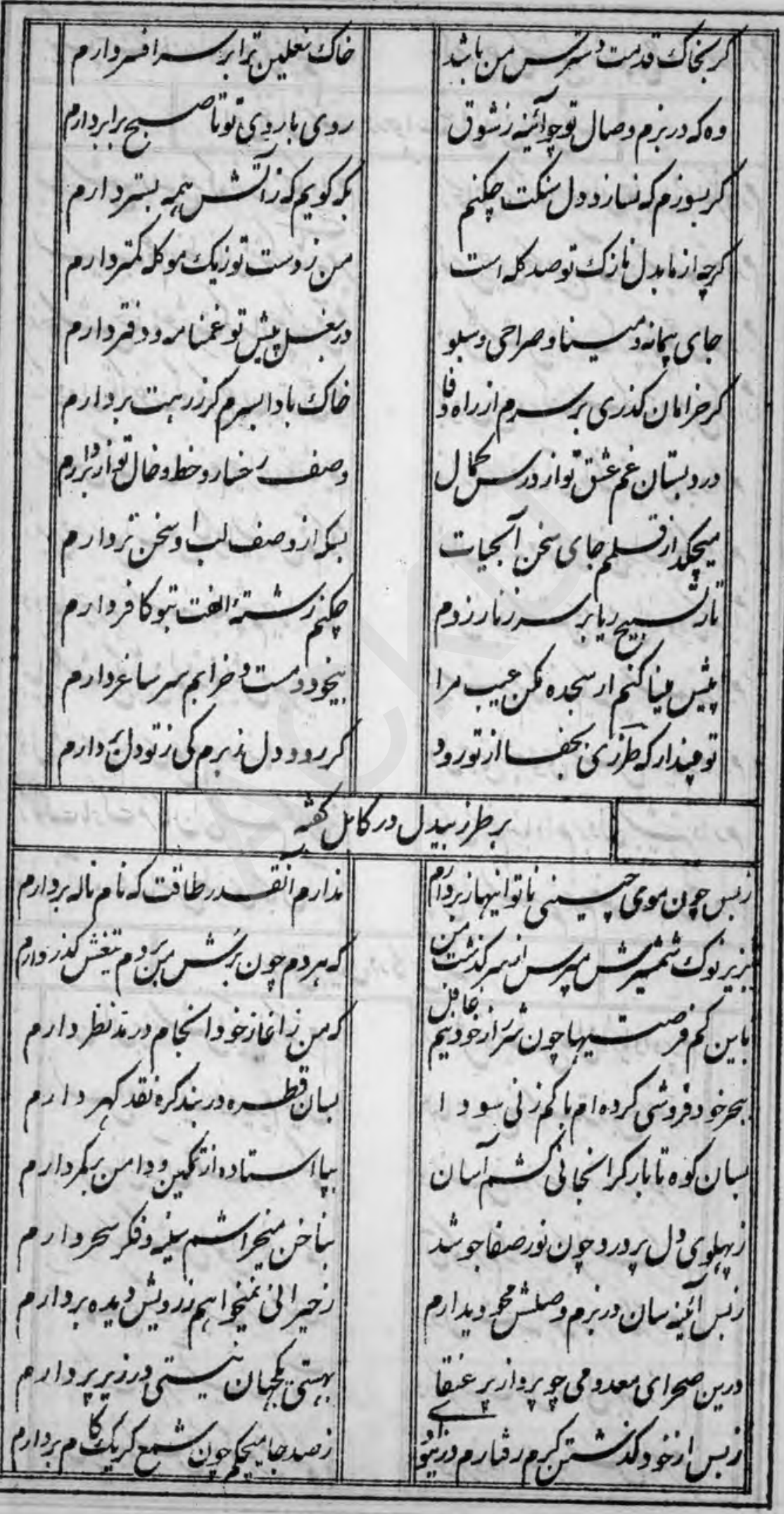


$-A T$

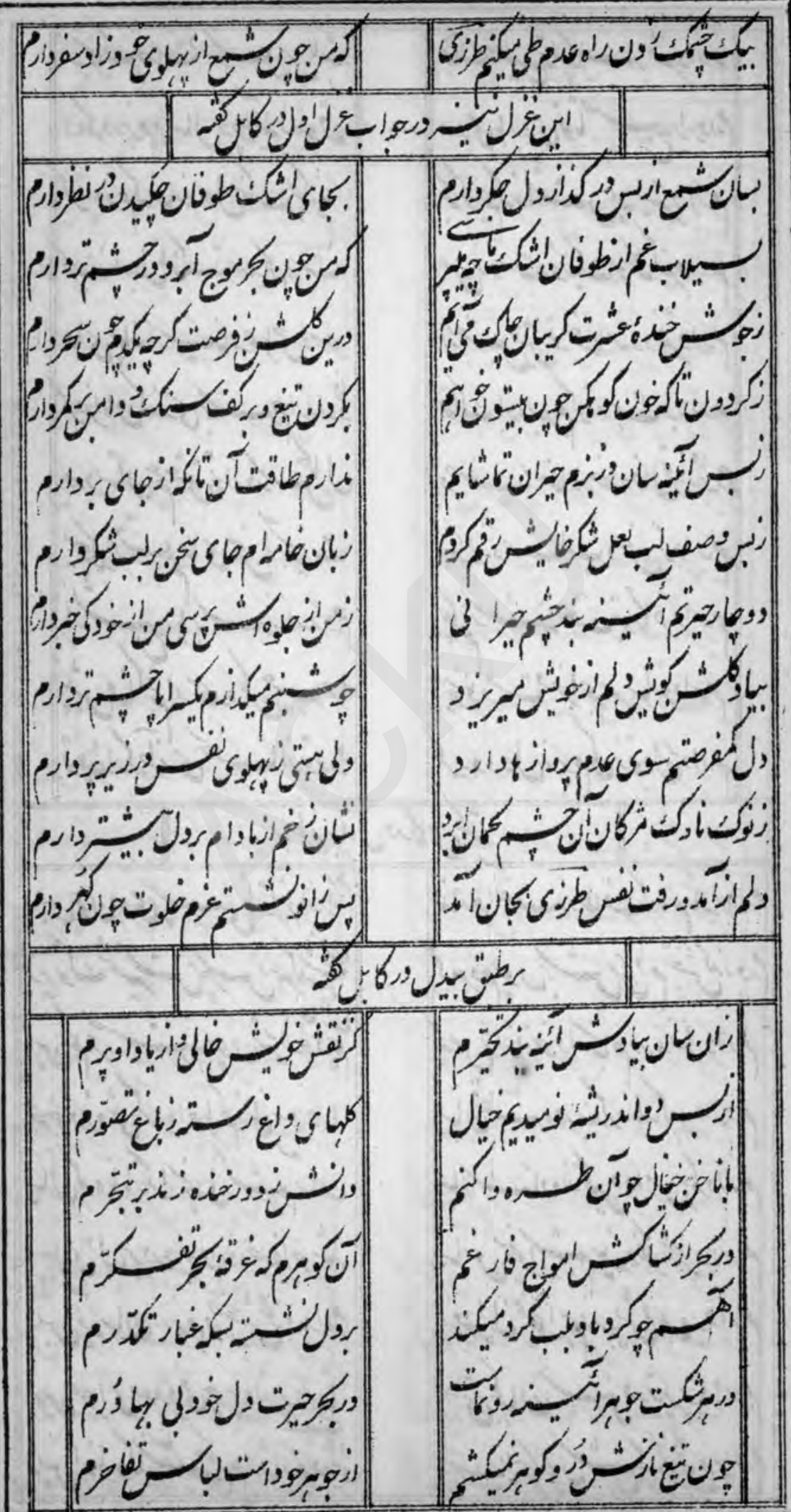


fAr

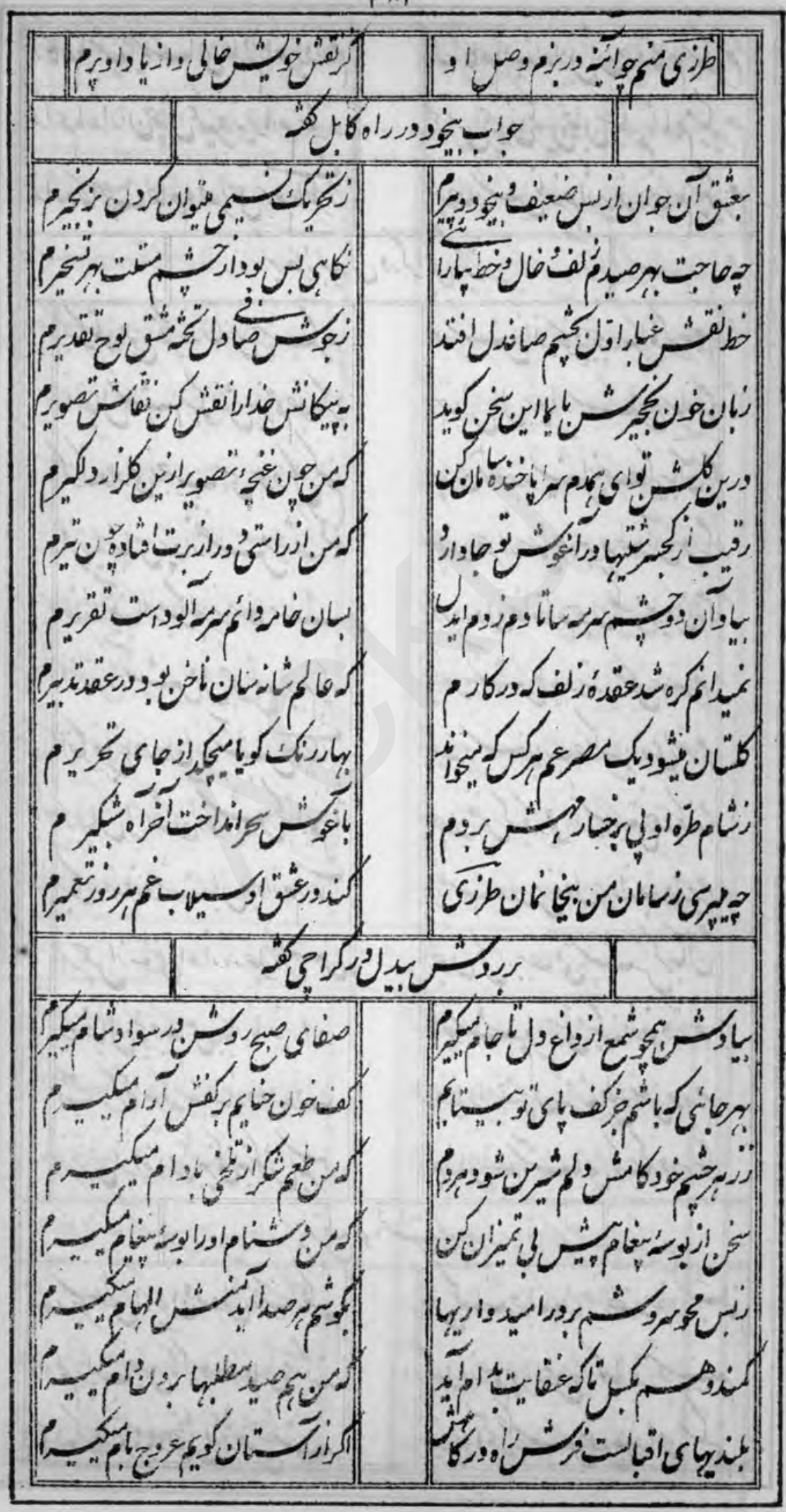


$F \wedge F$

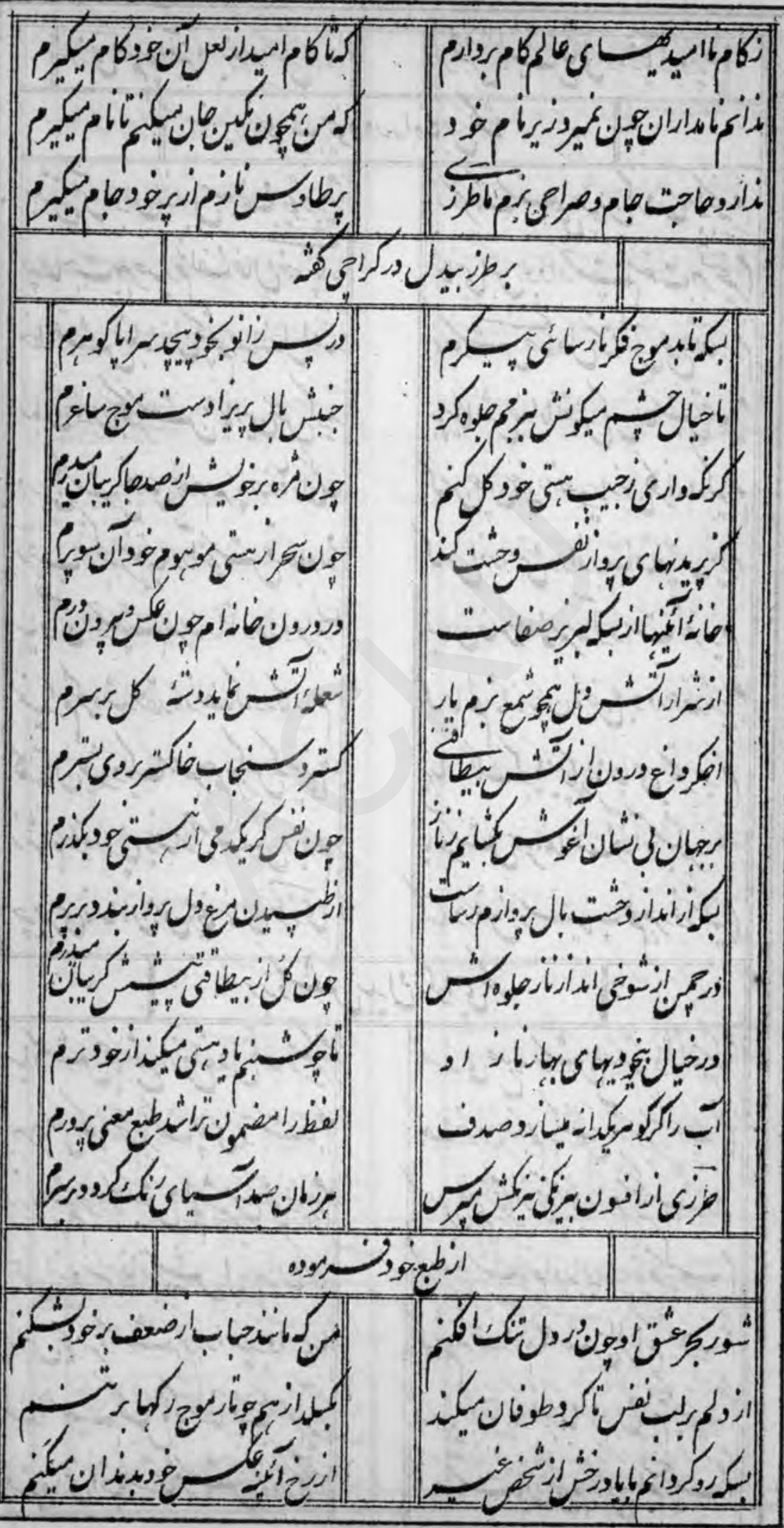


FA

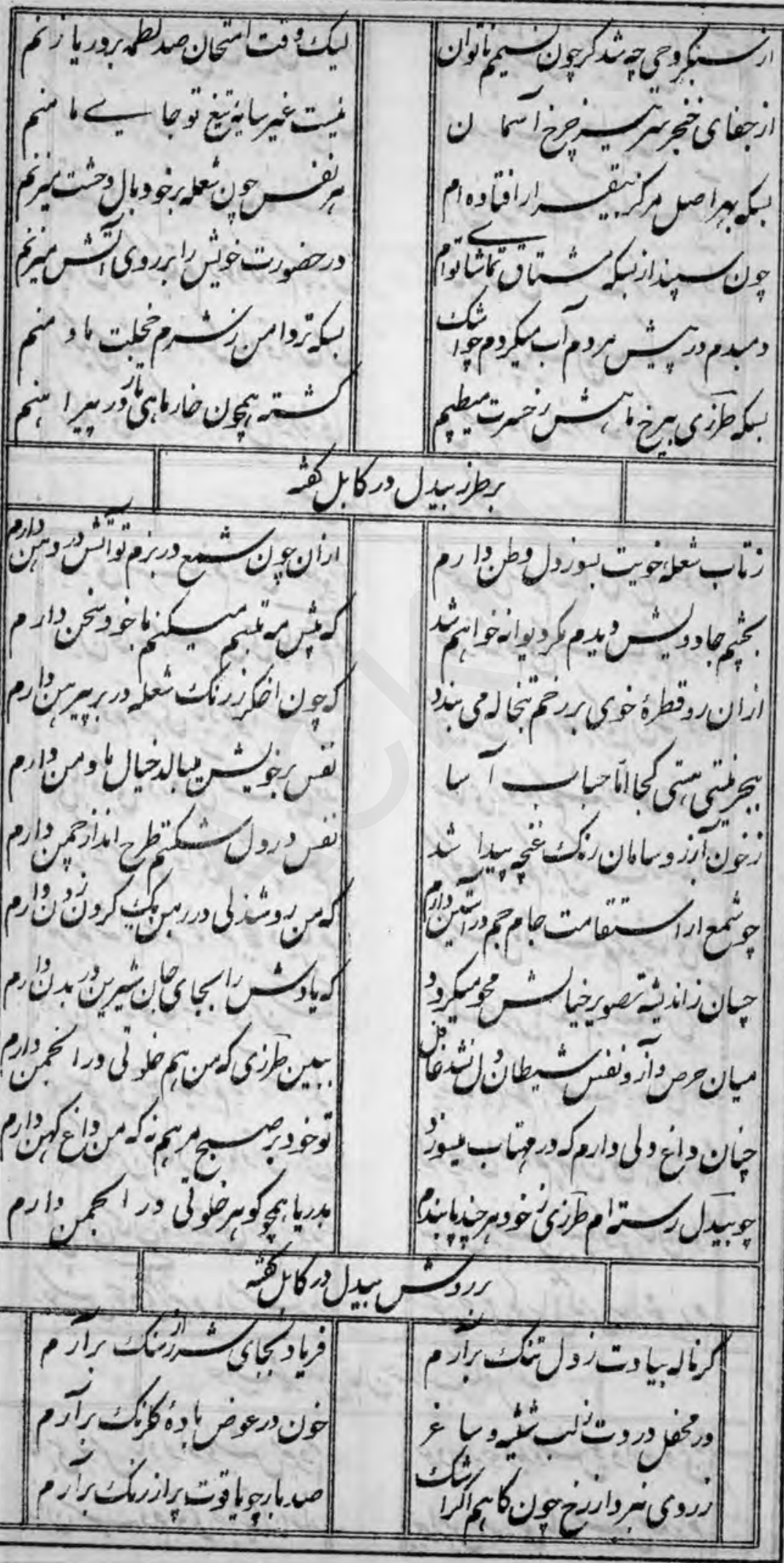


rAs

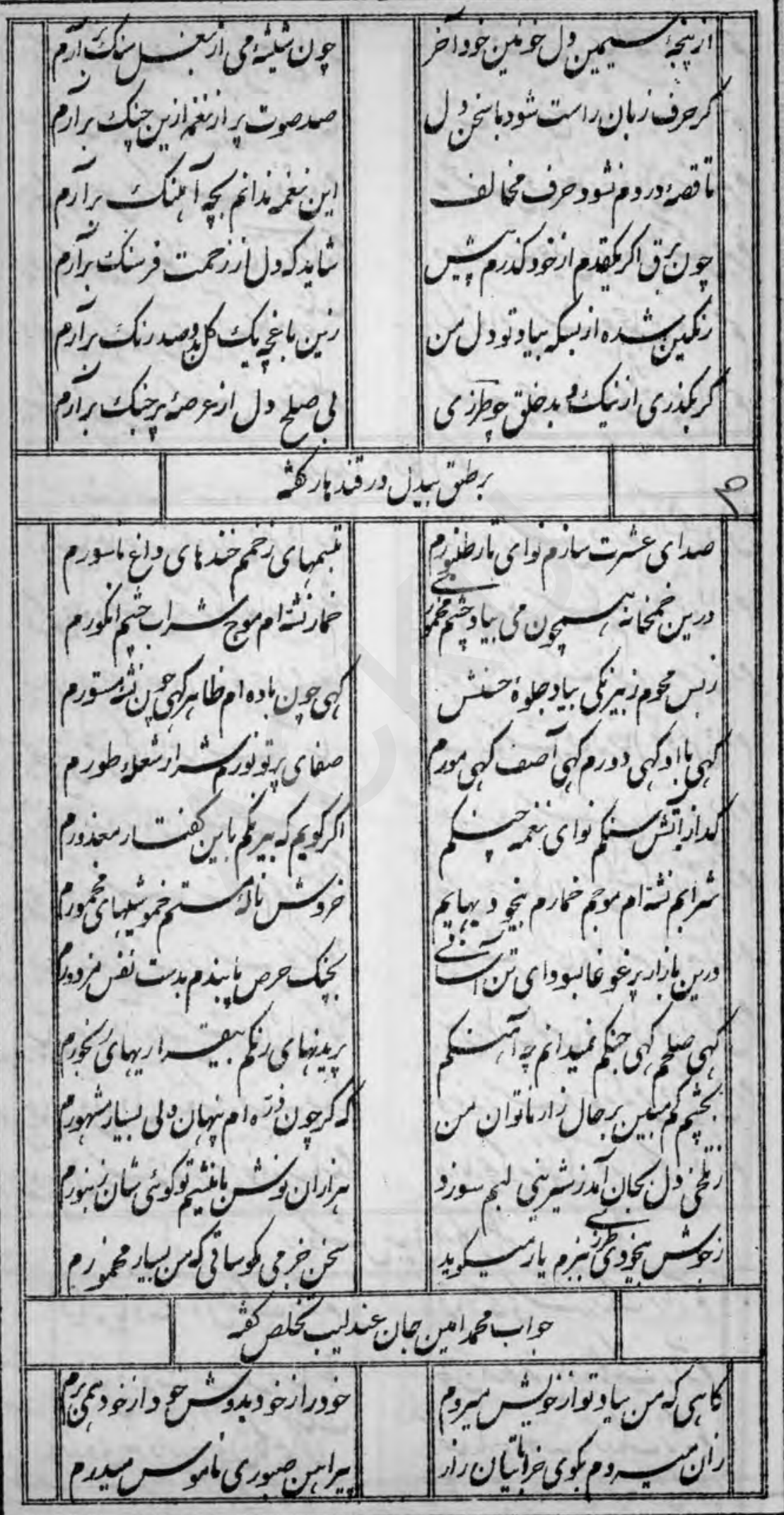


\&AL

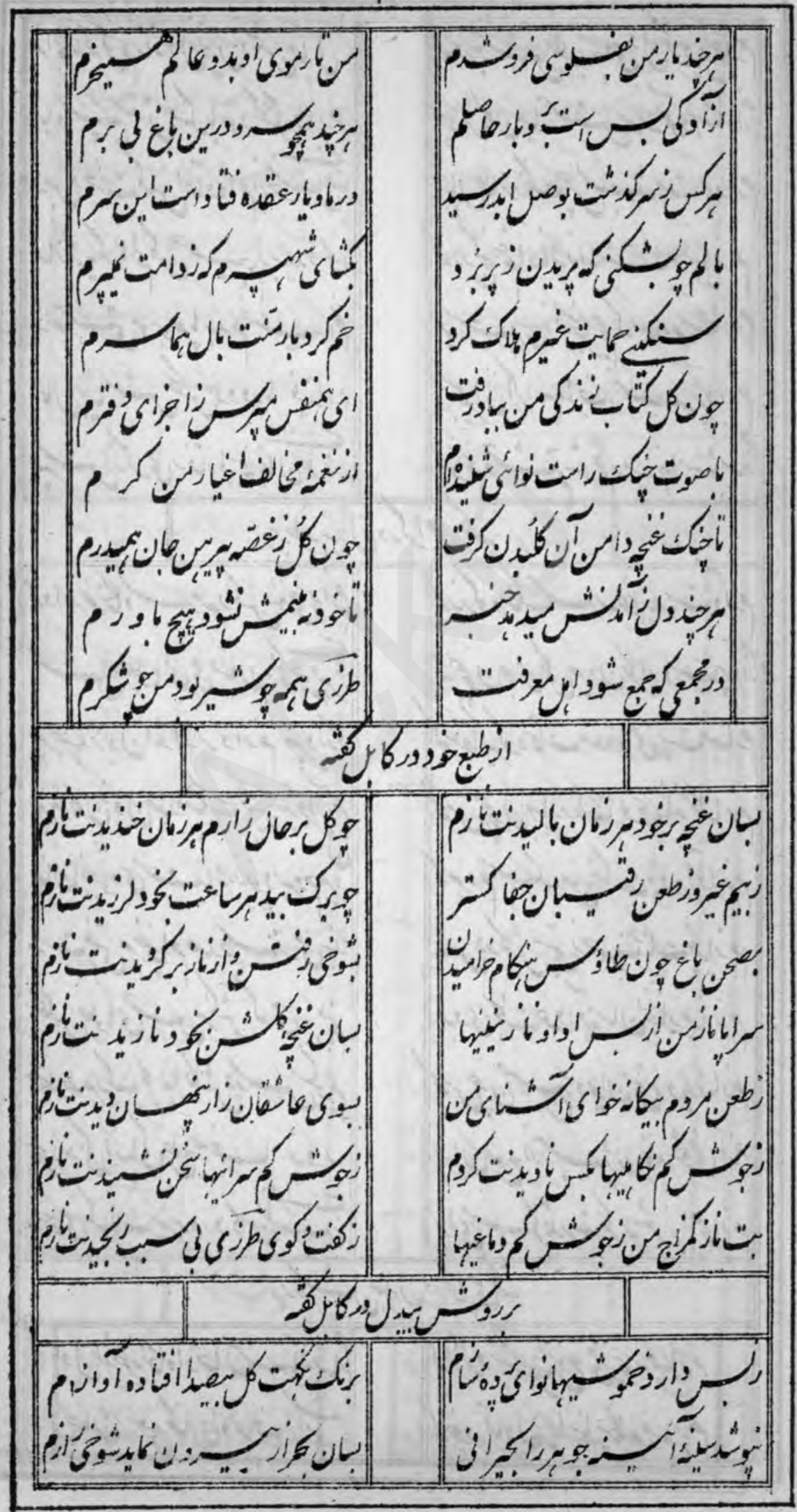


FAA

|


\& 4 9

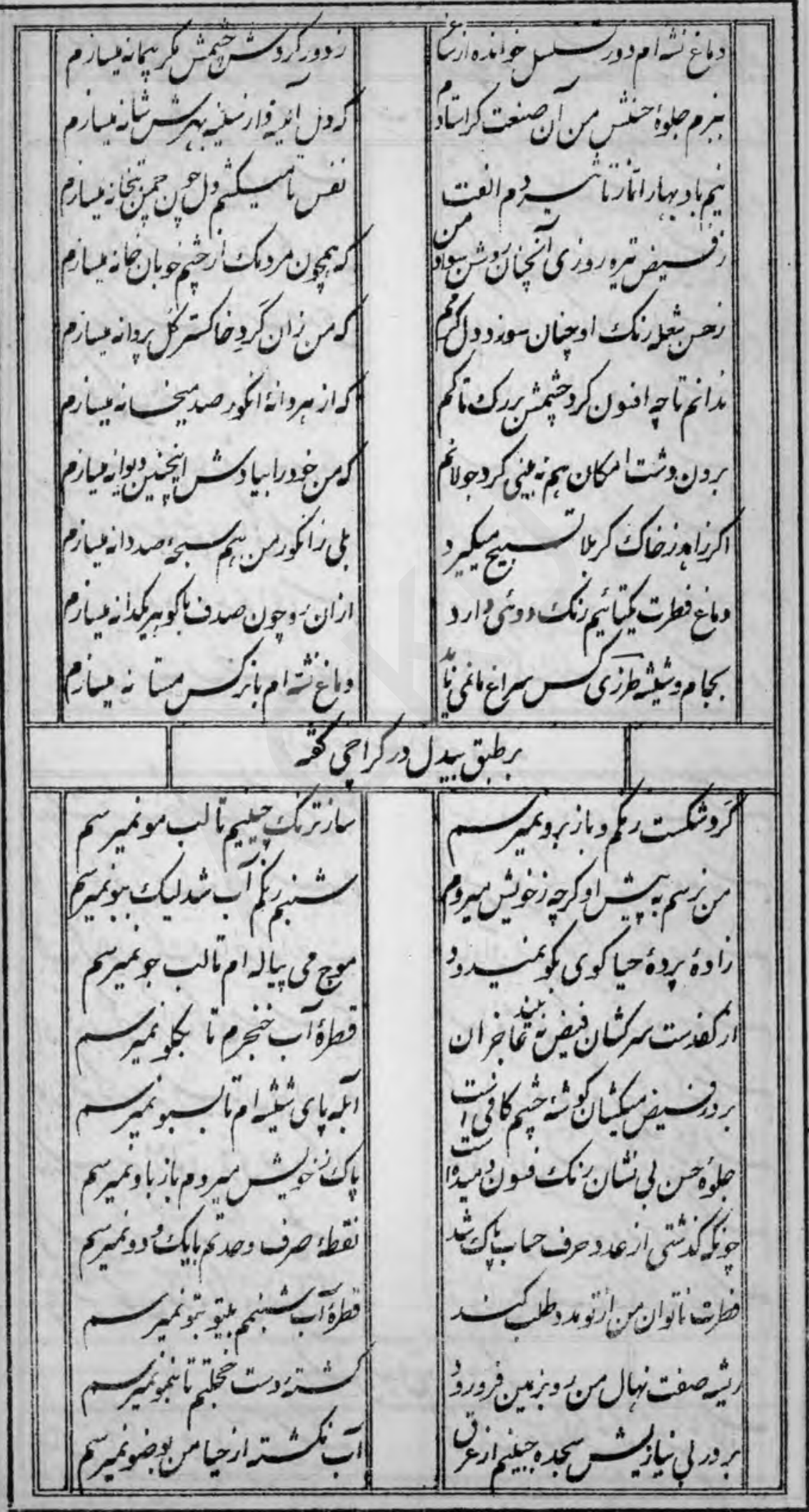


$r=4$.

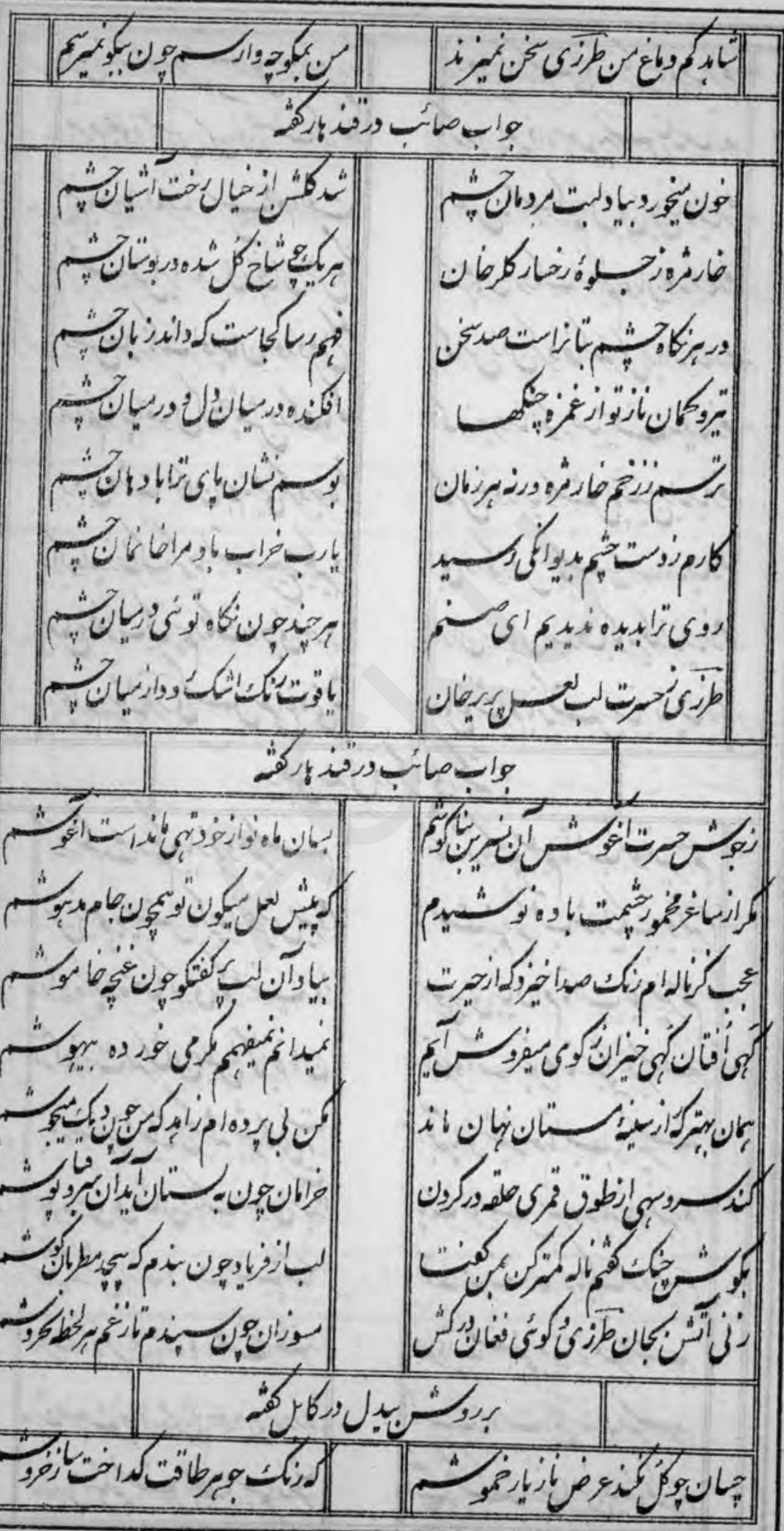




\section{F91}

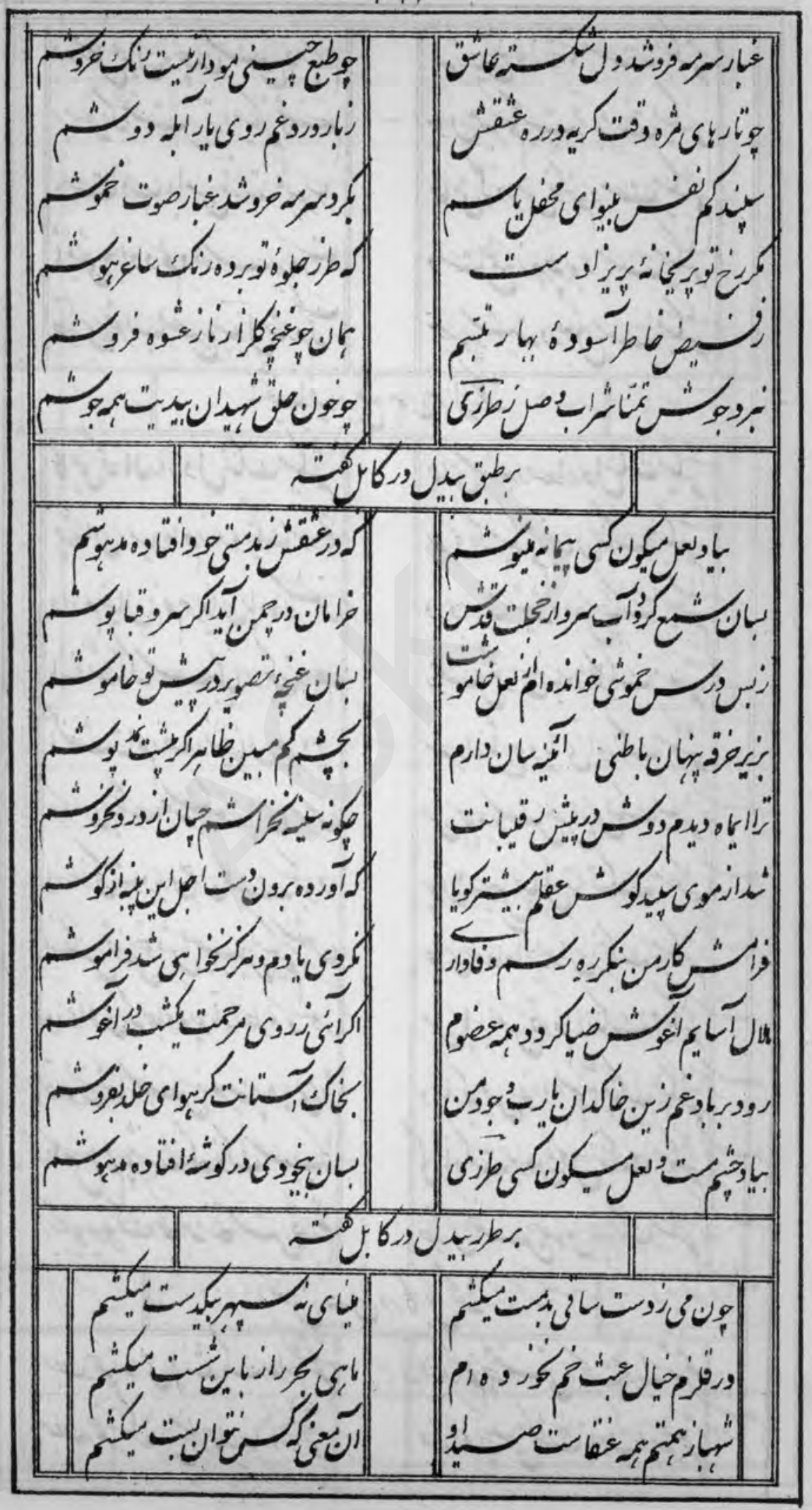


$r 4 r$

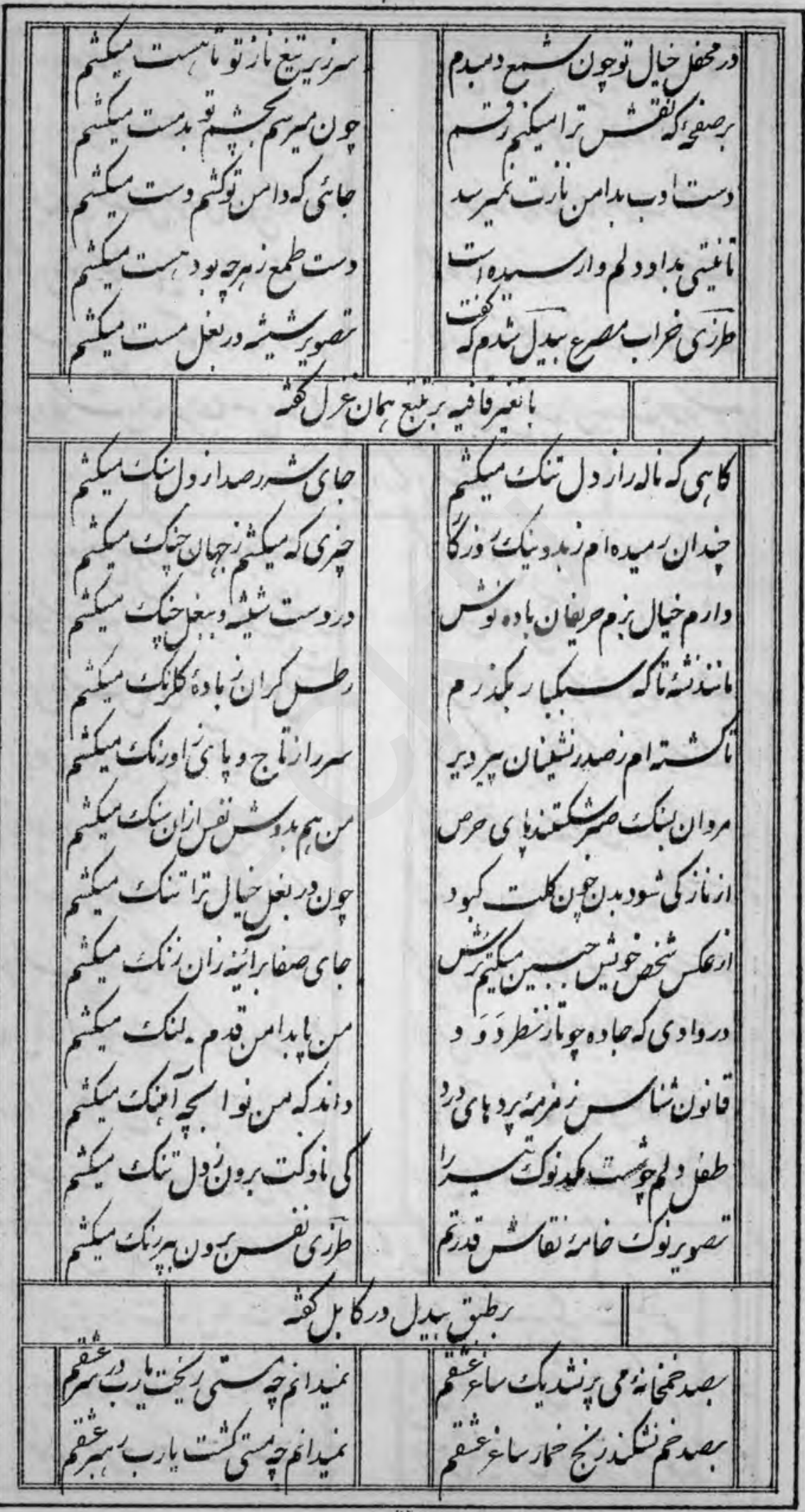


e $4 r$

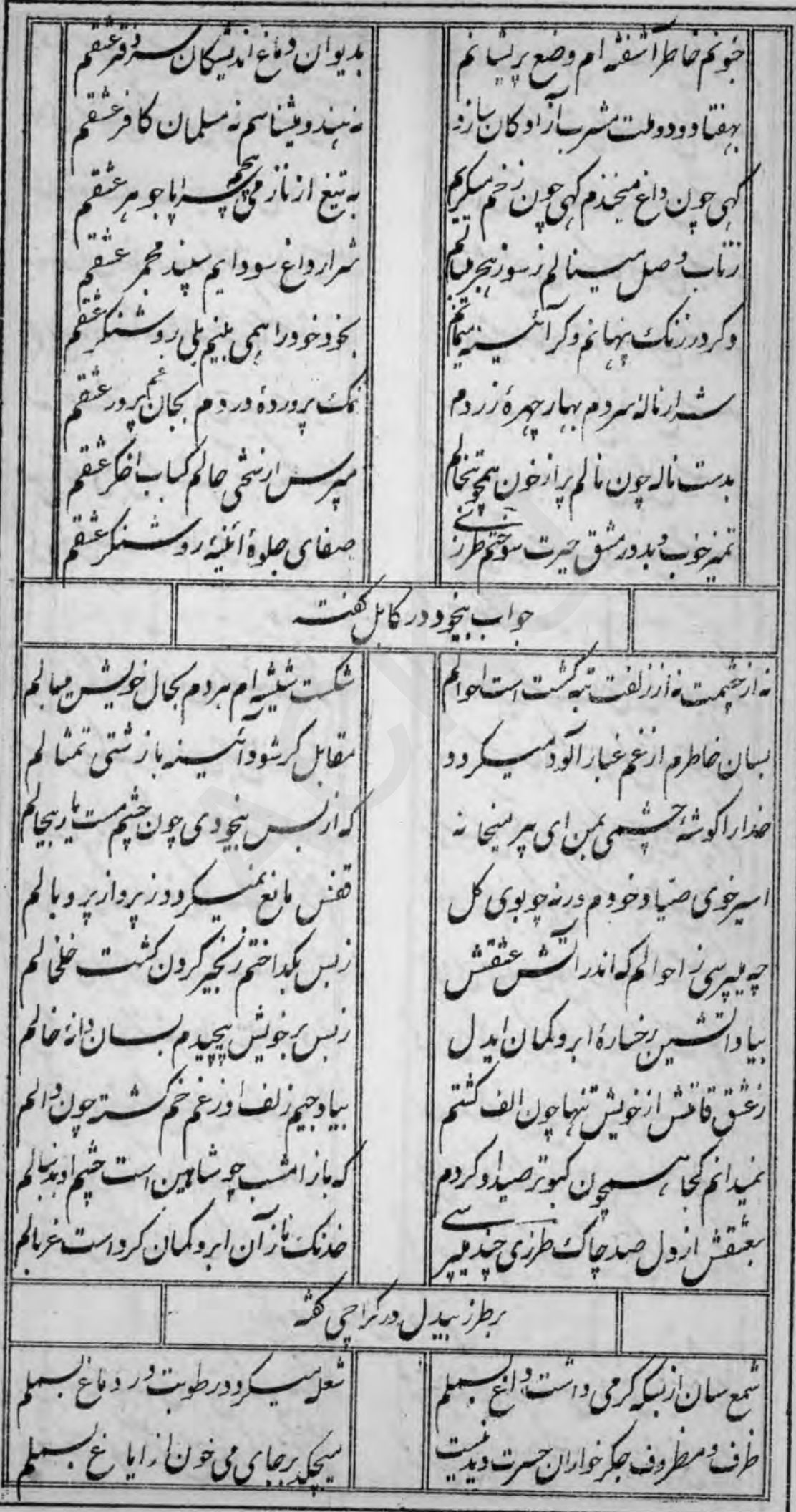


r $4 r^{2}$

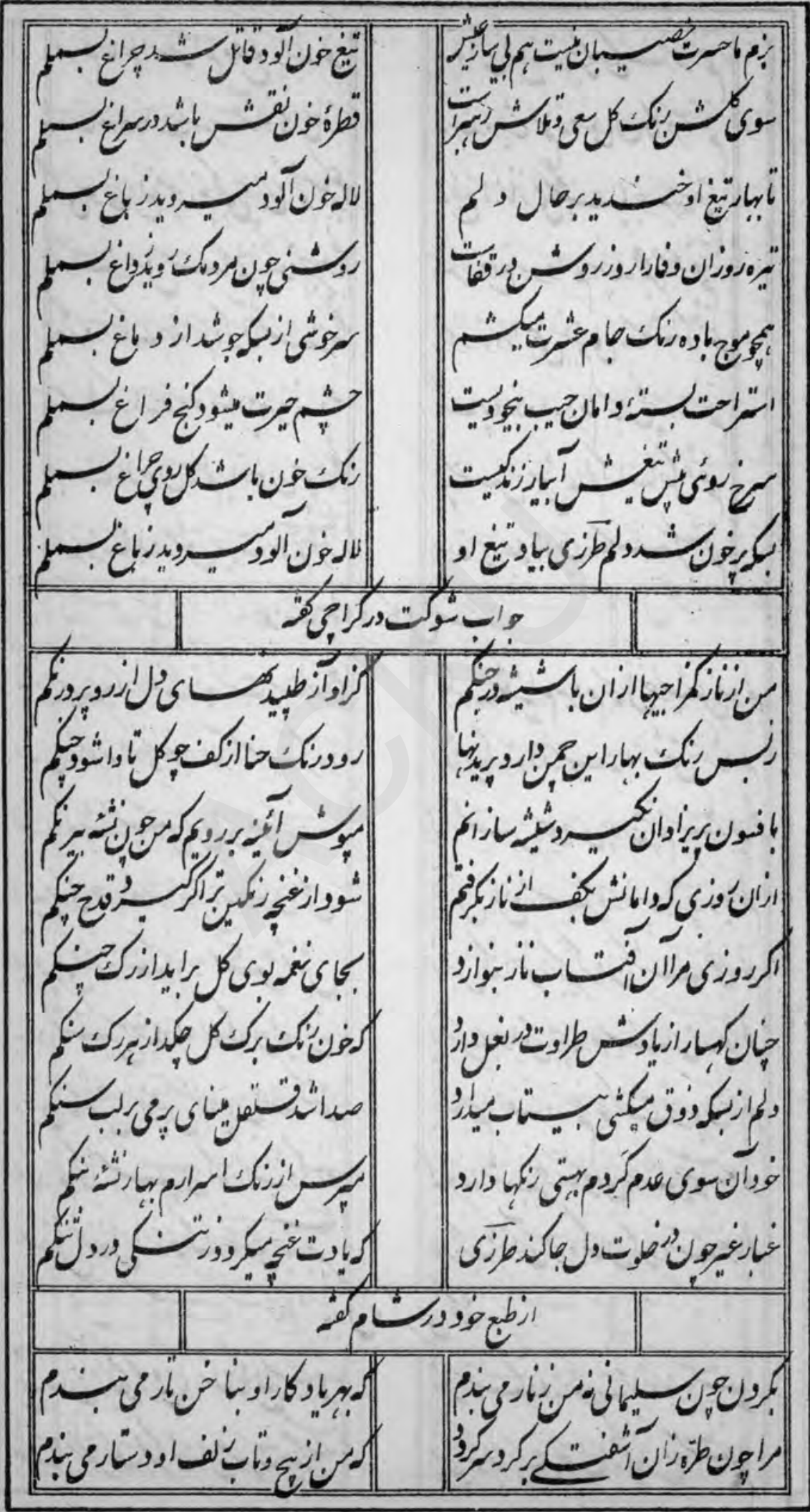

(5). 


\section{0}

|

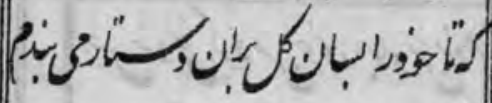

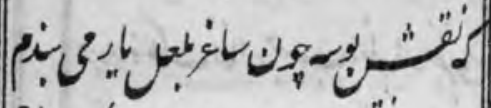

هـ

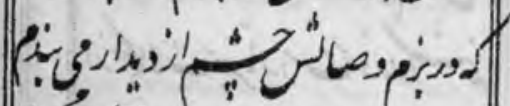

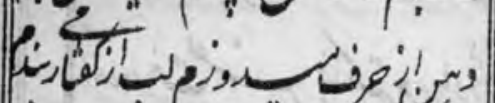

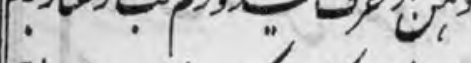

Pic

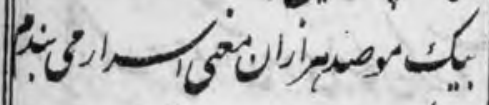

رن

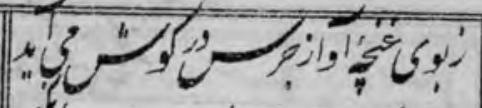

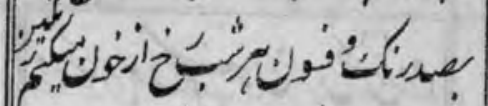

1

...

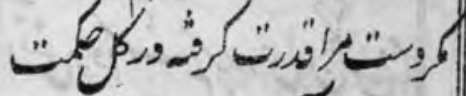

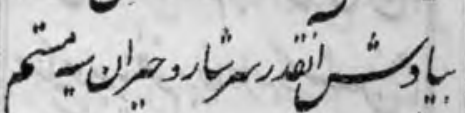

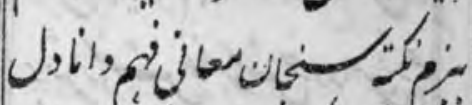

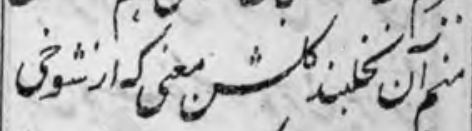
. o

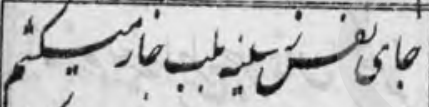
(15

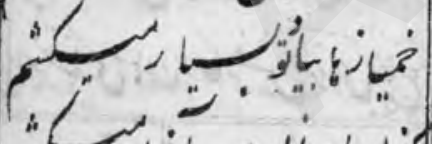

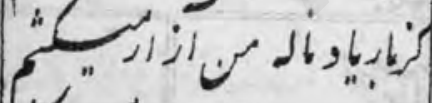

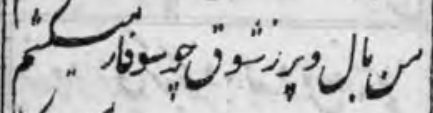
. $\left.\right|_{*}$ "L " " بـ (1)

أر

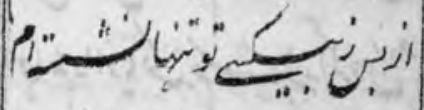

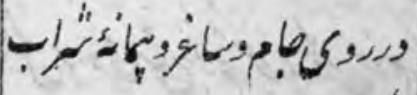

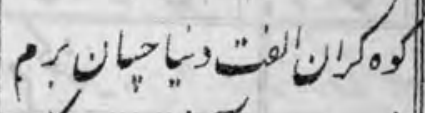

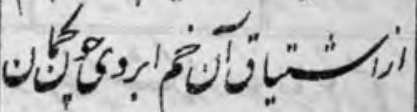

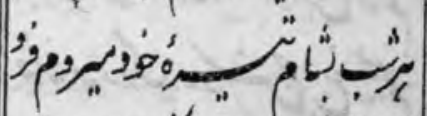

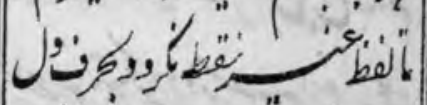
. 6

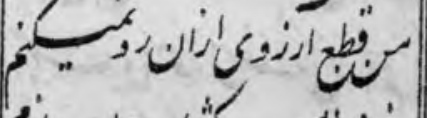

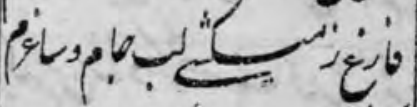

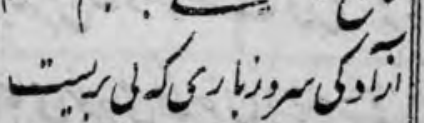
ק 


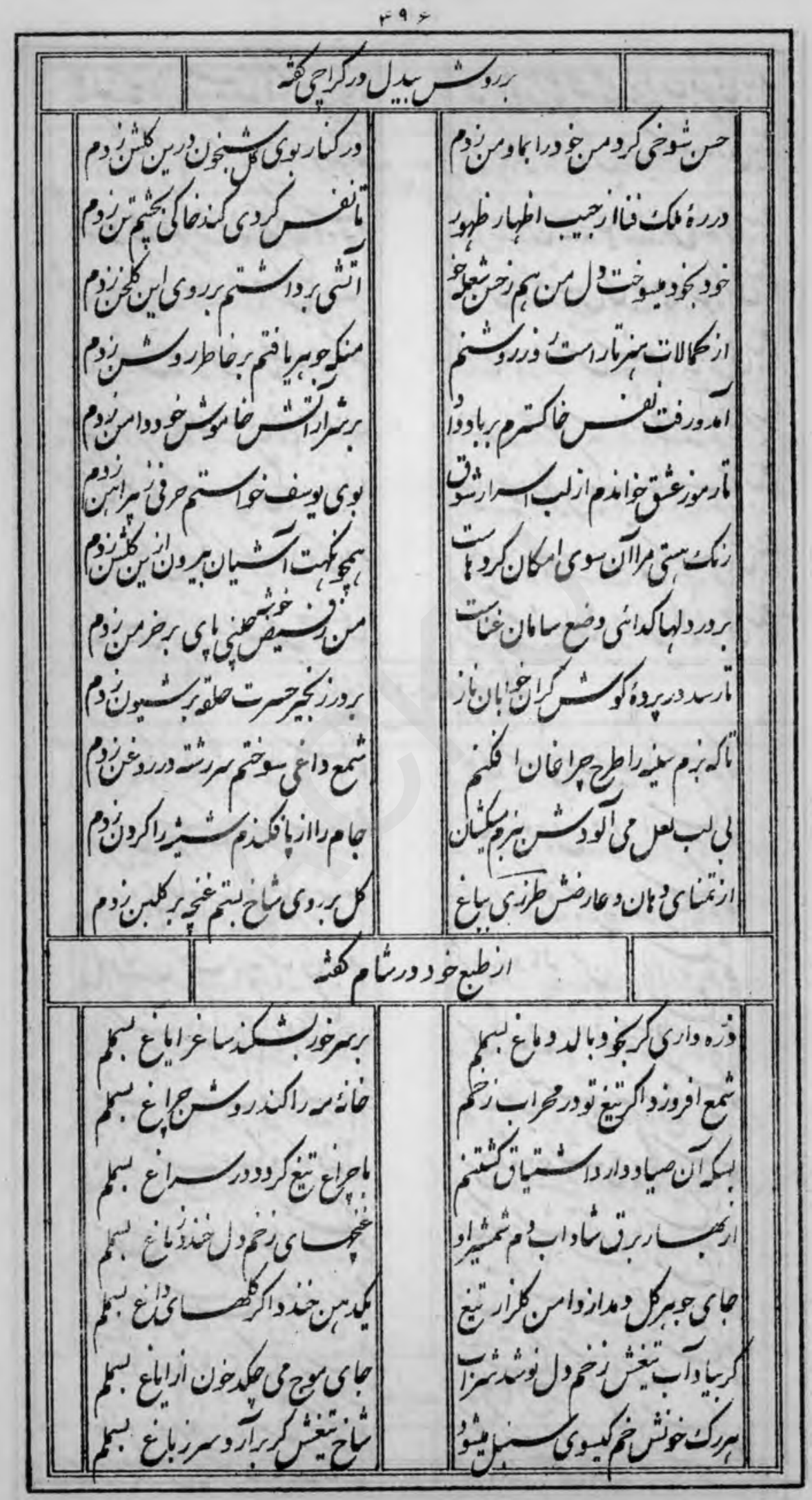


i 46

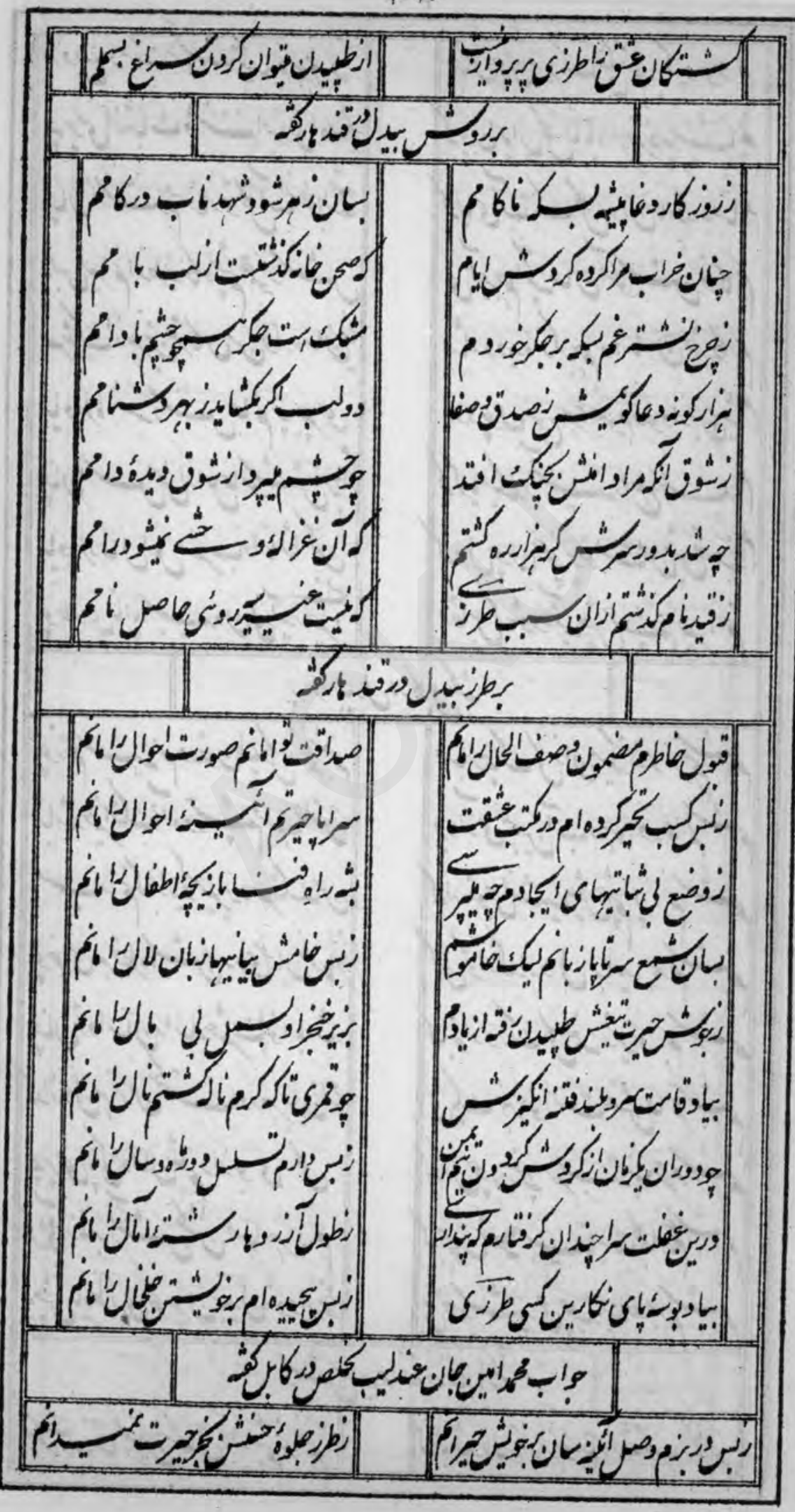


f $4 A$

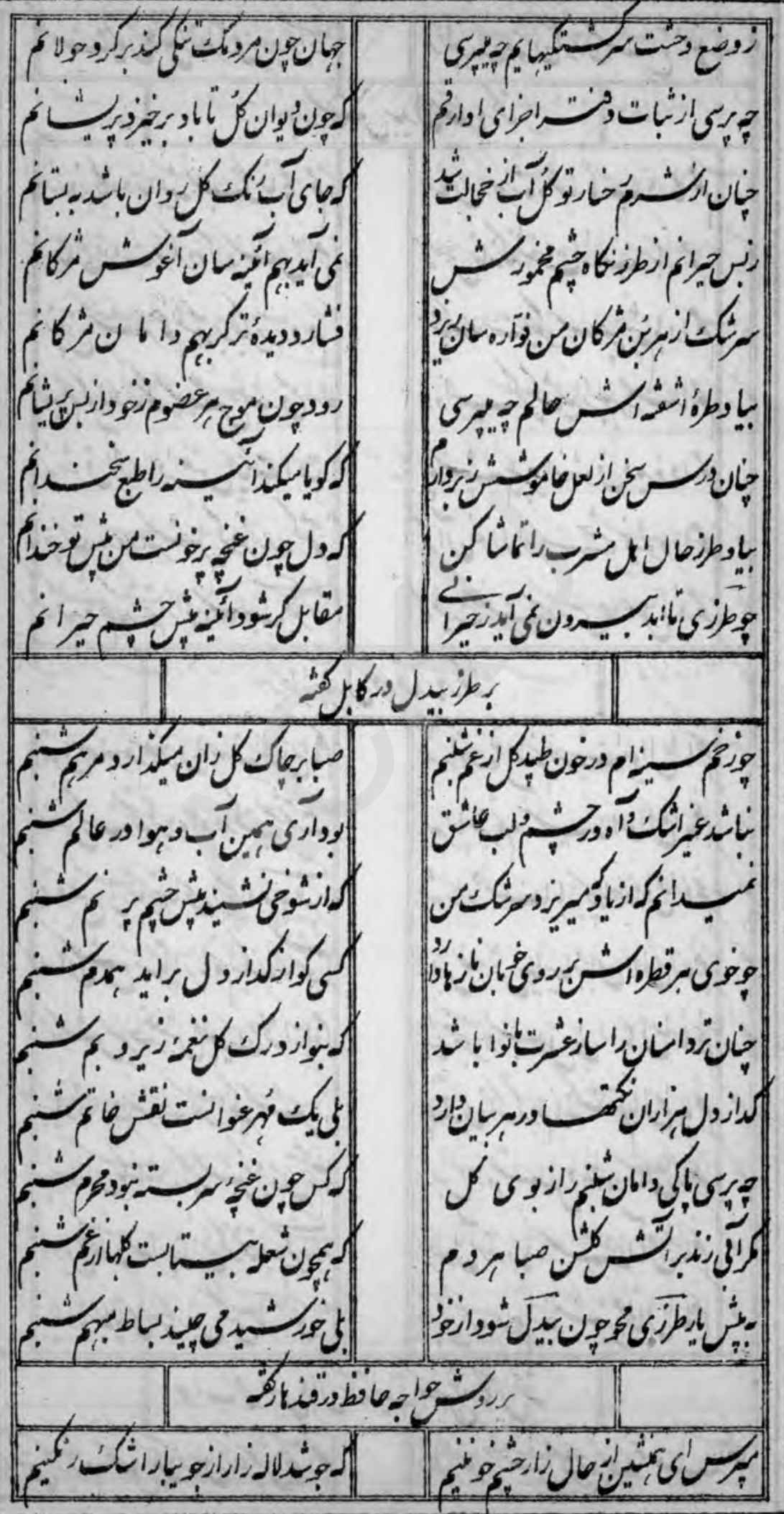


149

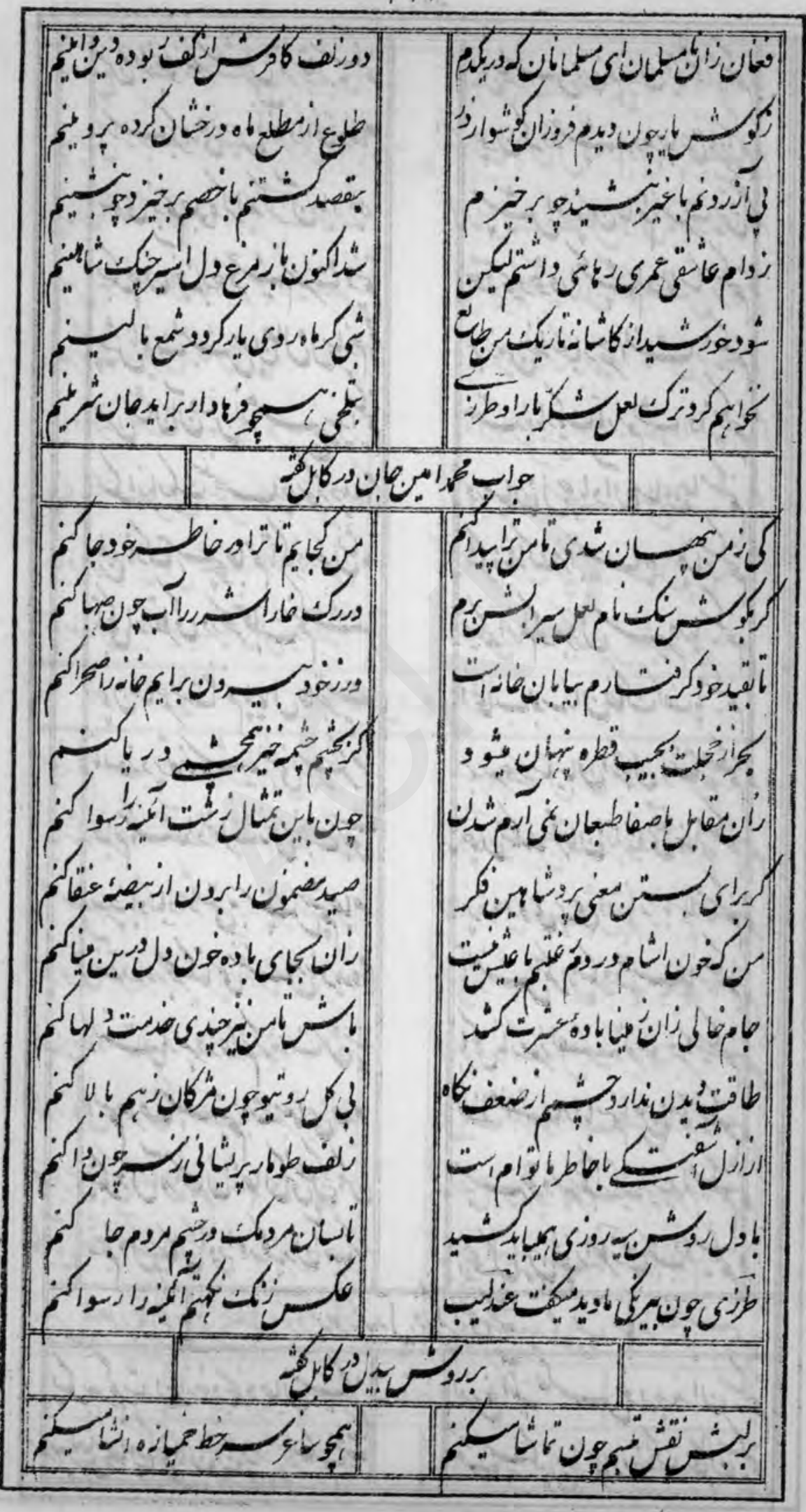


$\Delta$,

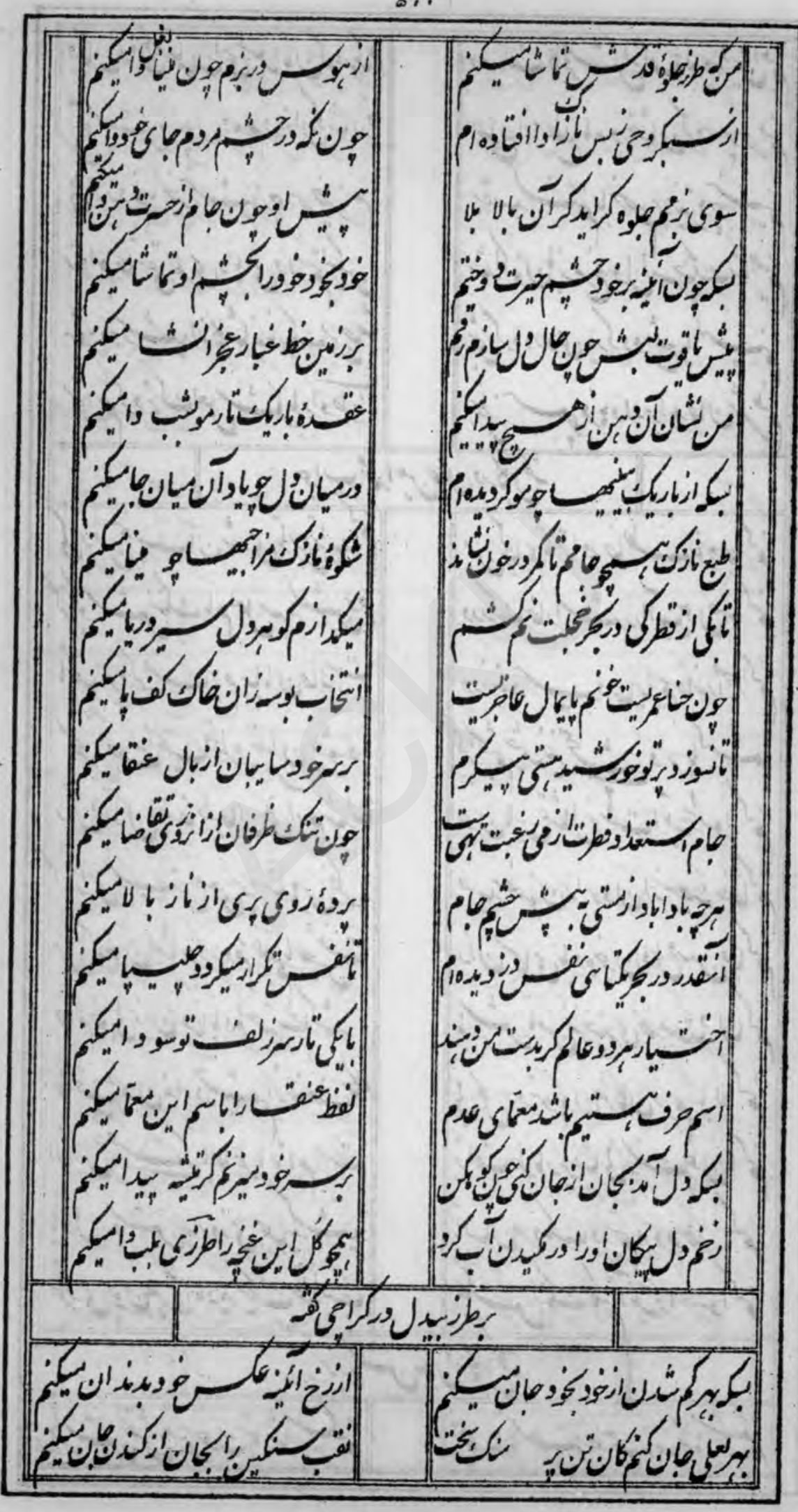


Q. 1

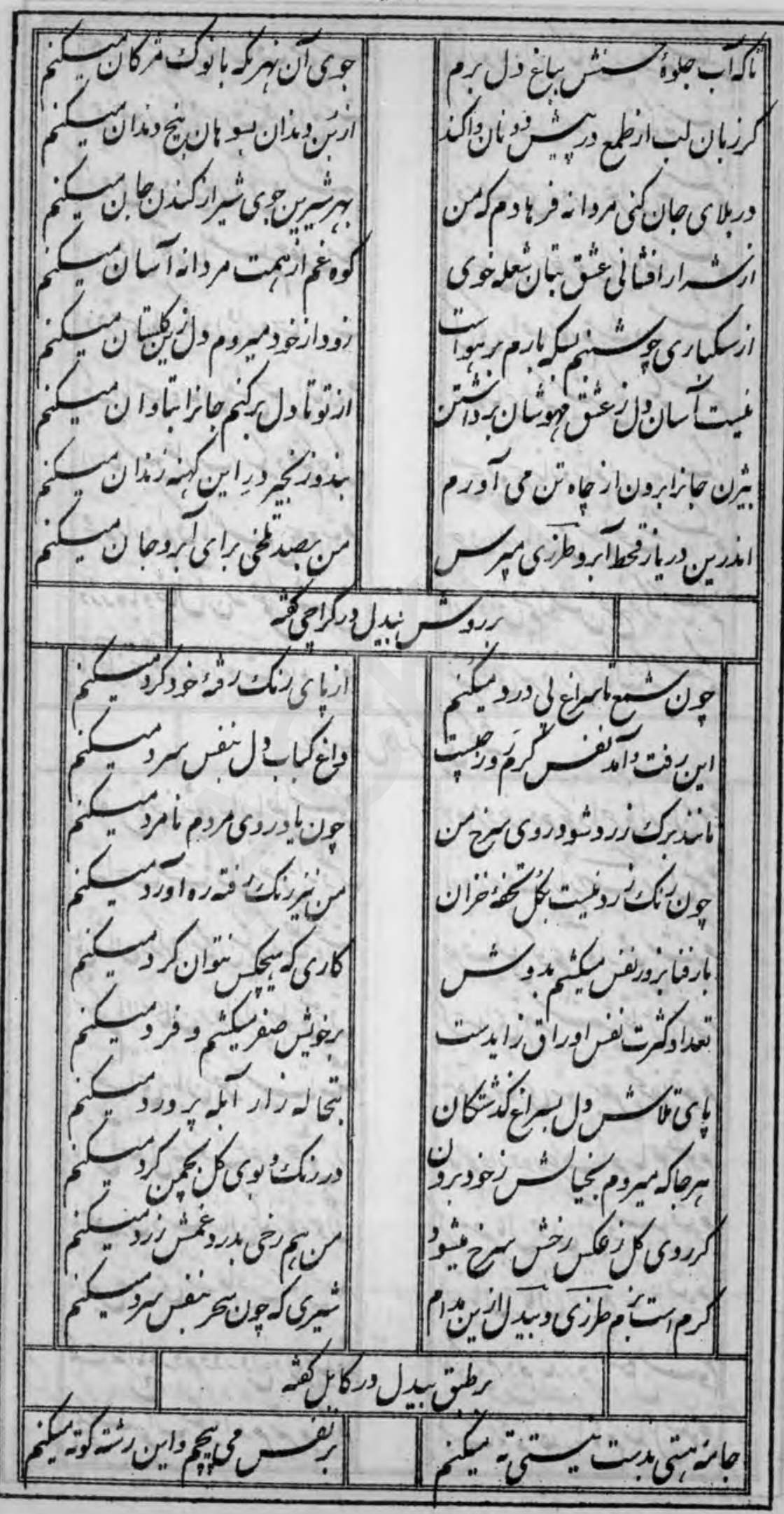


$0 . r$

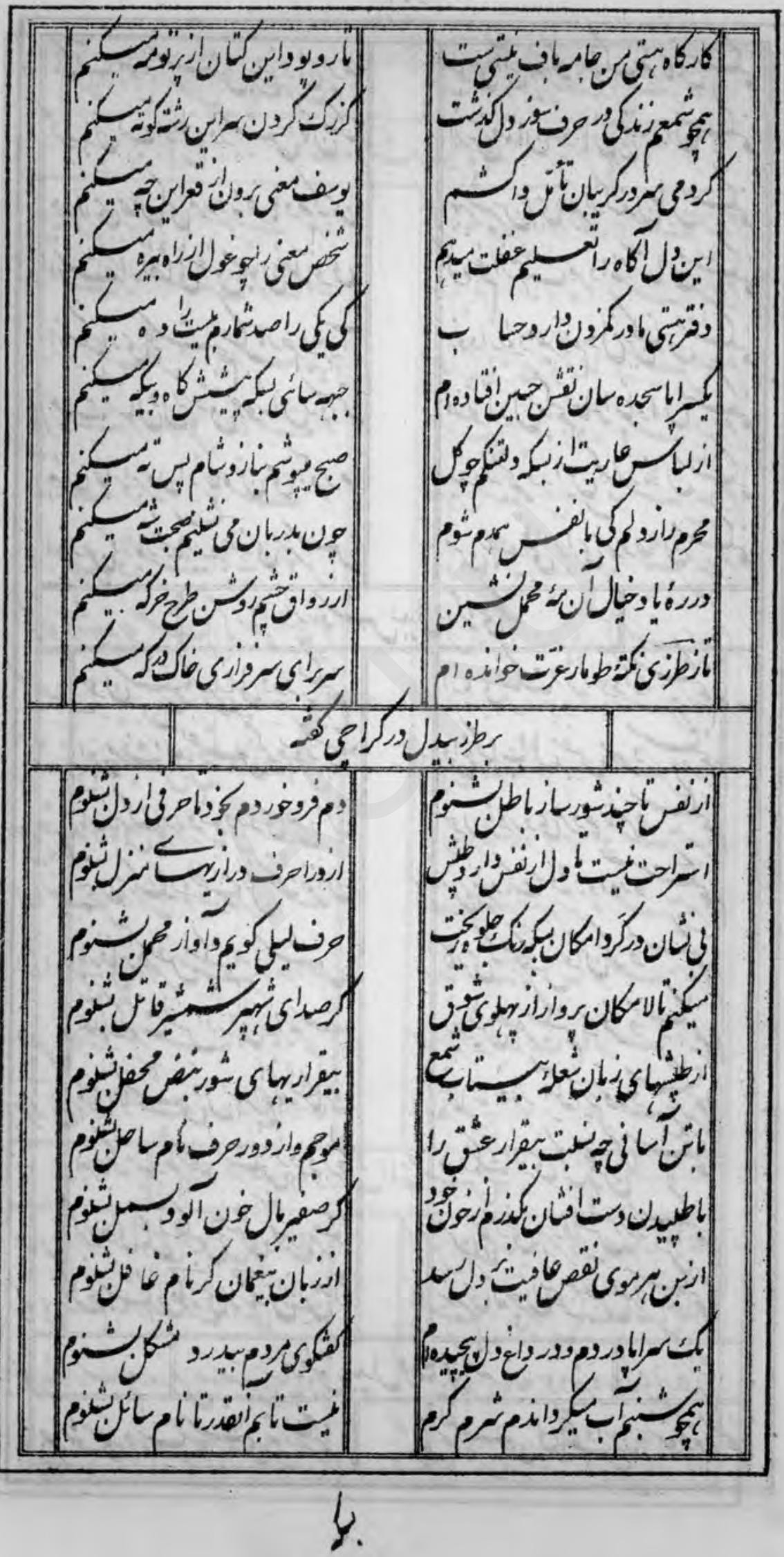


Q.

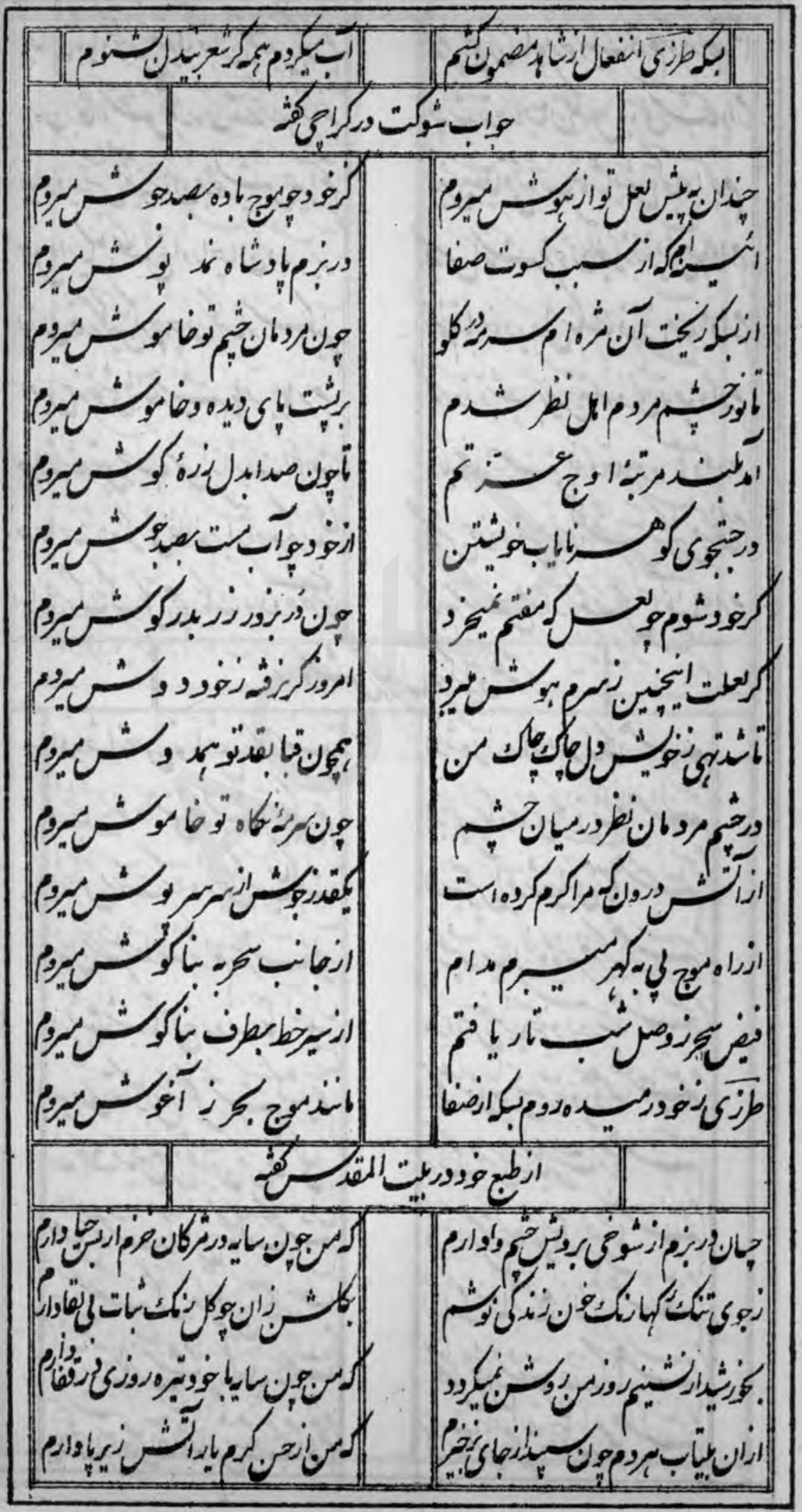


$Q \cdot r^{2}$

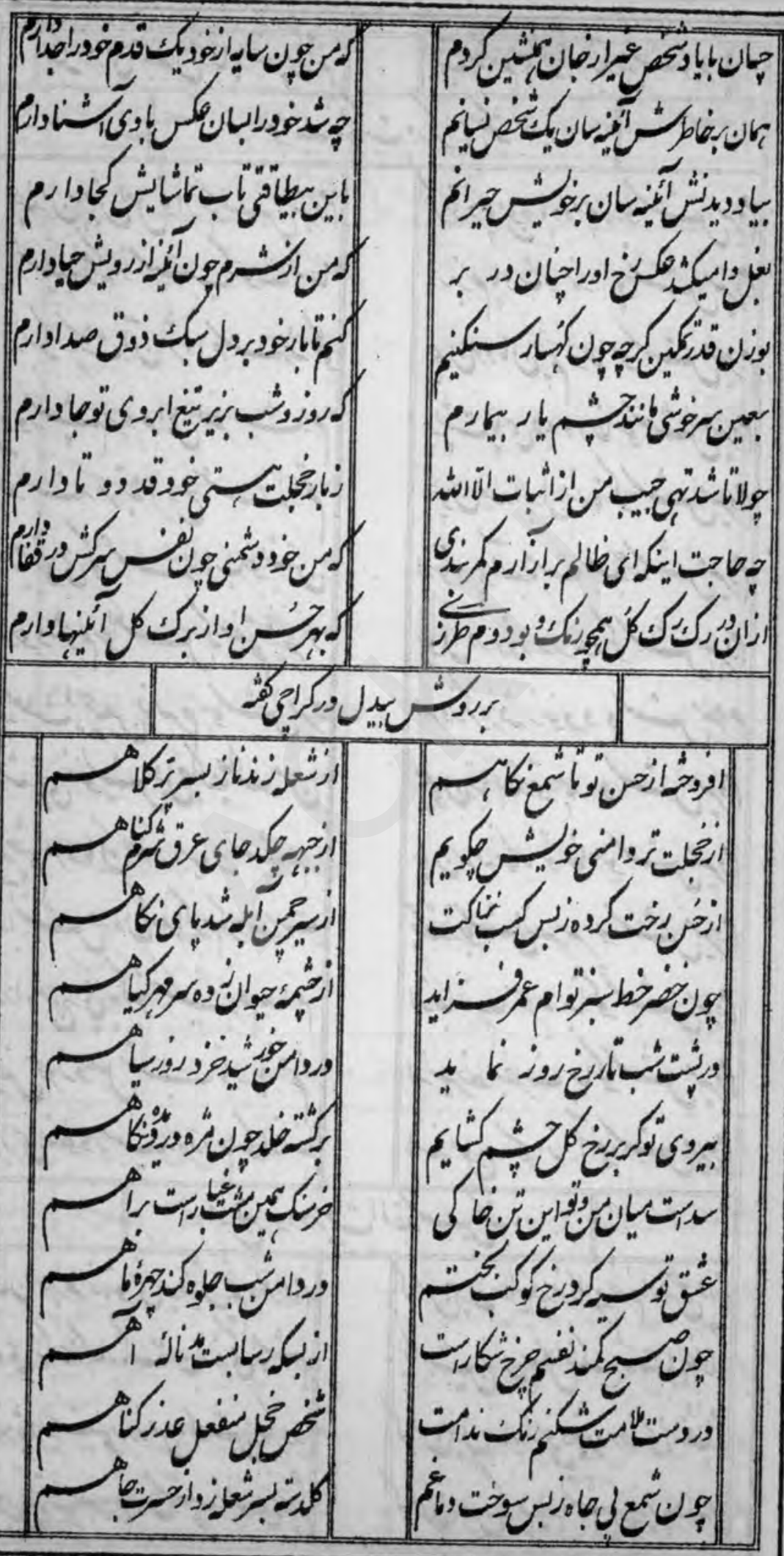


$\Delta \cdot \Delta$

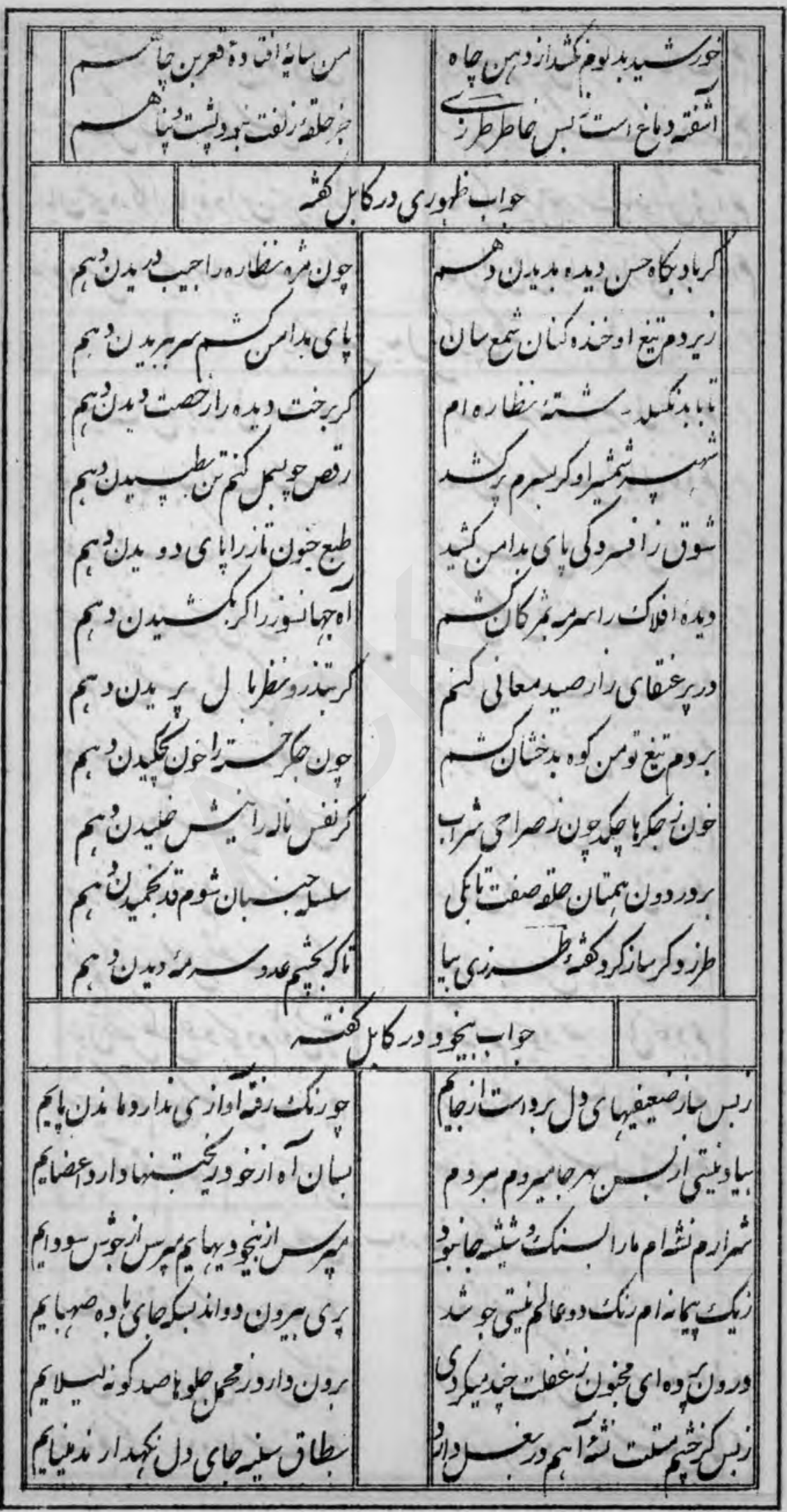




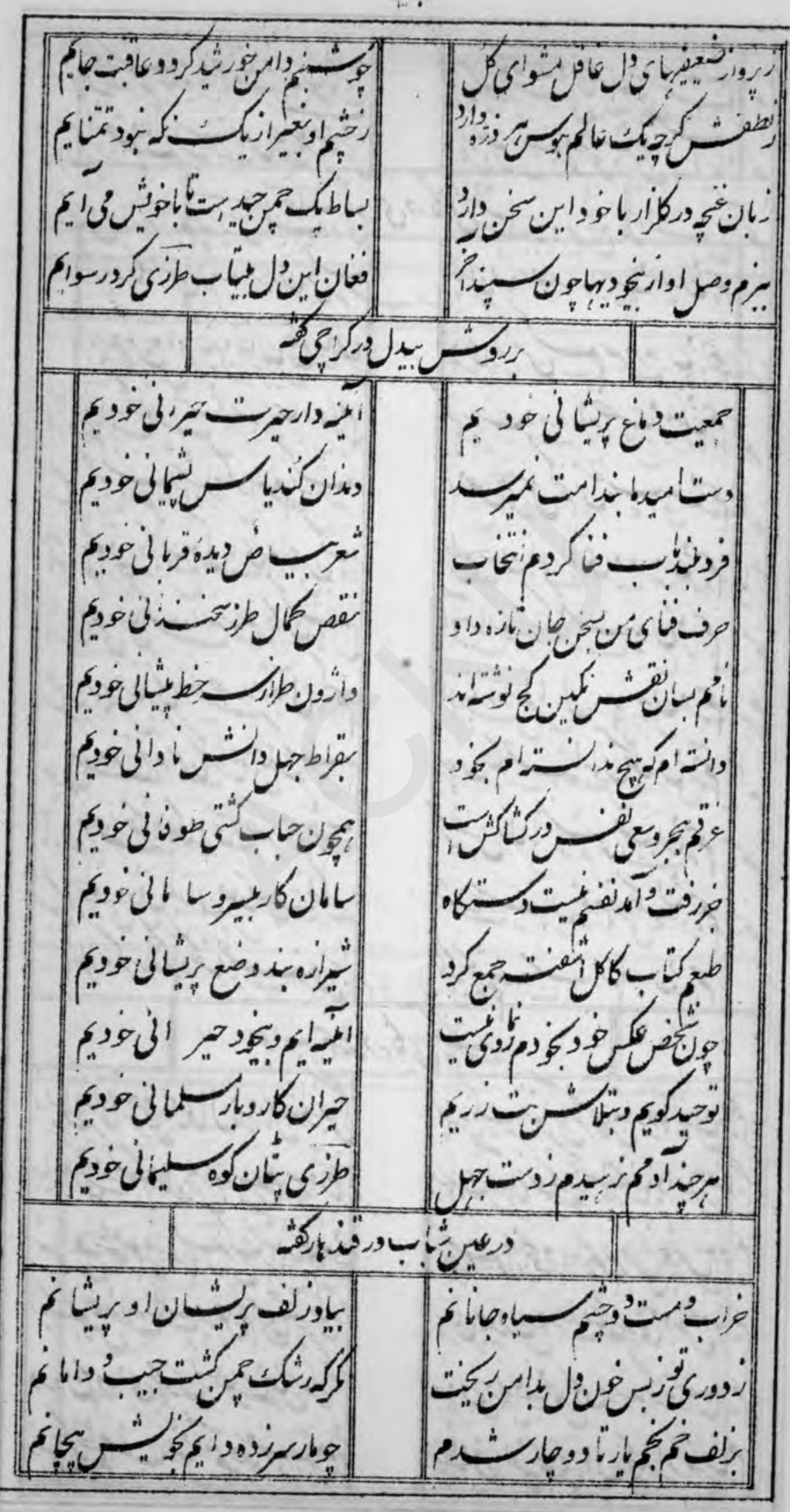




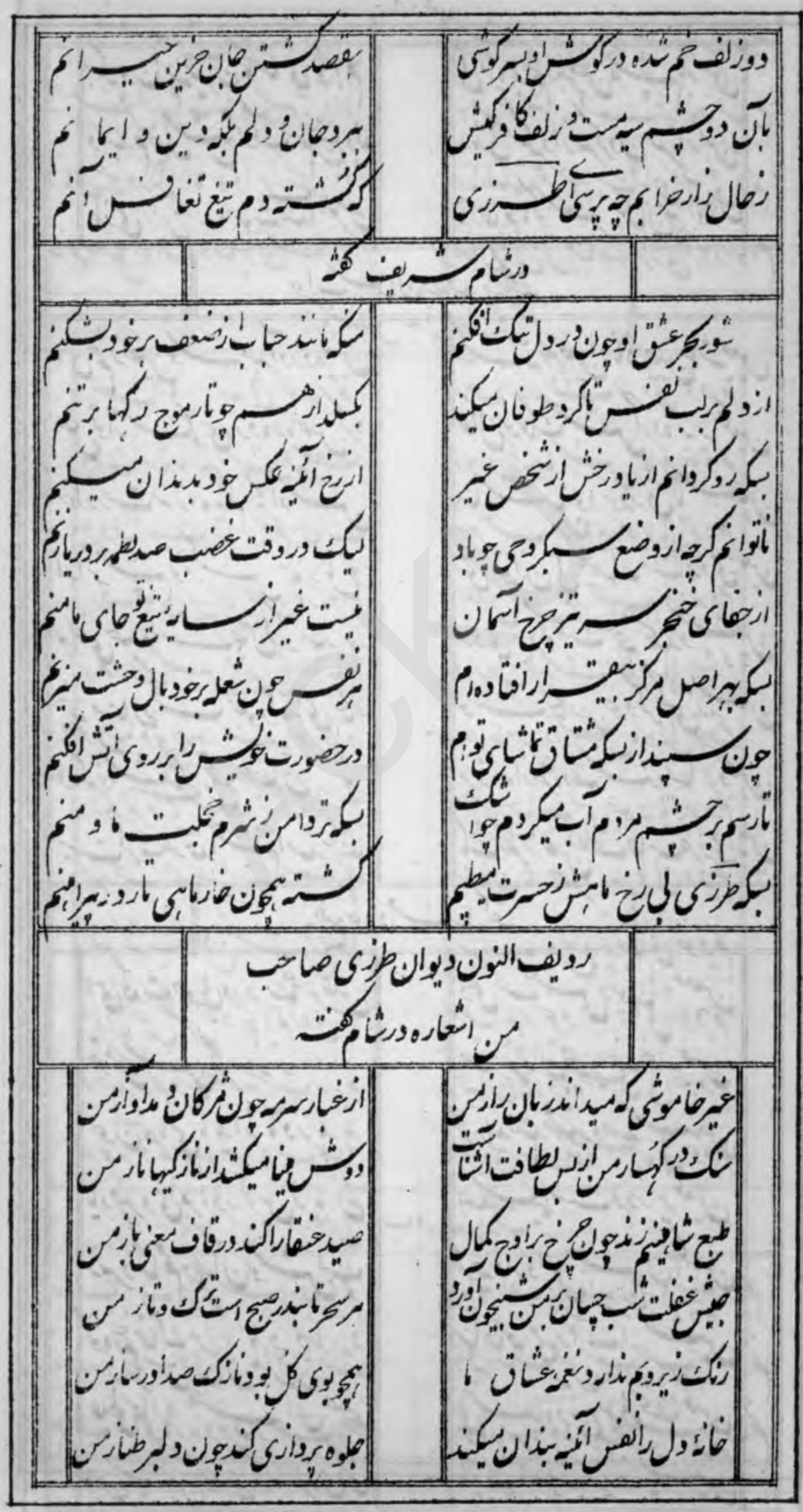


$\Delta \cdot A$

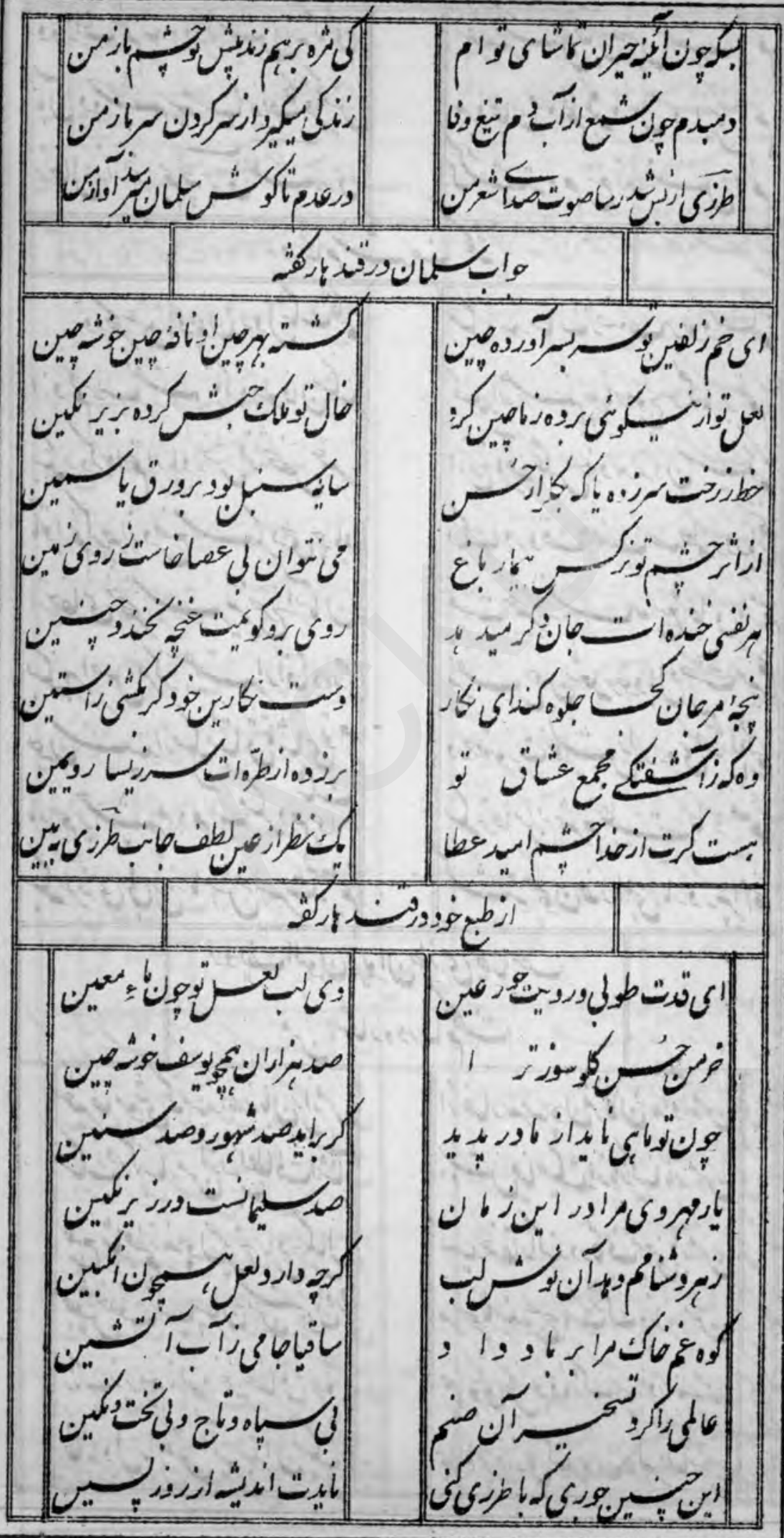


0.9

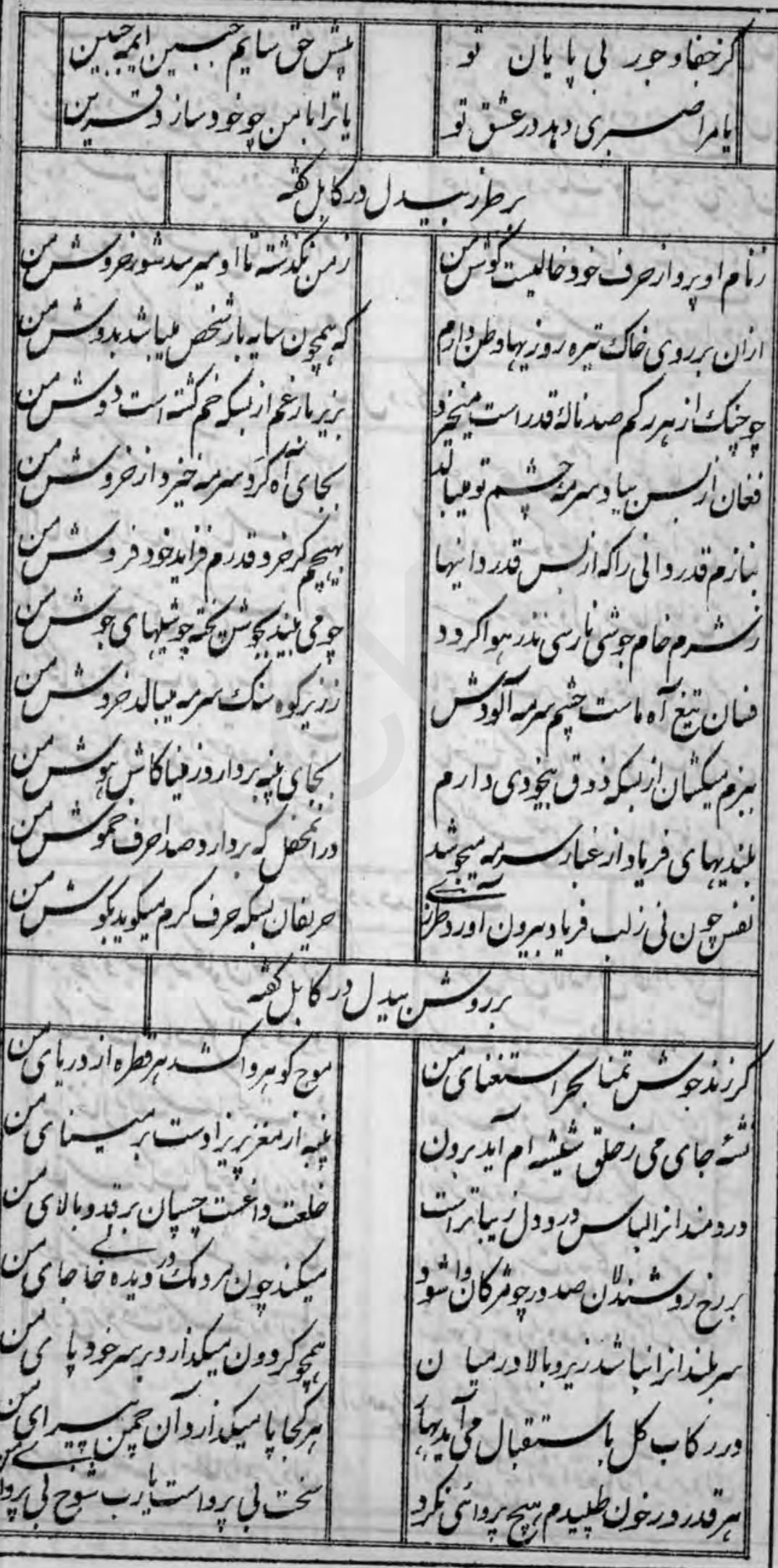


01.

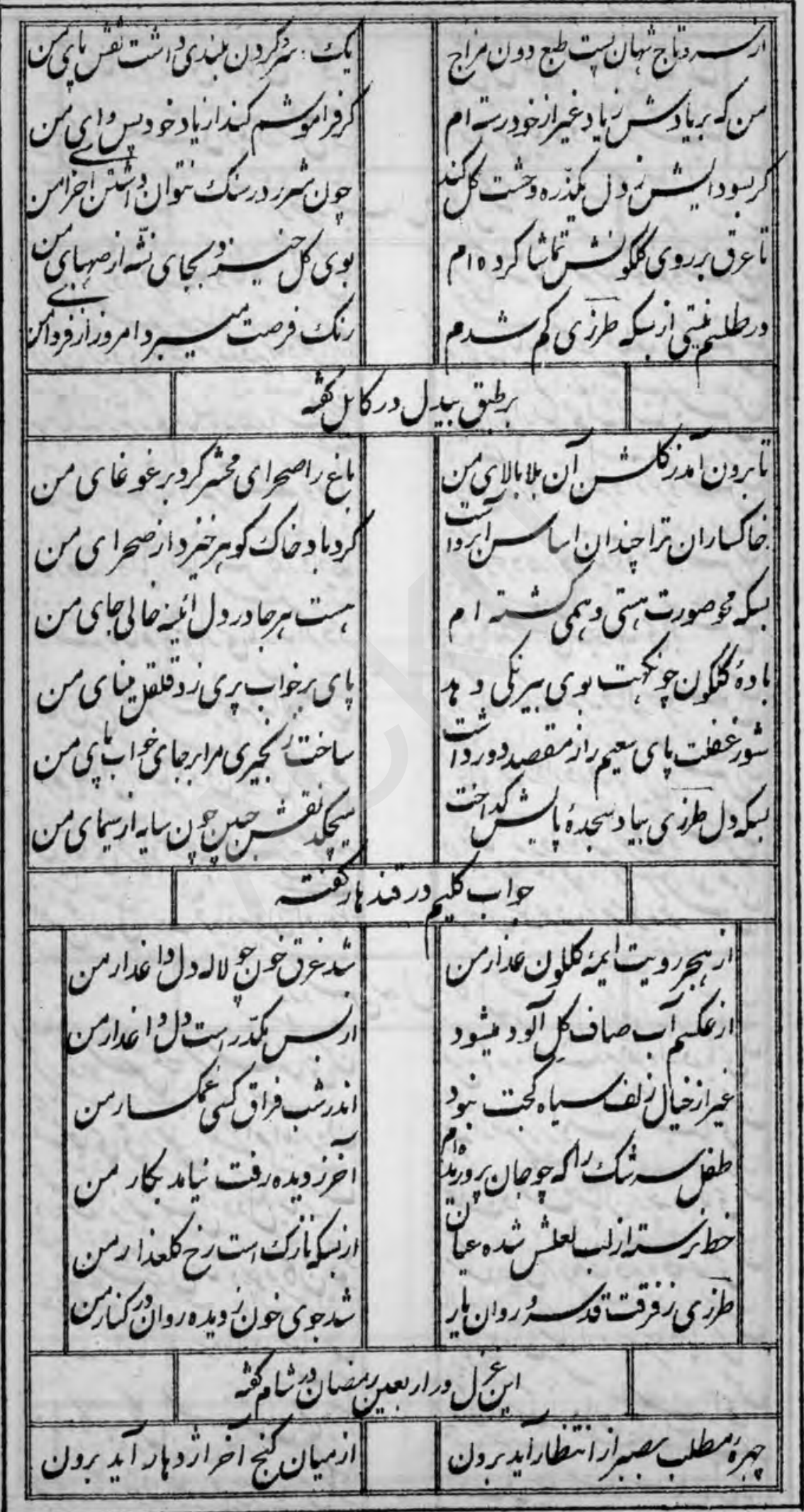


D, I

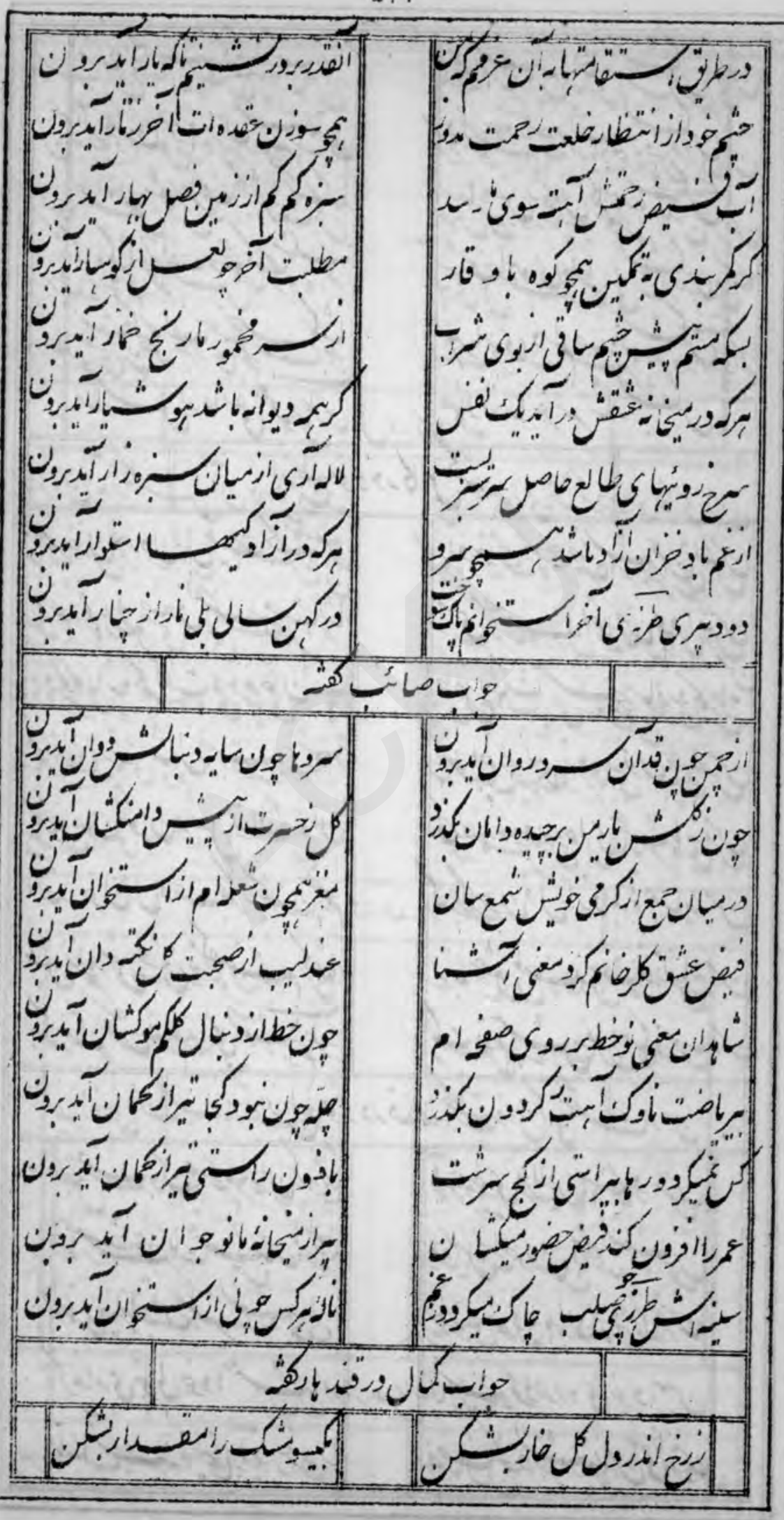


$\Delta$ ir

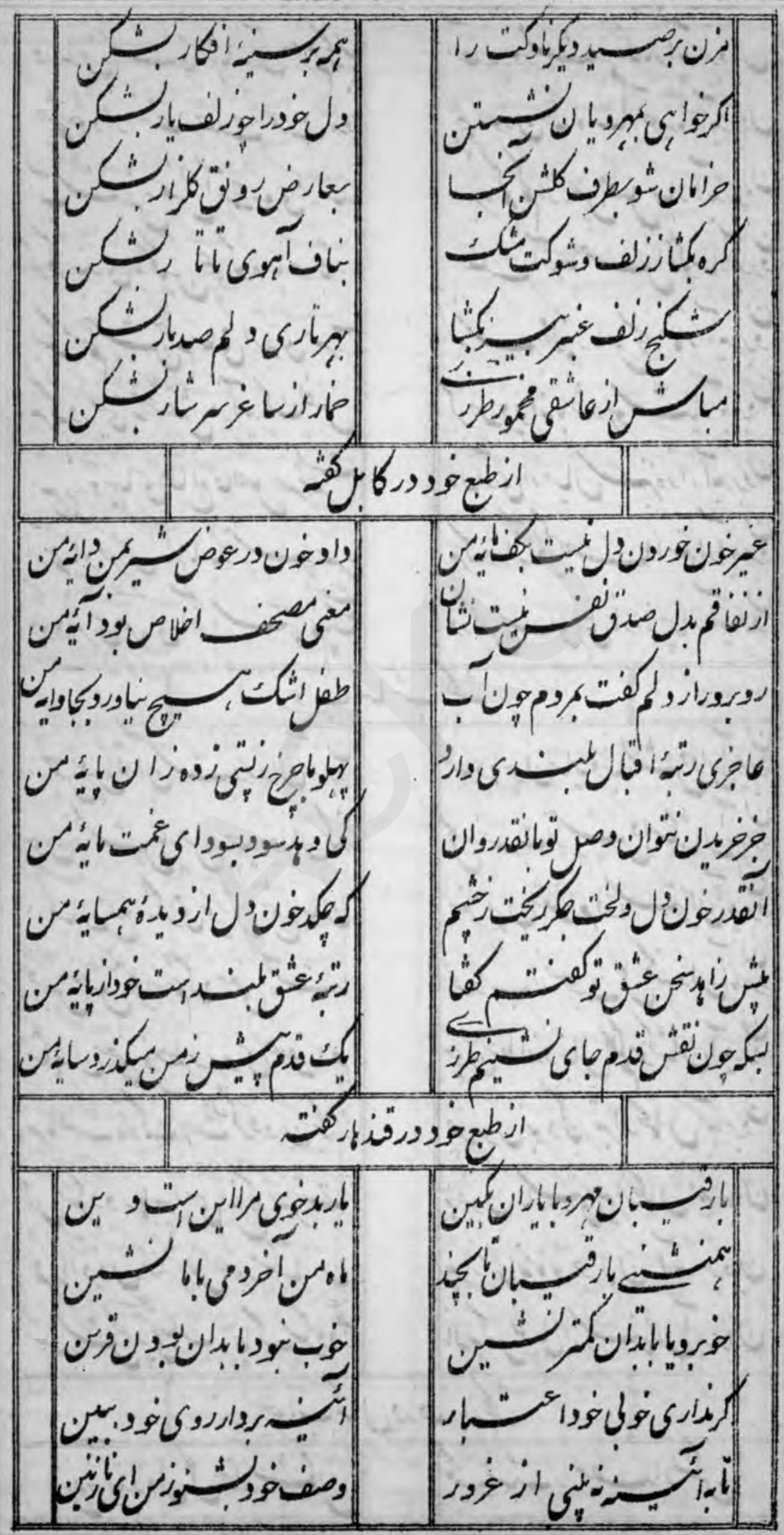


a ir

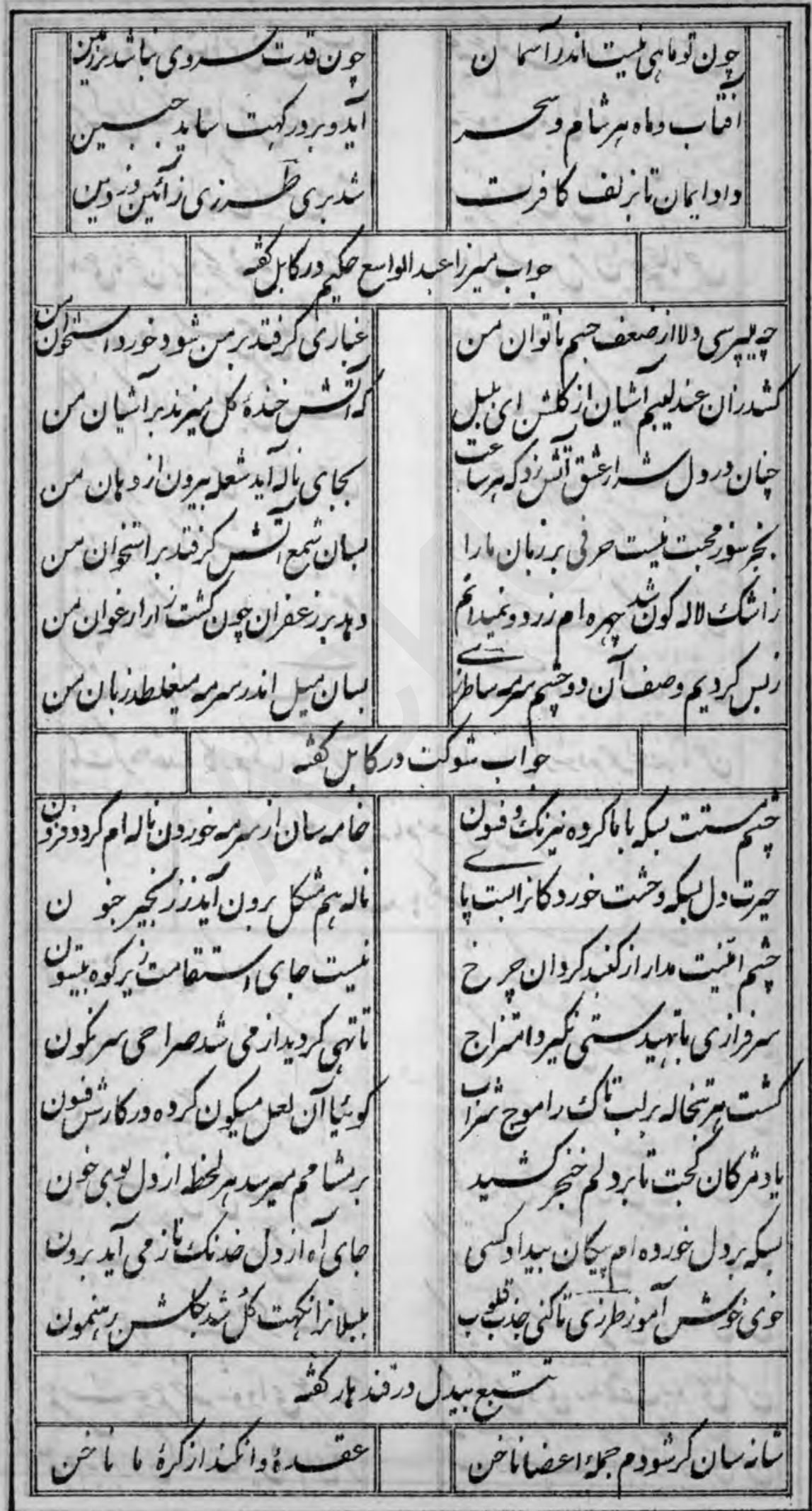


DIF

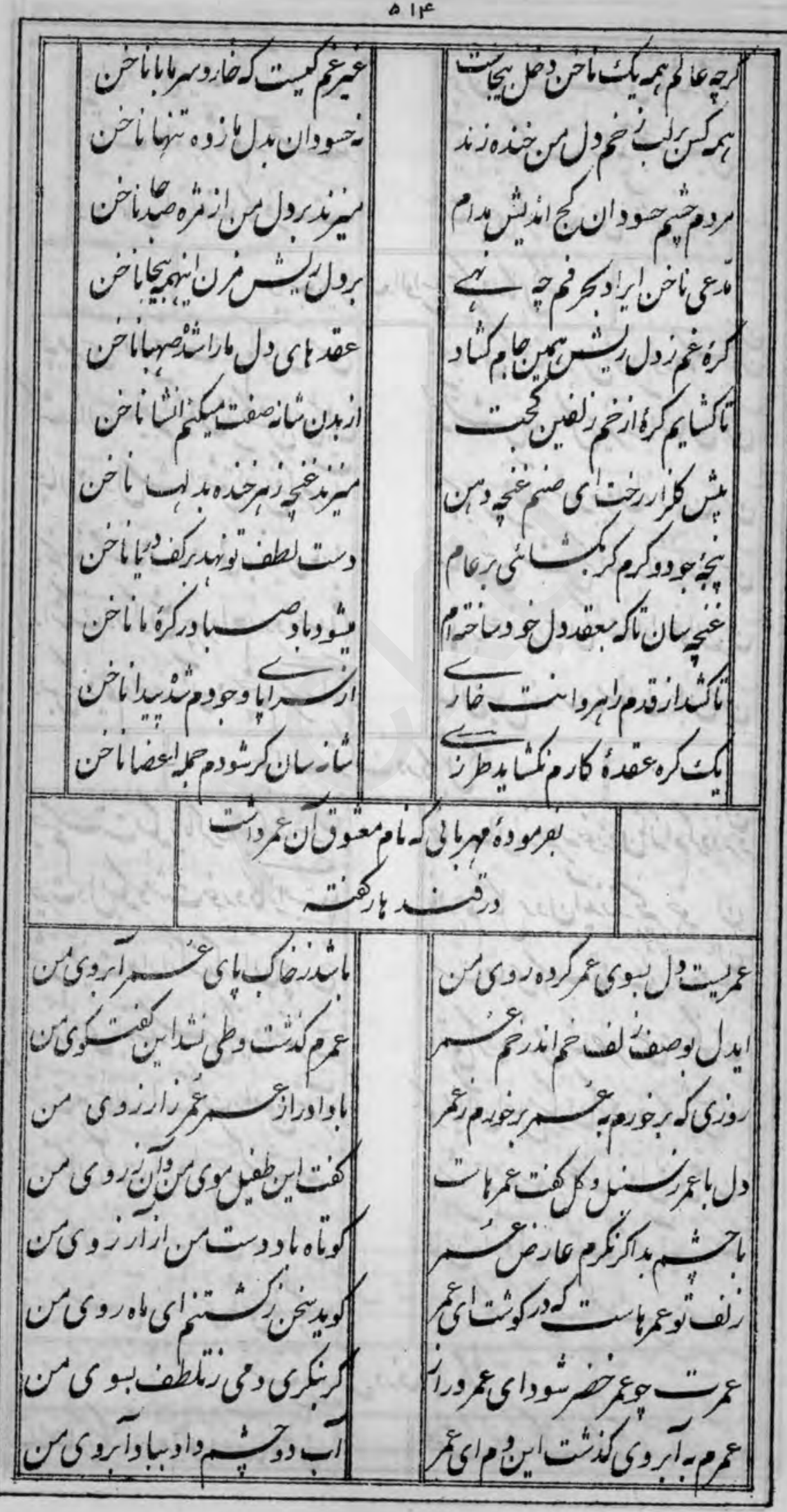


Q I O

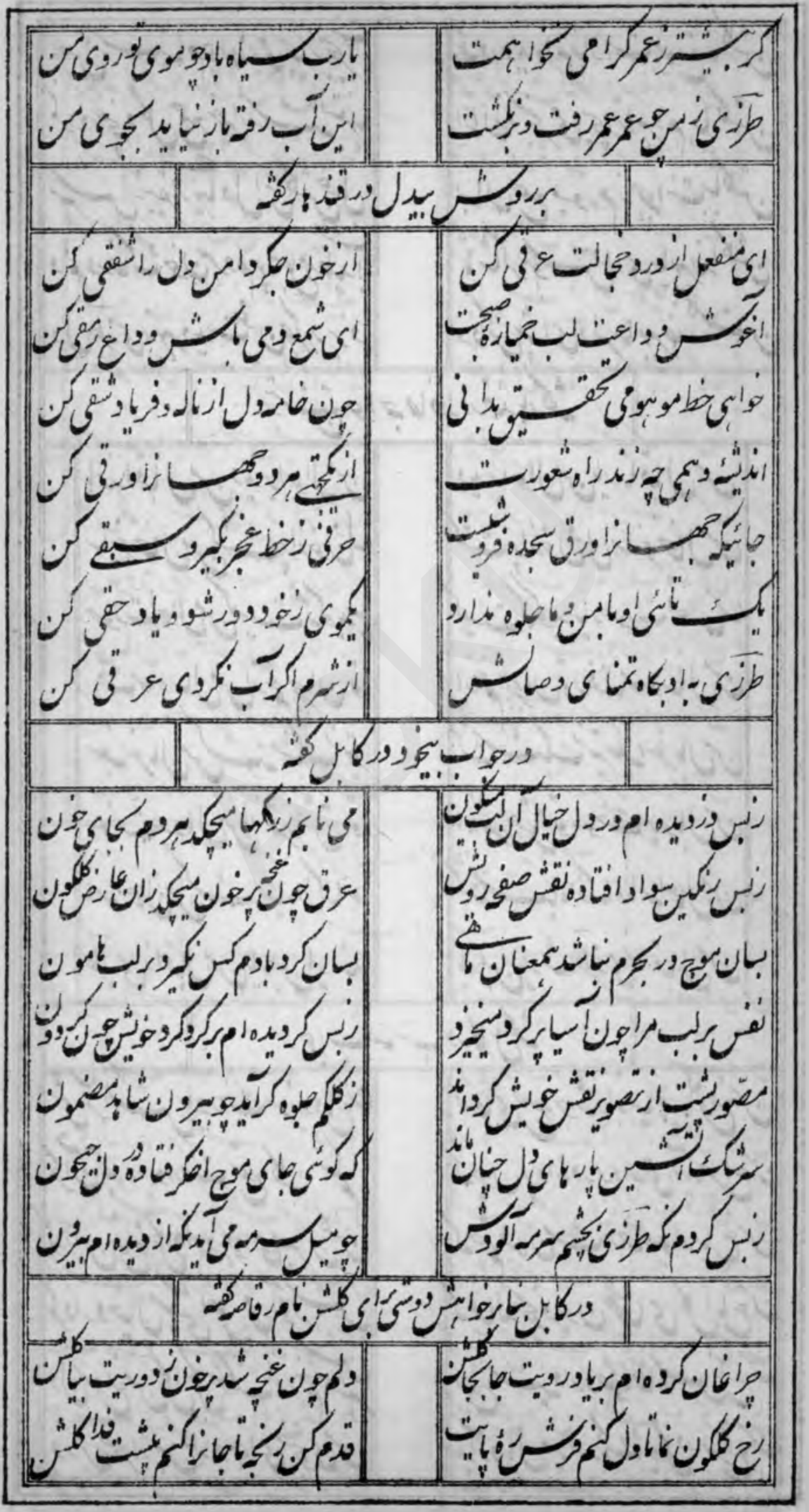


018

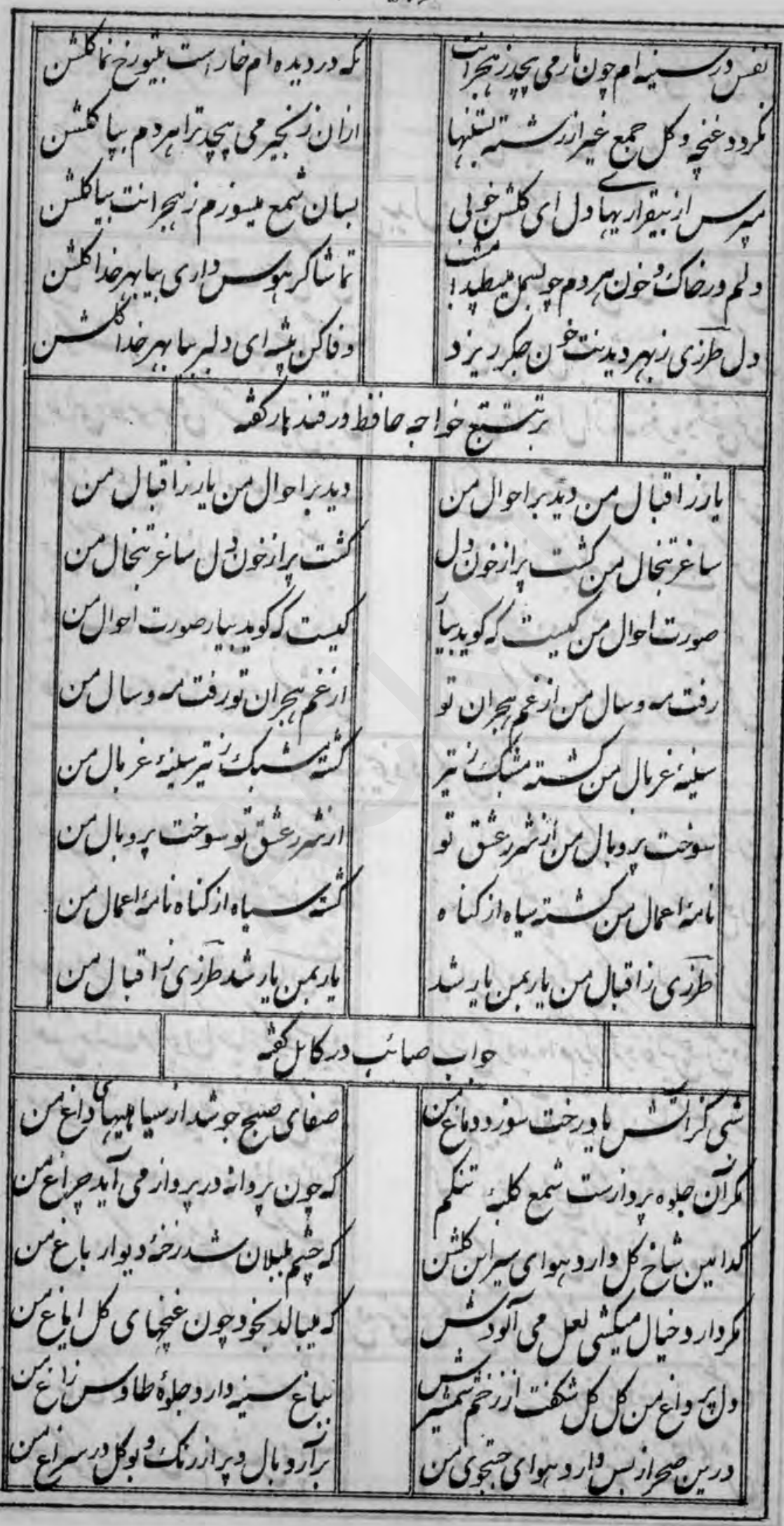


a I L

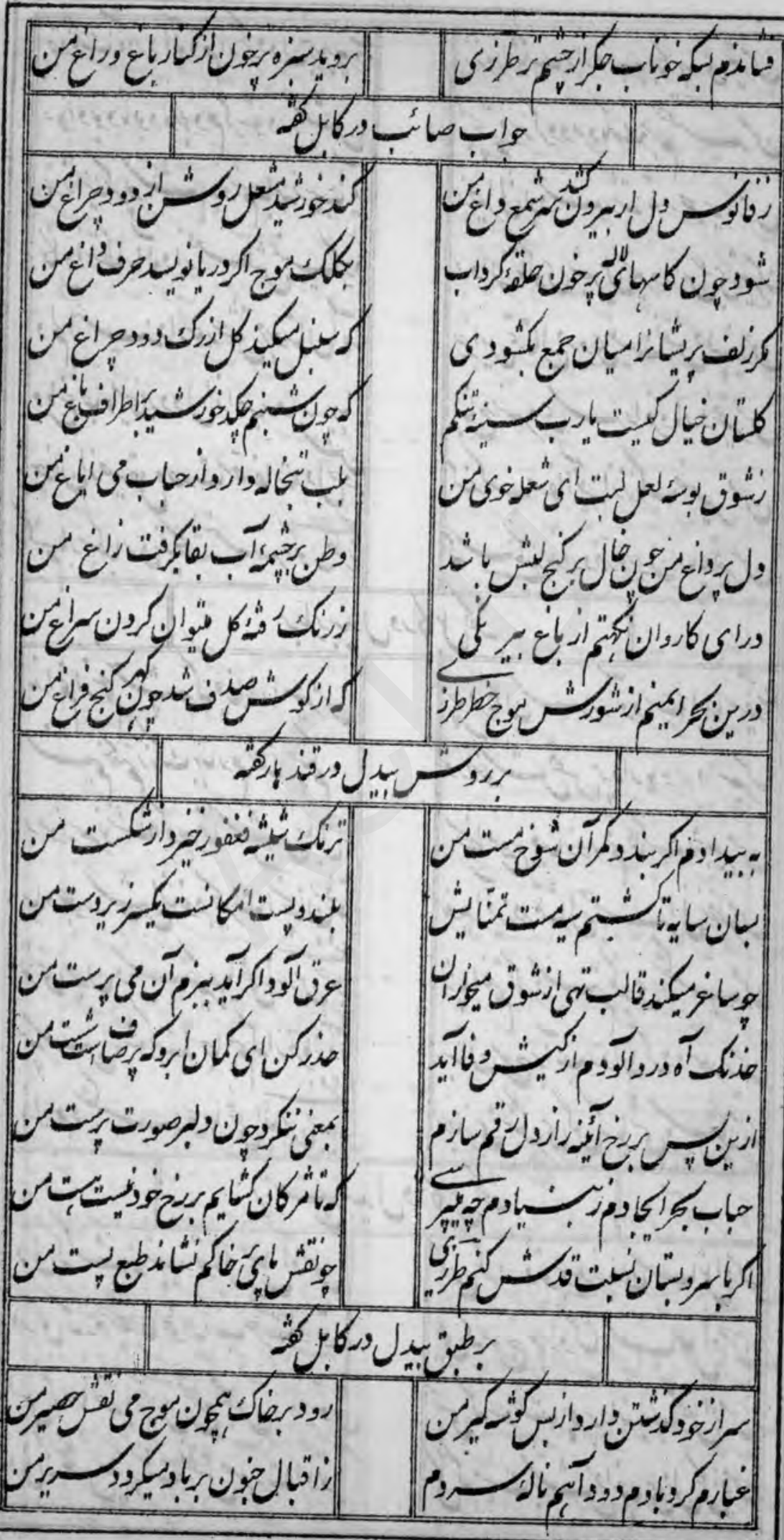


$\Delta \mid A$

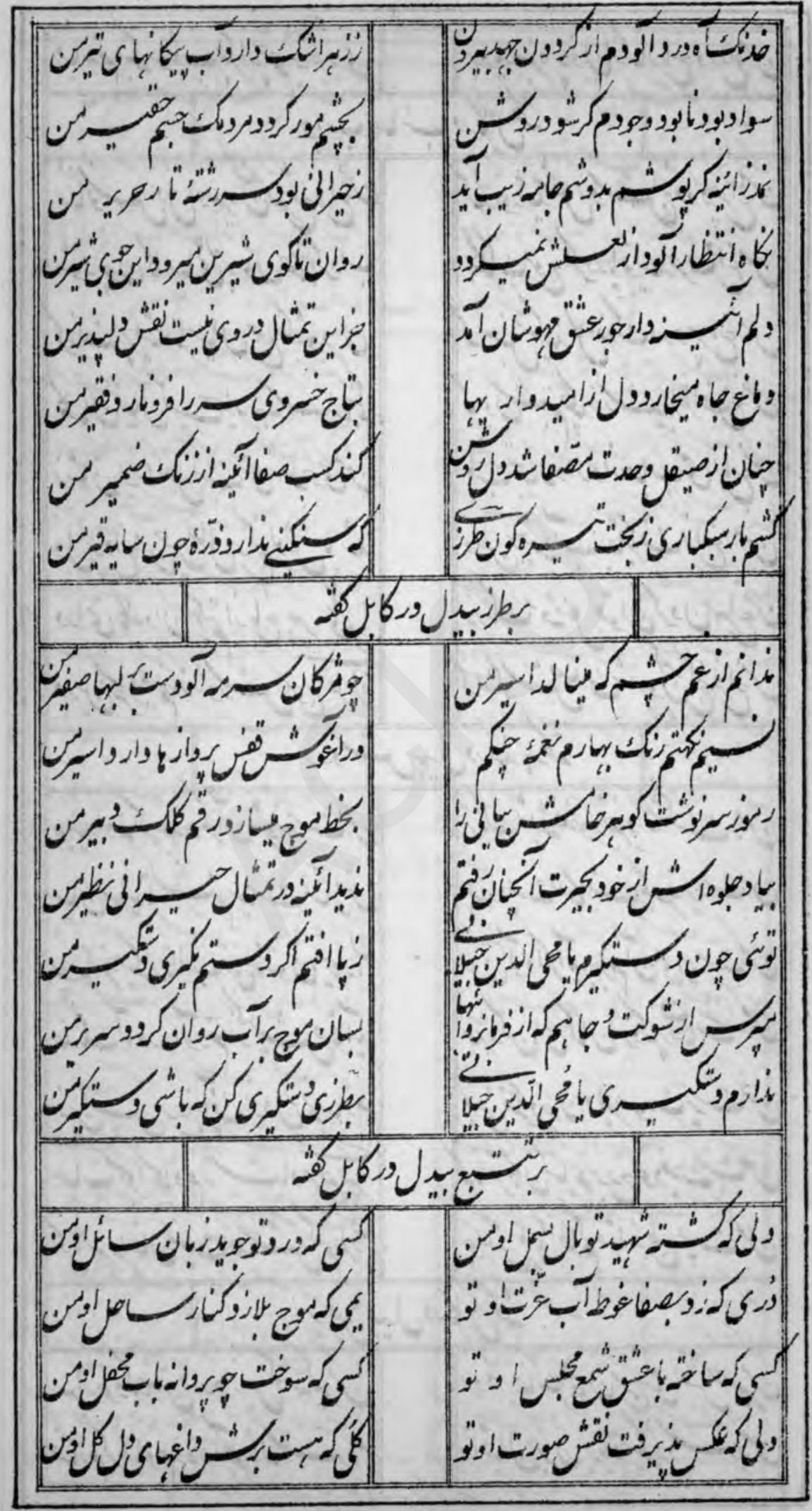


$\Delta 14$

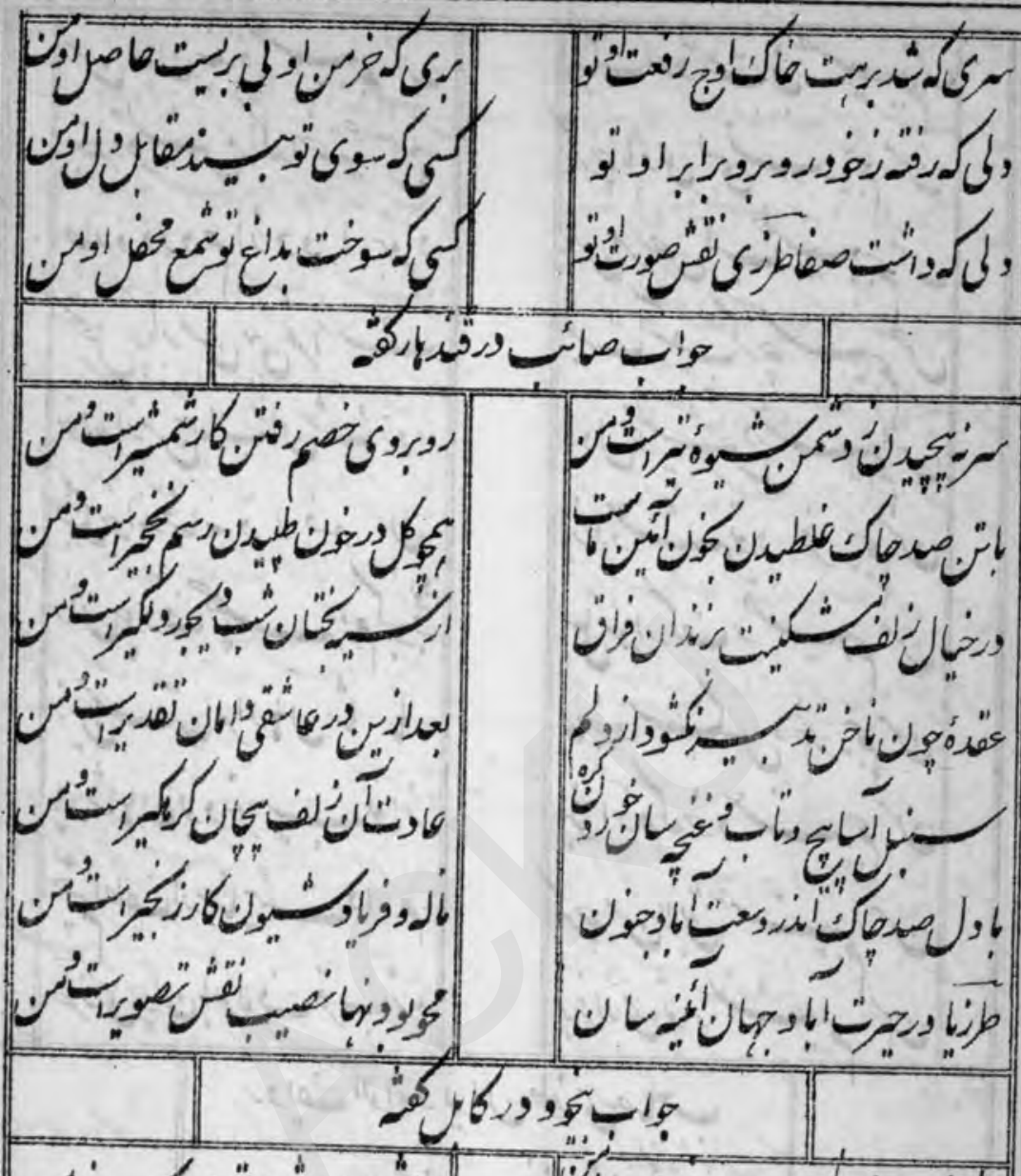

ن ن "

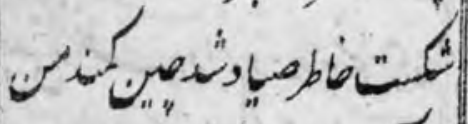
or ingirasing r

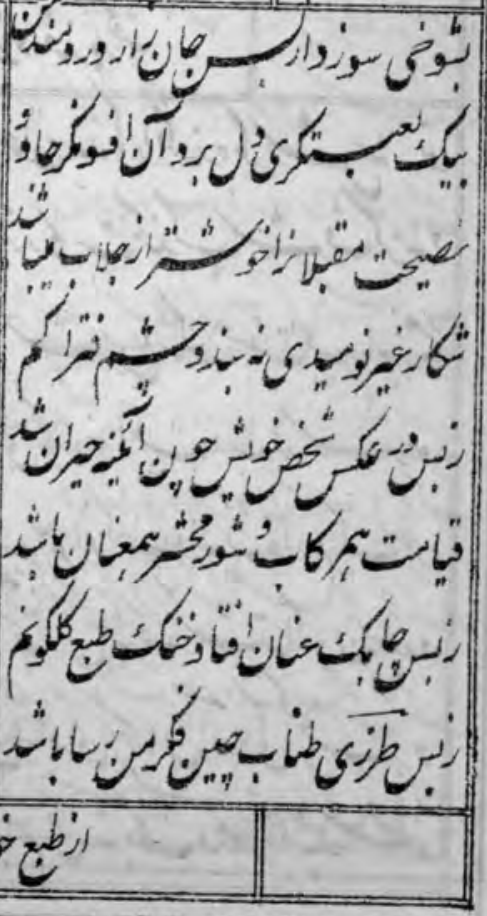


QP

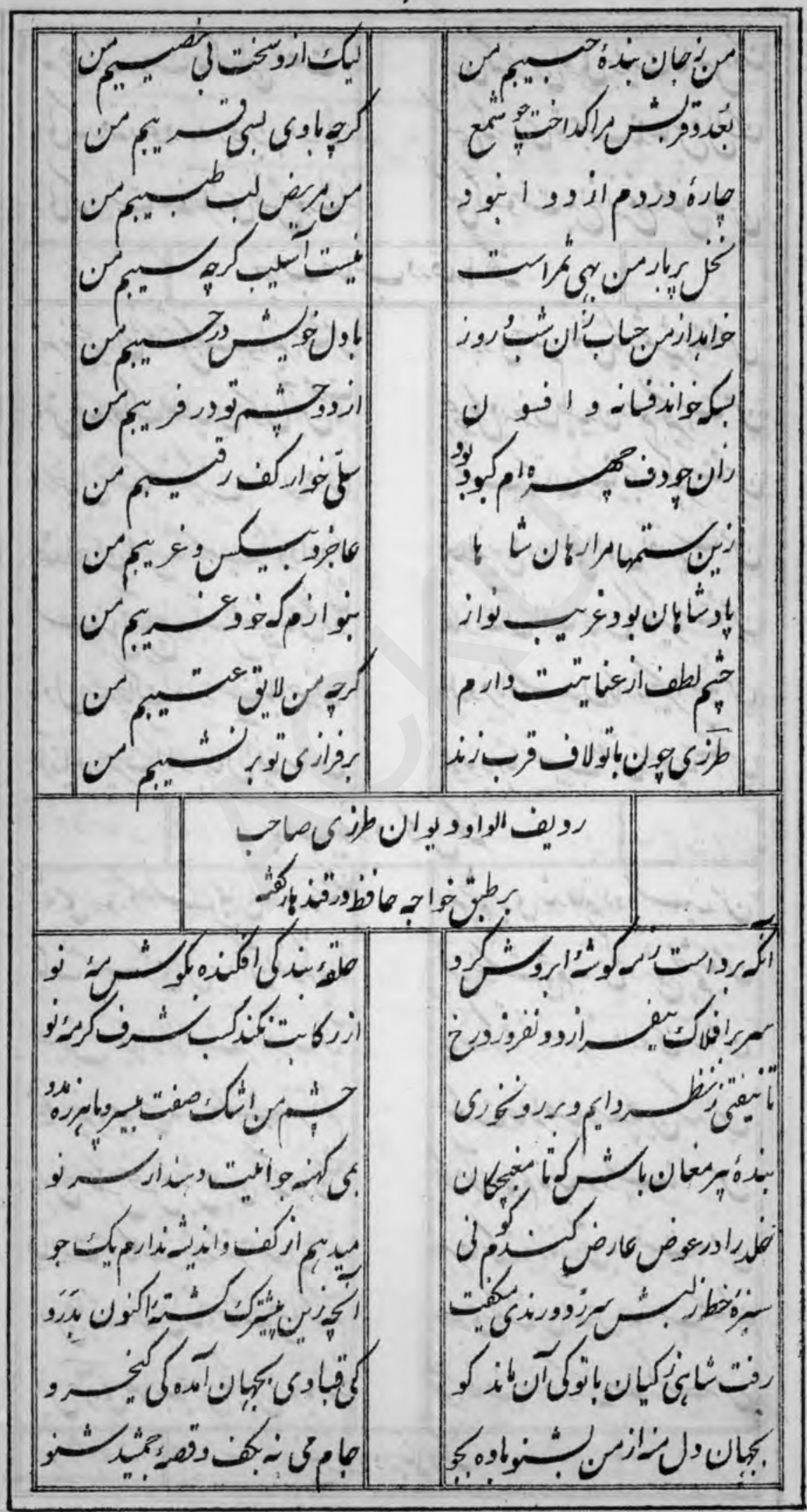


B $\mathrm{r} 1$

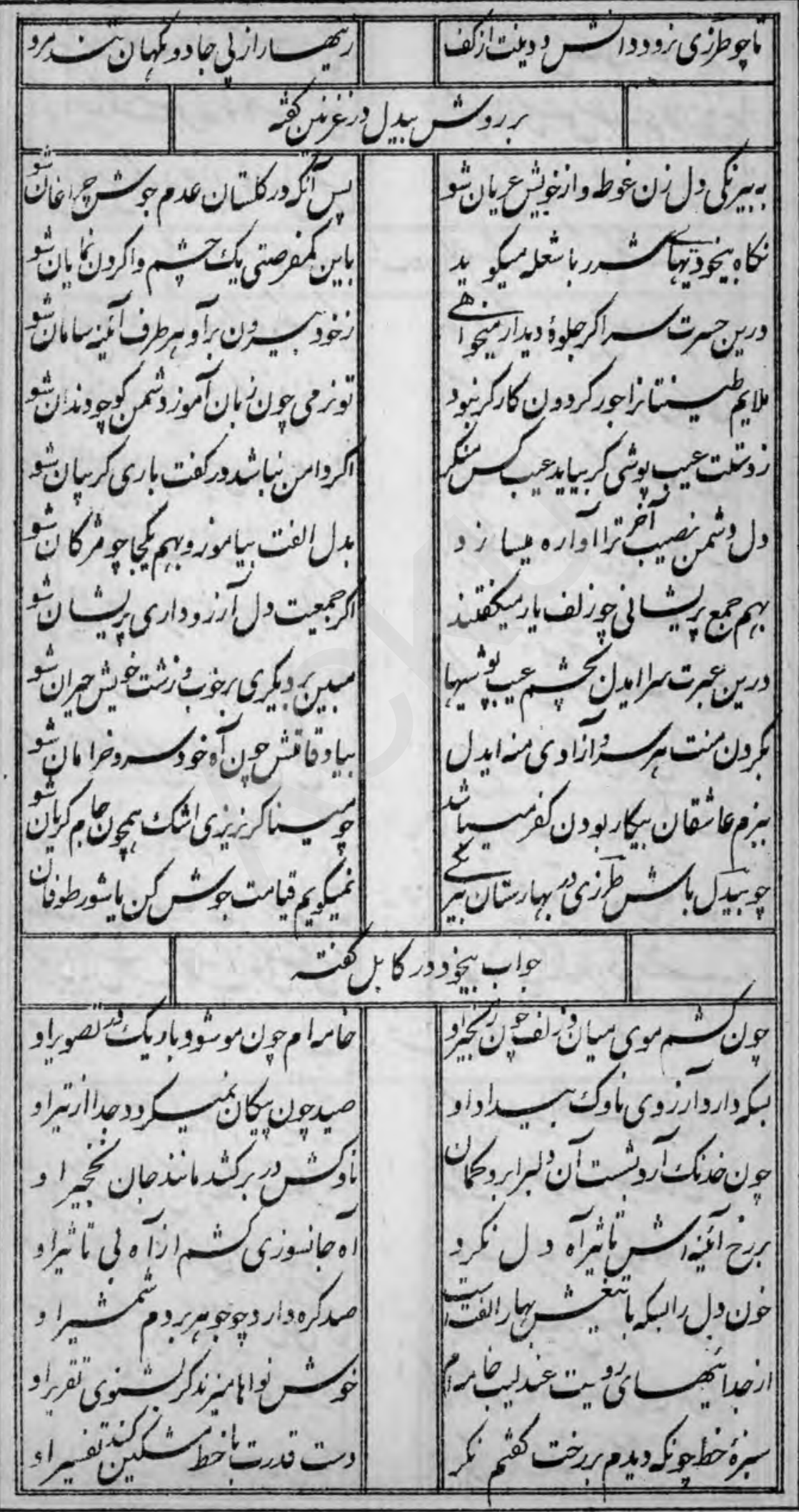


$\Delta r r$

$\mid$


orr

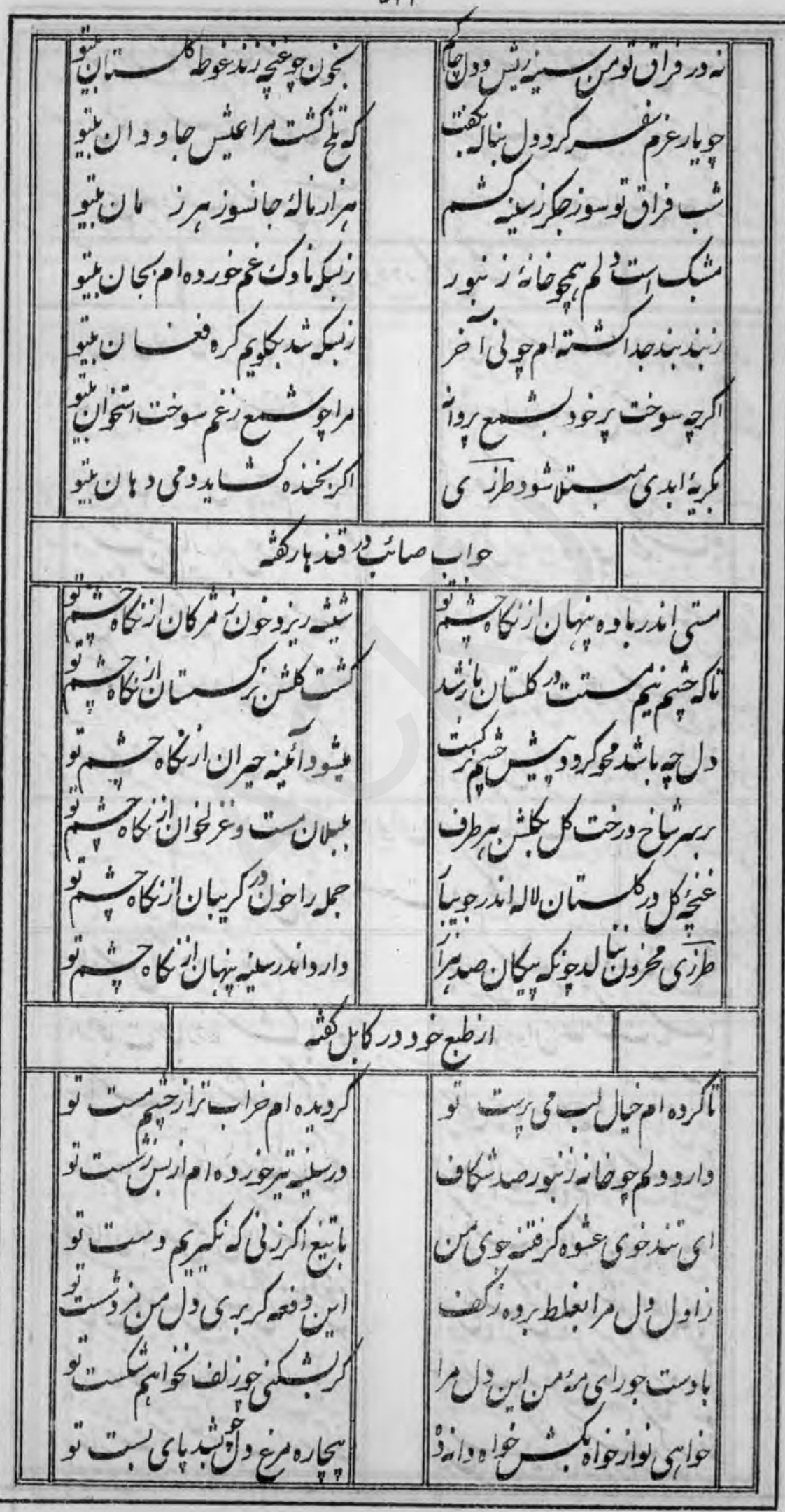


a r F

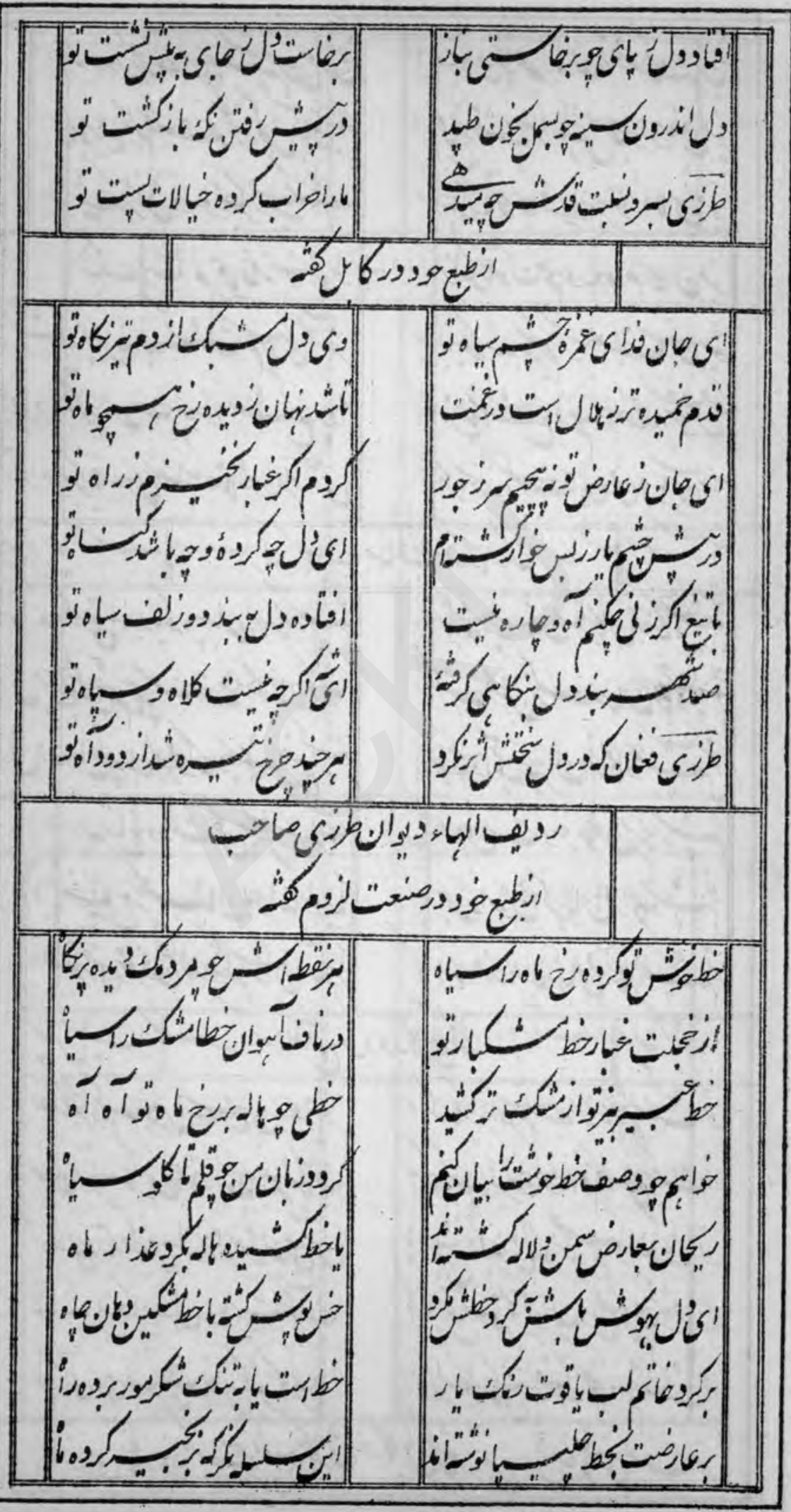




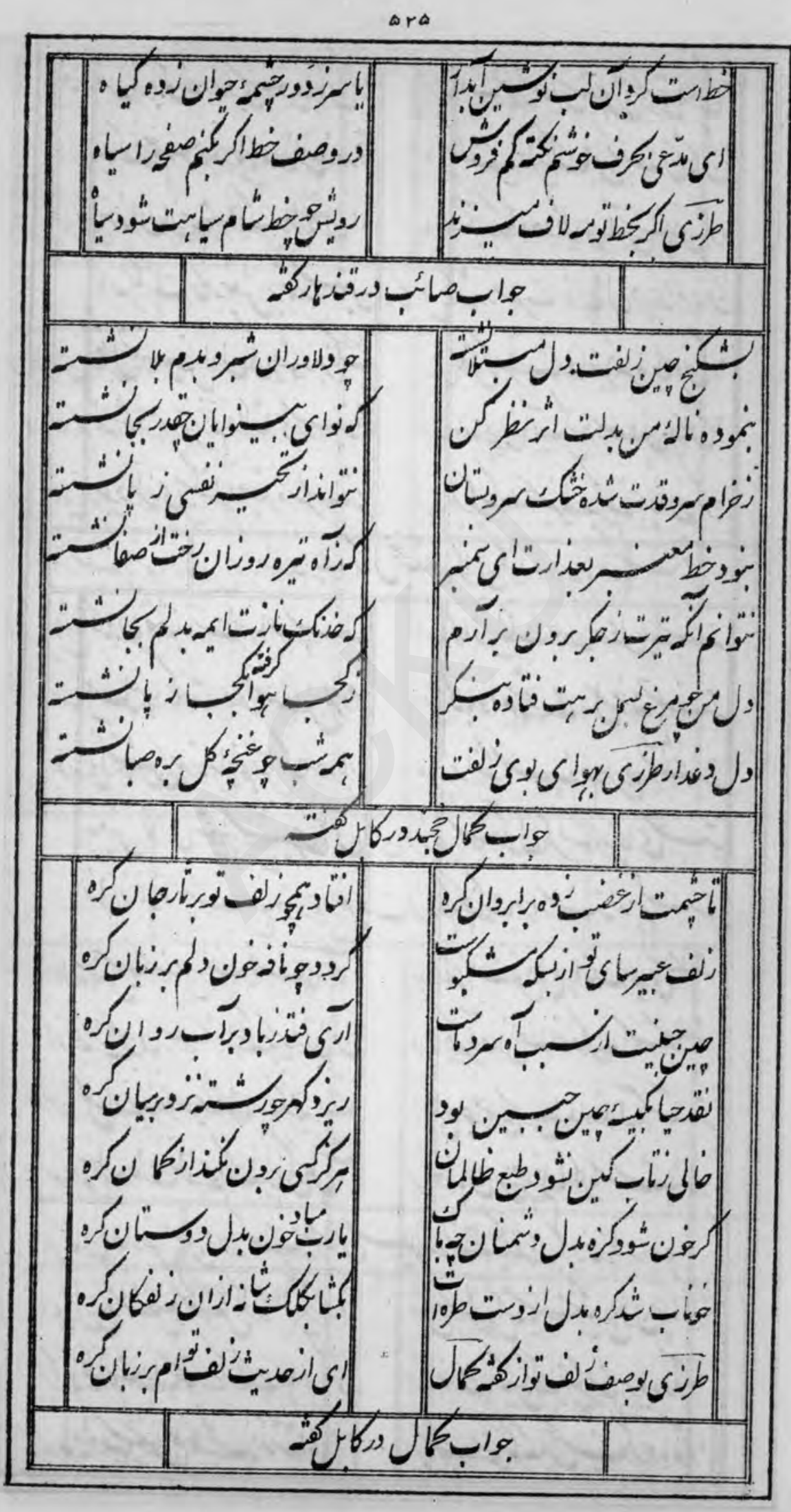


$0+\%$

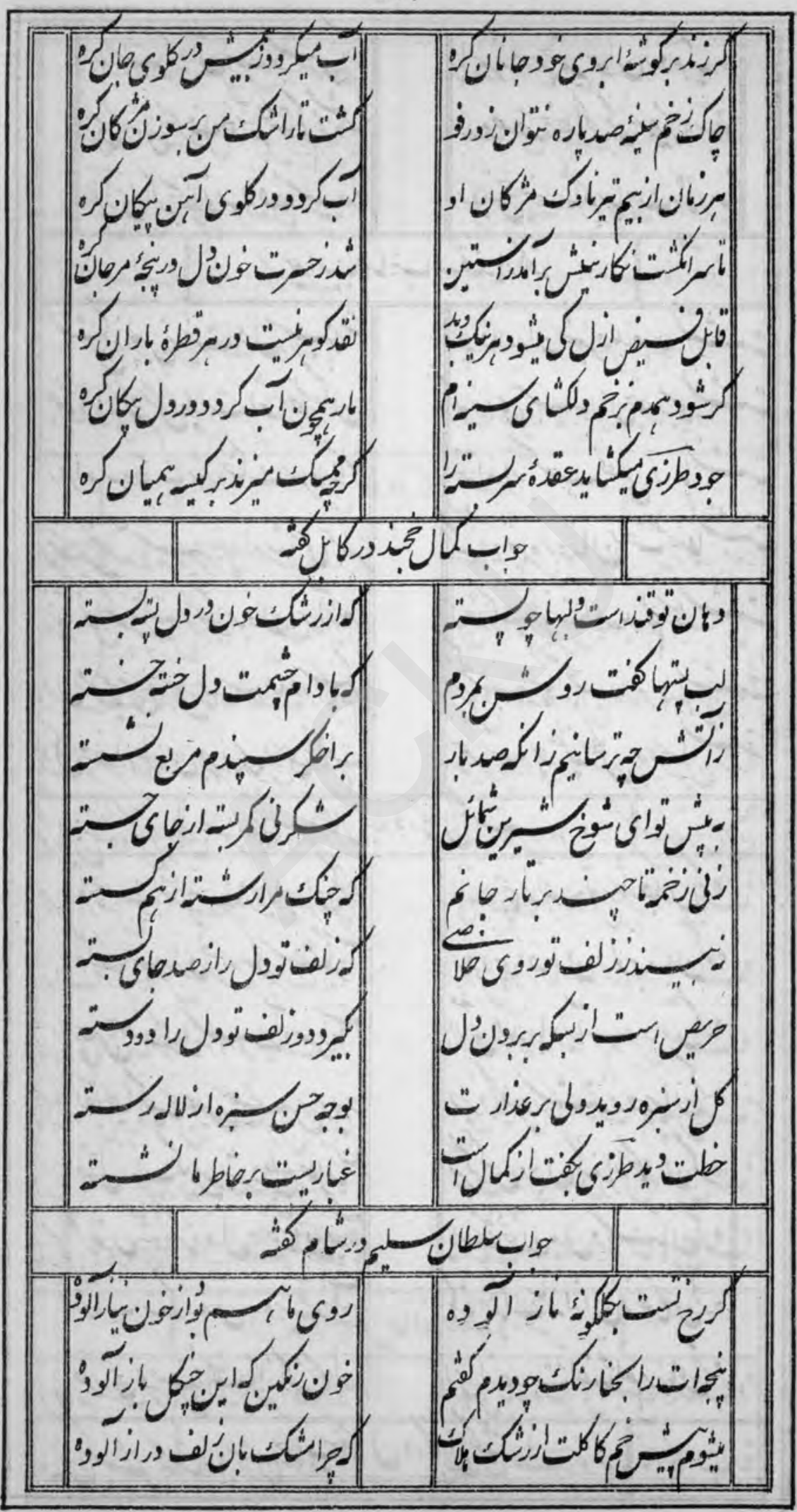


a r v

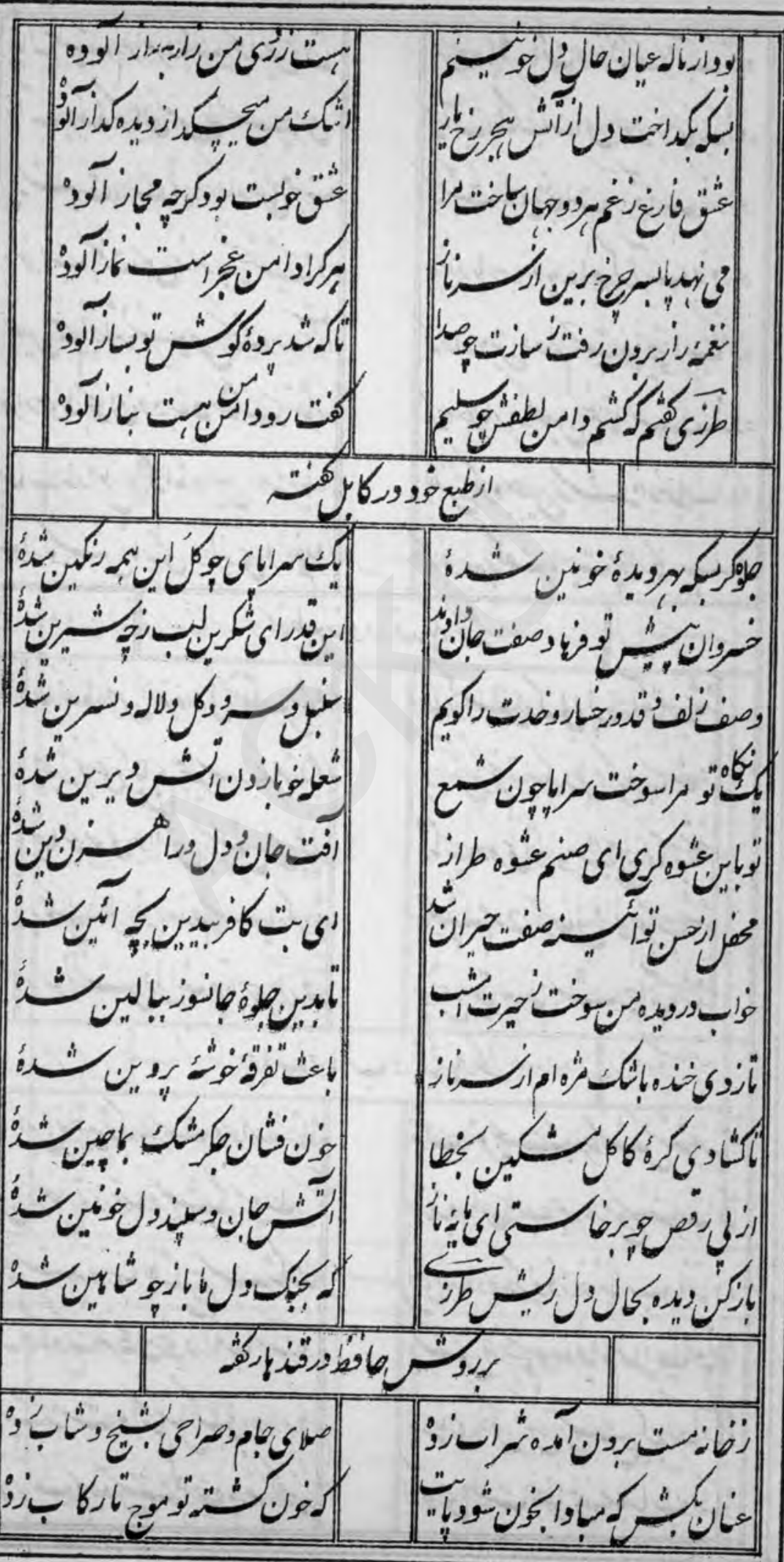


$\Delta+A$

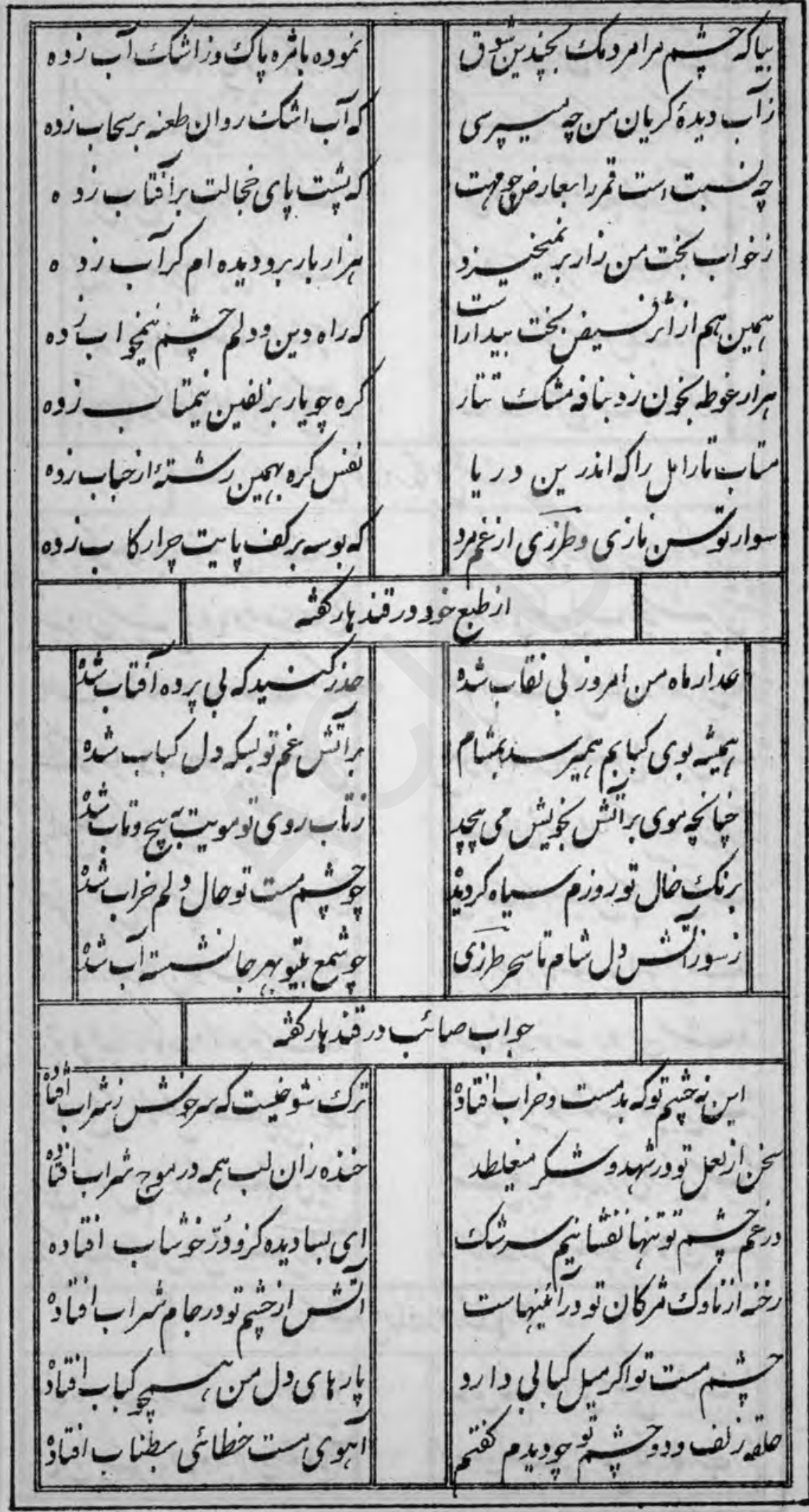


a 59

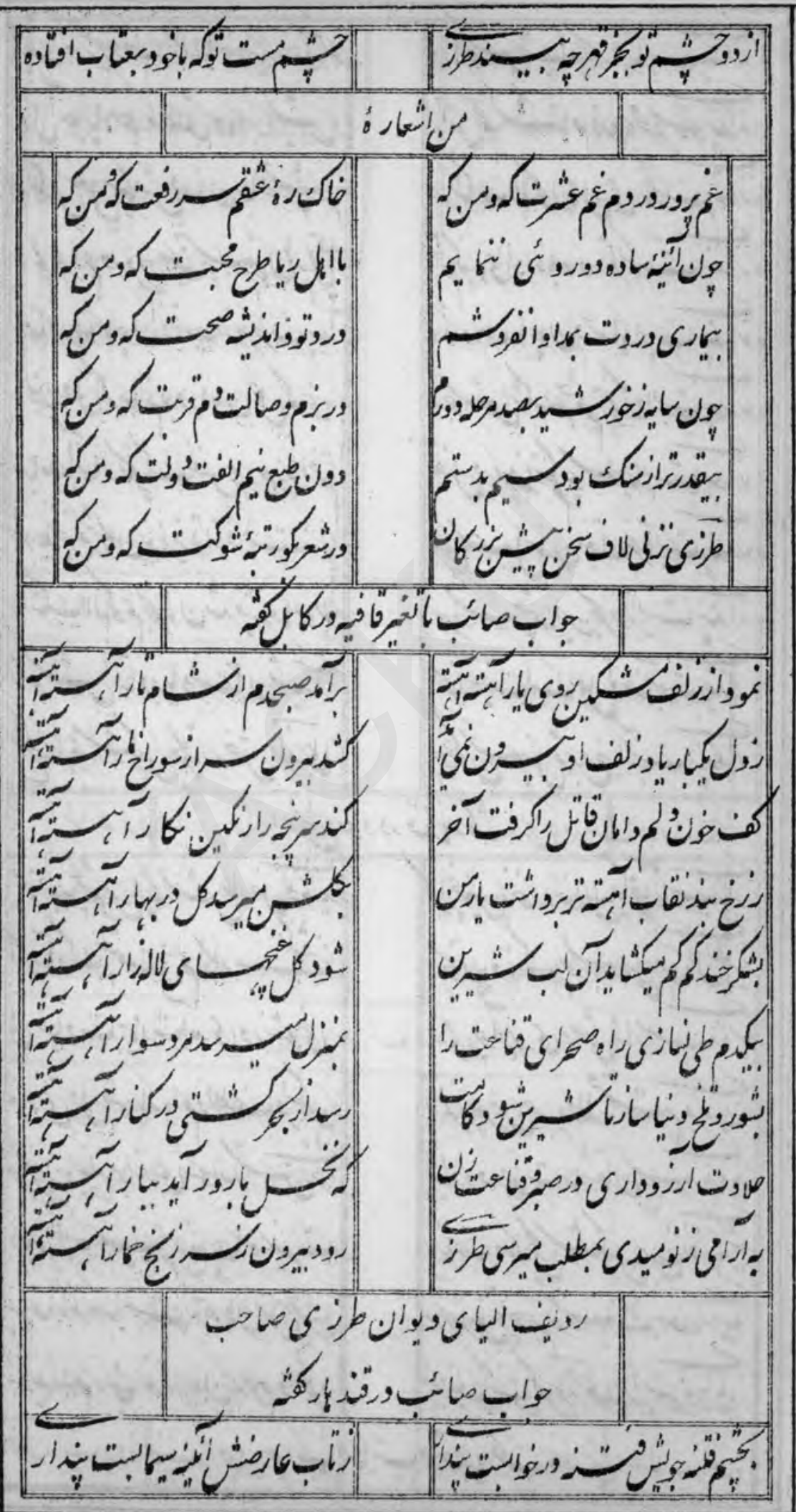


$\Delta r$

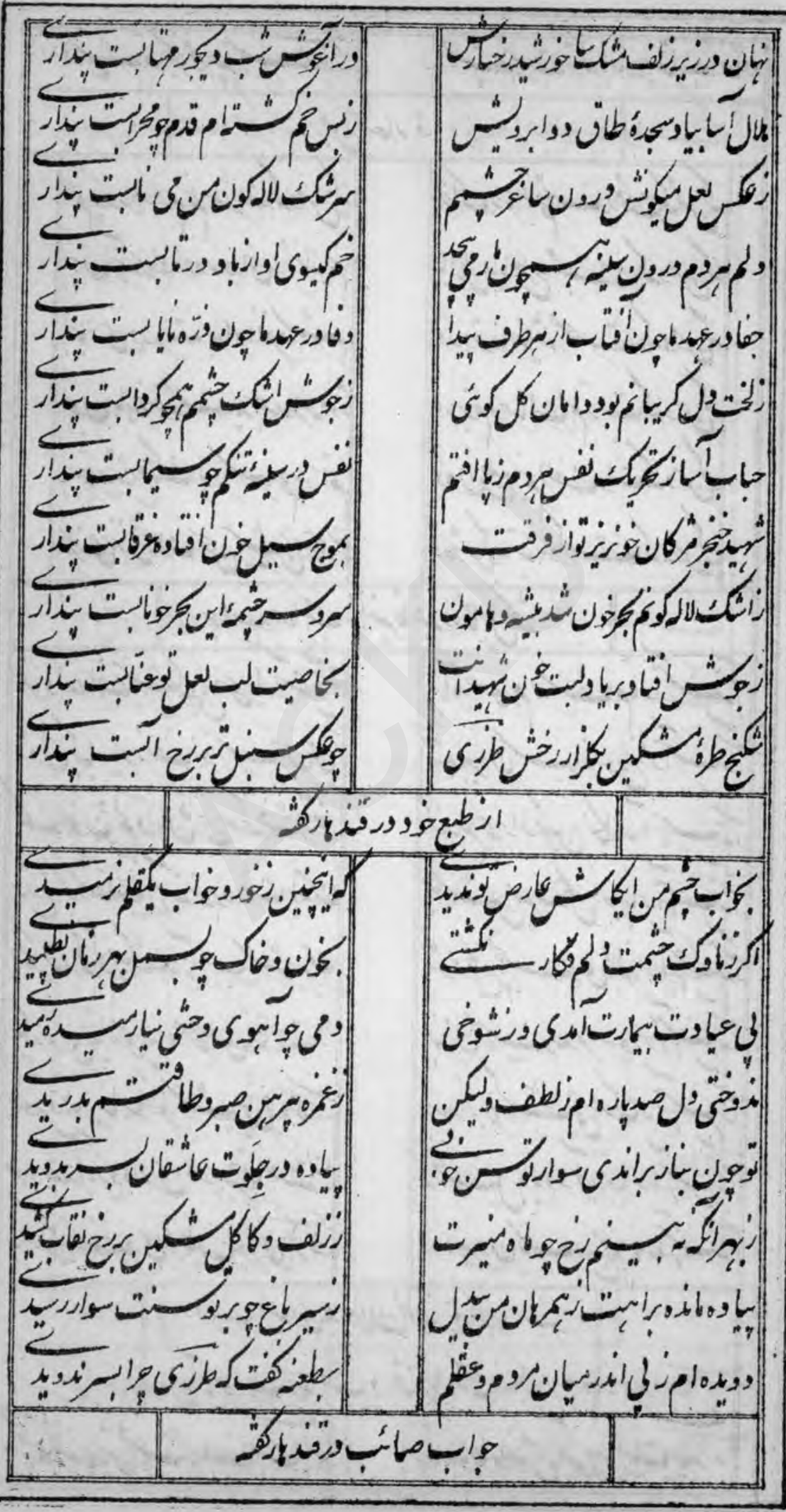


ar 1

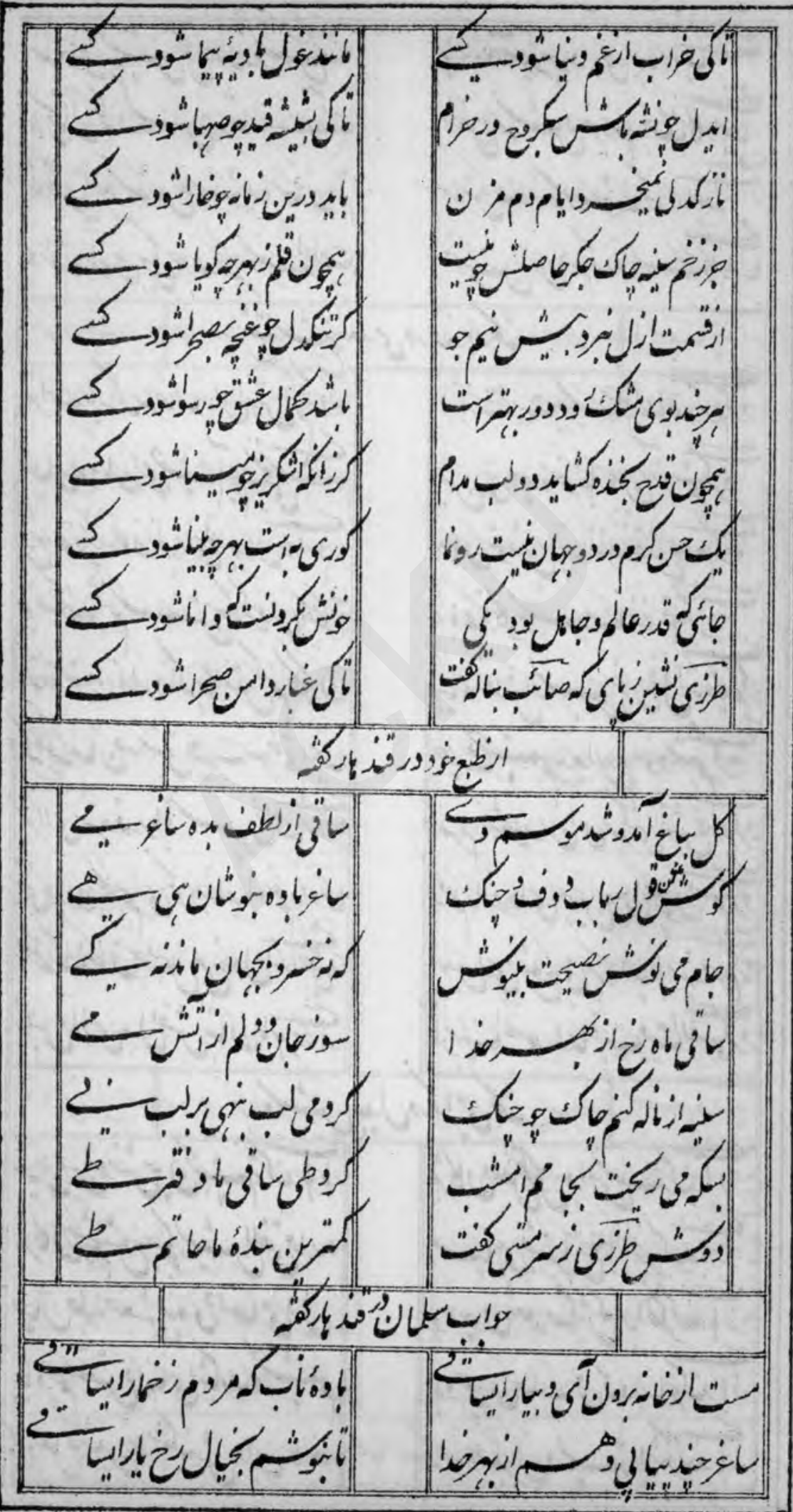


$\Delta r$

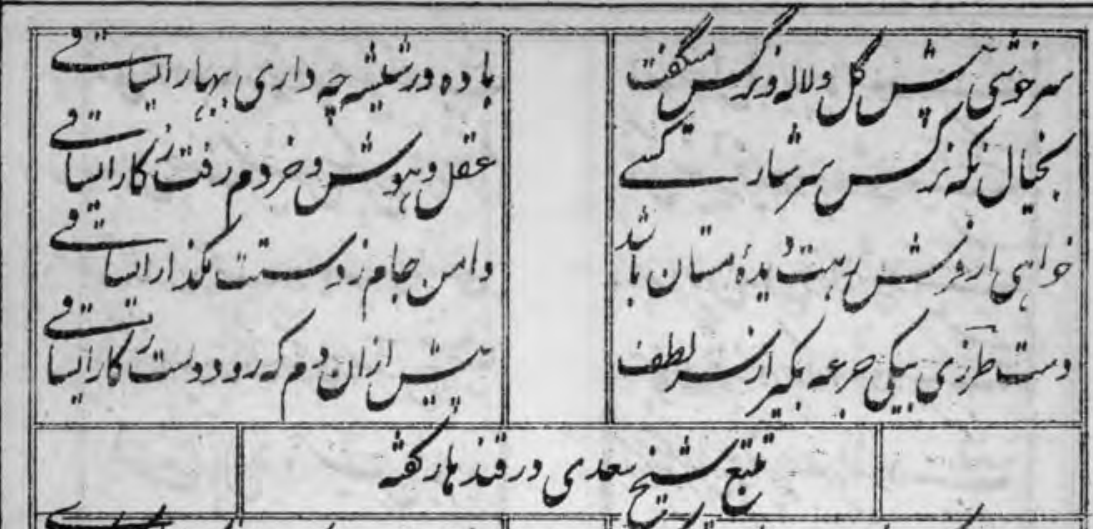

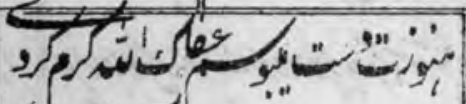

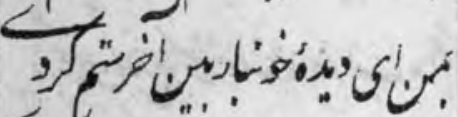

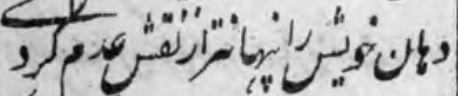

"

إ

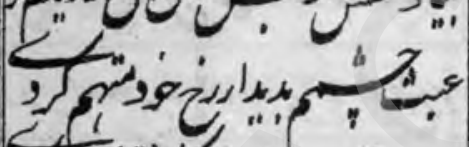

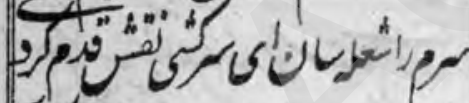

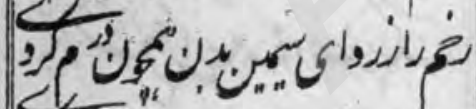

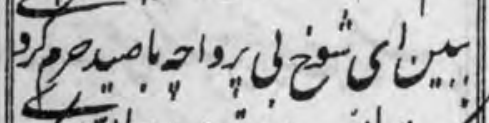

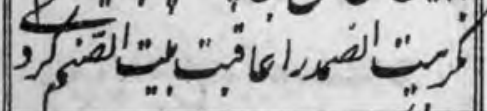

-

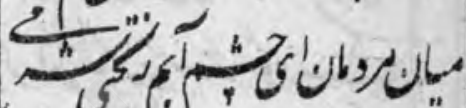
<

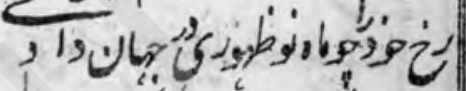
" 1.) " " |

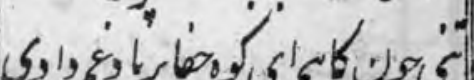

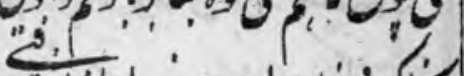

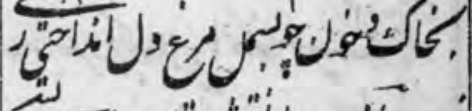
ג的

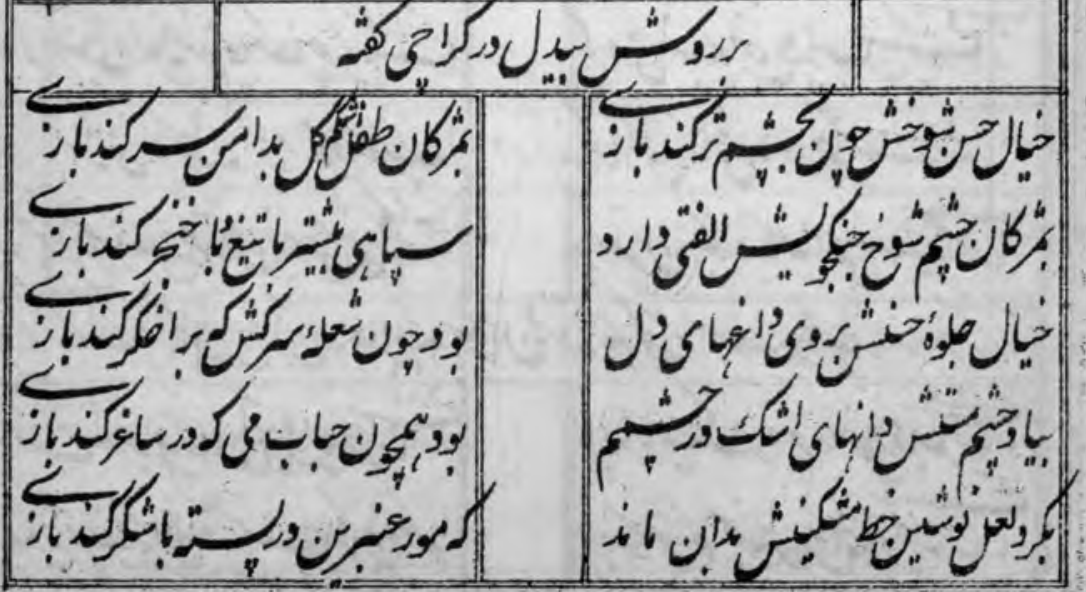


$\Delta r r$

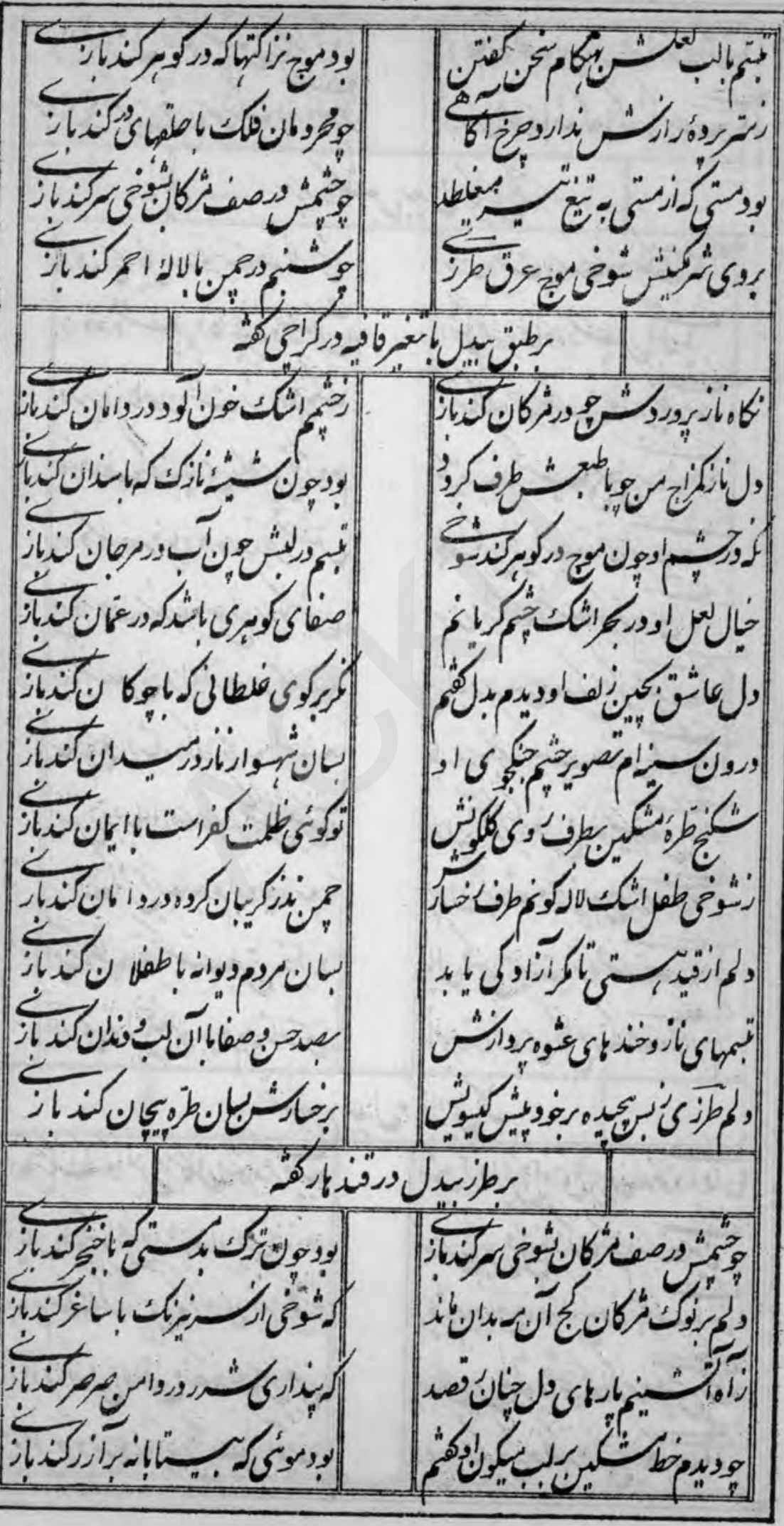


orr

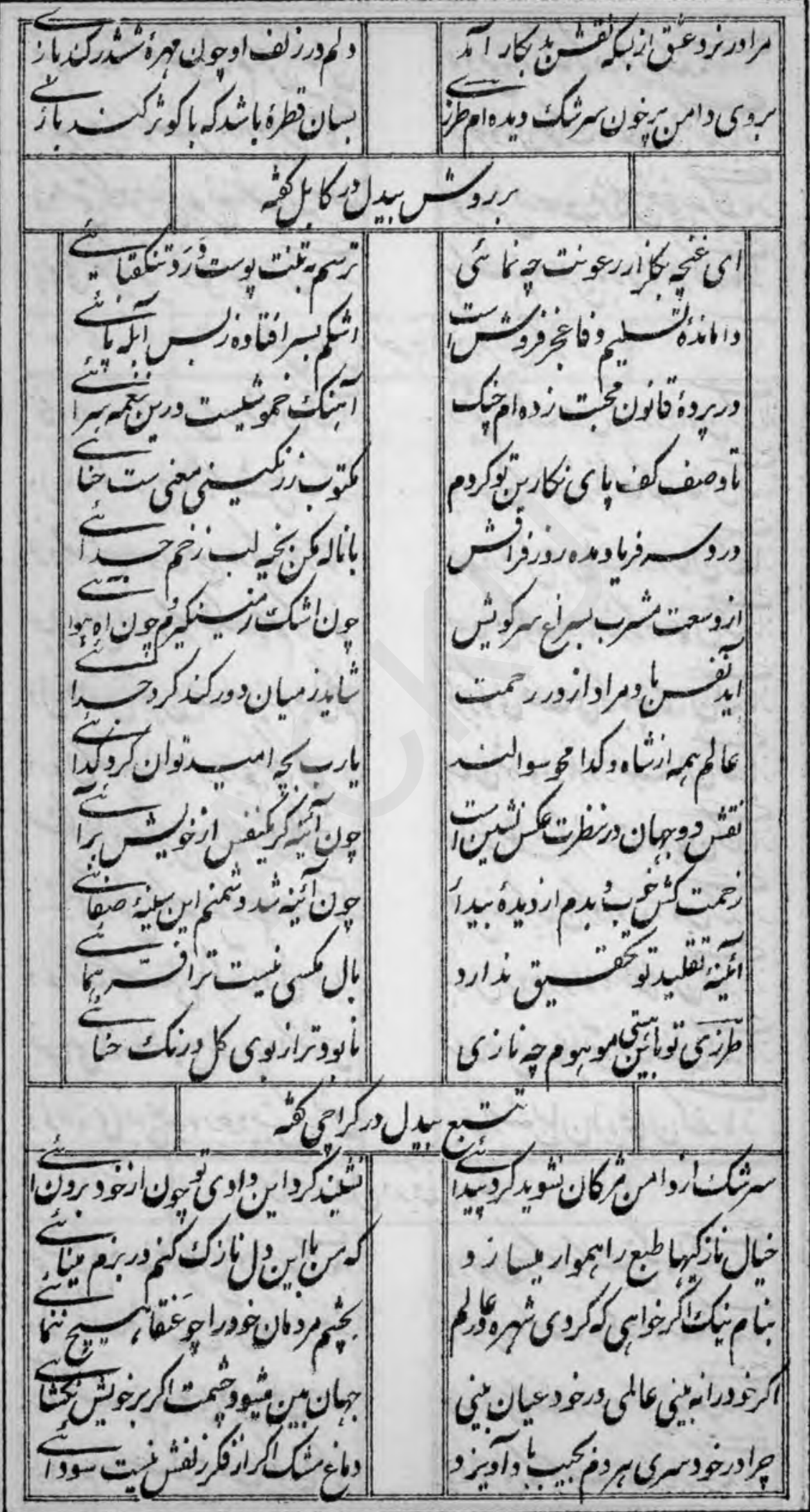

$J^{4}$ 
$\Delta r \Delta$

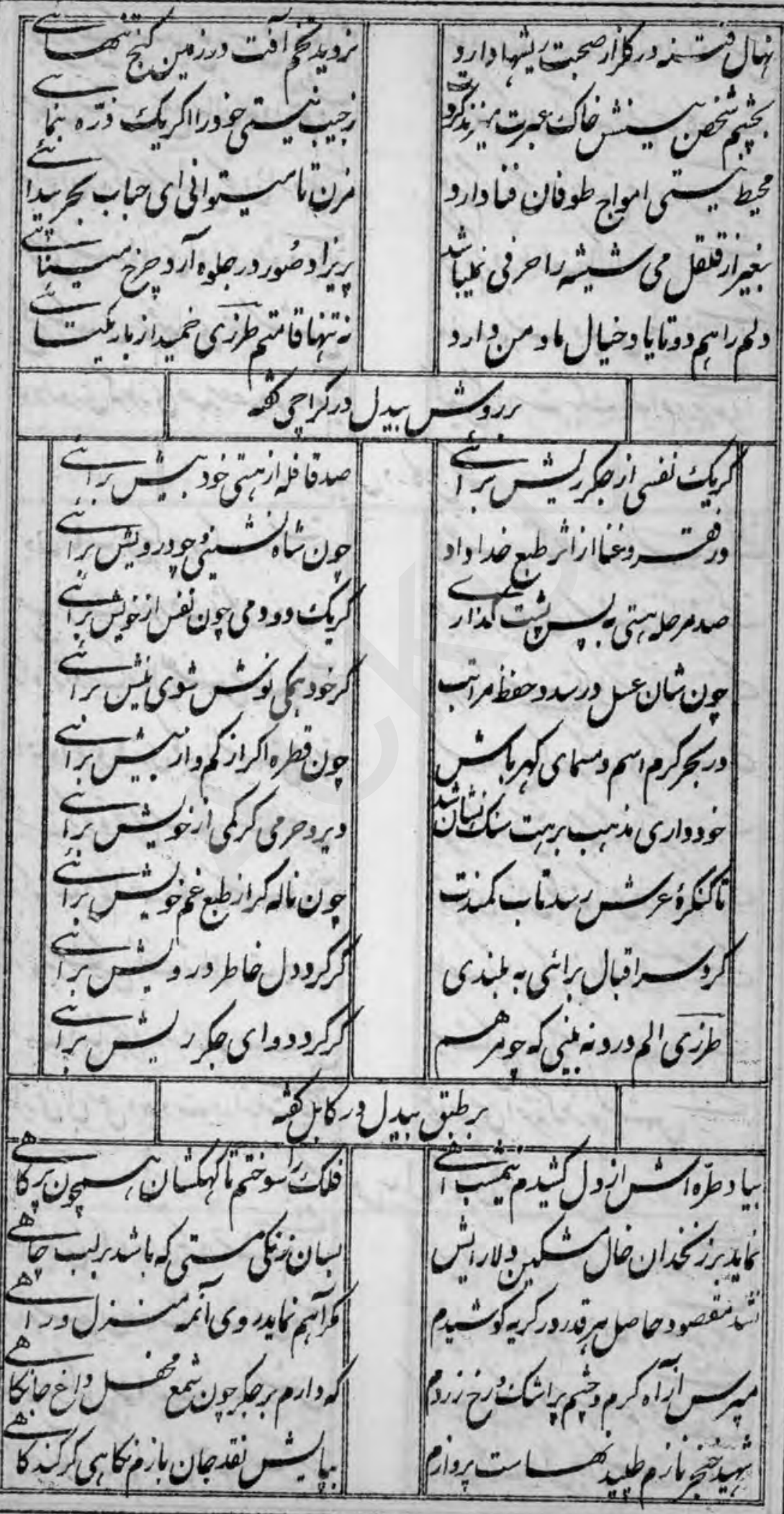


ors

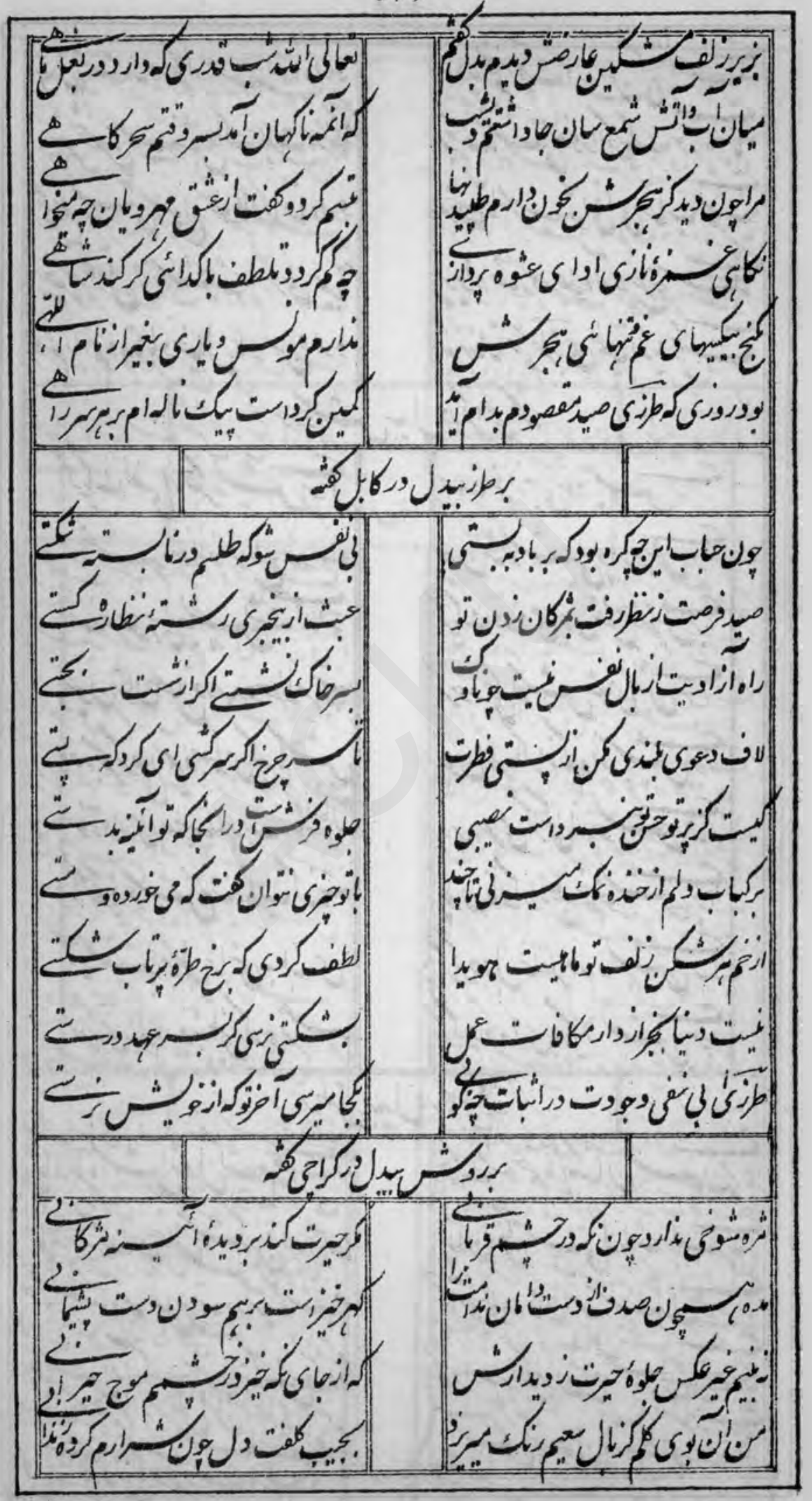




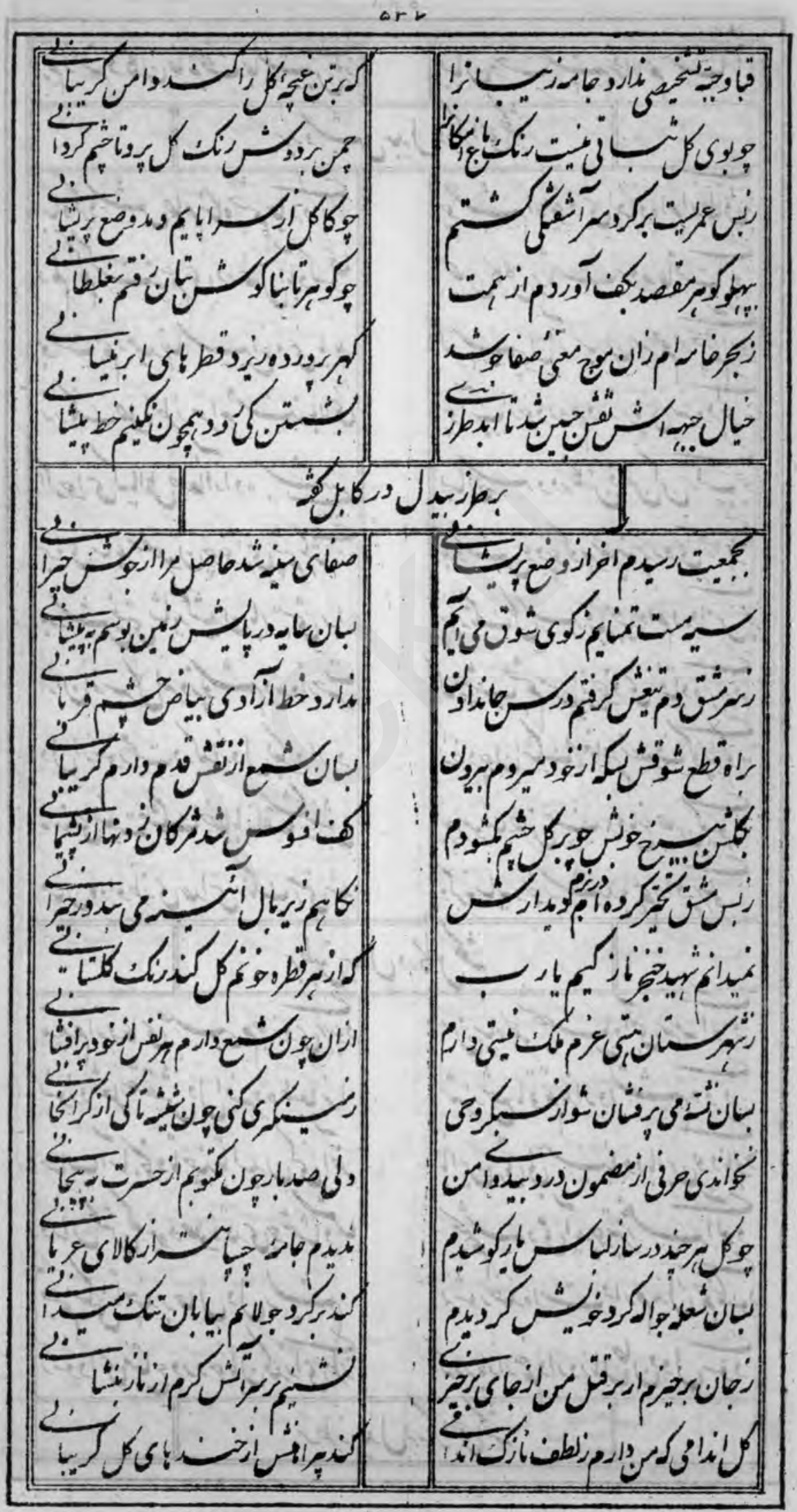


$\Delta r A$

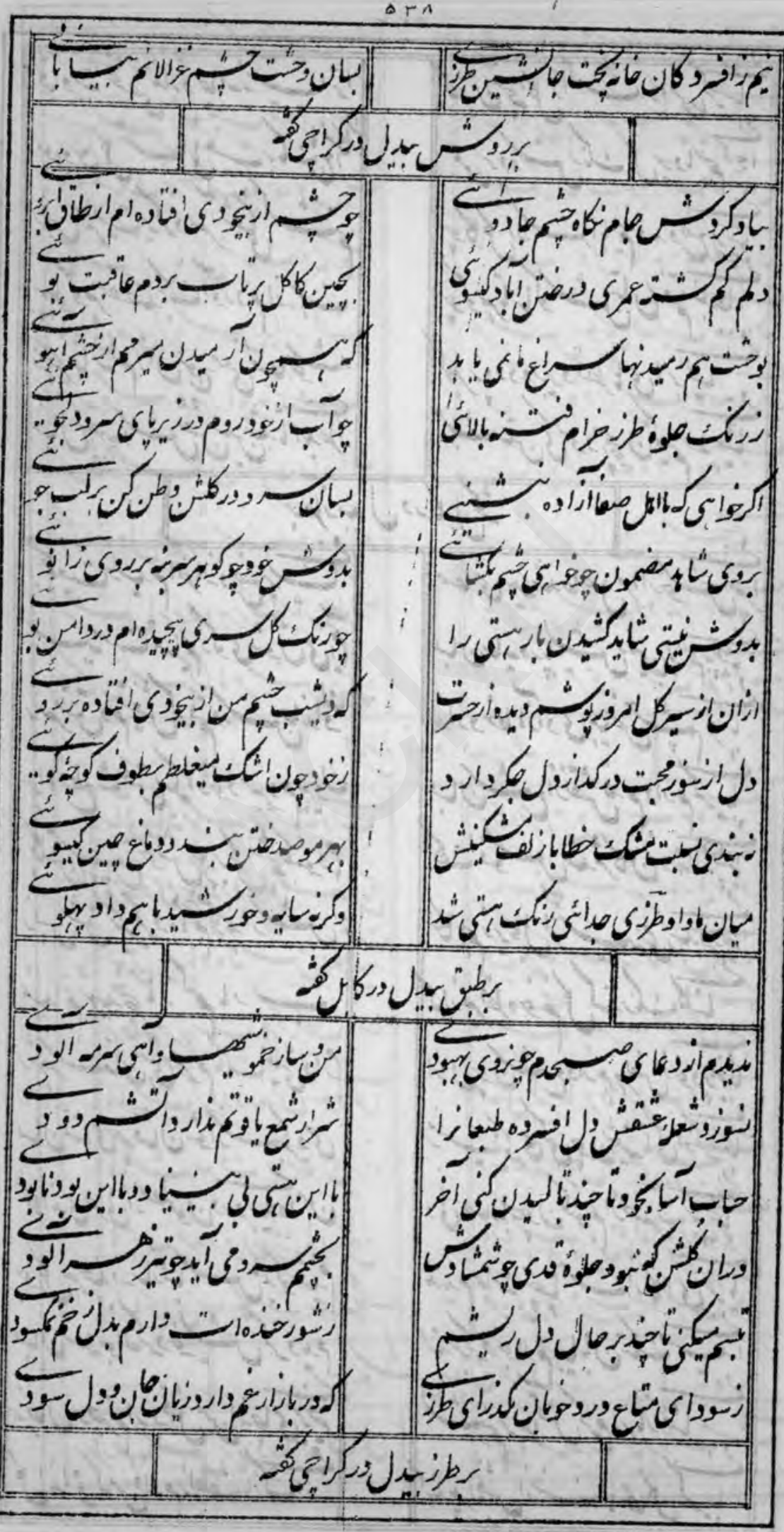

in 
$\Delta r q$
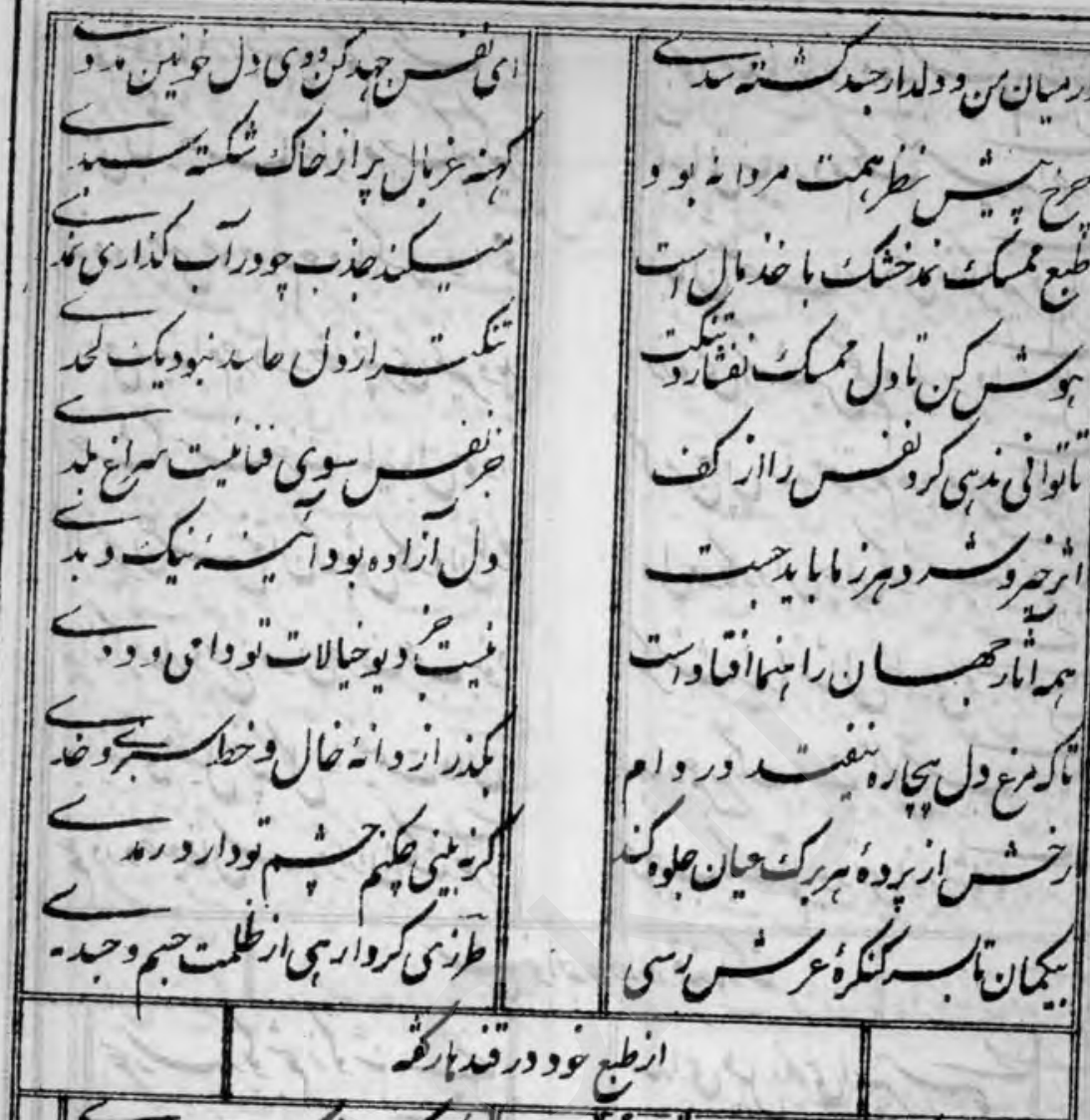

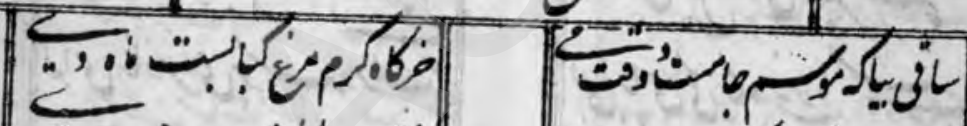
等 -

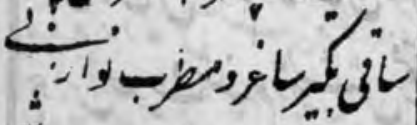
: 瓜

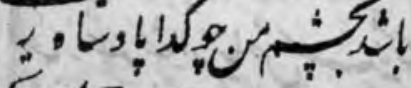
suling-isuip !

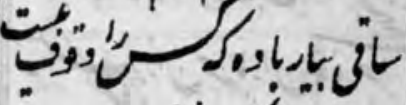
مان - .

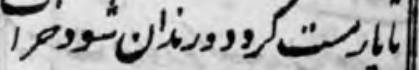
نا "إ....

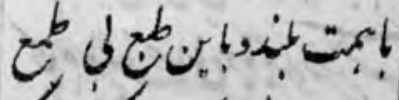
(i) -iverust,

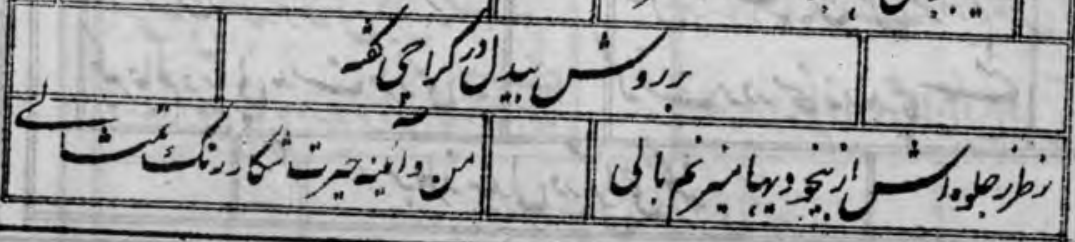


Q.

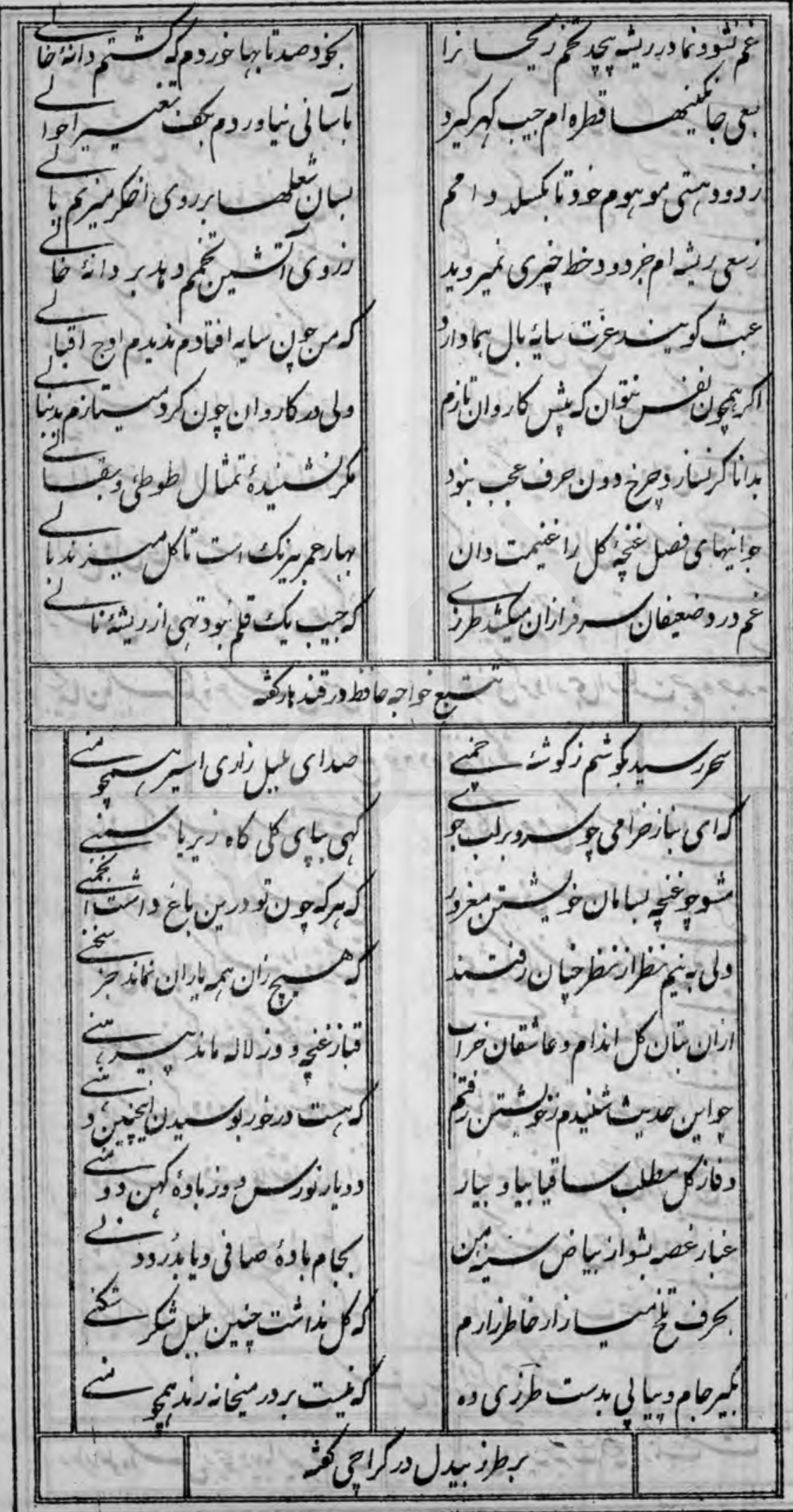


$\Delta r 1$

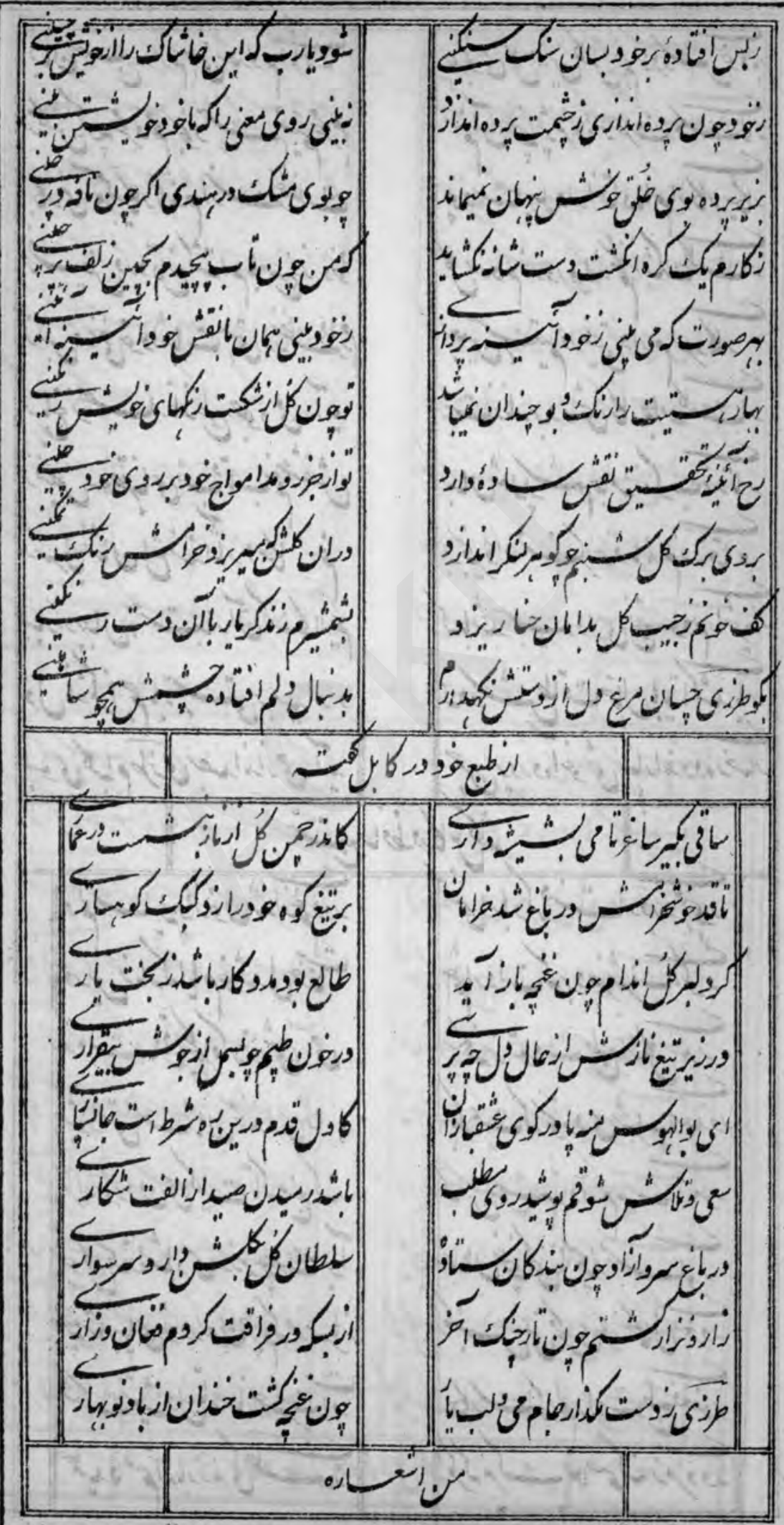


a fr

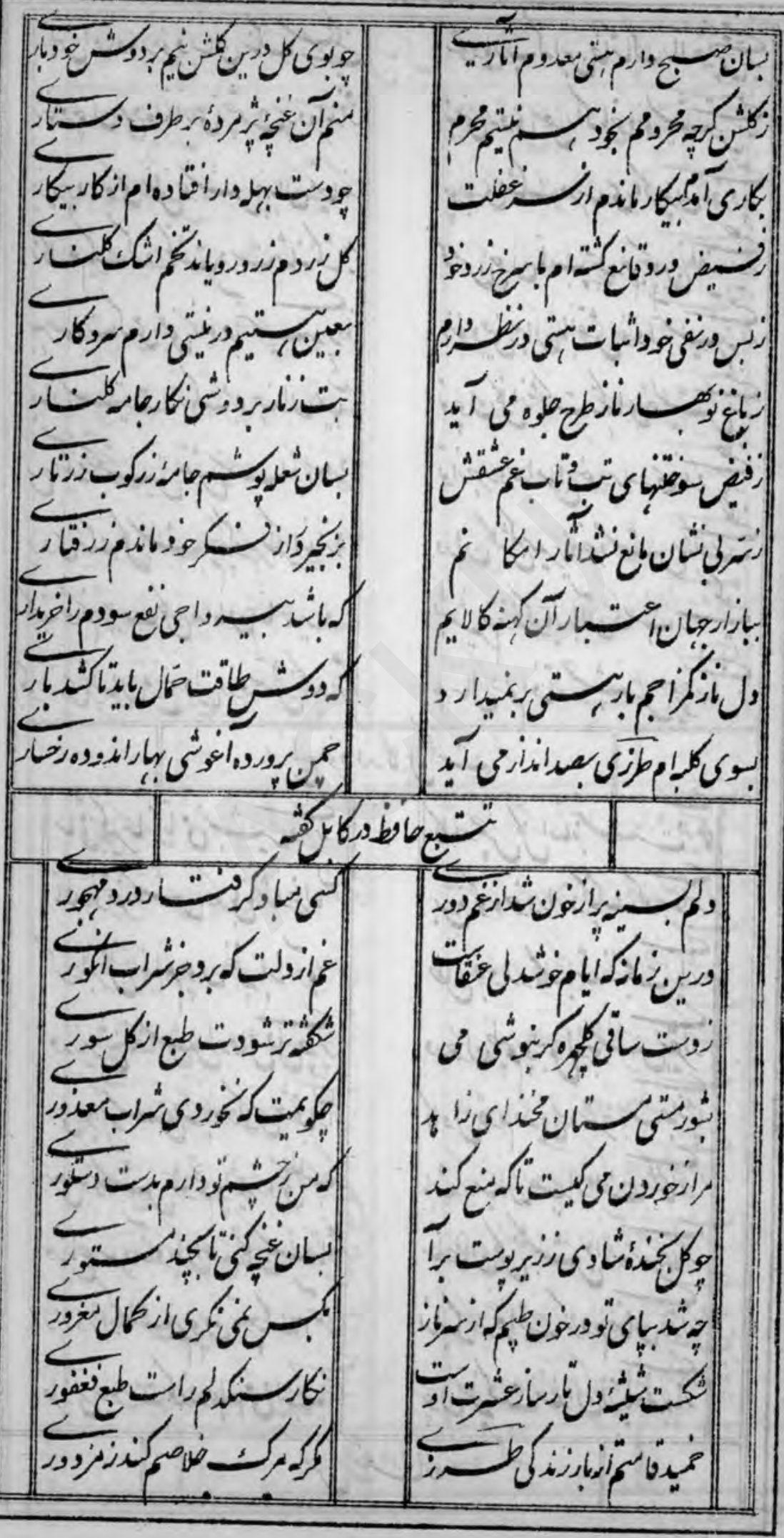




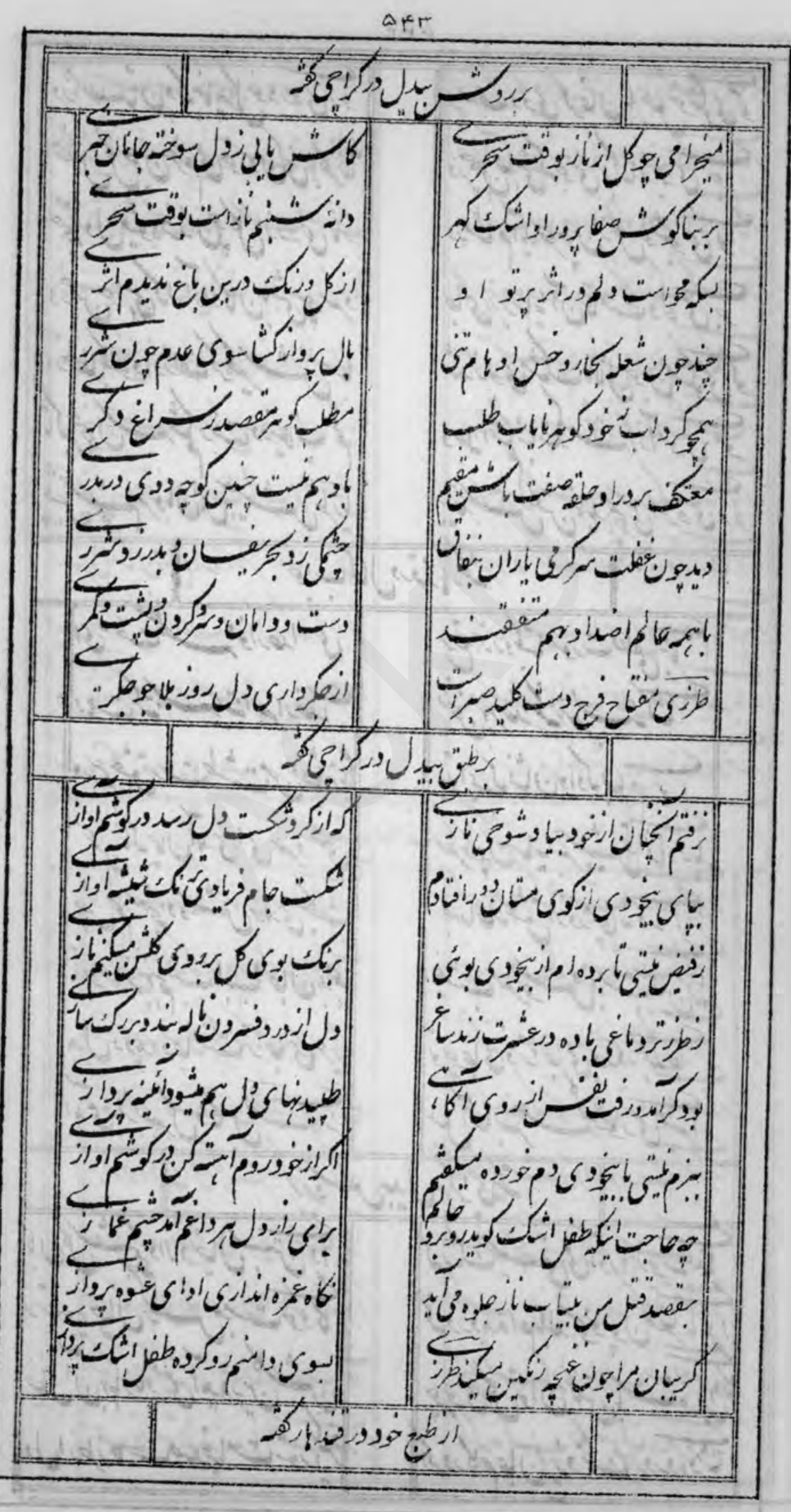


$\Delta r f$

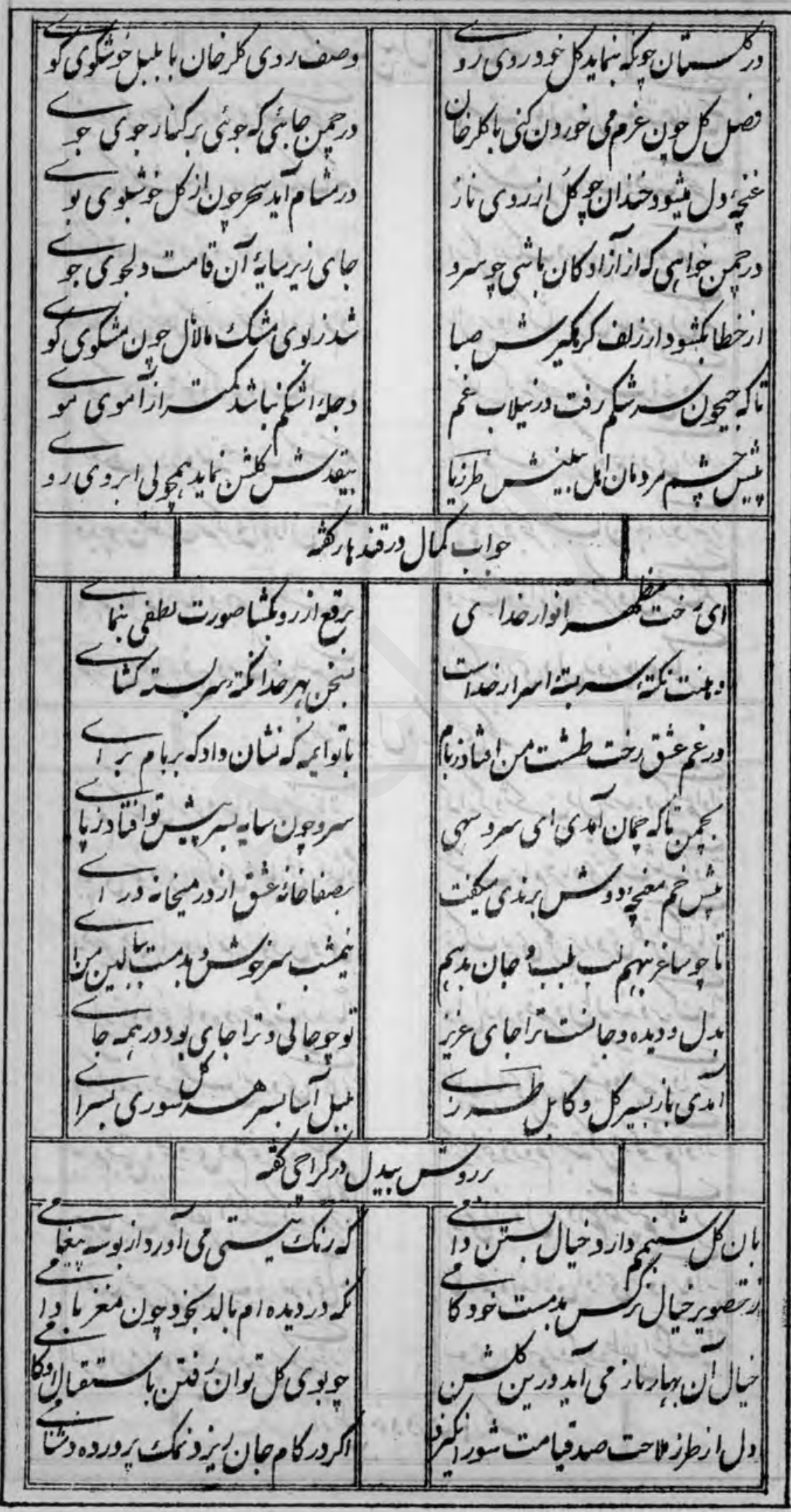

קיקוק. 
or $F$

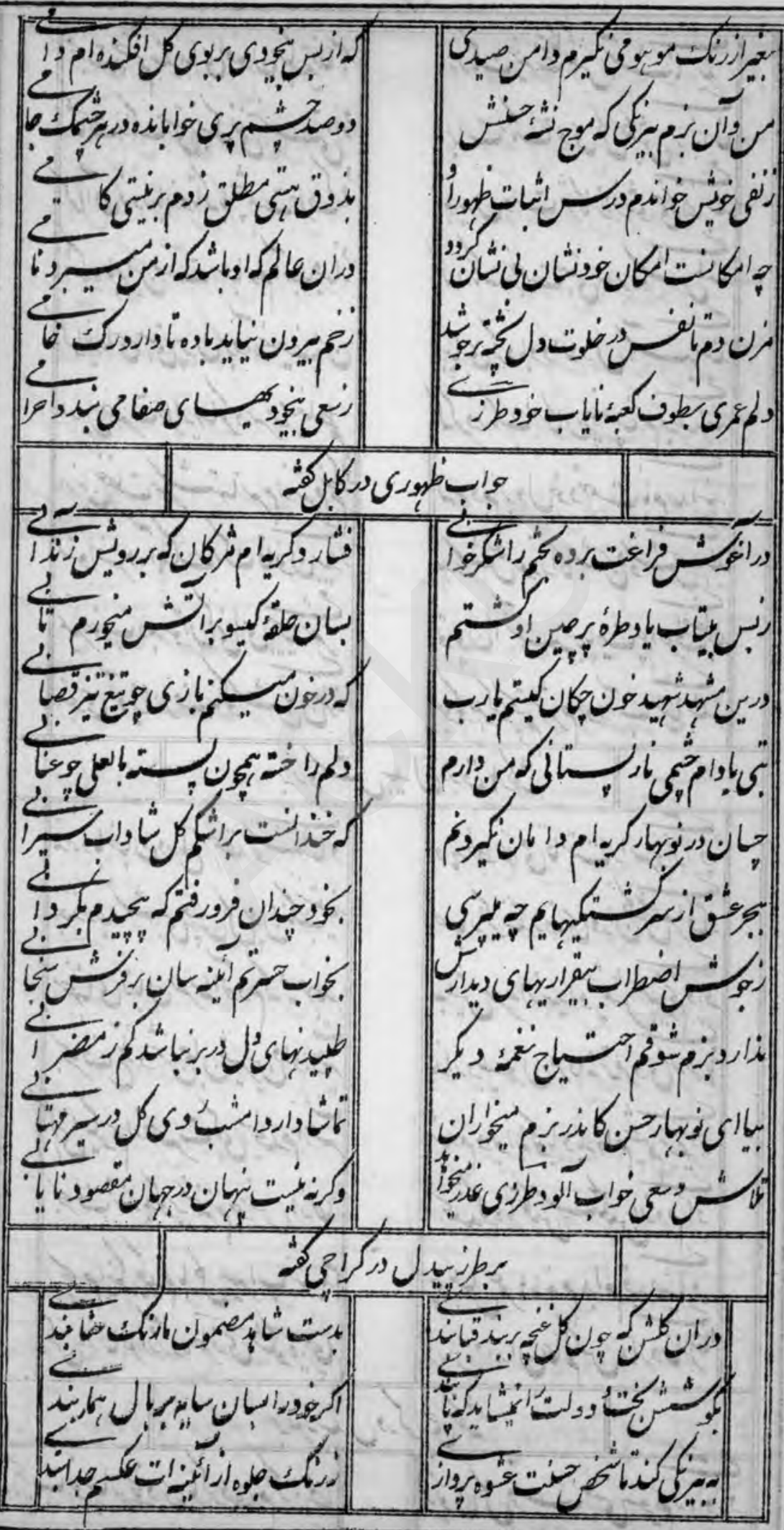


$\Delta F=$

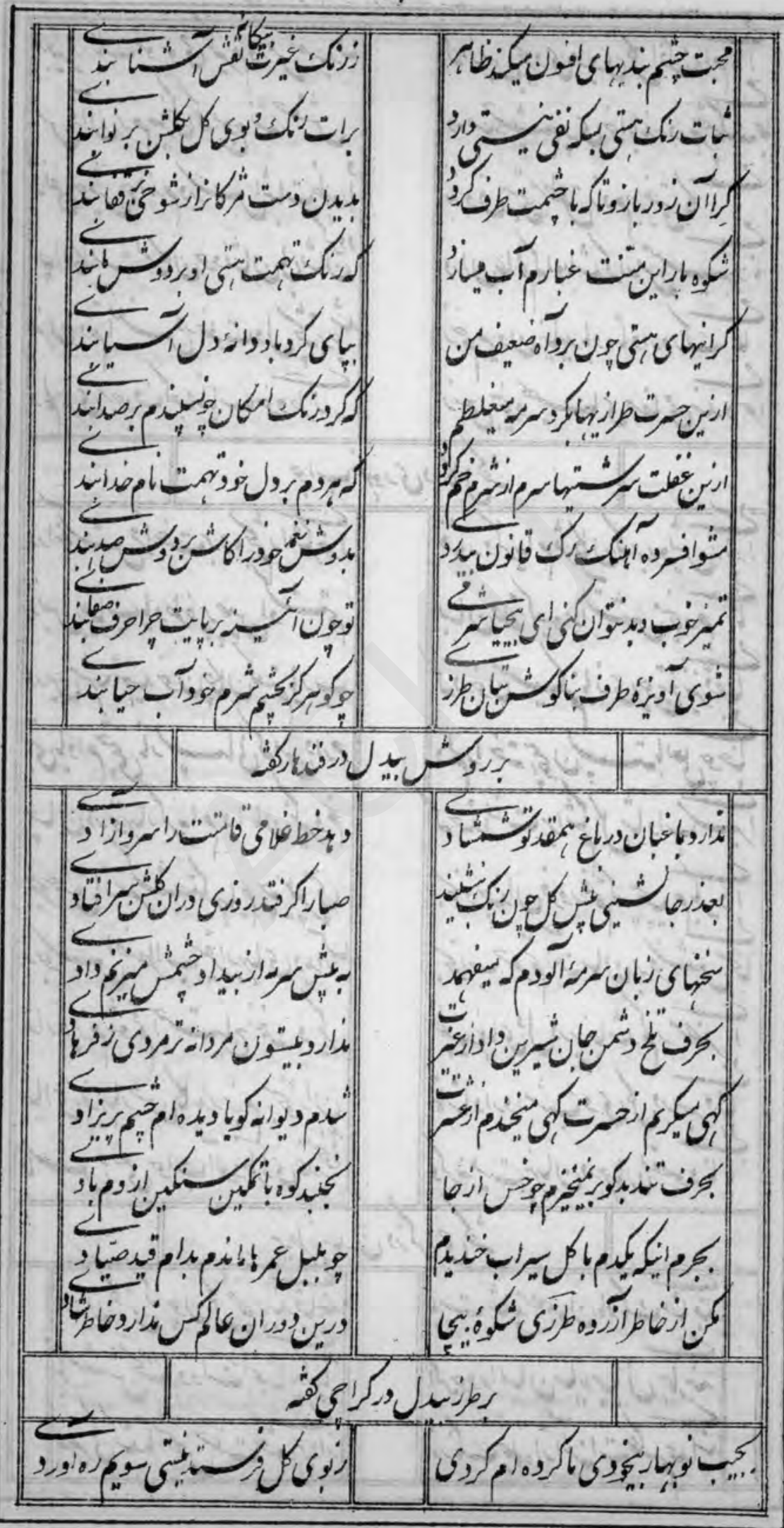


ofr

|


ofA

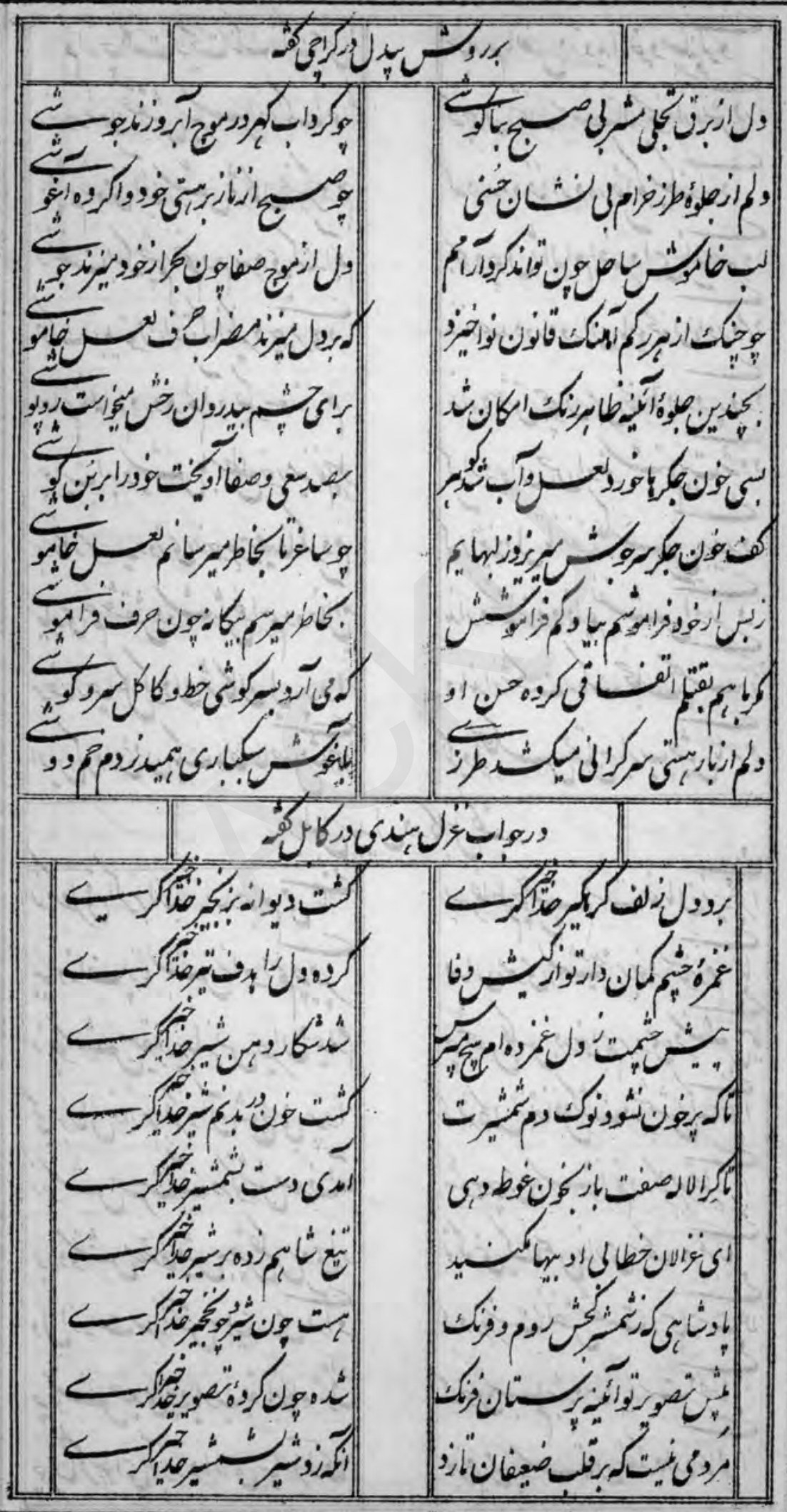


or 4

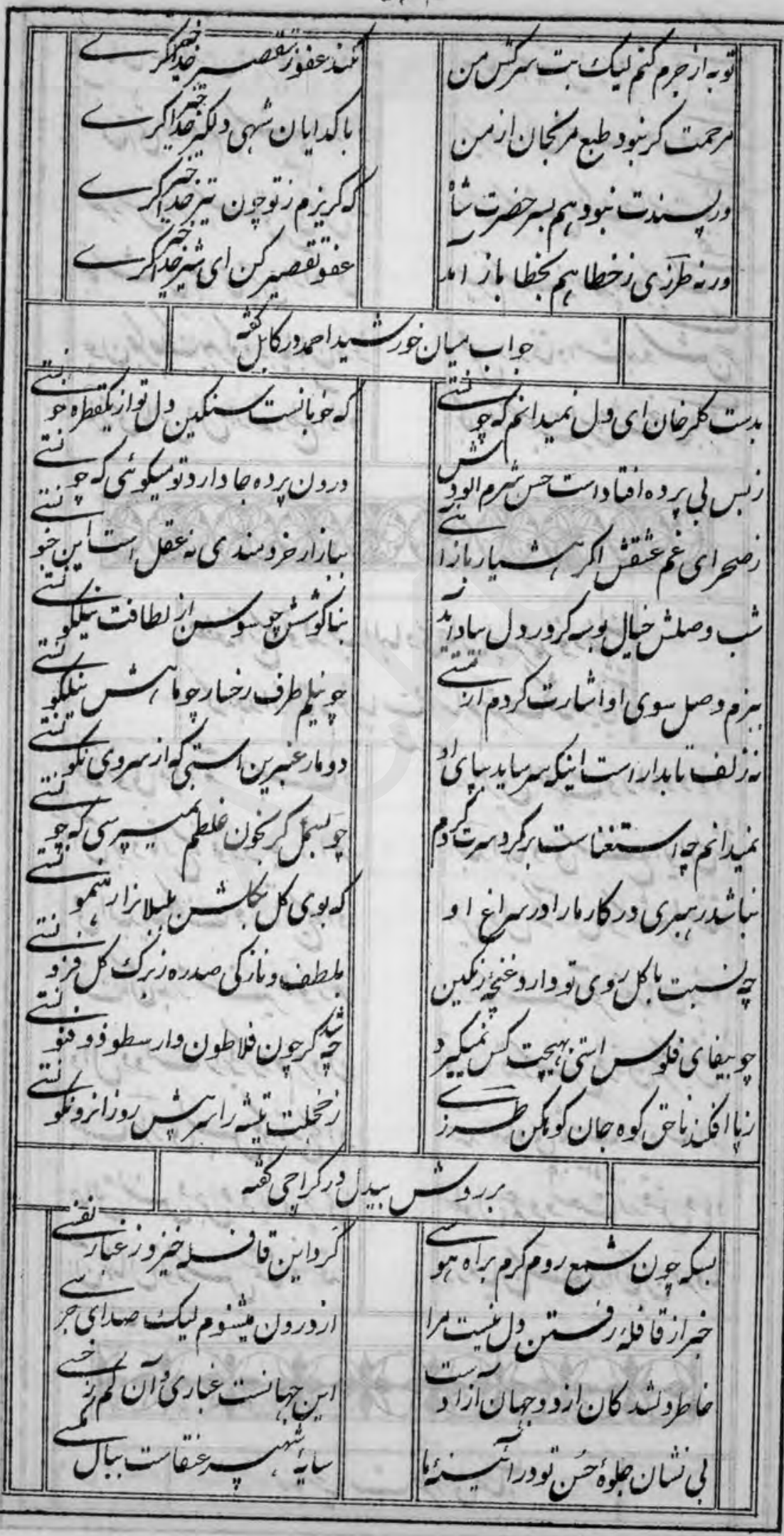


$\Delta \Delta \cdot$

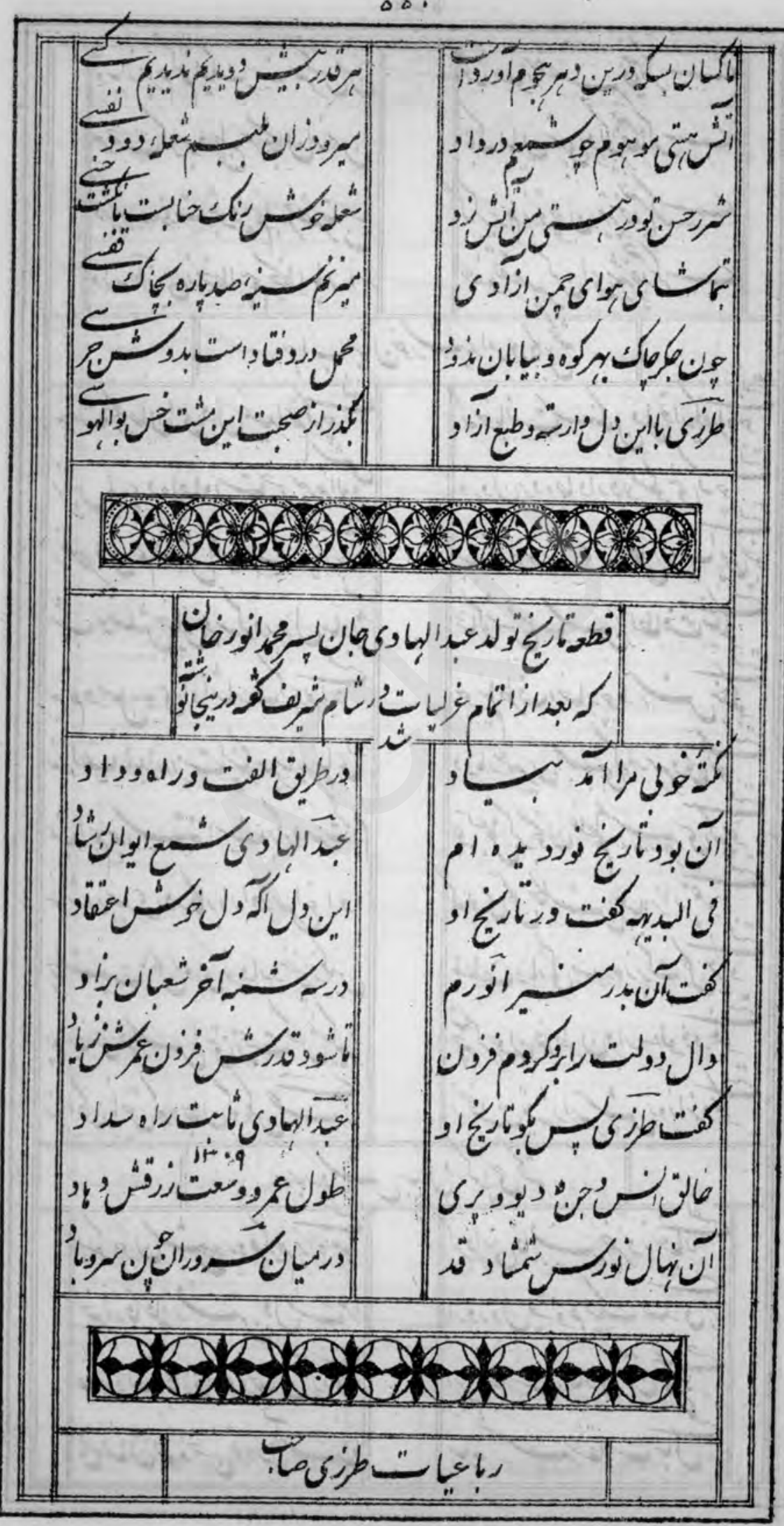


$\Delta \Delta 1$

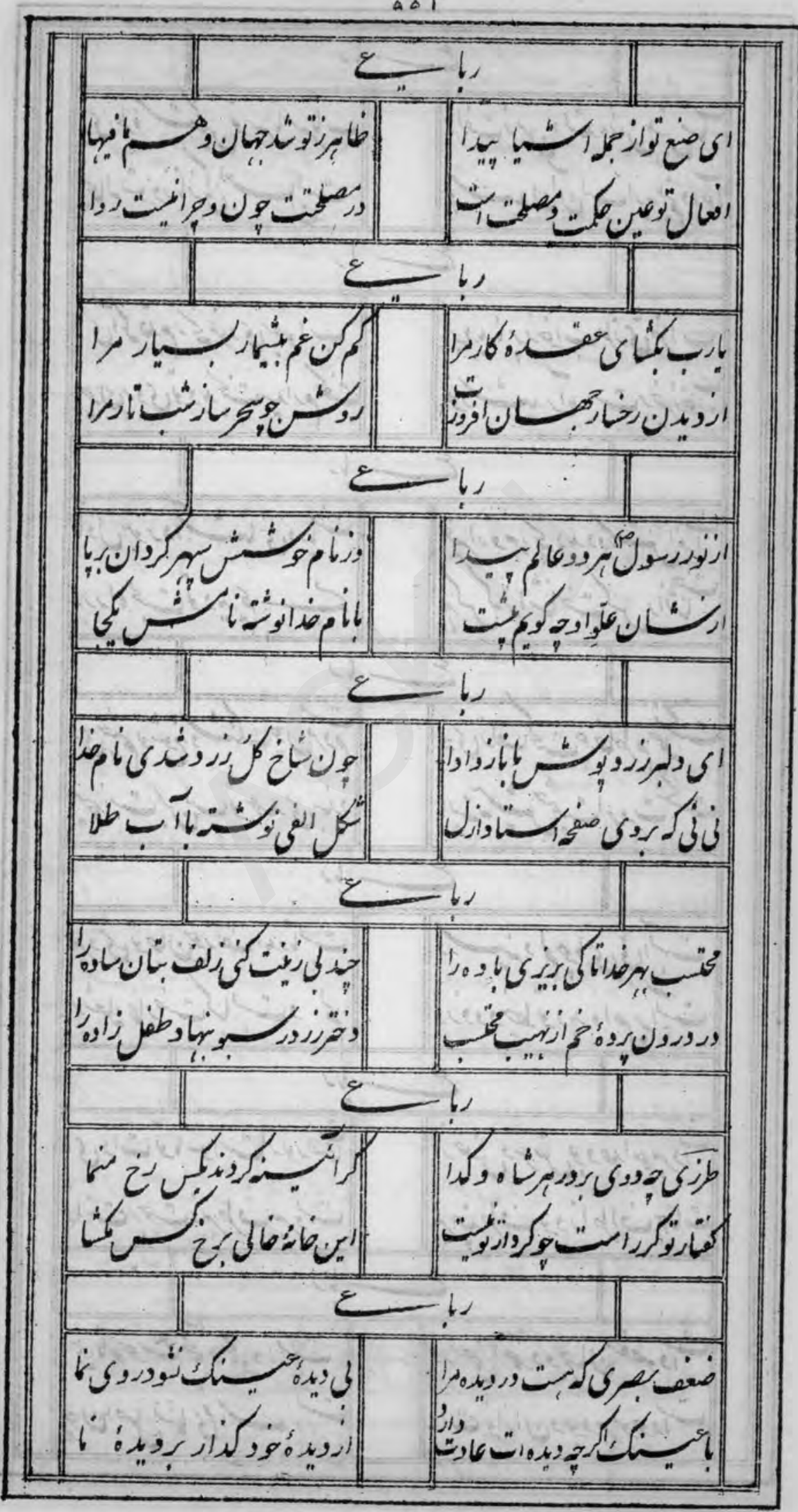




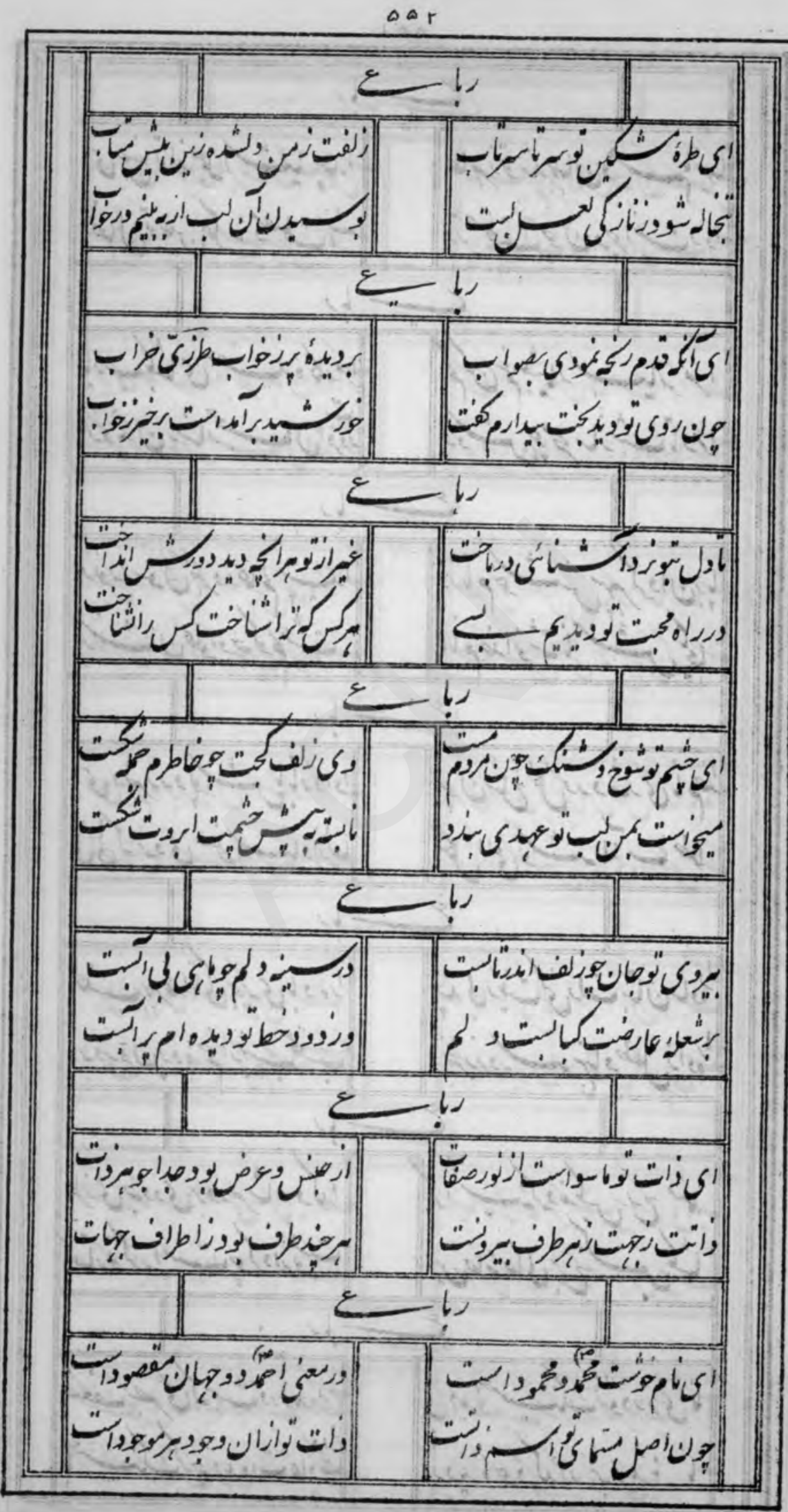


$\Delta \Delta \mu$

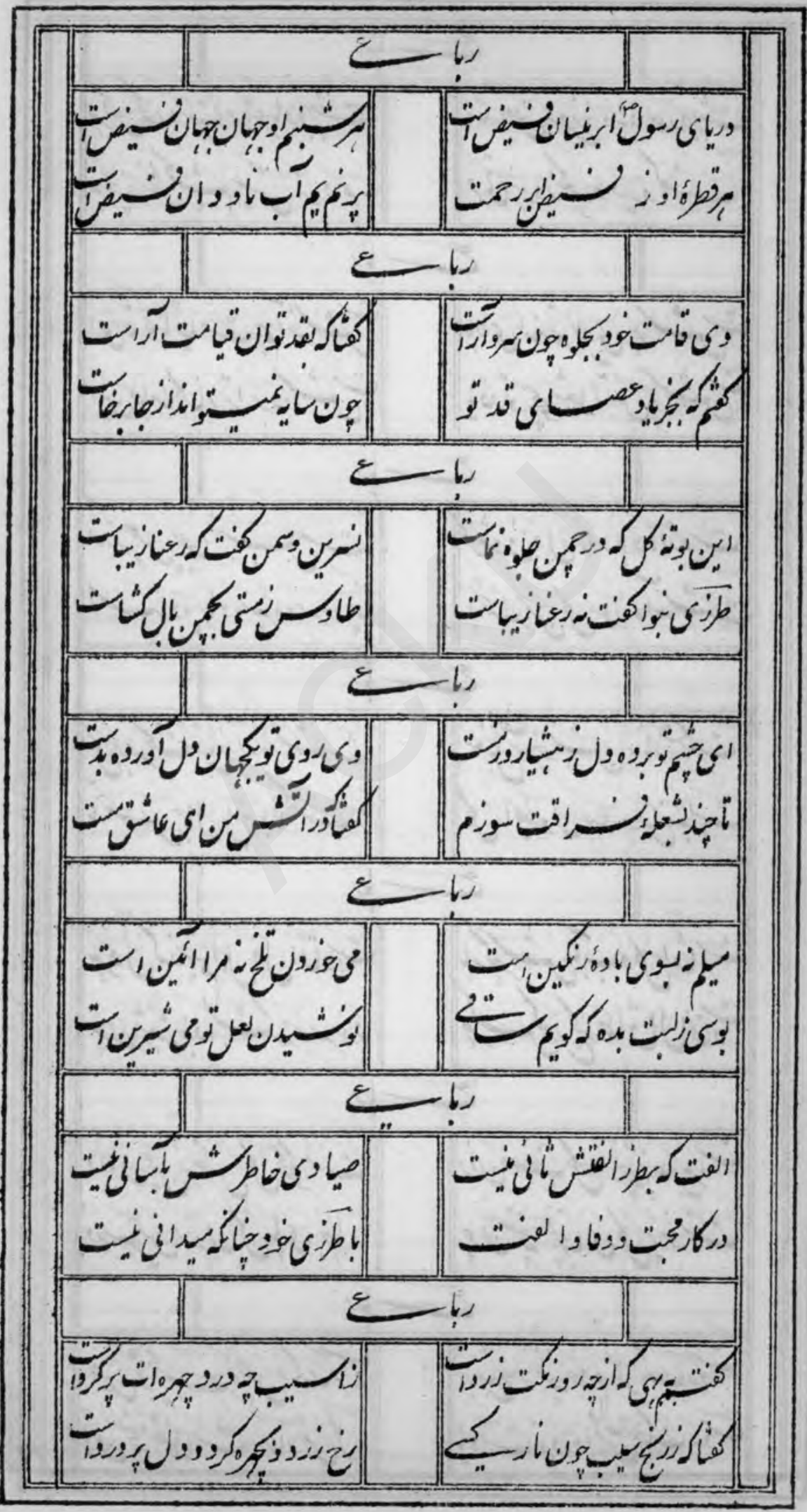


$\Delta \Delta r^{c}$

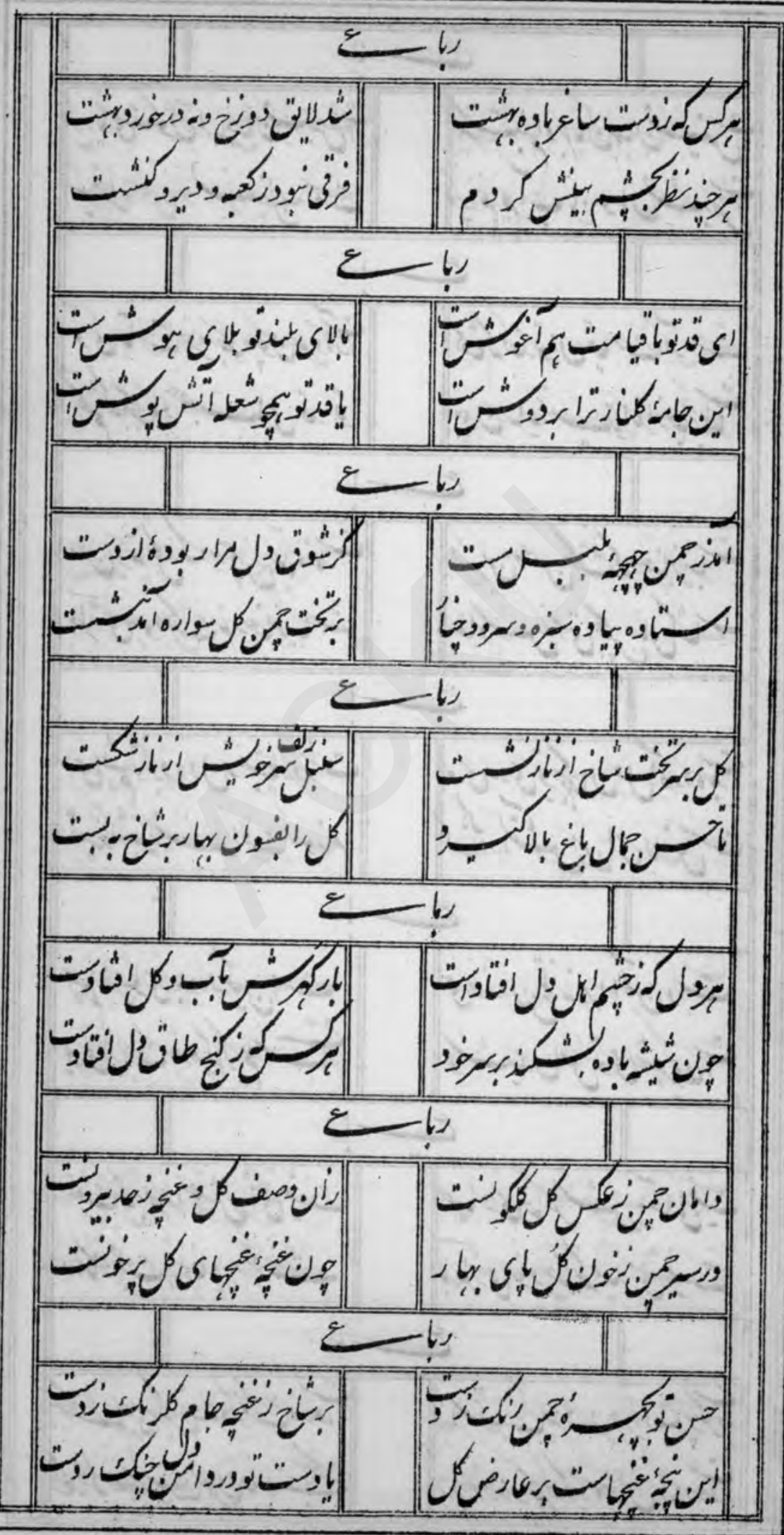


$\Delta \triangle A$

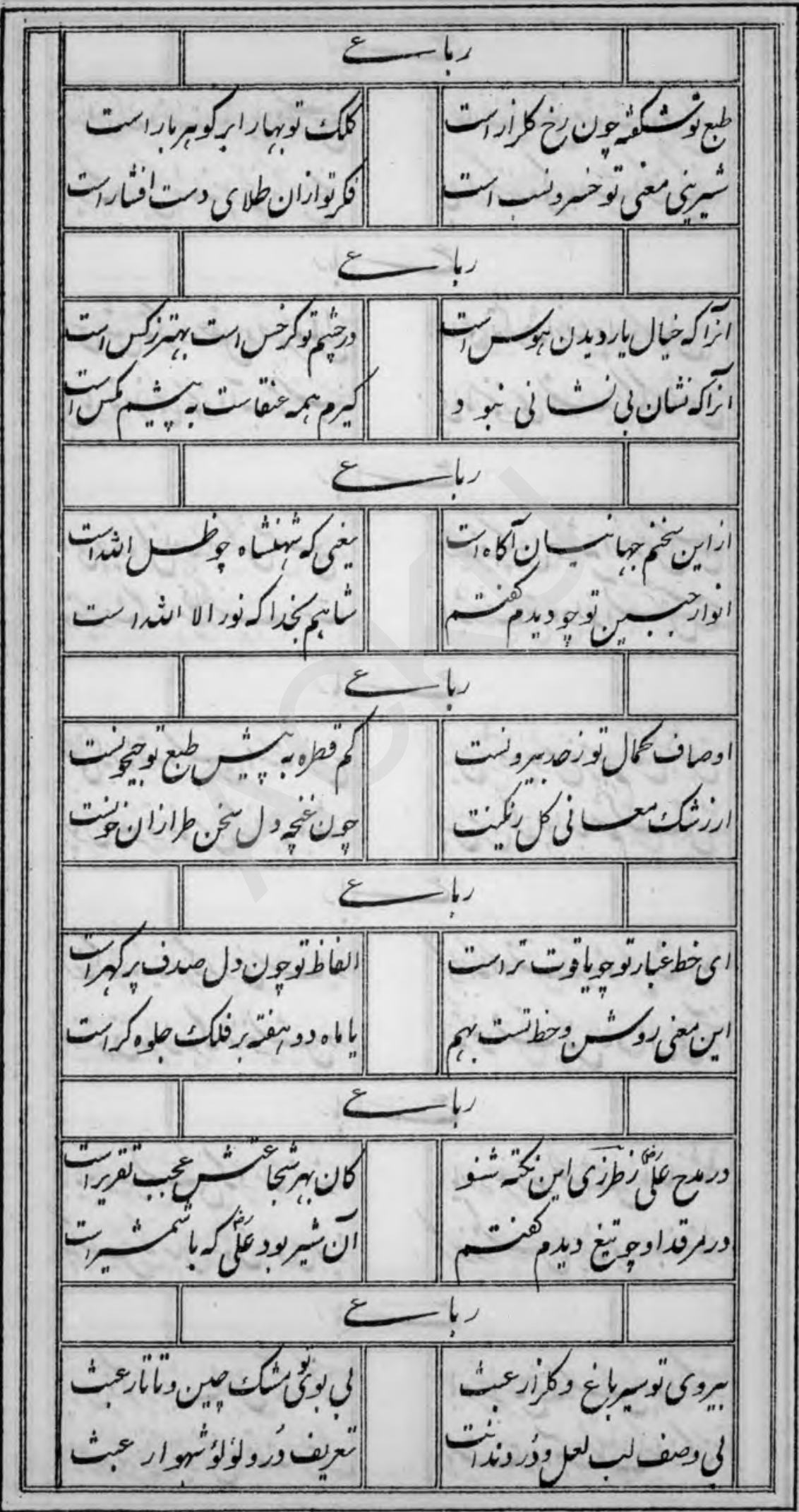


005

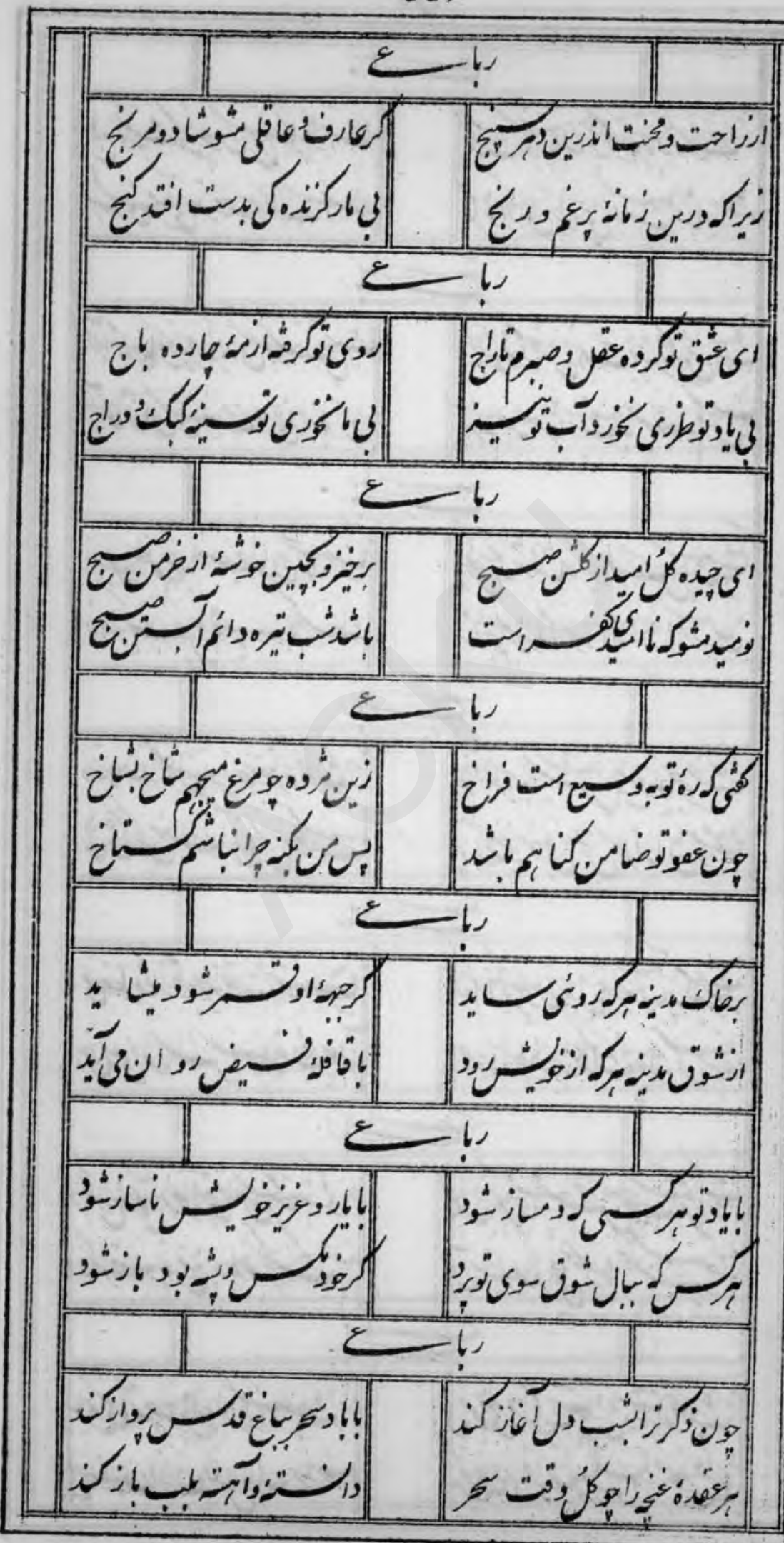




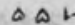

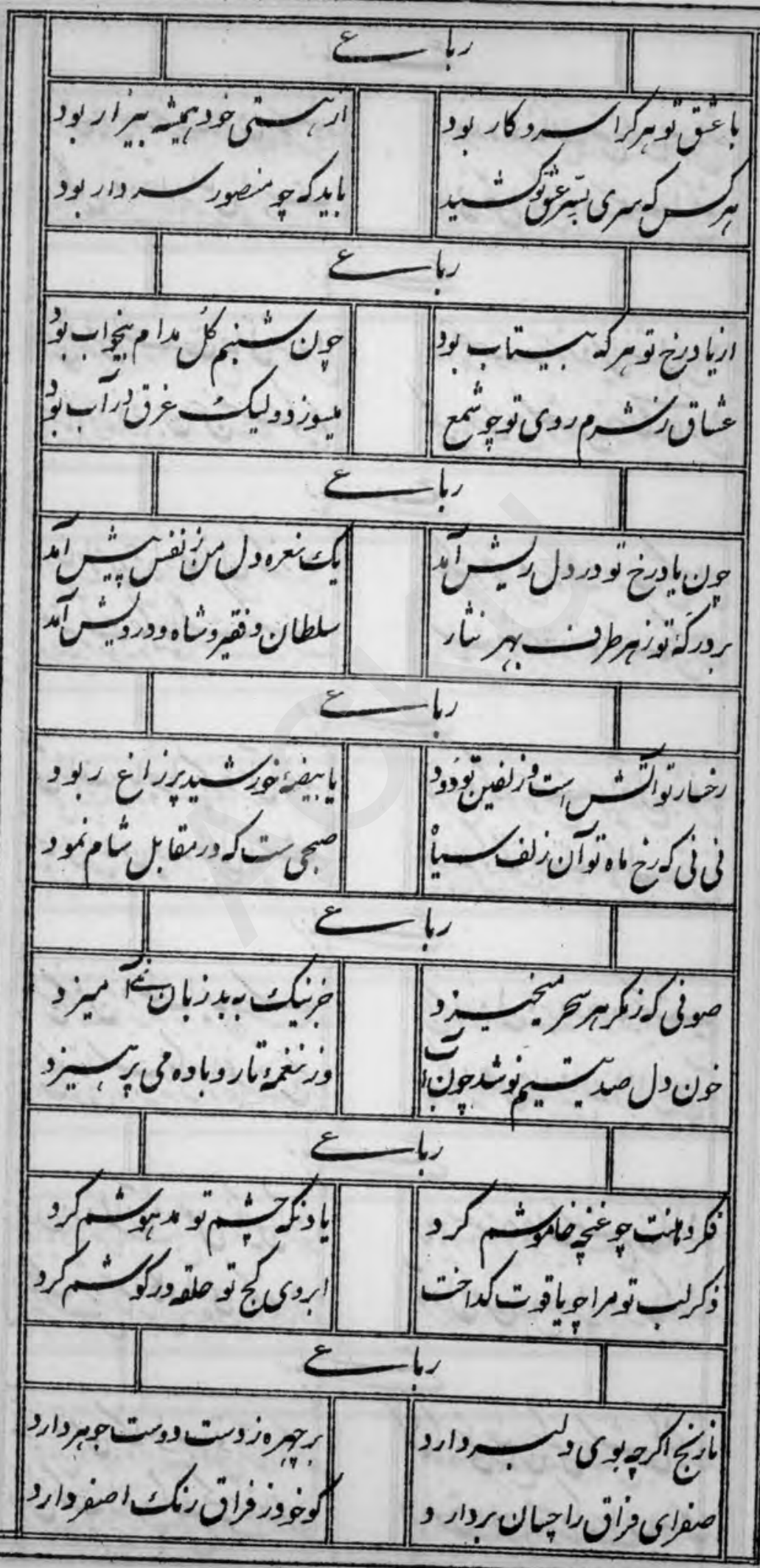


$\Delta \infty A$

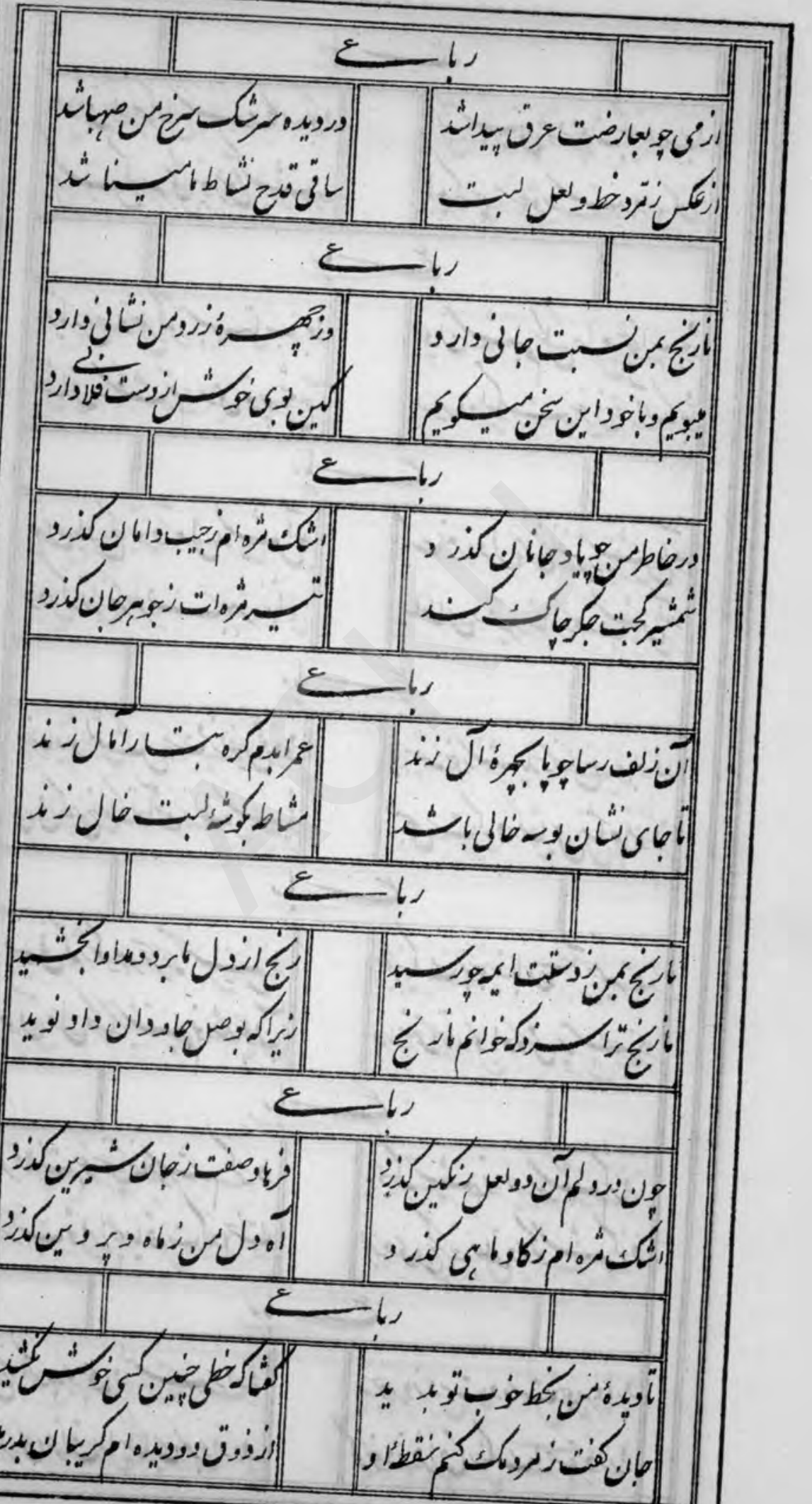


$\Delta \Delta 9$

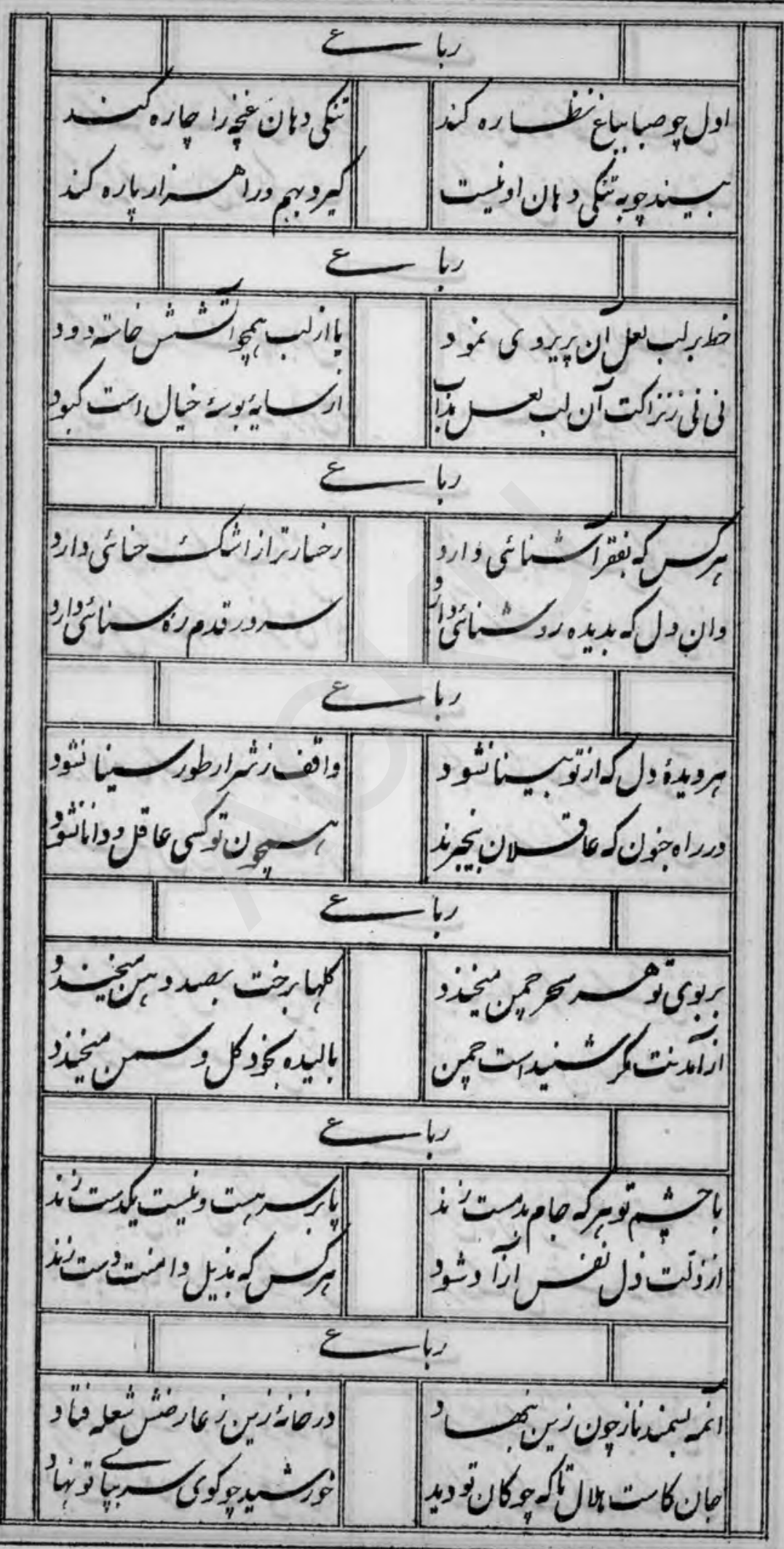


$0 \leqslant 1$

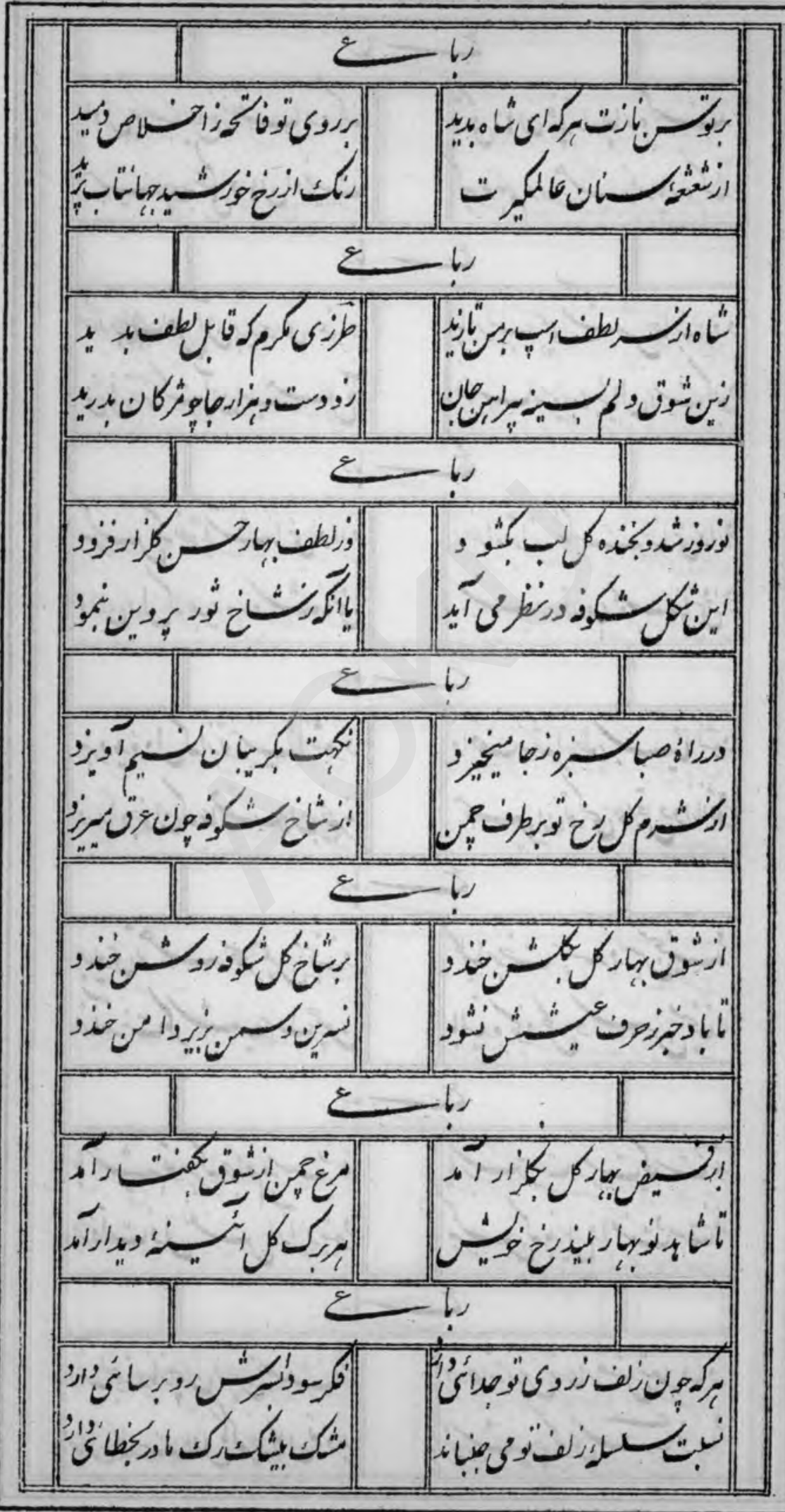


$\Delta<1$

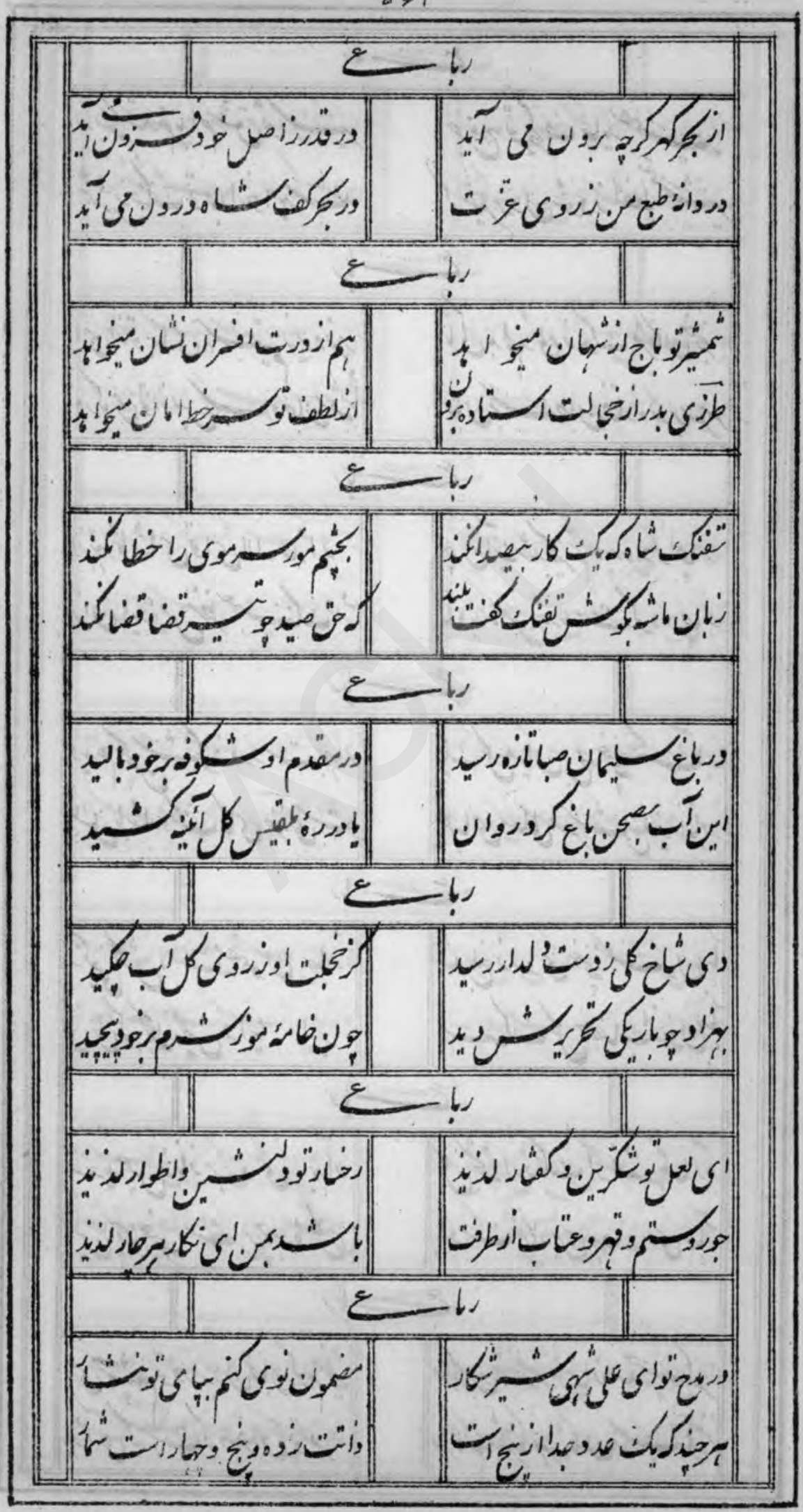


as

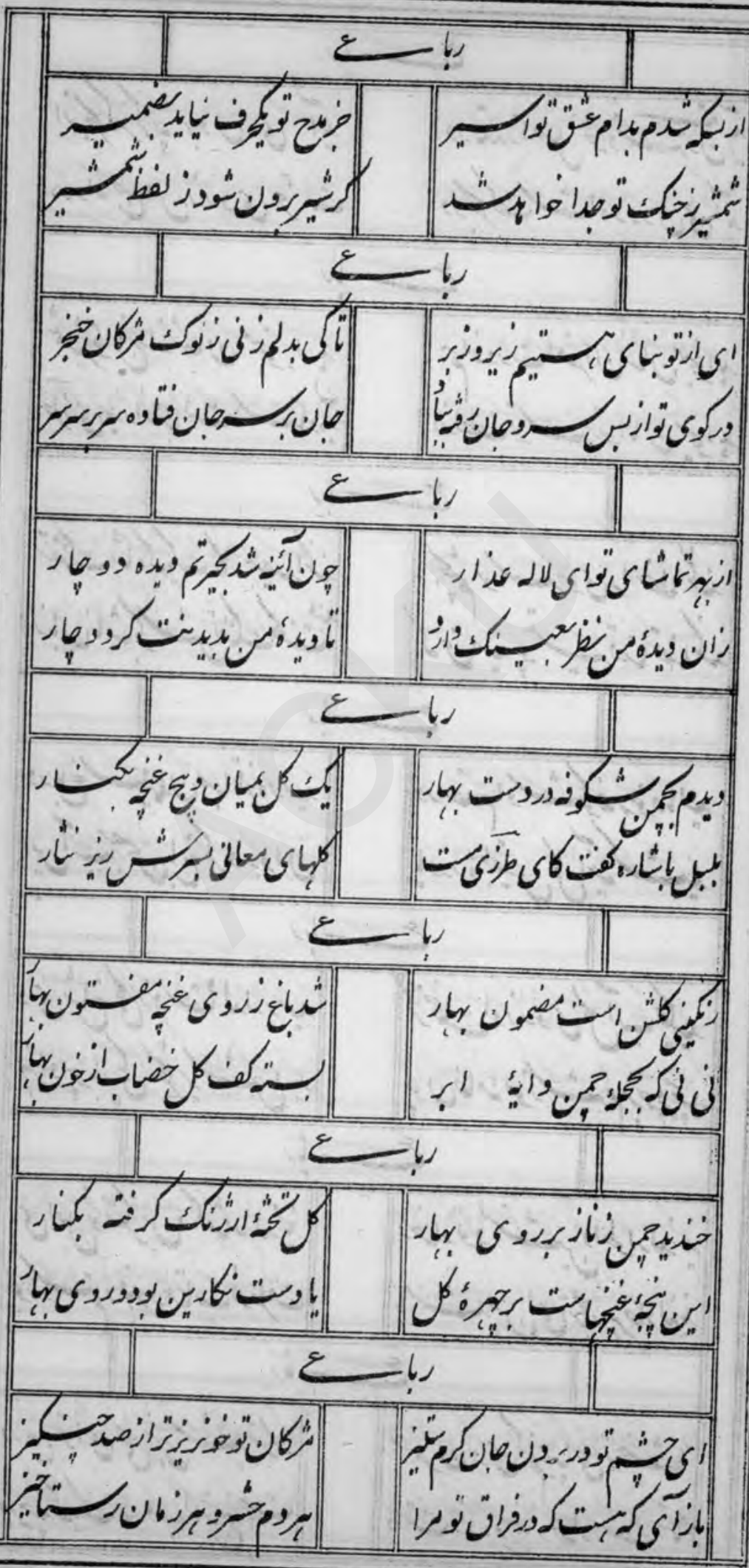




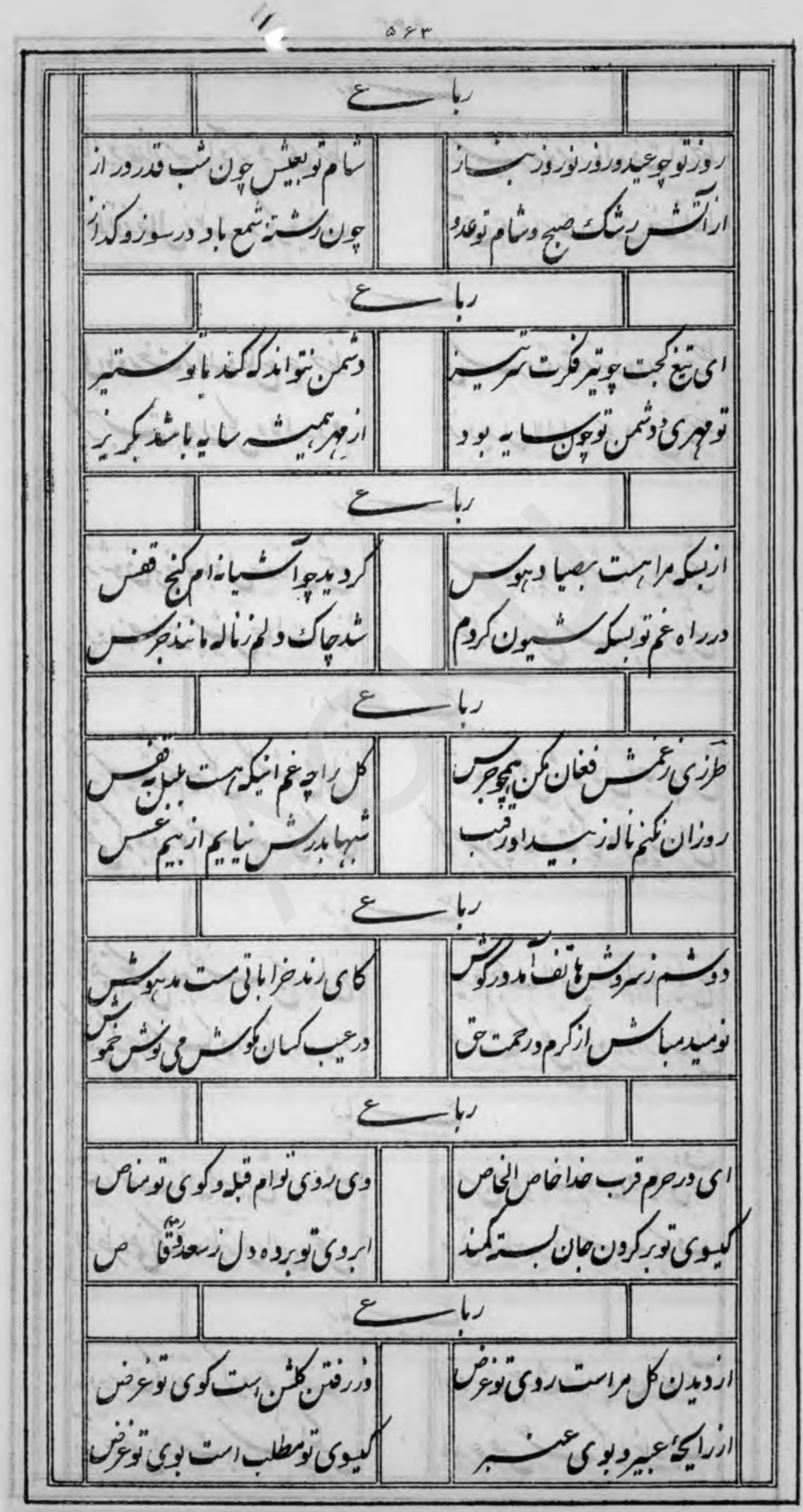


$\Delta r$

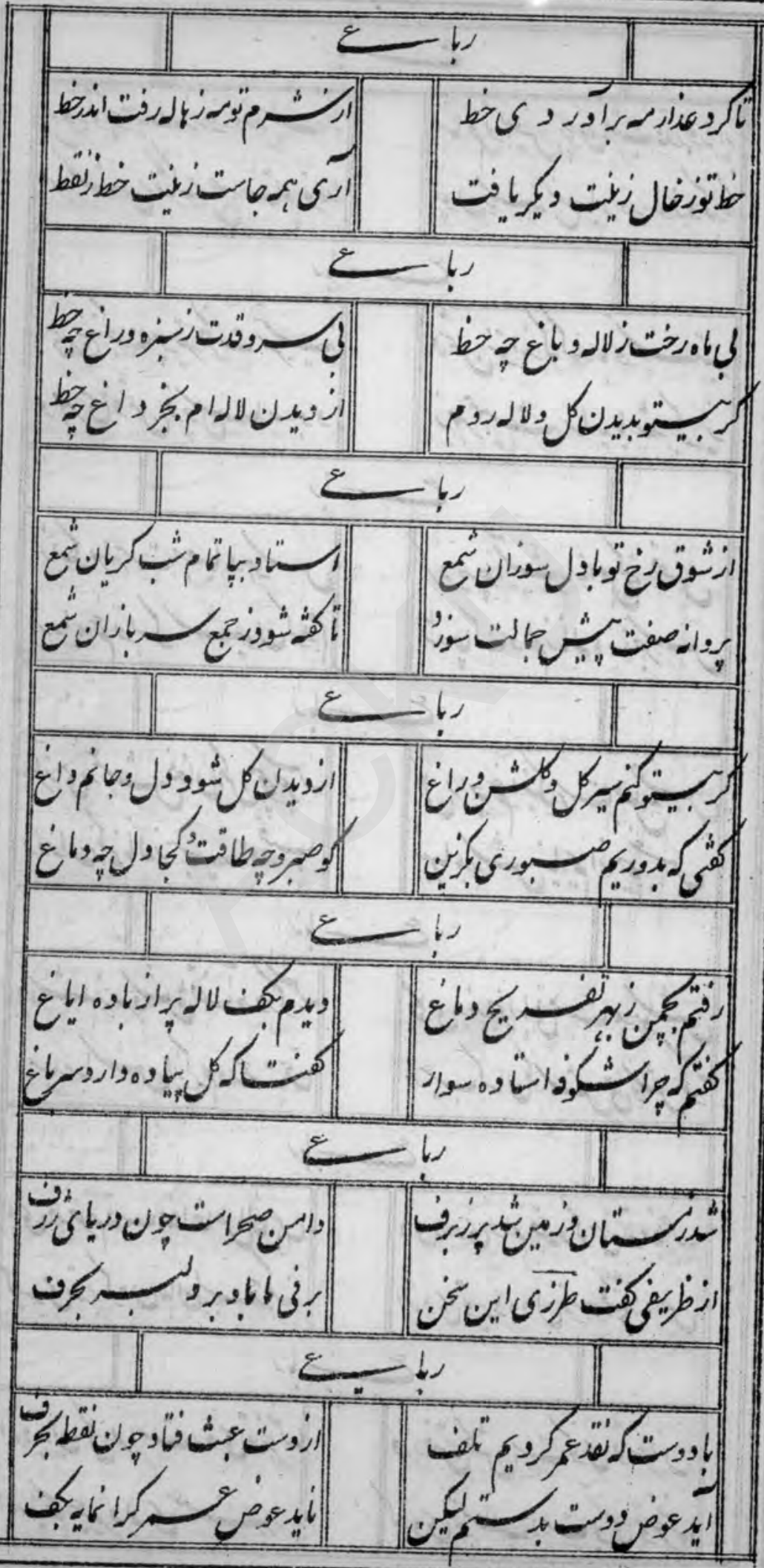


$\Delta \& 0$

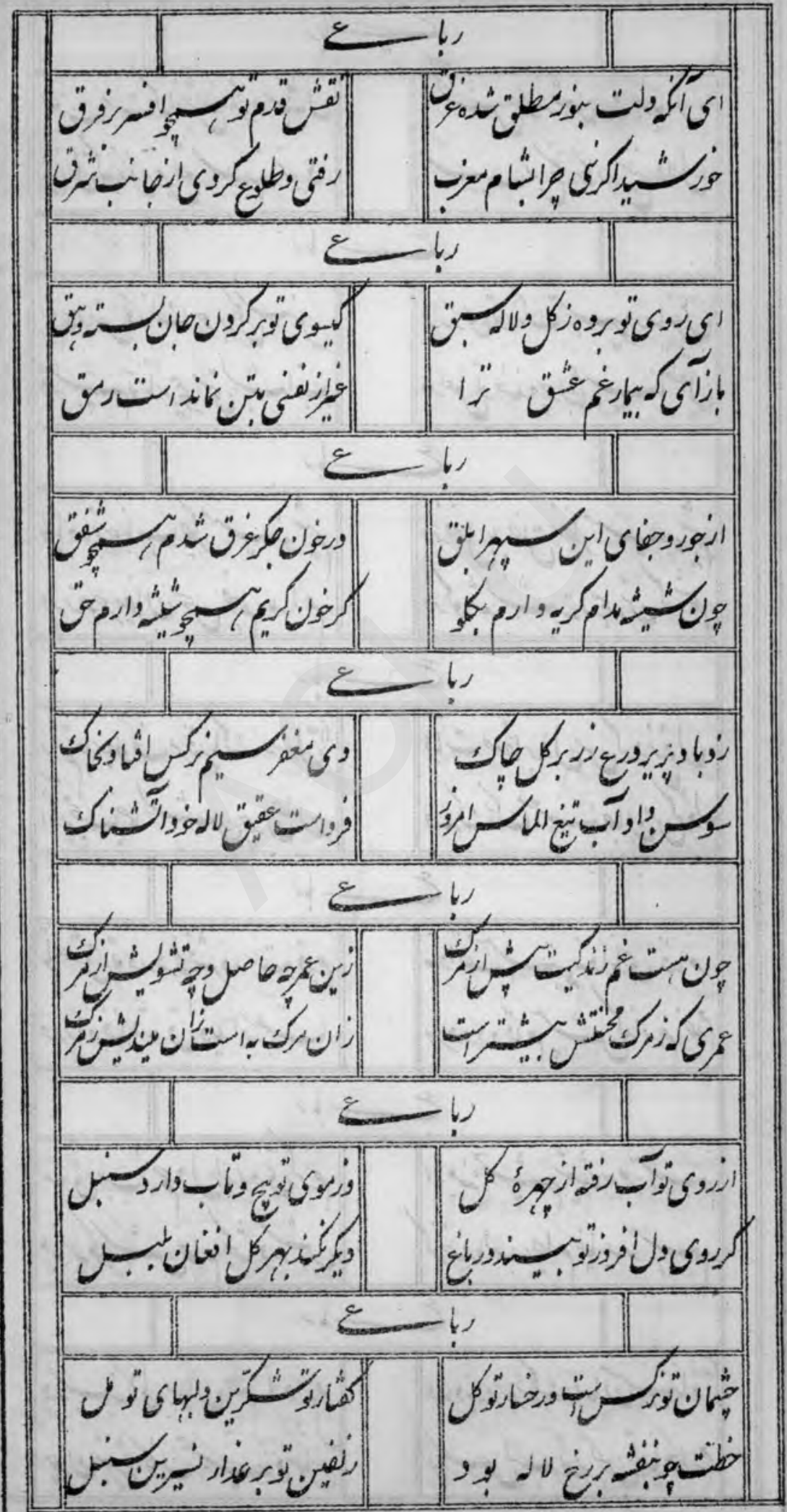


a)s

|


DSV

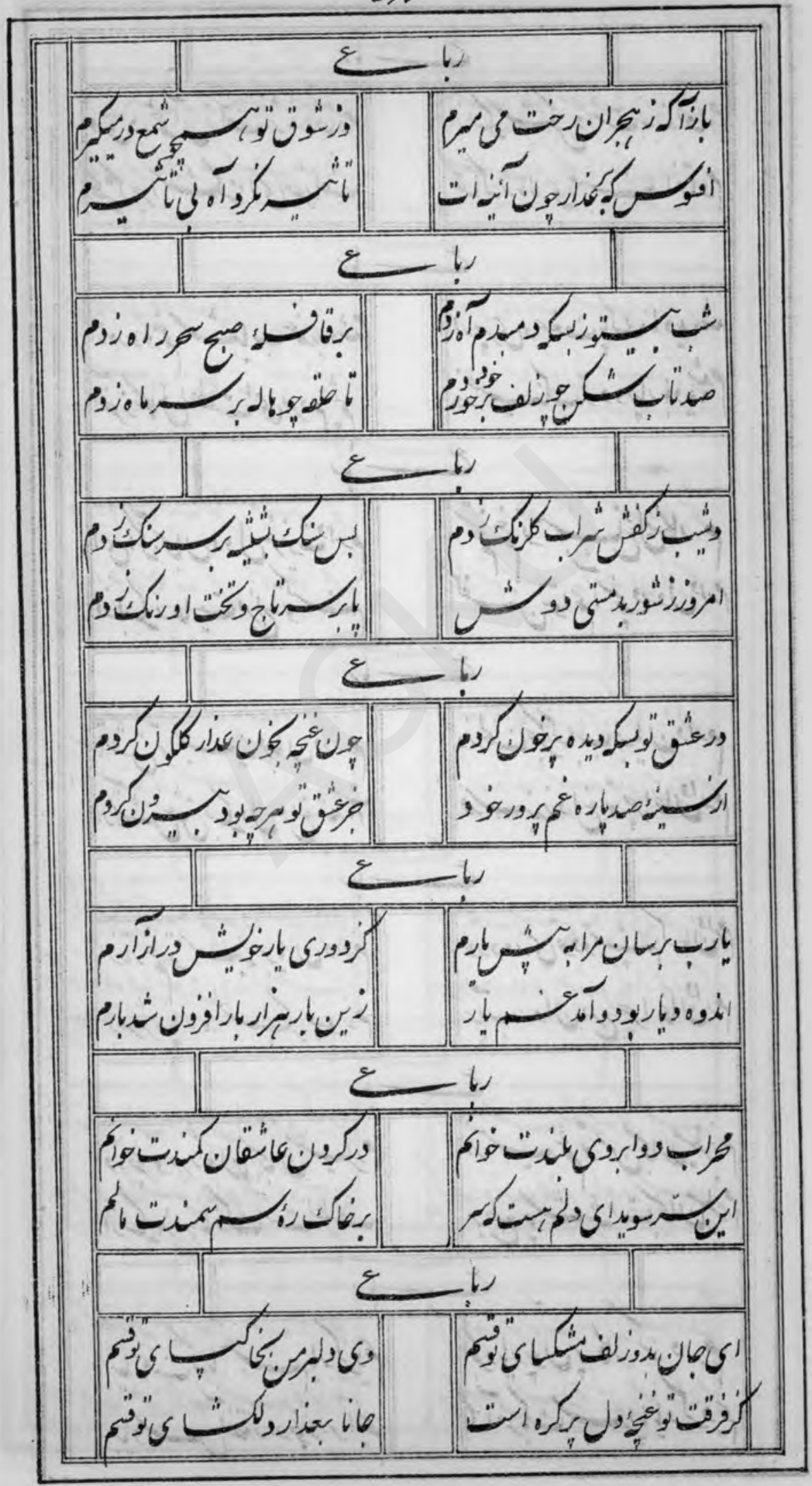


DSA

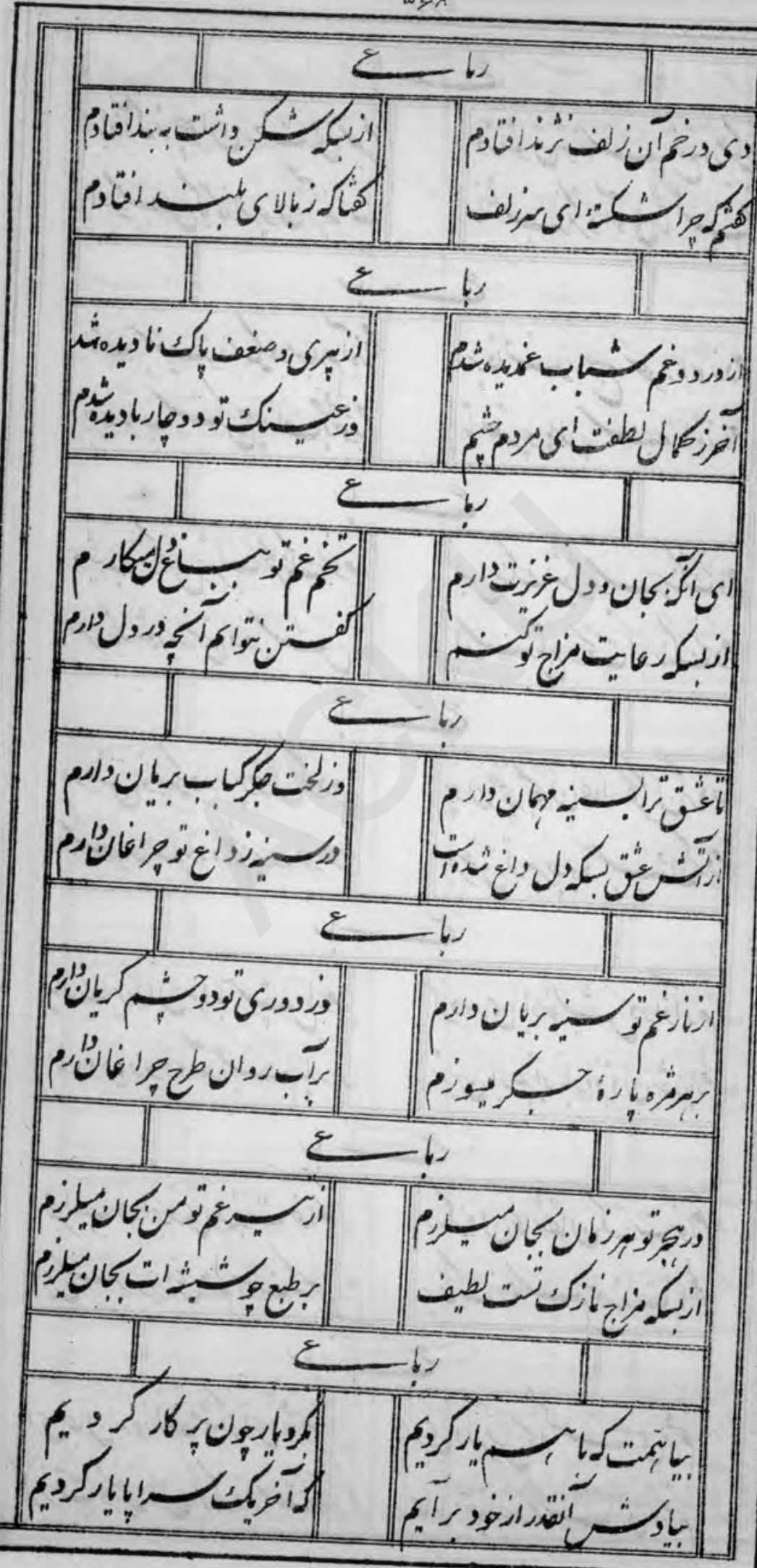

$\therefore$ 
D \& 9

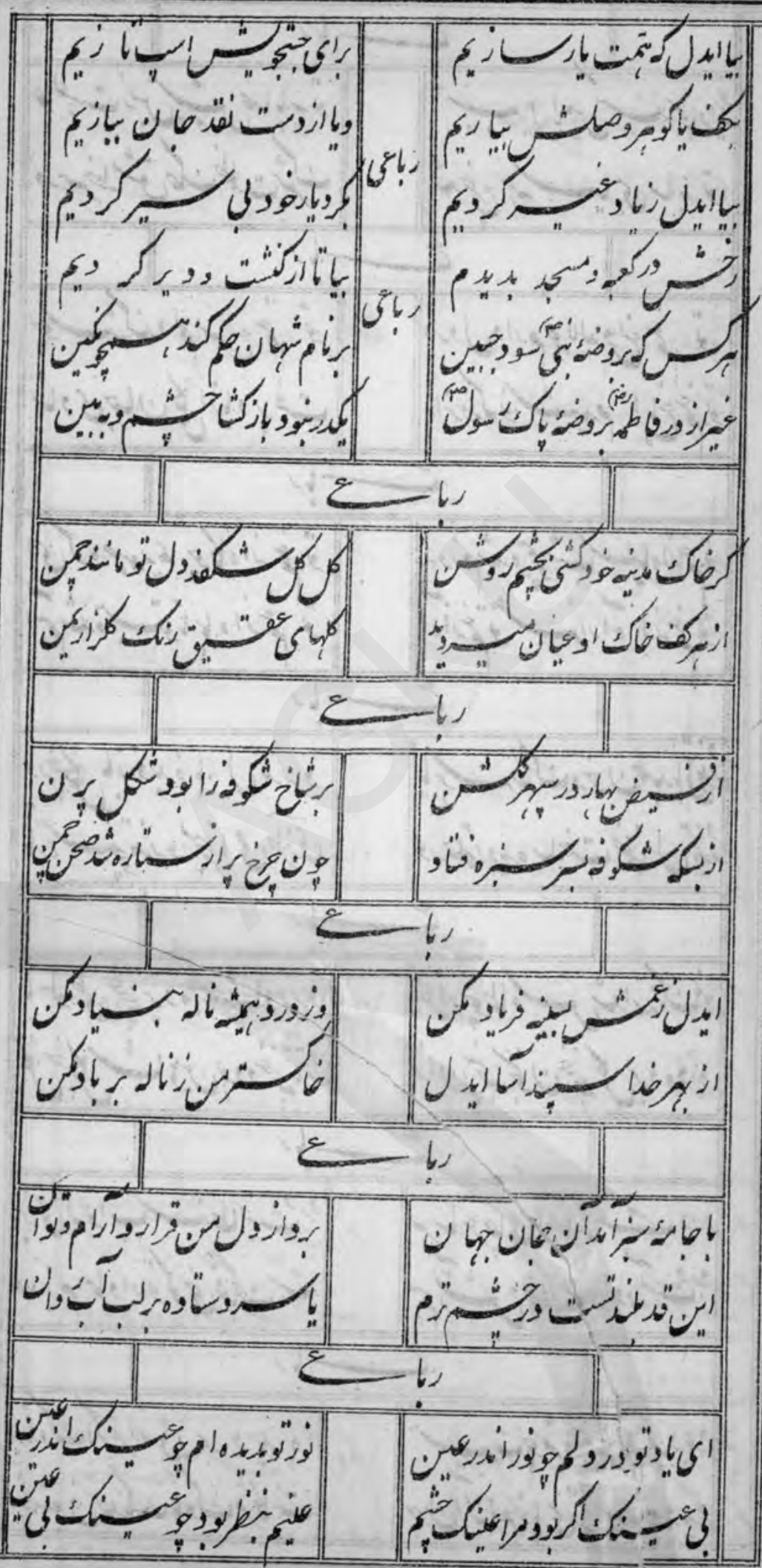


$\Delta V$

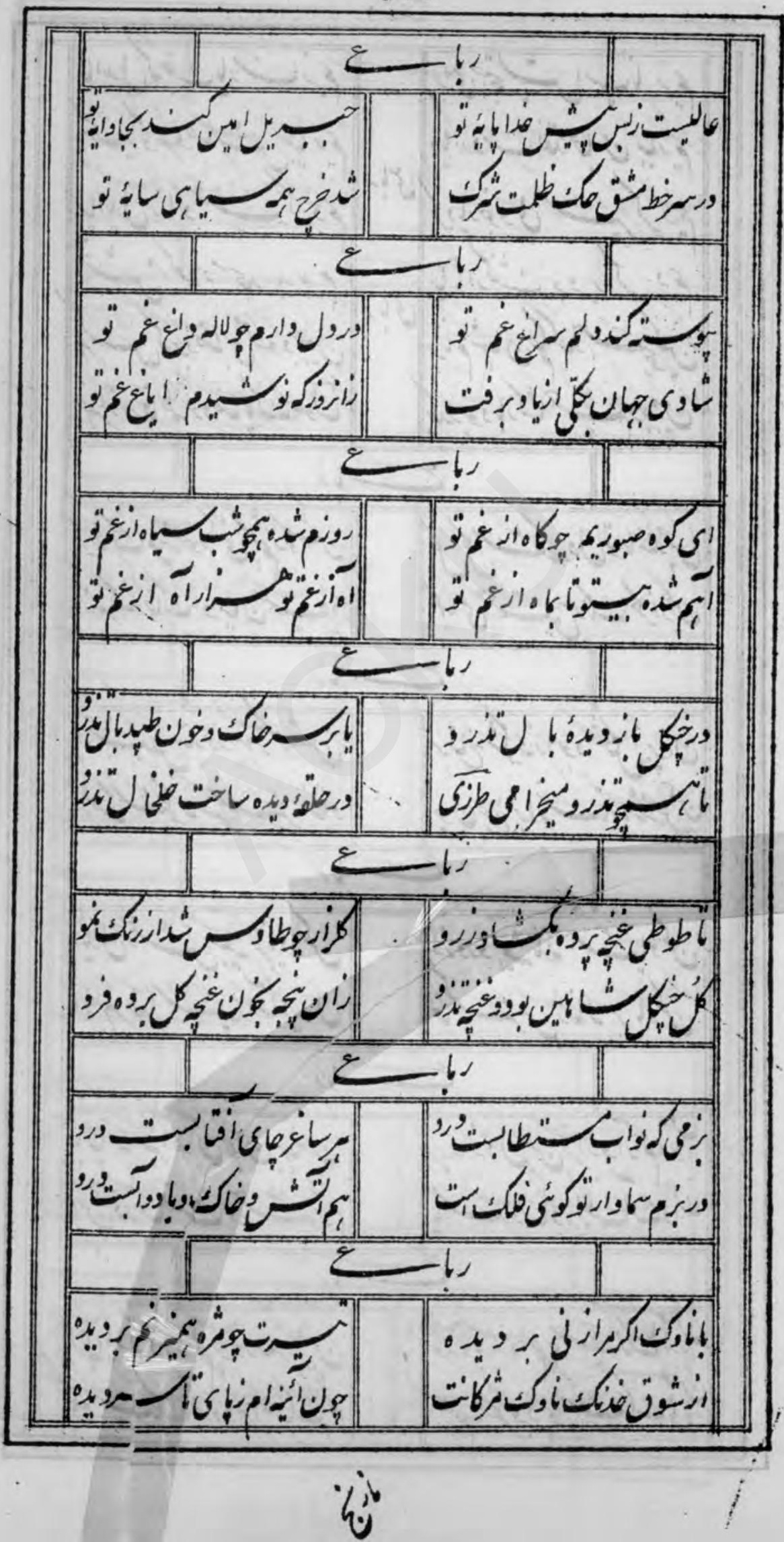


$\Delta \vee 1$

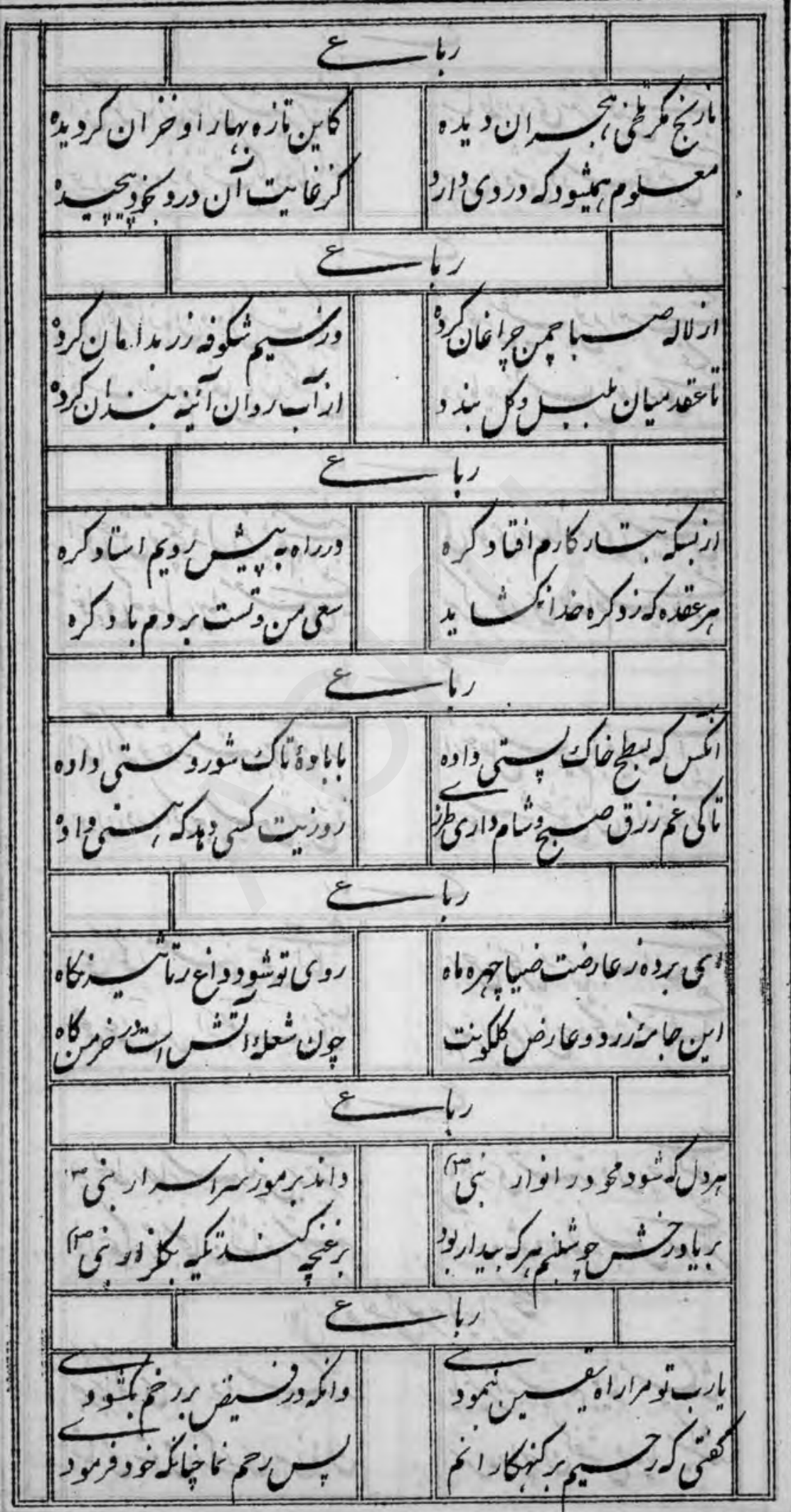


$\omega R$

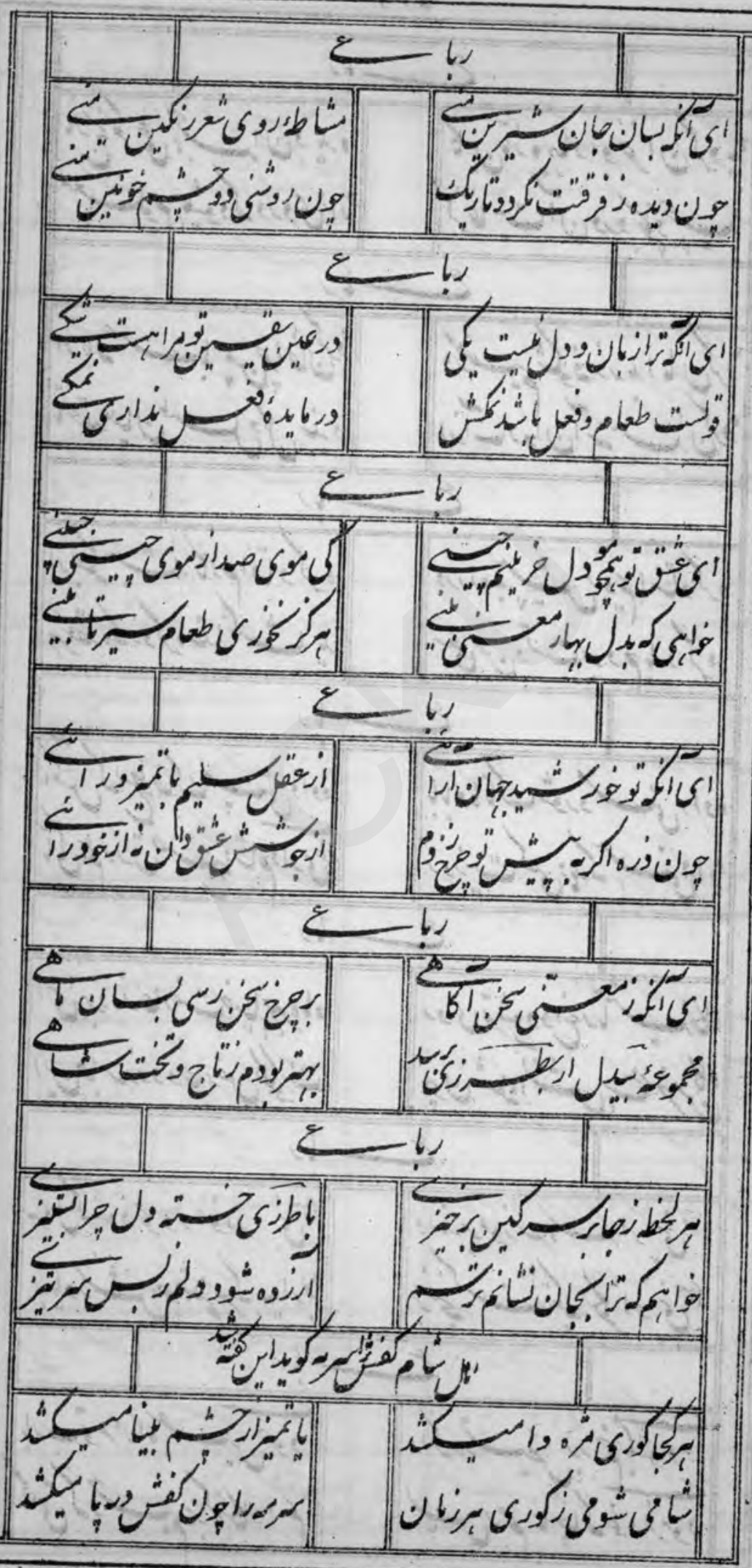


arr

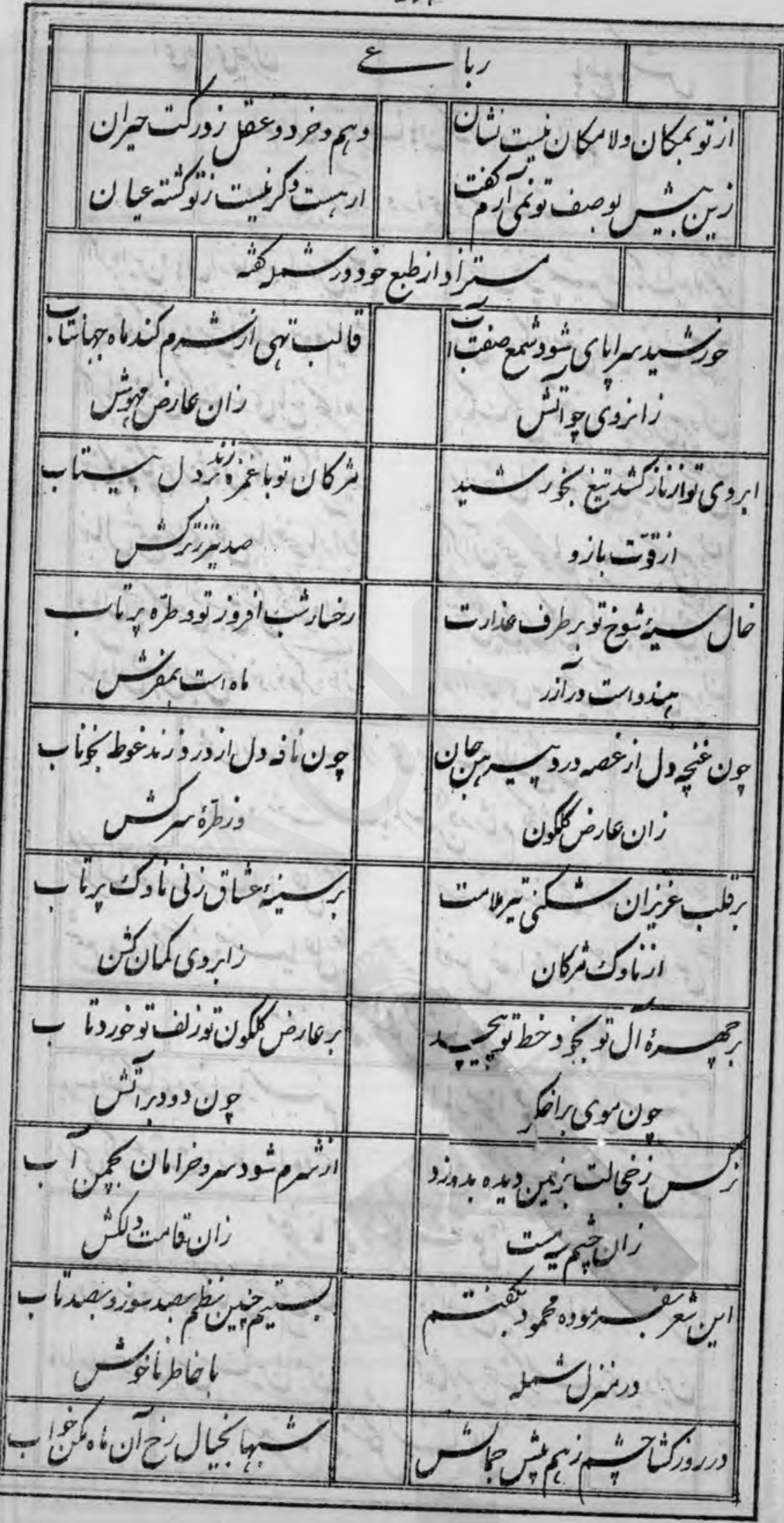


$\Delta \vee F$

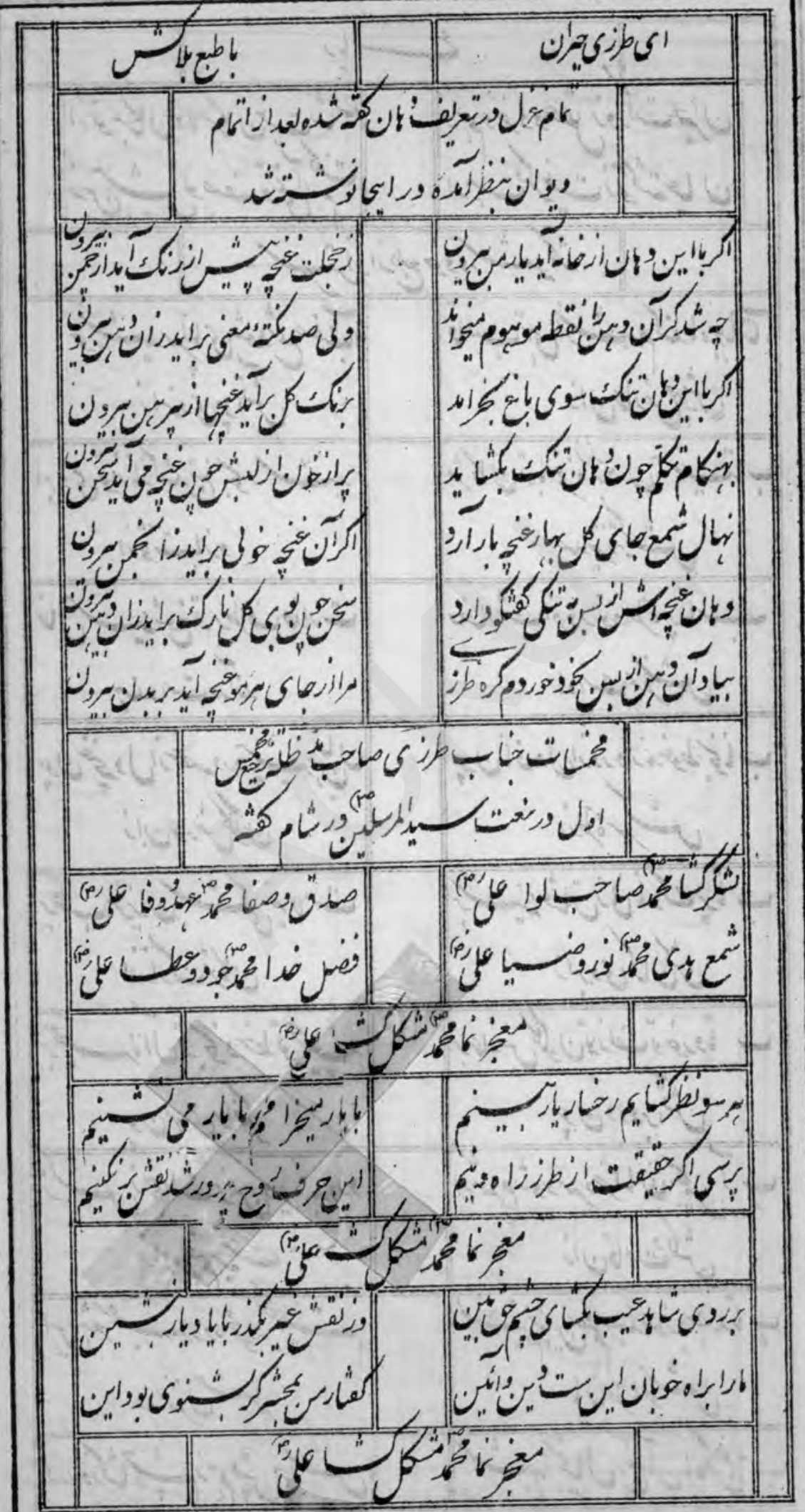


QLO

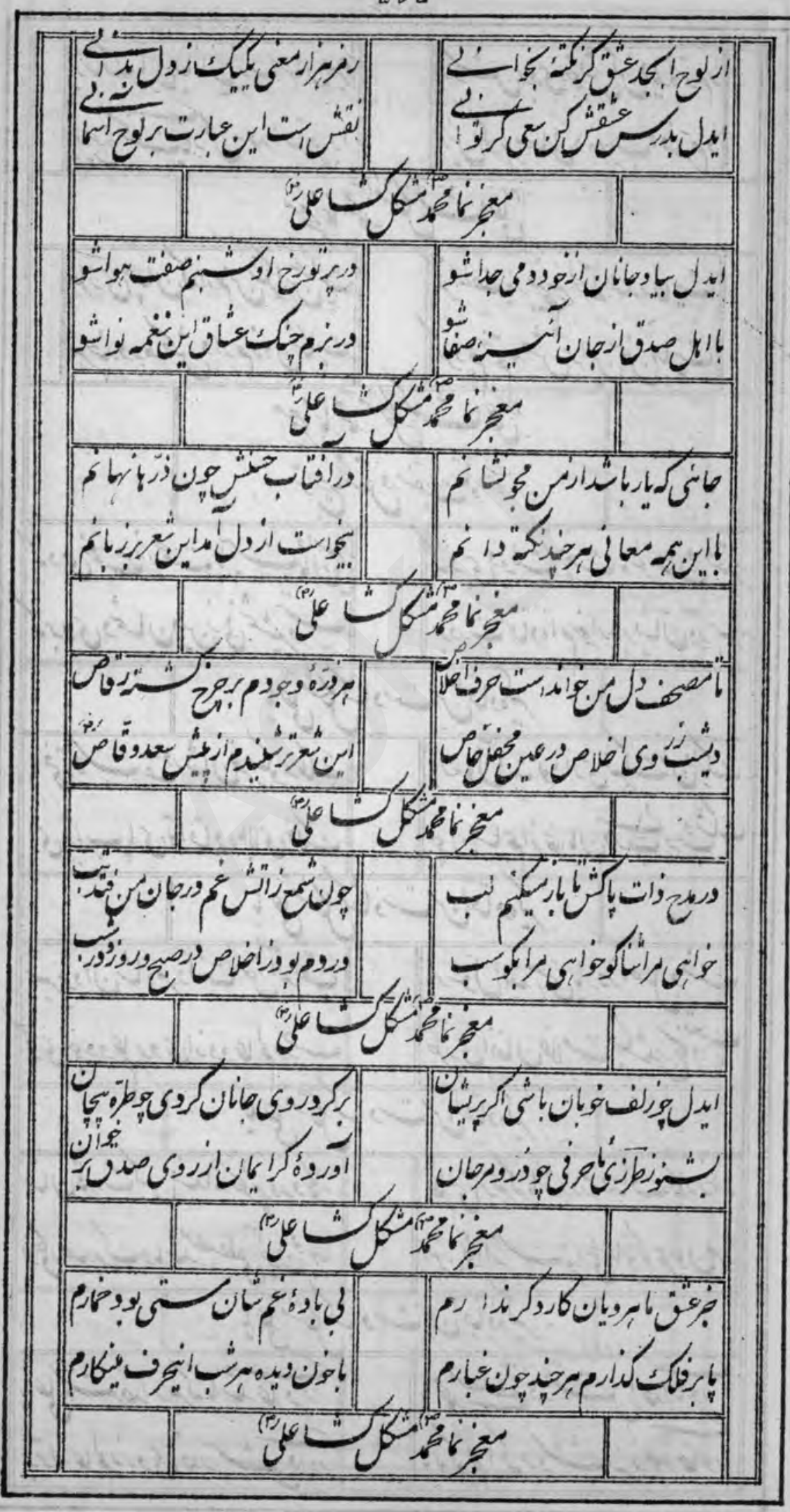


DL

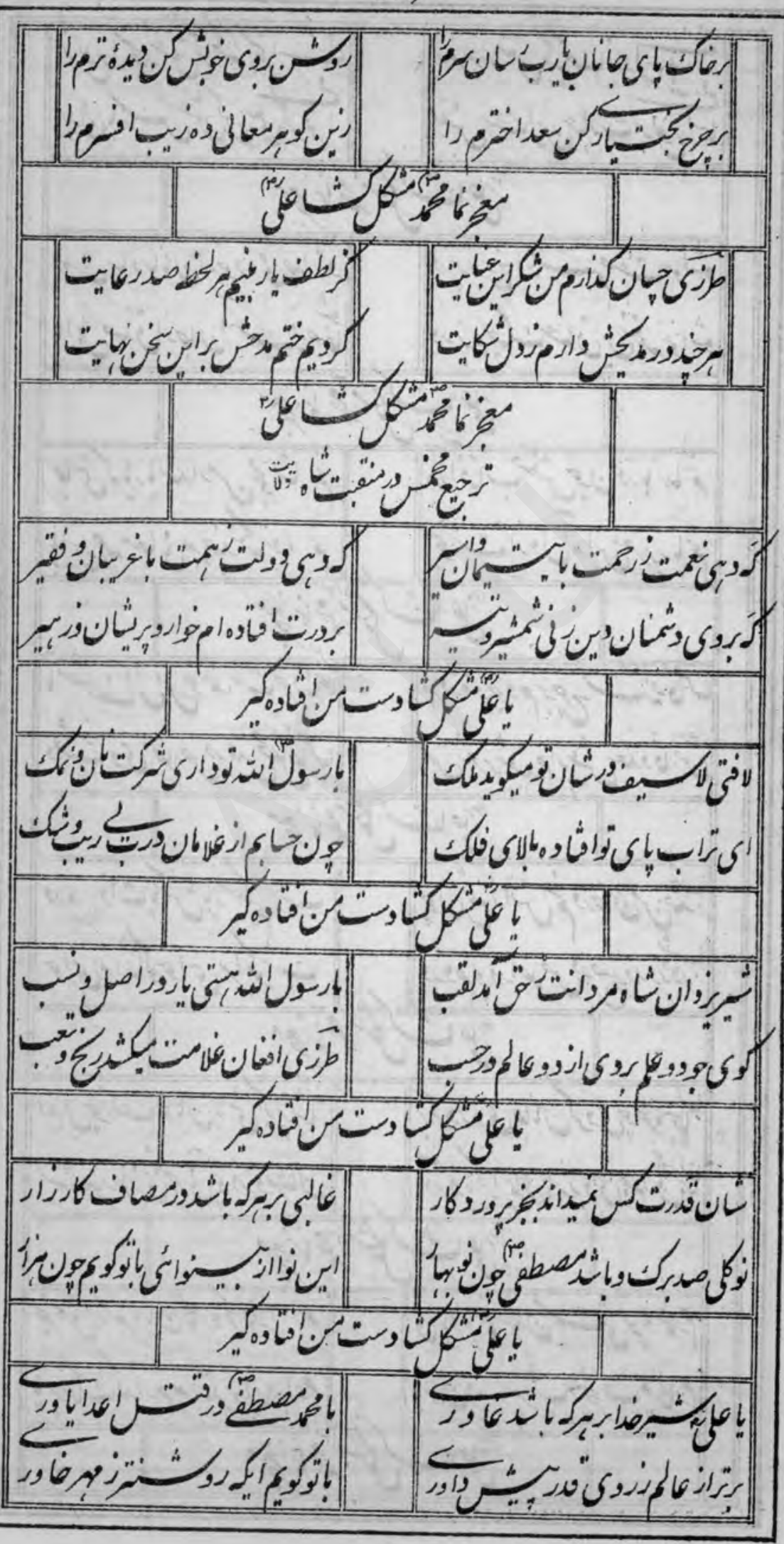


Aレレ

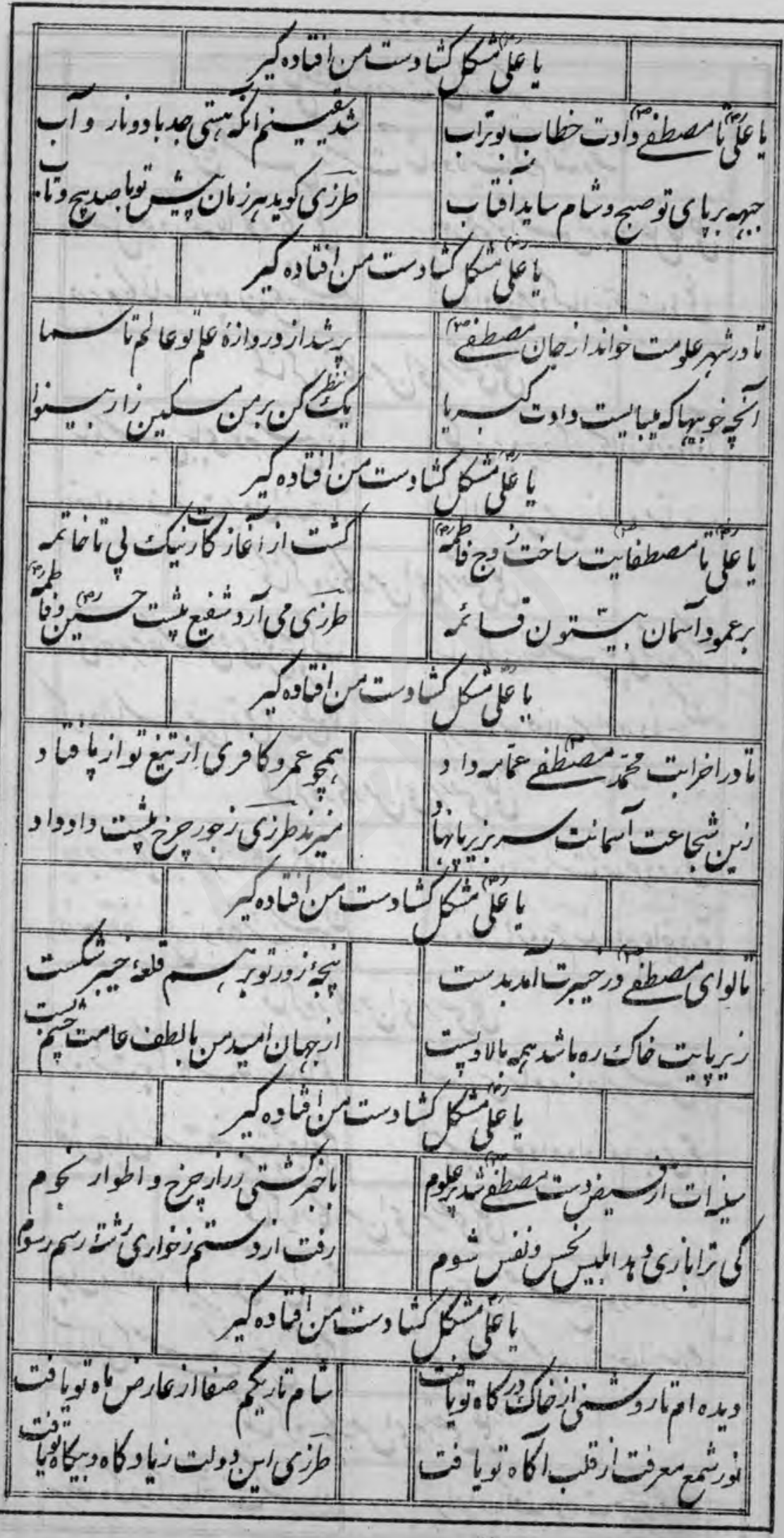




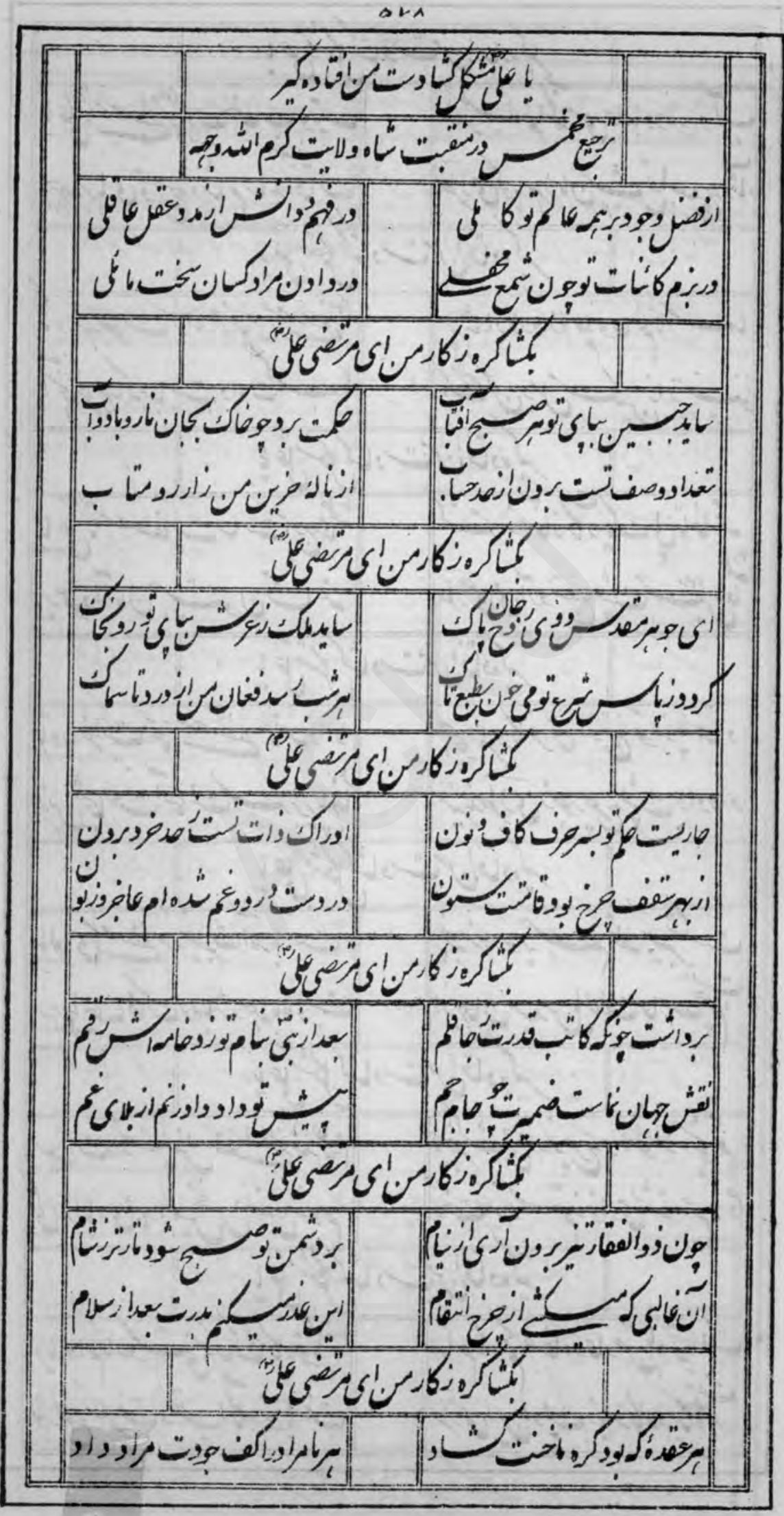


$\Delta \vee 4$

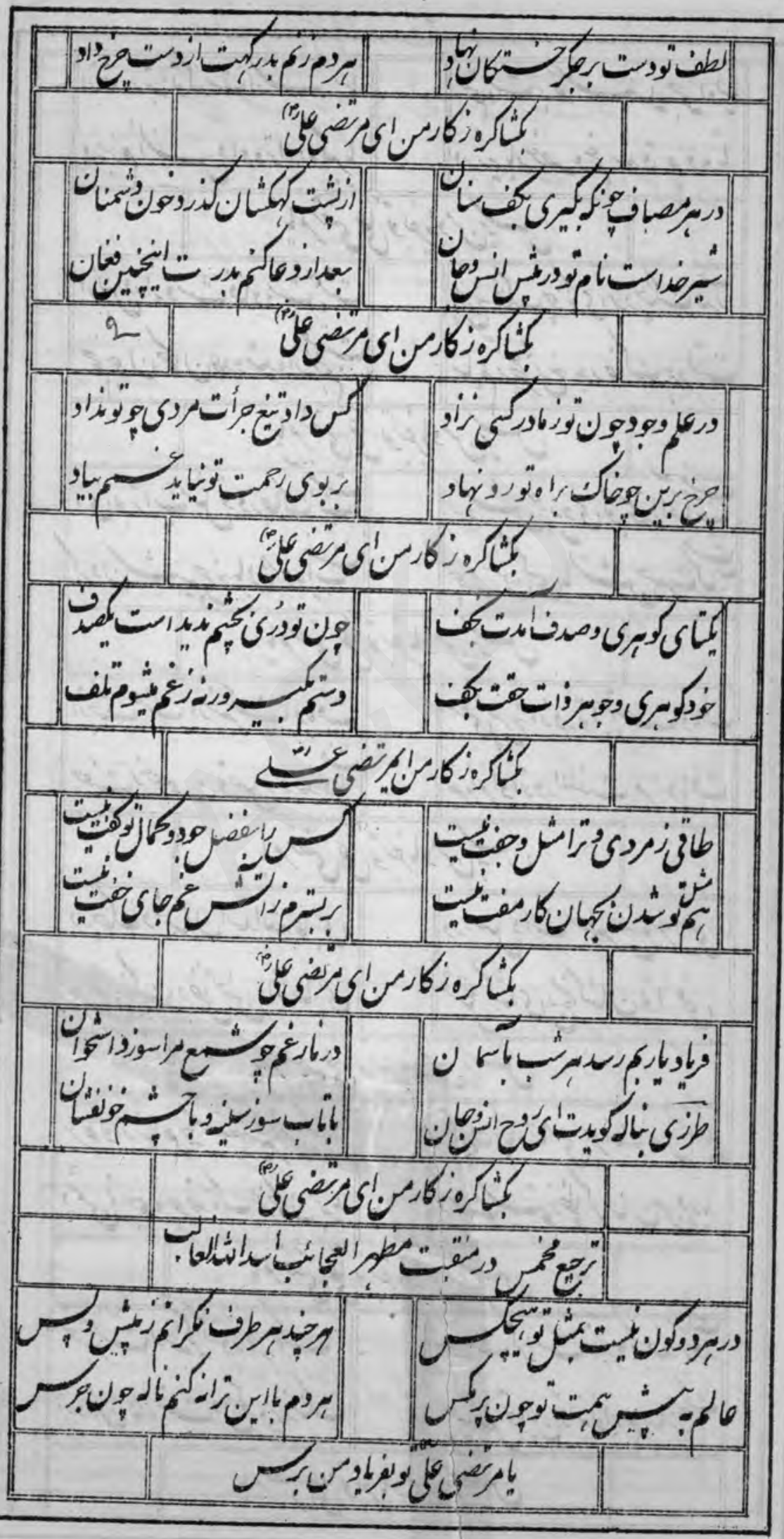




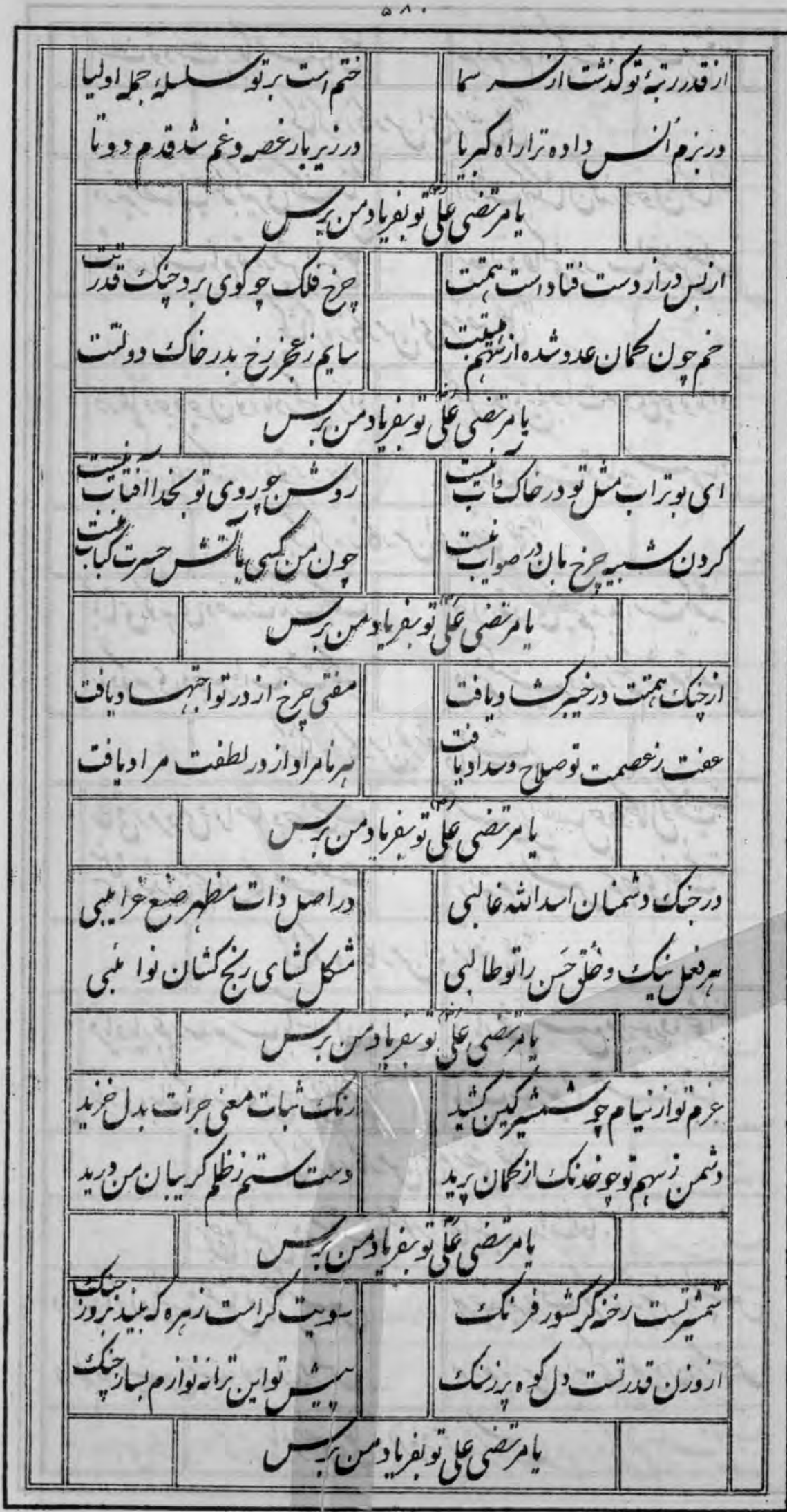


$\Delta \wedge 1$

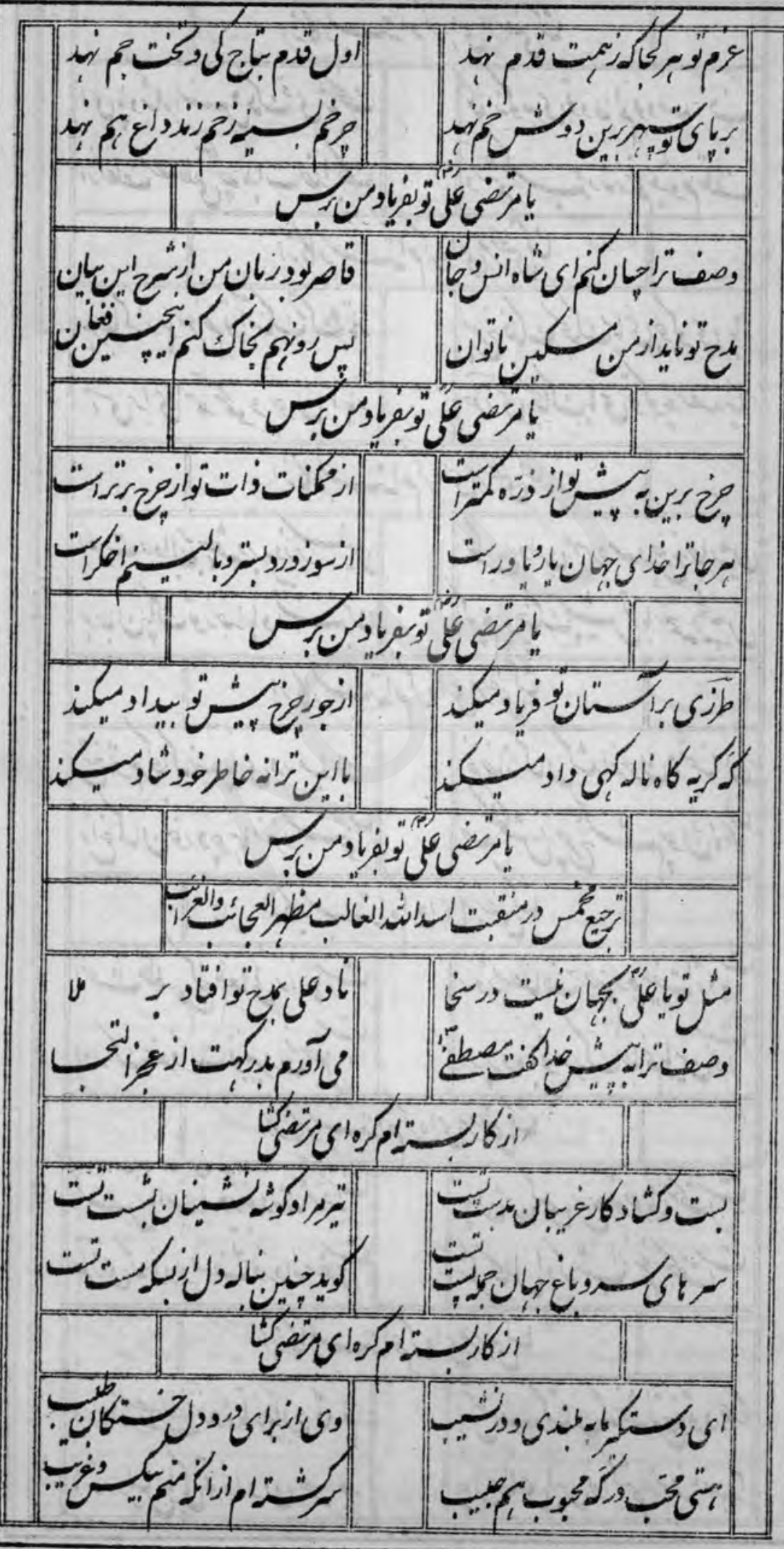


$\Delta \wedge r$

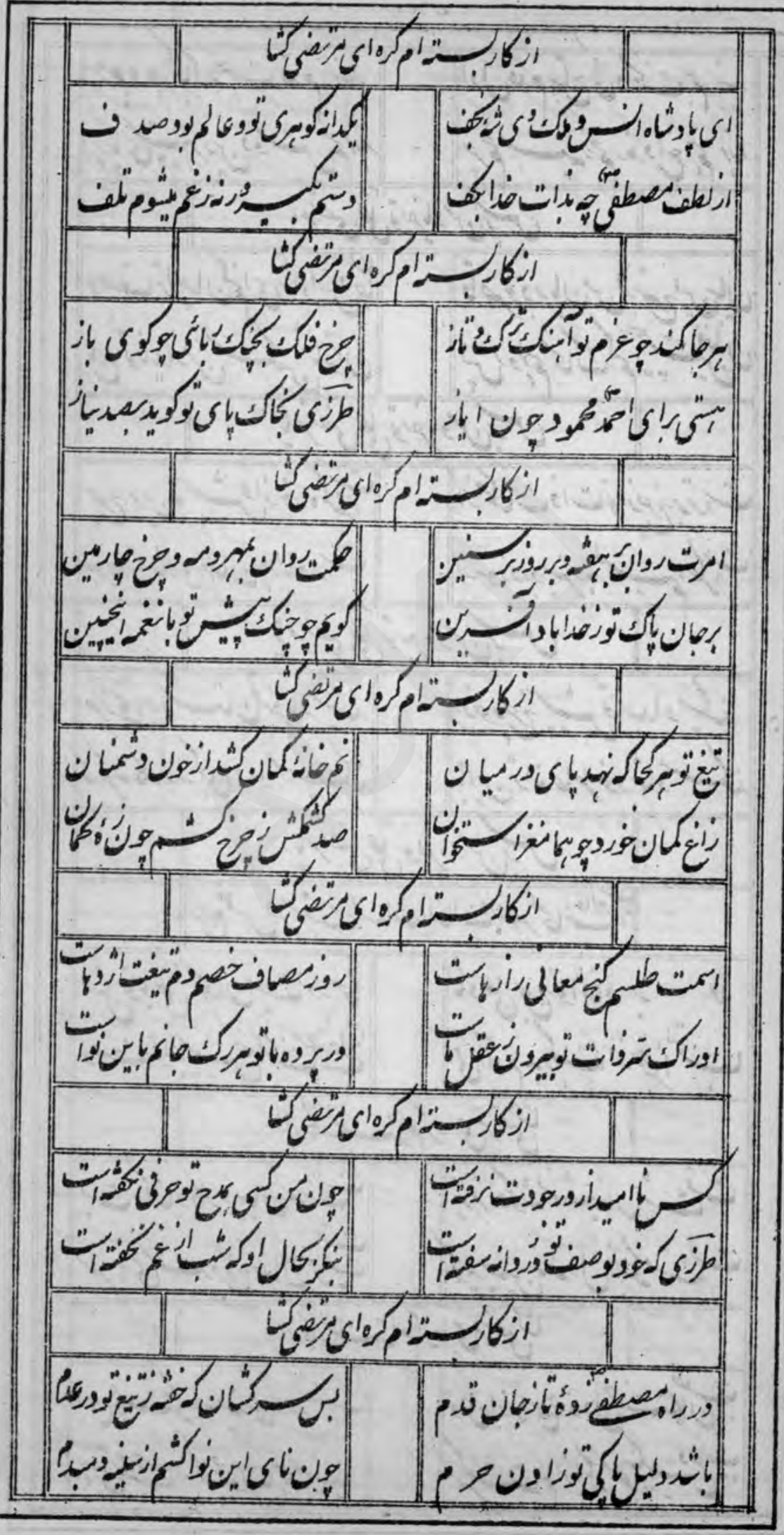


$\Delta \wedge r$

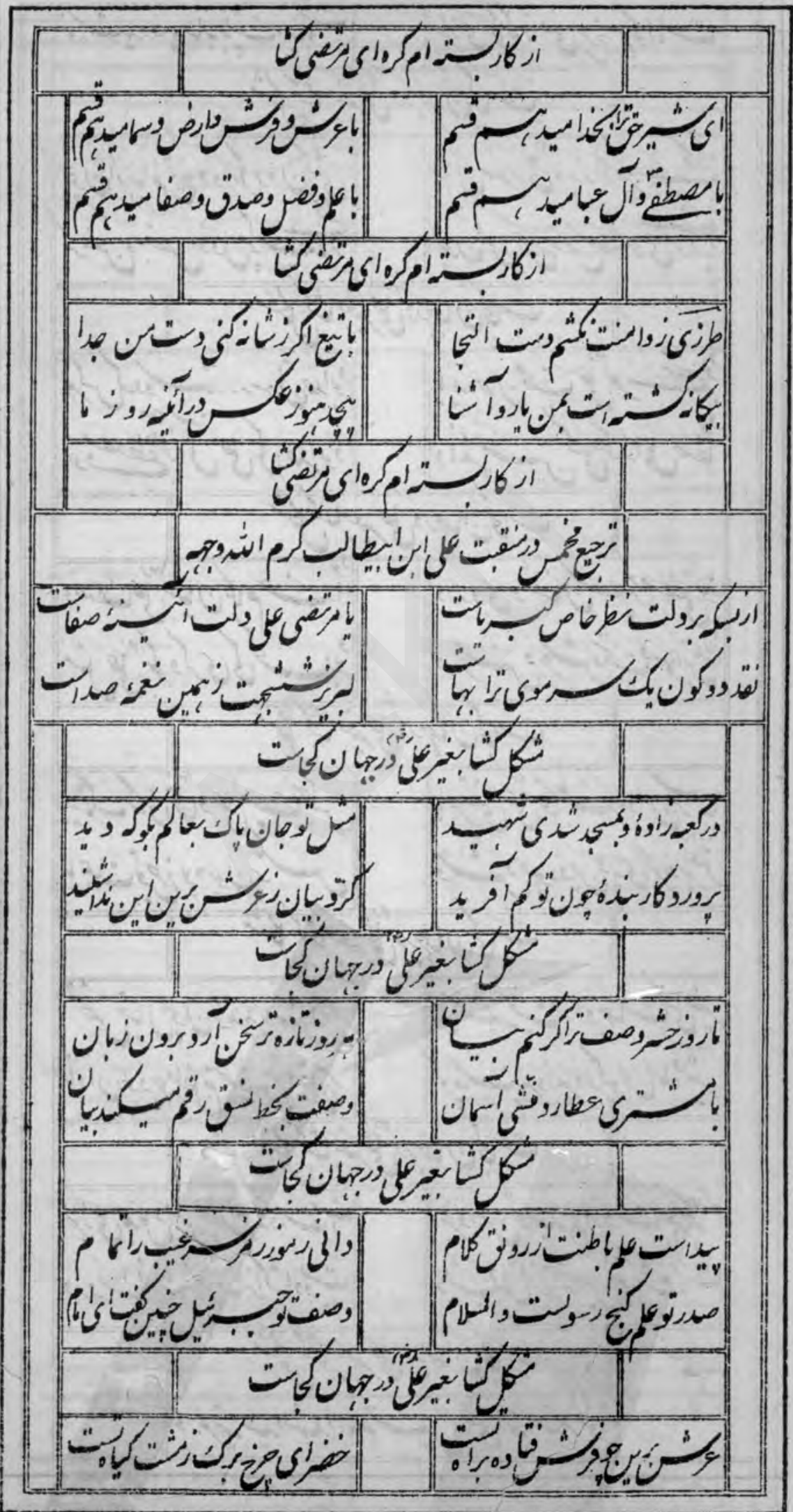


$\Delta A F$

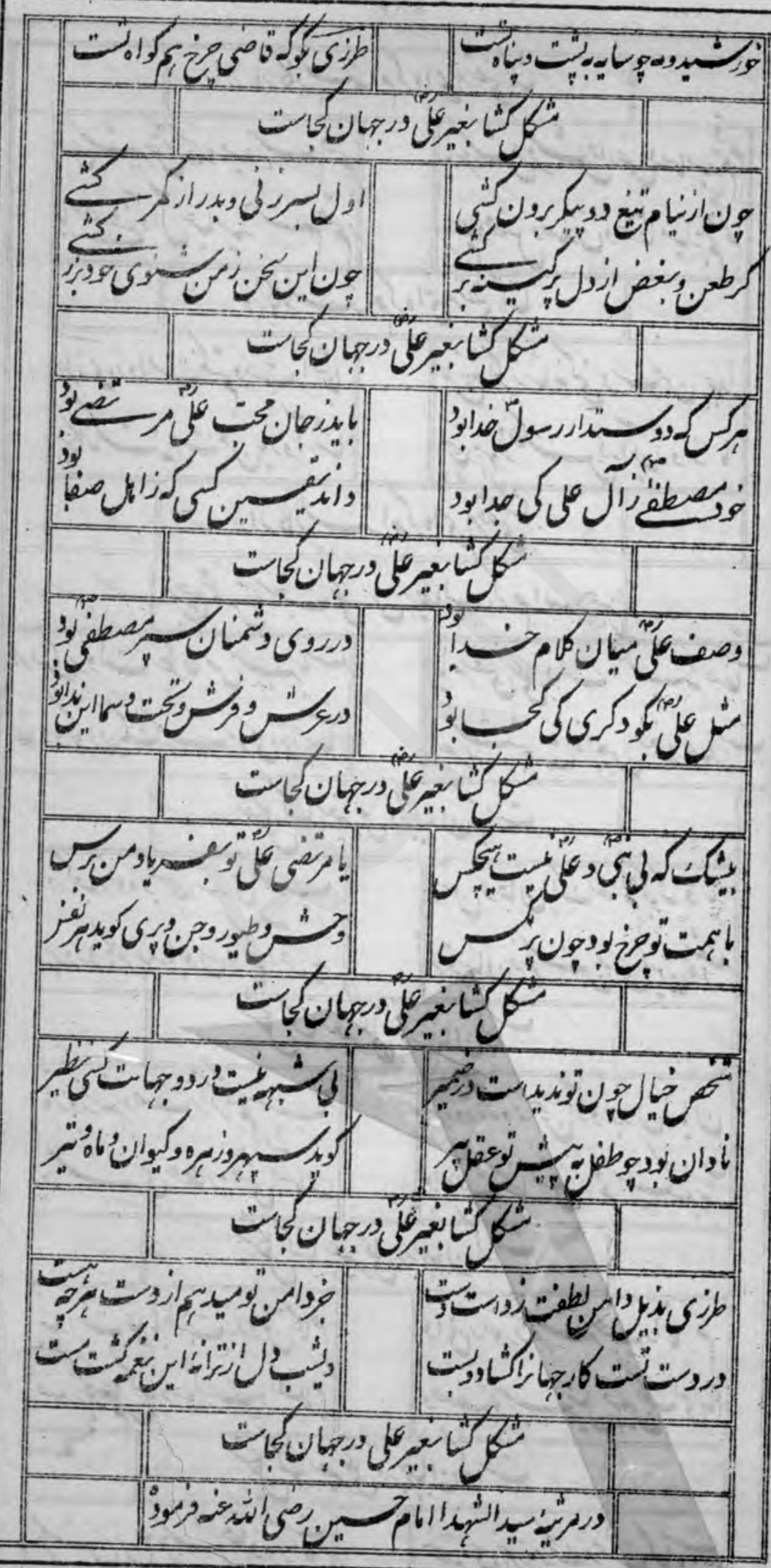


$\Delta \wedge \Delta$

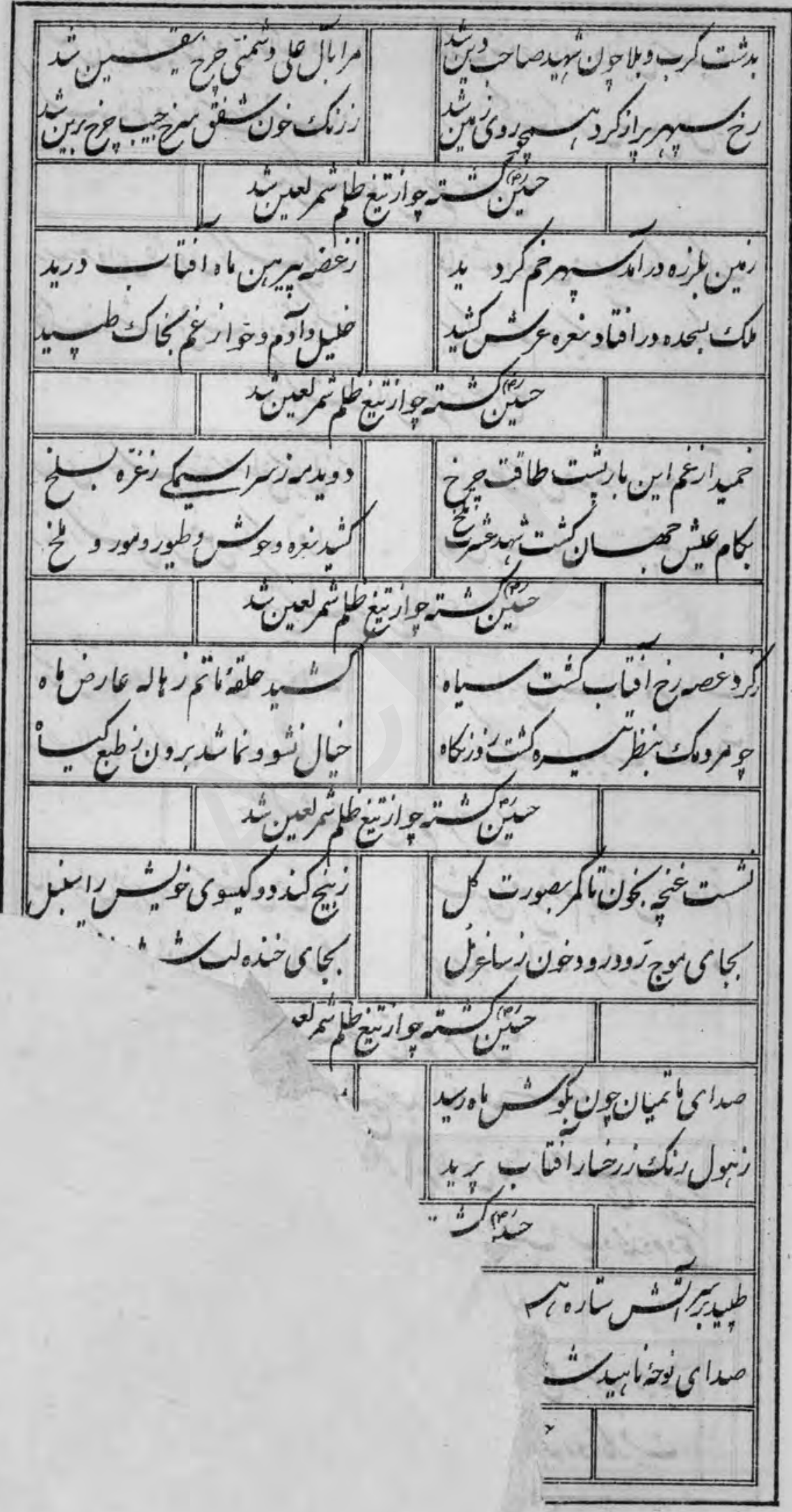


DA

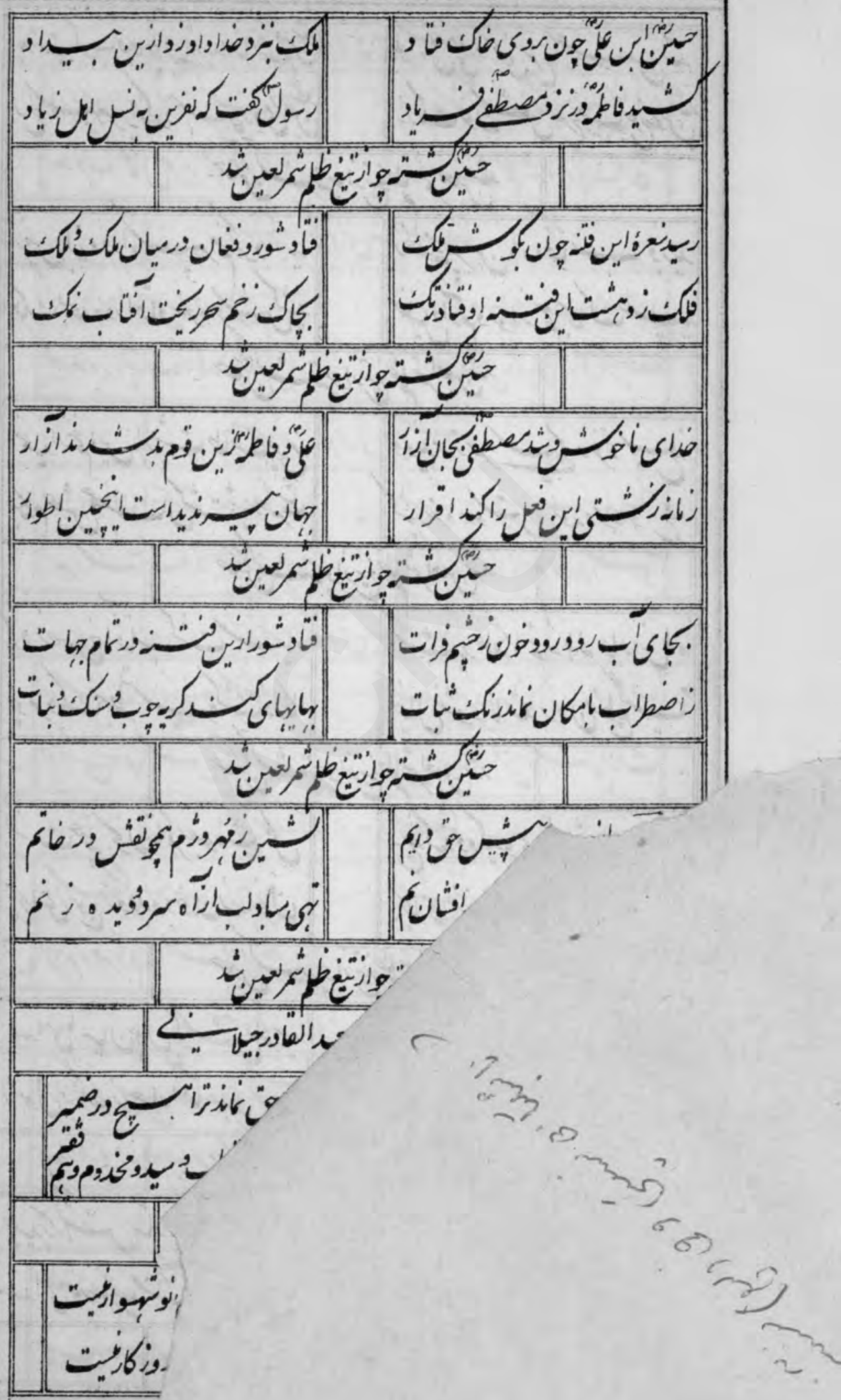


$\Delta A V$

|


$\Delta \wedge \Lambda$

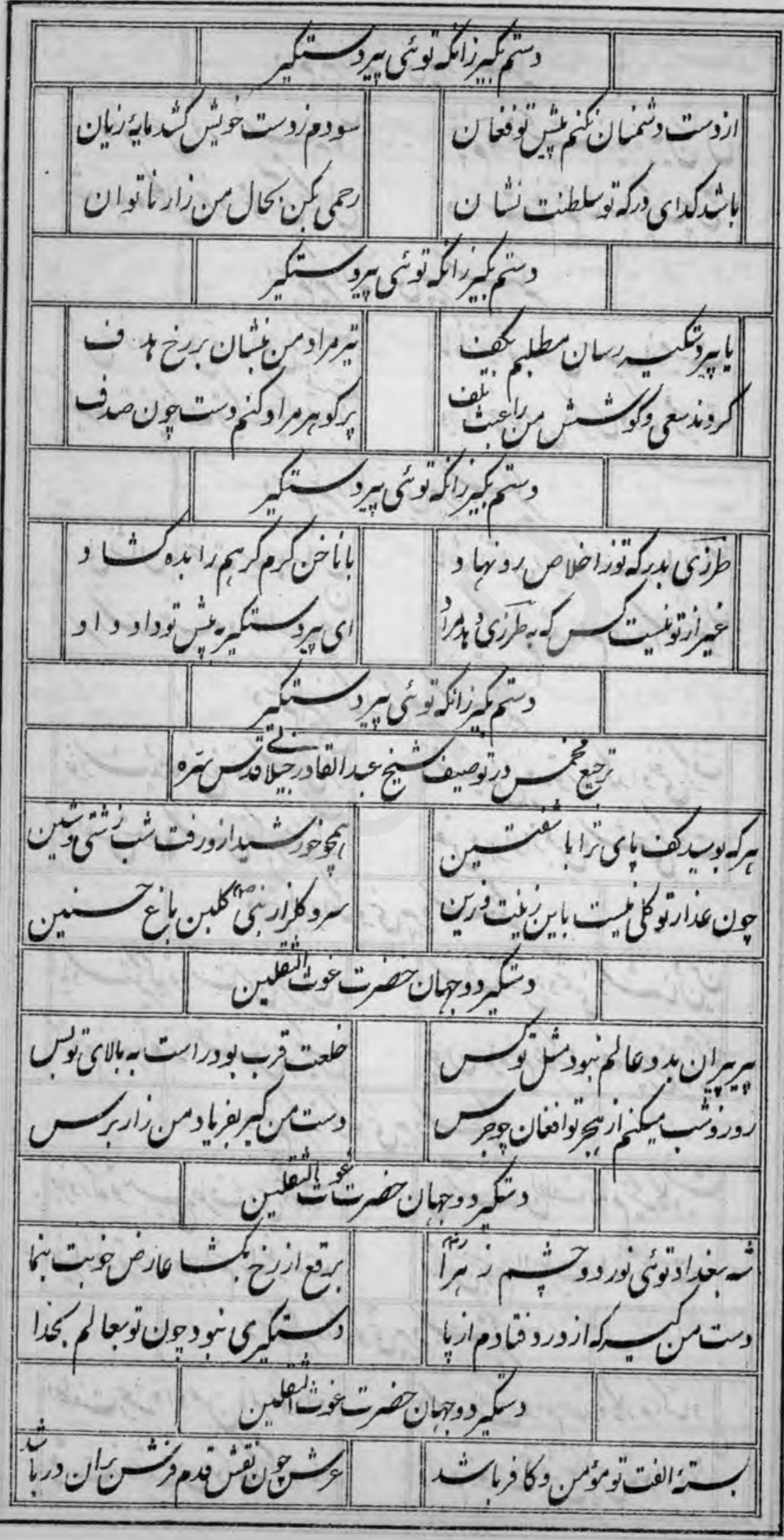

s): 


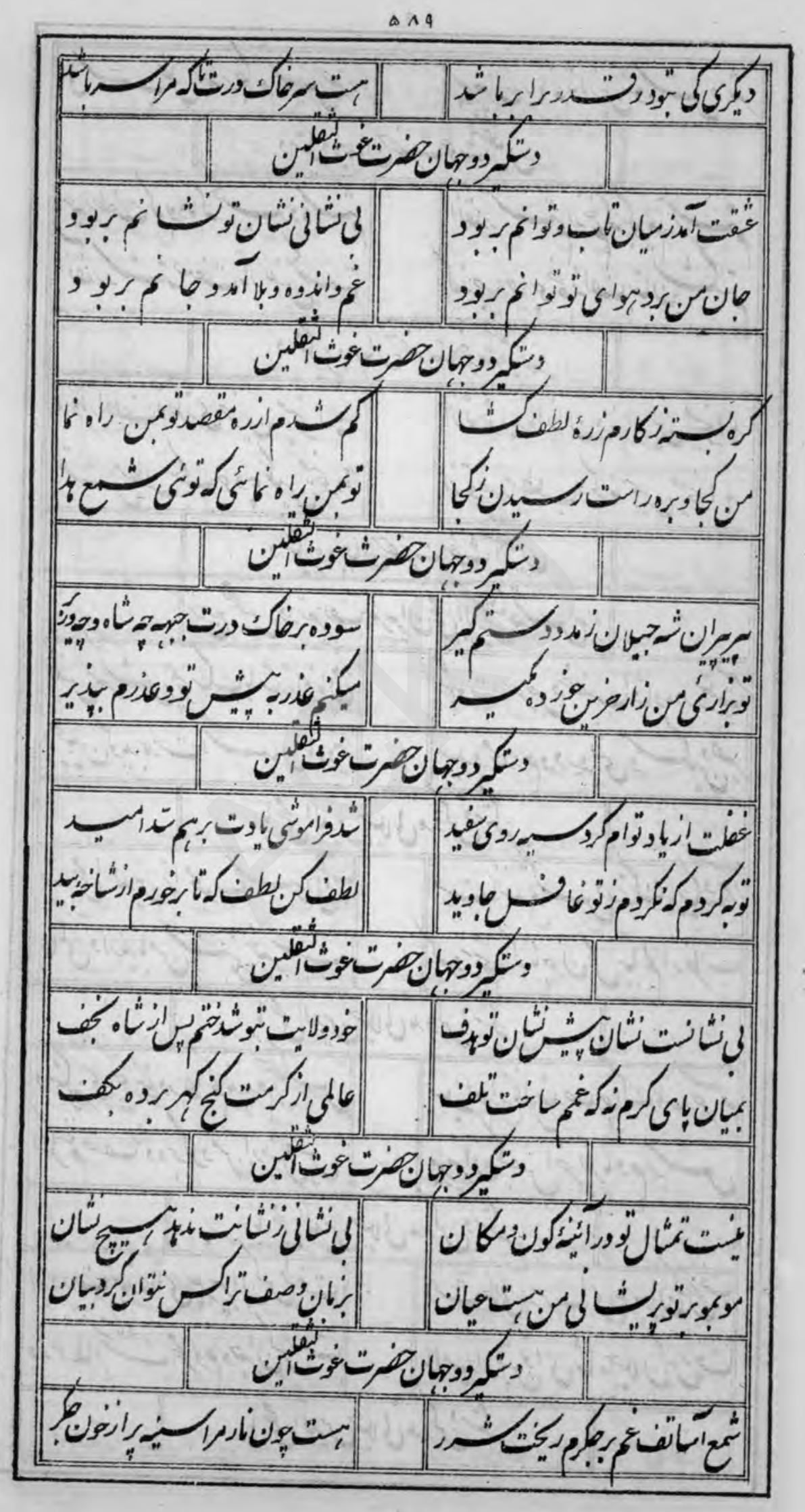


a a.

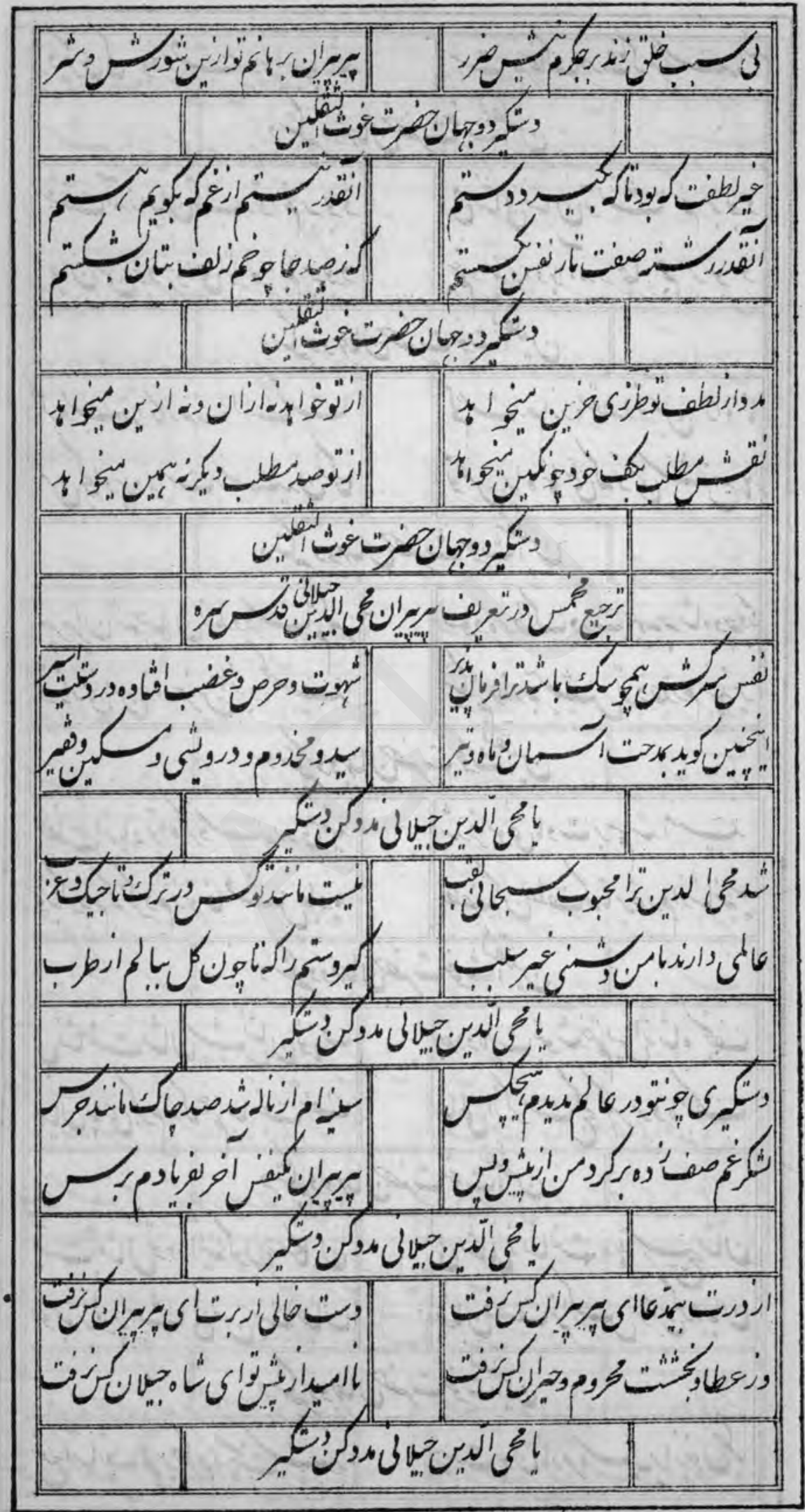


041

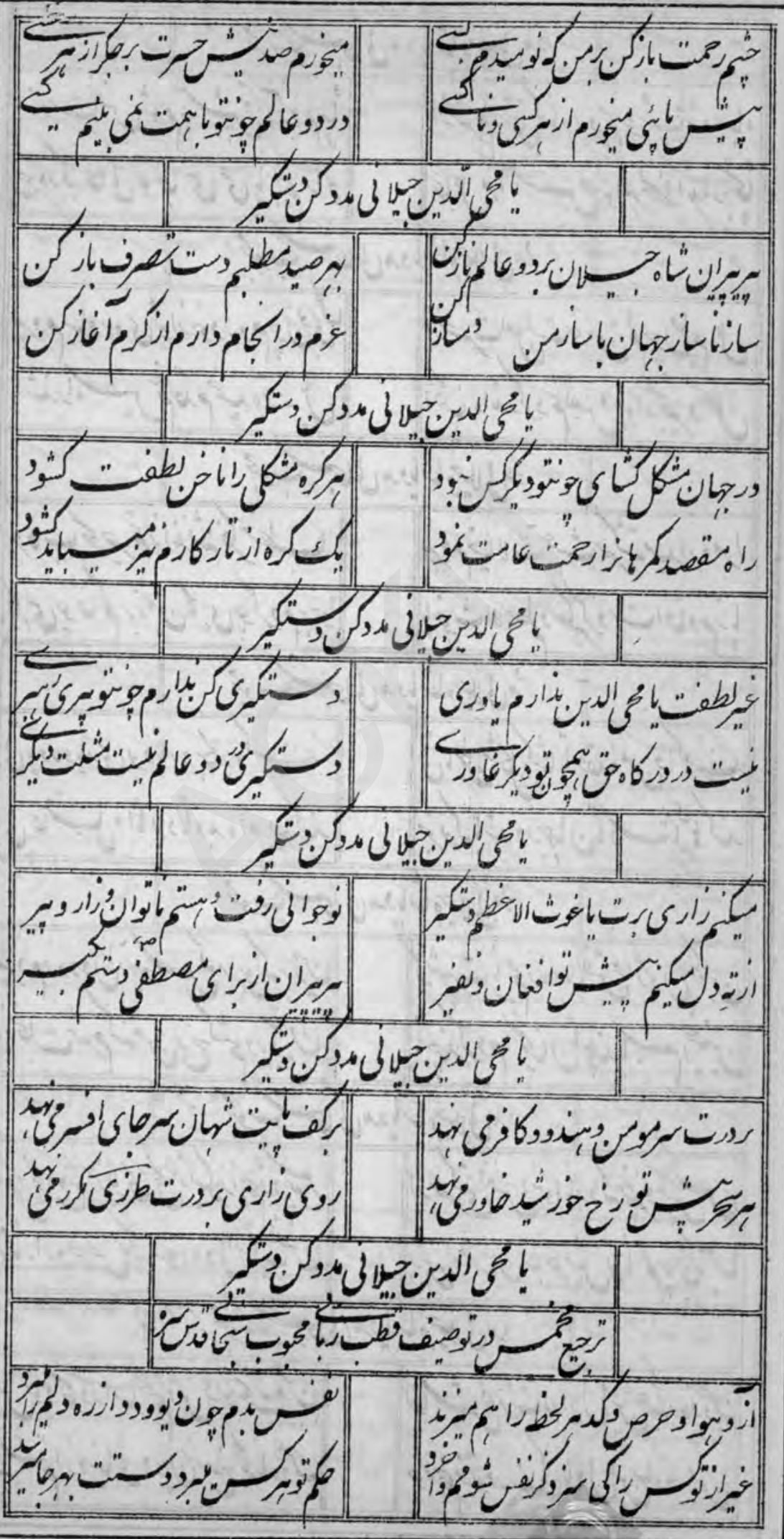


a $4 r$

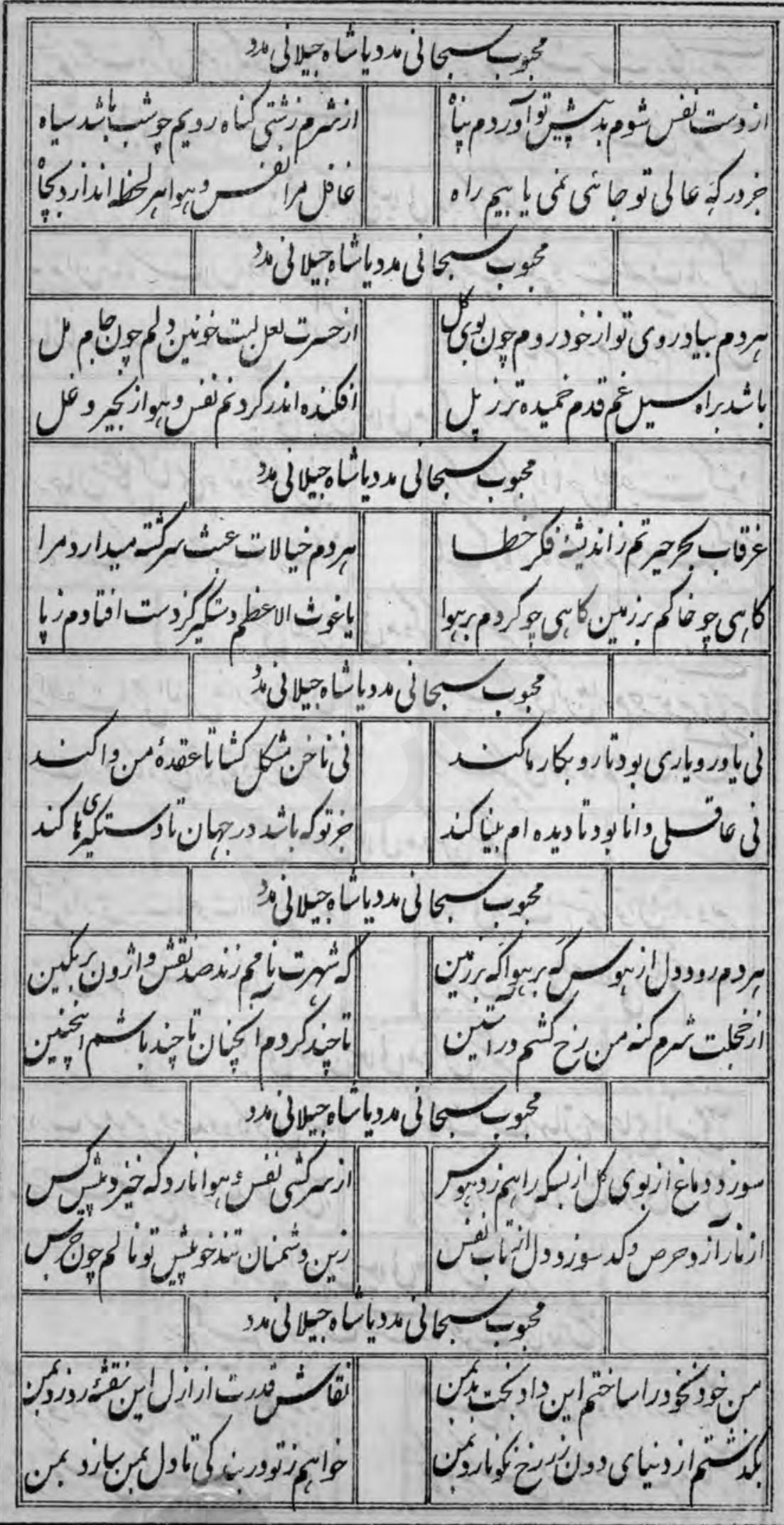


Q $4 r$

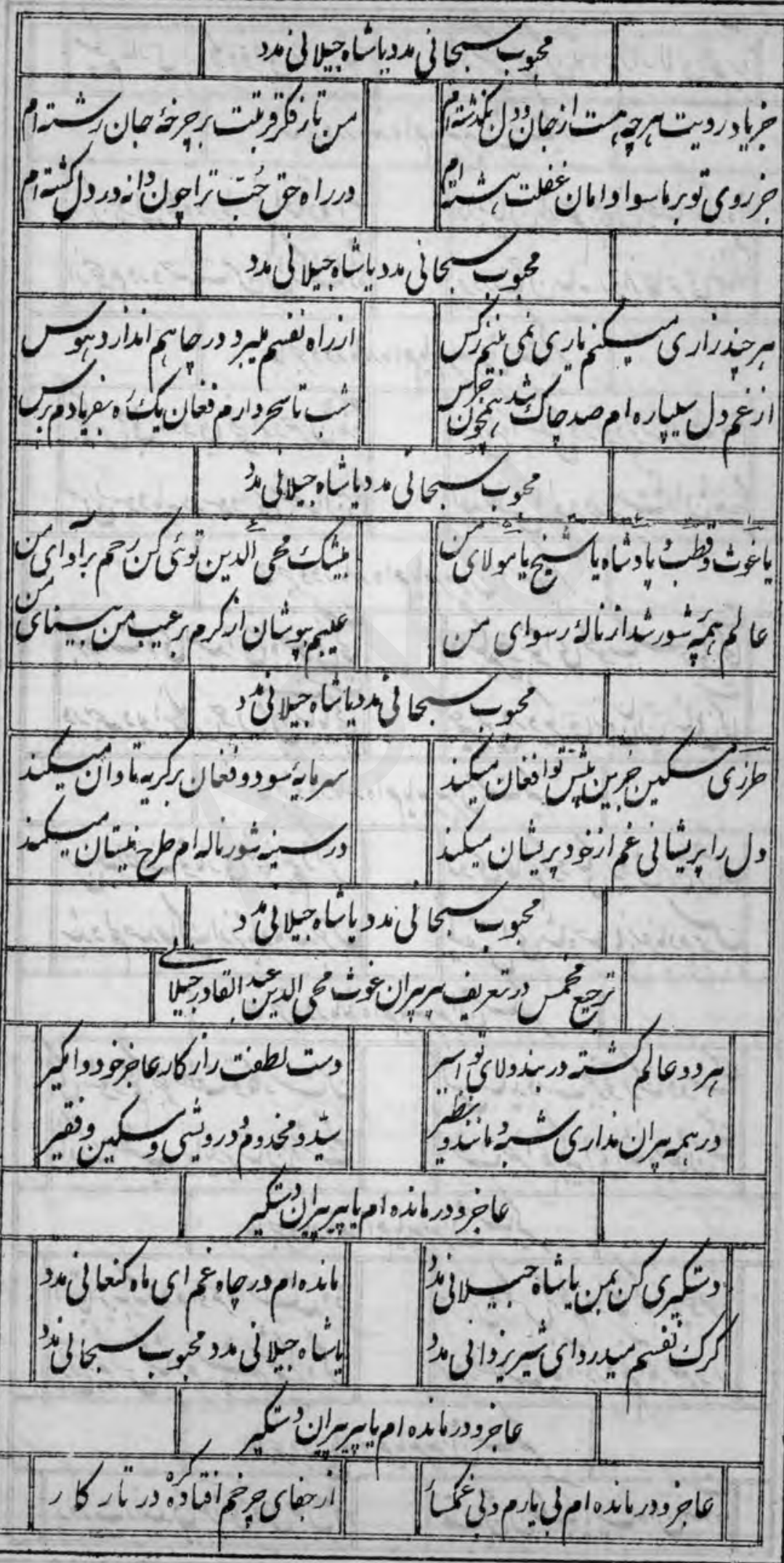


Q $4 \mathrm{~F}$

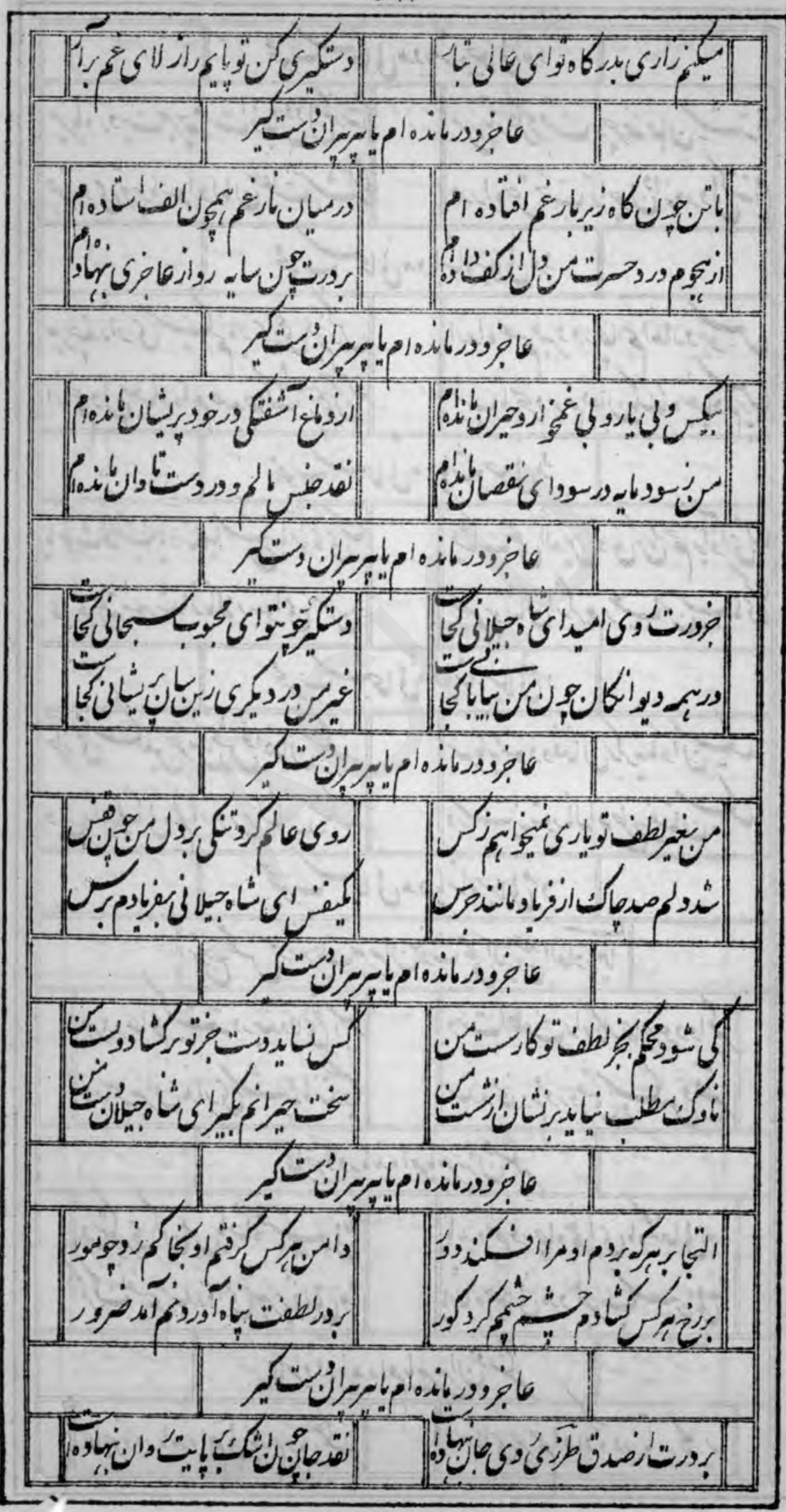

$=0$ 
Q 40

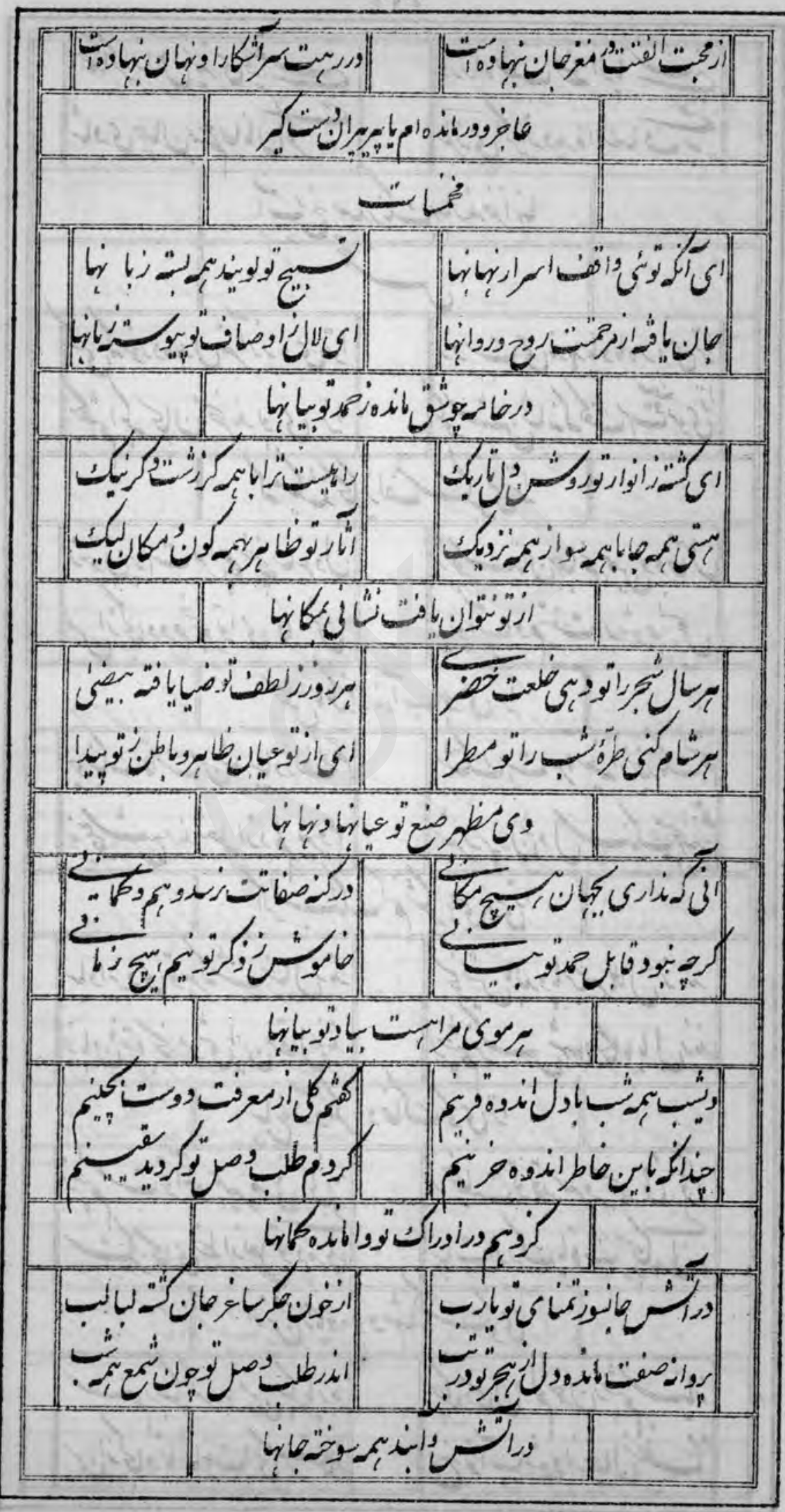


42

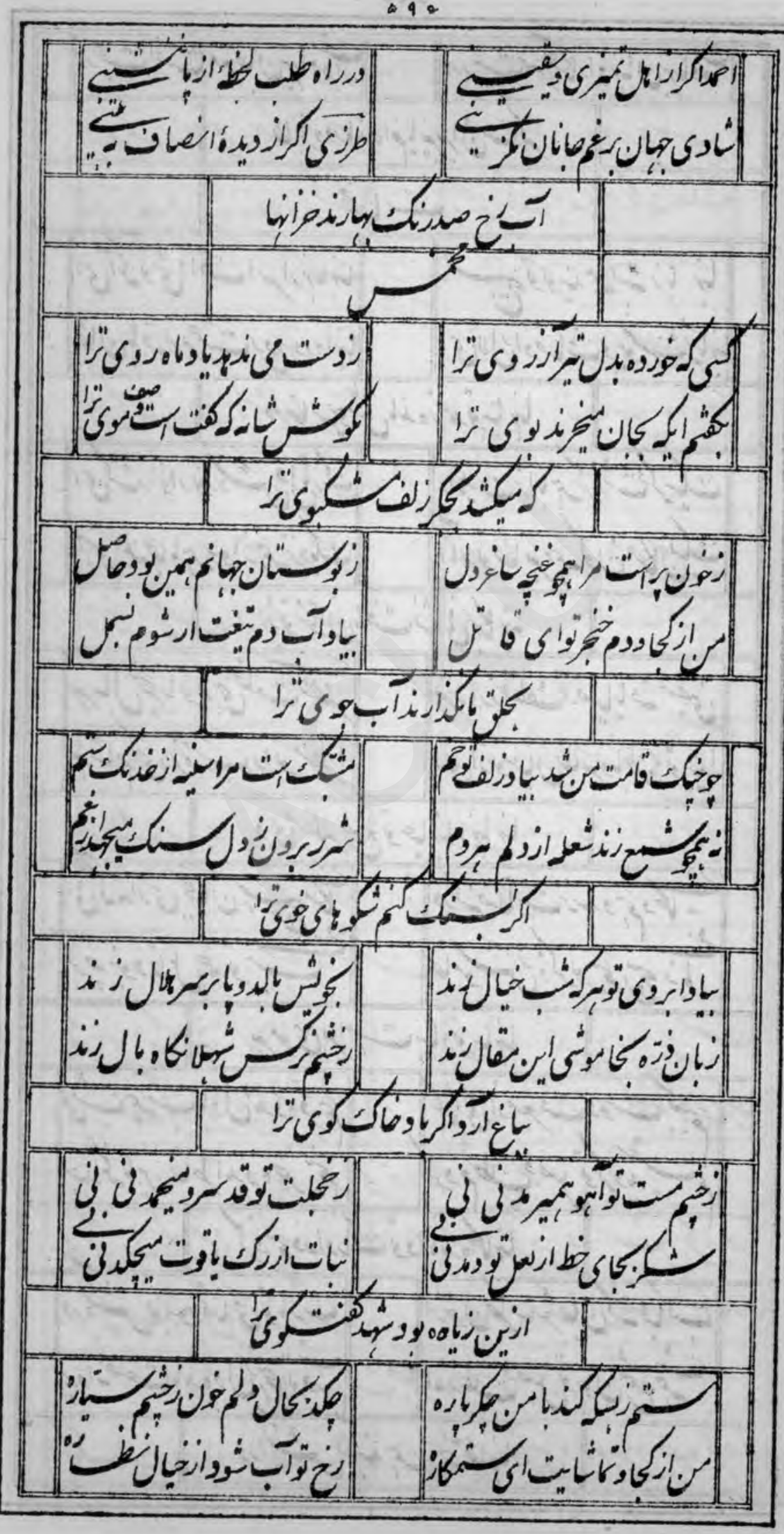


Q 9

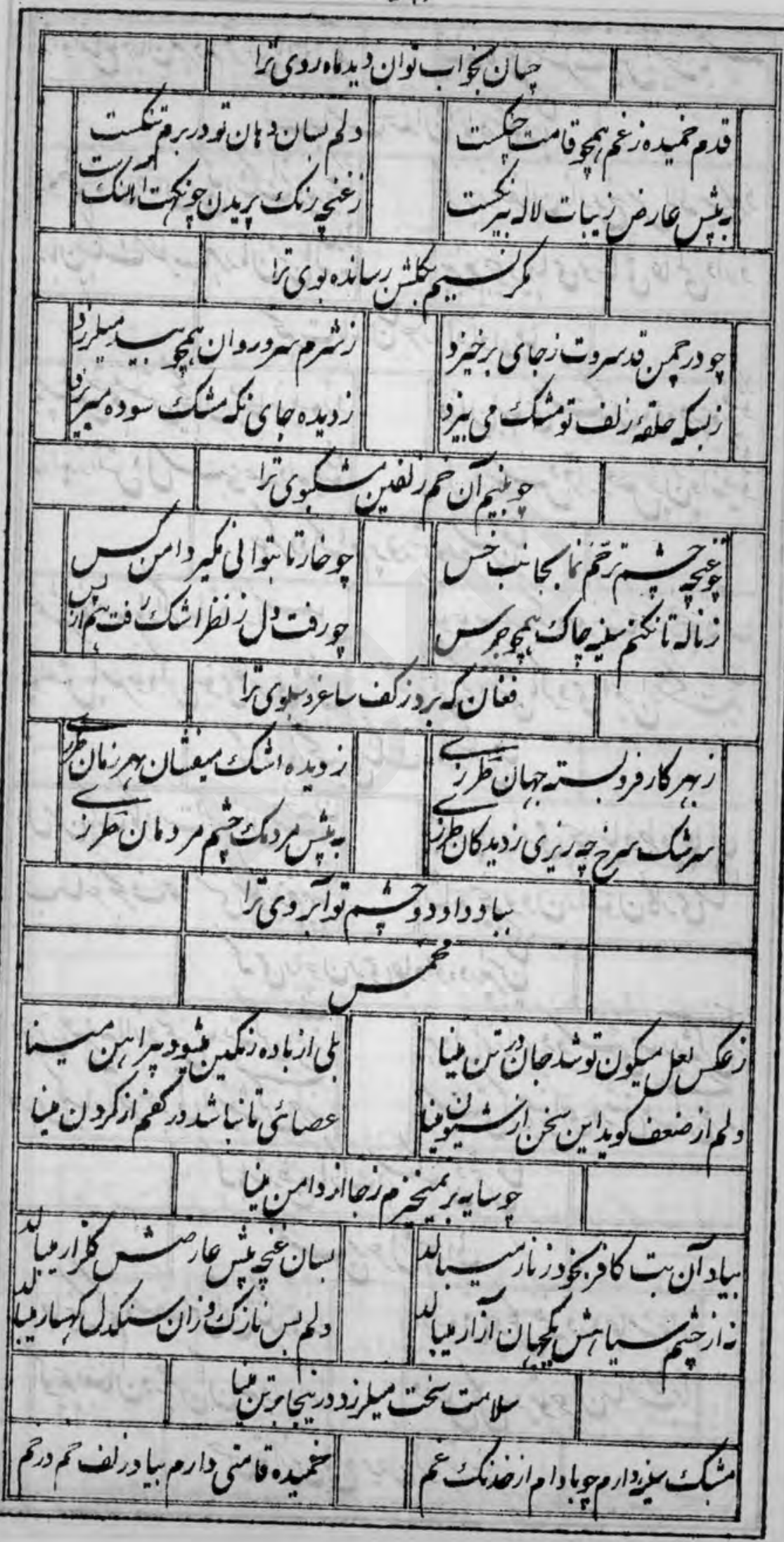


D 41

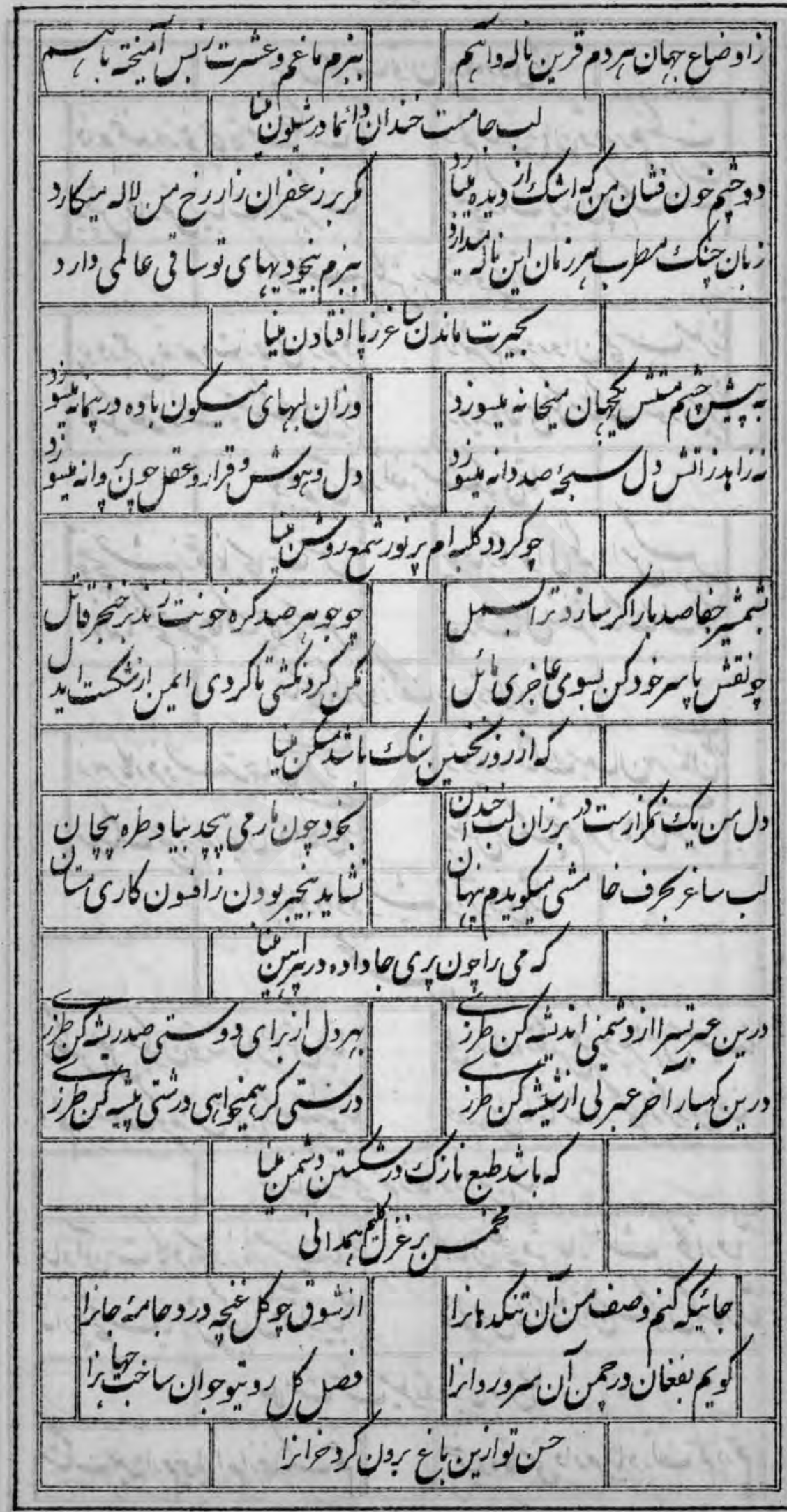


$\Delta 4 \%$

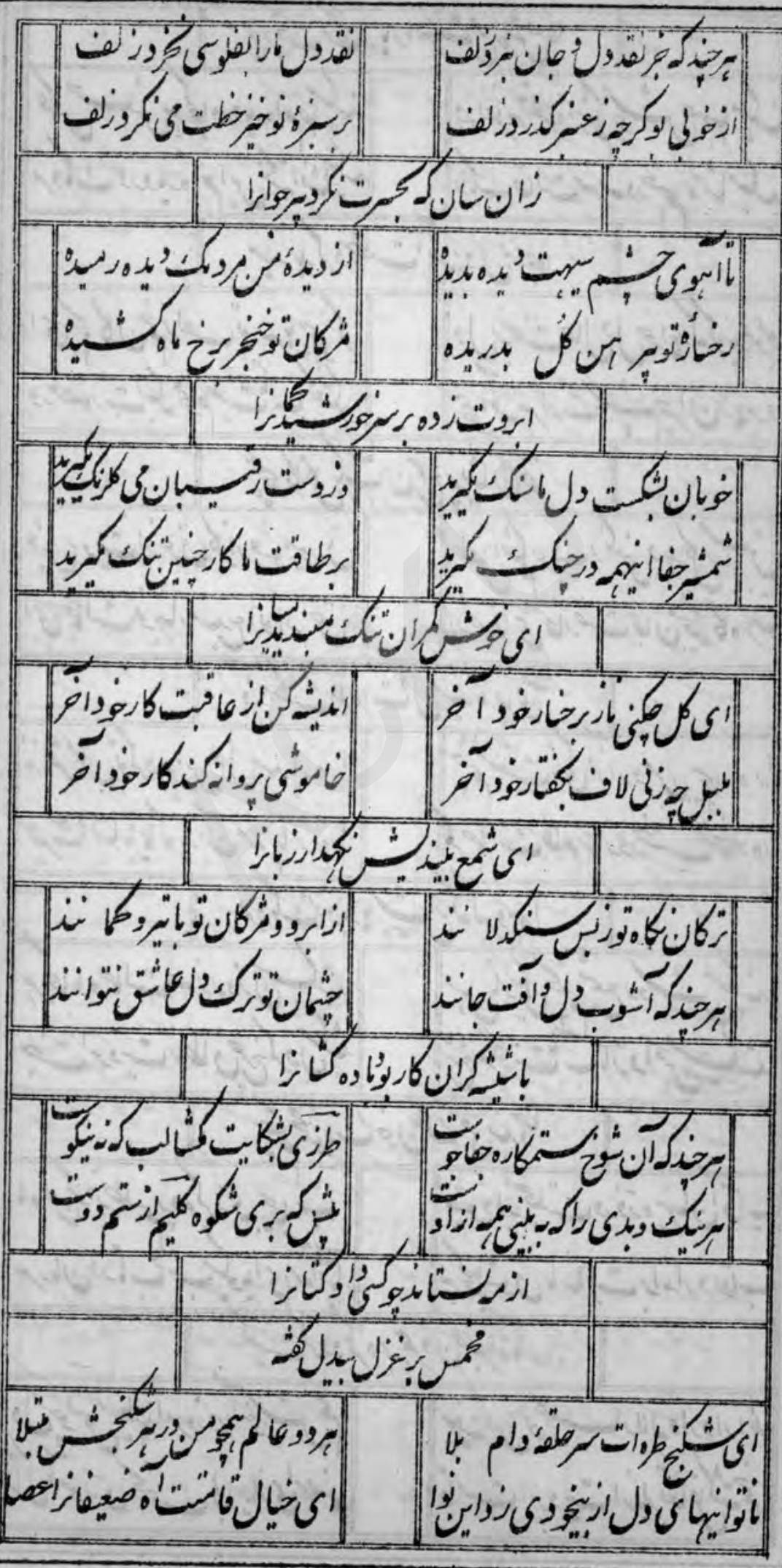




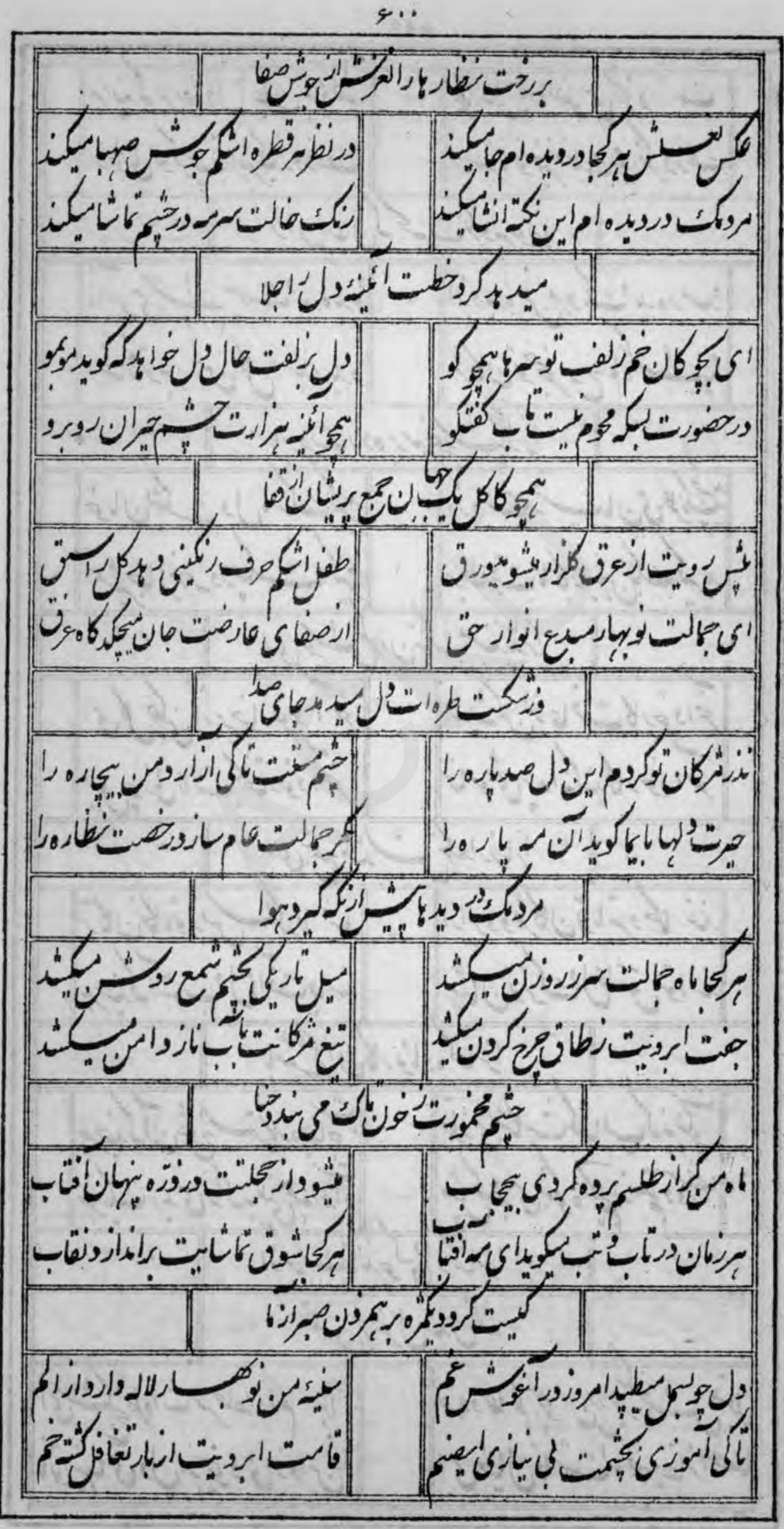




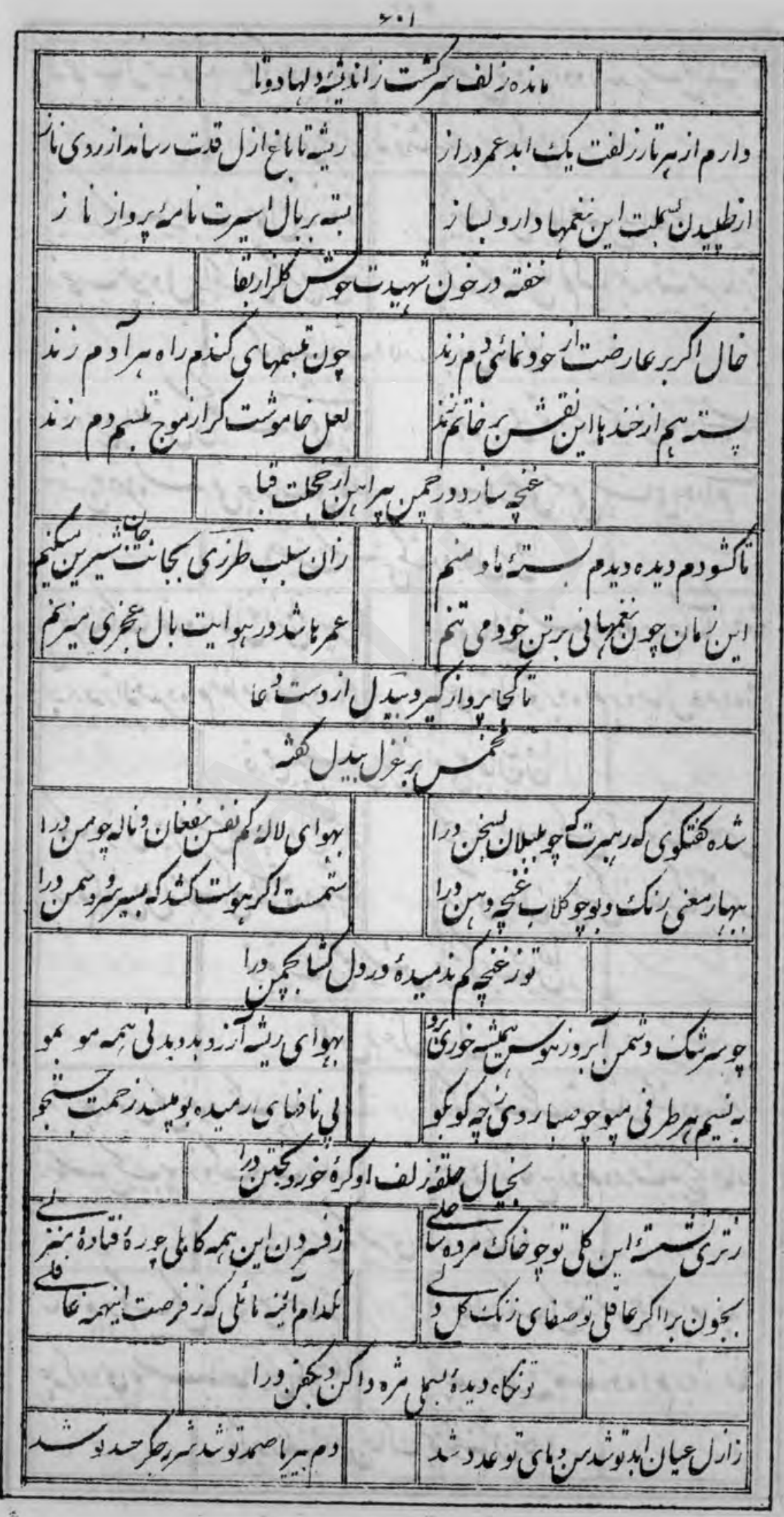




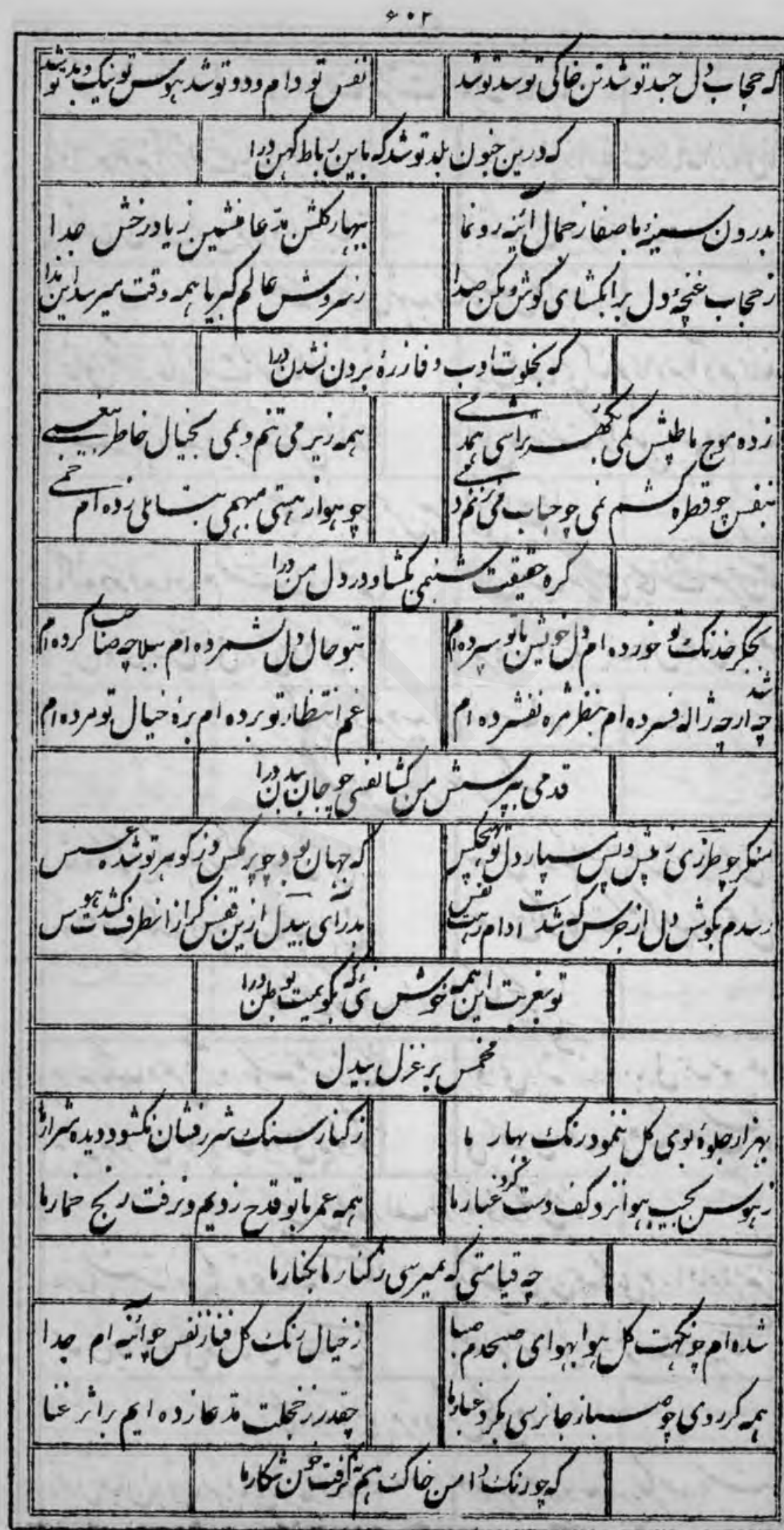




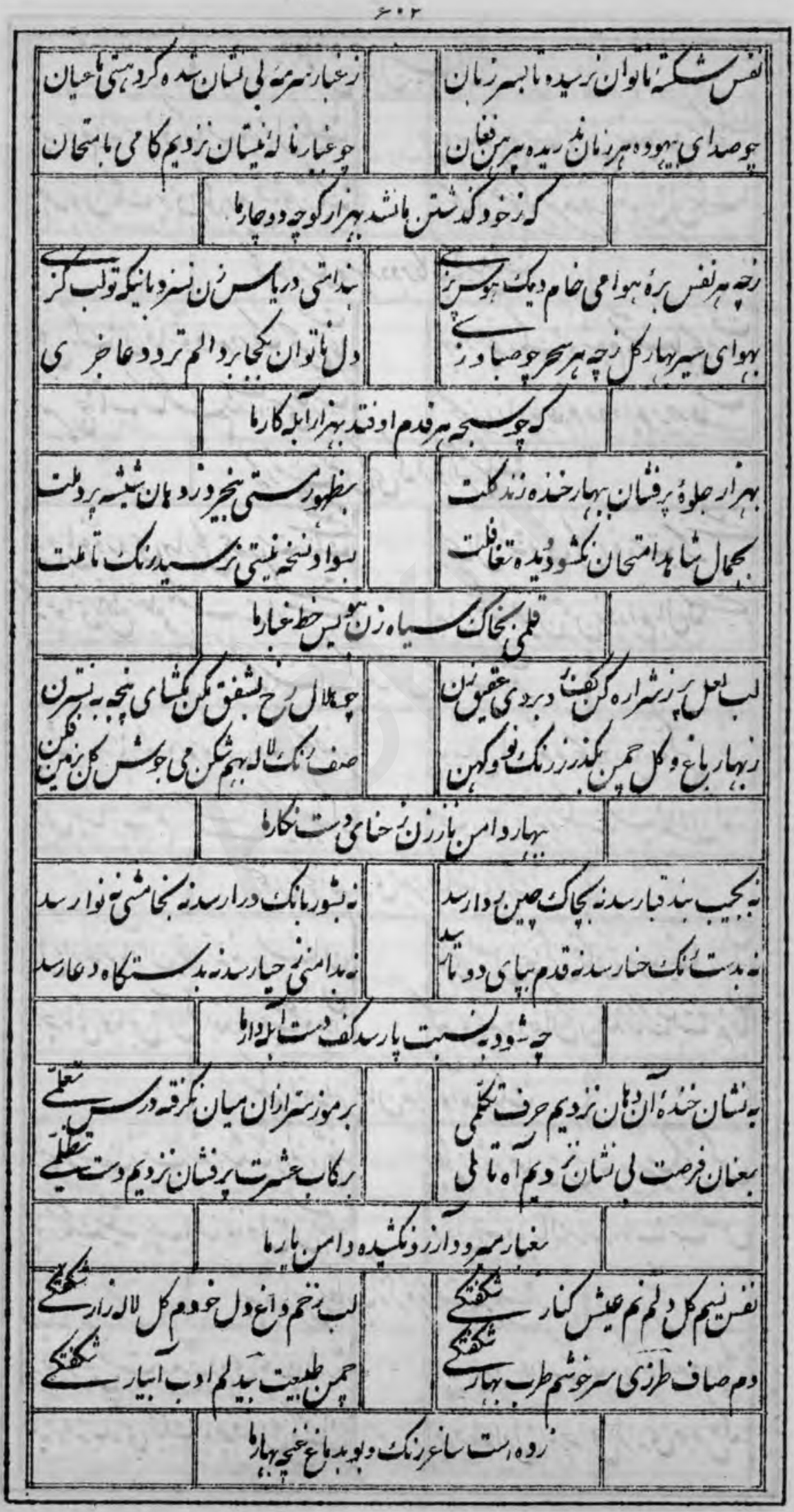




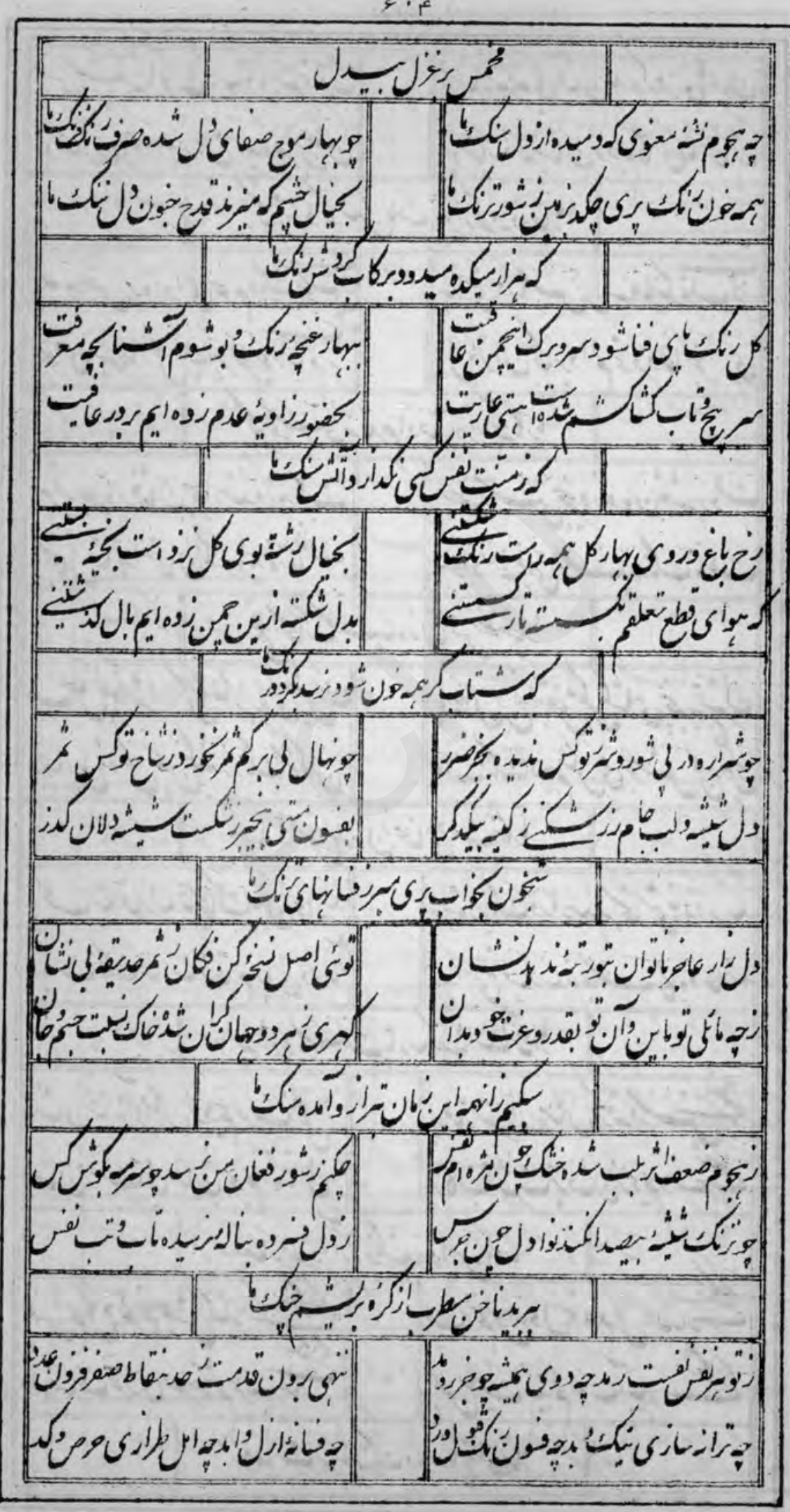

$\| r_{L}$ 
$4 \Delta$

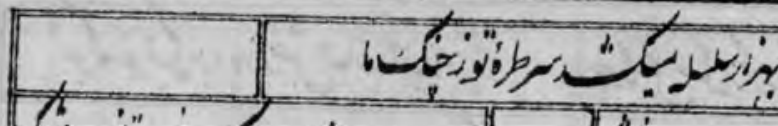

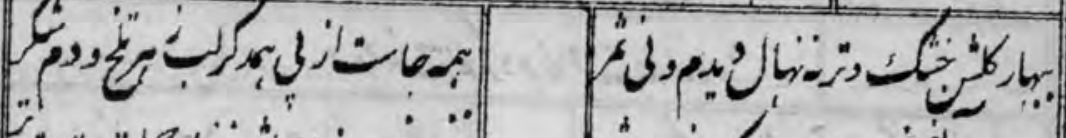

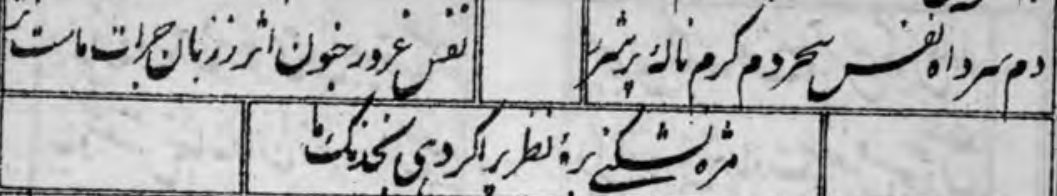

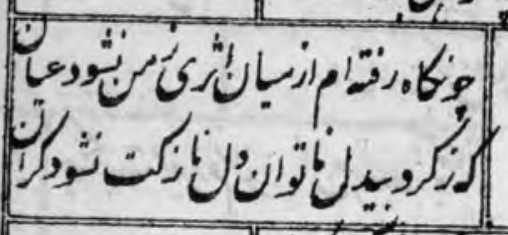

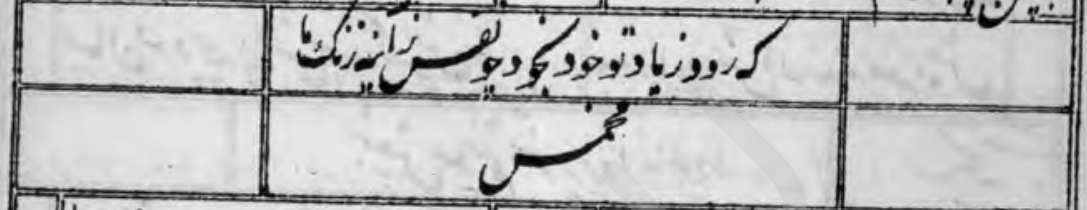

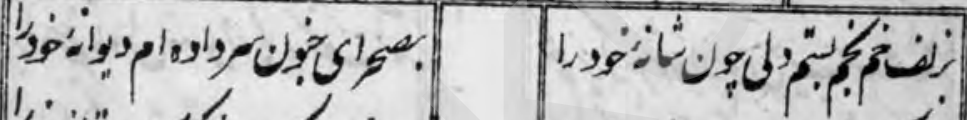

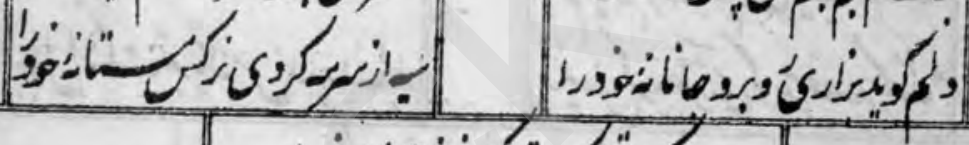
ن

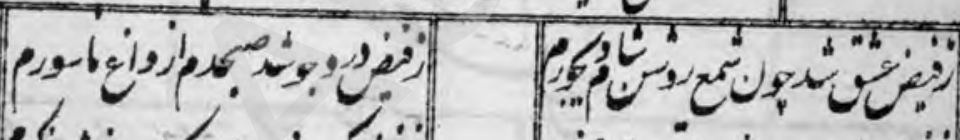

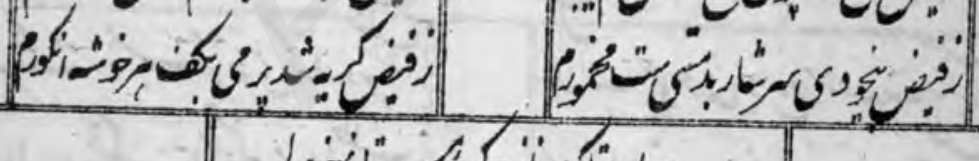
1.

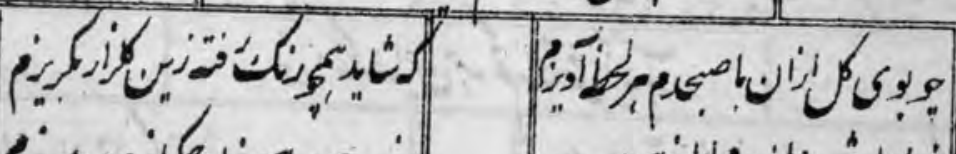

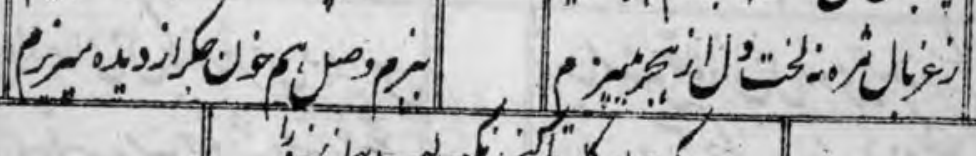

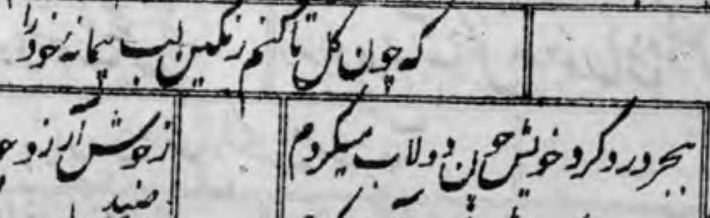

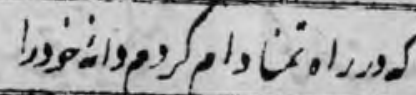

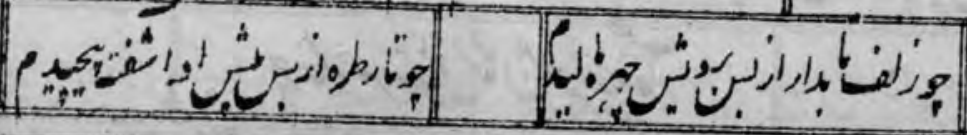




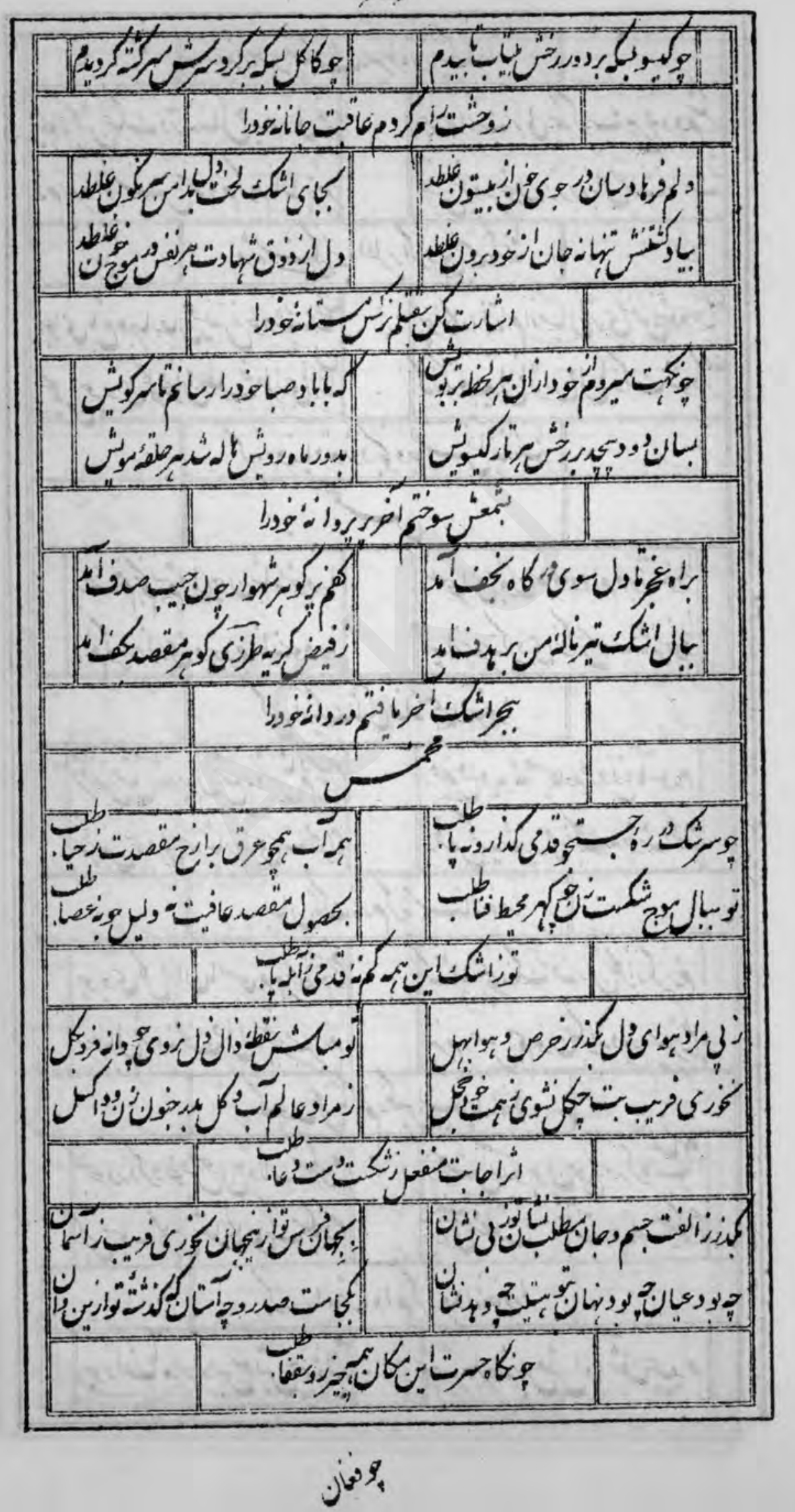




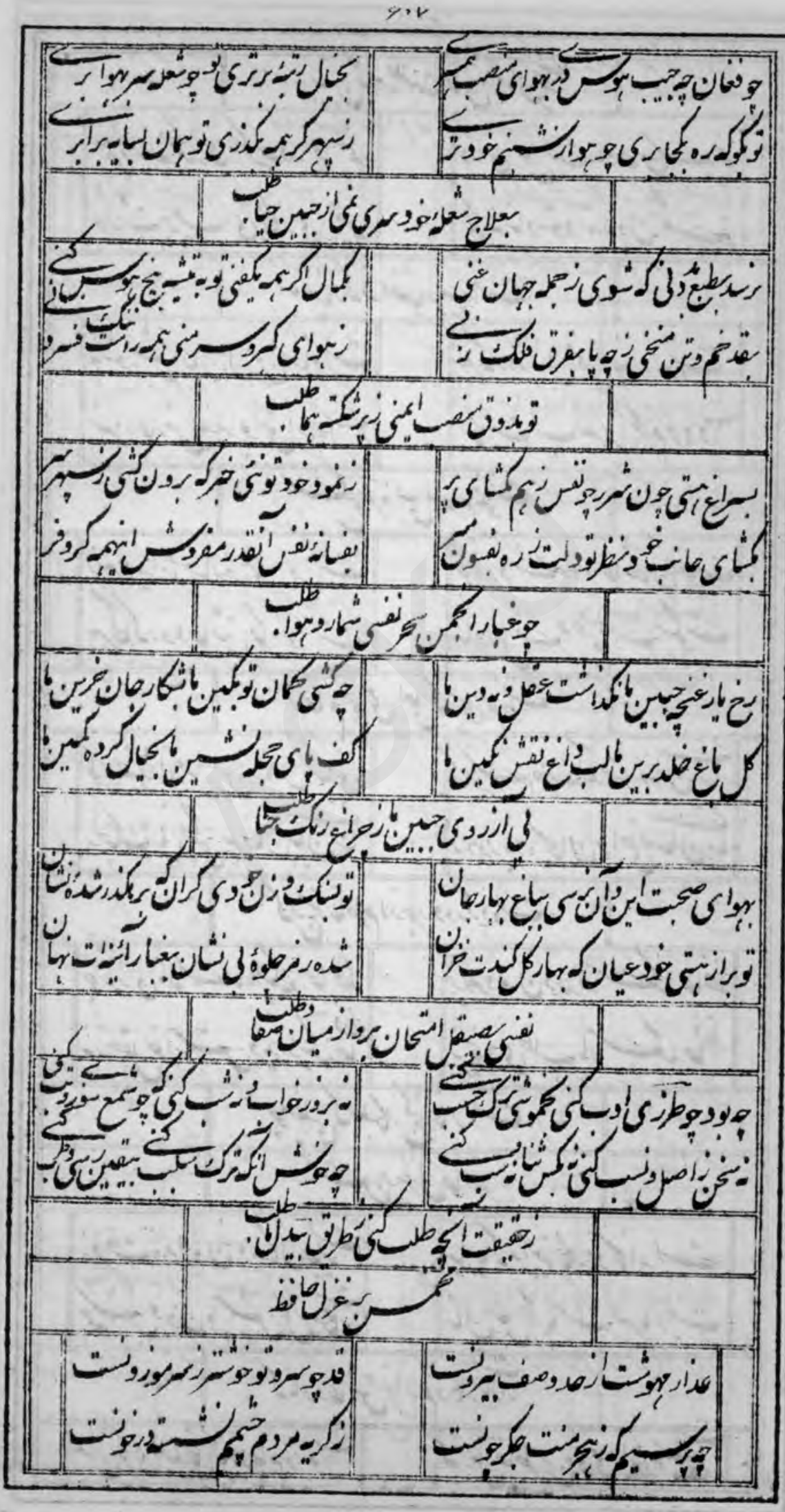


$5 \cdot 1$

\section{Tو.}

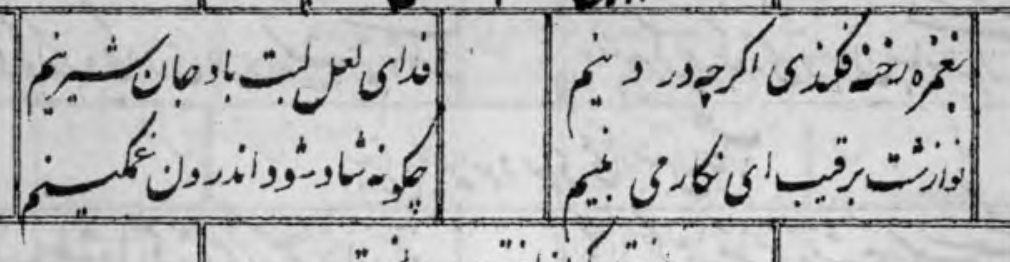

$$
\text { تز, }
$$

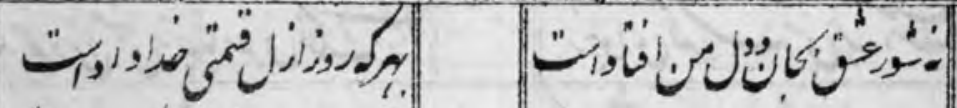

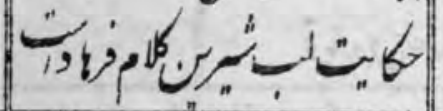

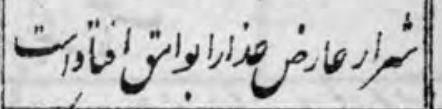

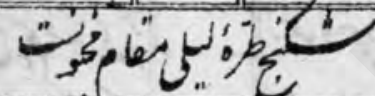

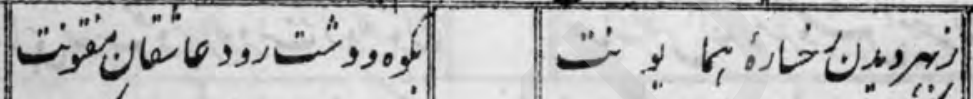

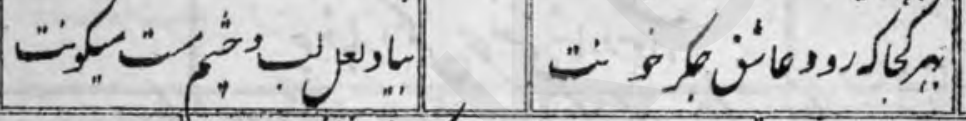

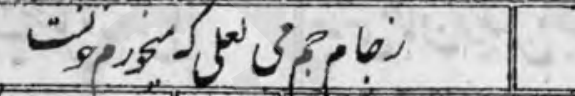

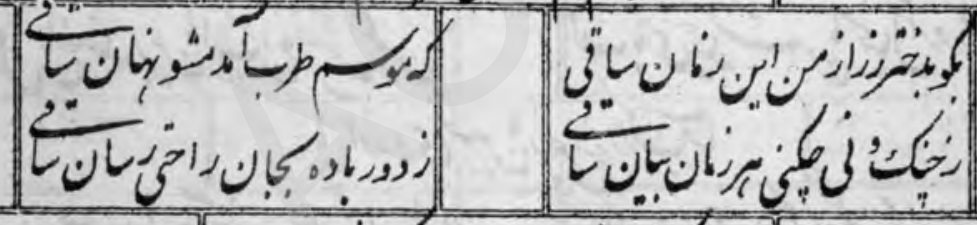

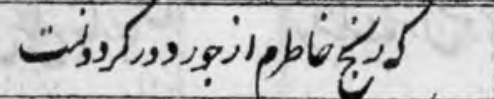

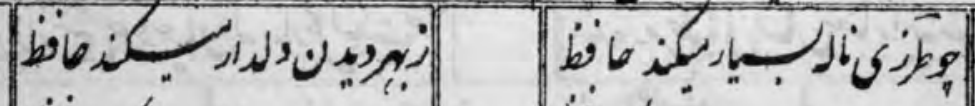

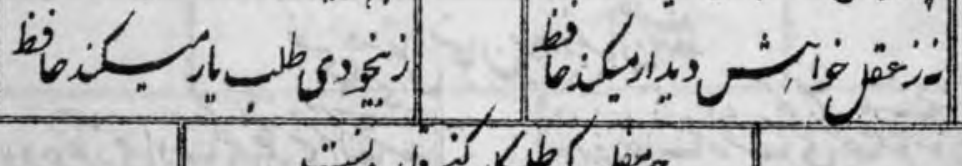

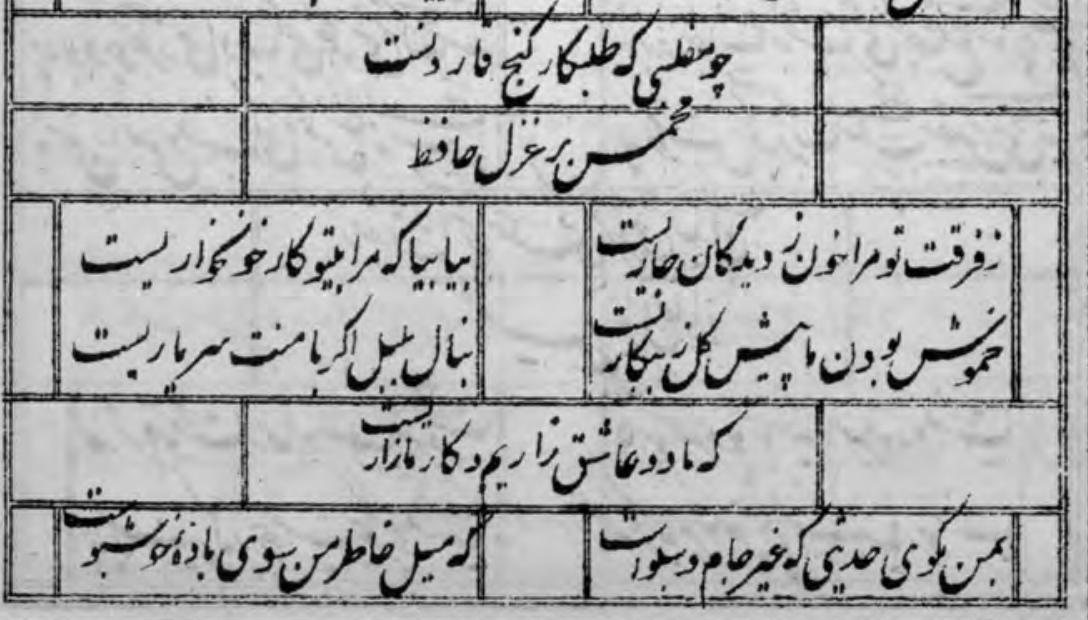


5. 9

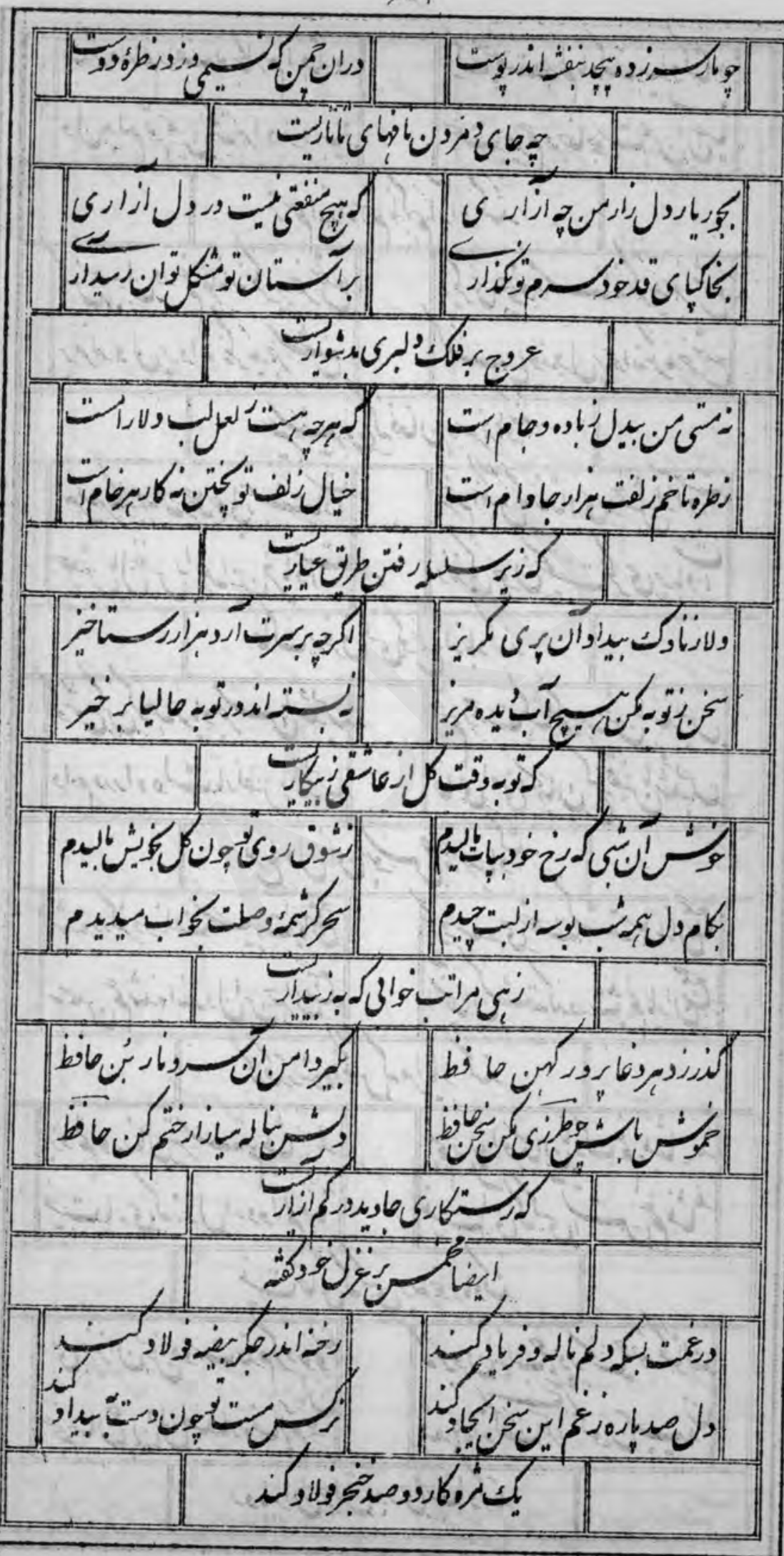


.81

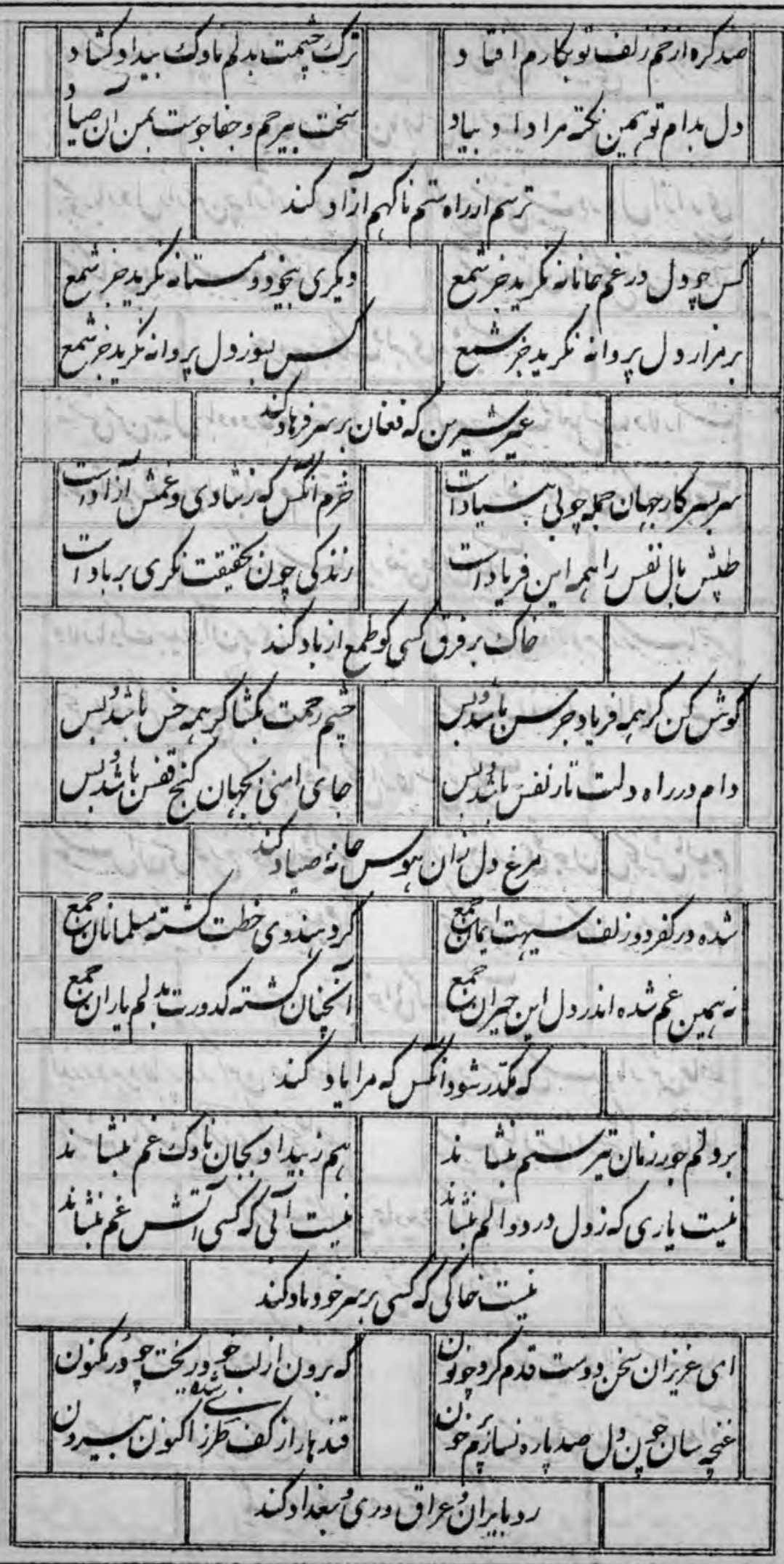




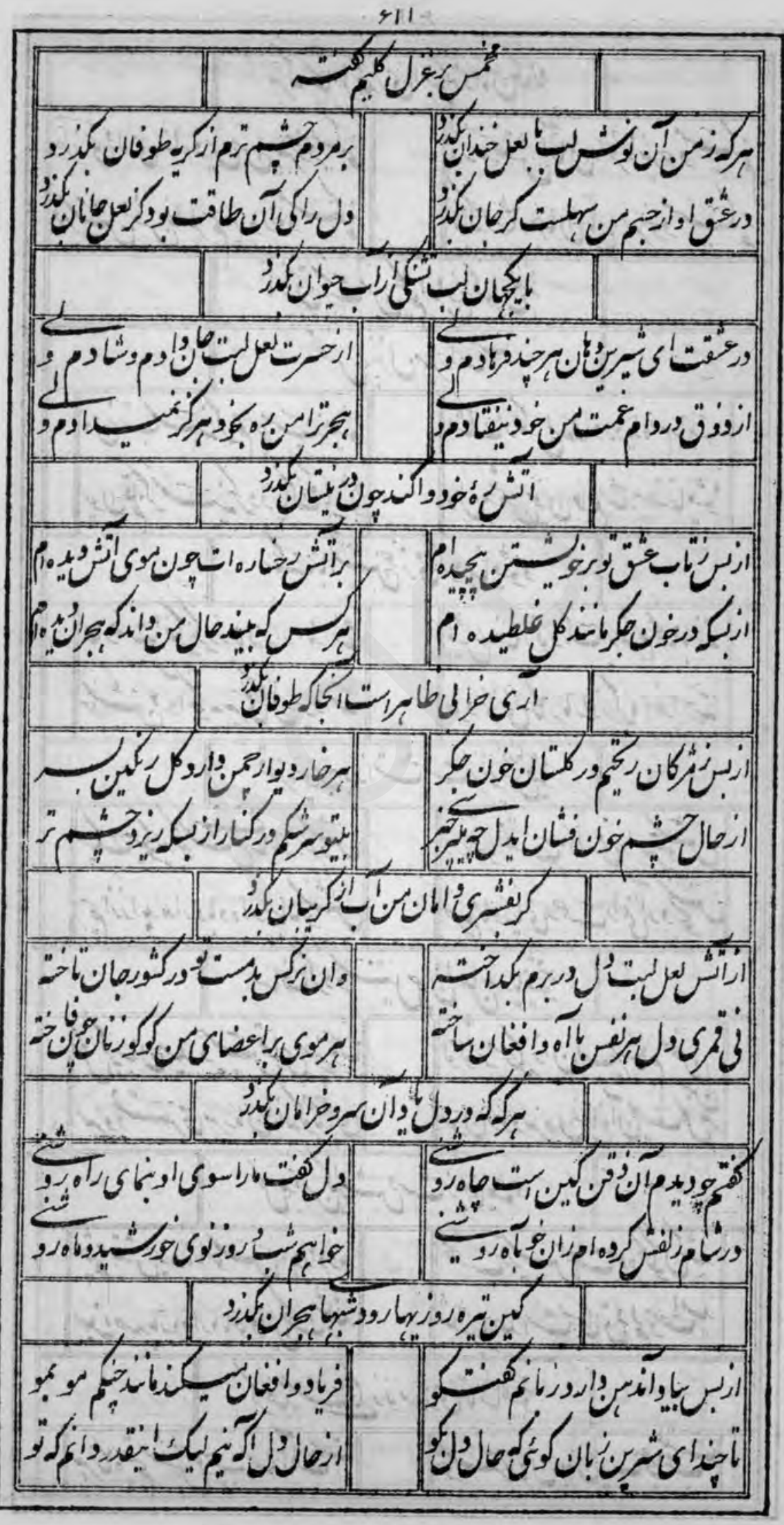




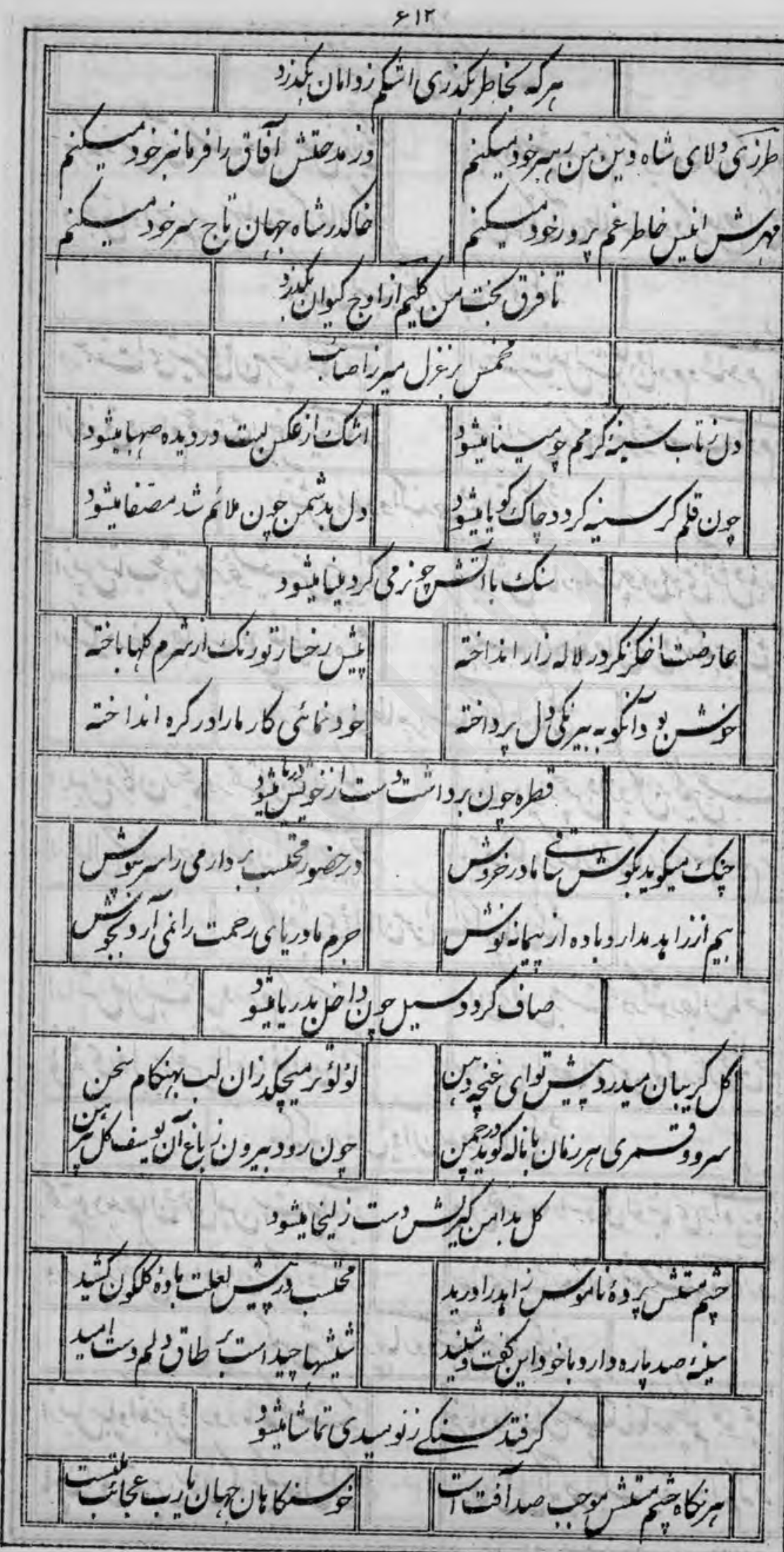




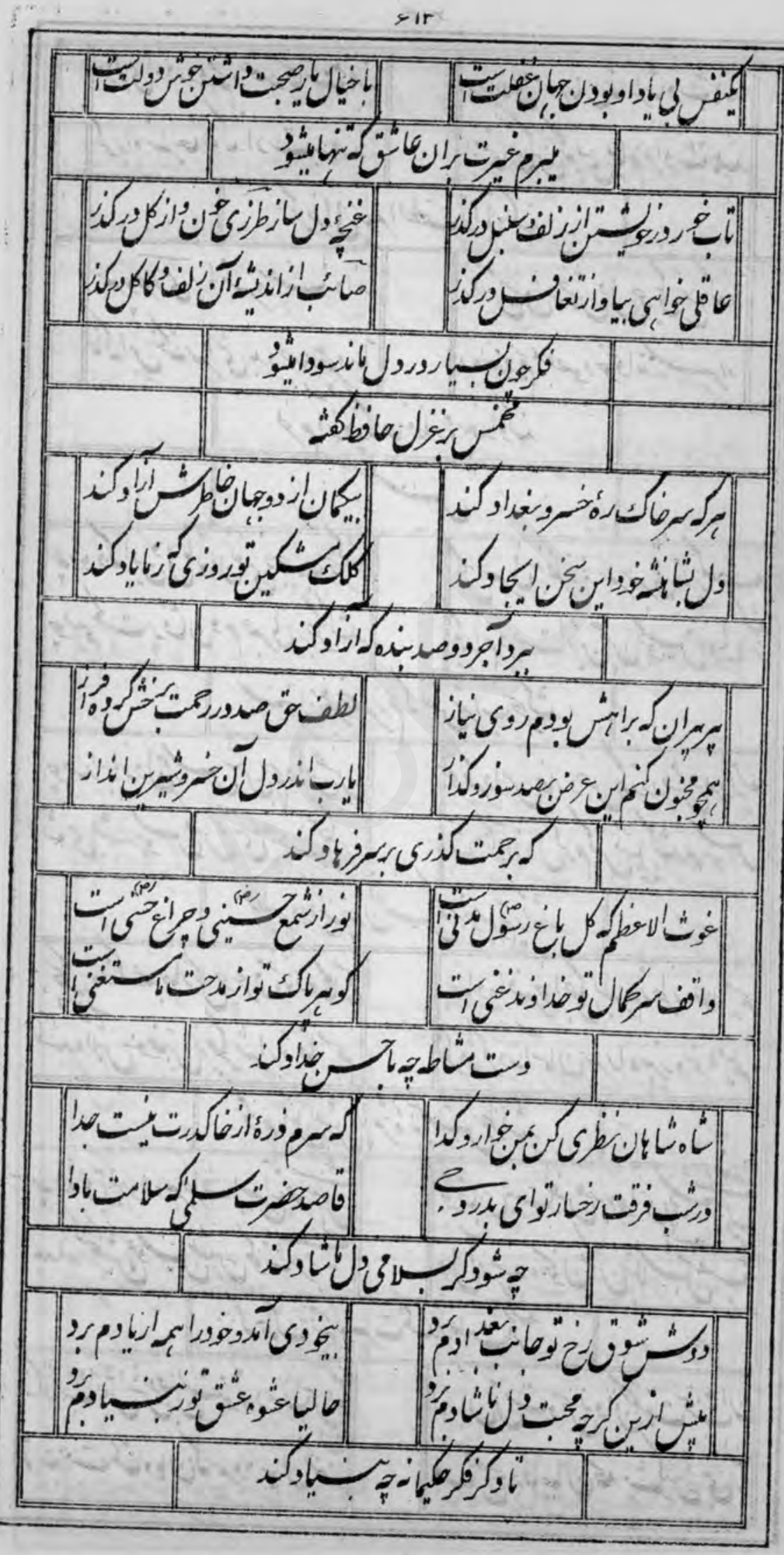


Sif

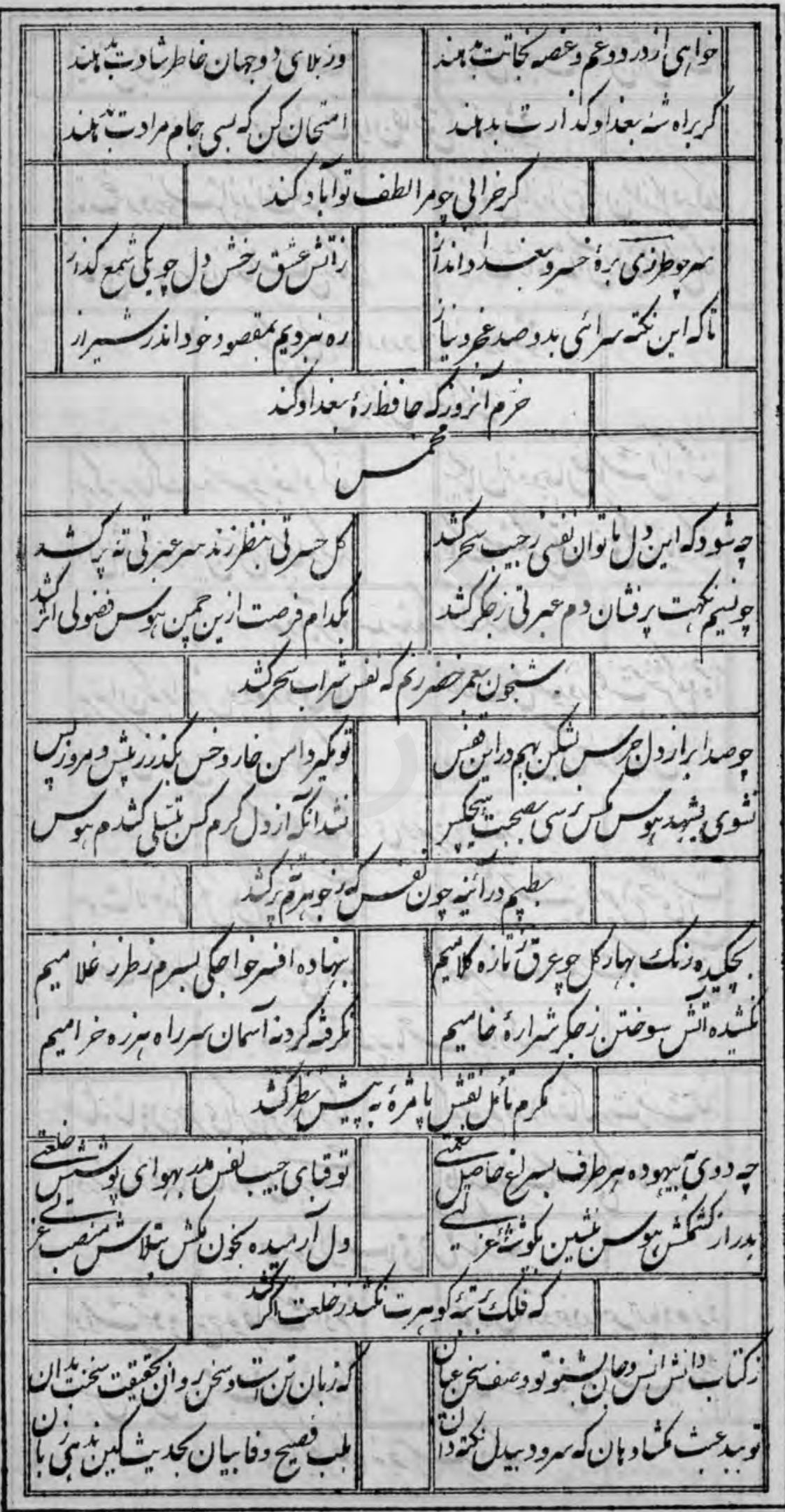


810

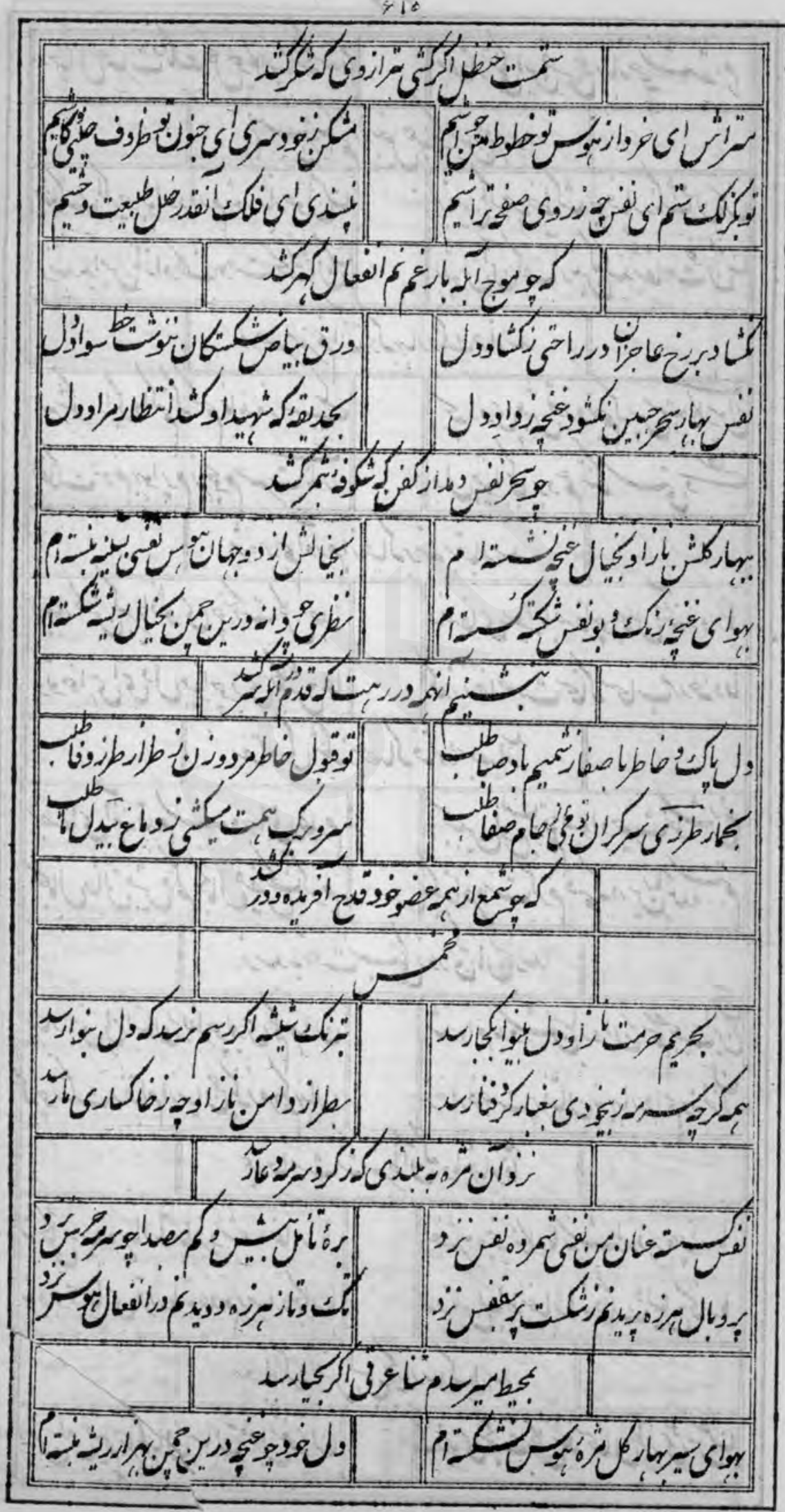


F15

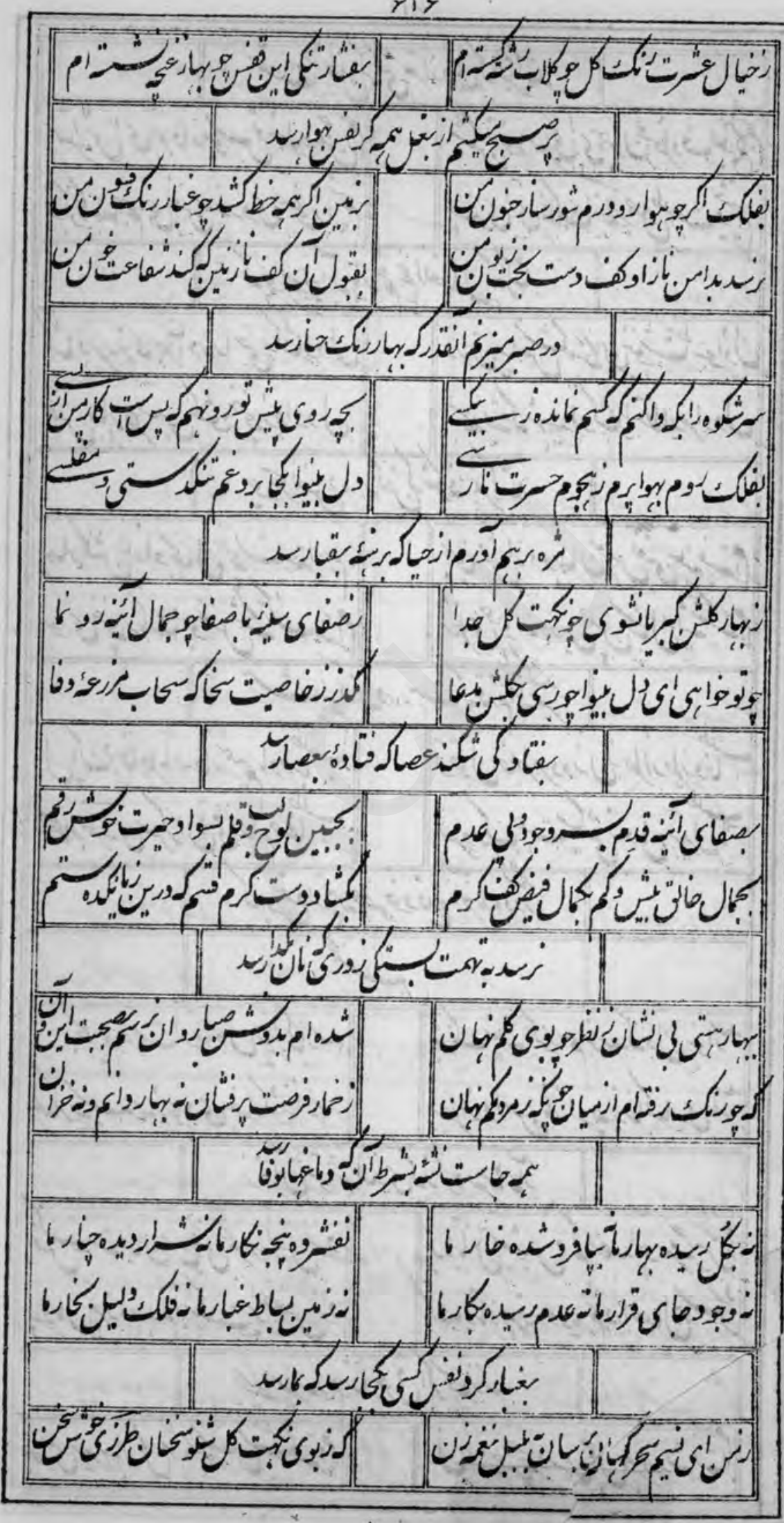




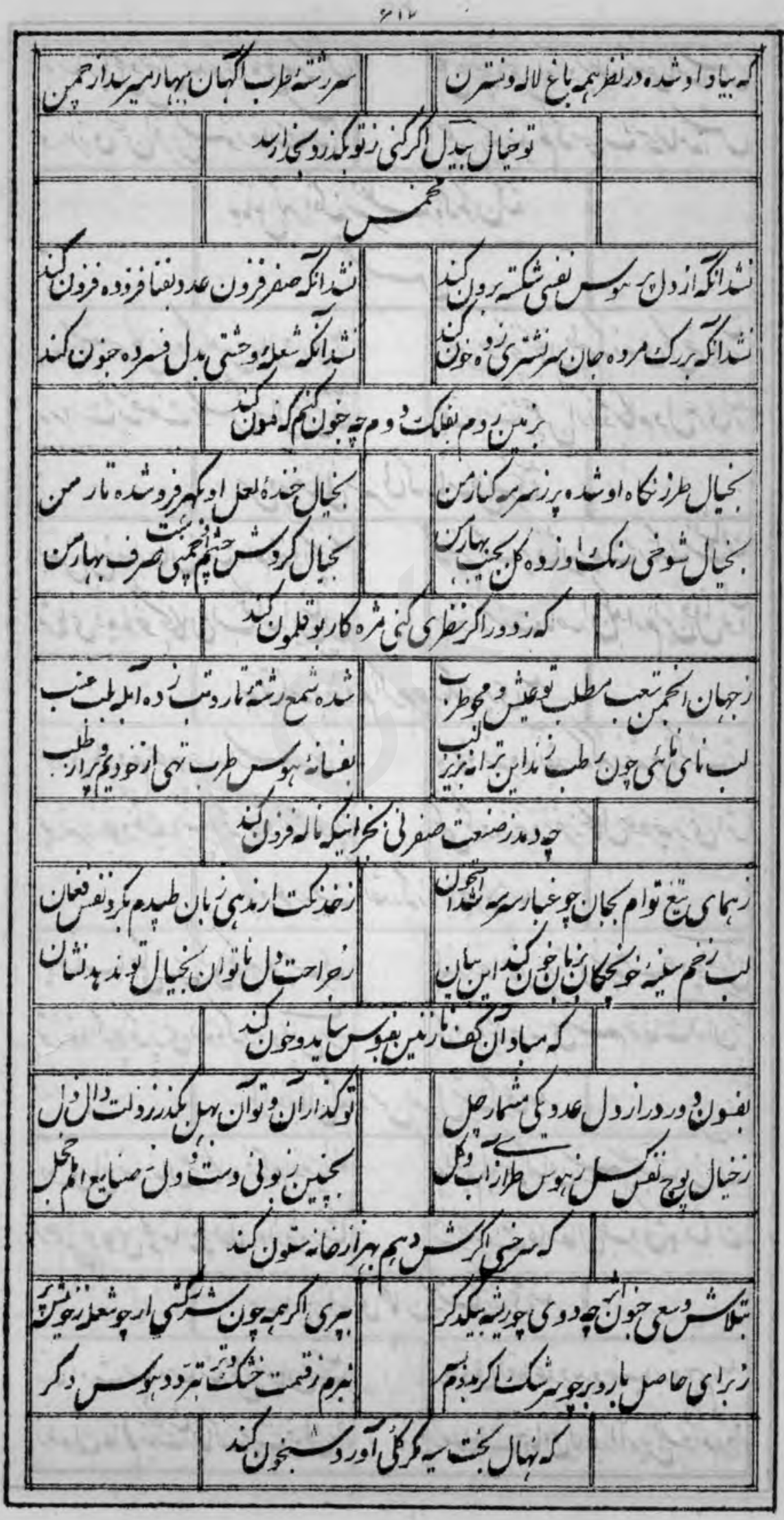


SI

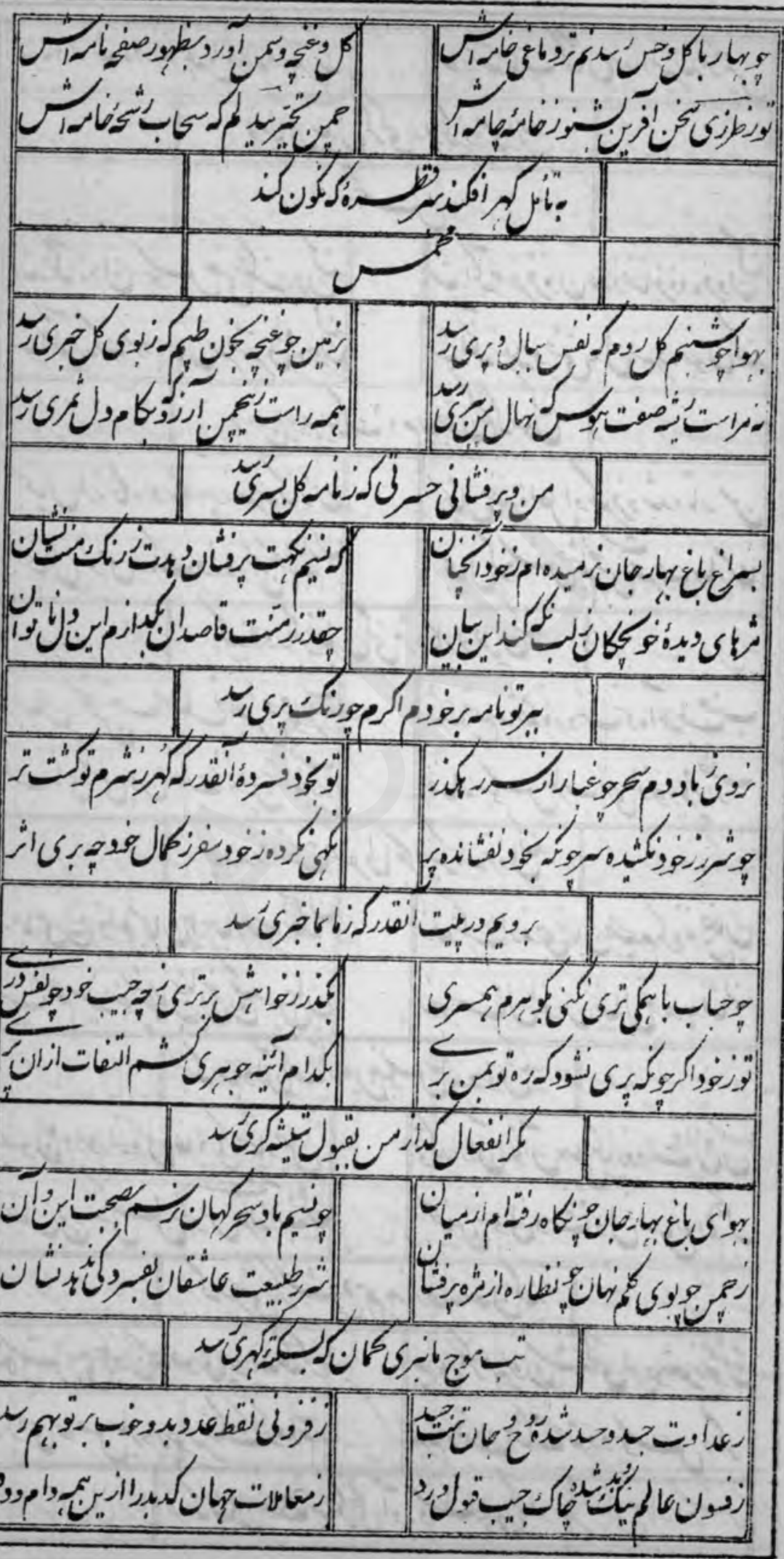




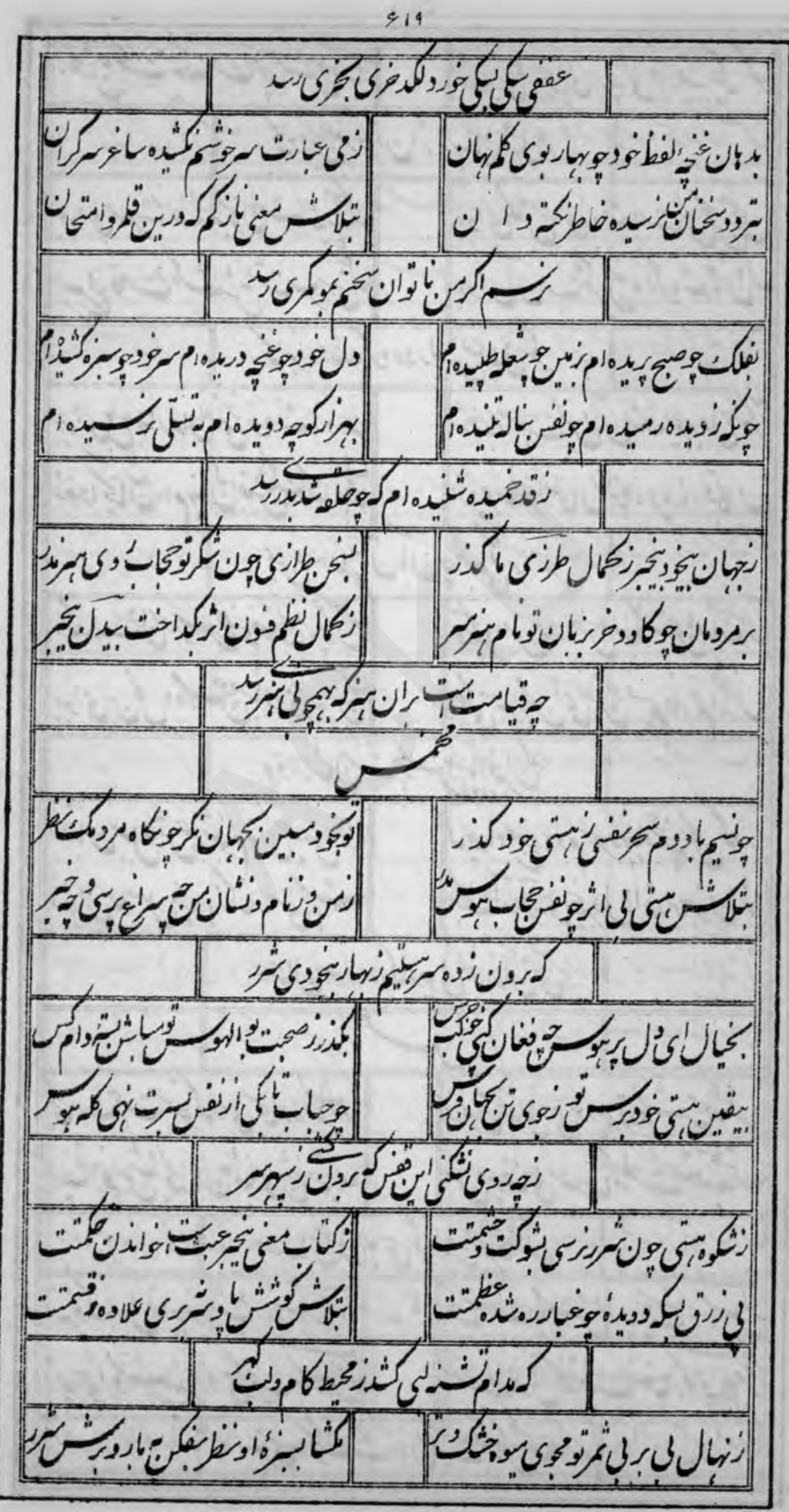


$5+1$

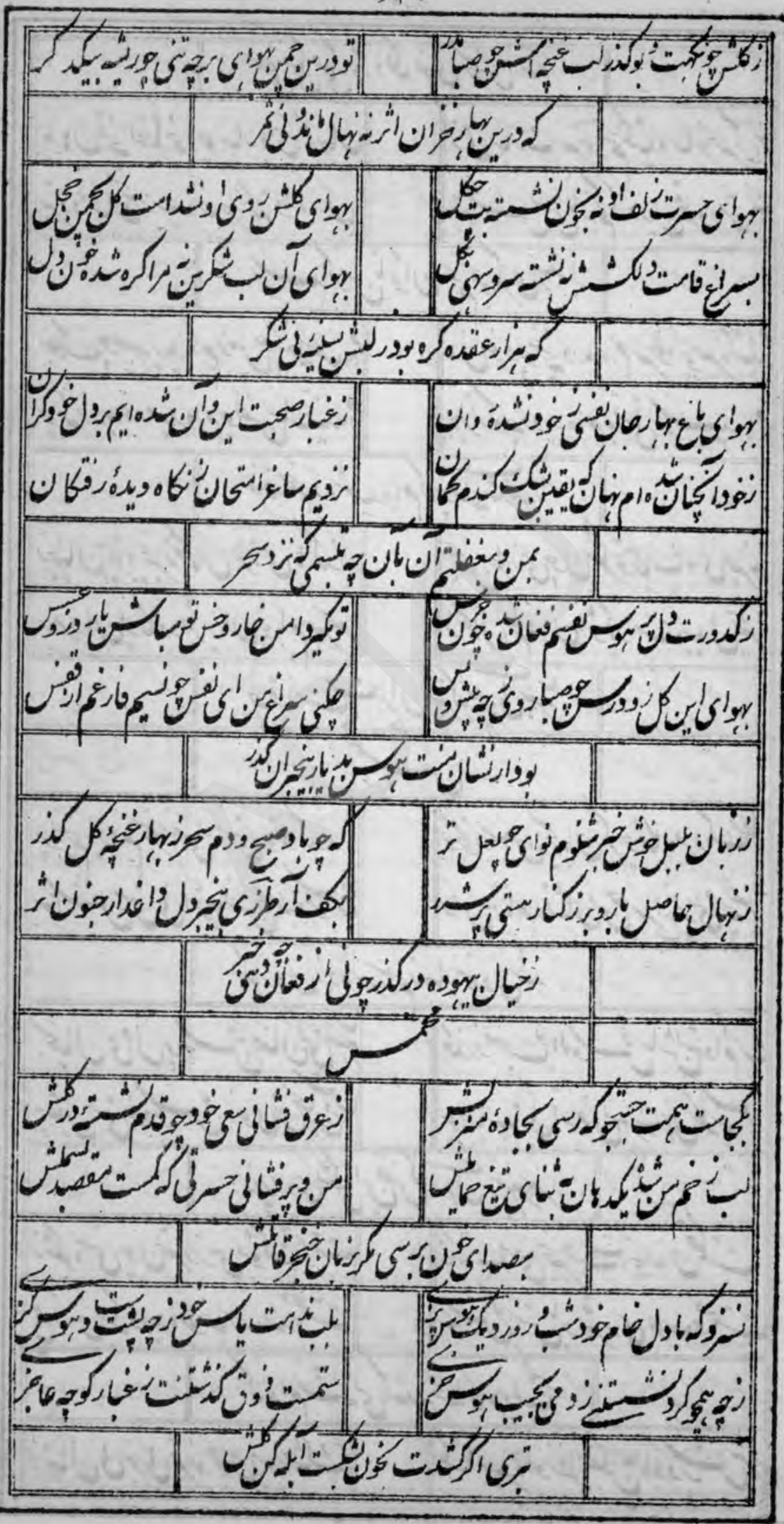




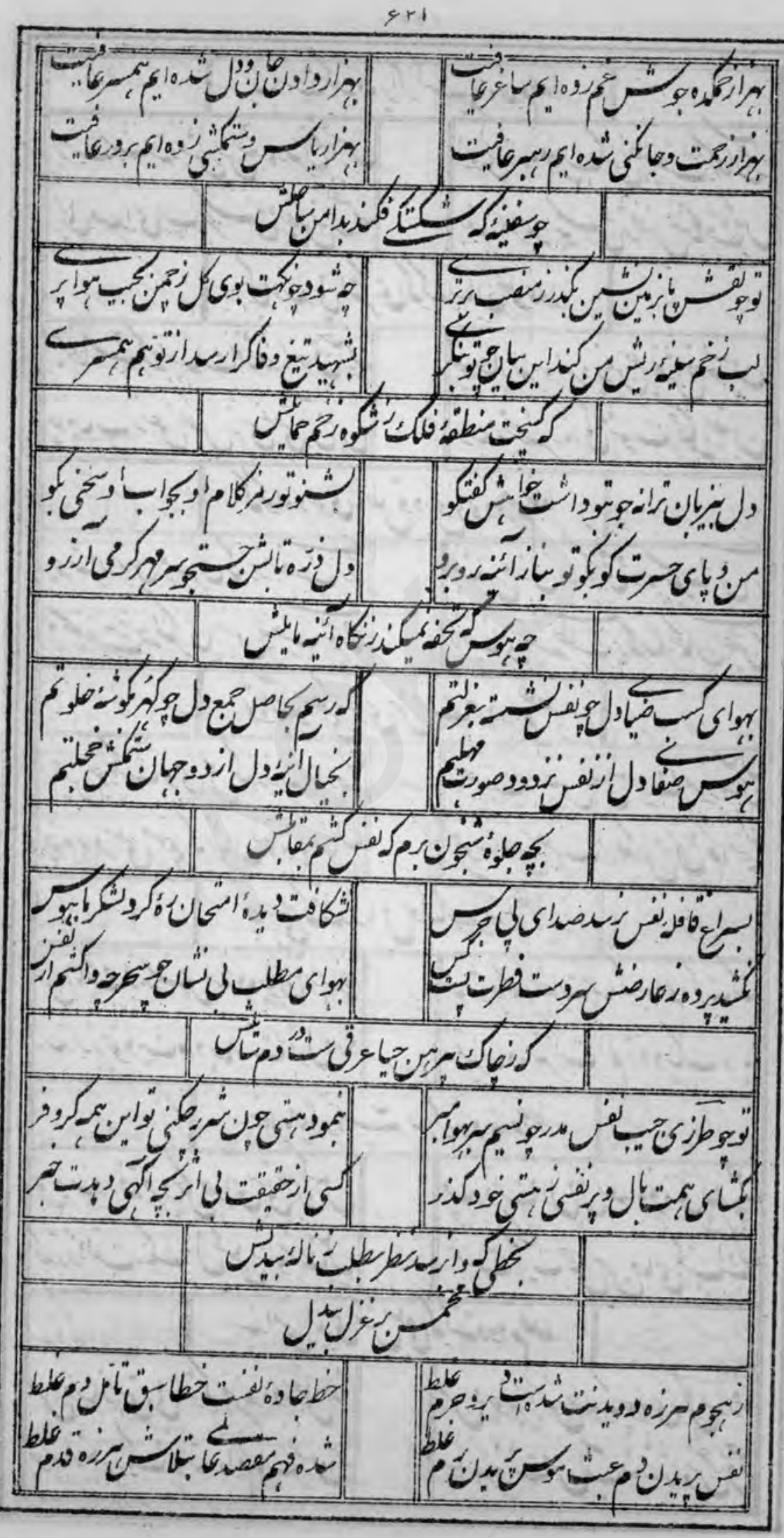




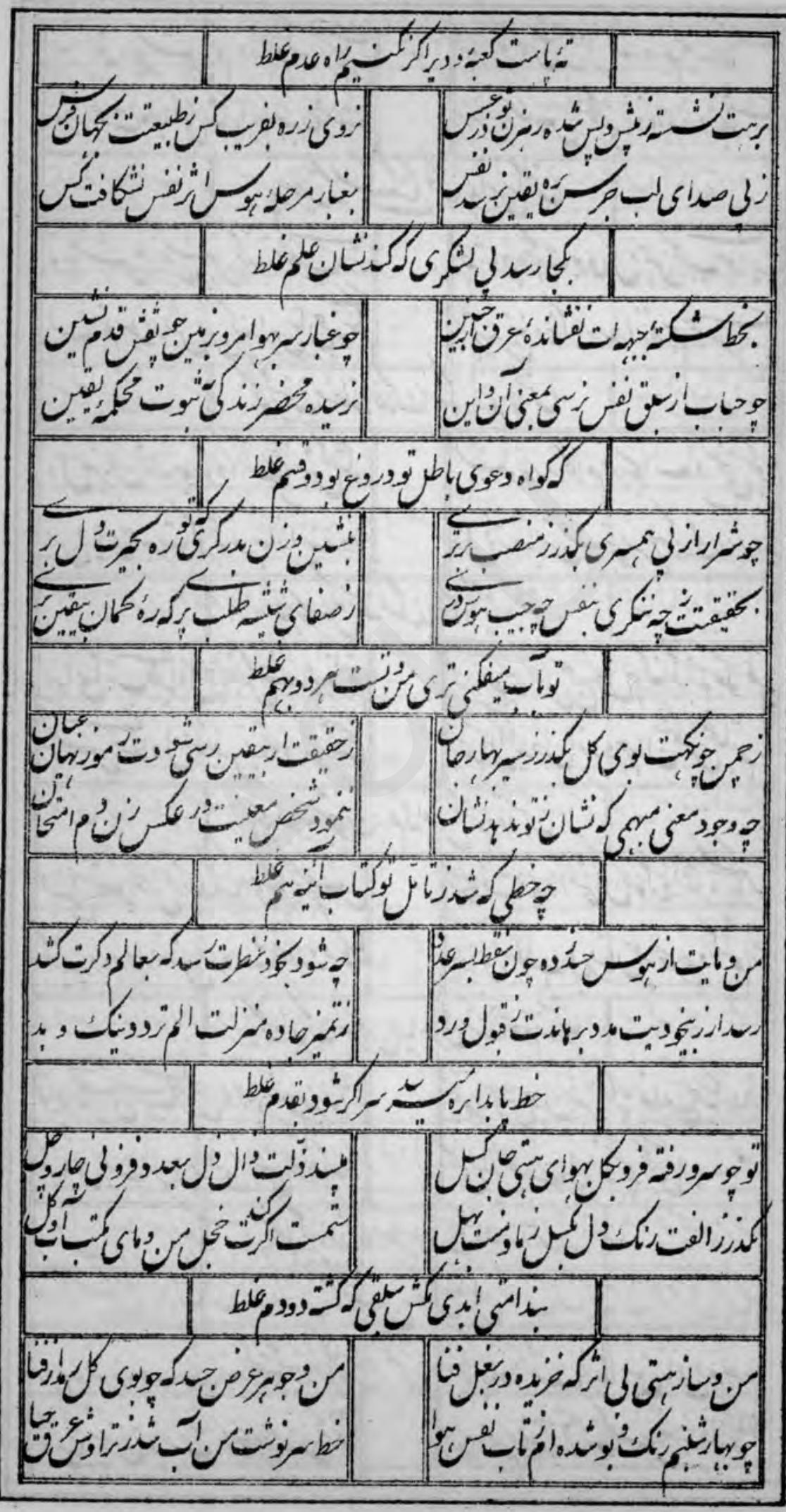


sr

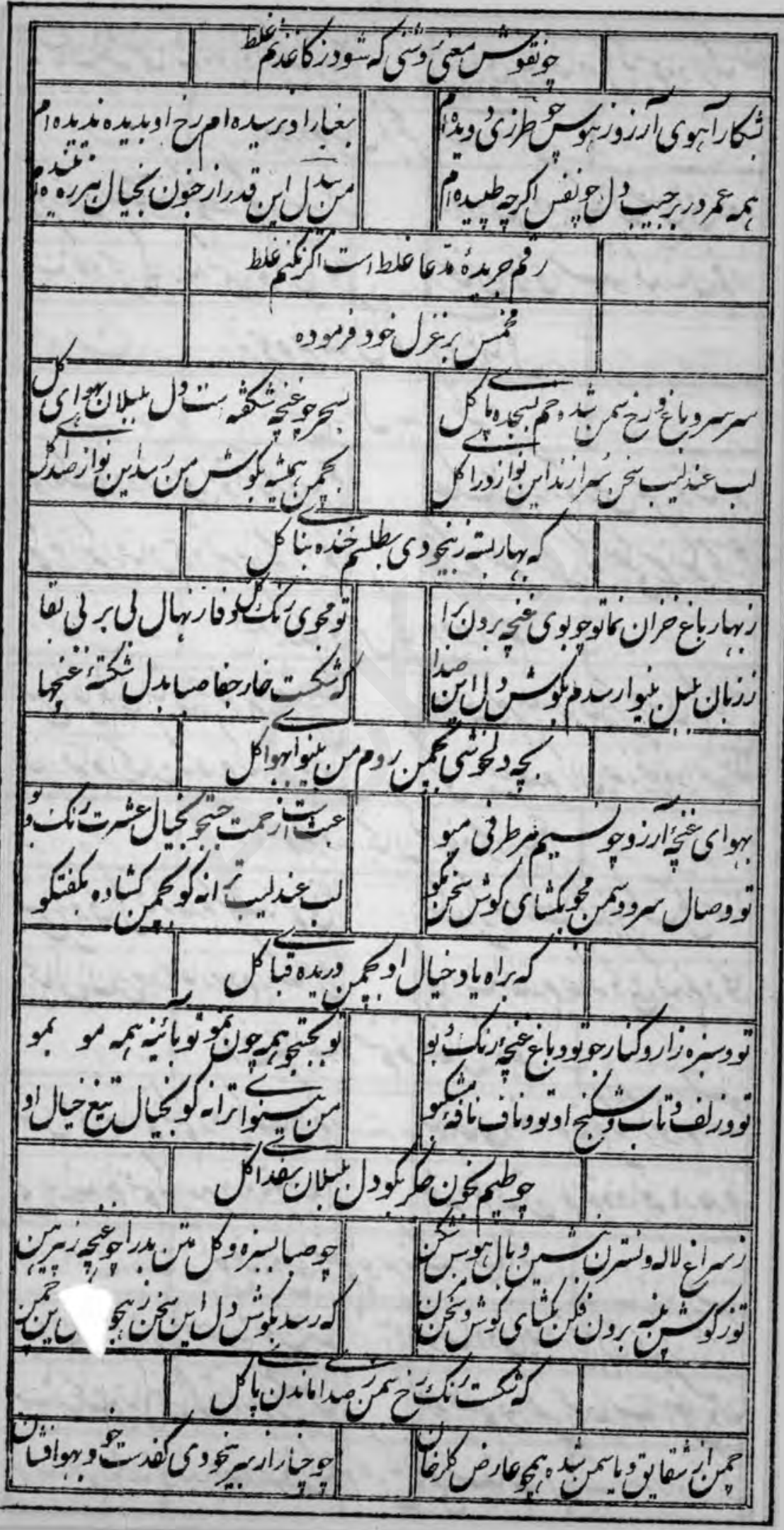


s r r

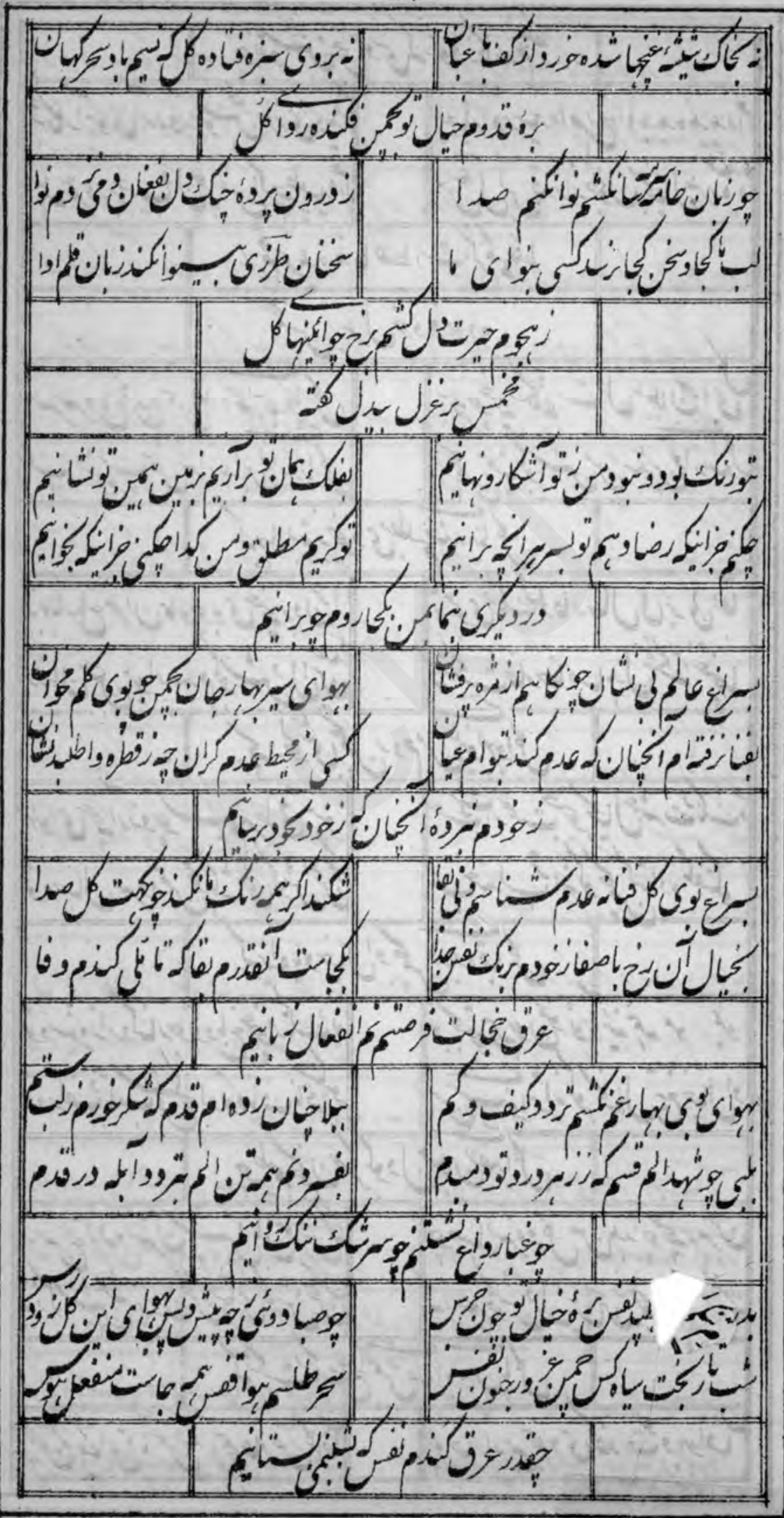




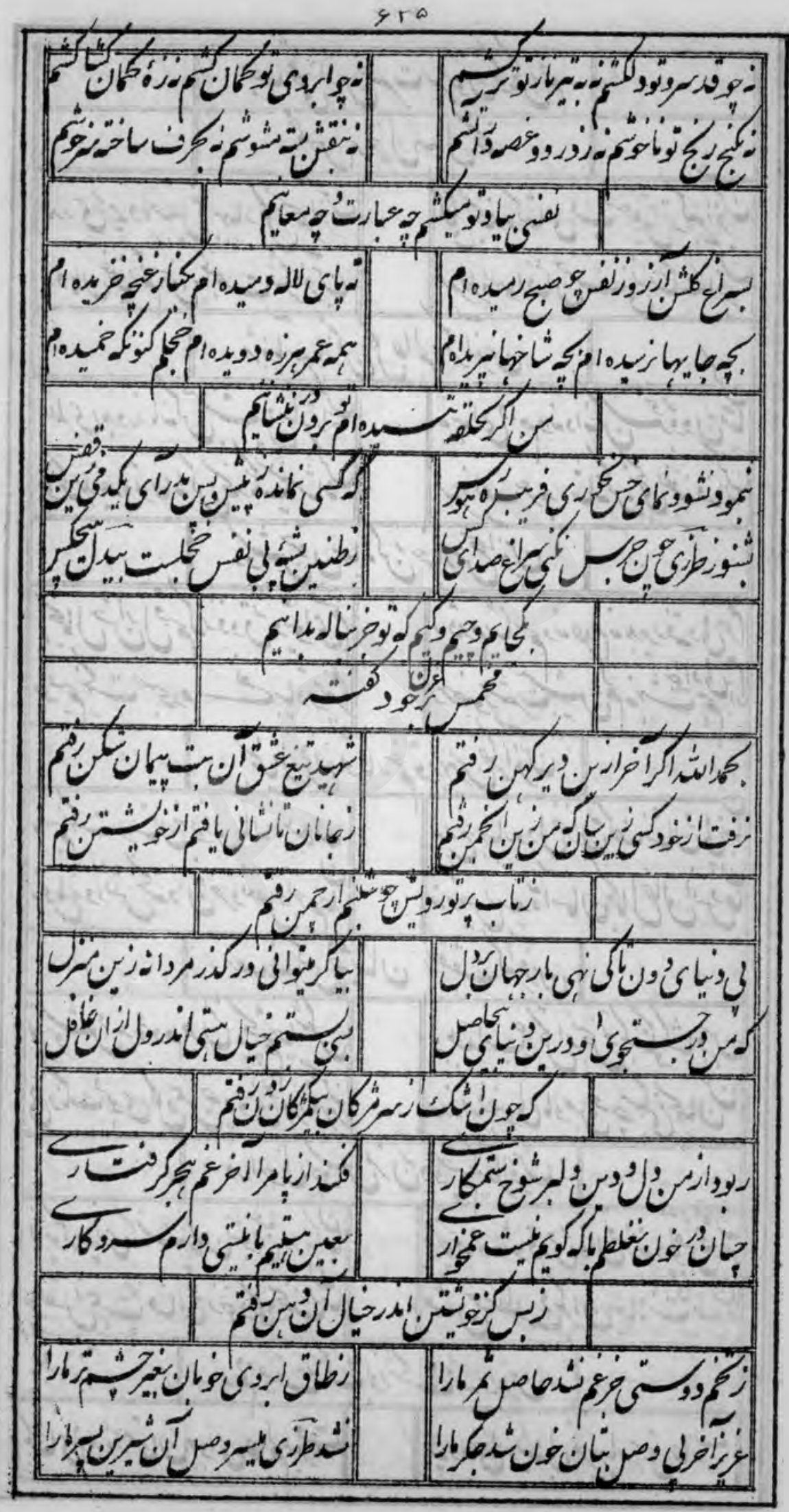




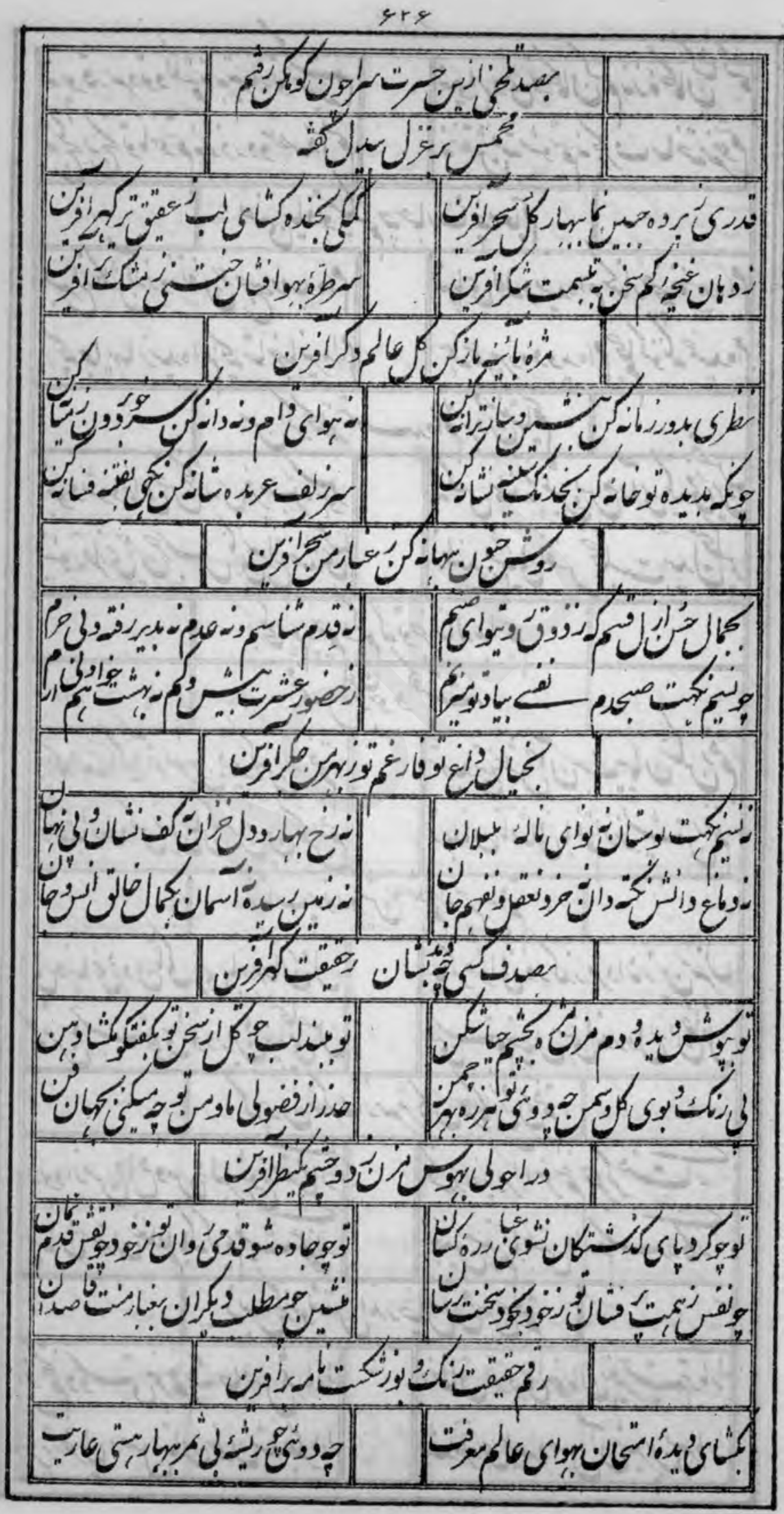

जें 
$4{ }^{\circ}$

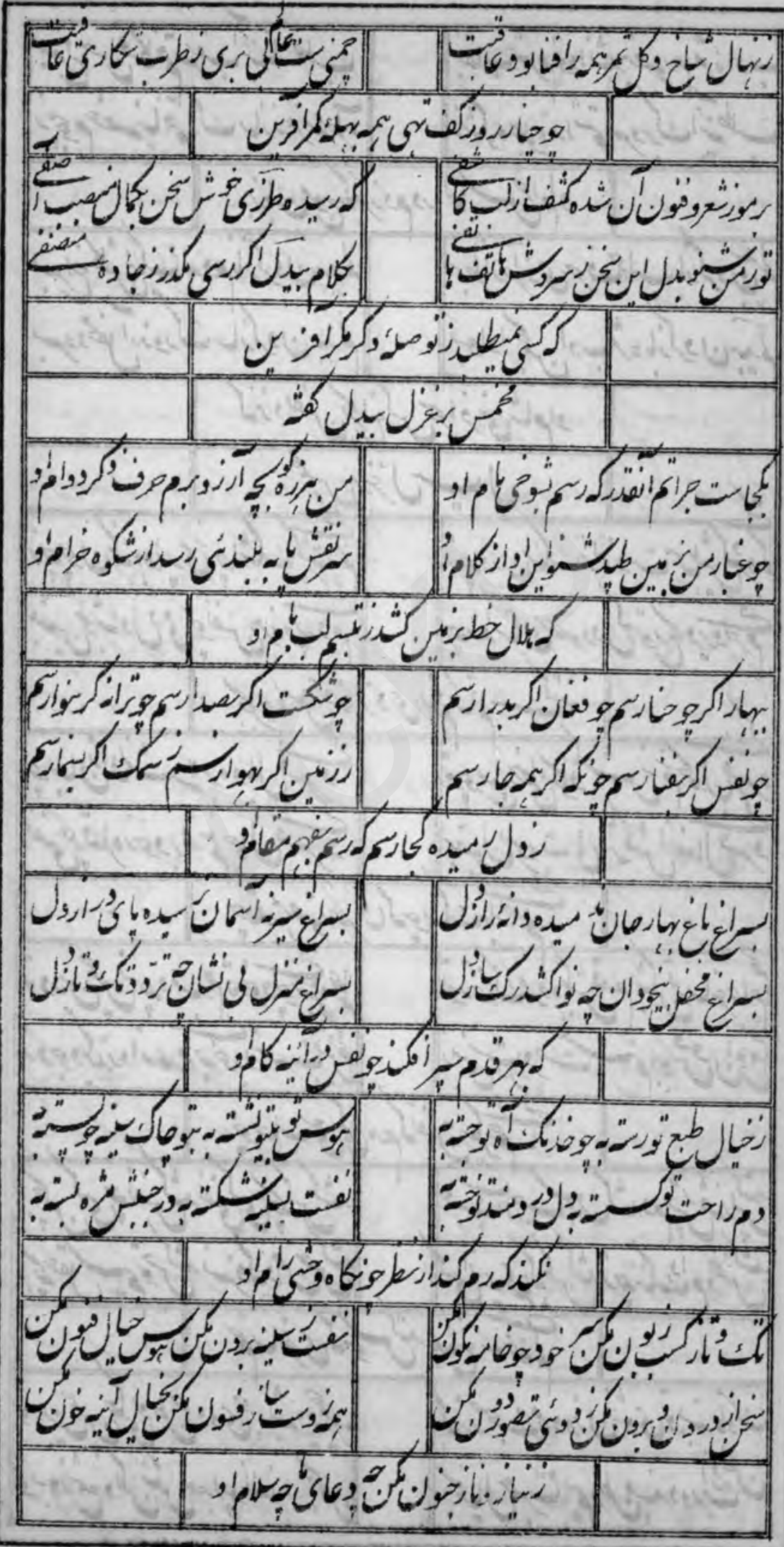




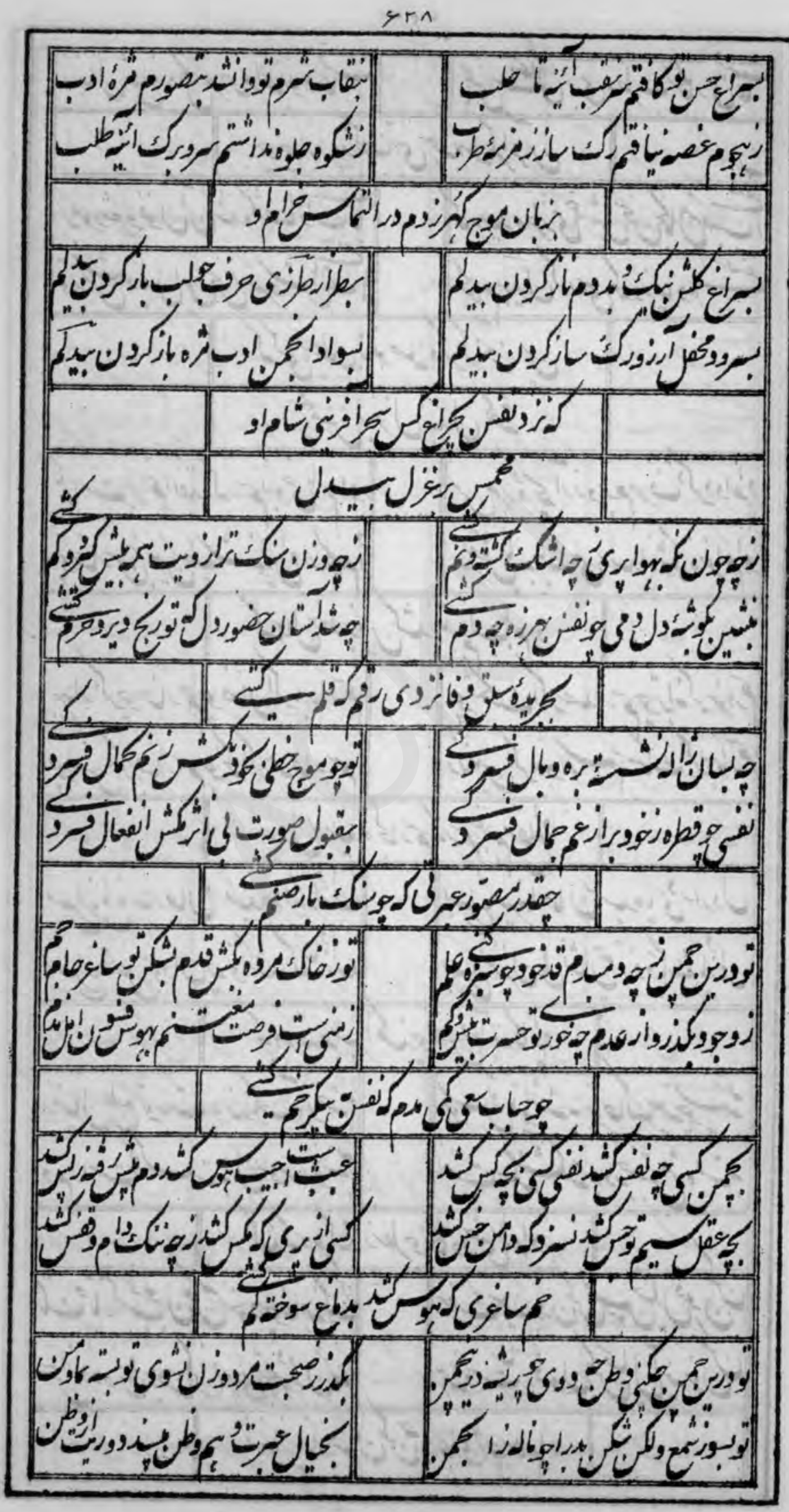




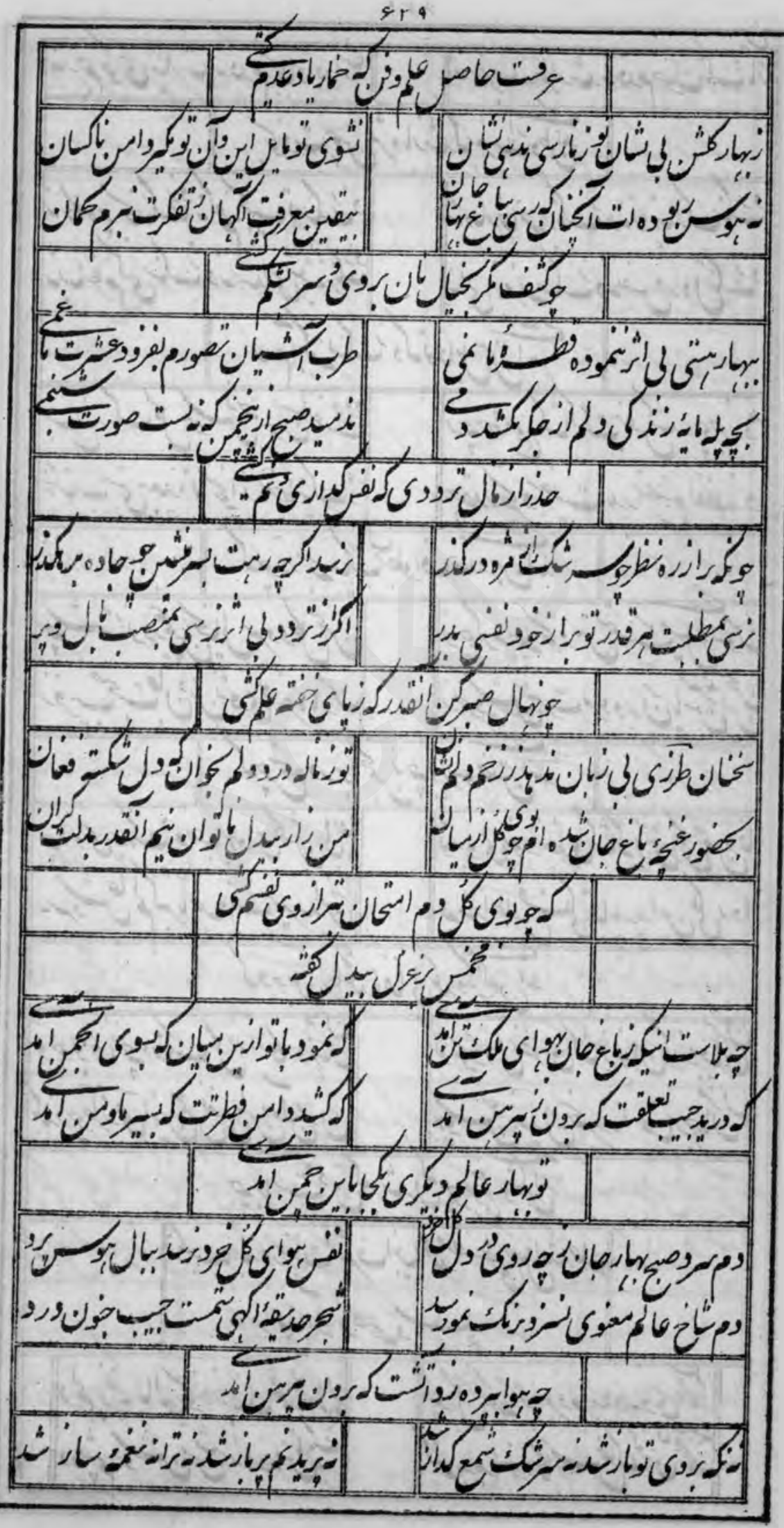




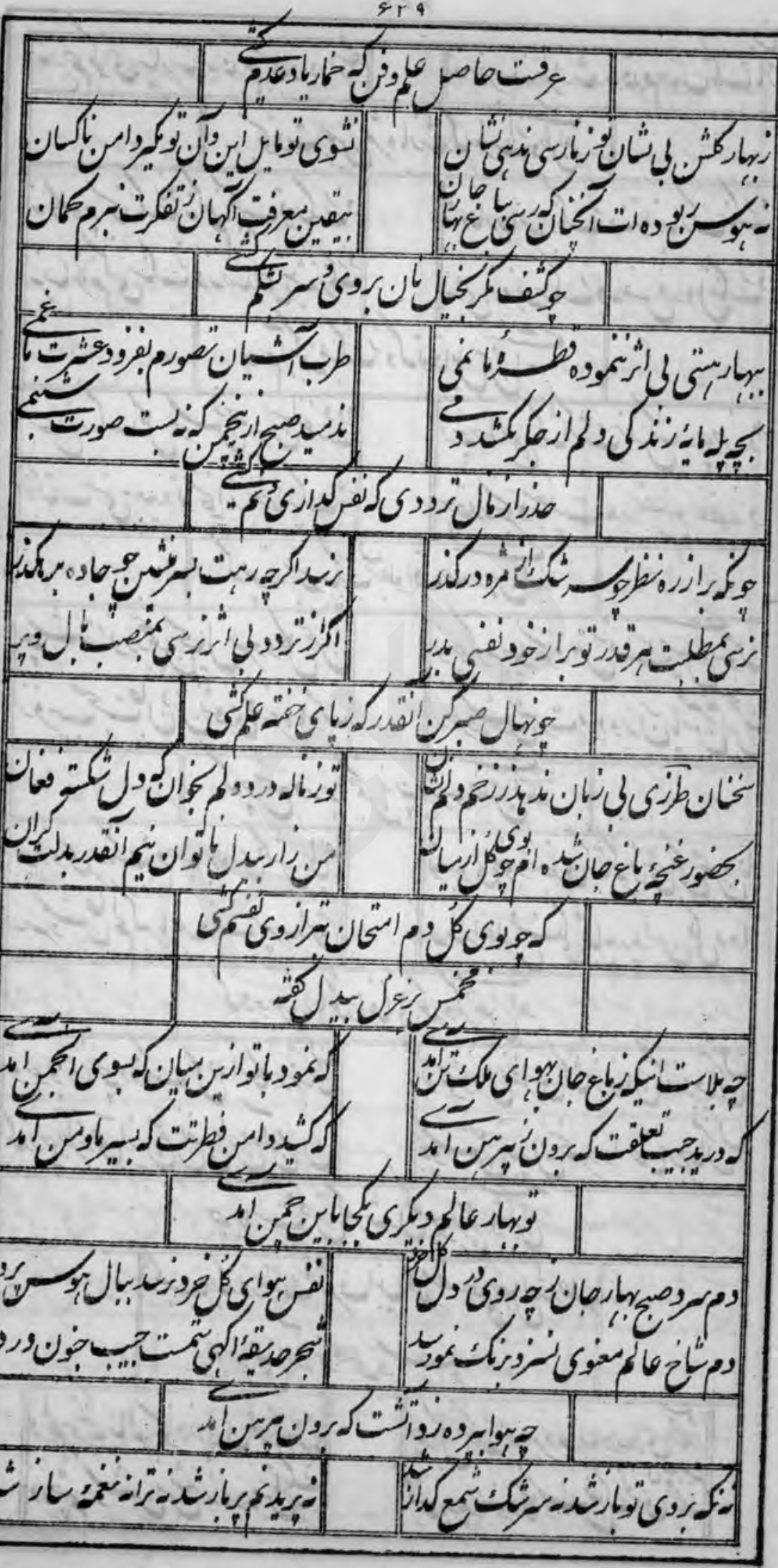




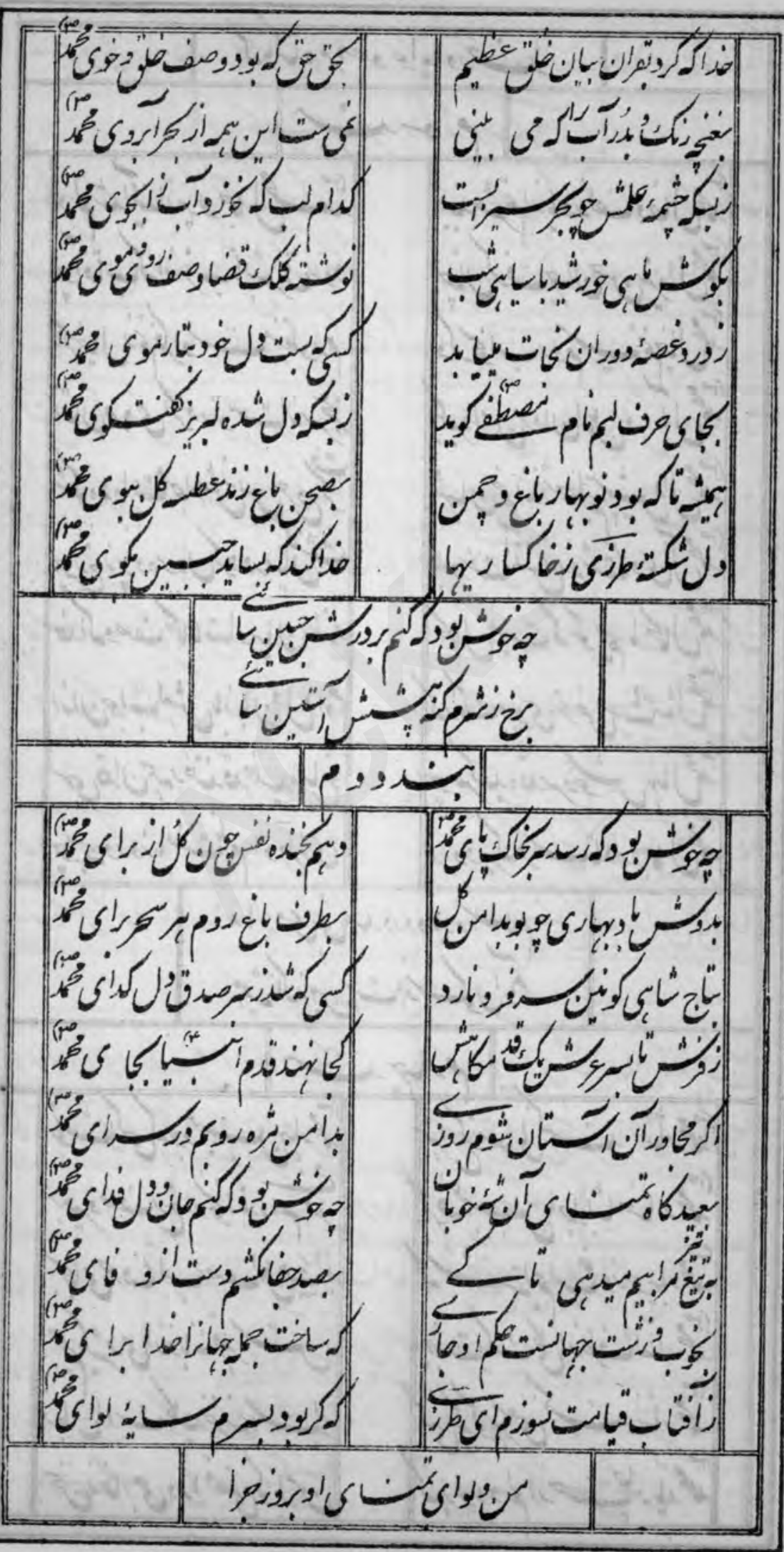




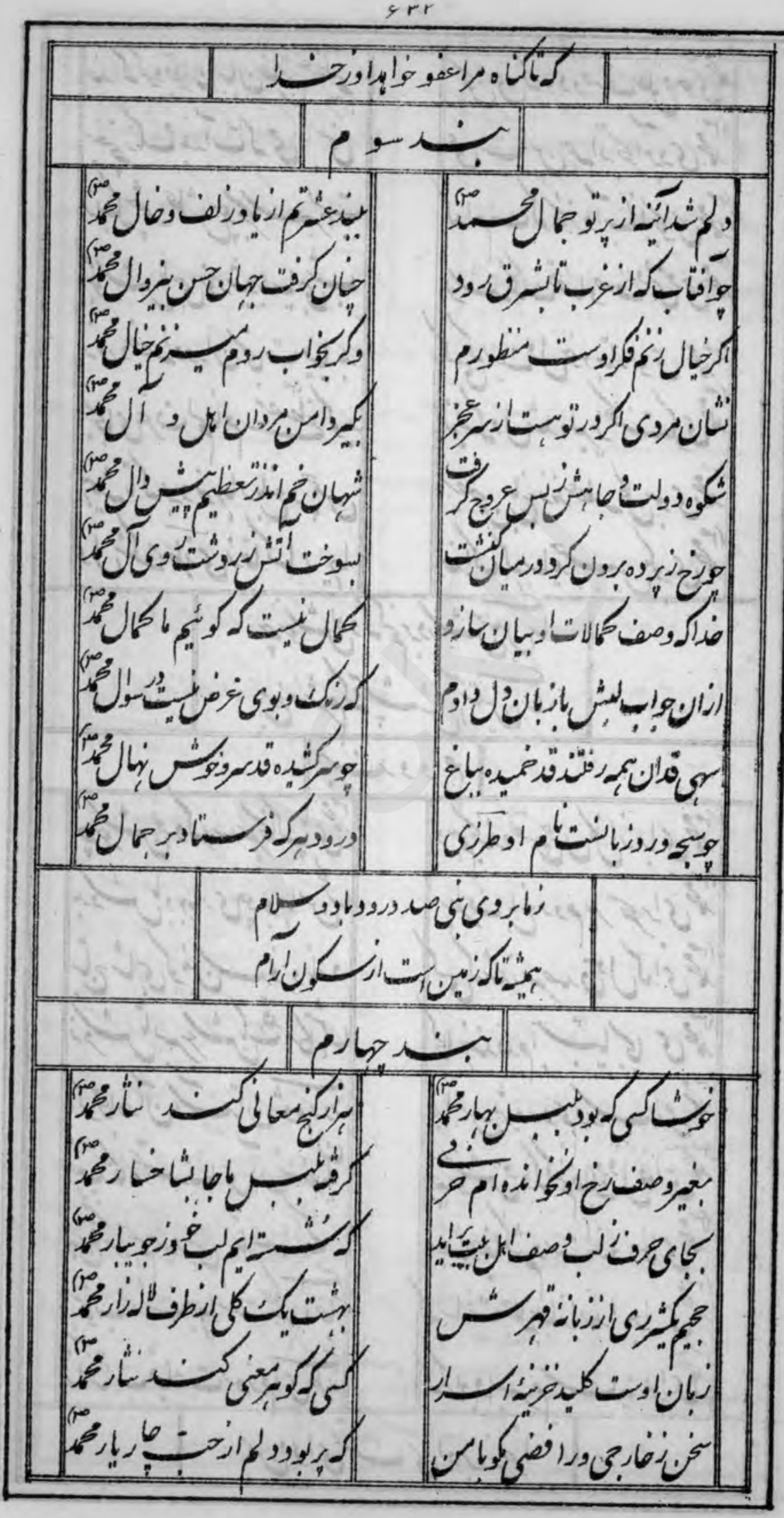

v. 


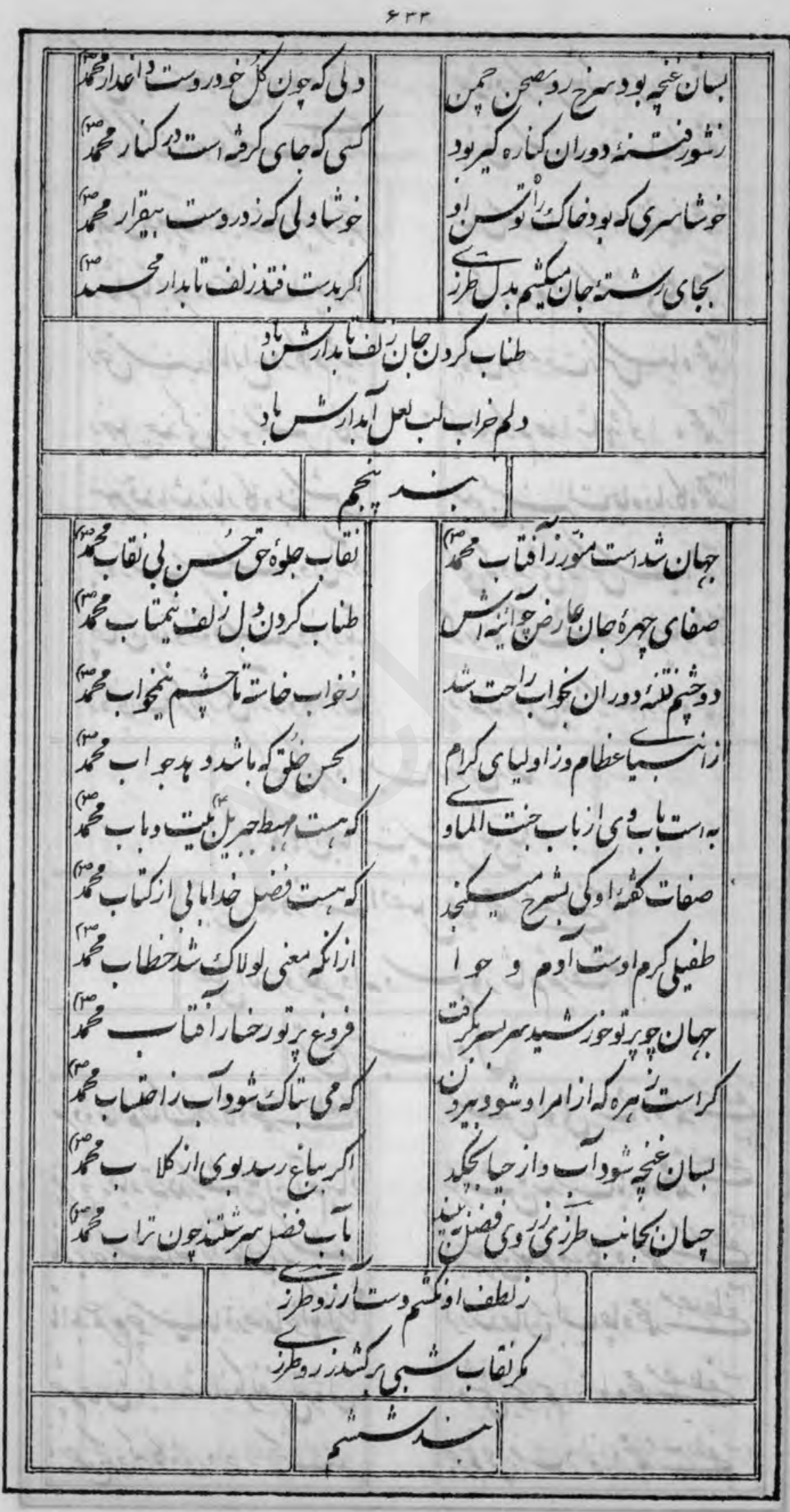




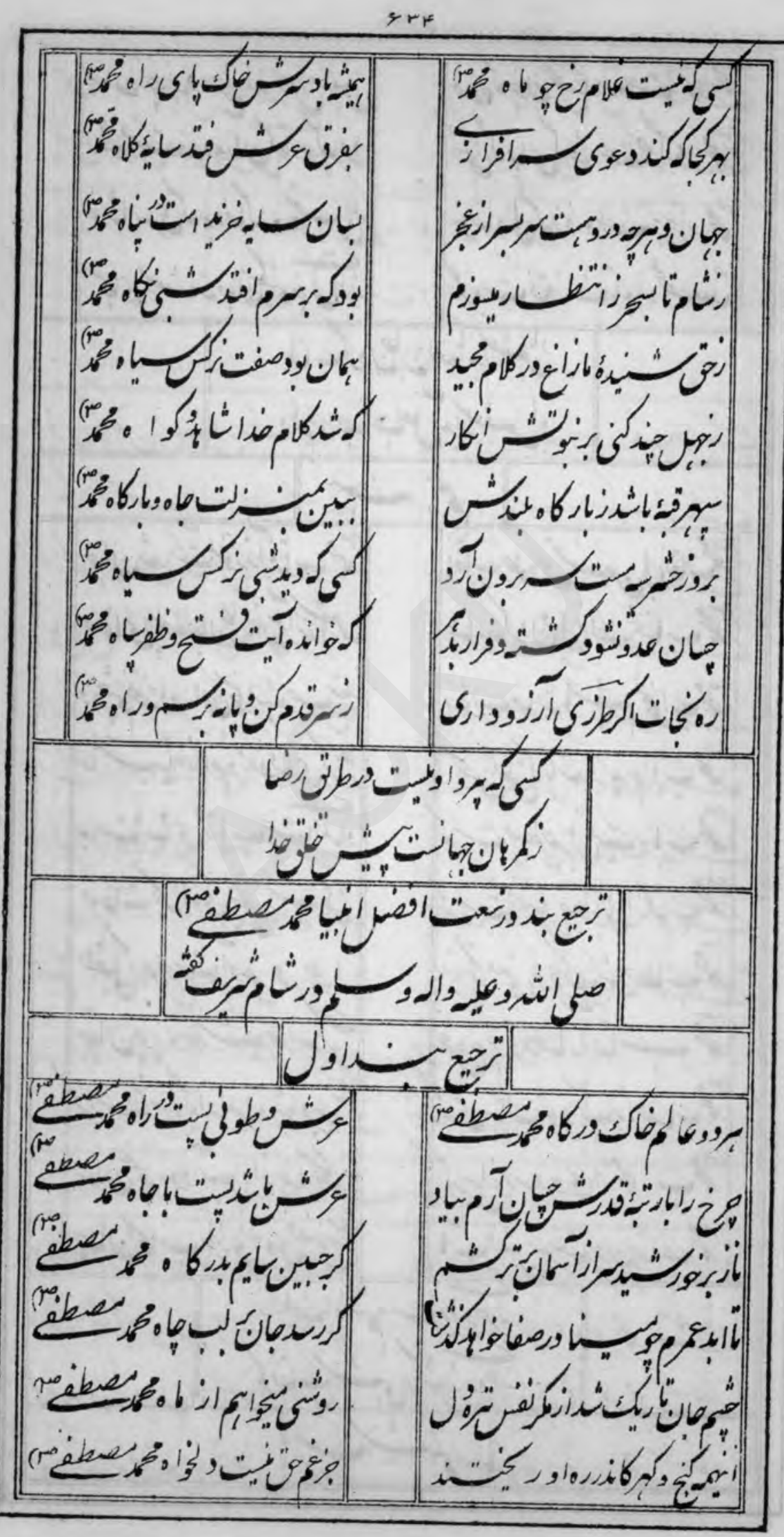




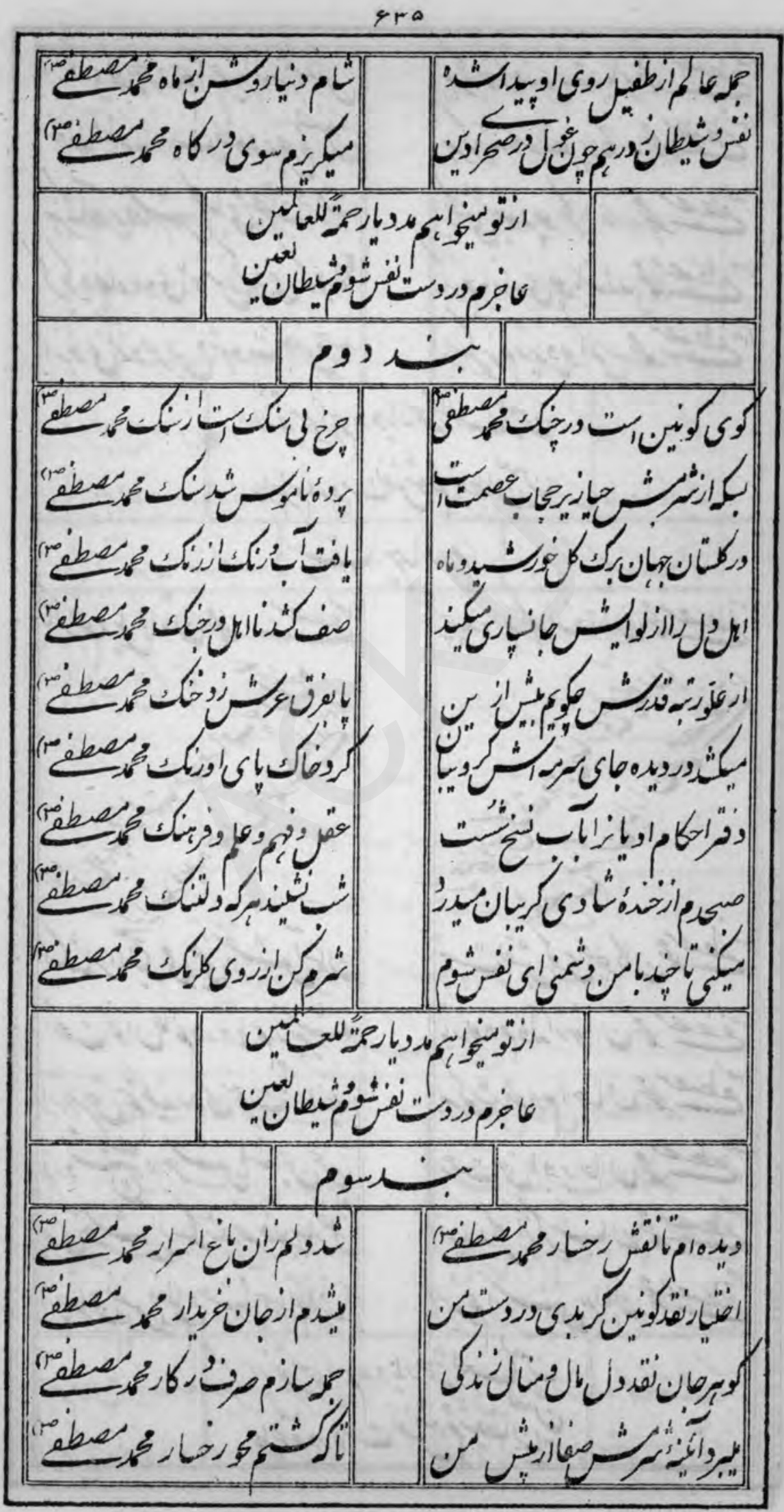




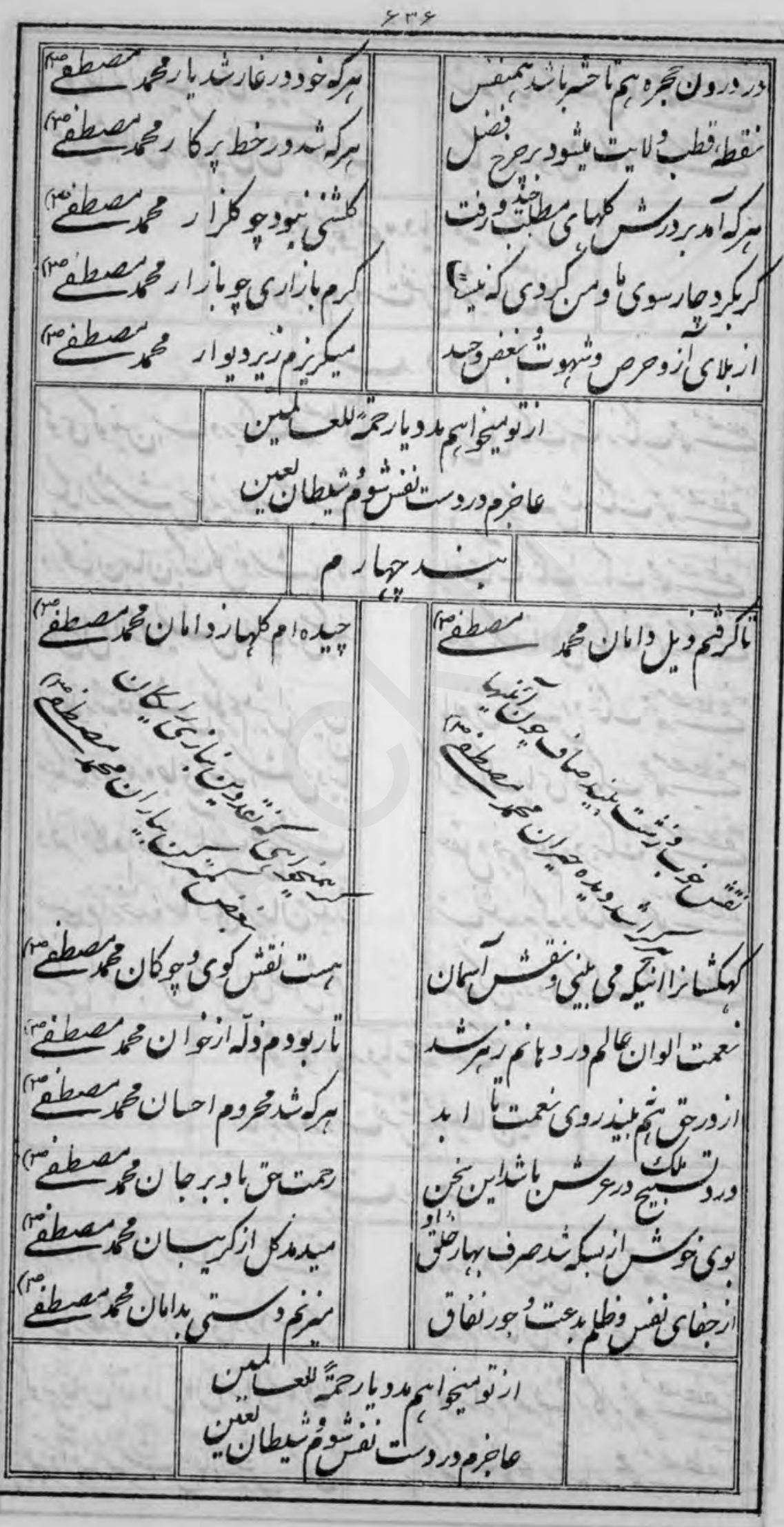




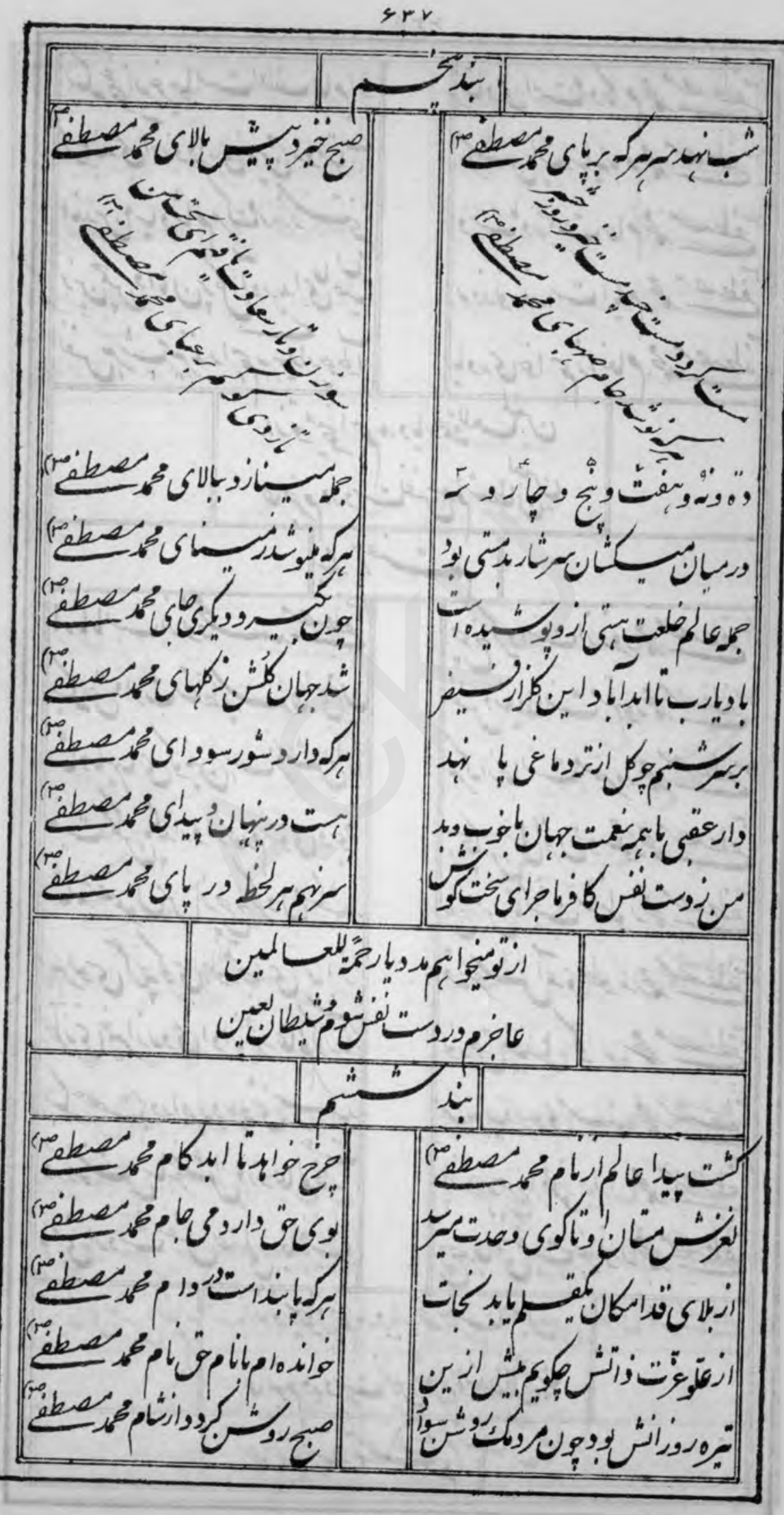


GHA

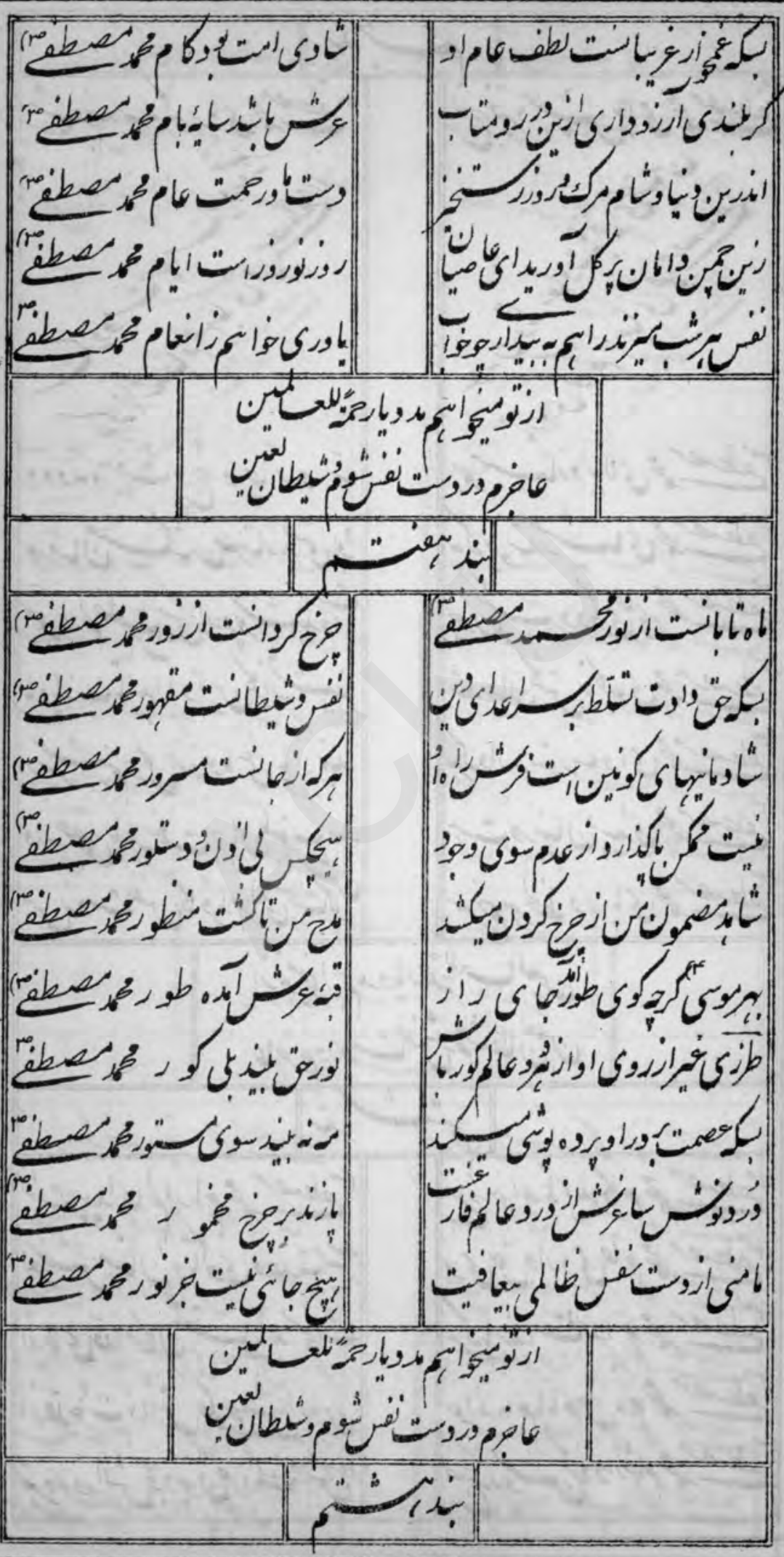


s r q

$\mid$ |




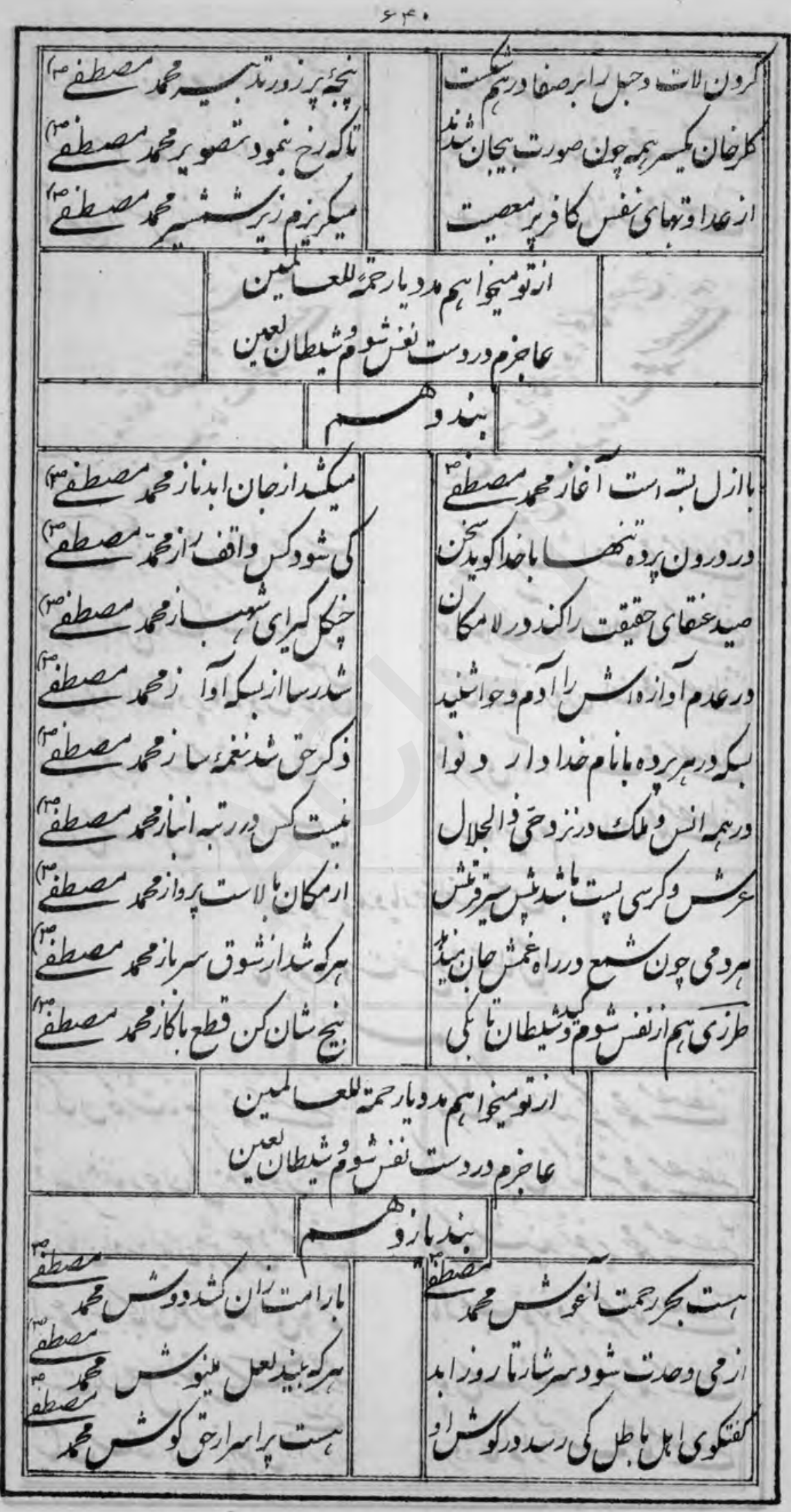


451

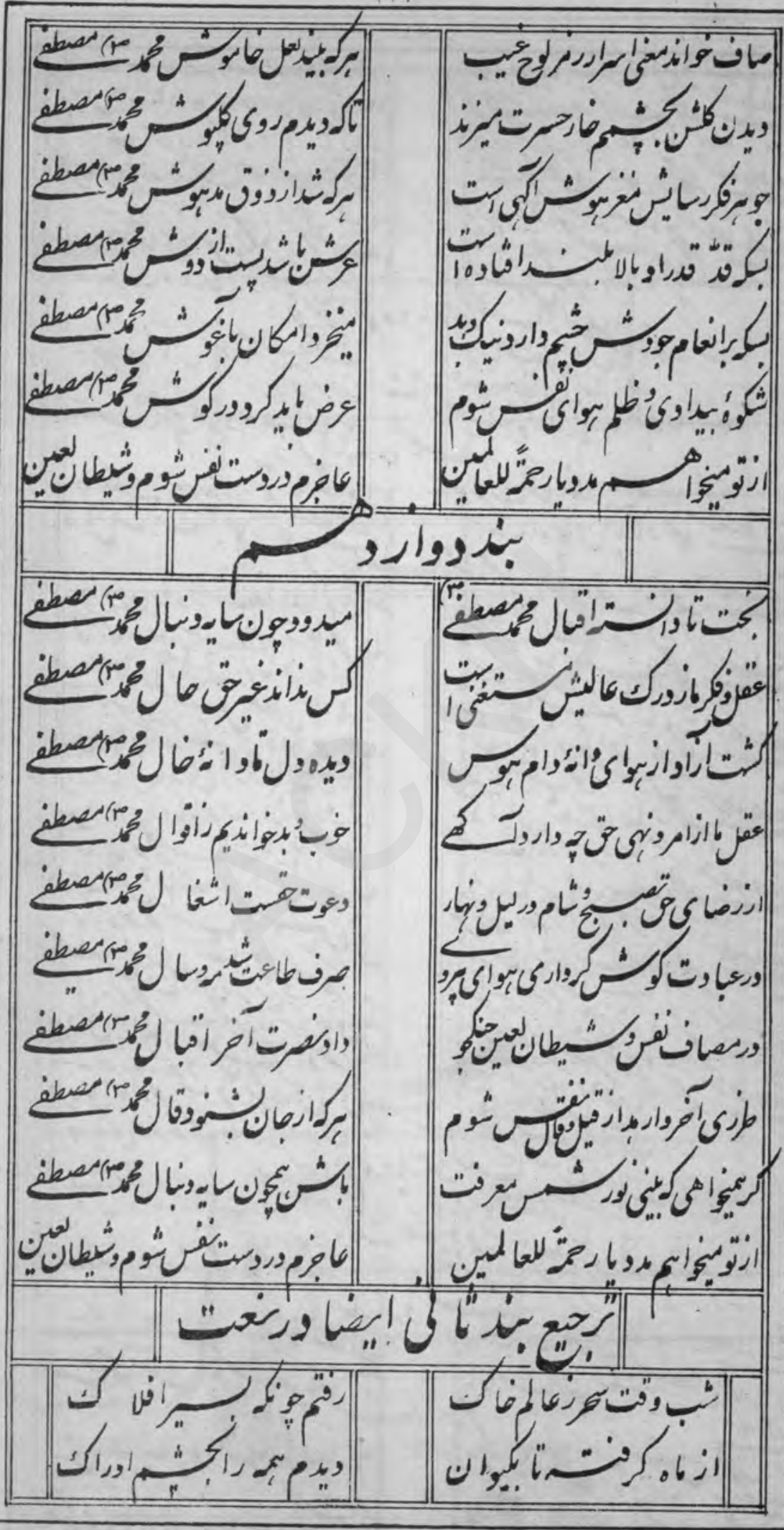




\section{$45 r$}

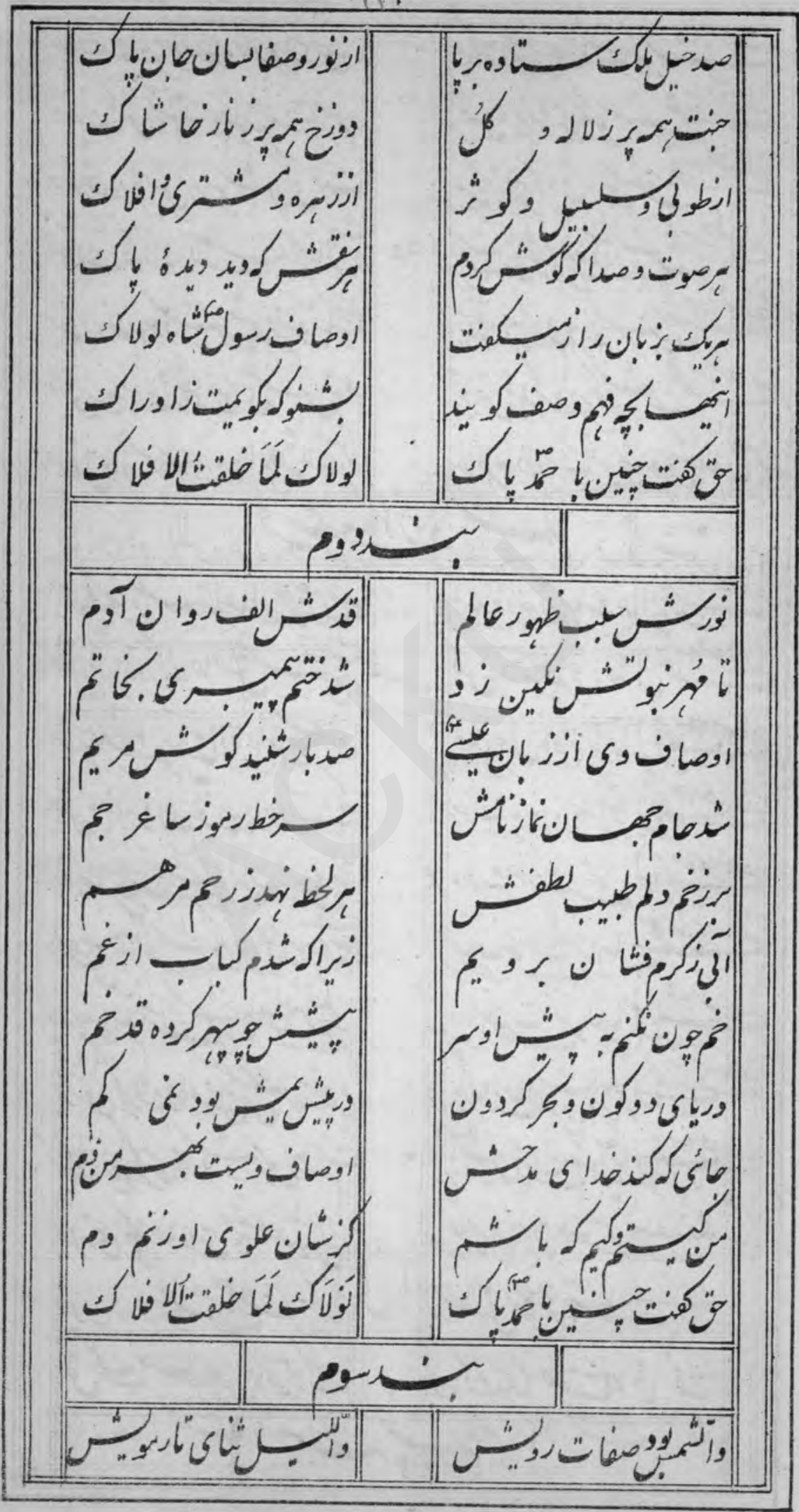




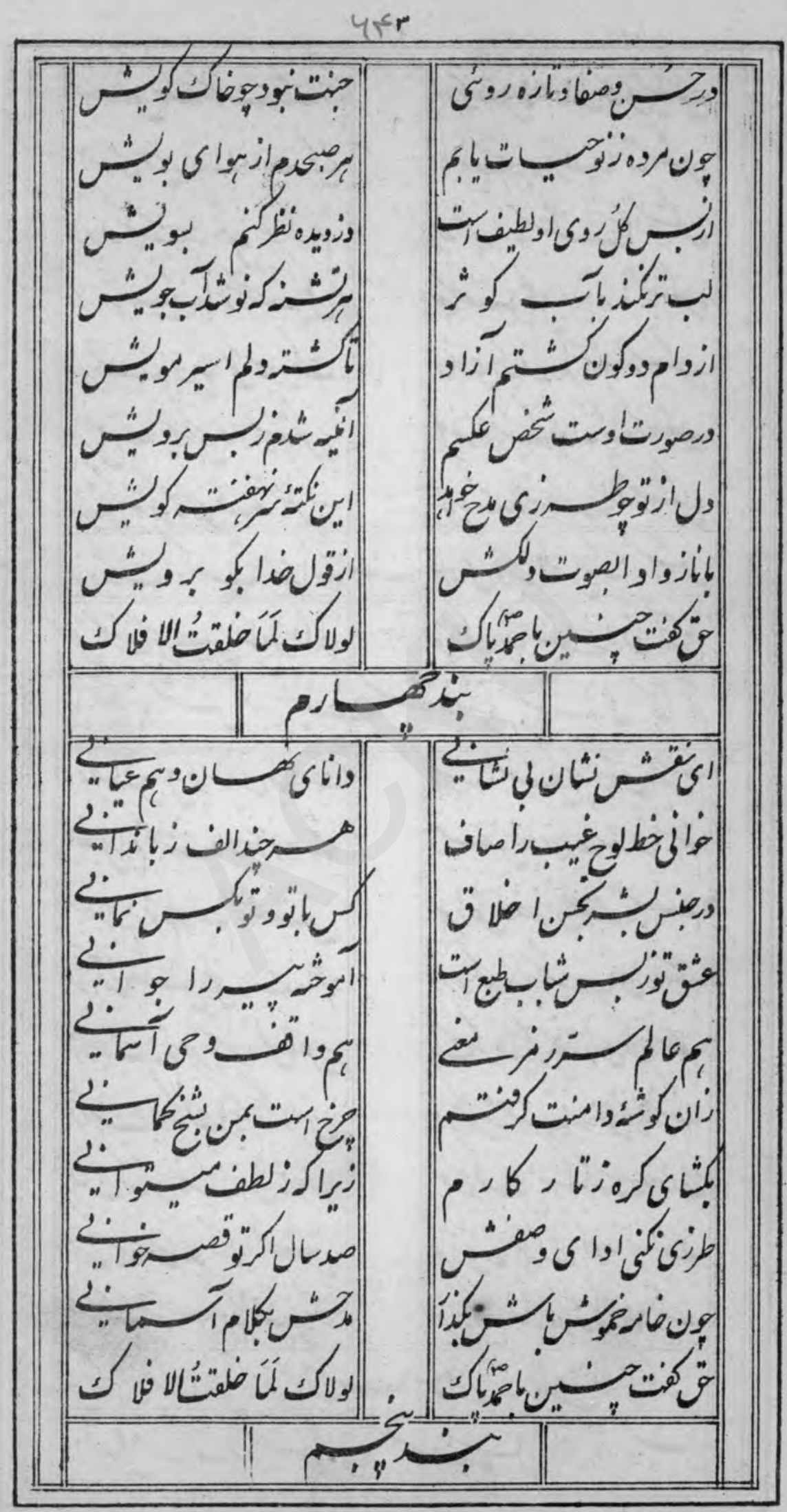


45

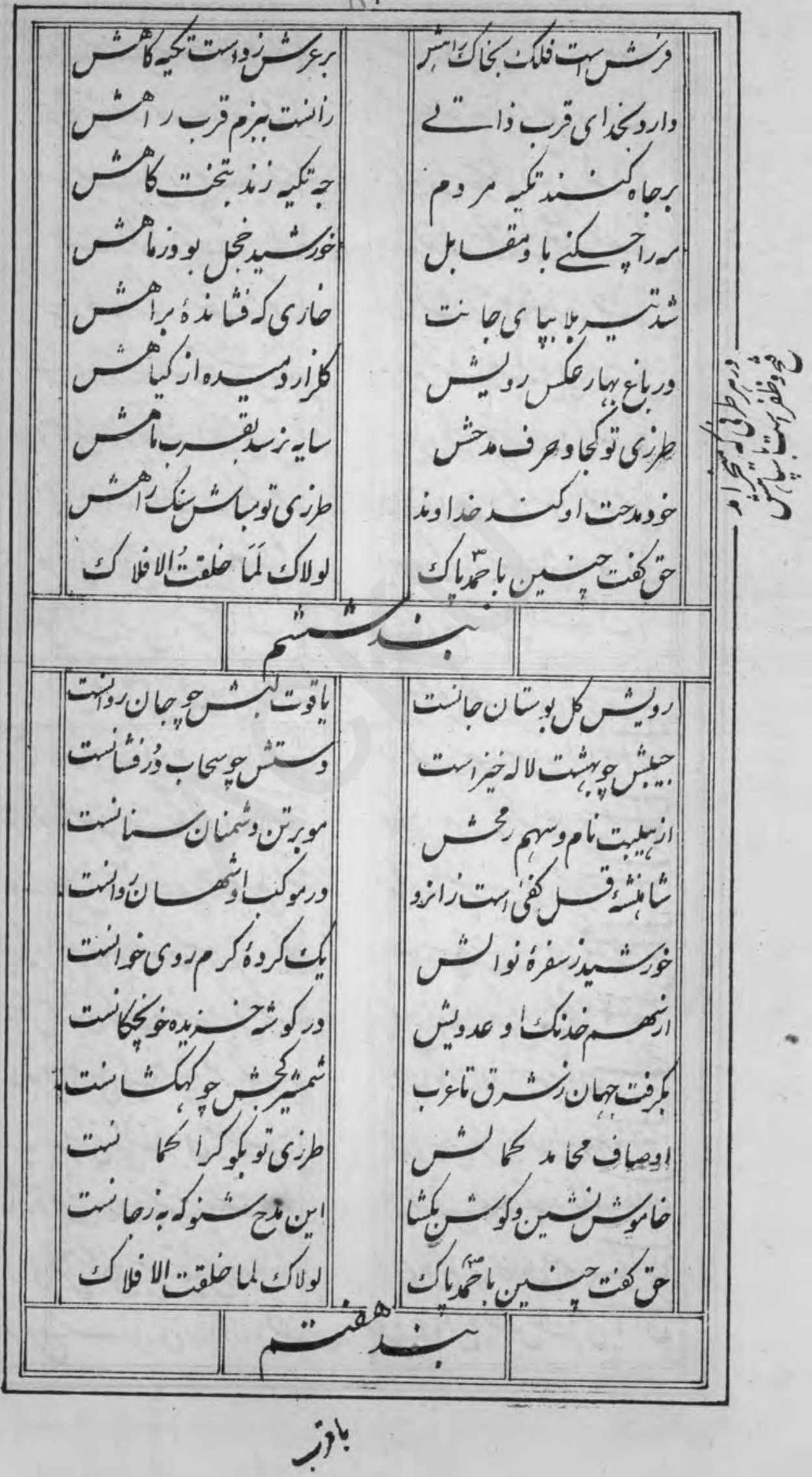


$4 \leqslant \Delta$

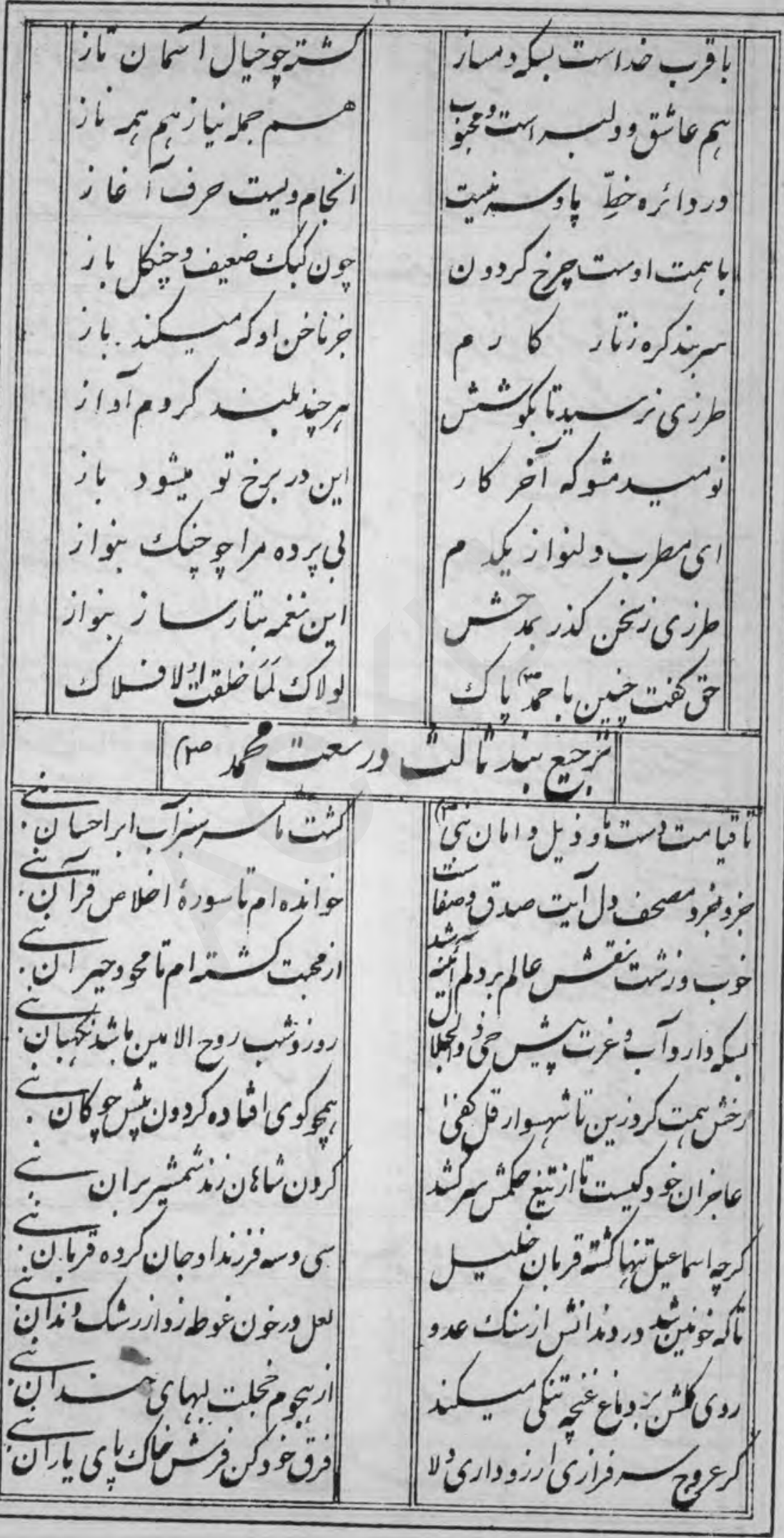




\section{$4 \sqrt{6}$}

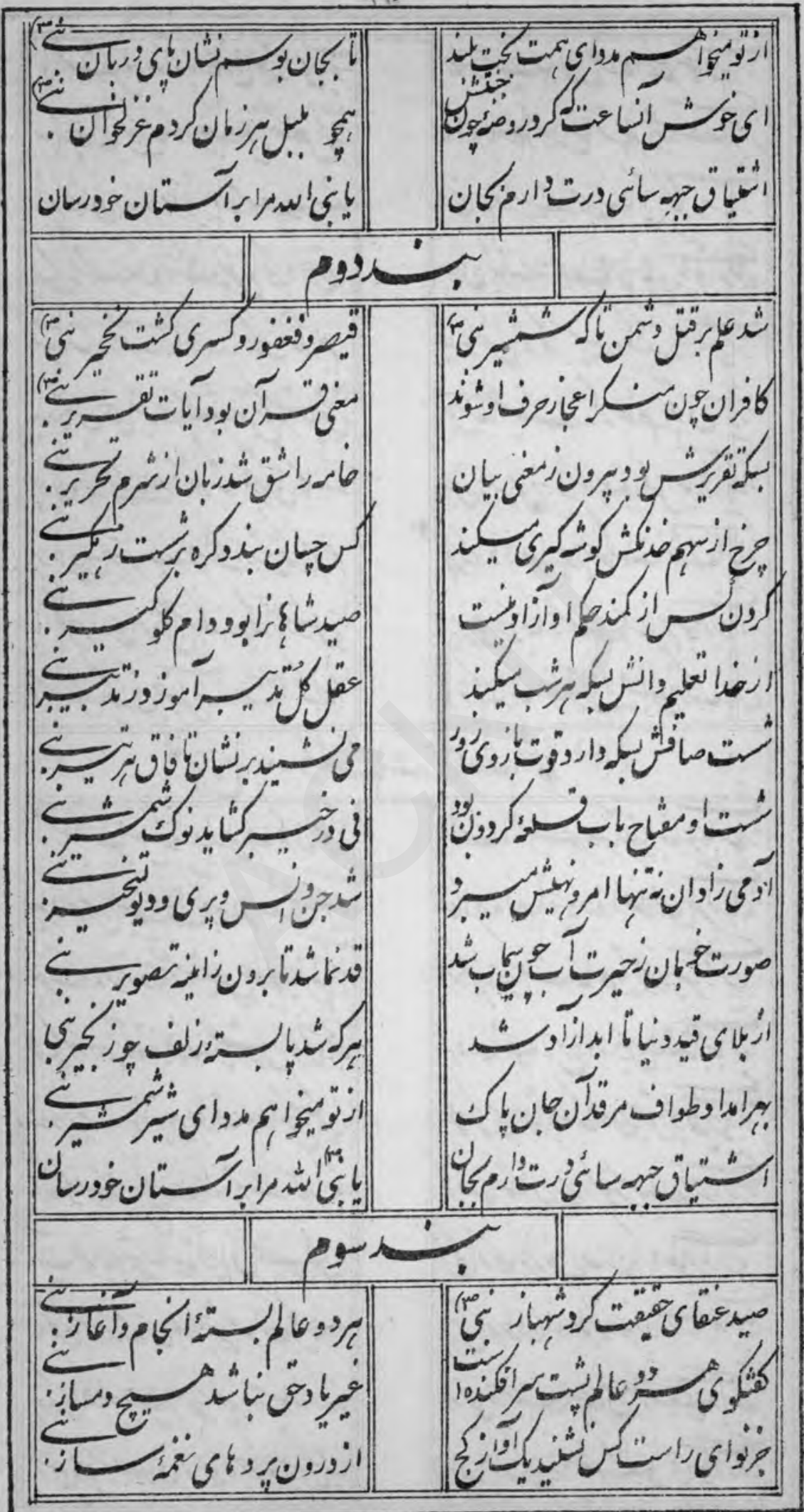


บร

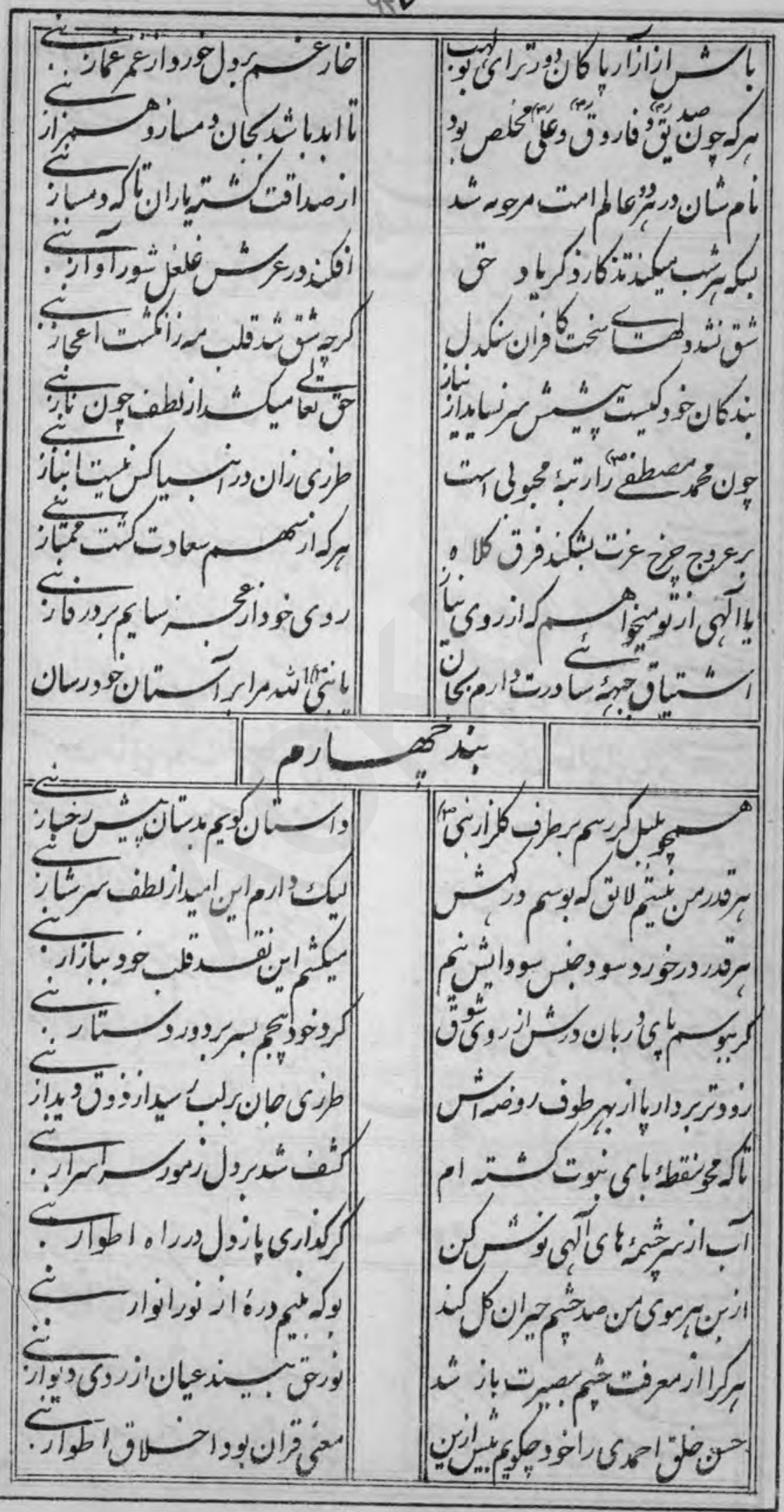


$4 \leqslant$

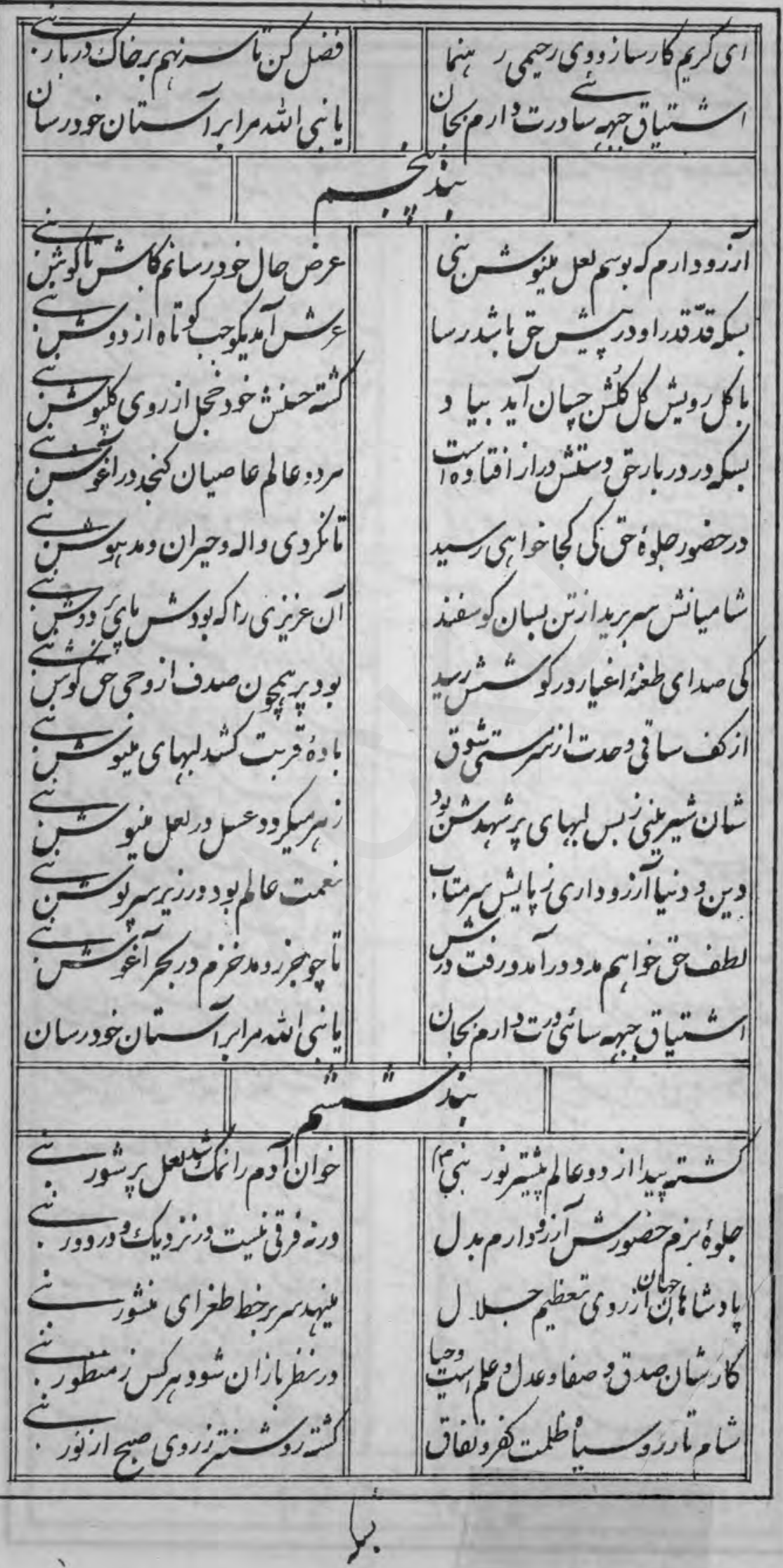


$41<9$

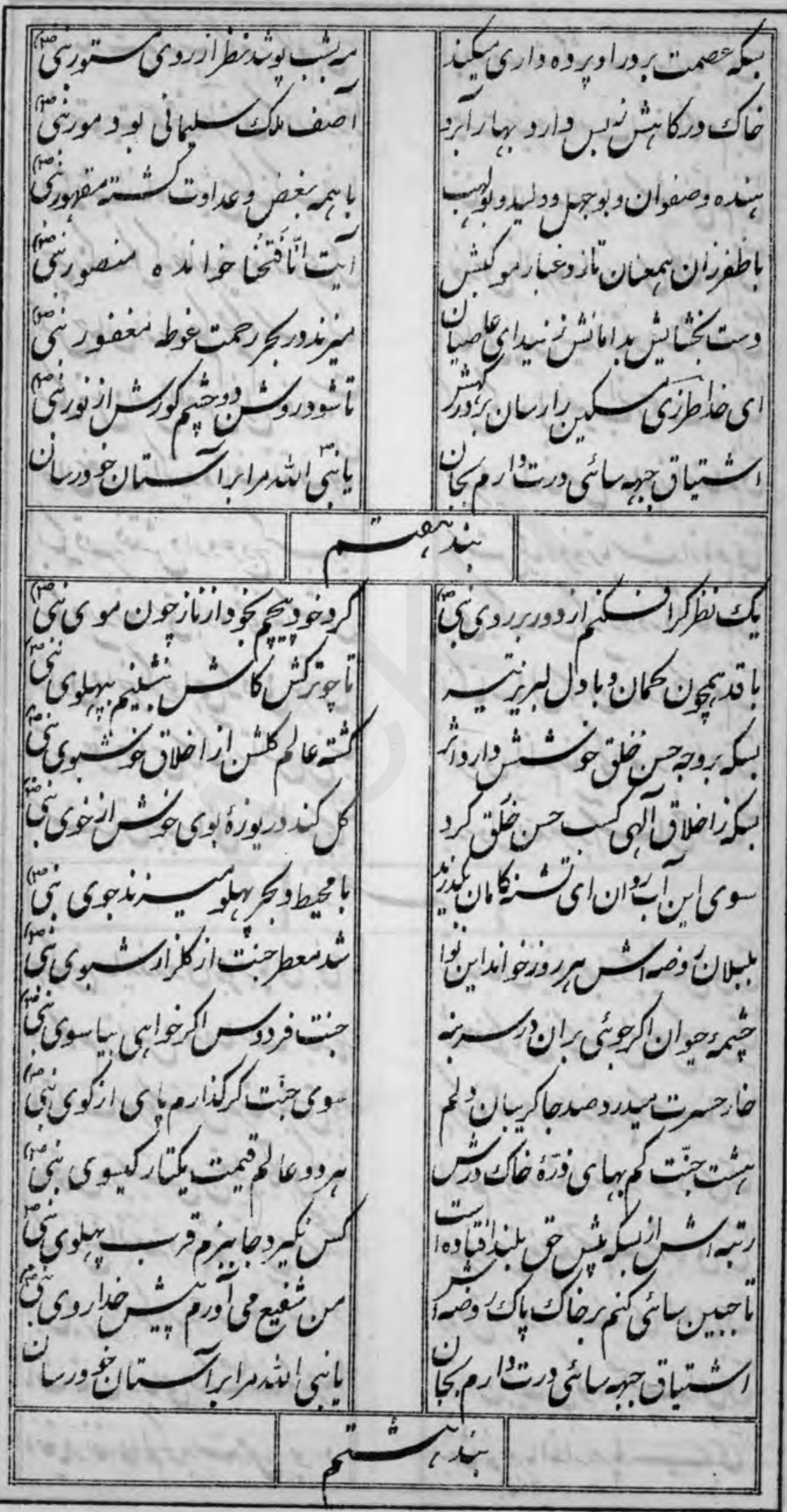


80

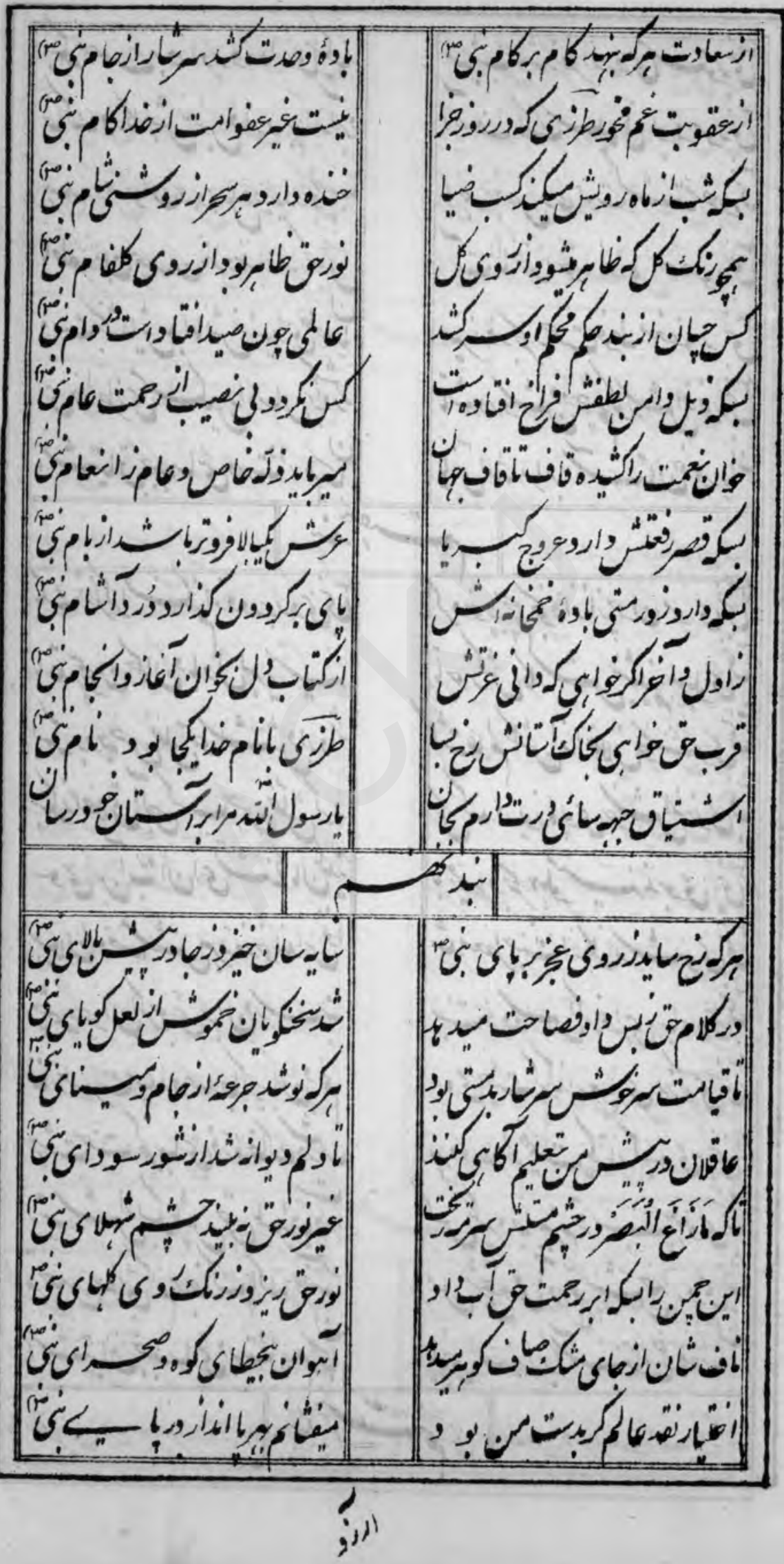


$\angle 01$

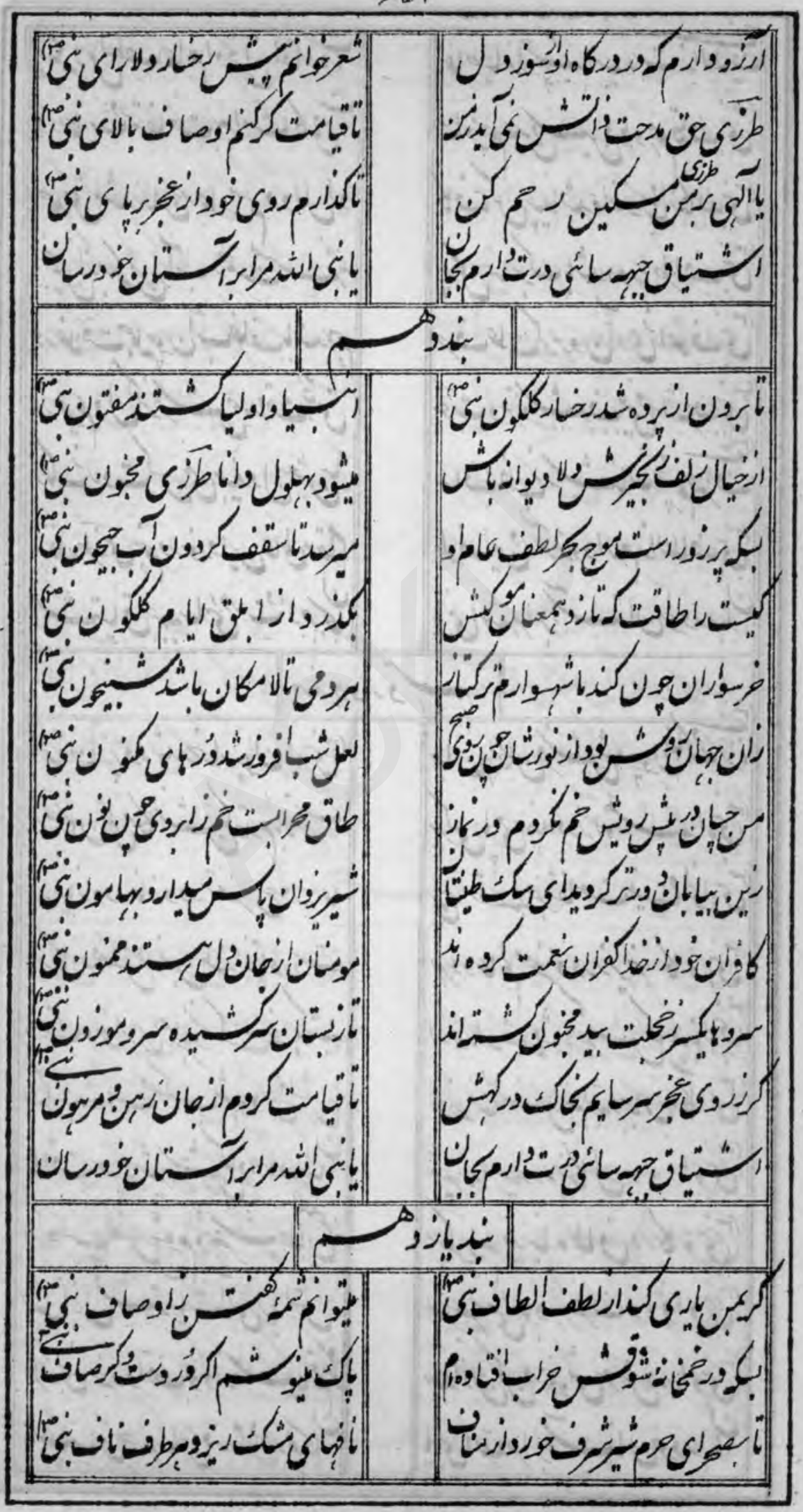


SQ

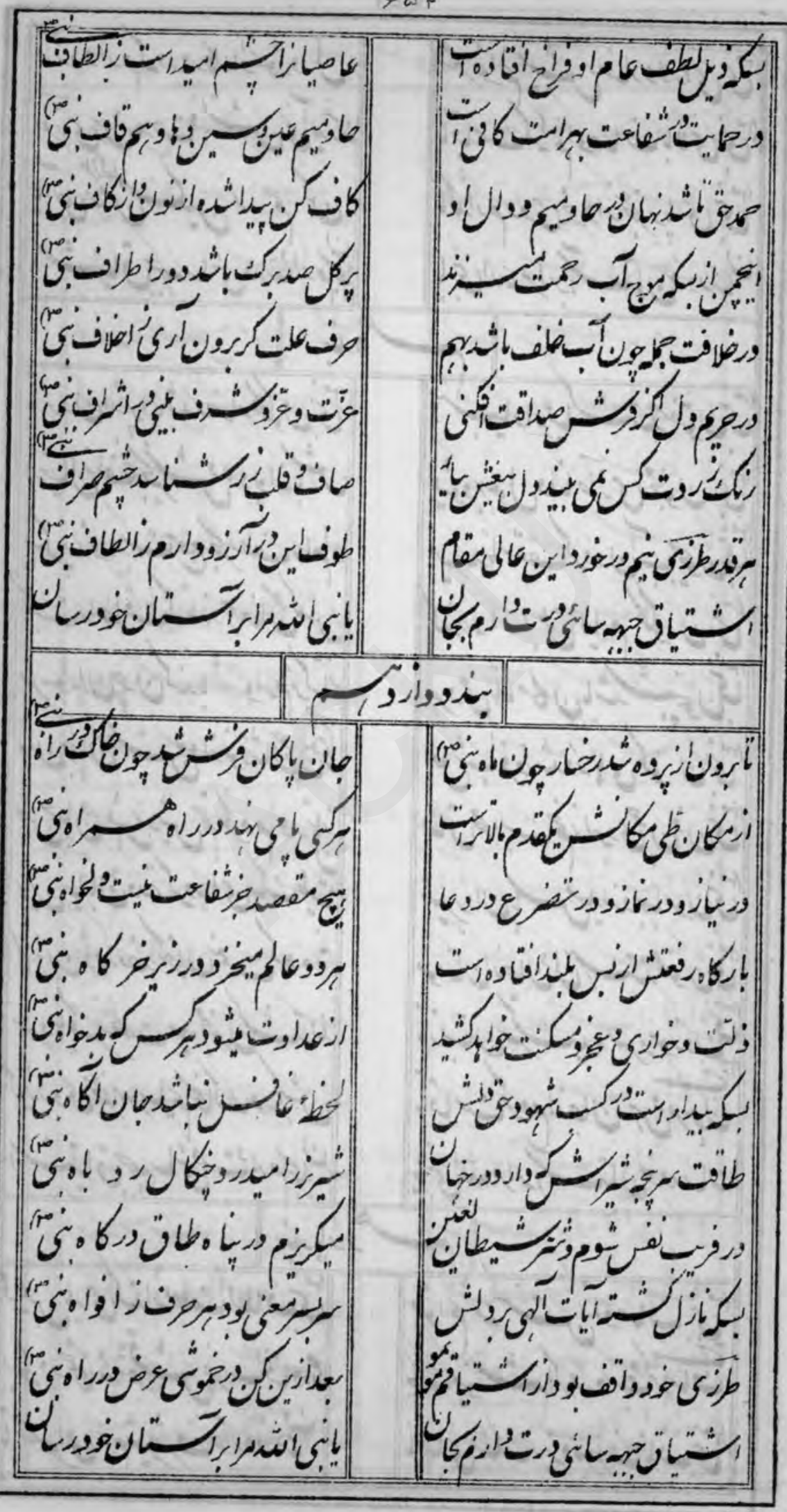




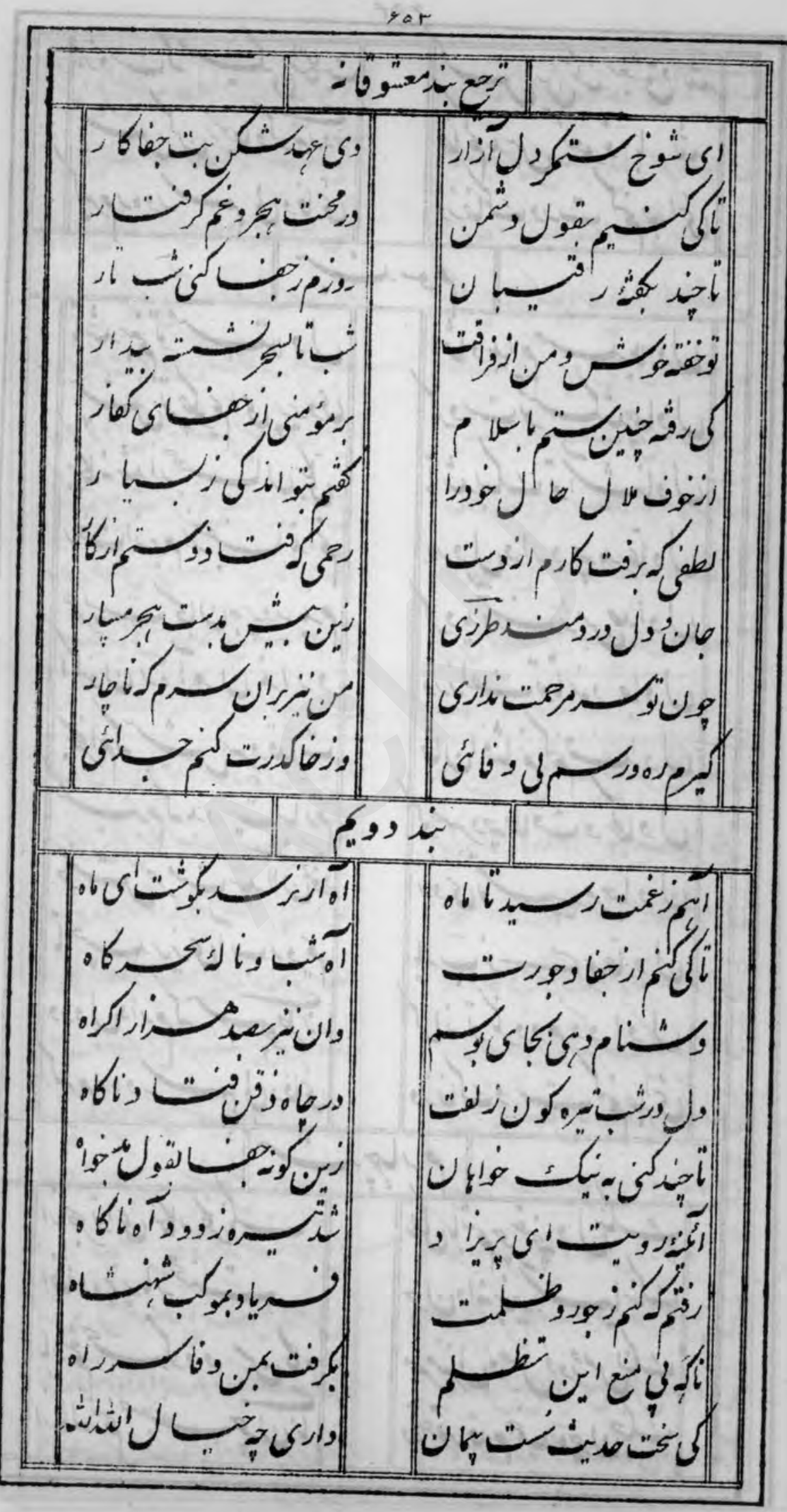




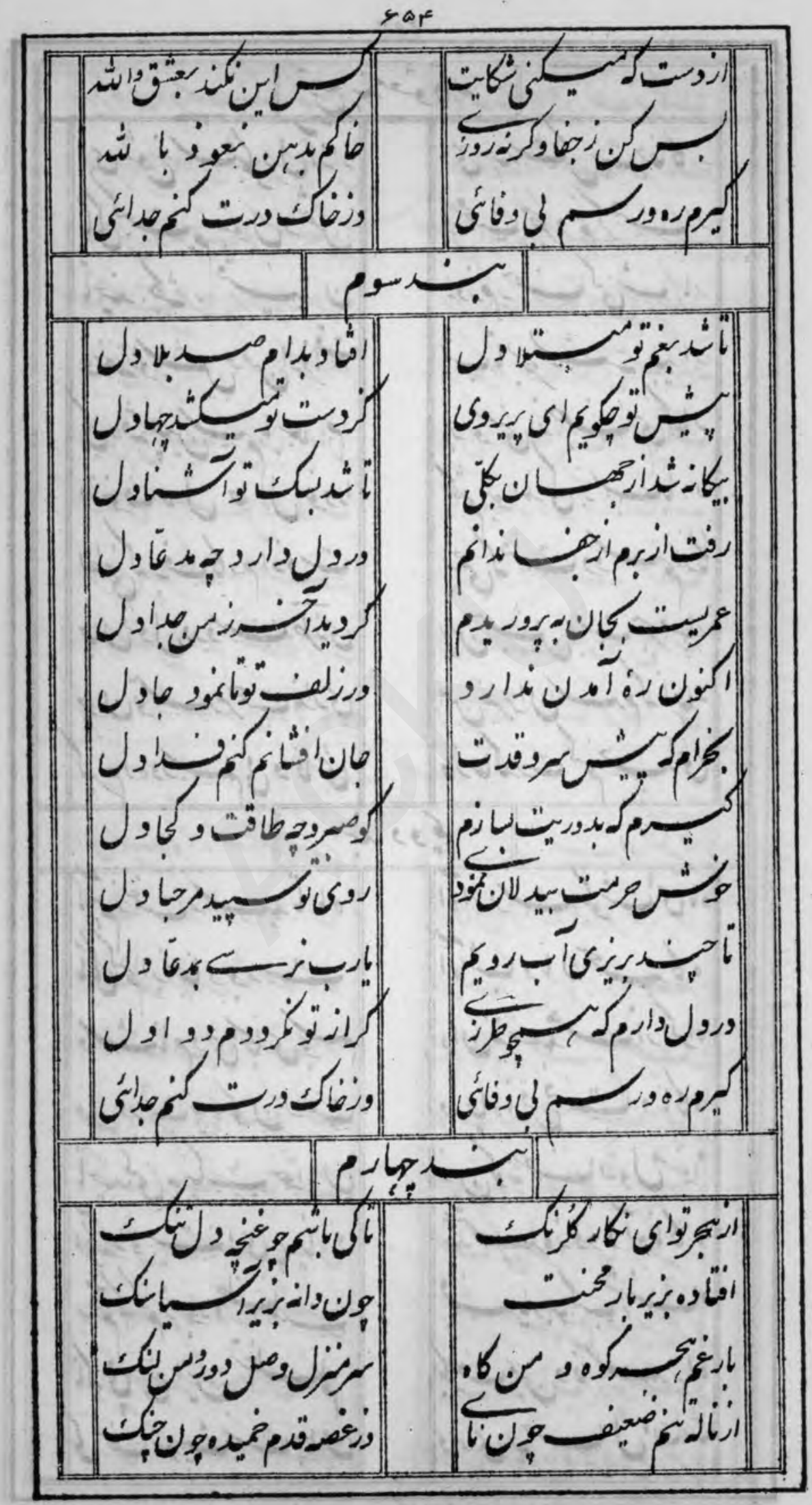


$\angle \Delta \theta$

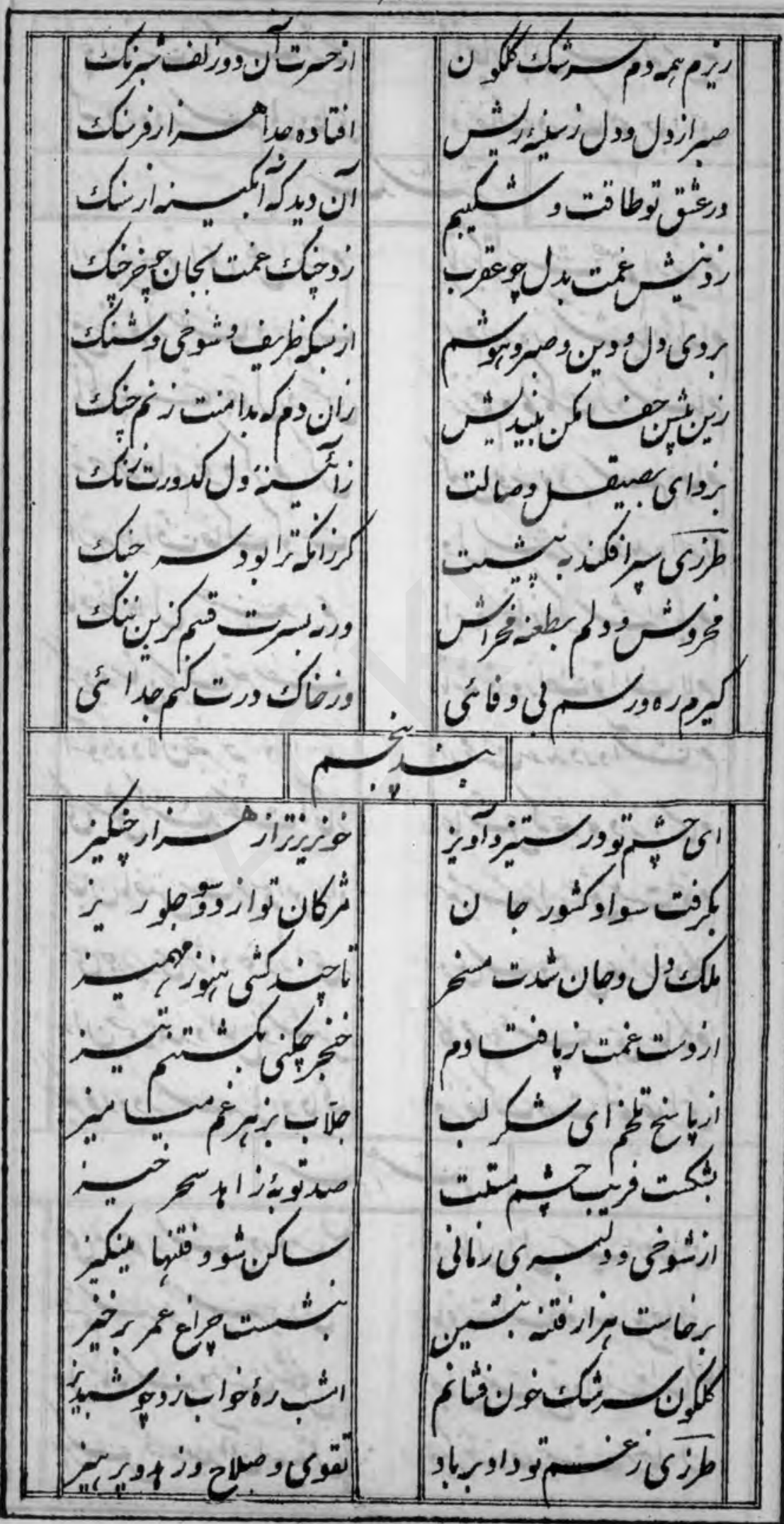


gas

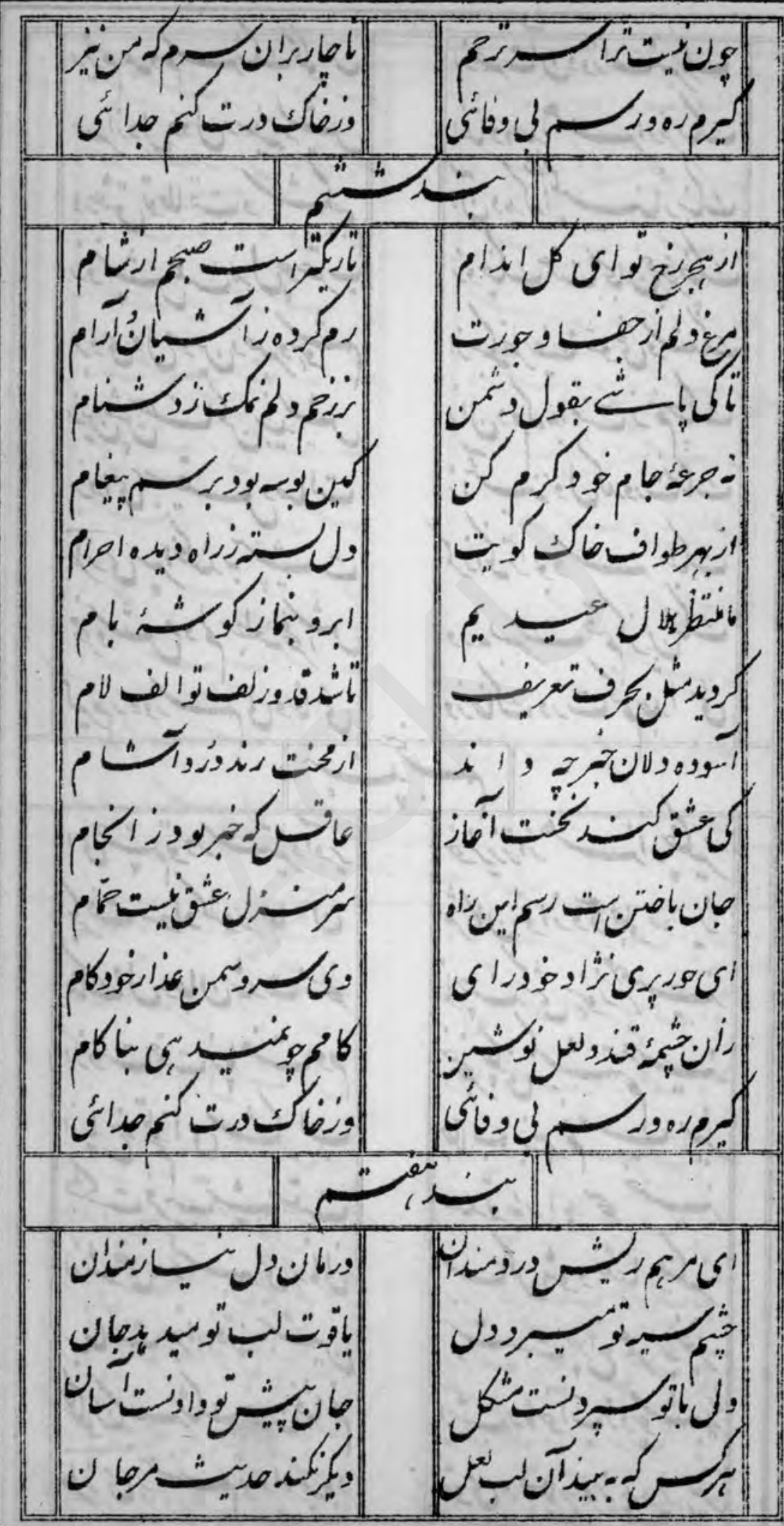




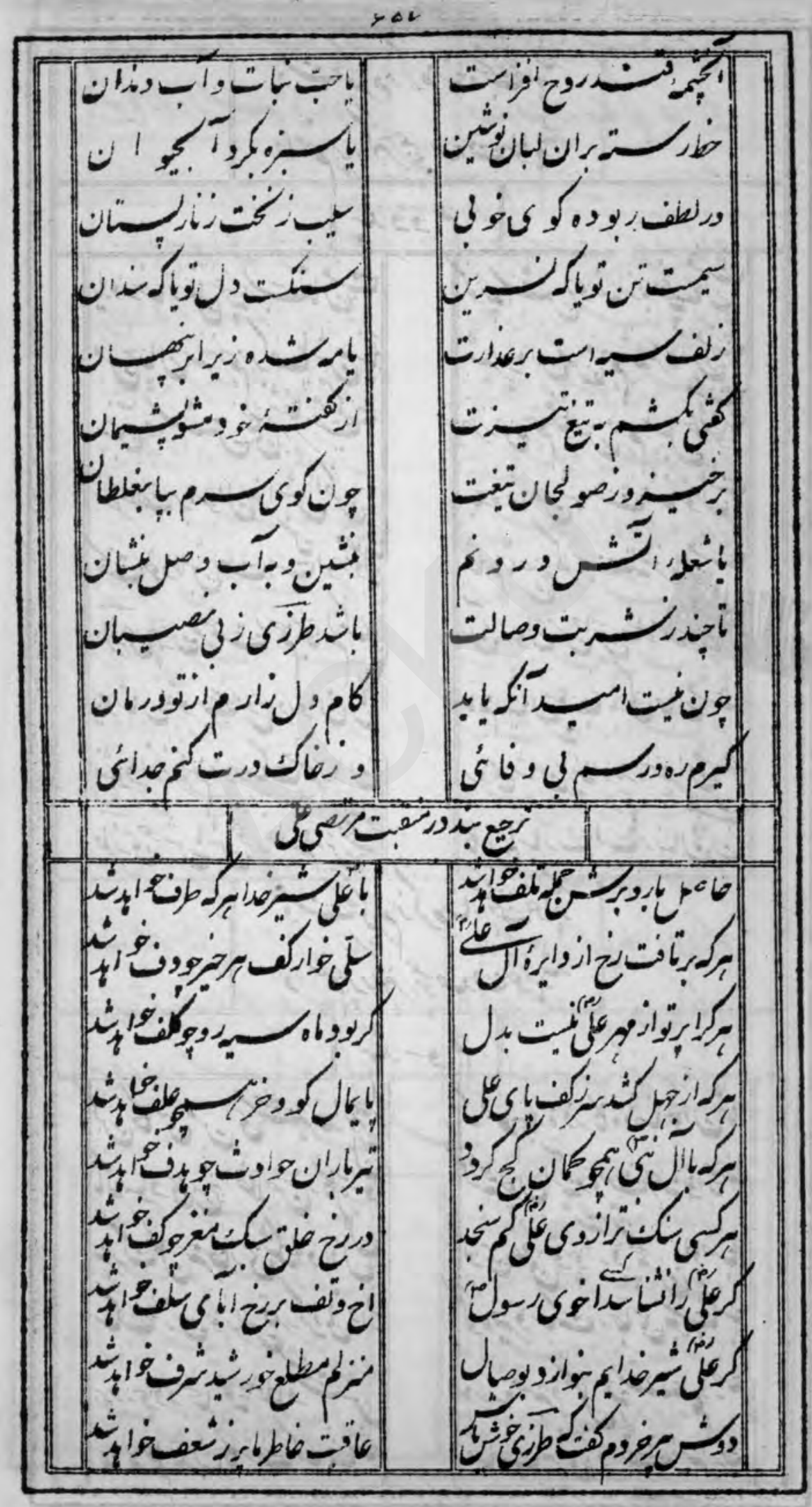




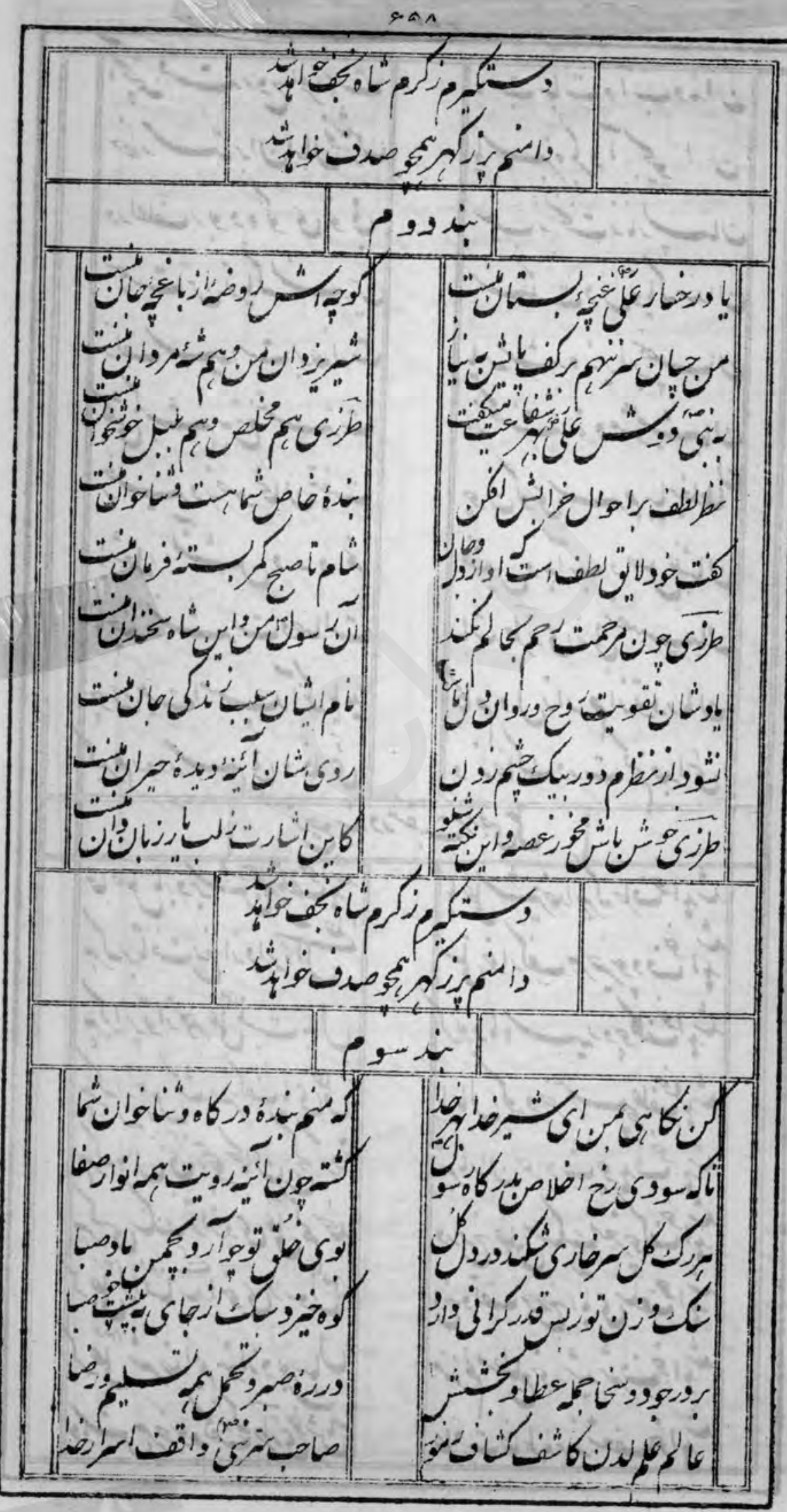


504

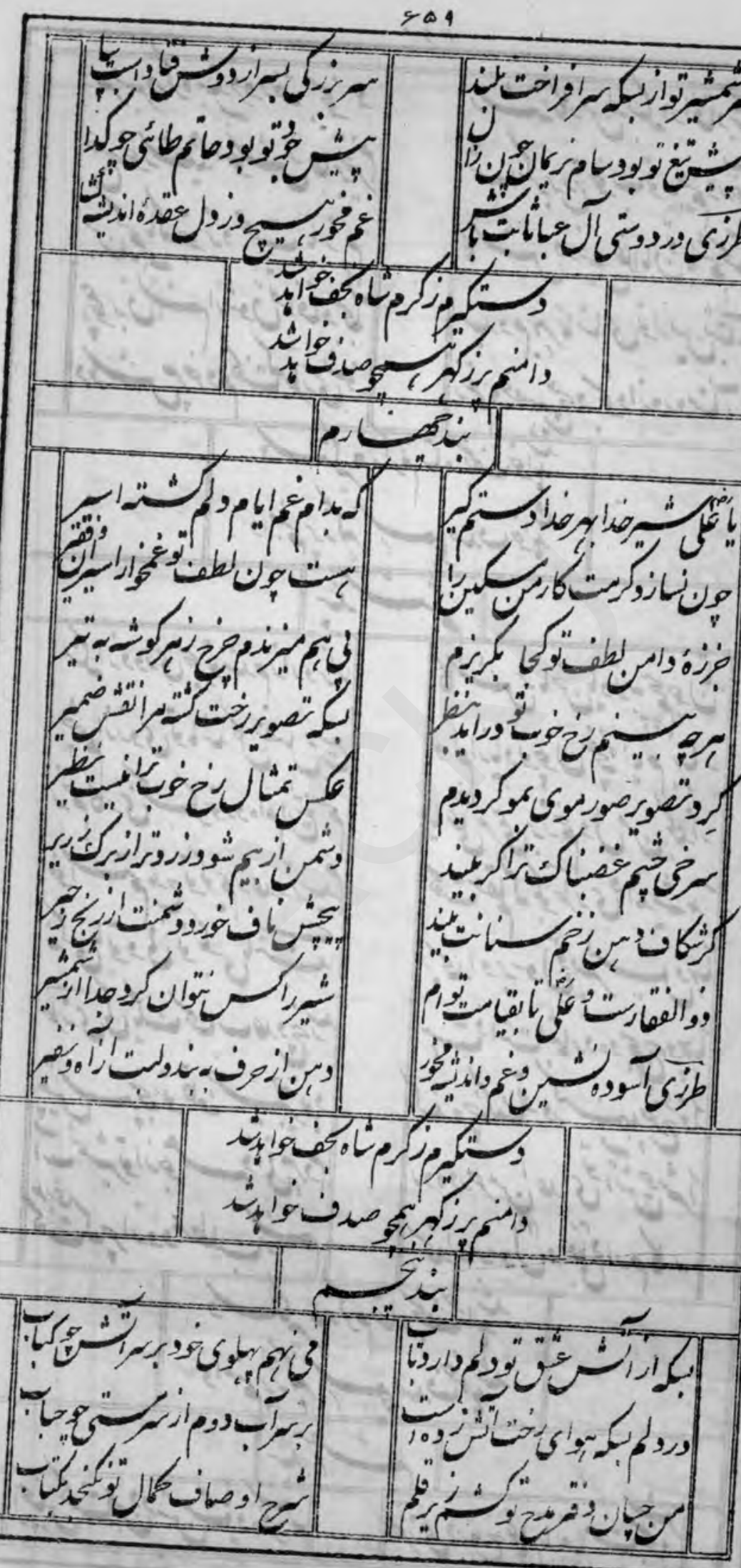




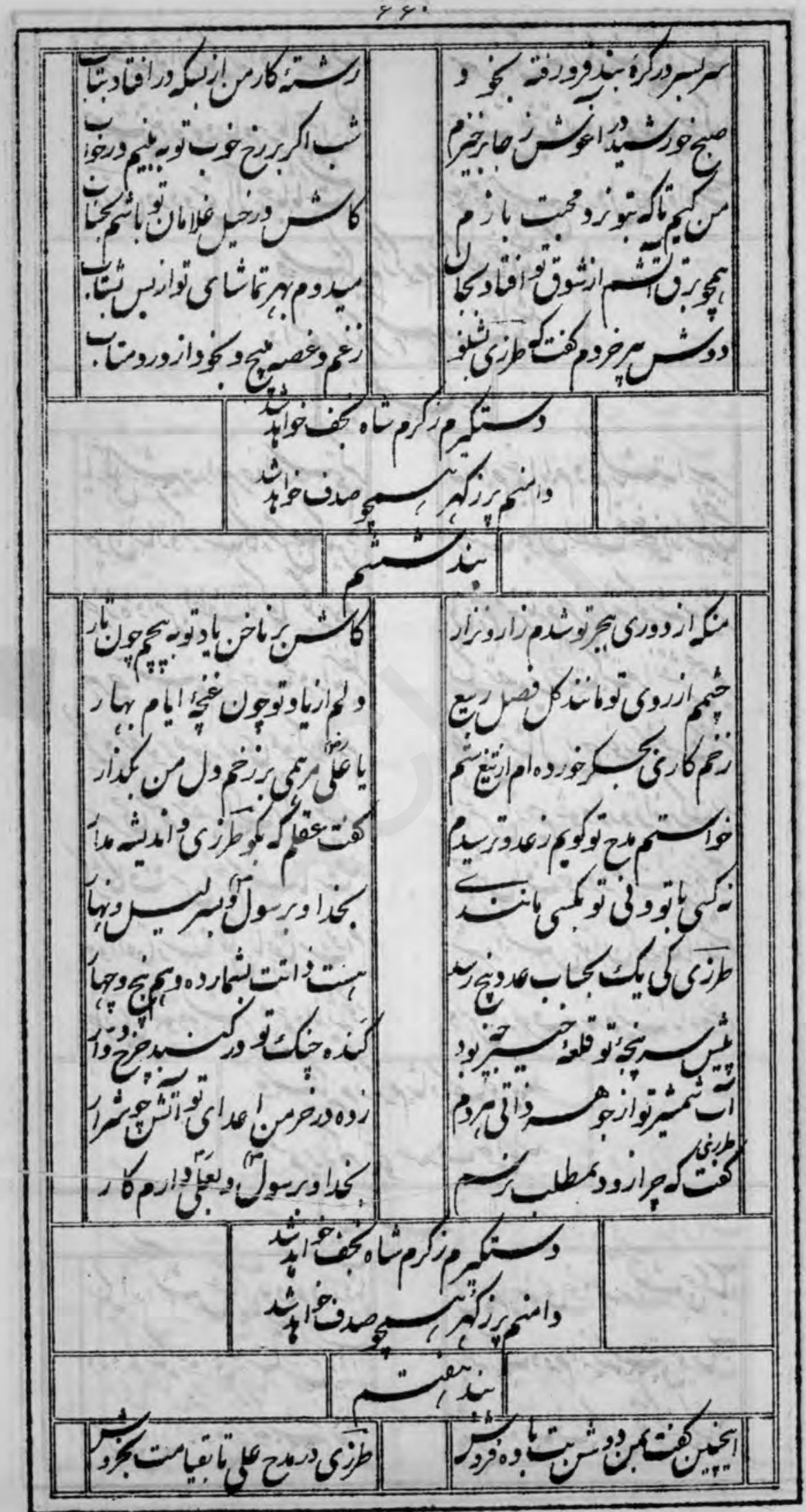




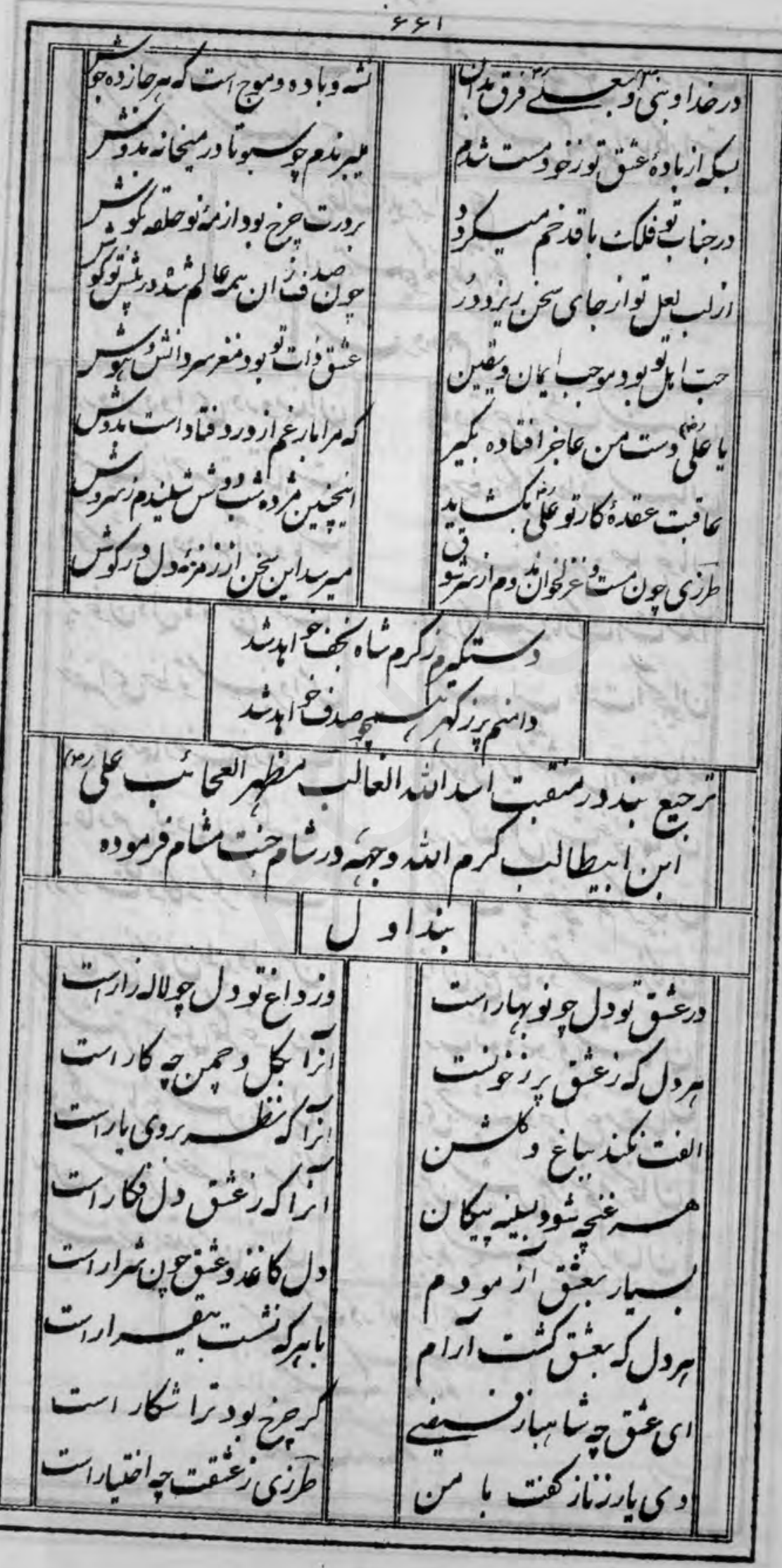


s r

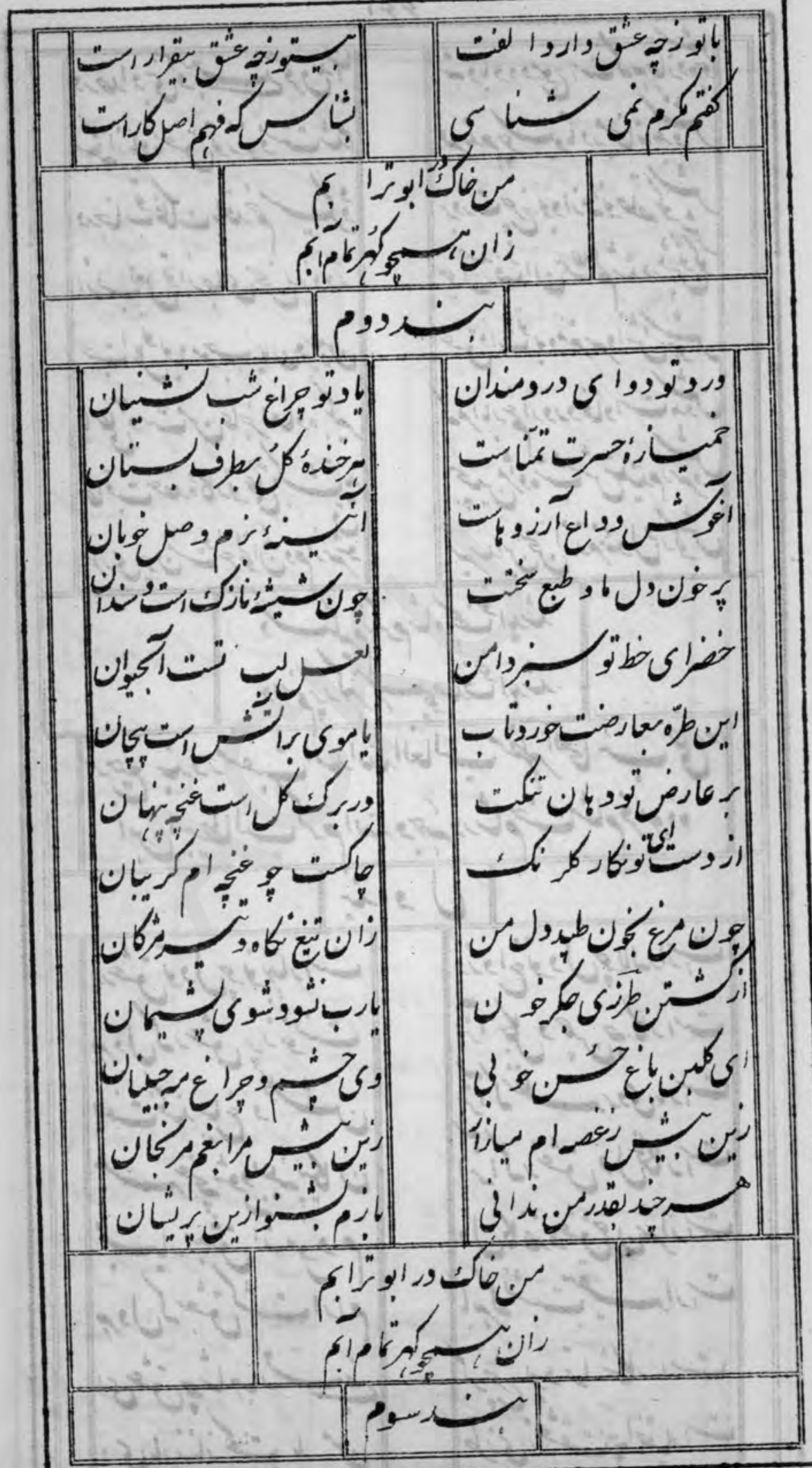




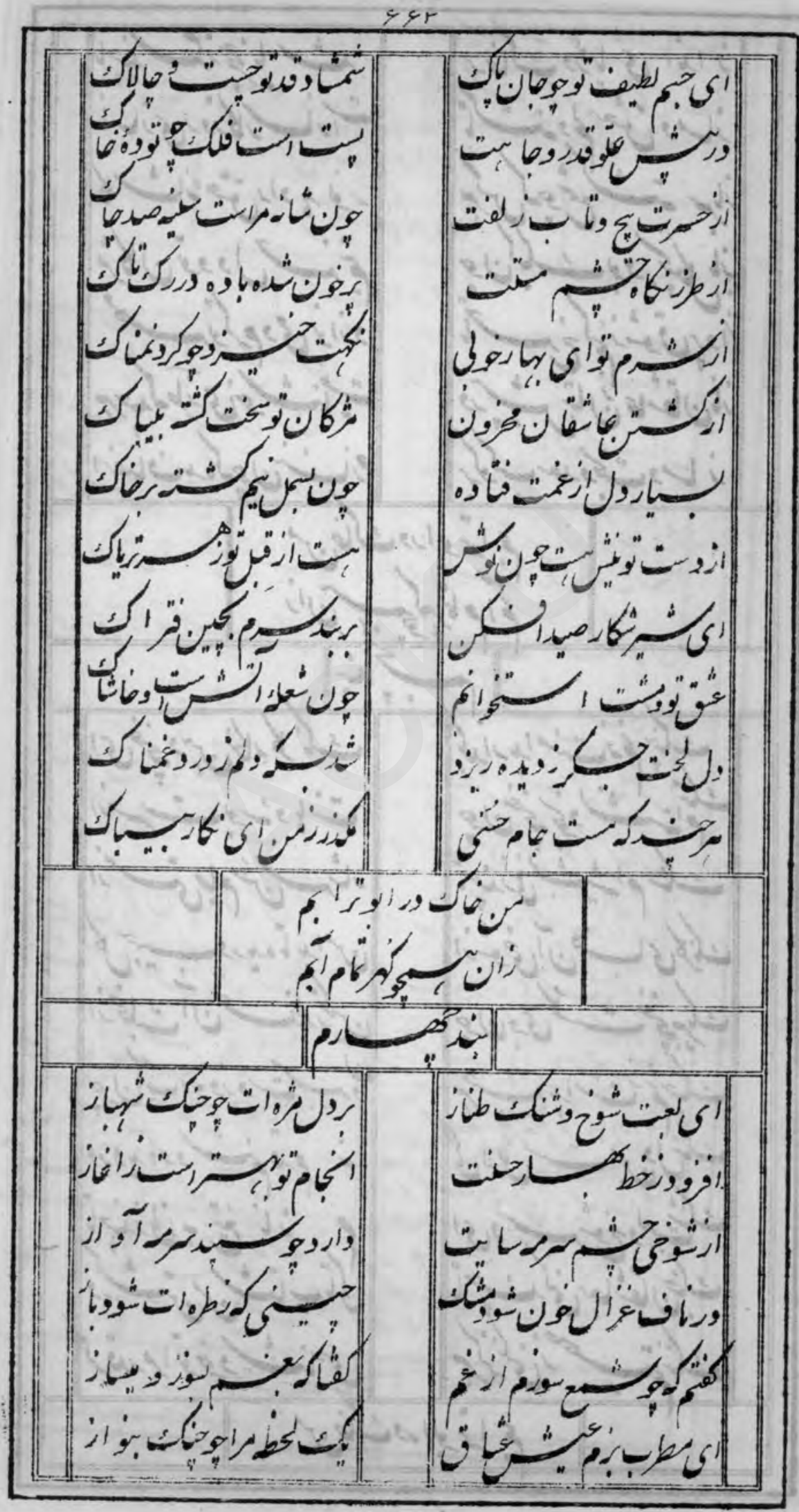


Fs

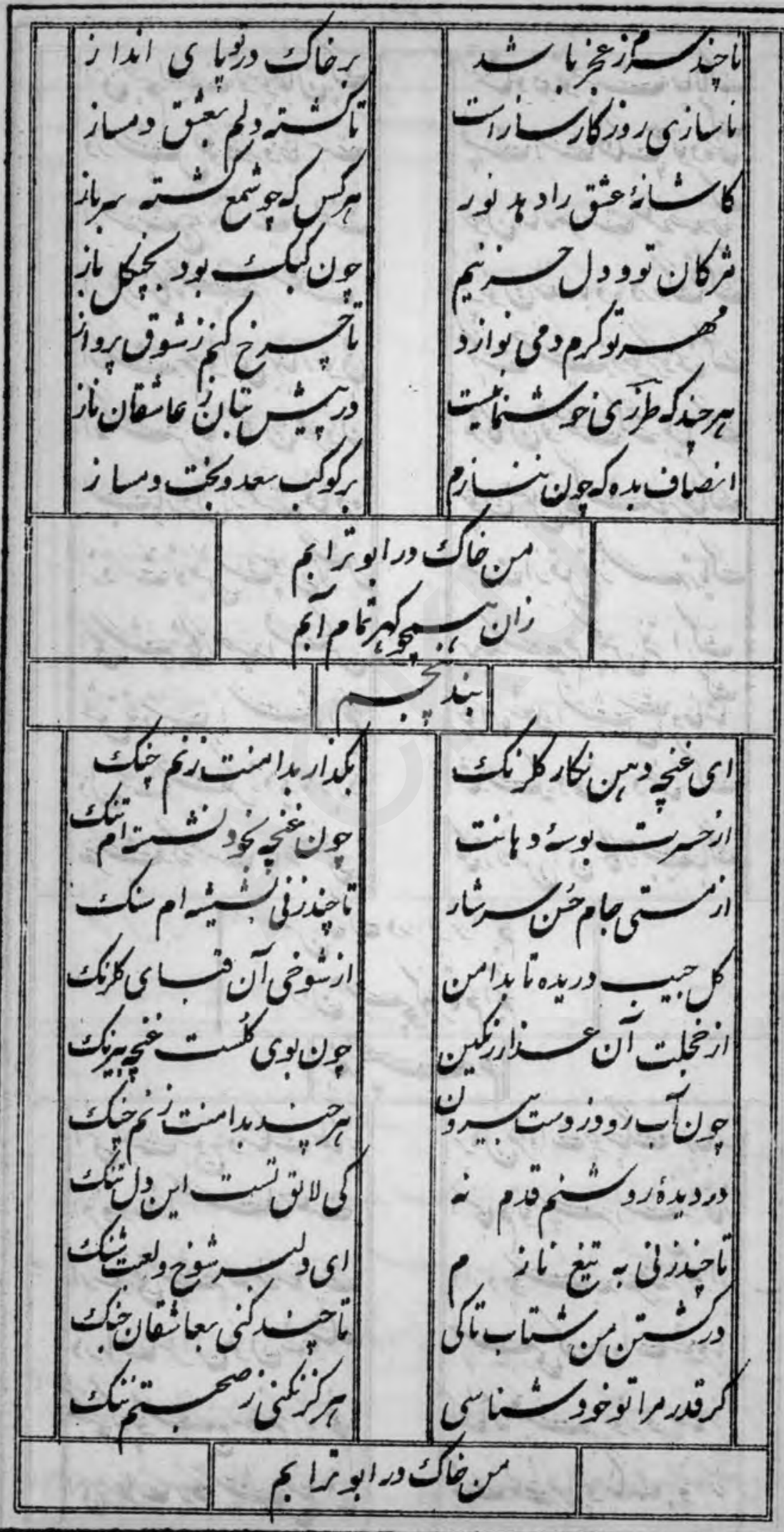

(1) 


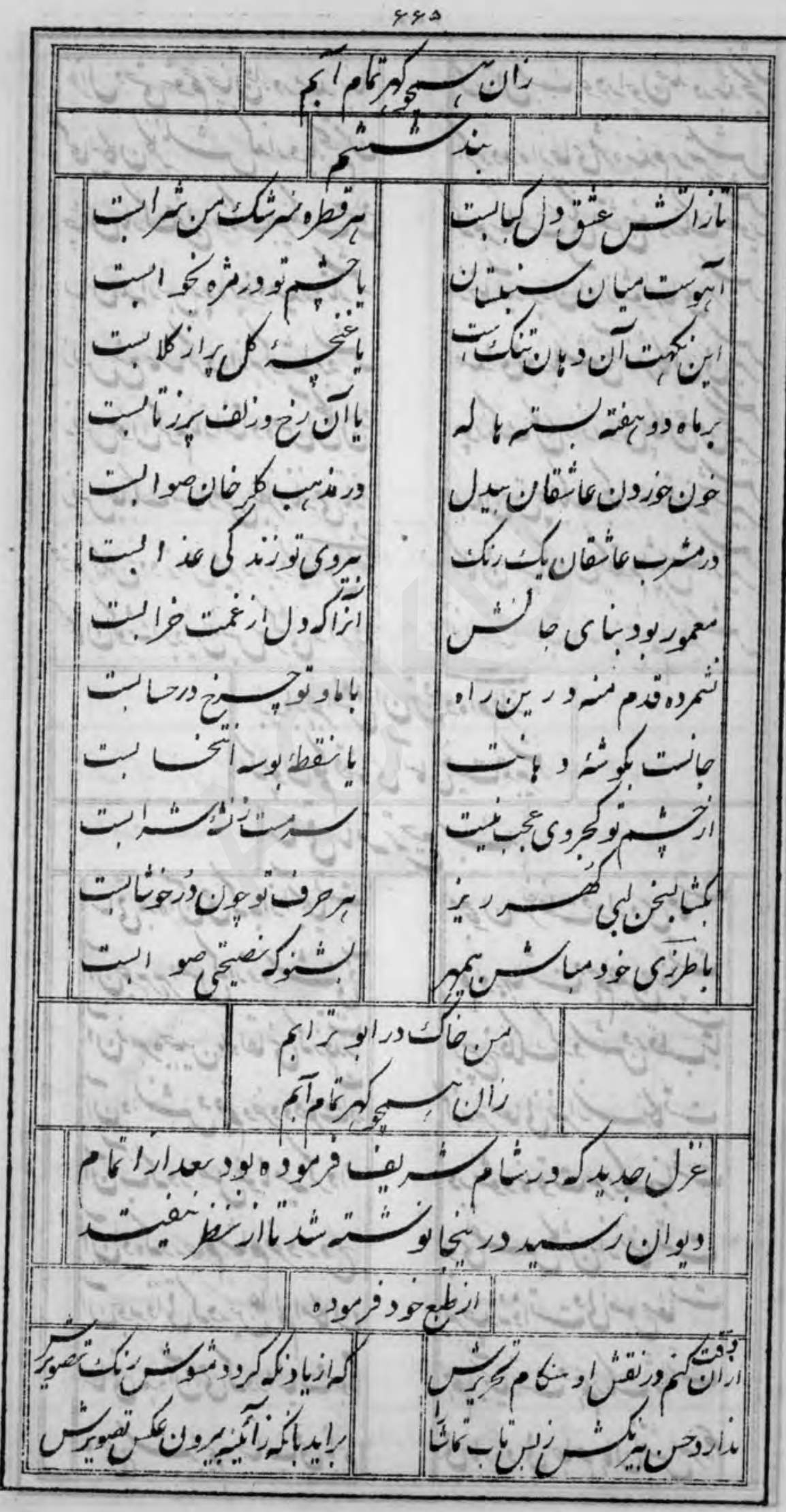


4.4

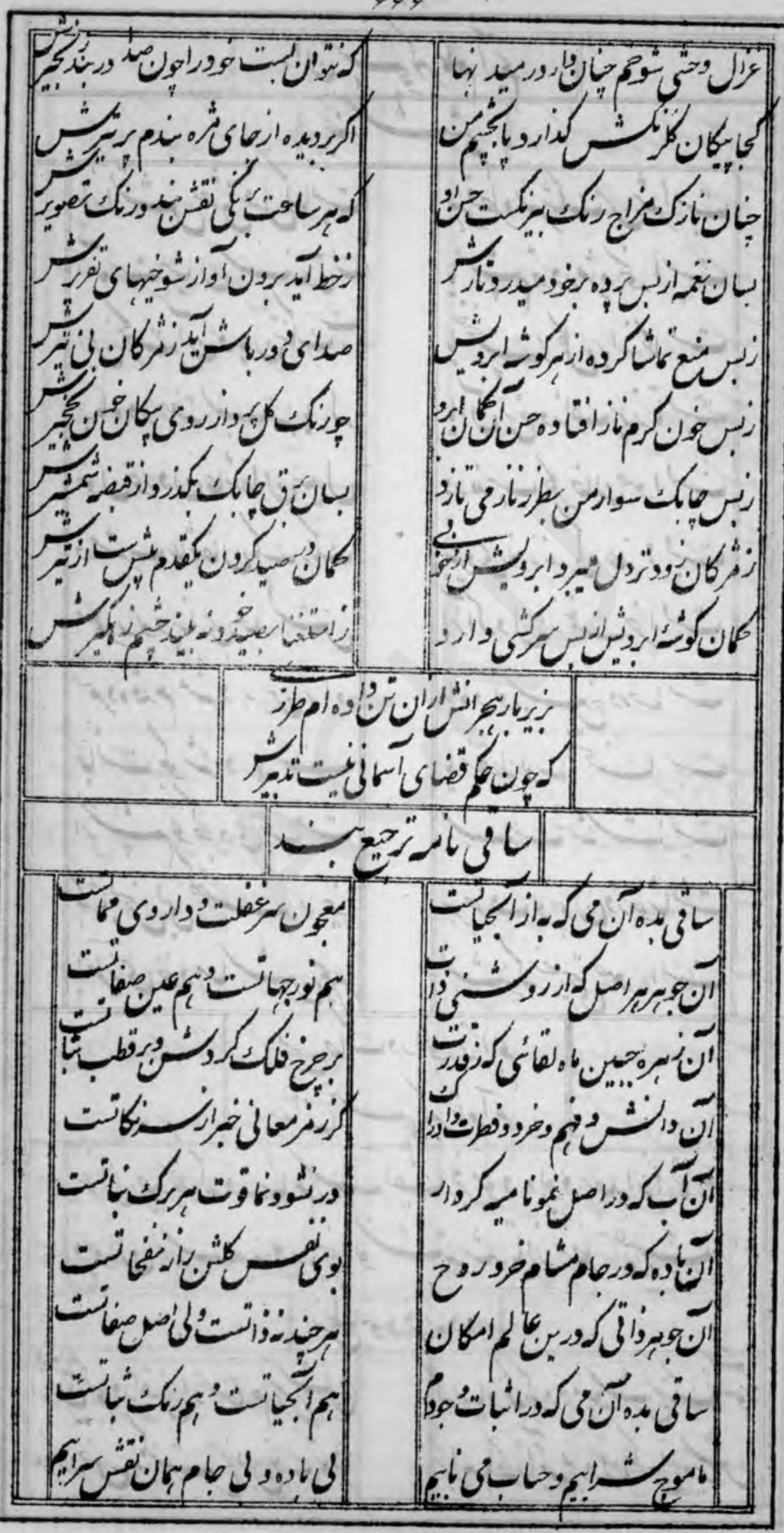




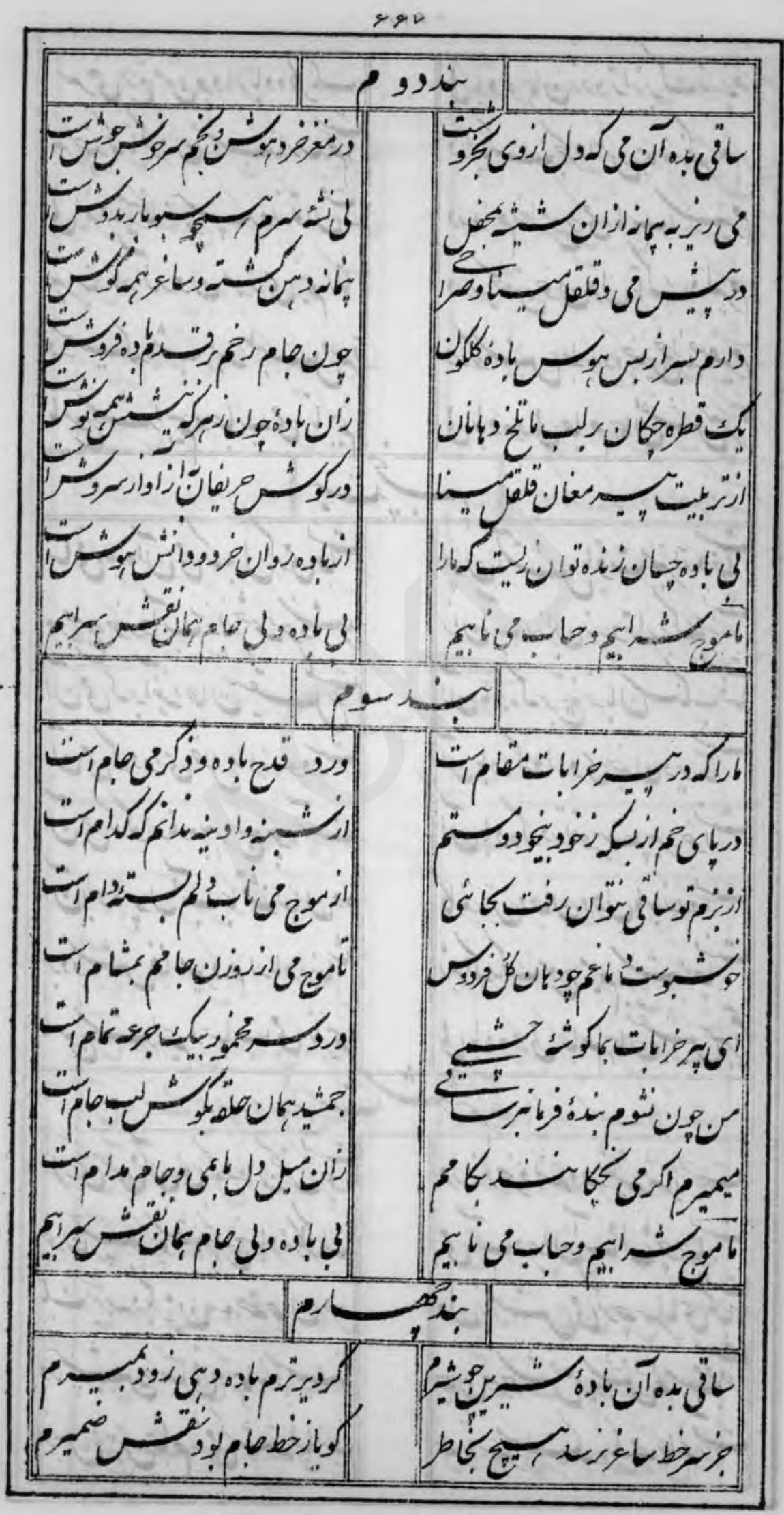


s 4

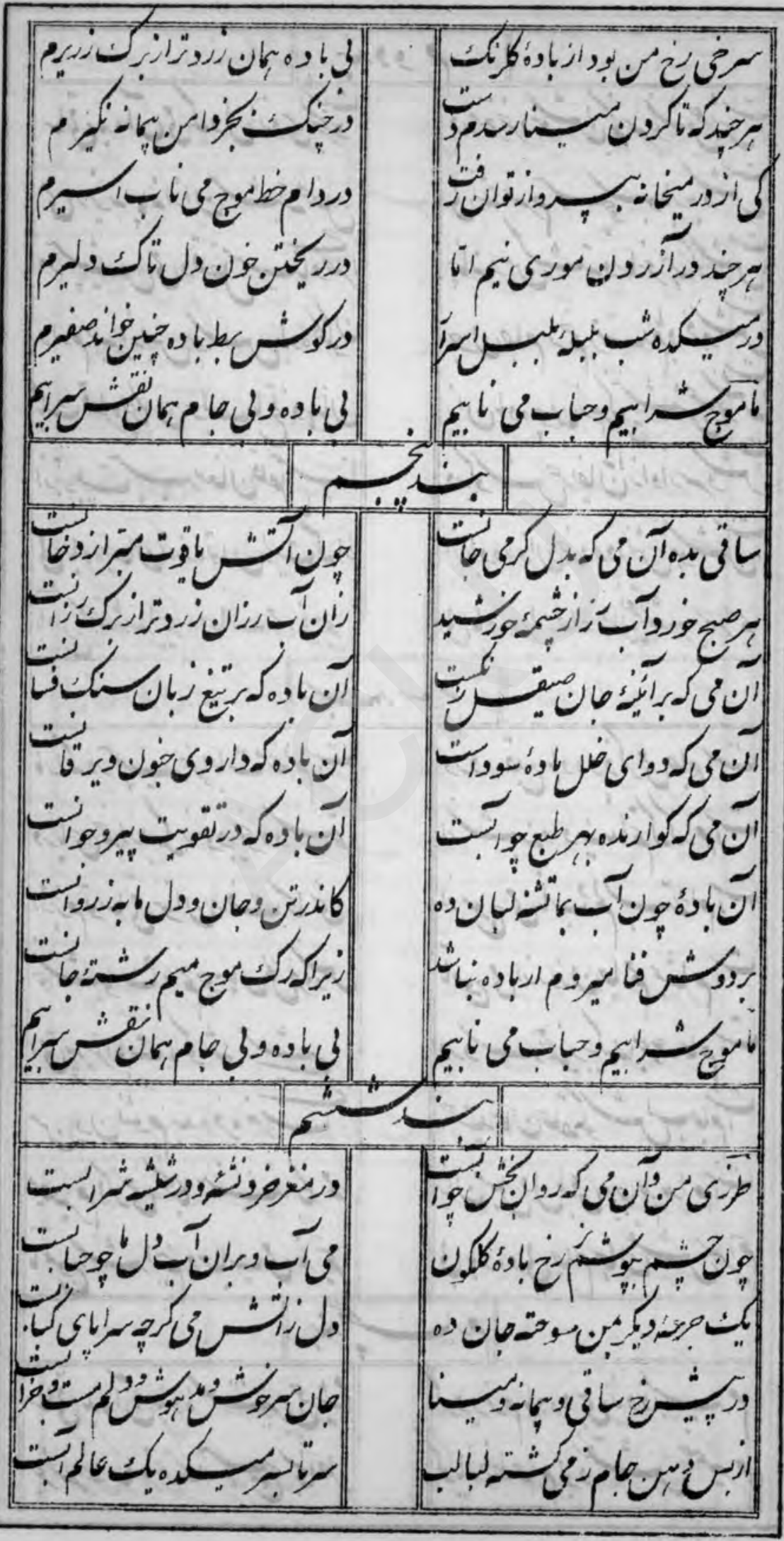


$5 \% 9$

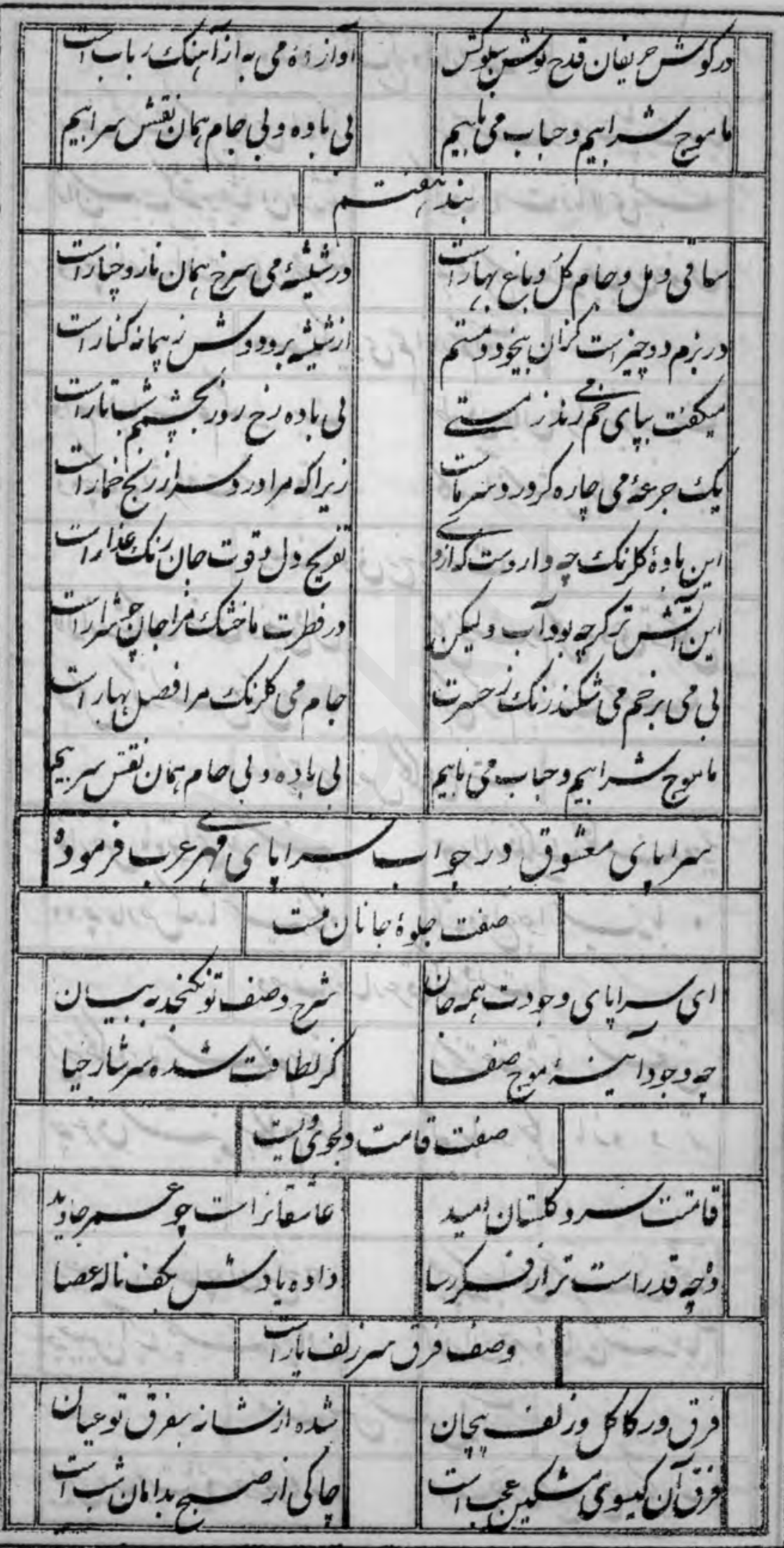


51.

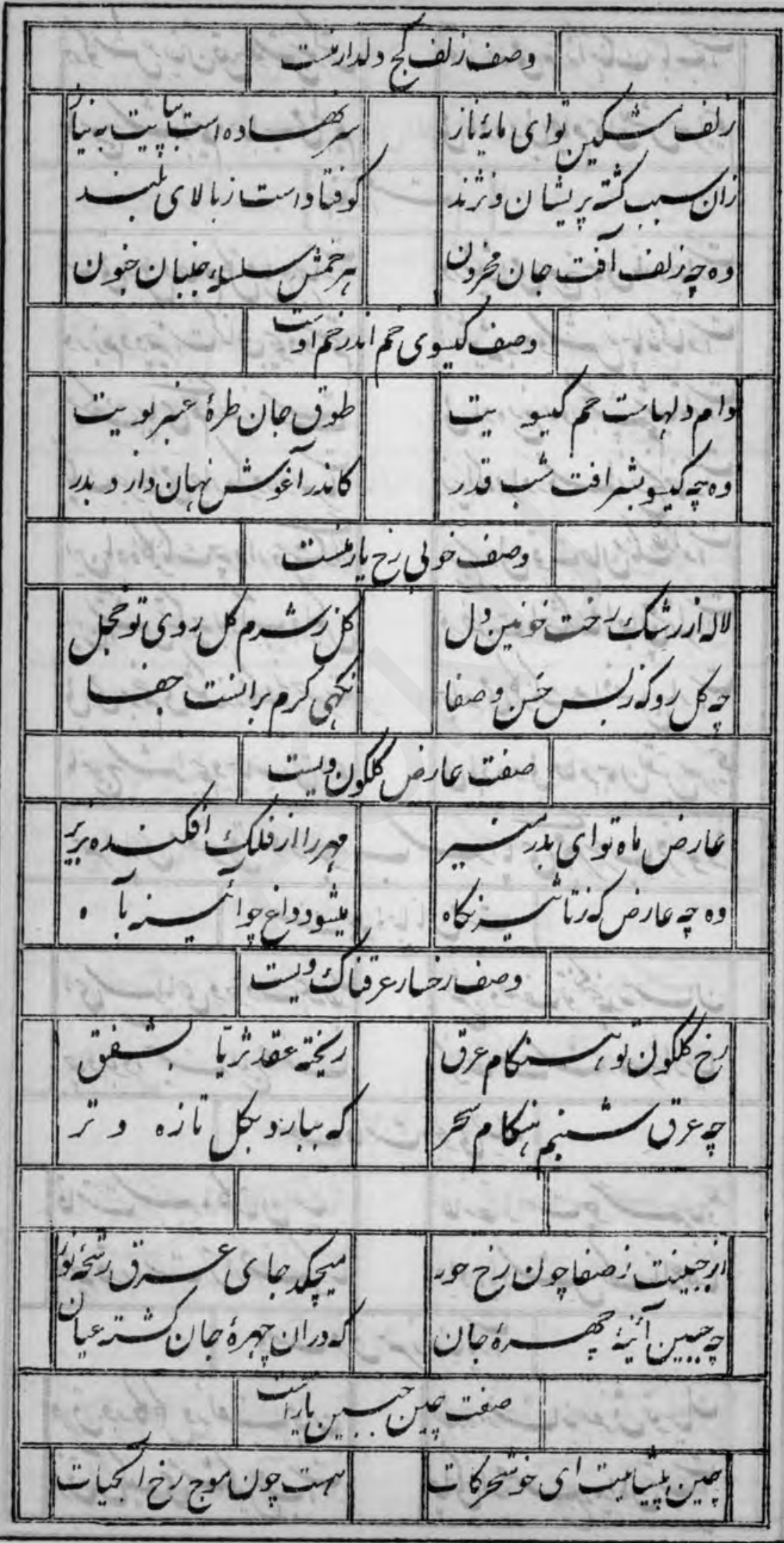




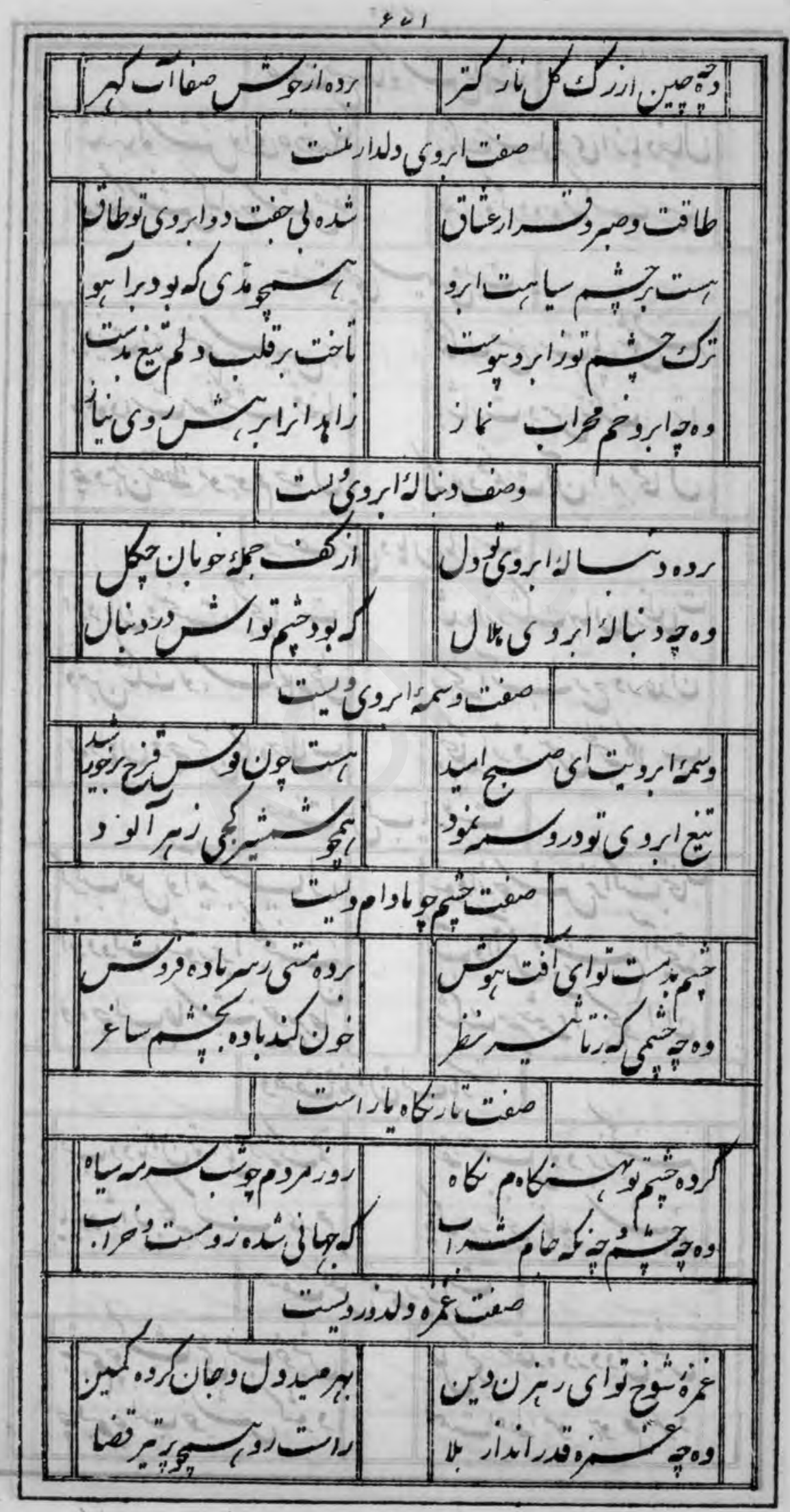




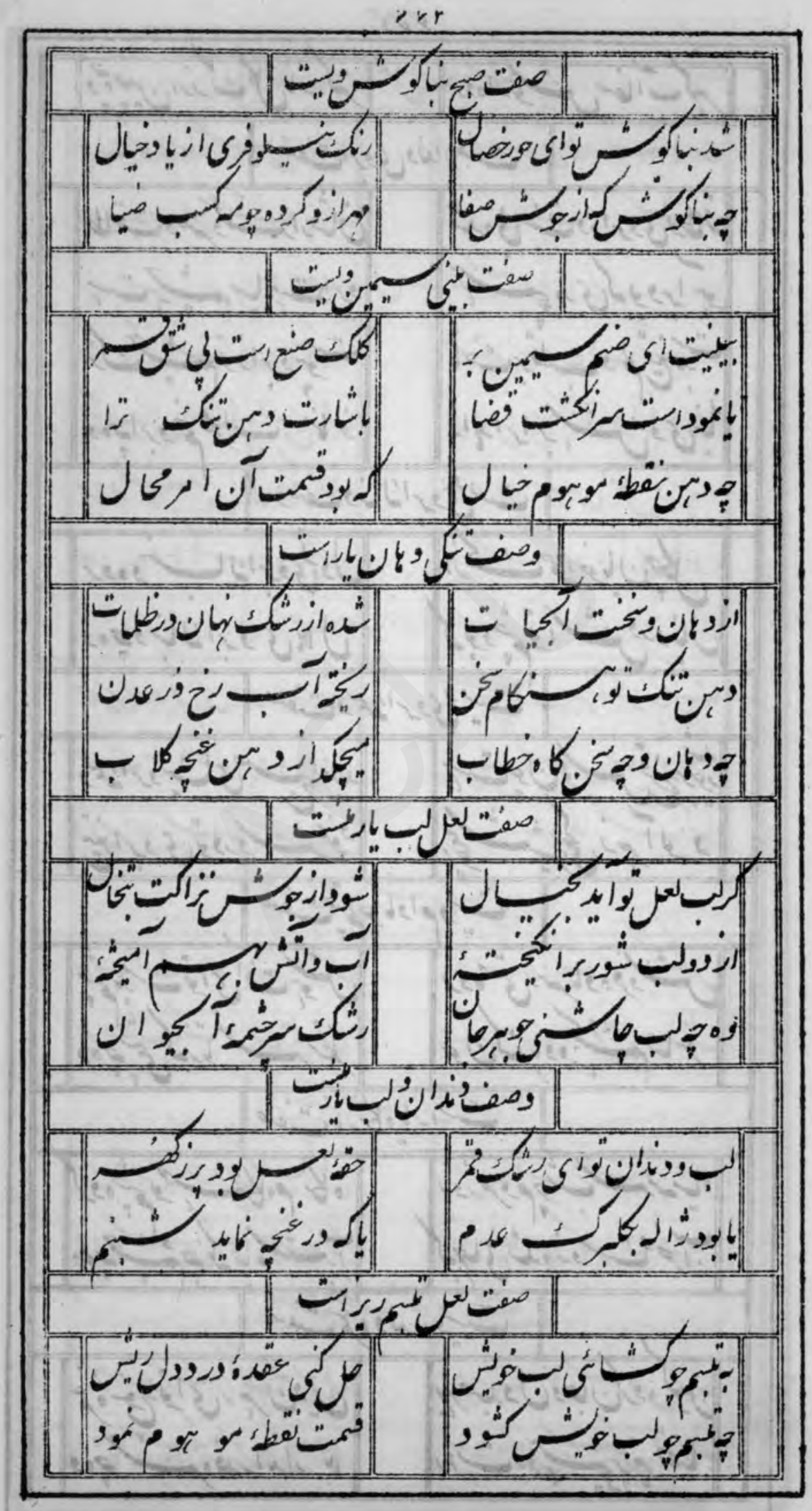




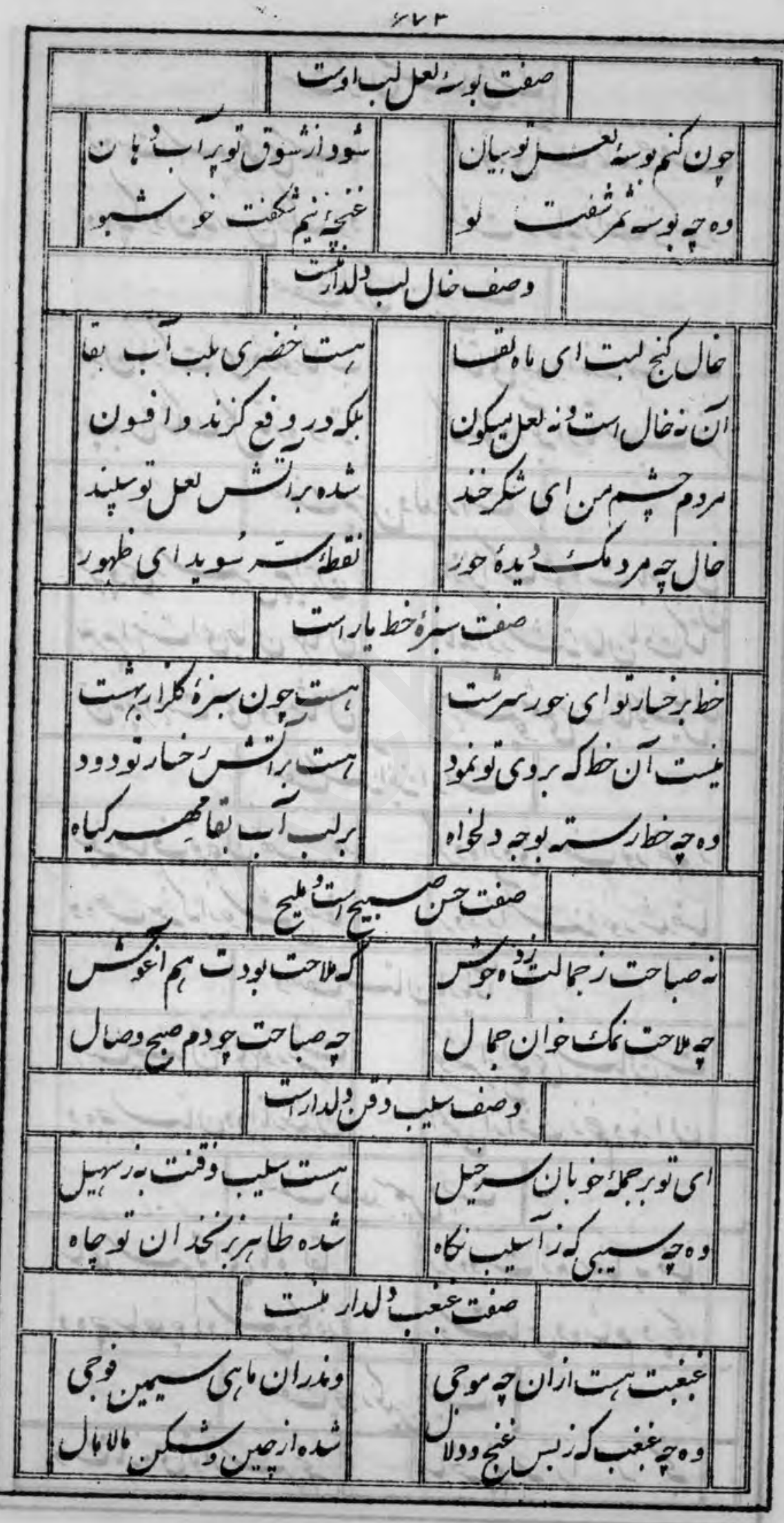




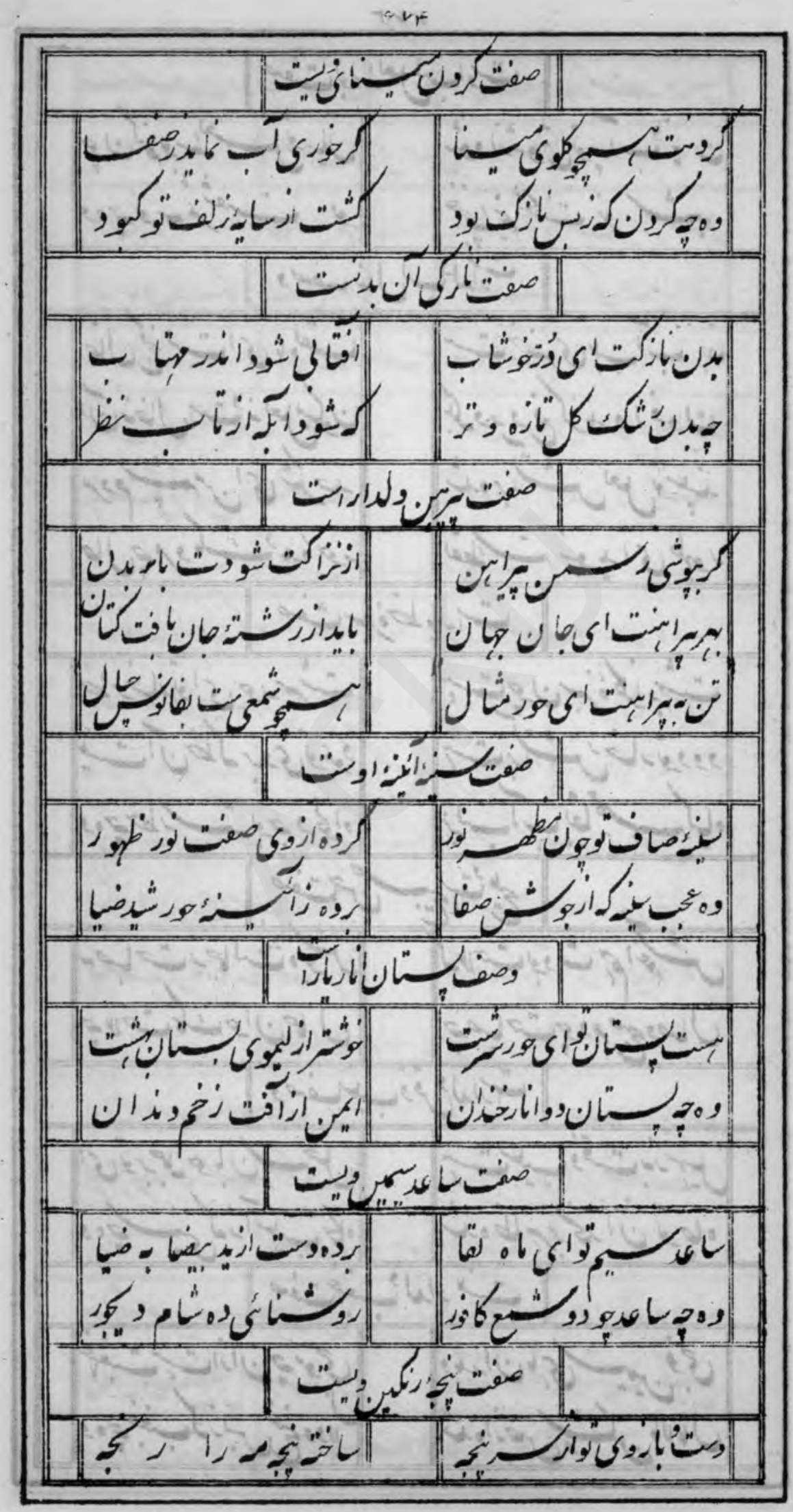




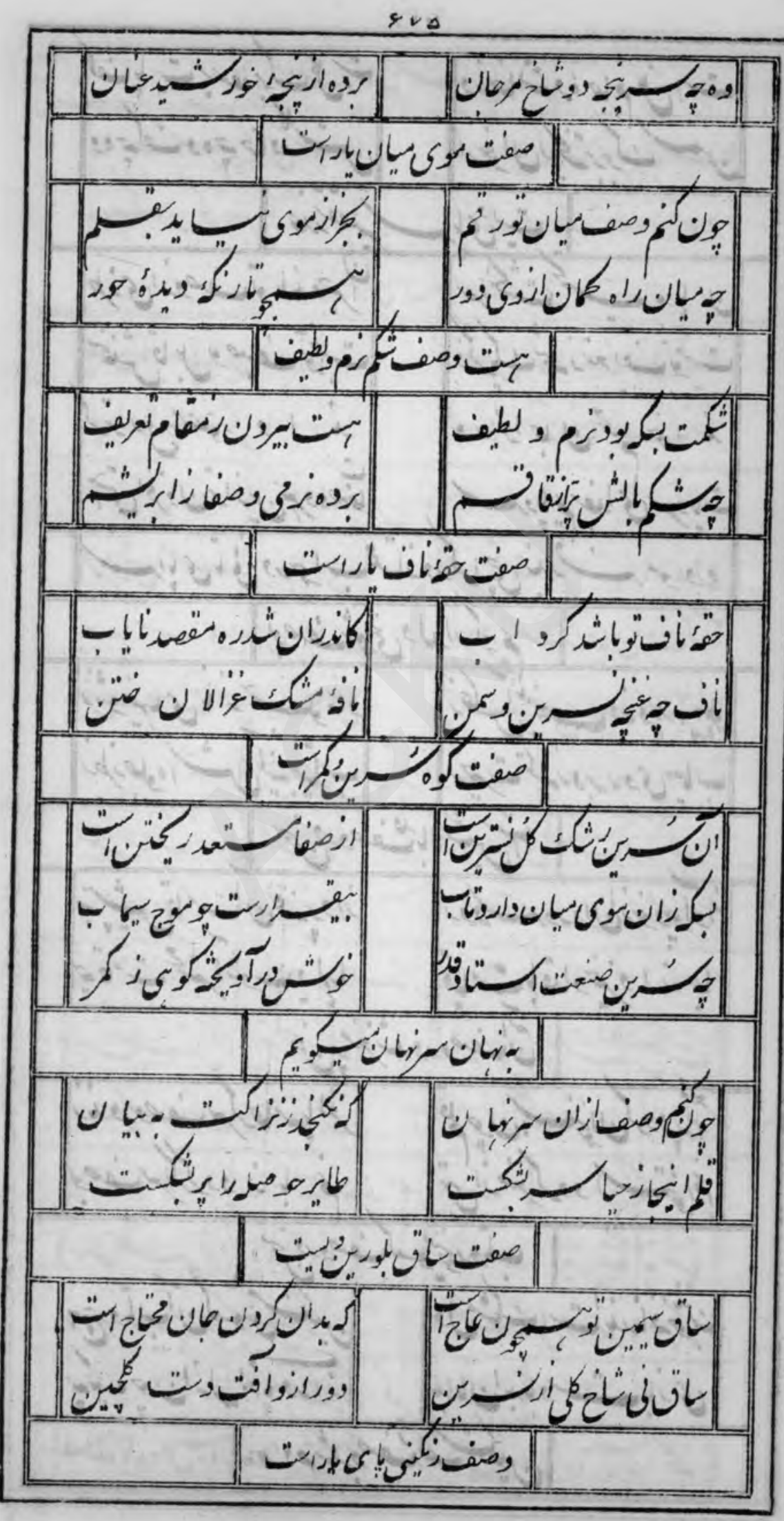


다

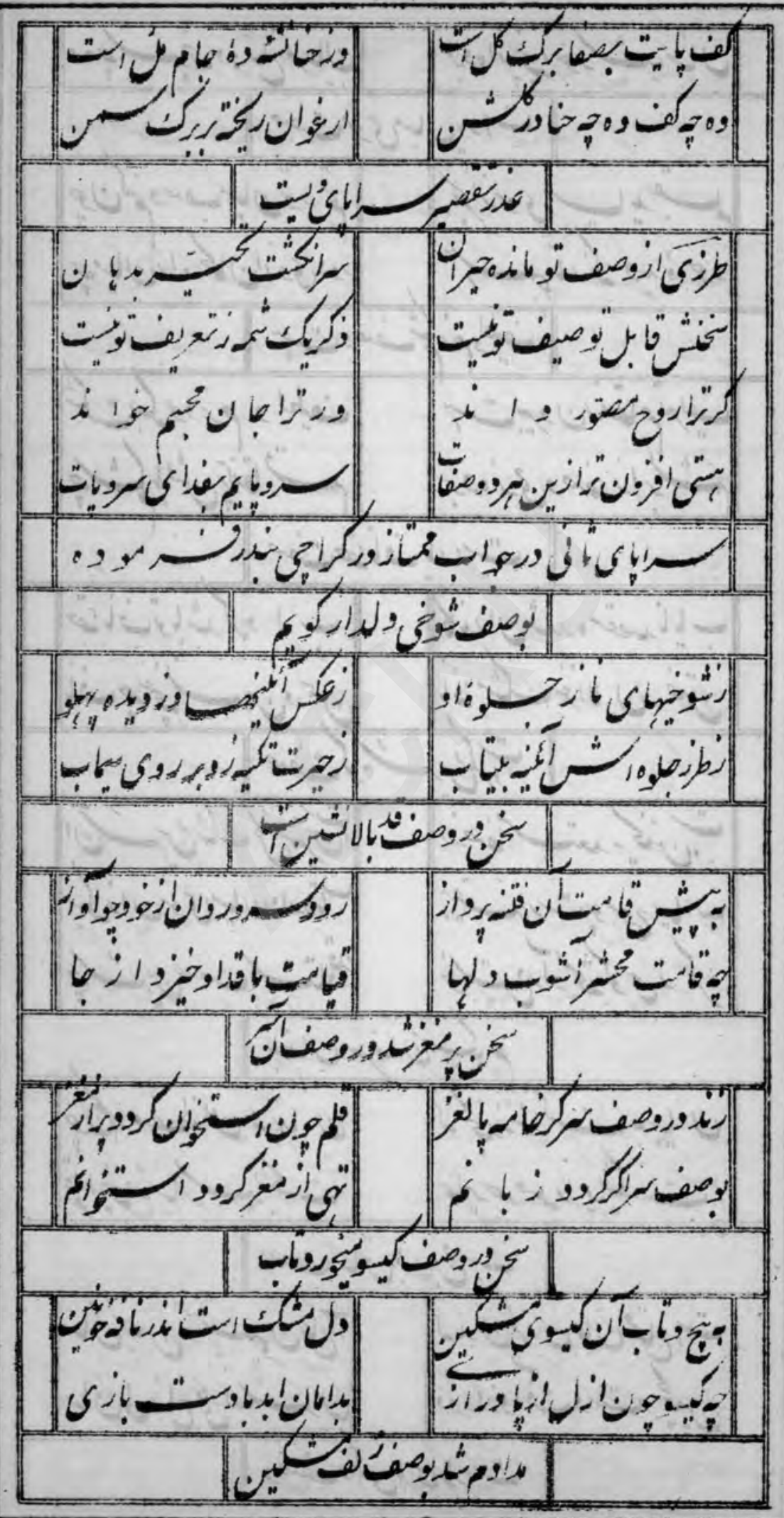




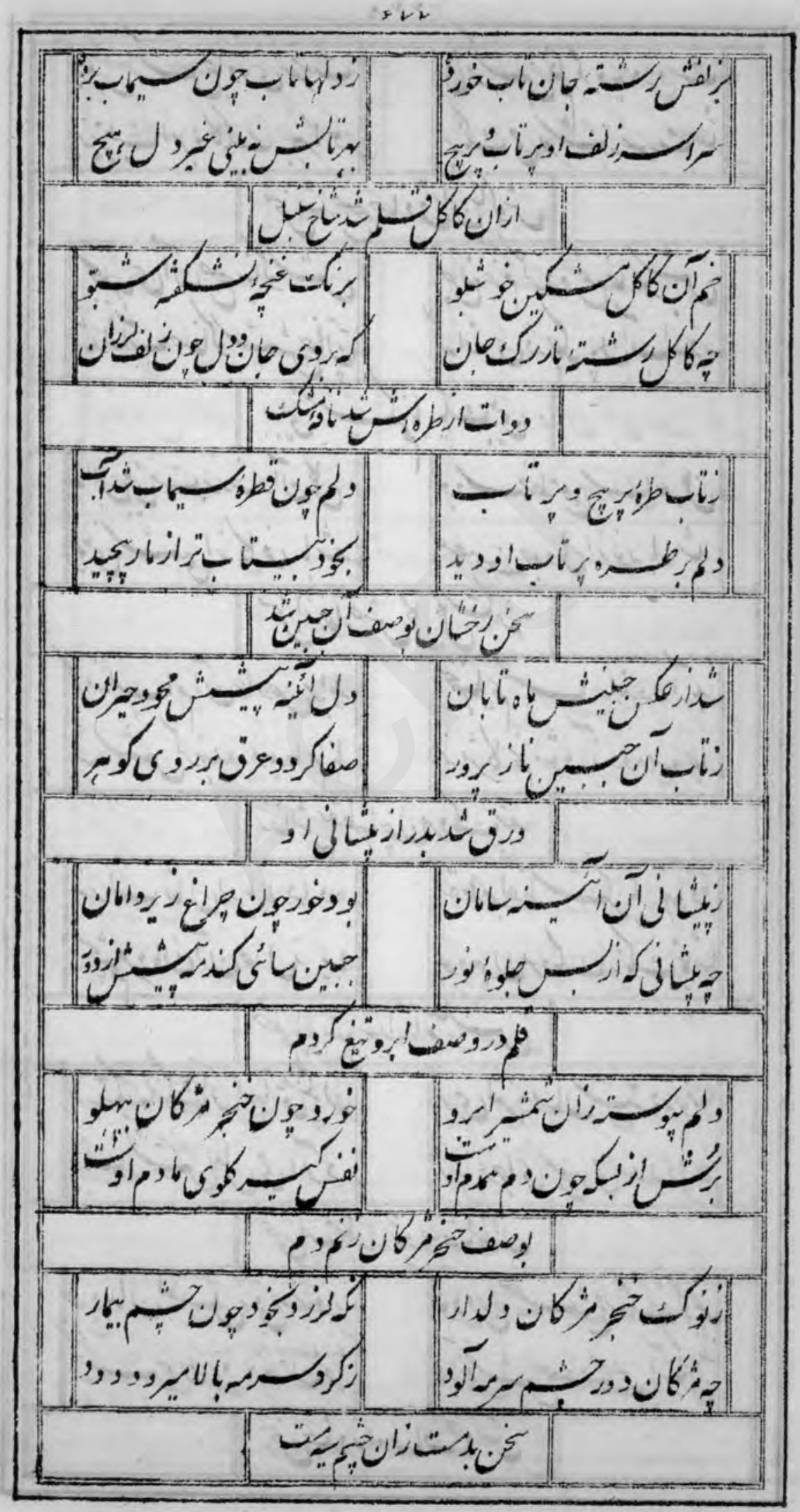




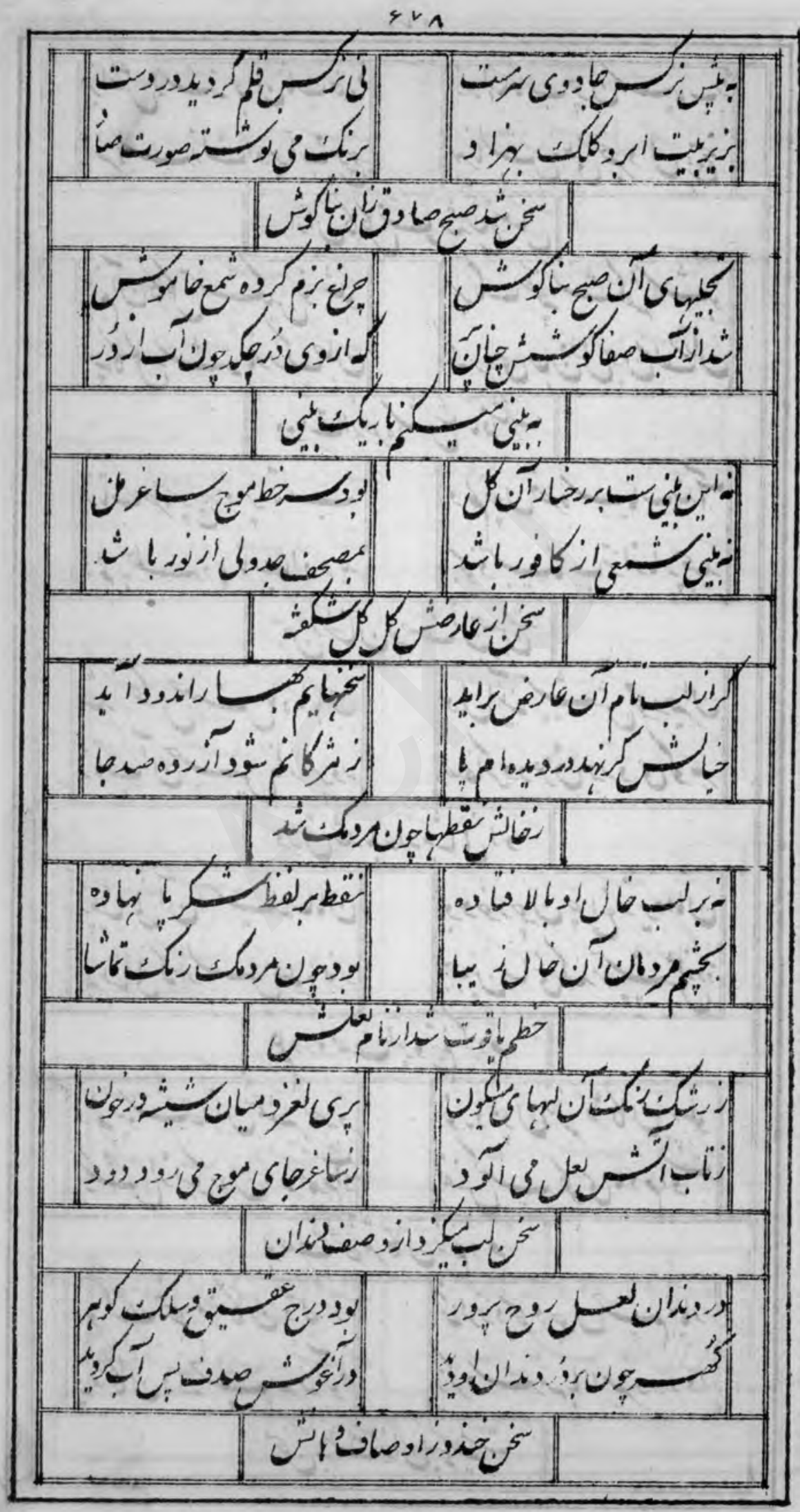

(4) 
$>29$

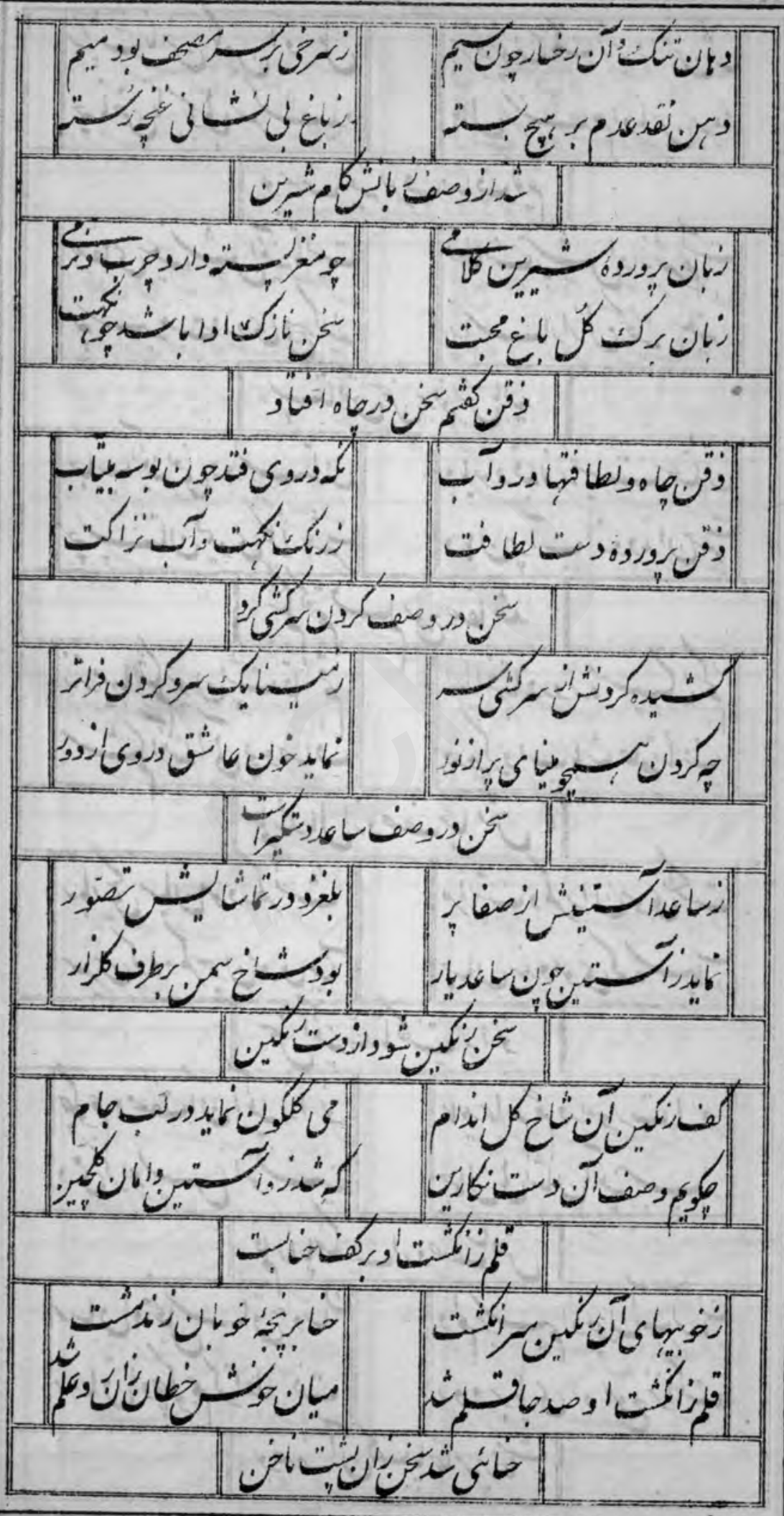


$4 A$.

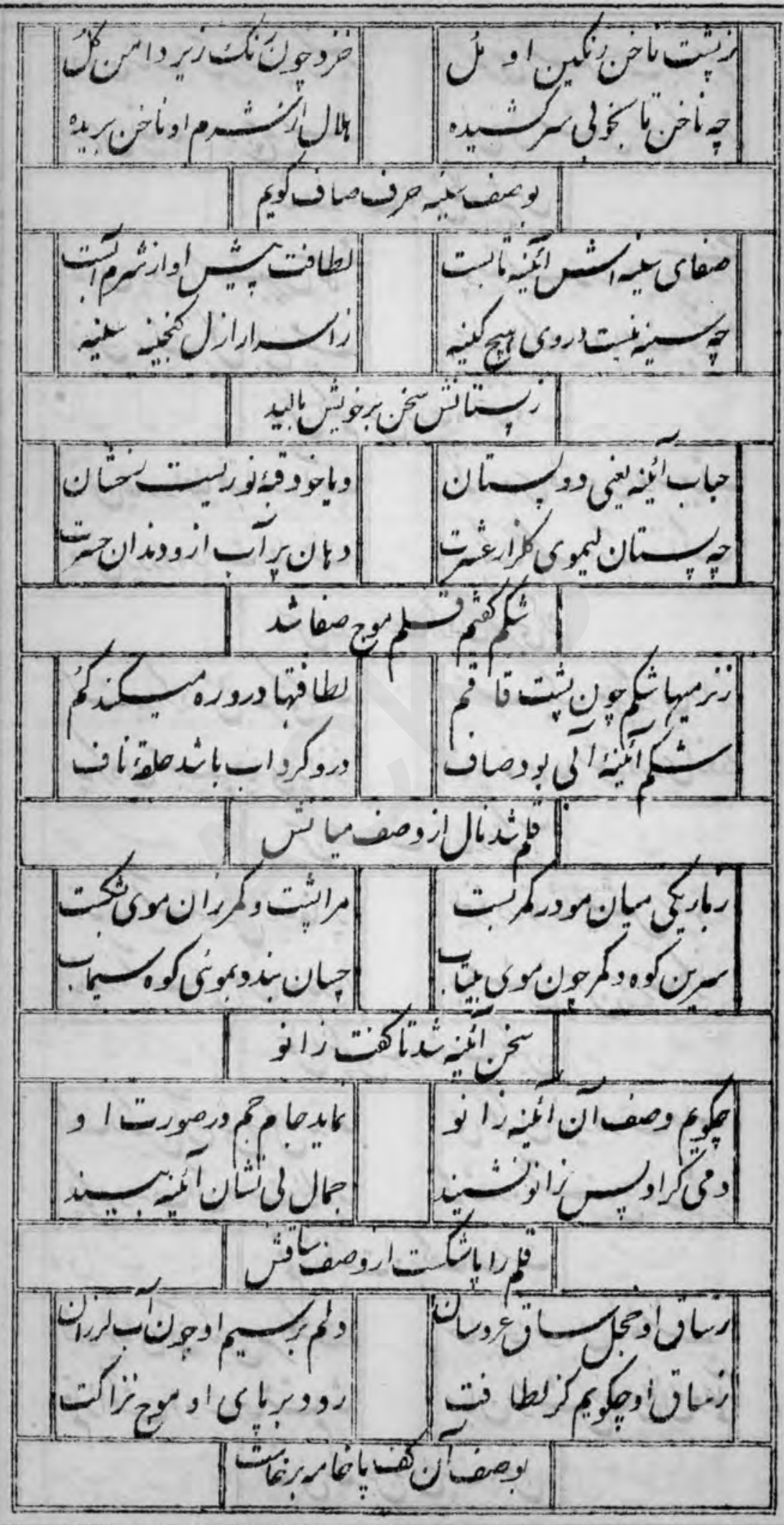


SA 1

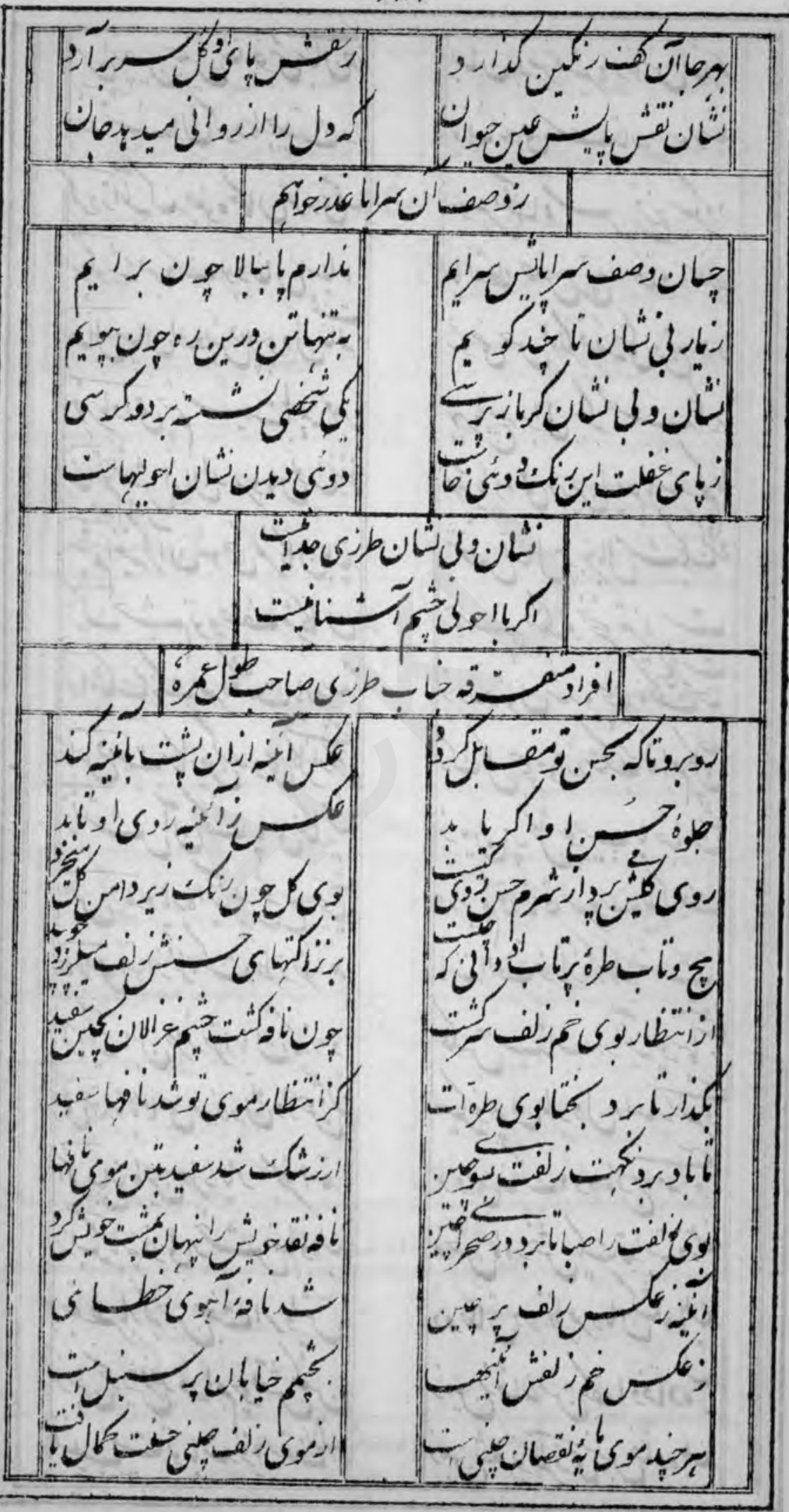


$>A r$

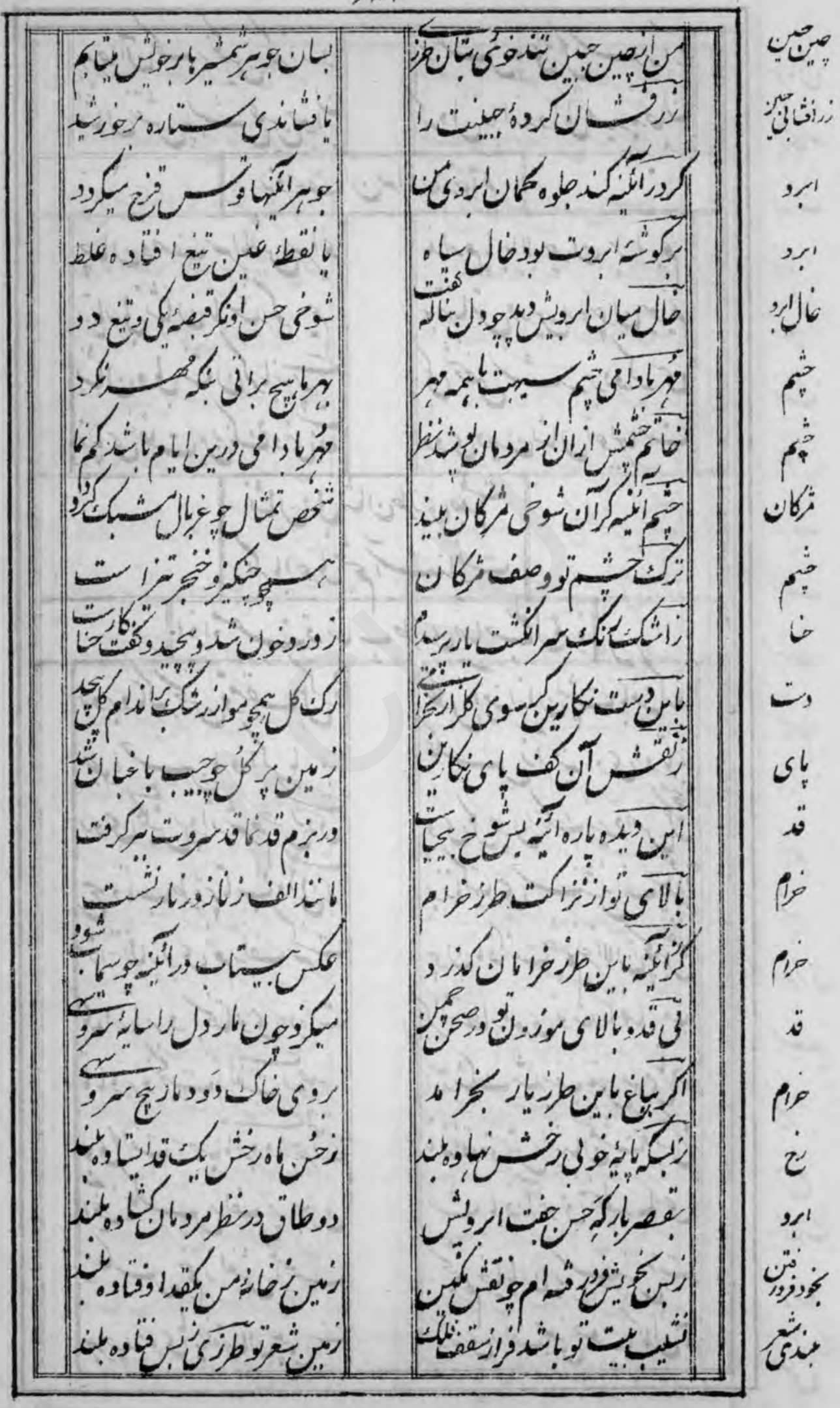


\&Ar

is

bi

$e^{2}$

is

$\ddot{1}$

رلغ

لלف

(ie-)

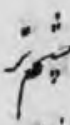

il

c

"i

ise,

है"

Lte

L:

$u^{\prime \prime}$
造, ¿lios

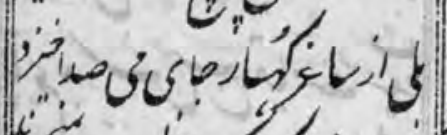

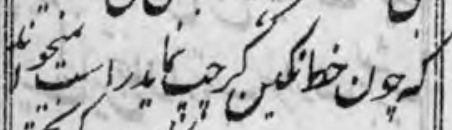
"20 $\log ^{2}$

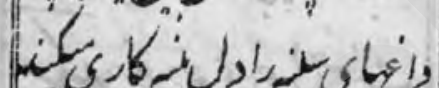
(6) , os (2) if is 2 ivb - 6 C C C 2 in

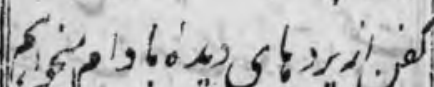

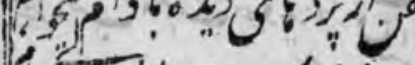

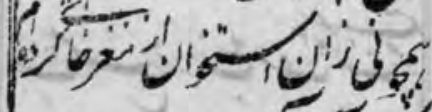
| (3) $\therefore$ ( (إ)

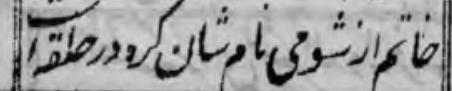

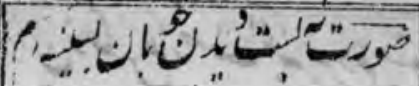

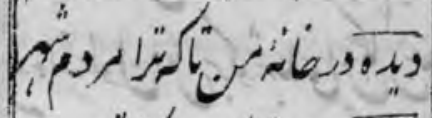
. 

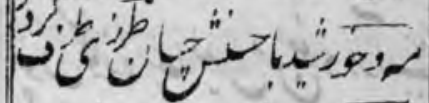

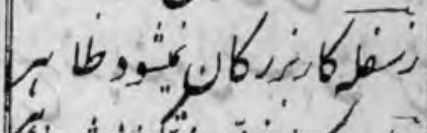
bو

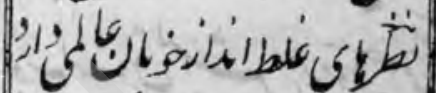

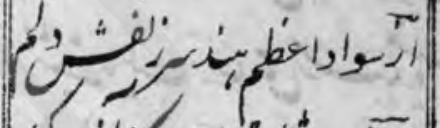

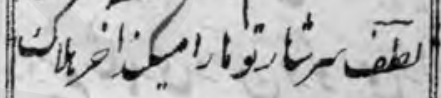

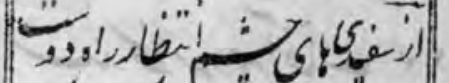
6 - 60

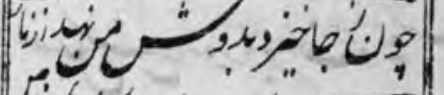

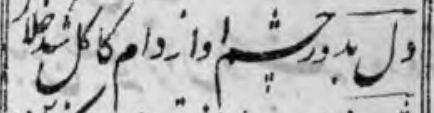

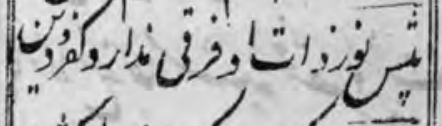
, 6/1. s a (i)

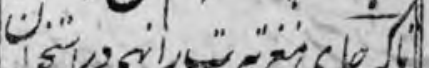
" 1.

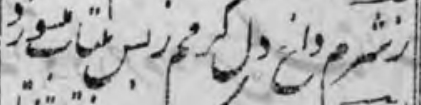
in $1 \% 6$ bु:

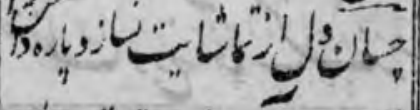

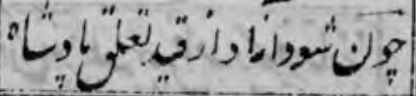


sor

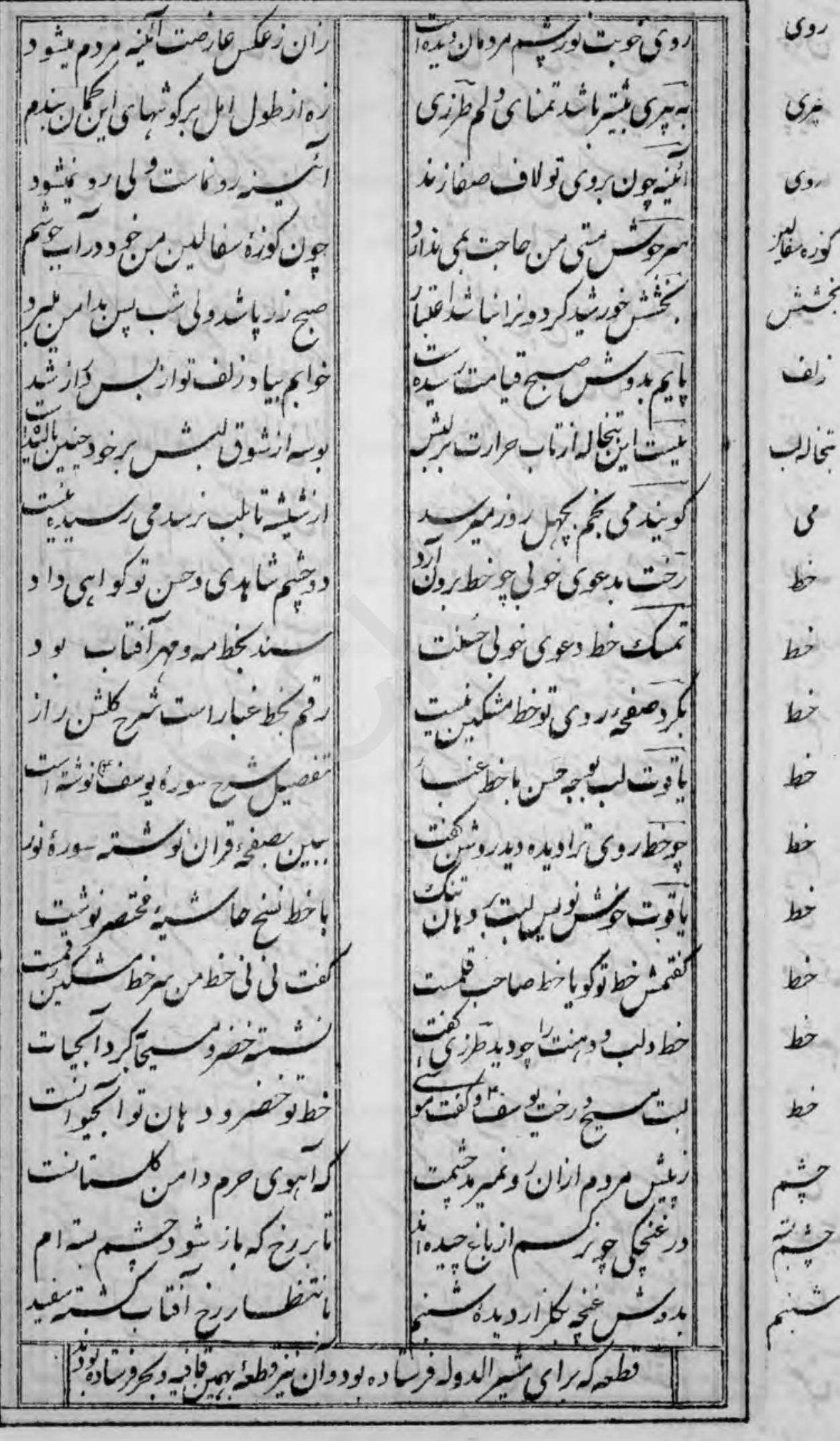




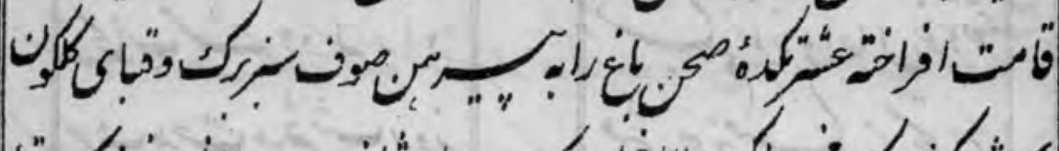

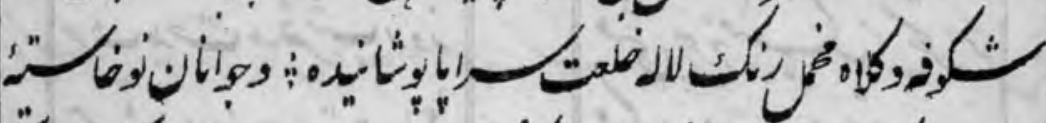

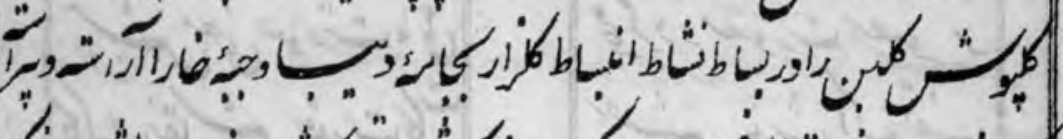
" هو

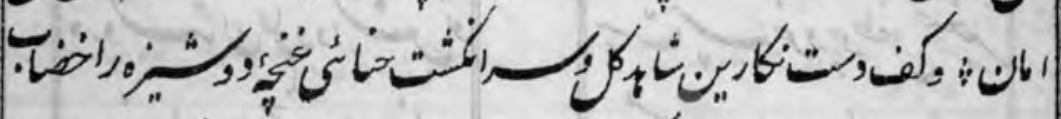

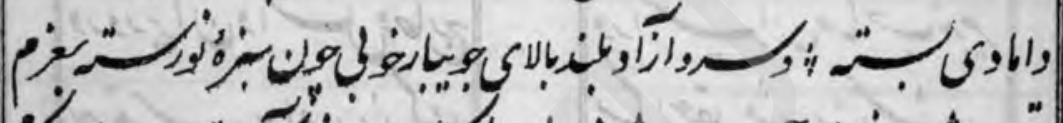

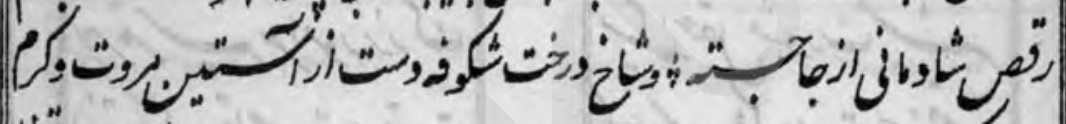

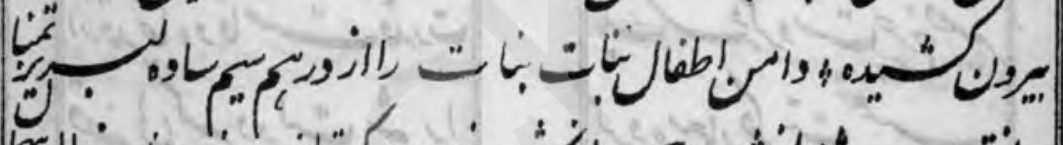

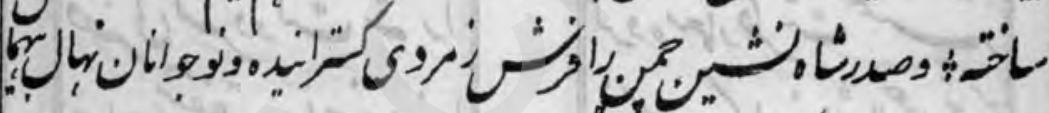

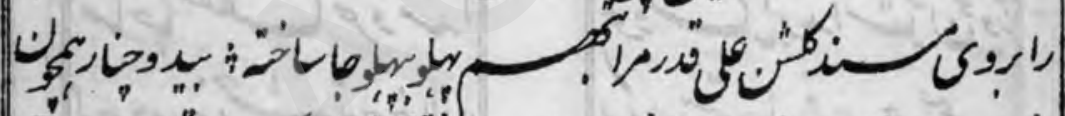

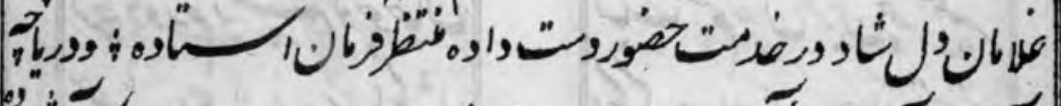

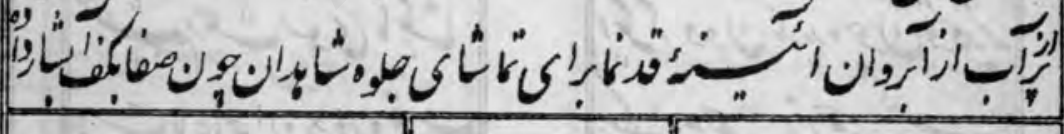

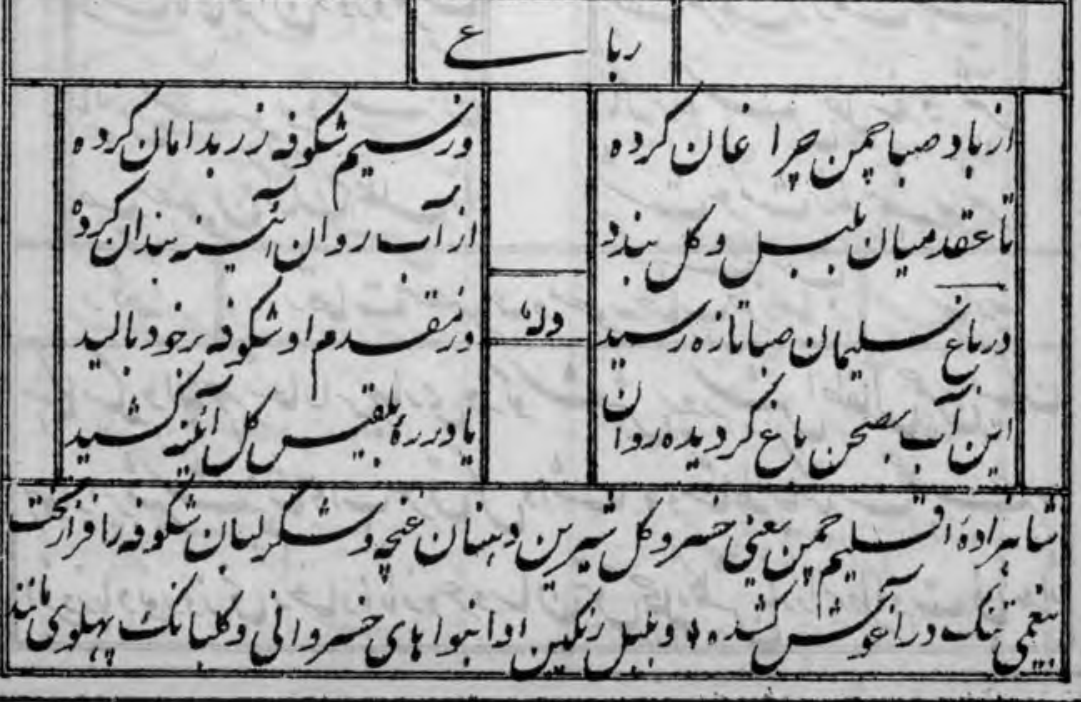




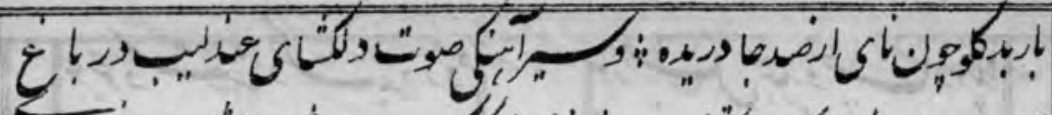

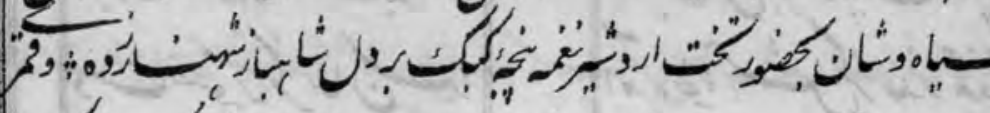

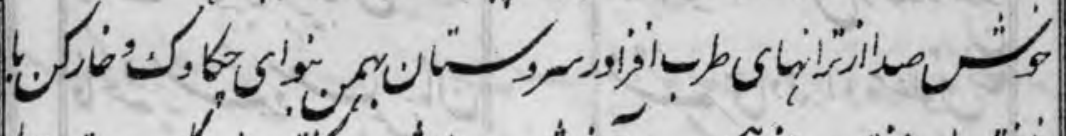

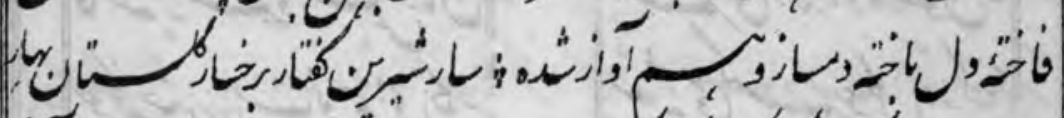

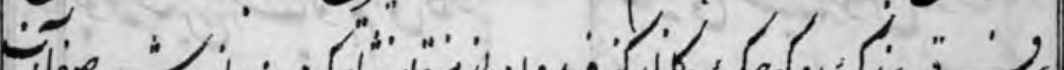

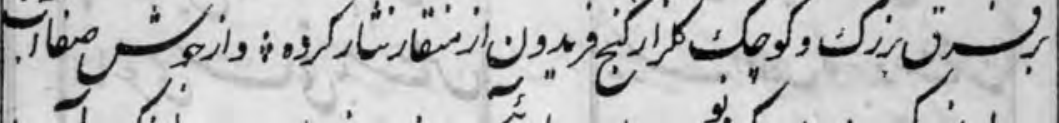

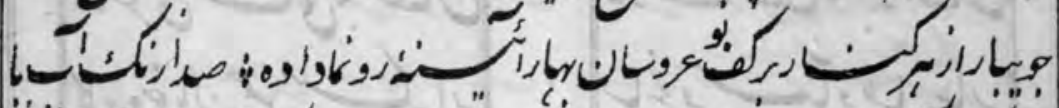

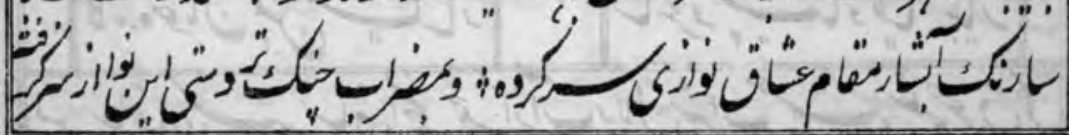
sipgoin غi-

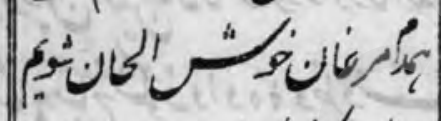

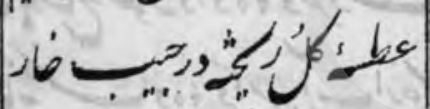
$\checkmark b, 6,0$ ركائي

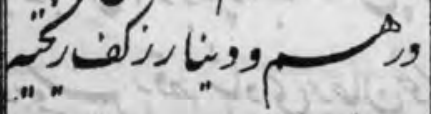

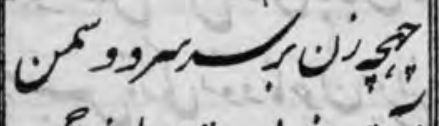
أبت

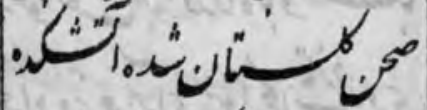
نو بـ كان

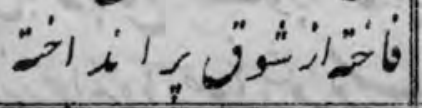

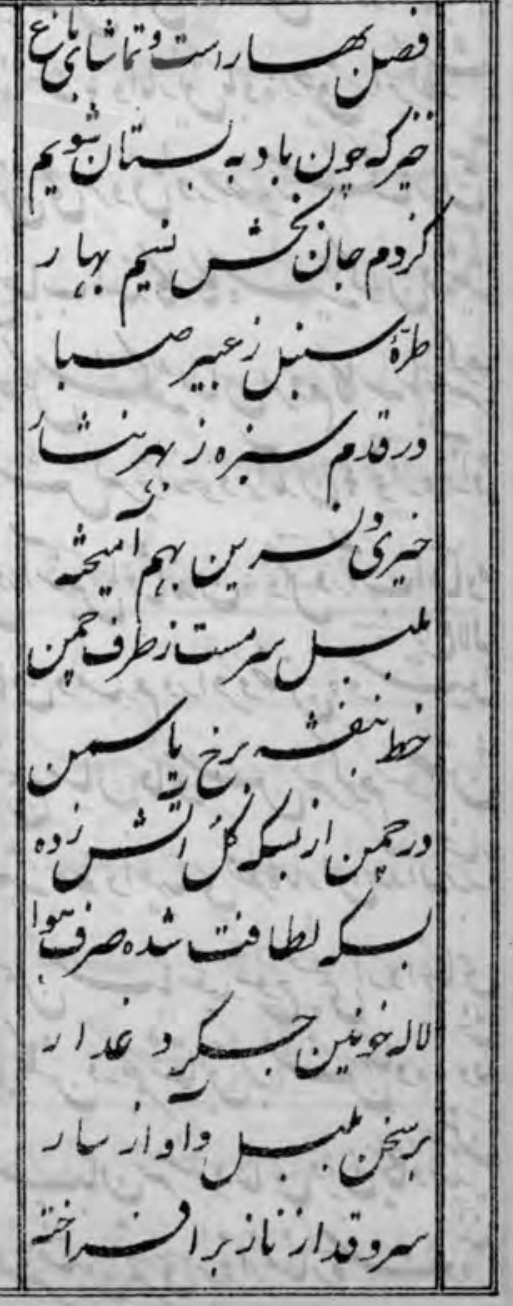




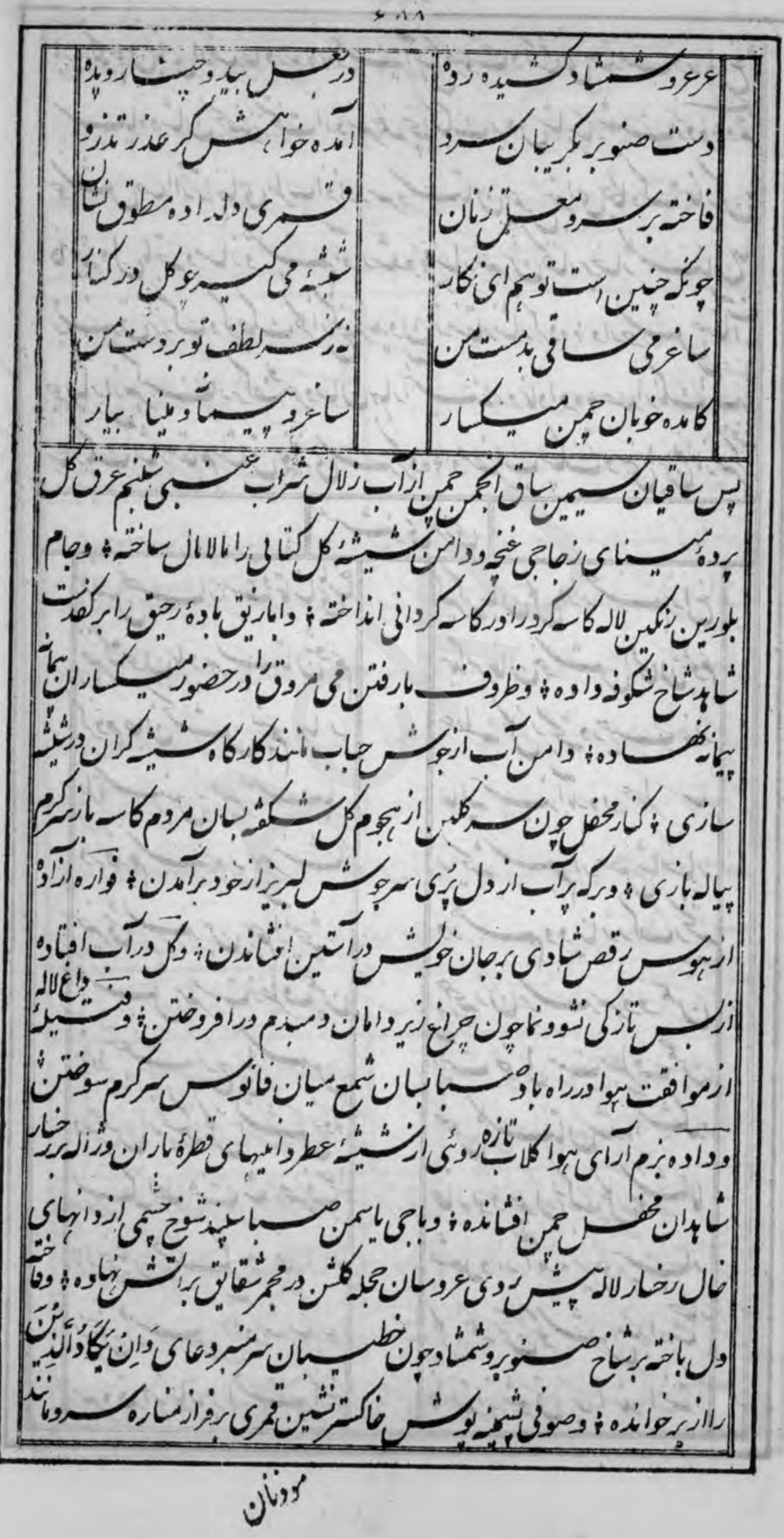




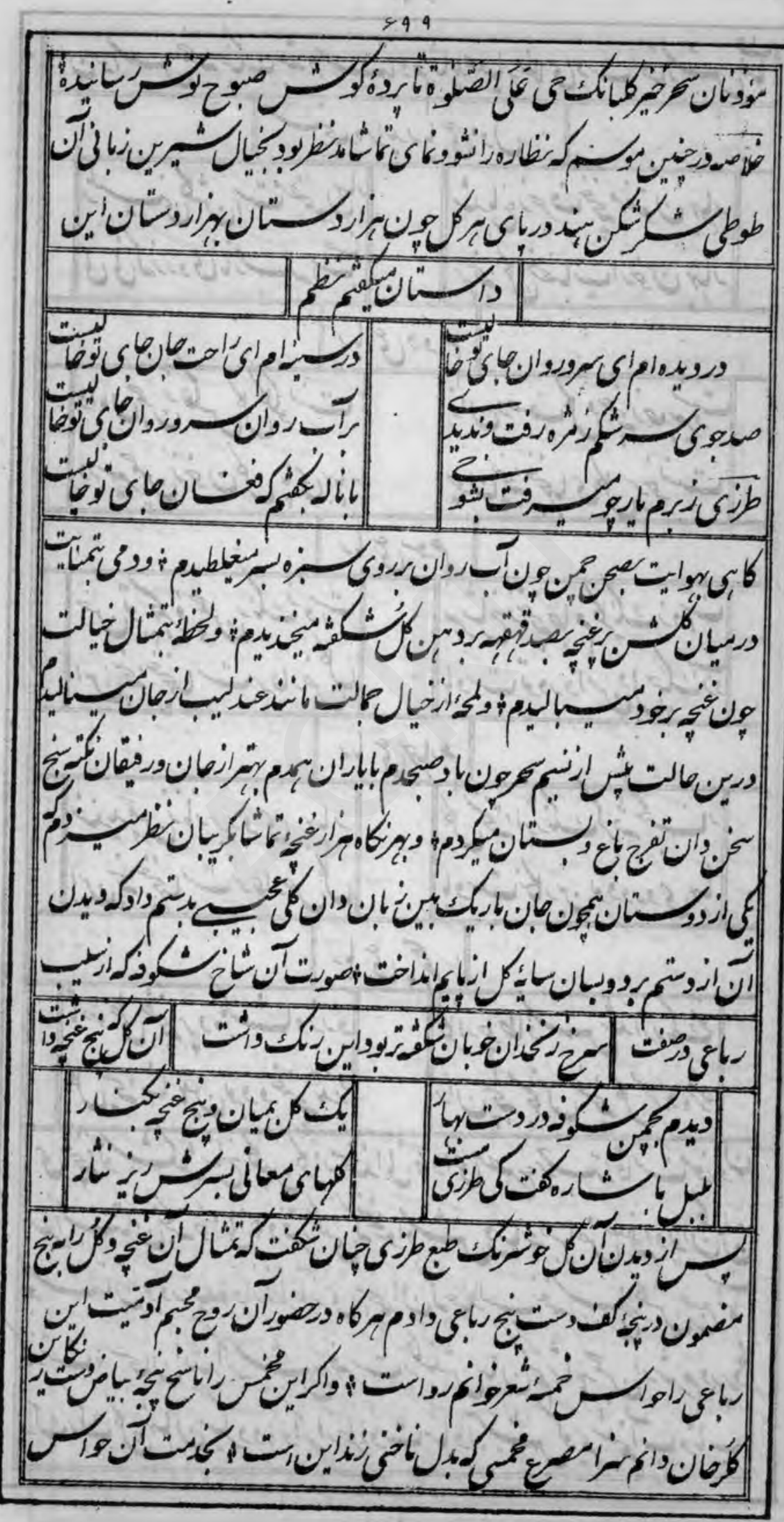


\& 9

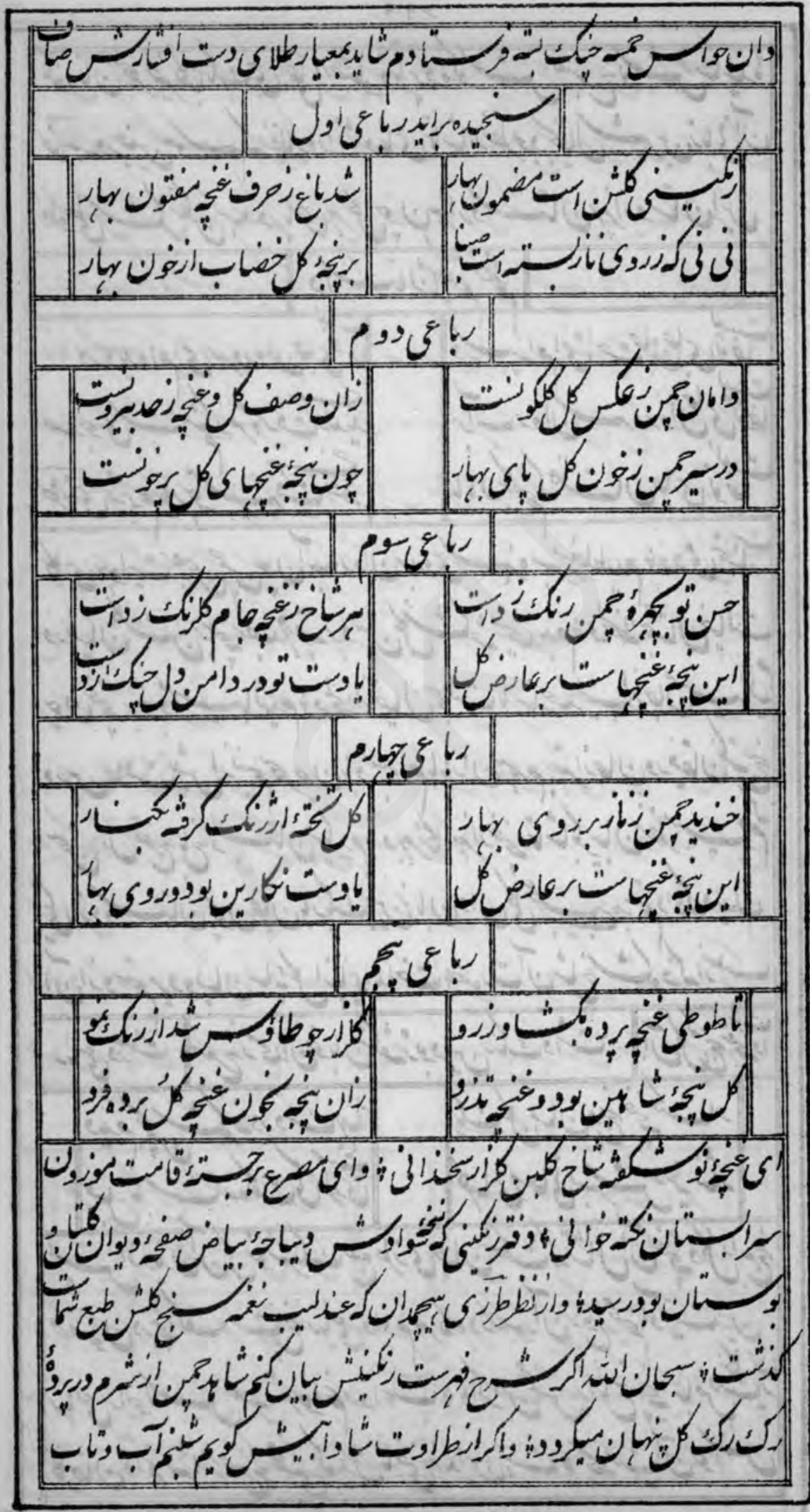




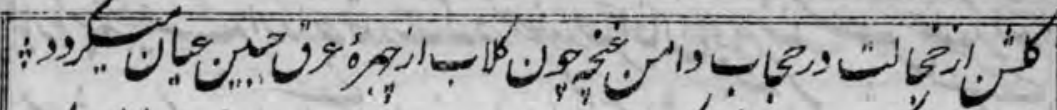

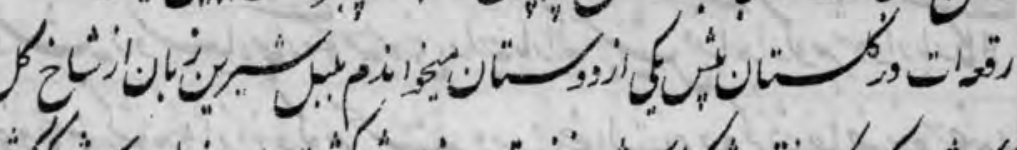

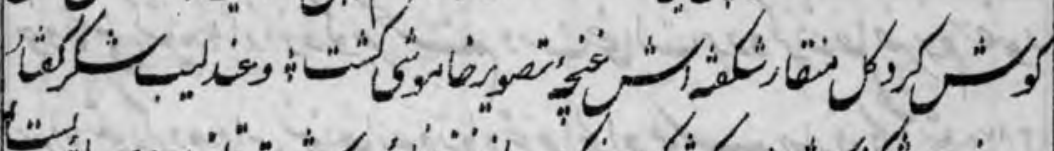

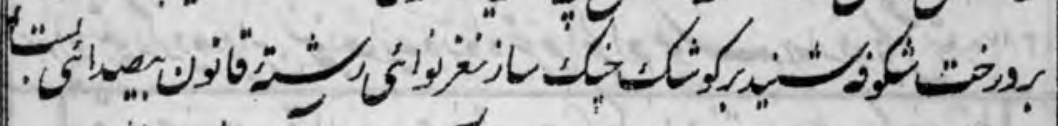
و r ن

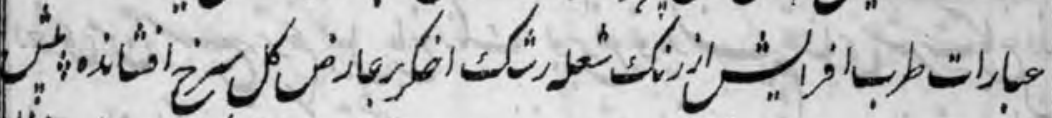

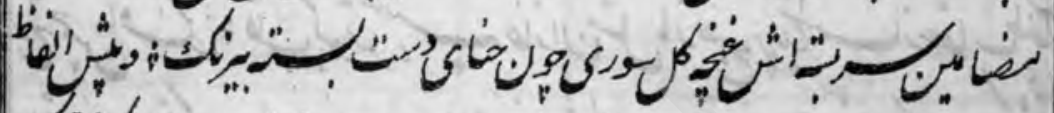

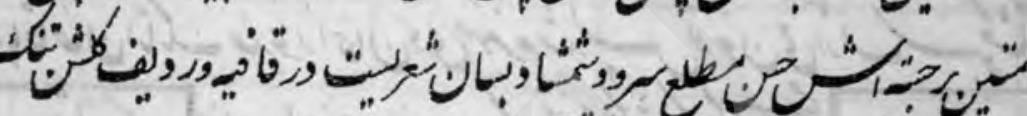
年

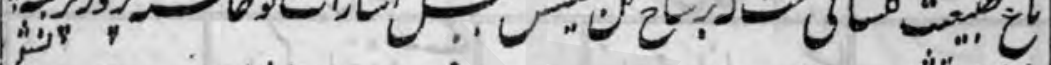

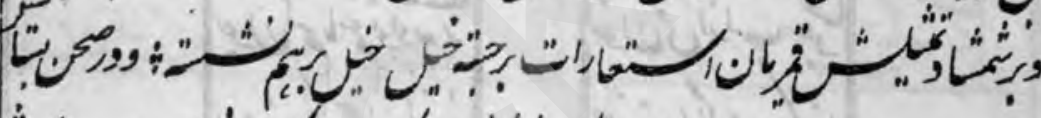

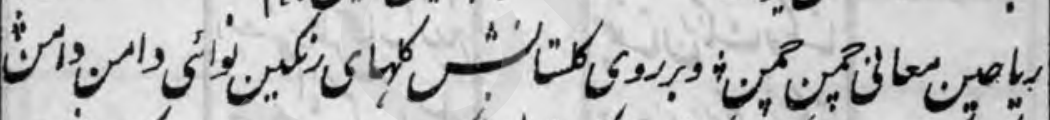

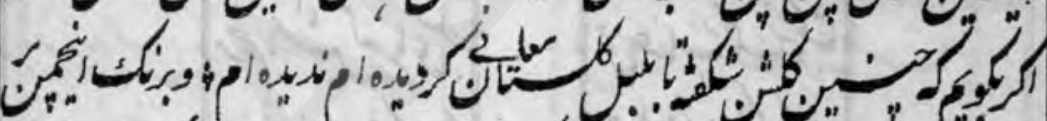
تح

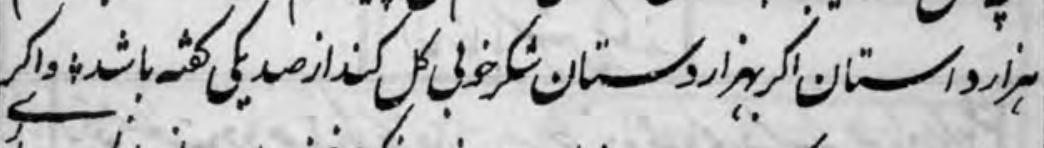

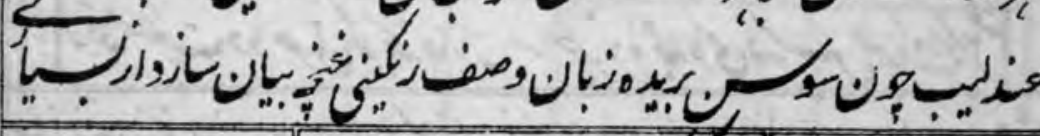

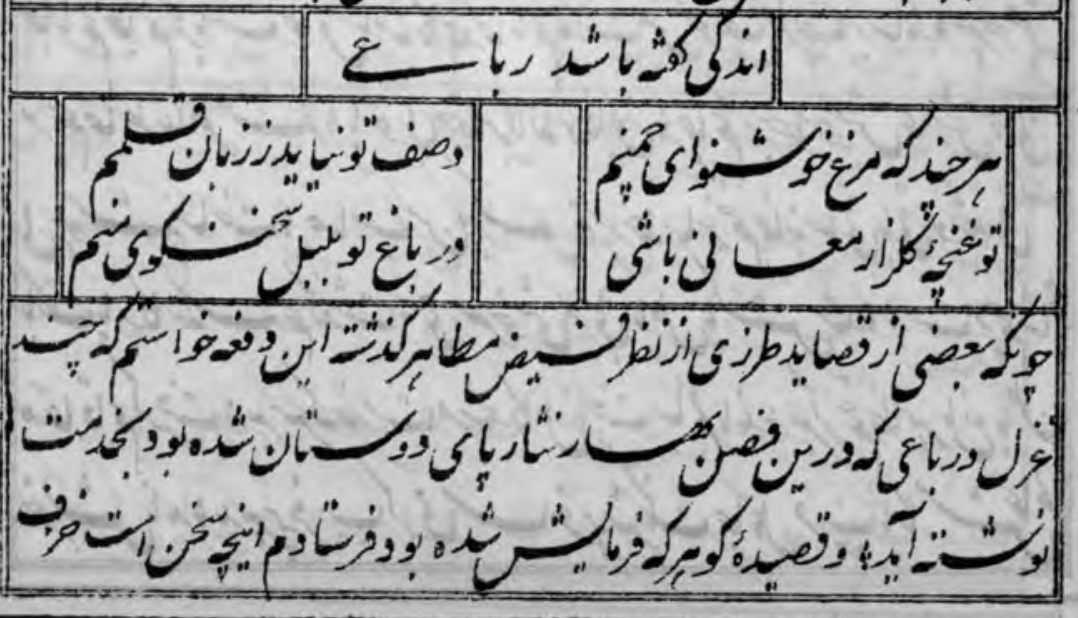




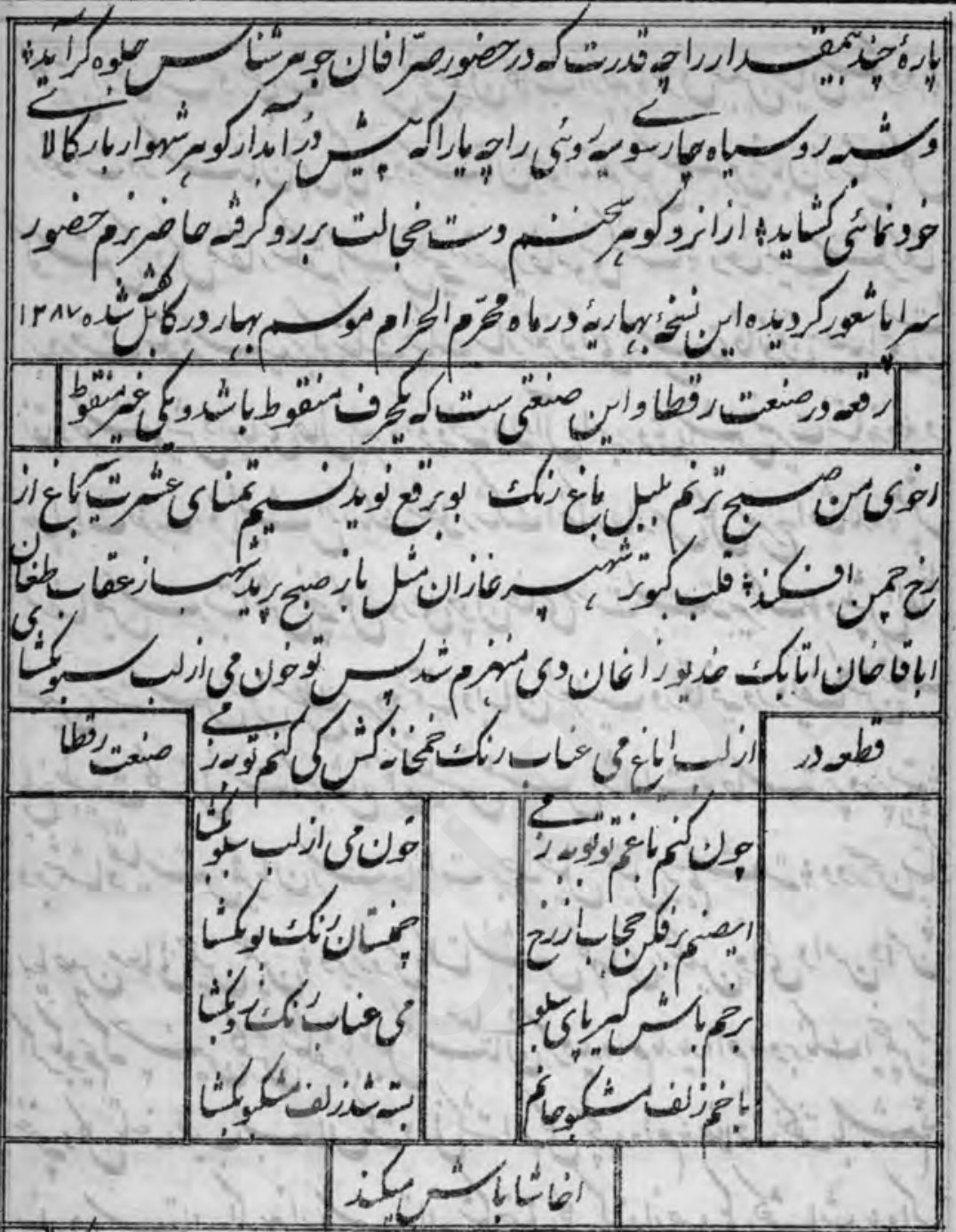

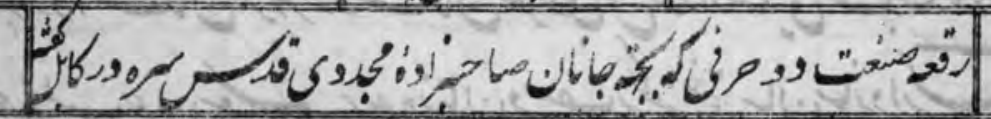

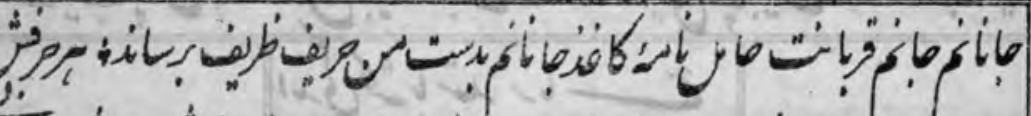

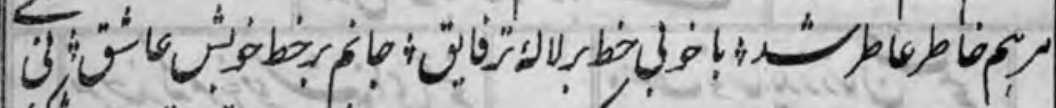

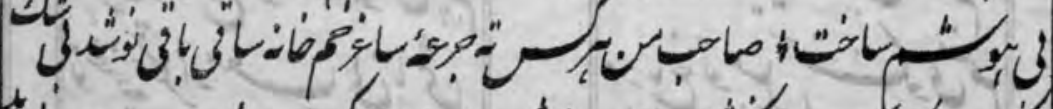
(4)

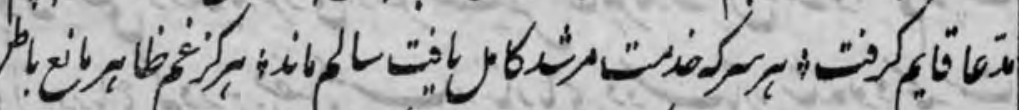

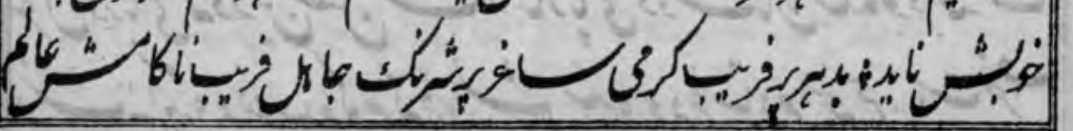




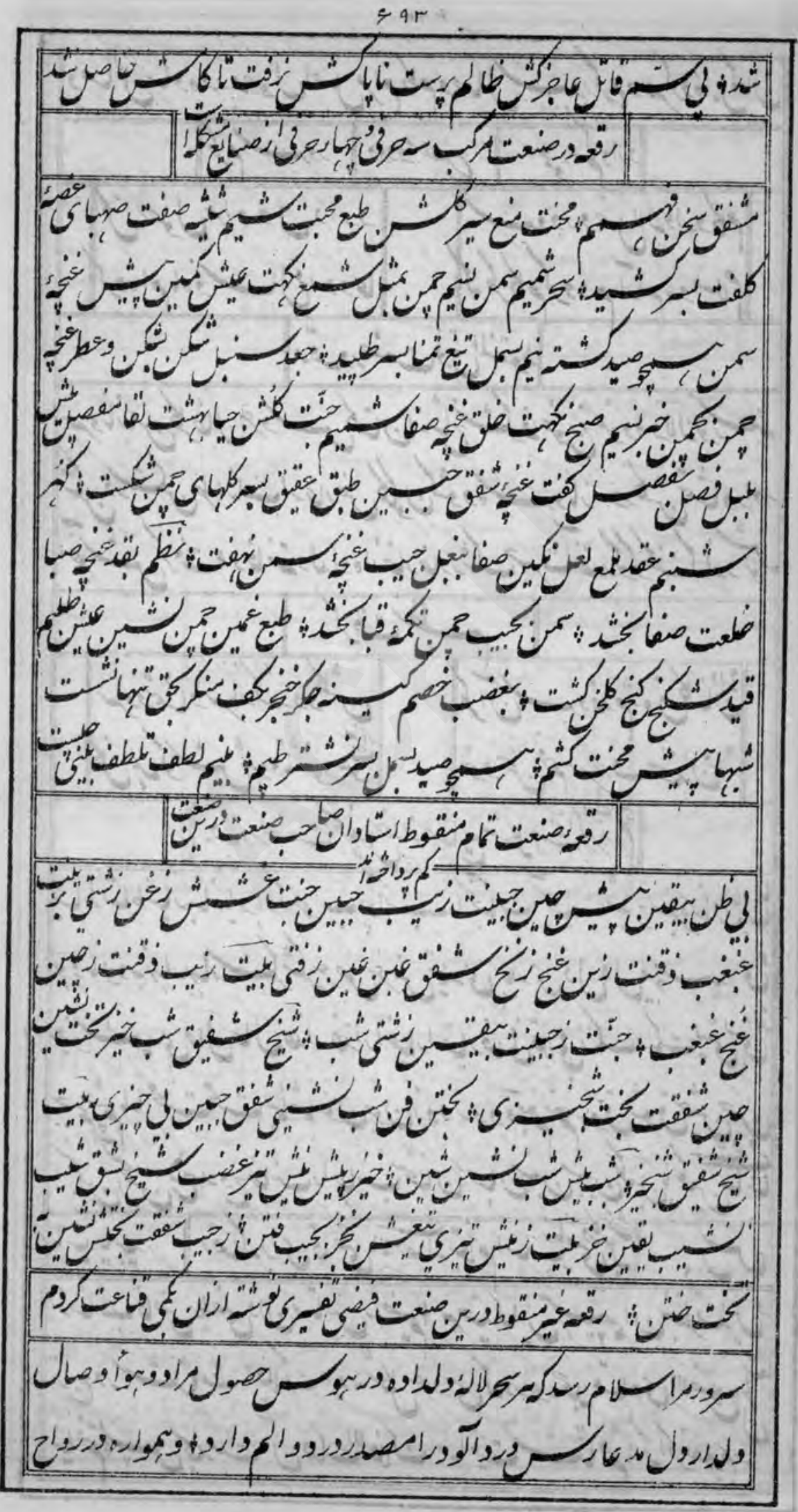


C. 916

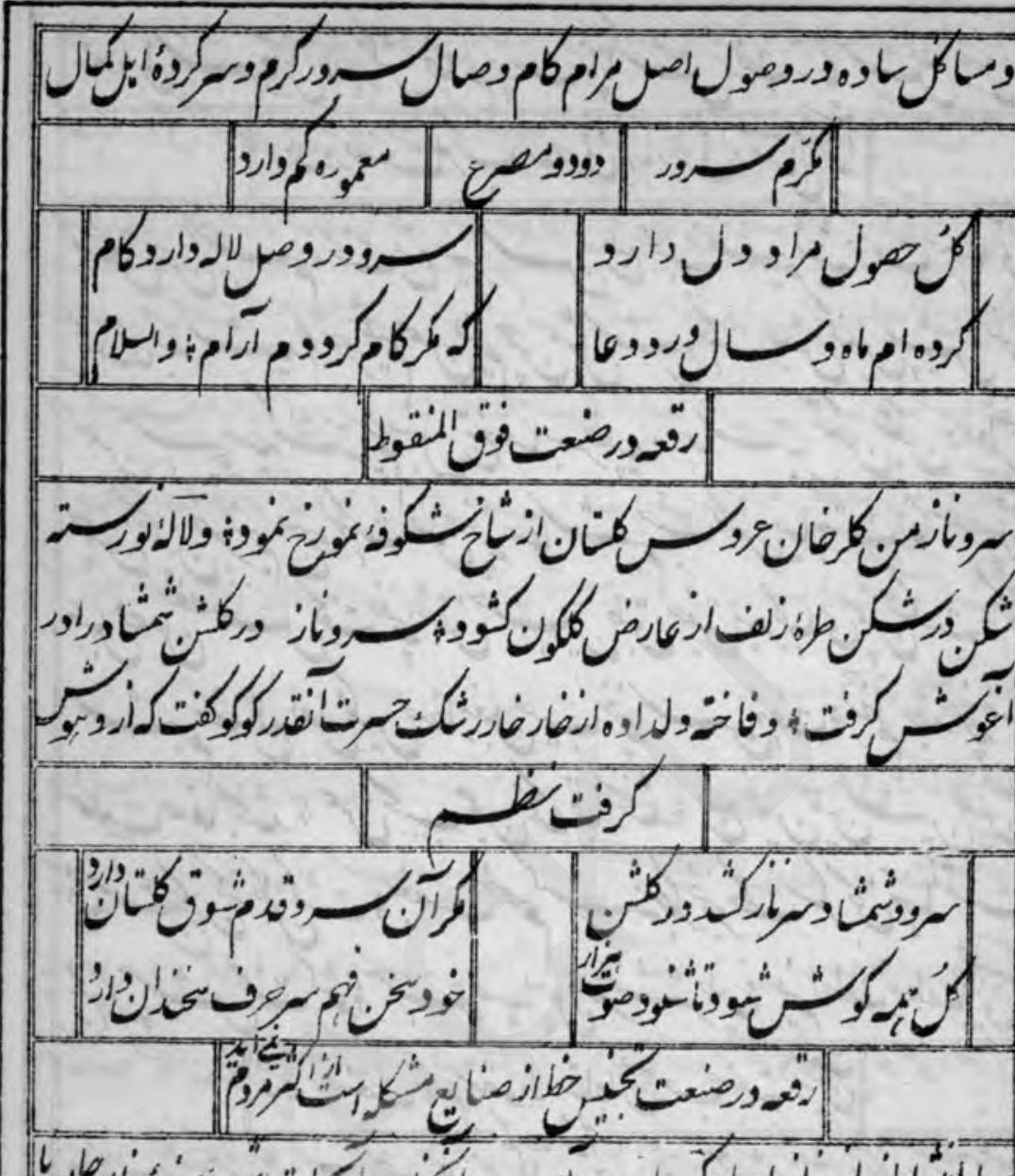

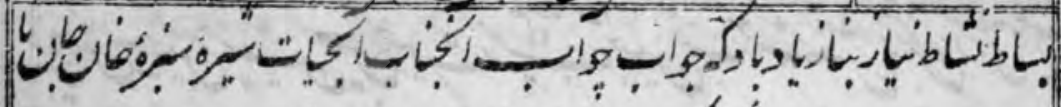
is a "

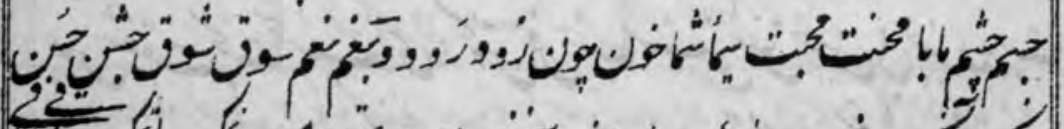
(25.0.

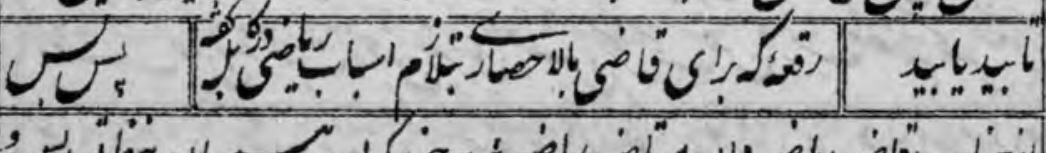

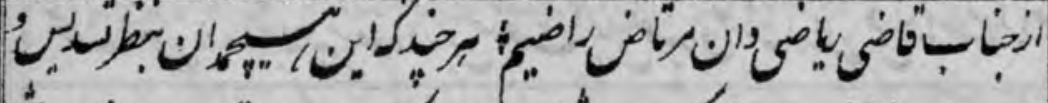

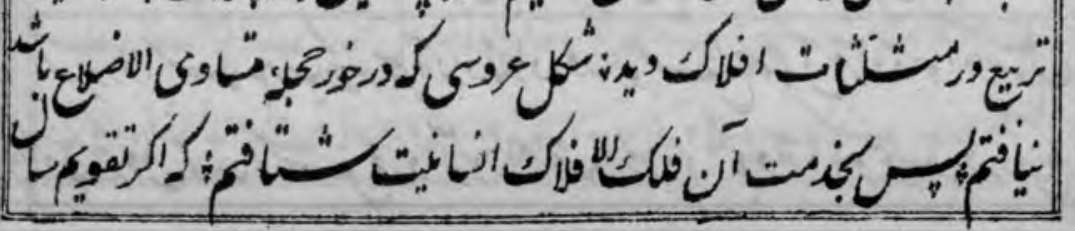


400

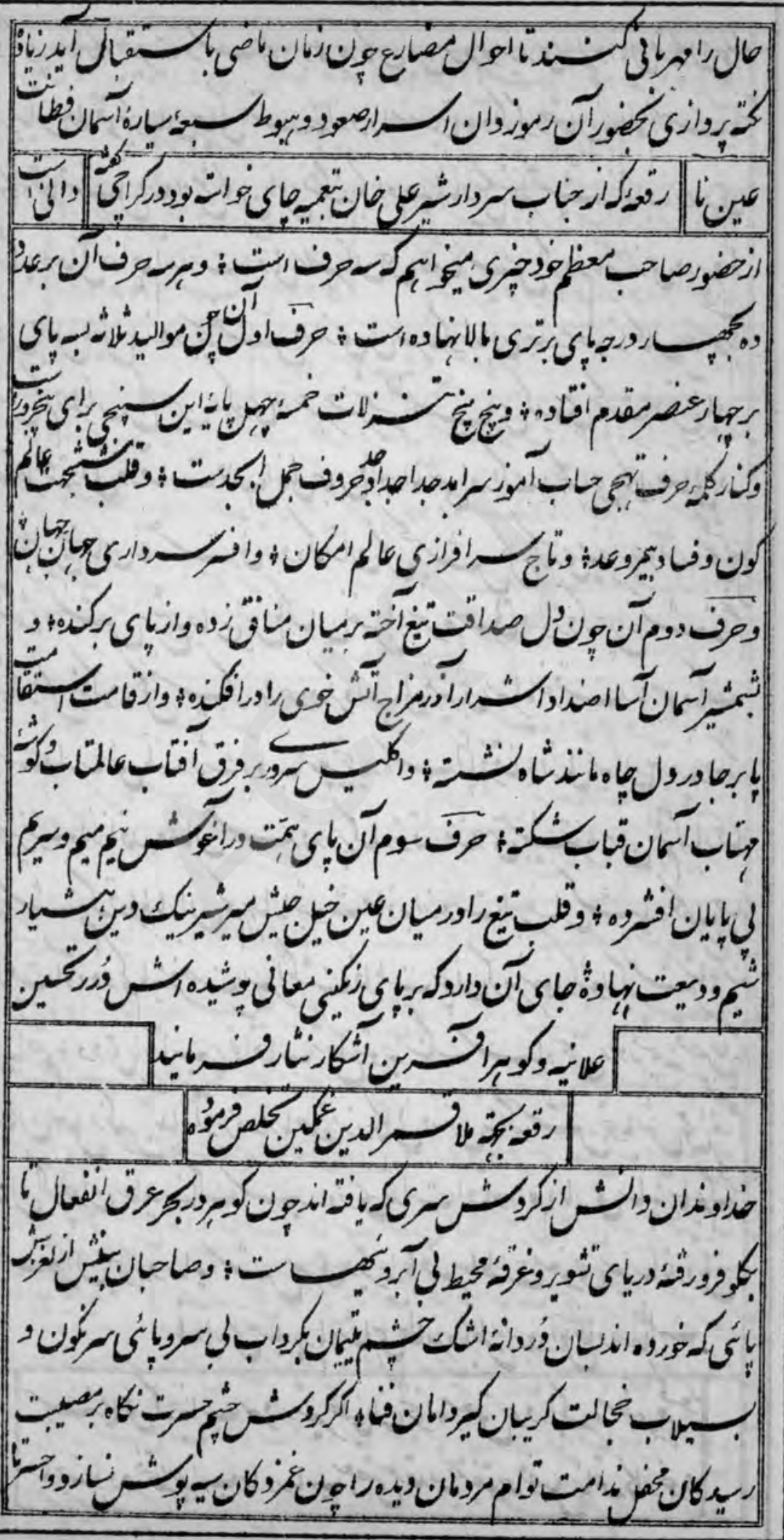




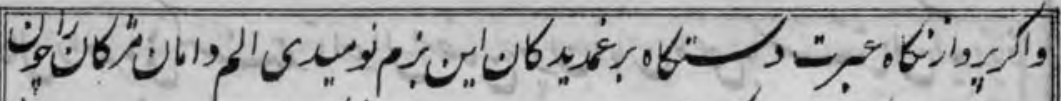
" ن

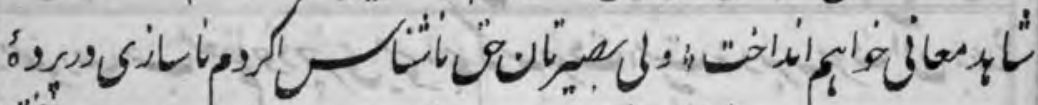

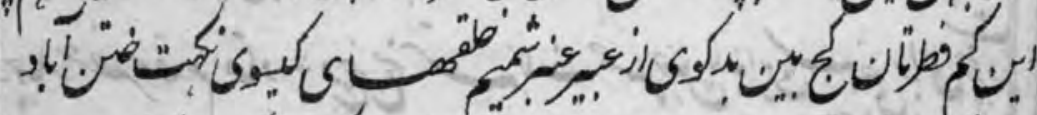

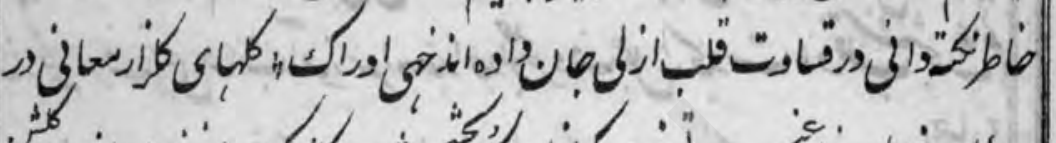

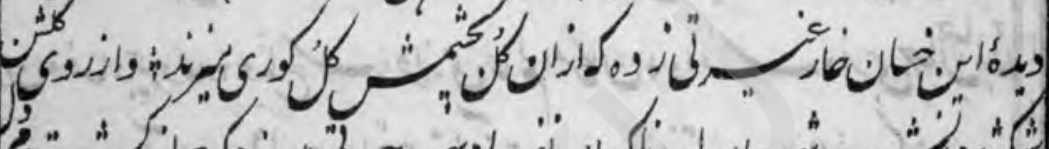

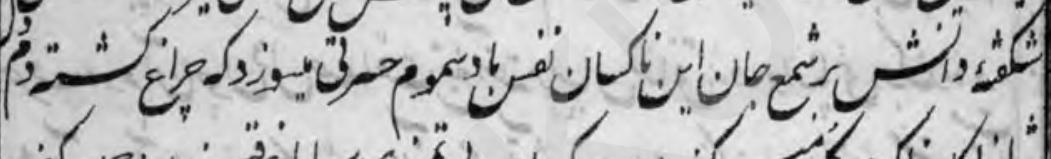

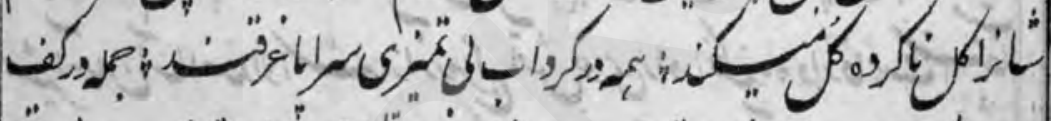
.

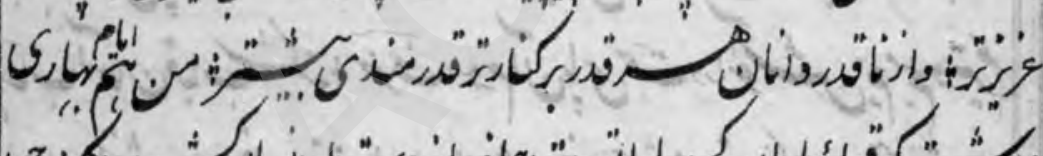

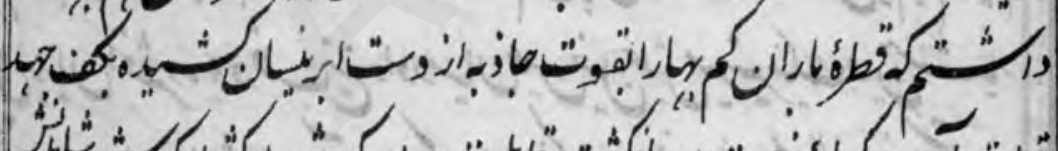

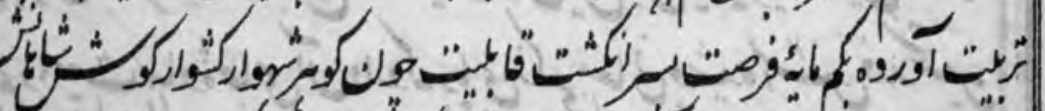

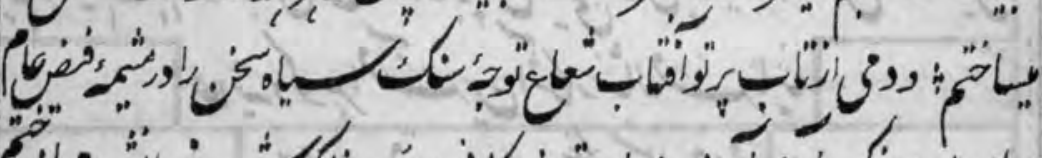

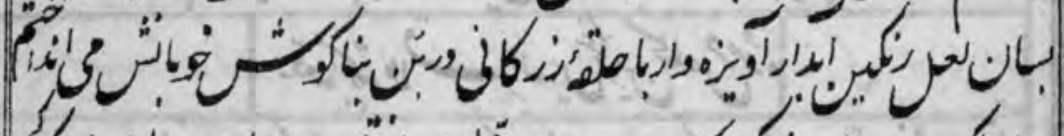
6

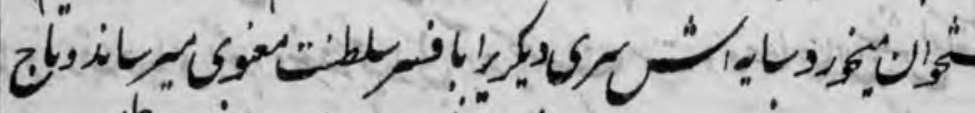
- 家"

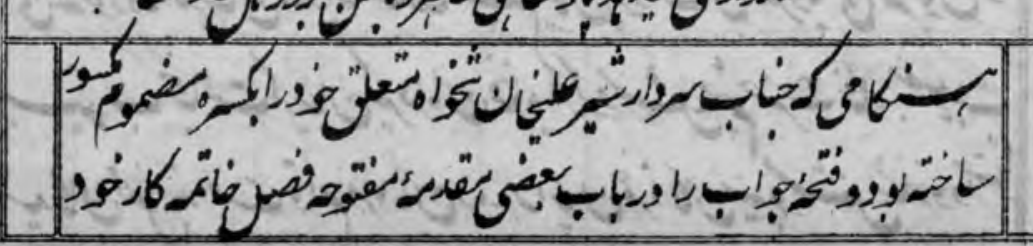


c $9 v$

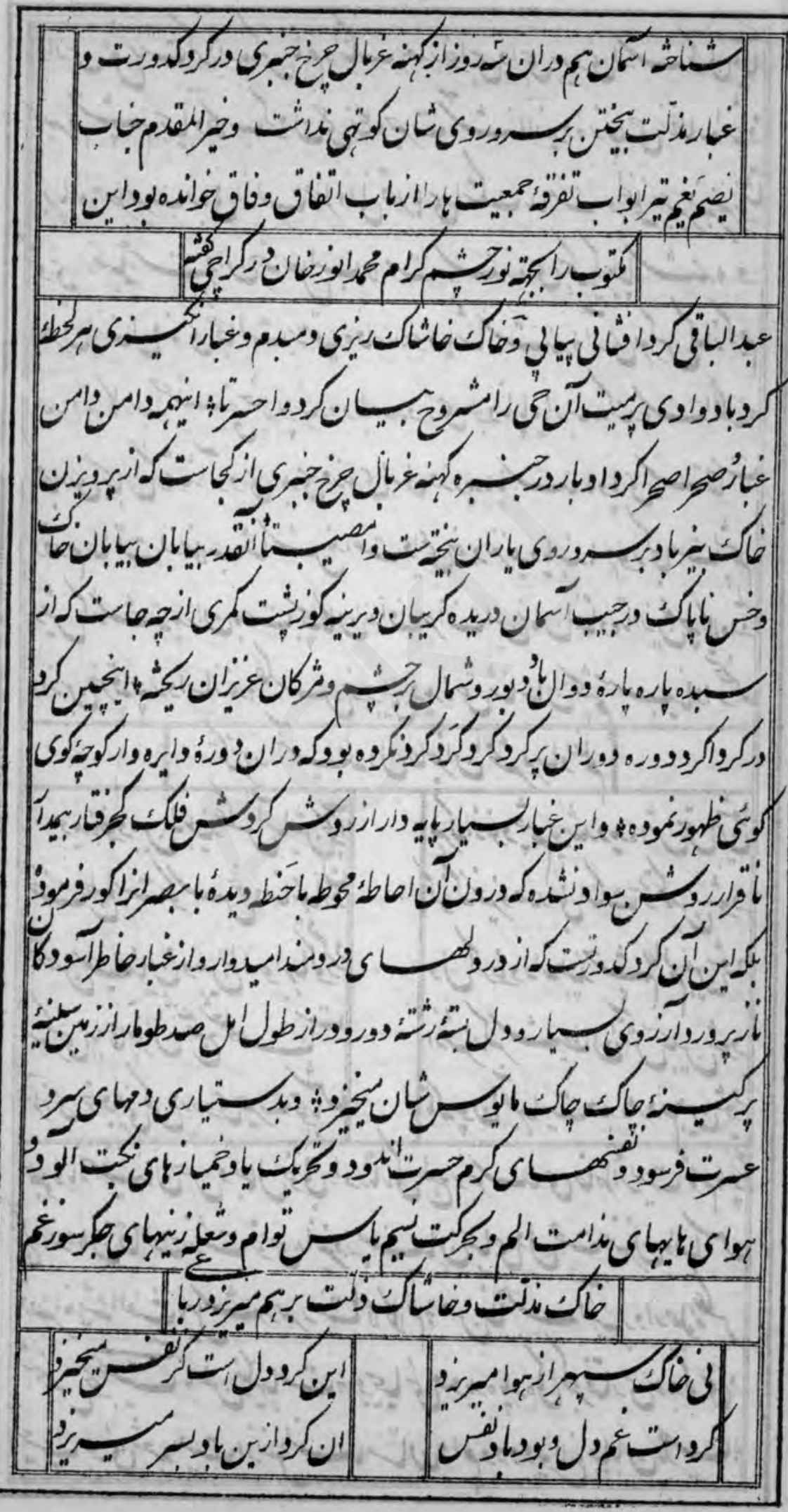




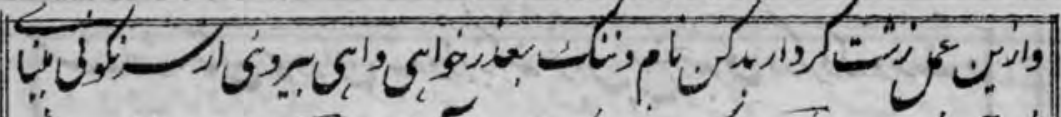

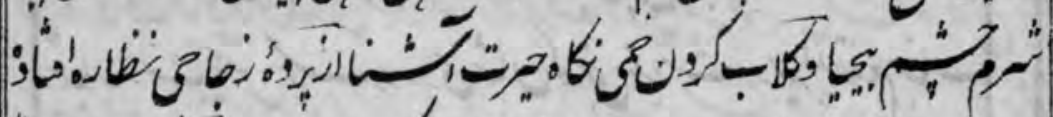

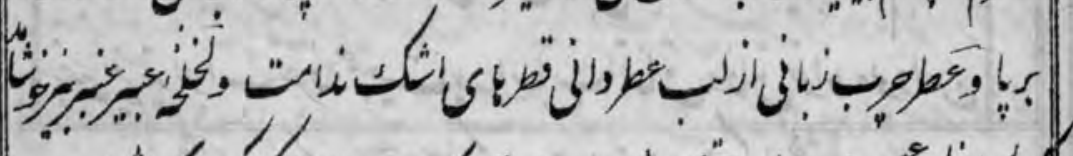

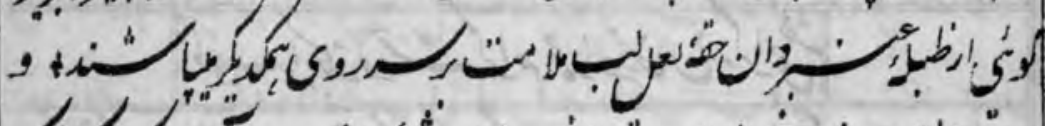

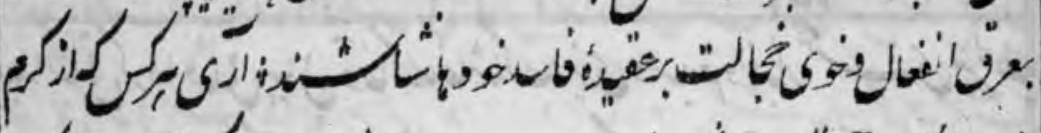

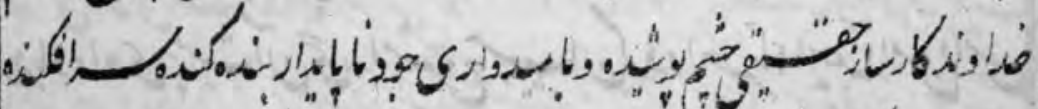

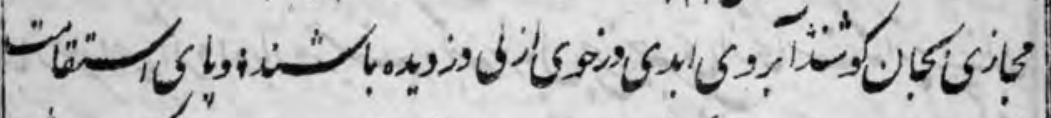

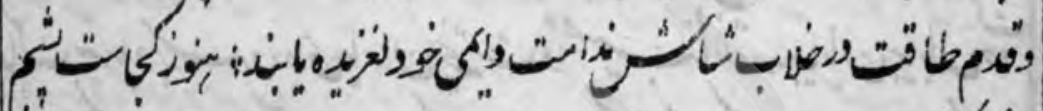

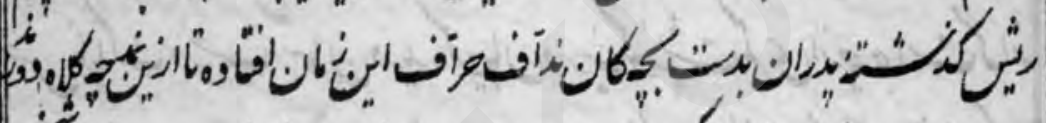

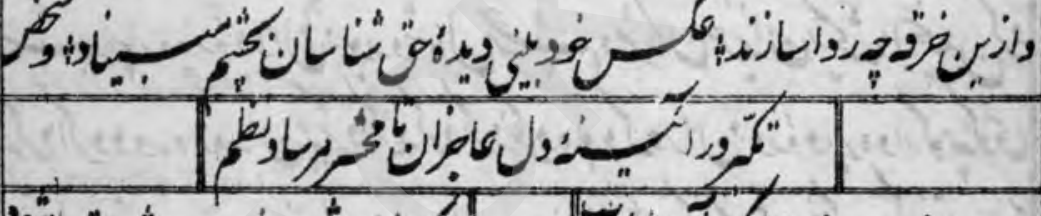

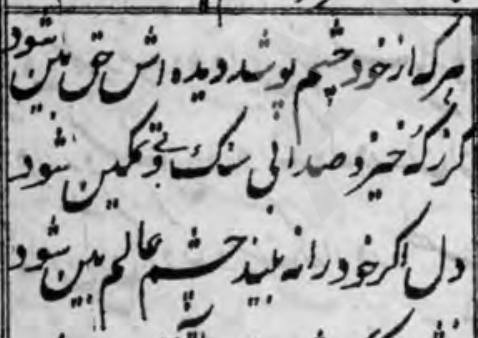

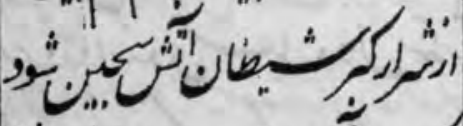

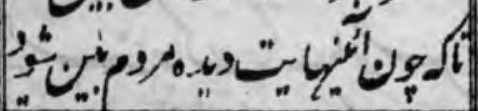
1 ". ( تح

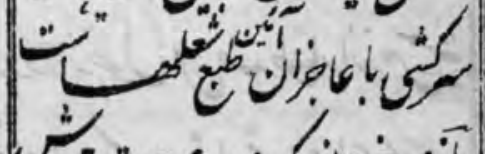
宊

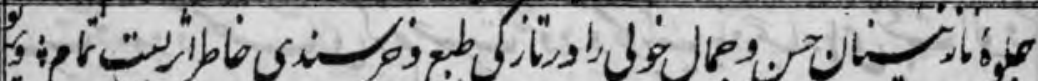

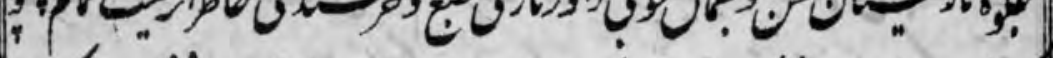

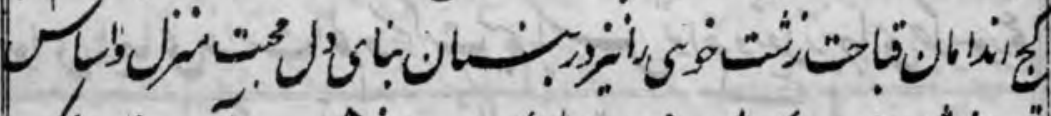

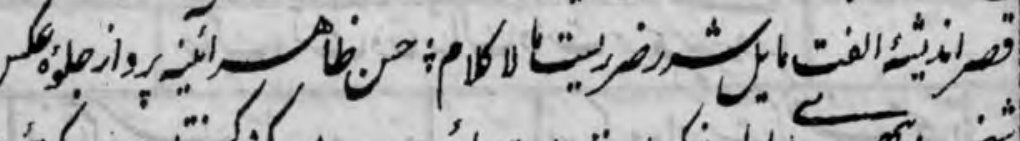

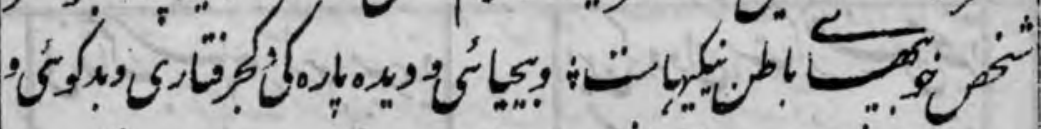

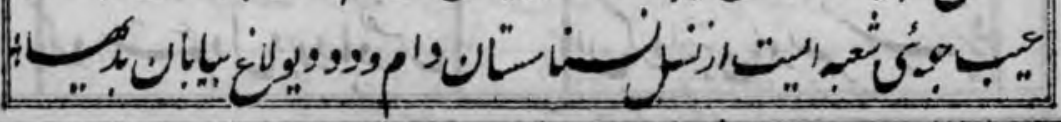


19

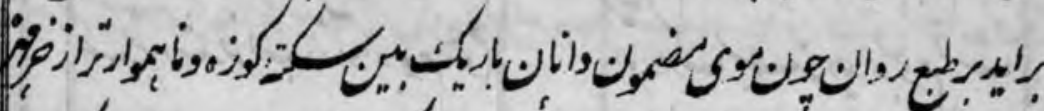

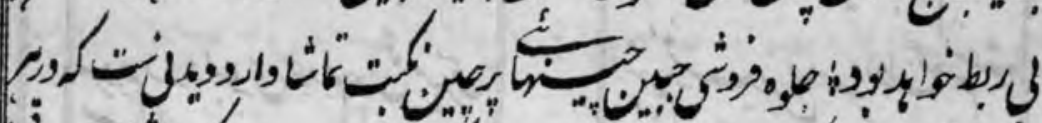

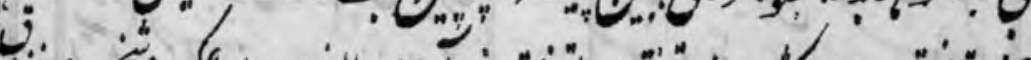

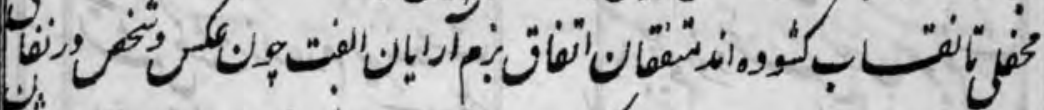

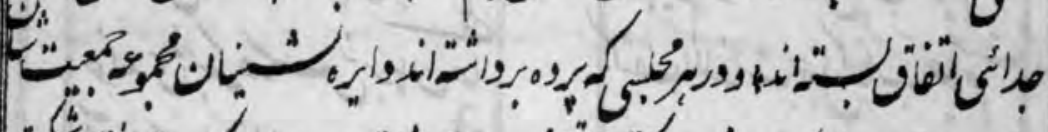

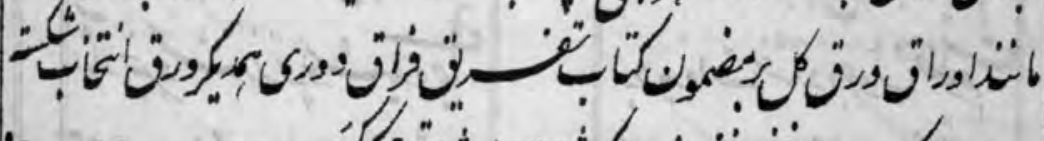

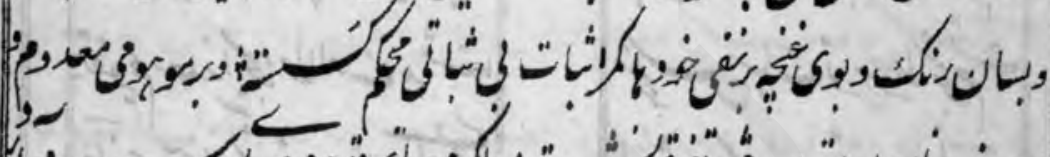

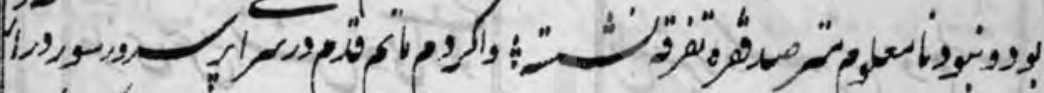

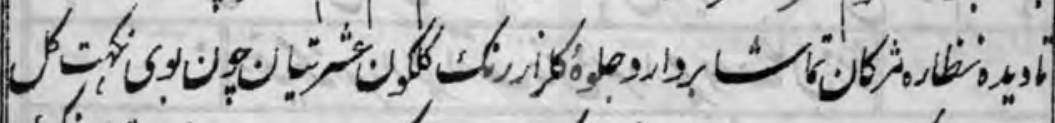

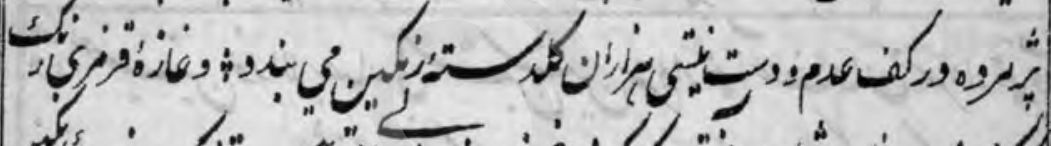

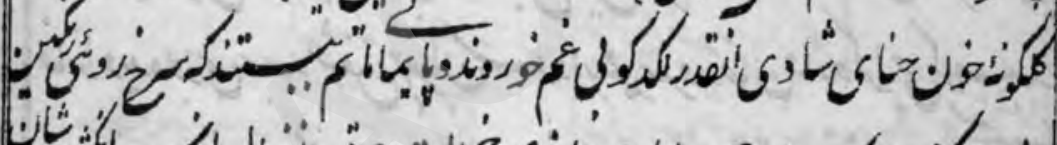

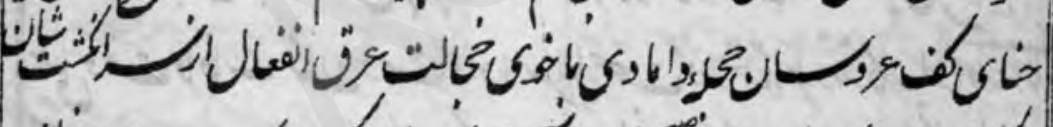

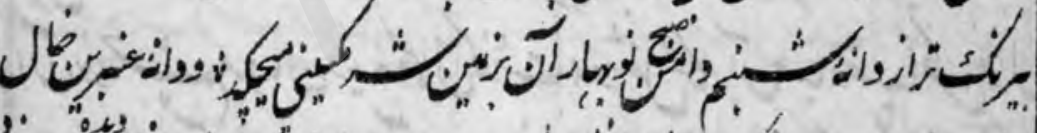

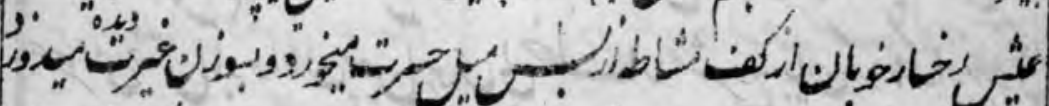

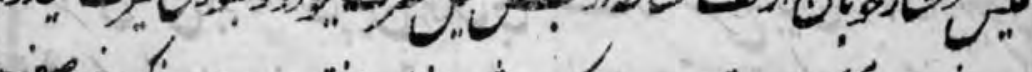

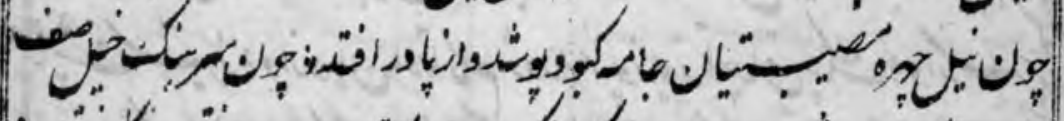

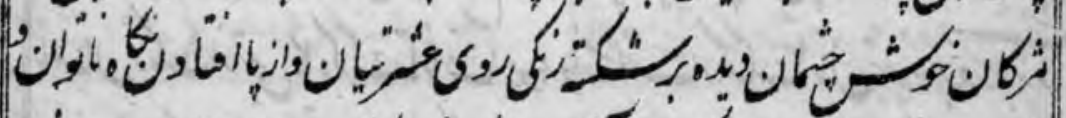

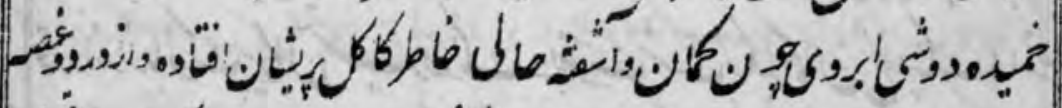

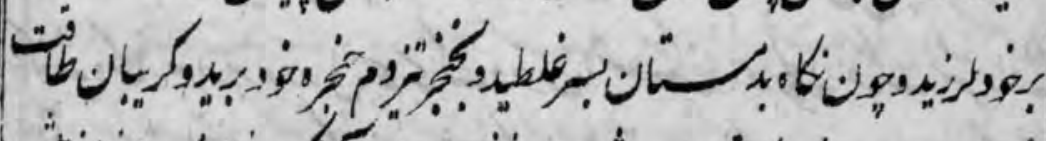

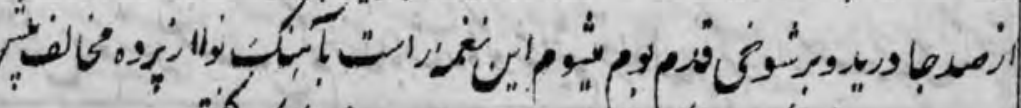

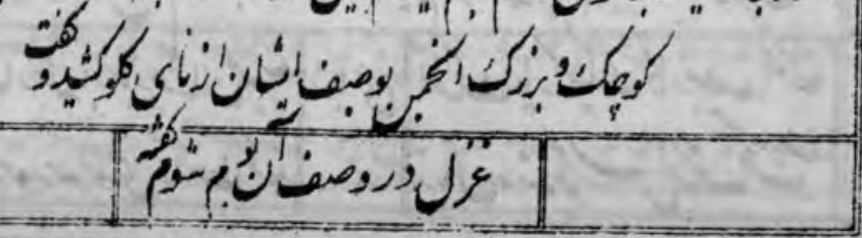


$v+1$

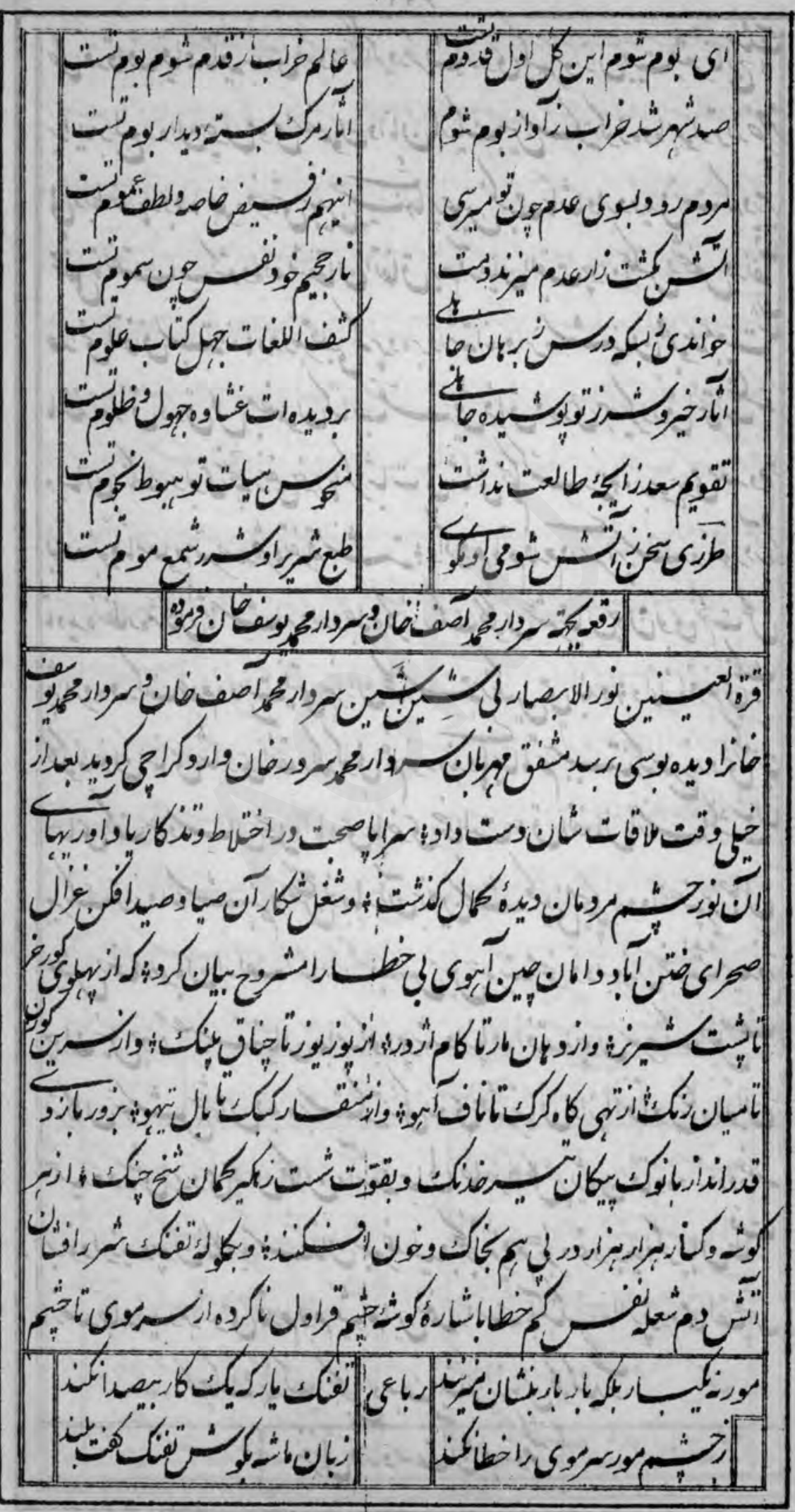


(2) ip

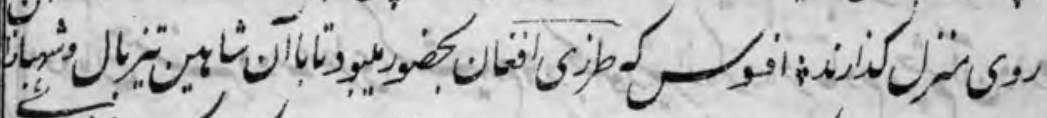

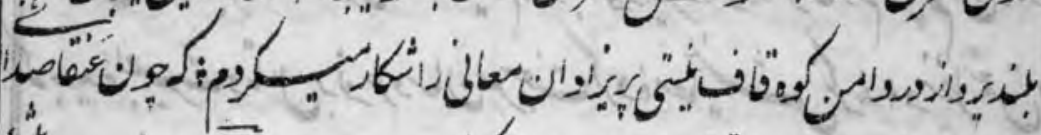

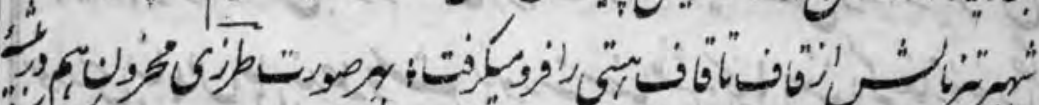
ris

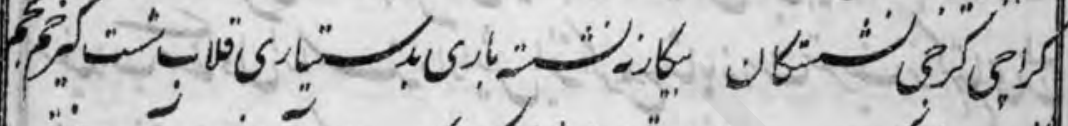

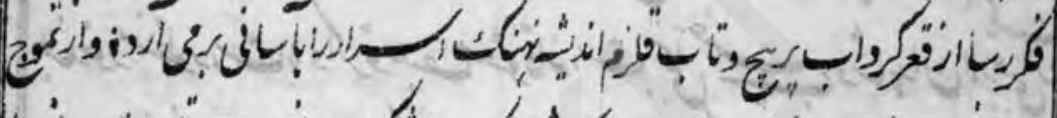

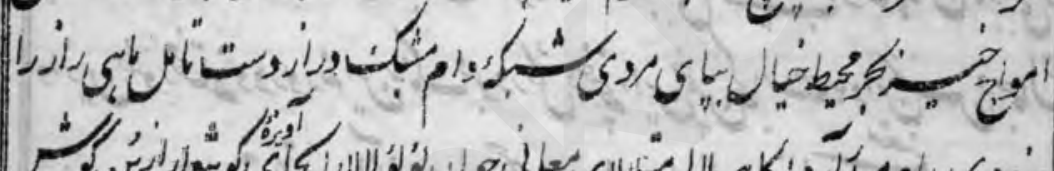

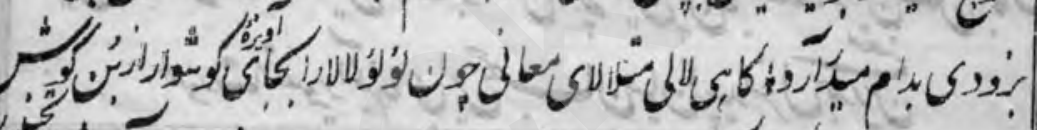
Fon 2. . . . !

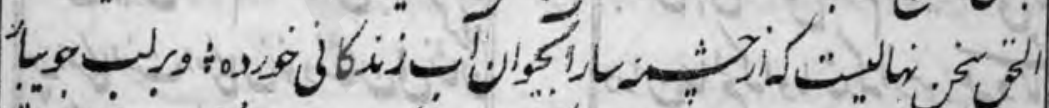

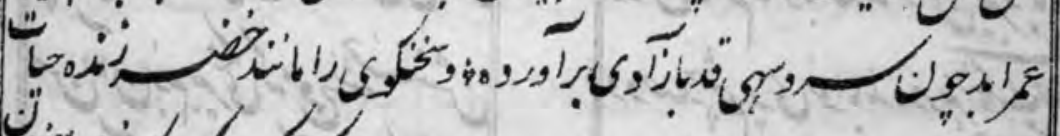
年

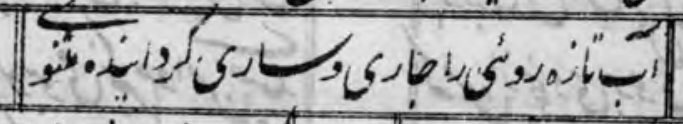
i

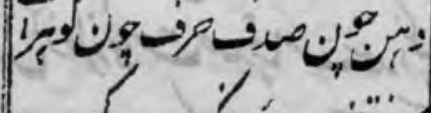
त) y uligh in

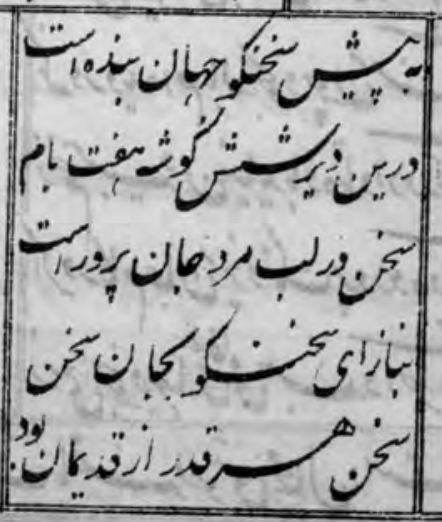




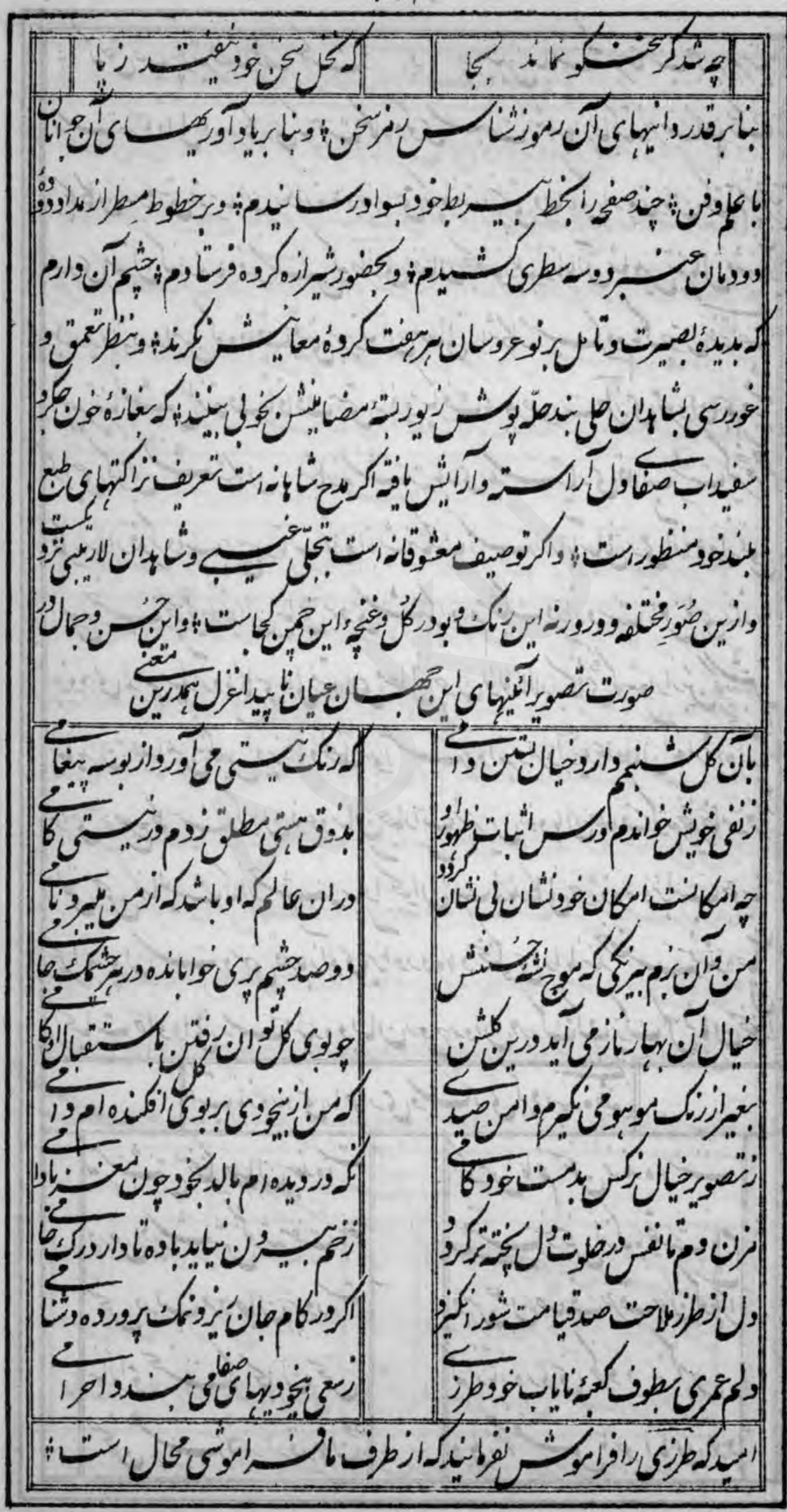


$v \cdot r$

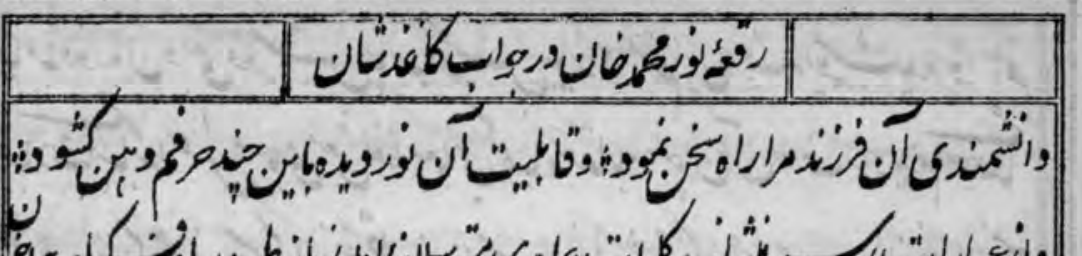

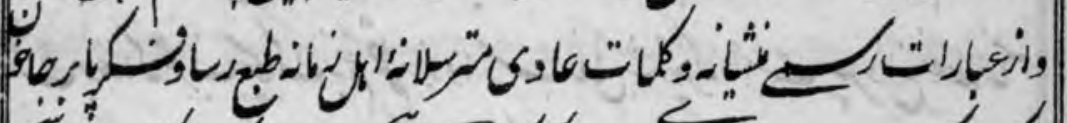
F" "Eg

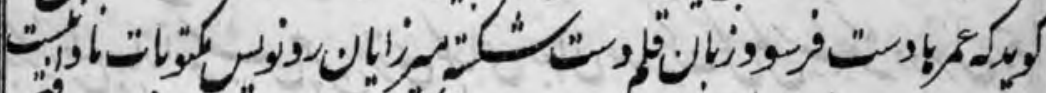

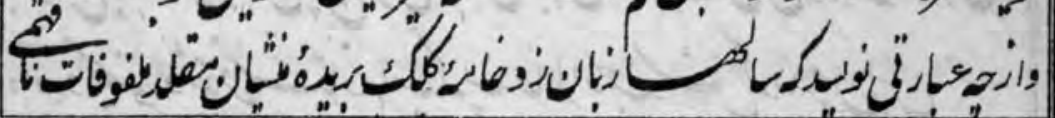

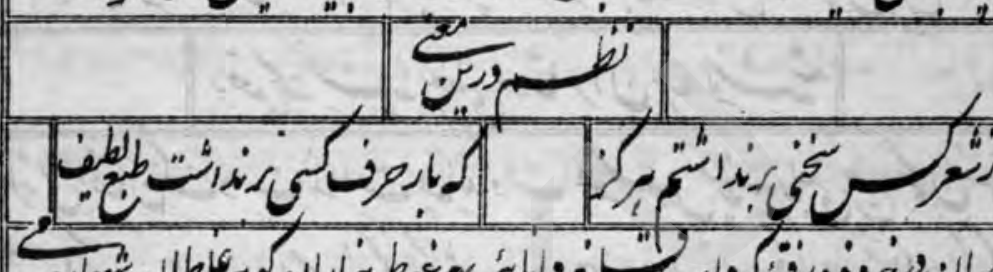
:

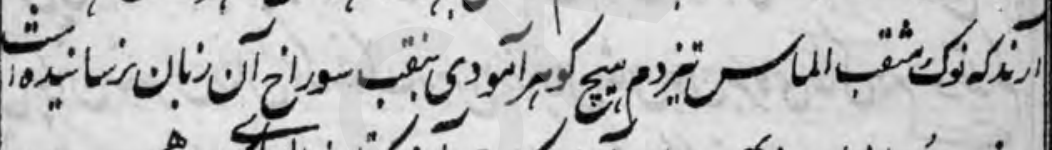

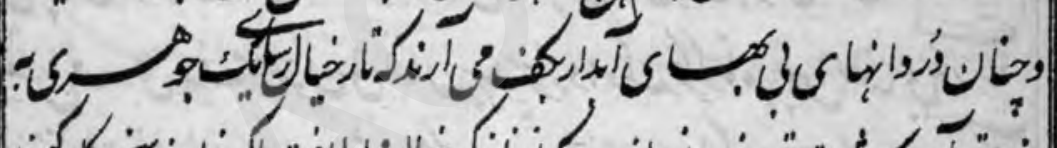

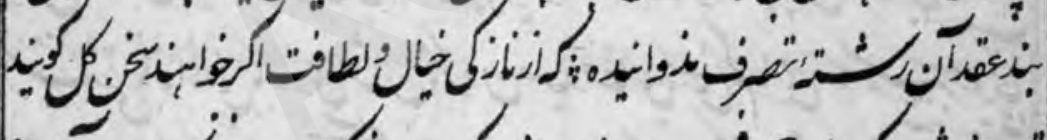

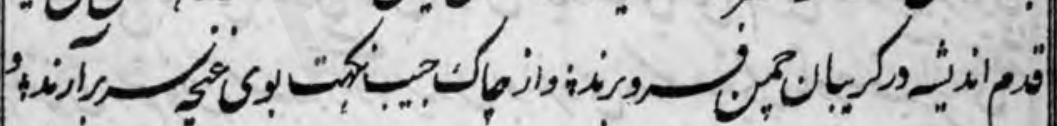
لير

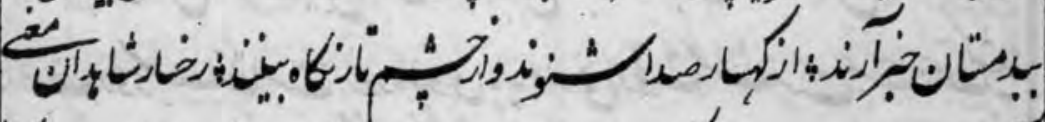

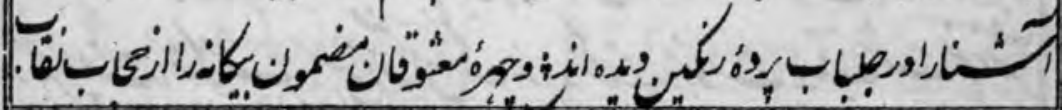
$\mid$\begin{tabular}{|c|c|c|}
\hline & 0 \\
\hline
\end{tabular} 
V.

| -

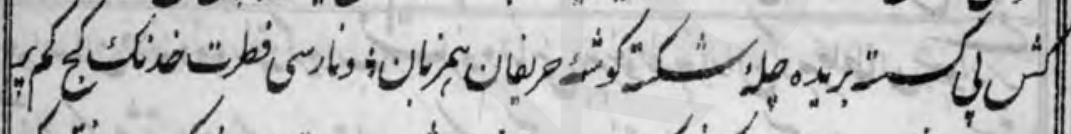
ن L ت (i)

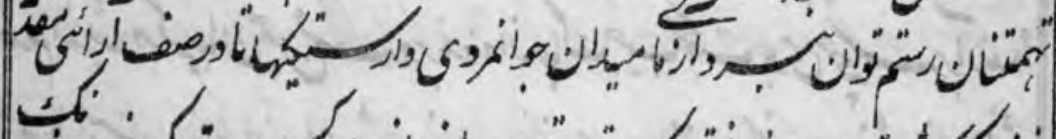

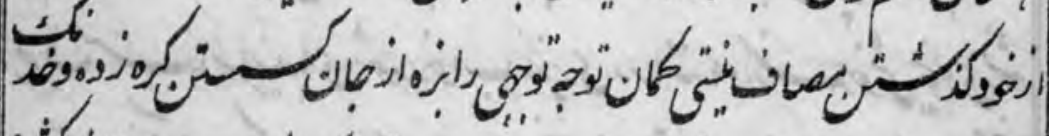

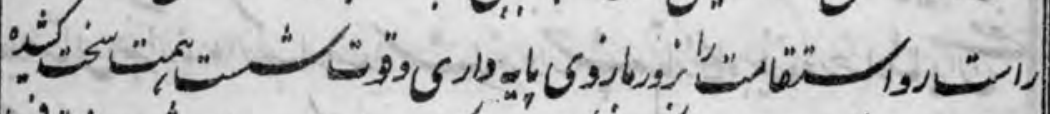

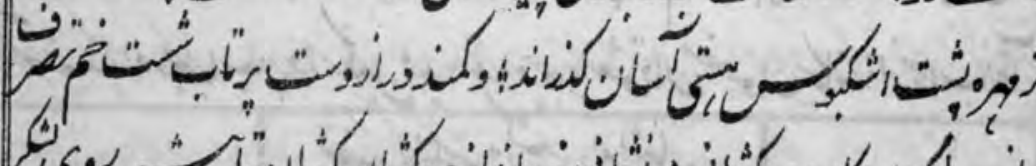

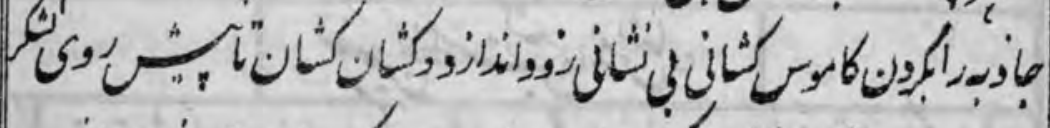
روبو 年

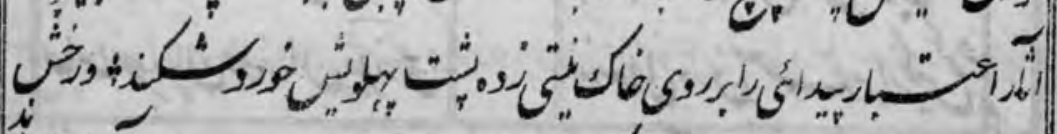

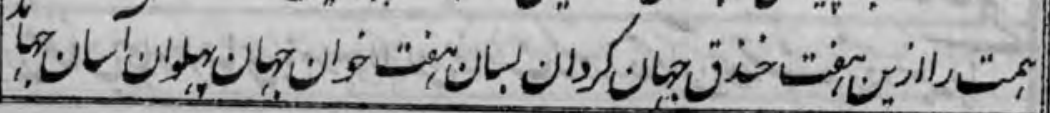


$V \cdot \Delta$

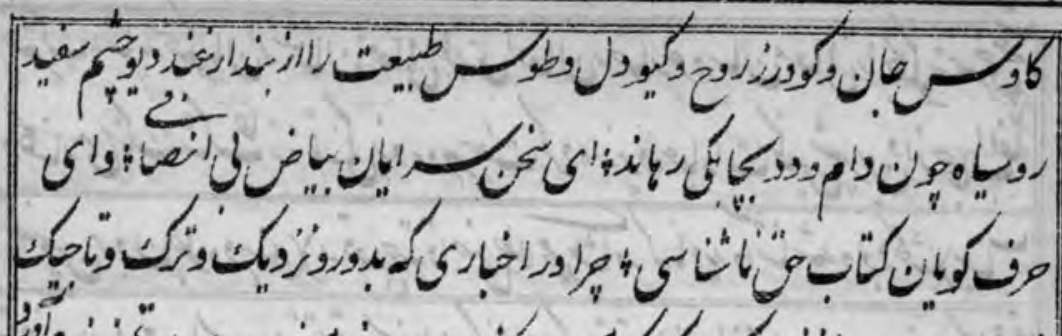

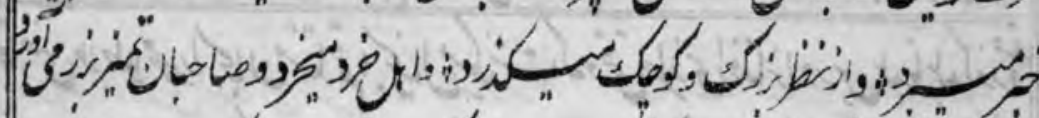
i. (1) 年

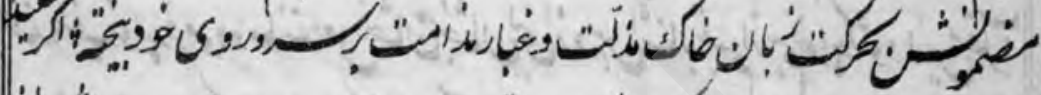
然

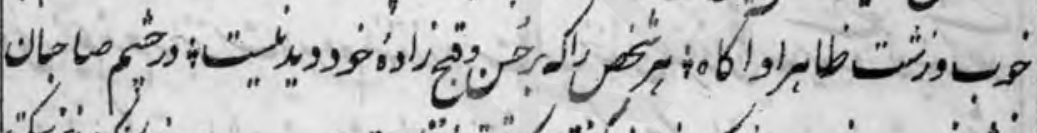

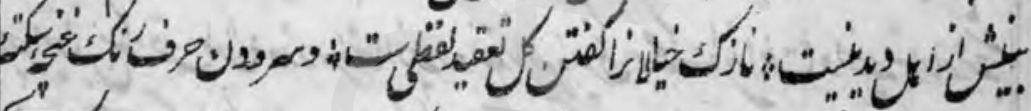
年

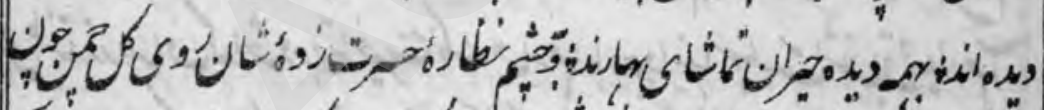

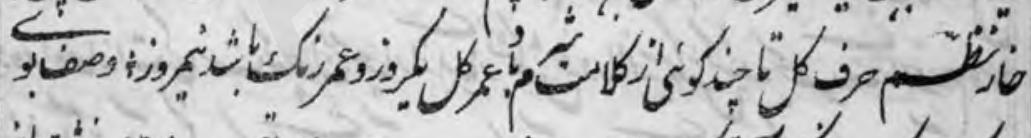

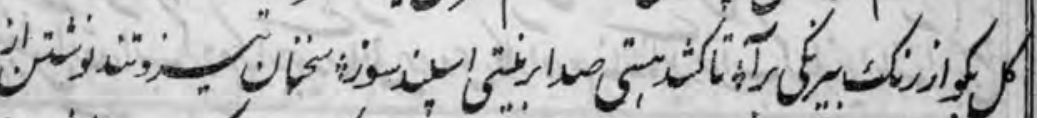
1. 1

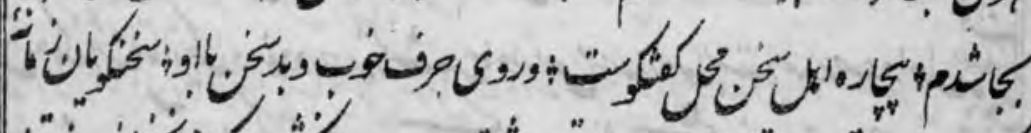

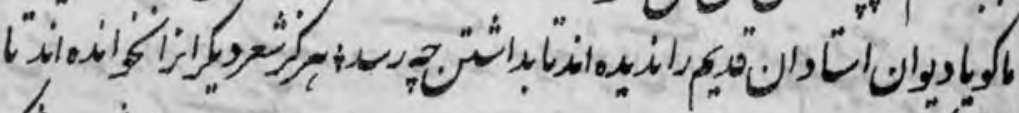
(4)

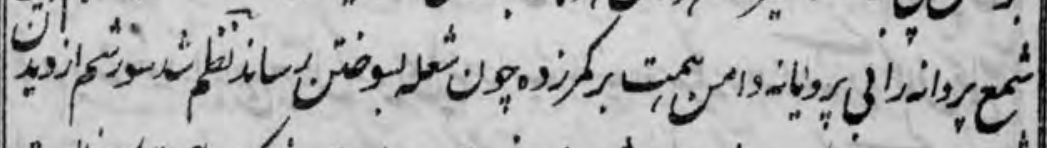
- ne 
$v \cdot s$

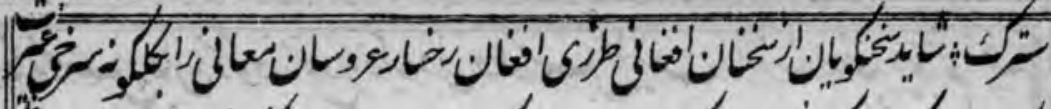

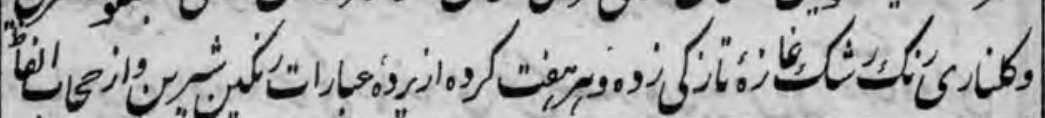
-

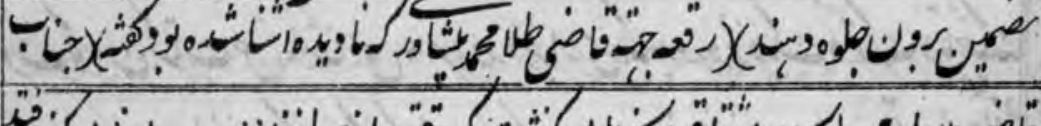

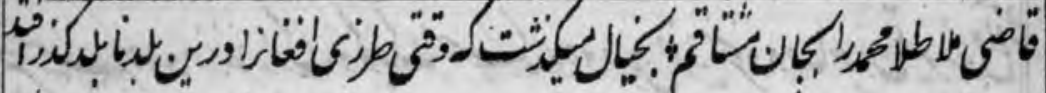

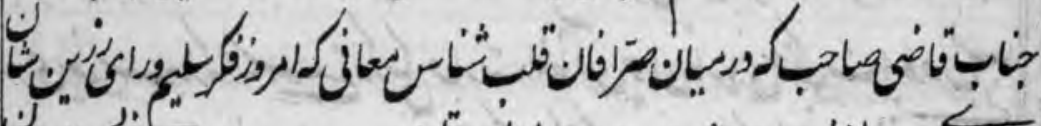

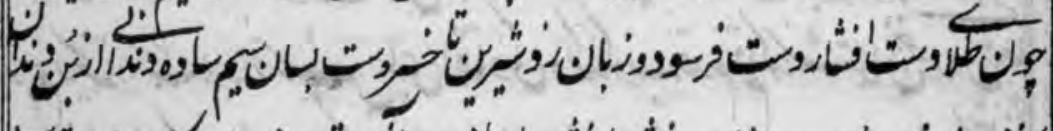

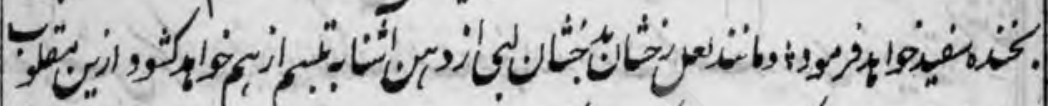

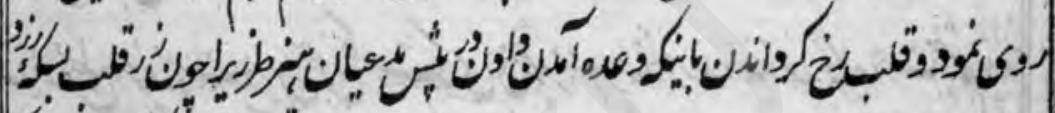
-

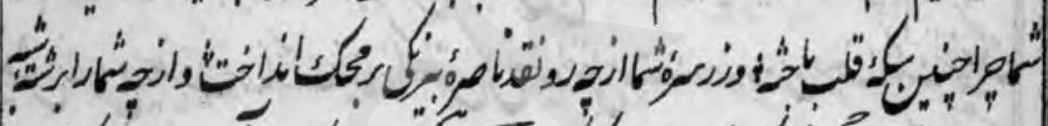

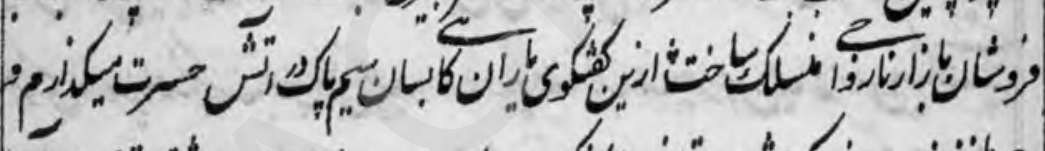
وق

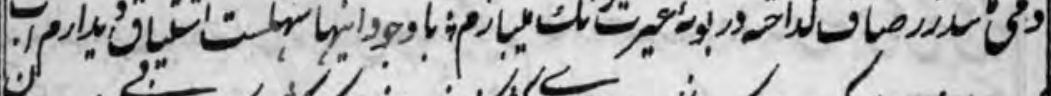

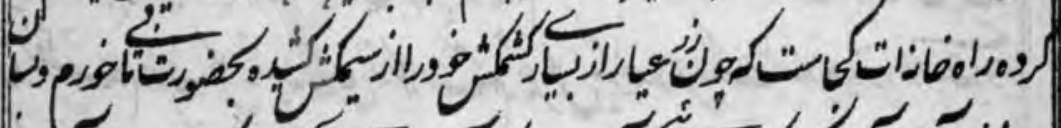

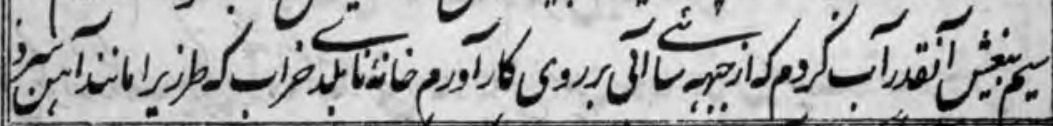

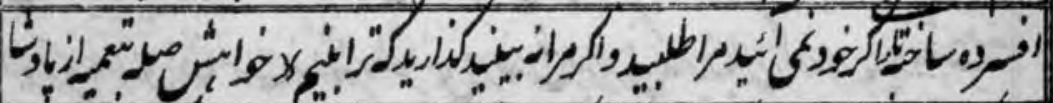

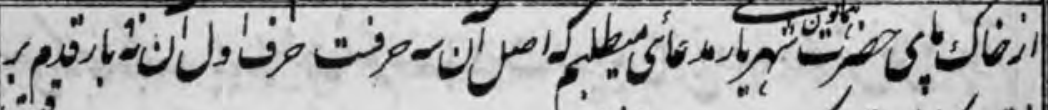

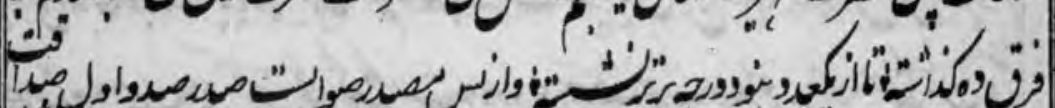
وט

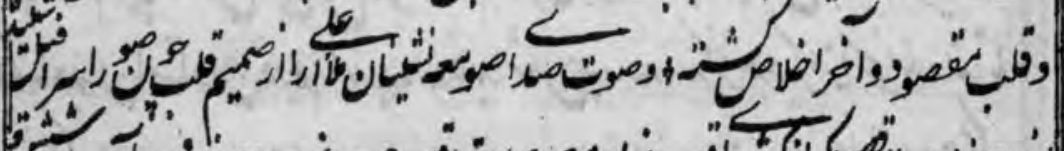
|

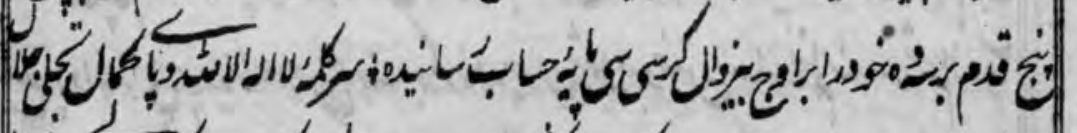

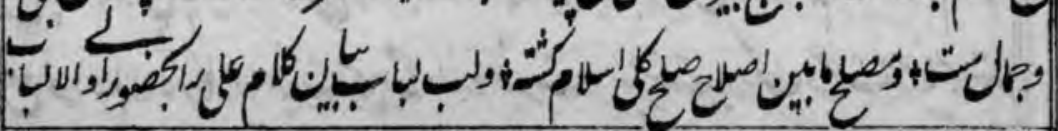


Five 60 Pus

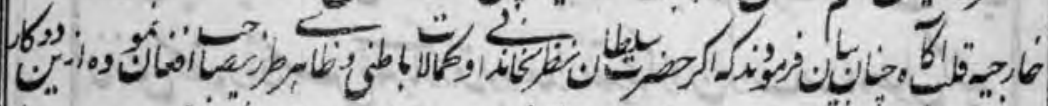
政

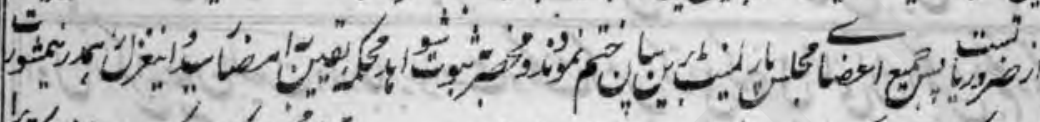
ond for Don

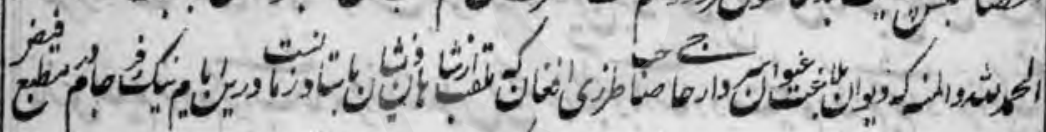

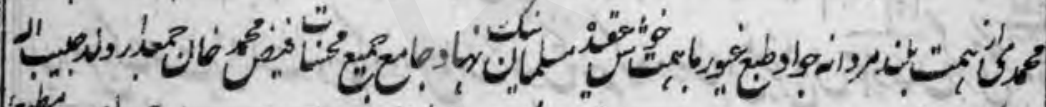

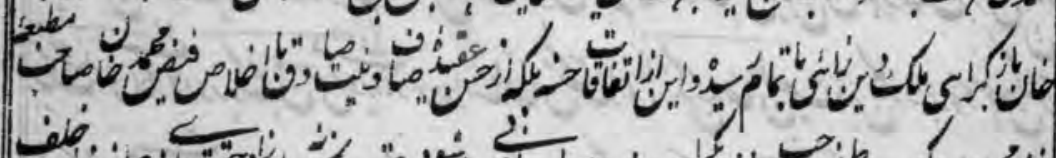

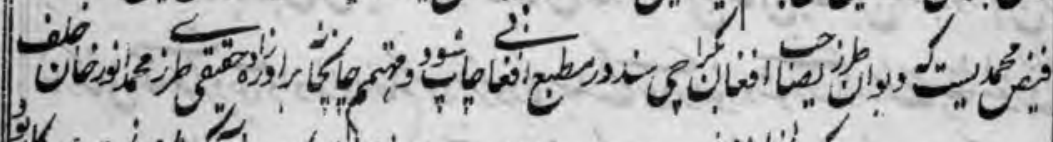

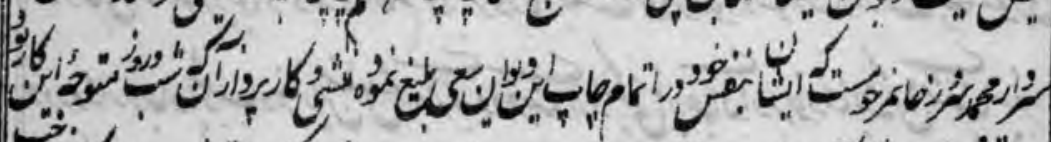
8 解

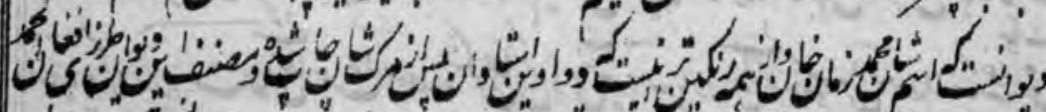

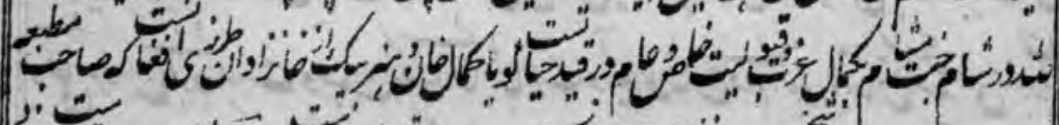
wey

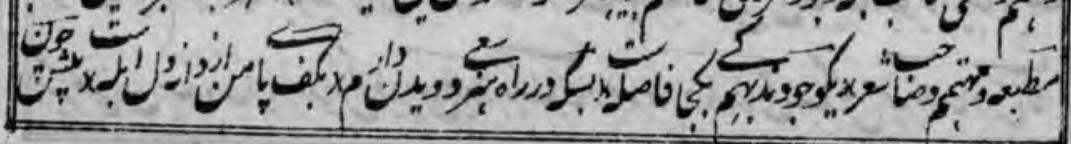

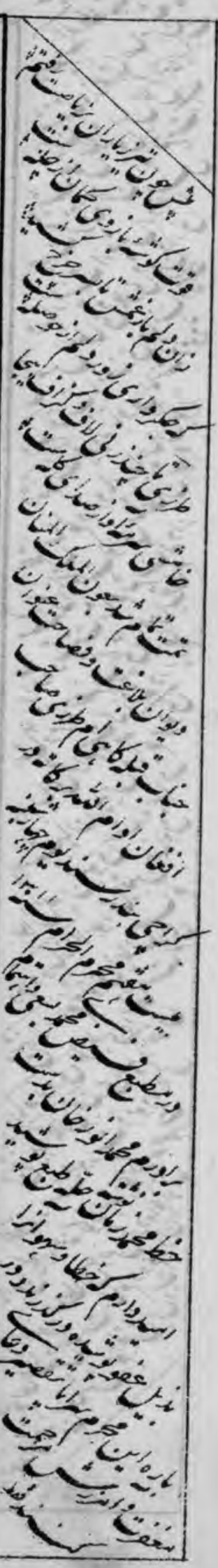




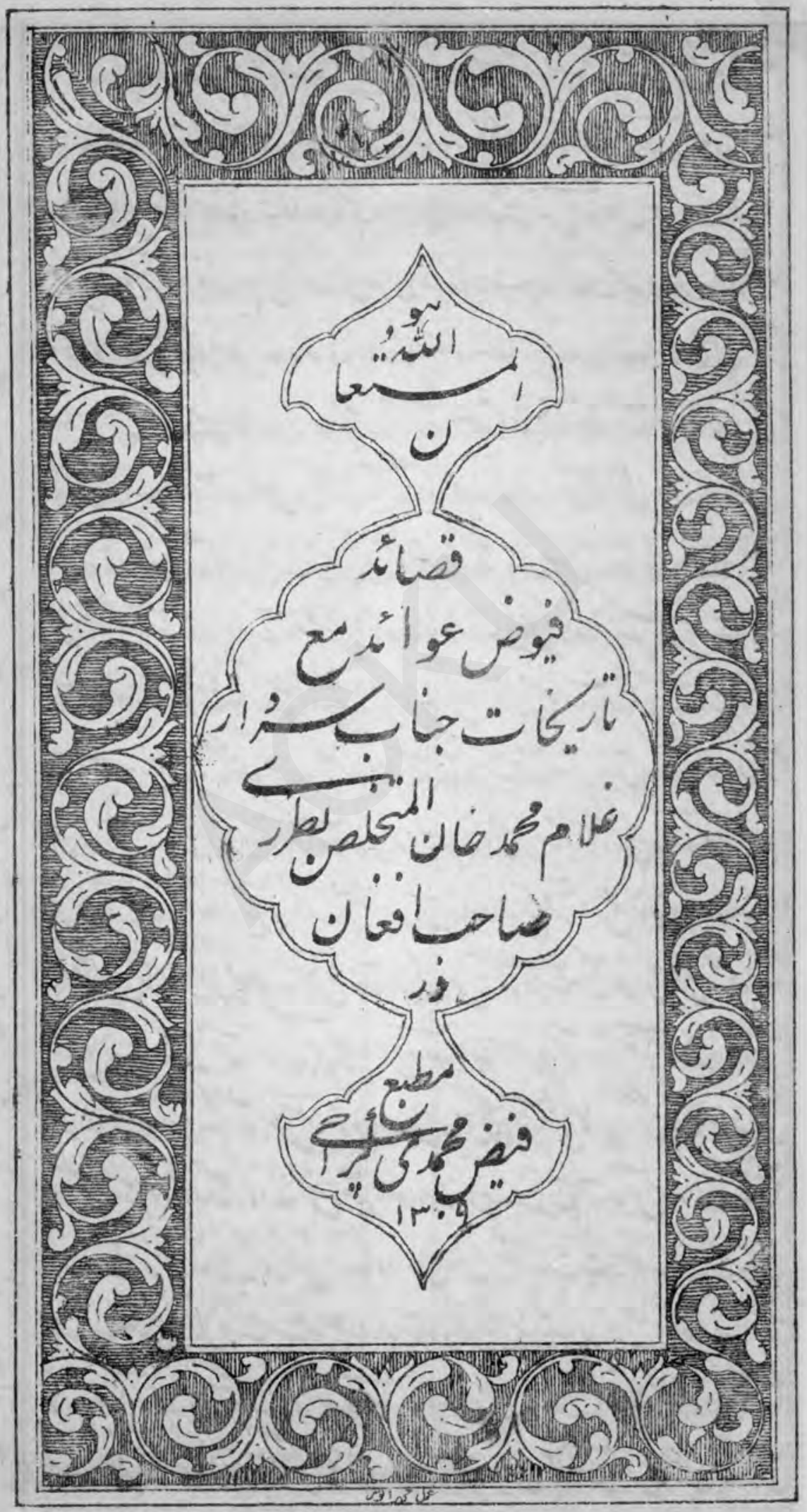




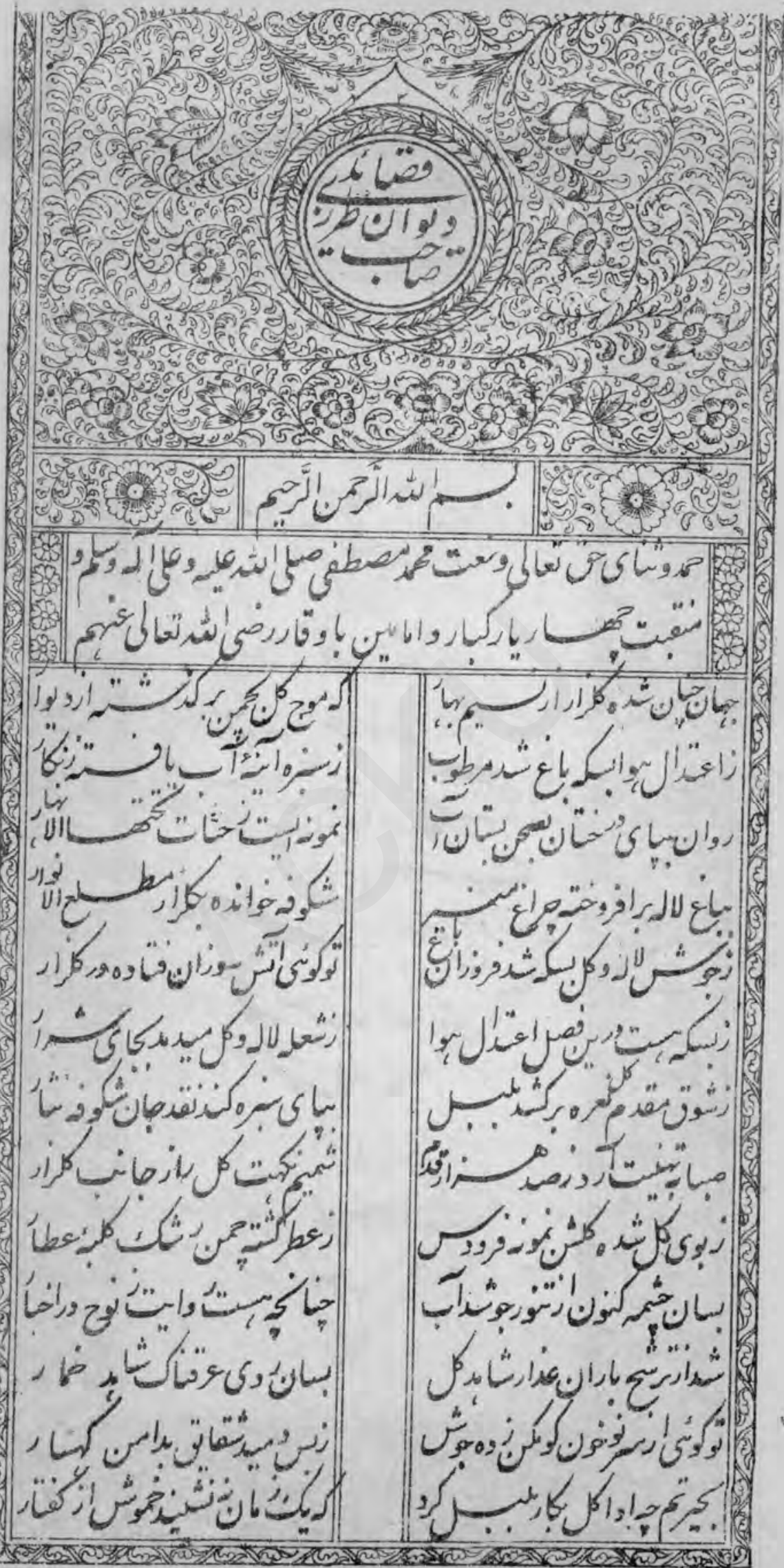


$r$

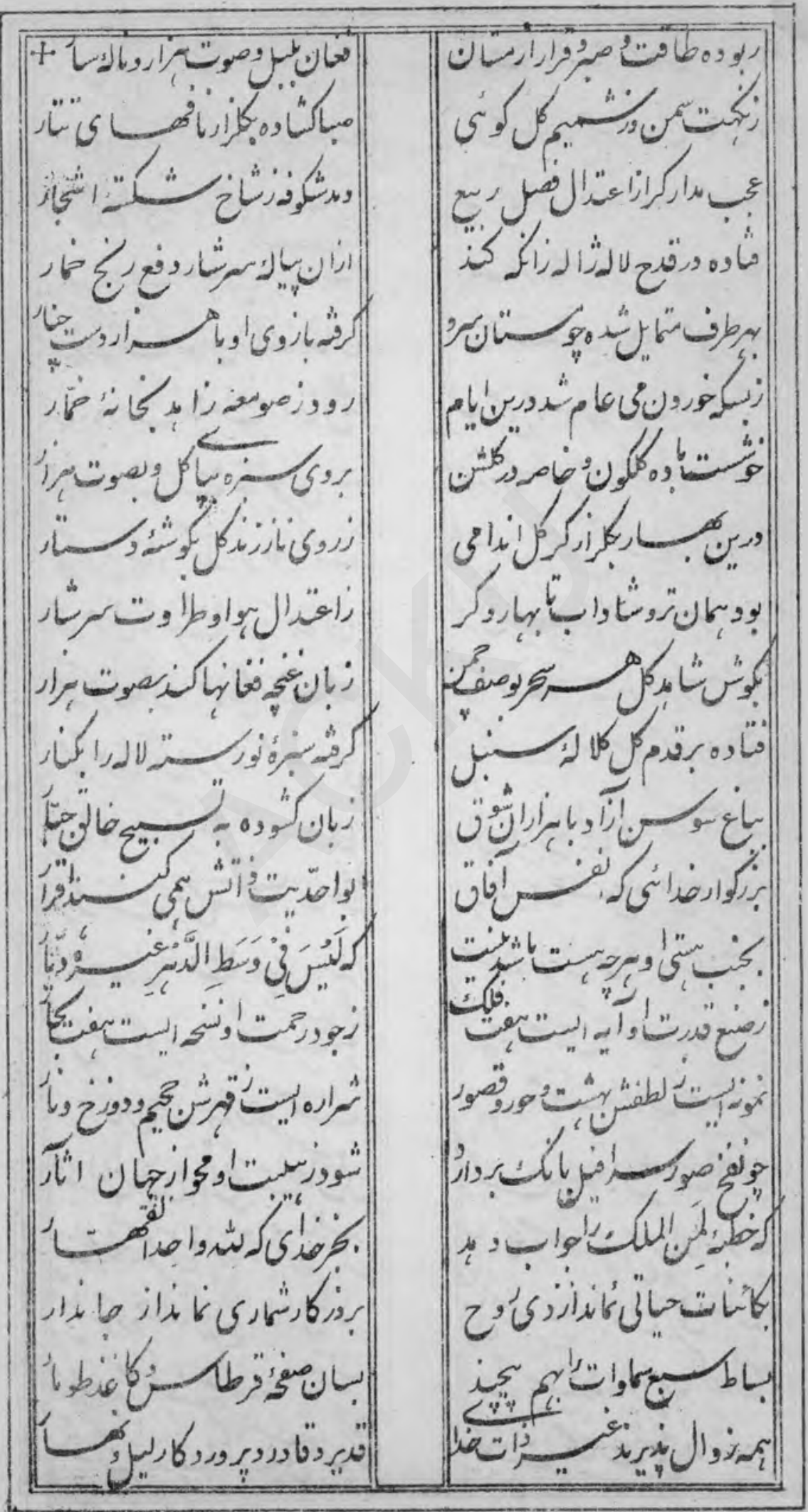




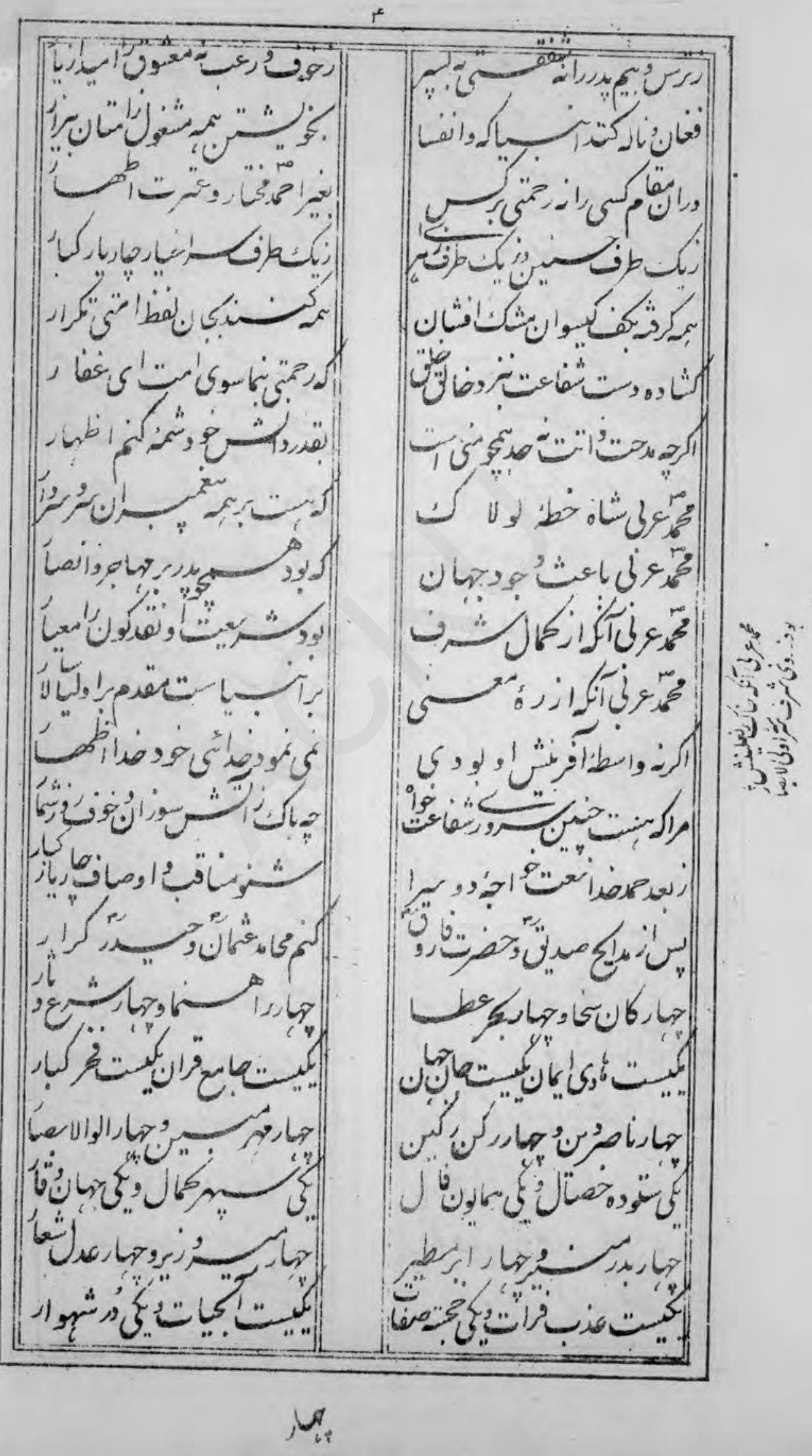




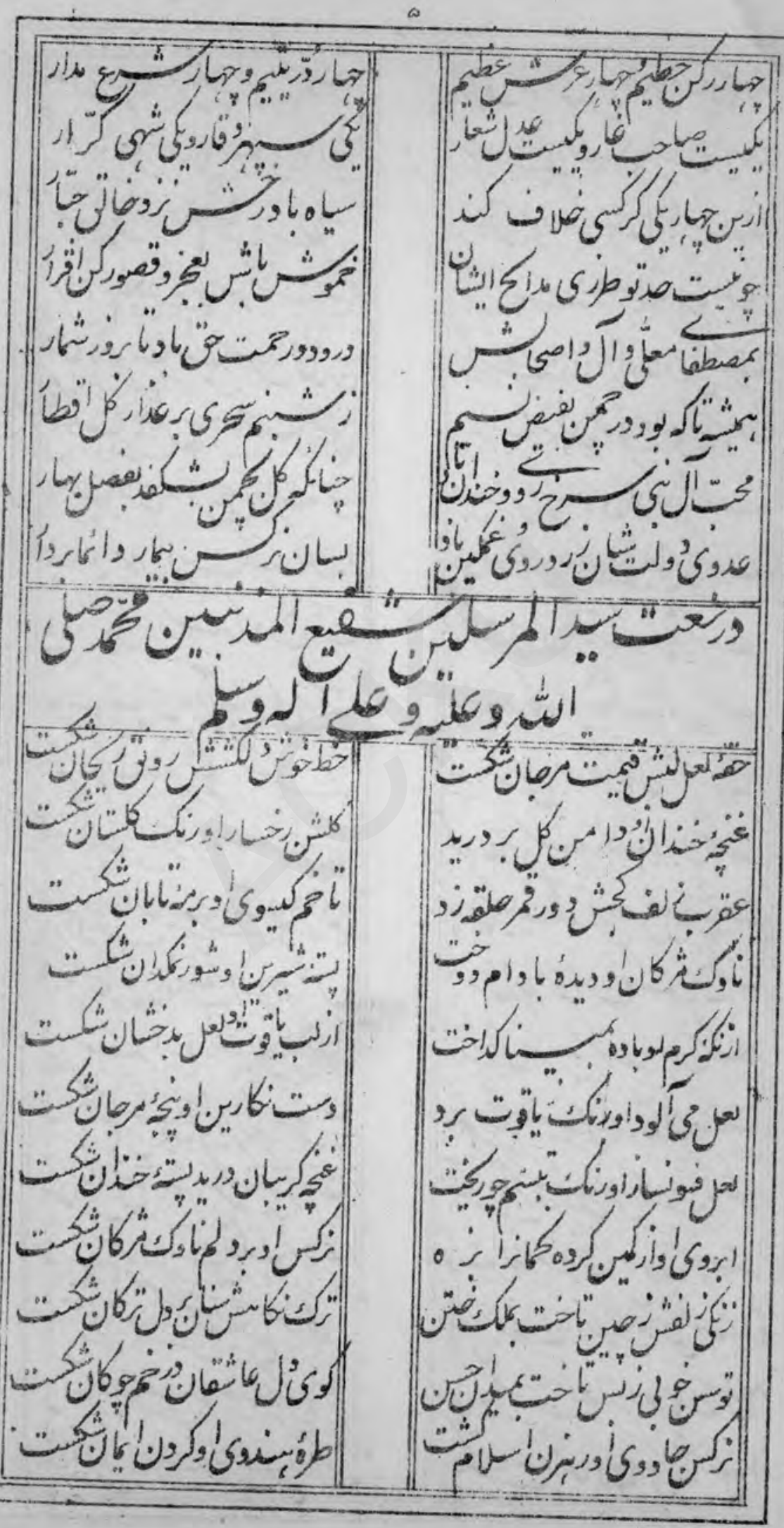


$s$

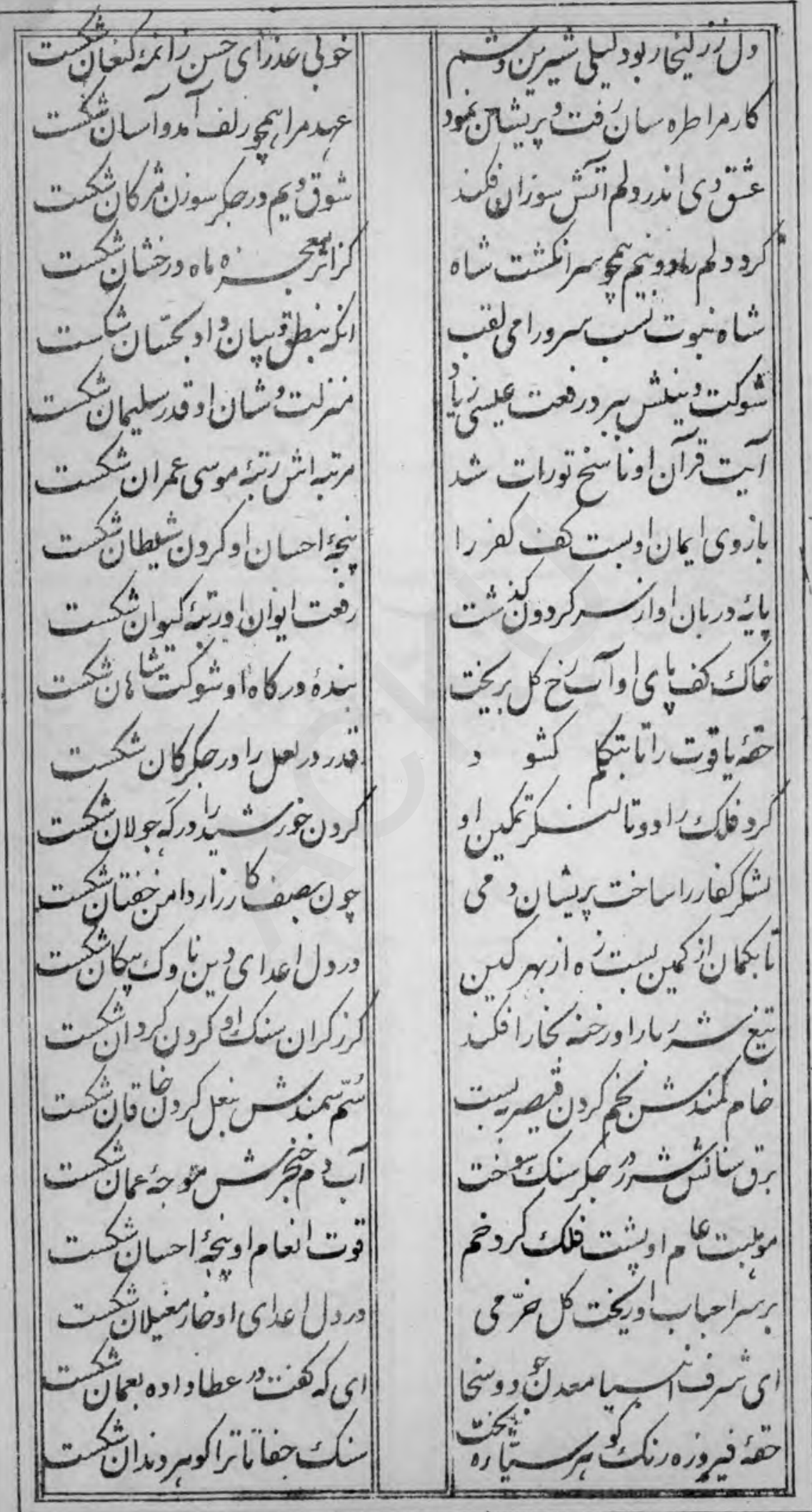




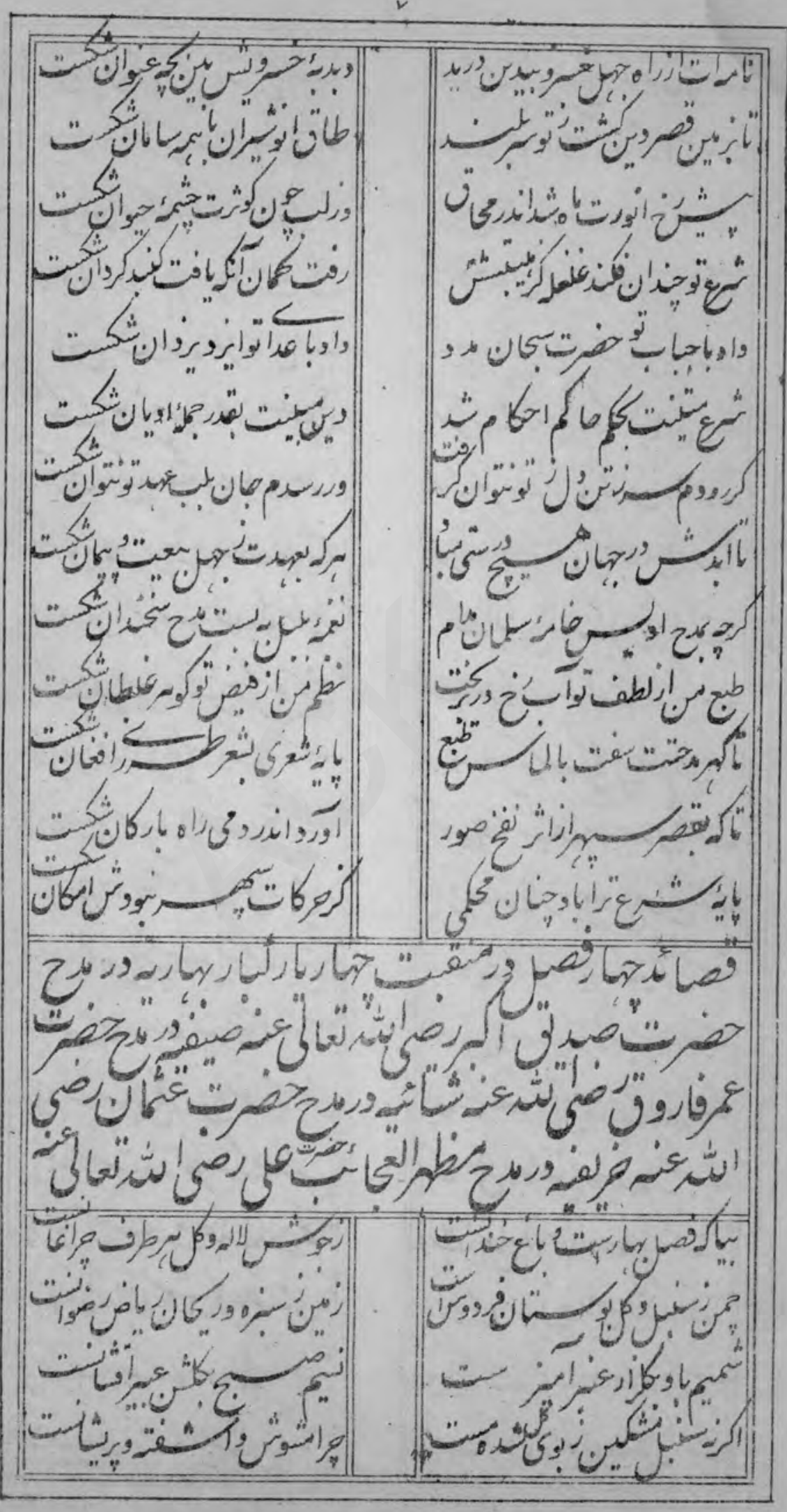


$A$

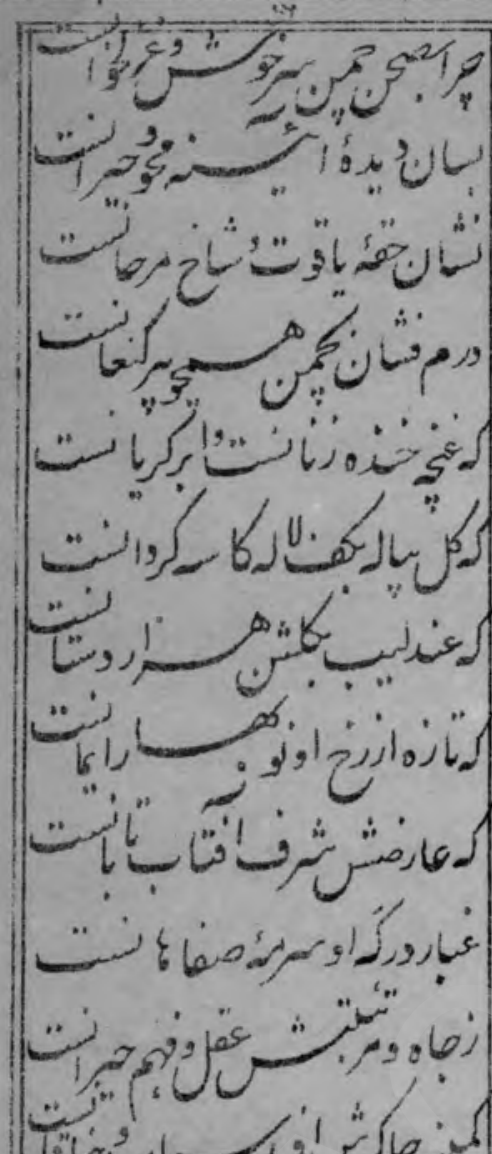

政

"

(2)

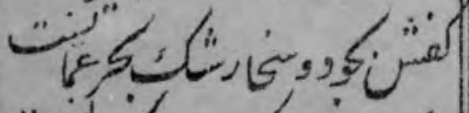

بn ل

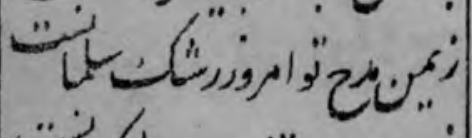

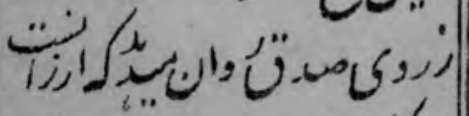

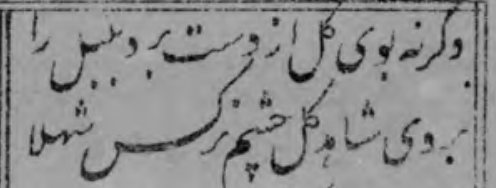

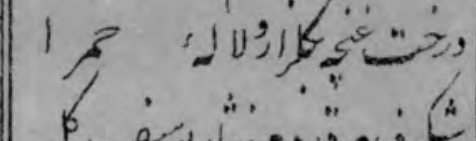
$\int 0$ os

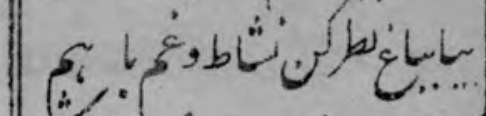
Uو

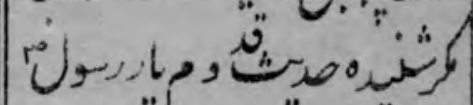

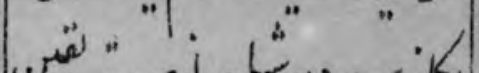

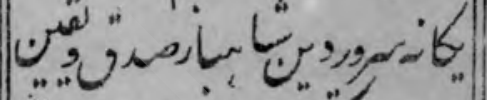

إن

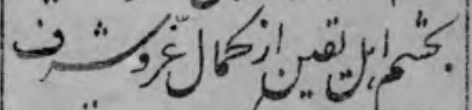
-

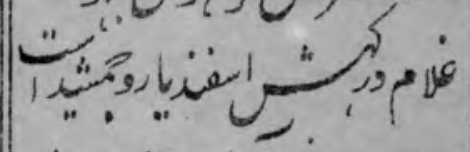

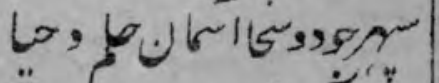

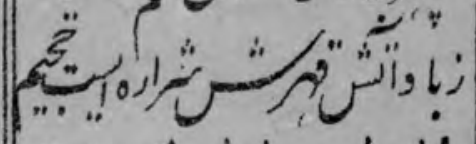

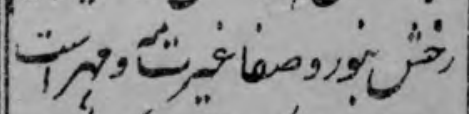

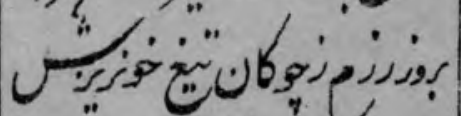
".,.." 7 1/

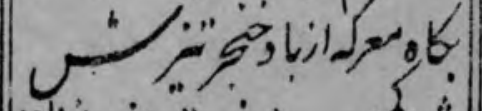
ن

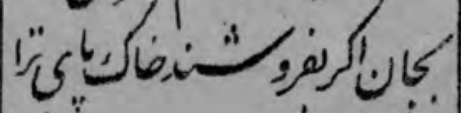

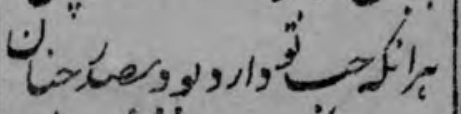
/1/

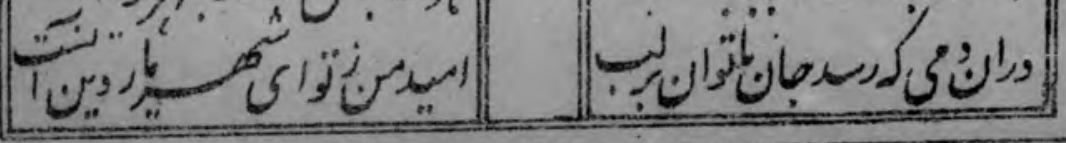




\section{4}

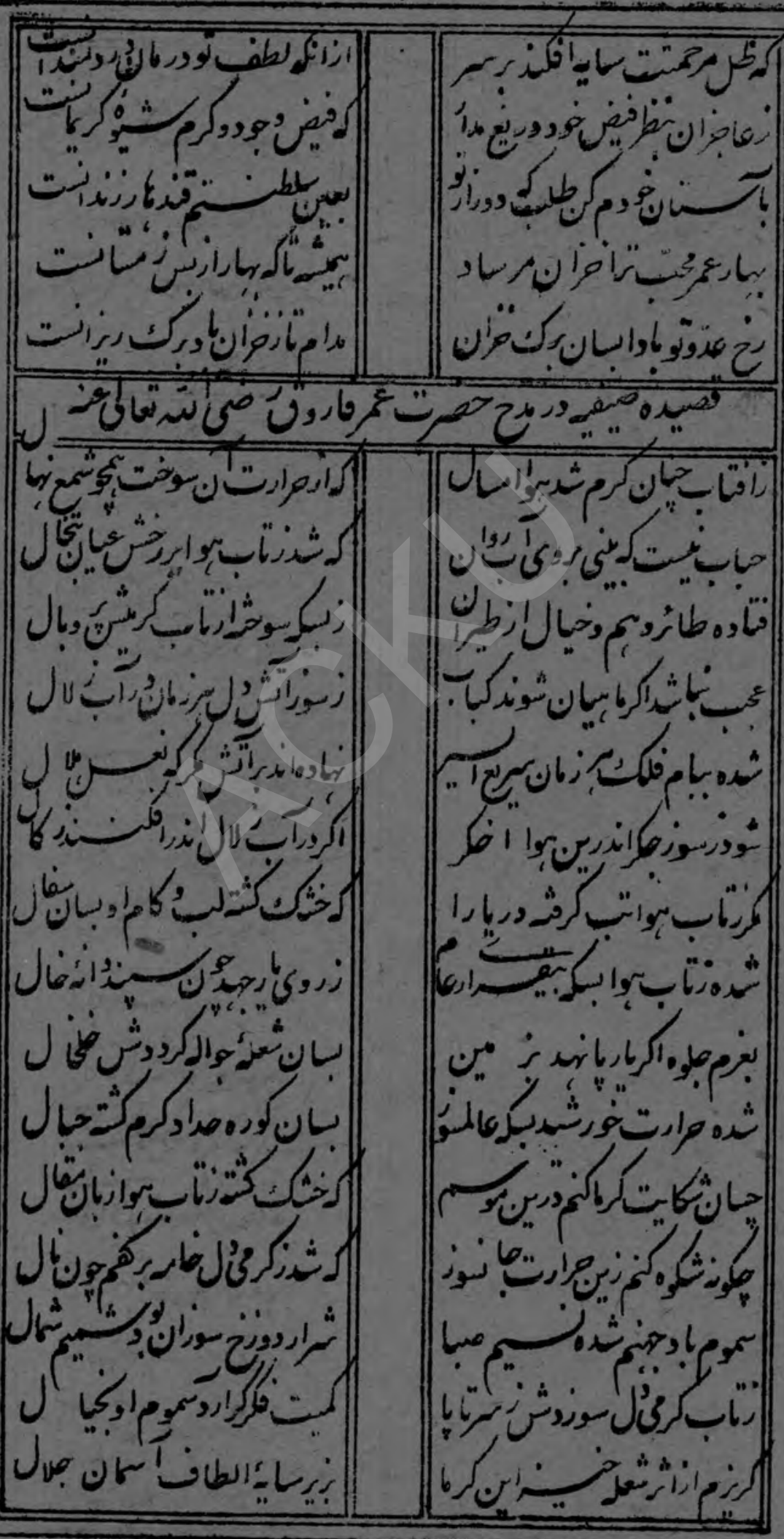


1.

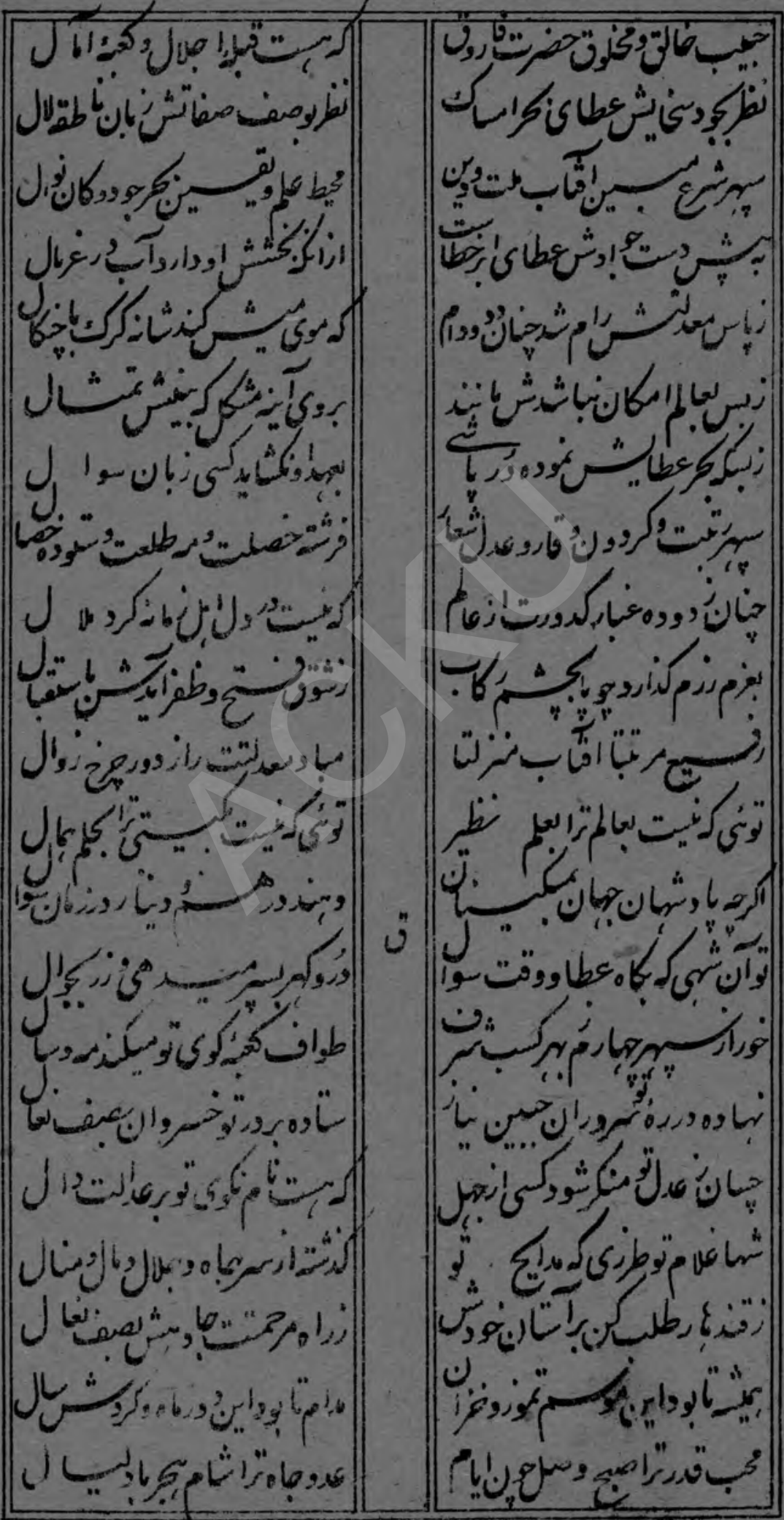


II

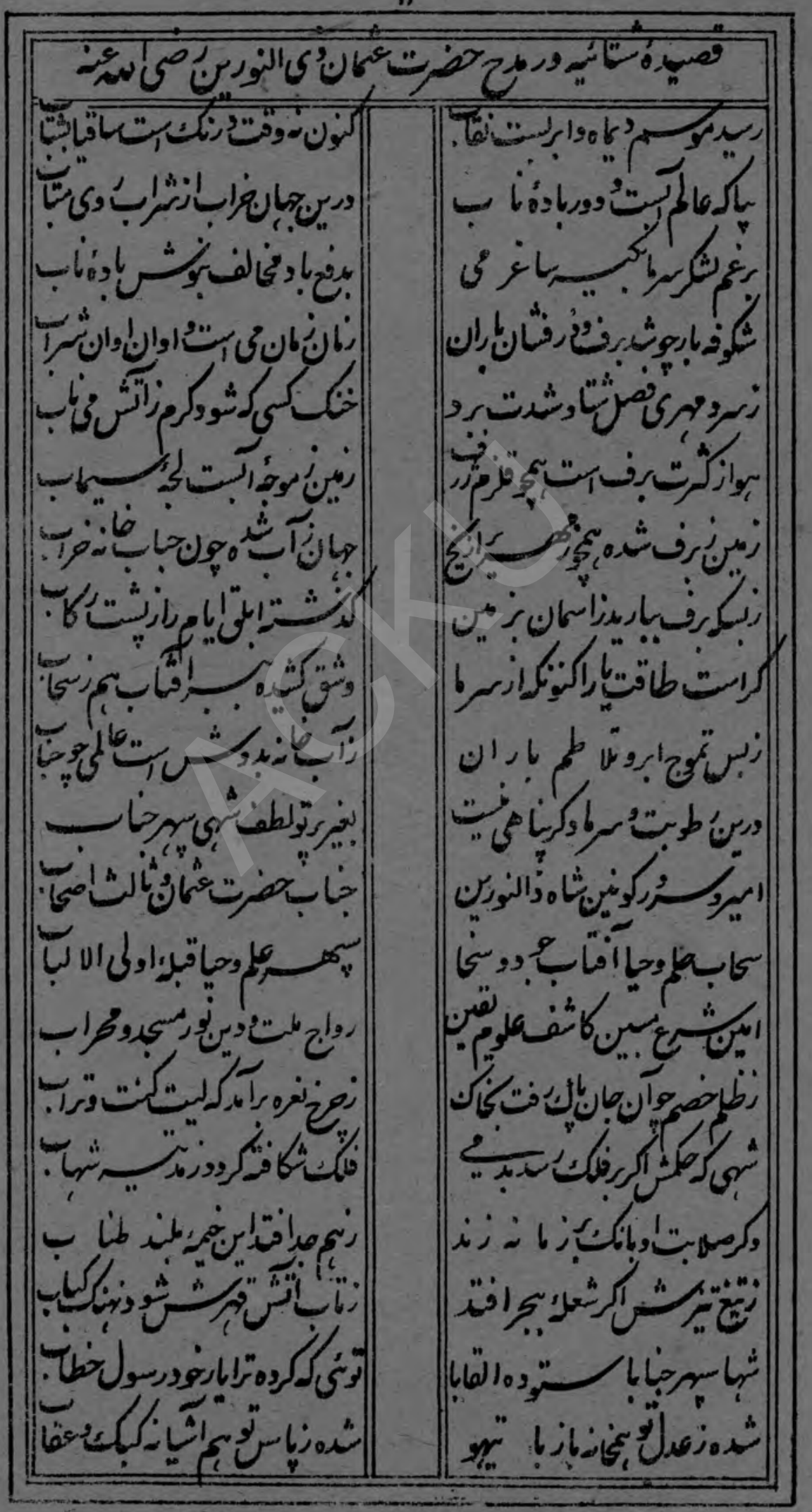




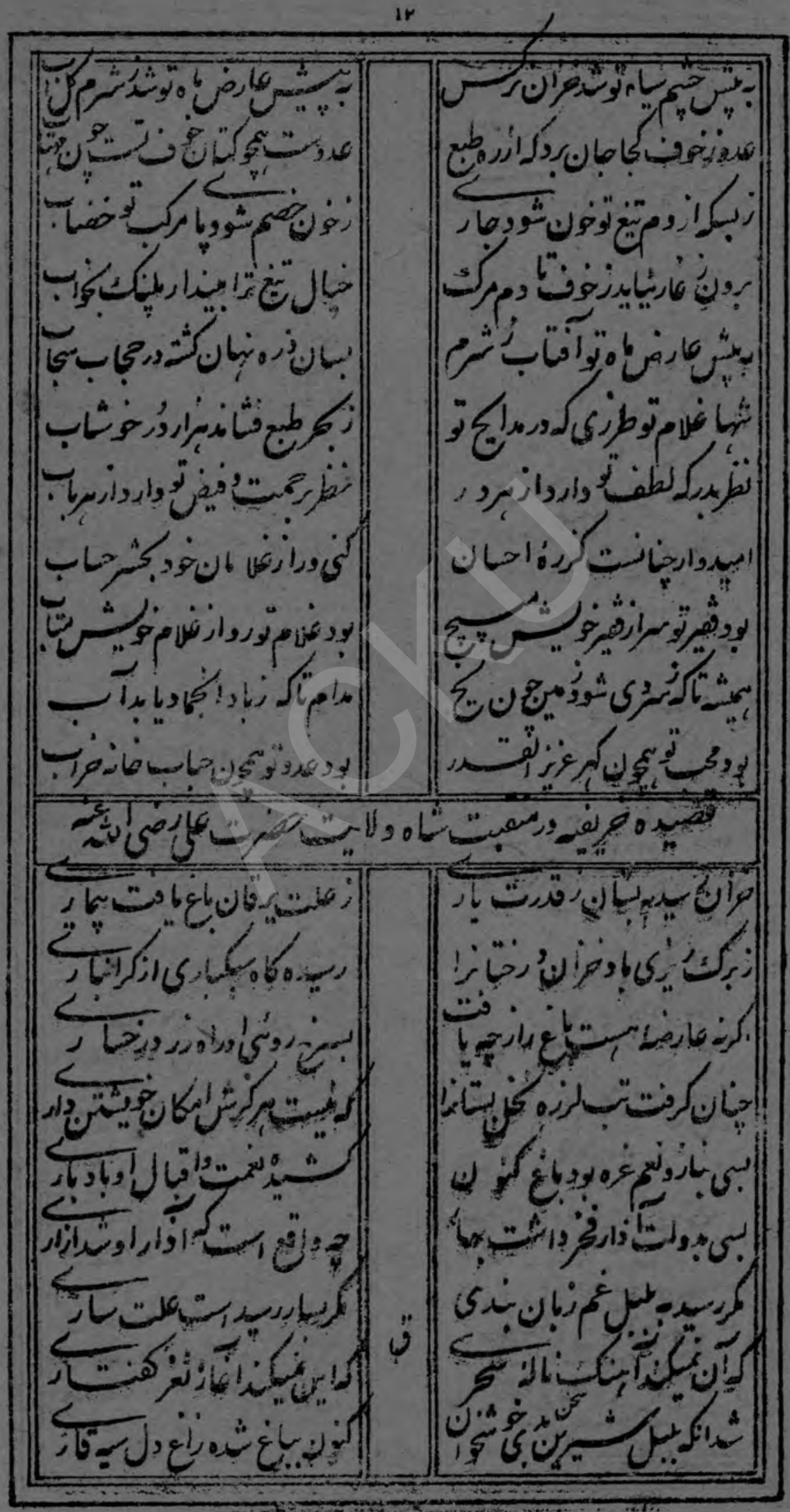


10

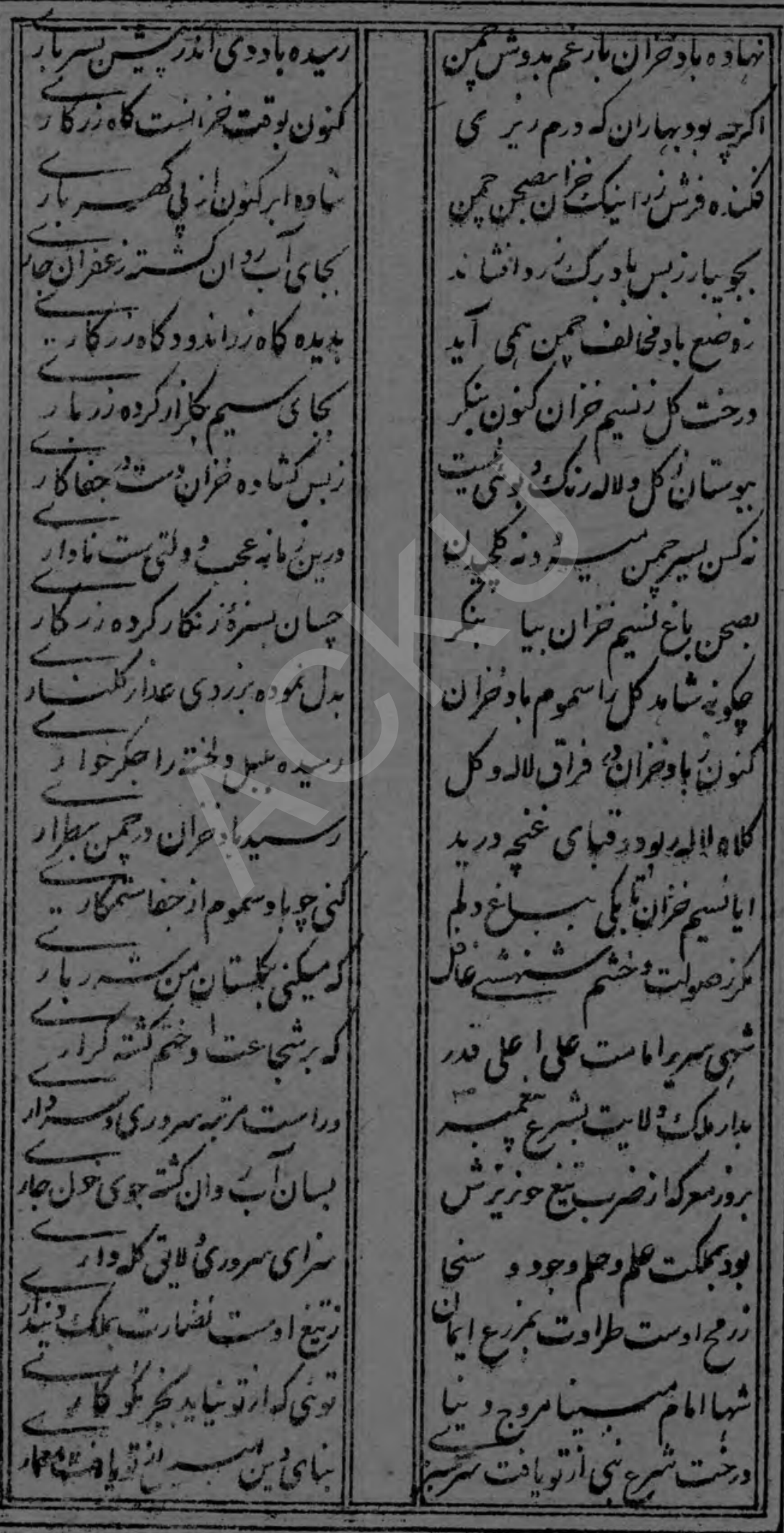


If

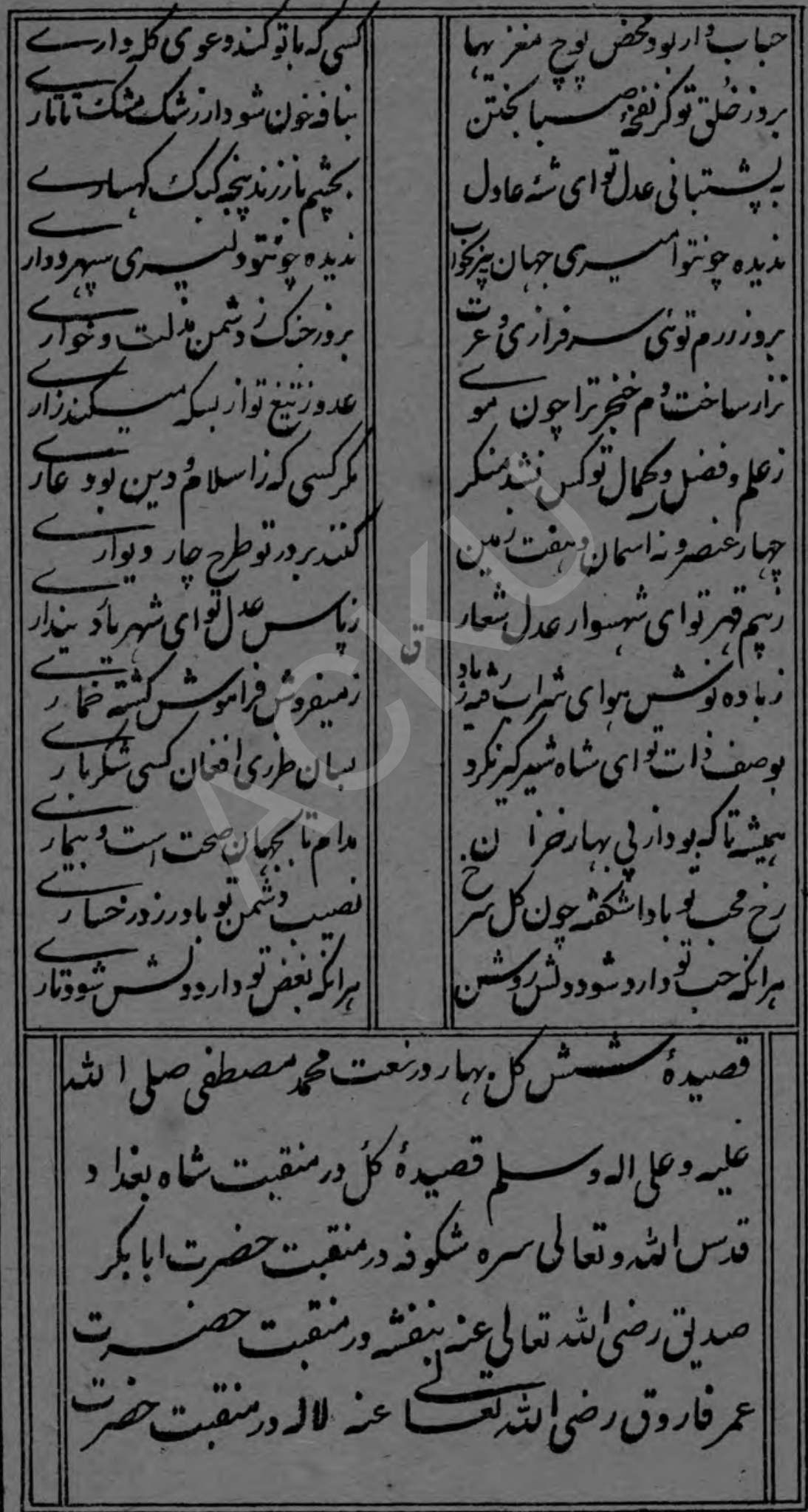




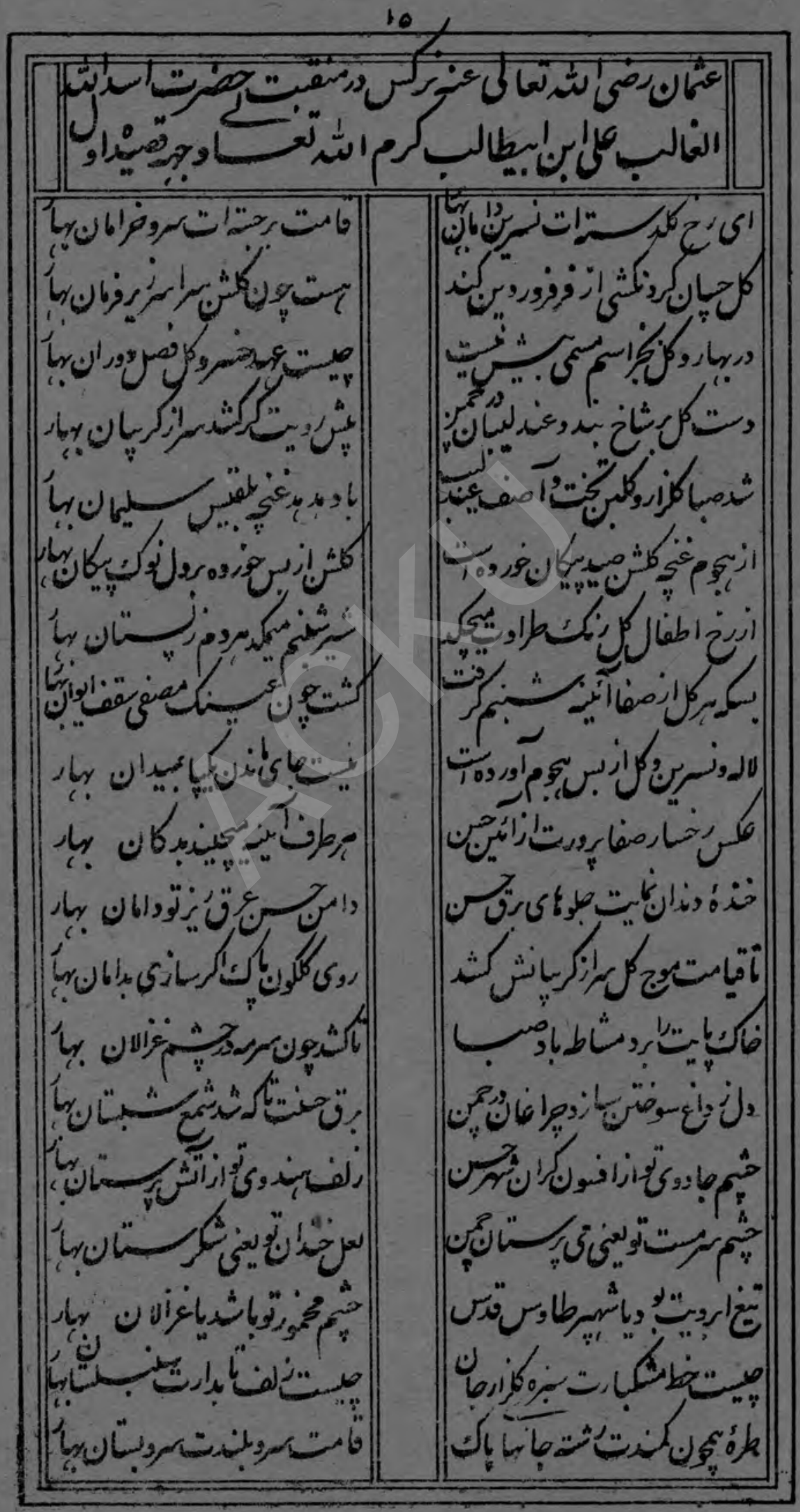




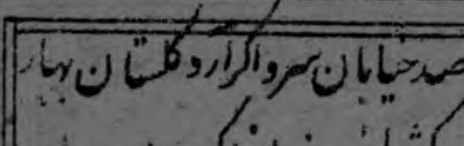

نوان

Wulis (4).

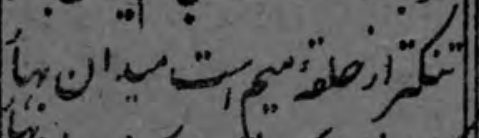
U.,

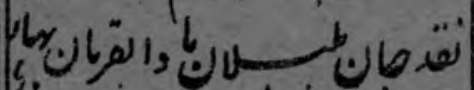
نان Lr. : Wul il

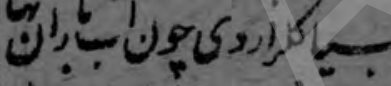
:

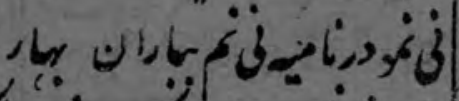

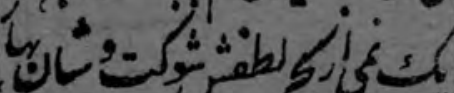
hollos

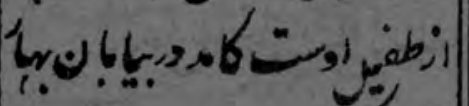
(r. c.

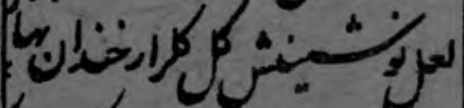
(4) ,
\% نrvor

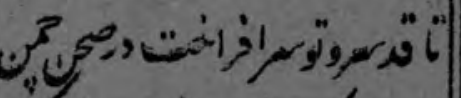

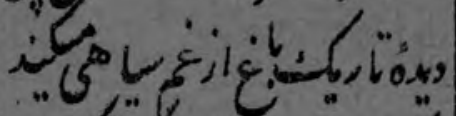
. رالمسان

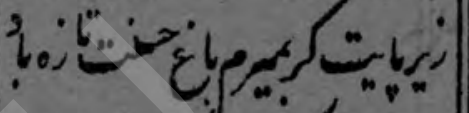

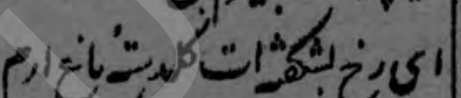
$\left.\right|_{0}$

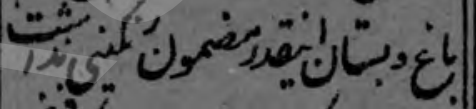

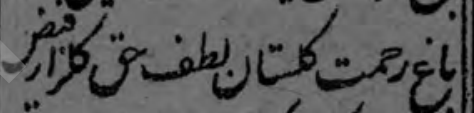
" ن ט.ं.

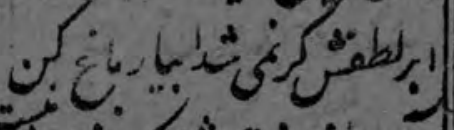
ن ק ג, ג

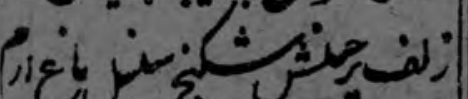
Q. $\varepsilon_{0} v^{*}$ - (2) م 
$i v$

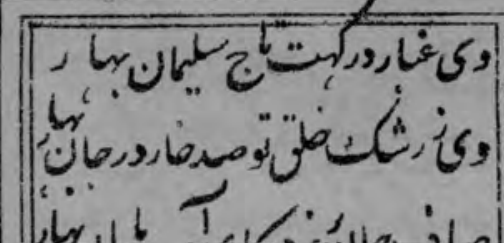
مأن (i)

(ט)

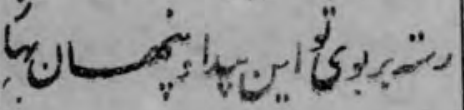
ري

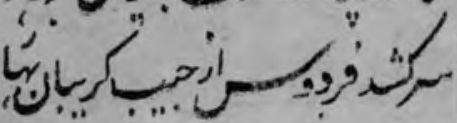

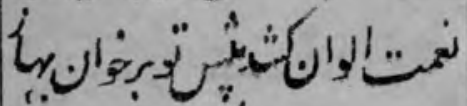

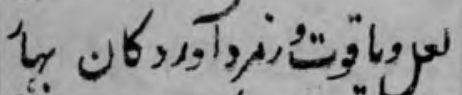
i. . ك, صوريته

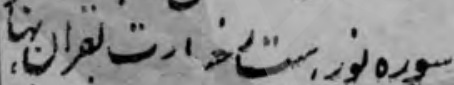

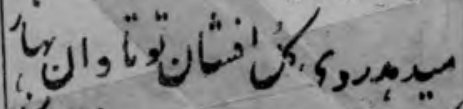

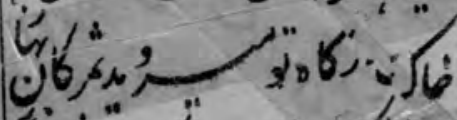

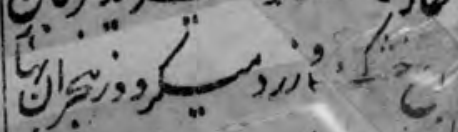

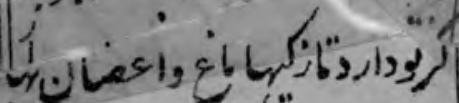

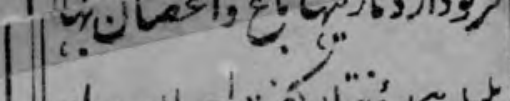
با. L.

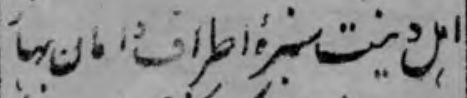
i.

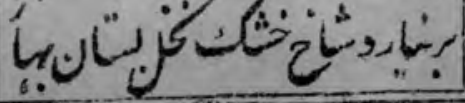

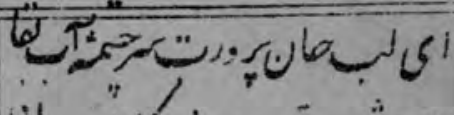

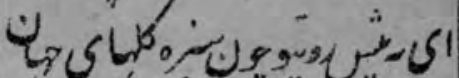
6. 6 . "

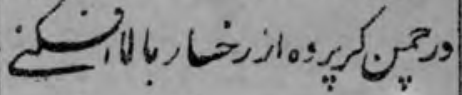

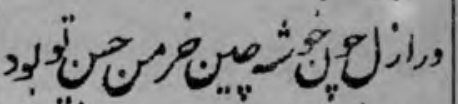

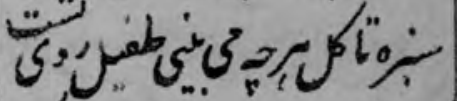

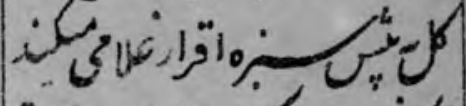

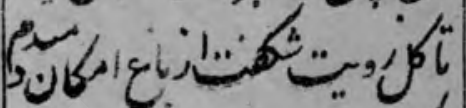
. . .

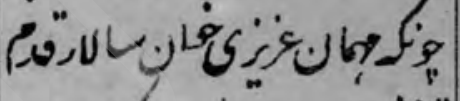
ט ع . . .

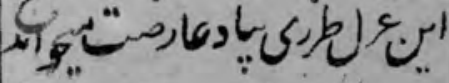

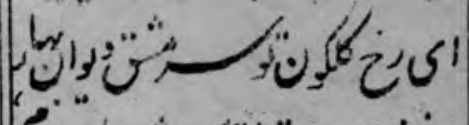

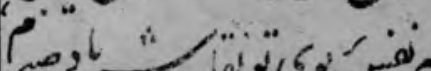

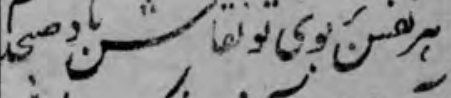

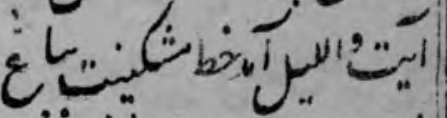
年"

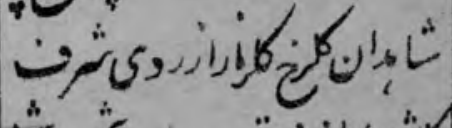

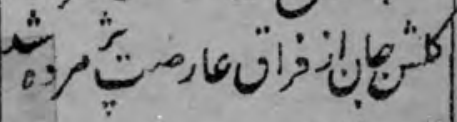

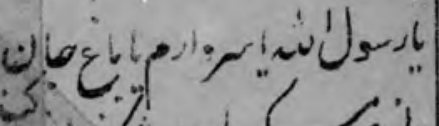
is " is

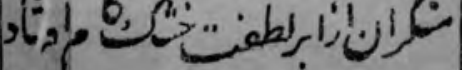


in

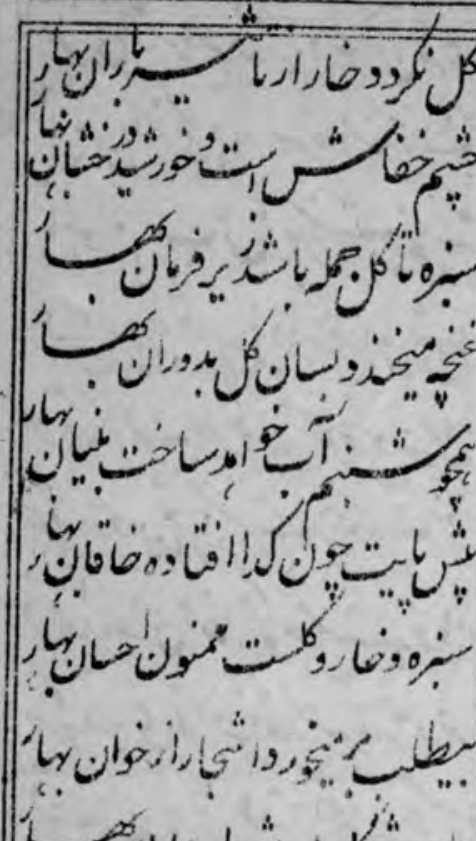

وان. (4)

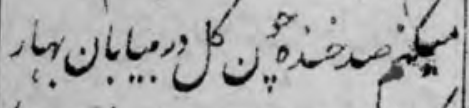

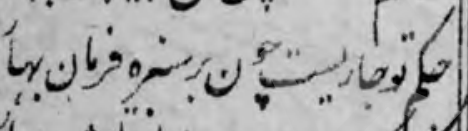

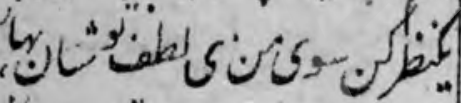
i. (6) (c) im ar ; vال (1)

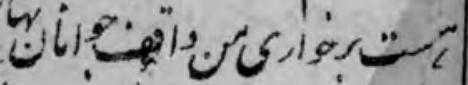
(5) ب.

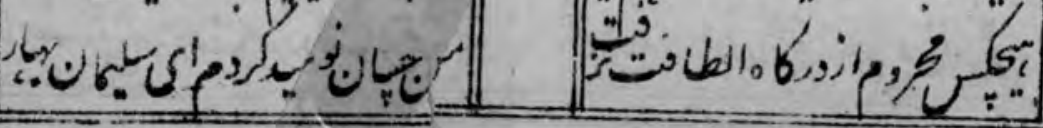
(2) سمارته إن و

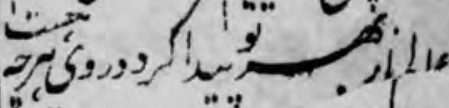

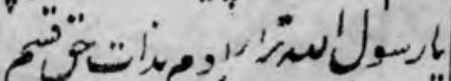

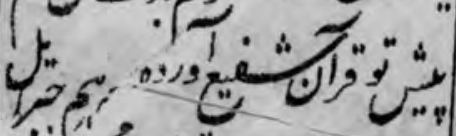

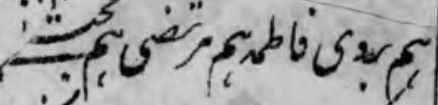

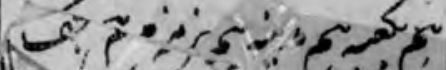
II $2: 1<1$. ن.jol

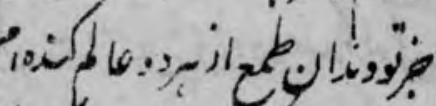

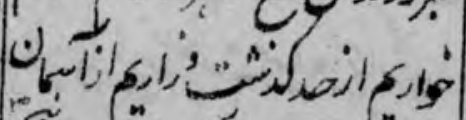
c.m. . 


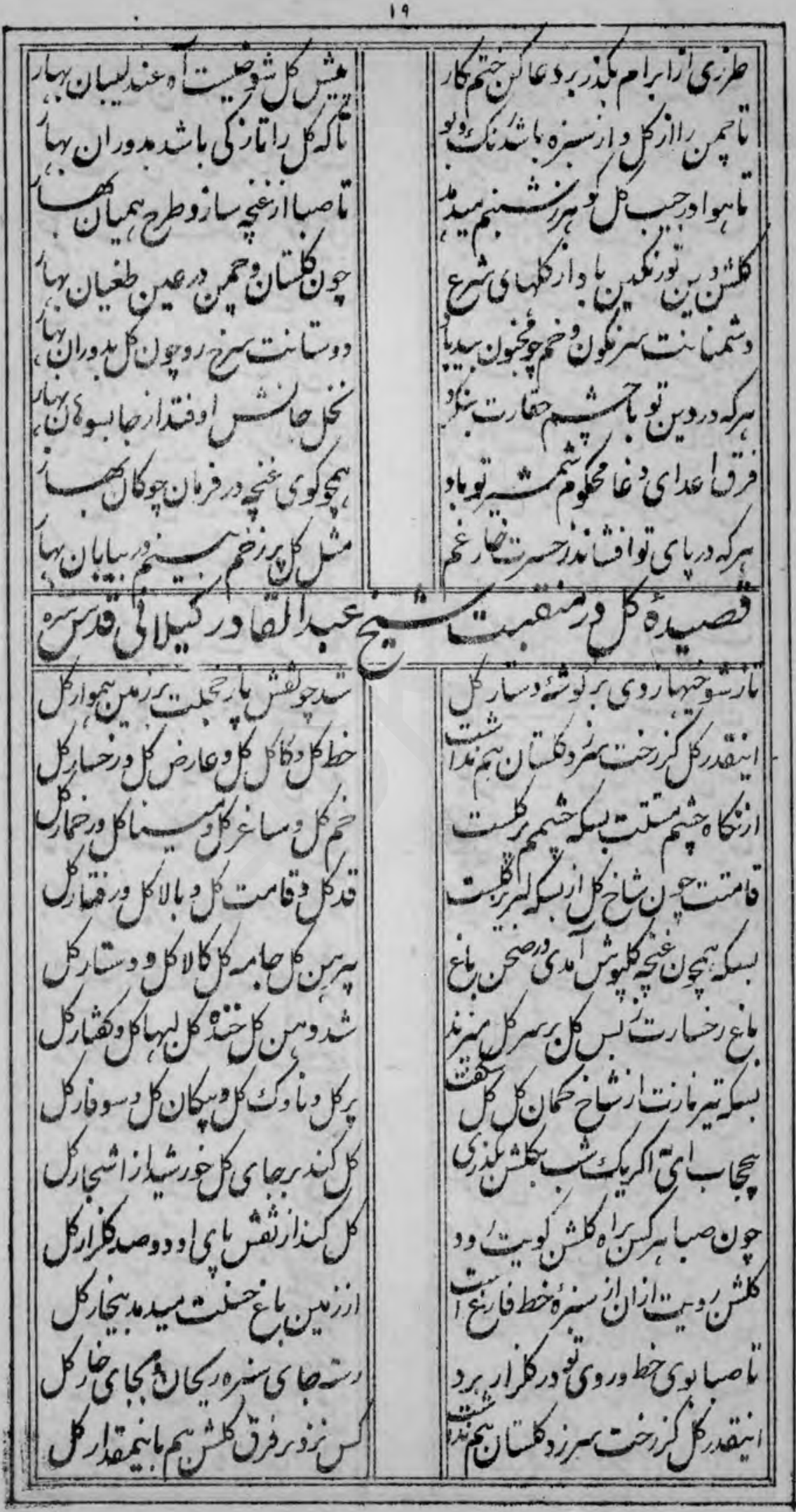




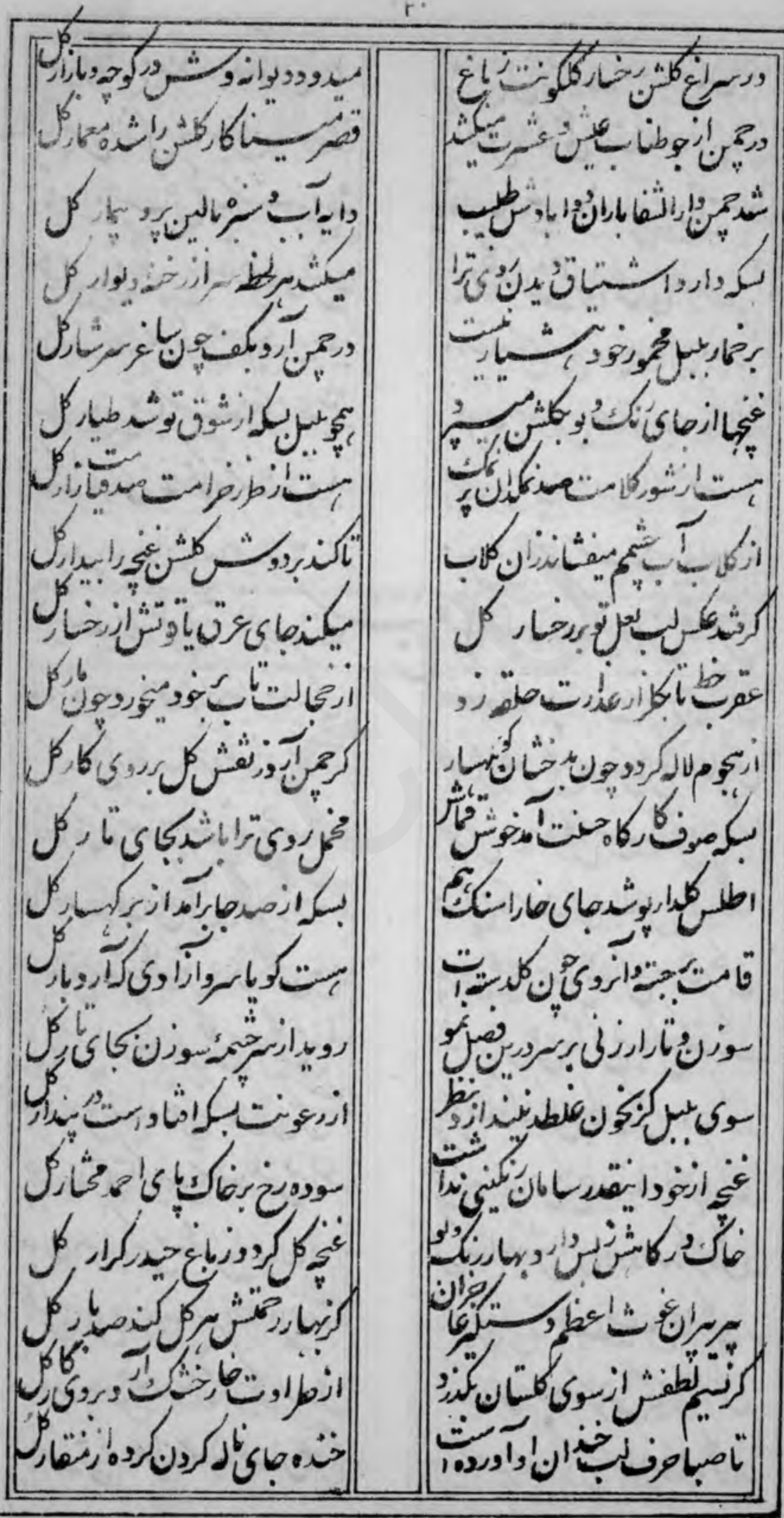




\section{9}

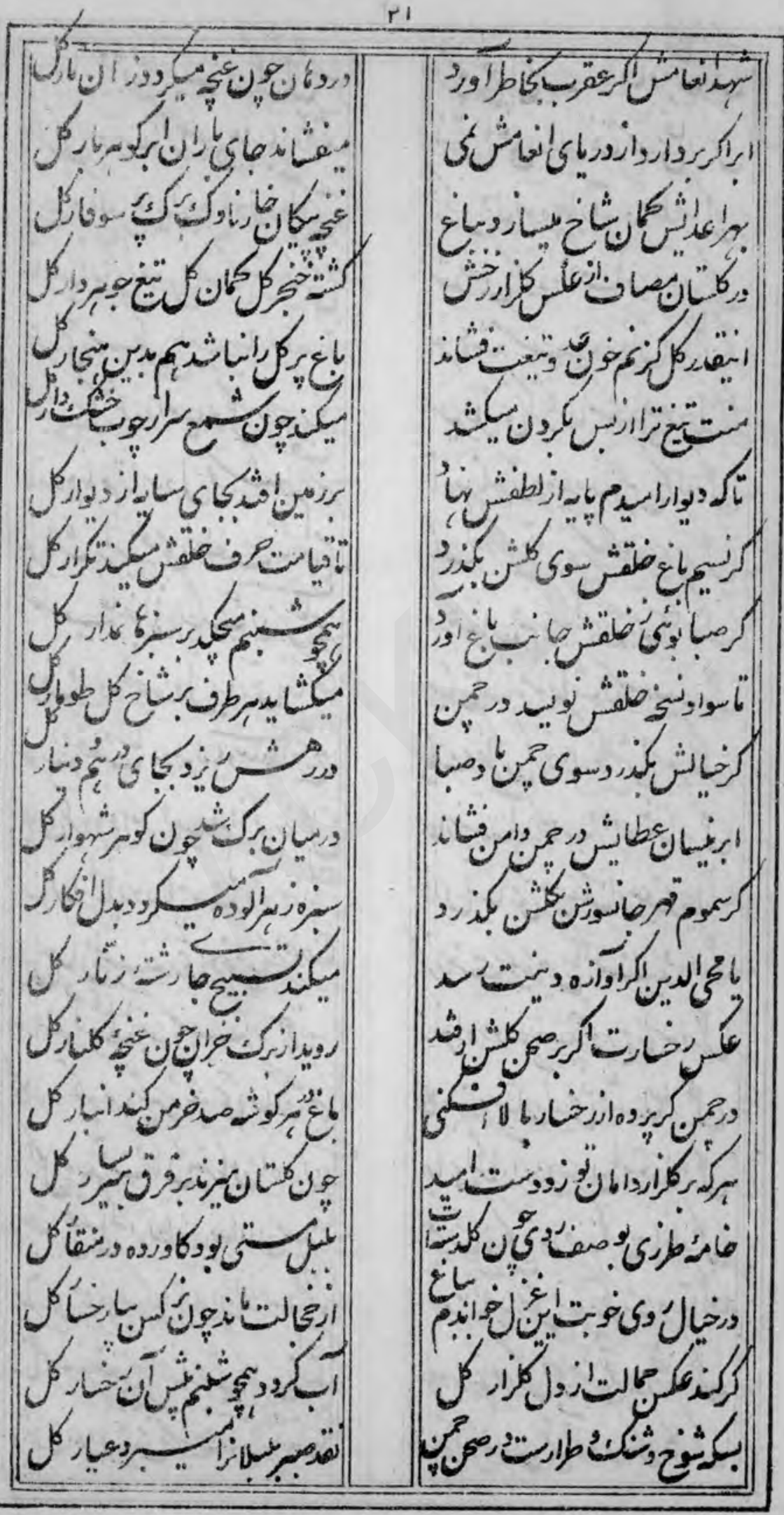


rr

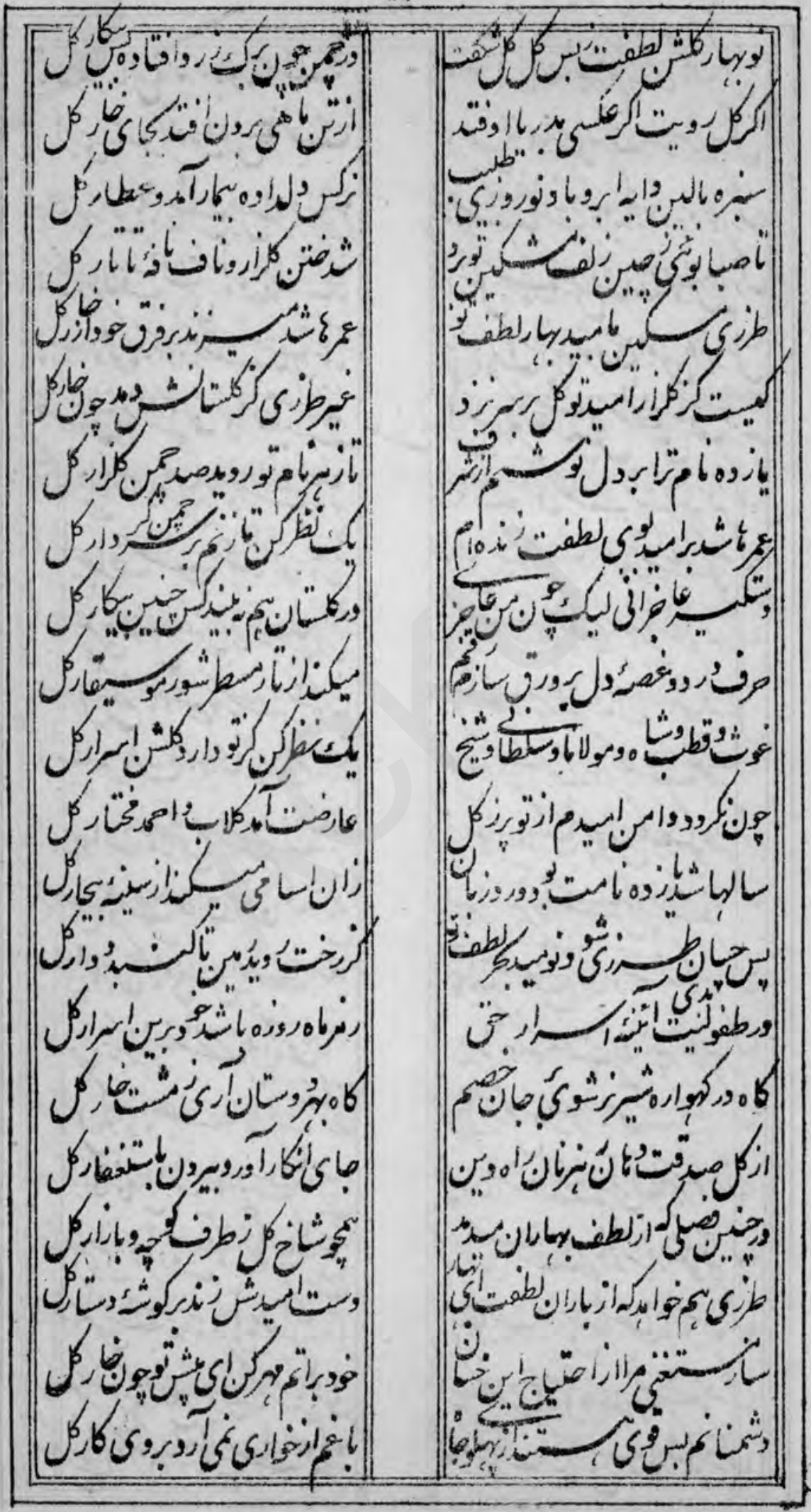




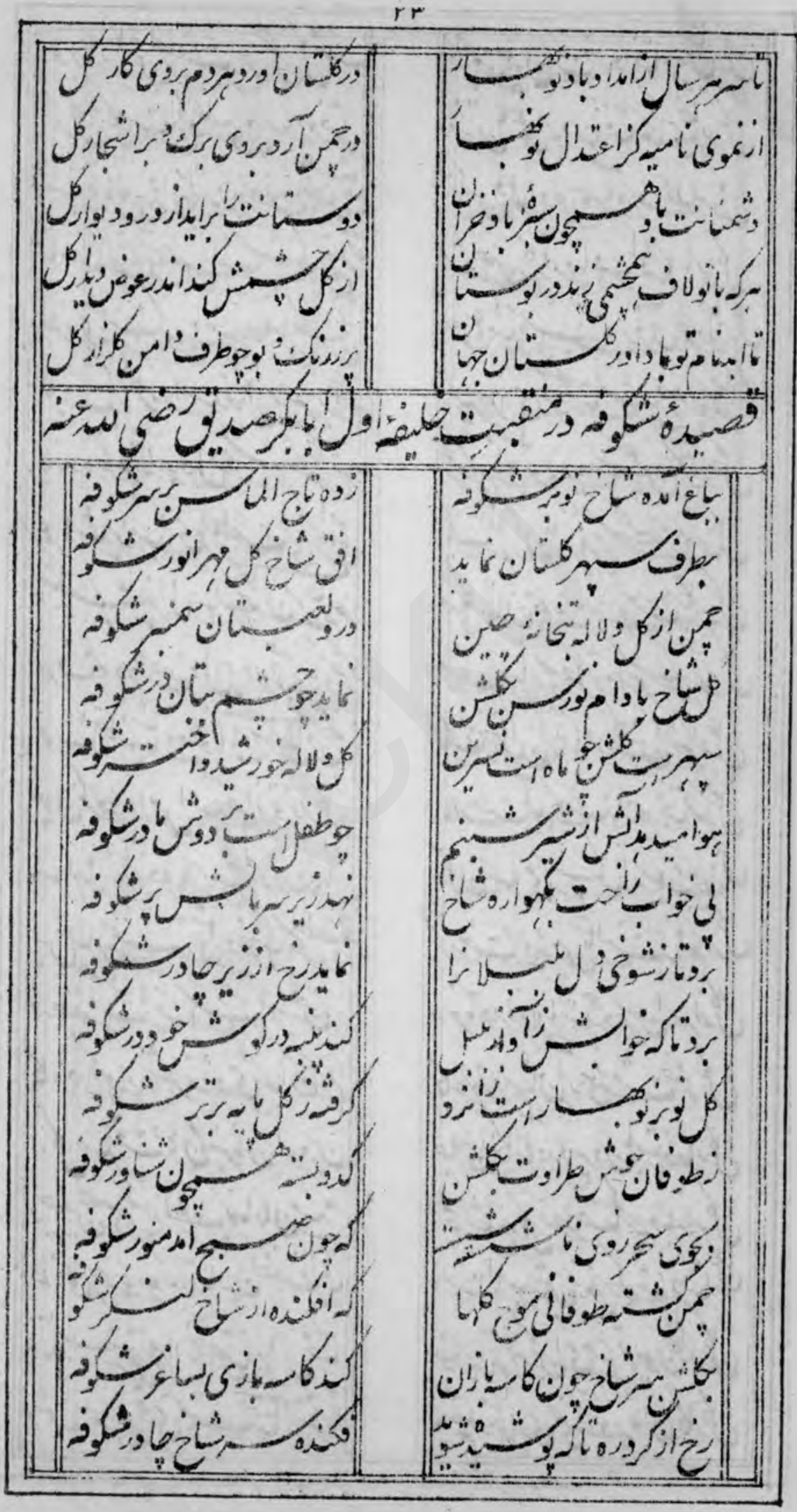


rT

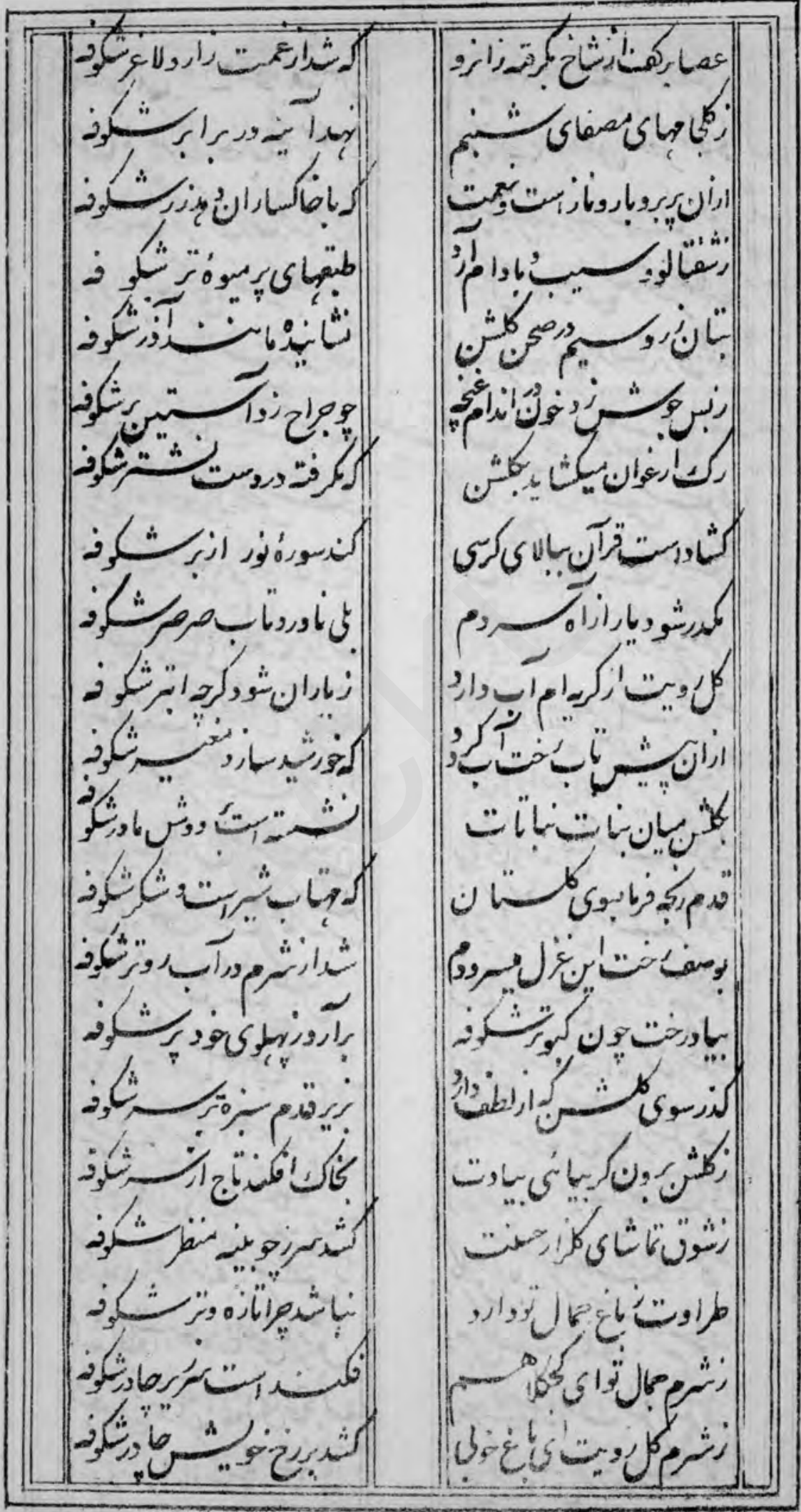


ro

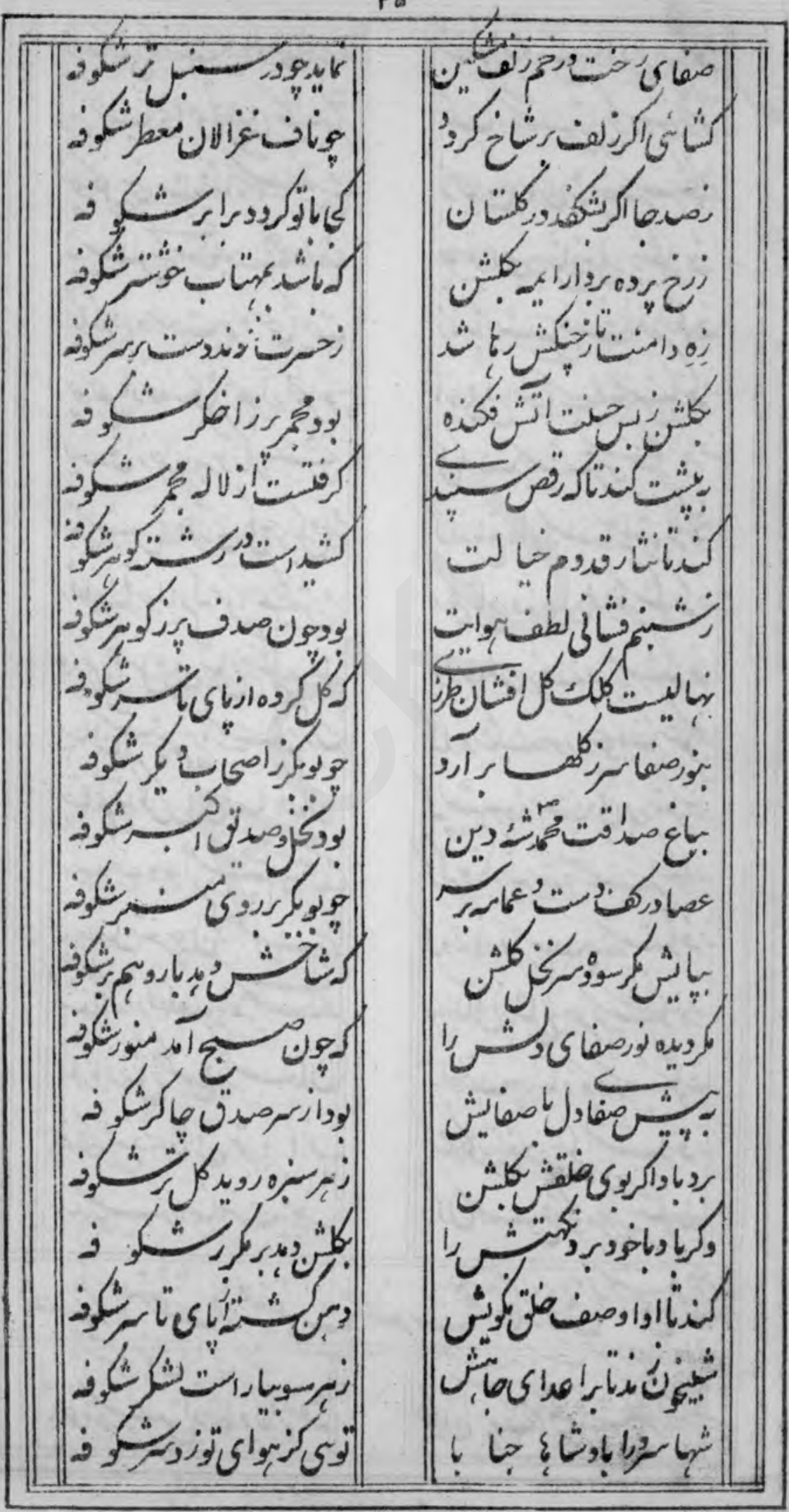


rs

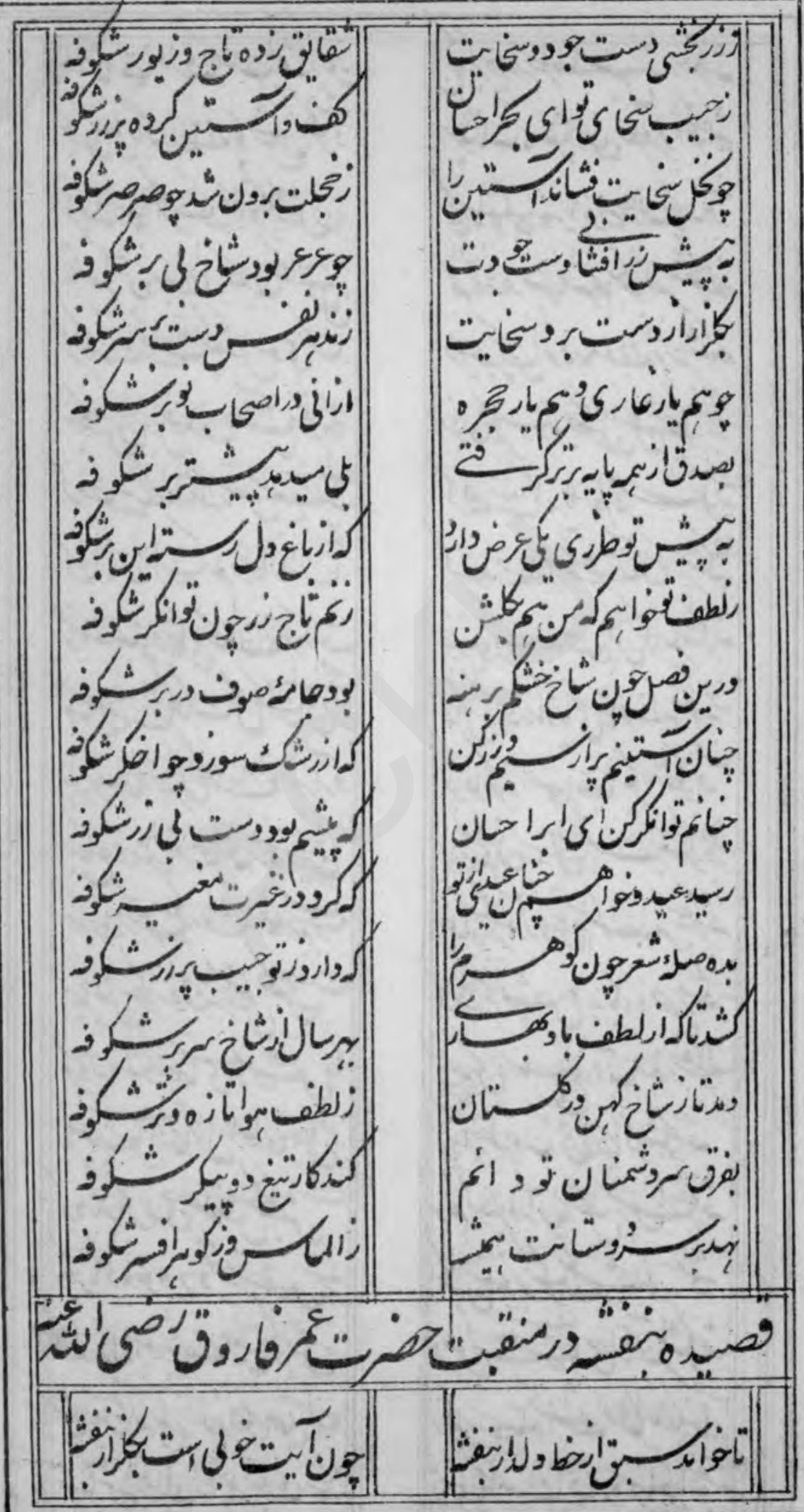




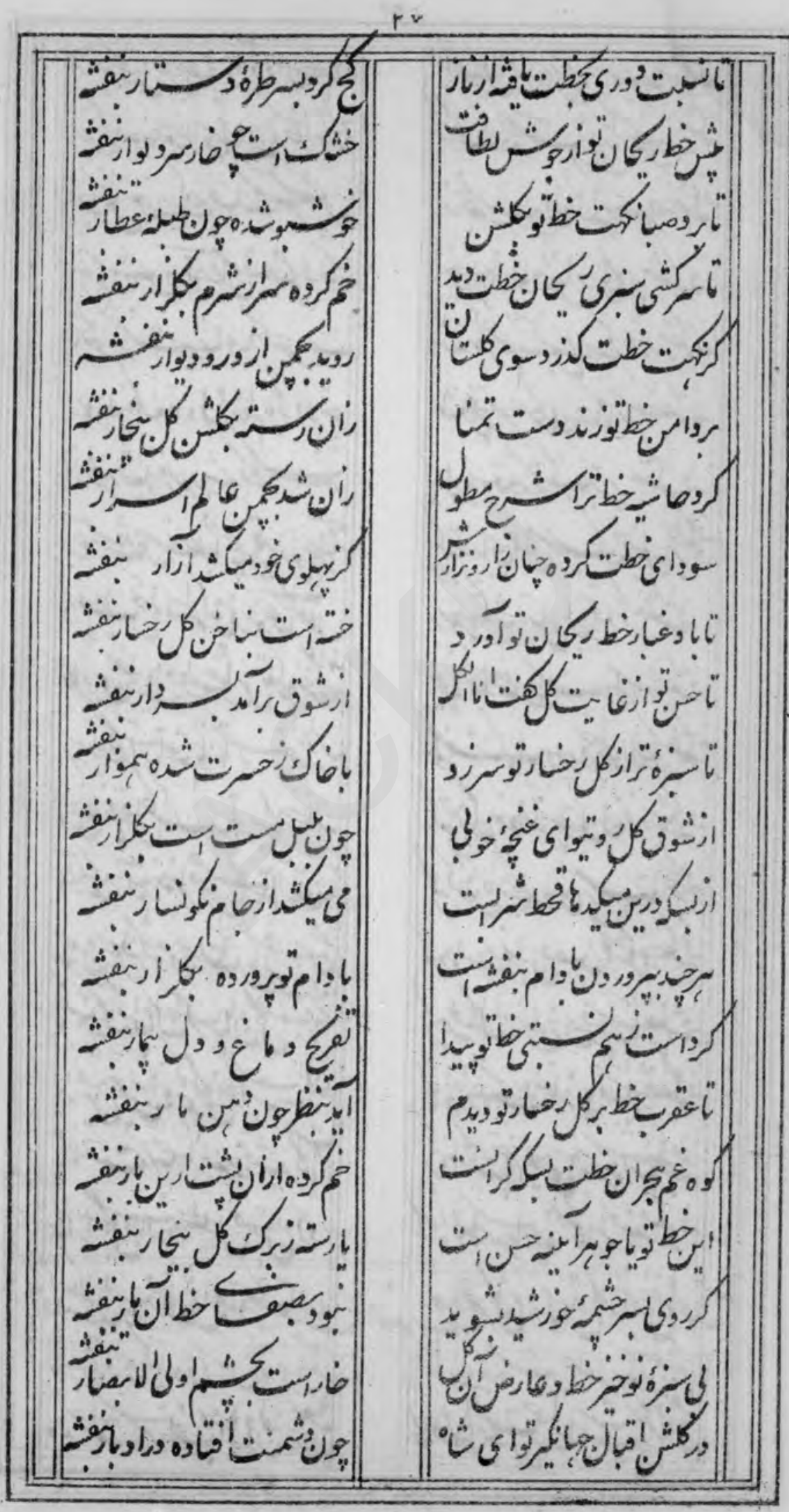




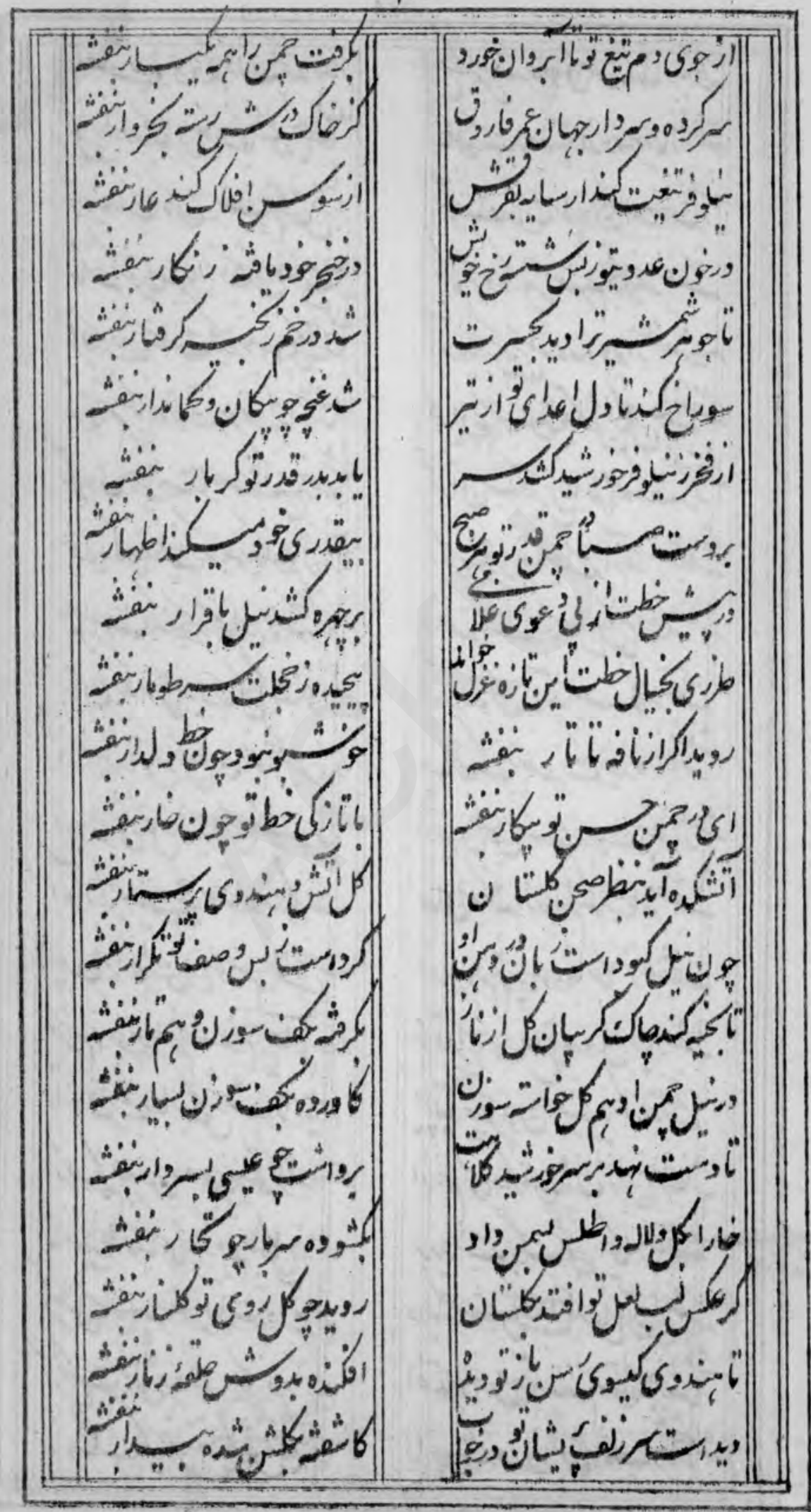


14

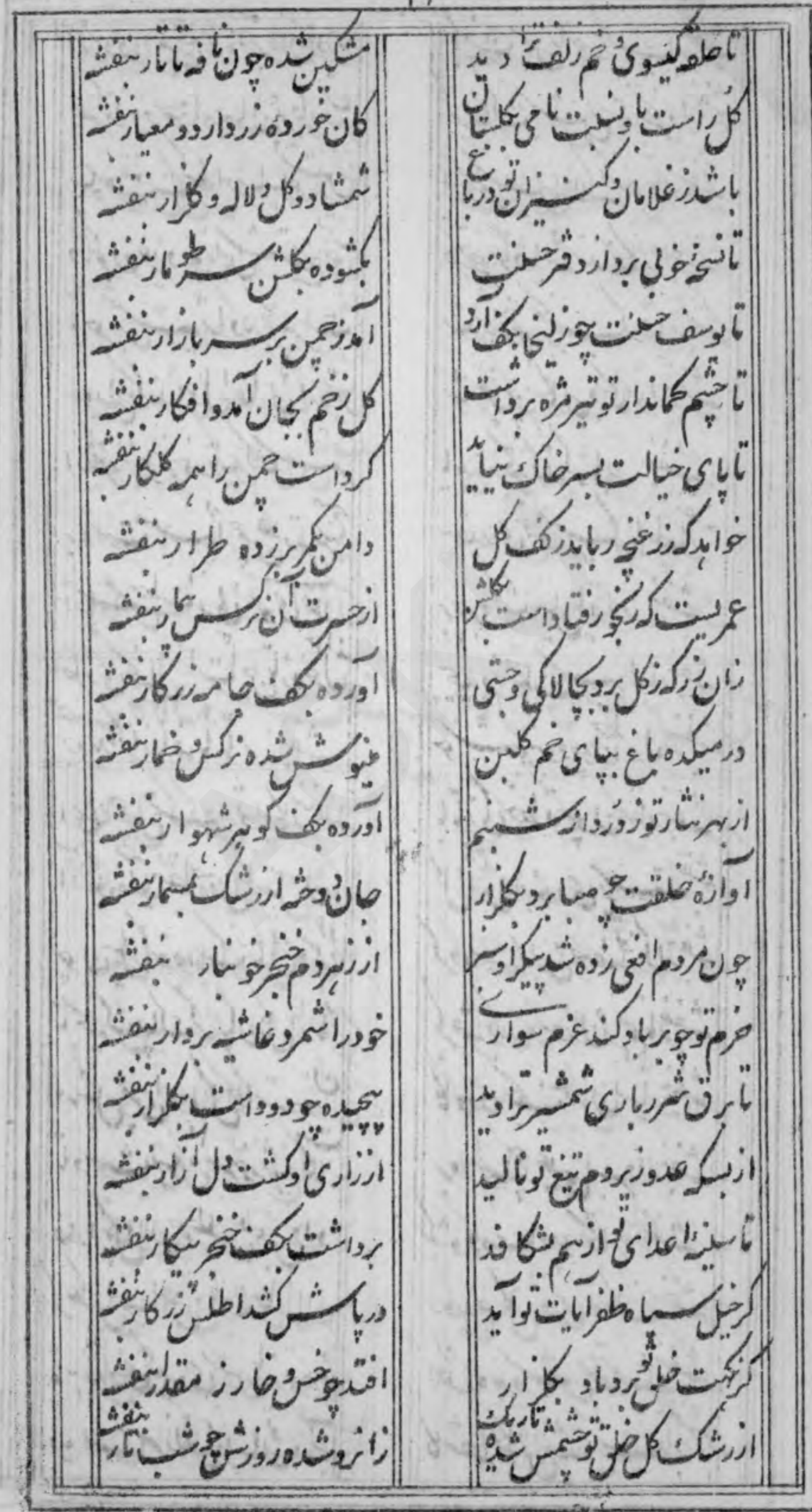




\section{8}

ro.

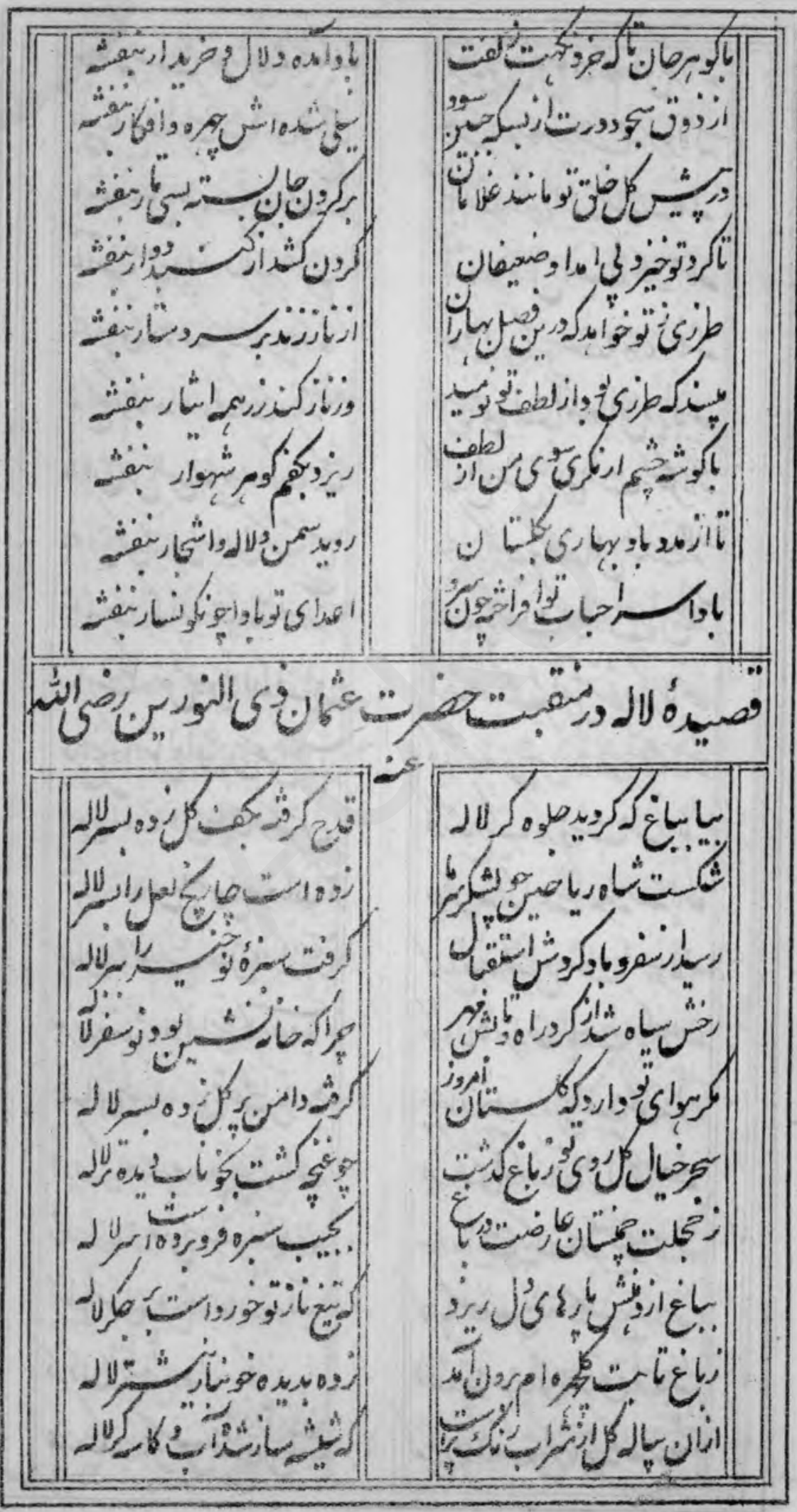




\section{9}

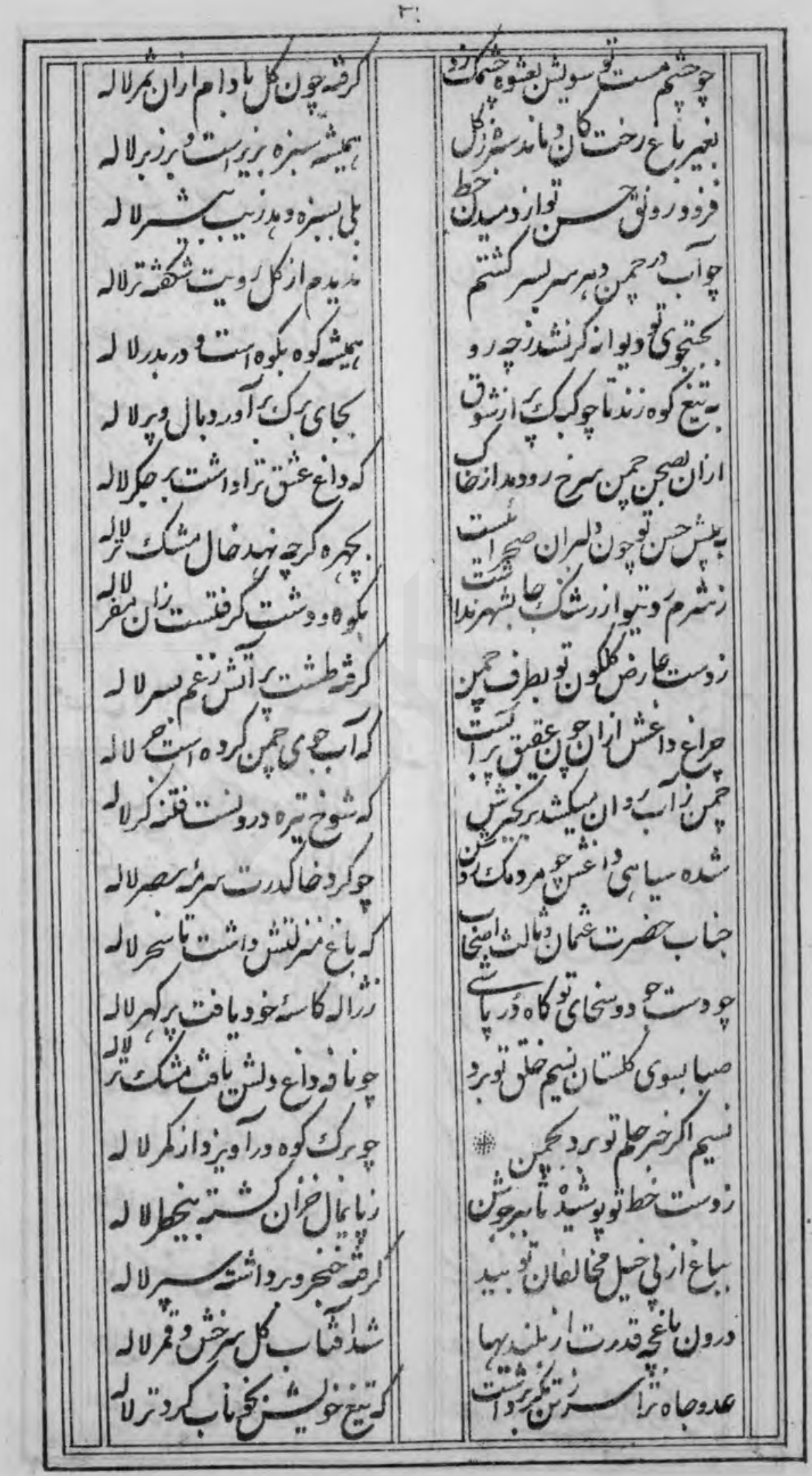




\section{0}

$r r$

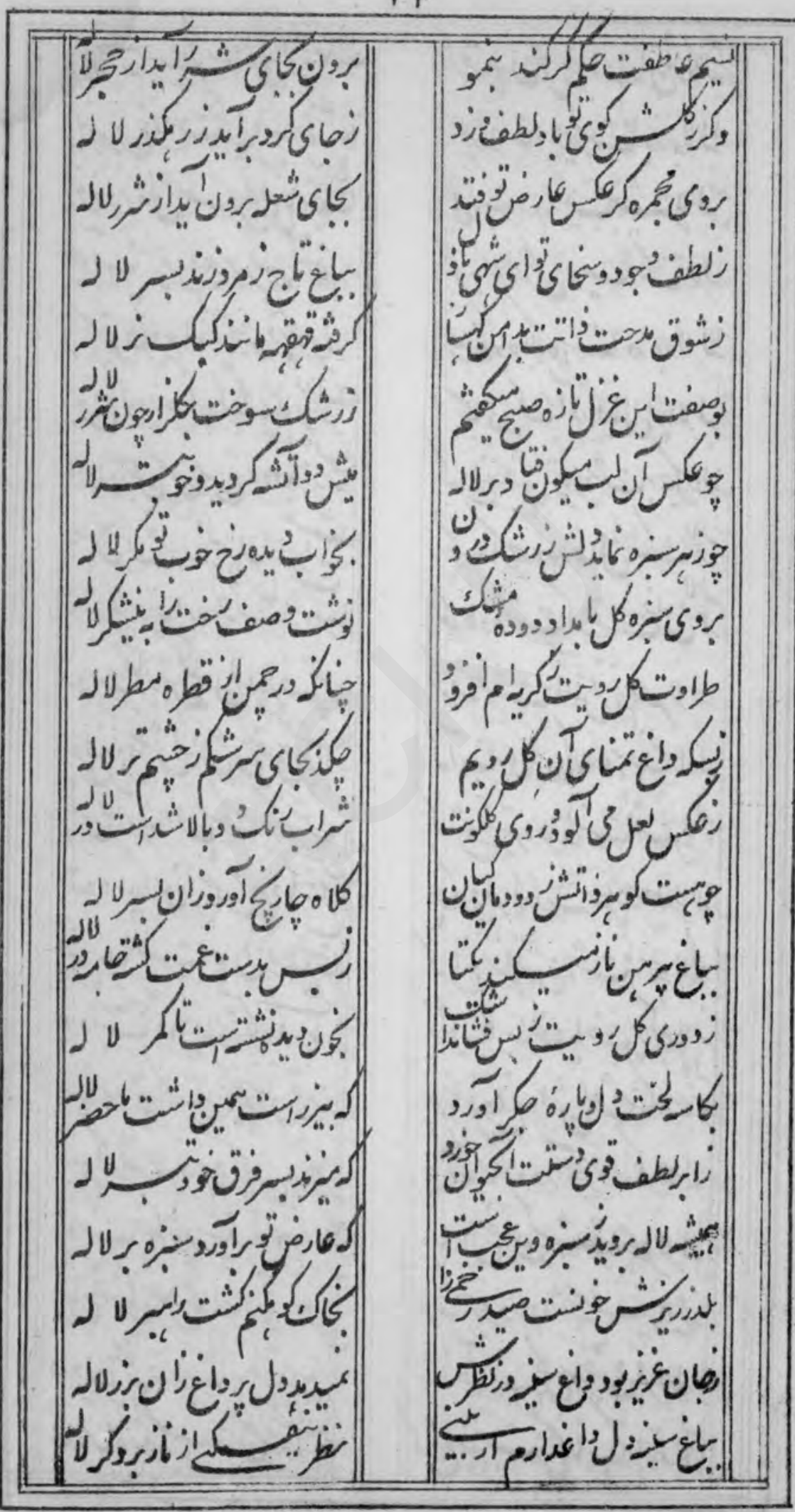

\& "yspi! 
$p r$

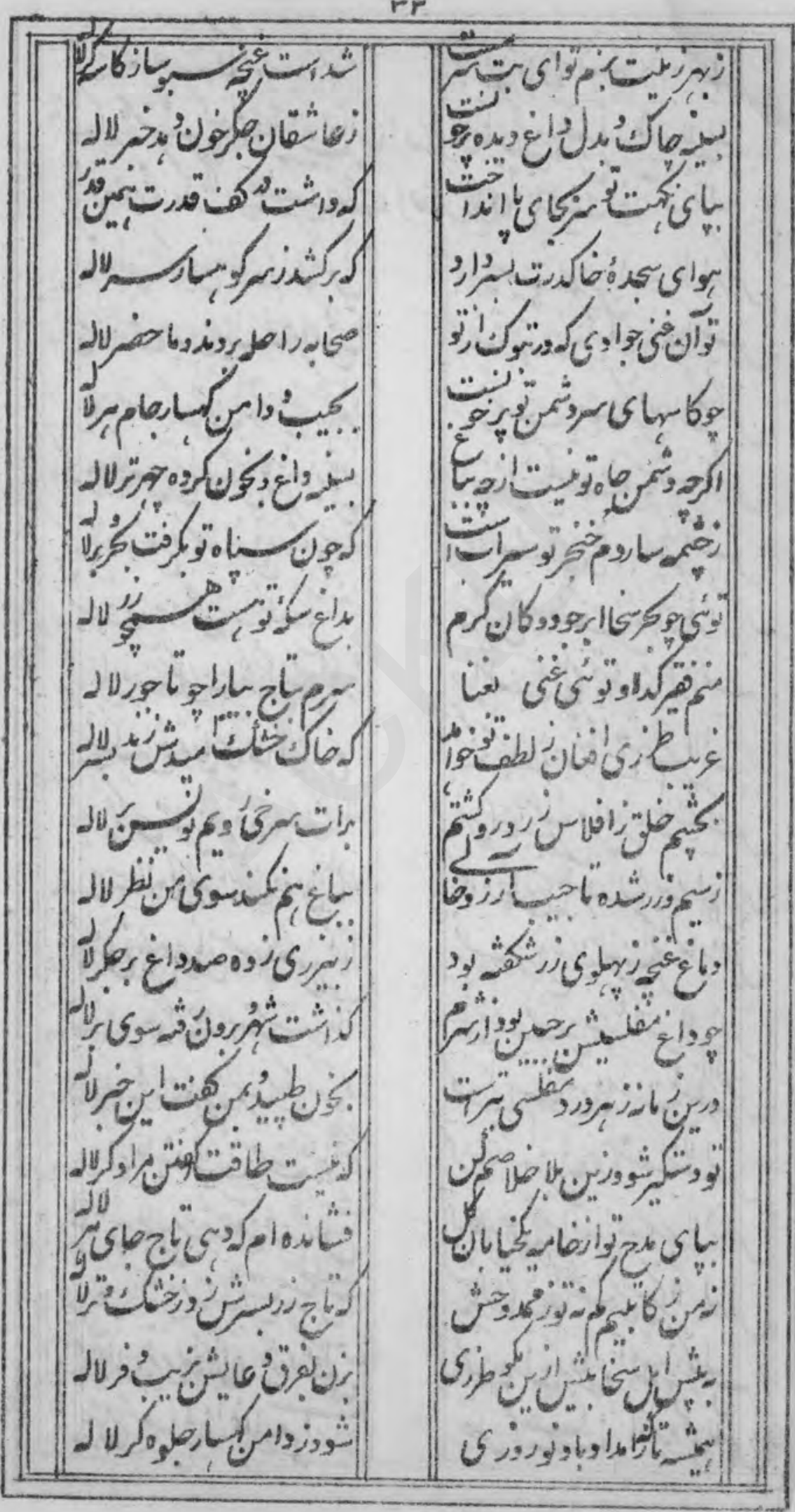




\section{2}

Nos

| 1.




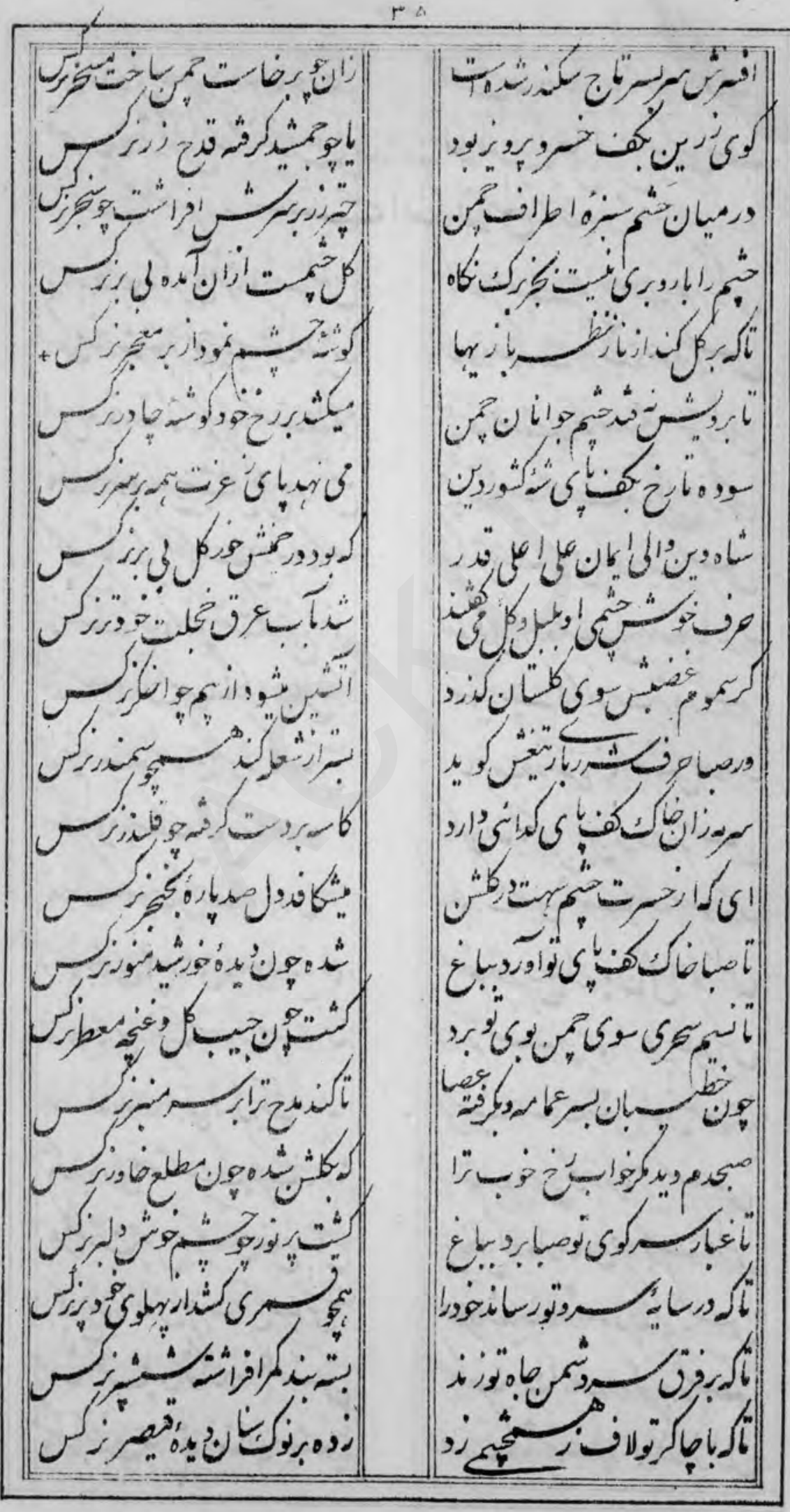


$1+5$

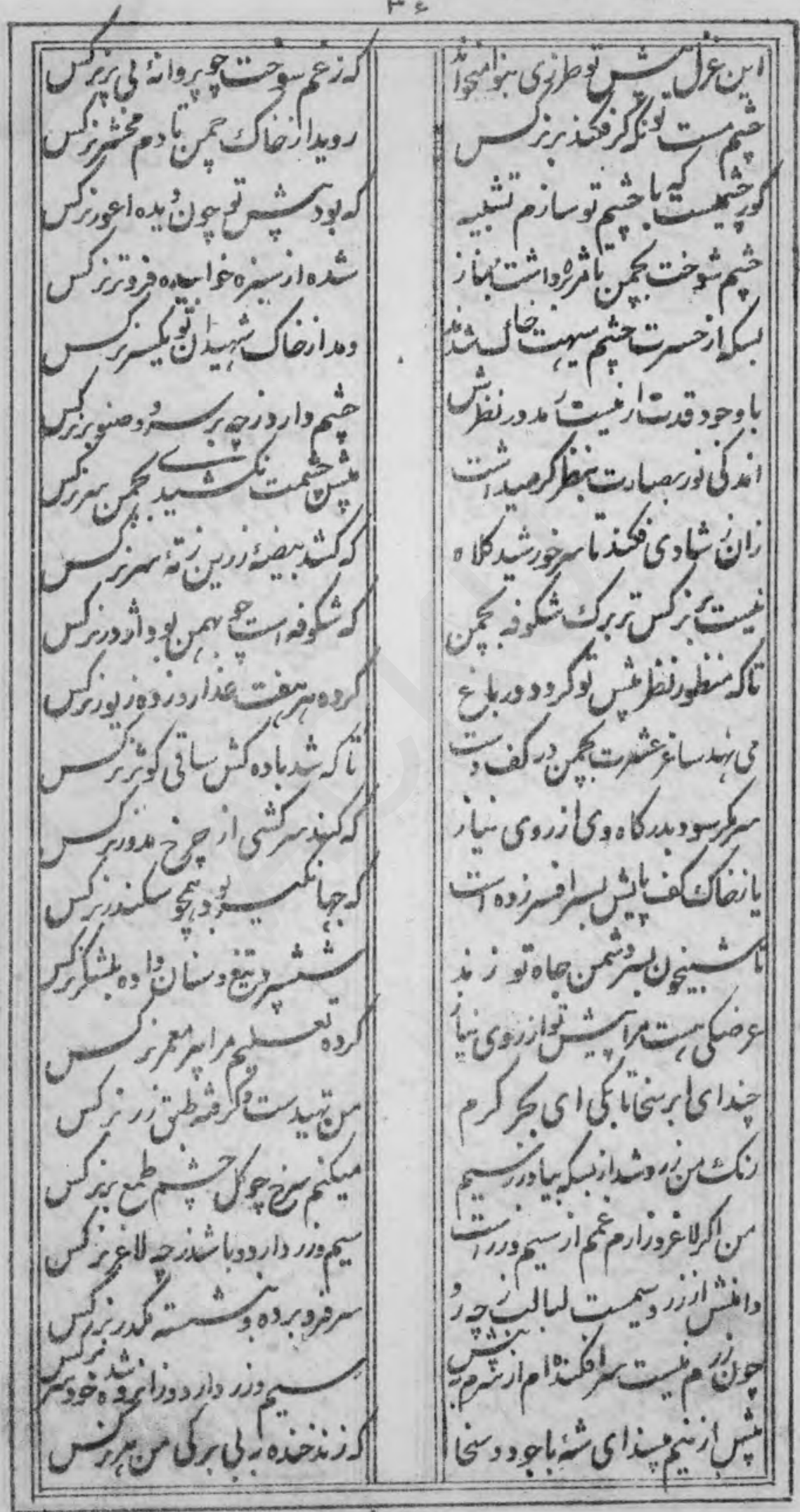




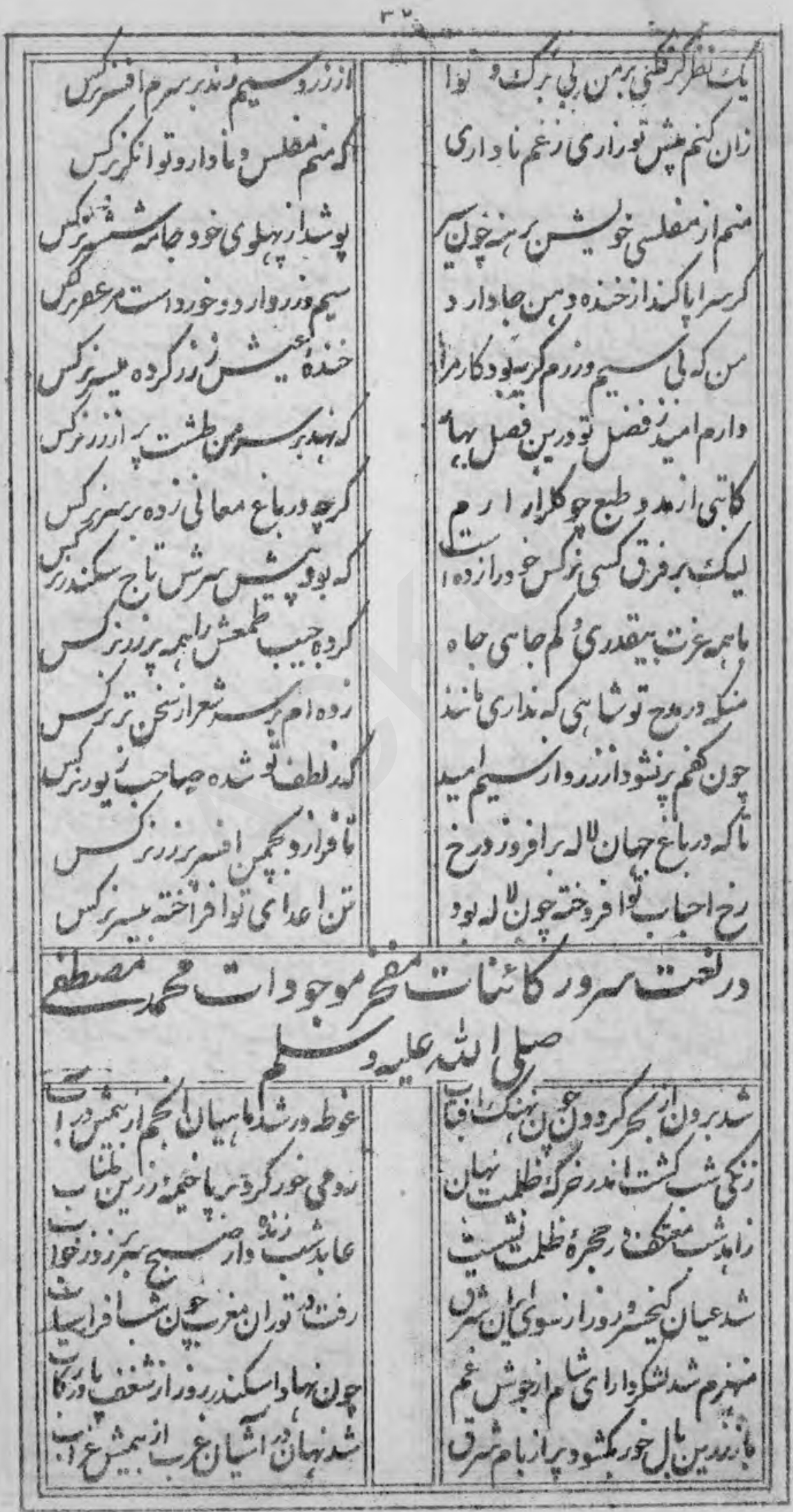




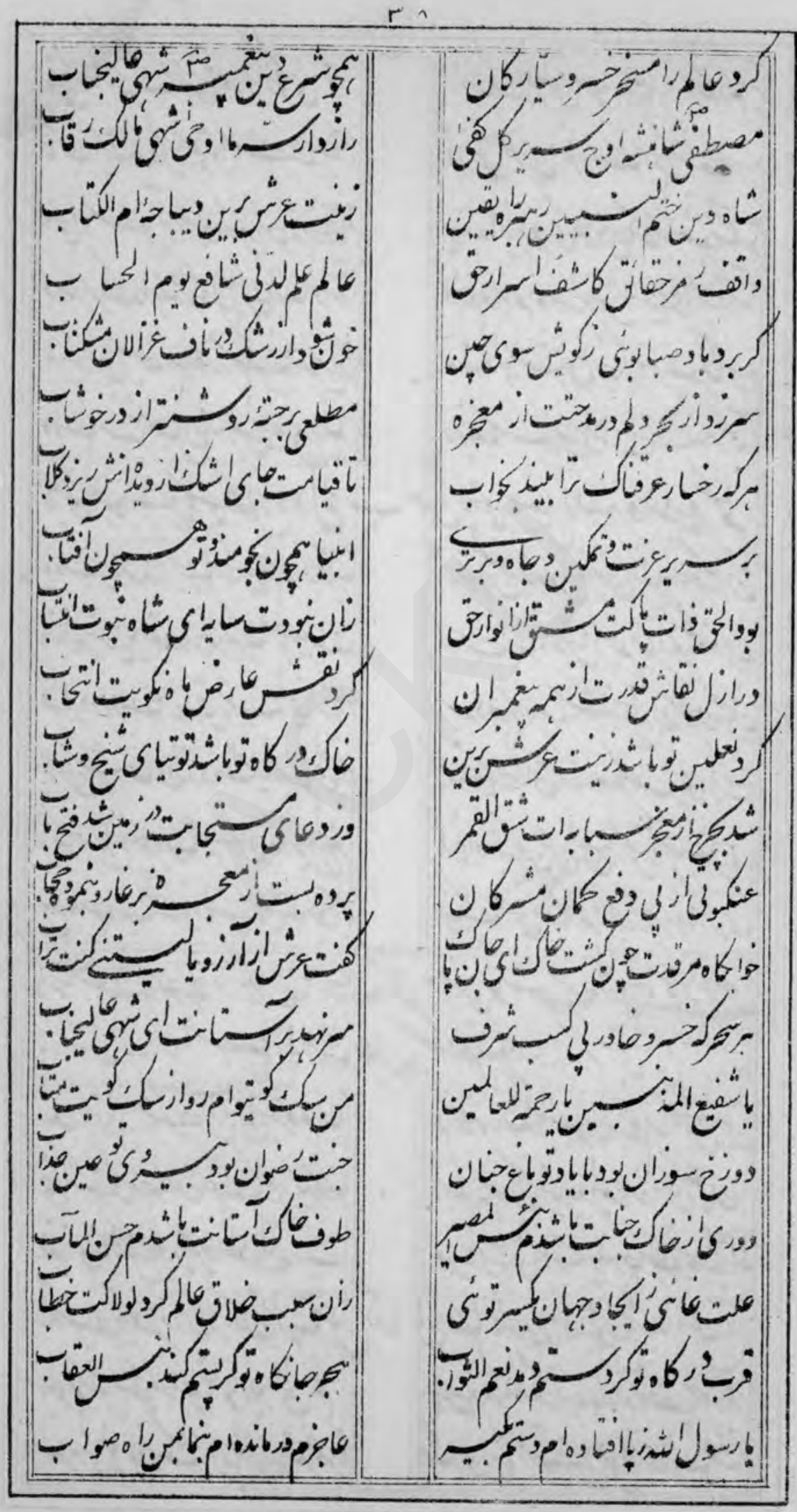


rq

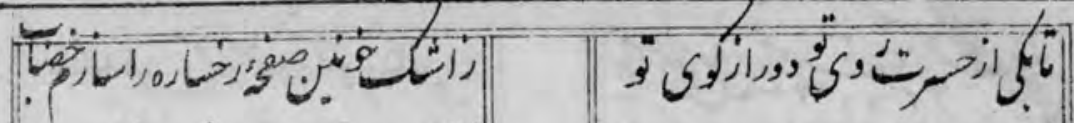

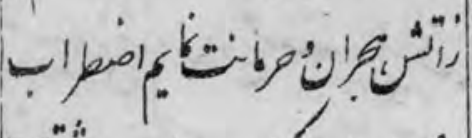
- Lublingis $=$ وز

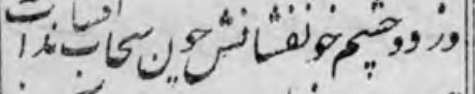
|

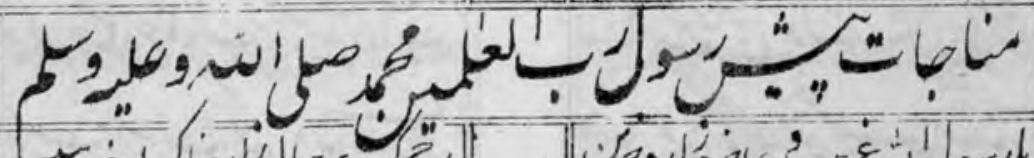

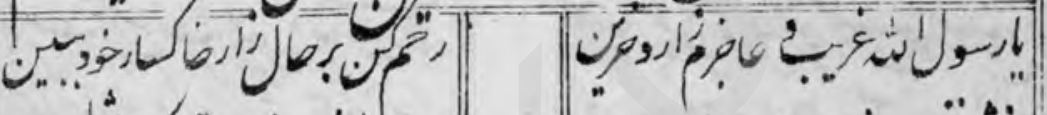

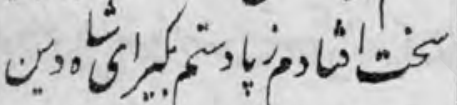
"يميران ving بs:

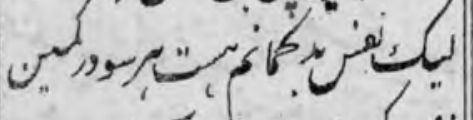
تصن

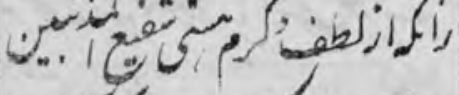
(1)

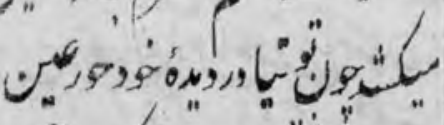

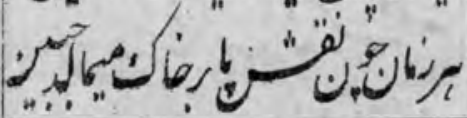

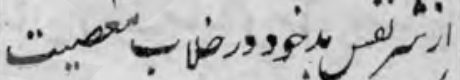

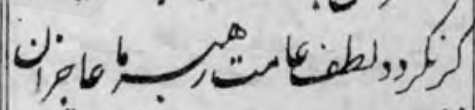

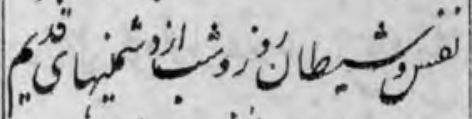
ros

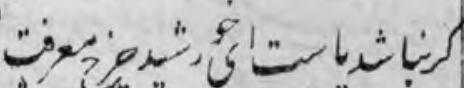
: " " 然 ن -

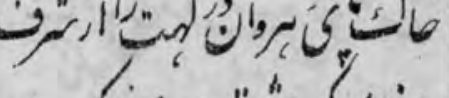
-

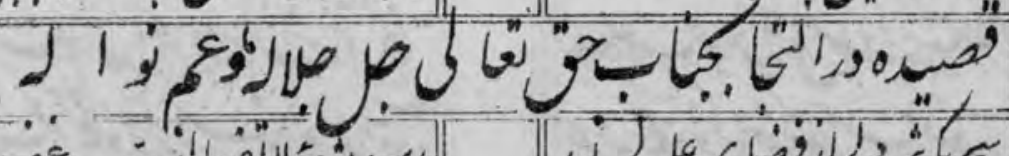
"

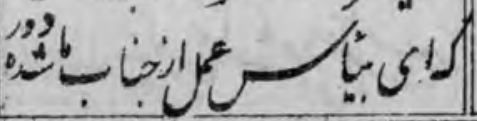

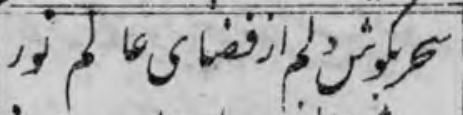

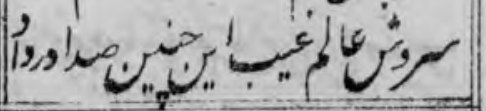




\section{8}

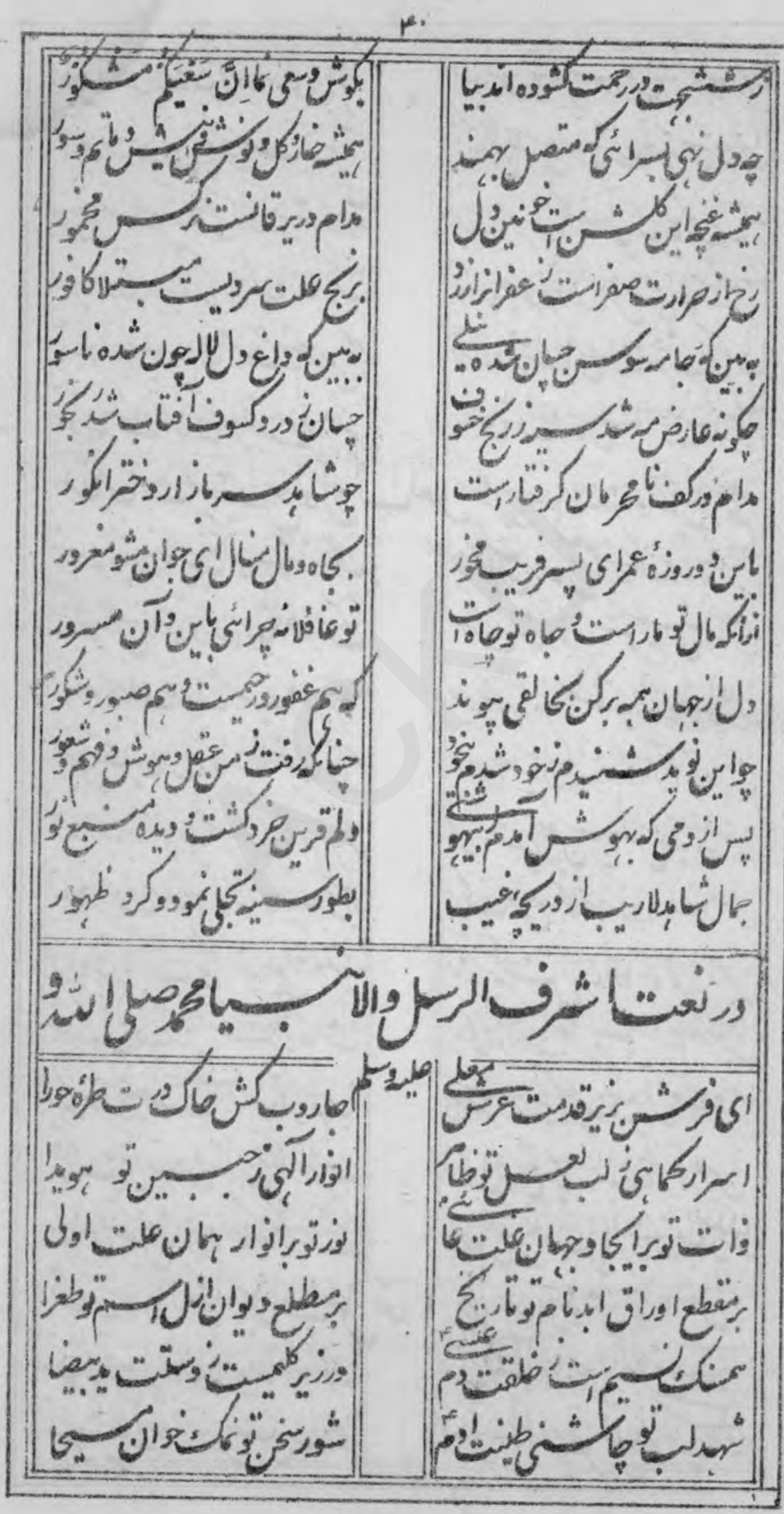

$\because \hat{p}^{\prime}$ 


\section{9}

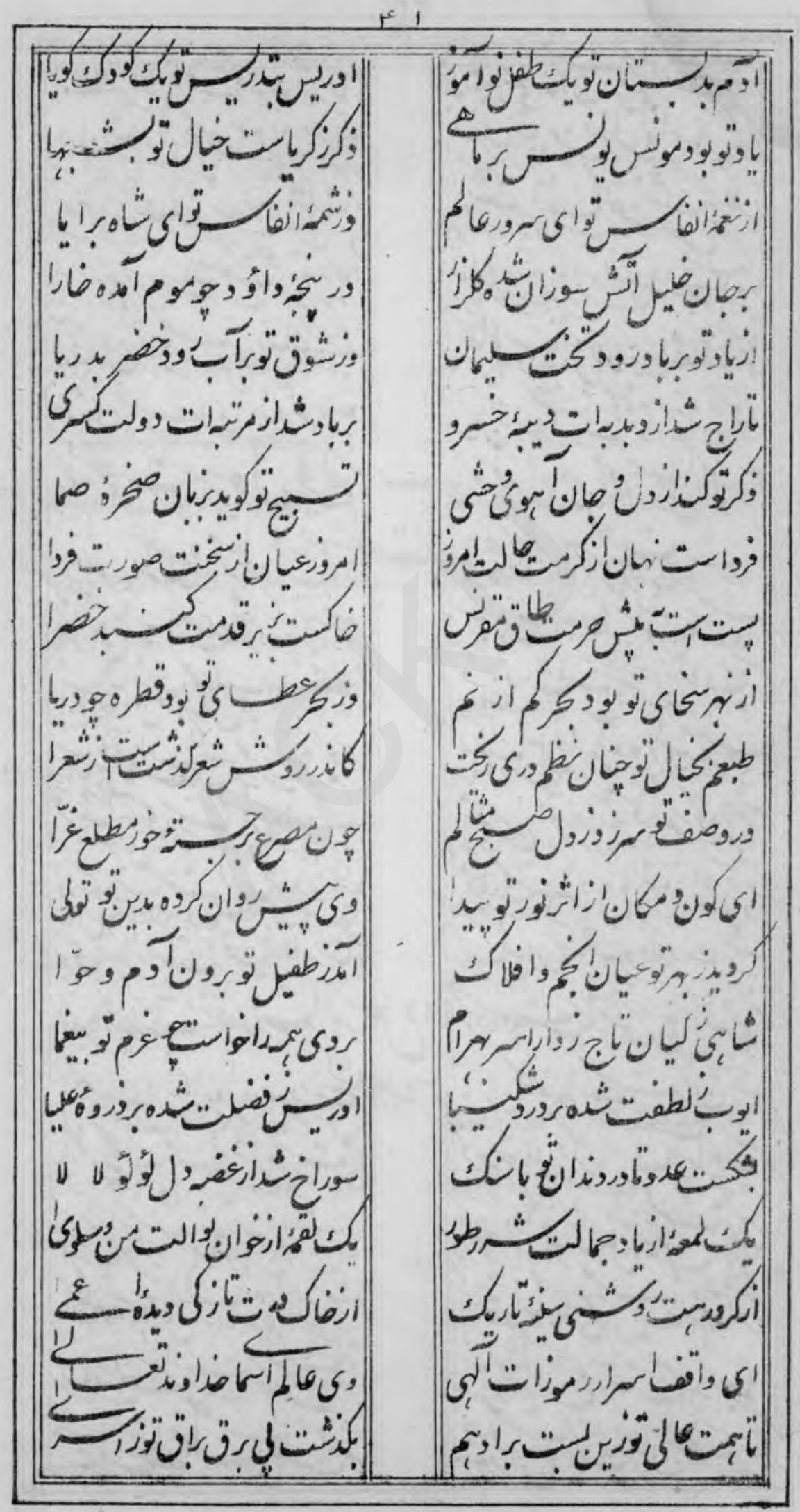




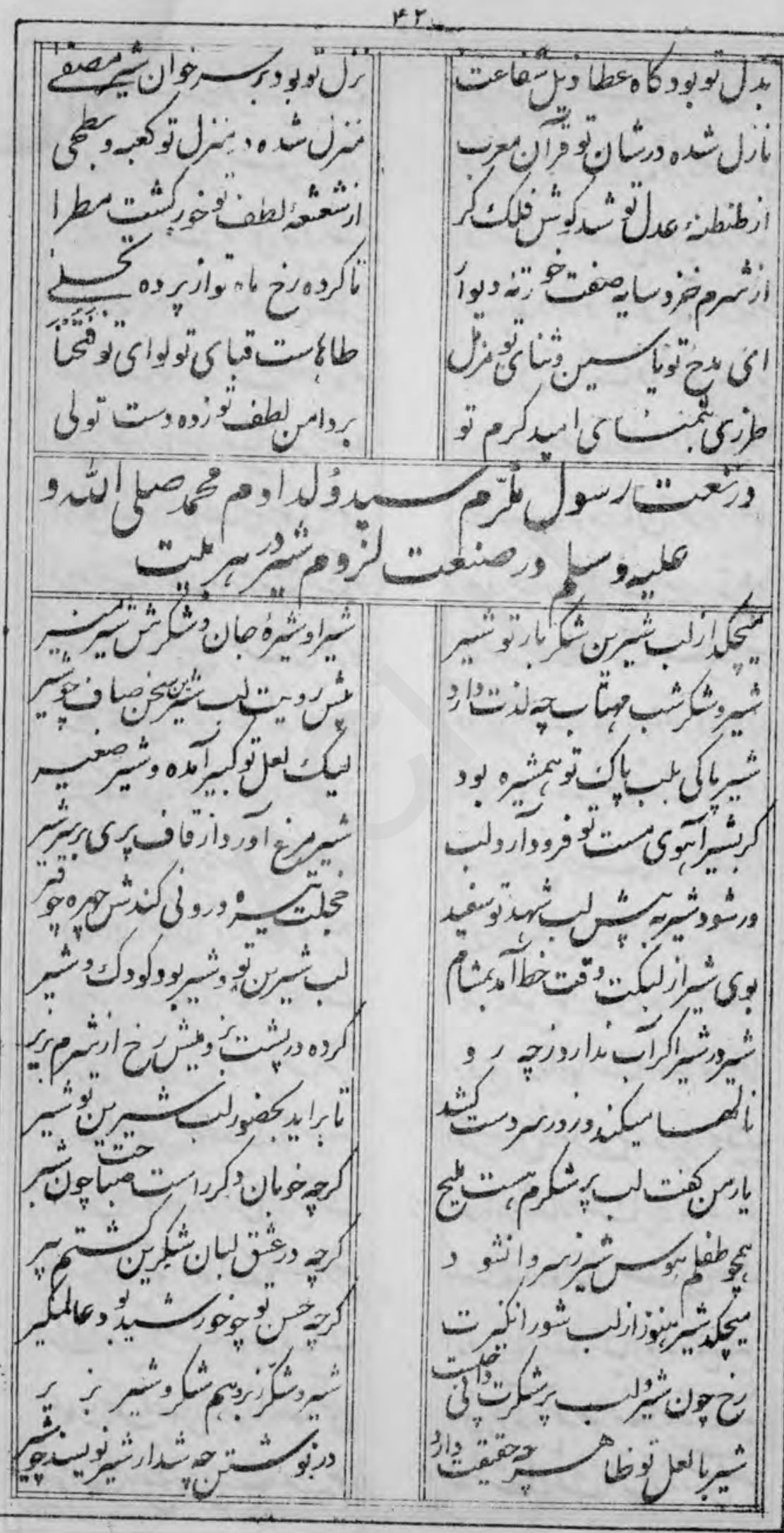


cr

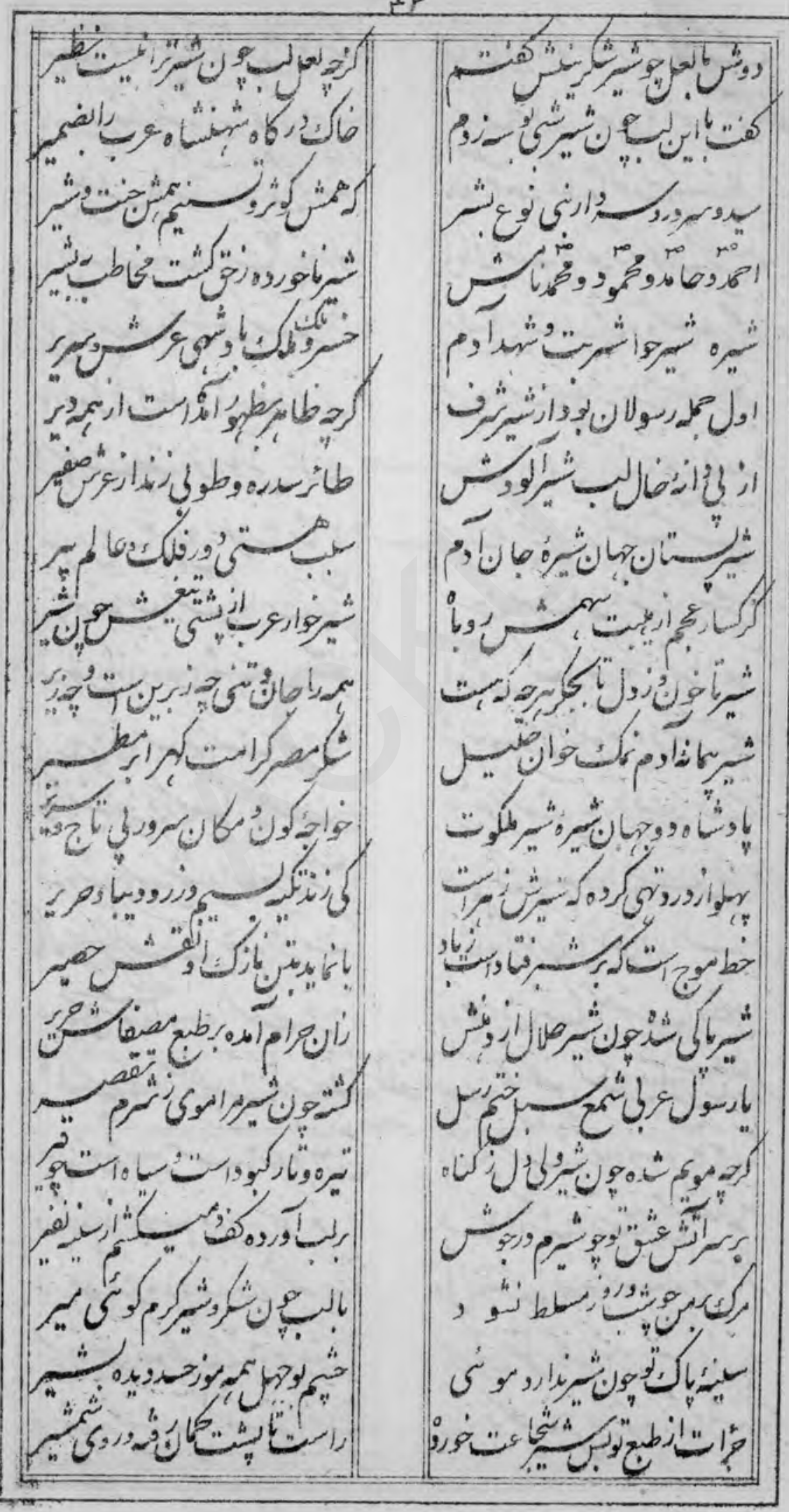


752

ع

|


so

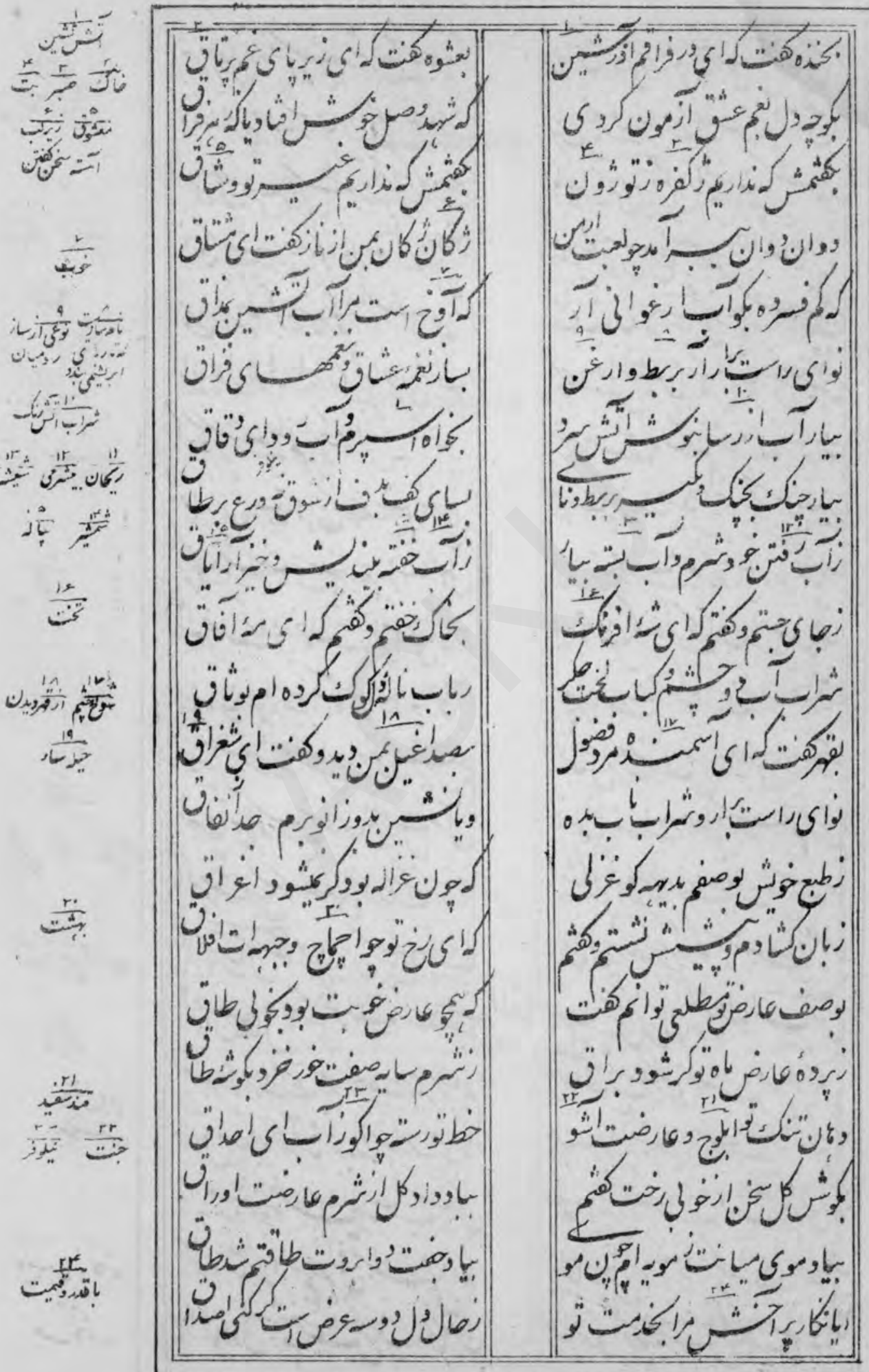




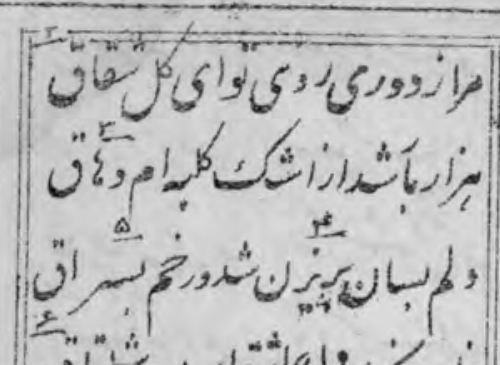

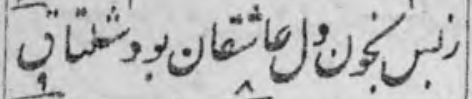

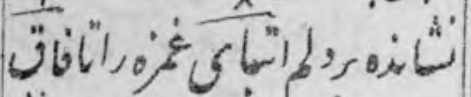
vib.

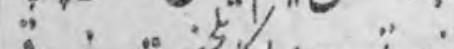

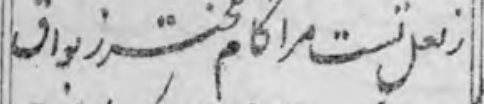
in Uigabicin

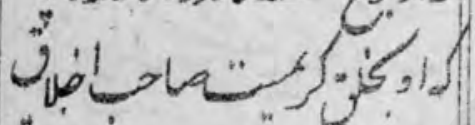

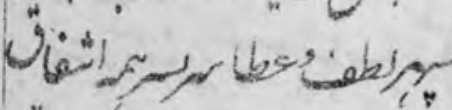

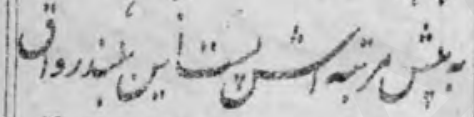

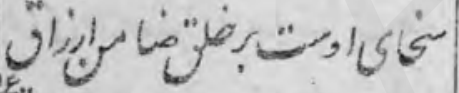

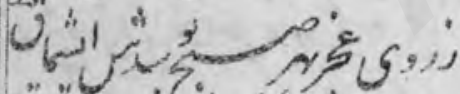
, in

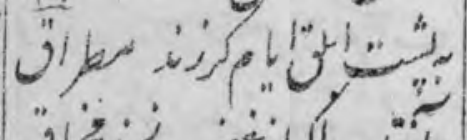

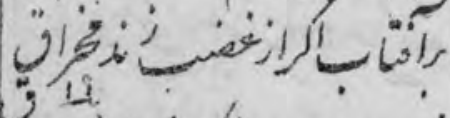

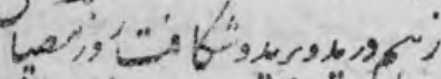

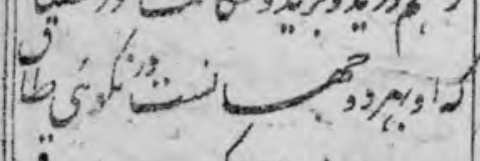

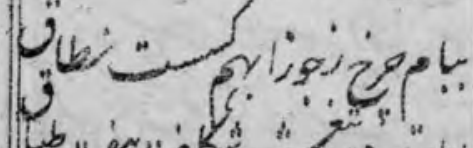
b $r^{2}$

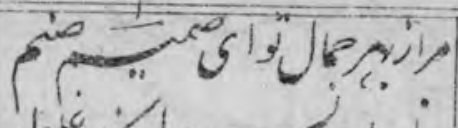
be aib * i cole...

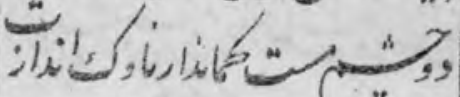

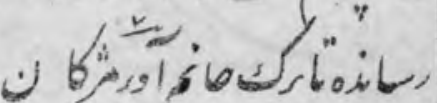

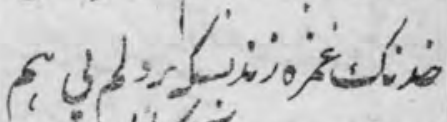
. vo , कु है

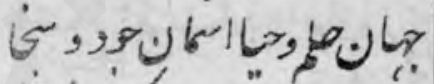
: $\int 1906$ be i,

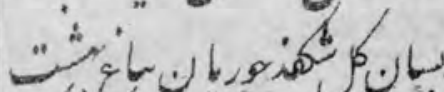
- E- . مem (… …"

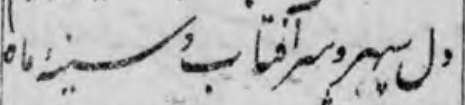
(1) " i"

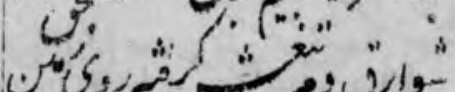

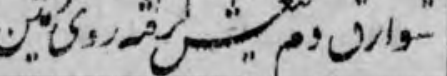




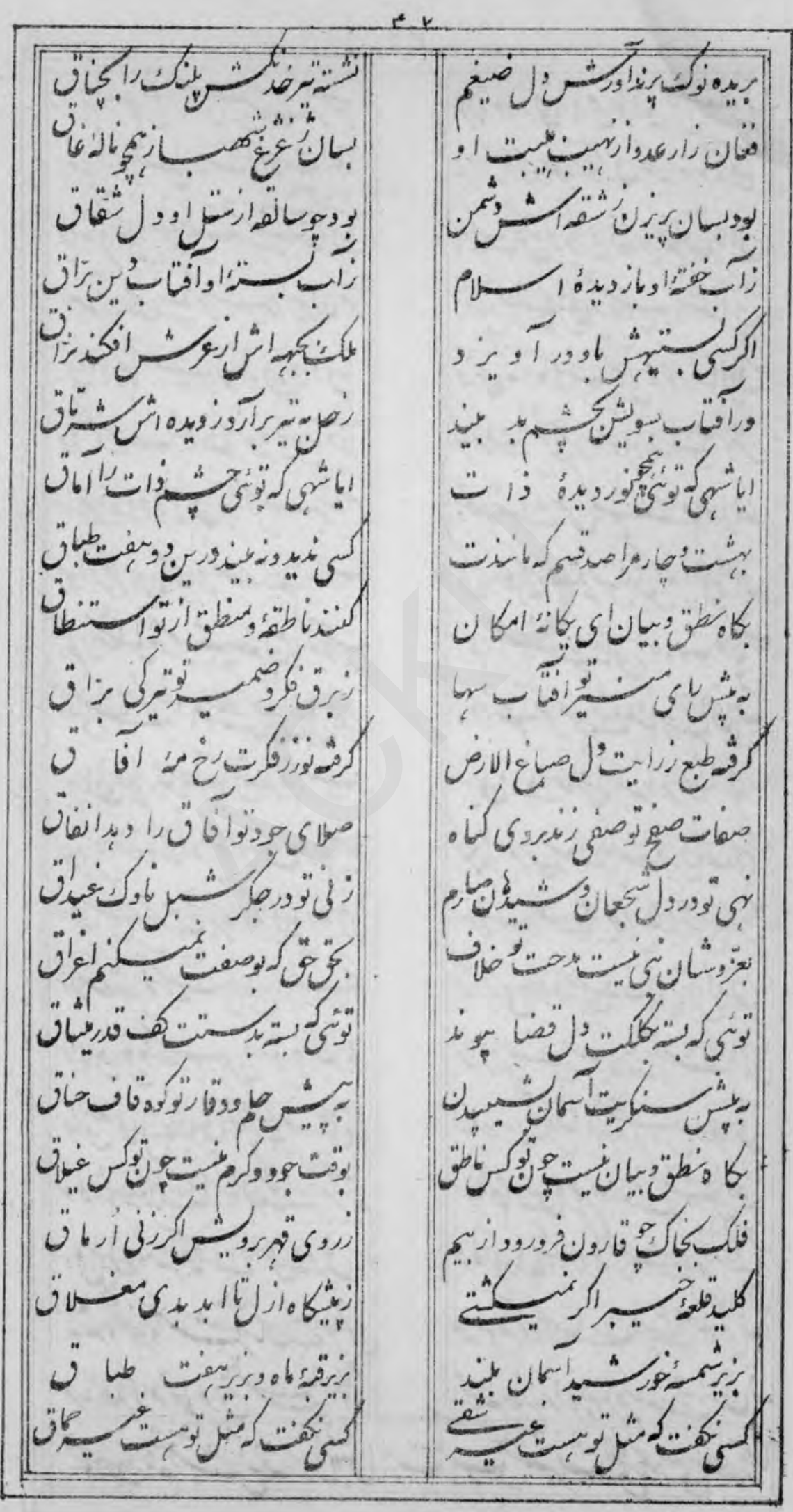




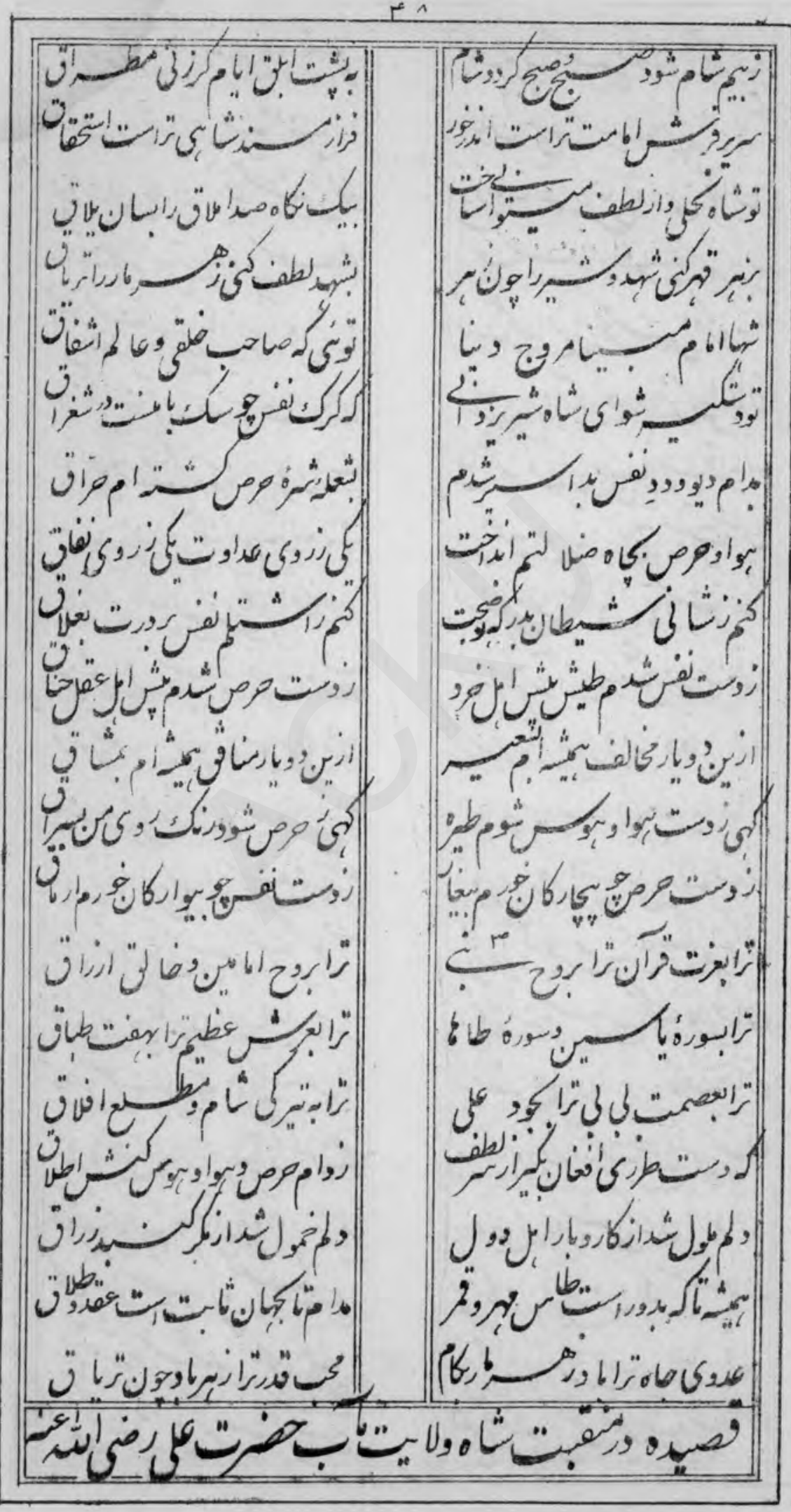


\& 9

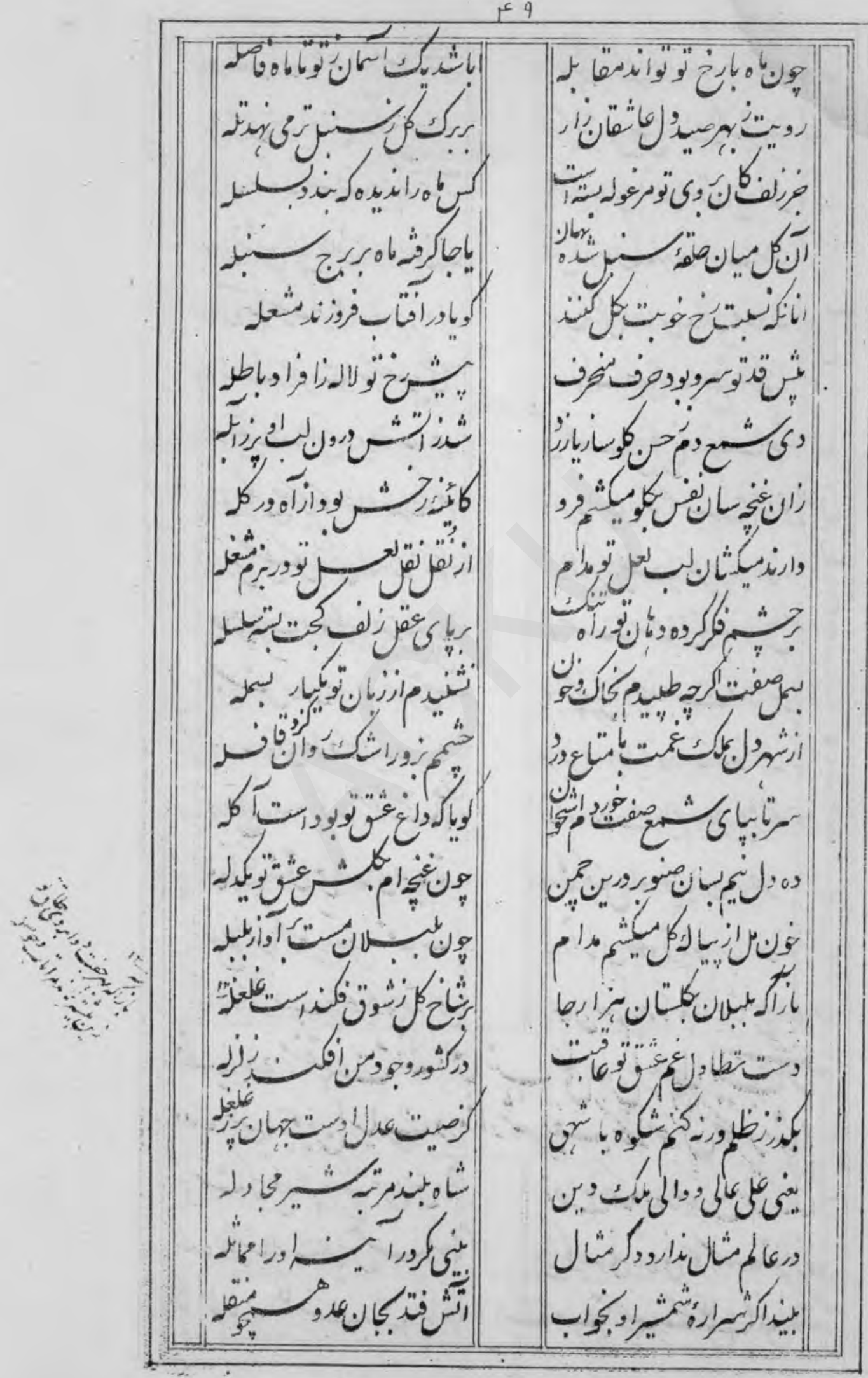


$\Delta$.

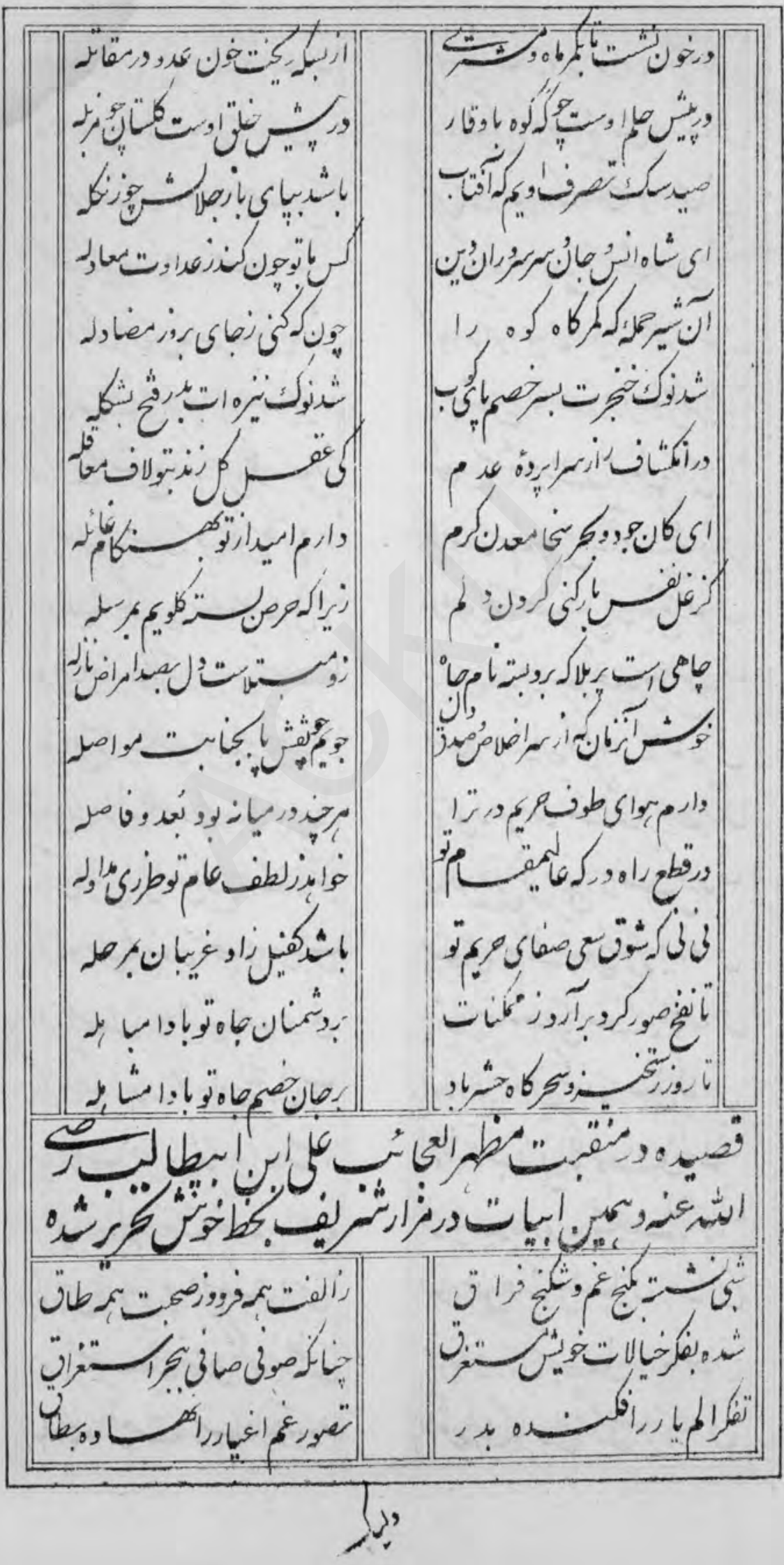


D 1

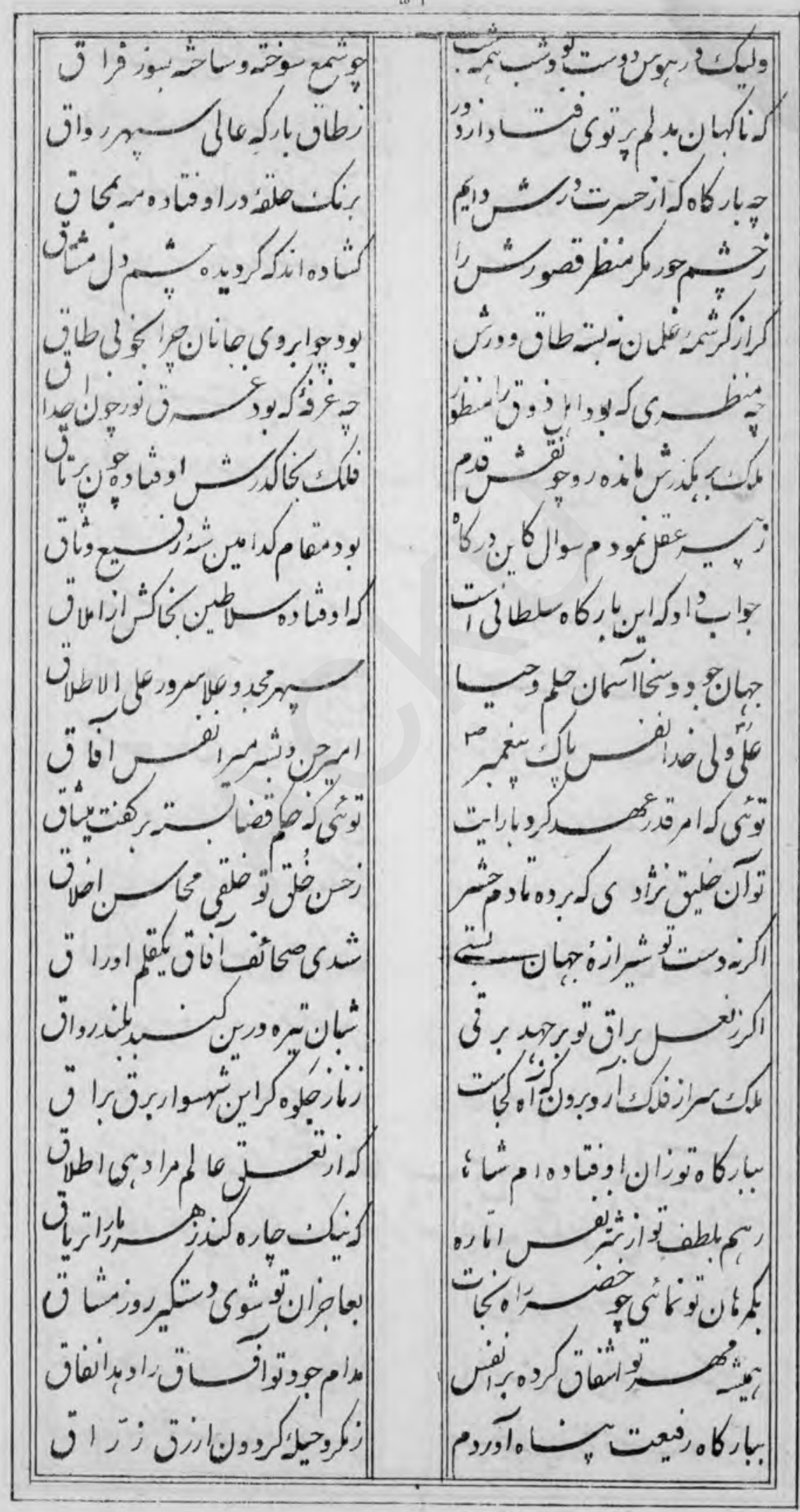




\section{0}

ar

|


$\Delta r$

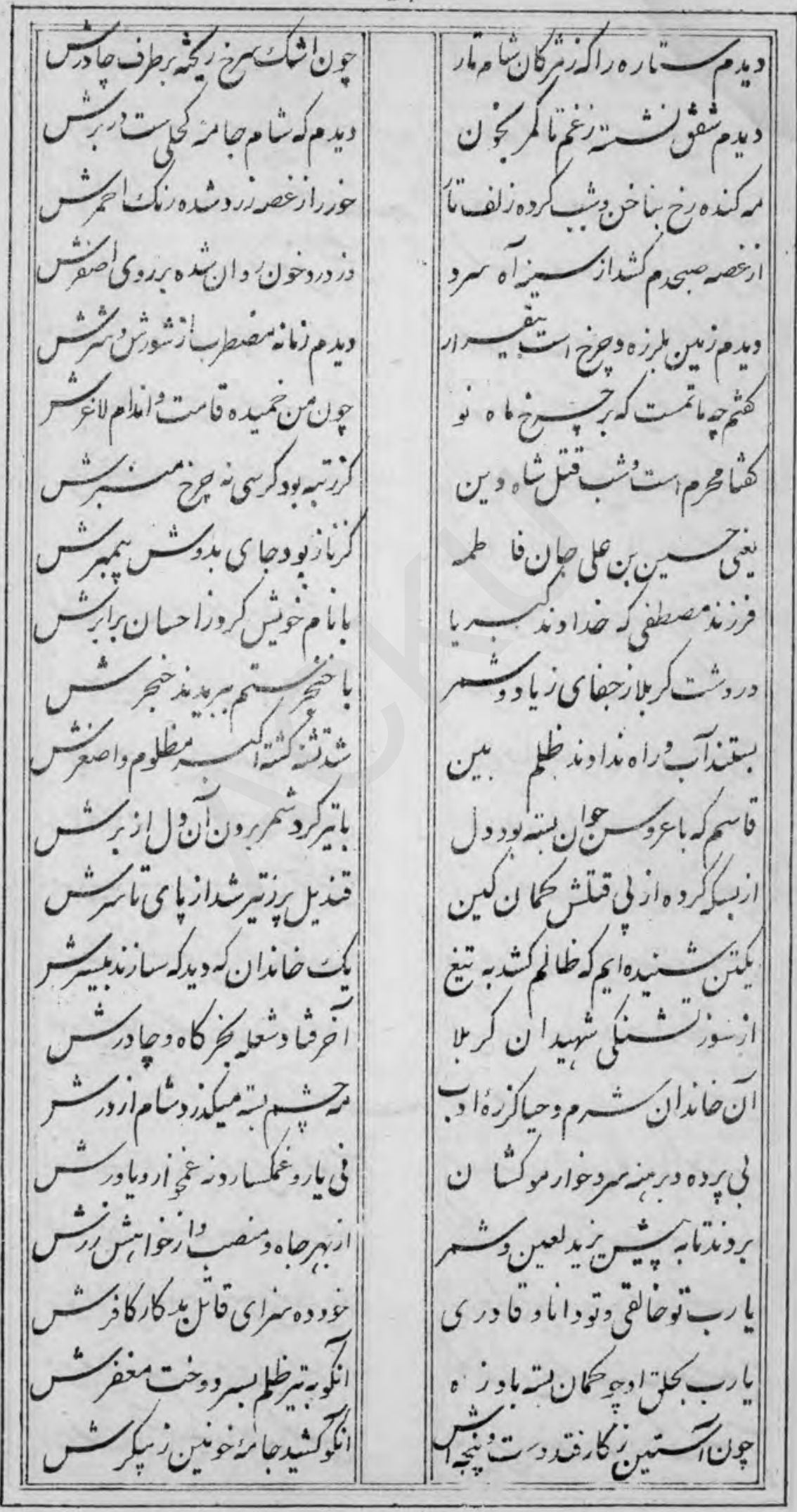




\section{2}

a r

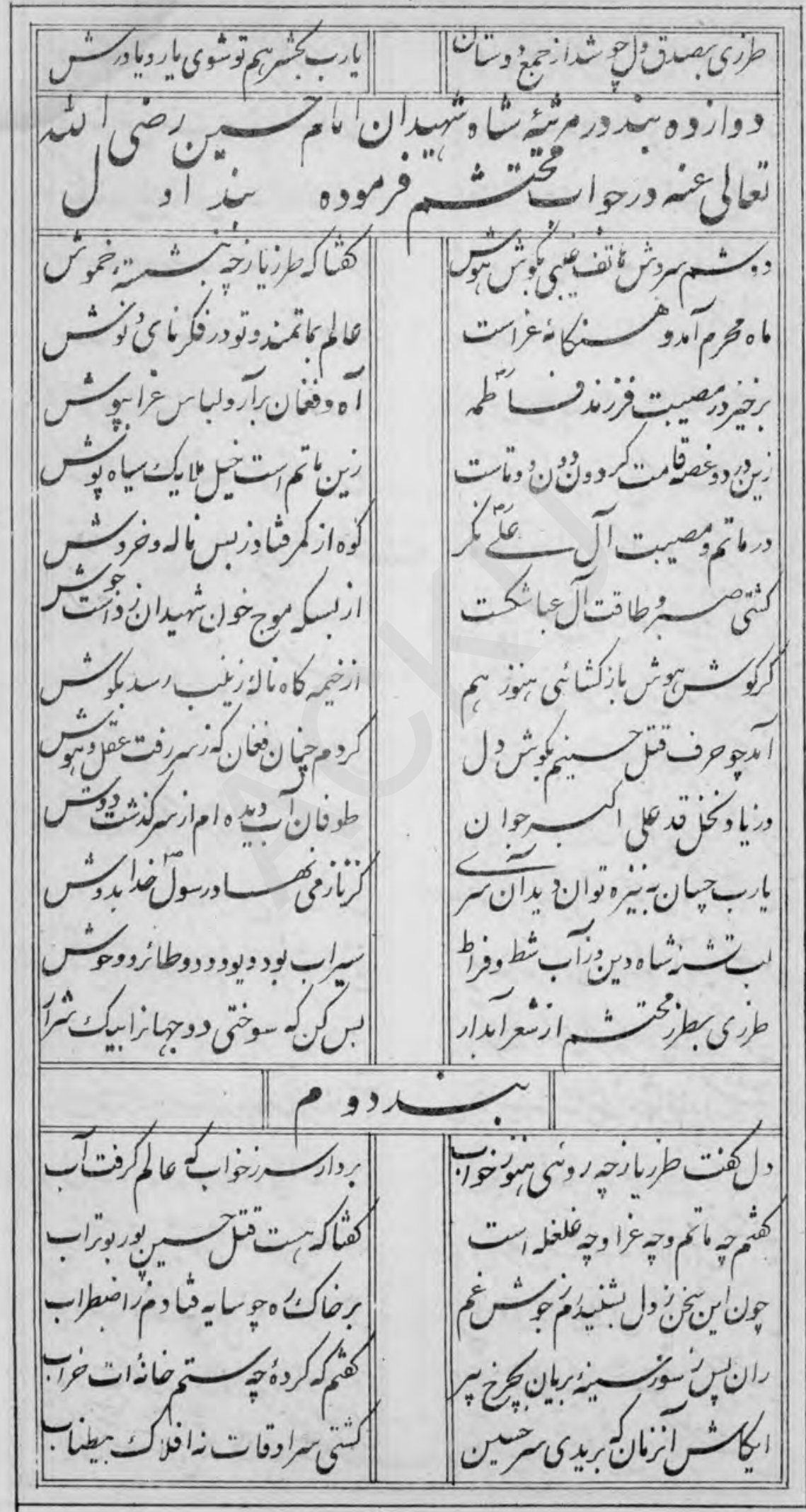




\section{3}

a) 1

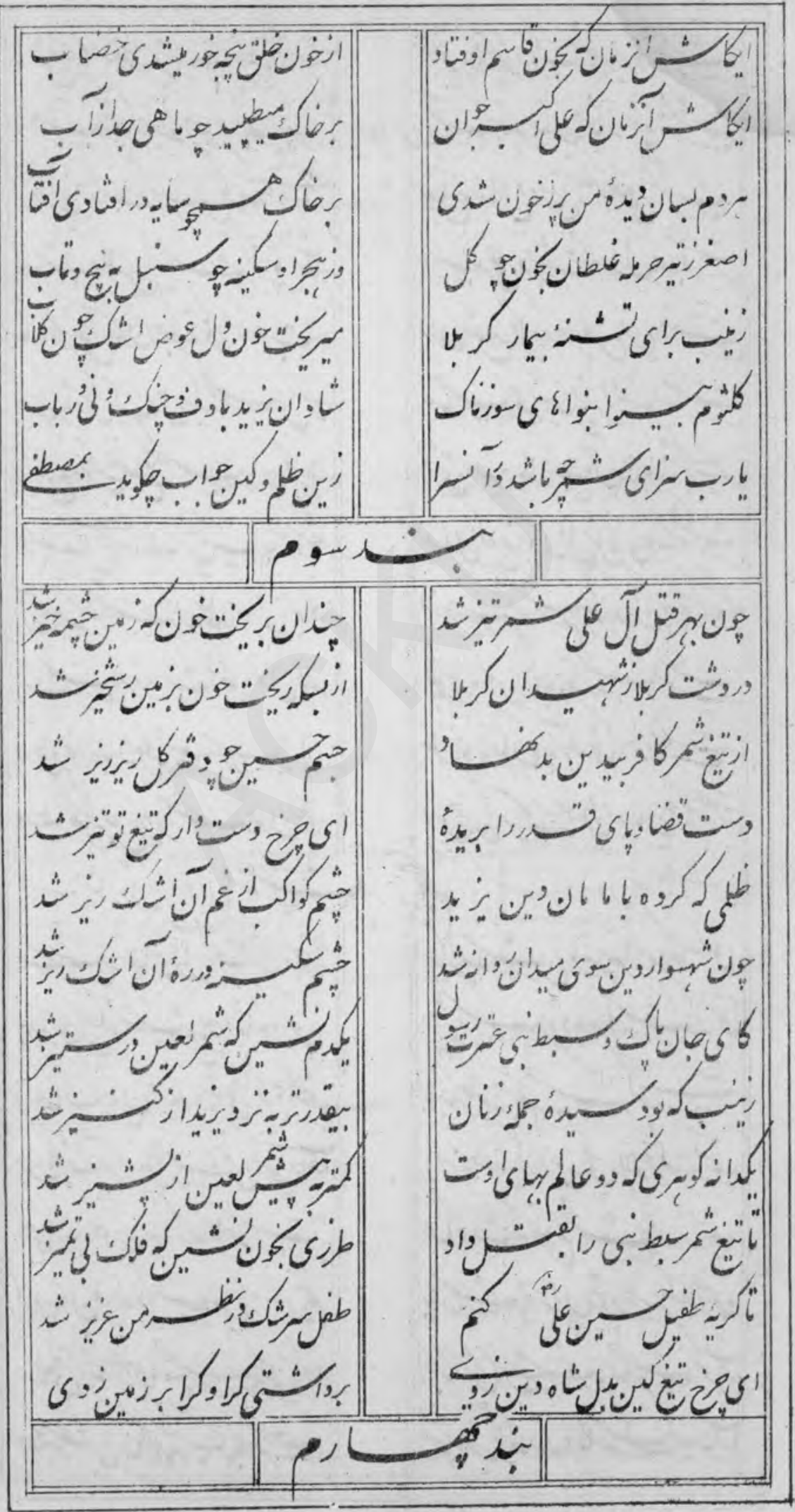




\section{4}

$\Delta S$

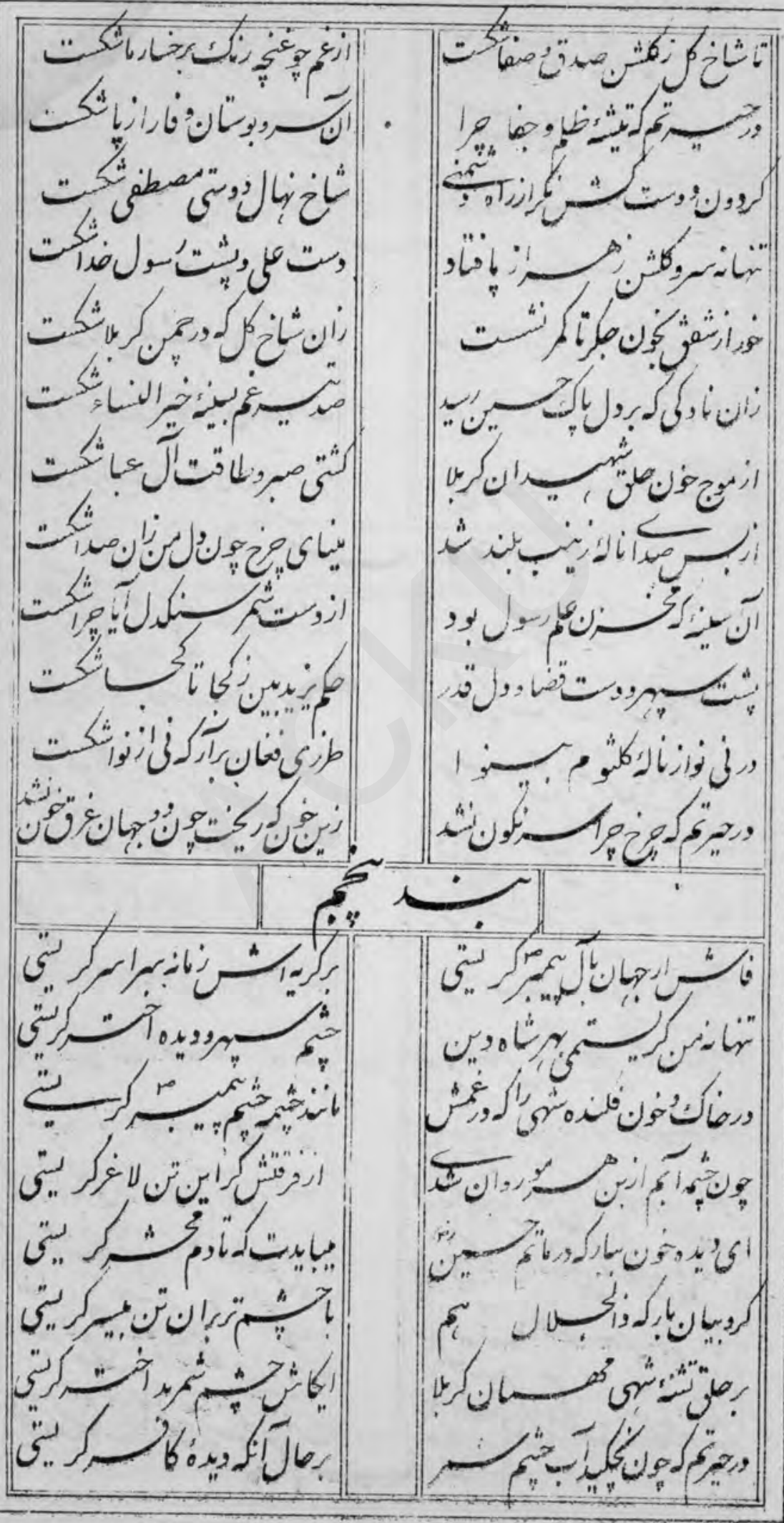

$\Rightarrow \quad$ 


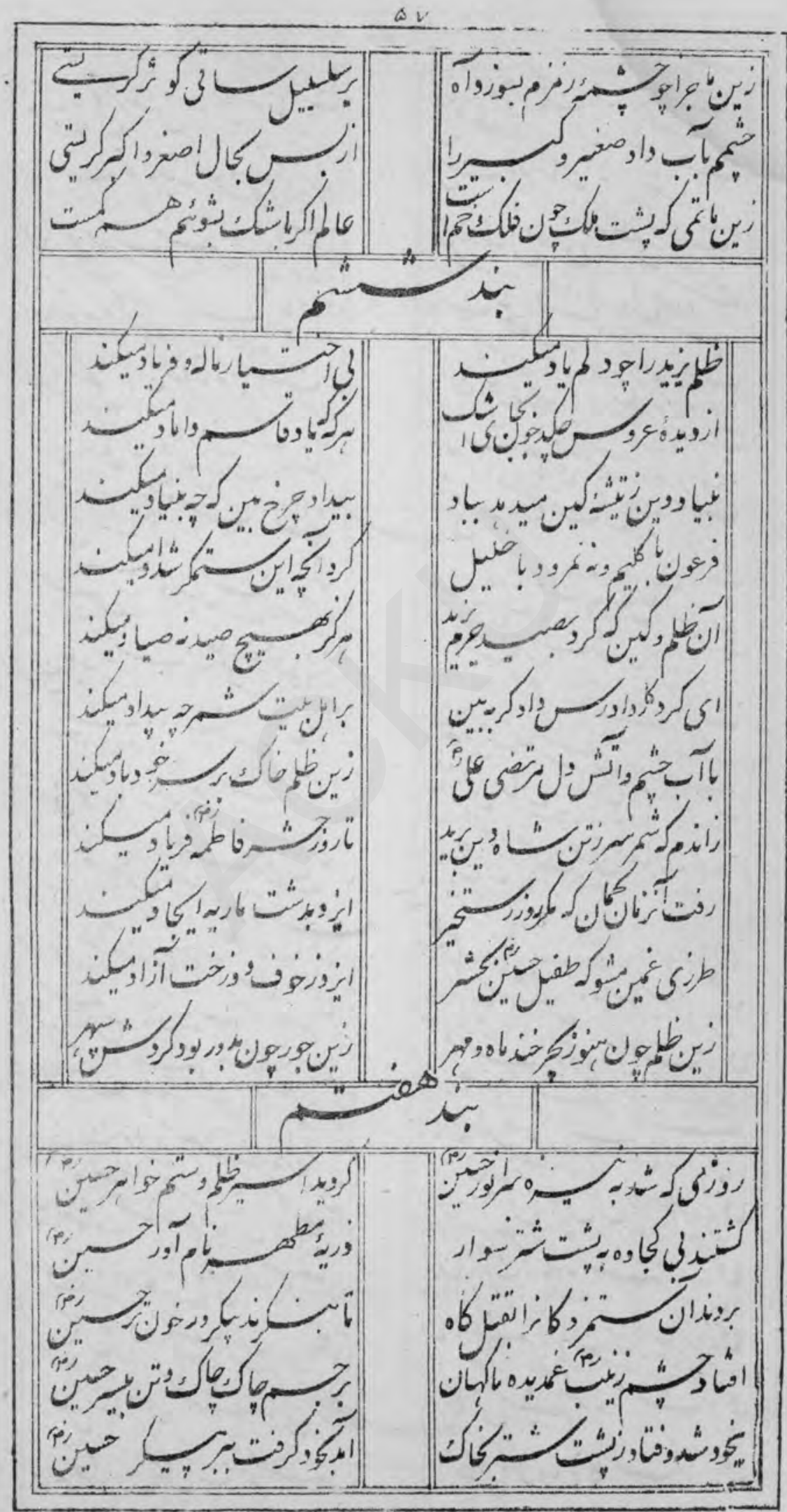




\section{6}

$\Delta \wedge$

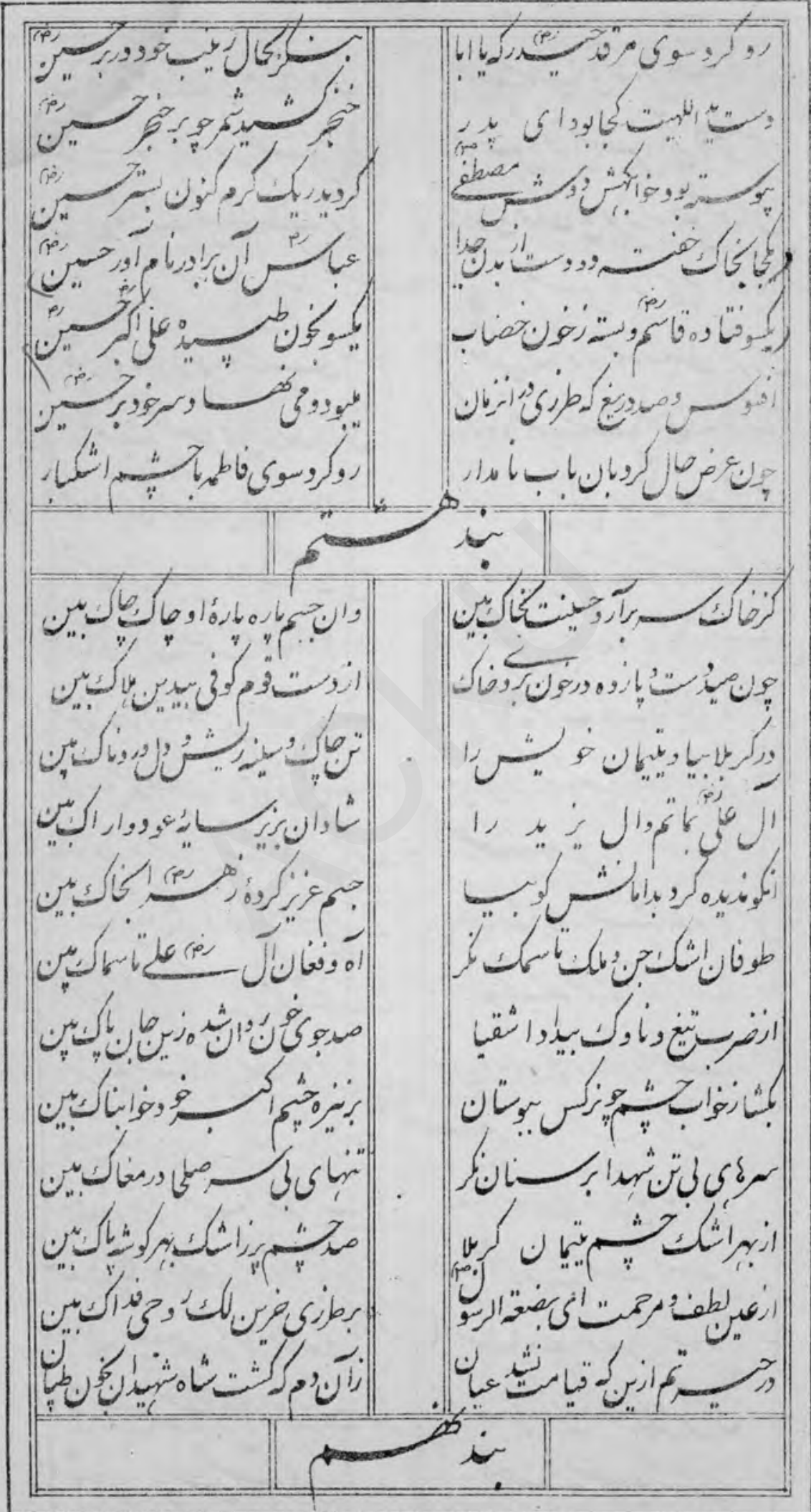


$\Delta q$

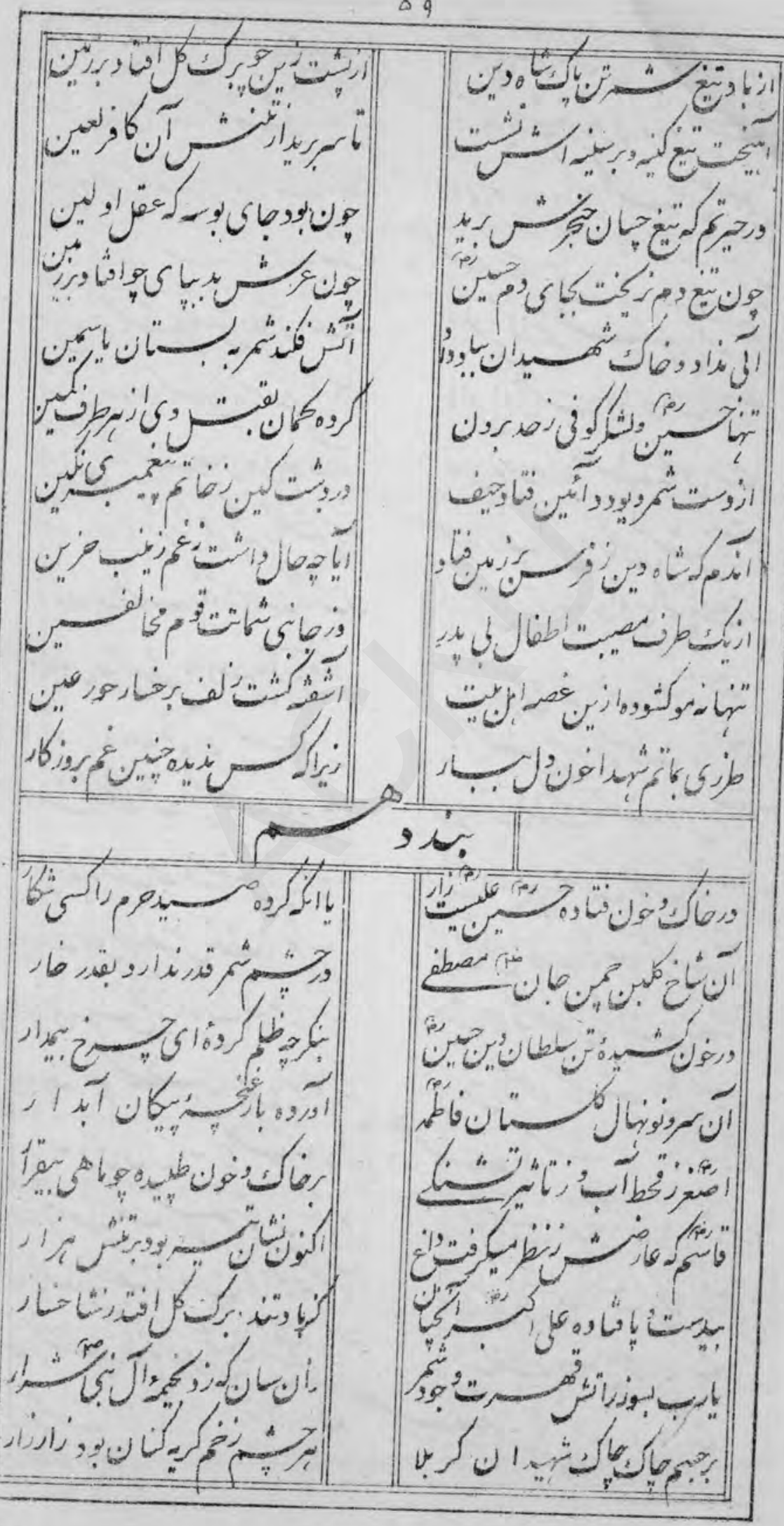


768

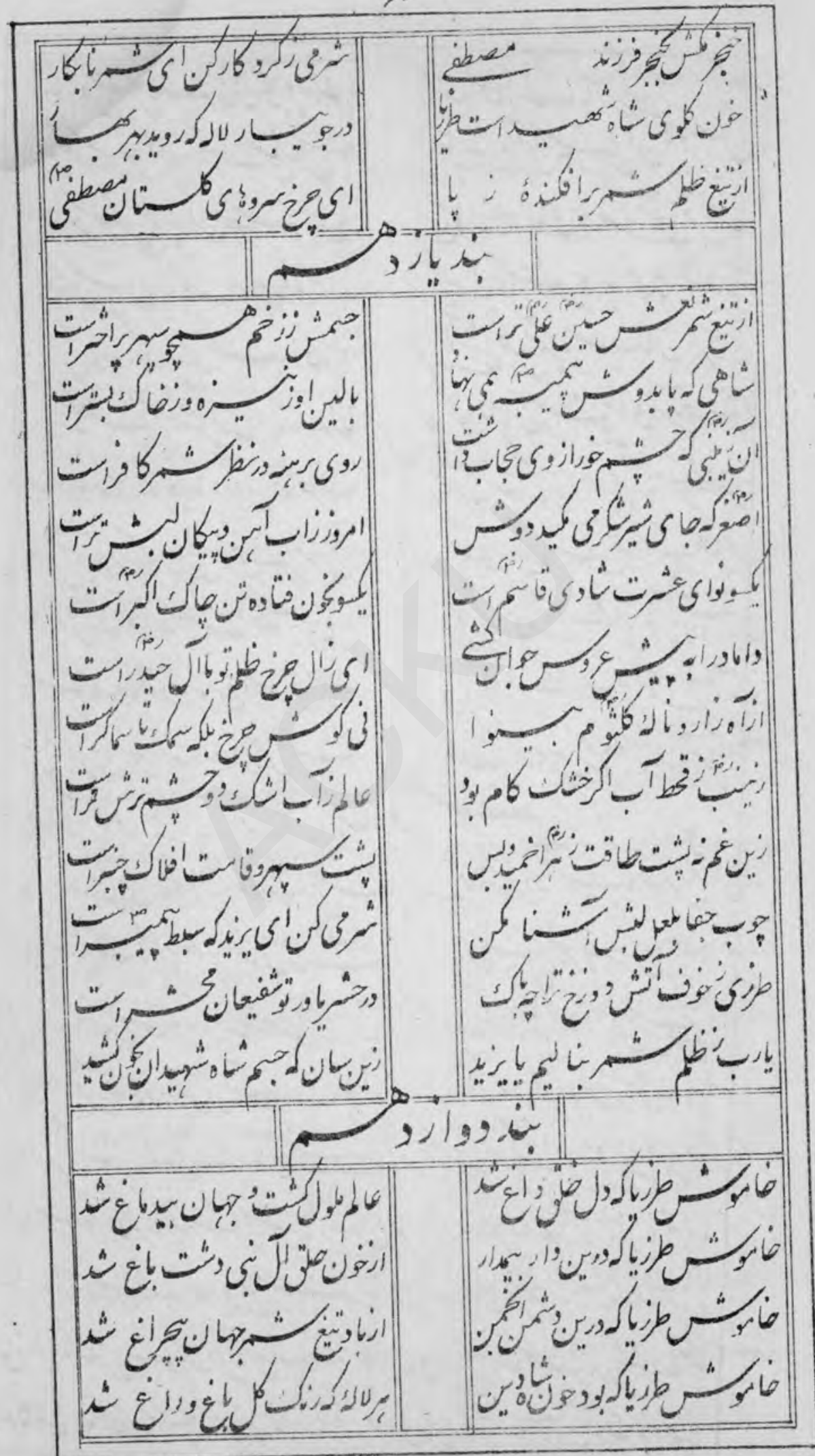

3 


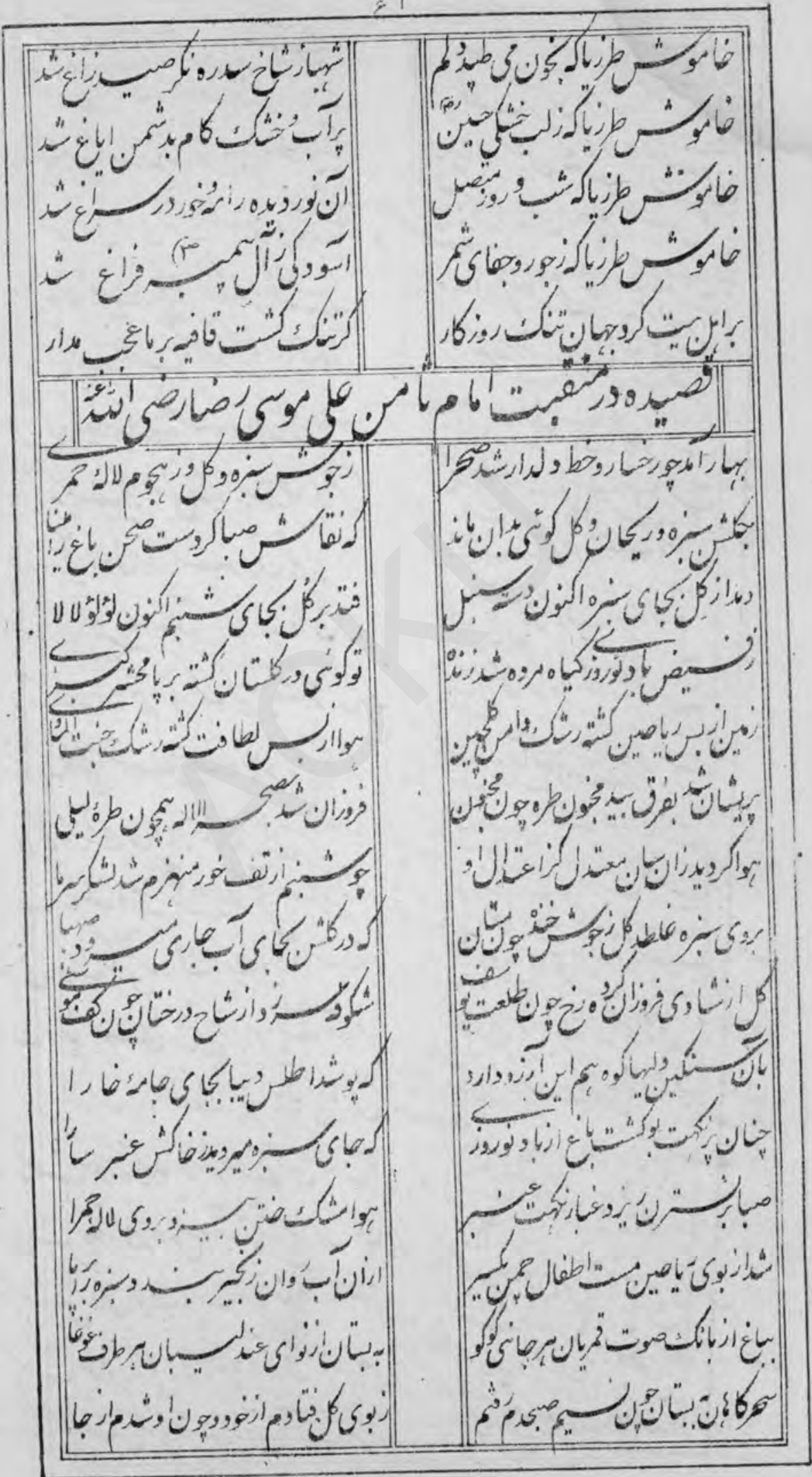




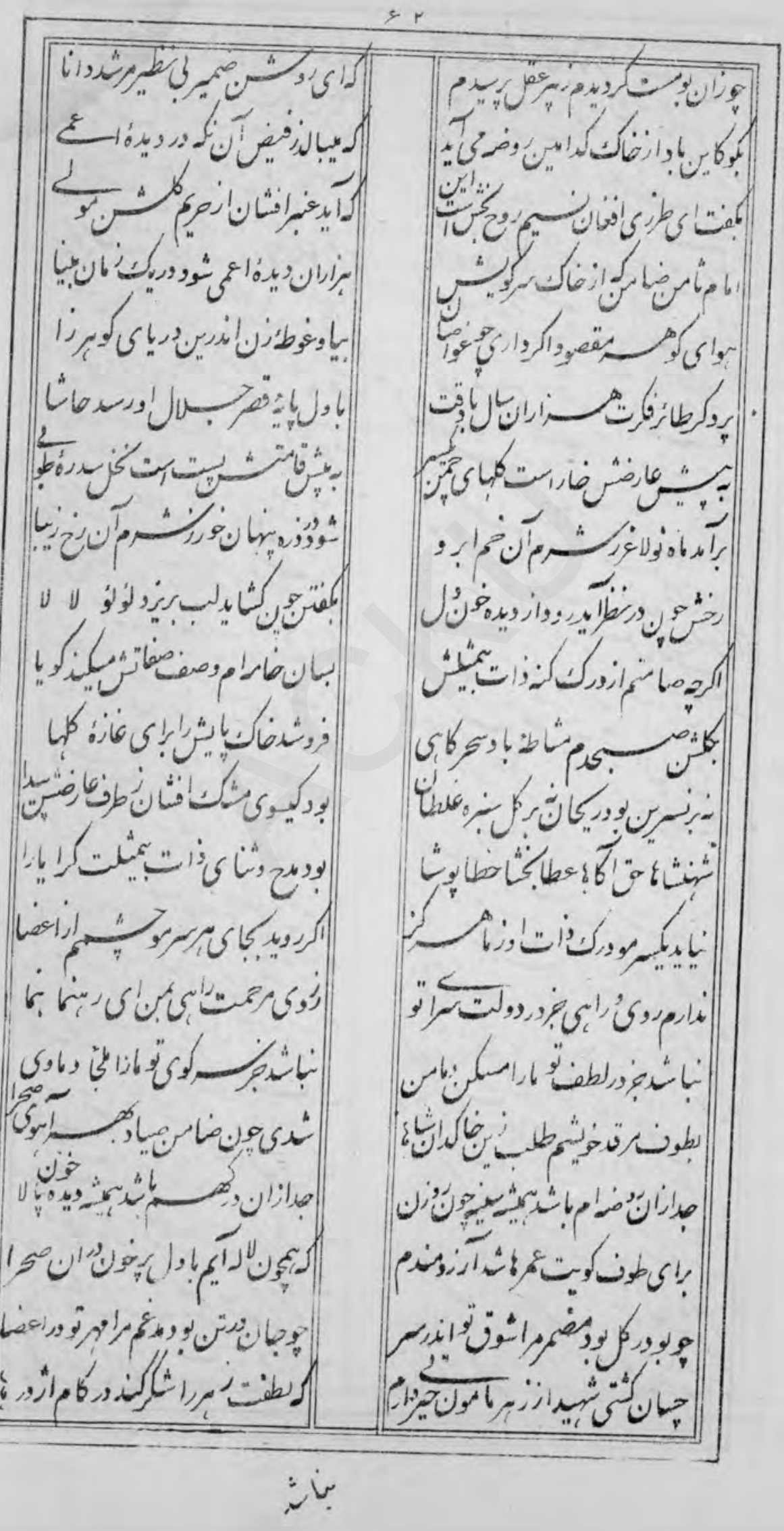




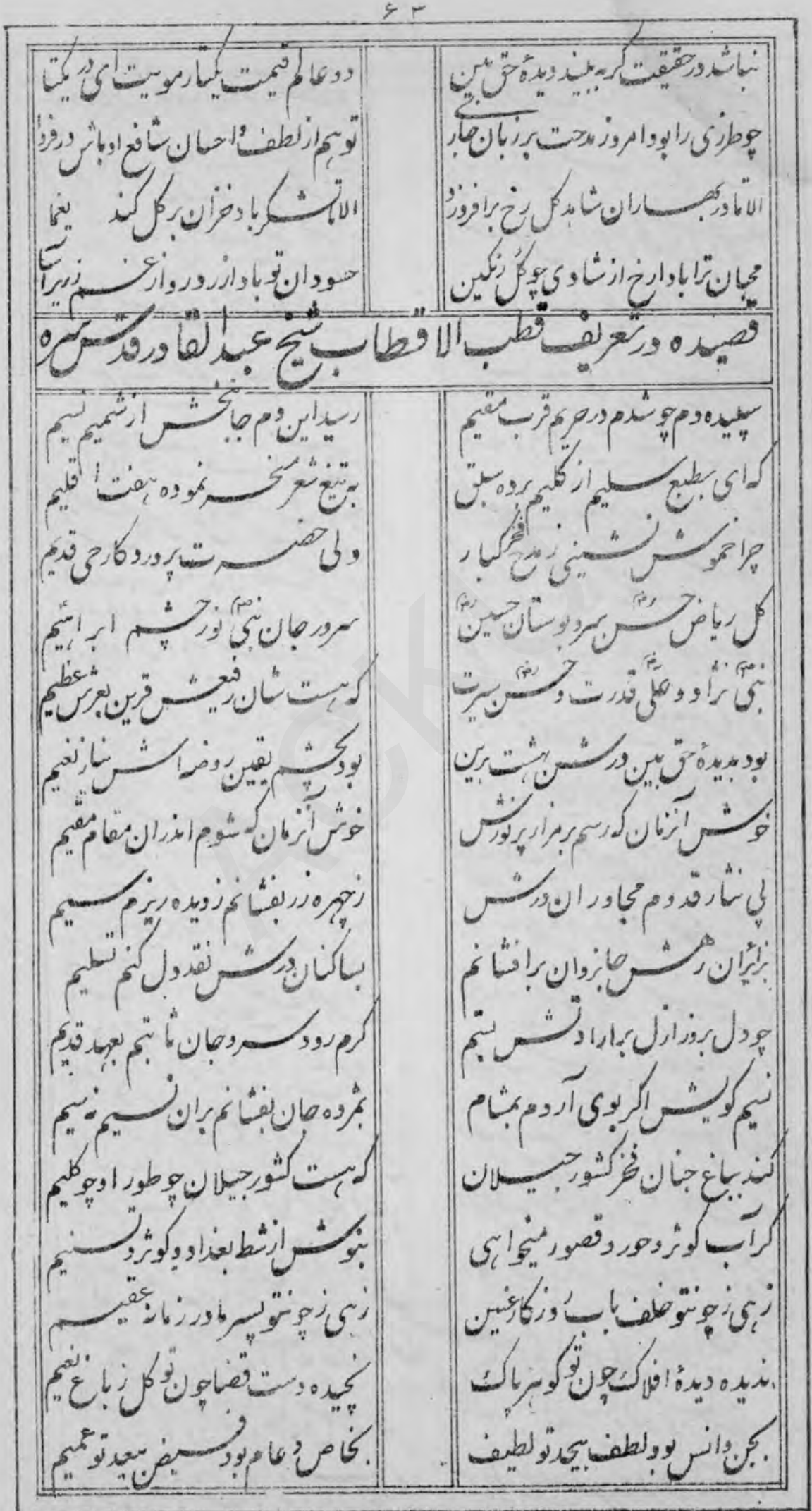


4

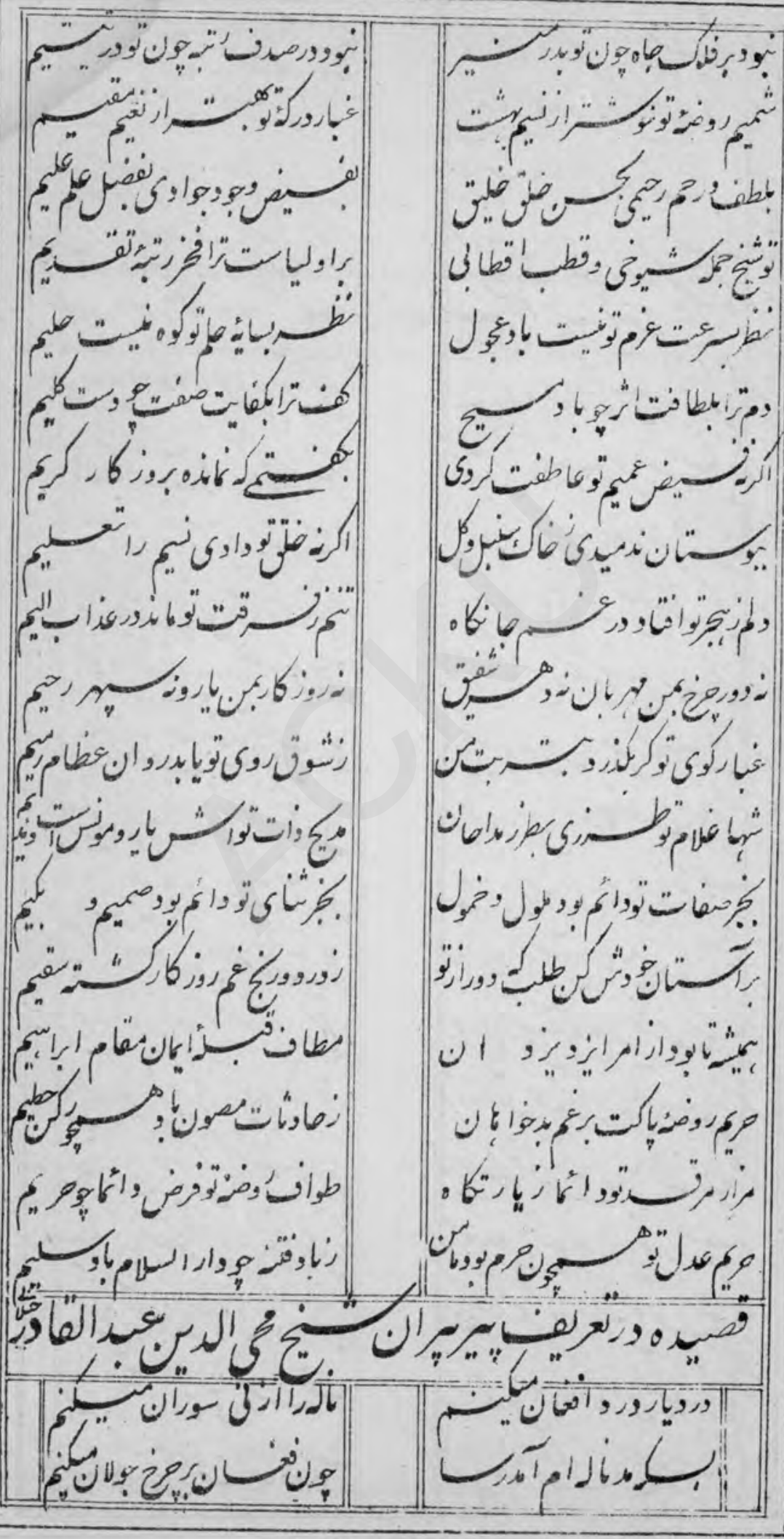




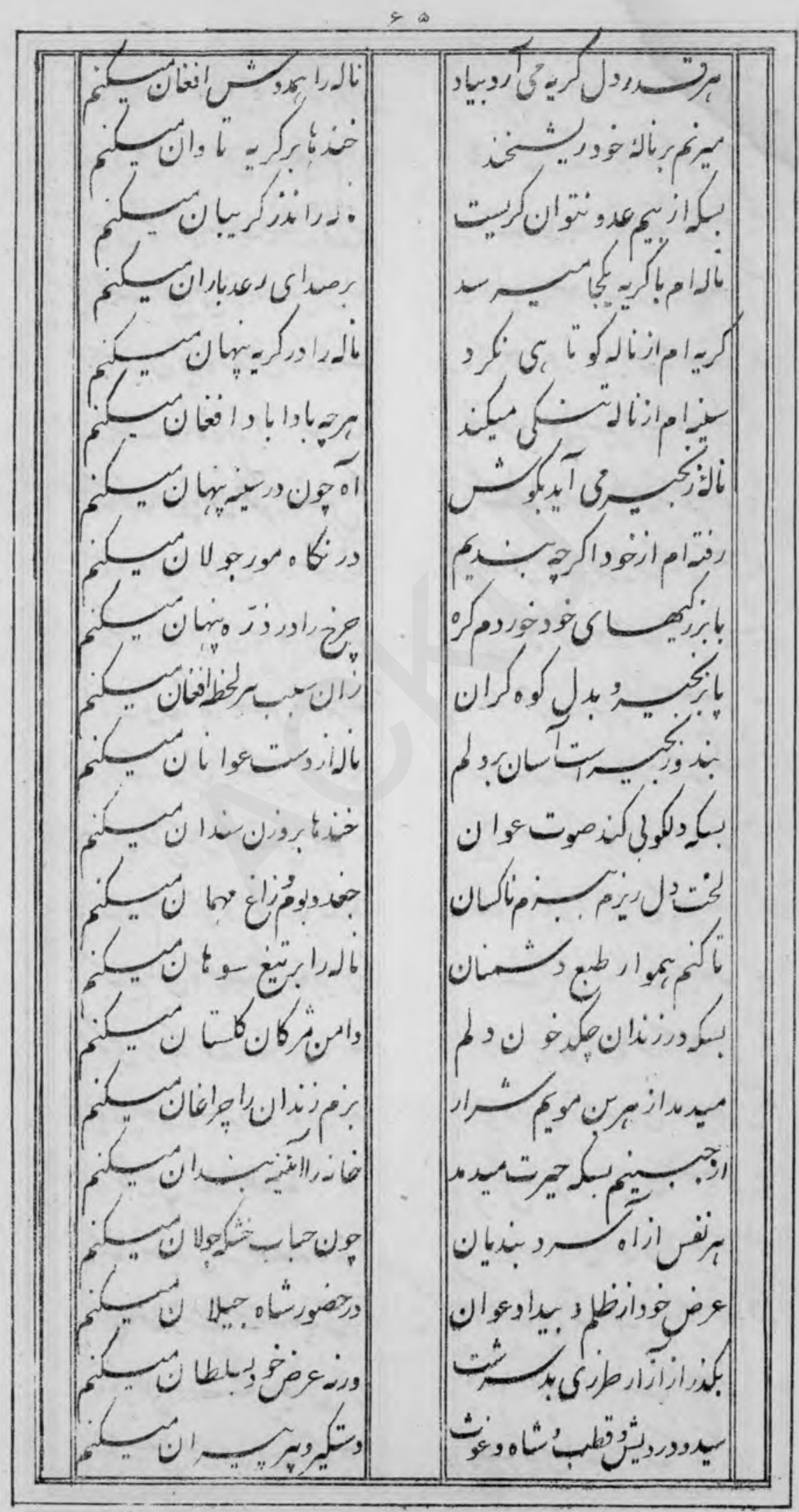




\section{4}

45

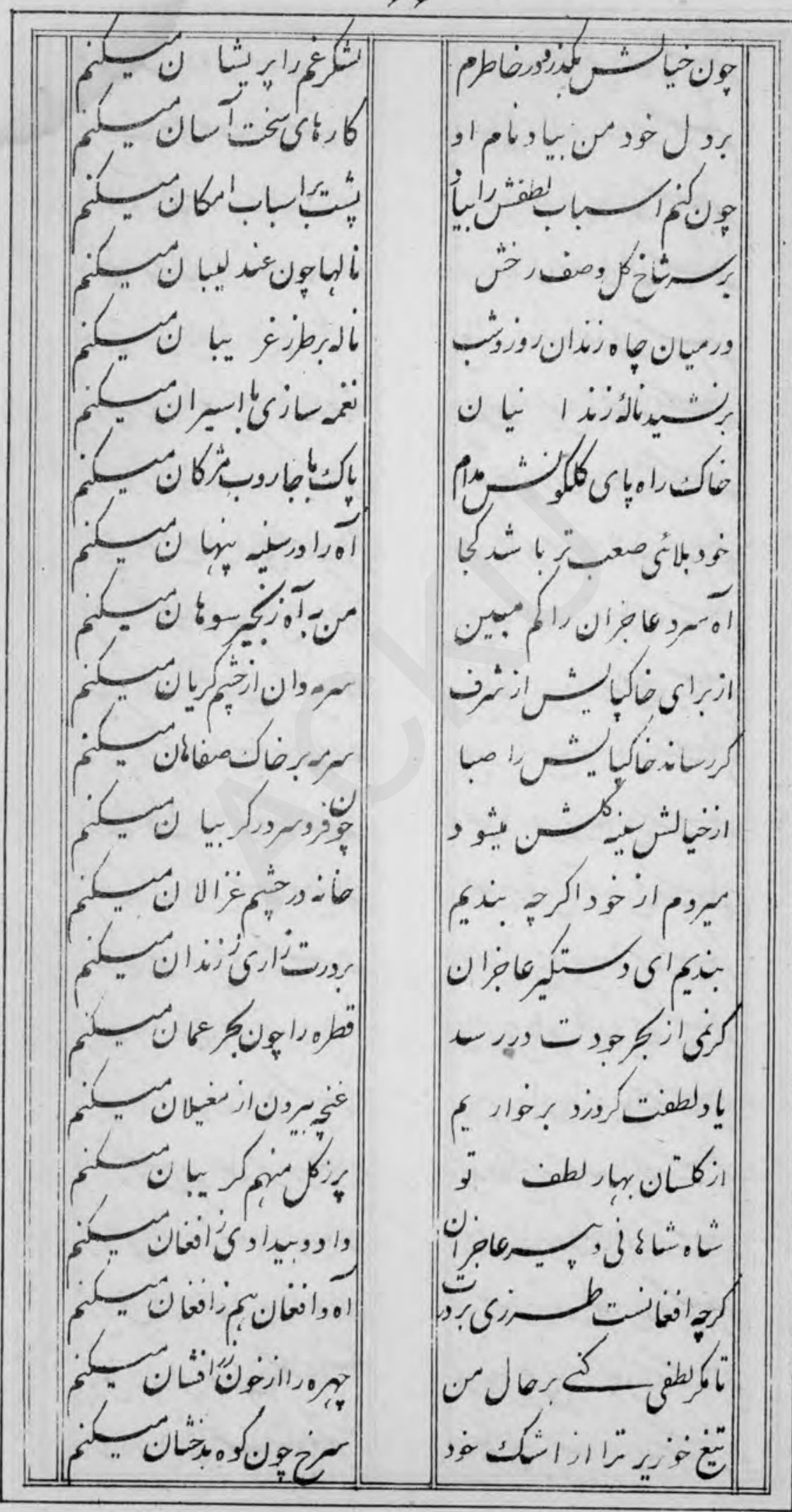

$y$ 


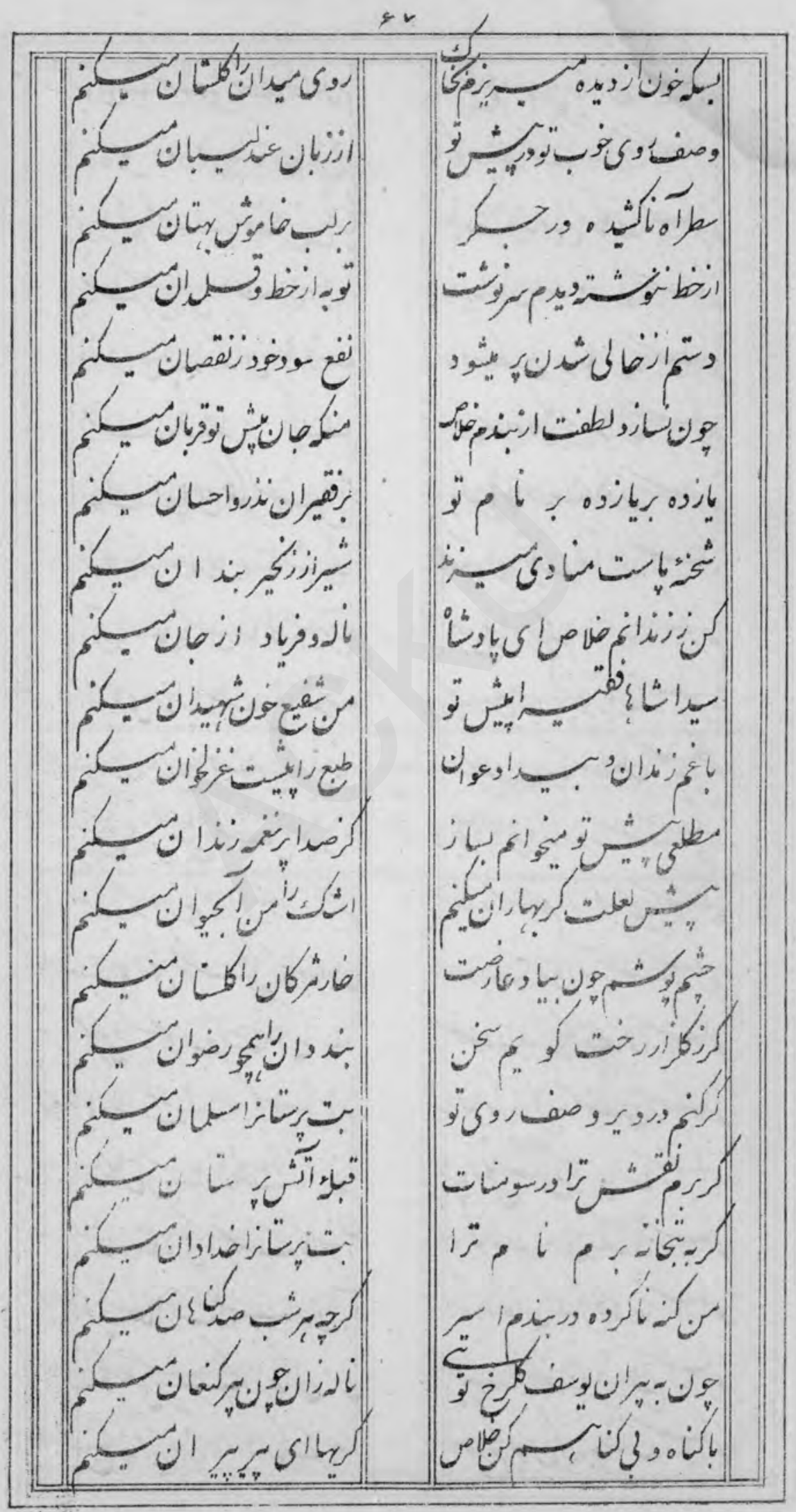




\section{6}

c 1

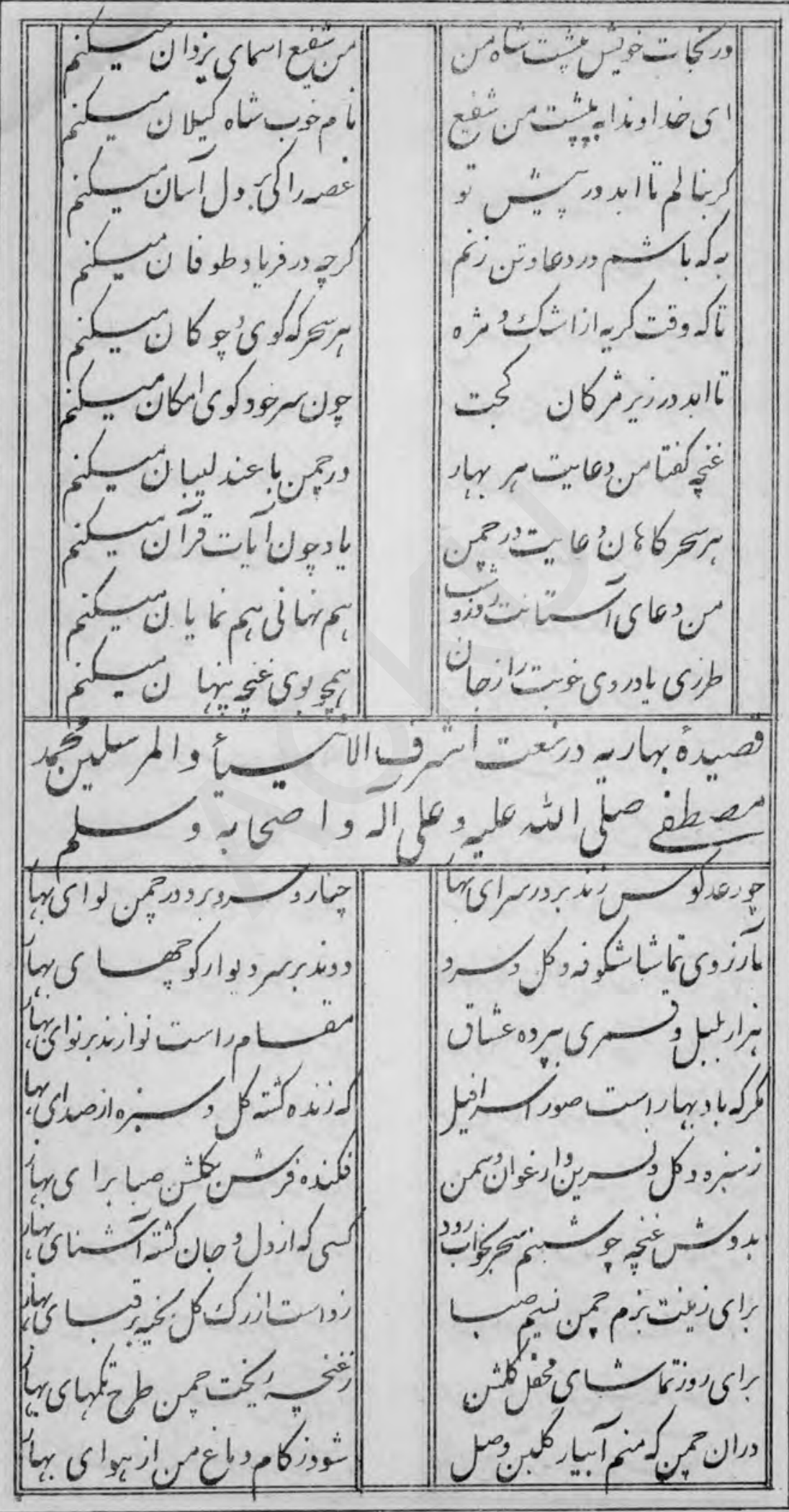




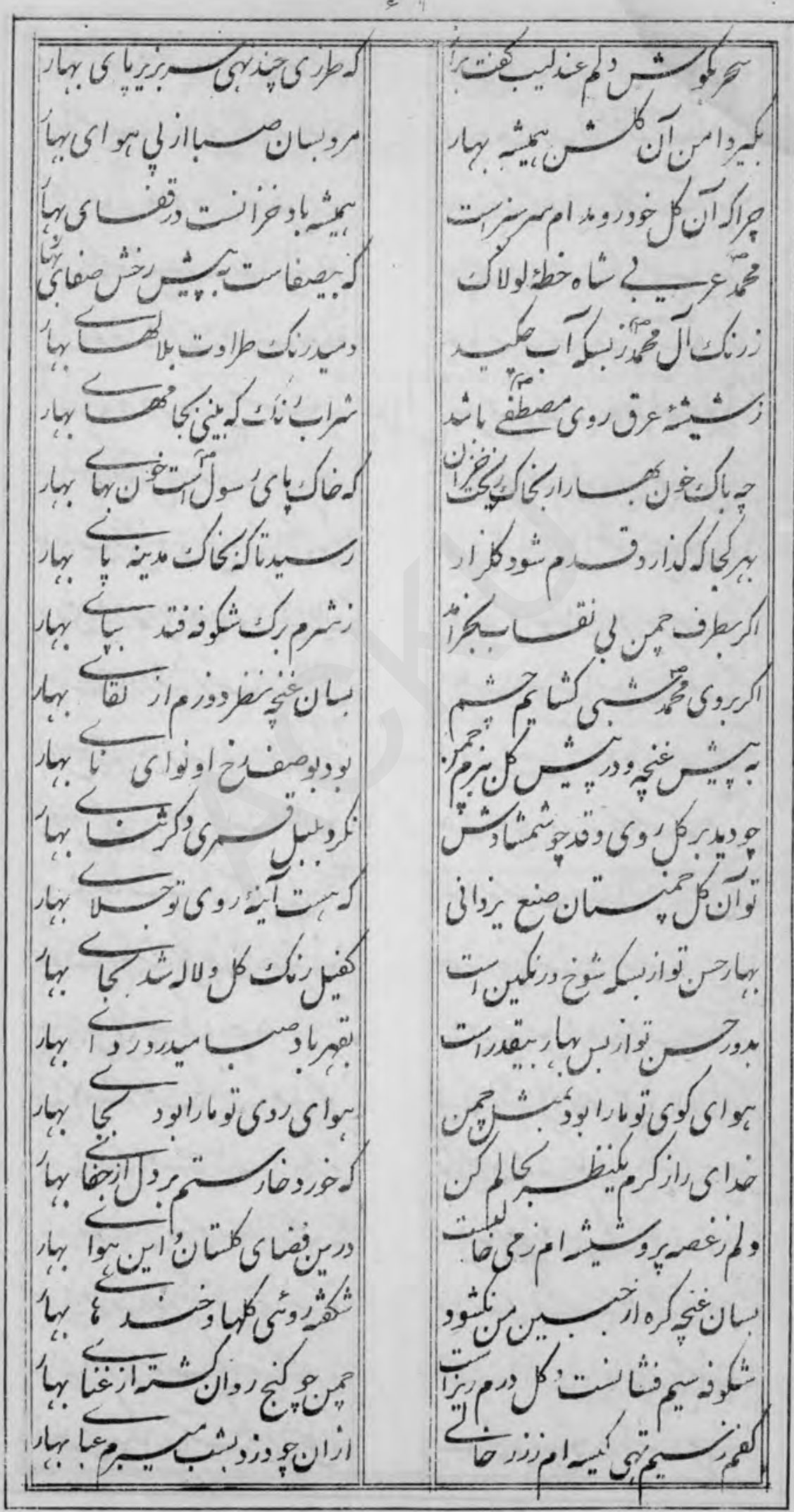




\section{8}

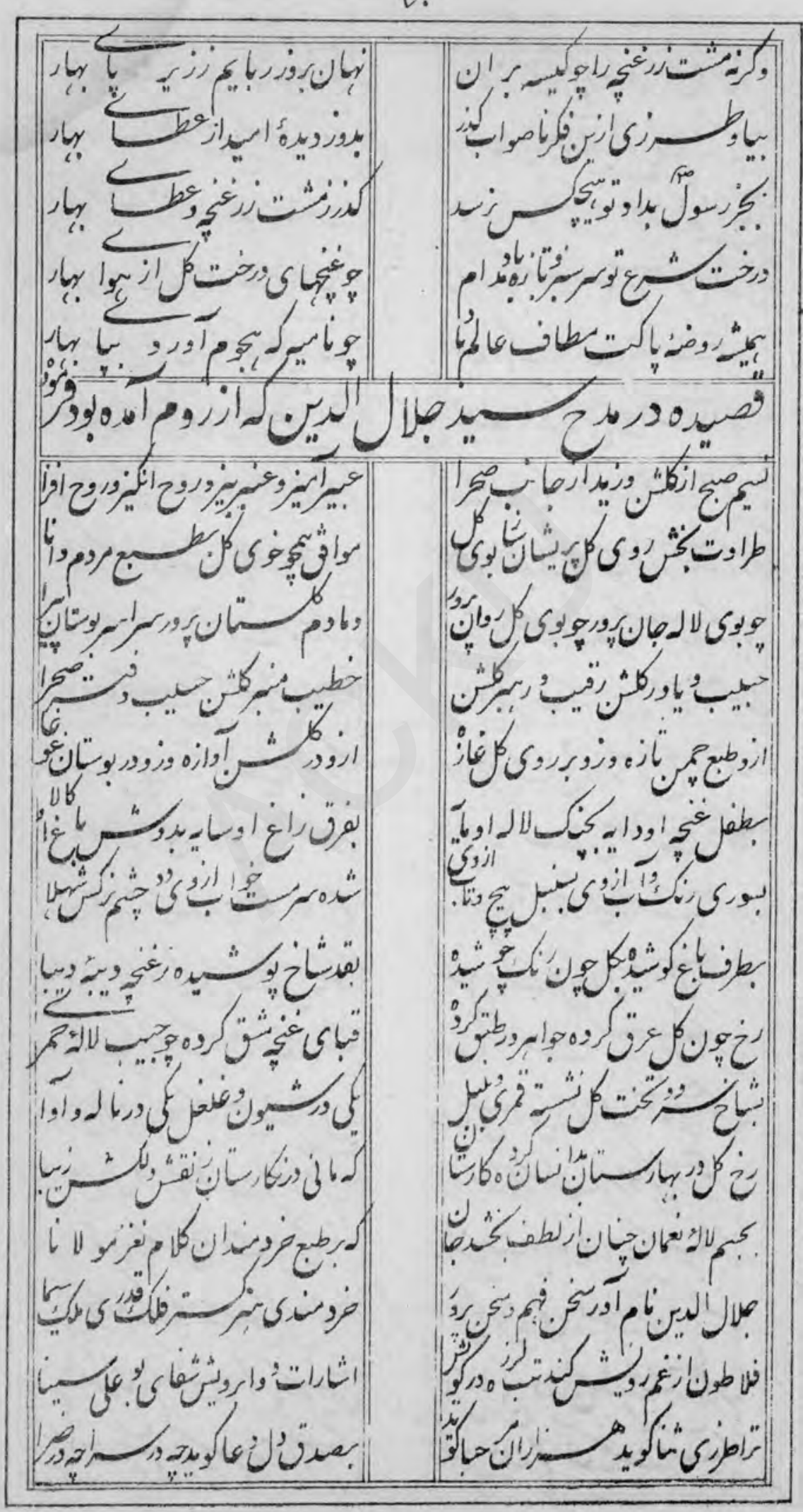




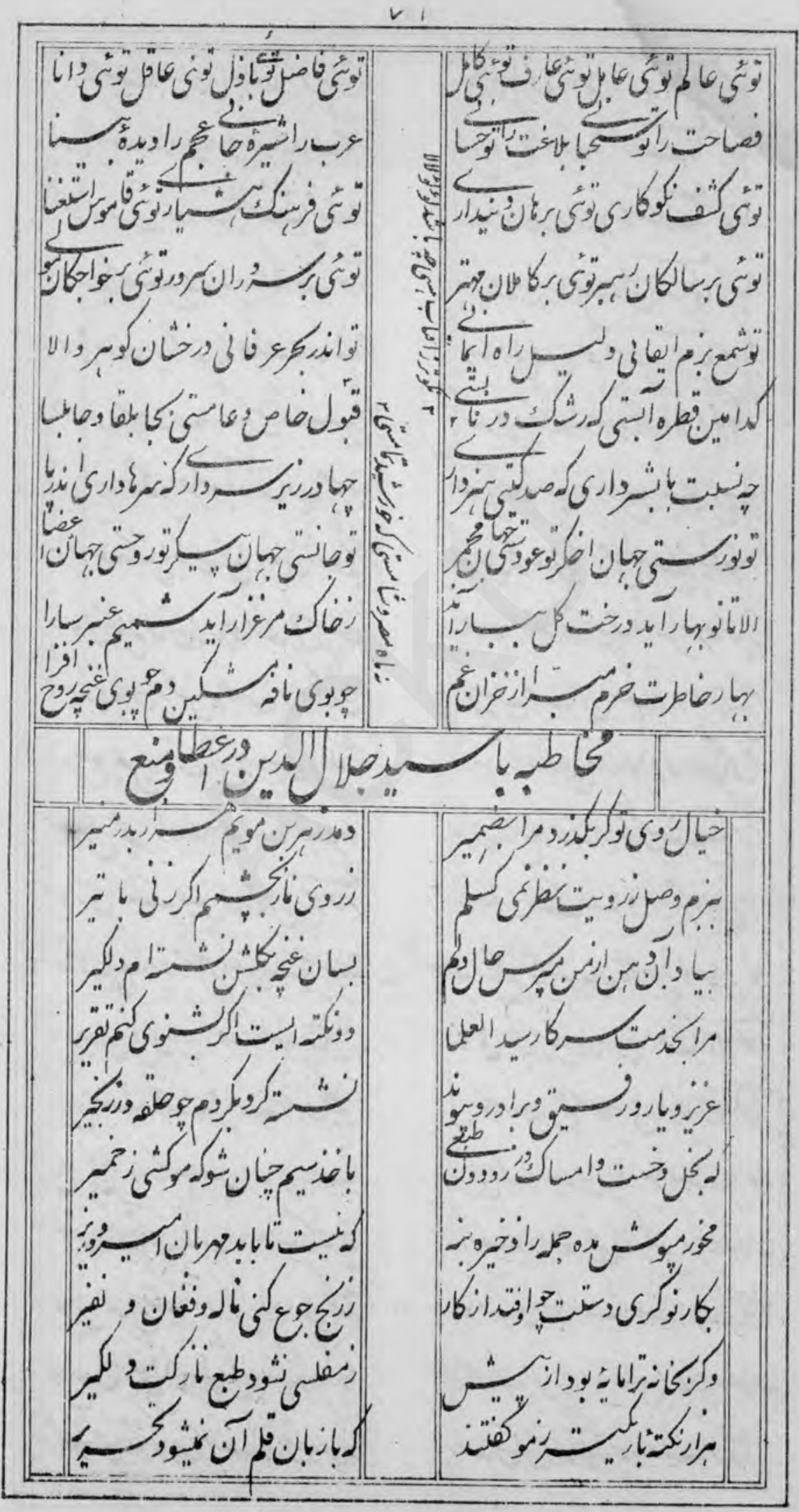


780

v r

|


$v r$

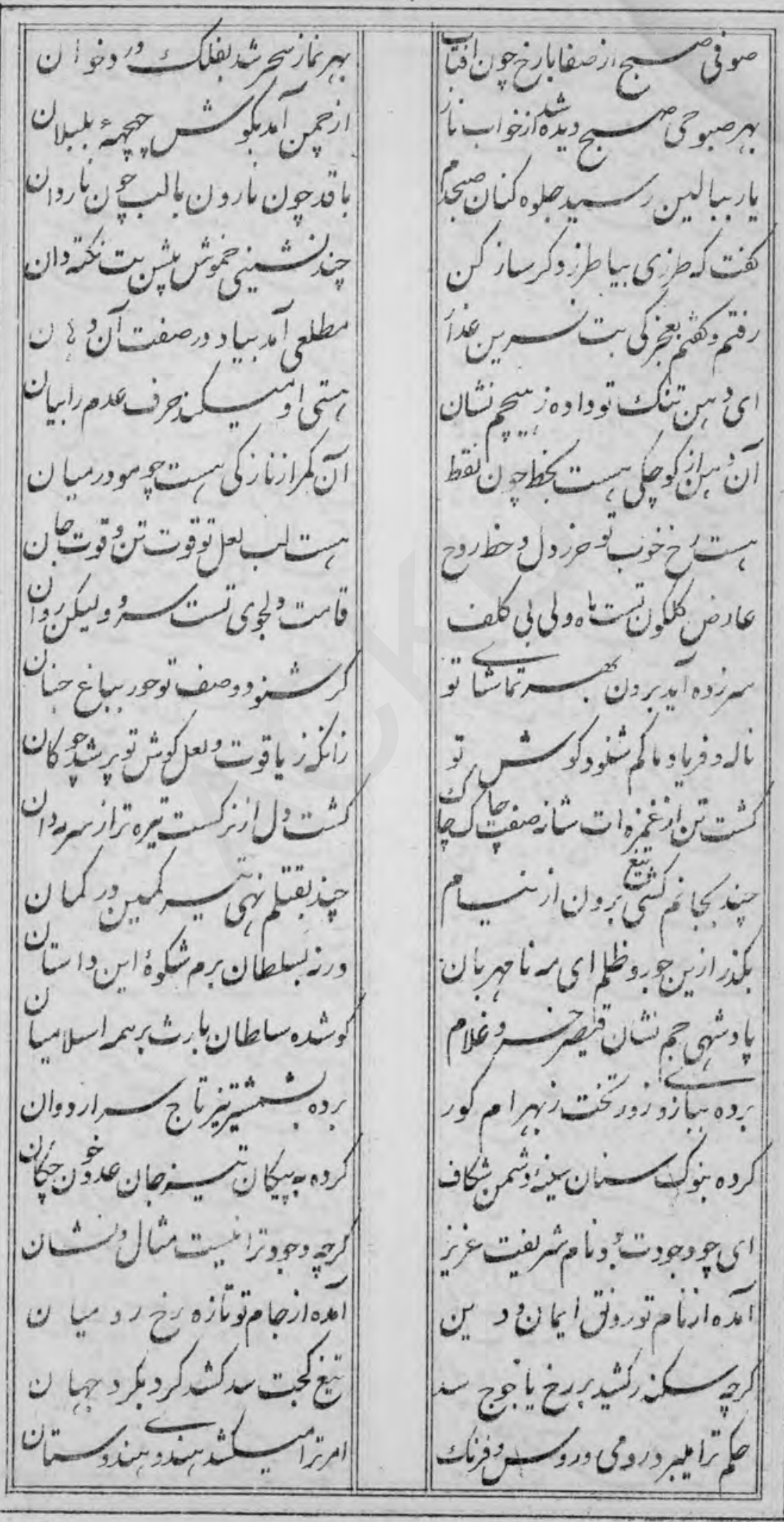


$\checkmark F$

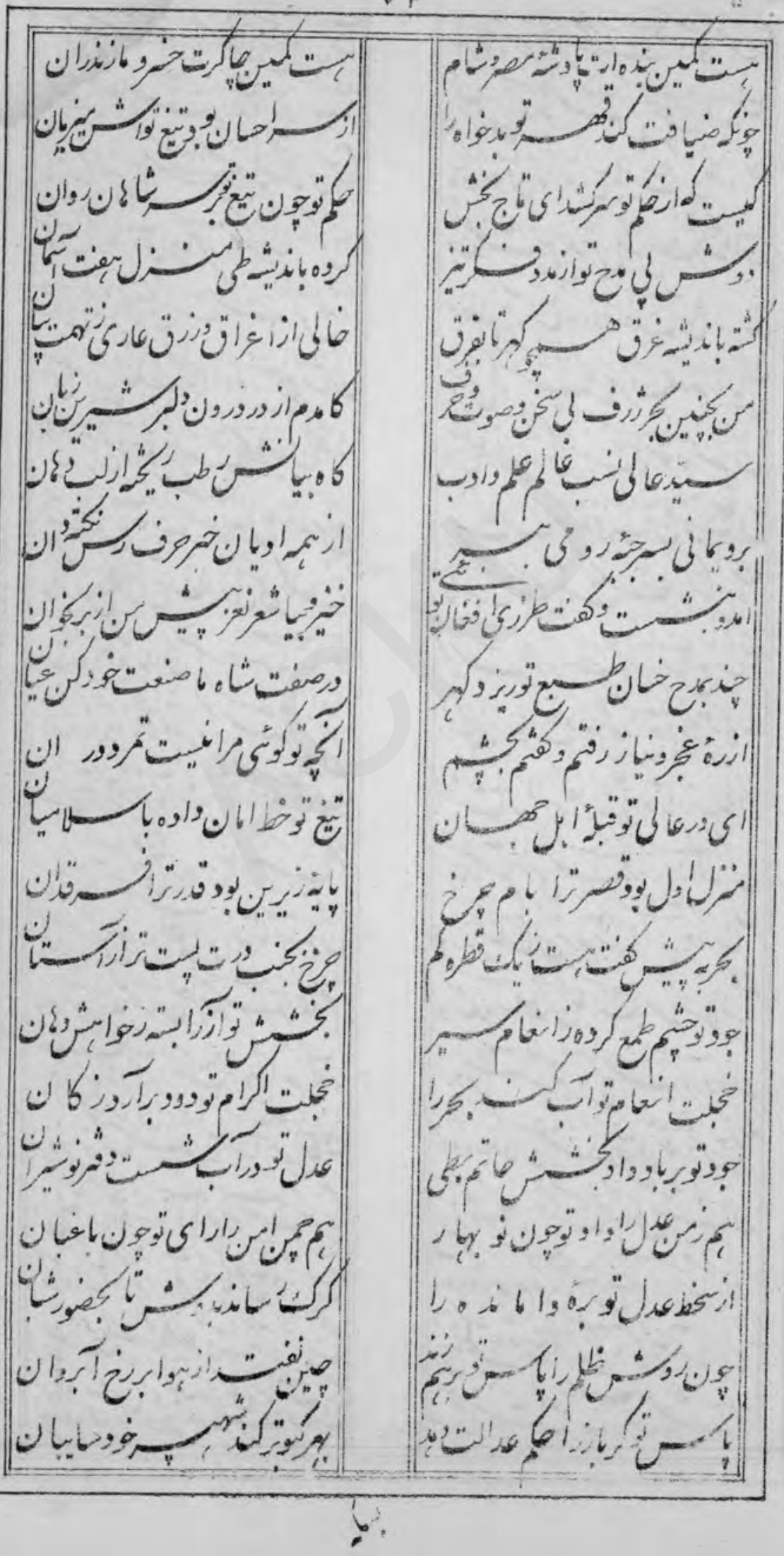




\section{3}

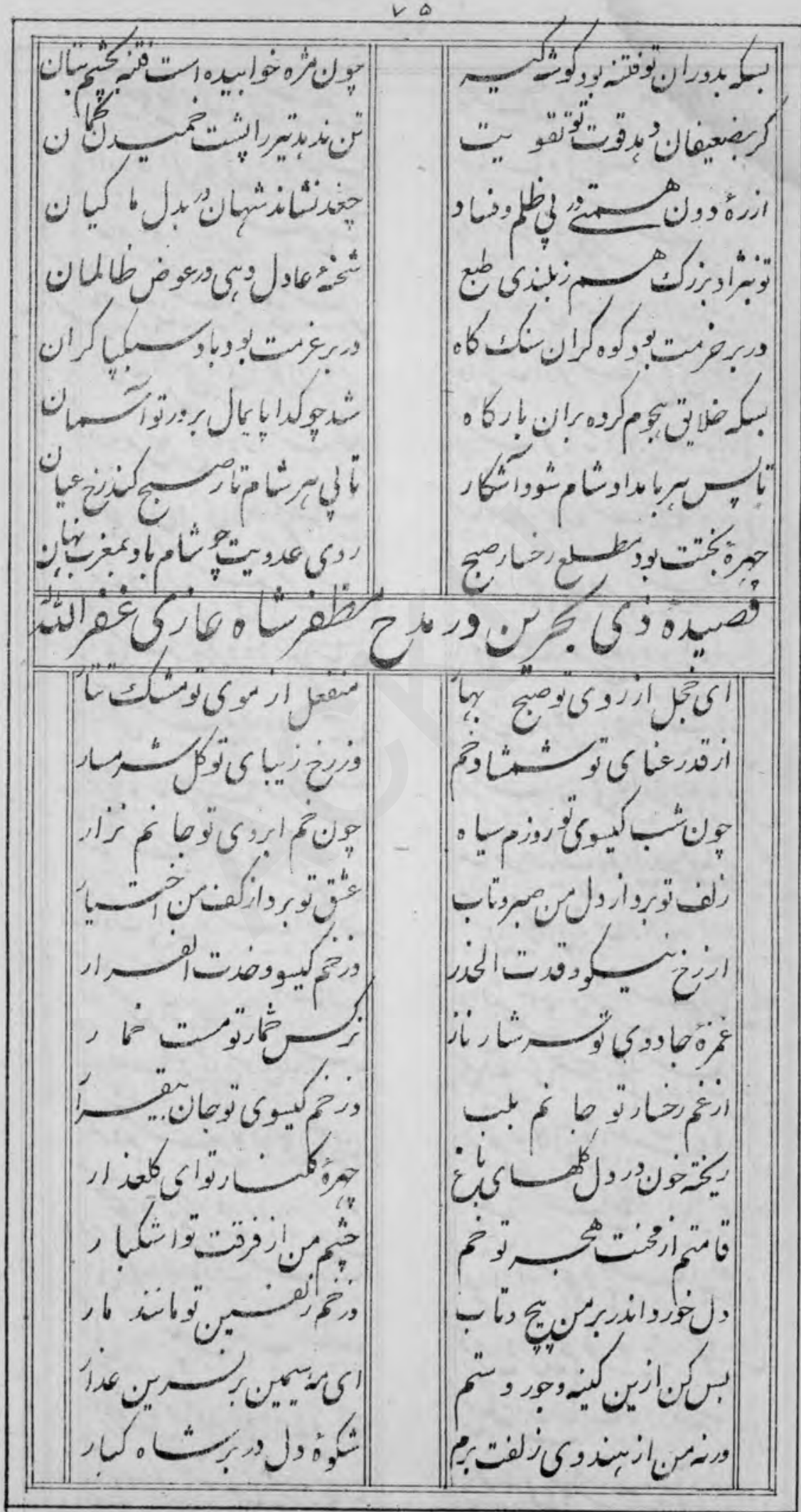


784

rs

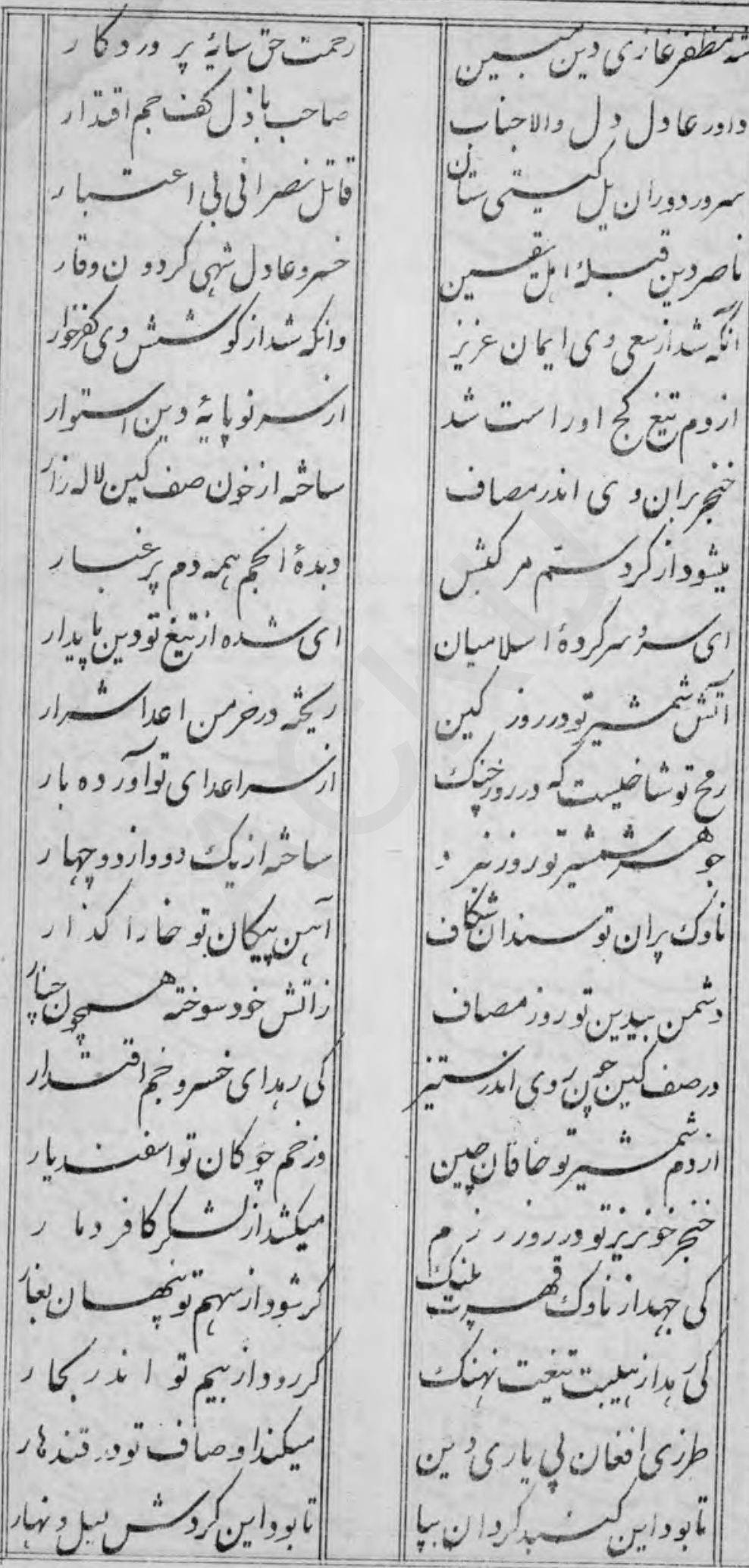




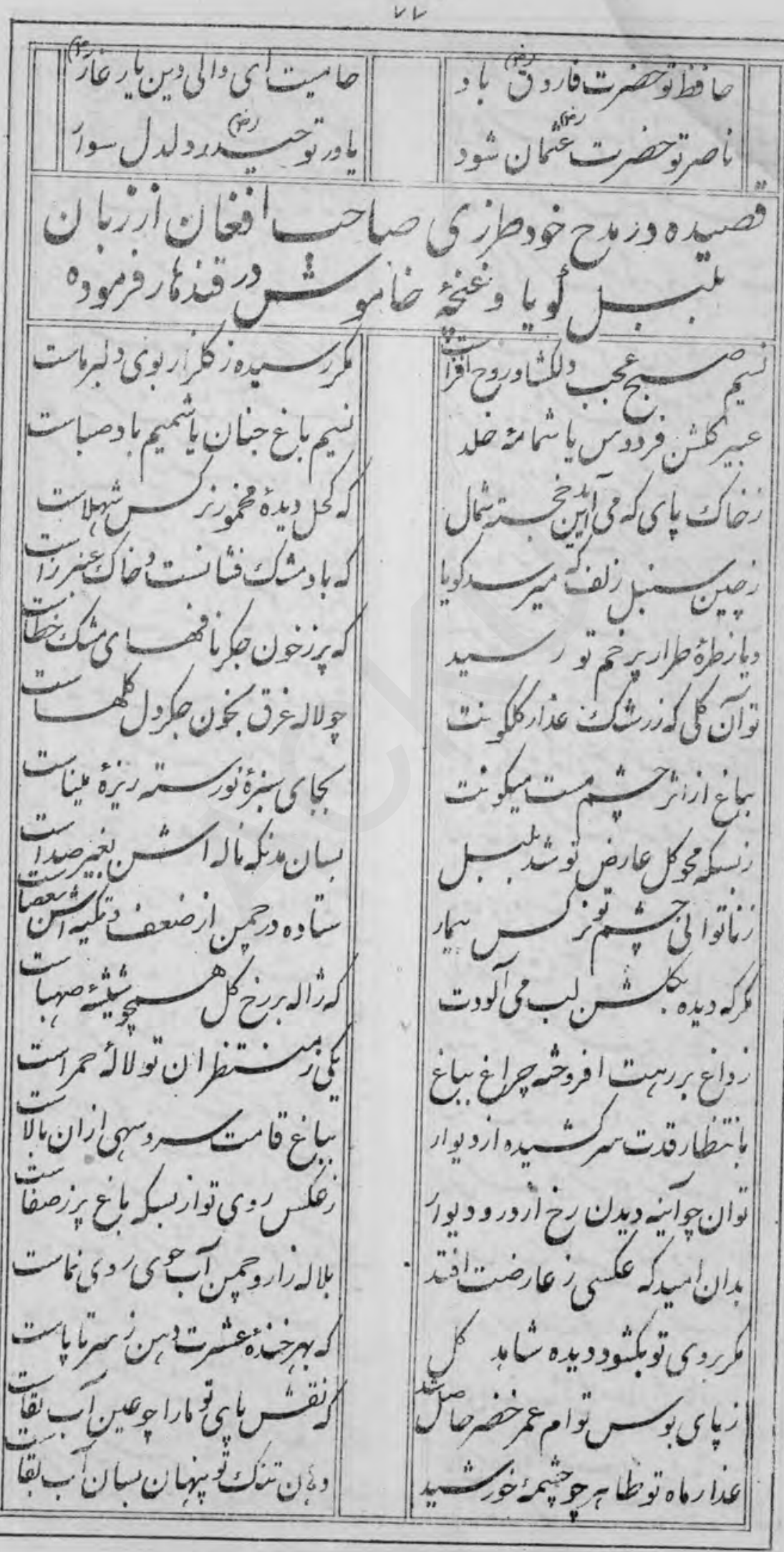




\section{6}

$\checkmark n$

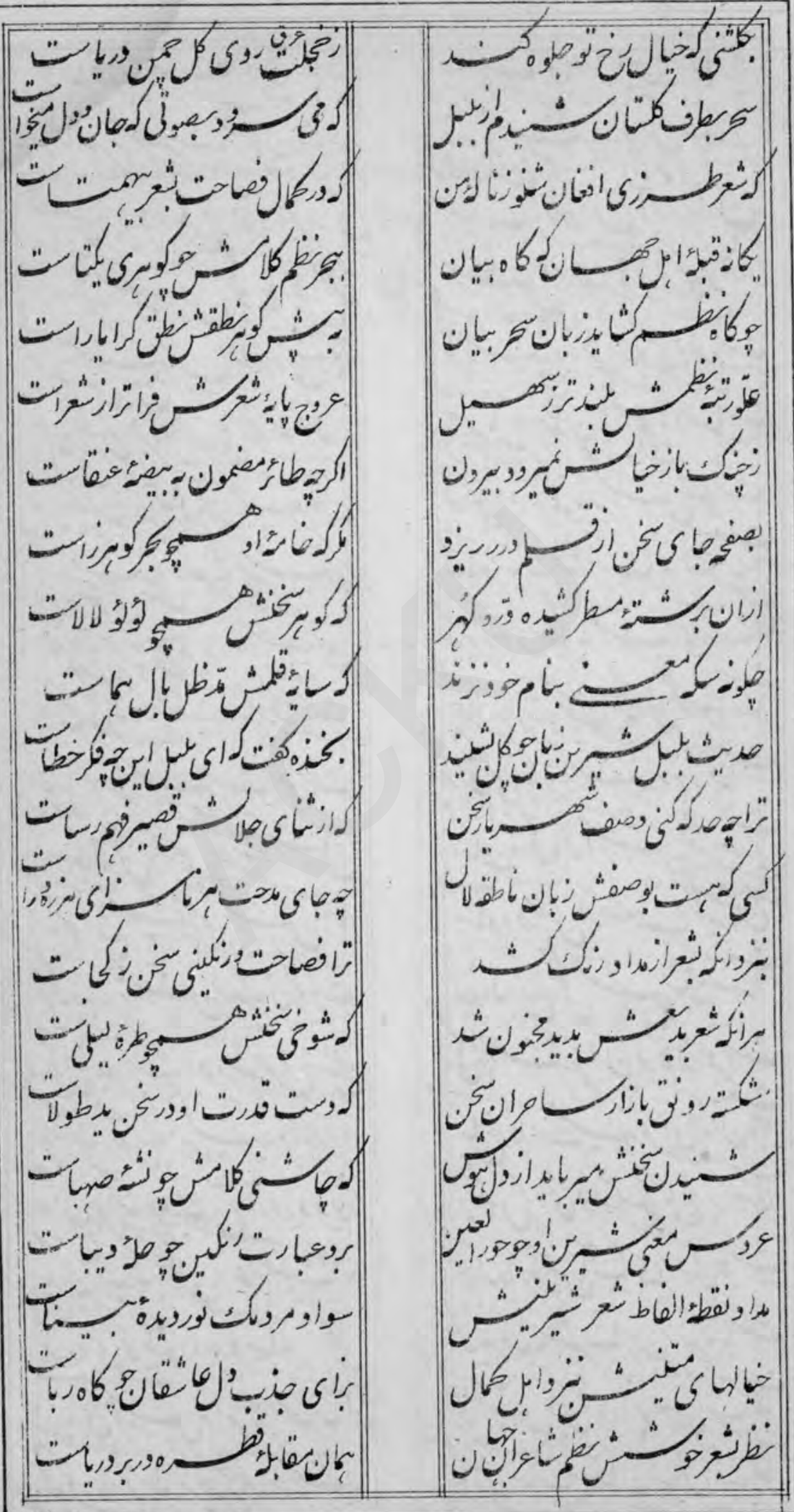




\section{7}

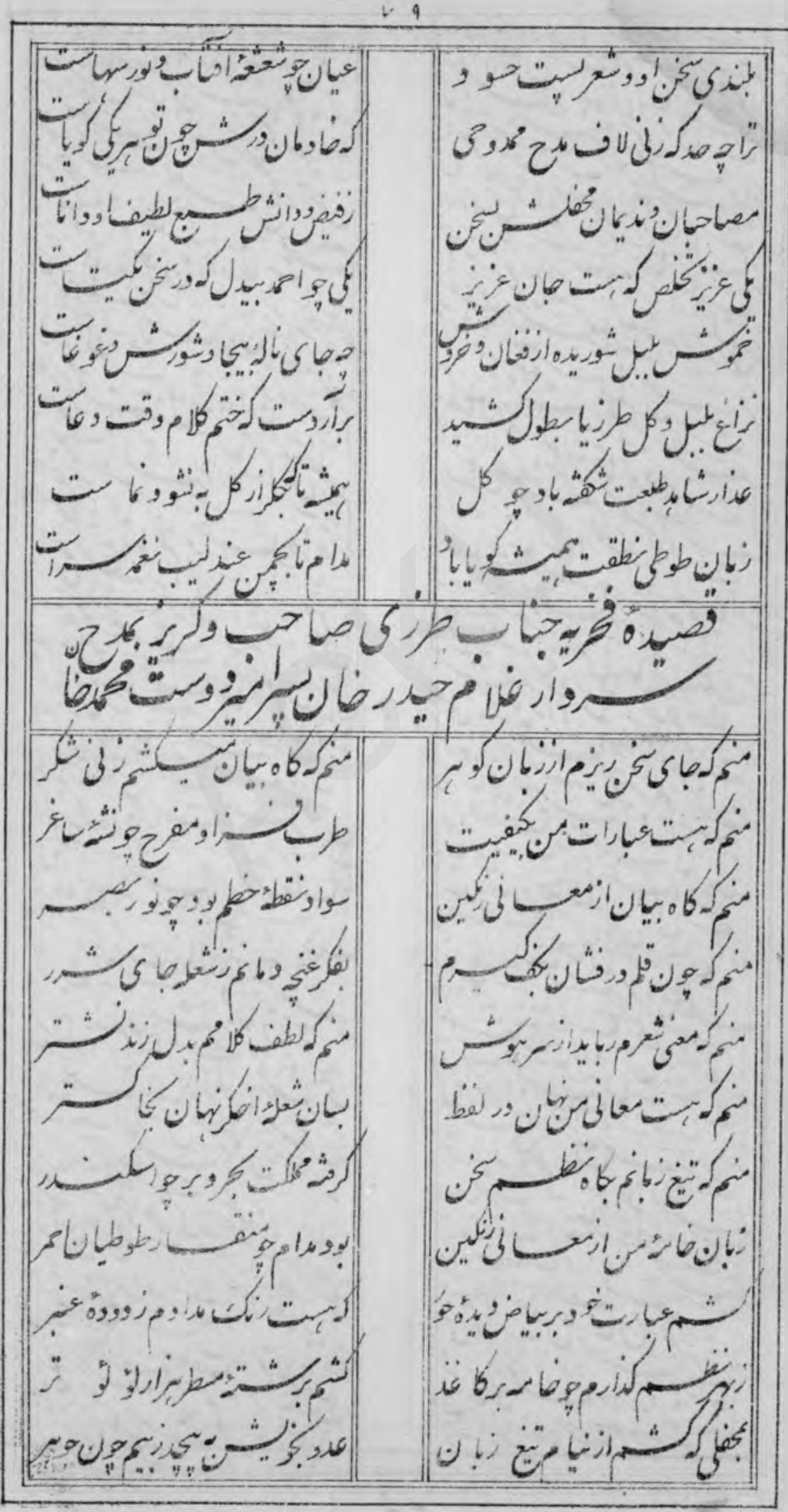




\section{8}

A.

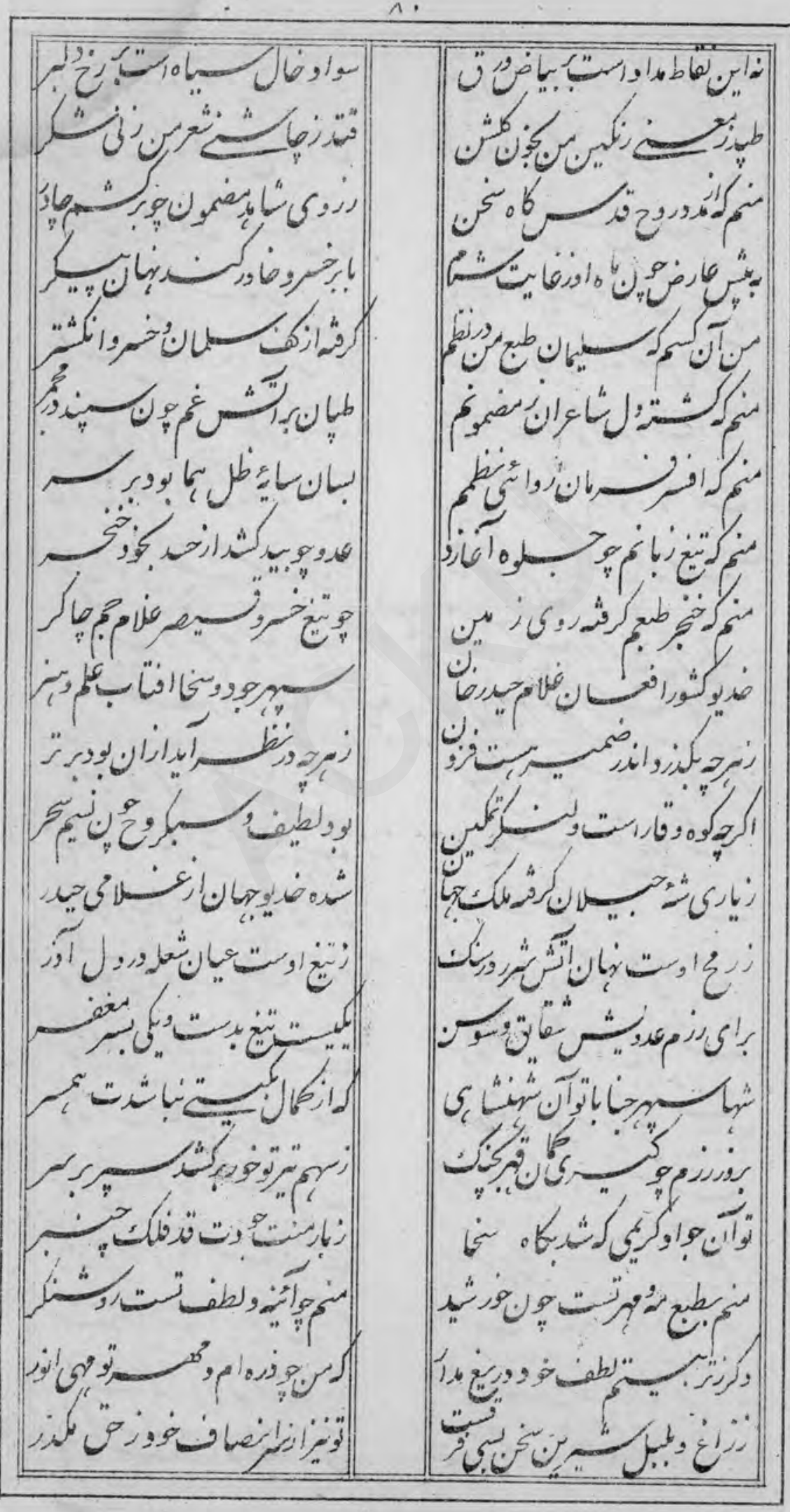

\% 


\section{9}

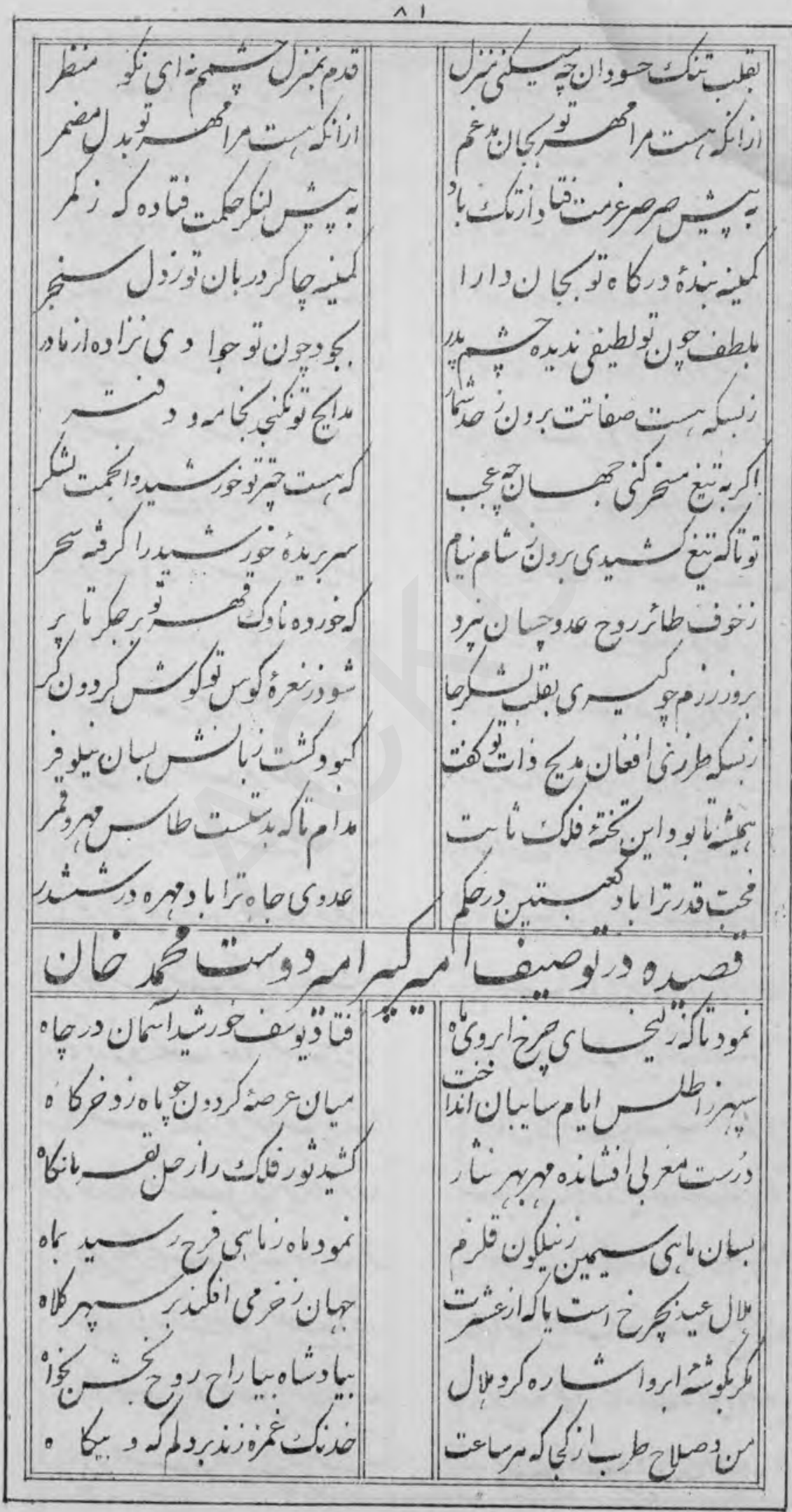




\section{0}

|




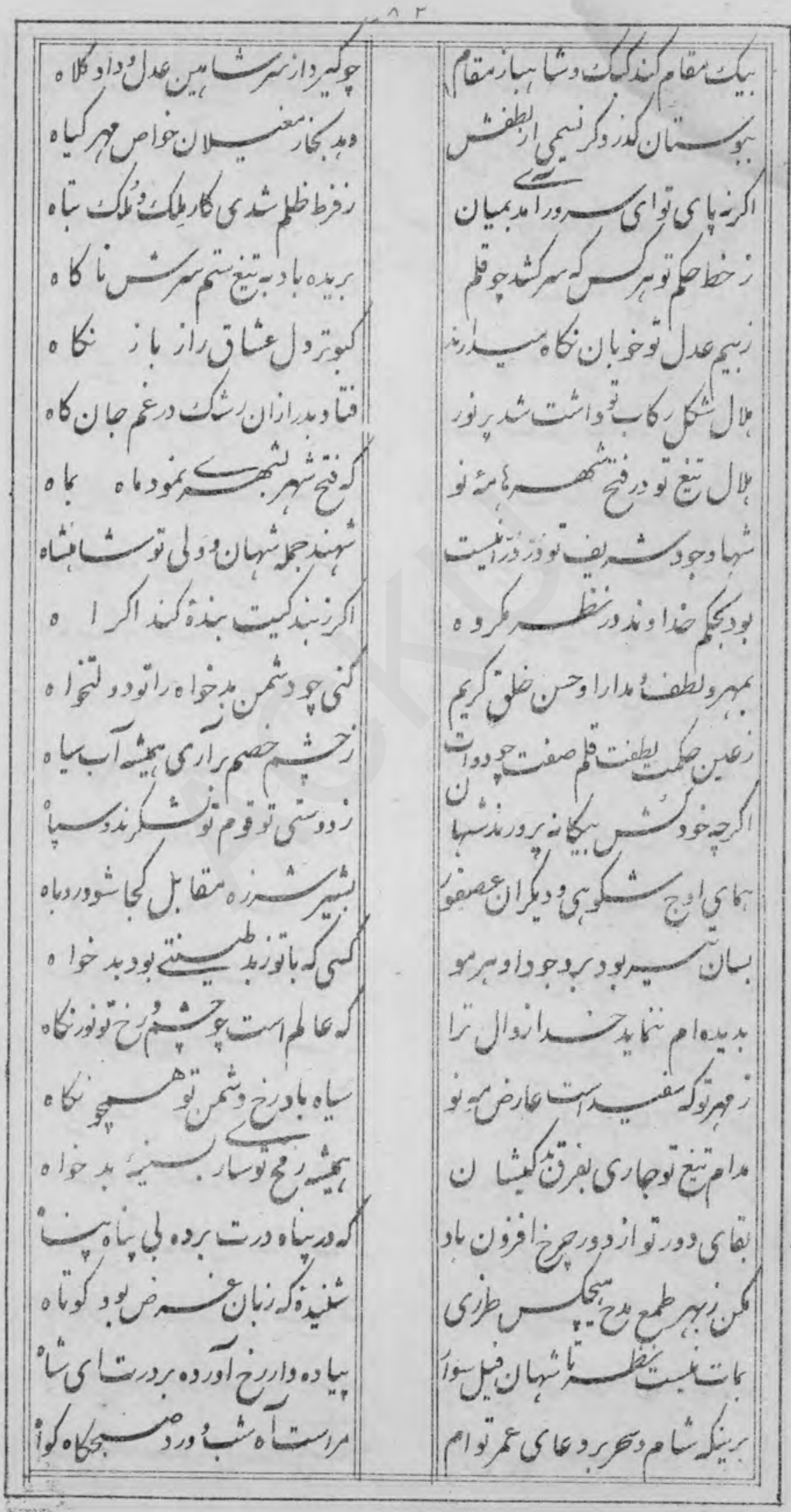


$A r^{2}$

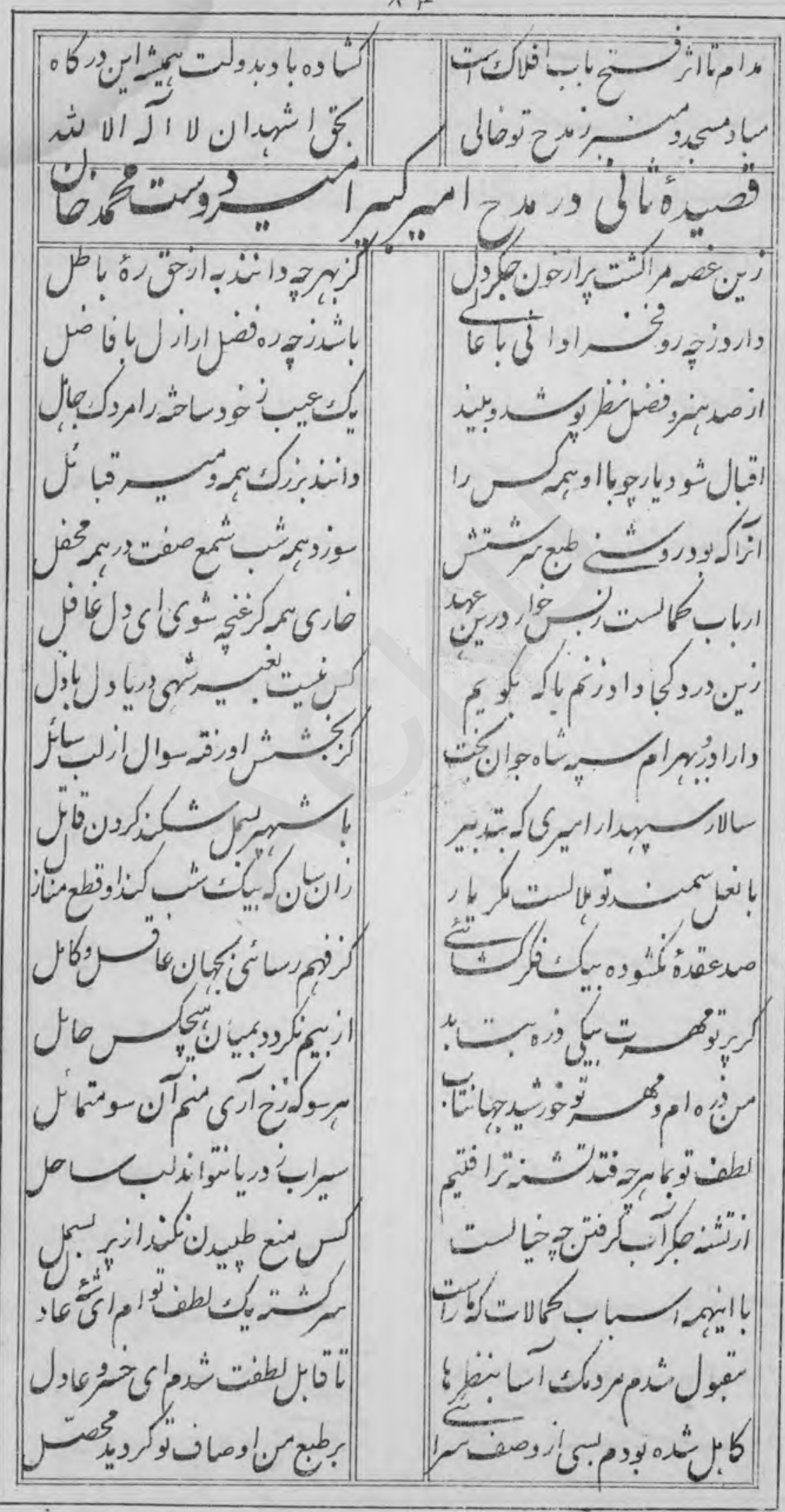




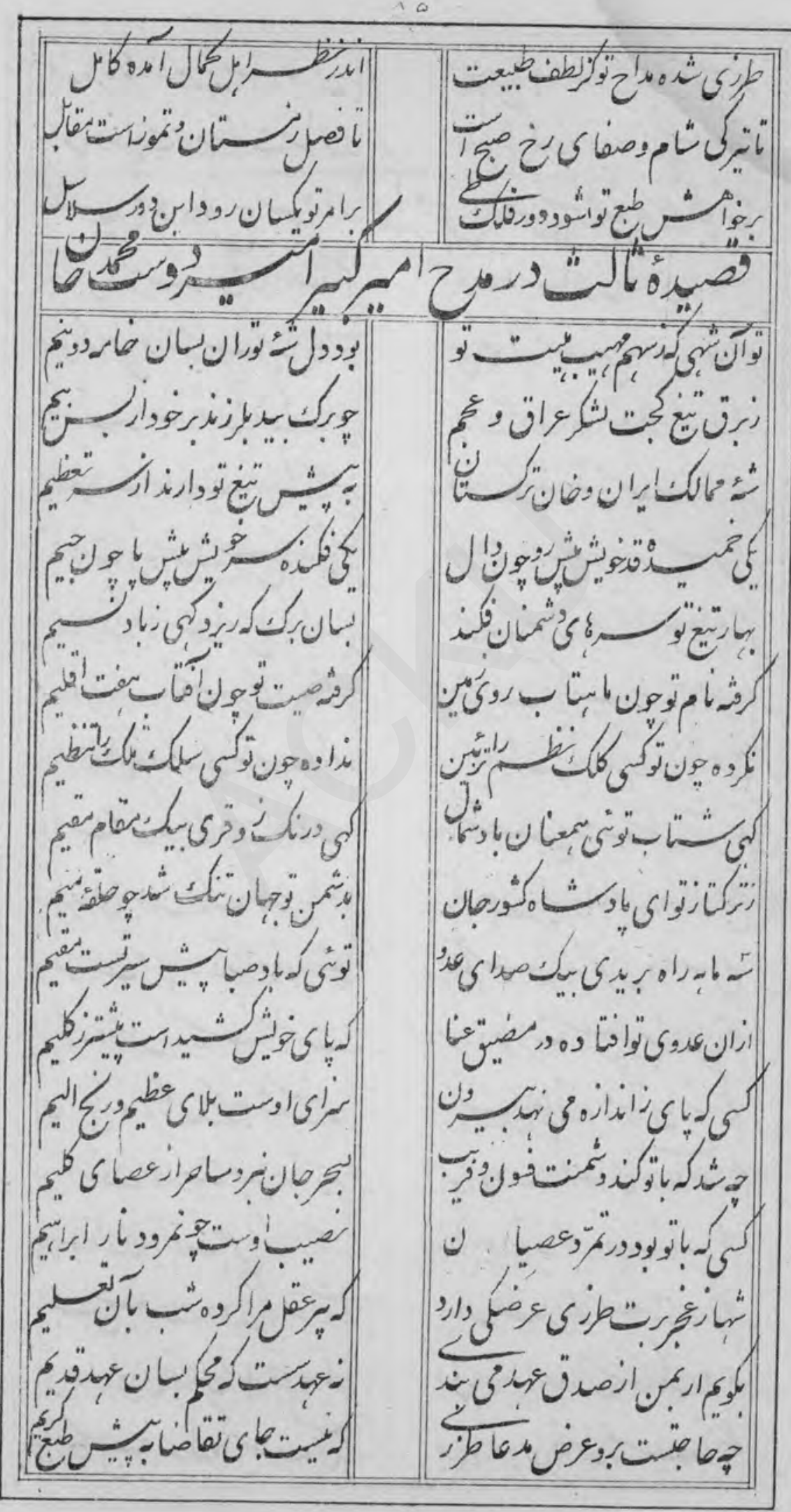


794

$1 \%$

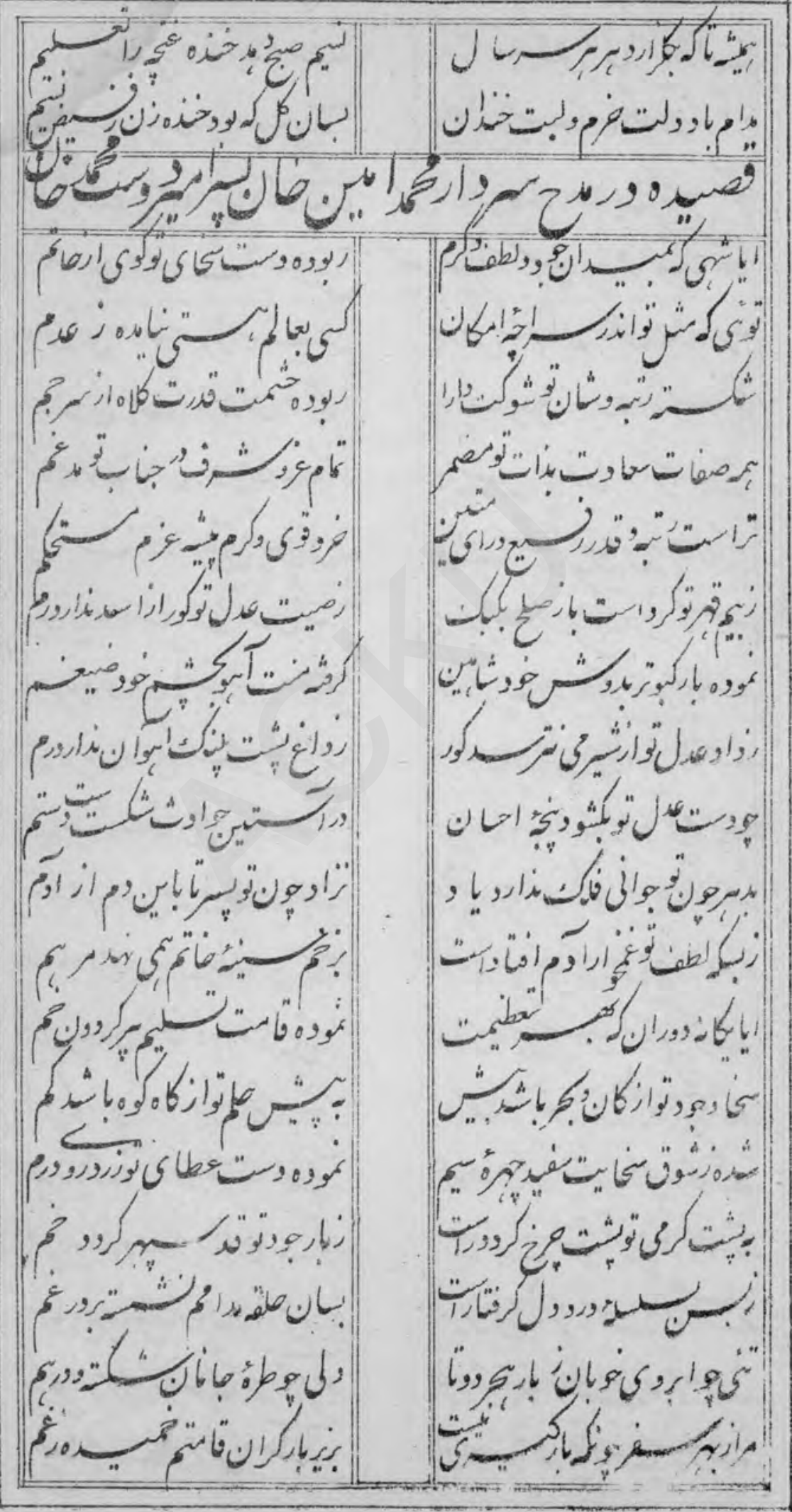

S'? 


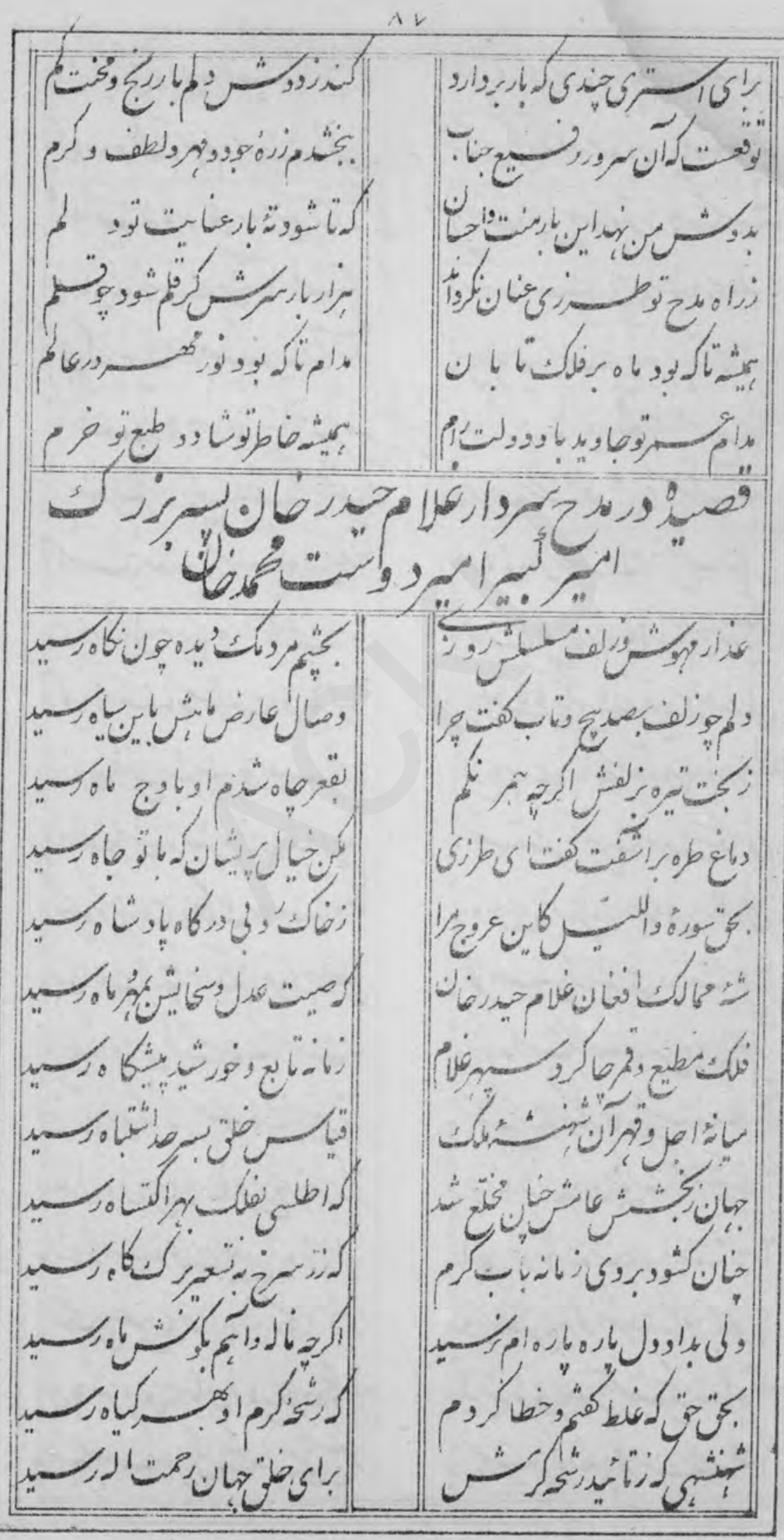




\section{7}

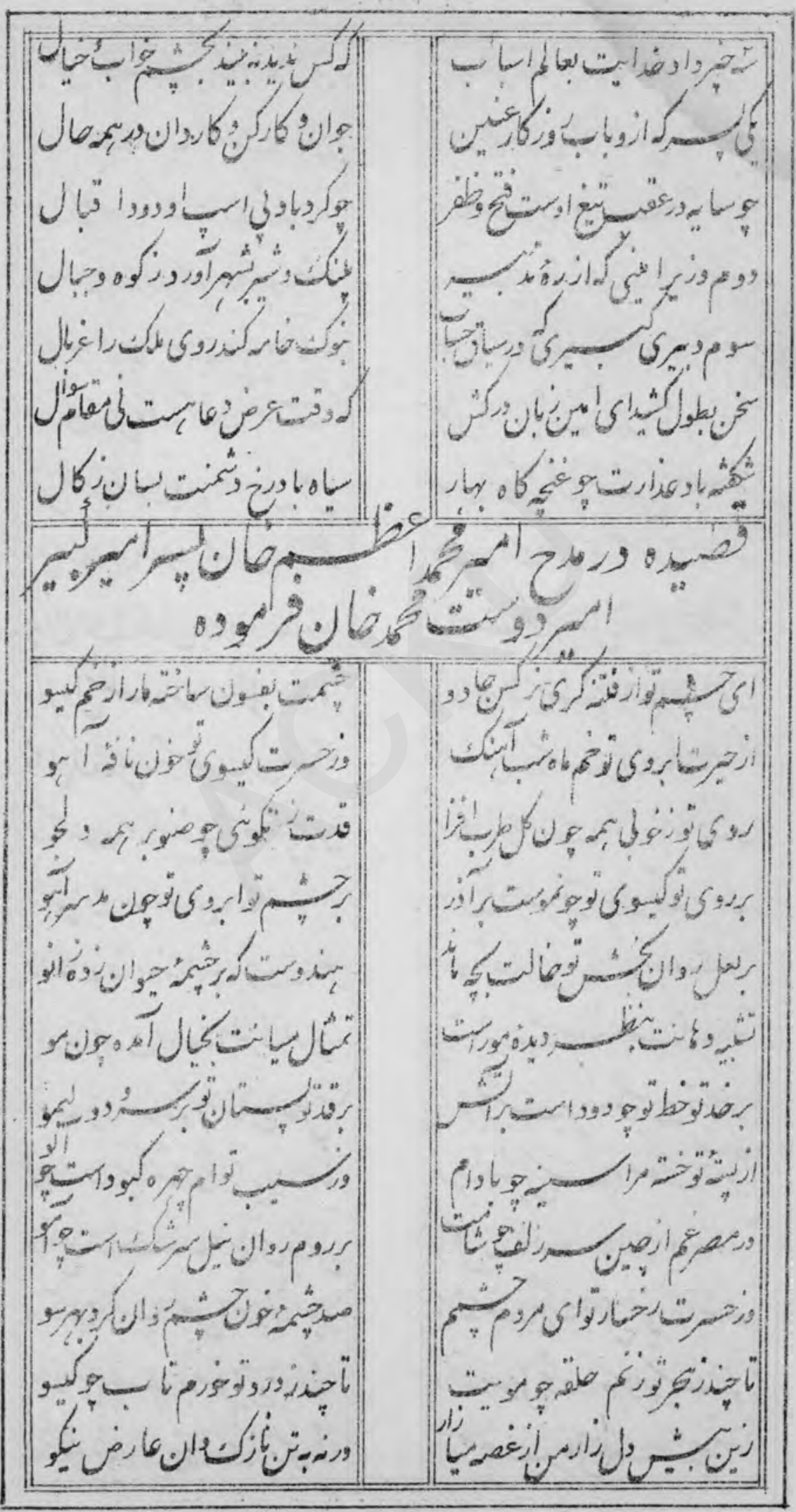


798

4.

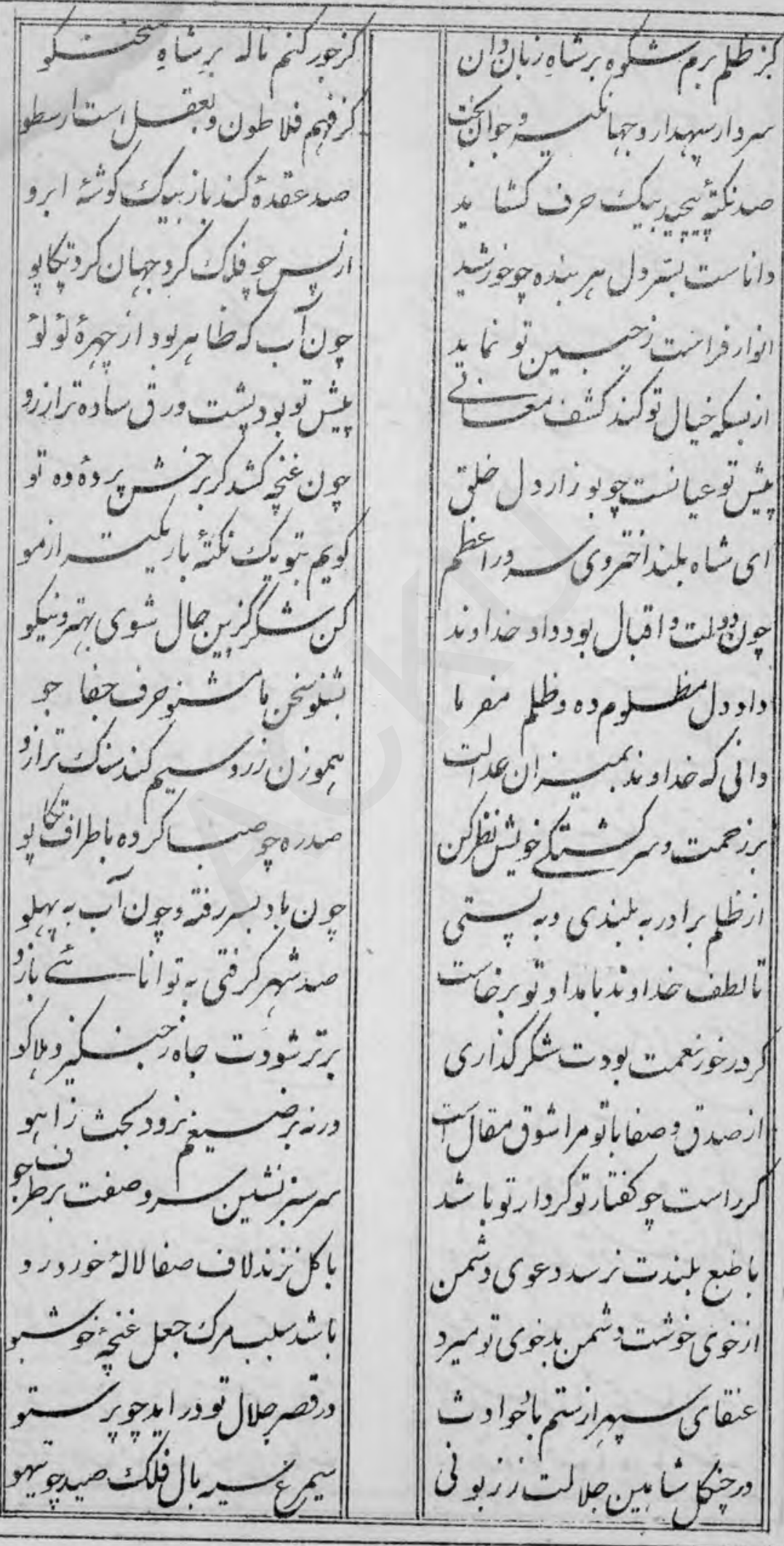


799

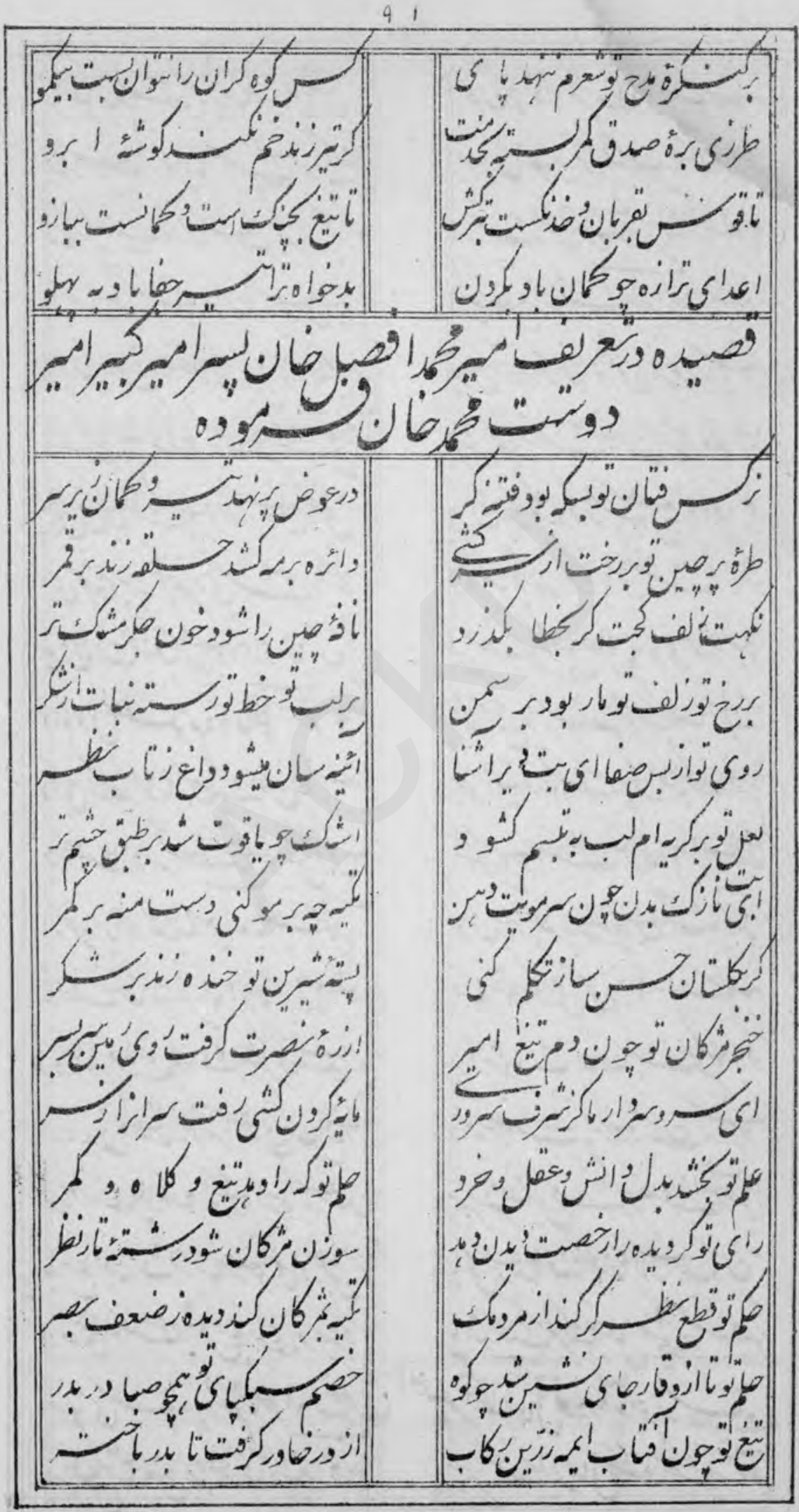


800

$9 r$

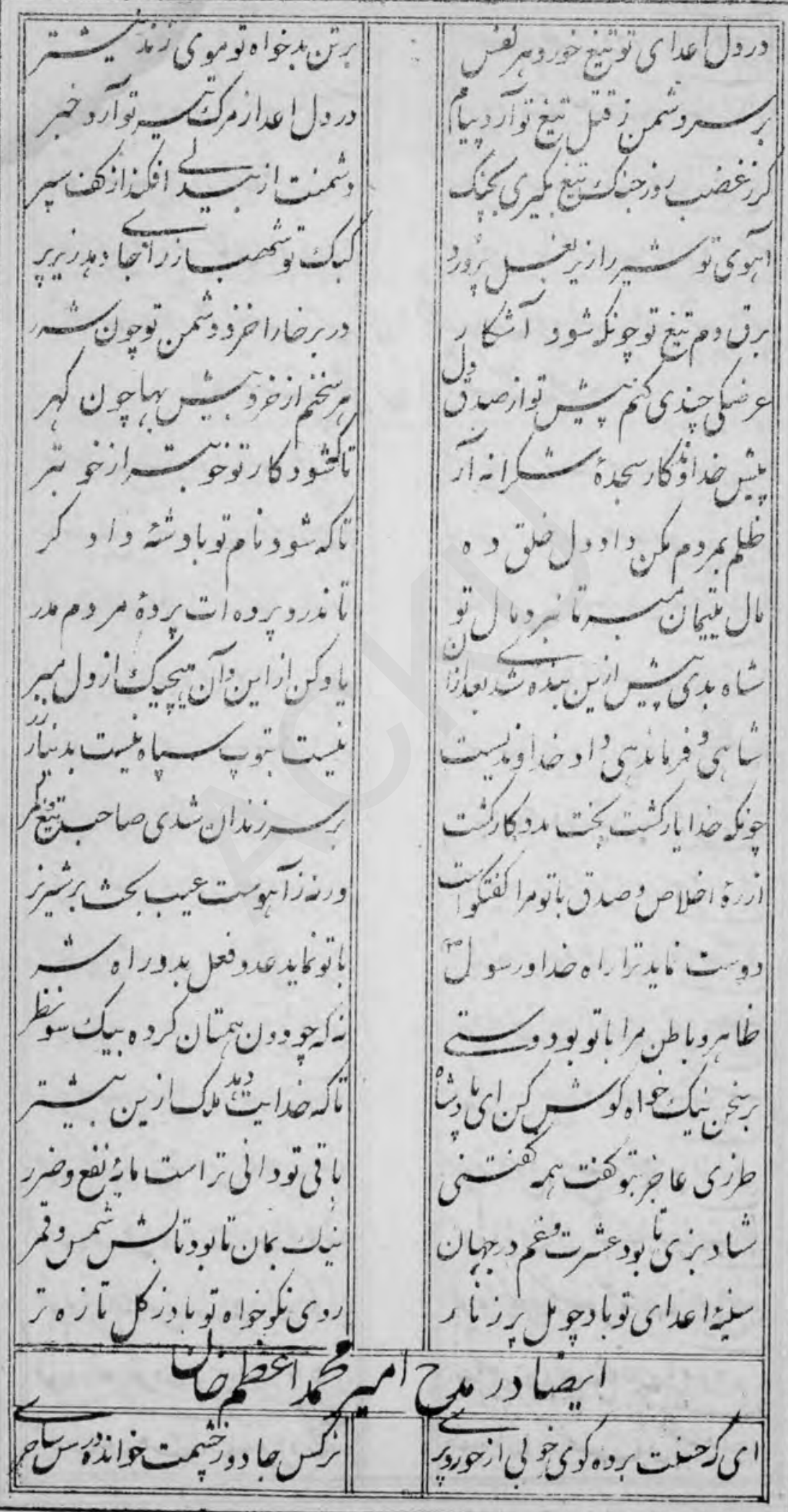

طاj 
45

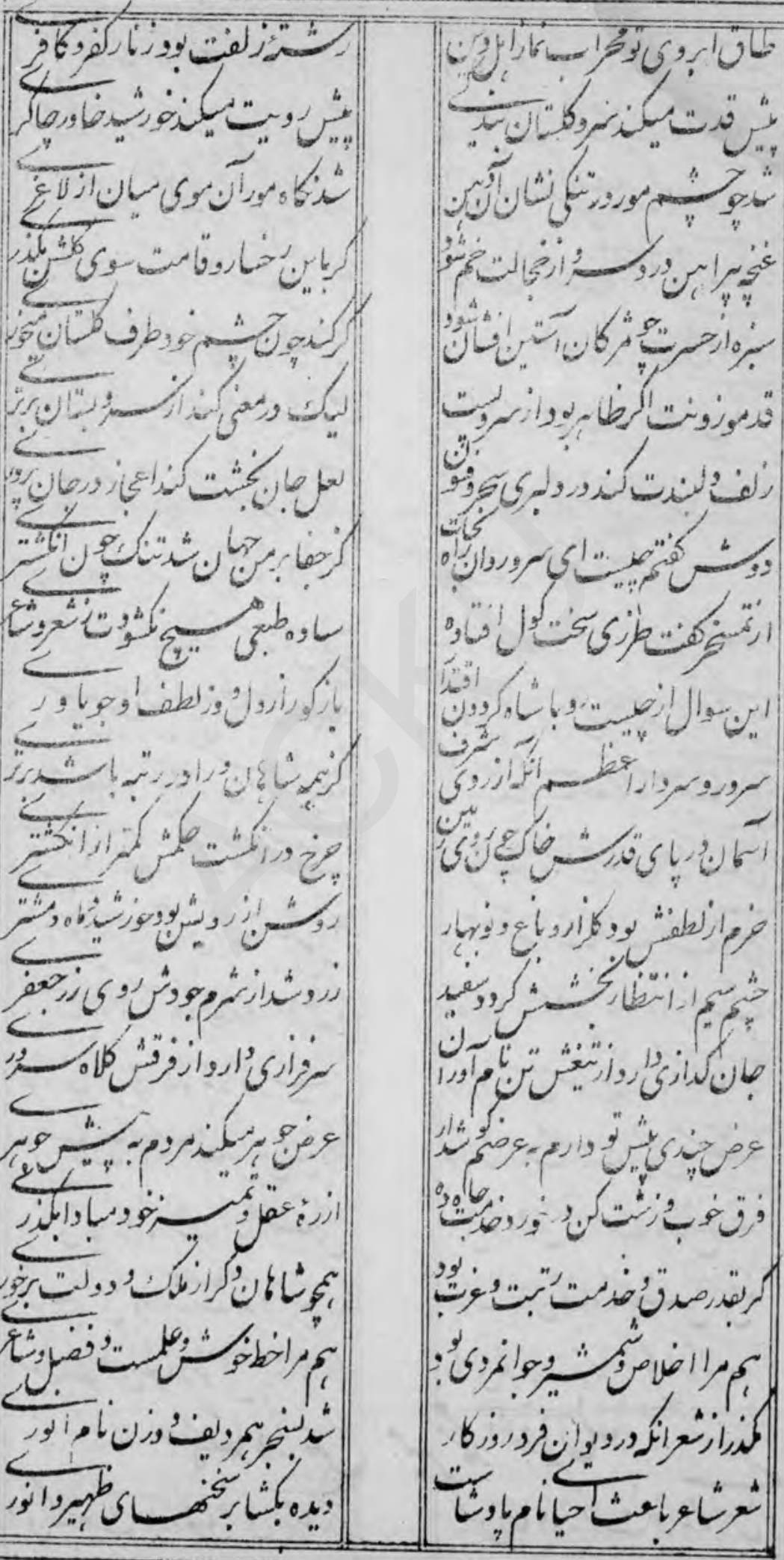


$9 \mu$

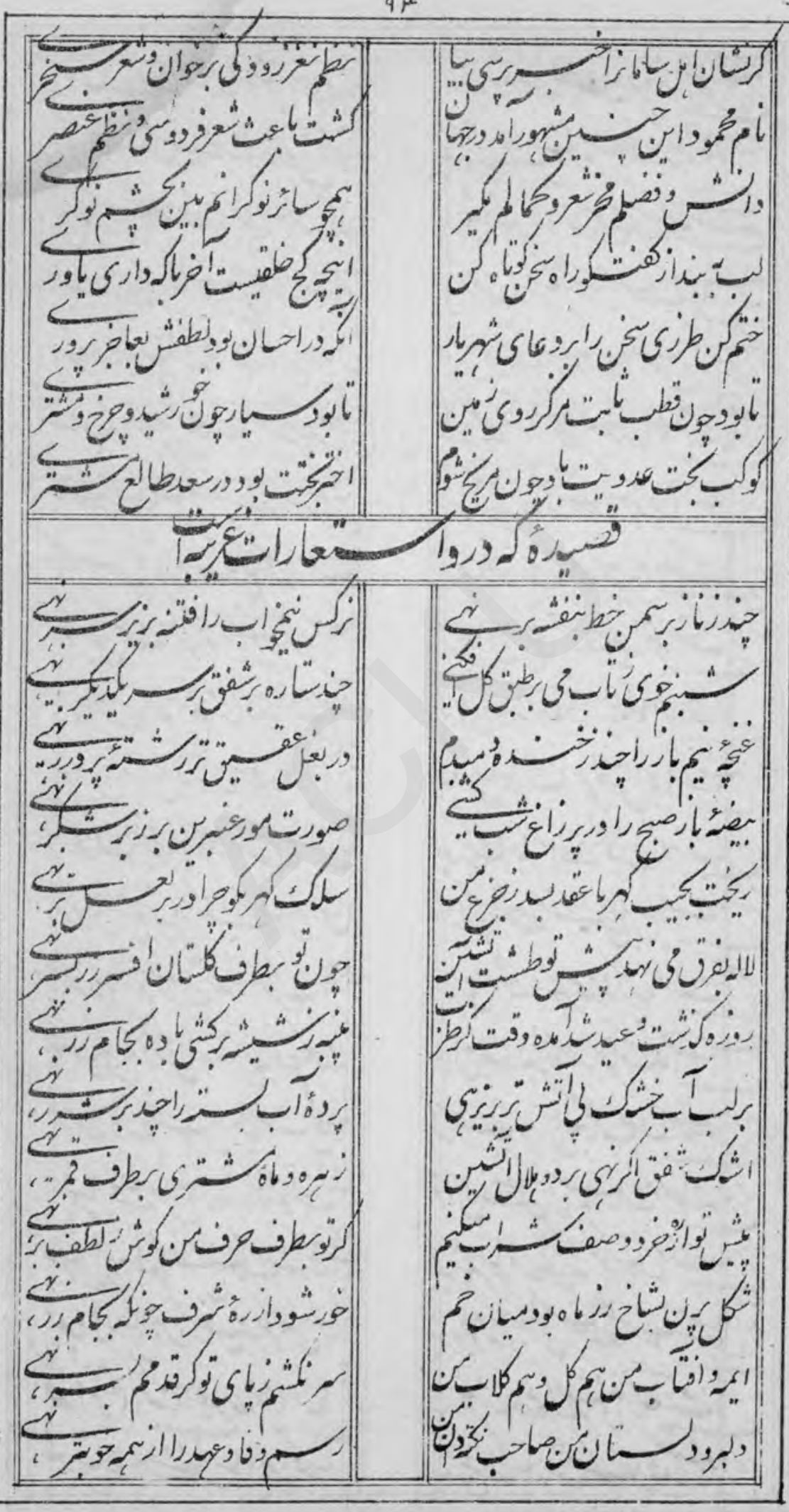




\section{3}

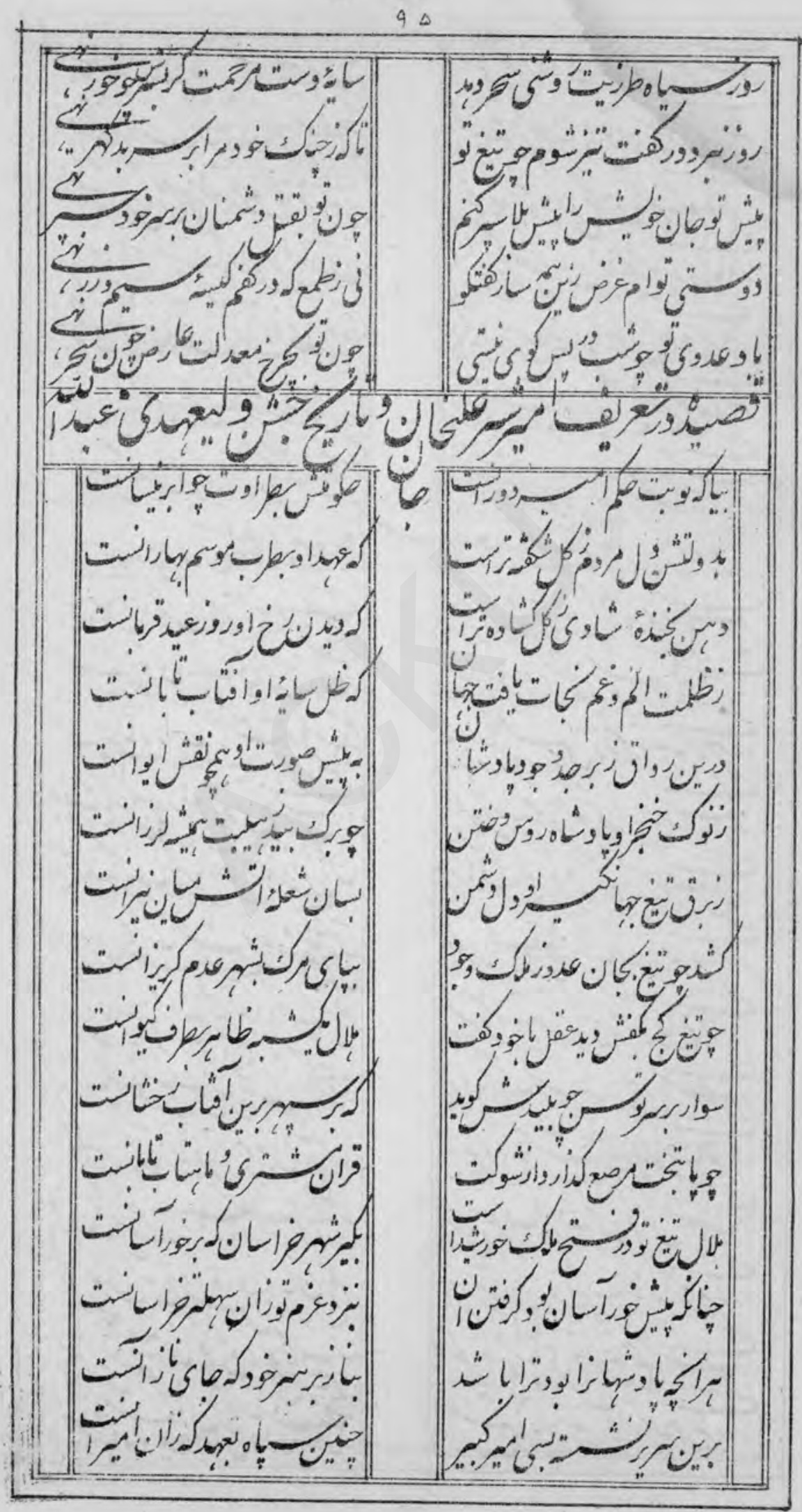




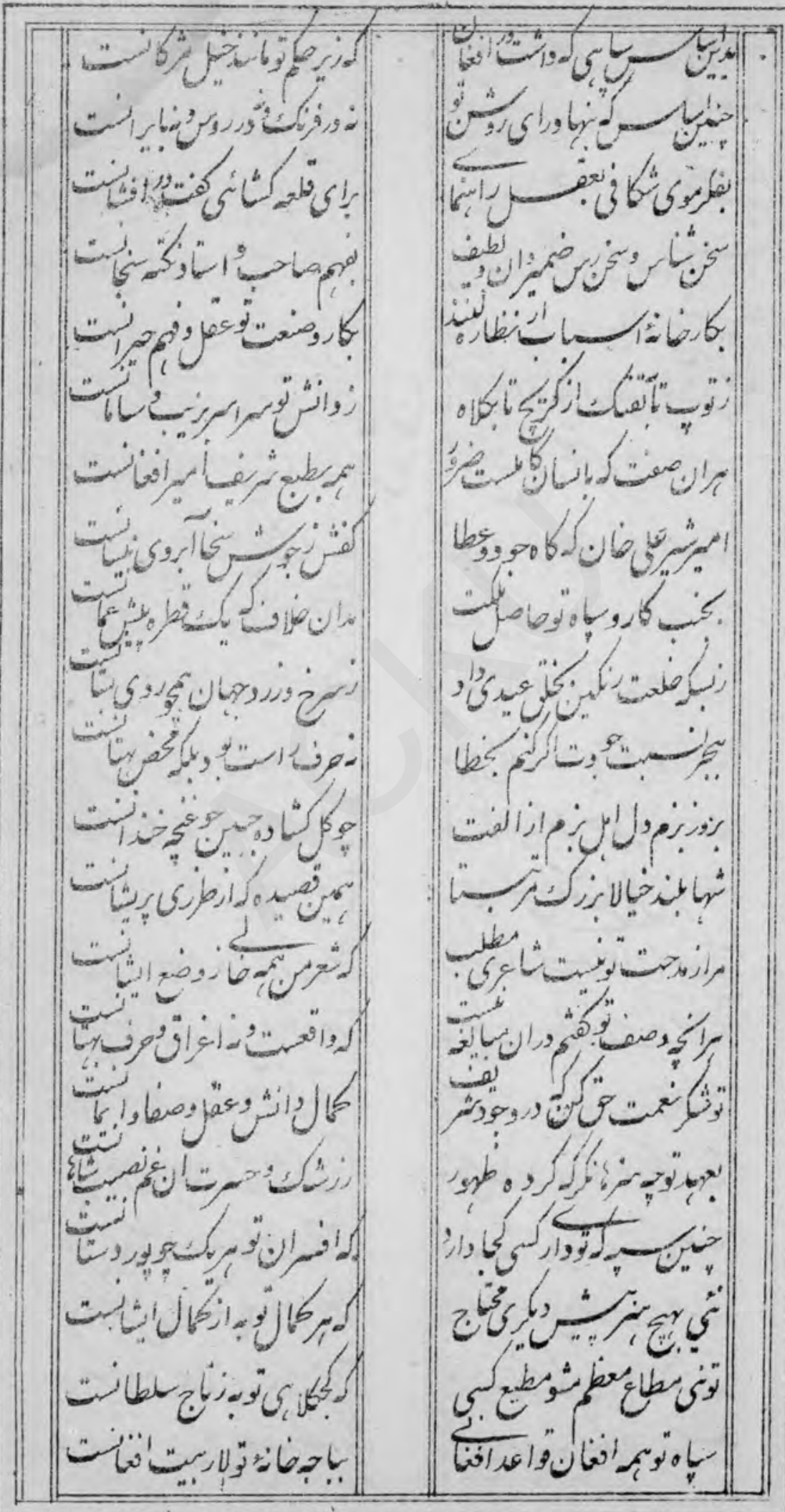

\section{4}

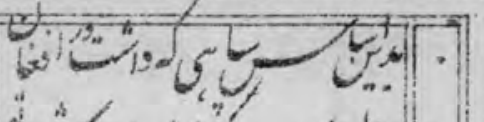

$y^{3}=6,060$, ن (a) $\Rightarrow>$ "

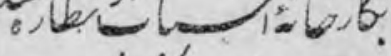

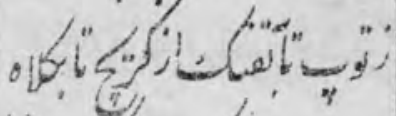

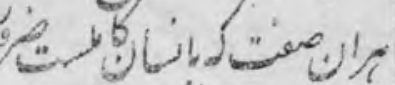
1) क $\log ^{3}, 9060060 \%$ "20.

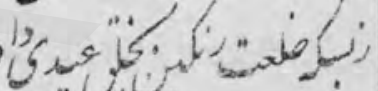
ह2: "

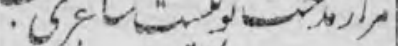
" 2)

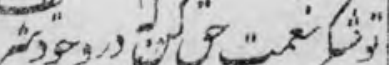
; 1... .

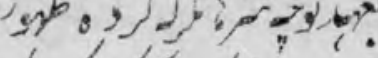
ओ $\left[\mathrm{S}_{\mathrm{g}}\right.$ $2 \log _{0.6}^{6}$ U.

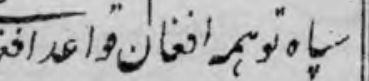




\section{5}

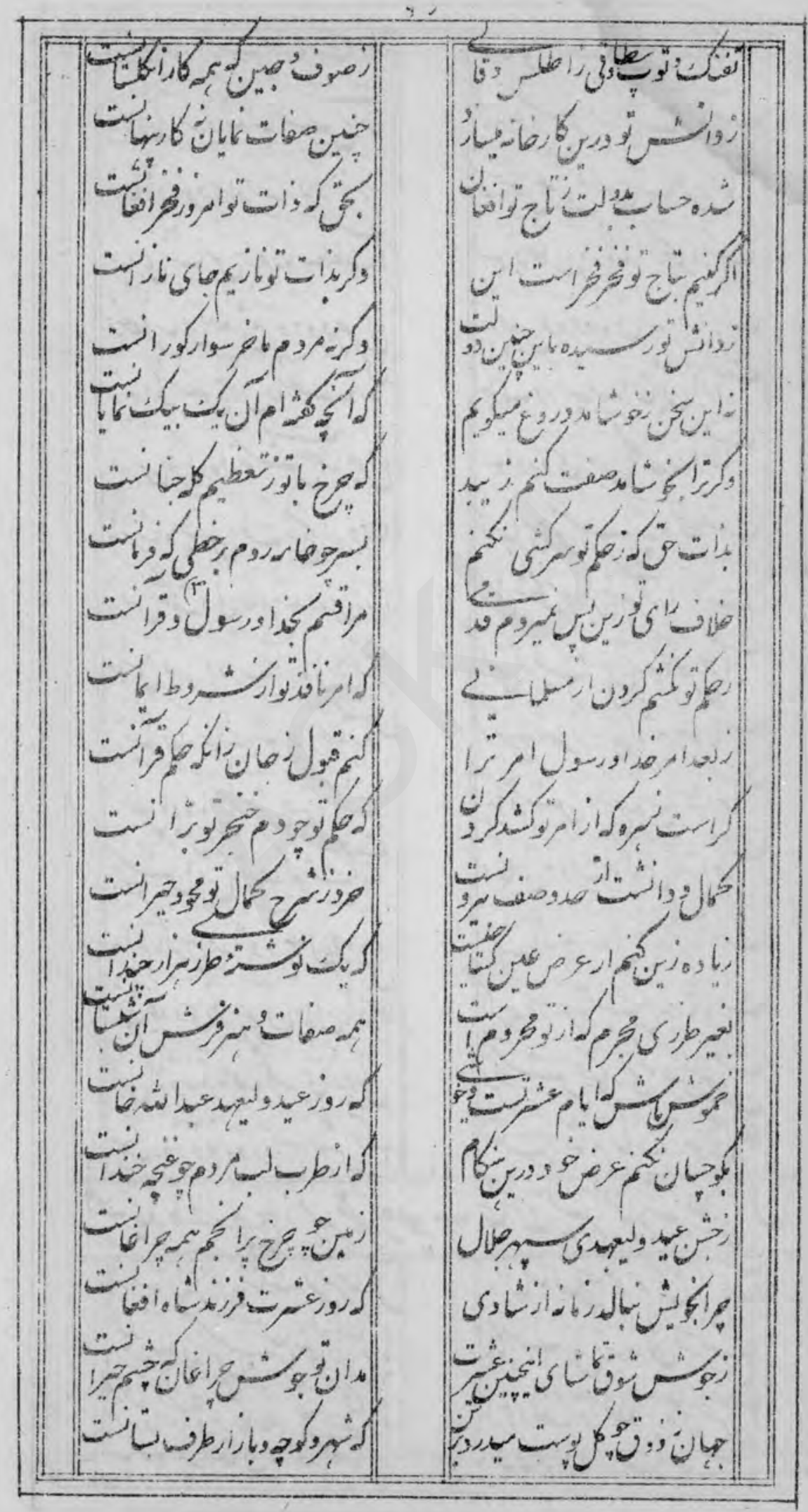


$9 A$

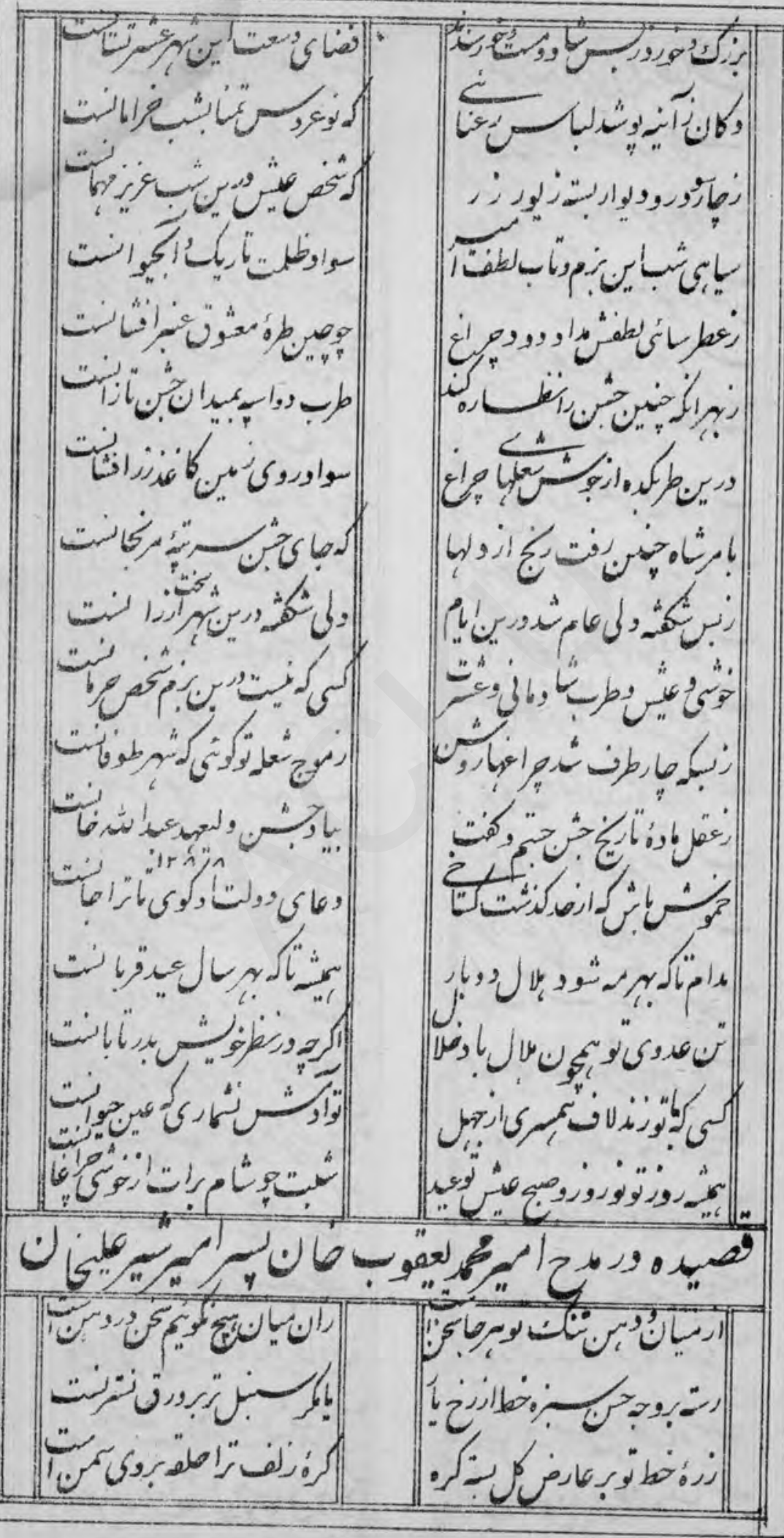




\section{7}

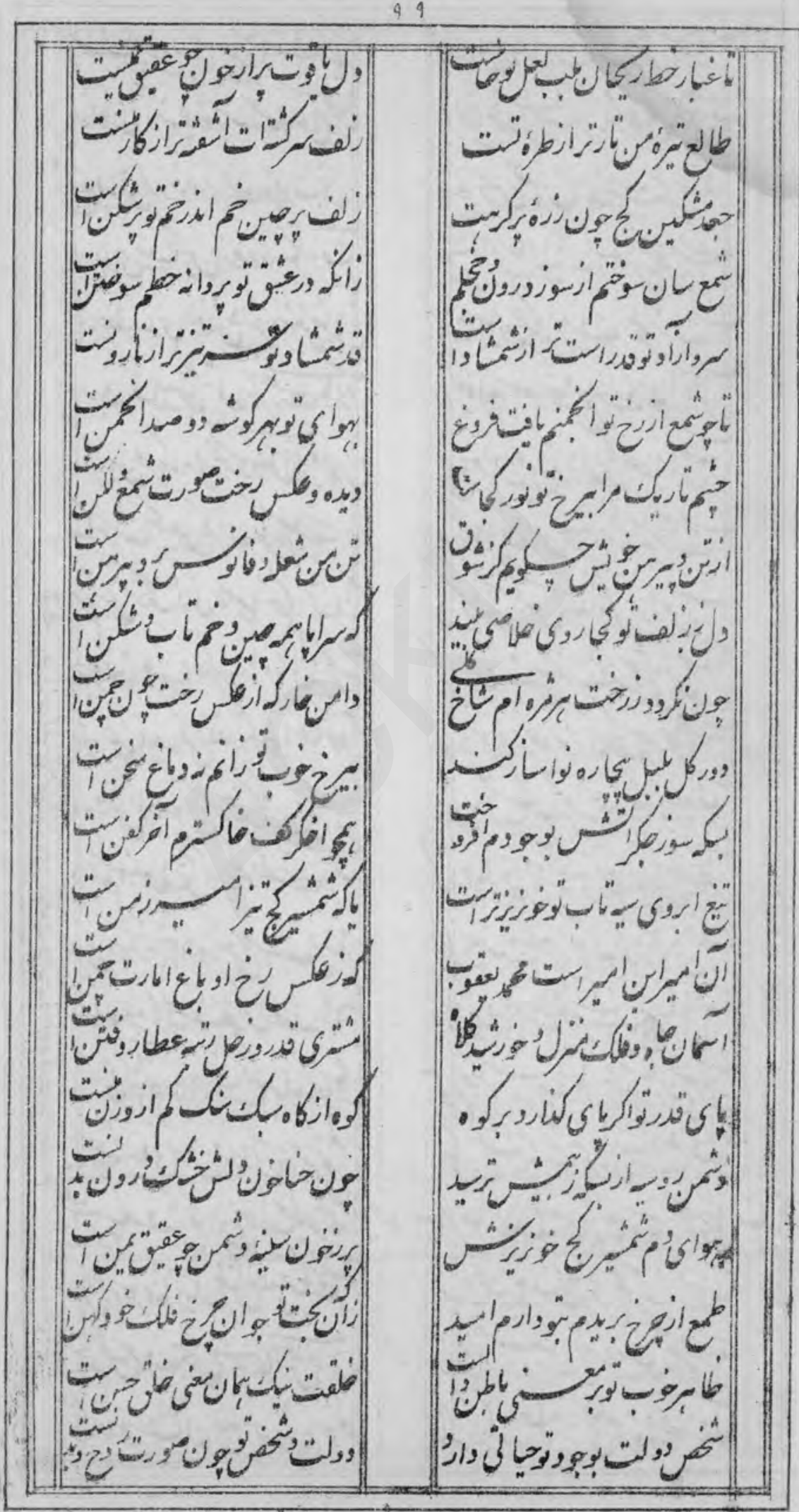




\section{8}

$1 \cdots$

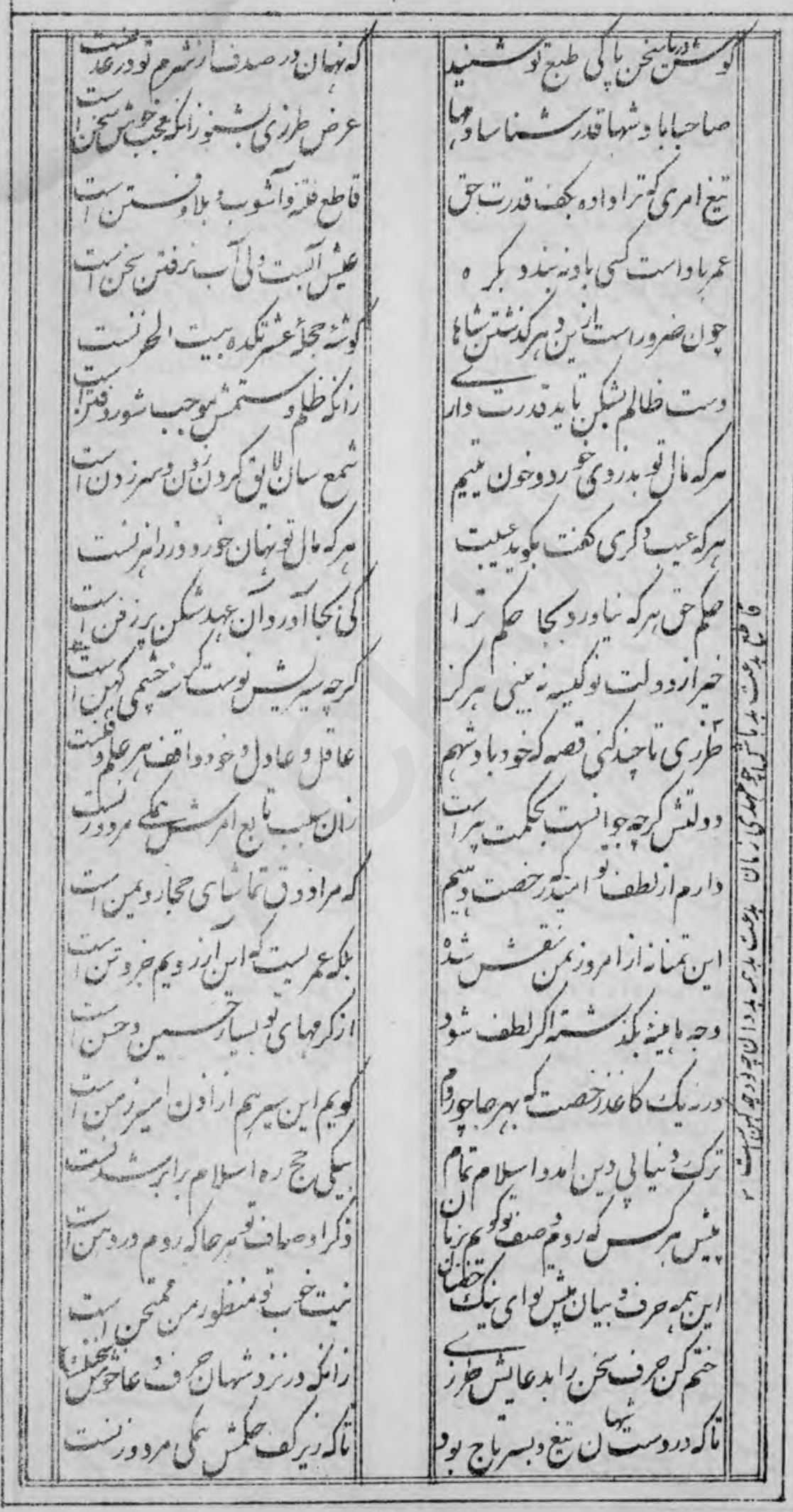




\section{9}

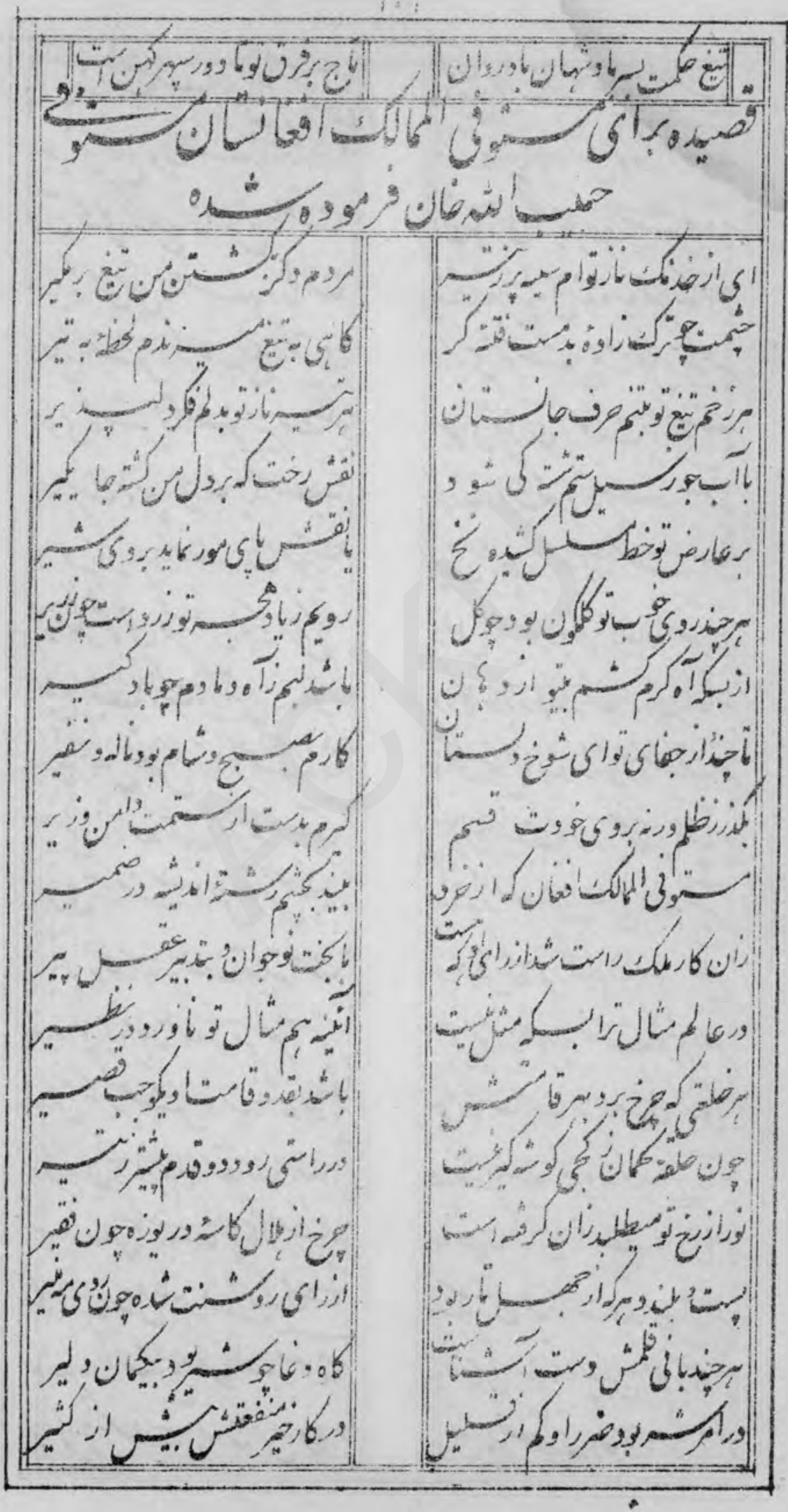


810

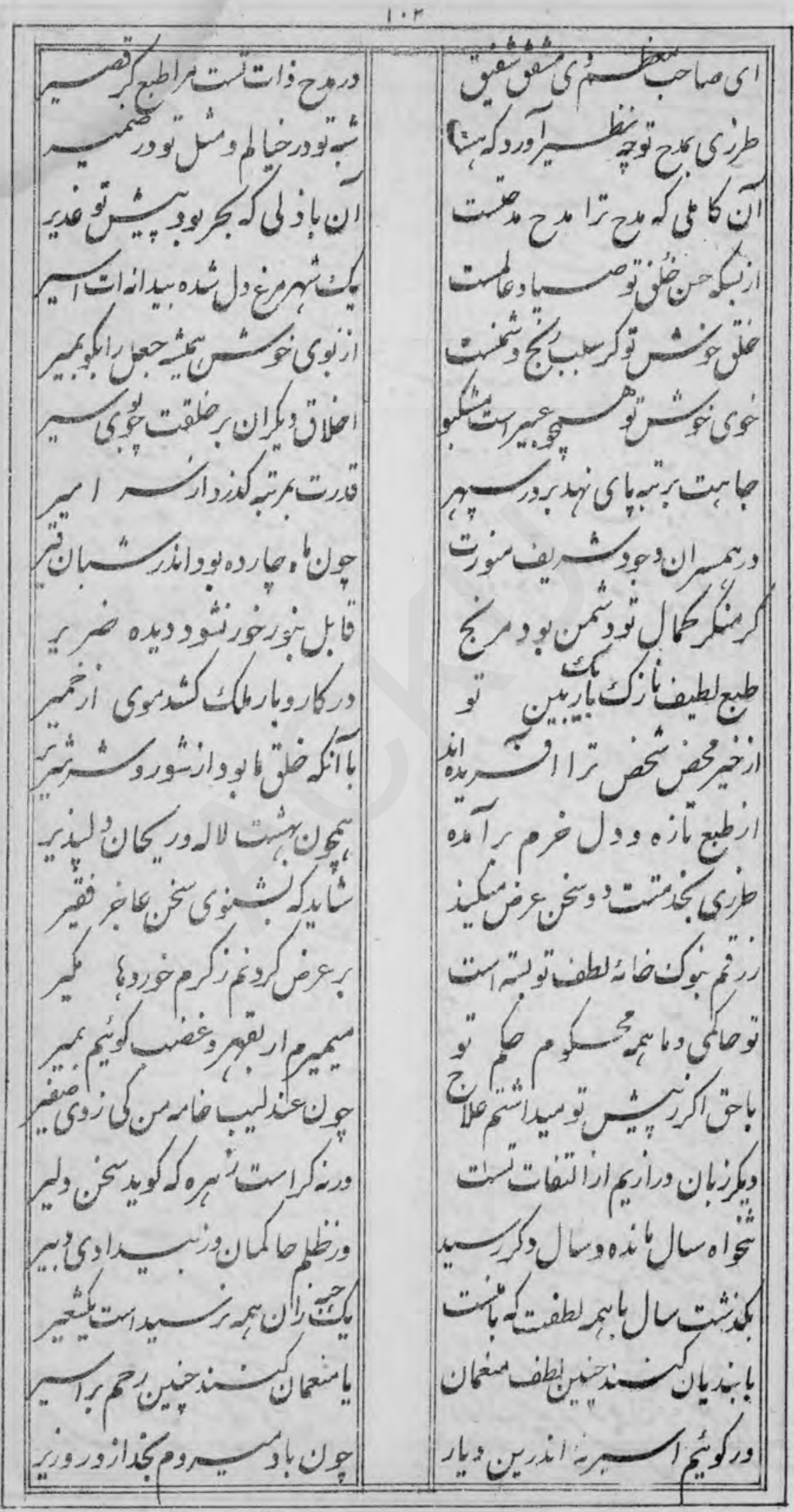




\section{1}

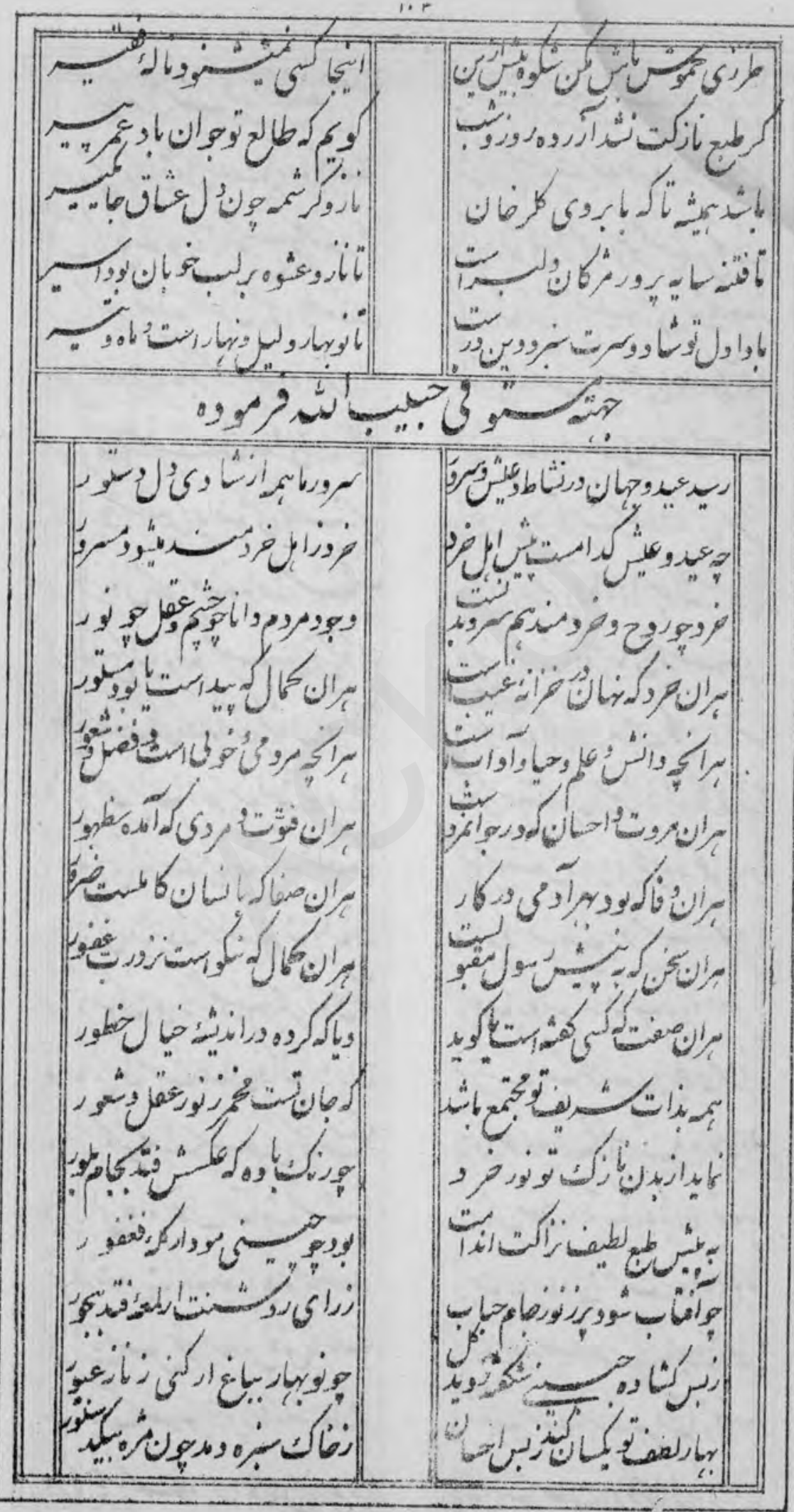




\section{2}

$1 \cdot f$

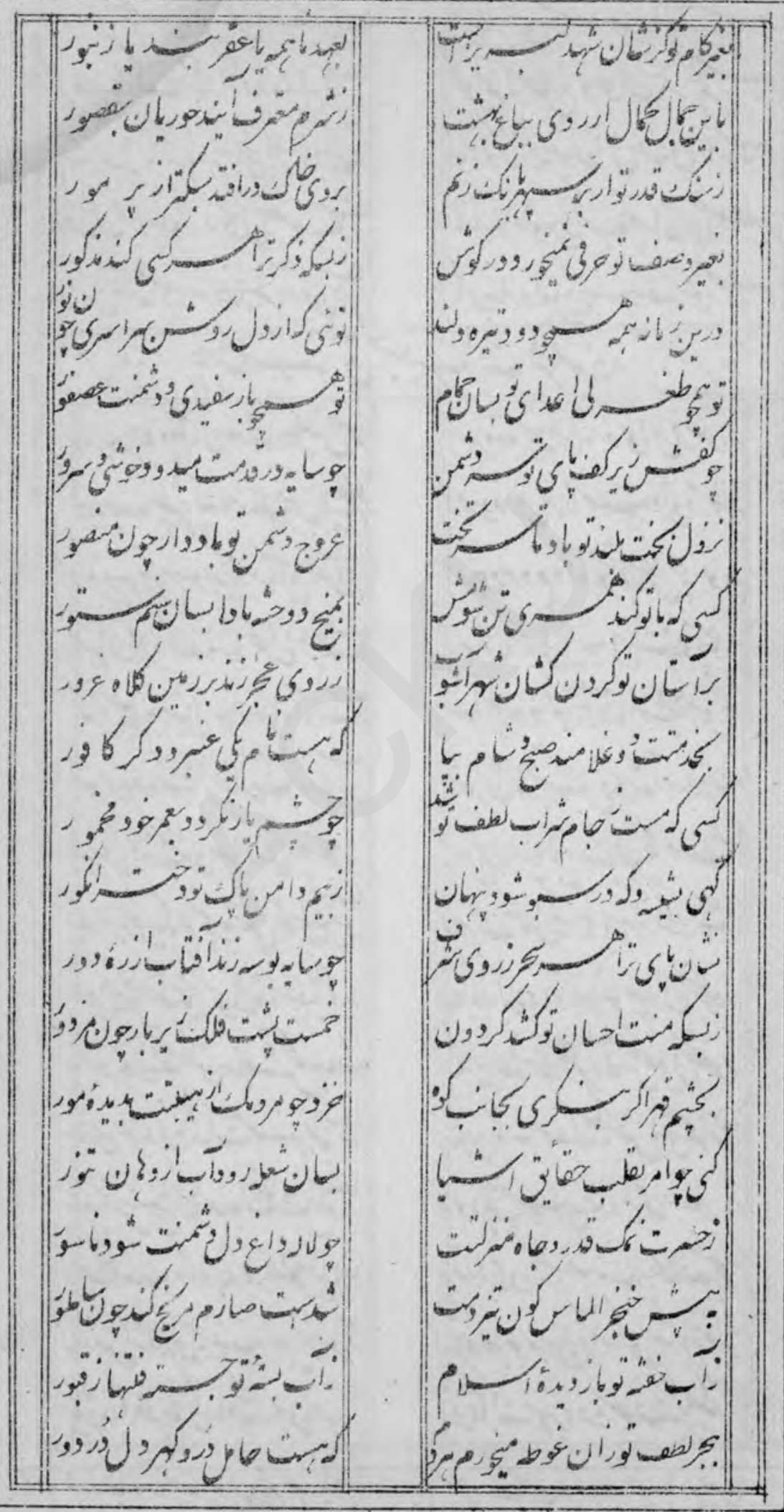

(.) 


\section{3}

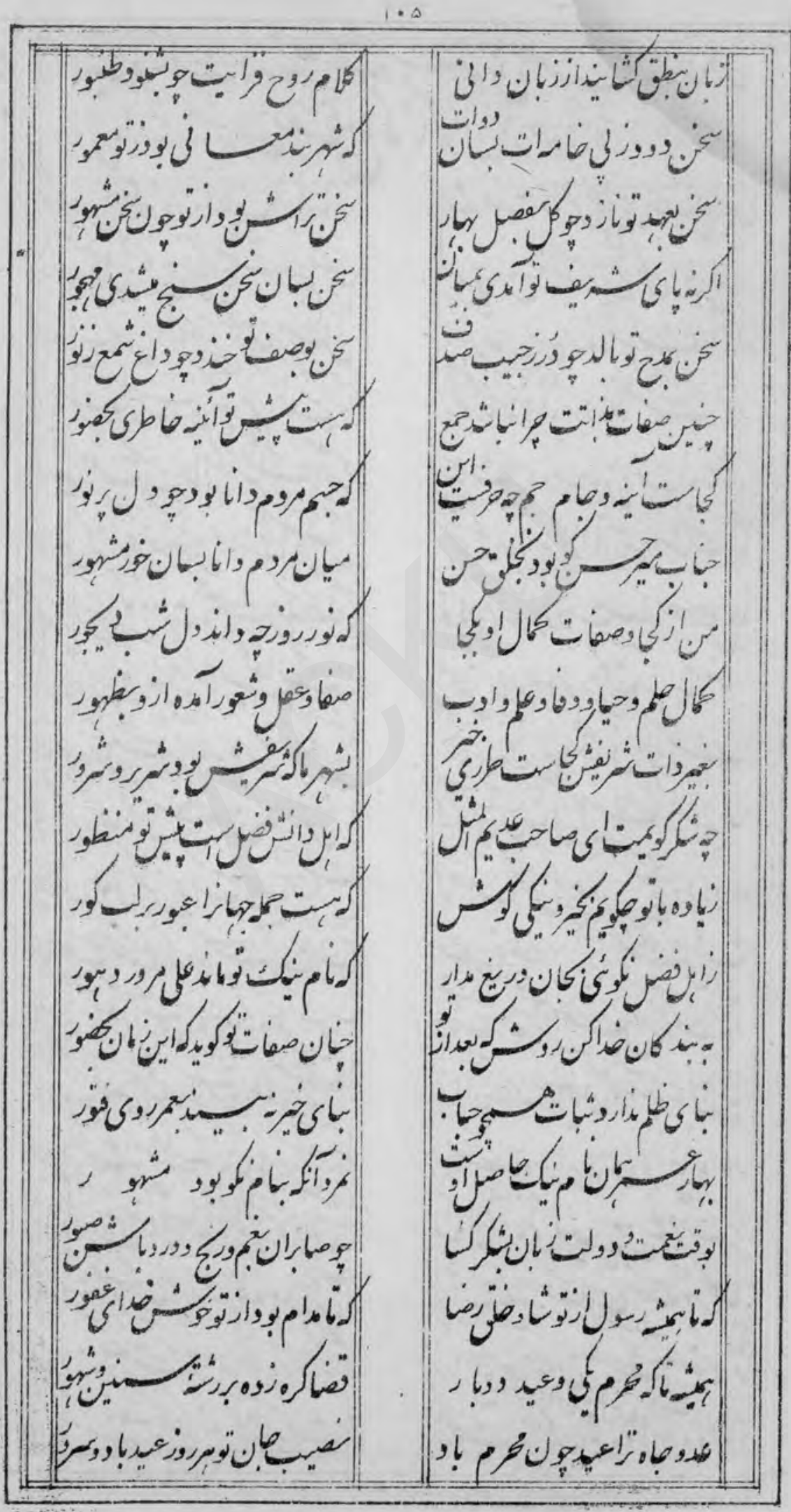


1.5

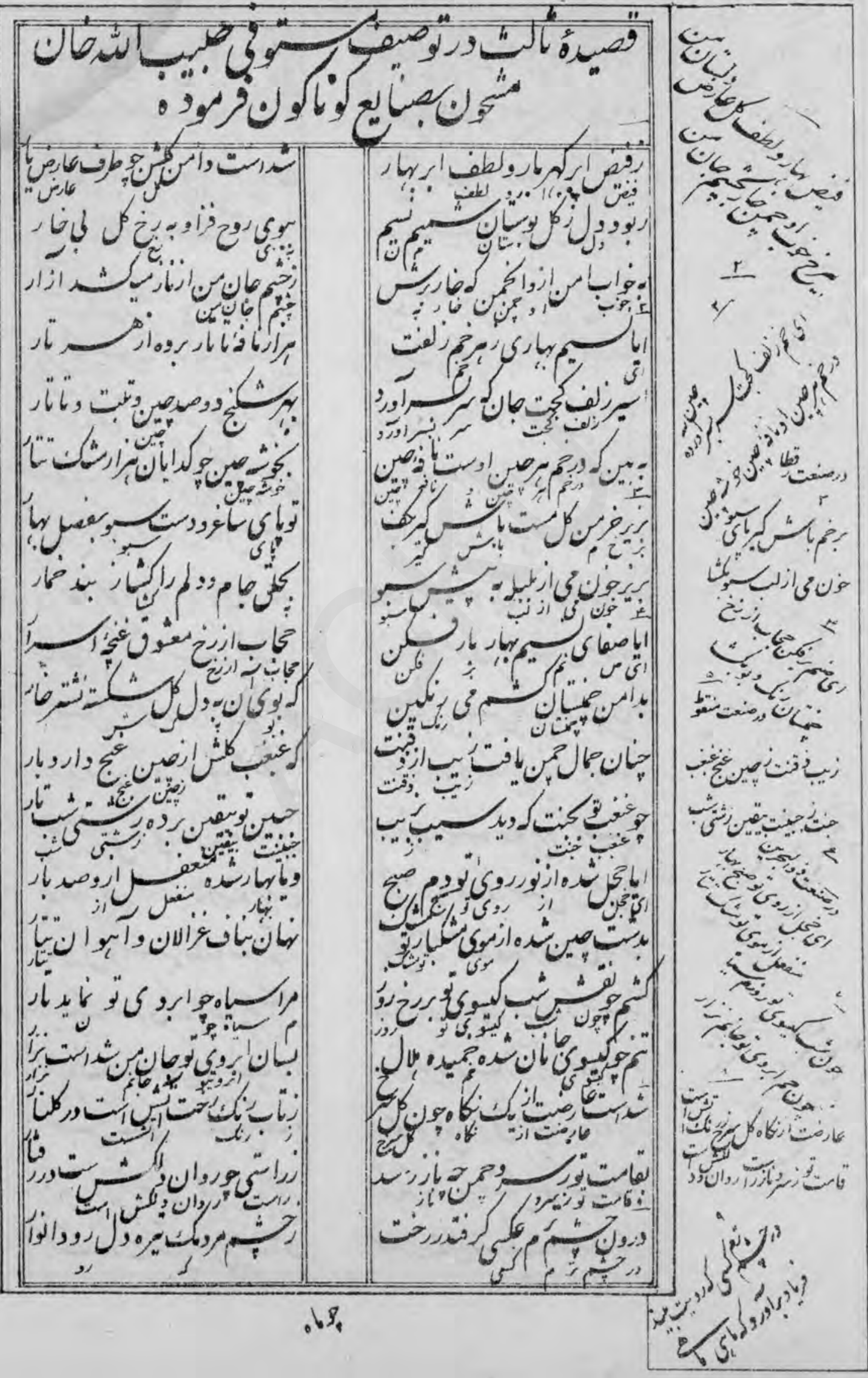




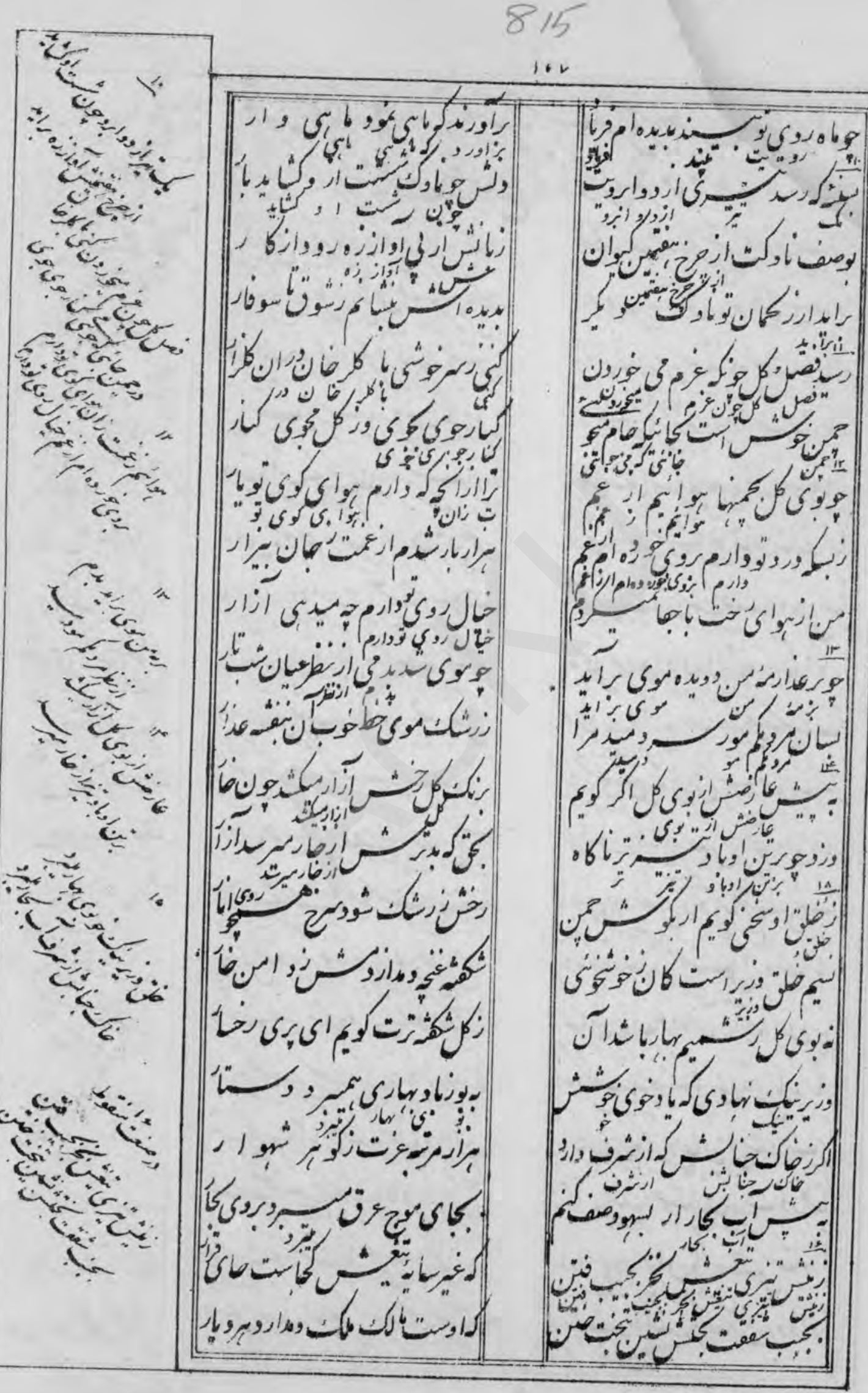


1.1

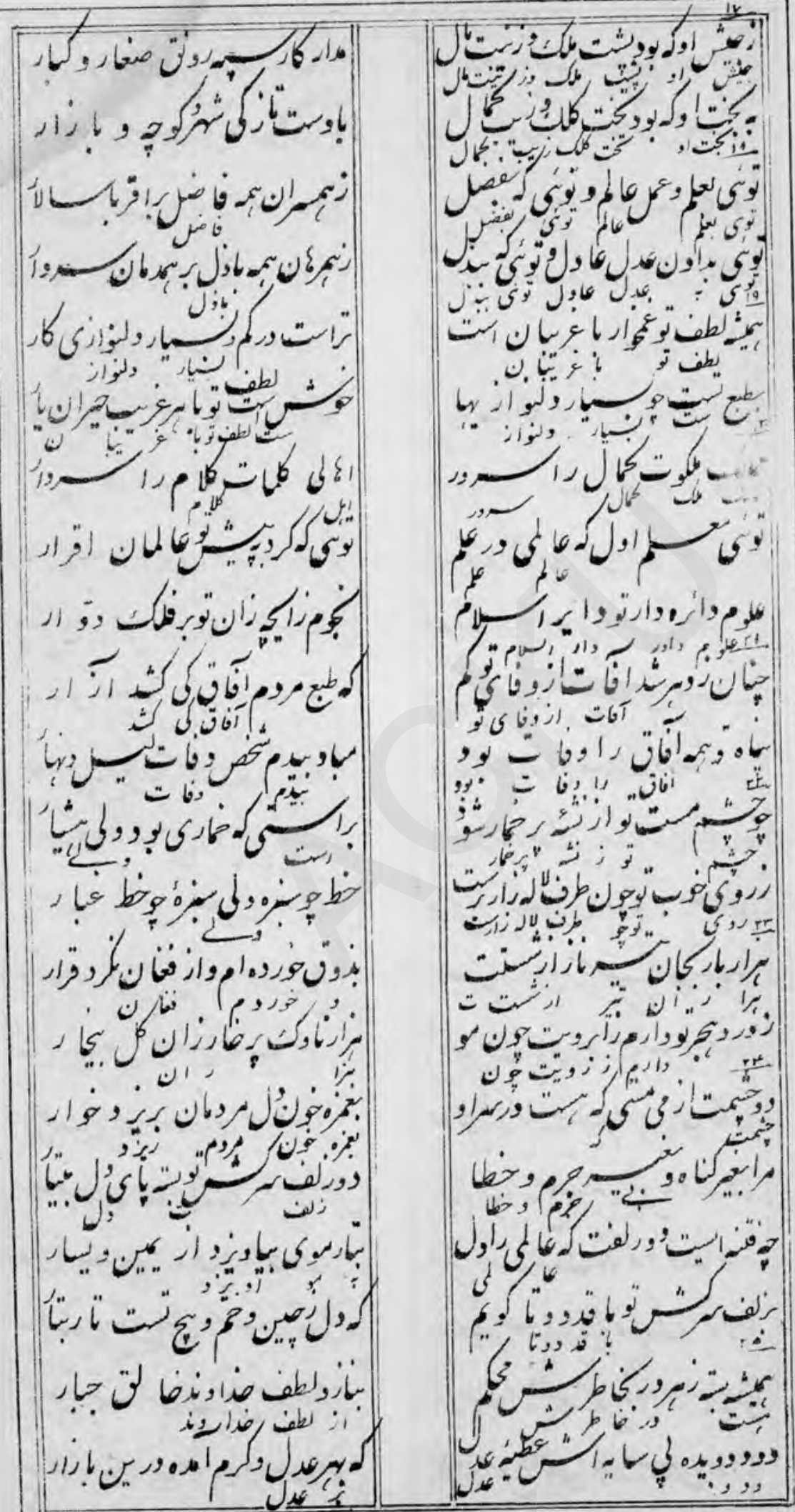

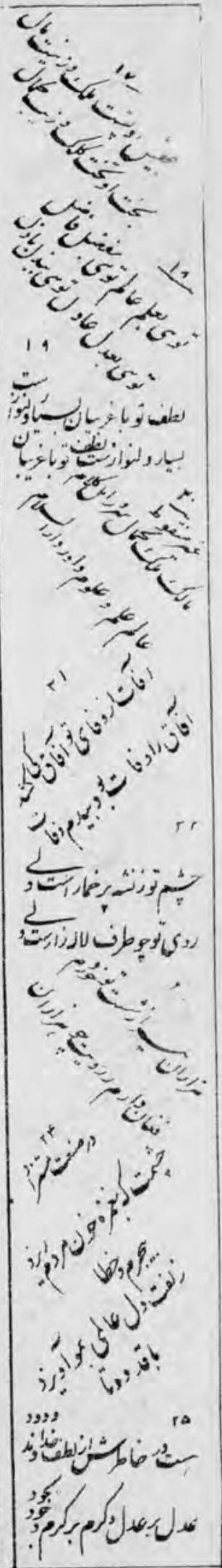




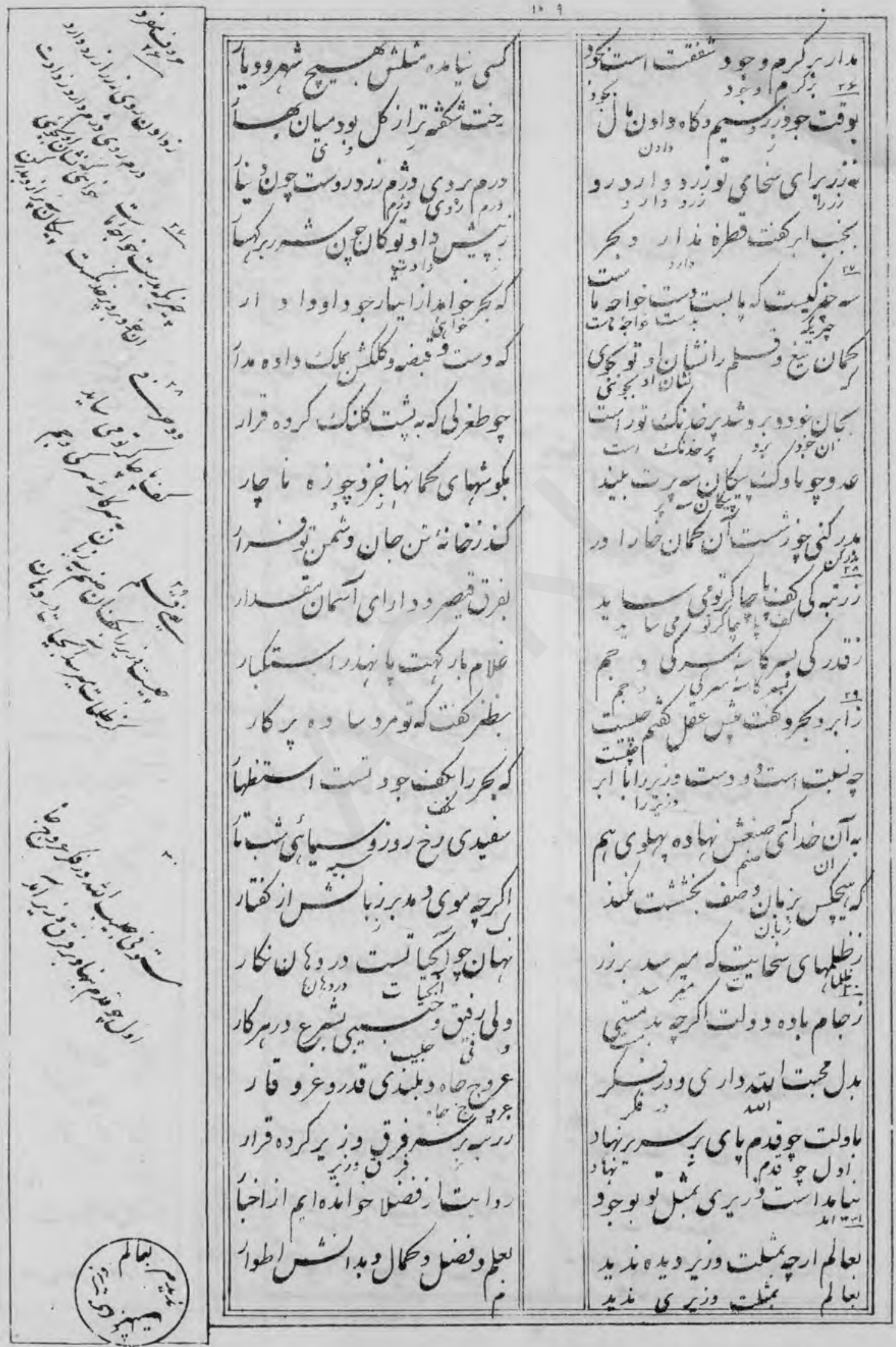




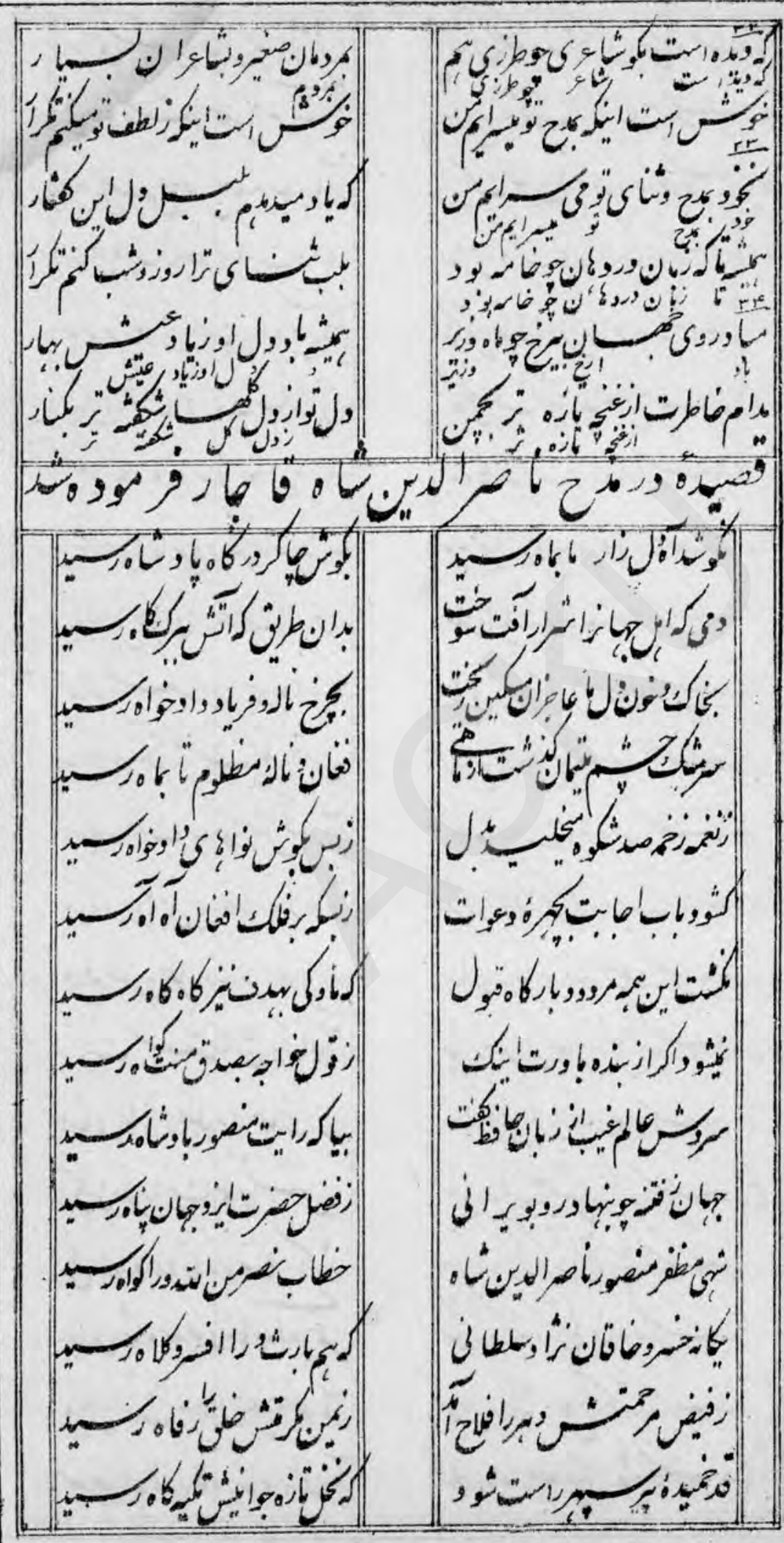




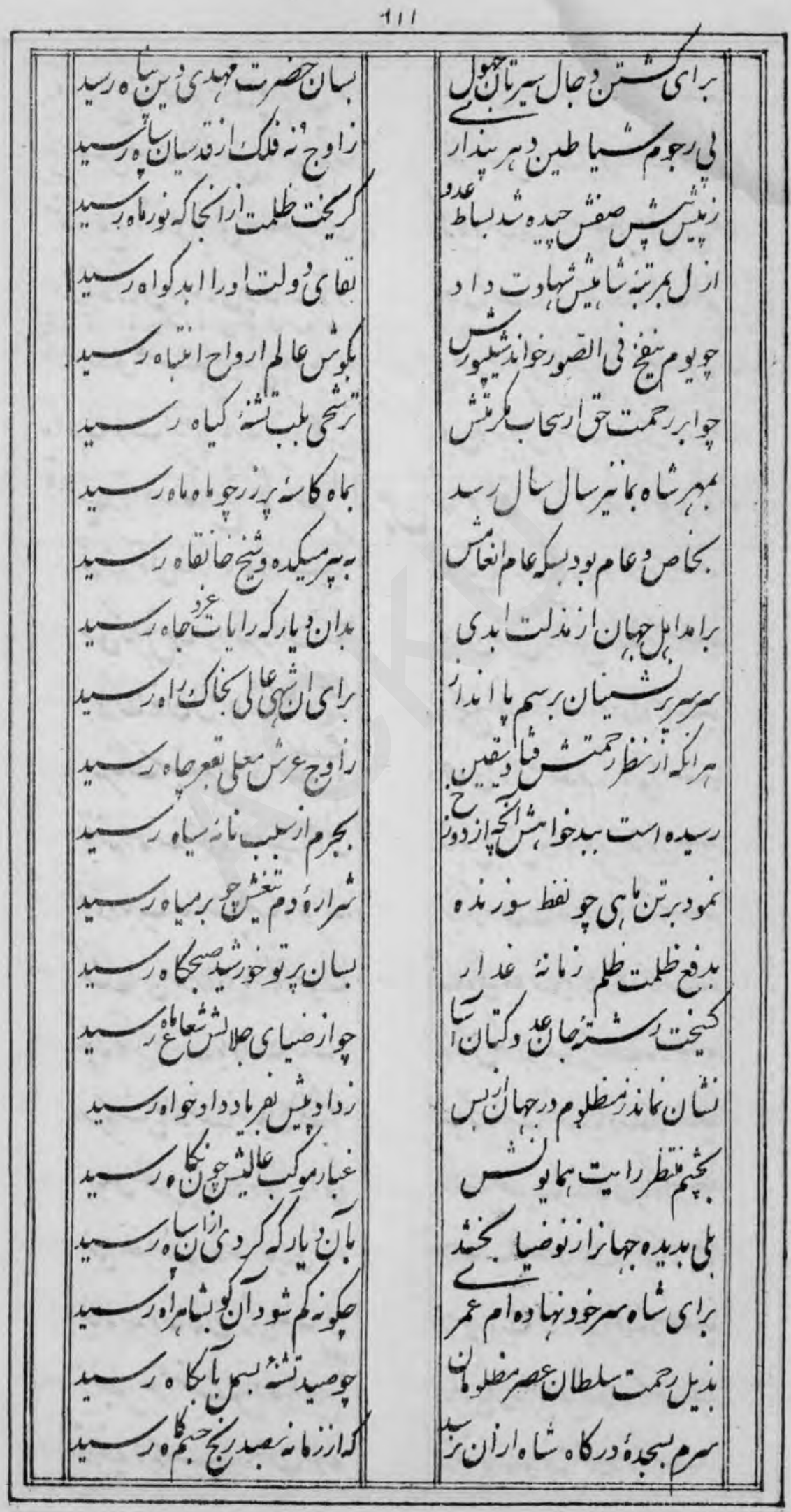




\section{0}

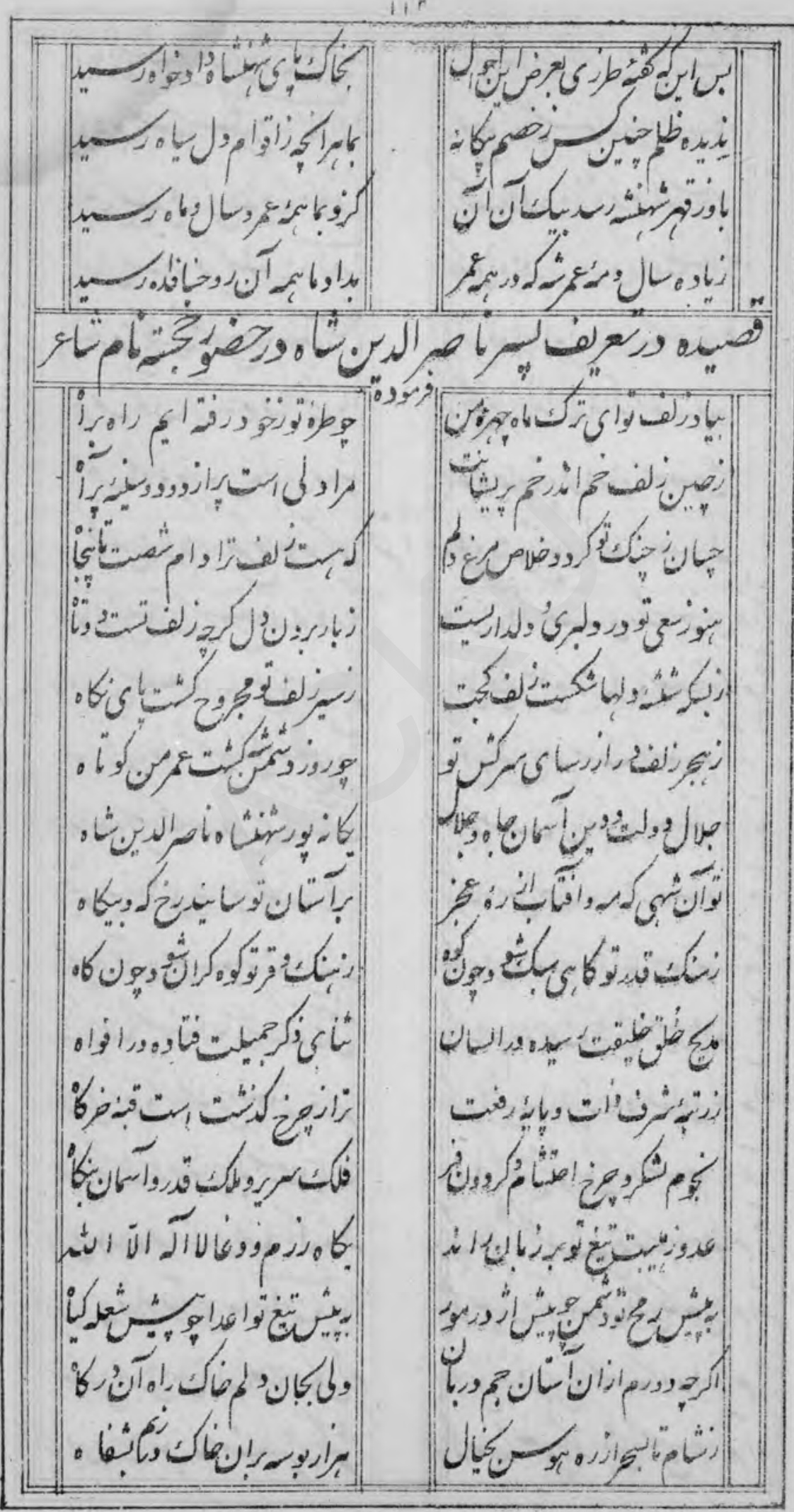




\section{1}

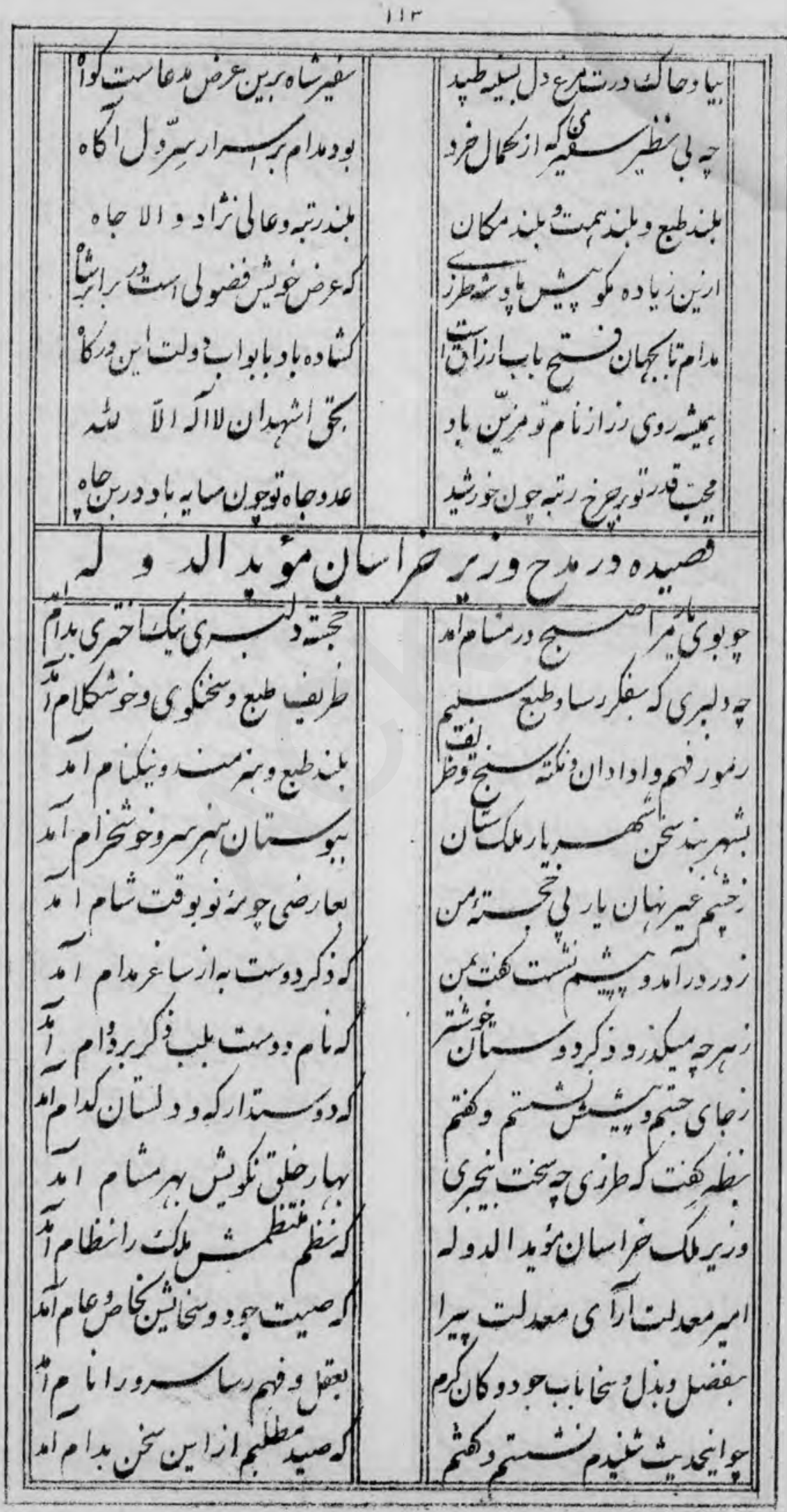




\section{2}

$11 \mu^{2}$

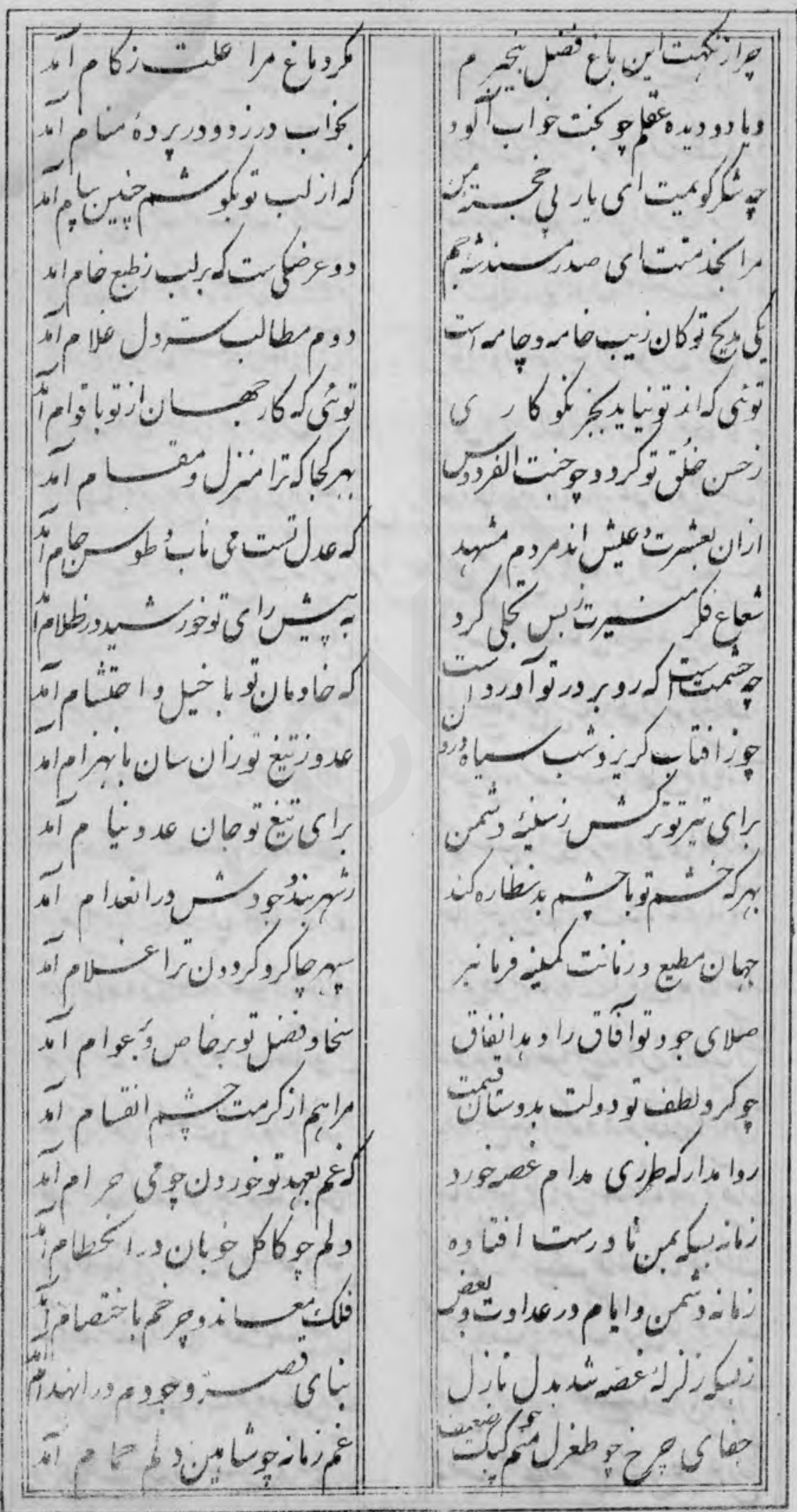




\section{3}

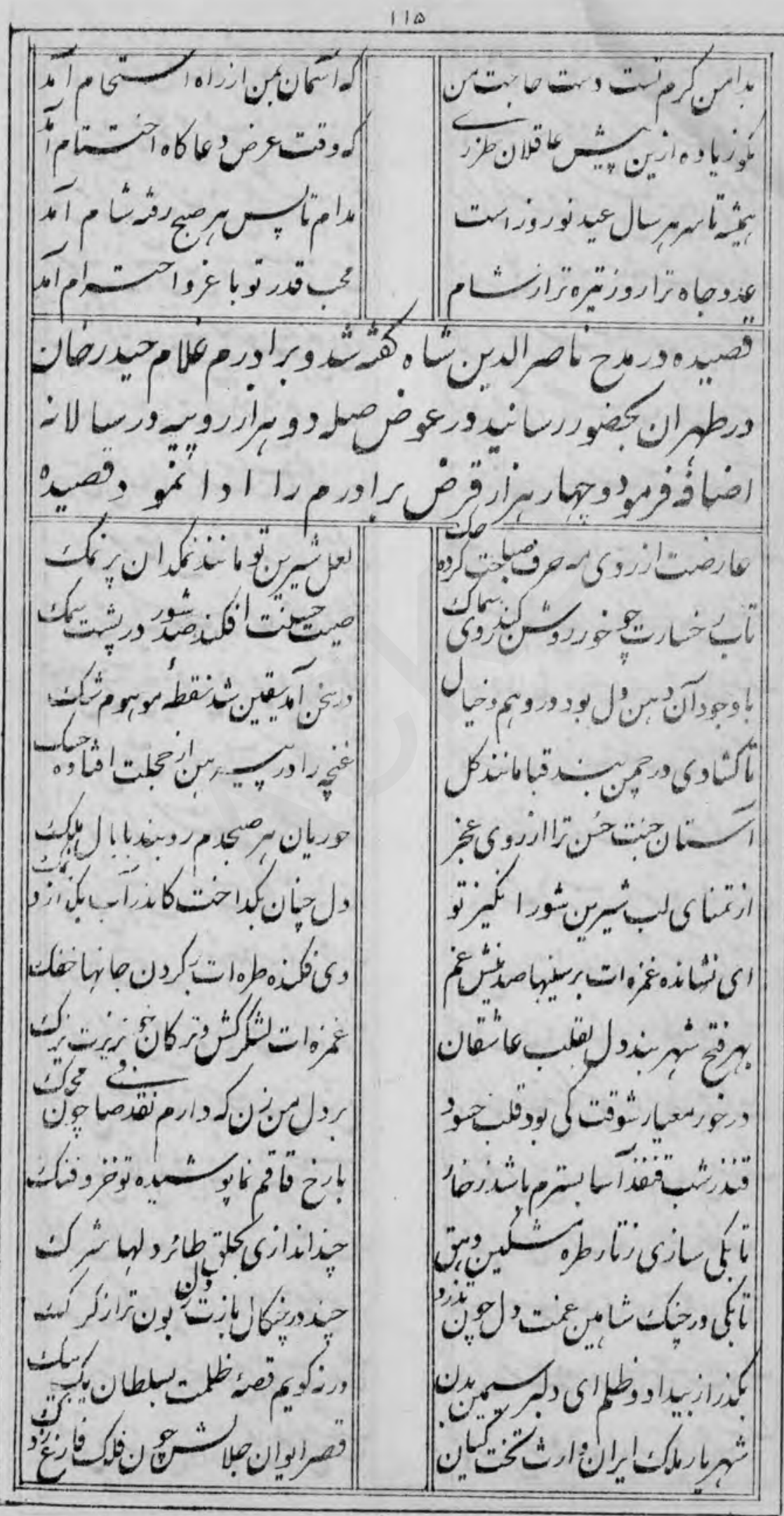


15

||




\section{5}

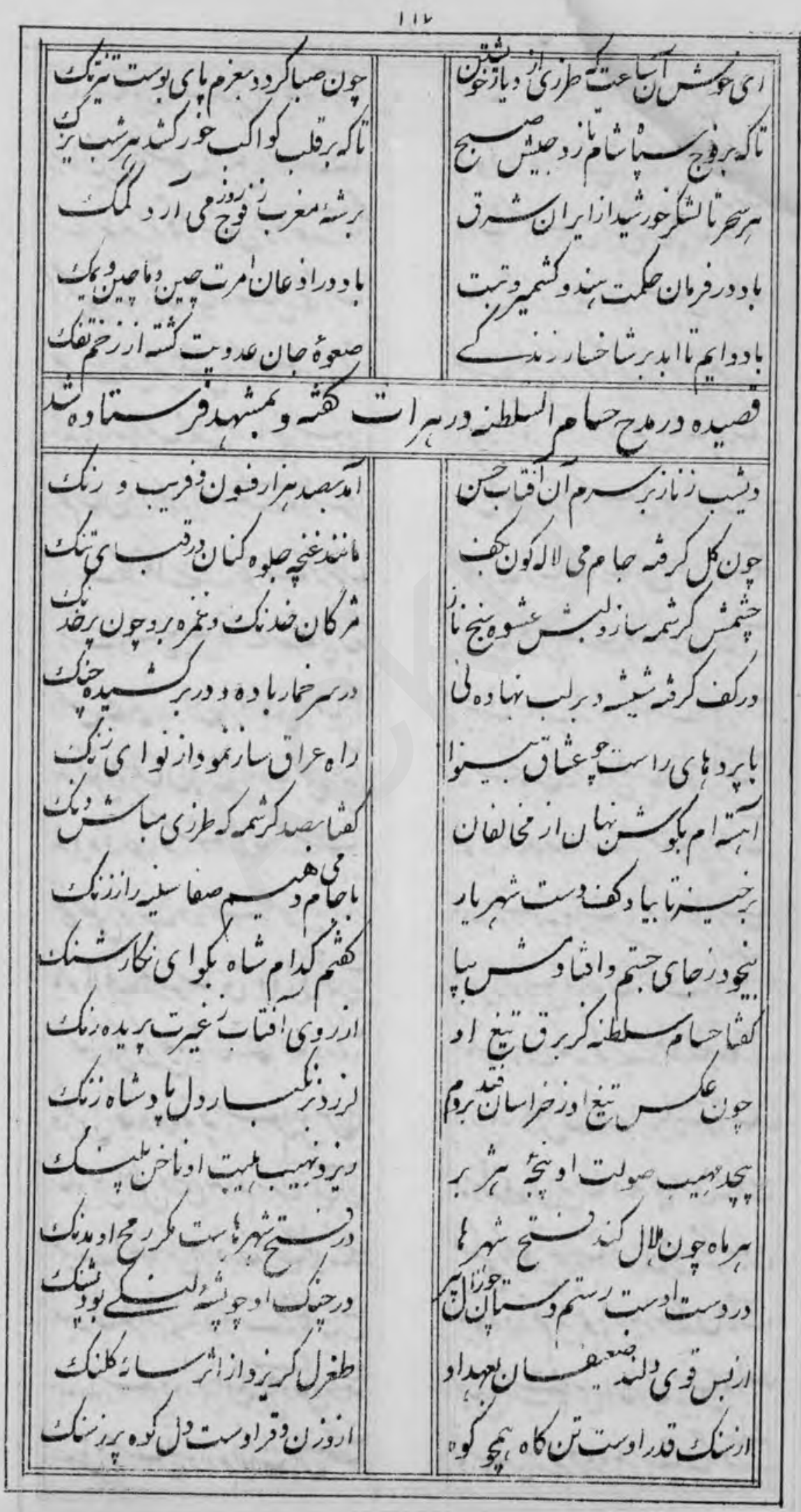




\section{6}

$11 \mathrm{~A}$

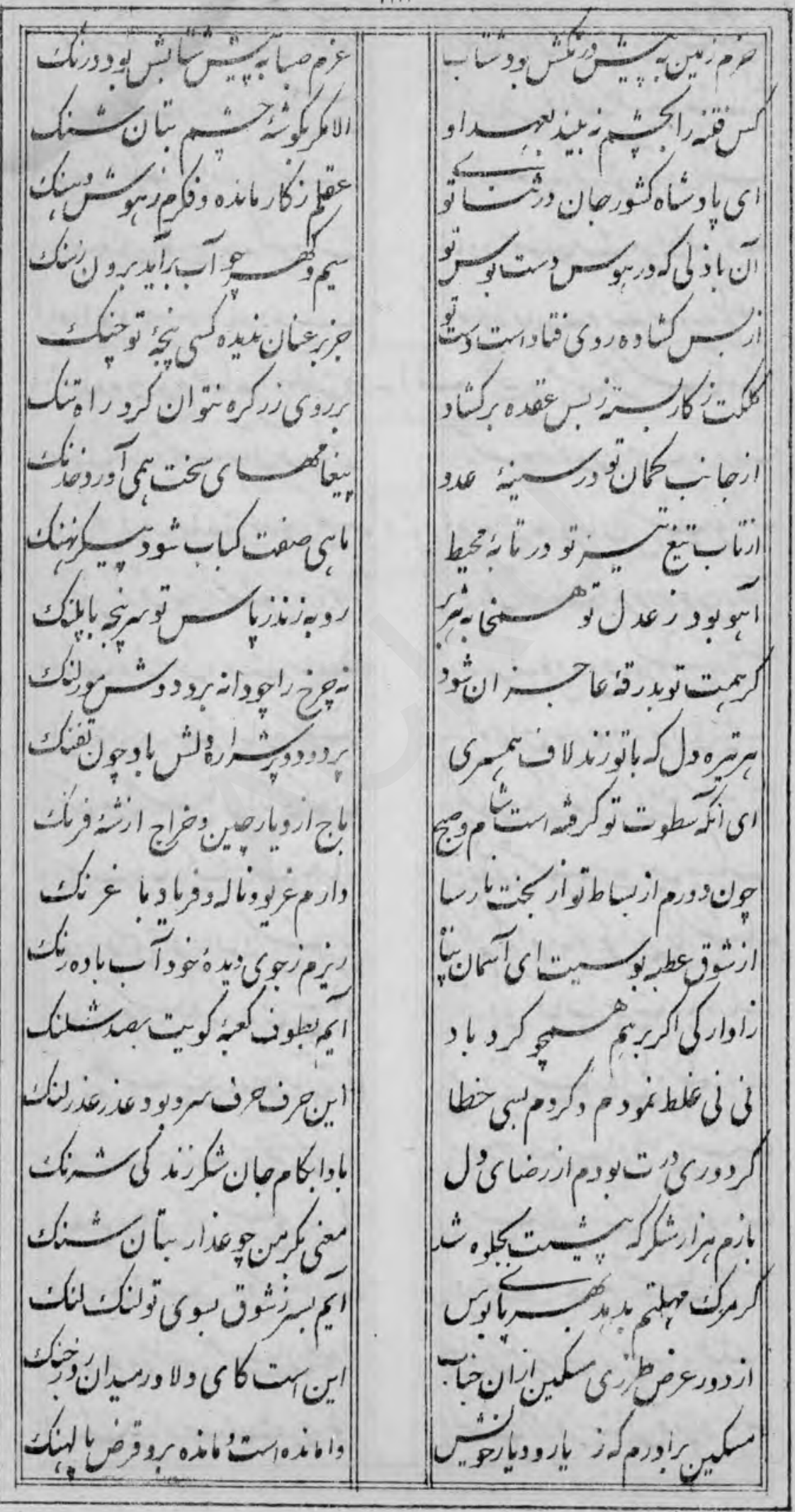




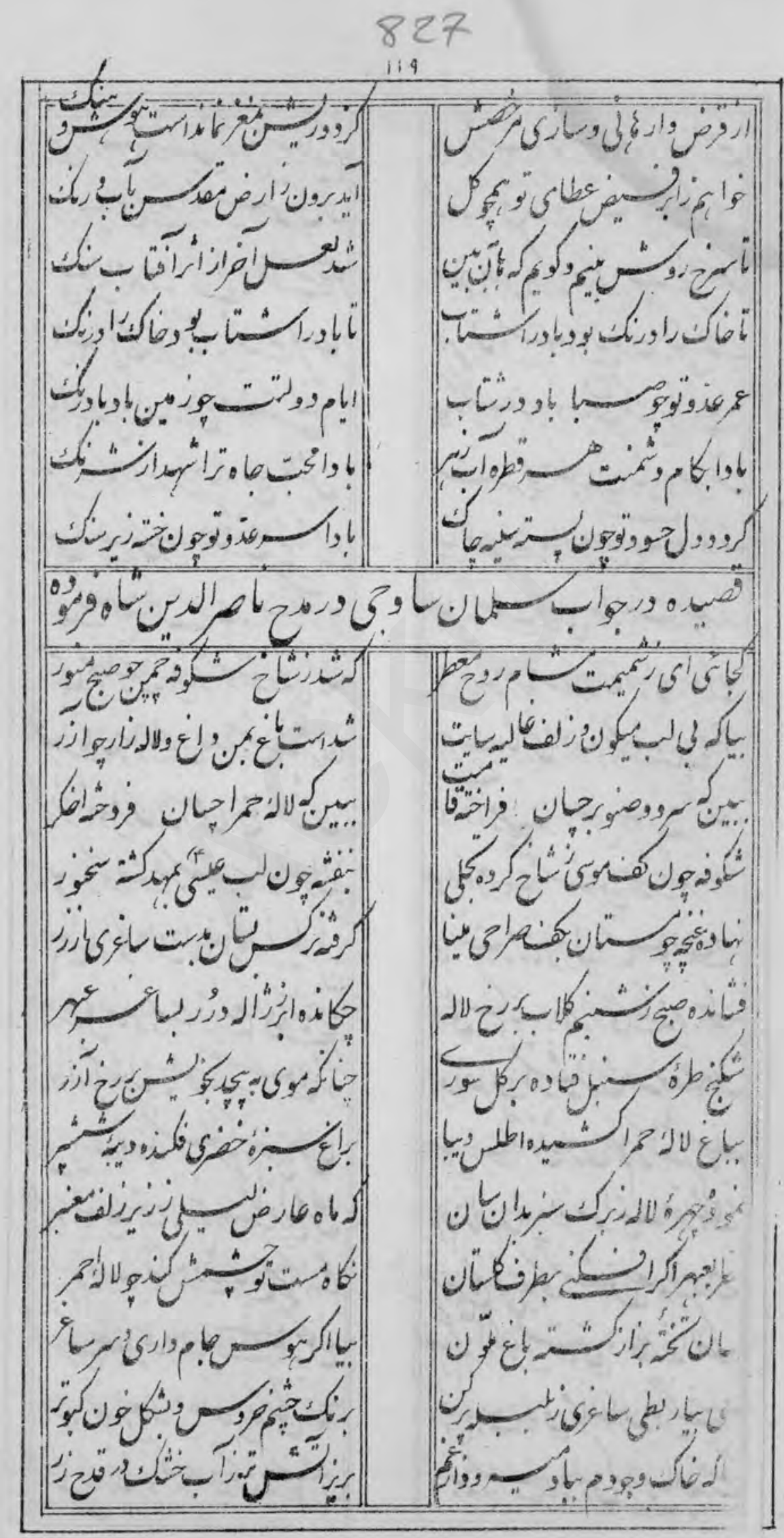


828

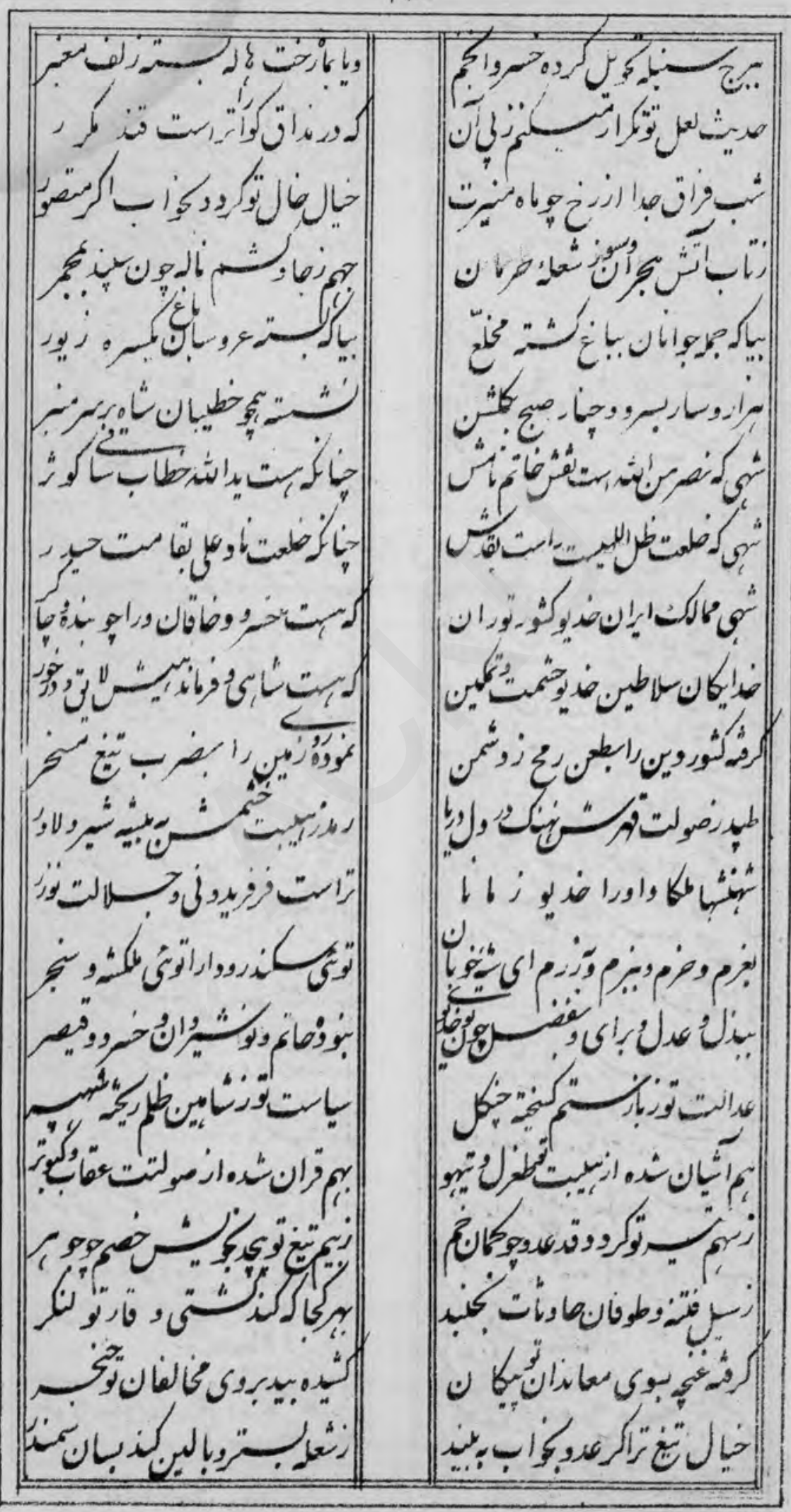




\section{9}

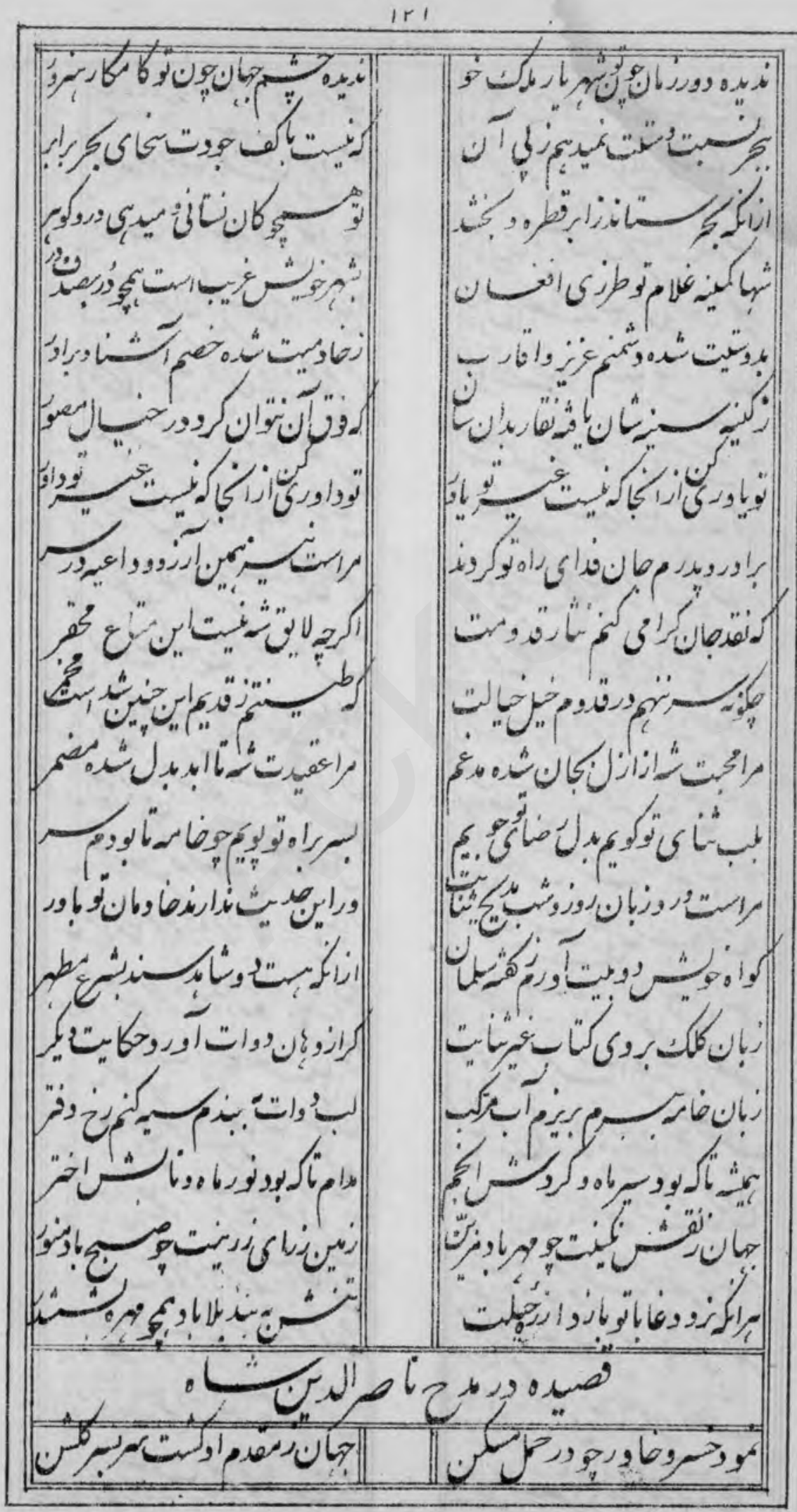


830

irr

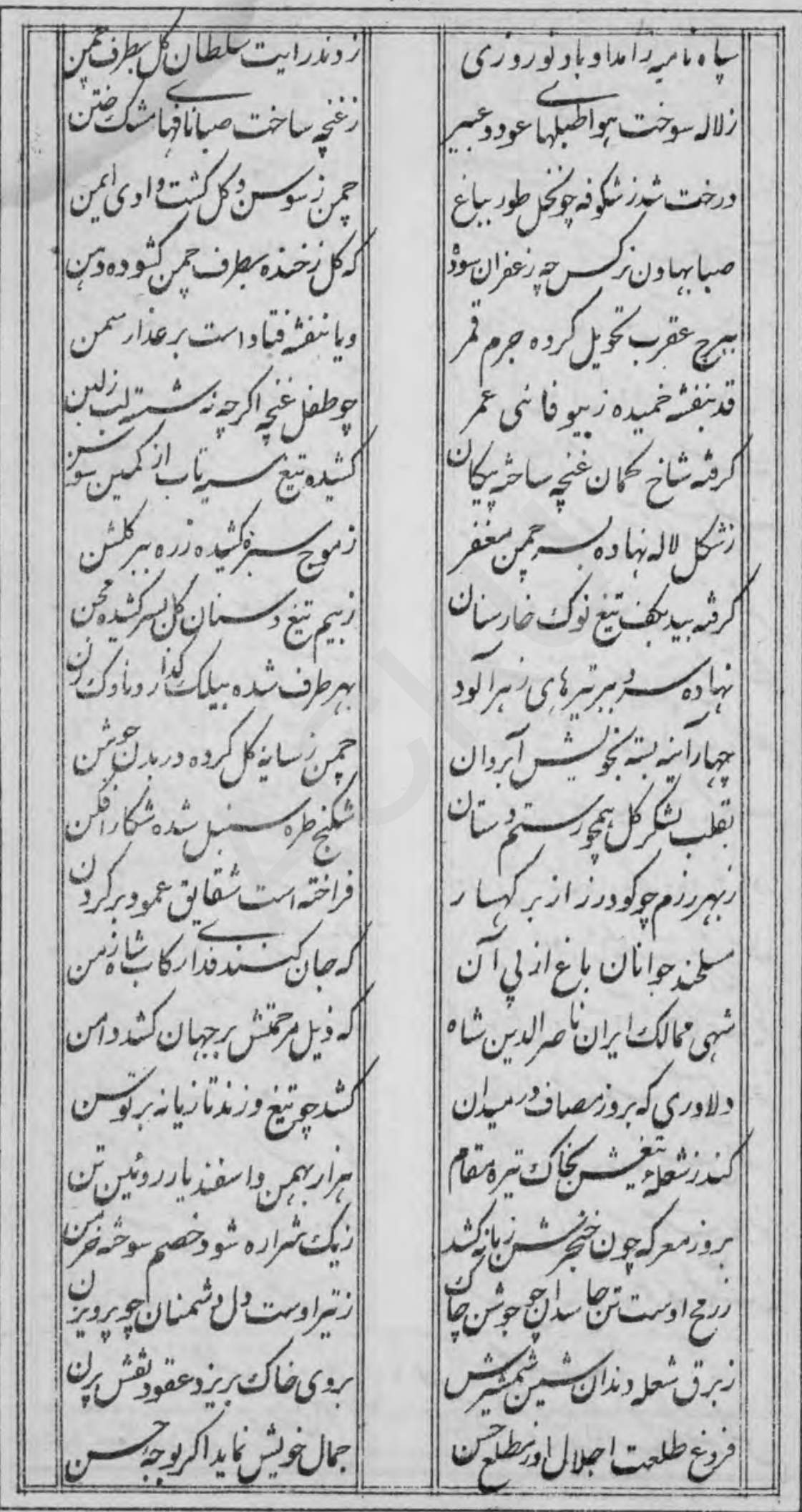

$u^{v}$ 
831

\section{j r r}

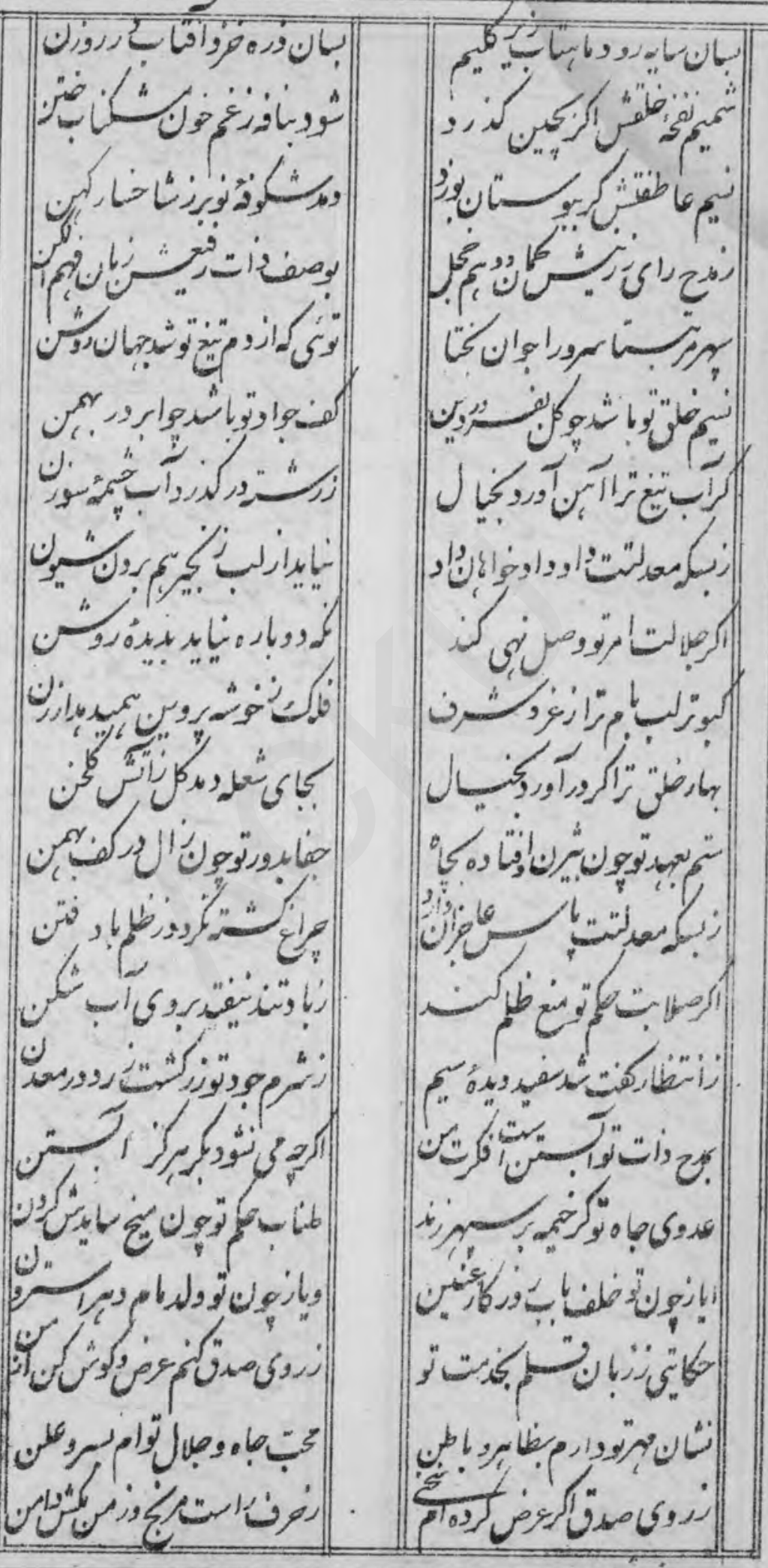


832

or

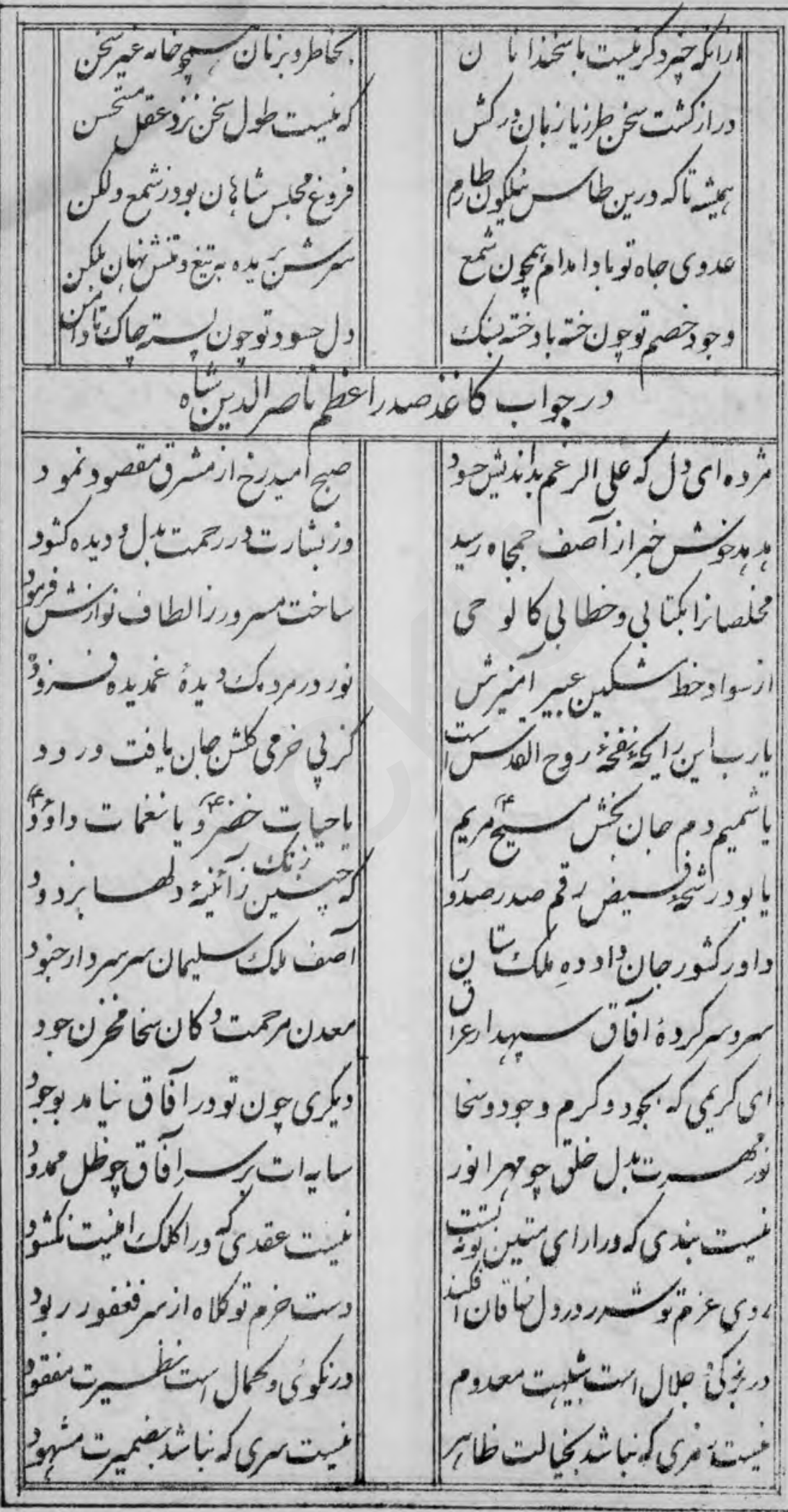

iv. 


\section{3}

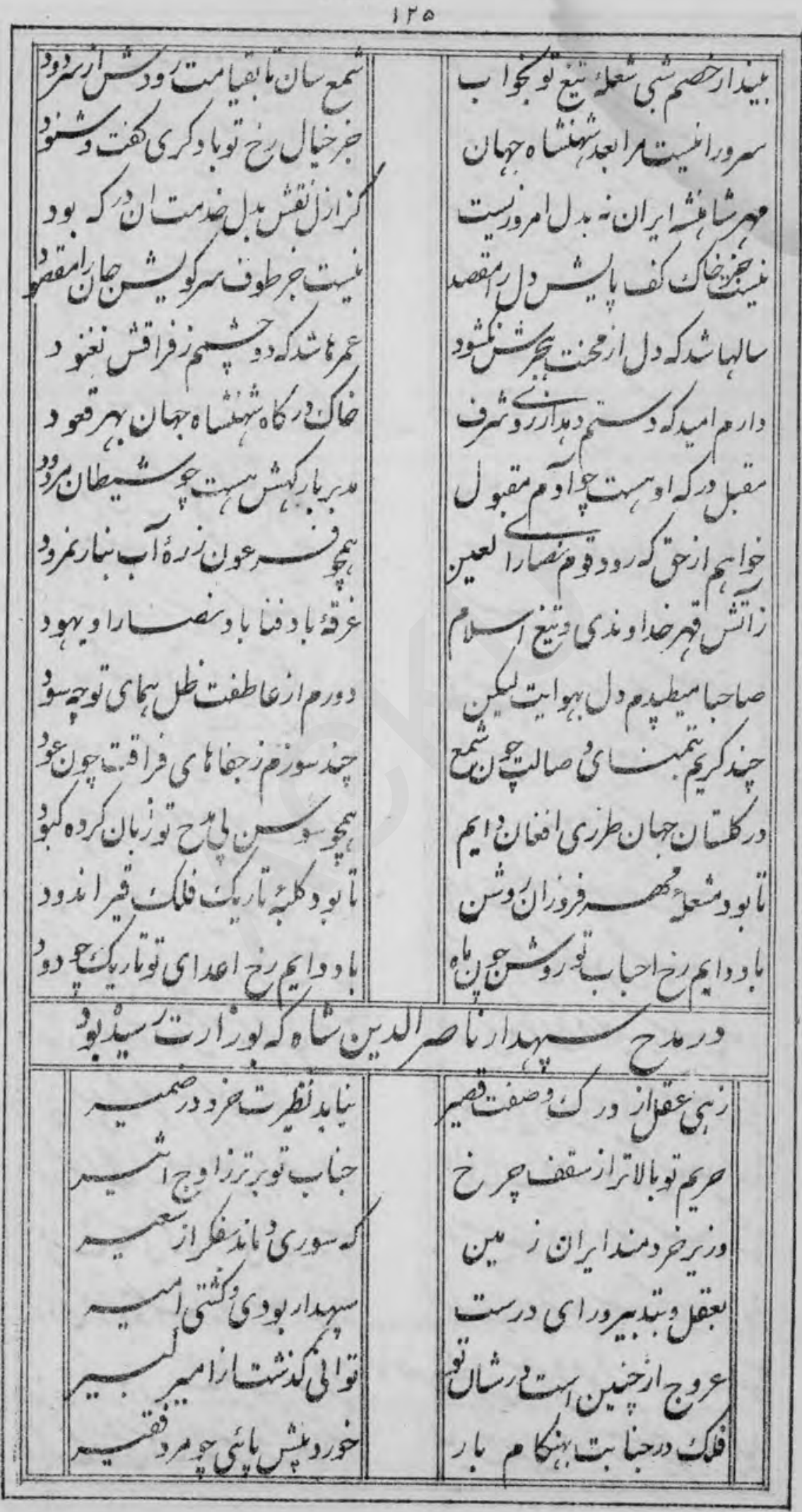




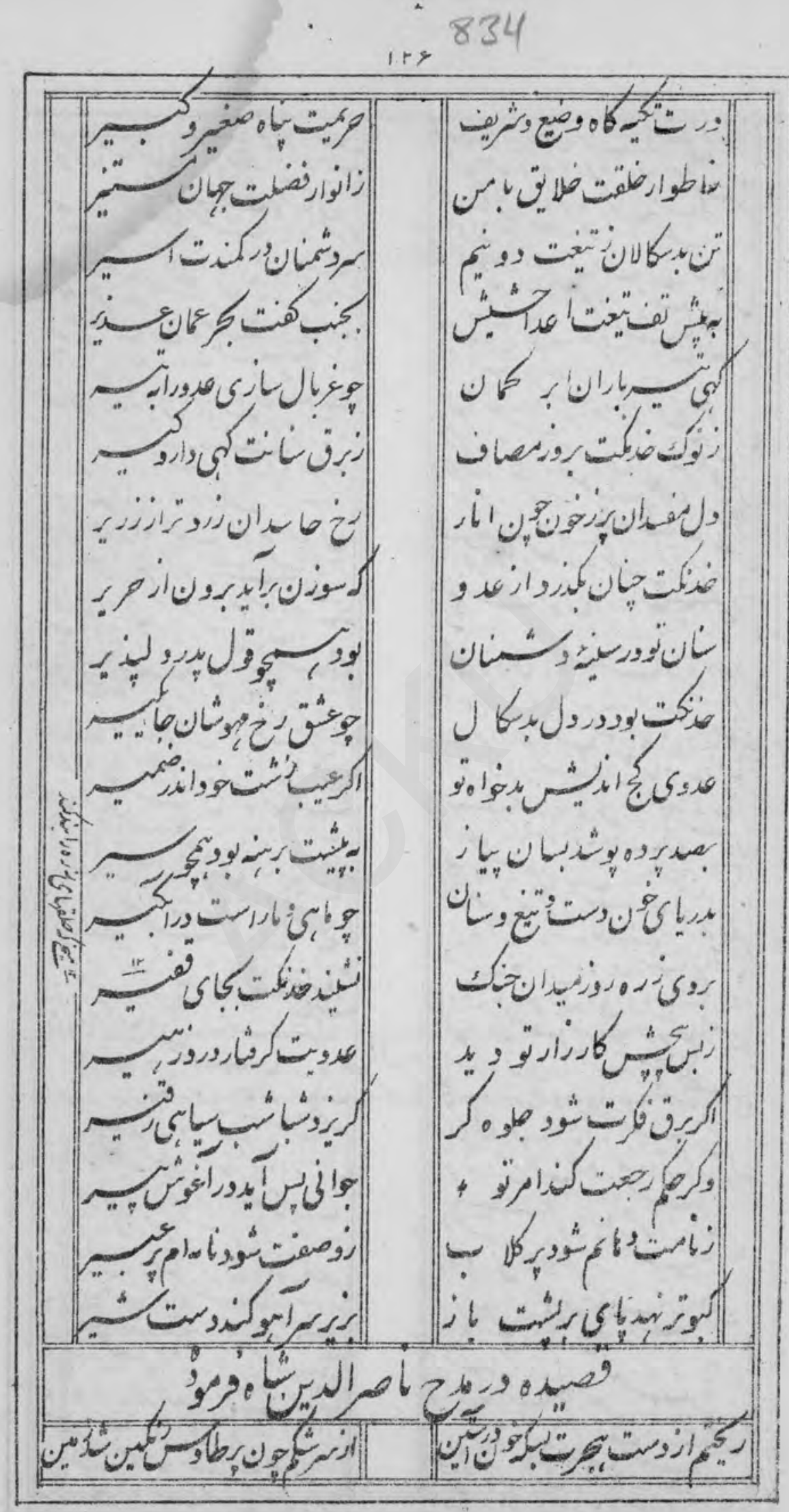

bi 


\section{5}

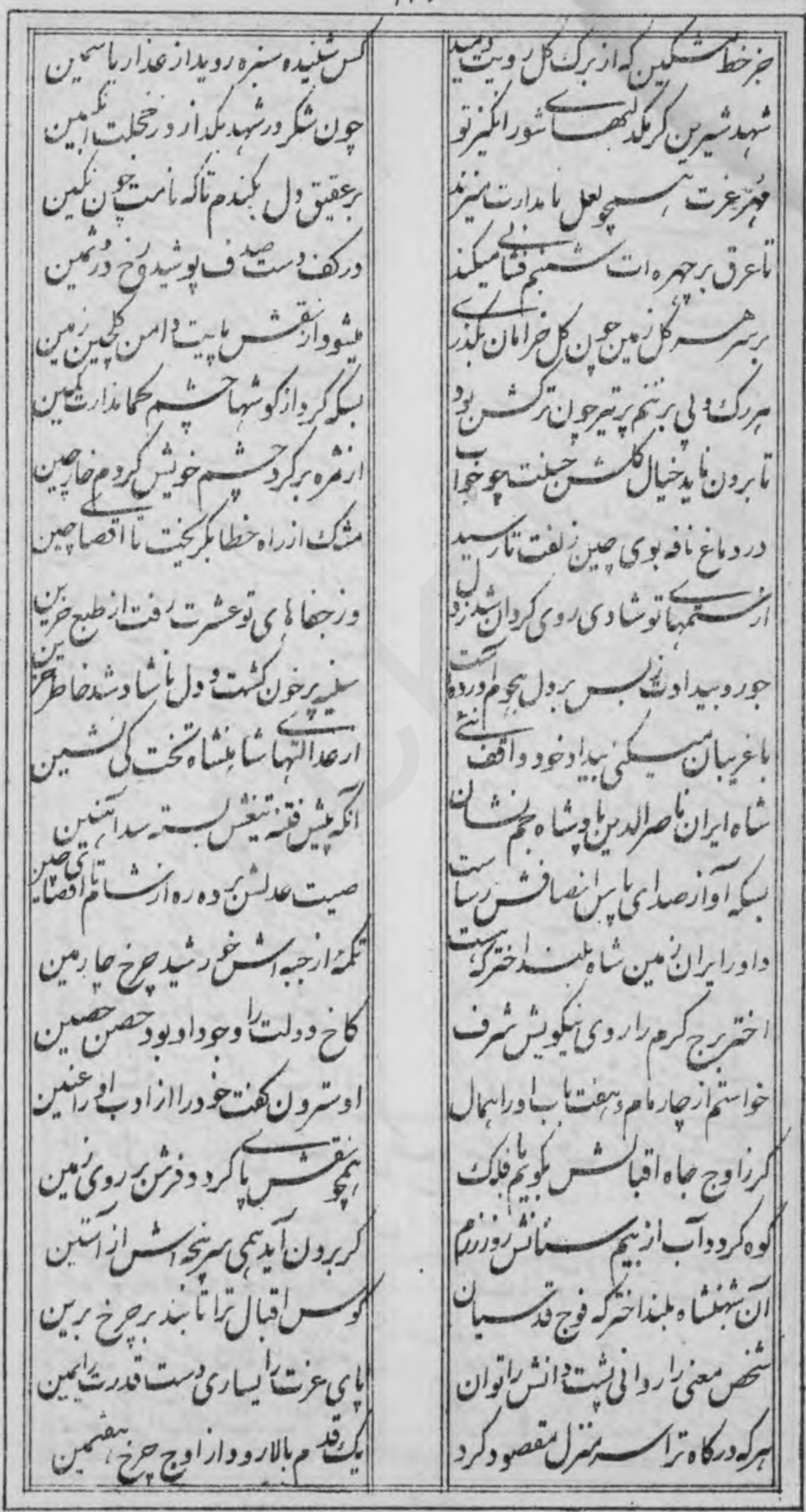


836

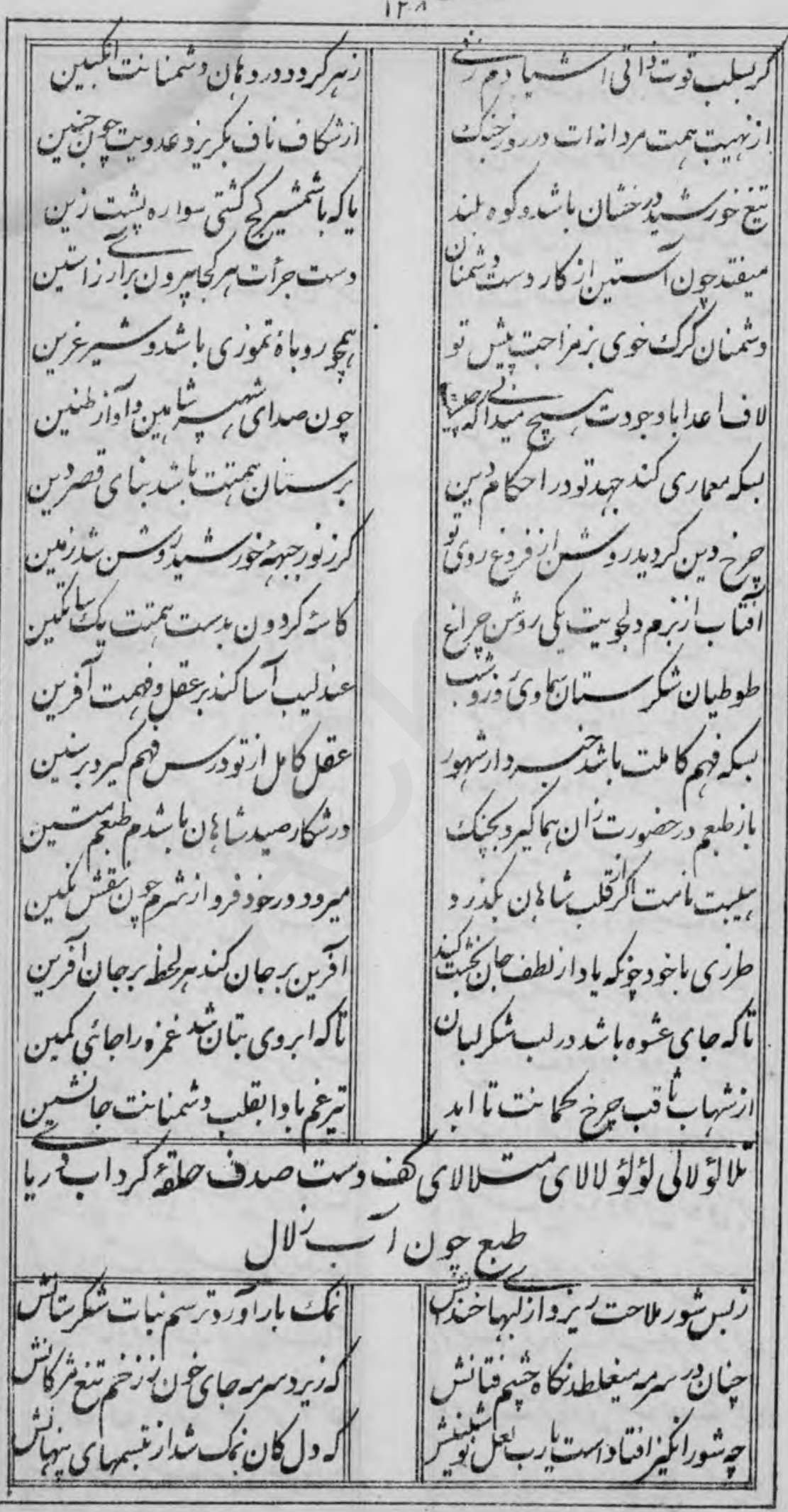




\section{7}

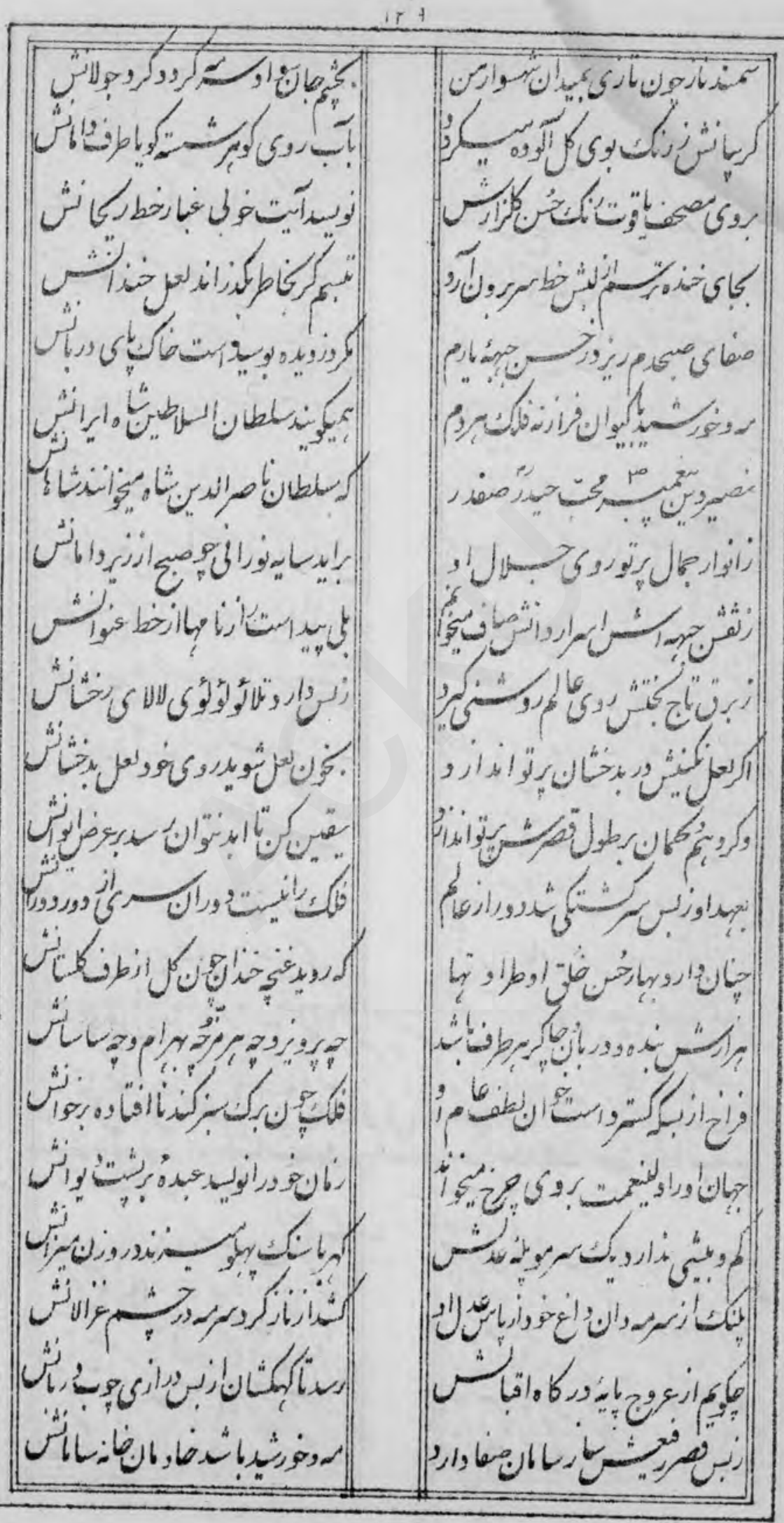


iro

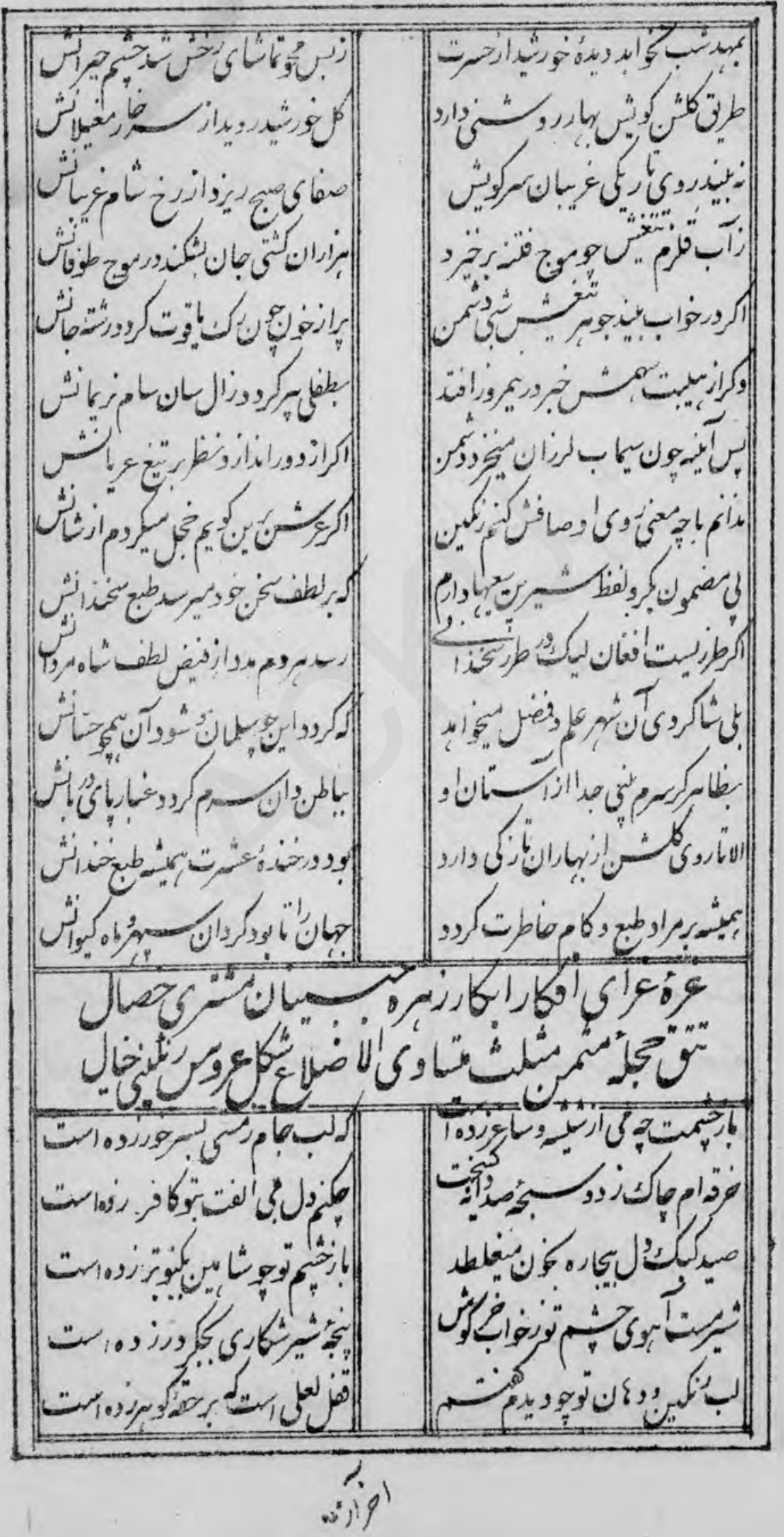




\section{9}

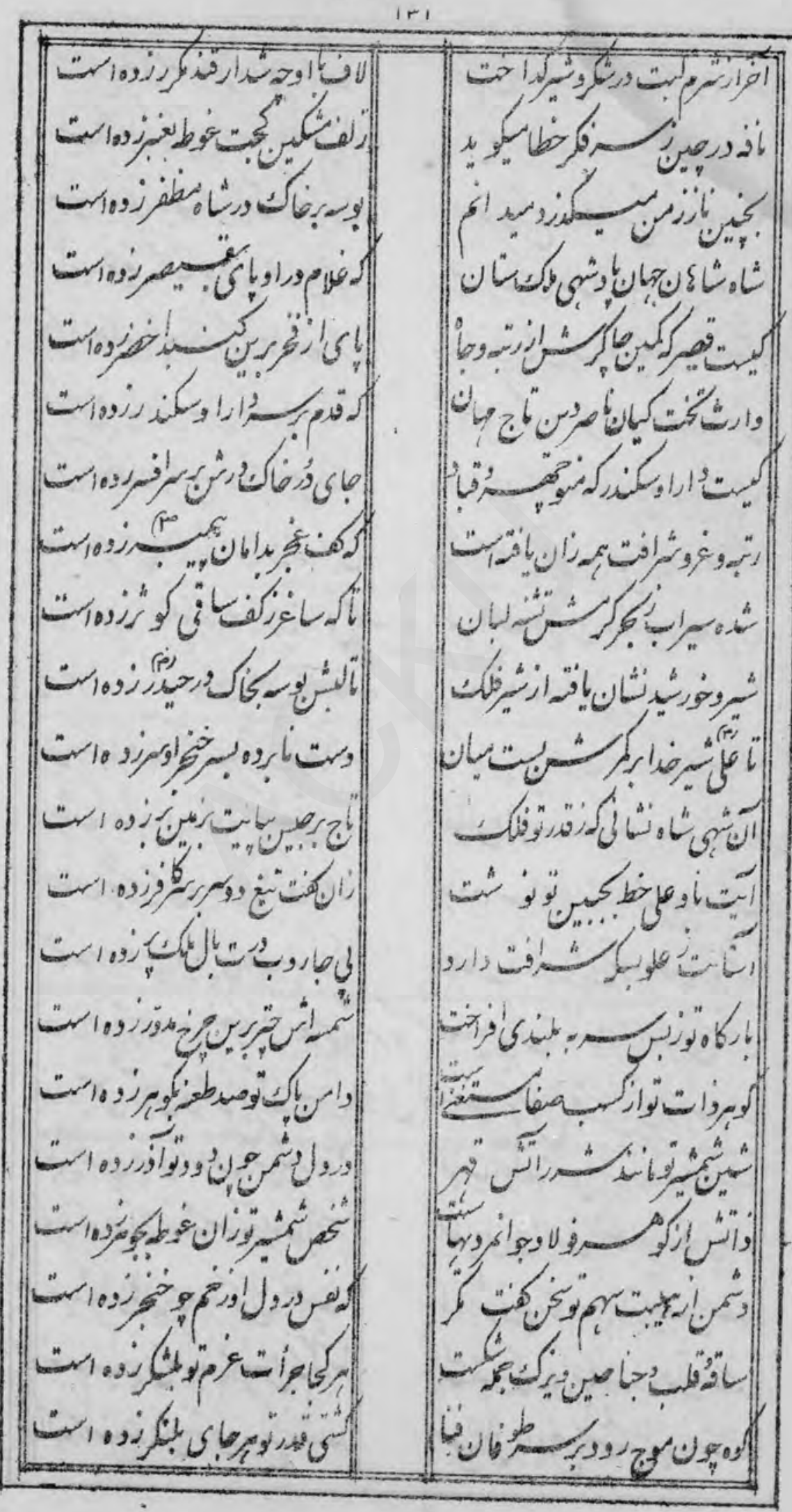




\section{0}

\section{Ir}

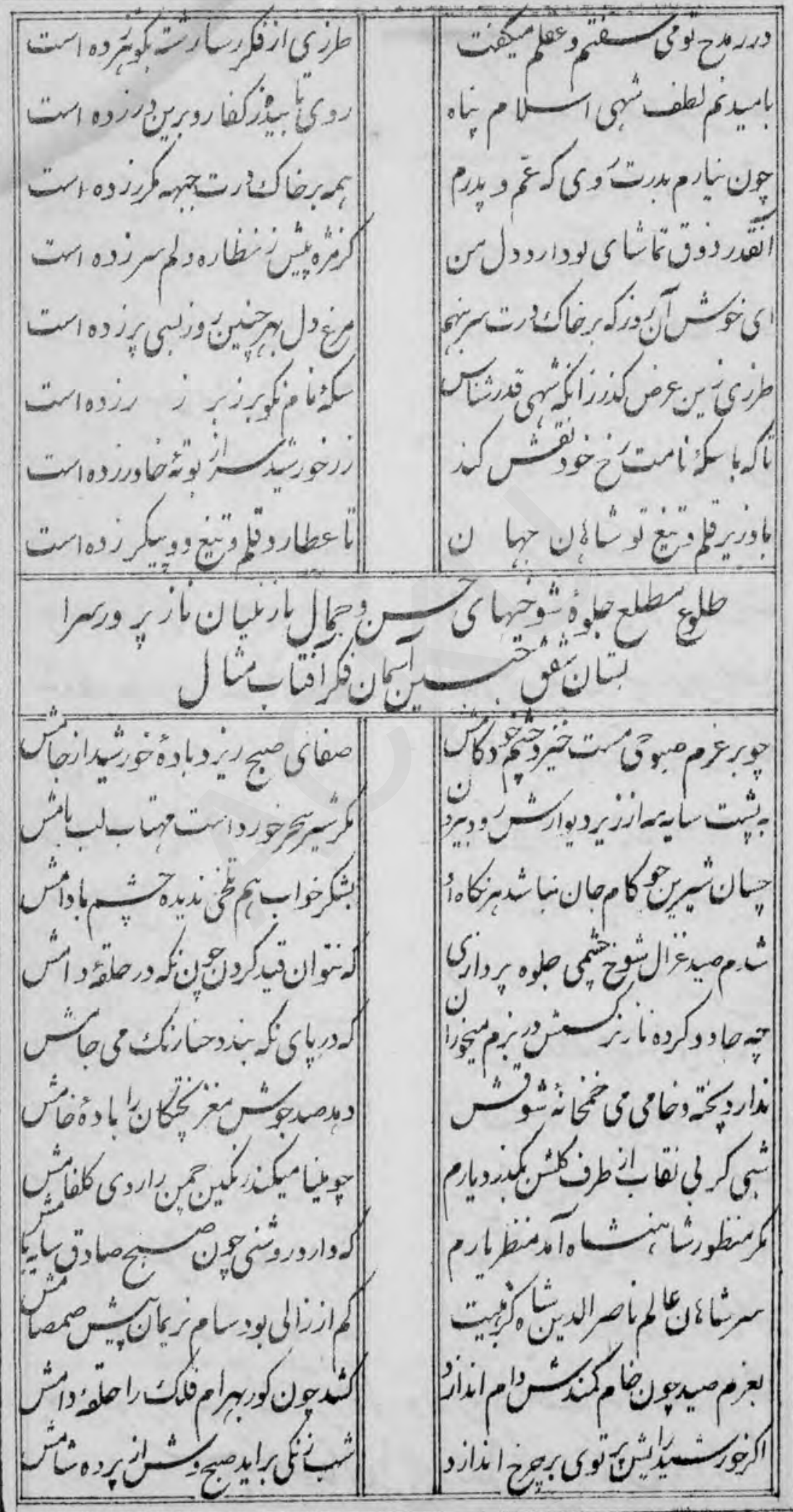

$\dot{J}^{\prime \prime \prime}$ 


\section{1}

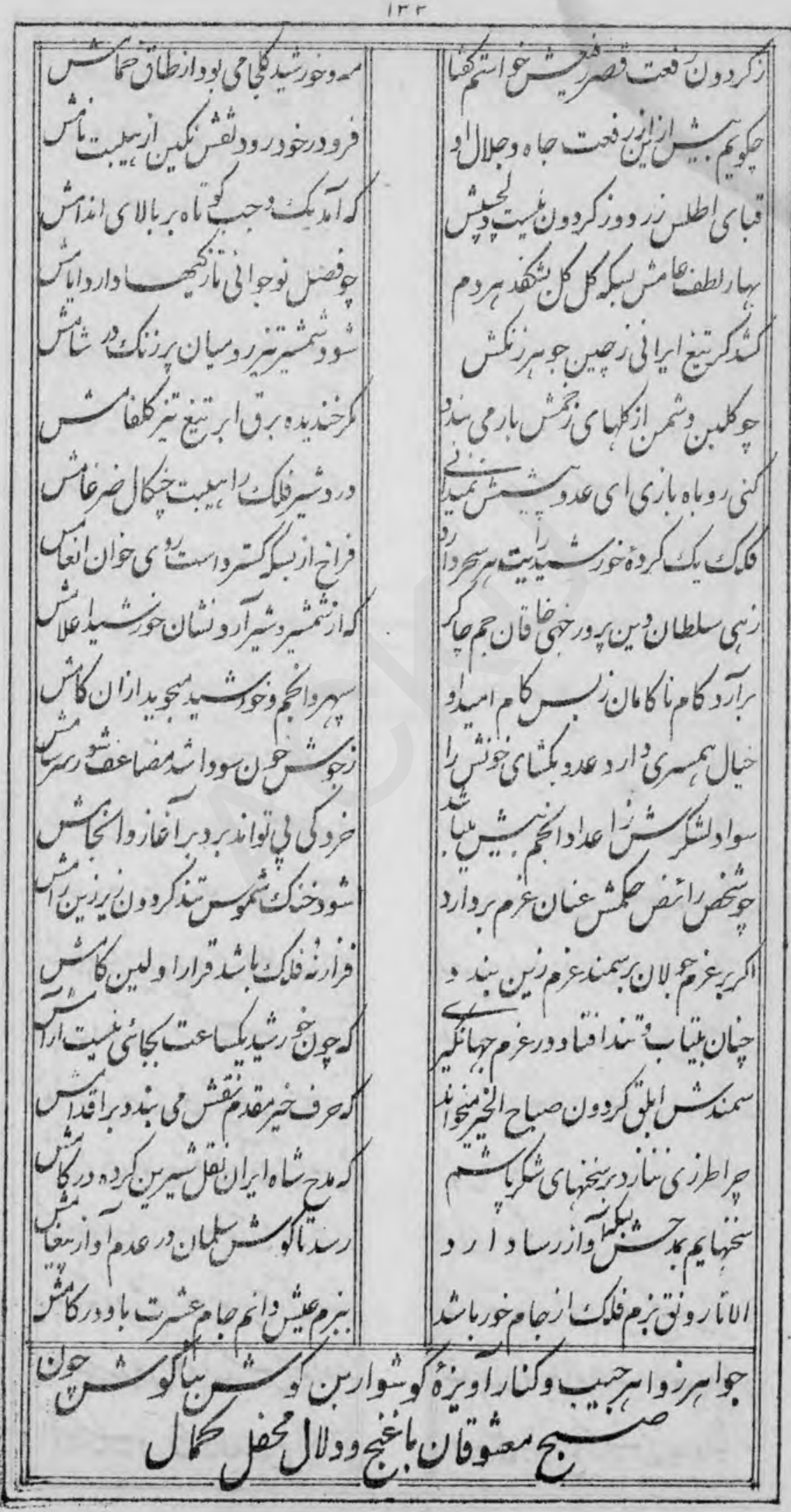


it r

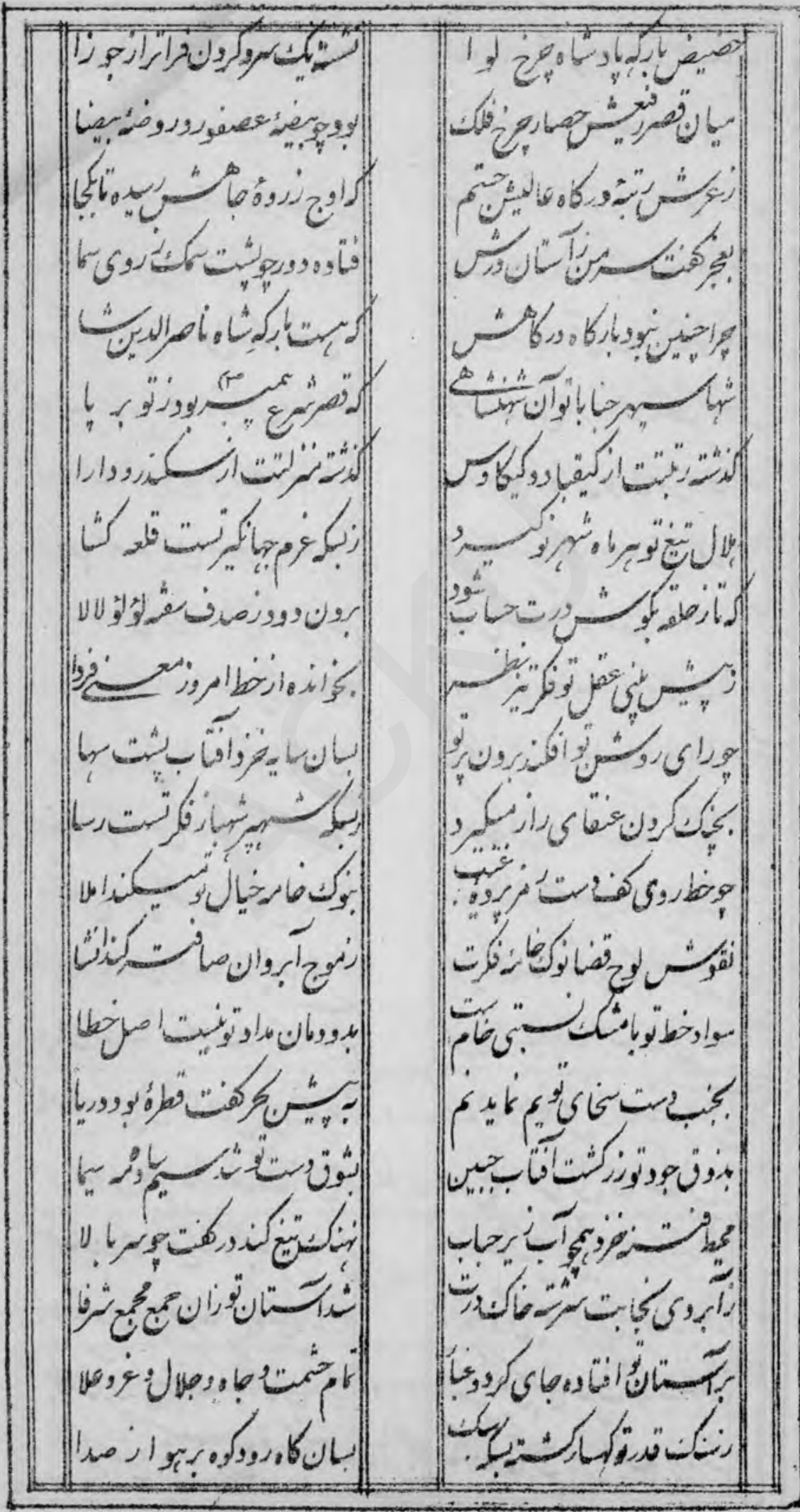




\section{3}

Irs

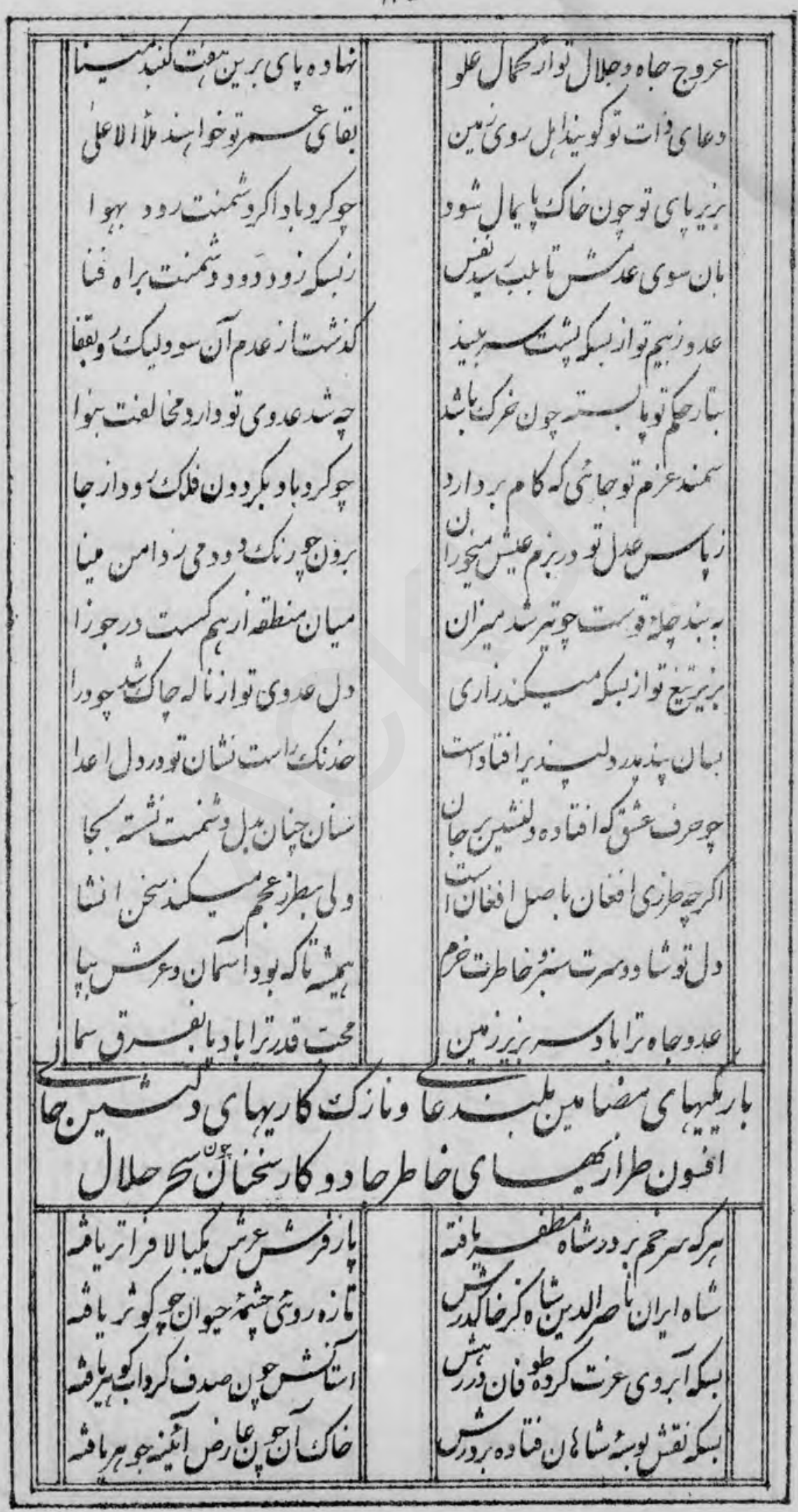


it

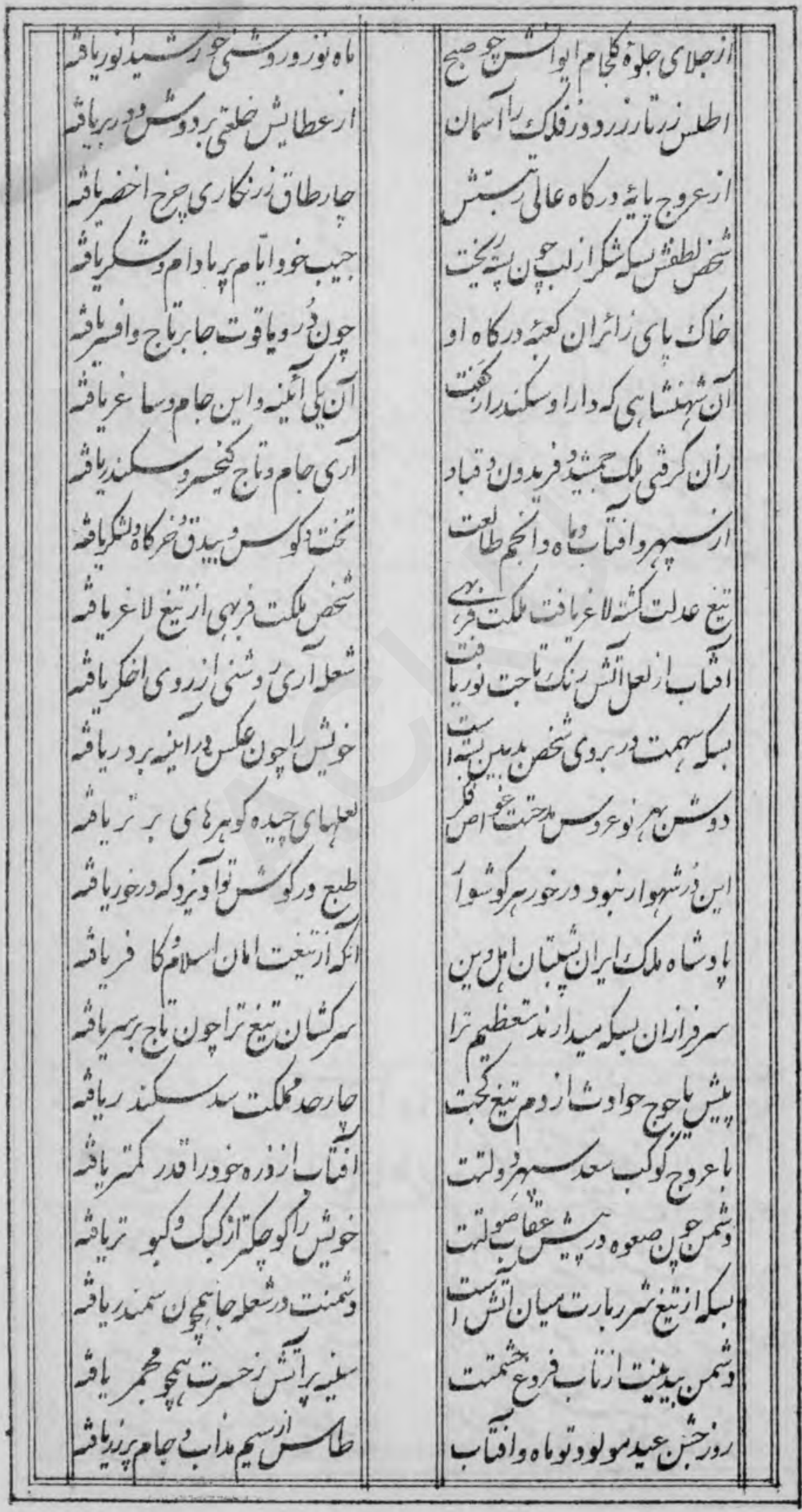




\section{5}

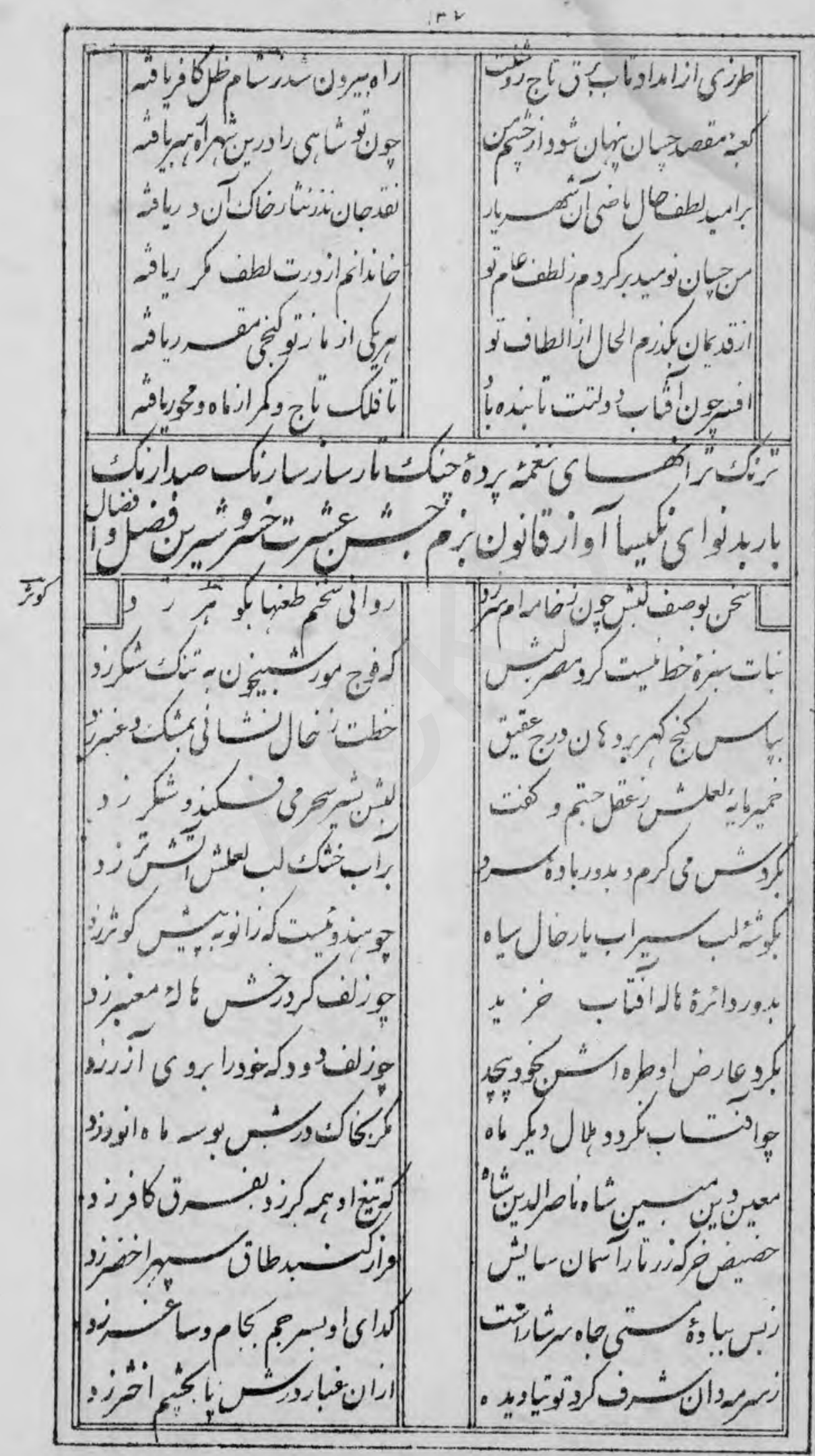




\section{6}

\section{Irs}

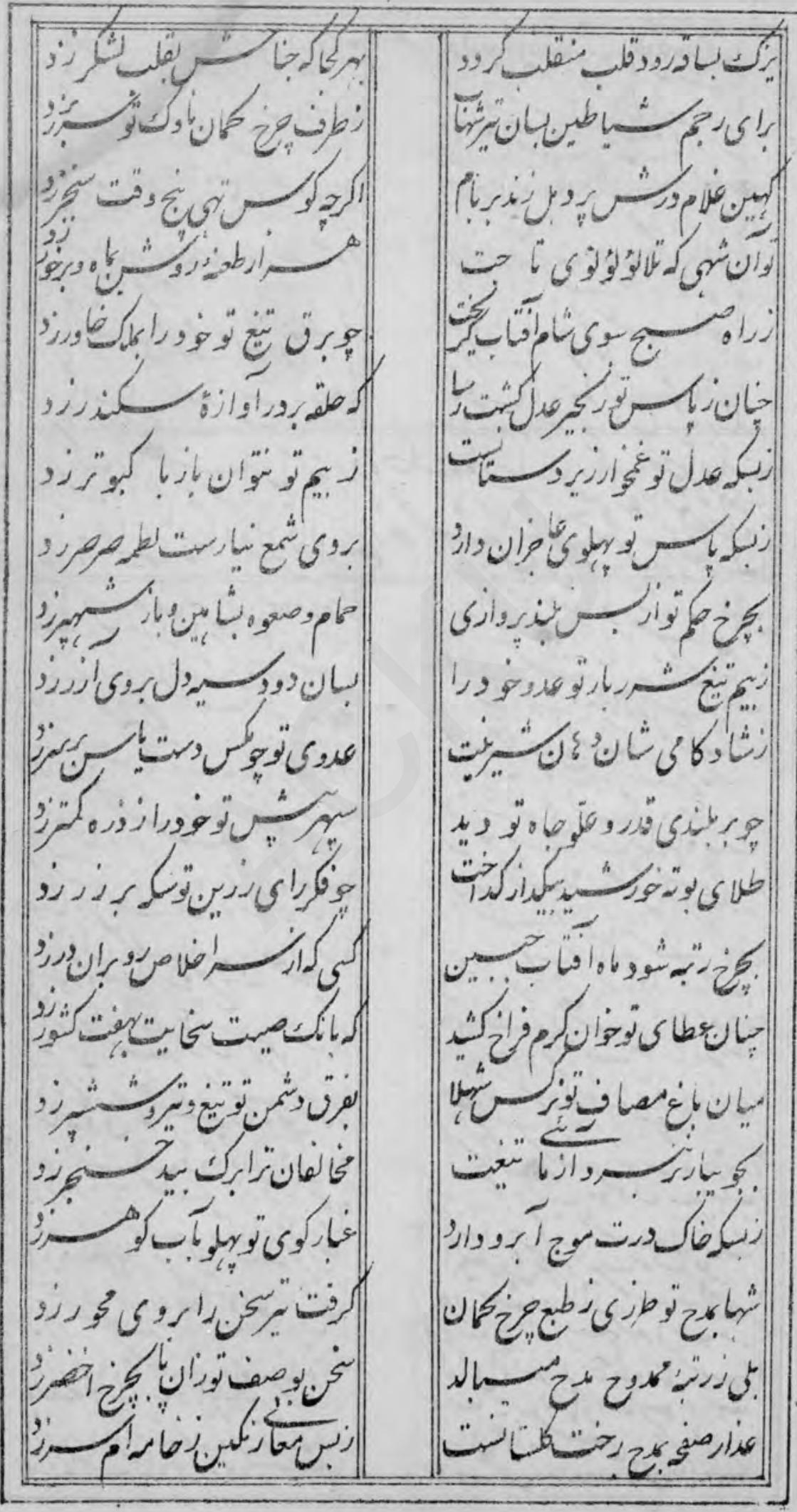




\section{7}

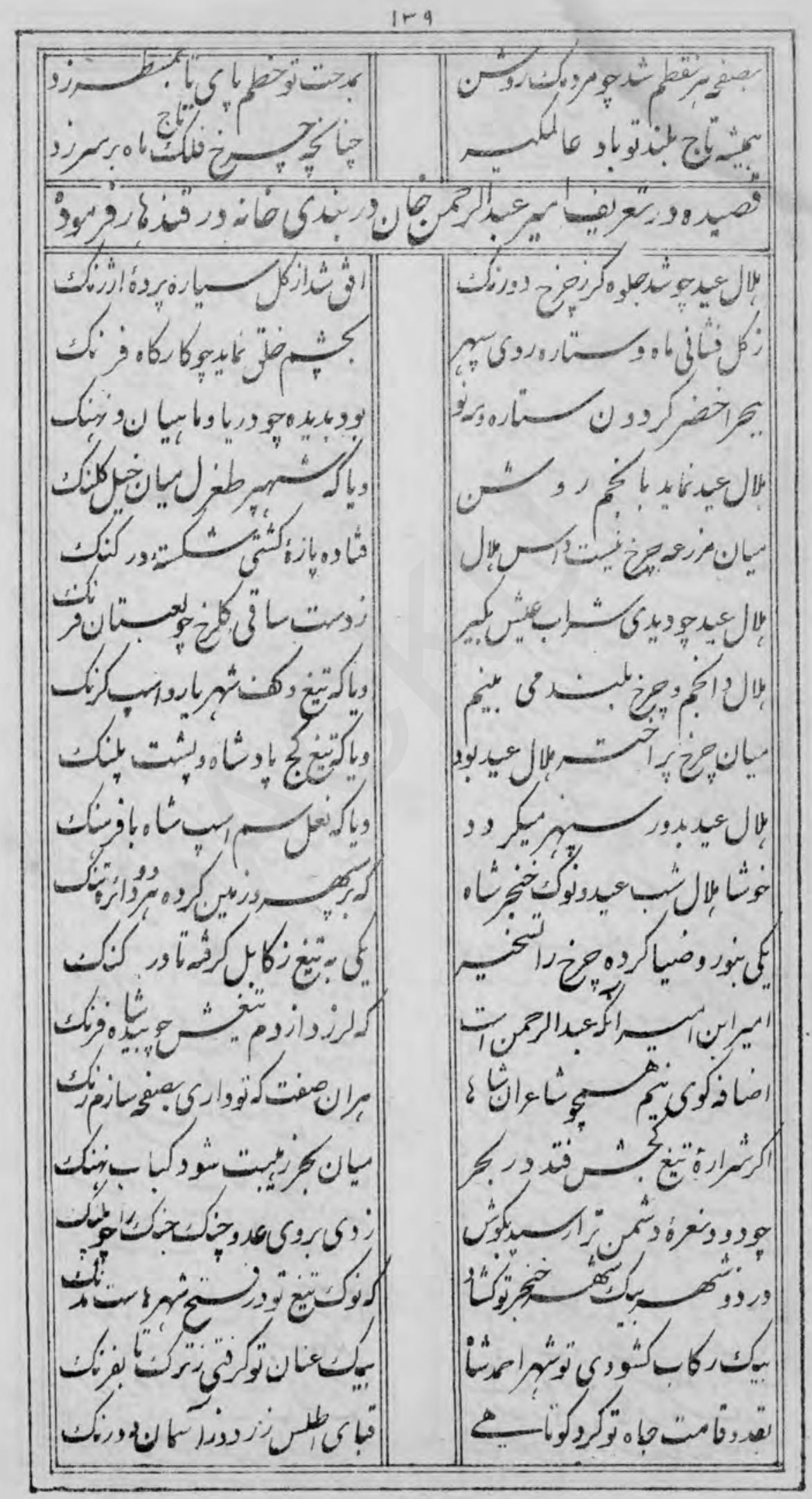




\section{8}

14

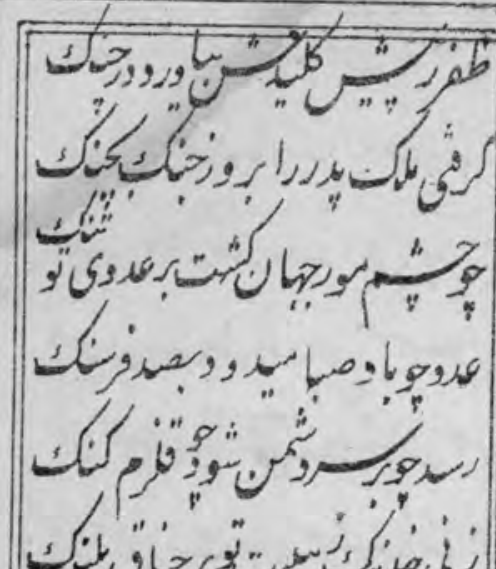
ن

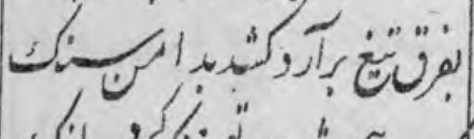
مئك

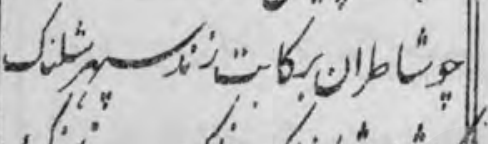

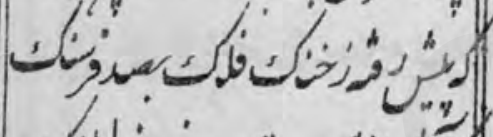
رالح كt:

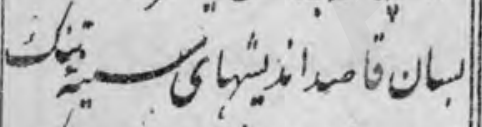
(

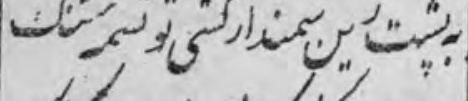

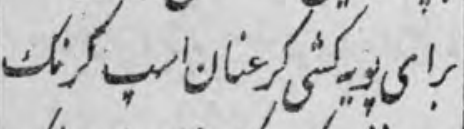
(j) : بالب

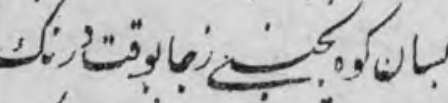

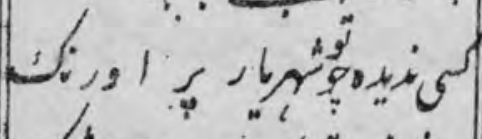

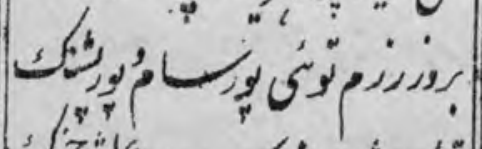
(5)

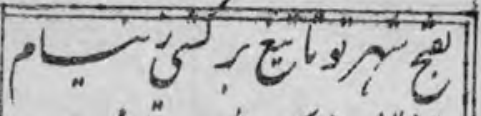

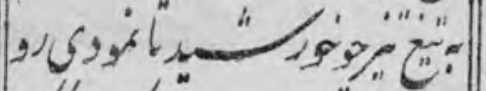
, (le

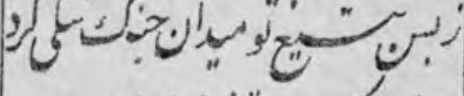

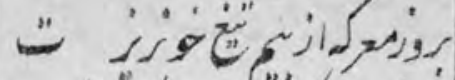

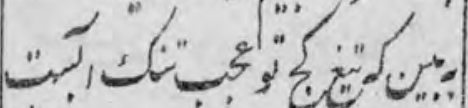
ن لز

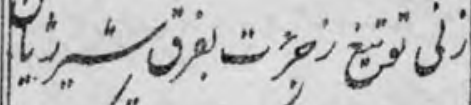
" " " "

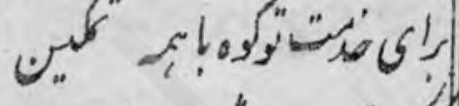

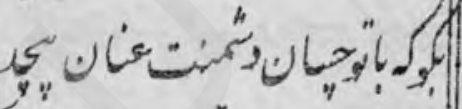

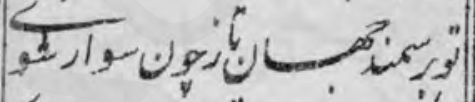

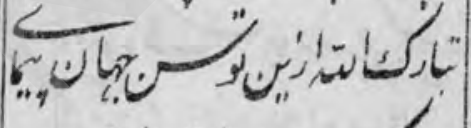

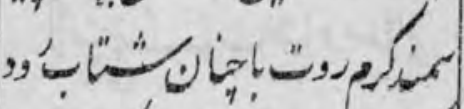
"2: ba $>$ is $\sum_{n+1}$

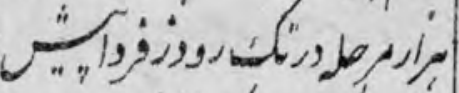

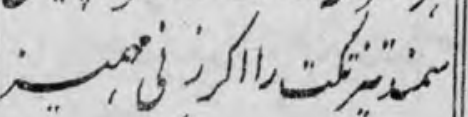

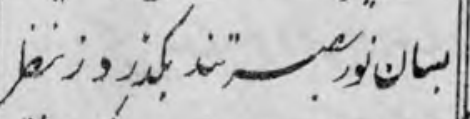

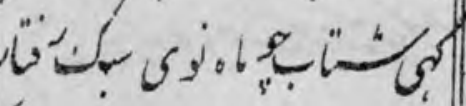

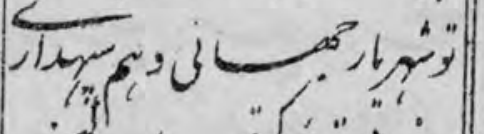
, ע. بs

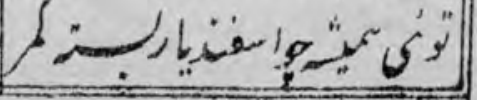




\section{9}

|

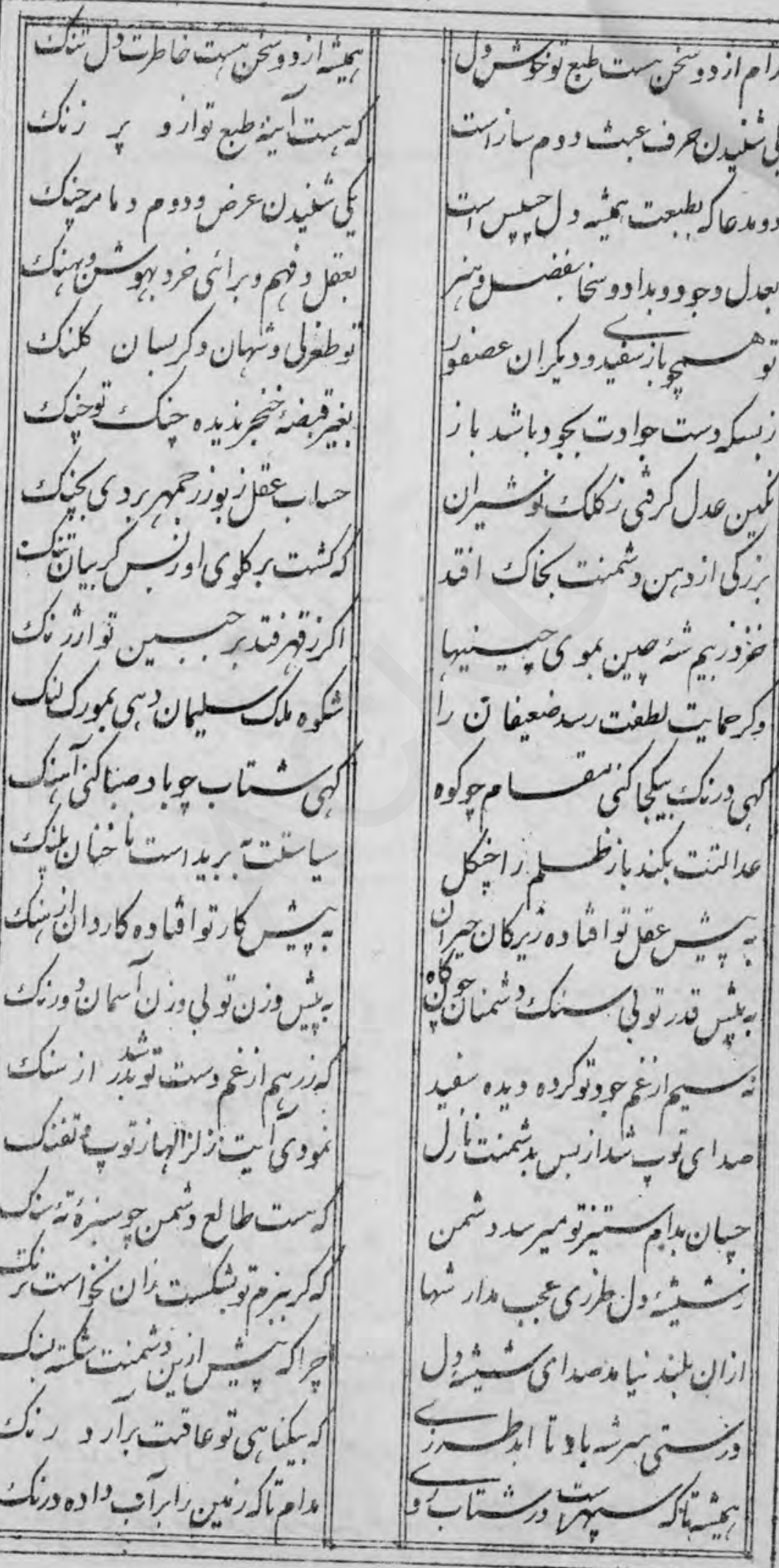




\section{0}

It

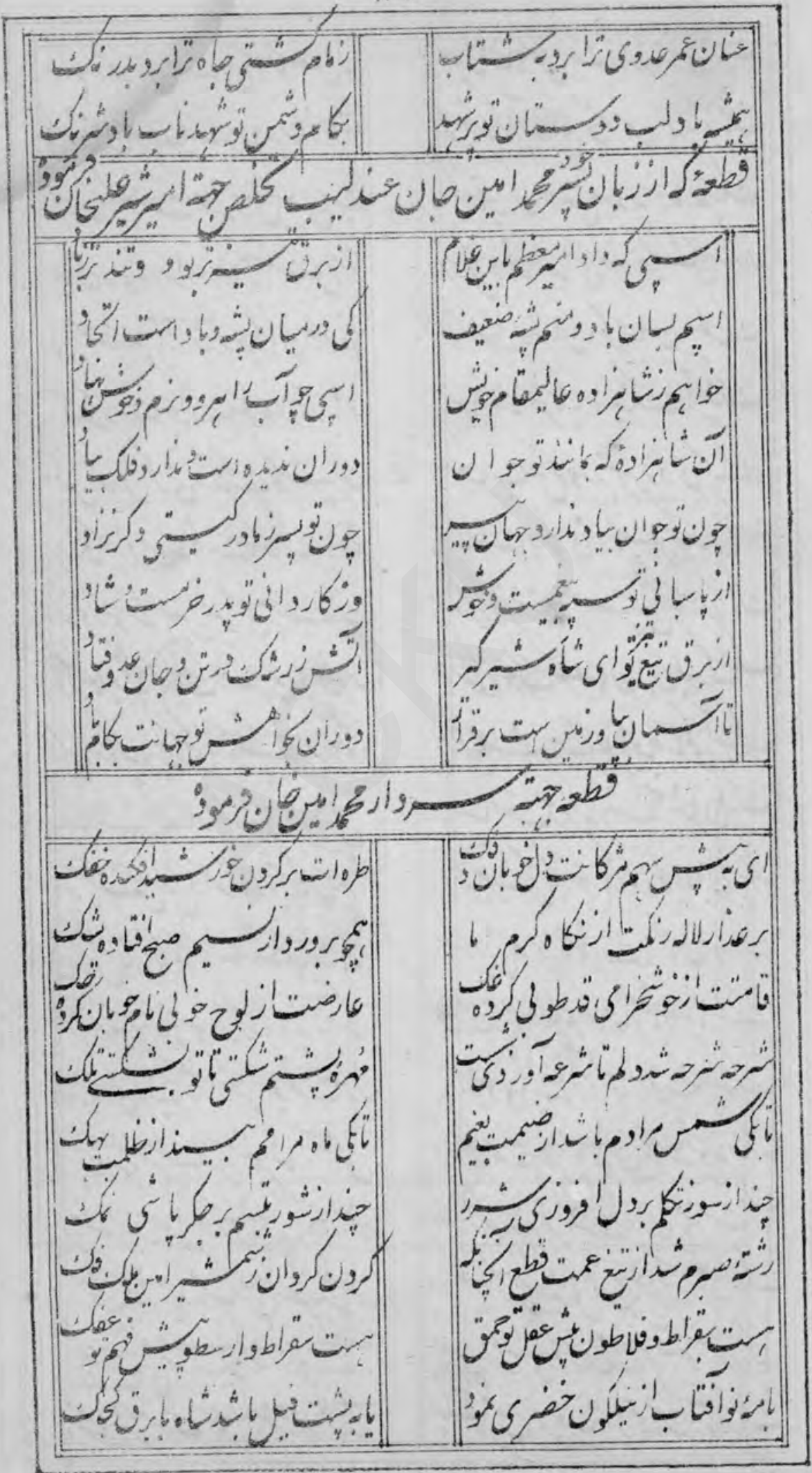




\section{1}

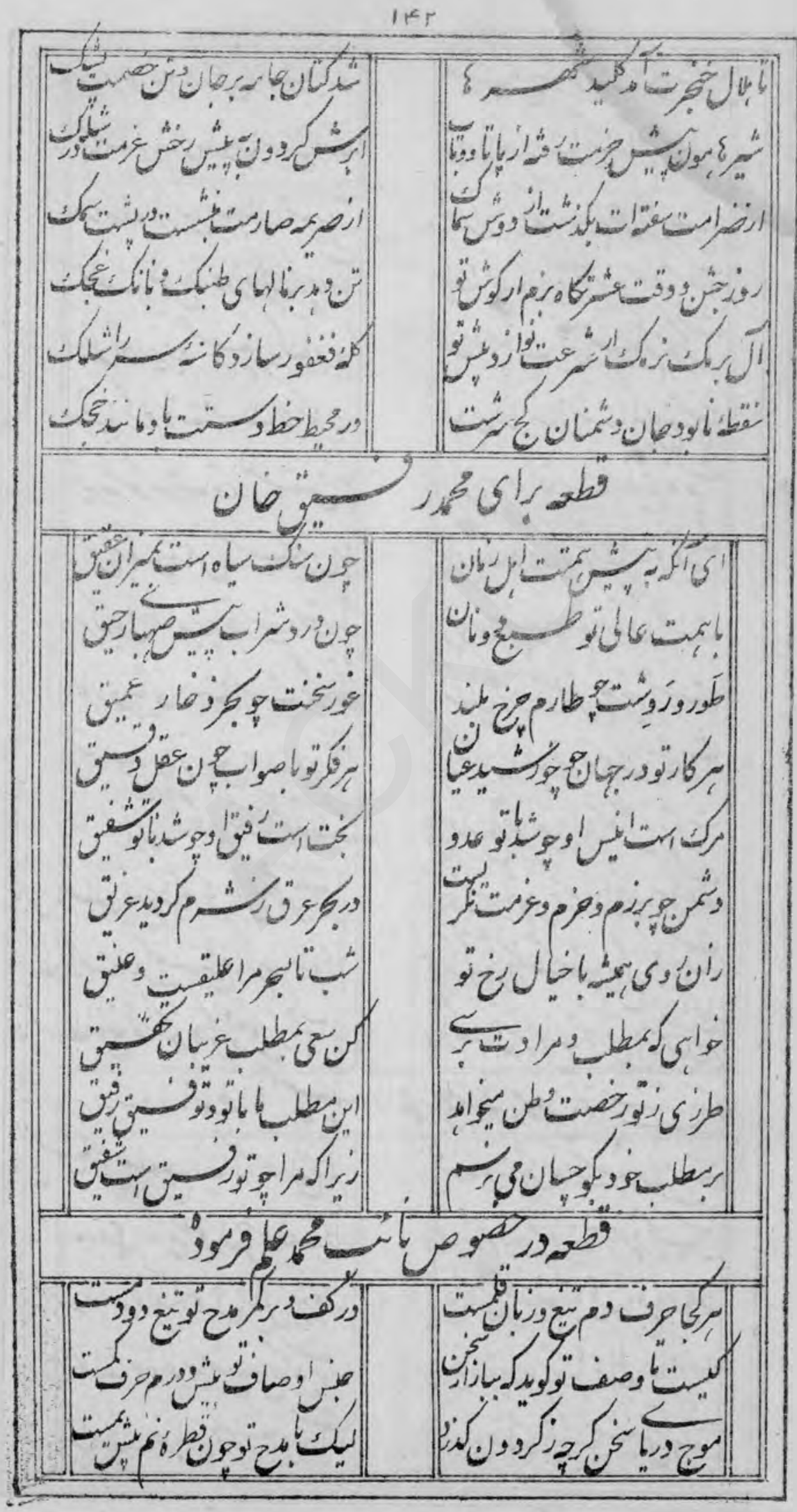


is

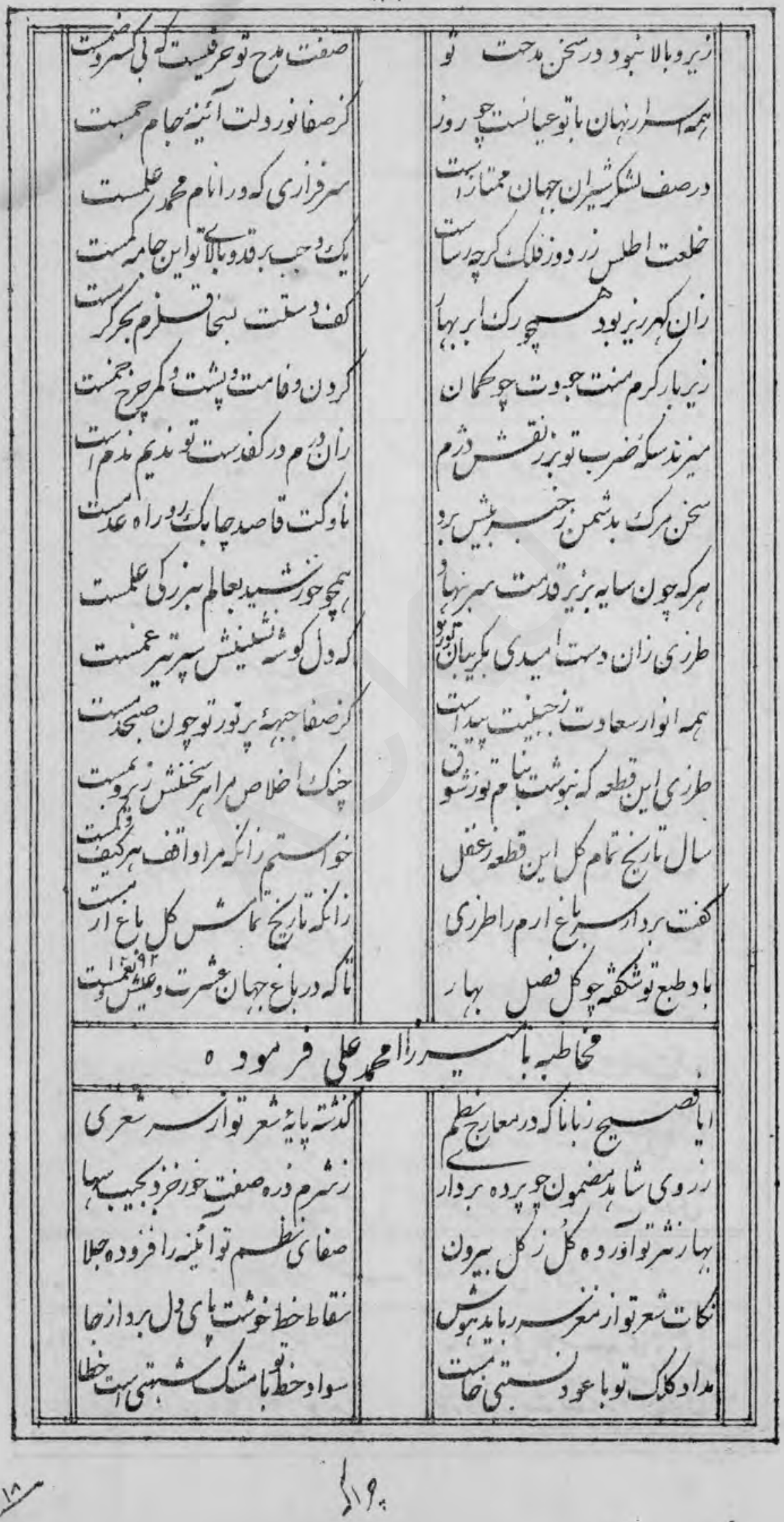


853

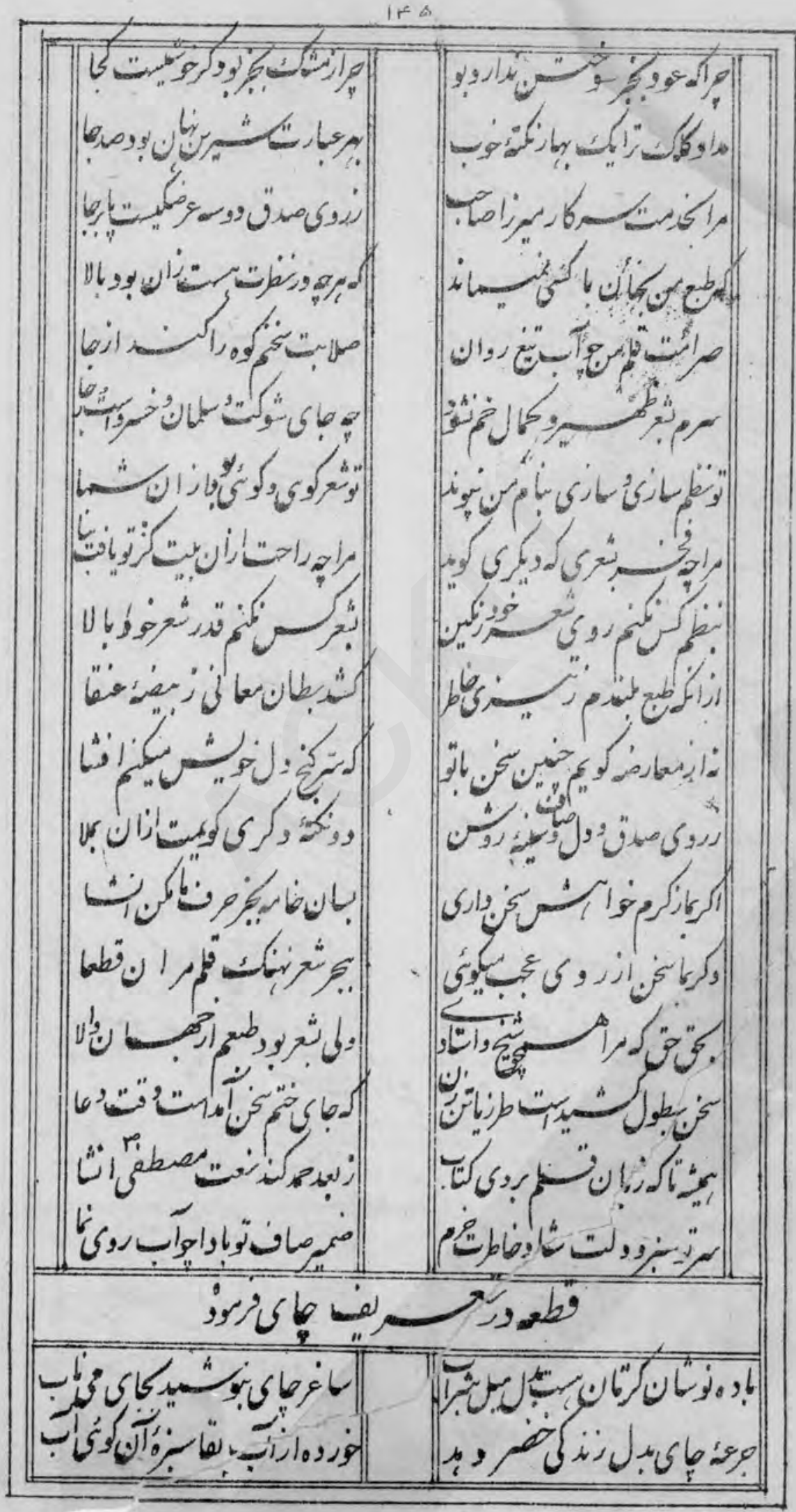




\section{4}

$15 x$

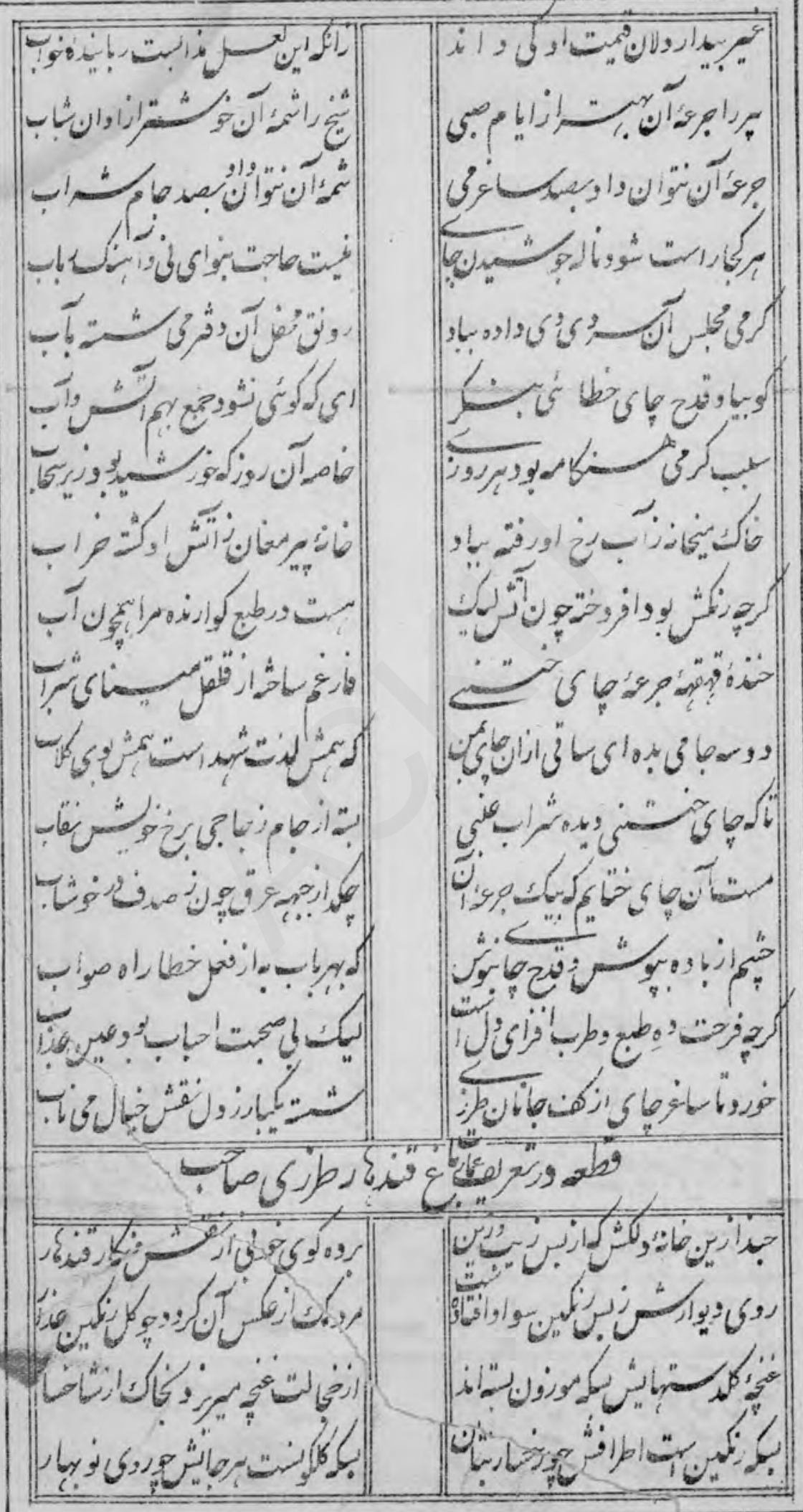




\section{5}

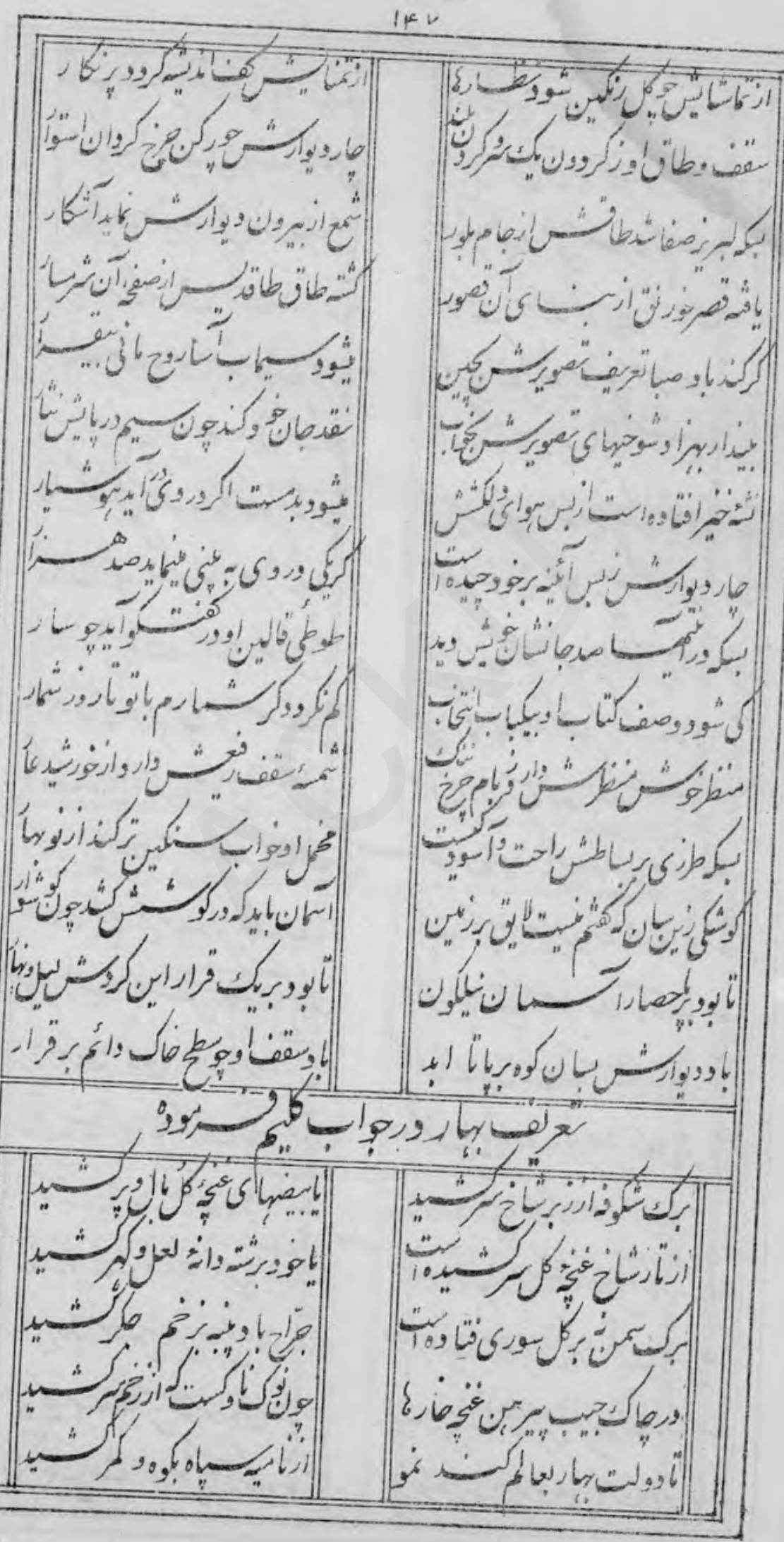


If

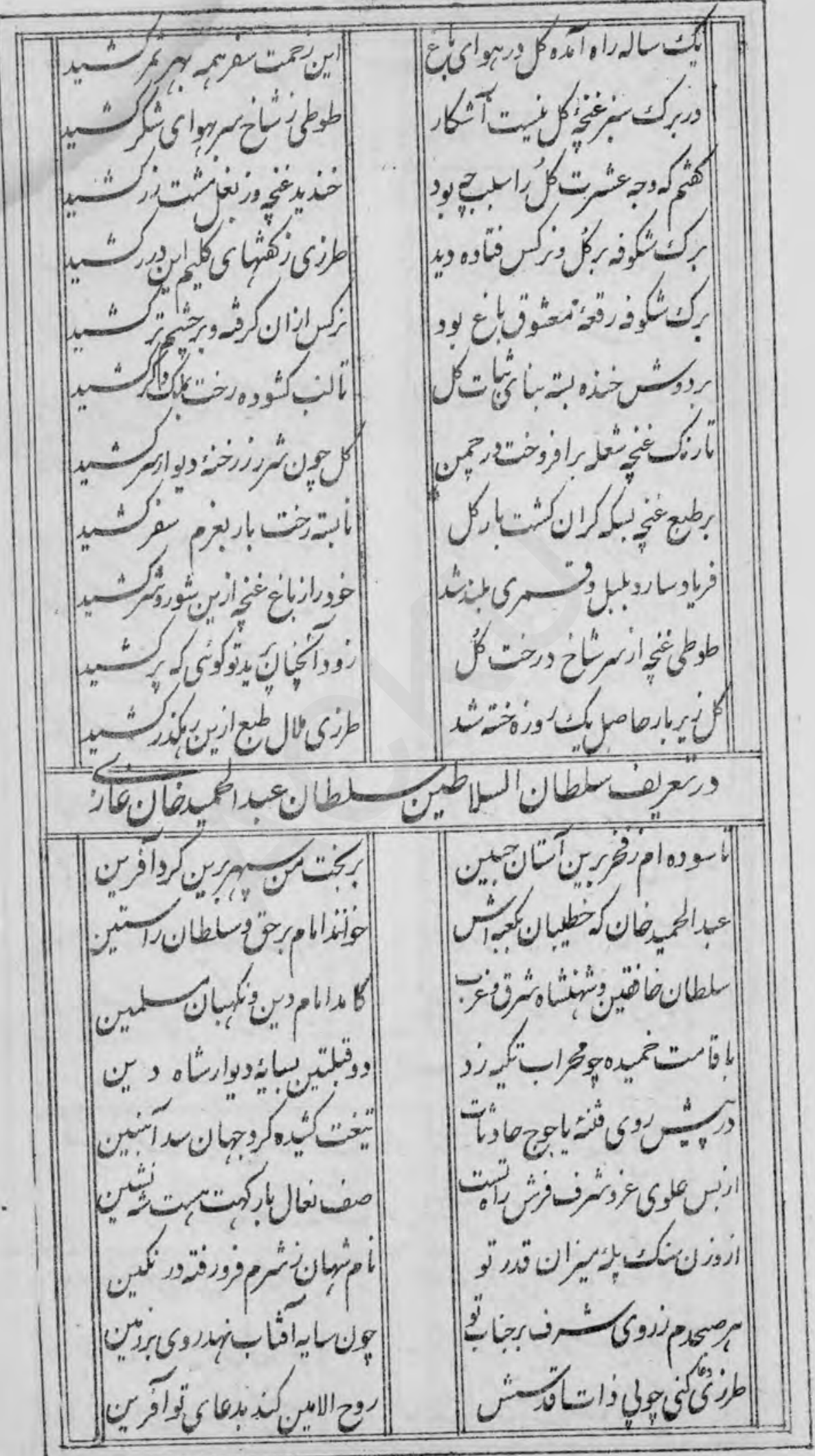


857

if 9

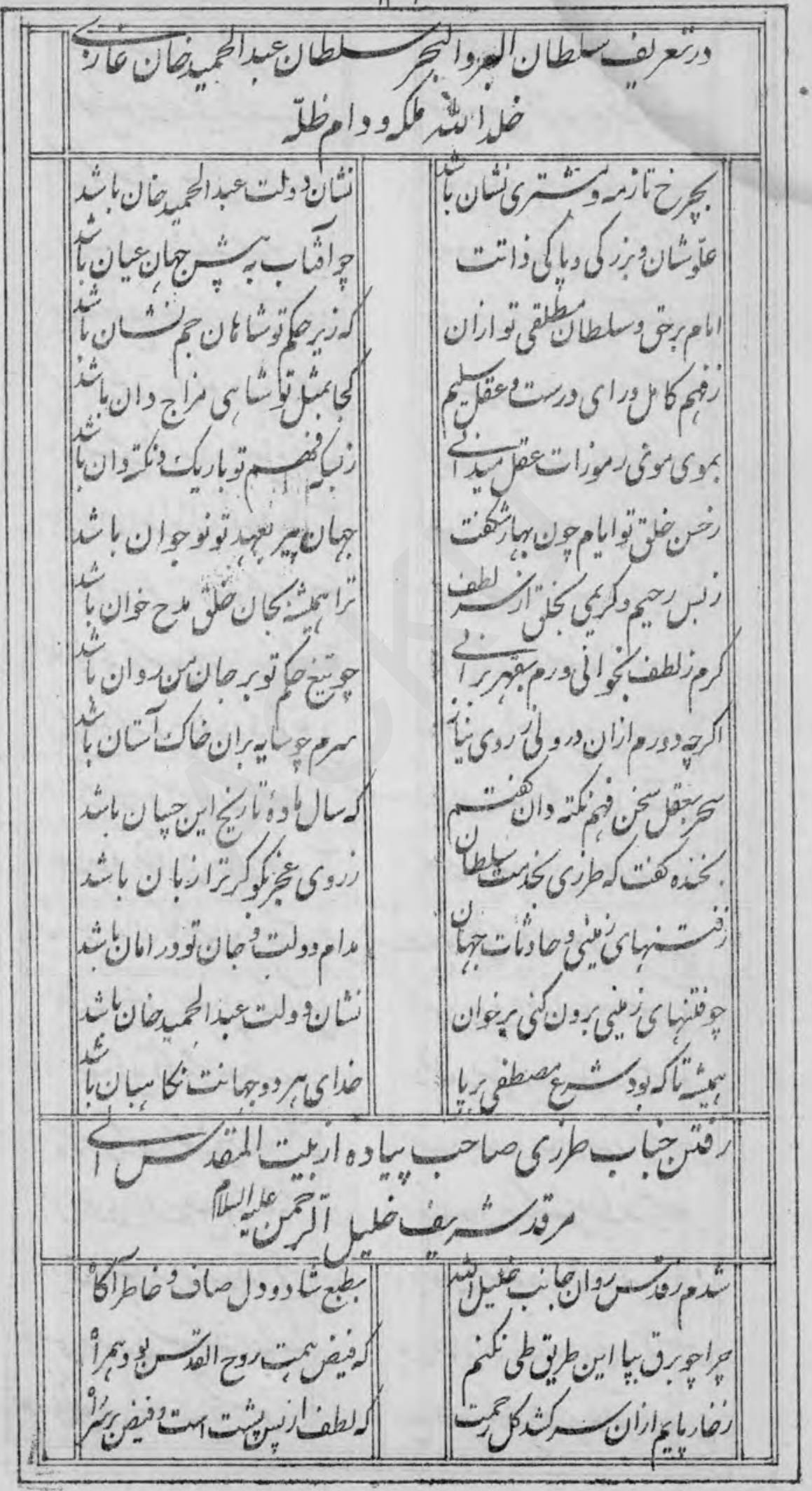


10

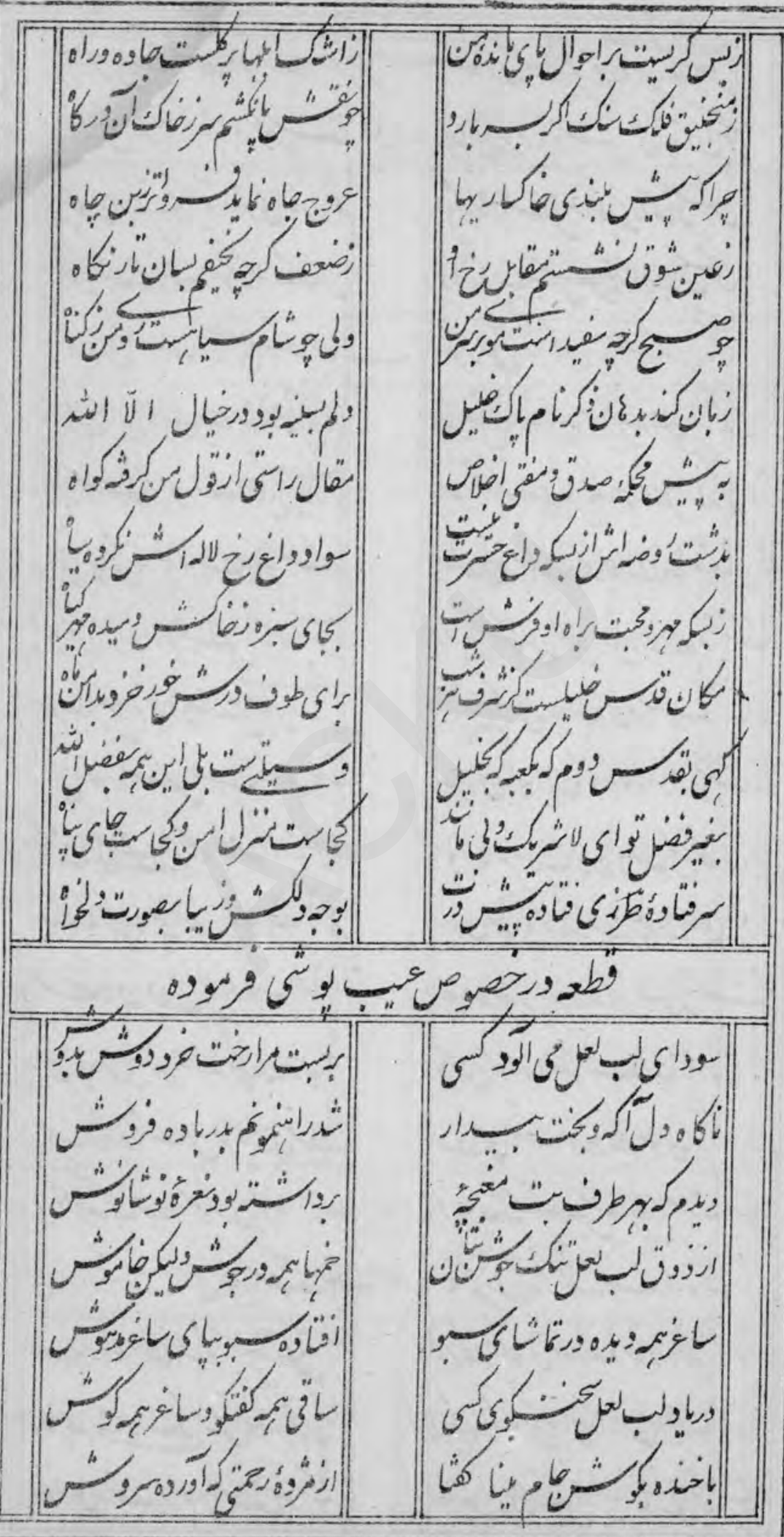




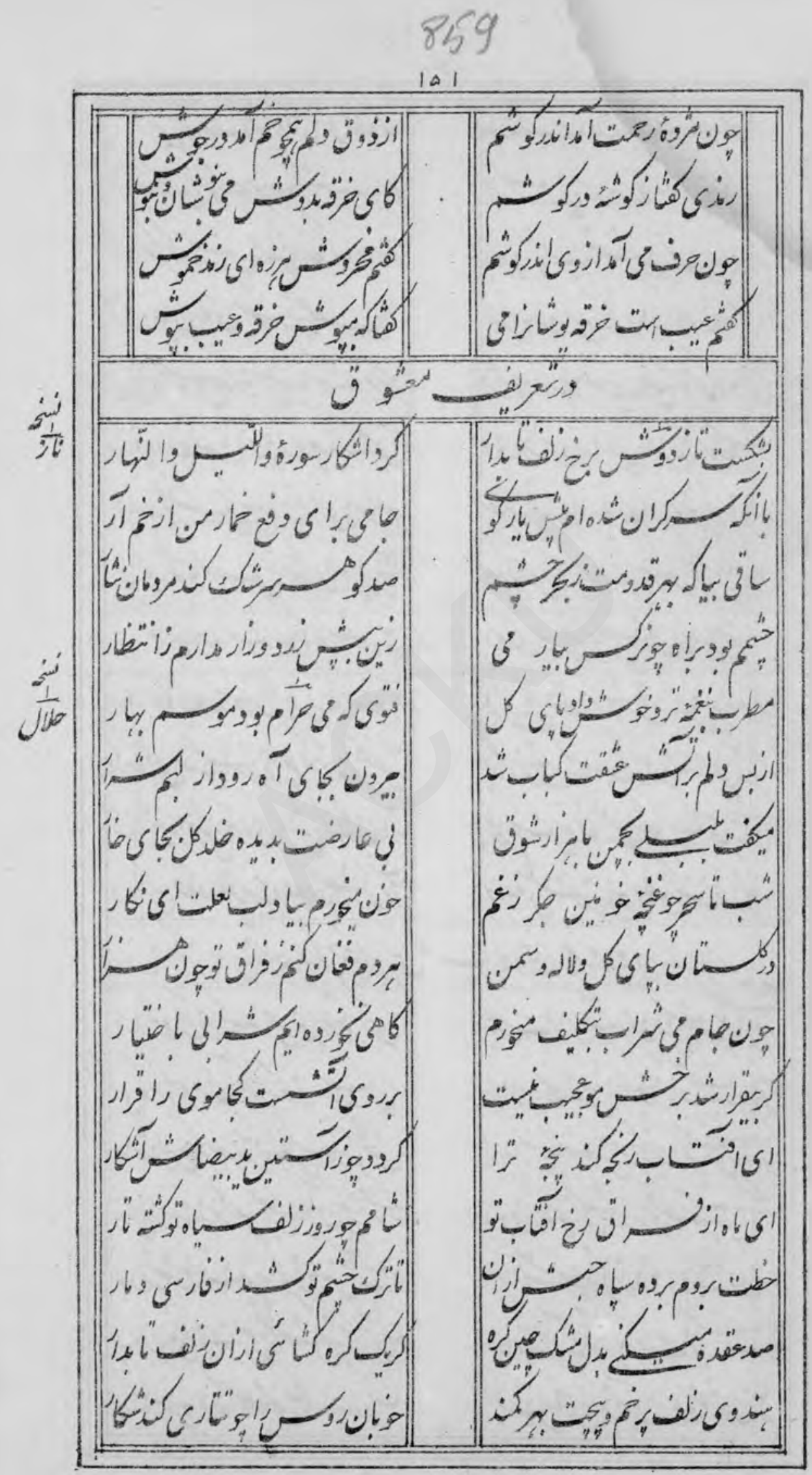




\section{0}

or

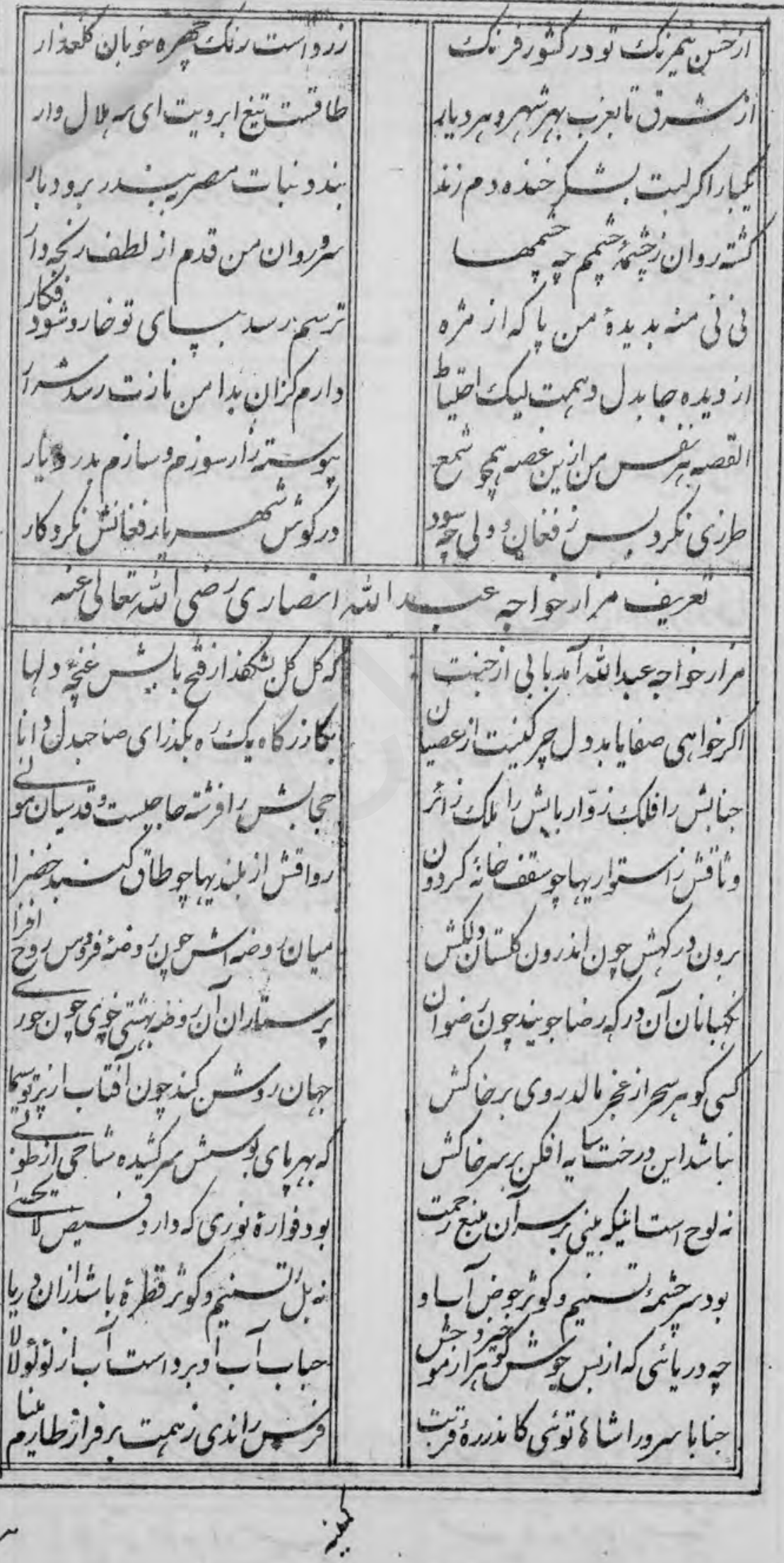


$1 \Delta r$

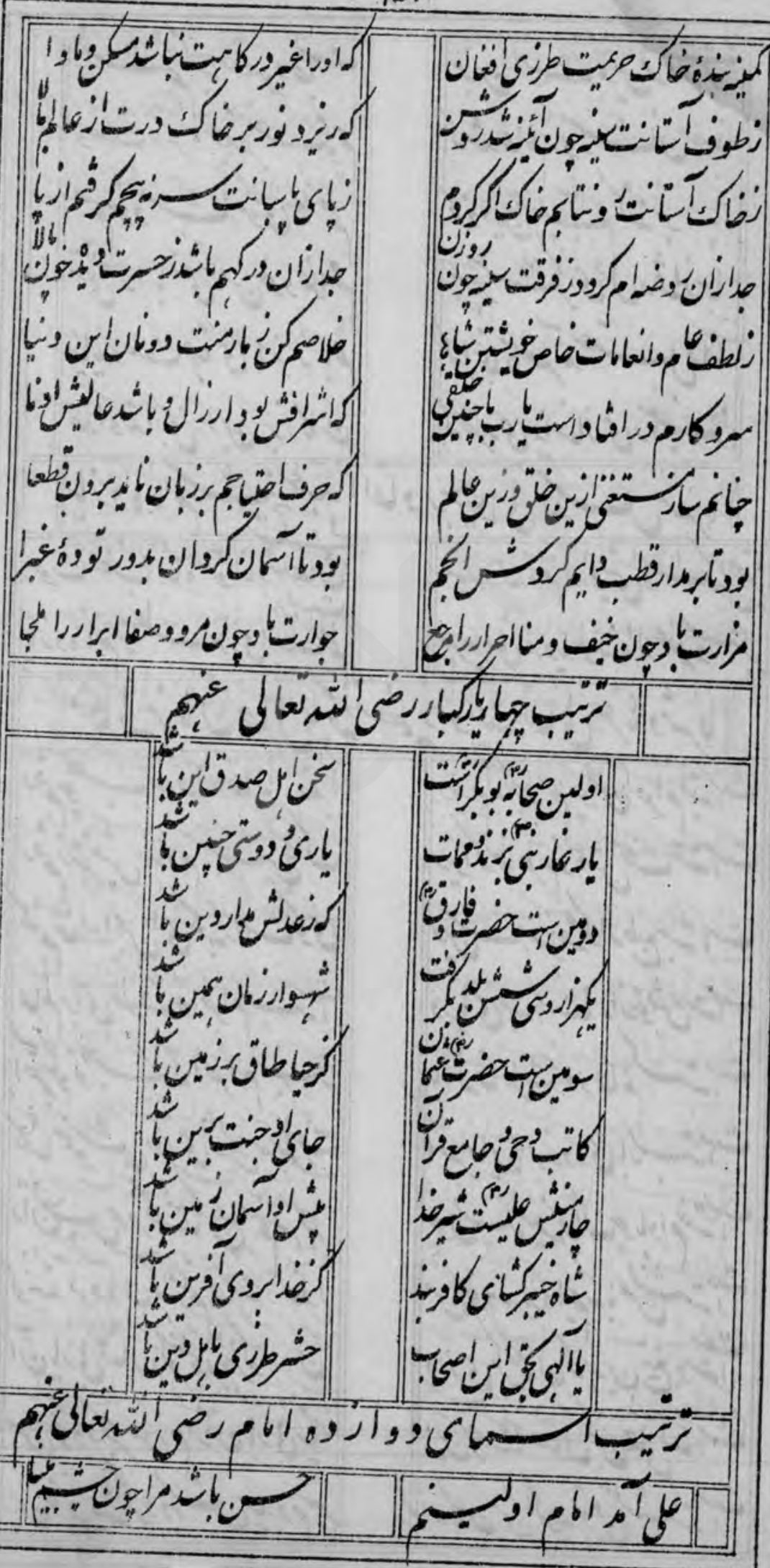


862

$10 \%$

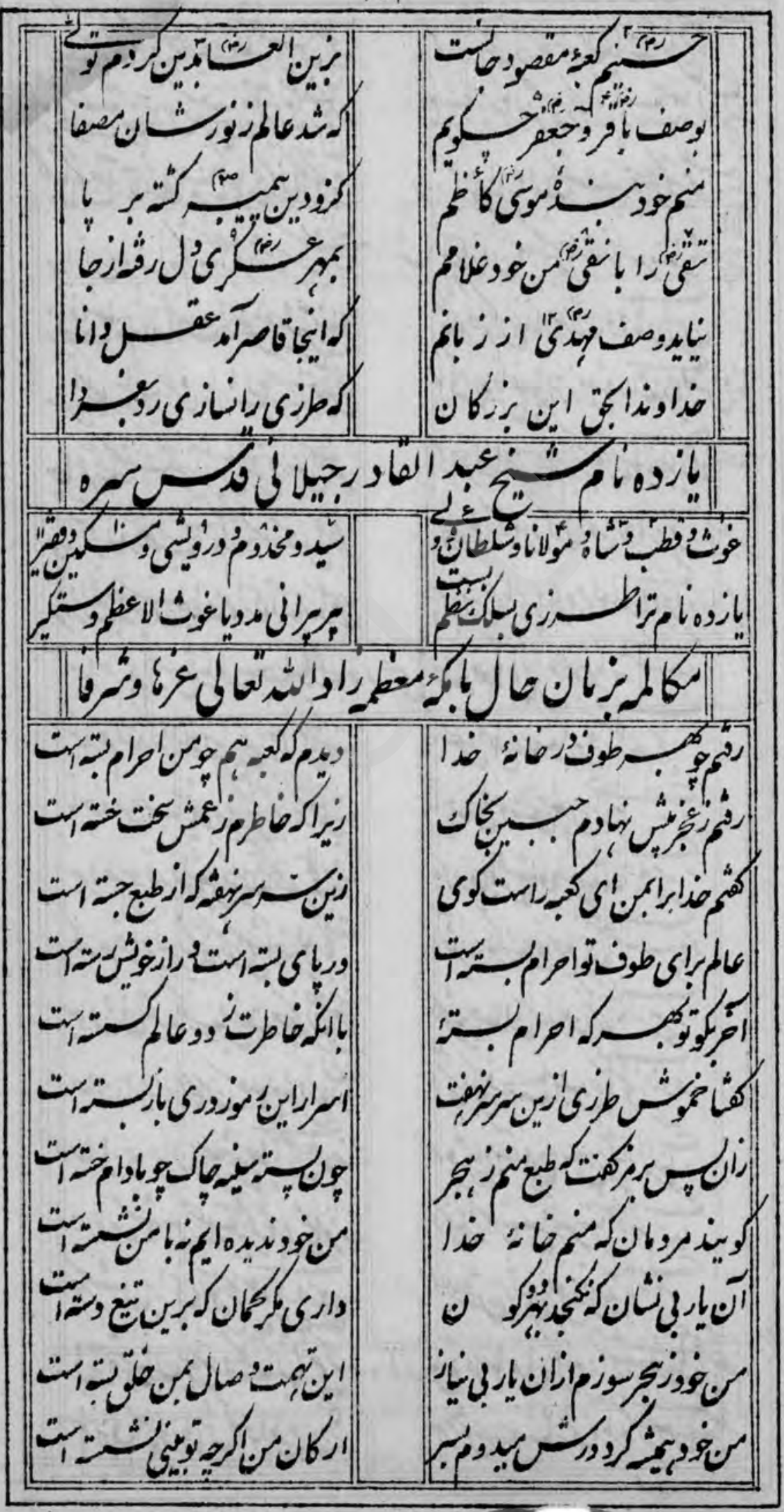


100

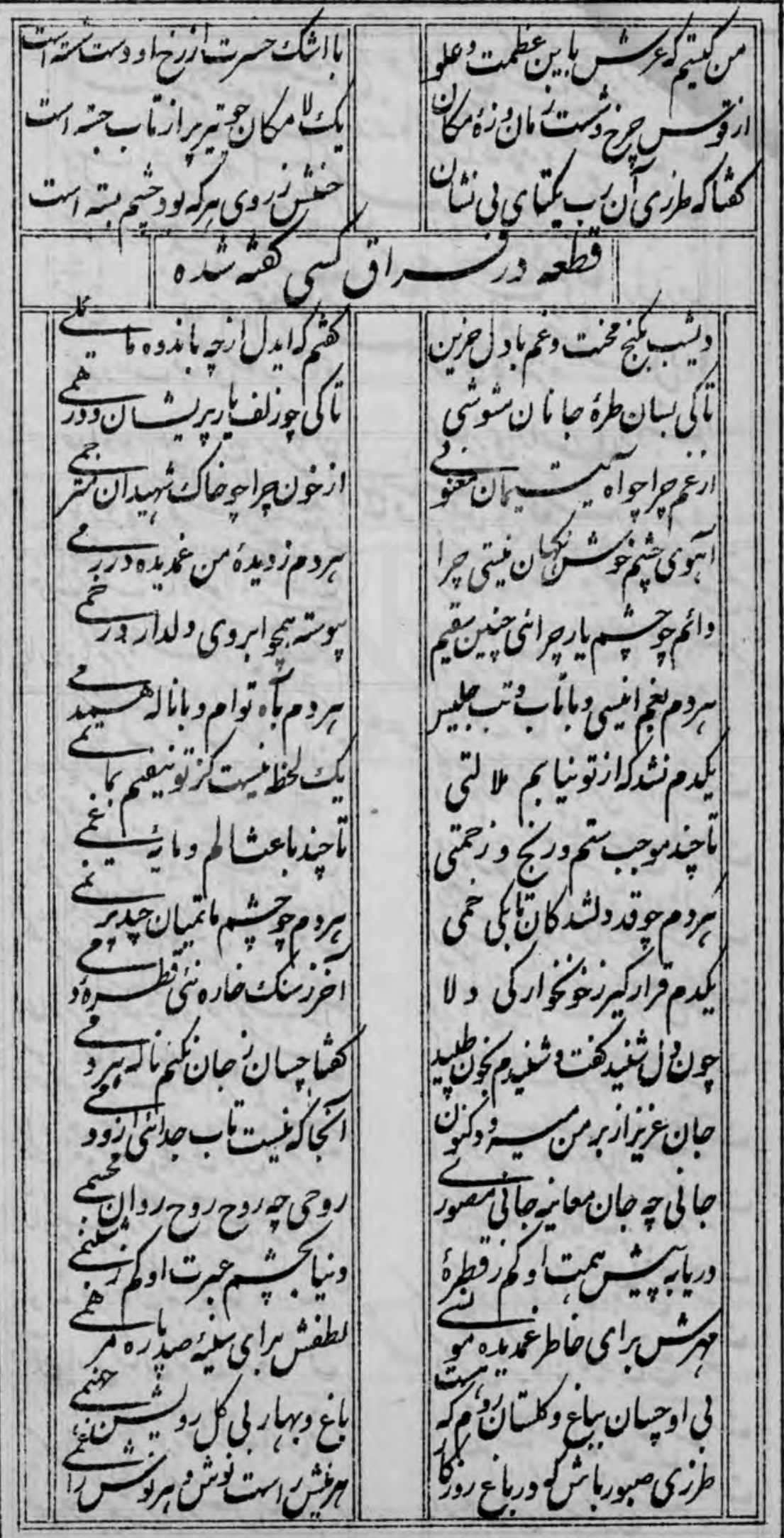


$10 \%$

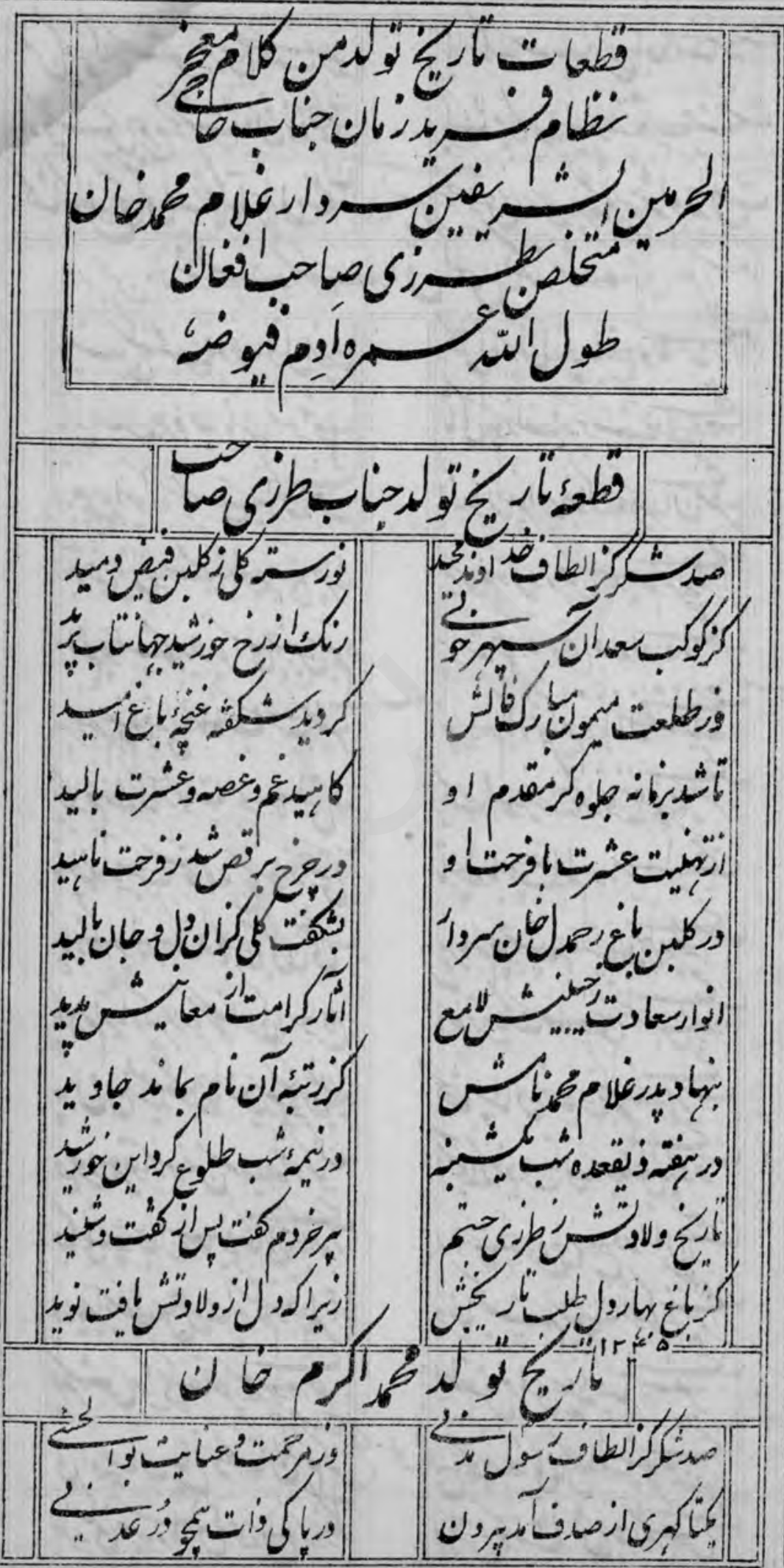




\section{5}

Ia

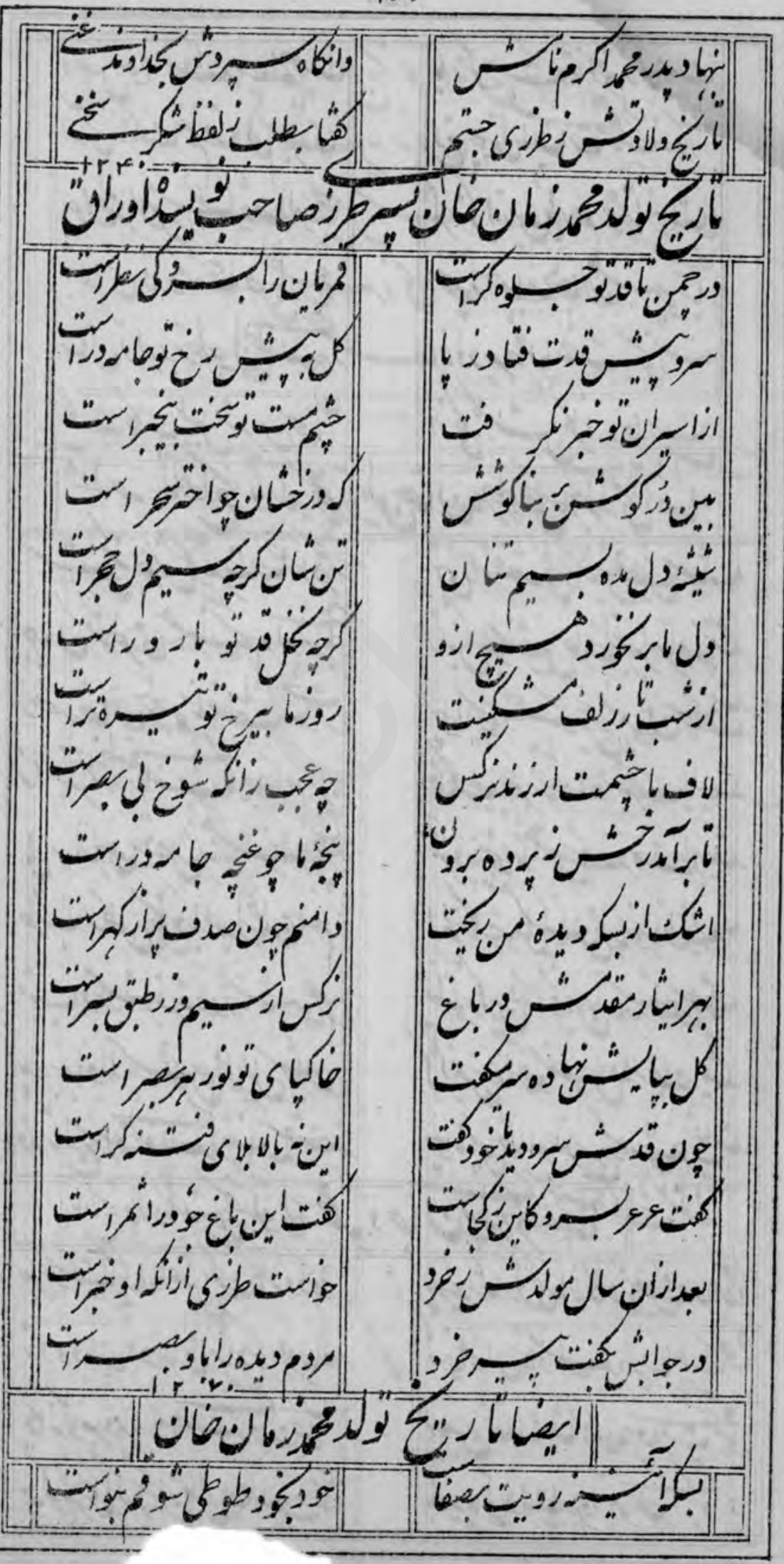


$10 A$

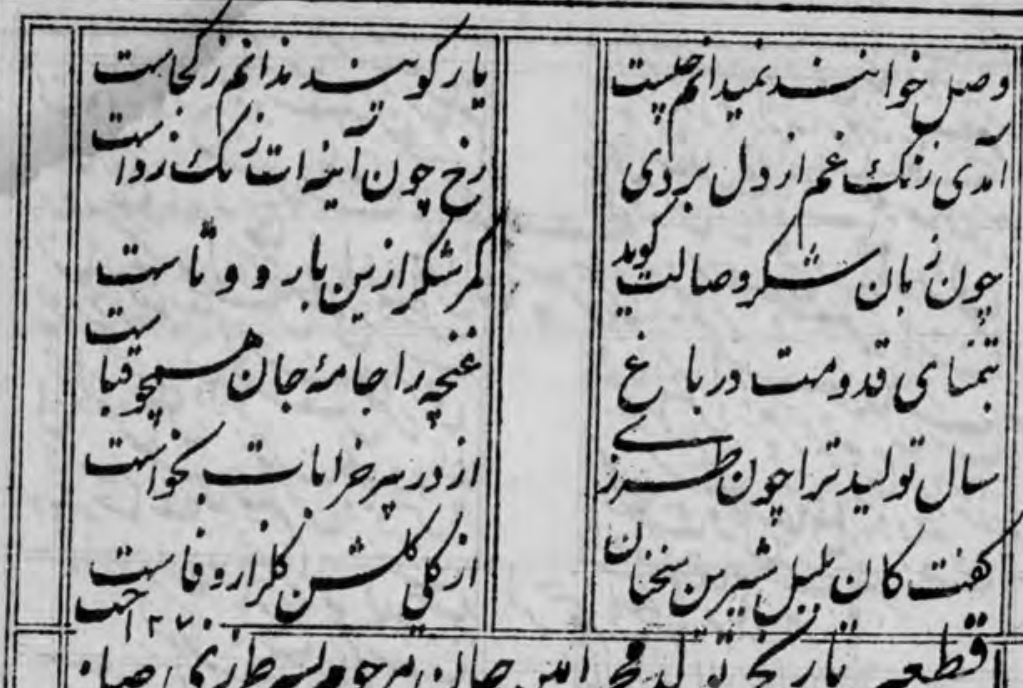

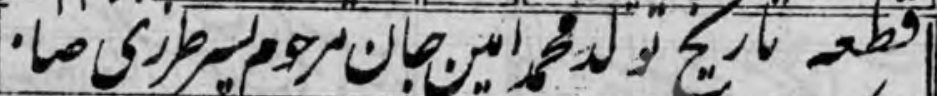
"

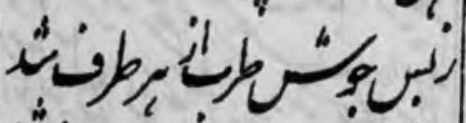
| ف ف ثن

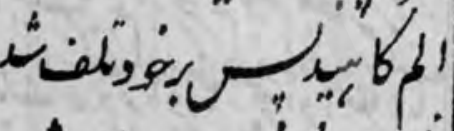

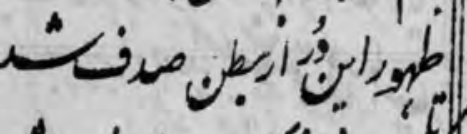

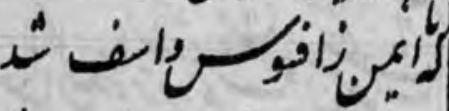

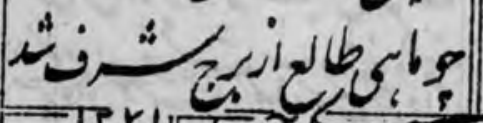

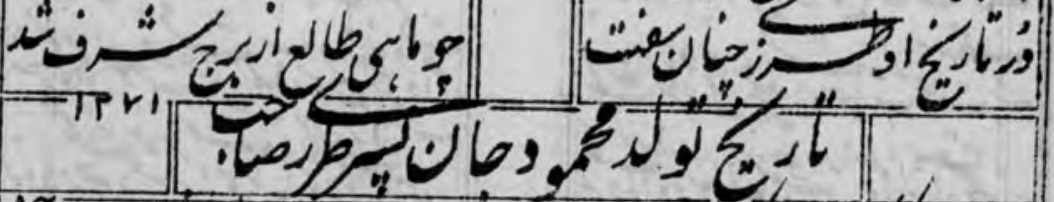
|

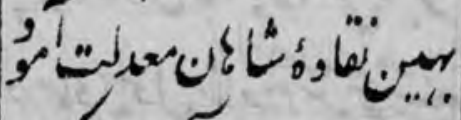

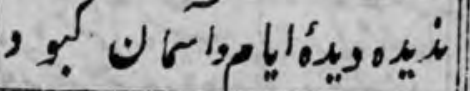
उ人is?

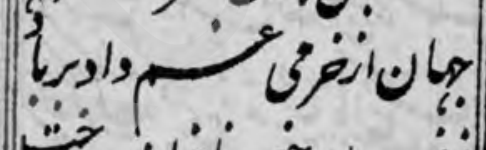

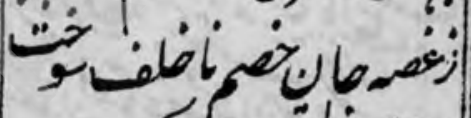
بان في

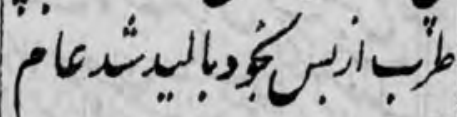
| (0) (1)

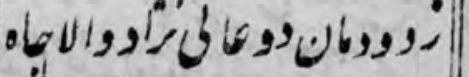

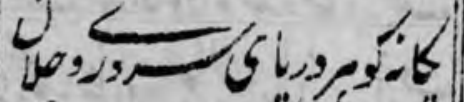

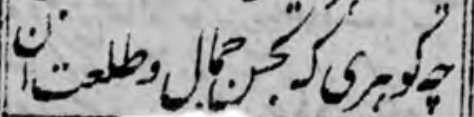


109

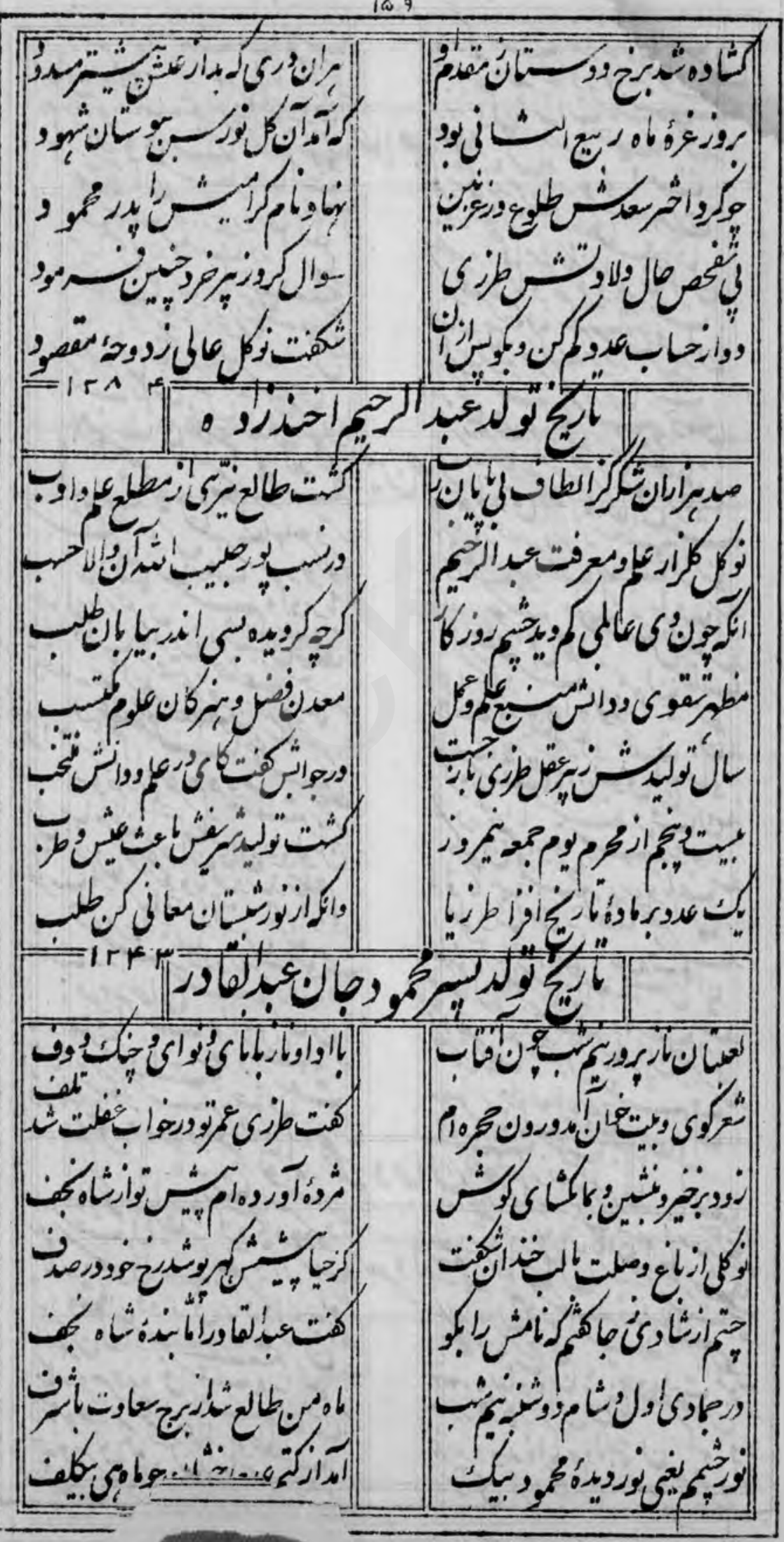


868

15

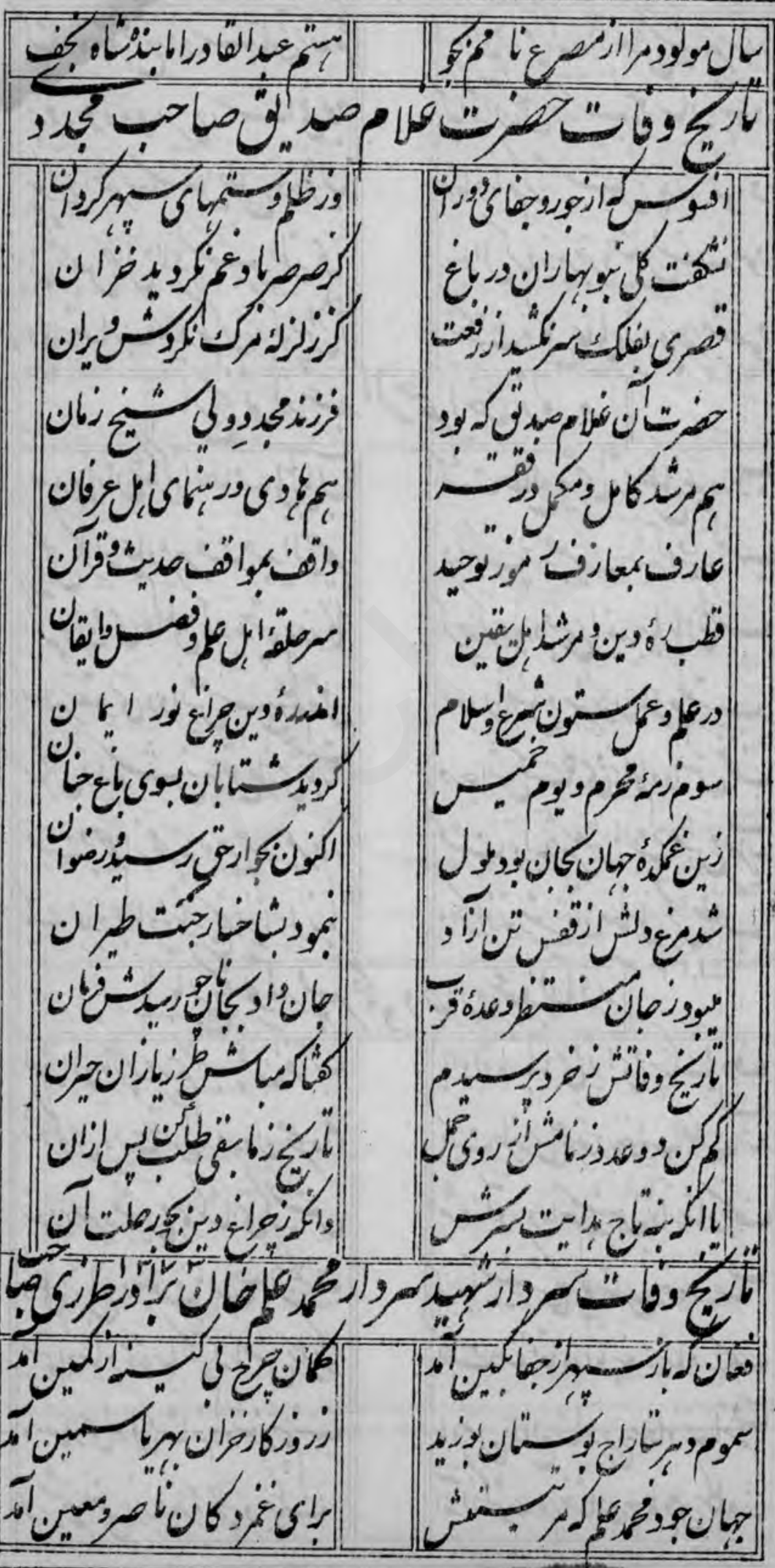


869

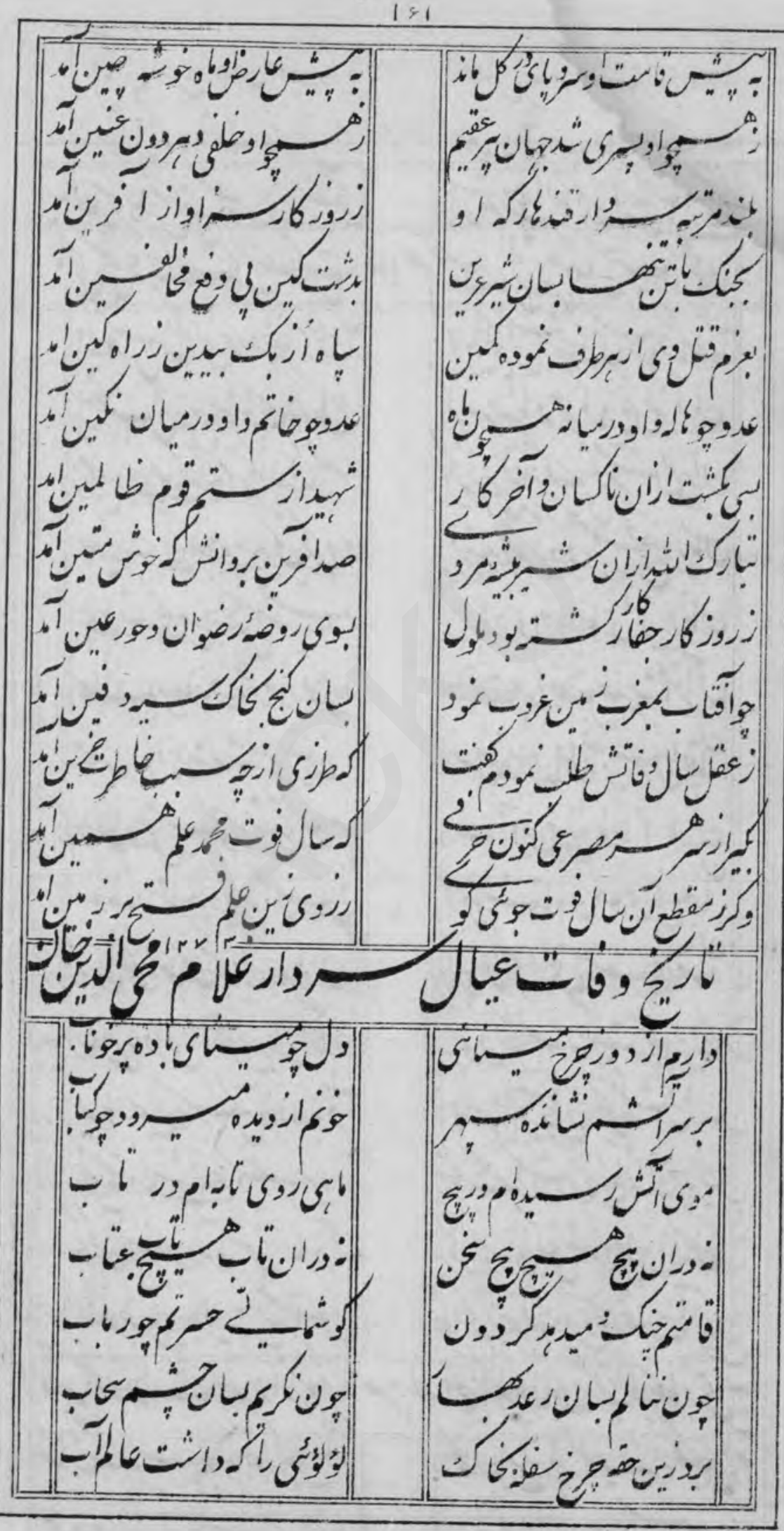


870

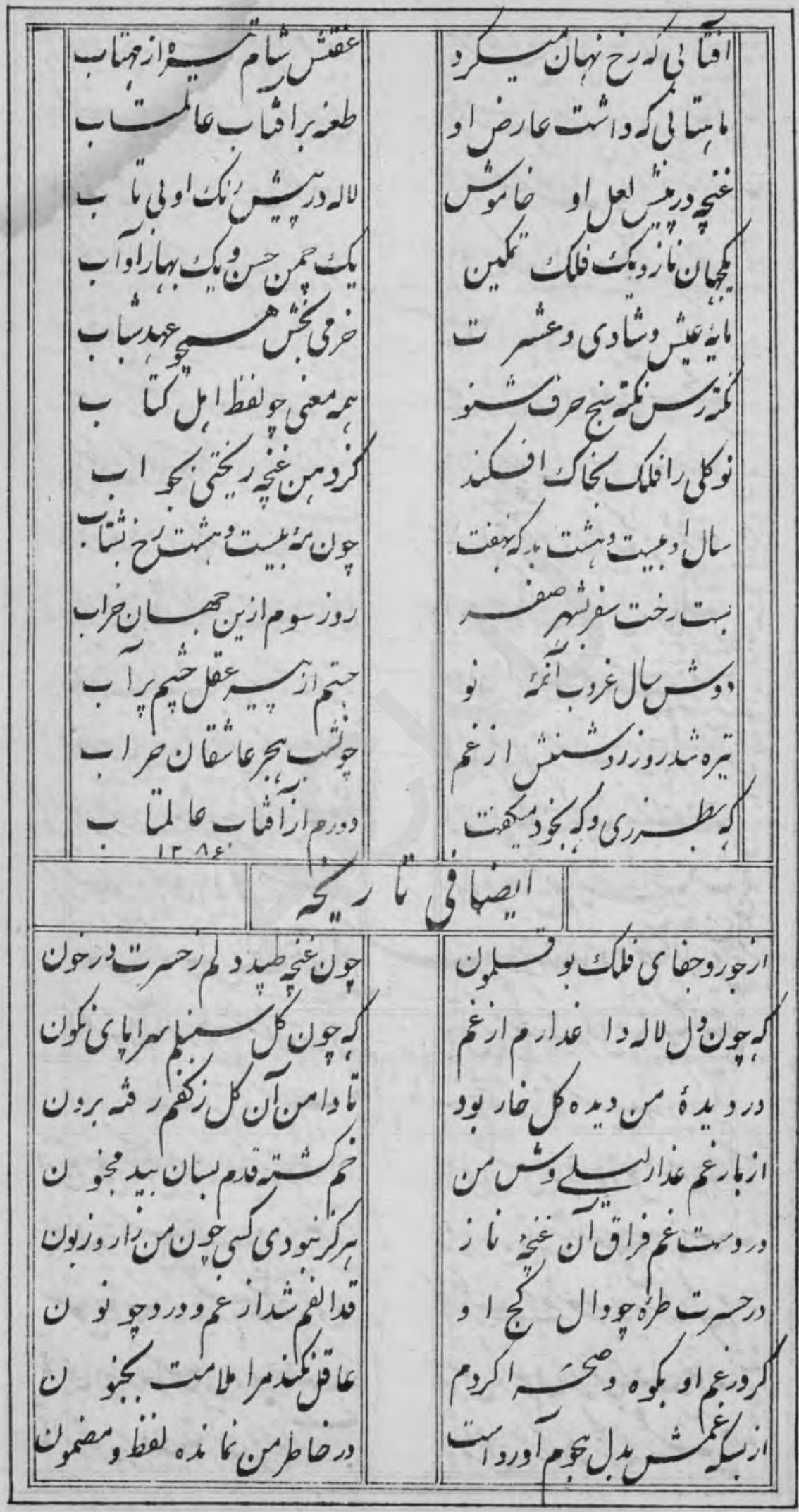

.61 


\section{1}

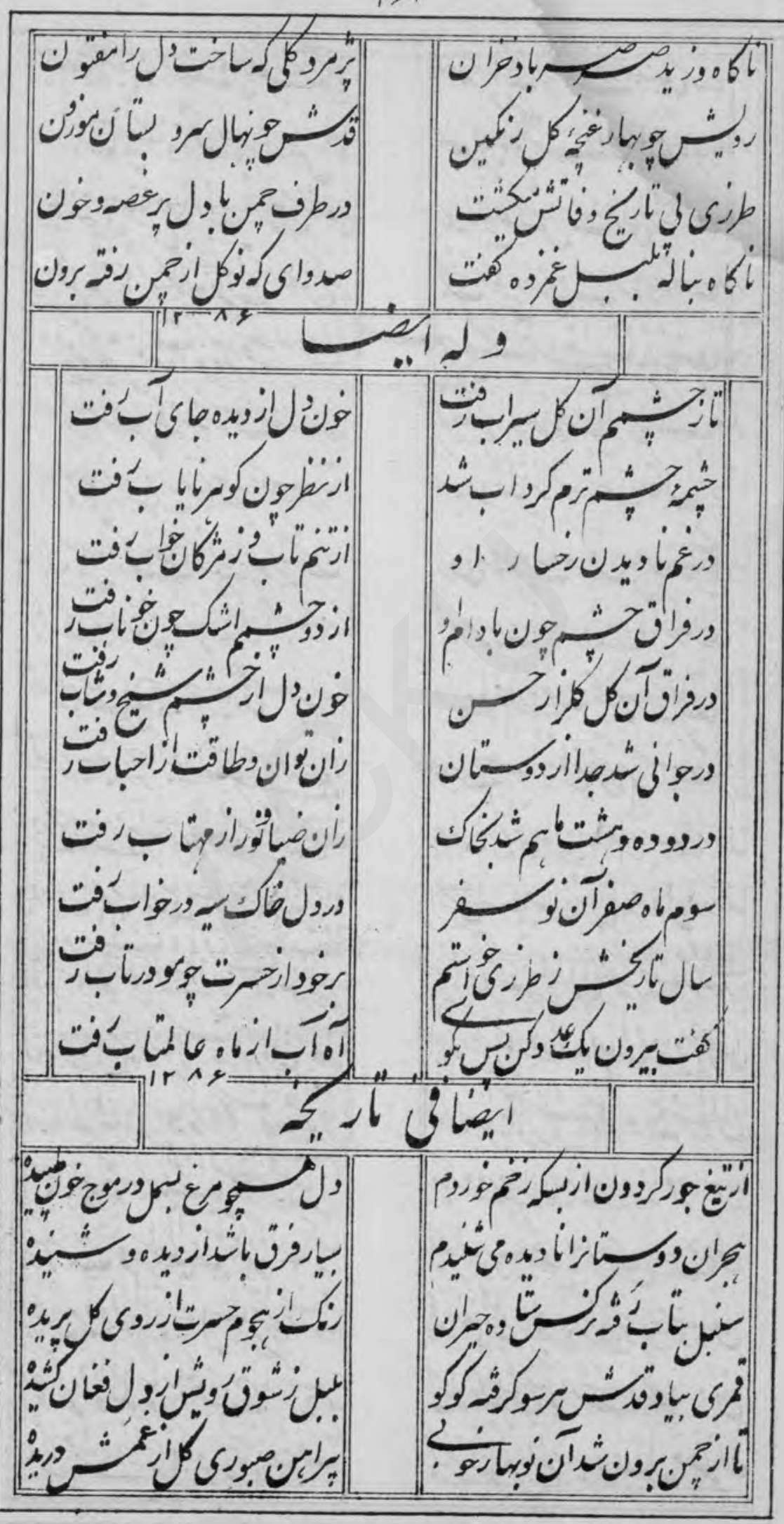


195

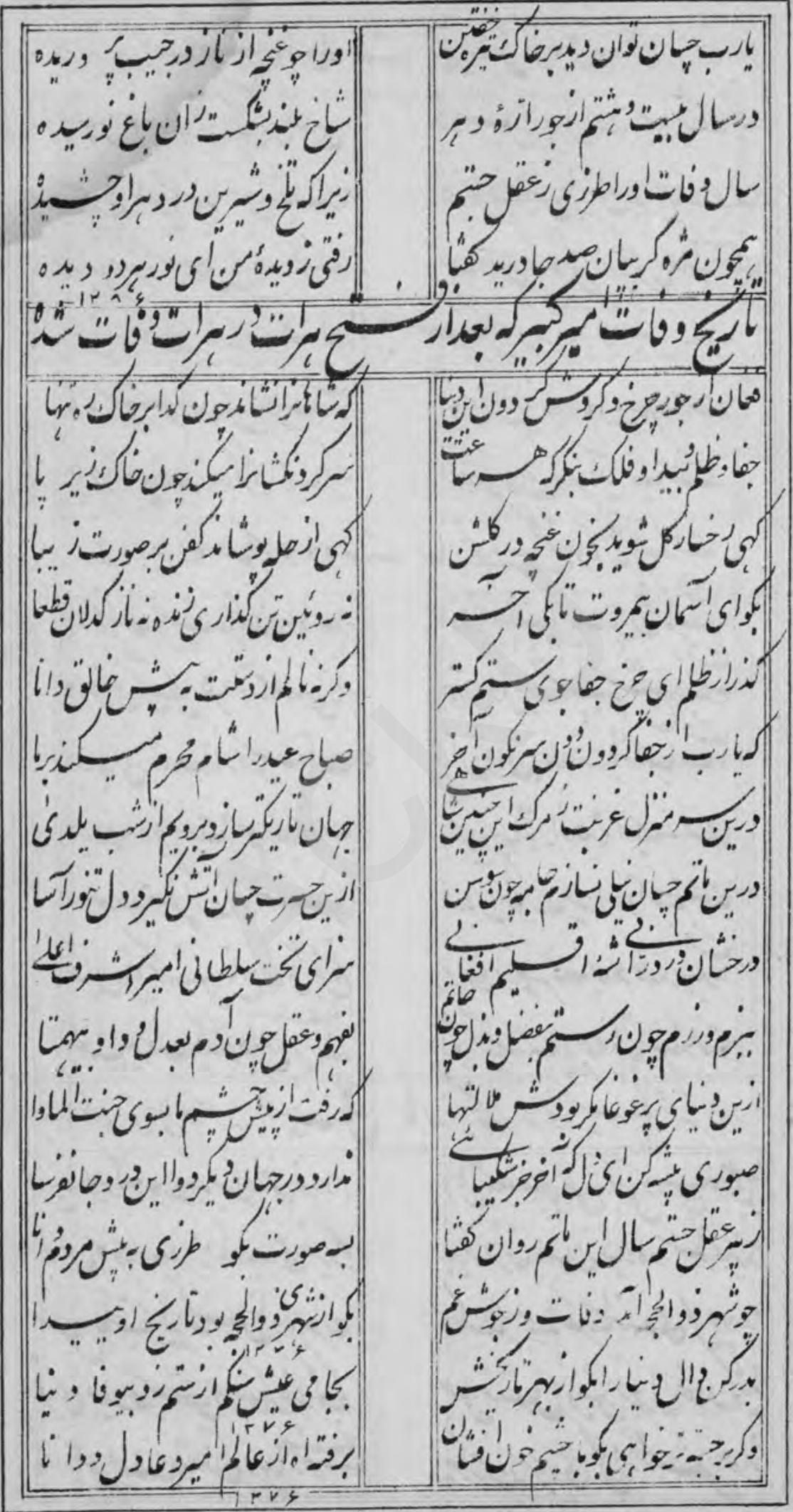




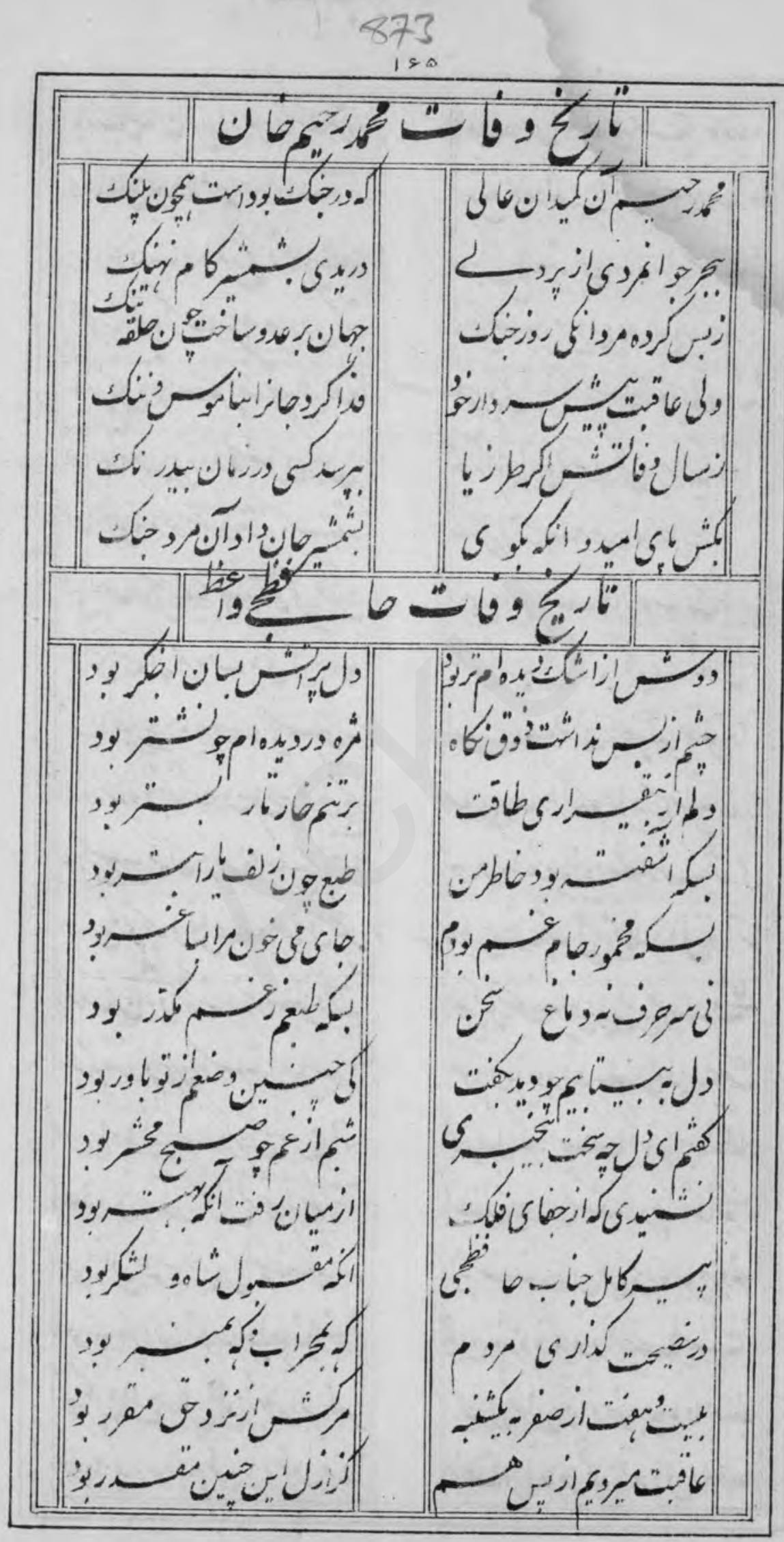




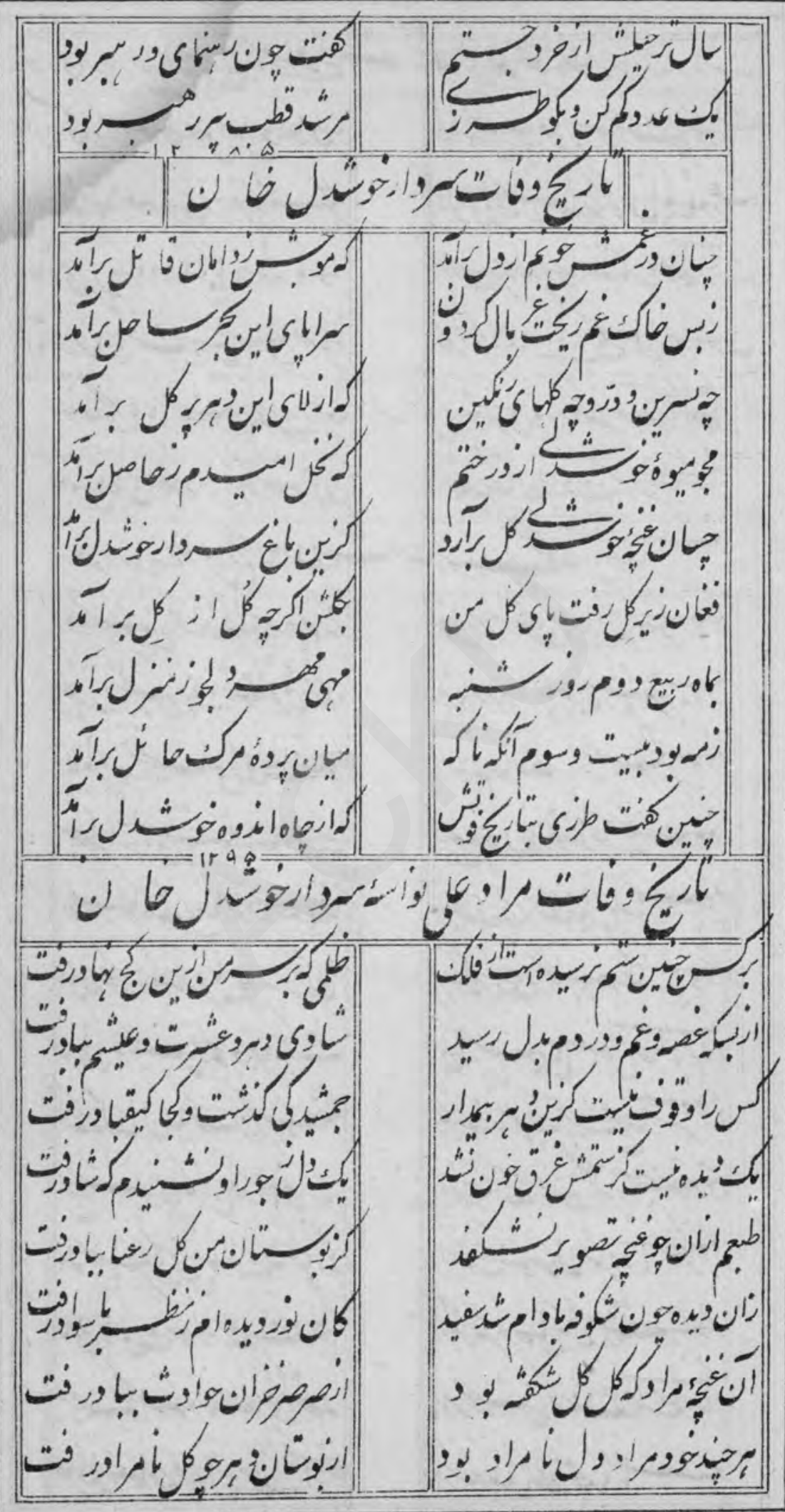




\section{5}

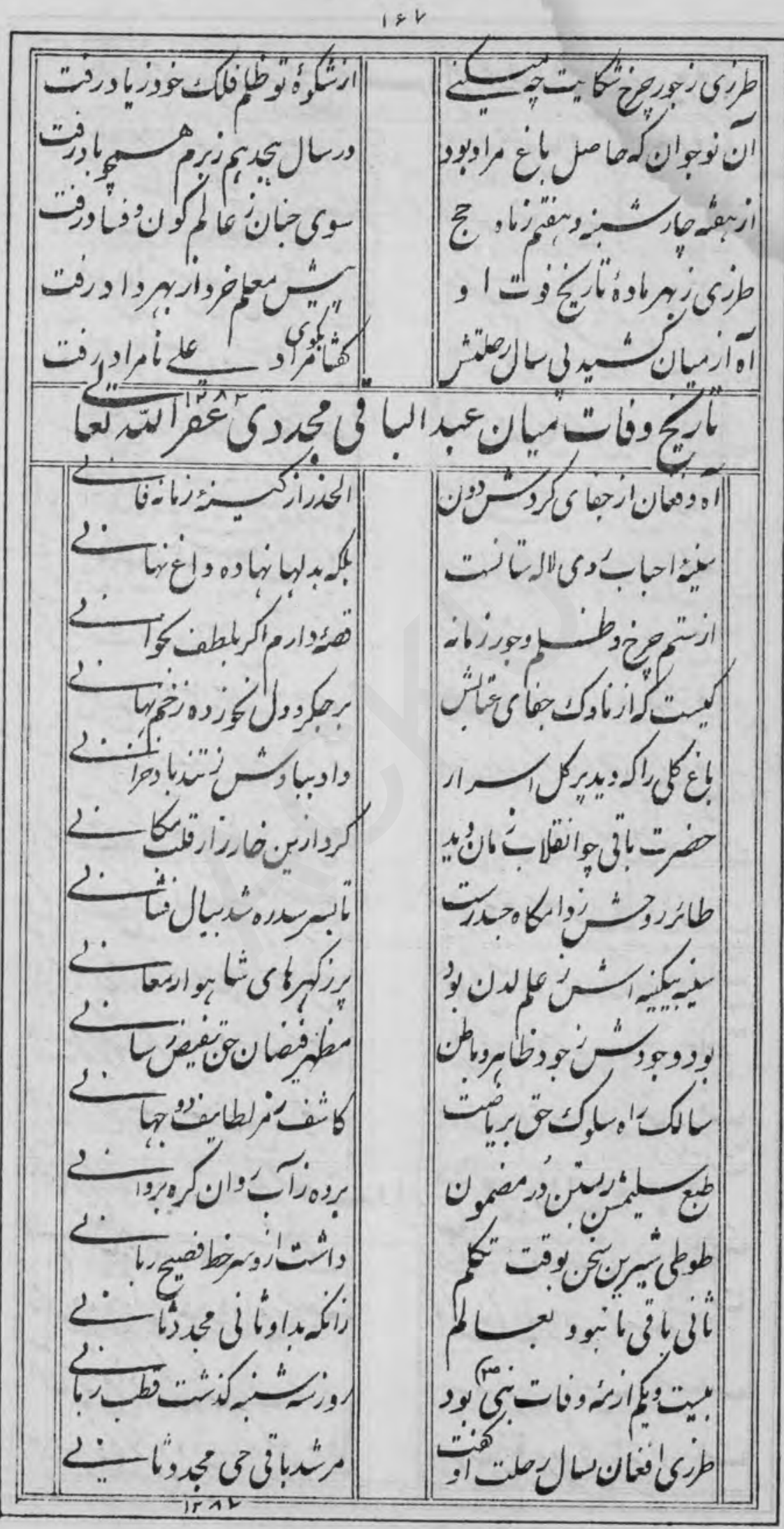


$4 x$

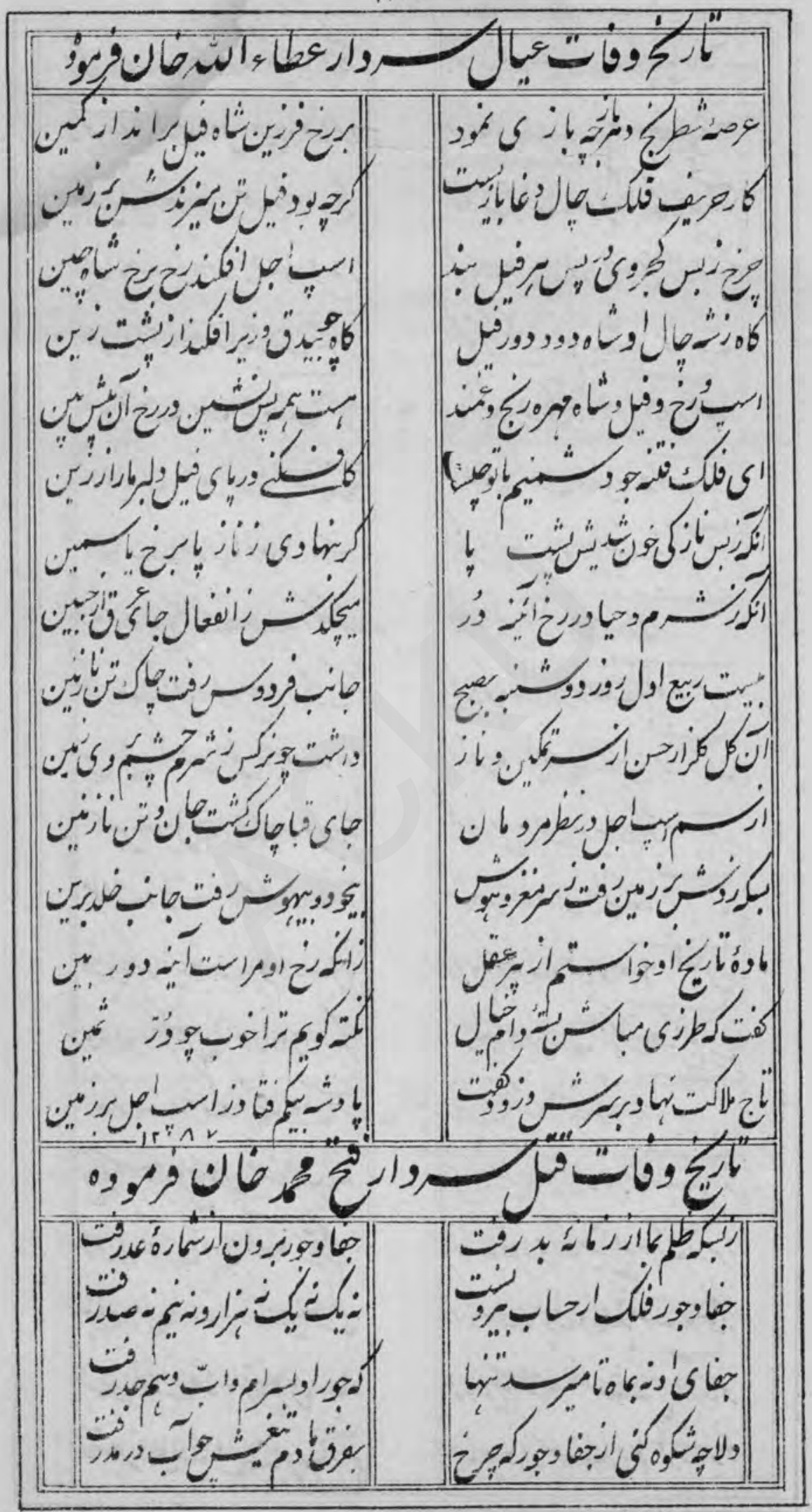


159

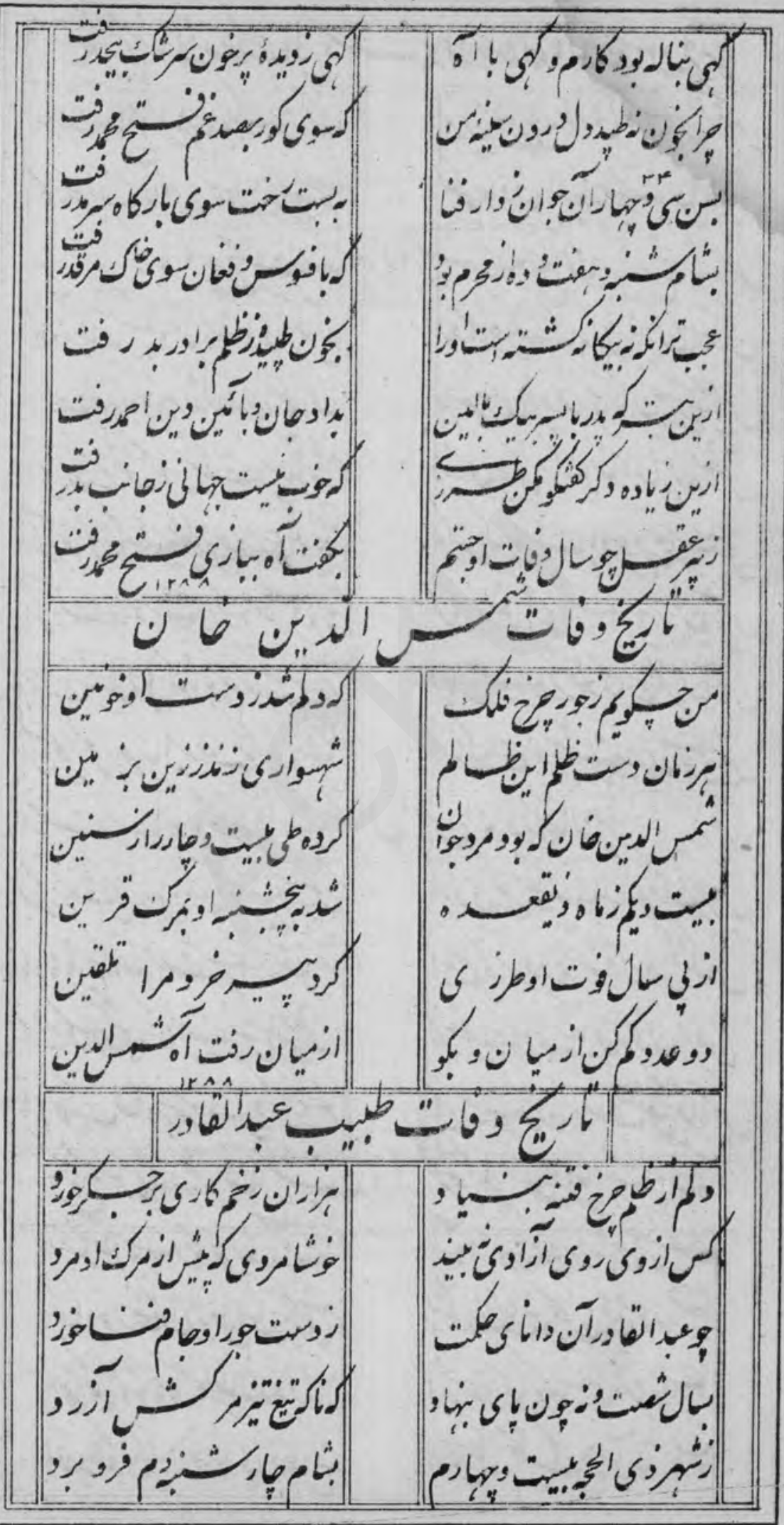


Iv

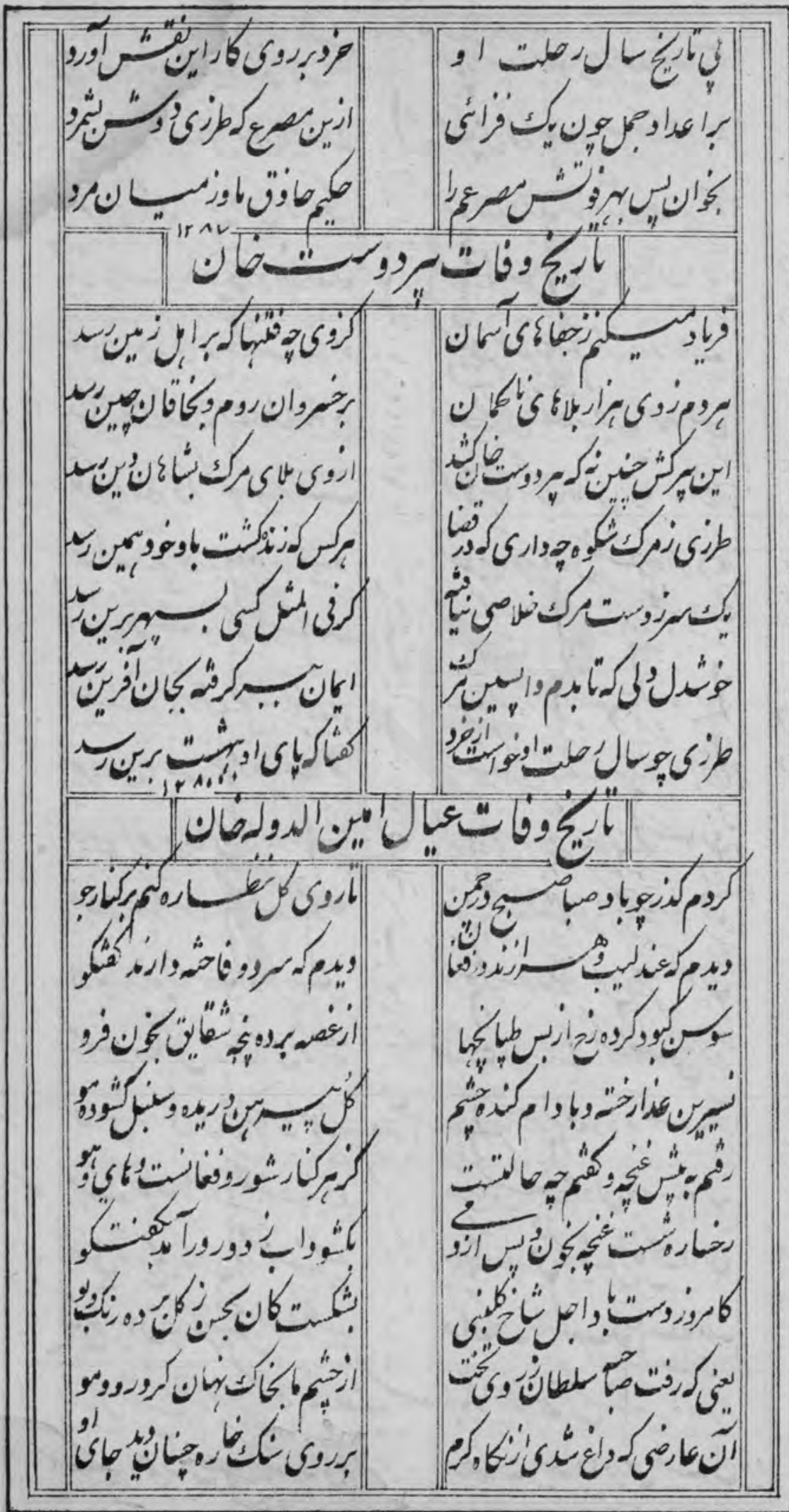

,. 


\section{9}

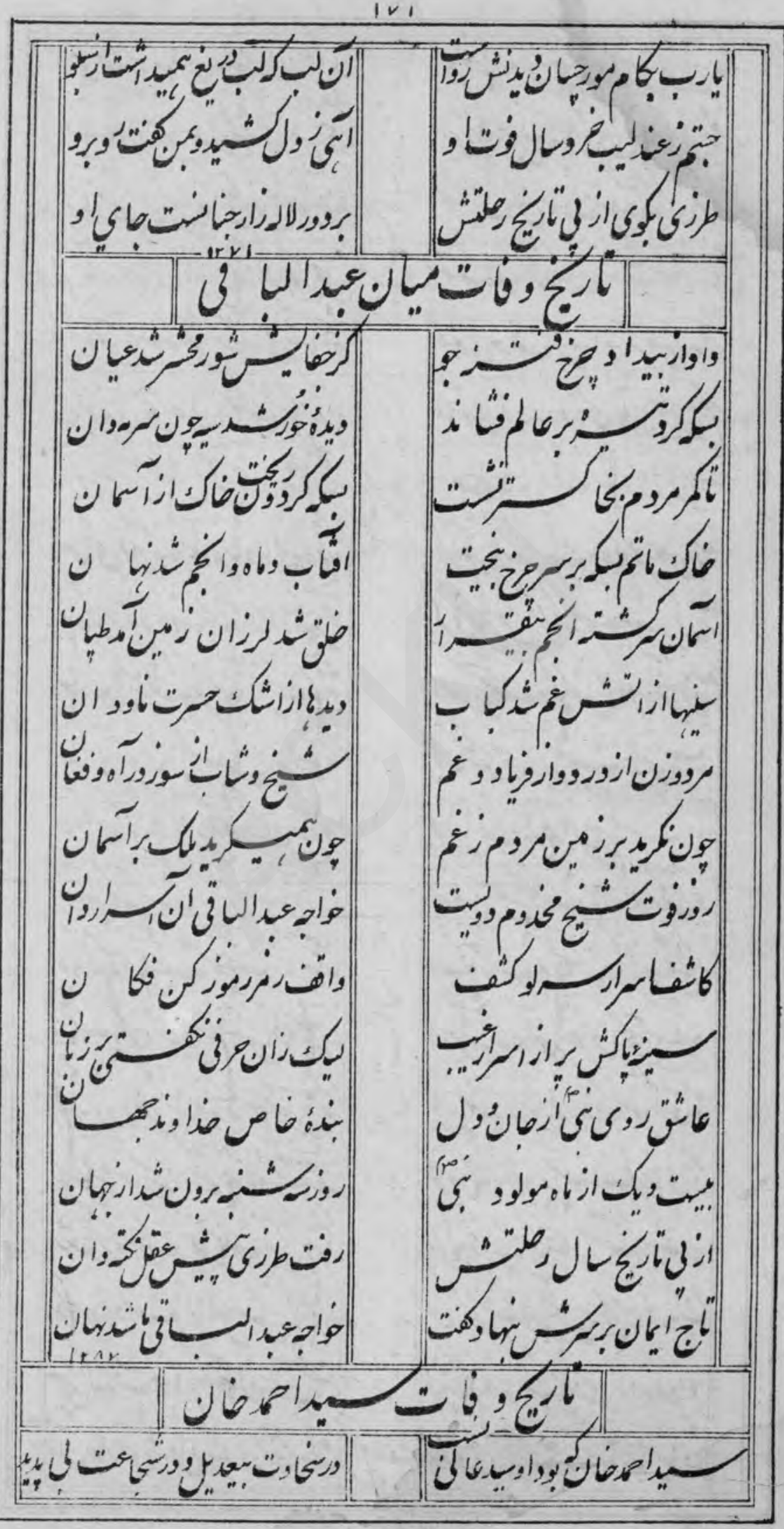




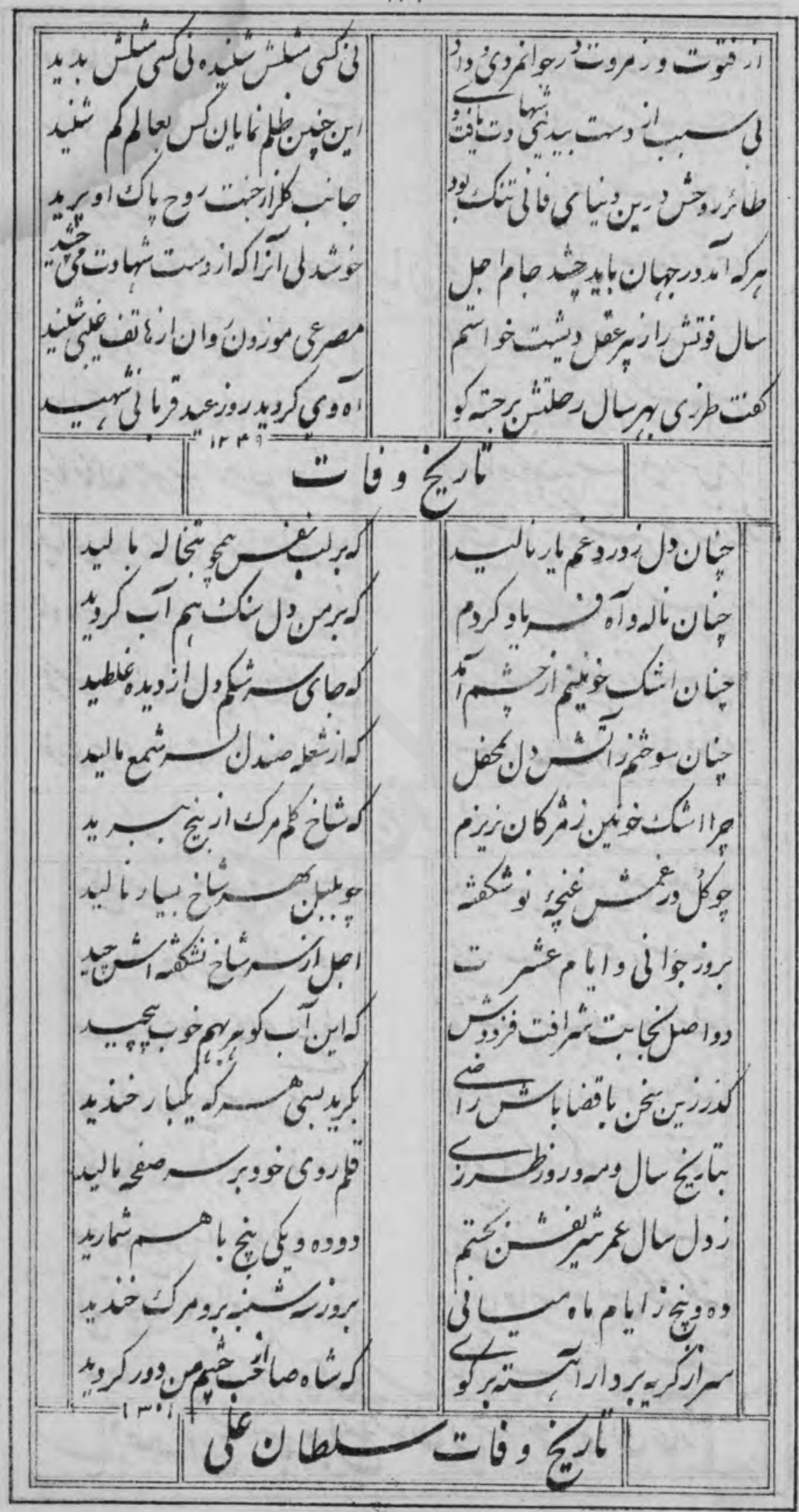


Ir

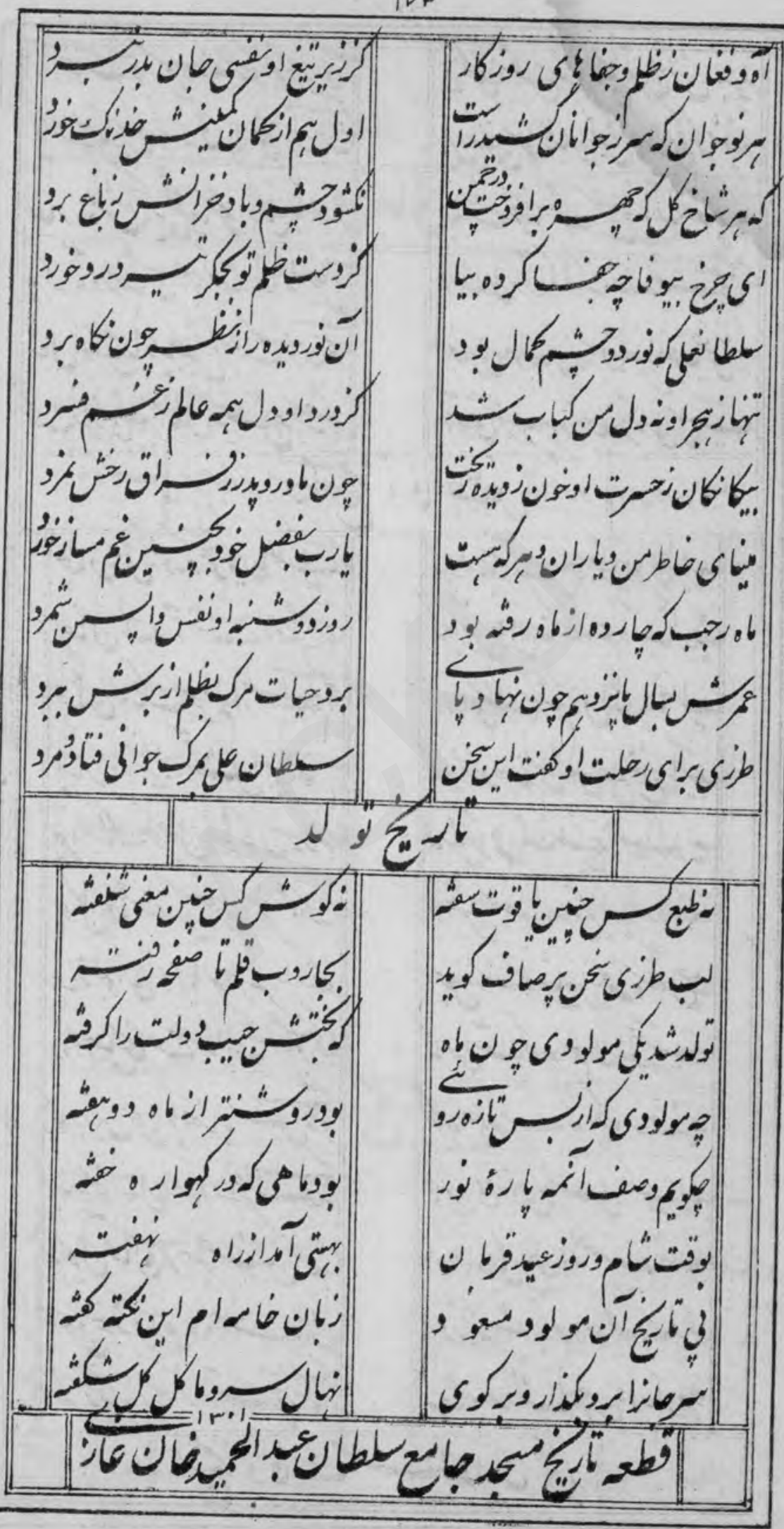


882

I v e

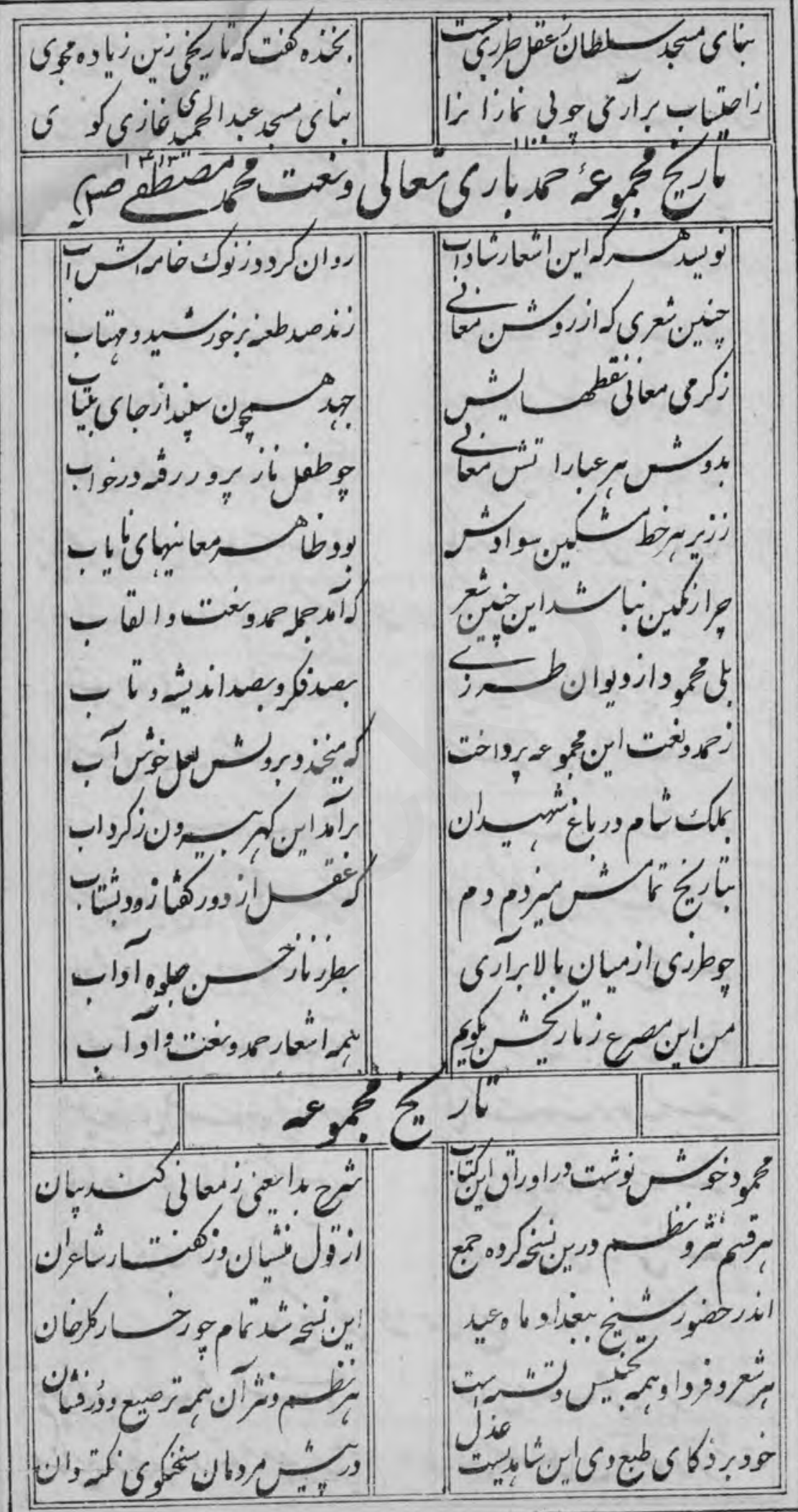


883

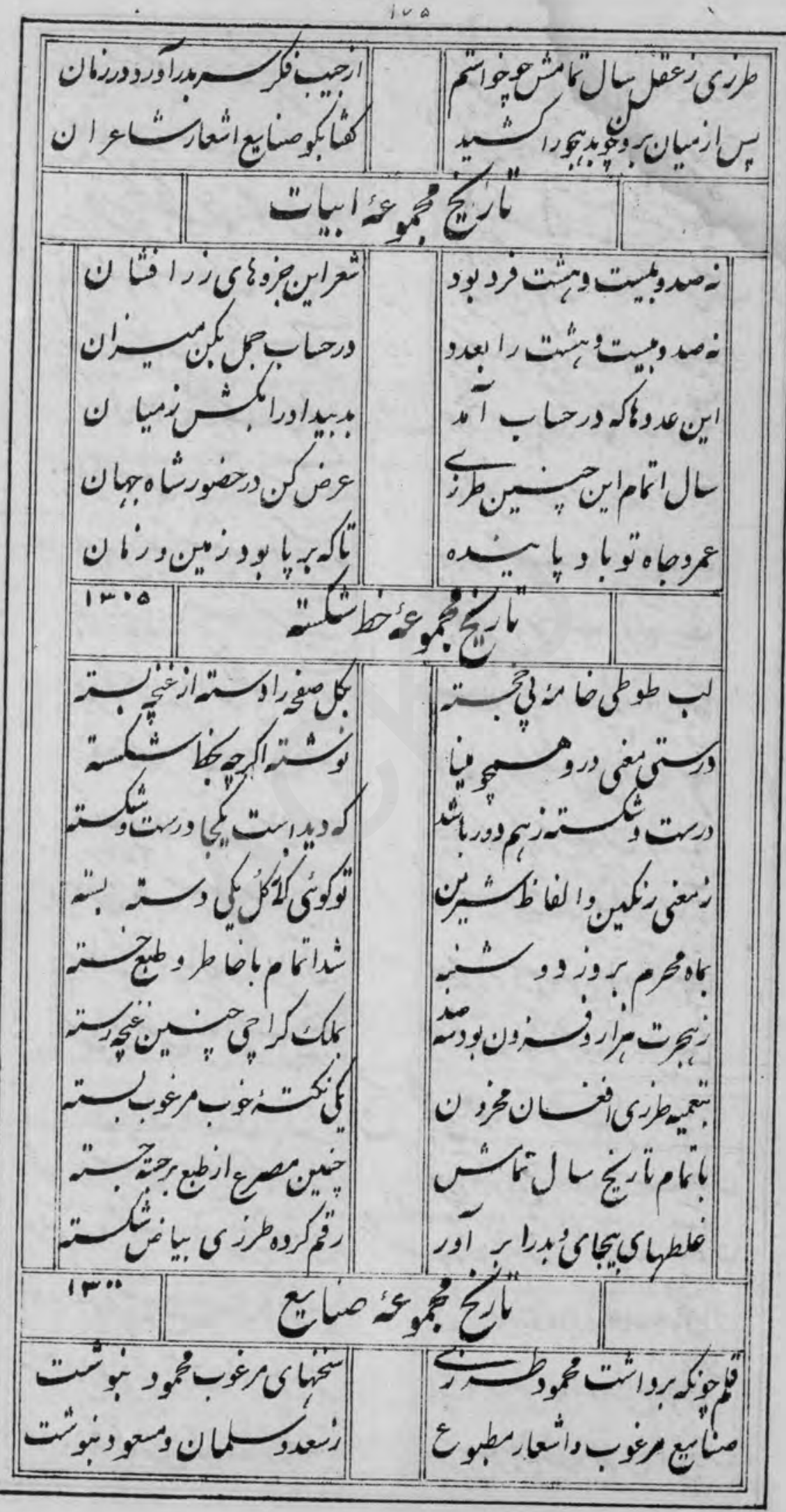


125

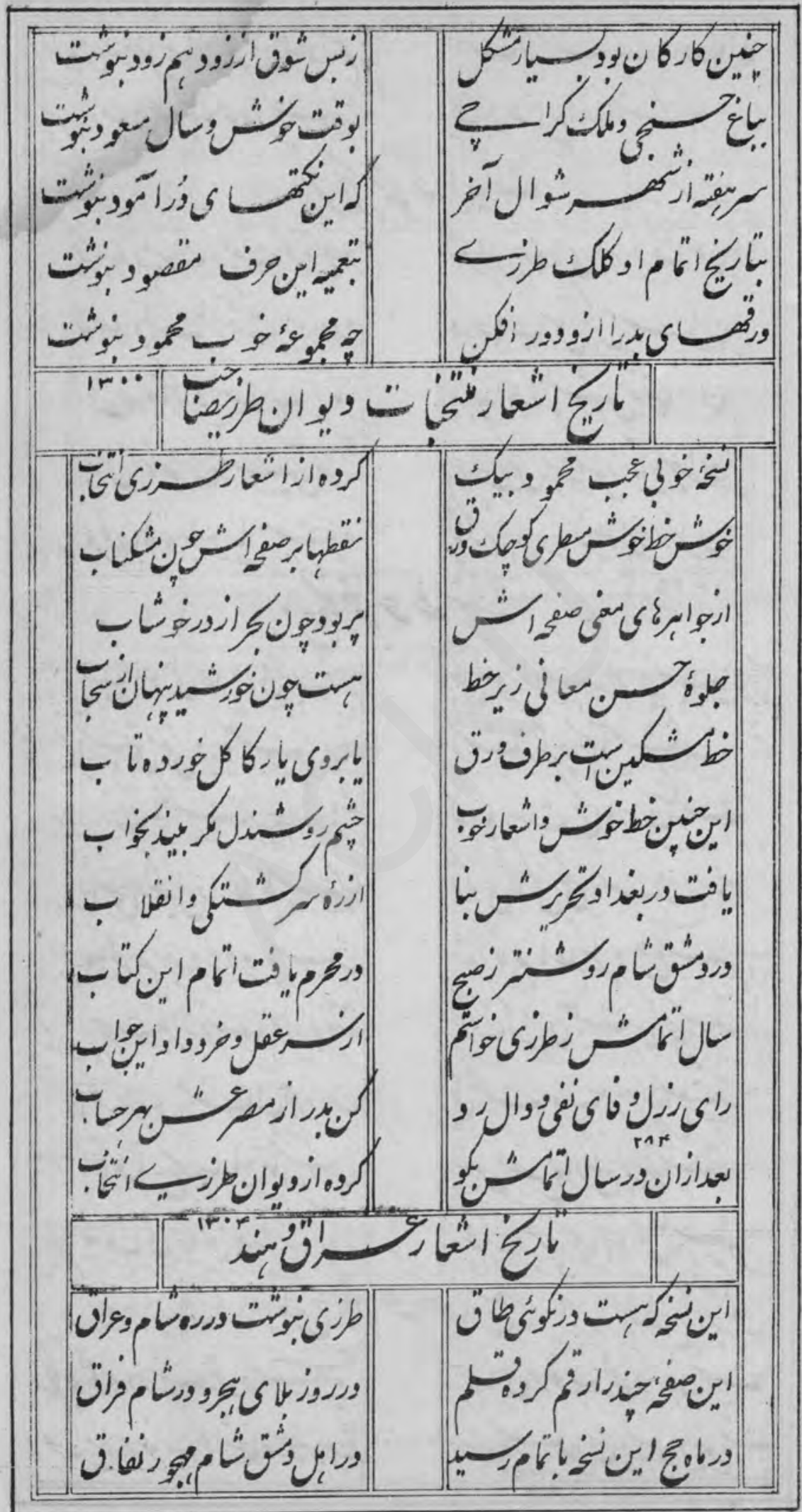

« 
885

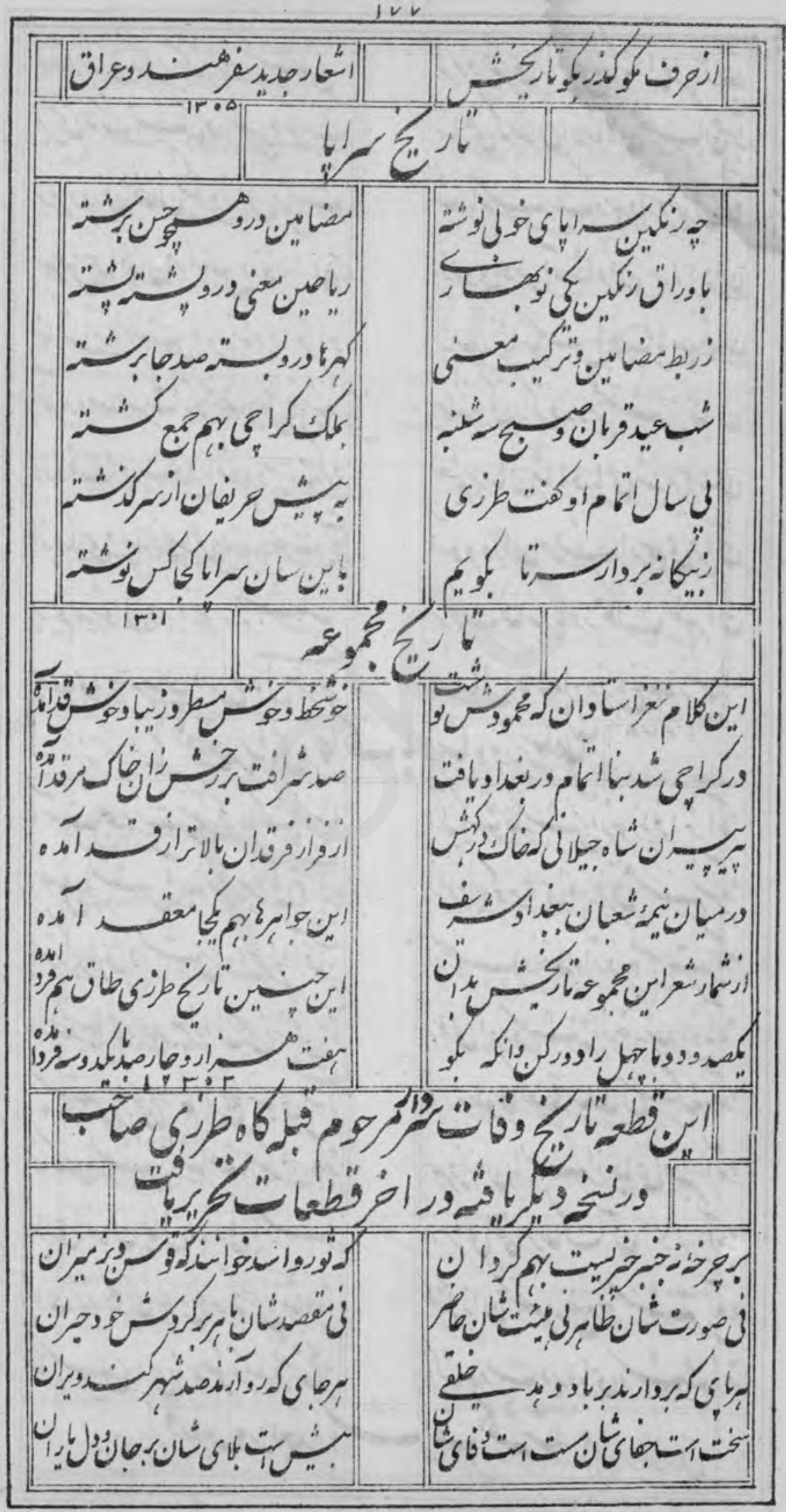


w 886

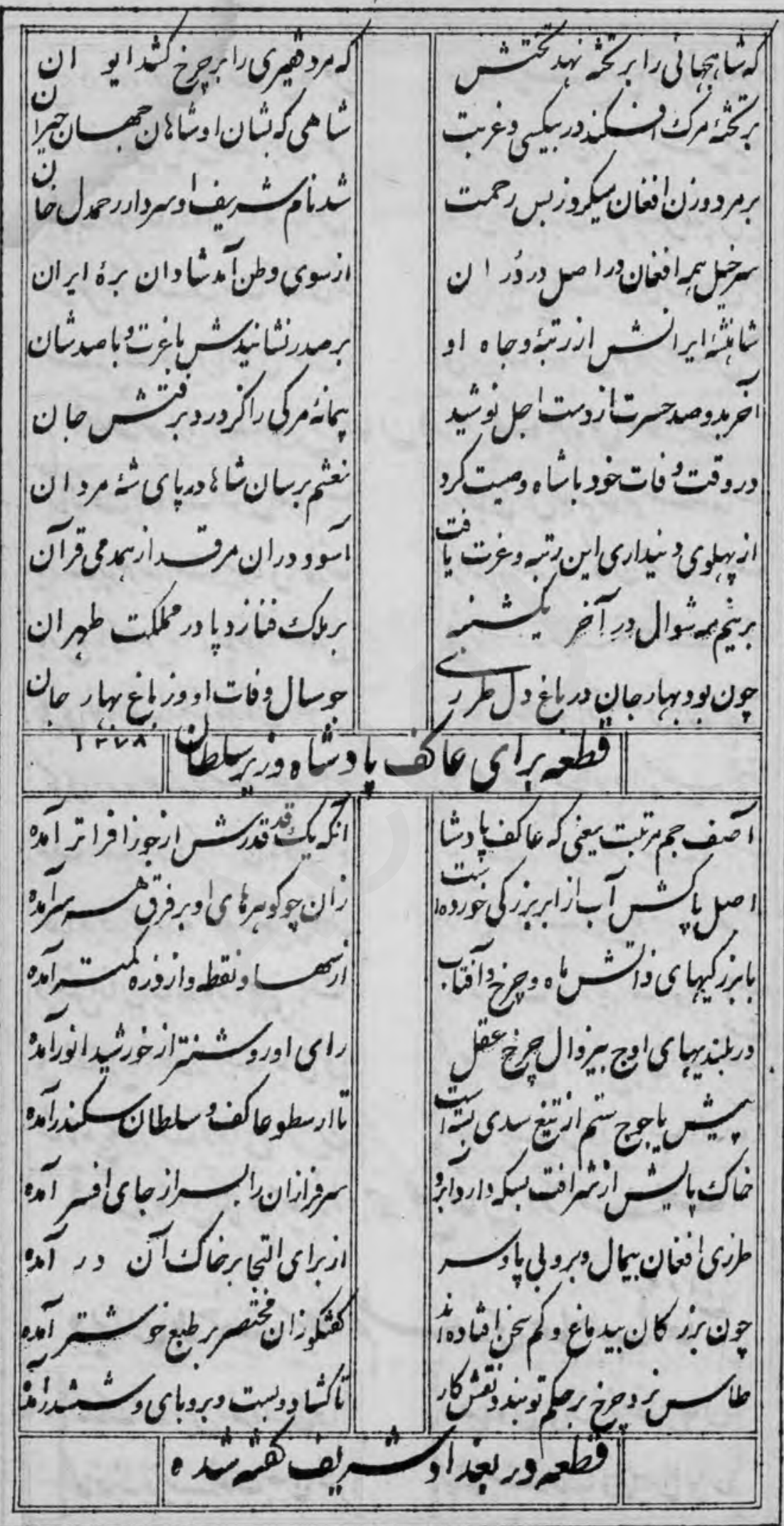




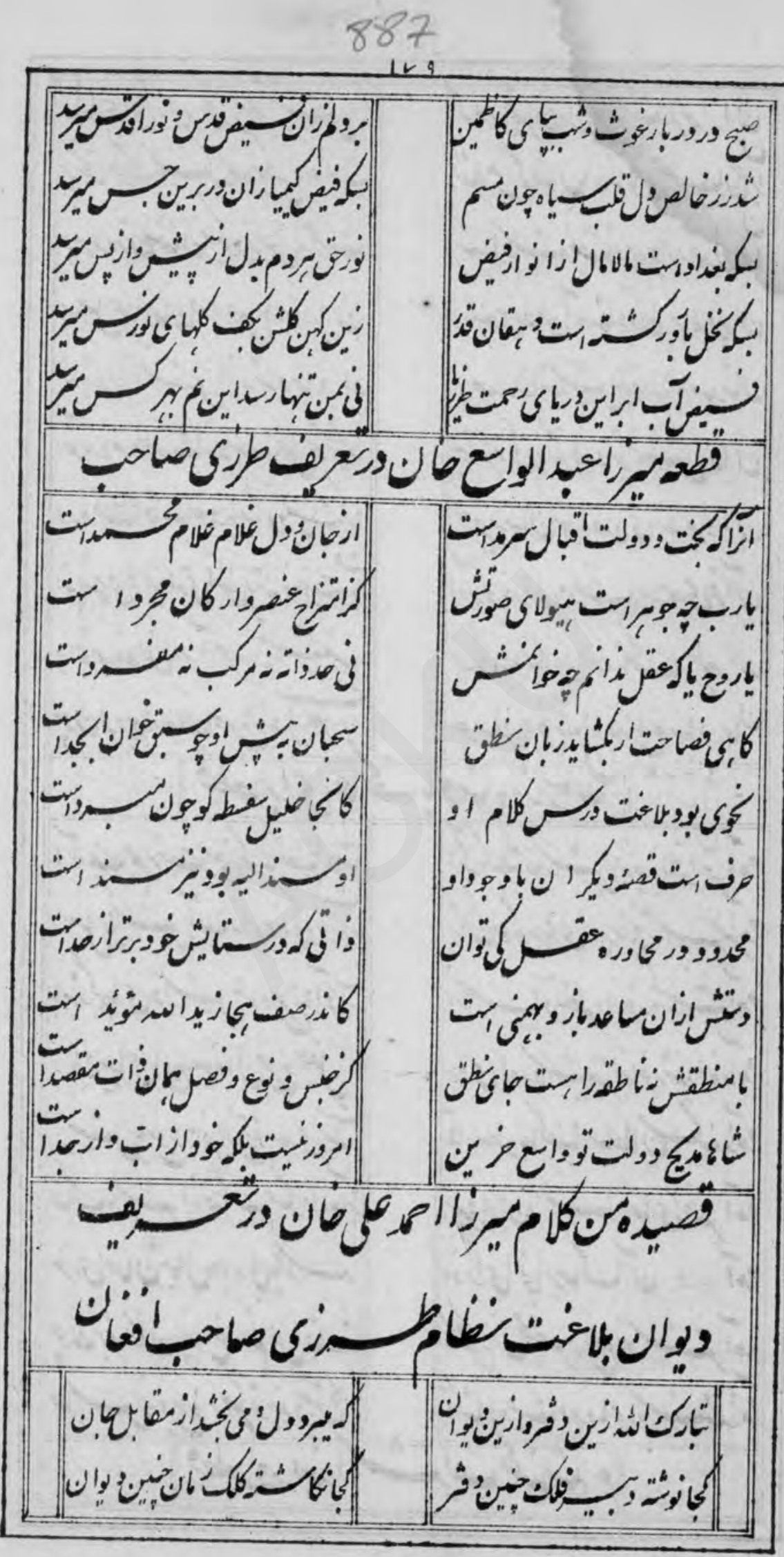




\section{8}

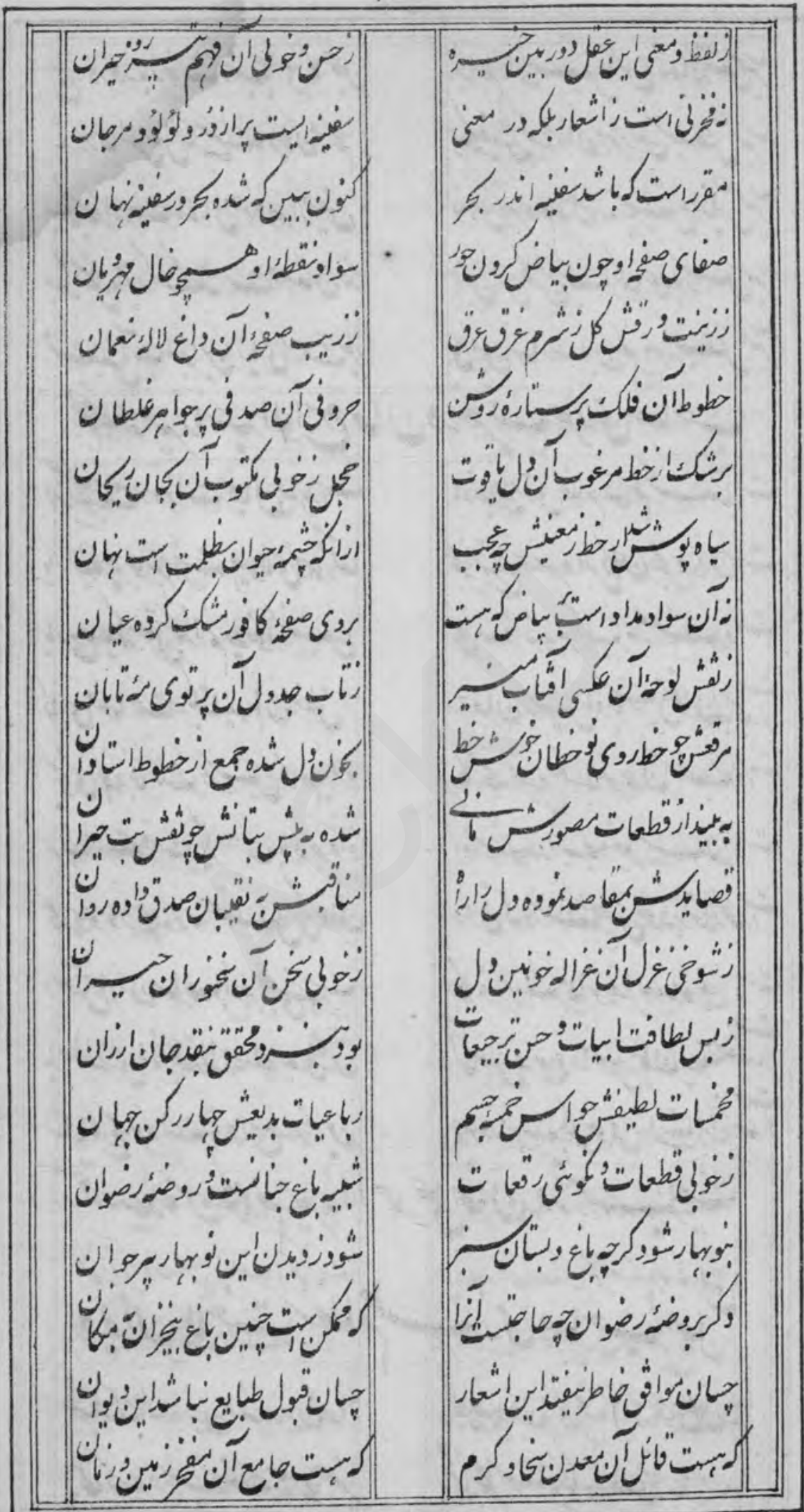




\section{9}

|n I

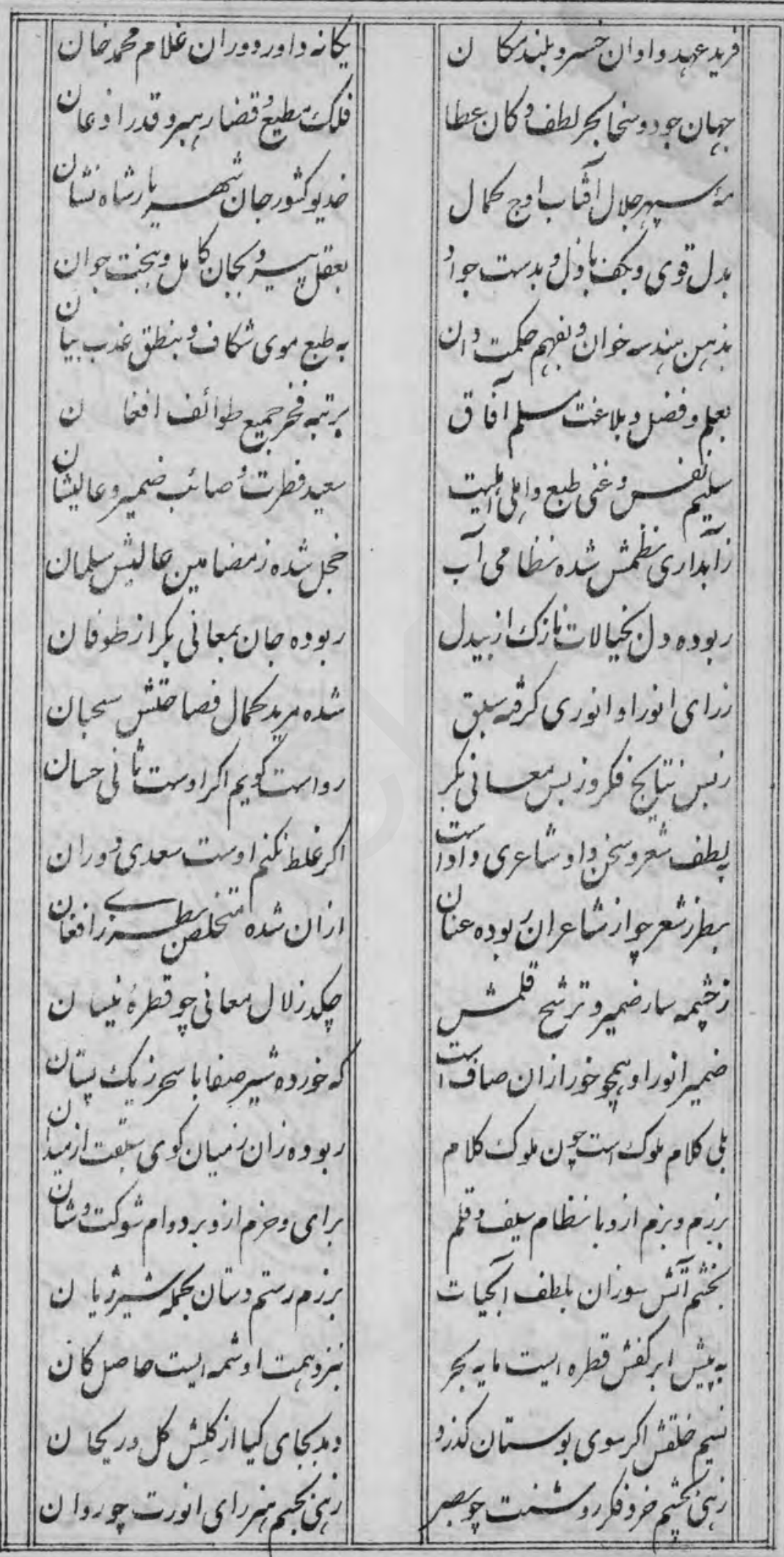




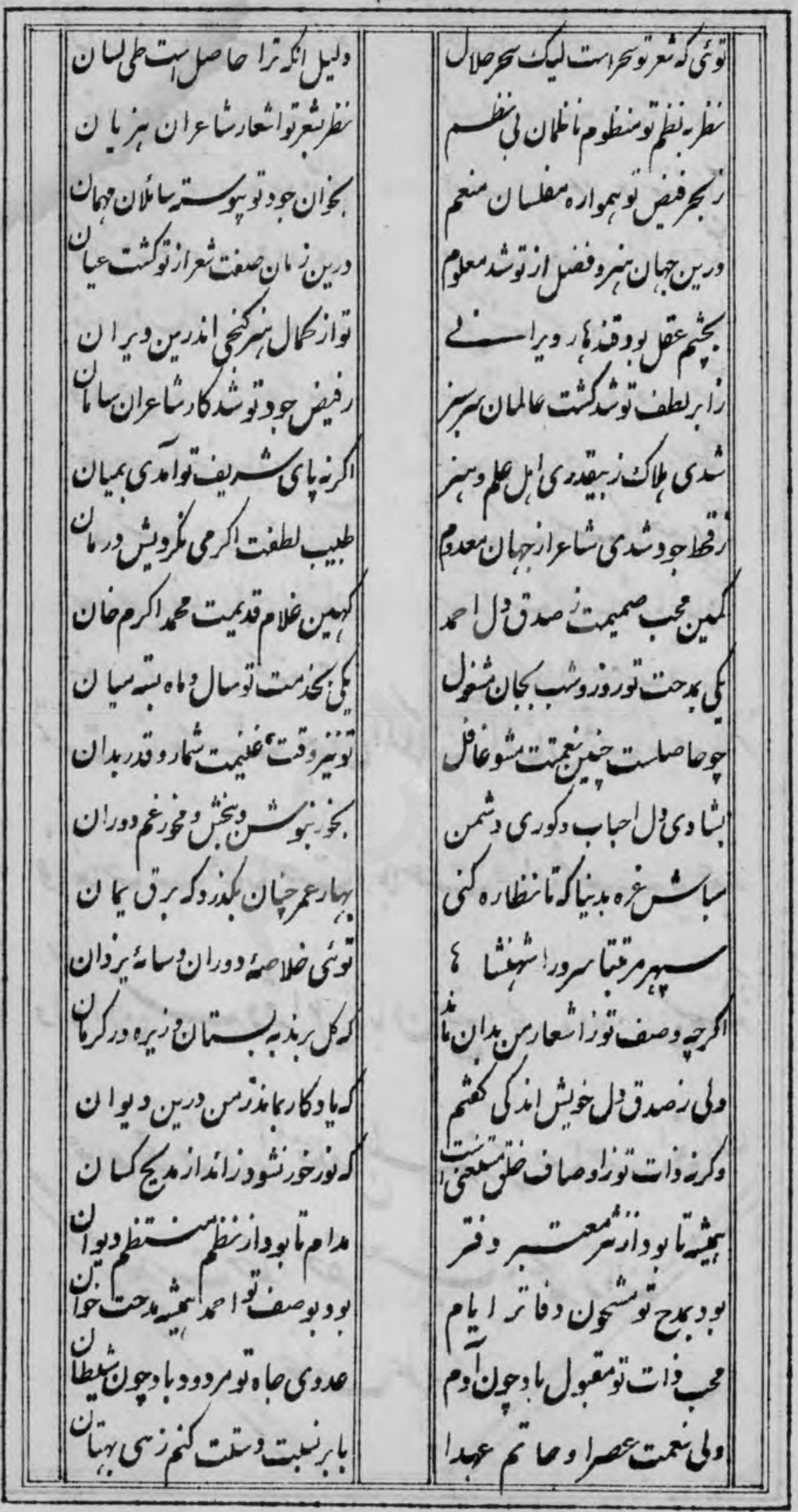




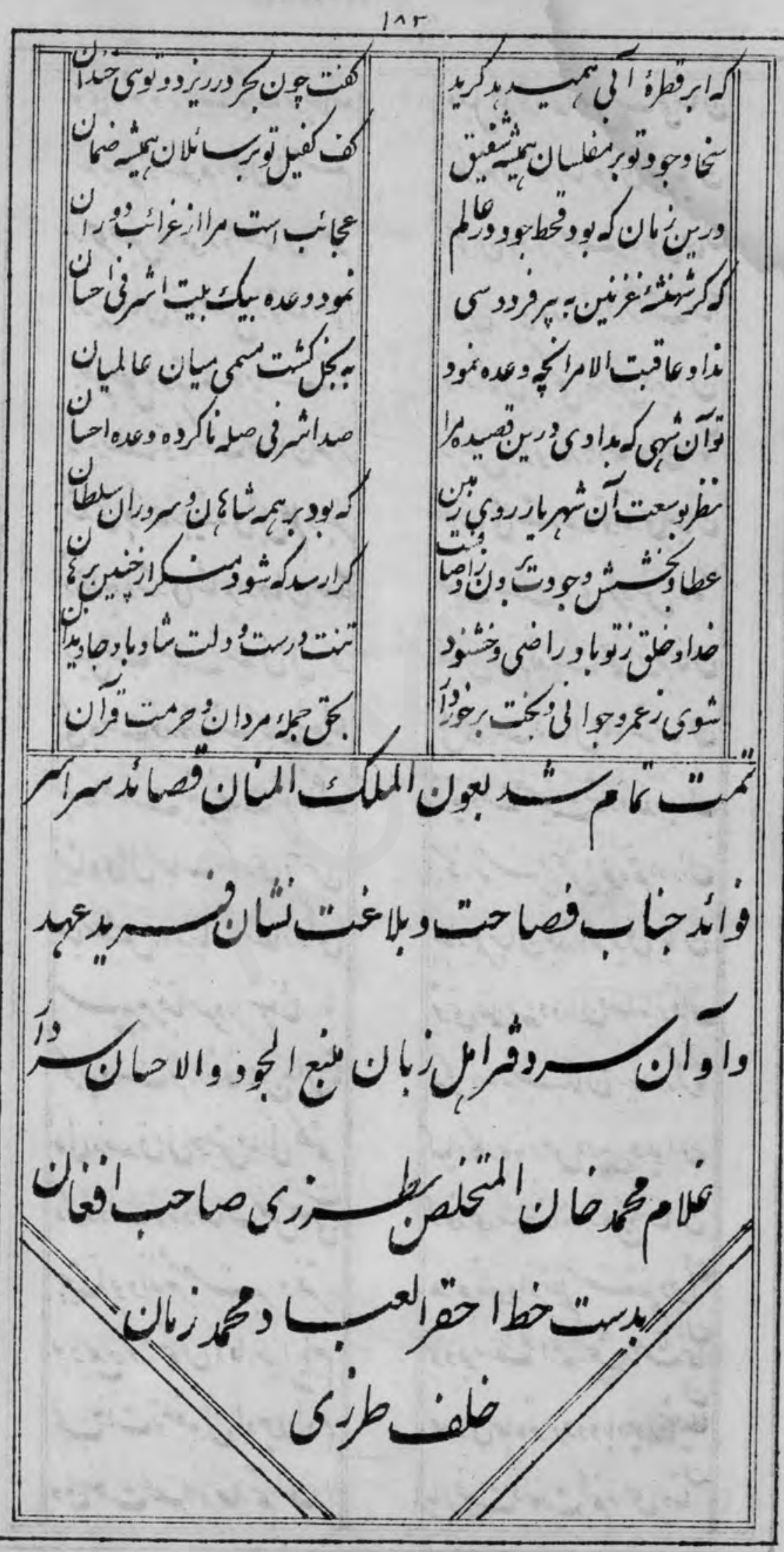




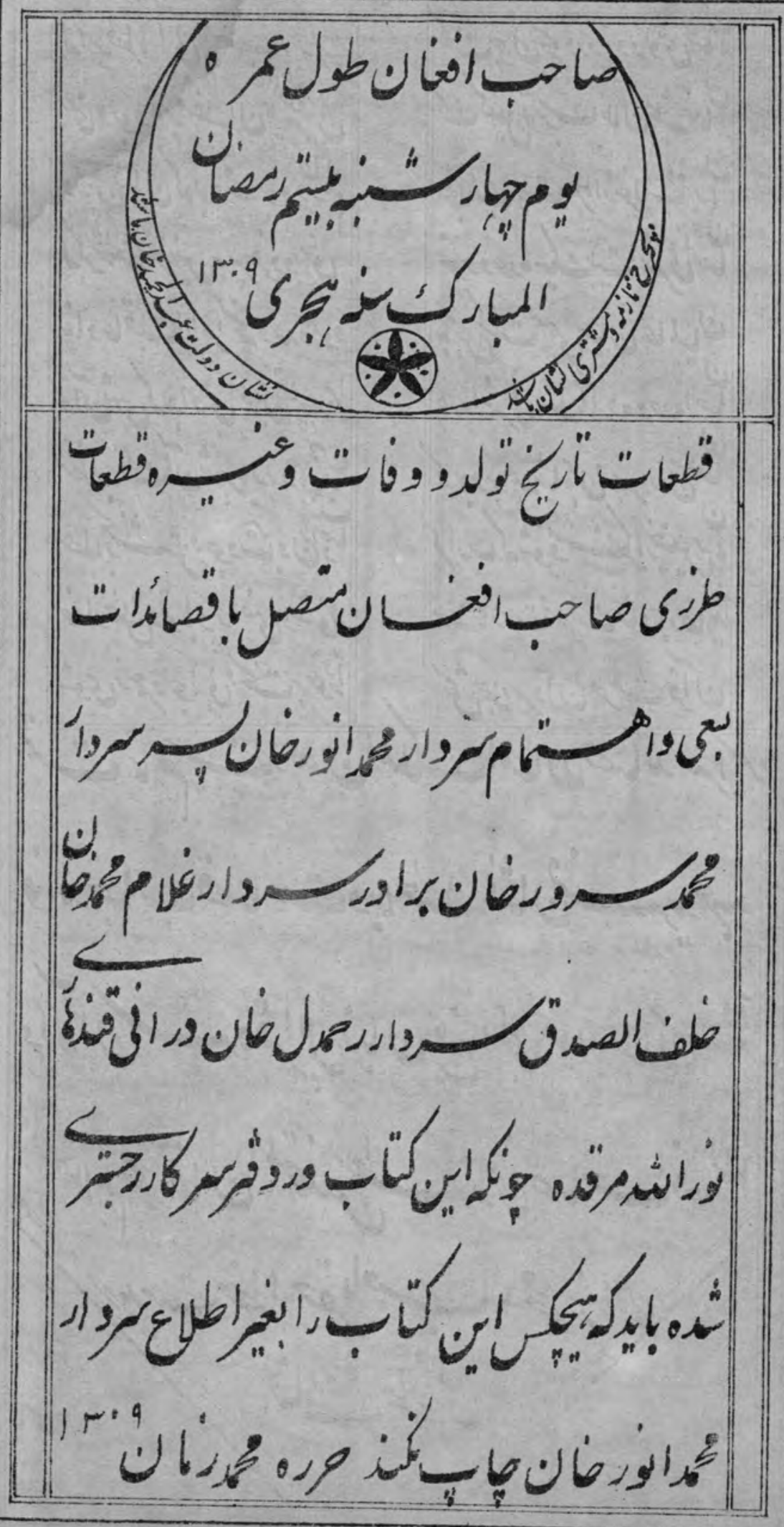




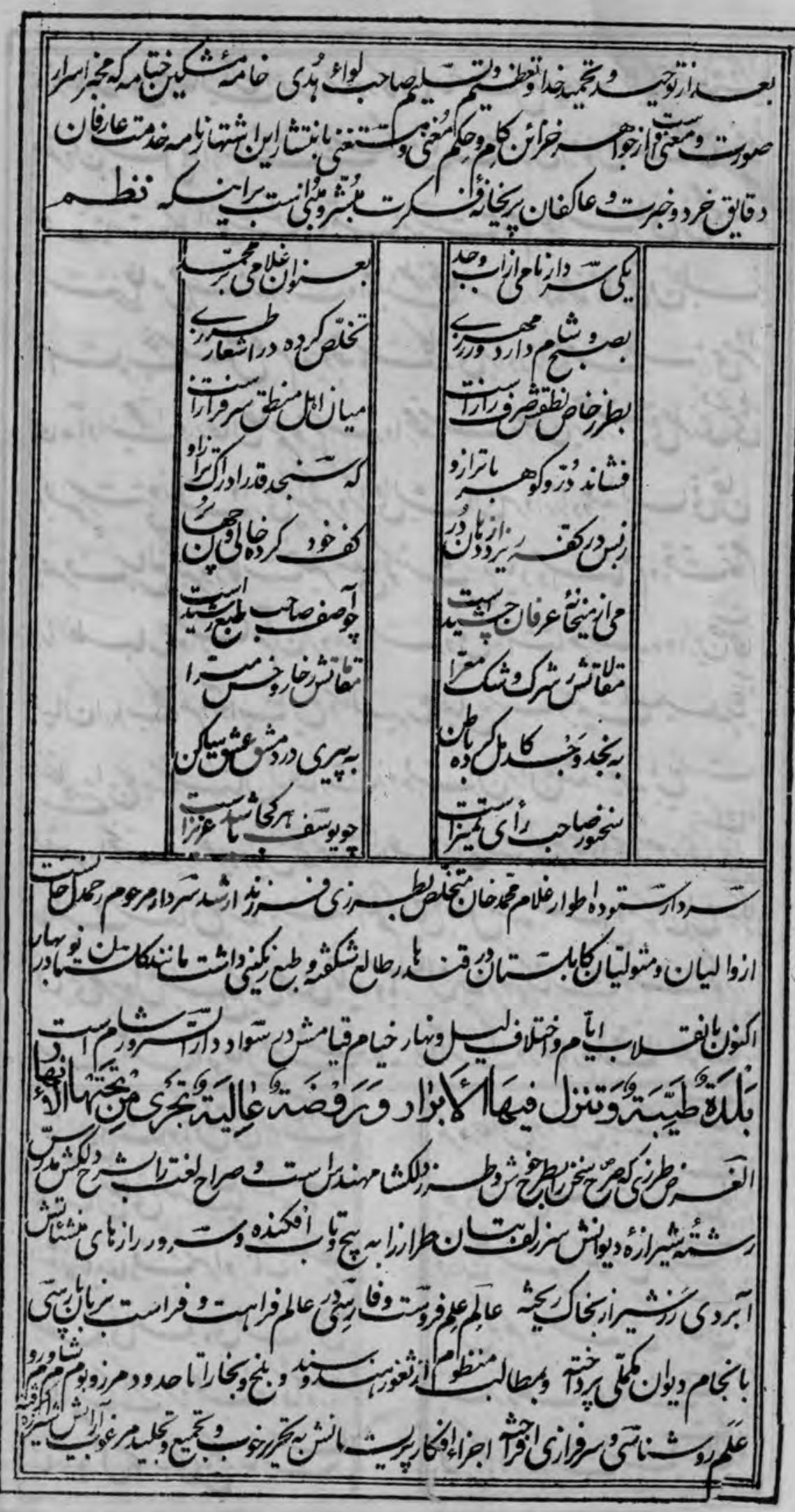




\section{4 $A$ ACKU}

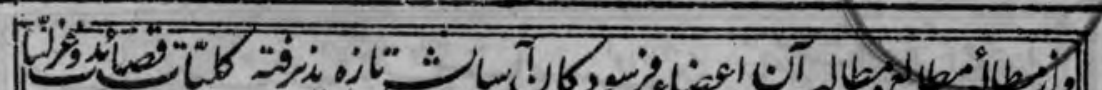

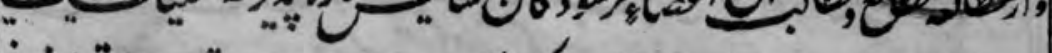

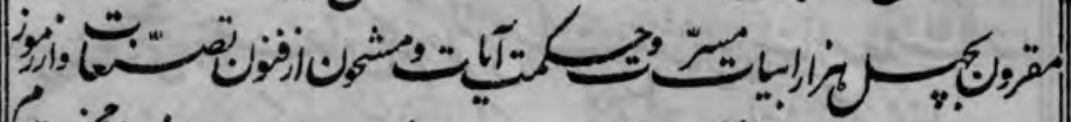

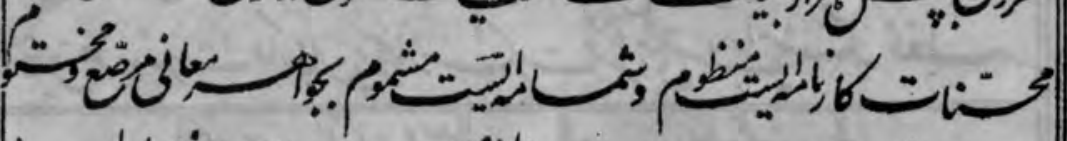
,

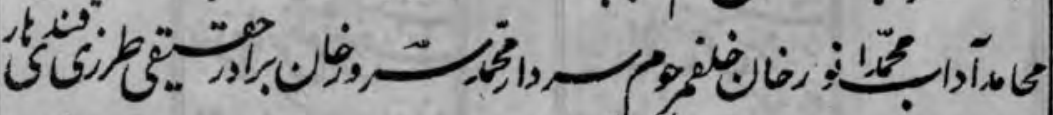
ب

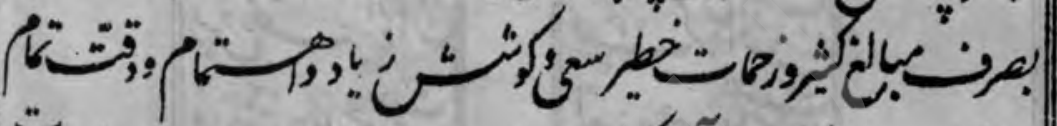

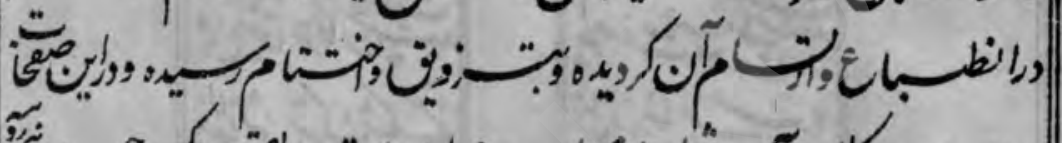

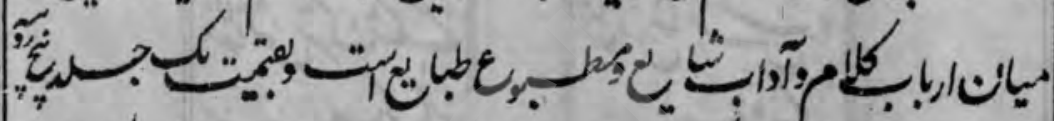

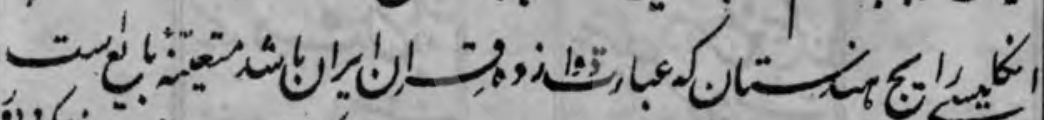

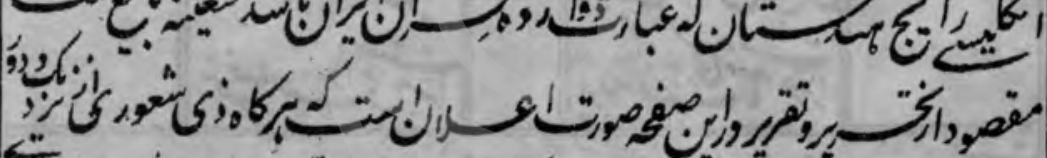
6

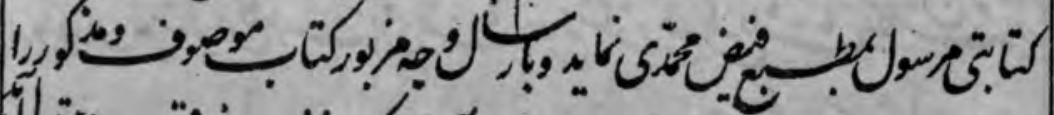

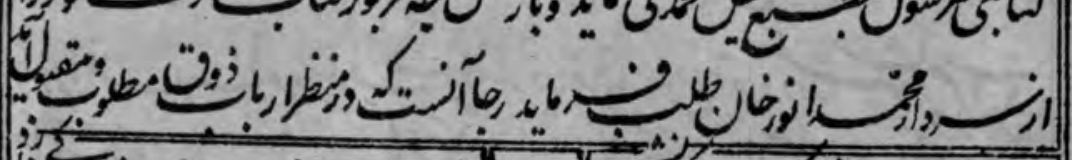

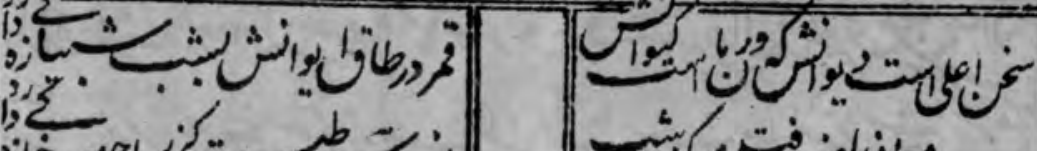
年 , 年 بـ 选- 这, ris indigus

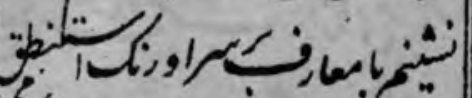
in $-2,-3$ (1)

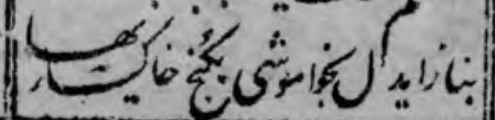

